\title{
LES LIEUX DE MÉTIER
}

\section{BOUTIQUES ET ATELIERS D’HERCULANUM}

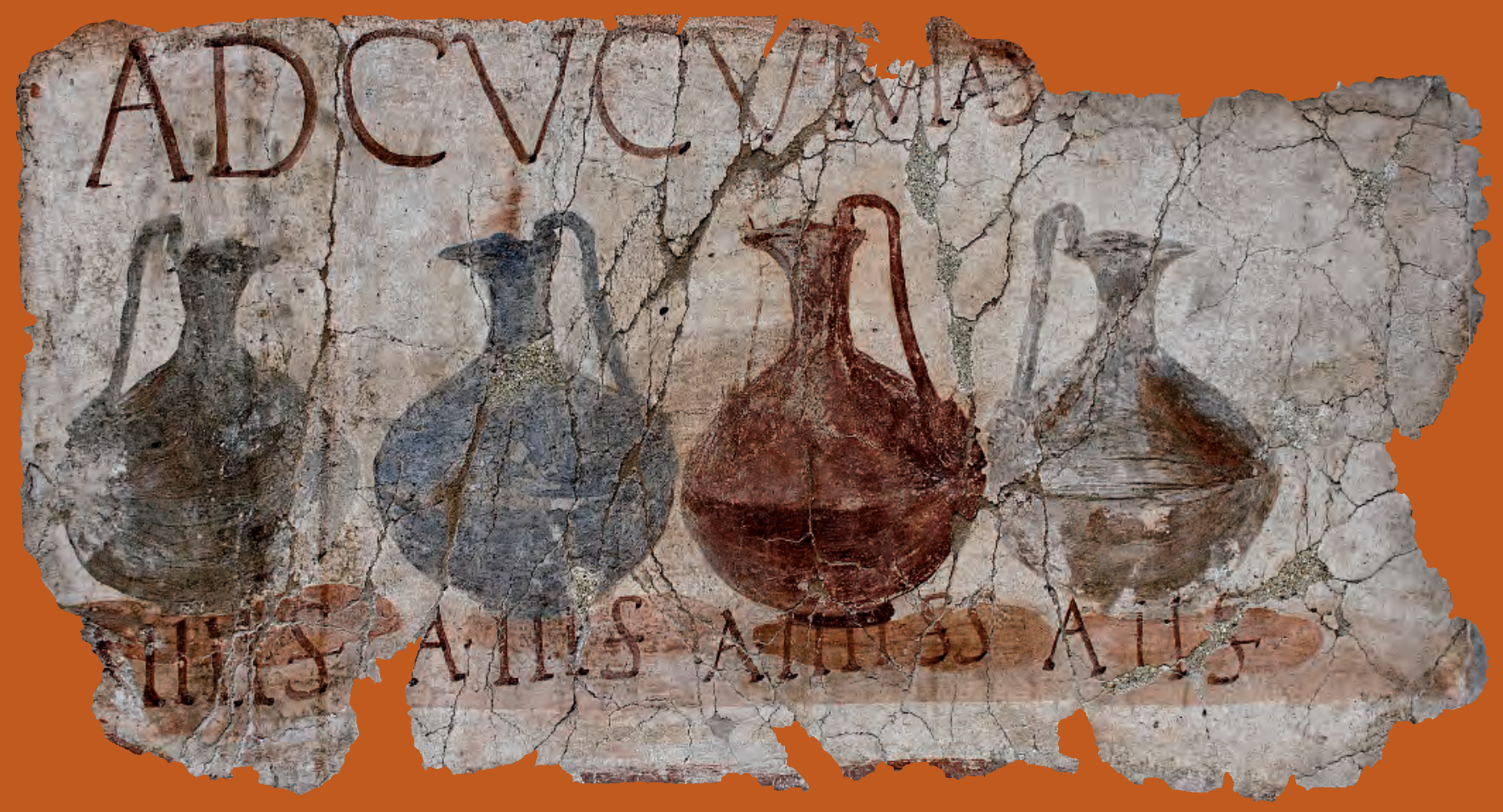

ÉCOLE FRANÇAISE DE ROME CENTRE JEAN BÉRARD 
BIBLIOTHÈQUE DES ÉCOLES FRANÇAISES D'ATHÈNES ET DE ROME Fascicule trois cent quarante-quatrième COLLECTION DU CENTRE JEAN BÉRARD 34

\title{
LES LIEUX DE MÉTIER
}

\section{BOUTIQUES ET ATELIERS D'HERCULANUM}

\author{
PAR
}

Nicolas Monteix 
Monteix, Nicolas, 1977-

Les lieux de métier: boutiques et ateliers d'Herculanum / par Nicolas

Monteix.

Rome: École française de Rome, 2010

(Bibliothèque des Écoles françaises d'Athènes et de Rome; 344)

(Collection du Centre Jean Bérard, ISSN 1590-3869; 34)

ISBN 978-2-7283-0891-0 (École française de Rome)

ISBN 978-2-918887-05-8 (Centre Jean Bérard)

1. Herculanum (ville ancienne) -- Conditions économiques 2. Pompéi (ville ancienne) -- Conditions économiques 3. Artisanat -- Italie -Herculanum (ville ancienne) 4. Artisanat -- Italie -- Pompéi (ville ancienne) 5. Fouilles archéologiques -- Italie -- Herculanum (ville ancienne) 6. Fouilles archéologiques -- Italie -- Pompéi (ville ancienne)

BIP - Bibliothèque de l'École française de Rome

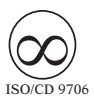

(C) - École française de Rome - 2010

ISBN 978-2-7283-0891-0 
À Catherine Mondeville

Quand la vie a fini de jouer

la mort remet tout en place

La vie s'amuse

la mort fait le ménage

peu importe la poussière qu'elle cache sous le tapis

Il y a tant de belles choses qu'elle oublie.

Jacques Prévert, «La belle vie », Fatras, Paris, 1966, p. 174. 
Liste des abréviations

Ant., Inv. $\mathrm{n}^{\circ}$ numéro d'inventaire des objets anciennement conservés dans l'Antiquarium de Pompéi.

GSE Giornale degli scavi di Ercolano.

GSP Giornale degli scavi di Pompei.

Inv. $\mathrm{n}^{\circ} \mathrm{E}$ numéro d'inventaire des objets conservés à Herculanum.

Inv. $\mathrm{n}^{\circ} \mathrm{P}$ numéro d'inventaire des objets conservés à Pompéi.

MANN Museo Archeologico Nazionale di Napoli.

SANP Soprintendenza speciale per i beni archeologici di Napoli e Pompei.

SAR-O Soprintendenza speciale per i beni archeologici di Roma - sede di Ostia.

[SNI] Sans numéro d'inventaire. 


\section{AVANT-PROPOS}

Lorsqu'un visiteur foule pour la première fois les voies dallées de basalte d'Herculanum, il parcourt la ville, entr'apercevant rapidement une série de petites pièces qui s'ouvrent sur la rue. Presque toujours dépourvues de peinture, et souvent de tout aménagement, ces dernières ne captent son regard que l'espace d'un instant, avant qu'il ne pénètre dans une de ces grandes maisons qui bordent ce qui était autrefois le rivage. En découvrant les perspectives offertes sur de vastes jardins bordés de colonnes, il oublie rapidement les pièces vides qu'il vient de dépasser. Il semble difficile de reprocher son attitude de dédain à cet innocent visiteur alors même qu'il reproduit inconsciemment celle des élites romaines face au commerce de proximité. En effet, sauf à consulter la littérature juridique dans son acception la plus technique, rares sont les textes littéraires qui affichent autre chose que du mépris envers les boutiques, les ateliers ou leurs occupants. Citerions-nous Cicéron que l'on se convaincrait avec lui que les artisans et les boutiquiers sont indignes, marqués qu'ils sont par leur occupation quotidienne ${ }^{1}$. Symboles de la vie citadine pour Horace, seules les boutiques, ou du moins les nuisances urbaines développées par leurs tenanciers, peuvent rapprocher Sénèque et Martial dans un jugement unanime et violemment réprobateur ${ }^{2}$. L'empereur luimême est décrit avec une image tachée d'infamie s'il vient à fréquenter certains commerces, particulièrement le soir ${ }^{3}$. Pourtant, que ce soit pour

${ }^{1}$ Cic., Off., 1, 150, cit. infra n. 1 p. 219.

${ }^{2}$ Hor., Epist., 14, 21 ; Sen., Ep. [6,] 56, 2; Mart., 7, 61, 9.
Cicéron ou l'empereur Claude, les boutiques et les ateliers ont constitué une part - si difficile soit-elle à évaluer - de leurs revenus, rendant ce mépris affiché parfois paradoxal ${ }^{4}$. Ce climat de répulsion à l'égard des boutiques justifierait à lui seul le recours à d'autres sources que les textes pour entreprendre leur étude. La tentation serait grande d'exploiter les cités ensevelies par le Vésuve, qui sont supposées être des instantanés du monde romain figées dans leur gangue de cendres et de boue volcanique. Pourtant, l'influence de la littérature latine sur l'appréhension des vestiges archéologiques n'a pas contribué à leur étude sans $a$ priori et les premières descriptions des sites, passé l'émerveillement de découvrir la diversité des commerces, reprennent des réflexes issus de la longue fréquentation des textes classiques.

Le principe général de ce travail s'inscrit en contrepoint de la tradition véhiculée par les textes: déterminer l'importance, dans la vie urbaine, des boutiques et des ateliers devrait permettre de définir la situation de leurs tenanciers qui, à défaut d'être directement associés à l'élite, n'en sont pas aussi éloignés que ce que les sources littéraires laissent paraître. Dans un premier temps, contentons-nous d'une définition sommaire et antithétique de ces lieux de métier: les boutiques correspondent à des espaces de vente et de diffusion, tandis que les ateliers sont consacrés à la production. Cette distinction très marquée entre ces deux formes

\footnotetext{
${ }^{3}$ Suet., Nero., 26, 1.

${ }^{4}$ Cic., Att., 14, 9, 1, cit. infra n. 46; Suet., Claud., 38, 4.
} 
d'espaces urbains est certainement le seul point convergent dans le bilan que l'on peut rapidement dresser des travaux sur ce thème: une stricte séparation a été maintenue entre, d'une part, les recherches consacrées aux boutiques et, d'autre part, l'extraordinaire balkanisation des études sur les productions artisanales. Les trois principales analyses consacrées aux boutiques au cours du dernier demi-siècle ont en commun d'avoir abordé ces espaces commerciaux par le biais d'une définition architecturale. En 1956, G. Girri a recensé les boutiques d'Ostie et en a proposé une typologie ${ }^{5}$. Dans le courant des années 1980, V. Gassner a dressé un catalogue des boutiques de Pompéi. Outre l'inventaire raisonné des 577 espaces considérés comme Kaufläden dans la cité ensevelie par le Vésuve, l'essentiel de son travail est articulé autour de questions touchant aux rapports entre les espaces commerciaux et les maisons en façade desquels ils se situent. Cette approche indéniablement novatrice et pertinente a toutefois été desservie par le recours à un classement typologique pour expliquer les liens entre l'habitat et l'espace commercial, alors même que la variété des situations obligerait à des regroupements plus ouverts $^{6}$. A. MacMahon a récemment publié sa thèse consacrée aux tabernae de Bretagne, dans laquelle une approche architecturale des vestiges d'Angleterre est associée à des remarques plus générales fondées sur Pompéi, Herculanum et Ostie $^{7}$. Au cours des trente dernières années, une réflexion sur les boutiques s'est également

5 Girri 1956. L'approche sur les tabernae d'Ostie a ensuite été considérablement renouvelée par C. Pavolini (1986), dans une étude cherchant plus à cerner la place des boutiques dans la construction privée ainsi que les formes d'habitat auxquels de tels espaces sont associés.

${ }^{6}$ Gassner 1986.

${ }^{7}$ MacMahon 2003. Cet ouvrage montre une approche très globalisante de l'espace commercial dans les villes romaines, et reste trop attachée aux sites italiens pour procéder à des interprétations. Pourtant, une étude strictement provinciale aurait sans doute conduit à proposer des critères différents pour reconnaître des boutiques, tout particulièrement en raison de l'état de conservation des vestiges pris en compte.

${ }^{8}$ Les réflexions amorcées par J. Packer (1975) sur le «middle and lower class housing » l'ont ensuite amené à se pencher sur l'insertion de certains commerces dans des maisons à plan «non traditionnel » (Packer 1978). Bien que développée de façon périphérique dans le cadre des études portant sur l'habitat pompéien différent de la domus "traditionnelle» à atrium et péristyle. Les premières analyses en ce sens ont été proposées par J. Packer au cours des années $1970^{8}$. Depuis, A. Wallace-Hadrill a fortement contribué au renouvellement de ces questions par sa remarquable synthèse dans laquelle il a cherché à donner des interprétations de nature anthropologique à l'ensemble des édifices domestiques pompéiens ${ }^{9}$. Enfin, la thèse de F. Pirson consacrée aux Mietwohnungen à Pompéi et Herculanum a notamment mis en évidence les formes d'habitat associées aux boutiques ${ }^{10}$. En ce qui concerne les études consacrées à l'artisanat, je ne saurais présenter ici ne serait-ce qu'une ébauche de synthèse sur les derniers acquis de la recherche dans ce domaine: l'accroissement des spécialisations, conjugué à la multiplication des fouilles préventives en Europe, font qu'il est impossible de proposer un cadre d'ensemble. Chaque forme de production est désormais prise en considération par un ou plusieurs spécialistes qui se consacrent à tout ou partie des différents procédés mis en jeu par chaque technique. Cette multi-spécialisation a encore été accrue durant les vingt dernières années par la part croissante prise dans les études sur l'artisanat par l'archéométrie ${ }^{11}$.

La nécessité de ne pas dissocier les espaces de commercialisation de ceux consacrés à la production artisanale, qui participent d'un même processus économique, m'a incité à choisir les

se dégageant progressivement des espaces commerciaux, ces réflexions ont été poursuivies par A. Hoffman (1979) puis, en opposition avec ce dernier par S.C. Nappo (1993, 1994, 1995, 1997).

${ }^{9}$ Wallace Hadrill 1994.

${ }^{10}$ Pirson 1997et 1999.

11 Bien que centré sur une période chronologique beaucoup plus longue que celle qui va nous intéresser, le colloque sur l'artisanat métallurgique dans les sociétés anciennes en Méditerranée occidentale tenu à Ravello en 2000 (Lehoërff 2004) est symptomatique de cette part croissante de l'archéométrie. Sur 21 communications publiées, 8 sont fondées directement ou essentiellement sur l'utilisation de techniques archéométriques. Cette situation pourrait être due au développement de plus en plus important de la métallographie dans le champ des études concernant l'artisanat des métaux. Toutefois, un constat similaire pourrait être effectué pour d'autres productions. 
cités ensevelies par le Vésuve comme champ d'étude. Entre Herculanum et Pompéi, détruites à la même date mais dans des conditions extrêmement différentes - la première recouverte par 20 à 30 mètres de flux pyroclastiques, la seconde par 5 à 6 mètres de cendres et de pierres ponces -, j'ai opté pour la petite ville d'Herculanum et étudié 55 locaux associés, soit par les recherches antérieures, soit à la suite de nouvelles interprétations, au commerce ou à l'artisanat (pl. III, h.t.). Si seuls 50 d'entre eux ont bénéficié d'une étude complète - interprétation, esquisse des transformations et des relations avec les édifices voisins -, c'est uniquement dû à une volonté de ne comparer que des espaces pouvant bénéficier des mêmes schémas d'analyse. Une étude sur l'ensemble de Pompéi aurait été nécessairement moins approfondie, sauf à recourir à la sélection d'un échantillon (pl. Iv, h.t.). Cependant, un tel procédé aurait amené à privilégier les îlots les plus récemment fouillés, situés dans la Regio I, et aurait ainsi modifié la diversité des questions possibles ${ }^{12}$. De plus, en centrant cette étude sur Herculanum, j’ai clairement choisi de m'intéresser à un site généralement pris en compte pour les quelques exemples qu'il peut apporter en contrepoint à l'analyse de Pompéi ${ }^{13}$. Cette situation est un héritage pesant des recherches sur les cités ensevelies par le Vésuve: à partir du moment où A. Maiuri a publié le résultat de ses fouilles, il a été considéré - tacitement - par

${ }^{12}$ Le développement de l'étude de Pompéi par échantillonnage est perceptible dans la recherche anglo-saxonne depuis la synthèse d'A. Wallace-Hadrill (1994). D'autres auteurs ont depuis également choisi cette voie (Berry 1997 a et b; Foss 1997; Schoonhoven 1999; Allison 2004; Schoonhoven 2006). Quant à la surreprésentation de la Regio I, elle s'explique par l'existence d'archives de fouilles récentes, d'une exploitation plus facile que les descriptions souvent laconiques rassemblées dans la Pompeianarum antiquitatum historia $(P A H)$. À l'exception de l'article puis du livre d'A. Schoonhoven $(1999 ; 2006)$ qui étudient la seule Regio VI, toutes les autres études mentionnées dans cette note ont des échantillons comportant un nombre important d'édifices situés dans la Regio I. On ajoutera à cette liste non exhaustive les études menées par R. Ling (1997 a) sur l'îlot du Ménandre (I 10) ou la reprise par l'équipe de Ph. Borgard (Centre Camille Jullian) de l'analyse de l'îlot I 8.

${ }^{13}$ Voir en ce sens la part consacrée à Herculanum dans les synthèses d'A. Wallace-Hadrill (1994) ou de F. Pirson (1999). la communauté scientifique que tout avait été écrit sur Herculanum. Ni les compléments de publication, ni les travaux de V. Tran Tam Tinh ou d'A. Allroggen-Bedel entre les années 1970 et $1980^{14}$, ni même la célébration du $250^{\mathrm{e}}$ anniversaire de la redécouverte du site ${ }^{15}$ n'ont fait évolué cette relégation. Si un certain nombre d'expositions a été réalisé depuis la fin des années $1980^{16}$, le dernier travail exclusivement consacré à Herculanum a été publié en $1989^{17}$.

S'il m'a semblé plus que nécessaire de consacrer des analyses socio-économiques au seul exemple herculanéen, Pompéi n'a pas pour autant été négligée. En effet, en dépit des différences substantielles pouvant exister entre les deux villes en matière d'importance économique, le nombre d'études - même ponctuelles - réalisées sur les boutiques de la Colonia Veneria Cornelia Pompeianorum interdit de ne pas la prendre en considération dans ce cadre. Il importe pourtant de se demander si une identité d'ensevelissement suffit à légitimer une exploitation conjointe des deux villes, même asymétrique. La seule différence de taille, même en restituant une partie de l'extension d'Herculanum, découragerait les tentatives de parallèle: le tissu commercial ne saurait être identique en termes quantitatifs ou de variété. Cependant, cette forte différence peut être surmontée pour deux raisons. La première tient au thème de cette recherche, les lieux de métier. Si l'échelle des mécanismes

\footnotetext{
${ }^{14}$ Des compléments à l'ouvrage fondamental d'A. Maiuri (1958 b) ont été publiés par G. Cerulli Irelli $(1971,1974)$ et M. Manni (1974). Il s'agissait d'études des peintures et d'une monographie sur la Casa del colonnato tuscanico, dégagée en 1961, ces différents points ayant été laissés en suspens par le décès d'A. Maiuri en 1963. A. Allroggen-Bedel (1974, 1975, 1983, 1991, 1993) a essentiellement étudié la peinture et les archives de fouilles du XVIII ${ }^{\mathrm{e}}$ siècle. V. Tran Tam Tinh $(1971,1977,1988)$ s'est penché sur les cultes orientaux et sur la Casa dei cervi.

${ }^{15}$ Franchi dell'Orto 1993.

${ }^{16}$ Voir la liste des articles rédigés par M. Pagano en bibliographie. Les catalogues d'expositions les plus récents sont les suivants: Pagano 2000, d'Ambrosio - Guzzo - Mastroroberto 2003, Mühlenbrock - Richter 2005, Guidobaldi 2008.

${ }^{17}$ Il s'agit de la thèse de Th. Ganschow (1989), consacrée à l'étude des techniques de construction employées à Herculanum.
} 
économiques risque d'être inégale, les chaînons de base ne sauraient être dissemblables; deux villes si proches géographiquement ne peuvent qu'appartenir à une même koinè technique, où les savoir-faire sont communs et où la compréhension du fonctionnement d'un atelier dans un site permet d'éclairer l'organisation d'un espace similaire dans l'autre ville. La seconde raison découle de la première: les différences - qualitatives, d'échelle de production - observées dans les boutiques et officines des deux villes permettent de définir le tissu des métiers et de faciliter la comparaison. En contrepoint de l'historiographie récente, j'éclairerai donc la situation herculanéenne avec des exemples pompéiens.

Cette focalisation sur Herculanum et, dans une moindre mesure, Pompéi a d'évidentes conséquences sur l'extension chronologique de ce travail. Ainsi, la date de l'éruption du Vésuve, en 79 ap. J.-C. - à l'automne plutôt qu'en août ${ }^{18}-$, marque un terme évident. Cependant, certaines analyses m'amèneront à déborder de ce cadre jusqu'au $\mathrm{III}^{\mathrm{e}}$ siècle, en particulier pour suivre certaines évolutions dans les textes littéraires et juridiques traitant des artisans et des boutiquiers. La définition d'une borne chronologique en amont s'avère plus délicate: la majeure partie de ce travail se concentre sur la situation d'Herculanum telle qu'elle se présente au moment de l'éruption, au sortir des perturbations causées par au moins deux séismes survenus dans les 17 années antérieures. Il s'agirait donc essentiellement d'une "photographie» des conditions économiques dans cette ville juste avant son ensevelissement ${ }^{19}$. Néanmoins, le recours à l'archéologie du bâti permet d'esquisser une évolution sur une période plus longue, du règne d'Auguste à l'éruption. Le contexte particulier

18 Reprenant un débat séculaire, M. Borgongino et G. Stefani $(2002$, 2007) ont proposé, avec des arguments désormais imparables, de décaler la date de l'éruption de l'été à l'automne 79.

${ }^{19}$ Le terme de photographie n'est évidemment pas à prendre au sens strict. En effet, d'une part l'hypothèse de l'existence d'au moins deux séismes tend à interdire de considérer qu'Herculanum ou Pompéi se trouvaient, au moment de l'éruption, dans des conditions de vie «normales». Ces deux catastrophes successives ont nécessairement troublé le fonctionnement des deux villes. Lors de l'éruption, une partie de la population a eu le temps de s'enfuir des deux des vestiges mis au jour à Herculanum fait que l'on peut considérer que cette recherche intéresse le premier siècle de l'empire, avec un développement plus soutenu pour la période allant de 62 à 79 de notre ère.

Le paradoxe souligné au début de cet avantpropos mérite d'être clarifié: l'élite de la société romaine, même entendue dans un sens large incluant les oligarchies municipales, constituait une minorité comparée au nombre des seuls citoyens; pourtant les études sur le monde romain se sont concentrées sur elles. Il est certain qu'une grande partie de cette situation est liée à la nature des sources dont dispose l'historien de Rome, majoritairement textuelles, qui ne donnent aucun éclairage sur les populations humbles - pour ne même pas mentionner les pauvres. En se concentrant sur les lieux de métier, il apparaît possible de donner un aperçu sur la condition et la position économique et sociale de cette catégorie aux contours flous qui regroupe les tenanciers de ces espaces indispensables au fonctionnement de la cité. Somme toute, je vais, à partir des vestiges matériels, en déployant des analyses techniques, architecturales et topographiques, tendre vers des conclusions d'une portée plus générale sur l'économie et la société d'Herculanum au cours du I ${ }^{\text {er }}$ siècle de notre ère.

Pour mener à bien cette réflexion, je me suis appuyé essentiellement sur les vestiges des lieux de métier, préservés d'une lente destruction millénaire par la catastrophe de 79. L'essentiel de mes données a ainsi été collecté par une longue enquête de terrain à Herculanum, en alternant promenades d'observation des vestiges, nettoyages de surfaces dans une dizaine de lieux de métier ${ }^{20}$ et fouille stratigraphique de

villes. De plus, que ce soient les récupérations immédiatement postérieures à l'éruption pour Pompéi, ou les fouilles du XVIII siècle pour Herculanum, les perturbations ont été importantes dans les deux sites. Aucune de ces deux villes ne s'est présentée lors de la fouille comme si, brutalement, le temps s'était arrêté. Sur l'existence de plusieurs séismes avant l'éruption, cf. infra, p. 233-238 et Fröhlich - Jacobelli 1995. Sur les perturbations consécutives à l'éruption, cf. Allison 1992 et 2004.

${ }^{20}$ Outre l'accord de la Soprintendenza Archeologica di Pompei représentée par le Prof. P. G. Guzzo, j’ai eu le plaisir de bénéficier du soutien toujours renouvelé de la Dott. ssa 
trois d'entre eux ${ }^{21}$. Ces observations de terrain ont été motivées, soutenues et développées par l'étude exhaustive des archives concernant les fouilles réalisées par A. Maiuri entre 1927 et 1961: la confrontation de la publication avec les vestiges mis au jour a soulevé de nombreuses questions qui ont pu souvent être résolues par de sibyllines mentions provenant des comptesrendus quotidiens. Ce travail de compréhension et d'interprétation des archives, bien qu'a priori éloigné des pratiques usuelles de l'archéologie de terrain, s'est rapidement avéré fondamental. Par un aller-retour constant entre les murs en élévation à Herculanum, leur description par A. Maiuri, la narration de leur mise au jour dans les journaux de fouilles et des nettoyages ponctuels, j'ai pu recueillir des données permettant une analyse synchronique et diachronique des lieux de métier à Herculanum. Avec une extension évidemment moindre, j'ai procédé de la même façon pour les locaux étudiés à Pompéi. Enfin, le dernier champ d'investigation que j'ai exploré est constitué par les textes littéraires et juridiques. Leur corrélation avec les vestiges matériels est loin d'être évidente: le vernis subjectif de mépris envers les boutiquiers et leur lieu d'exercice rend dès le départ le travail d'interprétation très délicat. Toutefois, que ce soit sur le simple plan de la terminologie ou en ce qui concerne l'histoire des techniques, l'apport des textes littéraires ou normatifs reste important. Le recours unilatéral à un seul des trois grands types de sources utilisés - vestiges matériels, études antérieures et textes littéraires - n'aurait eu pour conséquence que d'appauvrir cette recherche, la privant ainsi de développements souvent importants.

$$
\text { * } *
$$

M. P. Guidobaldi, directrice de l'Ufficio Scavi d'Herculanum, ainsi que de l'ensemble des gardiens du site pendant chacun de mes séjours à Herculanum. Qu'ils en soient tous remerciés.

${ }^{21}$ Ces fouilles se sont déroulées dans les trois boutiques (VI, 12, VI, 14 et VI, 15) situées en façade de la Casa del salone nero, dans le cadre du programme de recherches sur «l'artisanat à Pompéi et Herculanum» mené par le Centre Jean-Bérard et le Centre Camille-Jullian. Qu'il me soit permis
Je ne peux achever cet avant-propos sans tenter de rendre compte des dettes parfois abyssales contractées pendant douze années consacrées, du diplôme universitaire de maîtrise à l'achèvement de ce livre, aux boutiques d'Herculanum. Je suis irrémédiablement insolvable auprès de C. Virlouvet et d'O. de Cazanove; ce dernier pour m'avoir proposé de "regarder» ce sujet pour un mémoire de maîtrise en 1997; C. Virlouvet pour avoir généreusement accepté de prendre la direction d'une thèse dont cet ouvrage est issu et pour les patients conseils prodigués tout au long de mes recherches. Sans les enseignements palatins de M. Célié, j'aurais certainement du mal à "lire» les structures archéologiques.

Le support de trois institutions s'est avéré indispensable pour mener mes recherches à leur terme. Au cours de mes nombreux séjours campaniens, j'ai ainsi toujours pu bénéficier d'un accueil bienveillant de la part de P. G. Guzzo, soprintendente archeologo di Pompei, ainsi que des directeurs des deux sites, A. d'Ambrosio à Pompéi et, à Herculanum, d'abord M. Pagano, puis surtout M. P. Guidobaldi. Sans l'amicale gentillesse d'A. Cozzolino et de L. Sirano, je me serais perdu dans les méandres des archives de fouilles et des dépôts, et cette thèse n'aurait jamais abouti. Grâce au centre Jean-Bérard, à M. Bats et J. - P. Brun, ses directeurs successifs, et à M. F. Buonaiuto, j'ai obtenu un indéfectible et généreux soutien logistique et scientifique. Enfin, après m'avoir facilité l'accès à la vaste bibliotheca pompeiana, dispersée à travers les instituts étrangers romains, en m'accordant d'abord trois bourses de séjours puis un séjour post-doctoral de trois ans, l'École française de Rome, incarnée par ses directeurs successifs - A. Vauchez et M. Gras - et par les directeurs des études pour l'Antiquité - S. Verger et

d'exprimer de nouveau ma gratitude aux deux promoteurs de ce programme, J.-P. Brun (CJB) et Ph. Borgard (CCJ), qui m’ont généreusement offert cette opportunité. Mes plus chaleureux remerciements vont également à tous ceux qui ont l'amicale gentillesse de participer activement à ces deux campagnes, prenant parfois sur leurs temps de congé: C. Blonce, M. Celié, O. Cerasuolo, B. Chiaretti, A. Coutelas, B. Faticoni, A. Ferrandes, V. Monaco et M. Pernot. 
Y. Rivière -, m'a permis de largement bénéficier de cet élément indispensable à toute recherche, qui tend malheureusement à devenir un luxe: le temps.

Cet ouvrage a bénéficié des remarques de ses premiers lecteurs, constitués en jury en décembre 2006, alors qu'il n'était qu'une thèse de doctorat. Les sages conseils de C. Virlouvet, J. Andreau, J.-P. Brun, O. de Cazanove et F. Zevi ont fortement contribué à l'amélioration du texte qui suit. R. Figuier, directeur des publications de l'École française de Rome, et ses collaborateurs - F. Bruni et H. Franchi - auront fait tout leur possible au cours de longues discussions pour transformer un diplôme universitaire en livre. F. Fouilland, V. Jolivet, E. Botte, M.-B. Carre, A. Duvauchelle, M. Flohr, N. Laubry, F. Médard et N. Tran m'ont laissé abuser de leur temps et de leur savoir au gré de la relecture des épreuves. Enfin, sans la patience de S. Zanella, le dénouement aurait été radicalement différent.

Que tous trouvent ici l'expression de ma profonde reconnaissance et de mes plus vifs remerciements. Il va sans dire que je reste responsable de toutes les erreurs et omissions pouvant subsister.

Rome, le 29 août 2009 


\section{INTRODUCTION}

\section{INVENTIO HERCULANEI: AMEDEO MAIURI ET LES FOUILLES D'HERCULANUM}

«Le nuove botteghe ed officine, che s'aprivano sul lato opposto della via, e i nuovi quartieri d'affitto furono certo la principale causa dello stato di abbandono e di vetustà in cui troviamo la maggior parte degli edifici lungo il fronte occidentale della strada»

A. Maiuri, Ercolano. I nuovi scavi. (1927-1958), vol. 1, Roma, Libreria della Stato, 1958, p. 261.

Introduire un ouvrage sur les lieux de métier à Herculanum en présentant l'apport d'Amedeo Maiuri (1886-1963) pourrait apparaître comme un contresens. En occupant le poste de Soprintendente alle Antichità della Campania e del Molise et de directeur du Musée National de Naples de 1924 à 1961, A. Maiuri, en plus de ses autres activités, a dirigé la reprise des fouilles d'Herculanum à partir d'avril 1927. Durant ces trente années de travaux, il s'est formé une idée personnelle du site, de sa nature socio-économique et de son évolution topographique et édilitaire. Avec la parution du premier volume - qui restera le seul en raison du décès de l'auteur - consacré à Herculanum en 1958, c'est tout autant une somme de ces idées qu'une synthèse supposée exhaustive sur la ville qui est publiée. Quelles que soient les révisions, nécessaires mais partielles, qui ont été apportées à cette œuvre - essentiellement à partir des années $1990^{1}$-, il faut admettre que Ercolano. I nuovi scavi reste fondamental pour toute recherche sur Herculanum. Il est en revanche impératif d'adopter un point de vue objectif et raisonné

\footnotetext{
${ }^{1}$ Voir Guadagno 1993 sur des problèmes de topographie; Łos 1992 et 1995 sur le rôle des affranchis dans la ville de Pompéi, qui sert de modèle à A. Maiuri pour certains
}

pour éviter la paraphrase et la reprise d'interprétations qui ont été divulguées par fragments plus ou moins importants au gré des articles, livres et guides avant d'être rassemblées. Avant d'entrer dans le vif du sujet, il m'est apparu indispensable de comprendre la genèse et l'évolution des idées d'A. Maiuri sur Herculanum et en particulier sur le développement du commerce et de l'artisanat dans cette ville. Les excès des réflexions qu'il a développées, qui tendent à démontrer le caractère envahissant et indésirable des boutiques et ateliers, nécessitent des éclaircissements et doivent être appréhendés en intégrant les traditions historiographiques liées à Herculanum, les recherches du moment et les données nouvelles issues des fouilles menées au $\mathrm{XX}^{\mathrm{e}}$ siècle.

La principale théorie d'A. Maiuri concerne les transformations socio-économiques des villes campaniennes. Elle a été développée en premier lieu pour Pompéi, mais ensuite adaptée à Herculanum et complétée par un second volet qui concerne exclusivement les origines sociales et géographiques du peuplement de cette ville.

de ses développements sur Herculanum; Wallace-Hadrill 1994: 118-131 sur les liens entre l'élite et le commerce. 
L'énoncé originel du postulat sur l'évolution socio-économique des villes du Vésuve apparaît dans un ouvrage de vulgarisation sur Pompéi en 1928, première synthèse écrite par A. Maiuri depuis qu'il est Surintendant des fouilles ${ }^{2}$. Dans ce livre, il reprend l'ensemble des données de ses prédécesseurs, pour brosser un tableau aussi complet que possible de la ville. Un chapitre entier est consacré aux transformations économiques de la cité pompéienne: «la città mercantile ha ormai sopraffatto la città patrizia; commercio ed industria sono i nuovi grandi fattori della ricchezza». Il décrit ainsi le remplacement des élites traditionnelles par des "nouveaux riches». Ces derniers ne semblent avoir qu'une seule valeur identitaire, un seul but, « un'unica ansia, [...] una sola ardente febbre: il danaro ». Repoussées par ces hommes nouveaux, les anciennes élites, restées fidèles à l'économie agraire, doivent fuir, abandonner la ville pour se réfugier dans leurs terres. Cette transformation sociale et économique est dépeinte avec des termes d'une telle violence que l'on croit assister à une révolution:

Le botteghe si moltiplicano, si ampliano, invadono prepotentemente tutto lo spazio disponibile sulla strada, [...] si serrano ai fianchi dei ricchi portali come per tentare, dopo la prima parziale conquista di qualche vano accessorio, l'assalto definitivo e trionfale a tutt'intera la casa $^{3}$.

Ainsi, les nouveaux riches, affranchis et «étrangers » auraient réussi à évincer complètement les anciennes élites, dont ils occupent les maisons qui sont adaptées à leurs besoins et à leurs goûts grossiers ${ }^{4}$. En 1931, après quelques articles sur la reprise des fouilles et sur les objectif de celles-ci, A. Maiuri publie un article dans l'Illustrazione Italiana, destiné à donner un résumé des découvertes effectuées jusqu'alors 5 . Il met en avant les différences qui existent entre Herculanum et Pompéi. Si les transformations radicales de la société décrites en 1928

\footnotetext{
${ }^{2}$ Maiuri 1928: 81-104 = Maiuri 1978: 244-256.

${ }^{3}$ Maiuri 1928: 84 = Maiuri 1978: 244.

${ }^{4}$ Maiuri 1928: 87-89 = Maiuri 1978: 244-246.

5 Maiuri 1931 b. Un autre article concernant les nouvelles fouilles d'Herculanum a été publié en 1929 ( $\mathrm{I}$ nuovi scavi di Ercolano", in Le meraviglie del passato, Mondadori, Milan, 1929, fasc. 4, p. 1379-1385, n.v.).
}

ne semblent pas avoir eu lieu à Herculanum, l'accent est porté sur la composition sociale de cette ville: la salubrité de son climat et la beauté du site sont censées en avoir fait un des lieux de séjour favoris des élites romaines et campaniennes ${ }^{6}$.

L'année suivante paraît un premier ouvrage de synthèse sur Herculanum. Bien que dépourvu d'apparat critique, il sera ensuite considéré par A. Maiuri comme d'une ampleur supérieure à son guide touristique d'Herculanum ${ }^{7}$. La taille de l'ouvrage lui permet de développer de façon substantielle la différence entre Herculanum et Pompéi: les deux villes semblent avoir suivi une évolution différente jusqu'à l'éruption du Vésuve. Les maisons d'Herculanum paraissent avoir abandonné le plan traditionnel de la domus samnite; leurs façades ne sont pas pourvues des affiches électorales et des publicités murales que l'on retrouve si fréquemment à Pompéi. Les conditions économiques sont exposées de manière fort différente:

Le botteghe appaiono più rade e senza tutto lo sfarzoso e reclamistico apparato delle botteghe pompeiane: e di officine, fulloniche e tintorie per la lavorazione dei panni, nessuna traccia è finora apparsa dai vecchi e nuovi scavi. [...] Ci troviamo, insomma, in una città più tranquilla, più silenziosa, meno animata e sconvolta dal traffico mercantile e dalla folla del contado che invadeva quotidianamente il Foro e le vie di Pompei ${ }^{8}$.

Si les conditions d'ensevelissement semblent expliquer partiellement ces fortes différences, elles ne sont pas suffisantes. La position géographique d'Herculanum serait un facteur important de différenciation. Proche de Naples, coincée entre le Vésuve et la mer, Herculanum ne peut pas se développer économiquement, au contraire de Pompéi. En revanche, une autre fonction, déjà évoquée en 1931, est alors donnée à la ville: celle de lieu de détente pour les élites romaines et napolitaines, ainsi que pour les nouveaux riches, désireux de se reposer loin

\footnotetext{
${ }^{6}$ Maiuri 1931 b: 898.

${ }^{7}$ Maiuri 1936 a: 3 = Maiuri 1936 b: 3.

${ }^{8}$ Maiuri 1932: 46-47. Si plusieurs ateliers liés à l'activité textile ont alors été mis au jour, ils n'ont pas l'ampleur de ceux découverts à Pompéi. De plus, seules treize boutiques ont alors été fouillées.
} 
du tumulte des grandes villes, populeuses et rendues bruyantes par les commerçants9.

La proximité avec Naples permettrait également d'expliquer certains aspects architecturaux et culturels propres à Herculanum: si de riches pavements en opus sectile ont pu être utilisés dans la cité, cela serait exclusivement dû à des relations commerciales importantes entre Herculanum et les centres économiques du I ${ }^{\text {er }}$ siècle, Naples et surtout Pouzzoles ${ }^{10}$. La trame viaire de la cité, qui semble reproduire un plan hippodaméen, serait directement inspirée des quartiers "gréco-romains» de $\mathrm{Naples}^{11}$. L'influence de cette dernière, "città che conservò più a lungo nell'età romana lingua, usi e costumi greci e che fu centro di studi letterari e filosofici ", serait également perceptible sur le plan culturel, comme ont pu le montrer les fouilles effectuées au XVIII ${ }^{\mathrm{e}}$ siècle dans la Villa des Papyrus. Les statues de bronze, les portraits de philosophes grecs et les papyrus qui y ont été retrouvés seraient ainsi les meilleurs indices de cette supériorité culturelle d'Herculanum sur Pompéi ${ }^{12}$.

En 1936, un guide des fouilles donne les dernières évolutions de l'avancée des travaux. Dans cet ouvrage de moindre ampleur que le précédent, A. Maiuri reprend une partie de ses thèses, parfois approfondies. Le caractère principal d'Herculanum demeure son faible tissu commercial:

Les rues d'Herculanum ne sont pas, comme celles de Pompéi, tapissées de publicité murale et tapageuse. Si l'on rencontre, en certains points de la ville, les plus fréquentés naturellement, des magasins et des tabernae, souvent spacieux et bien aménagés, leur nombre et leur tenue nous montrent qu'Herculanum était loin d'avoir ce caractère éminemment mercantile que l'on note dans presque tous les quartiers pompéiens ${ }^{13}$.

Les boutiques et ateliers mis au jour se caractérisent par une apparence moins vulgaire. La grande spécialisation des ateliers (mosaïstes, sculpteurs, maîtres marbriers, ébénistes) ${ }^{14}$ incite très nettement à considérer que seuls des personnages aisés résidaient à Herculanum. Ce

\footnotetext{
${ }^{9}$ Maiuri 1932: 48.

${ }^{10}$ Maiuri 1932: 71.

${ }^{11}$ Maiuri 1932: 28-29. Sur ce point en particulier, voir les remarques faites par G. Guadagno (1993: 83-87).

${ }^{12}$ Maiuri 1932: 48-49.
}

trait renforce le postulat qui en fait une cité où la population, d'origine romaine ou napolitaine, ne séjournerait que pour se reposer et s'éloigner du tumulte urbain. Ce caractère fortement résidentiel s'illustre parfaitement dans la description donnée du quartier sud de la ville:

La ville était bâtie face à la mer qui lui envoyait ses salubres senteurs et la fraîcheur de ses brises. Aussi les maisons, les plus riches et les plus belles, s'installèrentelles naturellement, de façon à jouir le plus possible de ces avantages et de la beauté du panorama. On les voit venir se percher sur l'extrême limite de la crête du promontoire et disposer, bien en vue de la mer, leurs vérandahs (sic), leurs terrasses, leurs belvédères, les chambres réservées à la sieste et au repos. [...] On peut dire qu'elles reflètent à la perfection le caractère, les goûts et les habitudes des classes riches, au cours des derniers lustres de l'existence de la ville. [...] Le spectacle de toutes ces maisons vues de la mer, toutes bien alignées, les unes à côté des autres, tout le long de l'arête du promontoire, devait être féerique: une ceinture aérienne de portiques et de galeries ${ }^{15}$.

Toutefois, si Herculanum se caractérise alors par la présence de riches personnages, le «bas peuple» n'en est pas absent. Au contraire de Pompéi, où il se trouve impliqué dans les affaires commerciales et industrielles des nouveaux riches, il est présenté ici comme réduit à vivre de la pêche ${ }^{16}$. La société herculanéenne ne comporterait ainsi que deux strates: d'une part des riches se reposant au bord de la mer dans de somptueuses maisons, de l'autre une masse populaire vivant des ressources maritimes. Le commerce aurait alors eu à peine droit de cité à Herculanum. L'invasion des «nouveaux riches» dans les maisons de l'élite ne s'y serait pas produite. Si les maisons y présentent bien certains caractères visibles dans l'évolution de celles de Pompéi, aucun facteur explicatif n'est avancé:

Pompéi avait vu ses maisons patriciennes s'atrophier progressivement, sa domus antique se fractionner en maison marchande et en maison de rapport en gagnant, par des surélévations, un espace qu'elle ne pouvait occuper en superficie. À Herculanum, la métamorphose a été seulement plus rapide. Le type traditionnel de la maison antique, italique et hellénistique, s'est plus radi-

\footnotetext{
${ }^{13}$ Maiuri 1936 b: 16 (= Maiuri 1936 a: 14).

${ }^{14}$ Maiuri 1936 a: 14 = Maiuri 1936 b: 16 .

${ }^{15}$ Maiuri 1936 b: 17-18 (= Maiuri 1936 a: 15-16).

${ }^{16}$ Maiuri 1936 a: 14 = Maiuri 1936 b: 16.
} 
calement transformé [...] sous la pression, plus directe et plus profonde, qu'a dû exercer le voisinage de la grande métropole de Naples, trop comprimée, par suite du même phénomène de l'urbanisme, entre ses vieilles murailles grecques $^{17}$.

La représentation d'une société fortement contrastée à Herculanum va perdurer, dans les éditions suivantes de ce guide, en dépit des mises aux jours liées à l'avancement des fouilles. En revanche, dans les autres articles qu'il a rédigés entre 1938 et 1958, A. Maiuri s'en éloigne progressivement, pour mieux se rapprocher de l'évolution générale qu'il a pu dresser pour Pompéi. Ainsi, en décembre 1937, une peinture sur cadre de bois est mise au jour au premier étage de l'appartement V, 17-18 ${ }^{18}$. Ce type de tableau peint, pictura excisa, est considéré par A. Maiuri comme une œuvre d'art raffinée, particulièrement rare. Il devient difficile pour lui d'admettre que cette œuvre a été mise au jour à l'étage d'une boutique. Ses hésitations pour caractériser l'occupant de ce local, qualifié d'«umile artigiano o bottegaio», puis d'«artigianato [sic], per non dire di un taverniere ${ }^{19}$, cachent mal une certaine forme de mépris pour les activités commerciales.

Avec l'avancée des fouilles vers le decumanus maximus, à la fin des années 1930, A. Maiuri opère un rapprochement plus net entre la situation d'Herculanum et celle de Pompéi. À cette date, il rend compte de la découverte d'une "croix» à l'étage de la Casa del bicentenario $(\mathrm{V}, 15-16)^{20}$. Dans la description qu'il donne de la maison et de son évolution au cours du premier siècle de notre ère, il applique pour la première fois sa théorie sur l'éviction des élites traditionnelles par les nouveaux riches au cas d'Herculanum. Je reviendrai plus loin sur les arguments utilisés pour justifier ce postulat. Selon lui, cette maison aurait été occupée par des membres du «nobile patriziato» au moins jusqu'à la première moitié du I ${ }^{\text {er }}$ ap. J.-C., voire jusqu'aux premières années du règne de Néron. De grandes

\footnotetext{
${ }^{17}$ Maiuri 1936 b: 16 (= Maiuri 1936 a: 14-15).

${ }^{18}$ Cf. infra, p. 83-87.

${ }^{19}$ Le simple usage du terme de taverniere montre bien le mépris d'A. Maiuri pour les boutiquiers (Maiuri 1938:
} $484,488)$. transformations seraient advenues entre 55 et 60 ap. J.-C.: un appartement est aménagé audessus des boutiques $\mathrm{V}, 13, \mathrm{~V}, 14$ et $\mathrm{V}, 16$, et est donné en location aux boutiquiers; un étage est créé sur l'arrière de la maison. L'usage de ces étages serait complètement détaché du rez-dechaussée. Pour expliquer ces transformations, A. Maiuri considère que la maison est passée des mains d'un membre de l'élite traditionnelle à celles d'un affranchi ou d'un marchand enrichi; il serait nécessaire d'associer ces changements à la proximité du forum, dans le cadre d'un fort développement de la vie mercantile de la cité. En note, il explique qu'Herculanum n'est pas une ville entièrement aristocratique et "signorile». Cet article marque un tournant par rapport à sa vision antérieure sur Herculanum. La cité aurait subi le même phénomène que celui qui a affligé Pompéi:

Ad Ercolano, contro l'errato presupposto di essere una città tutta aristocratica e signorile, i nuovi scavi hanno mostrato che il fenomeno, pur ridotto in più modeste proporzioni, non era meno importante e diffuso ${ }^{21}$.

Cette thèse, à visées désormais généralistes, est développée en 1942 dans l'ouvrage consacré à la dernière phase de construction à Pompéi. Après avoir dressé un catalogue relativement exhaustif des transformations et des réparations effectuées à la suite du tremblement de terre de 62 ap. J.-C., A. Maiuri esquisse en conclusion une synthèse. Il ressort de celle-ci que les transformations de maisons en ateliers et les ouvertures de boutiques se font plus importantes après cette catastrophe:

Ma è anche questo il periodo in cui assistiamo alla trasformazione di molte case signorili in officine, all'intrusione di botteghe, di cauponae e di termopolî nell'interno e lungo il muro di facciata di abitazioni patrizie, al frazionamento di una sola grande casa signorile in più abitazioni modeste, al mutamento e pervertimento di gusto nel genere e nello stile della decorazione degli ambienti, sacrificandosi belle e nobili pitture vetuste p. 20.

20 Sur la chronologie de cette découverte, cf. infra,

${ }^{21}$ Maiuri 1939: n. 8 p. 198. 
per banali e povere ridipinture, all'invadenza insomma del ceto mercantile nella compagine del vecchio ceto patrizio romano e campano della città ${ }^{22}$.

Comme il l'avait déjà écrit sur Pompéi, puis fortement suggéré pour Herculanum, les causes de ces transformations seraient liées au mercantilisme croissant d'une fraction grandissante de la population. La présence de décorations à peine refaites en 79 ap. J.-C. dans certaines boutiques indiquerait une reprise importante de l'activité commerciale après le tremblement de terre, dans des maisons dont les propriétaires, membres de l'élite locale, auraient subi de plein fouet la catastrophe. Il faut relever le paradoxe de la situation décrite: les élites traditionnelles, dont le pouvoir économique est censé être lié aux activités agricoles, souffrent plus d'une catastrophe dont seuls ceux qui ont des intérêts urbains devraient avoir eu à pâtir ${ }^{23}$; pourtant, marchands et commerçants continueraient leur «invasion » et développeraient encore plus leurs activités en ville. Dans le même temps, mais en des lieux différents de Pompéi, le ralentissement du commerce et de la production urbaine serait perceptible par l'état de délabrement avancé de certaines boutiques ${ }^{24}$.

Après avoir exposé sa théorie sur l'évolution des commerces pompéiens, A. Maiuri ne l'a pas reformulée avant sa synthèse de 1958 sur Herculanum ${ }^{25}$. Dans son ouvrage articulé en trois parties - topographie de la ville; édifices publics; habitat -, faute de paragraphe ou de chapitre s'attachant à récapituler les caractères socio-économiques de la ville, ses postulats sont disséminés au fil des pages concernant chaque édifice décrit.

La synthèse est marquée par un amoindrissement des rapports auparavant supposés

${ }^{22}$ Maiuri 1942 a: 217.

${ }^{23}$ Son ouvrage étant consacré à la ville de Pompéi, A. Maiuri ne mentionne pas les dégâts subis par les bâtiments des exploitations agricoles, qui ont pourtant été également endommagés. Quelques exemples, issus de fouilles récentes, sont donnés dans De Spagnolis Conticello 1995.

${ }^{24}$ Maiuri 1942 a: 216-217.

${ }^{25}$ A l'exception des rééditions mises à jour du guide d'Herculanum, dont le texte préliminaire et synthétique demeure inchangé.

${ }^{26}$ Maiuri 1958 b : 27-28. étroits entre Herculanum et Naples; seule la trame viaire sert désormais de lien entre les deux villes:

Già chiaramente si ricava quel che è il carattere essenziale dell'urbanistica ercolanese: la sua geometrica regolarità e la sua piena rispondenza ai canoni della cosidetta urbanistica ippodamea.[...] Non diversamente ci si presenta la topografia della greca Neapolis con i suoi vecchi quartieri gradatamente discendenti dall'altura di S. Aniello a Caponapoli verso la linea dei porti ${ }^{26}$.

Il n'y a plus qu'une influence formelle revendiquée entre Naples et Herculanum ${ }^{27}$. Par répercussion, le contraste culturel avec Pompéi est désormais fortement atténué. Avant de revenir sur l'évolution socio-économique de la ville telle qu'elle est présentée, rappelons la façon dont est organisée la partie consacrée à l'habitat. Comme l'a déjà montré $\mathrm{A}$. Wallace-Hadrill, l'utilisation d'une typologie des maisons fondée sur des catégories sociales est fortement connotée. Cette classification a été dressée selon deux présupposés: les domus «traditionnelles» sont d'un rang supérieur aux autres; les maisons pourvues de boutiques sont d'un rang inférieur à celles qui en sont dépourvues ${ }^{28}$. Ce premier constat appelle plusieurs remarques. Tout d'abord, il montre là encore une forte évolution dans la pensée d'A. Maiuri concernant Herculanum. Contrairement à ce qu'il avait publié dans ses premiers écrits, la société herculanéenne n'est plus considérée comme divisée en deux groupes; la stricte opposition entre les riches citoyens venus de Naples ou de Rome et le peuple se consacrant exclusivement à la pêche a disparu. Herculanum apparaît alors moins comme une ville «de villégiature». En revanche, l'accent est mis sur les caractères « samnites » del'habitat, qui priment sur les autres. Ainsi, la première maison

${ }^{27}$ A. Maiuri mentionne encore une forte influence de Naples sur Herculanum dans la description de la «Palestre » : "Ma che Ercolano, sotto la diretta influenza delle istituzioni della Neapolis greca, avesse una Palestra-ginnasio, ci è esplicitamente attestato dalla menzione di ludi gymnici nel decreto onorario di M. Nonio Balbo [...]» (Maiuri 1958 b: 116). Dans sa description de la Casa del papiro dipinto (IV, 8-9), il considère que le lieu d'exercice du poète de la maison est la «Palestre», "ispirata al costume e all'insegnamento del ginnasio della greca Neapolis» (Maiuri 1958 b: 425). Cette « influence» reste la seule encore supposée par l'auteur.

${ }^{28}$ Wallace-Hadrill 1994: 124. 
décrite est la relativement petite Casa sannitica $(\mathrm{V}, 1-2)$, en raison de la persistance d'éléments décoratifs du premier style, de son plan traditionnel et de son absence de boutique:

Non ostante [...] l'angustia dello spazio in cui venne ad essere rinserrata, la Casa sannitica con il suo bel portale e sovratutto con la bella decorazione architettonica dell'atrio, costituisce l'esempio più nobile che abbiamo dell'architettura della casa ercolanese ed uno dei più perfetti e compiuti che si hanno della casa sannitica ${ }^{29}$.

Ces caractères traditionnels semblent même prendre le pas sur la présence de boutiques. Ainsi, la Casa del tramezzo di legno (III, 4-6.8-9.11), alors qu'elle présente cinq boutiques en façade, est décrite avant la Casa del bicentenario (V,15-16), qui n'en comporte que deux qui lui soient liées. L'explication de ce classement tient exclusivement au caractère traditionnel de son plan. Un paradoxe subsiste dans le cas de la Casa del tramezzo di legno: cette maison est vantée pour ses aspects traditionnels et par le maintien de son caractère "signorile», même après la création de boutiques en façade.

[...] L'ultimo proprietario che l'abitò e l'adattò a i suoi bisogni doveva anchégli appartenere a quel ceto mercantile di arricchiti che, [...] mentre riservavano per sé il quartiere signorile, non si distoglievano dai commerci mantenendo attorno alla propria abitazione, botteghe ed alloggi d'affari gestiti ed amministrati da liberti procuratori.[...]

${ }^{29}$ Maiuri 1958 b: 198-199.

${ }^{30}$ Maiuri 1958 b: 207.

${ }^{31}$ Dans le corps de la description de la Casa del tramezzo di legno (III, 4-6.8-9.11), A. Maiuri (1958 b: n. 20 p. 207) renvoie à l'exposé qu'il fait de sa théorie dans son ouvrage sur L'ultima fase edilizia di Pompei (Maiuri 1942 a: 217 sq.).

${ }^{32}$ Casa del bicentenario (Maiuri 1958 b: 223); pour d'autres maisons, la date est moins précise: «verso la metà del I secolo dell'impero " (Casa sannitica et Casa del tramezzo di legno, Maiuri 1958 b: 198, 207), «[...] sino forse all'età claudia» (Casa dell'Apollo citaredo, Maiuri 1958 b: 248), "negli ultimi tempi» (Casa di Nettuno e Anfitrite, Maiuri 1958 b: 393), «negli ultimi decenni della città » (Casa della fullonica, Casa con tabernae (V, 23-25), Maiuri 1958 b: 422, 444).

${ }^{33}$ Casa del bicentenario (Maiuri 1958 b: 223).

${ }^{34}$ Casa sannitica, Casa dell'Apollo citaredo (Maiuri 1958 b: 198, 248). A. Maiuri ne peut pas rattacher la construction de la "Palestre», dont la façade occidentale est composée de boutiques, à cette hypothétique transformation de l'économie de la ville. La solution invoquée est donc toute autre: «[...] si vole deliberamente destinare ad uso commerciale una parte del fabbricato affinché, col ricavato
Questa casa [...] è tra quelle che conserva ad Ercolano il tipo tradizionale della casa italica e romana, per la grandiosità dell'atrio e per la disposizione degli ambienti intorno all'atrio, dove, almeno da un lato, si conservò la regolare disposizione di due cubicoli e di un'ala ${ }^{30}$.

Le schéma de l'évolution socio-économique d'Herculanum ne peut qu'être recomposé à partir d'éléments épars. La trame générale se rapproche fortement de l'exposé sur Pompéi ${ }^{31}$. Vers les années 55-60 ap. J.-C. ${ }^{32}$, une grande mutation interviendrait dans les habitudes économiques de la cité ${ }^{33}$, essentiellement due à l'accroissement des courants commerciaux d'outre-mer ${ }^{34}$. Conséquence directe de ces transformations, le forum s'ouvrirait au commerce et le decumanus maximus ("Via del Foro») deviendrait alors la principale artère économique de la cité $^{35}$, dont le cardo V, avec ses nombreuses boutiques, serait l'extension logique ${ }^{36}$. Cette transformation de l'économie générale de l'Empire aurait eu des conséquences non seulement sur l'économie de la ville, mais également sur sa structure sociale. Ainsi, de nombreuses maisons auraient alors changé de propriétaires ${ }^{37}$ et subi des transformations architecturales qui se manifestent par la création de boutiques ou de structures «industrielles ${ }^{38}$, ou encore par de profonds remaniements de parcelles dans les insulae ${ }^{39}$. La plus importante des conséquences sociales de

delle locazioni, si potesse sopperire alle esigenze dell'erario municipale e ai bisogni della manutenzione e del funzionamento delle parti monumentali e d'uso pubblico dell'edificio ». (Maiuri 1958 b: 117).

${ }^{35}$ Casa del bicentenario, Casa dell'Apollo citaredo (Maiuri 1958 b: 224, 248).

${ }^{36}$ Maiuri 1958 b: 40.

${ }^{37}$ Casa sannitica, Casa del tramezzo di legno, Casa di Nettuno e Anfitrite, Casa della fullonica (Maiuri 1958 b: 198, 207, 393, 422). Pour la Casa del bicentenario, le doute subsiste quant à savoir si un changement de propriétaire a eu lieu ou non (Maiuri 1958 b: 223-224).

${ }^{38}$ Seules les créations de boutiques ou d'ateliers qui suivent sont explicitement liées à cette transformation économique: Casa del tramezzo di legno, Casa del bicentenario, Casa dell'Apollo citaredo, Casa di Nettuno e Anfitrite, Casa della fullonica (Maiuri 1958 b: 207, 224, 248, 393, 422). Aucun indice chronologique n'est donné pour les autres boutiques.

${ }^{39}$ Casa del tramezzo di legno, Casa del bicentenario, Casa dell'Apollo citaredo, Casa del gran portale, Casa con giardino, Casa con tabernae (V, 23-25) (Maiuri 1958 b: 207, 224, 248, $377,431,443)$. 
cette évolution économique serait le remplacement des élites traditionnelles, "le più vecchie famiglie patrizie ercolanesi », par des nouveaux riches, "libert(i) arricchit(i)», "liberti mercanti o artigiani $»^{40}$. Les membres de l'élite se seraient alors réfugiés dans leurs domaines, laissant la ville en proie à l'invasion des marchands.

D'autres considérations émergent de ce postulat. Tout d'abord, selon une affirmation exposée en des termes plus subtils que dans le cas pompéien, le gain semble être une des valeurs principales de ces marchands. Ceux qui ont réussi à envahir les demeures traditionnelles feraient tout pour surveiller la bonne marche de leur commerce, laissé en gestion à des esclaves ou à des affranchis ${ }^{41}$. En suivant le raisonnement donné pour la Casa del sacello di legno (V, 31), on pourrait croire que seul le commerce est une activité lucrative, ceux qui ne s'y adonnaient pas étant condamnés à vivre dans de piètres conditions:

Abitazione dunque vetusta, piccola ma decorosa, in cui par di respirare ancora l'aria di un'Ercolano più semplice e patriarcale, non ancora invasa dal gusto e dalla moda delle decorazioni sfarzose di colori e di marmi dell'età imperiale. Forse questo spirito conservatore, questa fedeltà all'ambiente familiare del buon tempo antico, si deve alle non prospere fortune economiche dei suoi ultimi proprietari inquilini, e forse anche alla professione stessa che l'ultimo di essi dové esercitare ${ }^{42}$.

Bien qu'il ne mentionne pas explicitement la profession de l'occupant de cette maison, A. Maiuri laisse entendre qu'il ne s'occupait

${ }^{40}$ Maiuri 1958 b: 248, 224, 422. Ces nouveaux riches formeraient leur propre milieu social selon cette expression: «quel ceto mercantile di arricchiti » (Maiuri 1958 b: 207).

${ }^{41}$ Des fenêtres auraient été aménagées dans ce but exclusif dans la Casa del tramezzo di legno et la Taberna con abitazione (devenue Casa del priapo, IV, 17-18) (Maiuri 1958 b: 207, 437).

${ }^{42}$ Maiuri 1958 b: 253.

${ }^{43}$ Dépourvue de boutique en façade, cette maison est considérée comme faisant partie des "Case del ceto medio nello schema della domus». Parmi les maisons de cette catégorie, seule la Casa dell'Apollo citaredo (ex Casa insula V n. 11) possède deux espaces commerciaux (V, 9-10 et V, 12) (Maiuri 1958 b: 507).

${ }^{44}$ Casa del sacello di legno, Casa del bicentenario, Grande taberna con abitazione. Le propriétaire de la Taberna con abitazione (IV, 17-18, Casa del Priapo) irait, à tort selon A. Maiuri, jusqu'à "lamentarsi della benevolenza di Mercurio», en pas de commerce, ce qui lui permet d'expliquer facilement l'aspect de la maison ${ }^{43}$. Ainsi, non contents d'avoir des revenus supérieurs au reste de la population, les boutiquiers chercheraient à étaler un luxe ostentatoire: par l'utilisation de pavements de marbre voyants, comme dans l'exemple précédent, par les boutiques ellesmêmes qui donnent à voir l'atrium, et même parfois par leur comptoir de vente ${ }^{44}$. Enfin, l'insertion des boutiques et des ateliers n'aurait pas pour conséquence unique la modification du plan des maisons; leur aspect général maisons, par la simple présence de marchands se corromprait, passant d'une forme "signorile» et "nobile» à un aspect plus «popolare» et « rustico » ${ }^{45}$.

Ce discours très normatif présente toutefois quelques dissonances par rapport aux explications données pour Pompéi. Contrairement à la colonie voisine, où le tremblement de terre de 62 ap. J.-C. est censé avoir accéléré le processus d'invasion, il n'est évoqué que deux fois pour expliquer certains changements dans les maisons d'Herculanum. A. Maiuri considère ainsi que la Casa dell'albergo (III, 1-2.18-19) était, en raison de son état de délabrement, destinée à perdre son caractère de demeure noble, pour être transformée «in una o più case mercantili d'affitto ». Le second cas concerne la Casa con giardino (V, 32-33a), où la mise en place du jardin serait liée au tremblement de terre. Une telle création le laisse étonnamment perplexe, notamment par rapport à son expérience pompéienne où l'utilisation d'une telle surface pour créer un jardin

faisant peindre un personnage priapique pour repousser les envieux (Maiuri 1958 b: 253, 224, 433-434, 437).

${ }^{45} \mathrm{La}$ Casa del bicentenario ne conserve pas son noyau originel "puro e incontaminato»; la Casa dell'Apollo citaredo prend un aspect "povero e disardono"; seule une vive réaction empêche la Casa dell'atrio corinzio de tomber dans la décadence; la Casa della fullonica est revêtue d'une décoration "banale e corrente»; la Casa del telaio devient "una delle case più rustiche dell'abitato finora scoperto"; la Grande taberna con abitazione (IV, 12-13.15-16) affiche un caractère «mercantile e popolare » après avoir été une noble habitation samnite; la Casa con tabernae prend un aspect insolite; l'Abitazione e botteghe (II, 4-8) perd son caractère noble au profit d'un usage plus commercial; le propriétaire du Pistrinum (Or. II, 1a et 2) transforme une élégante pièce en «magazzino per deposito di cereali» (Maiuri 1958 b: $223,248,261-263,422,426,435,443-444,446,454)$. 
n'aurait pas été possible ${ }^{46}$. Le tremblement de terre, à défaut d'être perçu comme accélérateur des transformations, est utilisé à Herculanum pour tenter de justifier des situations situées hors du cadre qu'il a délimité.

De la même manière, certains exemples semblent étrangers à son schéma de l'évolution de la ville. L'équation entre le niveau social perceptible - par la décoration essentiellement - et l'activité supposée de l'occupant ne serait pas toujours valable. À propos de la boutique V, 17-18, dont les fresques - et surtout la pictura excisa - semblaient particulièrement raffinées et peu adaptées aux activités d'un "taverniere", A. Maiuri doit changer son interprétation, en dépit de signes patents d'une activité commerciale dans ce local. Pour mettre en adéquation la décoration avec les activités du propriétaire, il considère qu'il vendait des biens peu communs, ou qu'il exerçait une autre profession, « più nobile di quella della mercatura ${ }^{47}$. De façon encore plus grossière, la Casa di Nettuno e Anfitrite l'oblige à s'extraire de son schéma, en développant une interprétation résolument anachronique:

[...] Negli ultimi tempi, [...] un proprietario [...], aveva trasformato in ben provvista bottega l'ambiente più spazioso accanto alla fauce e l'aveva messo in comunicazione con l'interno della casa. Ma questa installazione nulla o poco aveva tolto della fastosa e doviziosa veste decorativa dell'interno. Non sappiamo chi fosse l'ultimo proprietario ma, a giudicare dalla ricchezza e nobiltà che ancora traspare dai pochi brandelli superstiti della pittura parietale dell'atrio e degli altri ambienti del pianterreno, dal prezioso mosaico del Ninfeo del cortiletto, dal recupero di alcuni bronzetti e, sovratutto, di preziosi pannelli monocromi marmorei di artisti neoattici, si direbbe che il gusto e lo spirito di questo ignoto ercolanese non dovesse essere troppo dissimile da quello dei doviziosi mercanti del Rinascimento che amavano rifugiarsi dal banco di vendita del laniuolo, nella casa bella e ricca di opere d'arte ${ }^{48}$.

46 Maiuri 1958 b: 431. Si les grands jardins de la Regio I à Pompéi n'avaient pas encore été mis au jour, quelques exemples situés dans le centre de la ville étaient déjà connus, comme celui situé à l'arrière de la Casa di Pansa (VI 6, 1.8.12-13), ou encore les cultures maraîchères en VII 11, 11.14 et en VIII 6, 6 (Jashemski 1993: 127-128, 192, 219). Les surfaces de ces trois jardins $\left(820,380\right.$ et $\left.840 \mathrm{~m}^{2}\right)$ sont largement supérieures à celle de la Casa con giardino $\left(185 \mathrm{~m}^{2}\right)$. Des fouilles effectuées par l'Università degli Studi di Napoli - l'Orientale en 2007 en VIII 6, 6, dégagé à la fin du $\mathrm{XIX}^{\mathrm{e}}$ siècle, ont montré que le jardin était construit sur une décharge remblayant une probable carrière, créée dans les dernières années de vie de Pompéi (cf. Tosti - Zanella 2008).
Ces deux exemples montrent à quel point les interprétations proposées par A. Maiuri constituent un cadre théorique à vocation normative. L'ensemble de ses derniers écrits sur Herculanum est teinté d'une forte nostalgie face aux transformations advenues à la maison «traditionnelle». Il montre un refus d'accepter la réalité économique de la cité antique, camouflé derrière une vision souvent caricaturale des rapports sociaux. Les incohérences internes à ces propos, qui ont cependant fortement évolué entre 1927 et 1958 , jettent un voile de méfiance sur l'ensemble de son analyse. Il ne faudrait cependant pas considérer que ces écrits et leur évolution sont complètement détachés du contexte historiographique.

Lorsqu'A. Maiuri reprend les fouilles d'Herculanum en 1927, la bonne conservation du site en faisait miroiter un possible témoin privilégie de la vie antique sous tous ses aspects. Par ce simple fait, les études sur la cité se sont multipliées au fil des décennies. Progressivement, une vulgate s'est développée, reprise d'ouvrages en articles, sans qu'il soit toujours possible de déterminer les fondements de telle ou telle assertion. Une partie des premières réflexions d'A. Maiuri reprend ce discours dominant. Toutefois, l'absence de bibliographie dans ses ouvrages, souvent conçus comme des livres de vulgarisation, empêche de déterminer quelle part a eu tel ou tel auteur dans la conception de ses idées. Même dans sa synthèse de 1958, il cherche à donner l'impression que seules les données archéologiques ont servi de fondement à sa rédaction. Les ouvrages qu'il y cite le plus fréquemment sont ceux de C. Bonucci et M. Ruggiero, ses prédécesseurs ${ }^{49}$. Les autres publications XIX $^{\mathrm{e}}$ siècle n'occupent qu'une place anecdotique dans ses renvois de notes. Sa

${ }^{47}$ Maiuri 1958 b: 238. Pour des raisons différentes de celles invoquées par A. Maiuri, il nous semble qu'aucune activité commerciale ne se déroulait dans ce local au moment de l'éruption; cf. infra, p. 83-87.

${ }^{48}$ Maiuri 1958 b: 393.

${ }^{49}$ Carlo Bonucci a dirigé les fouilles d'Herculanum entre 1828 et 1855 . En 1835, il a fait paraître une première synthèse sur la ville. Ce texte est cité à 44 reprises. Michele Ruggiero (1885) a publié l'ensemble des journaux de fouilles. Son ouvrage est cité à 68 reprises. 
seule source importante "de seconde main" est constituée par ses propres écrits ${ }^{50}$. Pourtant, il paraît indéniable que A. Maiuri s'est appuyé sur l'importante littérature écrite sur Herculanum depuis le début des fouilles, qu'il connaissait nécessairement, au moins grâce à la publication de la bibliographie d'Herculanum mise à jour en 1928, en utilisant la documentation rassemblée par G. P. Zottoli ${ }^{51}$. Cependant, l'analyse des ouvrages mentionnés dans sa synthèse de 1958 montre que les préférences d'A. Maiuri ne s'accordent que partiellement avec les vues de G. P. Zottoli ${ }^{52}$. Bien qu'elle offre un panorama exhaustif des écrits sur Herculanum avant la reprise des fouilles en 1927, cette bibliographie facilite peu les recherches sur les racines intellectuelles de ces interprétations.

La réutilisation incessante de certaines idées traditionnellement attachées à Herculanum - et l'absence d'apparat critique dans les ouvrages du $\mathrm{XIX}^{\mathrm{e}}$ siècle - complexifie l'analyse de leur gestation. Il ne semble pas nécessaire de chercher leurs origines dans les descriptions des voyageurs du XVIII ${ }^{\mathrm{e}}$ siècle, peu enclins à traiter d'urbanisme ${ }^{53}$. Toutefois, l'une des idées qui domine à propos d'Herculanum concerne sa richesse, extrapolée à partir des objets qui y avaient été mis au jour ${ }^{54}$. Ce caractère domine l'ensemble du $\mathrm{XIX}^{\mathrm{e}}$ siècle et le début du $\mathrm{XX}^{\mathrm{e}}$ siècle, faute d'examen critique des méthodes des fouilleurs bourbons - tournés vers les plus belles pièces - et des dégâts produits sur les objets non métalliques par leur mode d'ensevelissement.

L'une des premières comparaisons entre Herculanum et Pompéi, retraçant leur histoire

${ }^{50} \mathrm{Il}$ renvoie 68 fois à ses articles concernant Herculanum et Pompéi.

${ }^{51}$ Zottoli 1928.

52 À titre d'exemple, le livre de Carlo Bonucci (1835), abondamment utilisé par A. Maiuri, n'apparaît que sous le numéro 185, dans la seconde liste alphabétique du volet consacré à "Storia, descrizione della città, topografia, culti ». Pour G. P. Zottoli, cet ouvrage est donc d'importance mineure.

${ }^{53}$ Grell 1982: 81-82.

${ }^{54}$ Les remarques de W. Drummond (1810: 3) à cet égard sont tout à la fois précoces et caractéristiques: «We cannot, however, doubt of the opulence of this city from its remains [...]. The statues, the pictures, the vases, the medals, the libraries, the furniture, the numerous articles of luxury and ornament, the houses, the baths, and the de la fondation à l'ensevelissement par le Vésuve, a été rédigée par B. Quaranta en 1833. S'il utilise essentiellement des sources textuelles, il rapproche les deux villes sur le plan archéologique ${ }^{55}$, tout en tendant à relever le caractère mercantile de Pompéi: à partir de la lecture erronée d'une inscription trouvée en façade des Praedia Iuliae Felicis (II 4), il affirme que Pompéi devait être fortement peuplée pour qu'un seul personnage puisse louer «nientemeno che novecento botteghe colle pergole $[\ldots] »^{56}$. La croyance en un tel nombre de boutiques à louer par un même propriétaire a dû jouer un grand rôle dans la différenciation qui s'est progressivement instaurée entre les deux villes.

Lorsque des vestiges purent être visités à Herculanum aussi facilement qu'à Pompéi, et malgré leur surface réduite, les comparaisons entre les deux cités se sont multipliées. En effet, pendant le $\mathrm{XIX}^{\mathrm{e}}$ siècle, tout auteur d'un livre sur Pompéi n'a jamais manqué de consacrer au moins un chapitre à Herculanum. Toutefois, leurs centres d'intérêt restent encore imprégnés d'esprit antiquaire, selon le jugement d'A. Maiuri en 1948: «l'interesse [...] fin alla 2a metà del secolo XIX si era limitato [...] al materiale artistico e antiquario delle case $[\ldots] »^{57}$. Durant la première moitié du XIX ${ }^{\mathrm{e}}$ siècle, quelques auteurs ont élargi leurs réflexions. En 1855, E. Breton rédige une description de Pompéi, accompagnée d'une notice sur Herculanum où il différencie les deux cités, à partir de constatations artistiques :

Herculanum paraît avoir été une ville plus artistique que Pompéi dont presque tous les habitants se livraient au commerce, et généralement, les peintures, les marbres,

spacious theatre, which have been discovered among the ruins of Herculaneum attest the splendour of the place, and the wealth of its inhabitants ».

55 «Intanto eran corsi appena dieci anni, quando facendosi un fosso ne'campi sottoposti al Vesuvio, si vide esser quivi la gemella di Ercolano, Pompei» (Quaranta 1833: 5960).

${ }^{56}$ Quaranta 1833: 52. CIL IV, 1136, cit. infra, p. 47. Cf. Pirson 1997: 179-180 et Pirson 1999: 18-19. Le problème posé par le terme nongentum et sa signification paraît avoir été réglé par Th. Mommsen dans son commentaire à l'inscription. Selon lui, il ne faudrait pas considérer nongentum comme le nombre 900, mais comme un qualificatif apposé au balneum, en plus de venerium. Voir également le commentaire d'A. Maiuri (1978: 553-559).

${ }^{57}$ Maiuri 1948: 12. 
les bronzes qu'on y a trouvés sont supérieurs à la plupart de ceux qui sont sortis des ruines de sa rivale ${ }^{58}$.

Avec ce guide, E. Breton mentionne pour la première fois un contraste entre les deux cités qui ne sont plus considérées comme jumelles, même si les fondements de cette constatation ne sont pas encore liés à une observation de zones nouvellement fouillées.

À partir des années 1860, d'abord sous l'impulsion de Giuseppe Fiorelli puis, à partir de 1870, sous celle d'August Mau en particulier, les domaines explorés commencent à s'élargir. Il n'est plus question de rédiger seulement des descriptions des ruines ou des monuments, entendus comme objets d'art, peintures et sculptures. L'intérêt se porte désormais sur les différents aspects de la cité, au-delà des seules considérations antiquaires. Les interprétations concernant l'urbanisme et les conditions socioéconomiques d'Herculanum commencent alors à se fixer. La reprise des fouilles à ciel ouvert en 1869, organisée par G. Fiorelli avec le soutien du Roi, a facilité ce processus.

Bien que n'ayant probablement pas bénéficié de l'apport des nouvelles fouilles, une série d'articles publiés en 1870 dans La Revue des Deux Mondes par Charles-Ernest Beulé n'en est pas moins caractéristique de cette période ${ }^{59}$. Pompéi y est décrite comme une cité uniquement tournée vers le commerce:

Ce qui frappe surtout, c'est que presque tous les habitants de Pompéi exerçaient une industrie, soit par euxmêmes, soit par leurs affranchis, soit par leurs esclaves. On conçoit l'exclamation naïve de ce Pompéien qui a fait encastrer en mosaïque dans le dallage de son atrium l'inscription suivante: «salut, gain» SALVE, LVCRV ${ }^{60}$.

Plus important encore pour la suite de son propos et la comparaison avec Herculanum, il estime que ce caractère hautement mercantile de la cité est associé à une absence complète de goût réel pour l'art:

${ }^{58}$ Breton 1855 : 346.

${ }^{59}$ L'ensemble est intitulé « Les drames du Vésuve », subdivisé en trois articles, "L'ancienne Campanie et le Vésuve primitif», "Les témoins et les victimes», "Le désastre de Pompéi et d'Herculanum », respectivement parus le 01 mai, le 15 mai et le 01 juin 1870 . Ces trois articles ont ensuite été rassemblés dans un volume en 1871 . J'utilise ici la seconde édition de 1872 .
On ne doit $[\ldots]$ comparer une petite ville commerçante comme Pompéi, ni à Pise, ni à Gênes, ni à Venise, qui ont à la fois la puissance et le génie, l'amour de la gloire et l'amour des belles choses. Habitants d'une cité sans influence, esprits peu élevés, épicuriens pratiques, ils ont mis la sensation à la place du sentiment du beau et allié l'ordre et le lucre à la recherche des jouissances matérielles. Les arts n'étaient à leurs yeux qu'un moyen d'augmenter ces jouissances ${ }^{61}$.

Une fois ces caractéristiques générales de Pompéi exposées, il définit celles d'Herculanum. Il considère que le site, propre au repos, aurait incité de nombreux personnages riches de Campanie et d'Italie à s'y installer ${ }^{62}$. L'explication de ce phénomène tiendrait à la proximité de Naples:

Dans tous les cas, ce pays devint un lieu de plaisance pour les Romains; ils étaient près de Naples, ils subissaient l'attrait du génie grec et de l'idéal que le génie grec répandait sur la vie matérielle [...]. Ainsi l'histoire établit déjà des différences entre Herculanum et Pompéi: [...] peuplée par des Grecs, [...] Herculanum est adonnée à la culture de l'esprit et aux élégants loisirs, [...] habitée par les plus riches Romains et accablée de faveurs [...]. On doit soupçonner qu'Herculanum a servi de modèle à Pompéi dans bien des détails de civilisation, on peut affirmer que Pompéi n'a rien appris aux Grecs d'Herculanum. [...] Herculanum était comme un faubourg de Naples et un lieu de repos ${ }^{63}$.

La comparaison se poursuit: Herculanum aurait été une importante enclave de la culture grecque, où la population, parmi laquelle «les Romains les plus riches et même les patriciens ", s'adonnaient à loisir aux arts et aux lettres ${ }^{64}$. Ch.-E. Beulé semble être le premier à avoir théorisée cette vision devenue ensuite traditionnelle d'Herculanum.

Quelques années plus tard, Julius Beloch parvient à des conclusions similaires, en ayant bénéficié d'une zone de fouille ouverte plus étendue. Il déduit de l'état du pavement des rues d'Herculanum que l'activité commerciale devait y être moins importante qu'à Pompéi et donne à Herculanum, le premier, le titre de ville de villégiature:

\footnotetext{
${ }^{60}$ Beulé 1872: 333-334.

${ }^{61}$ Beulé 1872: 43.

${ }^{62}$ Beulé 1872: 48-49.

${ }^{63}$ Beulé 1872: 247-249, 281.

${ }^{64}$ Beulé 1872: 281-282.
} 
Aber hauptsächlich verdankt Herculaneum seinen Wohlstand der anmuthigen, zur Villegiatur einlandenden Lage $[. .$.$] sich hier niederzulassen. Die frequens amoenitas$ orae rühmt Plinius; und auch ohne sein Zeugniss würden die Ausgrabungen uns dasselbe gelehrt haben ${ }^{65}$.

Son étude onomastique lui permet de conclure que les familles les plus riches avaient migré à Herculanum. Au contraire de Ch.-E. Beulé, qui voyait dans les origines grecques de la ville l'explication de sa supériorité culturelle, J. Beloch estime que ces riches sont à l'origine du patrimoine artistique mis au jour. Caractéristique des nouvelles avancées de la recherche historique dans la région du Vésuve, cet ouvrage, fondé sur le résultat des fouilles, l'épigraphie et l'utilisation des textes anciens, va servir de référence pour les études du début du siècle suivant: il a réussi à figer l'image d'Herculanum comme une ville résidentielle. Même si cette représentation n'est pas nouvelle, l'utilisation qu'il fait de toutes les sources disponibles lui permet de gagner une légitimité plus forte. Il demeure ainsi le premier à avoir utilisé un passage très bref de la lettre de Pline à Tacite pour caractériser Herculanum ${ }^{66}$. Cette interprétation devient ensuite la vulgate ${ }^{67}$.

${ }^{65}$ Beloch 1890: 224 (cf. également Beloch 1989: 257).

${ }^{66}$ Plin., Ep., 6, 16, 9: Deducit quadriremes ascendit ipse non Rectinae modo, sed multis (erat enim frequens amoenitas orae) laturus auxilium.

«Il fait sortir des quadrirèmes et s'embarque luimême, avec l'intention de secourir, outre Rectina [femme de Cascus, qui a demandé l'aide de Pline l'Ancien], bien des gens (les agréments du rivage y attiraient beaucoup de monde)». [trad. CUF].

Rien n'indique cependant que Pline ait voulu définir Herculanum quand il mentionne les agréments de la côte. Au contraire, le manque de précision des termes qu'il emploie laisse supposer qu'il a cherché à caractériser l'ensemble du golfe de Naples plutôt qu'une seule des villes qui le bordent. La confusion semble être due à l'identification de Rectina, longtemps considérée comme une ville, dont le nom aurait ensuite donné Resina, toponyme moderne d'Ercolano jusque dans les années 1950. Ainsi, J. Beloch (1989: 272) considère que Rectina désigne le port d'Herculanum. Une première rectification a été faite par Th. Mommsen dans l'introduction aux inscriptions d'Herculanum du CIL X, p. 157: Oppidum hodiernum Resina omnino novicium est mero enim errore feminae vocabulum quod est Rectinae apud Plinium ep. 6, 16 quidam ad id rettulerunt. Malgré cela, le lien entre la lettre de Pline le jeune et la mer bordant Herculanum reste affirmé par plusieurs auteurs (Sogliano
J. Beloch est également le premier à voir dans le plan d'Herculanum une réplique de celui de Naples, en fondant son assertion sur le schéma publié par Francesco La Vega en 1797:

Ein Blick auf den Plan des alten Neapolis zeigt uns das Muster, was beim Bau von Herculaneum befolgt worden ist [...]. Da der nördliche Theil der Stadt noch unerforscht ist, so lässt sich nicht bestimmen, ob ausser den beiden bekannten Decumani etwa noch ein dritter vorhanden war. Die Analogie mit Neapolis würde dann noch bezeichnender werden ${ }^{68}$.

Bien qu'il ne le dise pas explicitement, sa démonstration laisse supposer un fort lien entre les deux cités ${ }^{69}$. Cette interprétation, fondée sur l'utilisation d'un plan schématique et incomplet, est ensuite reprise intégralement par A. Maiuri.

En 1908, Charles Waldstein fait paraître la dernière synthèse sur le site avant celle de 1932. Le principal objectif de cette publication est de faire reprendre les fouilles à Herculanum, qu'il considère comme beaucoup plus intéressantes que celles de Pompéi. Pour défendre son point de vue, il renoue avec l'interprétation qui fait d'Herculanum une ville fortement teintée de culture grecque, en extrapolant les découvertes faites dans la Villa des Papyri au reste de la ville:

1914: 187-188 avec indications bibliographiques). Pour de probables questions de fierté locale, la proposition faisant de Rectina une ville associée à Herculanum a été soutenue jusqu'en 1953 (Catalano 1953 a). Selon la dernière mise au point publiée par A. W. Van Buren (1966: 961-962), l'amie de Pline l'Ancien serait Salvia Rectina, épouse de Cn. Pedius Cascus, consul suffect en 71. Selon A. Maiuri (1958 a: 125), le nom de Resìna viendrait d'une plante poussant sur les pentes du Vésuve.

${ }^{67}$ Comme exemple, considérons ces extraits de l'article de la Grande Encyclopédie consacré à Herculanum (Vast 1895): «[...] Son air salubre y attira de bonne heure les riches romains. Beaucoup de villas opulentes y furent construites ». "Les objets d'art, bijoux, etc., sont supérieurs à ceux de Pompéi [...]». "[...] Cependant Herculanum était beaucoup plus peuplé et plus riche que sa voisine (Pompéi)». Cette théorie, reprise ensuite par Ch. Waldstein et A. Maiuri, a connu un long succès. En effet, même après avoir été abandonnée par A. Maiuri, elle a été pleinement acceptée par E. Lepore (1955: 428-429), puis par M. et A. de Vos (1982: 260-261), en introduction de leur guide sur Herculanum.

${ }^{68}$ Beloch 1890: 230 (cf. également Beloch 1989: 263).

${ }^{69} \mathrm{~J}$. Beloch (1890: 230) utilise ainsi cette similitude de plans pour donner un terminus post quem à la fondation d'Herculanum. 
Our chief evidence concerning the character of the inhabitants rests on the rich find in superior works of Greek art and on the treasures of manuscripts discovered in one villa. These [...] lead us to assign to the inhabitants of Herculaneum a state of culture superior to that of the Pompeians ${ }^{70}$.

L'ensemble de sa démonstration se situe dans la droite ligne des propos de Ch.-E. Beulé et de J. Beloch, qu'il cite fréquemment. Ch. Waldstein conteste toutefois l'une des idées de ce dernier: l'absence de boutiques dans la zone fouillée ne peut être généralisée à l'ensemble de la ville. Il décrit les filets de pêche et les hameçons comme seules traces d'activité «industrielle » ${ }^{71}$. A. Maiuri reprendra cet exposé dans son intégralité. Ch. Waldstein conclut son chapitre sur les habitants d'Herculanum en pointant les différences existant avec Pompéi :

In conclusion, while we have some evidence for distinguished residents in the neighbourhood of Pompeii, and even forthe presence there of the imperial family, we have distinct evidence for maintaining that Herculaneum was a more aristocratic resort than her busy neighbour, whose motley population [...] carried the trade of Nola, Nuceria, and Accerae ${ }^{72}$.

En synthétisant divers points issus de la tradition historiographique sur Herculanum, Ch. Waldstein a ouvert la voie à A. Maiuri. Comme nous l'avons vu, les premières théories défendues par ce dernier reprennent ces idées fondées soit sur les textes littéraires antiques relatifs à la Campanie - la présence de riches patriciens sur la côte est extrapolée de la lettre de Pline le jeune; l'air sain propre à la villégiature de Strabon ${ }^{73}$-, soit sur l'importante quantité d'objets d'art mis au jour pendant les fouilles du XVIII ${ }^{\mathrm{e}}$ siècle. De ce point de vue, les découvertes de la Villa des Papyri ont déformé l'image de la ville, tandis que l'opposition avec Pompéi a été renforcée par le nombre inférieur de statues mis au jour, suite aux récupérations successives à l'éruption.

${ }^{70}$ Waldstein - Shoobridge 1908: 85.

${ }^{71}$ Waldstein - Shoobridge 1908: 95.

${ }^{72}$ Waldstein - Shoobridge 1908: 96.

${ }^{73}$ Strabo, 5, 4, 8, C 246.

${ }^{74}$ Cf. e.g. Wallace-Hadrill 1994: 122

${ }^{75}$ SEHRE $^{2}: 21-22$ = Rostovtsev 1988: 30-31.

${ }^{76} \mathrm{SEHRE}^{2}: 58$ = Rostovtsev 1988: 58. «Je suis convaincu que de nombreux habitants de cités de Campanie telles que Pompéi, ingénus et sans doute instruits, eurent une carrière
On estime traditionnellement que les considérations d'A. Maiuri sur le développement commercial dans les villes de Campanie prennent leur origine dans les écrits de Mihail Ivanovič Rostovtsev $^{74}$. Cette idée se révèle, après un examen attentif de la Social and Economic History of the Roman Empire (SEHRE), à la fois pertinente et fausse: A. Maiuri a plus pratiqué l'emprunt dénaturé que la simple acceptation.

M. I. Rostovtsev considère que c'est au $\mathrm{II}^{\mathrm{e}}$ siècle av. n.è. que l'urbanisation se développe en Italie. Une nouvelle bourgeoisie aisée, constituée de «boutiquiers municipaux et de propriétaires terriens » est à l'origine de ce phénomène ${ }^{75}$. Cette situation se maintient jusqu'au début du $\mathrm{I}^{\text {er }} \mathrm{s}$. av. J.-C. Cette nouvelle bourgeoisie est fortement impliquée dans les affaires. Le meilleur exemple d'un représentant de cette élite économique serait Trimalcion, avec un doute quant au caractère typique de son statut d'affranchi. Toutefois, le personnage représenterait un idéaltype présent dans toutes les villes italiennes:

I have no doubt that many a resident in Campanian cities like Pompeii, freeborn and probably not educated, had the same business career as Trimalchio. They were the owners of the large and beautiful houses and villas of the Augustan period in Pompeii, Stabiae, and Herculaneum $[\ldots]^{76}$.

Peu après la dictature de Sylla, et plus encore pendant le règne d'Auguste, on assiste à une industrialisation de l'ensemble de l'Italie, même dans les petits centres comme Pompéi. Dans cette ville, des transformations s'opèrent alors:

A clear sign of the industrialization of the town is the development of a new type of dwelling-house surrounded by shops. These shops were partly owned and managed by the owners of the houses, partly rented to artisans and retail traders ${ }^{77}$.

Dans le chapitre III de son ouvrage, M. I. Rostovtsev indique que l'étude détaillée de Pompéi pourrait donner de bons résultats pour

semblable à celle de Trimalcion. C'étaient des propriétaires des grandes et belles maisons et villas de Pompéi, Stabies et Herculanum [...]».

${ }^{77}$ SEHRE $^{2}: 73$ = Rostovtsev 1988: 67. «Un indice manifeste de l'industrialisation de la ville est l'apparition d'un nouveau type d'habitations entourées de boutiques. Ces boutiques appartenaient pour une part aux propriétaires des maisons qui en assuraient personnellement la gestion; les autres étaient louées à des artisans et à des détaillants ». 
la connaissance de l'histoire économique du $\mathrm{I}^{\mathrm{er}} \mathrm{s}$. ap. J.-C. Il décrit ensuite essentiellement l'amorce, sous les Julio-Claudiens, du développement économique des provinces. À l'inverse de la situation décrite pour l'Italie au $\mathrm{II}^{\mathrm{e}}$ siècle av. J.-C., l'urbanisation, voulue et développée par le pouvoir central, entraînerait la constitution d'une nouvelle bourgeoisie d'affaires ${ }^{78}$. Durant cette période, dans l'ensemble de l'empire, émergerait une nouvelle classe de bourgeois, les affranchis:

Indeed, the owners of these shops themselves were, to a great extent, former slaves who succeeded in receiving or buying their liberty and in acquiring a considerable fortune. The municipal freedmen formed the lower section of the municipal aristocracy or plutocracy $(\ldots)^{79}$.

Cette idée a pu être utilisée telle quelle par A. Maiuri. Toutefois, le contexte général de l'économie italienne dans les années 60 de notre ère ne correspond pas à ce qu'il avance. En effet, M. I. Rostovtsev laisse entendre "que les imprudentes extravagances des dernières années du règne de Néron ne furent pas étrangères à la ruine partielle de l'Italie », et que l'on assiste, à la fin de la période julio-claudienne aux « difficultés naissantes de la vie économique en Italie ${ }^{80}$. Il développe l'idée d'émergence d'une bourgeoisie urbaine dans le cinquième chapitre de son livre, en la généralisant aux deux premiers siècles de notre ère et à l'ensemble de l'Empire. Comme précédemment, l'accroissement de la bourgeoisie urbaine dans tout l'Empire serait partiellement dû à «l'ascension d'hommes nouveaux, et plus particulièrement d'indigènes et d'affranchis $»^{81}$. Il dégage ensuite les caractères de la fraction inférieure de cette bourgeoisie:

One step below on the social ladder stood the petty bourgeoisie, the shopowners, the retail-traders, the

${ }^{78}$ SEHRE $^{2}:$ 90-91 = Rostovtsev 1988: 81-82.

${ }^{79}$ SEHRE $^{2}$ : 104 = Rostovtsev 1988: 90. «En fait, les propriétaires de ces ateliers (industriels employant des esclaves) étaient eux-mêmes, dans une large mesure, d'anciens esclaves, qui étaient parvenus à obtenir ou à acheter leur liberté et à amasser une fortune considérable. Les affranchis municipaux constituaient la fraction inférieure de l'aristocratie ou de la ploutocratie municipale [...]».

${ }^{80}$ SEHRE $^{2}: 103,104$ = Rostovtsev 1988: 89, 90.

${ }^{81}$ SEHRE $^{2}: 187$ = Rostovtsev 1988: 148-149.

82 SEHRE²: 187 = Rostovtsev 1988: 149. "Sur une marche inférieure de l'échelle sociale, on trouvait la petite money-changers, the artisans, $[\ldots]$ and the like. The ruins of the ancient cities of Italy and the provinces with their hundreds of smaller and larger shops and hundreds of inscriptions, mentioning individual members of this class and their associations, lead us to believe that they formed the backbone of municipal life ${ }^{82}$.

A. Maiuri a donc pu s'inspirer de certains éléments des réflexions de M. I. Rostovtsev. Pourtant, il ne les cite dans aucun de ses livres sur Herculanum. De plus, il n'a pas suivi le schéma de développement économique de Pompéi exposé dans la SEHRE. Il a en fait appliqué aux cités campaniennes certaines des idées originellement développées pour les provinces. En utilisant certains flous dans les idées de M. I. Rostovtsev, il a finalement transformé ses thèses, exagérant certains aspects, comme la croissance du nombre d'affranchis. Les interprétations d'A. Maiuri ne sauraient donc être considérées comme l'application stricte à l'exemple d'Herculanum des idées développées dans la SEHRE. Il n'en reste pas moins que cet ouvrage est apprécié par le Surintendant, comme le montre une remarque sur l'évolution des études pompéiennes, à propos des villas de l'ager pompeianus:

[...] E tutti sanno qual frutto abbia tratto da queste scoperte il Rostovzev nel delineare le condizioni della Campania al I secolo dell'impero ${ }^{83}$.

De plus, les relations entre les deux savants sont amplement attestées. Ainsi, M. I. Rostovtsev a écrit un compte rendu élogieux du premier livre d'A. Maiuri sur Herculanum:

From a man [A. Maiuri] with such a record, such ability, and such a careful and such a scientific spirit, we are justified in expecting a careful and exhaustive study of the ruins of Herculaneum. A short visit to Herculaneum a few days ago, and a careful study of the book under review bourgeoisie, les boutiquiers, les détaillants, les changeurs, les artisans, [...] etc. [...]. Les ruines des anciennes cités d'Italie et des provinces, avec leurs centaines d'ateliers, grands et petits, et leur centaine d'inscriptions évoquant différents membres de cette classe et leurs associations, donnent à penser qu'ils formaient l'armature de la vie municipale».

${ }^{83}$ Maiuri 1948: 13. Déjà en 1945, dans son édition du texte de Pétrone, A. Maiuri faisait référence à la $S E H R E$, à propos des conditions économiques de Pouzzoles (Maiuri 1945 : n. 2 p. 8 ). 
have convinced me that Italy has got the right man, a man with wide and ripe experience and with full mastery of the methods of scientific exploration of ancient ruins ${ }^{84}$.

Outre cet éloge, un échange épistolaire a existé entre les deux hommes, essentiellement finalisé à l'obtention de clichés pour la $S E H R E^{85}$ ou de données - pour l'Histoire économique et sociale du monde hellénistique ${ }^{86}-$, parfois encore inédites ${ }^{87}$. Outre leurs relations diversement attestées, une réelle proximité intellectuelle existait entre M. I. Rostovtsev et A. Maiuri. Toutefois, certaines de leurs positions sont finalement communes aux courants historiographiques des années 1920. Ainsi, plusieurs auteurs mettent en avant le rôle prépondérant des affranchis dans la vie commerciale de Pompéi, avant la parution de la $S E H R E^{88}$. Il reste donc difficile de définir avec exactitude les emprunts d'A. Maiuri, d'autant plus qu'il est le seul à avoir exposé son analyse avec mépris et outrance: tandis que T. Frank et M. I. Rostovtsev mentionnent le rôle important des affranchis dans la vie économique au $\mathrm{I}^{\text {er }}$ siècle av. J.-C., ni l'un ni l'autre ne parle d'éviction complète et brutale des anciennes élites.

Une autre influence a été évoquée à plusieurs reprises: nommé surintendant de Campanie et de Caserte en 1924, A. Maiuri aurait été un archéologue du régime mussolinien. Toutefois,

${ }^{84}$ Rostovtsev 1932: 585.

${ }^{85}$ Cet échange épistolaire destiné à obtenir une reproduction de la fresque de Verecundus à Pompéi est conservé en deux lettres, dans un classeur non inventorié de l'Archivio Storico de la SANP. "17 luglio 1924 / Corpus Christi college Oxford / Carissimo Signor Professore! / Si ricorda del nostro colloqui [sic] a Firenze? Li mando un articolo che ho recentemente scritto e che potrà interessarla come mi dice il nostro comune amico F. Caumont. Vorrei domandarle un favore. Sto pubblicando un libro sopra la storia economica e sociale dell'Impero romano. Per questo libro avrei bisogno di una fotografia di Pompei. Si tratta della ben nota insegna della bottega di Verecundo della strada dell'Abbondanza. la Venera Pompeiana nel carro tratto da elefanti e la fattoria del Verecundo. L'affrescha e [sic] stato pubblicato anni fà nelle Notizie degli Scavi. Ne ho una fotografia ma mediocre e non potrebbe essere riprodotta. So che ci sono altre migliori. Potrei averne una copia? Mi preme di averla il piutosto possibile. Sono prontissimo a pagare le spese. / Suo devotissimo / M. Rostovtzeff ».

«26 Ag. 1924 / Parigi. / Egregio amico/ Tante grazie della fotografia che ha voluto bene mandarmi. È eccellentissima, ma mi rincrese [?] di non poter riprodurla perchè fa vedere una parte del dipinto solo. Mi preme di avere sulla fotografia la pittura della Venere e la bottega di Verecundus. comme l'a déjà montré $\mathrm{D}$. Manacorda, il n'est pas possible de classer les archéologues de cette période en trois catégories (fascistes, antifascistes et non fascistes) ${ }^{89}$. Le rapport entre la science et la politique pose un problème délicat, qui ne saurait être intégralement exposé ici. Je n'évoquerai que quelques faits susceptibles d'éclairer cette question.

L'acmé de l'activité archéologique à Herculanum se déroule entre 1927 et 1941. Avec l'aide de M. Castelli, haut commissaire à Naples, des crédits très importants sont débloqués pour permettre l'expropriation de plusieurs champs situés au-dessus du site. Avec le débarquement des Alliés en Sicile et leur remontée de la péninsule italienne, les fouilles sont momentanément arrêtées en 1943. Quoiqu'à un rythme bien moins soutenu, elles reprennent pendant les années 1950. Les Nuovi Scavi ont ainsi indéniablement été des fouilles voulues et largement financées par le régime fasciste: dans son discours de réception à la Società Romana di Storia Patria, prononcé le 9 avril 1927, Benito Mussolini offre à ses "confrères » la reprise des fouilles à Herculanum ${ }^{90}$. À cette occasion, il développe les interprétations accentuant les différences entre Pompéi, adonnée au commerce, et Herculanum, cité de la culture ${ }^{91}$. Bien que

Non è possibile di aver una fotografia che farebbe vedere la bottega e la pittura religiosa? Se è necessario di fare un altro negativo, la Clarendon Press è pronta di pagarlo. Mi scuserà di insistere ma lo scopo del mio libro è di far vedere la vita sociale e economica e per questo scopo mi preme di avere tutto l'affresco. Con tante scuse e vivissimi ringraziamenti. / Suo devotissimo. / M. Rostovtzeff

P.S. Siccome ritorno in America la prego di mandare la fotografia a J. de M. Johnson, Clarendon Press, Oxford ».

${ }^{86}$ Le 20 décembre 1936, Rostovtsev écrit une lettre à A. Maiuri non seulement pour le féliciter de ses fouilles à Herculanum, mais également pour lui demander une photo du «rilievo di Oreste» (reproduite dans Iezzi-Scafati 1984 : 269-270).

${ }^{87}$ Selon M. Buonocore (1999: 425), M. I. Rostovtsev aurait obtenu avant parution le texte de certaines inscriptions de Pompéi et d'Herculanum pour la traduction italienne de la SEHRE.

${ }_{88}$ Cf. e.g. Frank 1920: 190-218, part. 214; Gordon 1927.

${ }^{89}$ Manacorda 1982: 451.

${ }^{90}$ Mussolini 1927: 136-138.

${ }_{91}$ Le lien entre le nouveau régime et la reprise des fouilles avait été noté à l'époque par R. Cagnat (1927: 102103), qui cite le discours de B. Mussolini. 
cela soit très probable, il n'est pas possible - en l'état des recherches sur cette question - d'affirmer qu'A. Maiuri a tenu la plume du chef du gouvernement italien. Il convient en revanche de s'arrêter sur la portée de l'utilisation de ces idées: elles constituent, par la forte opposition entre les deux cités, le meilleur argument pour justifier la reprise des fouilles à Herculanum, qui ne constituerait pas ainsi un doublon inutile des travaux de Pompéi ${ }^{92}$. Bien évidemment, il ne saurait être question de placer l'adoption de cette opposition entre Pompéi et Herculanum sous le seul signe d'une adaptation aux besoins du régime fasciste: la tradition historiographique sur Herculanum a beaucoup plus pesé dans cette approche. Il apparaît très nettement qu'elle a été instrumentalisée par le pouvoir pour justifier les nuovi scavi, quitte à favoriser des développements parfois caricaturaux ${ }^{93}$. Le seul lien - ténu - entre cette théorie et la politique du régime fasciste au sens large pourrait tenir à son abandon: suite à la découverte de la "croix» dans la Casa del bicentenario en 1938, il n'est plus nécessaire de justifier la reprise des travaux de dégagement et d'éviter la redondance

\footnotetext{
${ }^{92}$ Cette opposition est particulièrement sensible dans cette phrase extraite de Pompei ed Ercolano..., écrite en 1931: "Ma Ercolano è una ripetizione di Pompei? Vana domanda!» (Maiuri 1931 b: 898; Maiuri 1950 a: 226), ou encore ce constat un peu plus nuancé: "The picture of Herculaneum now to be visualized not only completes in many respects that of Pompeii but presents an urban ensemble substantially different owed to different demographic and economic positions» (Maiuri 1931 a). Le contraste entre les deux villes reste clairement exprimé à chaque fois qu'il est question de la reprise des fouilles entre 1927 et 1938.

${ }^{93}$ La plan adopté par A. Maiuri lors d'une conférence faite au Reale Istituto di Archeologia e Storia dell'Arte le 17 avril 1930 est symptomatique de cette rhétorique (cf. Maiuri 1931 c). Après avoir rejeté tout rappel sur l'histoire des fouilles, il a présenté les premiers résultats des travaux commencés trois auparavant, en insistant particulièrement que les objets en bois mis au jour. S'appuyant sur ces découvertes, il a insisté sur les différences de caractère entre Herculanum et Pompéi, puis a conclu en dénonçant les pronostics pessimistes ayant entouré cette reprise.

${ }^{94}$ Cf. infra, p. 19-23. Les remarques de G. Guadagno (1993: 86) à ce propos ne sont pertinentes que pour la période allant de 1927 à 1938. Après cette date, cette opposition ne reste présente que dans le guide du site de la collection "Itinerari e monumenti d'Italia ». Écrit en 1936, cet ouvrage a été mis à jour à de nombreuses reprises. Les
}

avec Pompéi; les données de la fouilles peuvent être librement exploitées par A. Maiuri ${ }^{94}$.

Selon D. Manacorda, un des effets du conditionnement fasciste a été de transformer le mode de rédaction des archéologues et des historiens de l'Antiquité: l'écriture scientifique a été progressivement abandonnée au profit de formules plus « esthétisantes " ${ }^{95}$. Tant que dure le régime fasciste, A. Maiuri exprime ses analyses sur «l'invasion» de la maison patricienne par les affranchis voués au commerce dans un style très précieux. Après guerre, les mêmes idées sont présentées de façon plus scientifique et plus sobre ${ }^{96}$, sauf lorsqu'il s'agit de raconter les histoires personnelles des victimes de l'éruption $^{97}$. Le point où l'influence du fascisme est la plus nette paraît être la dénonciation de la ploutocratie des nouveaux riches, centrale dans les propos d'A. Maiuri, à Pompéi dès 1928, puis à Herculanum à partir de 1938. Toutefois, sur cet aspect également, il ne faudrait pas sous-estimer le poids de la tradition historiographique dans l'appréhension du développement numérique et économique supposé des affranchis, considérés comme une «bourgeoisie» montante.

éditions successives reprennent le corps principal du texte, en y ajoutant les nouvelles découvertes issues des fouilles. Le maintien, dans la 5e édition de 1959 de l'opposition entre Herculanum et Pompéi ne se justifie pas par la poursuite de l'adhésion à cette théorie par A. Maiuri, mais uniquement par un problème éditorial.

${ }^{95}$ Manacorda 1982 : 449-450. Voir tout particulièrement Maiuri 1928: 81-104.

${ }^{96}$ Il suffit de comparer la description épique de l'invasion des maisons de l'élite traditionnelle par les affranchis faite pour Pompéi en 1928 (Maiuri 1928: 81-104.) avec les indications sibyllines sur ce même phénomène dans la Casa dell'Apollo citaredo (V, 9-12) (Maiuri 1958 b: 248). Toutefois, comme il reste difficile de changer de style ou de réfuter ses propres écrits, ce rare élan de sobriété contenue n'entame en rien cette "poésie archéologique» vantée par tous ceux qui ont connu A. Maiuri (cf. e.g. Belli 1963). La publication en 1950 du recueil Pompei e Ercolano fra casa e abitanti reste de ce point de vue une remarquable anthologie. Voir en particulier "L'ultima infornata», narrant la conception de la dernière fournée de la boulangerie VII 1, 36-37 telle que retrouvée dans les années 1860 (Maiuri 1950 a: 46-51; sur cette boulangerie, cf. infra, p. 158).

${ }_{97}$ L'exemple de la "chambre de la brodeuse» (Maiuri 1958 b: 463, cf. infra, p. 20-22) en Or. II, 10 est symptomatique de cette recherche permanente de la tentation du récit vivant qui a animé A. Maiuri dans ses écrits.

${ }^{98}$ Maiuri 1941. 
Le rapport d'A. Maiuri au fascisme s'avère finalement particulièrement ambigu: le même homme prononce en 1941 un discours inaugural de l'Accademia d'Italia sur Roma e l'Oriente Europeo, où romanisme et germanisme s'unissent pour défendre la civilisation ${ }^{98}$, mais refuse d'aider G. Jacopi à obtenir une chaire à Bologne en 1947, en raison des difficultés que ce dernier a créées à M. Segre, épigraphiste juif ${ }^{99}$. En 1944, il a été nommé Direttore Generale delle Antichità e Belle Arti par Adolfo Omodeo, ministre de l'Éducation dans le second gouvernement Badoglio. Sa nomination n'a pas été suivie d'effet, car il s'est trouvé sur la liste des personnes à épurer, dressée par le commissaire allié Charles Poletti ${ }^{100}$. Lappui de Benedetto Croce lui a permis de voir son cas réexaminé101. Ensuite, il a été, dès 1946, réintégré dans l'Accademia dei Lincei, grâce au soutien de ce même B. Croce ${ }^{102}$.

Si le fascisme a pu exercer une influence sur le développement intellectuel d'A. Maiuri, il ne faut certainement pas en faire l'unique clé de lecture. Cette question de l'impact de l'idéologie dominante sur les travaux d'A. Maiuri serait à approfondir; aucune réponse univoque ne paraît possible ${ }^{103}$.

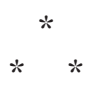

Après avoir passé au crible les influences historiographiques et idéologiques exercées sur

99 D. Manacorda (1982：467, 453-454) considère A. Maiuri comme un archéologue fasciste, mais note: "Maiuri fu personnalità complessa e contradittoria ».

100 L'épisode est notamment raconté par G. Maggi (1974: 168-170) qui réfute toute implication forte de la part d'A. Maiuri dans le régime, à l'exception du discours inaugural sur Roma e l'Oriente europeo. Cf. également Zevi 2001: 76 .

101 «Il che significa una sua non compromissione diretta in episodi condannabili » (Zevi 2001: 74).

102 Iezzi-Scafati 1984: 281

103 À l'heure actuelle, le débat n'a pas dépassé ce qu'il était après-guerre. Les tenants d'un A. Maiuri inféodé au régime utilisent la "consécration » de l'entrée à l'Accademia d'Italia et le discours de 1941; ceux qui refusent sa participation active se servent de l'attitude de $\mathrm{B}$. Croce à son égard lors de l'épuration pour contrer ces arguments (cf. not. l'introduction de M. Capasso dans Maiuri 1991). Seule une étude détaillée des papiers personnels et officiels laissés par le Surintendant permettrait de dresser un portrait nuancé de ces années noires.
A. Maiuri, il faut revenir sur sa pratique archéologique, en commençant par une rapide présentation des sources permettant de reconstituer cette dernière, les archives de fouilles créées lors des Nuovi Scavi. Majoritairement conservés à l'Ufficio scavi di Ercolano, les Giornali degli scavi di Ercolano (GSE) sont des comptes rendus présentant une entrée quotidienne entre 1927 et 1942, puis, avec de nombreuses pertes, seulement bimensuelle pour les années 1950, avant de redevenir quotidienne entre 1960 et 1961. Y sont décrits, plus ou moins sommairement selon la période et les qualités du rédacteur, la nature et le lieu des travaux de dégagement effectués, avec l'éventuelle mention des objets découverts. Fréquemment, la mise au jour complète d'un bâtiment - et sa restauration - entraîne sa description pièce par pièce. Source d'une rare richesse, les GSE sont d'un usage délicat puisque les références topographiques utilisées pour les descriptions sont fluctuantes et ne correspondent pas à la normalisation effectuée par A. Maiuri dans sa synthèse de 1958. Lors de la préparation de cet ouvrage, j’ai consulté et interprété l'intégralité des journaux de fouilles rédigés entre 1927 et 1961, ce qui m'a permis de mettre en évidence de nouvelles données dont l'exploitation constitue une part importante de l'ossature de ce travail et offre la possibilité de jeter un regard neuf sur les Nuovi scavi ${ }^{104}$. Toutefois, avant de procéder à

${ }^{104}$ Cette exploitation des journaux de fouille aurait été impossible sans l'amicale assistance d'A. Cozzolino, alors archiviste à l'Ufficio scavi d'Herculanum. Qu'elle trouve ici l'expression de mes plus chaleureux remerciements. Pour ne pas alourdir les notes, les citations des journaux de fouille renvoient à la seule date de rédaction, référencée par année. Pour les mois de novembre 1937 à mai 1938, un journal parallèle est conservé; il correspond au dégagement effectué dans la Casa del bel cortile et dans une partie de la Casa del bicentenario à partir du cardo IV. Ses citations sont signalées par un astérisque. La raison de ce double compte rendu tient au financement privé de ces travaux, probablement grâce à la Banca d'Italia qui donne brièvement son nom à la Casa del bel cortile.

GSE 1937*: « [avant l'entrée du 22 novembre] Giornale di scavo della casa posta a nord di quella di Poseidone. Detto scavo è fatto da somme versate da privati ».

GSE 1939: « 31 marzo. Si lavora nell’ambiente 17 della Casa del bicentenario. Sulla parete ovest si osserva un vano chiuso dagli antichi stessi. I pilastri sono di opera mista. Detto vano comunicava con il grande salone della Banca d'Italia posta del IV cardine Insula V casa n. 2 ». 
l'utilisation de cette source quasiment inédite, il est impératif de définir le rôle des données de fouilles dans les écrits du Surintendant. Pour ce faire, j'appuierai mon propos essentiellement sur sa synthèse de 1958. En effet, dans ses deux autres livres consacrés à Herculanum, A. Maiuri n'expose pas le cheminement de sa pensée. De même, il est rare que ses articles concernant des secteurs déterminés de la ville révèlent clairement les fondements de ses idées.

L'un des points sur lesquels A. Maiuri s'est trouvé à la pointe de la recherche de son temps reste l'utilisation de l'archéologie du bâti. Fort de son expérience pompéienne, il a cherché à retracer les différentes périodes d'occupation de la ville en dressant une typologie des modes de construction alors que M. Ruggiero considérait que les types d'opus utilisés à Pompéiétaient identiques à ceux d'Herculanum ${ }^{105}$. A. Maiuri a fait partie des promoteurs les plus féconds de cette méthode d'interprétation, d'abord utilisée pour dater les monuments romains ${ }^{106}$. Sa typo-chronologie comporte trois phases couvrant respectivement la période préromaine, la période romaine (républicaine et impériale), la dernière période (après le tremblement de terre de 62 ap. J.-C.). Schématiquement, à la première phase correspond l'opus incertum, à la seconde l'opus reticulatum et à la dernière l'usage des briques et de l'opus craticium. Les reconstructions liées aux réparations des dégâts du séisme auraient également été effectuées avec des techniques de construction antérieures ${ }^{107}$. L'établissement de cette typo-chronologie permet à A. Maiuri d'esquisser, pour certaines maisons, le schéma de leur évolution, ou bien de dater leur construction: la Casa della fullonica (IV, 5-7) serait, compte tenu du type d'opus utilisé, "una delle

\footnotetext{
105 «La forma delle case e i materiali con cui sono murate, non differiscono punto da quelli di Pompei [...]» (Ruggiero 1885: VIII).

106 Selon G. Lugli, les prodromes de cette méthode sont à chercher au XVII ${ }^{\mathrm{e}}$ siècle, dans l'œuvre de Giovanni Ciampini (Lugli 1942: 383). Si plusieurs continuateurs ont contribué à affiner cette forme d'interprétation, l'œuvre de G. Lugli (1957), par son extension et son caractère synthétique reste une étape fondamentale au cours du $\mathrm{XX}^{\mathrm{e}}$ siècle. L'influence des travaux de G. Lugli sur la typo-chronologie créée par A. Maiuri paraît assez forte. Les deux hommes
}

più antiche e più tipiche abitazioni del periodo preromano ${ }^{108}$. Fréquemment, il se contente de quelques remarques sur les changements survenus dans les maisons, sauf lorsque les transformations amènent à de grands bouleversements au sein d'un îlot; ses explications se veulent alors plus complètes et il énumère les différentes composantes architecturales de la maison en indiquant leur datation. Pour la Casa sannitica (V, 1-2), dont les transformations ont amené à la création de la Casa del gran portale (V, 34-35) et de la Casa con giardino (V, 32-33a), il décrit de façon diachronique les éléments décoratifs de la maison.

En dépit de cette capacité à esquisser l'évolution de chaque maison en utilisant les techniques de construction, A. Maiuri fonde la majeure partie de ses raisonnements sur des observations stylistiques. Pour la Casa del tramezzo di legno, il signale la présence de quelques rares éléments de second style pompéien dans certaines pièces autour de l'atrium. De même, il indique que le premier pavement de l'impluvium, recouvert dans une phase postérieure par des plaques de marbre, serait caractéristique de la période républicaine ${ }^{109}$. De cette manière, au lieu de présenter des phases de transformation claires et détaillées, il n'indique que certains de leurs éléments. Le résultat est souvent impressionniste.

Les objets mis au jour dans les différentes pièces des boutiques et maisons d'Herculanum sont assez peu utilisés dans le cours de la description de la ville. La principale raison à cette absence reste que ce premier volume sur les Nuovi Scavi est principalement consacré à la topographie et à l'architecture. Les fresques, les pavements et les objets auraient dû être ont été ensemble aux Lincei, A. Maiuri comme socio à partir de 1936, G. Lugli comme correspondant dès 1938, puis socio en 1946. Toutefois, autant G. Lugli cite clairement et fréquemment les travaux d'A. Maiuri sur Pompéi (cf. e.g. Lugli 1957: 594), autant ce dernier ne mentionne que très rarement les publications de son collègue romain - à cinq reprises pour des exemples lui servant de point de comparaison, jamais lors de l'exposition de sa typo-chronologie.

${ }^{107}$ Maiuri 1958 b: 62-74.

${ }^{108}$ Maiuri 1958 b: 422.

${ }^{109}$ Maiuri 1958 b: 207. 


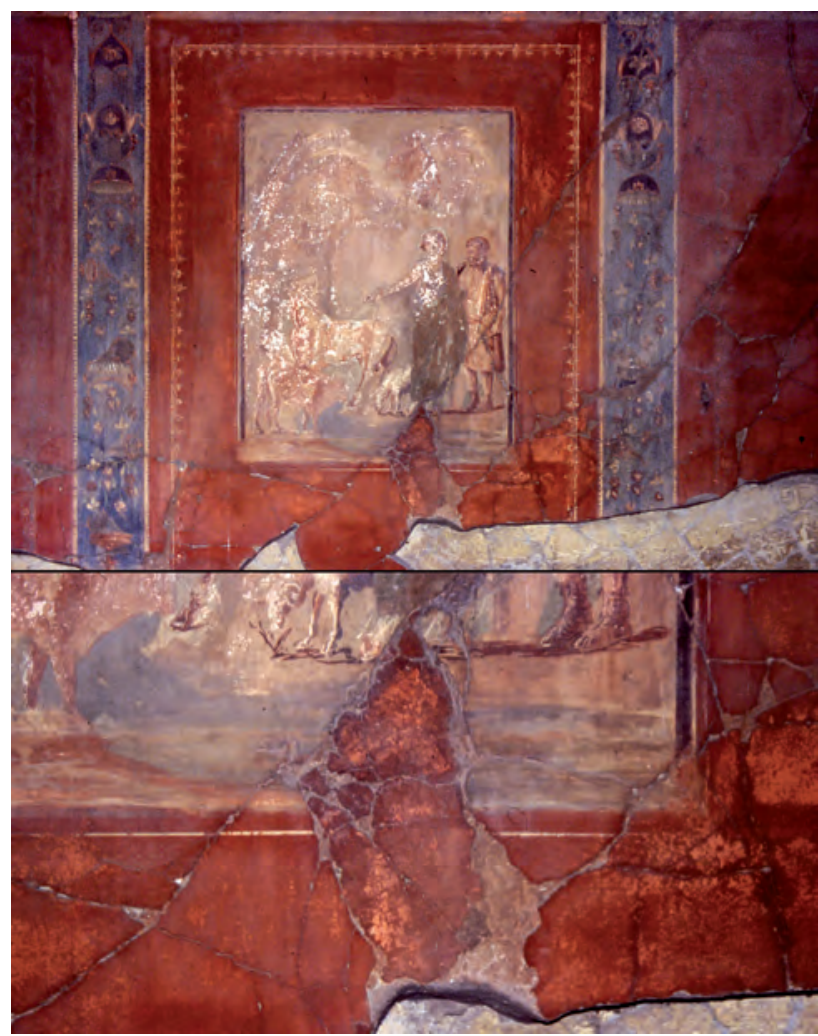

Fig. 1 - Casa del bicentenario, tablinum, mur ouest, vue générale et détail. Le cadre représentant Dédale et Pasiphaé présente une fissure en biais. Une partie de celle-ci a été restaurée par l'insertion d'un fragment d'enduit dont la couleur est sensiblement différente du reste de la fresque.

décrits dans un second volume qui n'est jamais paru $^{110}$. Ils sont cependant parfois mentionnés dans le texte, essentiellement pour interpréter les ateliers, comme dans le cas de la découverte de nombreuses gemmes et intailles en Or. II, 10 qui permettent de caractériser ce local comme celui d'un gemmarius ${ }^{111}$. Cette utilisation reste cependant exceptionnelle.

Au-delà de ces considérations architecturales dispensées par petites touches, A. Maiuri ne décrit précisément son raisonnement que dans le cas de la Casa del bicentenario (V, 15-16),

\footnotetext{
${ }^{110}$ Maiuri 1958 b: V-VI. Malgré la volonté de briser le mythe faisant d'Herculanum une mine de bronzes et de marbres, nous pouvons supposer que le second volume aurait eu une approche fortement antiquaire, comme l'indique la restitution de son titre: Ercolano. I nuovi scavi
}

qui servirait, à elle seule, à justifier l'hypothèse sur l'invasion de la maison traditionnelle par des affranchis s'adonnant au commerce ${ }^{112}$. Il commence par montrer que cette domus a été pendant un moment en communication avec la Casa del bel cortile (V, 8) et avec la Casa dell'Apollo citaredo, avant de décrire les vicissitudes qu'elle a subies, en raison de sa proximité avec le decumanus maximus, principale artère commerciale de la ville. Après avoir exposé les différents types de maçonnerie dont sont constitués ses murs, il conclut, en dépit de la présence d'éléments remontant à la période samnite, que la maison a été intégralement reconstruite entre 10 av. J.-C. et 5 ap. J.-C. Vers les années 55-60 de notre ère, des boutiques seraient créées dans trois des pièces de façade. L'une d'elles (V, 17-18) deviendrait indépendante de la maison. Dès lors, le nouveau propriétaire serait contraint d'habiter non plus autour de l'atrium et du péristyle, mais dans l'appartement qui se développe au-dessus des boutiques. Ce transfert est justifié par la seule richesse de la décoration de cet étage de façade, pourtant moins fine que celle du rez-dechaussée. L'absence d'utilisation par le dernier propriétaire des pièces entourant l'atrium serait également perceptible grâce au faible nombre d'objets mis au jour dans cette partie de la maison. La description de la pièce 7 montrerait parfaitement cet abandon du rez-de-chaussée. En effet, fermée par un panneau coulissant et repliable, cette pièce aurait abrité, en des temps plus nobles, soit des archives, soit les imagines maiorum $^{113}$. La décadence dans laquelle serait tombée la maison serait également perceptible par la fresque qui orne le côté ouest du tablinum, dont le cadre central représente Dédale et Pasiphae (fig. 1). Une réparation, faite avec un enduit rouge qui ne reprend pas le dessin et est d'une couleur différente de celle utilisée pour le reste du panneau, ampute une partie de la figuration mythologique. A. Maiuri estime que ce "replâtrage» témoigne du mauvais goût des derniers propriétaires.

(1927-1958). La decorazione - Le opere d'arte (Maiuri 1958 b: VI, 239, 464).

${ }^{111}$ Maiuri 1958 b: 463-464.

112 Maiuri 1958 b: 222- 224.

${ }^{113}$ Maiuri 1958 b: 229-230. 
En ce qui concerne les étages, il note que l'appartement de façade serait beaucoup plus soigné que celui auquel on accédait par le péristyle. $\mathrm{La}$ fraîcheur de la peinture du laraire mise au jour dans une pièce non numérotée permettrait de dater celle-ci des derniers travaux de réfection et de décoration. Ceci renforcerait son hypothèse d'une occupation de l'étage en façade par le dernier propriétaire de la maison. Pourtant, il indique que la seule source de lumière pour les pièces situées à l'ouest de l'appartement serait une fenêtre s'ouvrant au-dessus de l'atrium de la maison voisine $(\mathrm{V}, 11)^{114}$. Le dernier argument en faveur du changement de propriétaire de la maison, de sa division et de sa mise en location, est constitué par la "croix» mise au jour à l'étage: seule une famille de peregrini, de foi chrétienne aurait pu laisser un tel signe (fig. 2).

Sans entrer dans les détails chronologiques qui seront traités plus loin, les autres arguments avancés par A. Maiuri pour étayer son propos doivent être rapidement discutés. L'un des principaux éléments est constitué par le tableau représentant Dédale et Pasiphaé, supposé réparé avec un enduit différent de l'original. Son observation attentive permet d'entrevoir une autre explication (fig. 1): les bords inférieurs et supérieurs du fragment ajouté correspondent parfaitement avec la ligne de fracture qui s'est produite lors de la chute du panneau durant l'éruption. L'arrachement des fresques par le flux pyroclastique a été observé en d'autres endroits du site. Lors des travaux de dégagement, une fois les enduits mis au jour, ils sont transportés à proximité pour y être reconstitués avant d'être remontés sur leur lieu de découverte. Tout laisse à considérer que la restauration supposée antique par A. Maiuri a en fait été effectuée par les ouvriers du chantier peu après la mise au jour du tablinum. La "croix», autre élément primordial dans son raisonnement, peut être rapidement écartée: faute de pouvoir démontrer la nature chrétienne de cette trace en négatif d'un élément en bois pris dans un enduit,

${ }^{114}$ Cf. Maiuri 1958 b: 234-239. Avant de les reprendre dans sa synthèse de 1958, A. Maiuri a présenté ses idées sur

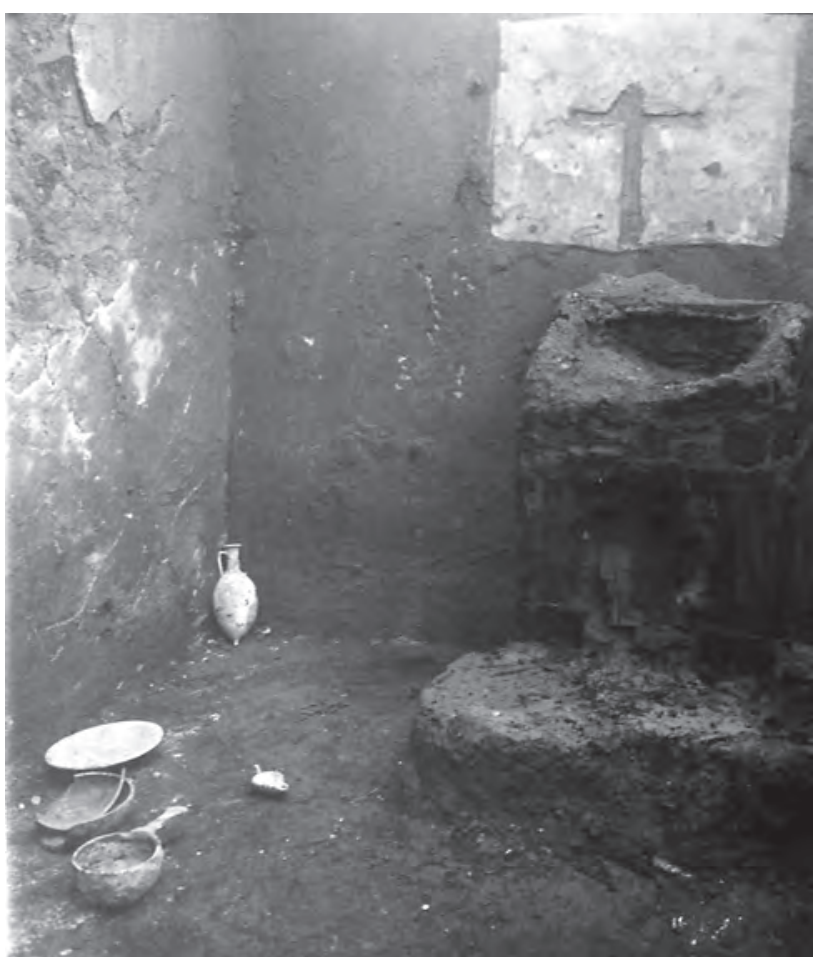

Fig. 2 - Casa del bicentenario, premier étage. La supposée croix chrétienne n'est qu'une empreinte en négatif dans un cadre peint en blanc. Il est probable qu'une étagère, éventuellement utilisée dans le cadre du culte domestique, se soit trouvée fixée au mur.

il convient de considérer cette empreinte simplement comme celle d'une petite étagère murale.

La réfutation de ces deux arguments réduit la portée des interprétations d'A. Maiuri à une simple conjecture. Il n'en reste pas moins que son hypothèse est présentée de manière cohérente. Le processus interprétatif est quant à lui trop fortement déductif: les faits observés sont insérés en renfort d'une théorie préexistante qui prime sur le reste. En ce sens, les données issues de la fouille ne sont qu'une illustration fragmentaire et téléologique d'un postulat préalable.

Pour compléter cette analyse introductive, il est nécessaire de s'interroger sur le mode de rédaction de la principale synthèse sur Herculanum. Le 
rôle de Surintendant de Campanie et de Caserte d'A. Maiuri et ses multiples chantiers lui interdisaient une présence permanente à Herculanum. Il venait inspecter les fouilles de temps en temps, sans qu'il soit possible de déterminer la fréquence de ses visites. Tout au plus semble-t-il se déplacer sur le site, en dehors de visites régulières, lorsque la découverte de structures ou d'objets particuliers nécessitait une décision de sa part. Selon les journaux de fouille, la «croix » de la Casa del bicentenario est découverte le 28 janvier 1938. Pourtant, dans son article consacré à la publication de cette découverte, A. Maiuri écrit que la croix a été mise au jour le 3 février 1938, selon son propre journal de fouille, ce qui correspond à la date à laquelle la fouille du meuble situé sous celle-ci est enfin mentionnée ${ }^{115}$. Cette anecdote n'aurait que peu de valeur si elle ne permettait pas de percevoir le mode de travail d'A. Maiuri. Lors de ses visites, il consignait ses observations sur un carnet. Malheureusement, ce ou ces carnets de notes, qui devaient faire partie de ses papiers personnels, n'ont pas été conservés par la Surintendance ${ }^{116}$. Seuls quelques extraits semblent être sortis des archives familiales ${ }^{117}$. Toujours est-il qu'il se servait de ses propres notes en lieu et place des journaux de fouille qu'il recevait pourtant pour contrôle avec une certaine régularité. S'il avait utilisé ces derniers, la date réelle de découverte de la "croix » aurait été mentionnée. L'incidence d'un décalage de

115 Maiuri 1939: 193.

GSE 1938*: "3 febbraio. Si è sterrata la cassa o ara votiva che trovasi nell'ambiente della croce [...]. »

${ }^{116}$ Un dossier en cours d'inventaire lors de la rédaction de ces lignes est conservé à l'Archivio storico de la SANP. Il contient des éléments épars de la correspondance d'A. Maiuri comme Surintendant. Au total, un peu plus de 80 pièces, traitant essentiellement de problèmes de service. Deux des trois chemises comportent des lettres des années 1925-1925, la troisième couvre un arc chronologique allant de 1925 à 1957. Le seul carnet de note consigné avec cette correspondance officielle contient des inscriptions grecques, vraisemblablement glanées lors de son séjour à la Scuola Superiore di Archeologia di Atene, en 1911. Je remercie vivement la Dott.ssa M.R.Esposito qui m’a laissé consulter ces dossiers alors qu'ils n'étaient pas encore inventoriés. Depuis, les différentes pièces ont été distribuées dans les dossiers correspondant aux sites évoqués par la correspondance (pour Herculanum: b.145.1-17).

117 Quelques extraits ont été présentés lors d'une exposition tenue à l'université de Naples en 1984 (IezziScafati 1984). Des fragments de ces carnets concernant la quatre jours pour la mise au jour de ce meuble est mineure. En revanche, cette préférence accordée à ses carnets personnels par rapport aux journaux de fouille officiels a des conséquences non négligeables sur les données qu'il a publiées. L'exemple du métier à tisser de la Casa del telaio $(\mathrm{V}, 3)$, et de son devenir entre la fouille et la publication, est à ce titre très instructif.

Cette maison, fouillée entre le 2 février 1931 et le 21 janvier 1933, s'est vue attribuer son nom après la découverte d'un métier à tisser. Dans les journaux de fouilles, seule une brève mention, insérée dans la description finale de la maison, indique la découverte de cet instrument dans la partie est du péristyle ${ }^{118}$. Dans le compte rendu journalier qui est donné de l'avancement des travaux, ni ce métier à tisser ni aucun de ses éléments ne sont jamais mentionnés. La seule date proche de la découverte est indiquée sur un dessin réalisé lors de la mise au jour par F. Ferrajoli, dessinateur du chantier, le 18 janvier $1933^{119}$. Le journal des travaux effectués indique le début de sa restauration à partir du 8 février 1933. Ce travail est assuré par les restaurateurs des peintures ${ }^{120}$. Dans sa synthèse de 1958, A. Maiuri mentionne trois métiers. Il évoque des pesons mis au jour dans les fouilles du XVIII ${ }^{\mathrm{e}}$ siècle dans la boutique VII, 1-1 $\mathrm{a}^{121}$ et il narre les activités de tissage dans la Casa del telaio ${ }^{122}$. La troisième occurrence du terme telaio dans son texte renvoie à l'histoire de la «chambre de la brodeuse» (Or. II, 10), parfaite

fouille de l'atelier de plumbarius VI, 12 ont été publiés par M. Pagano (2004: 360-361), puis de nouveau par mes soins (Monteix 2006: 66). Enfin, les premières entrées du carnet, concernant la reprise des fouilles à Herculanum ainsi que le bombardement de 1943, ont été insérées dans une reproduction d'articles écrits par A. Maiuri (2008: 125-129; 131132) choisis par M. Capasso.

118 GSE 1933: "Casa Nº 3 e 4. Sul IV cardine, lato est [description insérée à la fin du mois de janvier]. [...] Interessante però è il peristilio lato est l'unico trovato discretamente conservato per la sua chiusura di legno che si sviluppa nell'intercolumnio sopra ad un alto podio e un telaio? di legno carbonizzato posto sotto il peristilio al medesimo lato ».

119 Cf. fig. 86 p. 178 ; infra n. 129.

${ }^{120} G L$ : « 8 febbraio XI (1933); Casa ${ }^{\circ} 4$; Stuccatori; $[\ldots] ;[\ldots]$ Iniziato il restauro di un telaio per tessitura in legno carbonizzato dell'ambiente non numerato lato est quarto cardine».

${ }^{121}$ Maiuri 1958 b: 449.

122 «Il portichetto chiuso [...] ha conservato nell'area centrale un po' di terra vegetale, tanto da rendere possibile la coltivazione di qualche pianta o di qualche cespo 
description de la pièce telle qu'elle est représentée sur le cliché qui agrémente le texte ${ }^{123}$. On y voit une table en marbre, un lit en bois sur lequel ont été disposés les ossements d'un(e) adolescent(e), un candélabre en bronze, un tabouret ouvragé et un supposé métier à tisser.

La consultation des journaux de fouille permet de décrypter cette photographie mise en scène (fig. 3). Des différents objets censés provenir de cette pièce, seuls le lit et les ossements y ont été effectivement mis au jour ${ }^{124}$. La table en marbre provient bien de la boutique Or. II, 10 , mais pas de cette pièce ${ }^{125}$. Le candélabre en bronze a été mis au jour au sud de la ville, sans plus de précision ${ }^{126}$. Le tabouret est de provenance incertaine ${ }^{127}$. Quant au métier à tisser, il n'apparaît pas lors de la fouille de cette boutique. Le seul métier à tisser jamais mis au jour à Herculanum est celui qui a donné son nom à la Casa del telaio; le métier de la «brodeuse» est en fait celui découvert en V, 3 .

Esquissons rapidement le parcours du métier à tisser entre le moment où il a été dégagé dans la Casa del telaio, et sa description en Or. II, 10. Le 18 janvier 1933, F. Ferrajoli représente les restes du métier, vraisemblablement découvert plusieurs jours auparavant. La fouille a dû être interrompue dans cette maison en attendant l'intervention du dessinateur ${ }^{128}$. Son croquis représente les différentes pièces retrouvées, dans leur état au moment

di fiori. Era quanto bastava a rendere alla tessitrice seduta al suo telaio di lavoro, agli altri umili operai ed inquilini degli ambienti sotto tetto verso la strada [...], meno povera e disardona la vista della loro casa » (Maiuri 1958 b: 430).

${ }^{123}$ Maiuri 1958 b: 463, fig. 420.

${ }^{124}$ GSE 1936: « 8 ottobre. Nell'ambiente n. 2 della casa 10 posta sul $\mathrm{V}$ cardine $2^{\circ}$ Insula orientale si è sterrato un letto di legno carbonizzato. [...] Fu sollevato dalla lava di fango entrata dal vano d'ingresso. [...] Sul pavimento vi era uno scheletro di un giovanetto che a giudicare dallo scheletro poteva contare una quindicina di anni. La testa penetrava sotto il letto per circa una trentina di $\mathrm{cm}$. Lo scheletro era da nord ovest a sud est. Nessun trovamento.

${ }^{125}$ GSE 1936: " 5 agosto. Si lavora nella casa n. 10 e 11 poste ambedue sul V cardine $2^{\circ}$ Insula orientale. Nella prima casa a m. 0.50 di altezza dal pavimento, a 0.82 dalla parete sud e a 2.84 da quella est si è raccolto: Marmo bianco e alabastro fiorito. Tavolo alto m. 1.05. [...] Inventario n. [E]1580[=76858]».

${ }^{126}$ GSE 1936: «7 agosto. [...] Nello sterro eseguito in appalto, lavoro che si fa all'estremità sud della città, nel terreno alto si è sterrato: Bronzo. Candelabro mancante della base. Il fusto è liscio. L'altezza è di m. 1.40. Inventario n. $[\mathrm{E}] 1601[=76879]$ ».

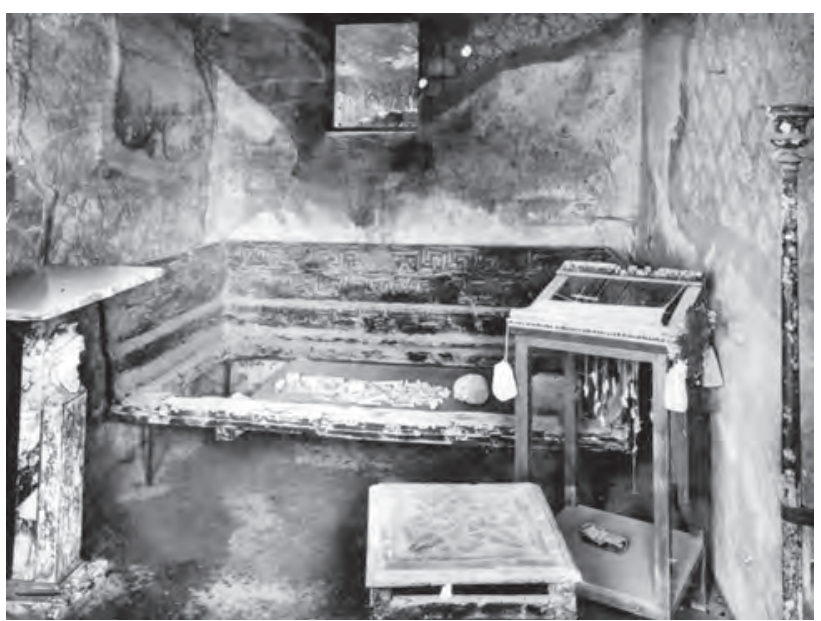

Fig. 3 - "Chambre de la brodeuse», pièce annexe de la boutique Or. II, 10. De tous les objets présentés sur cette photo, seul le lit provient effectivement de cette pièce.

de la fouille. Peu après, l'architecte réfléchit à une hypothèse de restitution ${ }^{129}$. Son étude représente les éléments observés: un fragment de tissu, les pesons, quelques pièces de bois. Le 8 février 1933, les ouvriers chargés des enduits peints commencent à restaurer le métier à tisser, sans se soucier de la tentative de restitution proposée par F. Ferrajoli. Quelques années plus tard ${ }^{130}$, il est installé dans la pièce annexe de la boutique Or.II, 10, avec d'autres objets dont seulement certains proviennent effectivement de ce local.

${ }^{127}$ Mols 1999: 167, cat. $n^{\circ} 23$ p. 182-183.

${ }^{128}$ Le 5 janvier 1933, la pièce 10 , qui correspond à la partie est du péristyle où le métier à tisser semble avoir été mis au jour, est décrite. Cette description indique que sa fouille était, à cette date, terminée ou en voie d'achèvement. Le 7 janvier, la fouille de cette maison est suspendue. Le 21 janvier, elle reprend, dans le péristyle, qui est vidé dans la journée, ce qui constitue l'achèvement de la fouille de la maison:

GSE 1933: « 21 gennaio. Si è ripreso il lavoro nella casa $\mathrm{N}^{\circ} 84$ sul $\mathrm{V}$ cardine lato est, ed è stato completamente svuotato il peristilio, lato est. Con questo ultimo sterro la casa è stata posta completamente alla luce».

${ }^{129}$ Le dessin des pièces de bois et l'épure de restitution sont conservés à Pompéi dans le carnet de l'architecte sous la cote $\mathrm{P} 658 \mathrm{f}^{\circ} 4$.

${ }^{130}$ Le cliché utilisé par A. Maiuri pour sa figure 420 est conservé dans les archives de la Surintendance de Pompéi (Nég. SAP E/B 28 [ex 3301 ex 28]). Il est daté de 1957. L'hypothèse de l'insertion de métier à tisser dans cette boutique avait déjà été entrevue par S. Mols. Selon les indications qu'il donne (Mols 1999: 167), l'objet aurait été présent dans la boutique dès 1937. 
À partir de cette restitution du fil des découvertes et des déplacements successifs, je ne peux que formuler des questions. A. Maiuri a-t-il placé une confiance trop élevée en ses assistants chargés de la mise en valeur du site? A-t-il accordé, dans son propre carnet de fouille, une importance telle aux intailles provenant de ce local qu'il n'a pas noté le détail des objets qui y ont été mis au jour? Il n'en reste pas moins que, lors de sa rédaction, fort de ses notes et d'une visite de contrôle sur le site, il décrit ce qu'il voit après la mise en valeur de cette pièce. Il crée alors un scénario touchant qui voudrait qu'une jeune brodeuse ait cherché à échapper à la mort en se cachant sous son lit.

Cette création artificielle d'un contexte de fouille "vivant», permettant de cerner des aspects de la vie quotidienne d'Herculanum, se fonde sur un postulat qui ne semble avoir été érigé en système que lorsqu'A. Maiuri s'est trouvé à la tête de la Surintendance. L'utilisation comme espace d'exposition du site en général, et des contextes de découverte en particulier, constitue un principe muséographique développé à Pompéi au moins dès le début du $\mathrm{XX}^{\mathrm{e}}$ siècle ${ }^{131}$. À Herculanum, une certaine publicité a été faite autour de cette décision:

The authorities have wisely decided to leave the various objects in the exact position and spot where they were found so that the visitor will have a vivid impression of the people who had once their homes in Herculaneum ${ }^{132}$.

De toute évidence, cette décision a été largement mise en pratique: les photos de fouille

${ }^{131}$ Cette pratique de laisser des objets sur le site ne paraît pas remonter à G. Fiorelli, ce dernier semblant, à en croire A. Maiuri, opposé à «ogni aggiunta del nuovo sull'antico » (Maiuri 1950 b: 14) - ce jugement porte essentiellement sur l'absence de restauration, mais pourrait être étendu à la présentation des objets sur le site. Une attestation sûre est constituée par les fouilles de V. Spinazzola, avec notamment le «thermopolium d'Asellina " (IX 11, 2), fouillé en 1912 et dont tous les objets mis au jour ont été laissés en place dans des vitrines.

${ }^{132}$ The Times, 7/12/1928, p. 15. Bien que pour cet article, divers éléments, tels que la description de la presse trouvée en III, 10 ou de certaines parties de la Casa del tramezzo di legno, permettent de supposer une visite du correspondant du Times à Herculanum, l'extrait reproduit ici possède le ton des informations communiquées officiellement par la Surintendance à la presse. La publication dans au moins trois journaux différents d'informations similaires entre le 5 et le 7 décembre 1928 (cf. McIlwaine 1988: n³.544-3.546) montrent bien qu'avec l'avancement des travaux, les bâtiments qui sont restaurés peuvent être dotés de vitrines en verre contenant des objets. La confrontation de ces photos avec les journaux de fouille d'une part et avec les descriptions d'A. Maiuri d'autre part permettent de voir à quel point sa vision du site a été déformée par ces expositions. Bien que jamais la description ne soit aussi suggestive que dans le cas du métier à tisser et de la chambre de la brodeuse en Or. II, 10, les exemples où $\mathrm{A}$. Maiuri a très clairement utilisé les vitrines pour compléter ses descriptions sont au nombre de huit ${ }^{133}$. A. Maiuri attribue à la boutique Or. II, 9 une amphore crétoise AC2, marquée au nom de L.R. Antigoni, sur la foi de sa présence dans les casiers à amphores de ce local. Cette amphore a été mise au jour en Or. II, 10 tant selon les journaux de fouille que selon M. Della Corte ${ }^{134}$. Bien que ces expositions et leur interprétation se déroulent essentiellement dans des locaux commerciaux, des domus sont également concernées. La cuisine de la Casa della gemma (Or. I, 1) est décrite avec une marmite et un chauffe-eau en bronze. Présents sur la photo illustrant ce propos, les deux objets ont été découverts dans l'atrium ${ }^{135}$. Dans le cas de la Casa di Nettuno e Anfitrite (V, 6-7), comme l'a fort bien montré D. Camardo, la restauration participe de la mise en scène, avec la volonté de créer l'illusion d'un éclaté axonométrique grandeur nature de la façade ${ }^{136}$. Cependant, dans le cas de cette maison, véritable idéal-type des distorsions survenues à Herculanum entre la fouille,

pourrait conduire à penser que toutes les données présentées par ces quotidiens sont issus de télégrammes officiels.

${ }^{133}$ Cette utilisation du site présenté après restauration est perceptible dans les descriptions des maisons suivantes: Casa a graticcio (III, 13-15; cf. infra, p. 32-35); Casa del priapo (IV, 17-18; comparer la description proposée par A. Maiuri [1958 b: 437] avec les objets trouvés dans la boutique donnée dans les GSE [1932: 20 gennaio], qui se limitent à deux monnaies); Casa del telaio (V, 3); boutique de la Casa di Nettuno e Anfitrite (V, 6); Casa della gemma (Or. I, 1); boulangeries Or. II, 1a (cf. infra n. 33 p. 139) et Or. II, 8 (cf. infra, p. 151-152); boutique Or. II, 9; boutique Or. II, 10.

${ }^{134}$ CIL IV, 10802 a; Maiuri 1958 b: 463; Della Corte 1958: n. 616 p. 285 ; GSE 1936: 21 agosto.

${ }^{135}$ Maiuri 1958 b: 339, fig. 269 p. 340 . Les deux objets ont respectivement été mis au jour le 7 mai 1934 ( $\mathrm{n}^{\circ}$ Inv. E1284=76562) et le 24 mai $1934($ E1289=76567).

${ }^{136}$ Camardo 2006: 76-77. 
la restauration et la publication, la scénographie est complète: les amphores exposées tant dans le porte-amphores que sur la mezzanine ne viennent pas du local commercial - trouvé dépourvu de ce type de conteneur - tandis que les «fave e ceci (?) depositati nei capaci dolii infossati nel podio del banco» proviennent vraisemblablement d'une amphore mise au jour à l'étage ${ }^{137}$. Plus qu'une simple exposition d'un contenu plus ou moins remanié, cette boutique constitue un exemple de reconstitution sans fidélité à la réalité observée durant la fouille.

Si ces descriptions ne portent que sur des détails et ne sauraient bouleverser l'analyse du site, elles n'en constituent pas moins des contrefaçons, et sont surtout des révélateurs du mode de rédaction d'A. Maiuri ${ }^{138}$. Je ne saurais déterminer l'implication de ce dernier dans ce procédé de présentation des objets hors de leur contexte d'origine, même en tenant compte de sa présence relativement rare sur le site. A-t-il donné des instructions générales pour organiser ces expositions sans se soucier ensuite du détail? Les personnes qui en étaient en charge ont-elles bénéficié d'une certaine autonomie de fait $^{139}$ ? Ici encore, la perte des carnets personnels d'A. Maiuri se révèle extrêmement dommageable à cet égard. Ces recréations, abusives mais pittoresques, de la vie quotidienne par la

137 Maiuri 1958 b: 402. GSE 1932: «7 novembre. Sterrando il IV cardine lato nord, abbiamo posto alla luce un balcone che fa parte di una casa non numerata perché il vano d'ingresso è ancora otturato dal materiale. [...] Una discreta quantità di anfore di terracotta, completamente rotte stavano accatastate tra la parete nord ed est. Una di esse conteneva: Commestibili. Fave $\mathrm{kg} 13$ [ $\mathrm{n}^{\circ} \mathrm{Inv}$. $\mathrm{E} 939=76216][\ldots] »$.

138 Moins de dix ans après la reprise des fouilles, A. Maiuri semble être conscient de ces déplacements, comme l'indique cette mention dans son guide de 1936, à propos de la Casa del tramezzo di legno: "Le bacheche collocate nell'atrio e nel tablino racchiudono i pochi oggetti superstiti della casa; notevoli fra essi avanzi di legumi secchi (fave) » (Maiuri 1936 a: 28). Des fèves ont été mises au jour le 15 mars 1928 dans la pièce 4 du plan publié (Maiuri 1958 b: fig. 162 p. 208). Gageons que certains déplacements ont acquis une nouvelle provenance légitime après avoir été exposés longtemps au même endroit.

${ }^{139}$ Cette hypothèse pourrait être confirmée par les incohérences perceptibles entre les descriptions des objets au fur et à mesure de la fouille et leur éventuel rappel lors de la description générale de la maison, une fois son dégagement terminé. présentation d'objets sur le lieu réputé de leur mise au jour restent paradoxales. Détaché de ses propres interprétations hostiles au milieu commercial, A. Maiuri a tenté de rendre les boutiques attractives aux yeux des visiteurs.

Enfin, certains éléments utilisés pour comprendre Herculanum sont issus des fouilles pompéiennes. Avec la volte-face opérée dans le courant des années 1930, Pompéi est finalement utilisée en appui des démonstrations sur Herculanum $^{140}$, en particulier pour l'évolution générale:

Ma gradatamente, con la invadenza del ceto mercantile e la trasformazione delle case dei quartieri del centro in botteghe, si nota ad Ercolano, e forse di più a Pompei lo spostarsi del centro della vita familiare dal pianterreno al piano superiore ${ }^{141}$.

Cependant, l'influence la plus forte des fouilles de Pompéi sur celles d'Herculanum s'est exercée sur l'Insula Orientalis $I I^{a}$, explorée en tunnels par les fouilleurs bourbonniens entre 1756 et 1760 mais dégagée à ciel ouvert peu avant la palestre pompéienne (II 7) dans les années 1930. Au XVIII ${ }^{\text {e }}$ siècle, l'entrée Or. II, 4 a fait l'objet d'une description précise par C. Weber, tant pour la voûte étoilée qui y est mise au jour écroulée qu'à cause de l'inscription rappelant les travaux effectués par Vespasien en 76 dans le temple de la Mater Deum ${ }^{142}$. La forte

\footnotetext{
${ }^{140}$ L'opposition n'est maintenue entre les deux villes que sur deux points: les portiques soutenant les avancées des maisons sur la rue, fréquents à Herculanum mais réservés aux zones des monuments publics à Pompéi, et les formes d'habitat: l'Insula Orientalis $I^{a}$ constituerait un nouveau mode d'habitation, éloigné de ce qui se rencontre habituellement dans la Campanie du I ${ }^{\text {er }}$ siècle ap. J.-C. (Maiuri 1958 b: 46, 113).

${ }^{141}$ Maiuri 1958 b: 62. La légère différence d'évolution entre Pompéi et Herculanum est effacée dans le cas de la Casa del bicentenario (Maiuri 1958 b: 223).

${ }^{142}$ CIL X, 1406 = ILS 250 (cit. infra, p. 235). Les journaux de C. Weber ont été transcrits par M. Ruggiero (1885). La découverte de l'inscription se produit entre le 18 et le 20 juillet 1757, un plan expliquant la façon dont elle a été retrouvée est annexé au rapport du 6 août 1757 (Ruggiero 1885: 231-234). Selon la remarquable reconstruction opérée par G. Guadagno (1995: 120-122), l'inscription se serait trouvée sur l'architrave séparant l'entrée avec ses deux colonnes de l'espace entouré d'un portique, sous la voûte étoilée. Les secousses accompagnant l'éruption de 79, après les premières coulées, ont fait tomber la plaque qui s'est cassée, puis la voûte s'est effondrée à la verticale dans le vestibule. Je reviendrai plus loin sur les différentes hypo-
} 
ressemblance entre le plan du vestibule et celui d'un temple a porté à le considérer comme l'édifice sacré consacré à Cybèle. Cette localisation a perduré jusqu'en $1936^{143}$ :

C'est précisément [...] <cet> édifice qui fut improprement désigné sous le nom de «Temple de la Mater Deum ", à cause d'une inscription, retrouvée dans le voisinage. [...] Les fouilles nouvelles nous ont appris qu'il ne s'agit nullement d'un édifice sacré mais d'un majestueux accès à une enceinte publique de la ville ${ }^{144}$.

Il faut attendre la synthèse de 1958 pour qu'une fonction soit précisément définie en contrepoint de celle proposée par La Vega au XVIII ${ }^{e}$ siècle. Entre-temps, en 1942, la découverte du cénotaphe de M. Nonius Balbus mentionnant des ludi gymnici donnés en l'honneur du défunt n'a fait que confirmer, pour le surintendant, une nouvelle interprétation déjà considérée comme acquise mais encore inédite ${ }^{145}$ : ce n'est que dans le volume sur les Nuovi Scavi qu'A. Maiuri écrit que l'Insula Orientalis II ${ }^{a}$ est une «palestre». Il indique que le changement radical d'interprétation est directement lié à la mise au jour de la palestre de Pompéi, fouillée à partir de 1935, mais tout particulièrement entre juillet 1936 et janvier $1937^{146}$.

Pour l'essentiel, si A. Maiuri semble bien avoir utilisé majoritairement - mais pas exclusi-

thèses proposées pour cet édifice, tout en signalant déjà que les arguments apportés dans ce débat par G. Guadagno sont les plus décisifs (cf. infra, p. 234-235 et 263-265).

143 Avant de rejeter cette hypothèse, A. Maiuri l'a adoptée, comme en témoignent tant les journaux de fouille à partir de décembre 1931 (cf. GSE 1931 : «3 dicembre. Nello sterro del tempio della dea madre si sono raccolti numero tre stelle di stucco che decoravano le volte [...]») que les télégrammes adressés à la presse lorsque les premières colonnes donnant accès à l'entrée Or. II, 4 sont mises au jour: "According to a telegram from Naples two columns of the temple of Cybele have been found at Herculaneum. The existence of this temple was discovered in the eighteenth century by the archaeologists Lavega [sic] and Weber» (The Times, 28/01/1932, p. 9). On notera le décalage entre l'annonce officielle et la date réelle de mise au jour des colonnes qui, sans être connue, ne saurait être postérieure au 3 décembre 1931, première attestation de l'identification du temple par les fouilleurs.

${ }^{144}$ Maiuri 1936 b: 66 (= Maiuri 1936 a: 56-57). Pour éviter toute discussion, rendue impossible par le format et le public de ce guide, l'inscription est rejetée dans «le voisinage », ce qui simplifie la réfutation de l'interprétation du XVIII ${ }^{e}$ siècle. Dans les journaux de fouilles, la dernière mention concernant la fouille du « temple » a lieu le 29 juillet 1936. À partir du 26 novembre de la même année, c'est le vement - les données issues des fouilles d'Herculanum pour bâtir sa synthèse sur le site, celles-ci paraissent avoir subi plusieurs filtres. Le principal d'entre eux est lié à l'irrégularité des visites durant lesquelles il prenait des notes, utilisées ensuite pour la rédaction. Si ses inspections extraordinaires - lorsqu'une découverte particulière le fait venir à Herculanum - n'ont eu pour effet qu'un léger décalage chronologique dans ses propres comptes rendus des mises au jour, l'espacement des contrôles routiniers a eu des conséquences plus importantes. À Pompéi et plus encore à Herculanum, l'un des points majeurs de l'action d'A. Maiuri a été de chercher à présenter de manière vivante et compréhensible les fragments d'antiquité qu'il a mis au jour sa vie durant. L'absence de contrôle sur les restaurations ou sur la disposition des objets n'a eu de cesse de l'induire en erreur: premier spectateur de ces mises en scène, A. Maiuri a également été le principal mystifié, jusque dans ses écrits quand il ne pouvait plus mettre en doute les restitutions proposées.

Le volume consacré aux Nuovi Scavi témoigne d'un important décalage entre les résultats de la fouille et ce qui en est présenté; il

terme de palestra qui est utilisé (GSE 1936: «26 novembre. I due ambienti a volta posti sul piano superiore dell'ambulacro lato nord appartenente alla grande palestra situata ad est dell'abside, uno il più grande sulle pareti vi era dello stucco a fondo nero, e l'altro l'aveva a fondo bianco. Nel primo parecchi frammenti si sono raccolti, mentre nel secondo una piccola parte è attaccata sulla parete ovest e nord. Non ancora si sono svuotati completamente, perciò non si possono segnare le misure definitive»).

145 Contra Guadagno 1995: n. 25 p. 127. Les variations observées dans l'appellation de la «Palestre» dans les journaux de fouille contredisent l'idée qu'A. Maiuri se soit détaché de l'interprétation traditionnelle une fois découvert le cénotaphe. Lors de la publication du décret honoraire consacré à M. Nonius Balbus ( $A E$ 1947, $53=A E$ 1976, $144)$, A. Maiuri indique très clairement que cette inscription ne ferait que confirmer sa précédente interprétation de la «Palestre » (Maiuri 1942 b: 277-278). Il renvoie d'ailleurs à la seconde édition de son guide des fouilles pour une première présentation de cet édifice (Maiuri 1942 b: n. 1 p. 278).

146 «Basta invece raffrontare gli elementi essenziali di cui si compone l'edificio ercolanese con la grande Palestra scoperta nel 1936 nel quartiere sud-orientale di Pompei, [...] per riconoscere nel vasto complesso dell'insula orientale d'Ercolano una non meno grandiosa Palestra » (Maiuri 1958 b: 116). 
aurait certainement pu être évité par une publication plus régulière et plus large de ces résultats. Sachant qu'entre 1927 et 1961, A. Maiuri a publié 67 articles et ouvrages traitant au moins en partie d'Herculanum, cette remarque pourrait paraître paradoxale ${ }^{147}$. Cependant, au-delà du nombre de publications, leur nature et leur fréquence soulèvent des questions, particulièrement si l'on dresse un parallèle avec Pompéi.

Depuis G. Fiorelli, les comptes rendus des fouilles sont publiés régulièrement, d'abord dans le Giornale degli scavi di Pompei, puis dans les Notizie degli scavi di Antichità (NSc) à partir de 1876. Cette publication de données brutes facilite la rédaction d'articles ou d'ouvrages de synthèse ainsi que la simple diffusion de l'actualité des fouilles. À partir de 1911, quand V. Spinazzola devient Soprintendente degli Scavi di Campania ${ }^{148}$, les comptes rendus publiés cessent d'être une reproduction des seuls journaux de fouille, pour devenir des descriptions topographiques synthétiques. À partir de 1917, les publications cessent, malgré la poursuite des fouilles ${ }^{149}$. En devenant Surintendant, A. Maiuri a concilié dans un premier temps les différentes formes de publication: d'une part des comptes rendus synthétiques réguliers, d'autre part des articles sur des points précis, associés à des ouvrages plus généraux à diffusion plus ample. Jusqu'en 1939, l'avancée des fouilles de Pompéi est régulièrement décrite dans les NSc. Après guerre, la publication perd toute régularité et seuls les articles sur les inscriptions dus à M. Della Corte permettent d'obtenir quelques informations sur les lieux alors fouillés.

147 Dans certains ouvrages ou articles traitant de Pompéi, A. Maiuri utilise parfois des exemples concernant Herculanum. Ces données sont tirées de la Nova Bibliotheca Pompeiana, (García y García 1998).

${ }_{148}$ Sur les vicissitudes de la carrière de V. Spinazzola, cf. Delpino 2001.

${ }^{149}$ Cet arrêt de la publication des rapports de fouille aurait largement contribué à l'éviction de V. Spinazzola de la Surintendance. Le reproche transparaît aussi bien dans un mémoire inédit de $\mathrm{M}$. Barnabei, cité par F. Delpino (2001: 51), que dans le témoignage des conversations entre A. Maiuri et V. Spinazzola: "[Spinazzola] non aveva altro pensiero che quello di pubblicare i suoi scavi di Pompéi, quegli scavi che, tenuti gelosamente segreti, non erano stati ultima causa della sua disgrazia» (Maiuri 1958a: 221).

${ }^{150}$ Sur ce point, je me contenterai de citer le discours prononcé par B. Mussolini à la Società Romana di Storia Patria le 9 avril 1927, tel qu'il a été traduit et commenté par R. Cagnat: «Les fouilles devront être au fur et à mesure photo-
La situation pour Herculanum n'a rien de comparable. Si, dès l'annonce de la reprise des fouilles, des déclarations solennelles ont été prononcées quant à la nécessité de notifications régulières, elles n'ont guère été suivies d'effet ${ }^{150}$. Les seules informations périodiques se font par le biais de télégrammes envoyés aux rédactions des journaux italiens et étrangers, éventuellement repris par eux, particulièrement dans les premiers temps, quand il est encore nécessaire de justifier la reprise des fouilles. Tout au long des années 1932-1958, des ouvrages généraux et des guides donnant une vision aussi complète que possible du site ont été publiés et régulièrement mis à jour. Il faut attendre 1938 pour qu'un article scientifique concerne les fouilles en cours, en traitant de la fresque insérée dans un cadre en bois, découverte en V, 18 $8^{151}$. Les autres publications, rédigées entre 1927 et 1938, se concentrent essentiellement sur les techniques de fouille et de restauration, sans aborder dans le détail ce qui a été mis au jour. L'organigramme de l'archéologie campanienne à cette époque pourrait offrir une explication à cette absence de comptes rendus réguliers: à partir de la création de la charge de Surintendant en 1806, Pompéi a toujours bénéficié de directeurs locaux - ou d'architectes - se consacrant uniquement aux fouilles; à Herculanum, la fouille a directement dépendu d'A. Maiuri, sans directeur scientifique présent en permanence sur le chantier ${ }^{152}$. Bien que cette situation soit largement liée à des contingences administratives, elle montre également la forte implication personnelle du surintendant dans ces fouilles ${ }^{153}$.

graphiées, commentées et publiées. C'est un ordre précis que je donne à ceux qui sont préposés aux fouilles, afin d'éviter ce dont beaucoup se sont plaints à Pompéi, où les ruines et les peintures se sont détériorées si souvent sans avoir reçu une illustration suffisante. Voilà qui est parler» (Cagnat 1927: 103). Dans les premiers articles qu'il a écrits après la reprise des fouilles, A. Maiuri reprend cette annonce de publication rapide et régulière (e.g. Maiuri 1927 a: 243; 1927 b).

${ }^{151}$ Maiuri 1938.

${ }^{152}$ Les différentes données concernant les Surintendants et directeurs locaux proviennent de la liste dressée par L. García y García (1998: 63-65), complétée avec celle donnée par A. Maiuri (1948: 40-41). Le premier directeur d'Herculanum est Giuseppe Maggi (1953-1960).

${ }^{153}$ Le fait qu'Herculanum ait été le domaine réservé d'A. Maiuri pourrait également transparaître dans le décalage entre la reprise des fouilles et la première visite de M. Della Corte pour y étudier les inscriptions, qui se déroule le 30 septembre 1929 (Della Corte 1958: 241). 
Toutefois, les retards qui ont affecté la publication des nouvelles découvertes n'ont pas complètement exclu la communication de données à la communauté scientifique. Il ne semble pas qu'A. Maiuri ait cherché à conserver l'exclusivité du résultat de ses fouilles en refusant de communiquer des informations de détail sur certains aspects. Je rappellerai ainsi tant les photos envoyées à M. Rostovtzev que la plaque concernant la propriété des murs, publiée par H.-I. Marrou et J. Meyerovitch ${ }^{154}$. Dans ce dernier cas, l'inscription est inédite et ses éditeurs indiquent clairement dans leur texte qu'ils ont pu la voir en se rendant sur place. En définitive, un seul débat a concerné les nouvelles fouilles, autour de la mise au jour d'une supposée «croix » dans la Casa del bicentenario (V, 15-16) ${ }^{155}$.

Malgré les lacunes constatées dans la publication scientifique et détaillée des résultats - notamment par rapport aux déclarations effectuées à la reprise des fouilles - je ne puis qu'insister sur ce dernier point: pendant toute la période durant laquelle il a dirigé l'archéologie campanienne, A. Maiuri n'a eu de cesse de chercher à diffuser son savoir à un public situé hors des sphères académiques ${ }^{156}$.

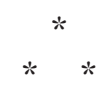

Les paragraphes qui précèdent pointent tous vers la nécessité d'utiliser les journaux de fouille, source archivistique "neutre», ou en

${ }^{154} A E 1937,176=A E$ 1945, 95: Iuliae pari[es]/privat(us) perpetuus // M(arci) Noni M(arci) l(iberti) Dama[e] / paries perpetuus priv(atus).

Cette inscription a été mise au jour sur le toit de la Casa del telaio $(\mathrm{V}, 3)$, le 3 février 1931. Il est probable qu'elle a été fixée sur la face sud de la Casa del mobilio carbonizzato (V, 5). Cf. Marrou 1937 et Marrou-Meyerovitch 1942.

${ }^{155}$ Sur le point de départ de ce débat, voir la communication d'A. Maiuri (1939) à la Pontificia Accademia Romana di Archeologia. Pour ses développements, on se reportera préférentiellement à la bibliographie sur Herculanum (McIlwaine 1988: 494-504).

${ }^{156}$ Sur cette volonté revendiquée de diffuser aussi largement que possible les résultats acquis par ses fouilles, cf. e.g. Maiuri 1933: 251.

${ }^{157}$ Le Giornale dei lavori, dont la consultation permet de suivre les travaux de restauration, n'est conservé à tout cas moins marquée par les dévoiements des écrits d'A. Maiuri. Si la publication intégrale de ces comptes rendus ne saurait trouver sa place dans cet ouvrage, il est impératif, pour mettre en évidence leur richesse, leur densité mais aussi leur difficulté d'utilisation, de développer un exemple précis et de le confronter aux données proposées par A. Maiuri sur le même cas. Parmi les différents édifices mis au jour à Herculanum, la Casa a graticcio (III, 13-15) est l'un de ceux dont la chronologie de la fouille est particulièrement ardue à établir. En effet, au contraire de la Casa dell'albergo, de la Casa dello scheletro ou de la Casa del tramezzo di legno, cette maison n'a pas été partiellement dégagée lors des fouilles de G. Fiorelli. Il s'agit donc de la première maison à être mise au jour intégralement, parfois dans plusieurs directions, depuis de la reprise des fouilles. De plus, du fait même de son mode de construction - la définition des pièces est assurée par des cloisons en pan de bois hourdé appuyées sur une armature de piliers maçonnés - faiblement préservé à Pompéi, cette maison a servi à la fois de laboratoire de restauration et de vitrine pour les Nuovi Scavi. En revanche, les archives concernant la maison sont incomplètes ${ }^{157}$.

La mise au jour de la Casa a graticcio a commencé le 30 août 1927, depuis la Casa dello scheletro $^{158}$. Les premières pièces découvertes sont celles numérotées de 11 à 15 (GSE M et F; fig. 4$)^{159}$. Pour faciliter l'accès aux pièces dans lesquelles sont disposées des vasques maçonnées, un mur est abattu ${ }^{160}$. La fouille progresse

Herculanum qu'à partir de 1929, alors que la Casa a graticcio est déjà complètement fouillée et restaurée.

${ }^{158}$ Les fragments de parois mentionnés dans les relations du 30 août et du 2 septembre 1927, bien que trouvés à l'aplomb de la pièce 11 de la Casa a graticcio, appartiennent à la Casa dello scheletro. Pour ne pas alourdir les notes, seuls les passages des GSE les plus importants pour mon raisonnement y sont reportés. La publication de l'intégralité des journaux de fouilles est en cours de préparation.

${ }^{159}$ Pour éviter toute incompréhension dans cette réalité mouvante que constitue la numérotation des pièces, j'ai indiqué entre parenthèse le numéro attribué dans les GSE au moment de la fouille. Les numéros définitifs utilisés sont ceux donnés par A. Maiuri (1958: fig. 345 p. 407, fig. 354 p. 416), complétés pour éviter l'emploi de lettres. Les différentes numérotations sont rassemblées sur la fig. 13, p. 33.

${ }^{160}$ GSE 1927: 10 ottobre. 


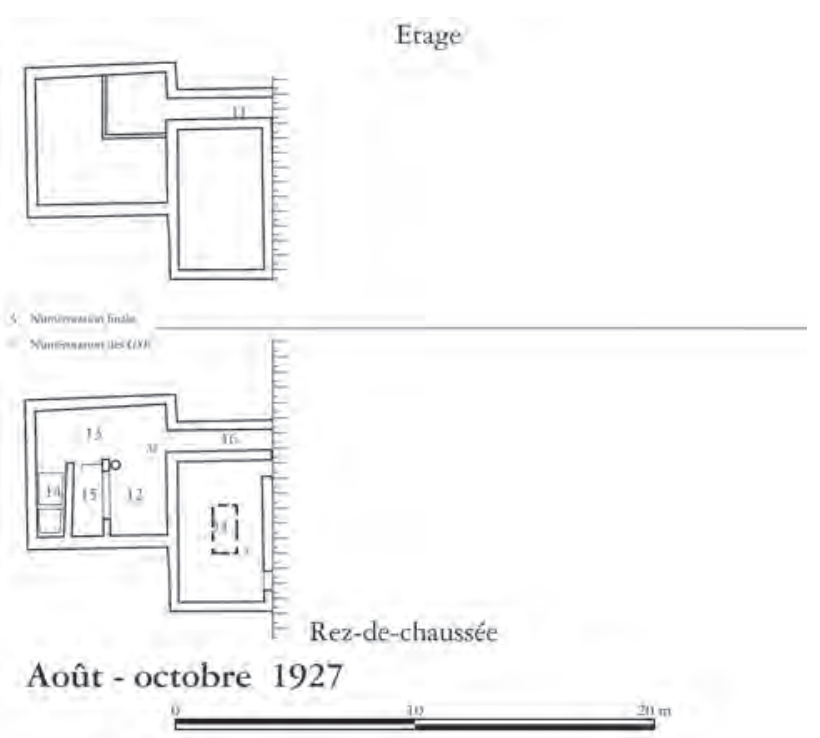

Fig. 4 - Avancée de la fouille de la Casa a graticcio entre août et octobre 1927.

alors d'est en ouest. Un plafond est mis au jour dans la pièce 11 (GSE F) mais, suite aux dégâts causés par l'éruption, seuls ses fragments sont recueillis $^{161}$. Le 9 novembre 1927, la fouille cesse dans la Casa a graticcio. Elle n'est reprise qu'en février 1928, en provenant du sud cette fois, après avoir mis au jour les portions occidentales des Case dell'ara laterizia (III, 17) et dell'erma di bronzo (III, 16) (fig. 5). Durant cette période, et sans qu'il soit possible de préciser quand, le système de numérotation des pièces

161 GSE 1927: "26 ottobre. [...] S'è incominciato lo svuotamento di quello immediatamente dopo che porta il numero F. [...] Alla distanza di m. 1.30 dalla parete sud e m. 1 da quella ovest sono stati rinvenuti: Due piedi di letto di bronzo. Uno è ben conservato e misura m. 0.28 di altezza, mentre l'altro è ridotto in frantumi. Inventario n. 76. Alla distanza di m. 1.60 dalla parete ovest, a m. 1.62 da quella sud si sono rinvenuti altri frammenti di piedi di letto. Una quantità di battuto di calcestruzzo che formava la copertura dell'ambiente sono stati raccolti e depositati ». A. Maiuri (1958 b: 414) décrit cette pièce de cette façon: «[...] Il grande ambiente n. 11 [...] non è che un residuo di un più nobile edificio preesistente. Nell'ultimo rifacimento della casa questo ambiente, abbandonato senza copertura doveva ancora avere sua destinazione».

${ }^{162}$ Il est possible que le début de l'utilisation des chiffres ait été antérieur au 1 ${ }^{\text {er }}$ février 1928 (GSE 1928: "1 febbraio. Completato lo svuotamento della parte alta dell'ambiente precedente 'mancante di numero o di lettera' si è passato all'altro ambiente che trovasi alle spalle nord dell'ambiente

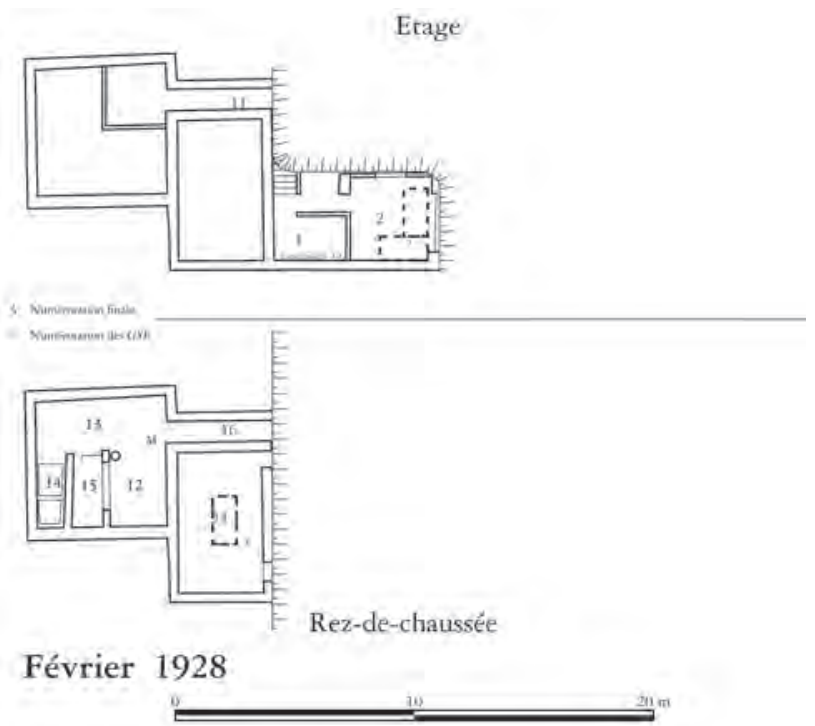

Fig. 5 - Avancée de la fouille de la Casa a graticcio en février 1928.

change: les pièces de la portion nord-orientale de l'insula III ne sont désormais plus indiquées par des lettres mais par des chiffres ${ }^{162}$. La pièce 1 de l'étage est la première à être mise au jour - les 13, 14, 15 et 20 février 1928 - suivie de peu par la pièce 2 - à partir du 16 février ${ }^{163}$. Dans le premier espace, seules une armoire fixée au mur et une table en marbre sont découvertes ${ }^{164}$. En revanche, dans le second, lors de cette première partie de la fouille, deux armoires - ne contenant que des objets d'usage domestique - puis

lettera $\mathrm{B}[\ldots]$ »). La première attestation d'une pièce numérotée date du 6 mars 1928. Ce changement paraît être lié au tarissement des lettres disponibles (la pièce Y, probablement située dans la Casa dell'erma di bronzo est mentionnée le 28 mars 1928). L'absence de numérotation pour les pièces 1 et 2 de la Casa a graticcio au moment de leur fouille pourrait indiquer une période de flottement ou de transition entre les deux systèmes de repérage des pièces.

${ }^{163}$ GSE 1928: "13 febbraio. Lo sterro è stato ripreso con 24 persone. Nell'ambiente che trovasi alle spalle lato est di quello segnato con la lettera $\mathrm{F}$ le pareti sono dipinte in rosso con decorazioni di festoni di fiori, prospettive, cavalli marini, sfingi eccetera $[\ldots]$

16 febbraio. È incominciato lo sterro del piano superiore del secondo ambiente, anche situato al lato est dell'ambiente lettera $\mathrm{F}[\ldots]$ ».

${ }^{164}$ Sur l'armoire, cf. Mols 1999: cat. n³5. La plaque de marbre a été trouvée en plusieurs morceaux le 14 février 1928. Son pied, également en marbre n'est mentionné et inventorié (Inv. n E190=75466) que le 20 février 1928. 


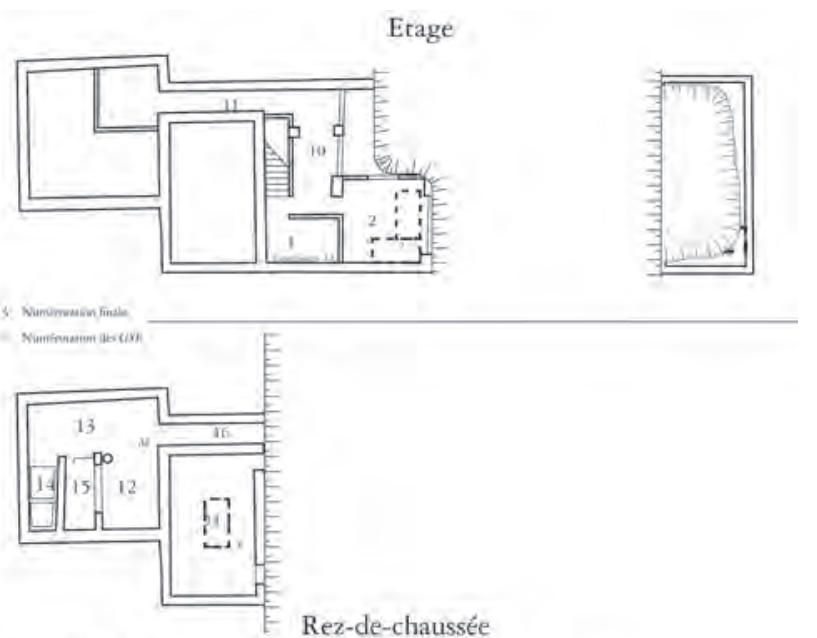

Mars 1928

Fig. 6 - Avancée de la fouille de la Casa a graticcio en mars 1928.

deux lits sont mis au jour ${ }^{165}$. Le 20 février 1928, la fouille de la portion occidentale de l'étage est achevée, laissant la place aux travaux de restauration $^{166}$. En mars, c'est le côté oriental de la maison qui est fouillé, suite au dégagement du

${ }^{165} \mathrm{La}$ découverte et la fouille de la première armoire se déroulent le 16 et le 17 février 1928. Elle se trouve dans l'angle sud-ouest de la pièce. La seconde armoire, située en hauteur sur la paroi occidentale est découverte le 17 février et vidée le lendemain. Les lits sont également décrits le 18 février 1928, et photographiés le 20 février (cf. cliché Archivio fotografico SANP, EC 33 (ex E44), pris du nordest).

166 Le 5 mars 1928, une entrée des GSE signale le démontage du lit situé le plus à l'est dans la pièce 2 pour restaurer le pavement.

${ }^{167}$ GSE 1927 : « 20 dicembre. Il cavo aperto nel secondo cardine misura m. 10 per 17 di lunghezza [...]».

${ }^{168}$ GSE 1928: 12 marzo. L'interprétation de ce passage comme se rapportant au balcon de la Casa a graticcio ne fait aucun doute. Lors de la reprise tardive de sa fouille, deux lits y sont découverts. Leur position est donnée par rapport à la rue et non au pavement de la maison (GSE 1928: " 12 dicembre. Nell'ambiente n. 18 dello scavo C piano superiore a m. 0.84 dalla parete sud, a m. 2.35 dall'estremità est, a m. 2.50 dal pavimento della strada, è apparso una parte di letto carbonizzato. [...] Un secondo letto trovasi in senso opposto al primo, e cioè ovest est non è ancora sterrato»). Cette forme d'indication de la hauteur n'est normalement utilisée que lorsque le sol de la maison n'a cardo IV, commencé en décembre 1927 (fig. 6) ${ }^{167}$. La première pièce mise au jour de ce côté de la Casa a graticcio correspond à son balcon sur la rue. C'est ici que la distorsion entre les données de fouilles et la restauration effectuée ensuite est la plus importante. En effet, les dimensions du balcon observées lors de sa découverte font qu'il déborde largement sur la rue: long de 7,70 mètres - soit la largeur de la Casa a graticcio -, il est large de 3,35 mètres, soit une extension de 1,35 au-dessus de la rue en débord du trottoir (fig. 7):

La parte superiore dell'ambiente n. 18 è stata svuotata. La stanza o terrazza è di forma rettangolare e misura $m$. 7. 70 di lunghezza per $m$. 3.35 di larghezza. Al lato nord sulla parete si nota un finestrino che è alto dal pavimento m. 0.74 e misura m. 0.94 di larghezza, l'altezza attuale è di m. 1.05 però è ancora più alto dato che le mura sono abbattute ${ }^{168}$.

Une fois les restaurations effectuées, la largeur du balcon est réduite à 1,90 mètre:

[...] Una terrazza che poggia sopra tre colonne di mattoni lunga $m$. 7,45 e larga $m$. 1.90 permette di affacciarsi sul $2^{\circ}$ cardine $[\ldots]^{169}$.

Ce débordement sur la rue, qui est parfaitement fonctionnel d'un point de vue architectural, est la seule solution envisageable pour

pas encore été dégagé. De plus, le jeu des renvois vers des descriptions précédentes lors de la mise au jour de la façade indique clairement que la pièce 18 n'est autre que le balcon se développant en façade. GSE 1928: « 28 dicembre. Al lato sinistro del vano numero 13 dello scavo del II [IV] cardine è apparso un sedile in muratura [...]. A m. 1.35 di lunghezza dalla soglia del vano numero 14 è apparso un altro sedile anche in muratura [...]. All'estremità sud di quest'ultimo sedile si nota un incasso di colonna [...] e poiché a m. 1.35 distante dal vano numero 13 sul pavimento del marciapiede si nota l'impronta di un'altra colonna [...] è certo che le colonne di mattoni si dovevano elevare fino all'altezza dei vani 13,14 e 15 . Un architrave dello stesso spessore di quello di fronte e cioè di m. 0.16 doveva adagiarsi sopra esse e questo serviva per sostenere il prolungamento dei travi della terrazzina o balcone 'descritta il $3 c$ [orrente] $m$ [ese]'»; GSE 1928: " 3 dicembre. L'architrave descritto il giorno 1 $c$ [orrente] $m$ [ese] è lungo m. 7. 60. I travicelli che sostenevano il battuto della terrazzina sono 16 dello spessore di $\mathrm{m}$. 0.15 per 0.13 [...]»; GSE 1928: "1 dicembre. L'architrave che sosteneva la terrazzina numero 18 dello scavo $C$ è alta $\mathrm{m}$. 0.35 , lo spessore è di $\mathrm{m}$. 0.16 la lunghezza non è ancora nota perché non del tutto sterrata $[\ldots]$ ».

169 GSE 1929: 23 febbraio (description finale de la maison une fois les restaurations achevées). 

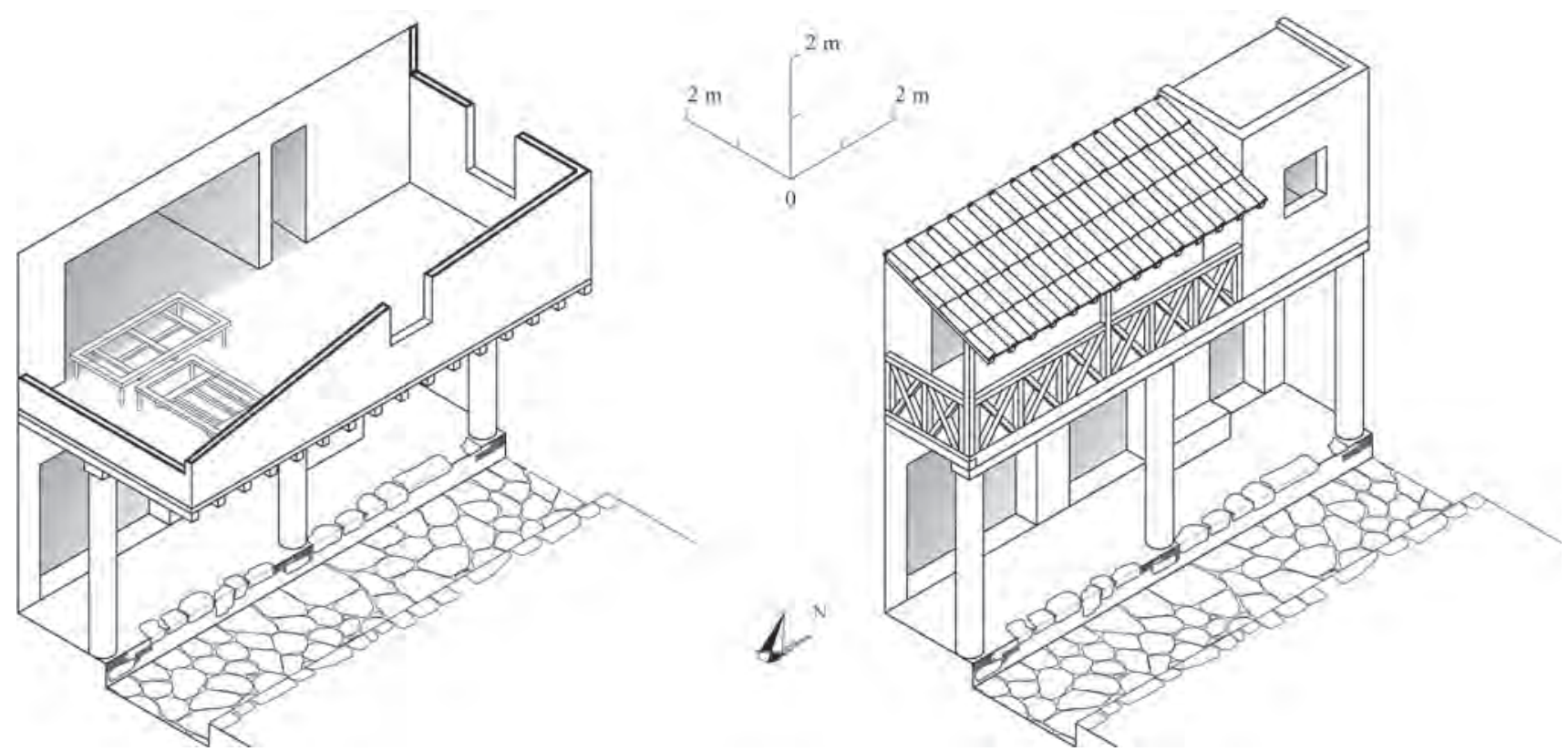

Fig. 7 - Restitutions isométriques de la façade de la Casa a graticcio. À gauche, l'extension de la terrasse et la position des lits correspondent aux descriptions données dans les journaux de fouilles. La portion septentrionale du mur ouest a été laissée aveugle faute d'indication quant à la localisation de la porte donnant accès aux autres pièces de l'appartement occidental. À droite, la restitution suit les restaurations effectuées après la fouille (échelle: 1/150).

faire correspondre les dimensions données par les $G S E$ avec les enduits peints de l'appartement oriental: il est improbable que ces derniers aient été retaillés et donc que les dimensions des pièces 3, 4 ou 5 aient été modifiées. Le balcon (GSE 18 sup) se développe intégralement au-dessus du trottoir et déborde sur le cardo $\mathrm{IV}^{170}$.

Après le dégagement partiel de ce balcon, les périodes de fouille dans la Casa a graticcio tendent à s'espacer, que ce soit en raison des travaux de restauration qui y sont probablement effectués ou du développement de la fouille dans d'autres secteurs (fig. 8). La pièce 4 de l'étage (GSE 7 sup) n'est mentionnée qu'une fois, pour signaler qu'elle a été vidée et qu'un lit y a été découvert ${ }^{171}$. La seule difficulté concernant cette période est liée à l'éventuel oubli de mentionner si la fouille se déroule à l'étage ou non. Ainsi, le surlendemain de la fin des travaux dans la pièce 4

${ }^{170}$ Il serait certainement nécessaire d'utiliser cet exemple pour modifier les restitutions proposées pour la plupart des étages d'Herculanum. En effet, comme le fait remarquer A. Maiuri (1958 b : 46-49), les portiques de rue sont beaucoup plus nombreux à Herculanum qu'à Pompéi. En l'absence de colonnes pour soutenir l'avancée sur la rue, l'étage ne paraît pas se développer au-delà de la verticale du trottoir. En ce

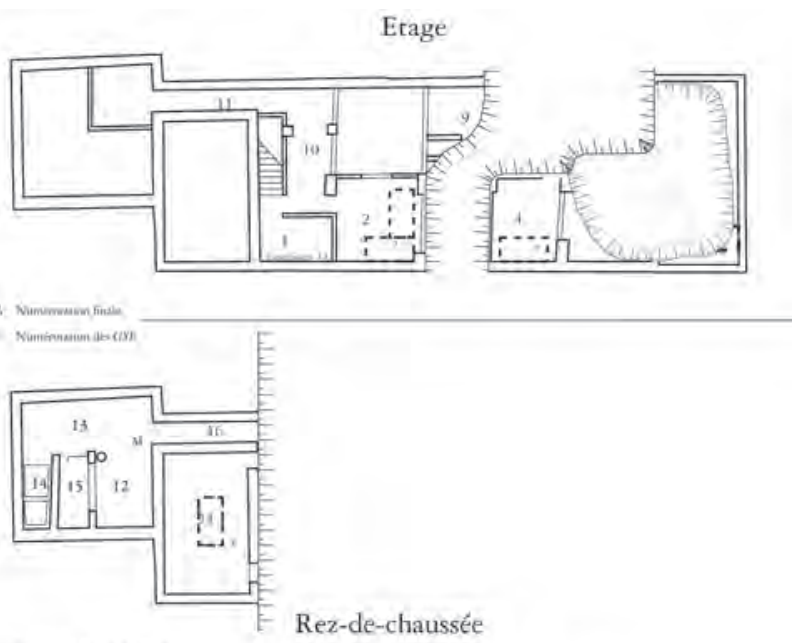

Avril 1928

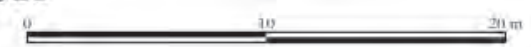

Fig. 8 - Avancée de la fouille de la Casa a graticcio en avril 1928.

sens, les colonnes et piliers soutenant ces balcons engagés sur la rue n'auraient d'utilité que pour accroître la portée de l'avancée au-dessus de la voie proprement dite. De cette façon, les rues présentant des colonnes sur chacun de leurs côtés - comme le tronçon septentrional du cardo IV entre les îlots V et VI - devaient être particulièrement sombres.

${ }^{171}$ GSE 1928: 17 aprile. 


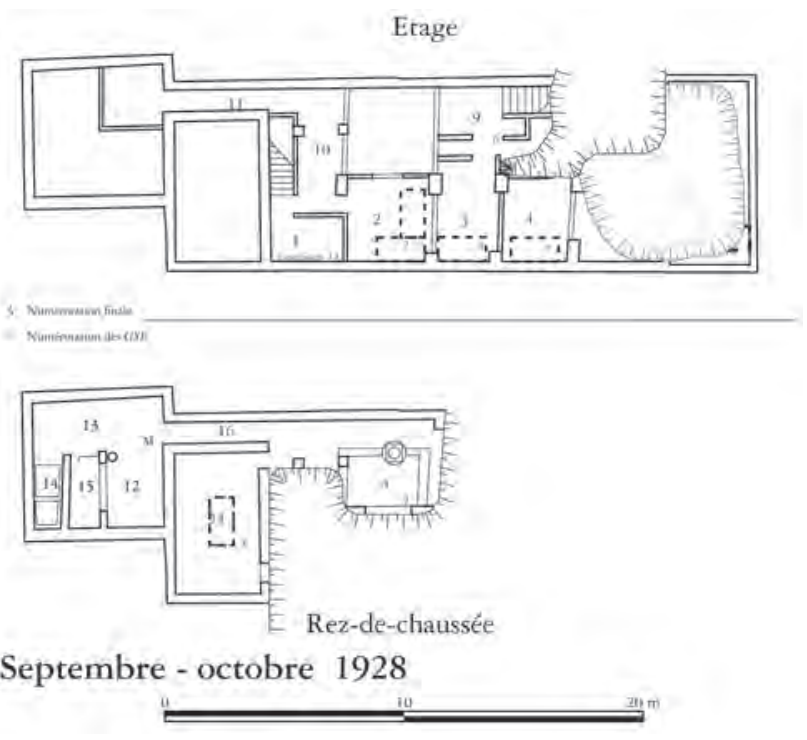

Fig. 9 - Avancée de la fouille de la Casa a graticcio entre septembre et octobre 1928.

(GSE 7 sup), un ambiente 6 est mentionné, sans autre spécification ${ }^{172}$. Bien que les numéros de (GSE) 1 à 7 aient été utilisés pour désigner les pièces de l'étage et du rez-de-chaussée de la Casa a graticcio, rien ne permet de supposer un changement de numérotation en cours de fouille. Ma restitution de l'avancée des travaux interdit que la pièce $6 \mathrm{du}$ rez-de-chaussée ait alors pu être mise au jour: elle se situe en dessous de la pièce 3 de l'appartement oriental, qui n'est fouillée qu'en septembre 1928. Il faut donc considérer que cette pièce GSE 6 [sup] correspond à la pièce 9 de l'étage. La même interprétation peut être proposée pour la pièce 8 de l'étage (GSE 5 [sup]), pour laquelle la distinction entre l'étage et le rezde-chaussée n'apparaît que le 17 octobre 1928.

Du 22 au 29 septembre puis entre le 4 et le 16 octobre 1928, les travaux de dégagement se

${ }^{172}$ GSE 1928 : « 19 aprile. Nell'ambiente n. 6 dello scavo C, sul pavimento a m. 1.70 dalla parete ovest, a m. 1.30 da quella sud si è trovato $[\ldots]$ ».

${ }^{173}$ GSE 1928 : « 4 ottobre. [...] Nello smontare l'armadio a muro che si trova nell'ambiente $n$. 3 piano superiore dello scavo C tra il letto e la parete est del suddetto armadio sul pavimento si è raccolto: [description d'une statuette en bronze représentant Mars, Inv. ${ }^{\circ}$ E318=75594]».

${ }^{174}$ Cf. GSE 1928: 9, 17 novembre. Statuettes inventoriées sous les numéros suivants: E343=75619 (Jupiter); E344=75620 (Abondance); E345=75621 (Esculape?);
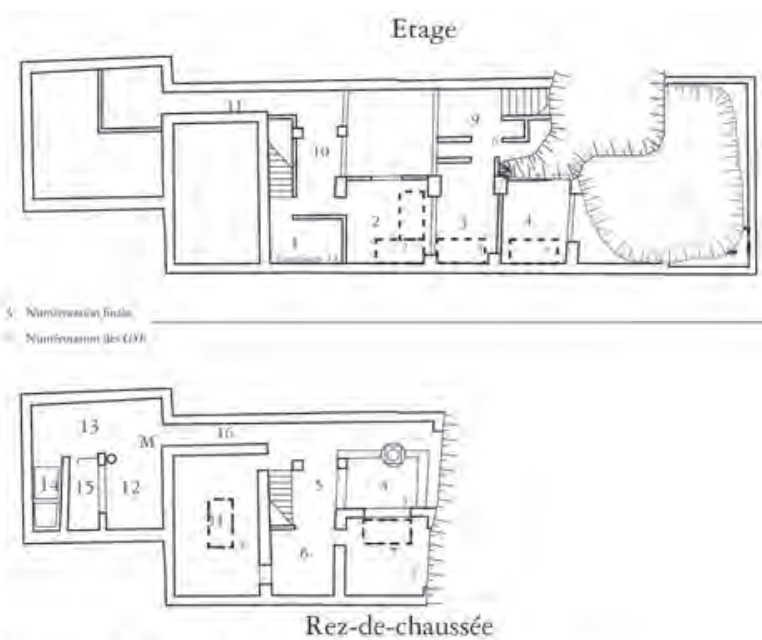

Novembre 1928 Fig. 10 - Avancée de la fouille de la Casa a graticcio en

déroulent entre les pièces 3,8 et 9 de l'étage (fig. 9). Durant cette période, le fait saillant reste la mise au jour d'une armoire - renfermant des statuettes liées au culte domestique - dans la pièce 3 , ainsi que d'un lit, qui n'est toutefois mentionné qu'incidemment ${ }^{173}$. Il faut attendre le mois de novembre pour que le rez-de-chaussée commence à être dégagé, alors que l'étage n'est pas complètement libéré du matériel éruptif (fig. 10). Un orage survenule 9 novembre accélère le démontage de l'armoire de la pièce 3 , permettant de mettre au jour neuf nouvelles statuettes, deux représentant les Lares, deux l'Abondance, les cinq dernières étant de probables Pénates Jupiter, Esculape, Diane, Minerve et Harpocrate, si l'on suit les interprétations proposées dans les $G S E^{174}$. Avec cette découverte, la fouille de l'étage est quasiment achevée. Elle n'aboutira véritable-

$\mathrm{E} 346=75622$ (Diane); E347=75623 (Lare); E348=75624 (Lare); E349 $=75625$ (Lare); E350 $=75626$ (Abondance); E351=75627 (Minerve); E352=75628 (Harpocrate?). Dans sa description des statuettes trouvées dans cette armoire, A. Maiuri (1958 b : 347), ne mentionne pas celle de Mars (cf. note précédente): il n'était présent que lors de la découverte des huit énumérées ci-dessus (GSE 1928: «17 novembre. Alla presenza del soprintendente oggi si è rotto il piccolo armadio a muro che fu trovato nella stanza numero 3 piano superiore dello scavo $\mathrm{C} »)$. 

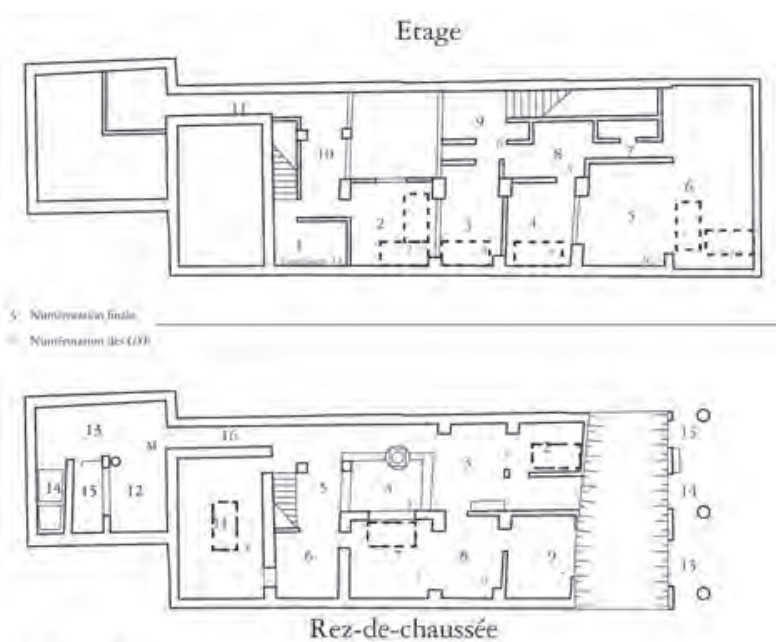

Décembre 1928

Fig. 11 - Avancée de la fouille de la Casa a graticcio en décembre 1928.

ment que durant le mois de décembre, une fois dégagée la cuisine de la pièce 8 (GSE 5 sup) et l'exhumation des deux lits provenant du balcon complétée $^{175}$. Le 19 novembre, la pièce 7 (GSE 3) du rez-de-chaussée est complètement mise au jour. Si rien ne permet de déterminer la date de la fouille des pièces 5 et 6 , il faut considérer qu'elles ont été dégagées avant la fin du mois de

\footnotetext{
${ }^{175}$ Deux lits sont mentionnés dans la description effectuée le 12 décembre 1928 (GSE 1928: 12 dicembre, cit. supra, n. 168). Pourtant, un troisième lit est indiqué lors du démontage final qui a lieu en janvier 1929 (GSE 1929: «9 gennaio. Il $3^{\circ}$ letto accennato il giorno $12.12 \mathrm{~s}$ [corso] $\mathrm{a}[\mathrm{nno}]$ è stato sterrato [...]»). Le renvoi à la description effectuée le 12 décembre - où seuls deux lits sont mentionnés - semble indiquer une erreur d'écriture.

176 GSE 1928: "19 novembre. L'ambiente n. 3 piano terraneo dello scavo $\mathrm{C}$ è stato svuotato. [...] Al lato nord vi è la finestra descritta il giorno 6 [8 août 1928 ?]. [...] Al lato nord dell'ambiente trovasi un avanzo di letto di legno carbonizzato. La larghezza è di $\mathrm{m}$. 1, la lunghezza attuale di m. 0.90 (era ancora più lungo) l'altezza è di m. 0.70 . Si osservano ancora i due piedi anteriori che sono alti m. 0.50 . Essi sono di forma quadrata e misurano m. 0.07 per lato. All'altezza di m. 0.70 si innestano ad essi due traverse larghe m. 0.03 e alte m. 0.03. Due traverse si sviluppano sopra i due laterali quella al lato est è ancora in sito e misura m. 0.185 di altezza per m. 0.02 di spessore, al lato sud è mancante ma si nota però l'incasso nel piede che doveva racchiudere la tavola in parola. È completamente mancante sia il lato
}

novembre. Sous la fenêtre s'ouvrant sur le puits de lumière 4 , un lit est découvert. Sa description ne paraît pas laisser de doute quant à l'interprétation proposée par les rédacteurs des journaux de fouilles ${ }^{176}$.

Entre décembre et janvier 1929, toutes les autres pièces du rez-de-chaussée sont dégagées, fouillées alternativement par l'ouest et par l'est (fig. 11). Dans ce secteur, on relève une légère confusion. Deux pièces GSE 5 sont individualisées au rez-de-chaussée. La première, dont la fouille est achevée le 11 décembre 1928, correspond à la pièce $3^{177}$; la seconde, soit à la pièce 2 , soit à la pièce 17: le 18 décembre, les pièces GSE 5 et 5 bis sont décrites successivement, sans que leur numéro ne soit spécifié. Cette erreur est gênante pour déterminer l'origine des objets mis au jour les 17 octobre et 7 novembre 1928. Toutefois, il me semble possible de les attribuer à la pièce 3 en raison de l'avancement de la fouille d'ouest en est dans cette partie de la maison. Notons également la présence d'un lit dans la pièce 2 qui était fermée par une porte en bois ${ }^{178}$. Enfin, la dernière découverte notable provient de la boutique III, 15. Il s'agit d'un treuil en bois, trouvé en plusieurs fragments, associés à 4 mètres de corde carbonisée ${ }^{179}$. Le 14 janvier 1929, avec la mise au jour de l'escalier extérieur permettant d'accéder à l'appartement oriental, la Casa a graticcio est intégralement dégagée. La restauration, très certaine-

nord che quello ovest. Il letto dalla parete nord dista m. 0.14 e da quella est m. 0.35 [...]».

177 GSE 1928: "11 dicembre. [...] Anche l'ambiente n. 5 dello stesso scavo è stato svuotato. Misura m. $2.30 \mathrm{di}$ larghezza per m. 3.85 di lunghezza. Al lato ovest è apparso un sedile di muratura [...]. Al lato sud del medesimo ambiente si trova un altro sedile $[\ldots]$ ». Ces deux bancs maçonnés sont toujours visibles dans la pièce 3 .

${ }^{178}$ GSE 1928: " 18 dicembre. L'altro ambiente è largo m. 2.05 e lungo m. 3.45. La soglia è di marmo bianco [...]. A m. 2.30 dalla soglia aderente alla parete sud dell'ambiente è stata trovato un avanzo di letto di legno carbonizzato [...]. Il vano è largo m. 1.52, ed alto m. 2.20. Anche questo vano teneva un avanzo di porta di legno carbonizzato ».

${ }^{179}$ GSE 1929: « 5 gennaio. [...] A m. 1.90 dall'estremità della soglia del vano n. 15 , a m. 1.15 dalla parete nord, ed a m. 0.90 di altezza dal pavimento della casa è stato raccolto: Vegetale. Corda carbonizzata m. 4.00, spessore m. 0.017. Inventario n. [E]393[=75669]. All'estremità di un capo di un nodo notasi un pezzo di legno carbonizzato a guisa di pinoli. [...] Si spera di poterne ricavare tutti i pezzi, per poterlo ricostruire». 


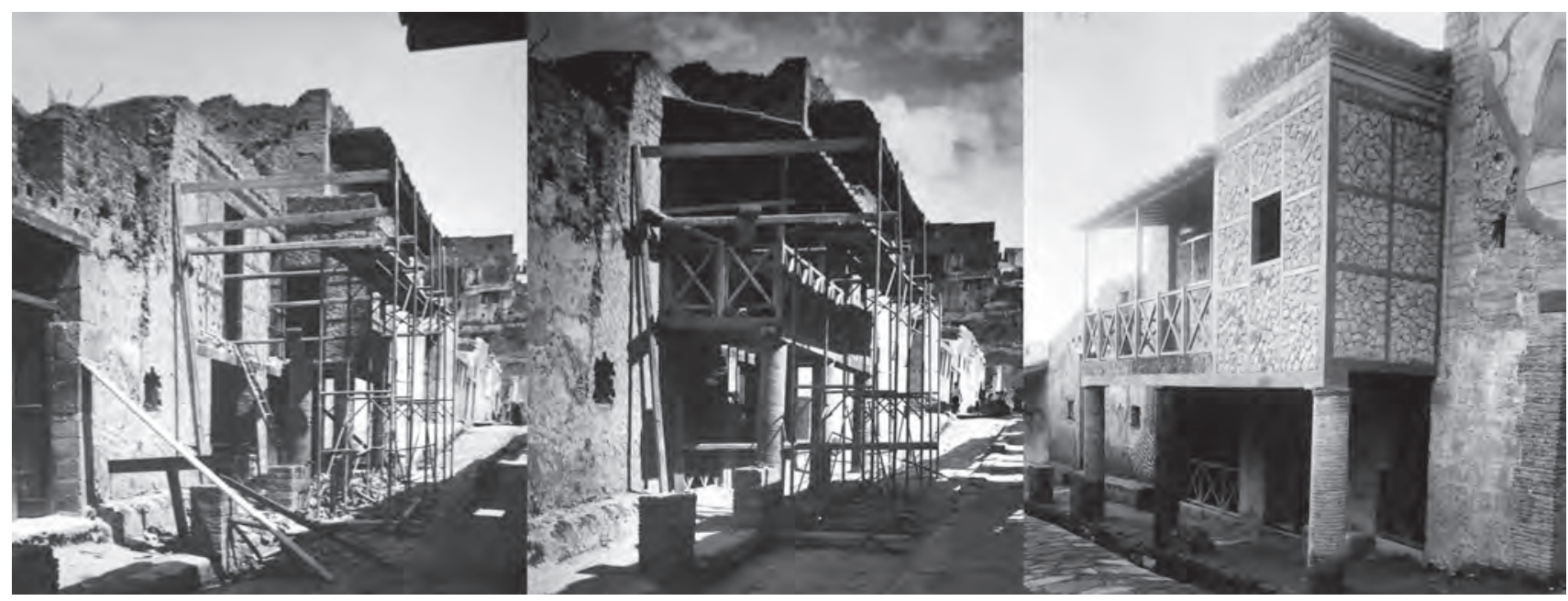

Fig. 12 - Les différentes étapes de la reconstruction de la Casa a graticcio en 1929.

ment effectuée par endroits au fur et à mesure de la fouille, peut être achevée (fig. 12).

Il faut toutefois attendre le 23 février 1929 pour que les GSE indiquent la fin du dégagement, qui correspond en fait à la fin des travaux de restauration. L'entrée rédigée à cette date est plus une description de la maison telle qu'elle a été reconstruite qu'une véritable synthèse des journaux de fouilles. En effet, bien que la découverte de certains objets et meubles soit mentionnée, leur position dans la maison ne correspond pas à ce qui a pu être indiqué dans les GSE. Comme je l'indiquais précédemment, la largeur du balcon donnant sur la rue a été réduite d'environ 1,40 m (fig. 7). Des lits ont été déplacés à l'étage (fig. 13): les pièces 1 et 5 qui n'en comportaient pas lors de la fouille disposent alors respectivement d'un et deux lits, tandis que les pièces 3 et 4 en sont désormais dépourvues ${ }^{180}$. Les statuettes découvertes dans l'armoire de la pièce 3 , appartenant à l'appartement oriental, sont indiquées comme provenant de la pièce 2 de l'appartement occidental ${ }^{181}$.

${ }^{180}$ Pour la pièce 4, l'état dans lequel le lit a été découvert paraît avoir interdit sa restauration (GSE 1928: 17 aprile).

${ }^{181}$ Cette distorsion entre la description d'A. Maiuri et le compte rendu des GSE a déjà été relevée par S. Mols (1999: 244).

${ }^{182}$ Maiuri 1958 b: 407-420. Cette description de la Casa a graticcio est organisée comme suit: réflexions générales
Ces distorsions sont encore accentuées par la description que propose A. Maiuri dans sa publication des fouilles. Après une longue description de l'usage de l'opus craticium, destinée à mettre en avant non seulement la conservation exceptionnelle d'Herculanum mais aussi l'usage certainement très développé de ce mode de construction, A. Maiuri décrit l'ensemble de cette maison. Il commence par la façade, puis procède pièce par pièce, d'abord au rez-de-chaussée puis à l'étage ${ }^{182}$. L'un des points très rapidement souligné est que l'ensemble de l'édifice était divisé entre deux locataires, l'un occupant le rez-de-chaussée et l'appartement situé à l'arrière de l'étage, accessible depuis la cour 4 , le second ayant à sa disposition l'appartement situé en façade, en empruntant l'escalier III, $13^{183}$. Dans sa description, oubliant les pieds de lits et les fragments de plafond découverts dans la pièce 11, il estime qu'elle était dépourvue de toiture. Il indique la présence de sept lits. Au rez-de-chaussée, un seul aurait été mis au jour dans la pièce 2 , qualifiée de «rustico cubicolo».

sur l'emploi de l'opus craticium p. 407-410; description de la façade, p. 410-411; description pièce par pièce du rez-dechaussée, p. 412-416; description pièce par pièce de l'étage, p. 416-420.

${ }^{183}$ Maiuri 1958 b : 410-411. 


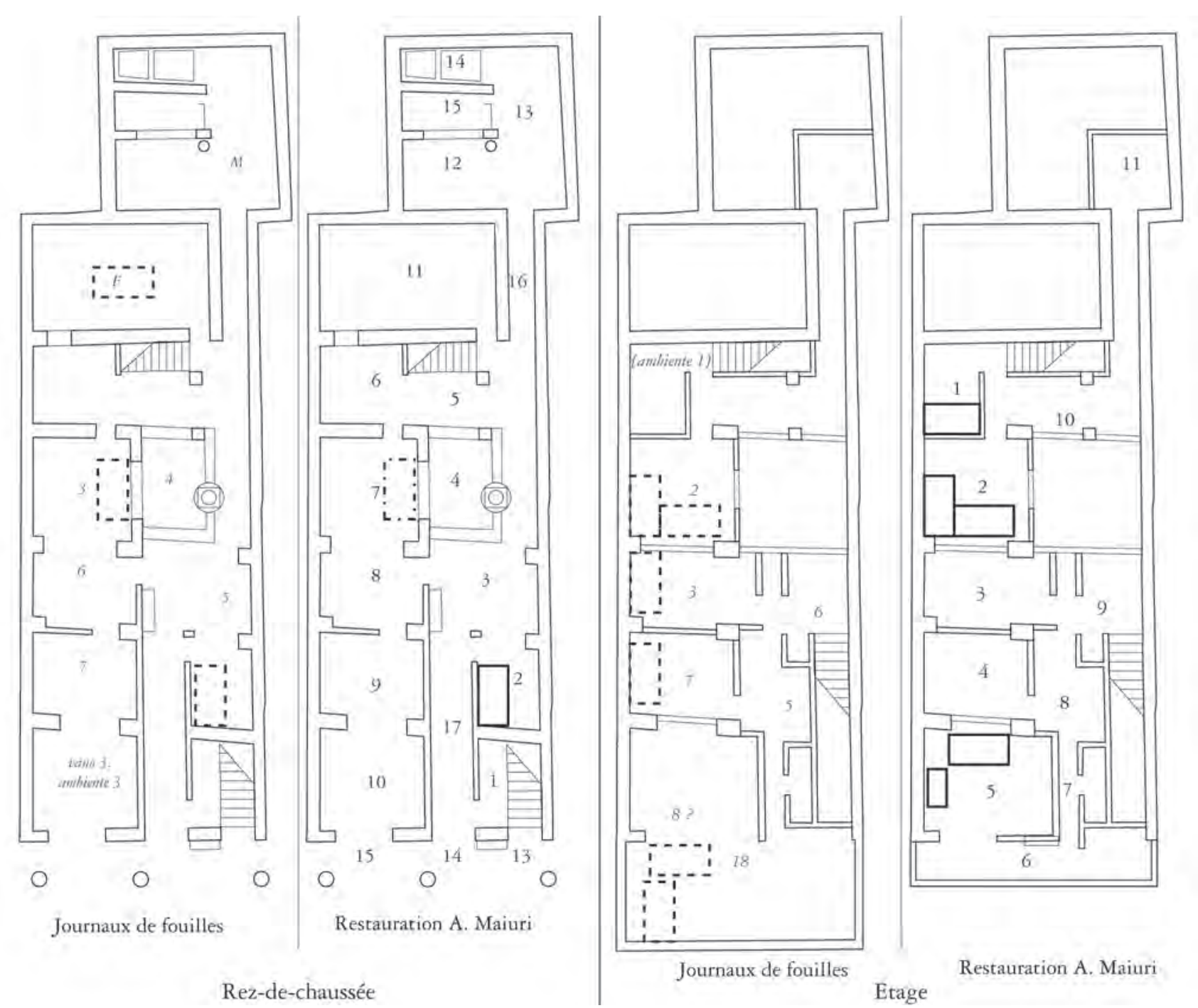

Fig. 13 - Variations dans les positions des lits de la Casa a graticcio entre la fouille et la restauration. La dimension des lits est schématique.

Les restes en bois découverts devant la fenêtre entre la pièce 7 et le puits de lumière 4 sont interprétés comme "un tavolo o una cassapanca », en raison de la cote - non spécifiée - à laquelle ils ont été trouvés ${ }^{184}$. À l'étage, dans le "quartier occidental », accessible depuis l'intérieur de l'édifice, trois lits sont mentionnés. L'un dans la pièce 1, les deux autres disposés en équerre le long des parois orientale et méridionale de la pièce 2 . En plus de ces lits, le mobilier indiqué comporte une armoire en bois et une table en marbre dans la pièce 1 , une seconde armoire contenant des statuettes associées au culte domestique dans la pièce $2^{185}$. De ce fait, il se méprend sur le contexte réel de découverte: l'armoire et son contenu proviennent de l'appartement oriental et non de l'appartement occidental; ce sont bien onze statuettes et non dix qui y ont été exhumées. Dans le quartier oriental, trois lits ont été découverts. L'un provient de la pièce 4 , les deux 
autres - l'un pour adulte, le second de taille plus réduite, pour enfant - de la pièce 5 qui s'ouvre sur le balcon. Signalons que ce dernier est censé être ouvert à claire-voie et qu'il ne déborde pas au-dessus du cardo IV. Enfin, le seul «meuble» à avoir été trouvé dans cet appartement, en plus des lits, est constitué par le fronton d'un laraire en bois, découvert sous le lit "pour adulte» de la pièce 5 ; l'origine de ce fragment de menuiserie reste pourtant inconnue ${ }^{186}$. A. Maiuri ajoute aux objets provenant de la Casa a graticcio un petit dé en marbre portant une inscription difficilement lisible ${ }^{187}$. Enfin, signalons que la corde du treuil présentée dans la boutique III, 15 est en fait une corde moderne noircie pour la faire apparaître antique.

Cette relecture de la Casa a graticcio ne saurait s'arrêter à un bilan comptable ou à un jeu des différences. Les données contenues dans les GSE, couplées à l'observation des rares portions de cette maison qui n'ont pas été reconstruites, autorisent une interprétation différente de la division de cet habitat. Ainsi, il me semble que

${ }^{186}$ Maiuri 1958 b: 418-419. Dans les descriptions des armoires en bois découvertes dans la Casa a graticcio, aucune ne prend cette forme. Selon S. Mols (1999: 188), ce sommet d'un édicule en bois aurait été découvert en novembre 1928. Il suit toutefois la reconstitution proposée par A. Maiuri et ne mentionne cette date que par vraisemblance par rapport aux autres découvertes de mobilier. L'absence de toute mention de cette fraction de meuble dans la description proposée une fois la restauration achevée (cf. GSE 1929: «23 febbraio. [...] Il corridoio tiene due aperture, la prima al lato sinistro, larga m. 1.00 e porta in una stanza lunga m. 2.50 e a destra nell'ambiente n. 3. In questa stanza vi sono due letti di legno carbonizzato, uno da sud a nord e l'altro da ovest ad est. Una terrazza che poggia sopra tre colonne di mattoni lunga m. 7,45 e larga m. 1.90 permette di affacciarsi sul $2^{\circ}$ cardine $\left.[\ldots] »\right)$ pourrait inciter à supposer que ce meuble a été trouvé dans une autre maison avant d'être exposé dans la Casa a graticcio. Peut-être s'agit-il de la partie supérieure de l'armoire ayant contenu les statuettes du culte domestique provenant de la pièce 3 de l'étage. Pour des exemples complets de ce type d'armoire prenant la forme d'un temple, cf. Mols 1999: cat. $n^{\circ} 28-30$, provenant respectivement de l'appartement V, 17, de la Casa del sacello di legno (V, 31), de la Casa del salone nero (VI, 11.13).

${ }^{187}$ Le dé en marbre noir portant une inscription lue Philad[e]lp[hi]a Cn(aei) Octavi fili[a] par A. Maiuri (1958 b: 418) et Philadelp[hus]/ac No[e]tul[us]/Fili V(otum solvunt) L[ibenter?] par M. Della Corte (1958: n 18 p. 241; Guadagno 1978: $\mathrm{n}^{\circ} 51$ p. 152) a été découvert le 28 mars 1928. Selon les GSE (1928: «28 marzo. [...] Nell'ambiente la Casa a graticcio comportait non pas deux mais quatre unités d'habitation différentes. L'appartement accessible depuis le cardo IV ne pose pas de problème. En revanche, je ne saurais souscrire à l'association entre l'appartement occidental et les pièces qui se développent à l'ouest de la boutique III, 15. Il me semble plutôt que ces pièces étaient occupées conjointement avec la pièce 11 - comme le suggère la présence d'une fenêtre entre les pièces 6 et 11 au rez-de-chaussée. L'appartement occidental aurait ainsi été une unité d'habitation en luimême. Enfin, la possibilité de fermer la pièce 2, ainsi que la découverte d'un lit qui y a été faite, incitent à soulever la question de son indépendance par rapport aux autres espaces et à y voir un appartement réduit à sa plus simple expression. La cour 4 aurait en revanche été un espace commun de circulation.

Même avec cette nouvelle interprétation de l'articulation des espaces, le bilan des différences entre le contenu des GSE concernant la Casa a graticcio et la description qui en a été publiée

n. 16 all'altezza di m. 2.30 dal pavimento nell'angolo nord ovest della stanza si è trovato: [description d'une amphore, Inv. $\left.\mathrm{n}^{\circ} \mathrm{E} 205=75481\right]$. A m. 0.90 dal descritto oggetto in direzione sud si è trovato: Marmo nero. Basetta di forma rettangolare alta m. 0.045, larga m. 0.075. [Inv. n E206=75482]. Sopra una facciata si legge la seguente iscrizione: [lecture de l'inscription, cf. supra]»), il provient de la pièce 16 , qui ne se trouve pas dans la Casa a graticcio, mais dans la Casa dell'erma di bronzo (III, 16).

En effet, la pièce GSE 18 est l'avancée sur la rue de la Casa a graticcio; la pièce GSE 17 est celle de la Casa dell'erma di bronzo (GSE 1929: "15 febbraio. Nello scavo C, ambiente n. 17, piano superiore esterno della casa del piccolo atrio tuscanico [...], a m. 3.40 dal sottostante pavimento, $[. .$.$] poggiato sul pavimento è apparso: [description$ de l'hermès en bronze donnant son nom à la maison (Inv. $\left.\left.\left.\mathrm{n}^{\circ} \mathrm{E} 403=75680\right)\right] »\right)$. La pièce GSE 13 est l'atrium 10 de la Casa dell'ara laterizia (GSE 1928: "14 aprile. L'ambiente n. 13 dello scavo $C$ è stato svuotato. In esso si accede sia dal corridoio lettera Y che trovasi al lato ovest che da due vani al lato est. [...] È da supporre che l'ambiente n. 13 altro non è che un atrio con il compluvio testudinato o displuviale») et la pièce GSE 15 paraît être la pièce 7 de cette même maison (GSE 1928: " 30 marzo. L'ambiente Y dello scavo C è un corridoio che mette capo nell'ambiente n. $15 »)$. Comme il semble que les numéros ont été attribués dans l'ordre d'apparition des pièces, du sud au nord, la pièce 16 , située à l'étage, ne peut que se trouver dans la Casa dell'erma di bronzo: aucun étage n'a été identifié dans la Casa dell'ara laterizia (Maiuri 1958 b: 422), seulement des mezzanines. 
pourrait sembler bien maigre. Cependant, ces erreurs, omissions et déplacements d'objets sont caractéristiques de la façon dont A. Maiuri a rédigé la seule synthèse sur les fouilles d'Herculanum: en se fondant sur ses propres notes prises durant les travaux et sur une observation du site une fois les restaurations et mises en scène effectuées.

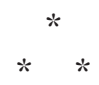

Dans ces pages introductives, j'ai tenté de mettre en évidence ce qui a constitué l'arrièreplan de mes recherches sur Herculanum: deux expériences de cette ville existent, parfois incompatibles, rarement identiques, la première consignée dans les journaux de fouille - observations fragmentaires d'une ville détruite en cours de fouille -, la seconde publiée après restauration. L'évidente distorsion entre elles permet de considérer qu'Amedeo Maiuri a inventé Herculanum, tant au sens de la découverte qu'à celui du façonnage des faits.

Parmi les différents facteurs permettant d'expliquer ce constat, la modalité d'arrivée au poste de Surintendant de Campanie et de Caserte me semble avoir joué un rôle non négligeable. Comme le fait remarquer $\mathrm{F}$. Zevi, la carrière d'A. Maiuri à Pompéi s'est déroulée dans une étroite continuité - paradoxale - avec celle de V. Spinazzola: rejeté par le régime fasciste ce dernier a été suffisamment lié aux fouilles de Pompéi et à leur absence de publication pour contraindre A. Maiuri à feindre de se borner à continuer l'œuvre inachevée de son prédéces-

${ }^{188}$ Cf. Delpino 2001 et Zevi 2001, part. p. 76. Le jugement d'A. Maiuri sur les activités de V. Spinazzola est notamment publié dans sa description de l'évolution des fouilles de Pompéi entre 1879 et 1948 (Maiuri 1950 b: 2226). Outre une critique des choix faits lors du dégagement de la Via dell'Abbondanza, il souligne chez son prédécesseur la perception des fouilles: «[...] Vittorio Spinazzola [...] arrideva soprattutto [all']idea di portare una sua impronta personale nella condotta dei lavori » (Maiuri 1950 b: 22). En cela, il met en avant son propre détachement par rapport à Pompéi, mais ne mentionne évidemment pas Herculanum.

${ }^{189}$ Si l'eredità di cultura a été - et demeure - très forte à Herculanum, elle n'est rien comparée au poids de celle qui s'attache à Pompéi. Ce poids est tel que, au moment de la reprise des fouilles à Herculanum, et en dépit de la continuité des travaux à Pompéi, seules de larges synthèses seur tout en développant un projet propre qui lui soit rattaché personnellement ${ }^{188}$. S'appuyant sur une forte eredità di cultura - pour reprendre la belle expression de G. Guadagno - il a réussi à obtenir les financements nécessaires à la réouverture d'Herculanum, ville alors perçue comme l'anti-Pompéi mais pouvant servir de vitrine au régime fasciste, tant par l'hypothétique promesse de définir d'autres aspects de la romanité que par le défi technique impliqué.

Ce puissant investissement personnel a eu plusieurs conséquences. La première semble être l'absence de publication régulière approfondie, effective en dépit des critiques adressées à son prédécesseur mais également à cause de l'opposition entre les deux villes, qui devait être maintenue autant que possible pour amorcer les travaux ${ }^{189}$. La seconde conséquence a consisté en un contrôle étroit par A. Maiuri des travaux de dégagement, comme il ressort de l'utilisation exclusive de ses carnets de fouilles personnels, du très faible nombre de publications sur la ville parues de son vivant à l'exception des siennes ou de l'absence de toute délégation sur le site. L'étroitesse du contrôle n'a vraisemblablement - et paradoxalement - pas empêché des déviations lors des restaurations et des restitutions, tant il semble difficile d'accepter un travestissement délibéré de la part d'A. Maiuri. Enfin, par choix personnel au plus haut point respectable, le surintendant a toujours voulu donner à voir à un large public les meraviglie d'Herculanum, privilégiant en cela une approche didactique, perceptible tant dans ses écrits que dans la mise en scène du site ${ }^{190}$. Conjugués, ces trois éléments ont fait qu'il a fini par accepter comme véridi-

peuvent être consacrées à cette seconde ville. Dès lors, pour marquer la différence entre les deux sites, seuls des ouvrages également synthétiques pouvaient être écrits sur Herculanum. La similitude de format, de présentation et de ton - malgré une vive opposition dans le texte - entre Pompei (Maiuri 1928) et Ercolano (Maiuri 1932) est tout particulièrement révélatrice de cette situation.

${ }^{190}$ Outre ses écrits de divulgation, en particulier ceux des années d'après-guerre (e.g. Maiuri 1950 a, 1954 a, 1958 a), cet art de la présentation didactique développé par A. Maiuri atteint son apogée dans le documentaire Resina - Ercolano réalisé par G. Lisi en 1960: lors de cette visite guidée, tournée alors que les fouilles ont à peine repris au sommet de l'Insula VI, le Surintendant a employé les habitants de Resina comme figurants pour repeupler Herculanum et redonner vie aux vestiges antiques. 
ques des faits passablement modifiés ${ }^{191}$. C'est alors que la seconde invention d'Herculanum a eu lieu, rassemblée par écrit en 1958.

Toutefois, en dépit de ces observations critiques, il n'en est pas moins évident, compte tenu de la somme que cet ouvrage représente, qu'Ercolano. I nuovi scavi représente à la fois un point d'aboutissement et une nouvelle fondation pour toute étude sur cette petite ville qu'a été Herculanum. Je me suis efforcé, lors de la rédaction des pages qui suivent, d'exploiter l'autre expérience d'Herculanum, contenue par bribes dans les journaux de fouilles, contrepoint nécessaire et complément évident des restitutions publiées.

Pour cerner l'ensemble des aspects spécifiques aux espaces commerciaux dans la société urbaine d'Herculanum, deux niveaux d'analyses doivent être superposés. Tout d'abord, à l'échelle du seul espace commercial ou artisanal, il est possible de chercher à mettre en évidence les caractéristiques matérielles permettant d'identifier une boutique ou un atelier. À partir de cette première approche, une interprétation fonctionnelle peut être proposée, en se fondant sur les aménagements construits et sur les objets trouvés dans ces locaux. Certains espaces artisanaux ou commerciaux sont présents avec une fréquence suffisamment élevée pour autoriser des regroupements par «secteur d'activité» et procéder à une première analyse générale des caractéristiques économiques d'Herculanum en comparaison avec celles de Pompéi.

En se fondant sur une définition affinée des lieux de métier et en se déplaçant à l'échelle supérieure de la parcelle, il est possible d'aborder la question du rapport entre les boutiques et les autres édifices qui les abritent. Si l'absence de fouilles extensives dans les différents locaux commerciaux et artisanaux d'Herculanum empêche de suivre l'évolution des fonctions qu'ils ont prises, l'archéologie du bâti - analyse de la stratigraphie des parois - permet d'esquisser un schéma des transformations du tissu commercial entre la période augustéenne et l'éruption de 79. La définition des types de construction et de leur séquence chronologique est un préambule nécessaire à une telle étude. Ensuite, j'analyse en détail les transformations survenues dans l'Insula Orientalis $I I^{a}$, vaste complexe public disposant de boutiques et d'appartements dans sa façade. Enfin, cette méthode est appliquée aux quatre autres îlots intégralement mis au jour. Les séquences chronologiques obtenues permettent de proposer une vision alternative à celle promue par A. Maiuri.
191 Il me semble que des publications comme celles qui ont existé sur Pompéi auraient permis, en exigeant de synthétiser régulièrement les informations issues des fouilles, de réduire cette distorsion. 
PREMIÈRE PARTIE

DES MOTS AUX ESPACES : AMÉNAGEMENTS ET FONCTIONNEMENT DES LIEUX DE MÉTIER 

«[...] On vint en procession acheter chez eux, uniquement pour voir la boutique. Le revêtement était tout en marbre blanc; au plafond, une immense glace carrée s'encadrait dans un large lambris doré et très orné, laissant pendre, au milieu, un lustre à quatre branches [...]. À droite, le comptoir, très grand, fut surtout trouvé d'un beau travail; des losanges de marbre rose y dessinaient des médaillons symétriques. À terre, il y avait, comme dallage, des carreaux blancs et roses, alternés, avec une grecque rouge sombre pour bordure. Le quartier fut fier de sa charcuterie [...]».

E. Zola, Le ventre de Paris, $10^{\mathrm{e}}$ éd., Paris, G. Charpentier, 1878, p. 62-63.

Une première distinction - toute théorique - peut être effectuée entre les boutiques et les ateliers, fondée sur un critère économique. Dans les premières, l'activité de vente est supposée dominer, tandis que seule la production se déroulerait dans les seconds. Pourtant, une telle distinction apparaît trop simpliste: certains ateliers ne peuvent-ils procéder à la vente des produits qu'ils fabriquent sans aucun intermédiaire? Des boutiques aussi banales que les commerces alimentaires ne présentent-elles pas des activités de transformation d'une matière première en produit immédiatement consommable, ce qui permet de les considérer comme des lieux d'artisanat culinaire-donc des ateliers? Quelle que soit la nuance que l'on cherche à donner à ces termes recouvrant les lieux d'exercice d'un métier, l'utilisation d'un critère écono- mique - la situation du lieu dans la chaîne allant de la production à la vente au consommateur - implique de pouvoir connaître les activités qui s'y déroulaient; il faut donc étudier l'ensemble des données recueillies dans les locaux supposés avoir accueilli des commerces ou des ateliers.

Pour orienter cette recherche, il faudrait réussir à circonscrire le ou les espaces dévolus à la pratique d'un métier dans les maisons, en commençant par l'analyse des textes littéraires et juridiques. Quelle que soit l'activité commerciale ou artisanale exercée au sein de l'espace urbain, elle doit pouvoir être facilement identifiable par de potentiels clients. Il ne faudrait pas tirer de ce postulat l'idée que les boutiques ou les ateliers puissent être de manière très générale insérés dans une typologie unique. La variété des métiers ${ }^{1}$, des aménagements directe-
${ }^{1}$ M. Della Corte (1965: 484-486) propose une liste de «métiers » provenant de ses lectures des graffites pompéiens. Toutefois, outre les répétitions de certaines appellations variant selon leur orthographe, une partie des titres répertoriés ne correspondent pas à des activités professionnelles
- e.g. forenses, seribibi, poppaenses. Pour la ville de Rome, S. Treggiari (1980: 61-64), dans un inventaire qu'elle considère comme incomplet, mentionne 162 noms de métiers, dont certains peuvent relever de grandes catégories indistinctes, comme les tabernarii ou les officinatores. 
ment associés à ces métiers ou des localisations au sein des bâtiments interdit toute vue synthétique. Seuls certains aspects architecturaux sont suffisamment récurrents pour permettre une caractérisation large. Dans un premier chapitre, nous verrons ainsi quels sont les éléments pouvant permettre l'interprétation a minima d'un local comme espace commercial ou artisanal. Dans de nombreux cas, cette hypothèse ne saurait être affinée. En effet, le faible intérêt à l'égard des boutiques a eu pour conséquence de fréquemment interdire la caractérisation de ce qui était vendu ou produit dans ces locaux.
Toutefois, l'implantation de certains métiers est identifiable à partir des aménagements nécessaires à leur bon déroulement. Ensuite, dans des chapitres distincts, je traiterai d'activités essentielles - commerces alimentaires, boulangeries et métiers liés au textile. Le choix de ces productions tient essentiellement à des facteurs de conservation. En effet, ces espaces de transformation des matières issues de l'agriculture disposent en général d'aménagements maçonnés facilitant leur reconnaissance sans être complètement tributaire des données recueillies durant les fouilles. 


\section{CHAPITRE I}

\section{ANATOMIE GÉNÉRALE DES BOUTIQUES}

«L'ambiente era un magazzino o bottega e ciò lo dimostra la scanalatura sulla soglia $[\ldots]$ ».

Giornale degli scavi di Ercolano, 8 gennaio 1929.

"Cela étant, l'identification des locaux est évidemment une entreprise aléatoire».

T. Kleberg, Hôtels, restaurants et cabarets dans l'antiquité romaine. Études historiques et philologiques, Uppsala, Almqvist \& Wiksells

Boktryckeri, 1957, p. 39.

Se poser la question des moyens permettant de reconnaître une boutique pourrait paraître aussi trivial qu'illusoire. Les journaux de fouilles font preuve d'un automatisme interprétatif parfois désarmant: la seule présence d'une large ouverture sur la rue fait reconnaître une boutique au rédacteur; dans un second temps, une précision sur la nature des objets vendus peut être donnée en fonction des éléments mis au jour dans le local. Il faut ainsi admettre qu'il n'existe aucun critère objectif permettant de définir une boutique ou un atelier. Seule la conjonction de certaines données architecturales, éventuellement complétée par les objets mis au jour à l'intérieur de l'espace défini,

${ }^{1}$ P. Allison (2004: 112) refuse, dans son ouvrage, de considérer ces espaces comme des boutiques. En revanche, ces derniers sont souvent indiqués comme tels (shop) dans sa base de données électronique, avec une précaution toute rhétorique rendant les seuls fouilleurs responsables de l'interprétation ( «has been identified as a shop»). En dépit des réels apports de cette recherche, la volonté souvent ambiguë de P. Allison de n'utiliser que les objets mis au jour - alors qu'elle est consciente des pertes de données entre la fouille proprement dite et la rédaction des comptes rendus - fait permet de proposer une telle interprétation. Si l'hypercritique récemment développée par P. Allison à propos des pièces situées en façade et s'ouvrant largement sur la rue ne saurait être acceptée ${ }^{1}$, il convient cependant d'effectuer une nouvelle analyse des sources écrites pour en extraire les caractères utilisés par les Anciens pour décrire les lieux de métier. À partir de là, il est possible, en procédant de l'extérieur vers l'intérieur, en prenant en considération successivement la façade des espaces commerciaux puis les différents aménagements internes et finalement les objets qui y ont été découverts, de proposer différents moyens d'identifier les espaces commerciaux.

que son discours est souvent critiquable, notamment en ce qui concerne certaines interprétations isolées. Comme postulat assumé, particulièrement pour éviter l'abus de l'argument a silentio, je considère qu'il est beaucoup plus probable que les pièces largement ouvertes sur la rue, liées ou non par une porte à une domus, soient d'abord des espaces commerciaux. Pour les interpréter comme espaces de réception, hall précédant l'atrium, il faudrait en apporter la preuve matérielle. 


\section{I.1 Analyse des mentions textuelles de taberna}

À l'aube du nouveau millénaire, dans un article consacré aux différentes méthodes déployées pour comprendre la sphère domestique dans le monde romain, P. Allison a donné un lointain écho à la querelle des Universaux qui a fortement agité le monde intellectuel médiéval au XII ${ }^{e}$ puis au XIV ${ }^{e}$ siècles. Dans cette étude qui se veut critique, elle a en effet dénoncé les usages abusifs de la terminologie latine pour décrire des vestiges archéologiques ainsi que les effets de cette utilisation, qui mènerait souvent à une interprétation excessive des textes et à des conclusions douteuses ${ }^{2}$. Si une telle entreprise peut être considérée comme salutaire face à certaines facilités terminologiques, ses propres excès tendent à la discréditer. Toutefois, il convient de laisser à P. Allison le mérite d'avoir soulevé la question de l'emploi de termes latins pour caractériser des pièces et leur attribuer de la sorte une fonction.

Je limiterai ma participation à cette réflexion aux seuls espaces commerciaux et artisanaux. Les enjeux d'une telle recherche sur les termes latins utilisés pour caractériser boutiques et ateliers sont multiples. Le premier est certainement de déterminer ce que recouvre un terme a priori générique comme taberna souvent utilisé dans les écrits archéologiques pour définir des espaces commerciaux. À partir de cette étude terminologique, il est possible de cerner les contours de la vision propagée par les auteurs anciens sur le commerce de proximité. Cette critique des sources littéraires permet en retour de mieux cerner les éventuels abus d'usage de ces termes dans l'historiographie. L'analyse d'un terme comme taberna, généralement traduit comme boutique, avec toutefois l'émergence progressive de nuances, est primordiale. Il ne saurait toutefois être question de prendre en considération l'ensemble des occurrences de ce mot dans la littérature latine, où les redondances et les mentions n'apportant aucune spécification matérielle sont légions. J'ai fait le choix de ne pas prendre en

${ }^{2}$ Allison 2001 b: 185-192.

${ }^{3}$ Cf. $T L L, 9^{2}$, s.v., II, 2.

${ }^{4}$ Kleberg 1957: 19-22; Gassner 1984.

${ }^{5}$ Sur les renseignements topographiques apportés par les textes mentionnant des tabernae, cf. Morel 1987:133137 ; LTUR V, s.v. tabernae argentariae, tabernae circa forum, compte le mot officina tant il semble - mais cela mériterait certainement un développement ultérieur - être lié à des établissements généralement non urbains d'une dimension importante. Ses occurrences les plus nombreuses proviennent des estampilles sur briques ou tuiles. Quant aux quelques mentions où le terme d'officina est suivi d'un adjectif ou d'un complément du nom, le sens semble alors celui très général d'atelier ou de fabrique ${ }^{3}$. Pour les autres appellations liées à l'artisanat, leurs spécificités sont telles que leur étude sera menée, le cas échéant, conjointement avec celle de leurs vestiges archéologiques.

L'étude des différents sens de taberna a déjà fait l'objet de plusieurs analyses. À la suite de T. Kleberg, V. Gassner a conclut à l'existence de deux acceptions pour ce terme, d'une part celle de boutique - local dans lequel des échanges commerciaux sont conclus -, d'autre part celle d'auberge (Gasthaus) ${ }^{4}$. Ce double sens semble exister dès l'époque de Plaute et se maintenir jusqu'au $V^{e}$ siècle de notre ère. En dépit de ces recherches, certains points méritent d'être précisés. Il convient de chercher à déterminer l'aspect de ces tabernae, ou, à défaut, leur position dans un édifice, ainsi que l'extension des possibilités offertes par ces locaux. Je ne tenterai pas d'élargir ces réflexions à la situation topographique des tabernae en ville. En effet, par-delà certaines positions très générales, l'essentiel des occurrences de ce terme qui se bornent à renseigner sur un lieu ont déjà été étudiées et renvoient surtout principalement à la situation dans Rome. Les problèmes de topographie de l'Urbs dépassent de loin le cadre de cet ouvrage ${ }^{5}$.

\section{I.1.1 Analyse des textes littéraires}

La plus claire définition de la boutique provient du Commentaire à l'édit du préteur d'Ulpien, transmis par fragments dans le Digeste:

«tabernae» appellatio declarat omne utile ad habitandum aedificium, non ex eo quod tabulis cluditur 6 .

tabernae lanienae, tabernae novae, tabernae veteres; Papi 2002: 45-53.

${ }^{6}$ Ulp., ad ed., 28 (Dig. 50, 16, 183): "On appelle 'taberna' tout édifice qui sert d'habitation, non pas parce qu'il est fermé par des planches». 
Pour limpide qu'elle soit, cette seule définition aurait tendance à remettre en cause l'idée que les tabernae ont pour vocation première à abriter des transactions commerciales. Dans l'édition du Digeste dirigée par Th. Mommsen, celui-ci a proposé d'apporter une correction au texte: le non devrait selon lui être placé avant omne ${ }^{7}$ Ce simple changement a pour effet immédiat d'inverser complètement le sens de la définition. Je reviendrai plus loin sur cet extrait d'une glose juridique d'utilisation éminemment délicate; retenons simplement l'association taberna - habitation - fermeture par des planches, sans préjuger du rapport entretenu par ces différents termes.

Faute de pouvoir se fonder sur cette définition, même comme première approche, il faut se tourner vers des textes plus elliptiques, dont la taberna n'est guère le sujet principal. Ainsi, Cicéron a fréquemment utilisé les tabernae et leurs gérants comme exemples dans ses discours et dans ses réflexions. Ne nous attardons pas sur les variations des jugements qu'il porte à l'encontre des boutiquiers: souvent méprisés, considérés comme la lie de la société romaine ${ }^{8}$, les boutiquiers, portion

${ }^{7}$ Mommsen-Krüger-Kunkel 1954, ad loc.

${ }^{8}$ Cf. Cic., Off., 1, 150, cit. infra n. 1 p. 219. Dans son plaidoyer en faveur de L. Valerius Flaccus, Cicéron assimile boutiquiers et artisans à la lie de la société (omnem faecem civitatum), sous prétexte que D. Lelius Balbus les aurait achetés pour les faire témoigner contre son client:

Cic., Flac., 18: Opifices et tabernarios atque illam omnem faecem civitatum quid est negotii concitare, in eum praesertim qui nuper summo cum imperio fuerit, summo autem in amore esse propter nomen ipsum imperii non potuerit?

«Des artisans, des boutiquiers, toute la lie des cités, estil bien difficile de les ameuter, surtout contre un homme qui venait d'avoir sur eux une autorité souveraine et qui ne pouvait pas être très aimé, en raison même de son titre de chef suprême? » [trad. CUF].

${ }^{9}$ Cic., Cat., 4, (VIII), 17: Quare, si quem vestrum forte commovet hoc, quod auditum est, lenonem quendam Lentuli concursare circum tabernas, pretio sperare sollicitari posse animos egentium atque imperitorum, est id quidem coeptum atque temptatum; sed nulli sunt inventi tam aut fortuna miseri aut voluntate perditi, qui non illum ipsum sellae atque operis et quaestus cotidiani locum, qui non cubile ac lectulum suum, qui denique non cursum hunc otiosum vitae suae salvum esse velint. multo vero maxima pars eorum, qui in tabernis sunt, immo vero - id enim potius est dicendum - genus hoc universum amantissimum est oti. etenim omne instrumentum, omnis opera atque quaestus frequentia civium sustentatur, alitur otio; quorum si quaestus occlusis tabernis minui solet, quid tandem incensis futurum fuit?

«Si donc il en est parmi vous qui s'affolent au bruit qu'un certain entremetteur, gagé par Lentulus, tourne du peuple aisément manipulable selon l'orateur, peuvent devenir, à l'occasion des discours contre Catilina, d'une vertu incorruptible, fût-elle fondée sur la volonté de préserver leurs gains. Sans taberna, pas de bénéfice (quaestus), les tabernae sont le lieu de transactions commerciales ${ }^{9}$. Bien que dans une acception plus technique et précise, ce constat est sanctionné au $\mathrm{III}^{\mathrm{e}}$ siècle par une définition d'Ulpien:

'instructam' autem tabernam sic accipiemus, quae et rebus et hominibus ad negotiationem paratis constat ${ }^{10}$.

En mentionnant la possibilité que la taberna soit instructa et donc dotée des moyens humains et matériels de fonctionner, le juriste réduit lui aussi cette dernière à un espace destiné à accueillir un négoce sans précision quant à sa nature.

Pour définir les affaires pouvant être effectuées dans ces tabernae, la plus grande variété semble régner. Ainsi, pour expliquer le mode de formation des adjectifs à partir d'un substantif, Varron donne une liste de différents commerces pouvant s'exercer dans une taberna et la caractérisant ${ }^{11}$. Il est particulièrement intéressant de

autour des tabernae, espérant pouvoir soulever à prix d'argent les besogneux et les naïf, oui, pareille entreprise a bien été tentée; mais il ne s'est trouvé personne de condition assez misérable, personne d'âme assez abjecte pour ne pas vouloir que le lieu qui abrite son tabouret de travail et son gain quotidien, que sa chambrette et son petit lit, qu'en un mot la sécurité de la vie ne lui fussent conservés. En fait, la majeure partie de ceux qui tiennent boutique, ou pour mieux dire - car c'est là la vérité -, tous les gens de cette sorte ont plus que personne le culte de la paix. Car tout métier, toute profession, tout commerce est favorisé par l'affluence des clients, alimenté par la paix: or si le commerce diminue quand on ferme les tabernae, que serait-il enfin advenu si on les leur eût incendiées? » [trad. CUF].

${ }^{10}$ Ulp., ad ed., 28 (Dig., 50, 16, 185): «Nous considérons qu'une taberna est instructa, si elle est comprend les choses et les hommes servant aux affaires ».

${ }^{11}$ Varr., L., 8, 30, 55 : quoniam taberna, ubi venit vinum, a vino vinaria, a creta cretaria, ab unguento unguentaria dicitur, analogon si essent vocabula, ubi caro venit, carnaria, ubi pelles, pelliaria, ubi calcei, calcearia diceretur, non laniena ac pellesuina et sutrina.

«Etant donné que, quand on vend du vin dans une taberna, on la dit vinaria à partir de vinum, cretaria à partir de creta, unguentaria à partir d'unguentum, si les mots étaient formés par analogie, on dirait [la taberna] carnaria; quand c'est de la viande, on la dira carnaria, pelliaria pour des peaux, calcearia pour des chaussures et non pas laniena, pellesuina ou sutrina». 
noter que parmi les activités mentionnées sont mélangées celles désignant nécessairement un simple commerce - vente de vin ou de viande - à celles qui pourraient également impliquer une production - tabernae cretaria, unguentaria, pelliaria, calcearia. Il semble en effet difficile de supposer que les chaussures (calcei) vendues dans une telle boutique n'aient pas été également produites au même endroit. Cette seule notule grammaticale tendrait ainsi à faire des tabernae des lieux génériques qui peuvent abriter des «ateliers» en plus des simples espaces de vente. Une telle suggestion est partiellement confirmée par l'analyse des sources juridiques menées par M. A. Ligios: en dépit de la mention récurrente, notamment en ce qui concerne les institores, de l'emptio-venditio ou de la negotiatio, mais également de l'emploi de termes précis pour certaines activités - pistor, fullo -, le terme de taberna est également employé pour désigner des lieux de production d'échelle réduite ${ }^{12}$.

En revanche, seuls de rares textes renseignent sur la situation des tabernae dans les édifices où elles sont installées. La première mention est tirée de l'ouvrage de Varron sur l'agriculture:

[...] si ager secundum viam et op $<$ p $>$ ortunus viatoribus locus, aedificandae tabernae devorsoriae, quae tamen, quamvis sint fructuosae, nihilo magis sunt agri culturae partes $^{13}$.

${ }^{12}$ En dépit d'un titre de paragraphe sans ambiguïté ( $\mathrm{La}$ 'taberna' non è un luogo di produzione), M.A. Ligios (2001: 42-47) en conclut que la taberna a pu abriter des activités de production. Bien que les activités de foulerie aient reçu un traitement particulier dans les sources juridiques en raison du problème casuistique que constitue le dépôt de linge à nettoyer chez un tiers, l'association dans un même fragment d'Ulpien (ad ed., 28 [Dig. 14, 3, 5, 10]) des mots fullo et taberna (instructa) incite à considérer que les tabernae étaient propres à abriter des activités artisanales. Sur la gestion des tabernae par des institores, cf. Aubert 1994: 95100. Il convient de noter que, malgré la délicate définition de la taberna proposée par Ulpien, ces locaux n'apparaissent toujours qu'en incise dans un discours de toute autre portée. Le seul point sur lequel la taberna est au cœur de la discussion juridique est constitué par la définition de ce qu'est une taberna instructa, dans le cadre plus général des problèmes de transmission du patrimoine. Sur ce point, cf. Dubouloz 2010: 118-124.

${ }^{13}$ Varr., $R ., 1,2,23$. "Si une terre est en bordure de la route et si l'endroit convient aux voyageurs, on doit y cons-
Il semble ici que la taberna devorsoria soit un édifice à part, intégré à une propriété rurale. Sa position en bord de route est bien évidemment dictée par la fonction même de ce local, accueillir des voyageurs pour qu'ils puissent faire étape lors de leur déplacement. Quant à la négation du lien entre un tel commerce et les activités agricoles, elle permet de dissocier les revenus de la terre des investissements d'une autre nature. Il ne s'agit pas ici de trouver un mode d'écoulement pour la production de la villa, mais bien de dégager du profit grâce à une situation particulière dans un contexte rural ${ }^{14}$. La précieuse mention de Vitruve sur la localisation de la taberna dans un cadre urbain offre un sens différent:

Qui autem fructibus rusticis serviunt, in eorum vestibulis stabula, tabernae, in aedibus cryptae, horrea, apothecae ceteraque, quae ad fructus servandos magis quam ad elegantiae decorem possunt esse, ita sunt facienda ${ }^{15}$.

Rappelons que ce texte est tiré d'une partie du livre VI où Vitruve expose le lien qu'il est nécessaire de développer, lors de la conception de sa maison, entre le statut de l'occupant et le plan de l'édifice ${ }^{16}$. La similitude formelle avec le texte de Varron est assez importante. Toutefois, contrairement au traité agronomique, les tabernae sont ici présentées comme un moyen

truire une taberna devorsoria qui, si elle rapporte de l'argent, ne fait pas pas partie de l'agriculture pour autant». [d'après trad. CUF].

${ }^{14}$ Contra Capogrossi Colognesi 1981 : 447. Rien, ni dans le texte, ni dans la nature du commerce installé, ne semble autoriser cette interprétation.

${ }^{15}$ Vitruv., 6, 5, 2. «Pour ceux, par ailleurs, dont l'activité est liée aux produits agricoles, il faut faire, dans leur vestibulum, des écuries et des tabernae, dans leur maison même, des caves, des greniers, des resserres et toute autre installation visant à une bonne conservation des produits plutôt qu'à une esthétique recherchée » [trad. CUF].

${ }^{16}$ Soulignons en incise que la première partie de la phrase - qui autem fructibus rusticis serviunt - implique que, selon l'architecte, tirer des revenus d'une propriété foncière rurale n'aurait aucun caractère normatif. Pour pragmatique qu'il soit, un tel propos va à l'encontre de certaines valeurs sur l'origine de la richesse généralement dispensées dans les textes littéraires. 
permettant d'écouler, en ville, les fruits d'une exploitation rurale. Quant à la situation de ce local par rapport à la maison, la position dans le vestibulum implique qu'il devait se situer vers l'extérieur, en façade, même en considérant le vestibulum comme un «large espace séparant la rue de la maison, [...] une aire neutre de travail et de passage ${ }^{17}$. En revanche, l'idée que les tabernae soient ici des magasins, au sens de stockage du terme, semble délicate à suivre: cela constituerait un double emploi avec les cryptae, horrea, apothecae cetera disposés dans la maison elle-même. Le sens de boutique convient beaucoup mieux ici ${ }^{18}$. Un dernier texte confirme cette position frontale de la taberna. Dans une discussion sur l'action à utiliser en cas de dommages causés par un animal à quatre pattes, Paul évoque le cas d'une personne mordue par un chien dans une taberna après qu'elle s'y soit jetée sans discernement pour éviter de croiser un autre personnage ${ }^{19}$. Sans chercher à cerner les débats induits par ce cas, comme la nécessité pour les propriétaires de chiens d'attacher l'animal, le réalisme induit par la casuistique implique que la taberna ne peut que se trouver ouverte sur la rue.

Cette situation privilégiée des tabernae en façade ne donne pas pour autant de renseignement sur leur aspect, si tant est qu'une apparence uniforme ait existé, ce qui semble difficile si l'on prend en considération la multitude des métiers ayant pu se dérouler dans ces locaux. En revanche, certains détails textuels permettent de préciser un caractère récurrent des tabernae: leur système de fermeture. La description la plus claire de ce dernier est fournie par Sénèque. Dans son traité Des bienfaits, il raconte l'anecdote d'un pythagoricien qui s'achète des

17 Commentaire de L. Callebat dans l'édition CUF (2004) du texte, p. 177.

${ }^{18}$ Contra Ligios $2001: 35$.

19 Paul., ad ed., 22 (Dig. 9, 1, 2, 1): Si quis aliquem evitans, magistratum forte, in taberna proxima se immisisset ibique a cane feroce laesus esset, non posse agi canis nomine quidam putant: at si solutus fuisset, contra.

" $\mathrm{Si}$, en cherchant à éviter disons un magistrat, quelqu'un se jette dans la taberna la plus proche et s'y fait mordre par un chien féroce, certains pensent qu'il ne peut pas agir contre le chien. Si celui-ci n'était pas attaché, il peut le faire» chaussures mais ne peut pas les payer immédiatement au vendeur. Lorsqu'il revient, l'artisan est décédé. Après avoir goûté brièvement au plaisir de l'achat gratuit, il retourne à la taberna pour y déposer la somme due à l'artisan:

Deinde per clostrum, qua se conmissura laxaverat, quattuor denarios in tabernam inservit ac misit poenas a se exigens inprobae cupiditatis, ne alieno adsuesceret ${ }^{20}$.

Pour mon propos, les éléments essentiels de ce passage se situent dans l'existence d'une fente dans la porte, par laquelle les pièces sont déposées. Comprendre le terme de clostrum comme l'indication d'une cloison ne correspond guère aux autres sens ce mot - de la serrure à la barrière - et est difficilement acceptable par rapport à la situation du pythagoricien, resté à l'extérieur de la boutique. De plus, il serait loisible de se demander quelle cloison, si mal entretenue fût-elle, aurait des fissures permettant d'insérer des pièces jusqu'à l'intérieur de la boutique, in tabernam. L'espace par lequel le personnage de cette anecdote paye ses chaussures doit donc être compris comme celui entre les planches qui permettent d'obturer la taberna. L'interprétation de ce passage comme la description d'une fermeture utilisant des planches emboîtées est soutenue par un débat sur l'étymologie de taberna. Si l'on suit les commentaires de Festus, le seul élément consensuel dans cette question serait le lien entre taberna et tabula - planche. Les tenants d'une explication par la construction des tabernae avec des planches, parmi lesquels Festus, s'opposeraient à ceux prônant une fermeture des tabernae avec les mêmes planches ${ }^{21}$. Il n'importe guère ici de départager les uns ou les autres, d'autant plus que selon V. Gassner, l'étymologie du mot serait

\footnotetext{
${ }^{20}$ Sen., Ben., 7, 21, 2. «Puis, à travers la porte (clostrum), sans avoir à élargir de fente, il introduisit quatre deniers dans la boutique, se punissant d'une convoitise malhonnête, ne voulant pas prendre l'habitude [de conserver] le bien d'autrui ».

${ }^{21}$ Fest. (éd. Lindsay, p. 490): (tabernae) quae ipsae, quod ex tabulis olim fiebant, dictae sunt, non ut quidam putant, quod tabulis cludantur.

«Les tabernae sont ainsi appelées car elles étaient autrefois construites avec des planches, et non, comme certains le pensent, parce qu'elles étaient fermées par des planches ».
} 
trabs, la poutre ${ }^{22}$. Le seul fait que certains grammairiens aient pu faire dériver taberna de tabula à cause du système de fermeture semble suffisant pour y voir une confirmation de l'interprétation proposée du passage de Sénèque.

Le dernier point à aborder est l'idée que le terme de taberna ait renvoyé à des cabanes ou à des espaces habitables. Les occurrences d'un tel sens sont particulièrement rares; la plus claire provient de deux vers d'Horace:

pallida Mors aequo pulsat pede pauperum tabernas / regum que turris $[\ldots]^{23}$.

Il est nécessaire d'aborder ce texte avec circonspection. En effet, outre de probables problèmes de scansions, taberna a pu être choisi pour accentuer le contraste avec les tours dans lesquelles les rois sont censés vivre. Si le sens général reste que la mort frappe riches et pauvres, il est délicat d'inférer de ce texte que la taberna a pu servir de logement. Il est inutile de prendre en considération les passages de Cassiodore ou d'Isidore de Séville qui utilisent très vraisemblablement ces vers d'Horace pour affirmer que les Anciens vivaient dans des tabernae ${ }^{24}$. Le seul passage de la littérature latine qui associe très clairement des tabernae et un probable espace d'habitation provient de la correspondance de Cicéron:

Sed quod quaeris quid arcessierim Chrysippum, tabernae mihi duae corruerunt reliquaeque rimas agunt; itaque non solum inquilini sed mures etiam migraverunt ${ }^{25}$.

${ }^{22}$ Gassner 1984: 108-110.

${ }^{23}$ Hor., $O ., 1$, 4, 13-14. "La pâle mort heurte du même pied les tabernae des pauvres et les tours des rois ».

${ }^{24}$ Cassiod., Psalm., 14, 1 ; Isid., Etym., 15, 2, 43.

${ }^{25}$ Cic., Att., 14, 9, 1. "Tu me demandes il est vrai pourquoi j'ai fait venir Chrysippe: c'est que deux de mes tabernae se sont effondrées et les autres ont des fissures, si bien que les locataires et même les souris ont émigré » [trad. CUF].

${ }^{26}$ Il est également possible que ce terme d'inquilini renvoie aux occupants de tout l'immeuble de rapport que possède Cicéron: (Att., 14, 10, 3) Quod quaeris iamne ad cen<ten $>a$ Cluvianum, adventare videtur; sed primo anno $\underline{\underline{L X X}}$ detersimus ( Tu me demandes si l'immeuble de Cluvius me rapporte déjà 100.000 sesterces: il s'en approche, semble-t-il; mais la première année je n'en ai tiré que 80.000 » [trad. CUF]).

${ }^{27}$ Paul., ad. ed., 30 (Dig. 50, 16, 184): Inde tabernacula et contubernales dicti sunt.

«De cette façon, nous parlons de tentes et de contubernales ».
Encore serait-il possible d'argumenter que les inquilini dont il est question ne louent que la taberna; la mention de la migration des souris permet tout de même de suggérer que l'effondrement de ces deux espaces commerciaux n'a pas seulement été perçu par les locataires comme une perte momentanée de leur instrument de travail, mais également comme la destruction de leur logement ${ }^{26}$. Dans ce passage, Cicéron ne distingue pas le local proprement commercial des pièces habitables en son sein. Il est possible de ce fait, tout en restant prudent, de supposer dans ce cas un automatisme: les tabernae seraient louées avec une ou plusieurs pièces à vivre. Cette possibilité renvoie à l'extrait du commentaire à l'édit du préteur d'Ulpien cité plus haut et à la controverse sur la position de la négation dans ce passage. Sans la correction suggérée par Th. Mommsen, le texte indique qu'Ulpien se pique d'étymologie alors qu'il est censé proposer une explication juridique du terme taberna. Une telle supposition n'est appuyée que par l'insertion, par les compilateurs du Digeste, d'un paragraphe extrait du commentaire de l'édit du préteur rédigé par Paul qui emploie les termes de tabernacula et de contubernales $^{27}$. Si l'on suit la restitution proposée par O. Lenel, le passage problématique s'insérerait après une discussion sur les actions pouvant être intentée contre un apprenti ayant pris la fuite avec des vêtements confiés au fullo: Ulpien aurait expliqué après cet exemple ce qu'il entend par taberna instructa, en commençant par définir taberna, puis instructa ${ }^{28}$. De cette façon, la correc-

${ }^{28}$ Ulp., ad. ed., 28 (Dig. 14, 3, 5, 10): Sed et cum fullo peregre proficiscens <aliquem> rogasset, ut discipulis suis, quibus tabernam instructam tradiderat, imperaret, post cuius profectionem vestimenta discipulus accepisset et fugisset, fullonem non teneri, si <discipulus $>$ quasi procurator fuit relictus: sin vero quasi institor, teneri eum. plane si adfirmaverit mihi recte me credere operariis suis, non institoria, sed ex locato tenebitur.

"Alors qu'un foulon se met en route pour un voyage, il donne des ordres à son apprenti (discipulus), à qui il laisse la taberna apprêtée. Après son départ, l'apprenti accepte des vêtements et prend la fuite. Le foulon ne peut être poursuivi, s'il l'avait laissé comme un procurator. En revanche, si l'apprenti était comme un institor, on peut le poursuivre. S'il m'avait affirmé que je pouvais croire ses ouvriers, on peut le poursuivre avec l'actio ex locato, mais pas avec l'actio institoria».

Ulp., ad. ed., 28 (Dig., 50, 16, 183.185): 'tabernae' appellatio declarat <non> omne utile ad habitandum aedifi- 
tion proposée par Th. Mommsen devient beaucoup plus significative. Il serait alors possible de traduire le fragment par « on appelle 'taberna' tout édifice qui ne sert pas d'habitation, parce qu'il est fermé par des planches ». Pour précieuse que soit cette définition, n'oublions pas qu'elle est extraite d'un texte technique et doit être replacée dans son contexte originel ${ }^{29}$. Cette définition qui nie tout caractère d'habitation à la taberna ne saurait être généralisée: Ulpien entend ici préciser la nature juridique d'un lieu et non pas son usage.

Cette rapide analyse des textes comportant le mot taberna permet déjà de proposer une définition minimale: un espace où se déroulent des affaires commerciales, ouvert sur la rue, fermé par des planches et pouvant abriter des espaces d'habitation.

I.1.2 Les inscriptions pompéiennes mentionnant des tabernae

Les trois inscriptions découvertes sur les murs de Pompéi mentionnant des tabernae permettent d'approfondir cette ébauche de définition. Deux d'entre elles ont fait l'objet d'une analyse précise de la part de F. Pirson. La troisième est d'autant plus intéressante qu'elle ne laisse que peu de place à l'ambiguïté des lieux mentionnés. La première est une offre de location découverte sur la façade occidentale de la Casa di Pansa (VI 6, 1.8.12-13):

cium, \{non\} ex eo quod tabulis cluditur. 'instructam' autem tabernam sic accipiemus, quae et rebus et hominibus ad negotiationem paratis constat.

«[...] Nous considérons qu'une taberna est instructa, si elle présente les choses et les hommes nécessaires aux affaires ». Sur cet ordre de restitution, cf. Lenel 1889: §824827.

${ }^{29}$ La correction proposée par Th. Mommsen a été rejetée par M.A. Ligios (2001 : 27-32), en se fondant sur des textes de grammairiens qui, à l'exception de Festus, sont tous postérieurs à Ulpien (Donat, Diomède, Cassiodore, Isidore de Séville).

${ }^{30}$ CIL IV, 138. "Dans l'insula Arriana Polliana de $\mathrm{Cn}$. Alleius Nigidius Maius, on loue, à partir des calendes de juillet, des tabernae dotées de pergulae, et des cenacula equestria et la domus. Le locataire (conductor) doit rencontrer Primus, esclave de Cn. Alleius Nigidius Maius ».

${ }^{31}$ CIL IV, $1136=$ ILS 5722. "Dans les propriétés de Julia Felix, fille de Spurius, on loue un balneum élégant et distingué, des tabernae, des pergulae, des cenacula à partir des ides d'août jusqu'aux ides d'août de la sixième année, pour cinq années sans interruption. Au terme de
Arriana / Polliana [C]n. Al[le]i Nigidi Mai / locantur ex [k(alendis)] Iulis primis tabernae / cum pergulis suis et c[e]nacula / equestria et domus conductor / convenito Primum [C]n. Al[le]i / Nigidi Mai ser(vum) ${ }^{30}$.

La seconde est une inscription du même type, lue dès le XVIII ${ }^{\mathrm{e}}$ siècle en façade des Praedia de Julia Felix (II 4):

In praedis Iuliae Sp (urii) f(iliae) Felicis / locantur/balneum venerium et nongentum tabernae pergulae / cenacula ex idibus Aug(ustis) primis in idus Aug(ustas) sextas annos / continuos quinque / s(i) q(uinquennium) d(ecurrerit) l(ocatio) e(rit) n(udo) c(onsensu) $)^{31}$.

Ces deux affiches présentent des éléments communs, tabernae, pergulae et cenacula qui ont permis à F. Pirson, par comparaison entre les plans et en étudiant les différents espaces de ces deux îlots, de définir les pièces pouvant correspondre à ces trois termes - en dépit des critiques formulées par P. Allison à l'encontre de cette étude - qui concordent avec la définition obtenue par l'étude des textes littéraires et juridiques ${ }^{32}$. En effet, au moins six espaces sont situés en façade et disposent d'un accès à l'étage, ce qui semble correspondre à la locution taberna cum pergula sua ${ }^{33}$. Un septième aurait pu faire partie de cet ensemble, l'espace VI 6, 23. Toutefois, des doutes subsistent sur l'existence d'un escalier permettant d'accéder à l'étage le surplombant ${ }^{34}$. L'étude des pièces des Praedia Juliae Felicis permet de distinguer trois espaces

la cinquième année, le bail peut être reconduit par accord simple ». Il est inutile de s'arrêter sur l'identité de Julia Felix et donc sur la détermination de son éventuelle état de fille naturelle. Cette inscription a joué un rôle non négligeable dans la perception du commerce de proximité à Pompéi. En effet, le terme de nongentum a longtemps été considéré comme une indication chiffrée du nombre de boutiques mises en location par Julia Felix (cf. not. Rosini 1797: chap. $10, \S \mathrm{xv}$-xxv et bibliographie complémentaire dans le commentaire du corpus). Il faut attendre le commentaire de Th. Mommsen à cette inscription pour que cette idée disparaisse, cf. supra n. 56, p. 9.

${ }^{32}$ Pirson 1999: 23-34, 47-49. Contra Allison 2001: 186188. Gageons que la violence de ces critiques aurait été adoucie par la lecture de l'ouvrage de F. Pirson (1999) plutôt que de l'article résumant sa démarche (Pirson 1997).

${ }^{33} \mathrm{Il}$ s'agit des espaces VI 6, 2, 3, 4-5, 14, 15 et 16. Quant à la définition de la pergula comme un espace situé à l'étage, perçu dans les sources littéraires comme un signe d'une basse extraction sociale, cf. Pirson 1999: 19-20.

${ }^{34}$ Pirson 1999: 33. 
du même type (II 4, 1, 5 et 7) et donc d'associer ces pièces ouvertes sur la rue au mot taberna ${ }^{35}$. La troisième inscription permet de confirmer cette identification:

Urna aenia pereit de taberna / Sei quis rettulerit dabuntur / HS LXV sei furem / dabit unde [rem] /servare [possimus HS] $X X{ }^{36}$.

Cet avis de recherche pour un vase en bronze a été mentionné pour la première fois en 1837 par Ch. Wordsworth. L'indication topographique qu'il donne, confirmée ensuite par les commentaires du Corpus, permet de savoir que l'inscription était peinte sur le pilier séparant les espaces VIII 5, 33 et VIII 5, 3437. Ces deux espaces sont similaires (fig. 14). L'un comme l'autre sont pourvus d'une large ouverture sur la rue, qui peut être close avec des planches insérées dans une rainure ${ }^{38}$. Le seul point qui les distingue l'un de l'autre est que l'espace VIII 5, 34 communique par une porte avec le péristyle de la Casa della calce (VIII 5, 28-29.34-35). Les tabernae identifiées jusqu'à présent dans les îlots II 4 et VI 6 bénéficiaient d'accès propres et ne communiquaient pas avec les maisons voisines, en vertu de leur statut d'espace à louer. Ici, cette restriction ne joue pas en raison de la nature même de l'inscription qui mentionne la taberna. Les similitudes entre les deux locaux interdisent de choisir entre l'un ou l'autre pour attribuer un lieu au larcin; cependant, la correspondance qu'ils

35 Pirson 1999: 49. Le fait que les deux commerces alimentaires II 4, 5 et II 4, 7 disposent de portes donnant dans le complexe thermal n'empêche pas d'envisager leur location, en particulier conjointement avec le balneum. En effet, il ne faudrait pas chercher des précisions que l'annonce CIL IV, 1136 n'apporte pas. Il s'agit uniquement d'une courte liste signalant les types d'espaces proposés à la location, certainement pas d'un relevé détaillé de ces espaces qui aurait spécifié leur nombre.

${ }^{36}$ CIL IV, $64=C I L \mathrm{I}^{2}, 1154=I L L R P$ 1122. " Une urna en bronze a disparu de cette taberna. 65 sesterces seront donnés si elle est rapportée. Si on nous dit où le voleur conserve l'objet, nous pouvons (donner) [au moins] 20 sesterces ...». La transcription de cette inscription a fortement varié en fonction de ses lecteurs. Cf. CIL IV ad loc. et p. 191.

37 «In leaving this building [the Basilica], in the way to what is called the Forum Nundinarium, we pass through a street now termed the Strada de' Teatri. On the plaster wall of the third house on the right as you descend that street, you see traced in red letters an advertisement conerning the

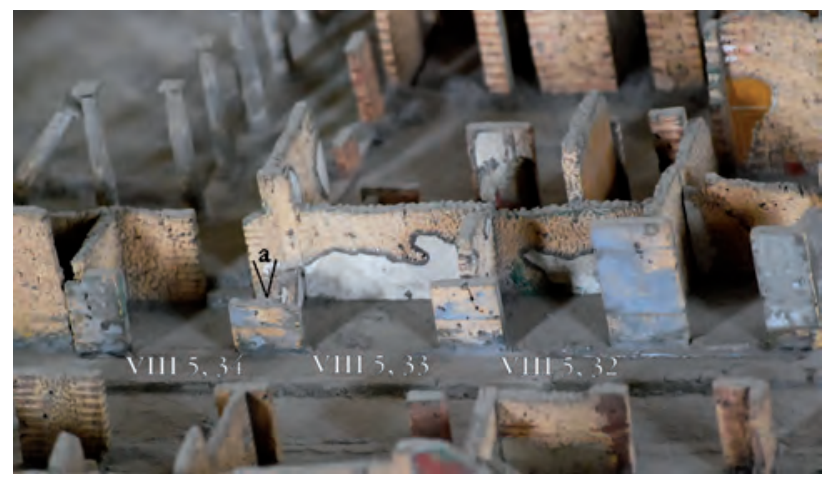

Fig. 14-Casa della calce (VIII 5, 28-29.34-35) sur la maquette en liège de Pompéi conservée au MANN. L'inscription CIL IV, 64, lue sur le montant (a) indique une taberna dans l'espace VIII 5, 33 ou en VIII 5, 34.

présentent avec la description des boutiques issue de l'analyse des textes permet de considérer que l'un et l'autre étaient des tabernae. Ces trois exemples d'inscriptions pompéiennes autorisent donc à définir certains vestiges archéologiques comme des tabernae.

\section{I.2 La façade des lieux de métier}

En félicitant Domitien d'avoir nettoyé les rues de Rome des abus des boutiquiers, Martial décrit ceux-ci, en associant un instrument propre à chaque métier ${ }^{39}$. Sans s'attarder sur ces usages

loss of a wine-vessel, which was stolen from this shop in the time of Horace's thieves, Coelius and Birrhius » (Wordsworth 1837: 25). Cette inscription n'est pas mentionnée dans les rapports de fouilles publiés dans la $P A H$. Lorsqu'il révise le texte, R. Garucci ne précise pas son origine (BullArchNap 1853: 7).

${ }^{38}$ Pour une description de tels seuils, cf. infra, p. 57-59.

39 Mart. 7, 61: Abstulerat totam temerarius institor urbem/Inque suo nullum limine limen erat./Iussisti tenuis, Germanice, crescere uicos, / et modo quae fuerat semita, facta via est. / Nulla catenatis pila est praecincta lagonis / nec praetor medio cogitur ire luto, / stringitur in densa nec caeca nouacula turba / occupat aut totas nigra popina uias. / Tonsor, copo, cocus, lanius sua limina seruant. / Nunc Roma est, nuper magna taberna fuit.

"L'institor irréfléchi nous avait enlevé Rome toute entière, dans laquelle son seuil était sans limite. Tu as ordonné, Germanicus, d'agrandir nos ruelles, et ce qui était un sentier est devenu une rue. Plus aucun pilier n'est entouré par des bouteilles enchaînées, plus d'obliga- 
du sol public, cette épigramme souligne l'indissociable lien entre la rue et le commerce. S'il apparaît difficile de trouver des traces archéologiques de ces pratiques abusives, la bonne conservation des élévations à Herculanum et à Pompéi permet d'étudier de façon exhaustive les façades des lieux de métier.

I.2.1 Les "enseignes», entre manifestation religieuse et représentation des métiers

Les fouilles menées par V. Spinazzola le long de la Via dell'Abbondanza à Pompéi ont notablement contribué à mettre en évidence ce qui serait l'un des traits caractéristiques des boutiques, la présence «d'enseignes» en façade de celles-ci. Avant d'esquisser une rapide synthèse sur la fonction de ces peintures, analysons les deux seuls exemples mis au jour à Herculanum $^{40}$. En 1961, sur le montant ouest de la boutique VI, 14 (cat. $n^{\circ} 29$ ) une "enseigne» a été découverte (fig. 15) ${ }^{41}$. Constituée de deux cadres superposés, elle se développe à 1,70 m du sol sur une hauteur de 1,85 m. La partie supérieure est constituée par un cadre rectangulaire vertical, large de 0,63 m et haut de 1,30 m. Une divinité barbue, couronnée de feuillage, vêtue d'une toge blanche, tient dans sa main droite une patère. Son bras gauche, légèrement replié tient une longue verge. Une inscription disposée de part et d'autre de la tête $-A D S A N C^{V M}$ - permet d'identifier le dieu représenté: selon l'interprétation proposée par M. Pagano, il s'agirait de la première attestation iconographique de Semo Sancus dius fidius ${ }^{42}$. Sous ce dieu, un second cadre, horizontal, se développe sur 0,96 m de large pour $0,48 \mathrm{~m}$ de haut. Sous une inscription - AD CVCVMAS - sont représentés quatre brocs dont la forme est identique: corps globulaire

tion pour le préteur de se déplacer au milieu de la boue, plus de rasoir aveugle tiré dans une foule dense, plus de noire popina encombrant la rue. Barbier, copo, cuisinier et boucher font attention à leur seuil. Désormais, Rome existe; naguère c'était une grande taberna».

${ }^{40}$ Jusqu'aux études de M. Pagano sur les deux enseignes d'Herculanum, on considérait que l'absence d'inscription pariétale - à vocation politique ou "économique» - était due à la petitesse de la ville et à la faiblesse de ses activités économiques, à cause de sa proximité avec Naples (Solin 1973 : 100-101). Ce manque - à peine réduit par la redécou-

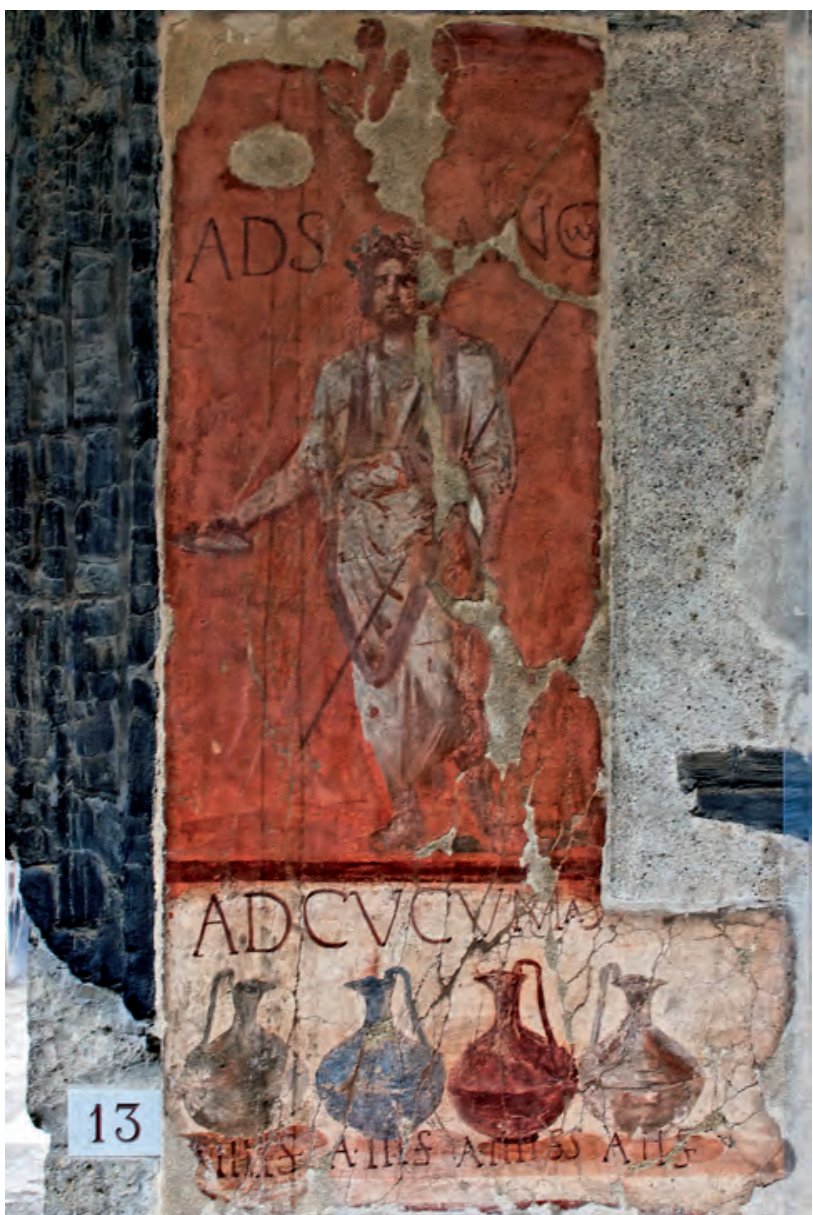

Fig. 15 - «Enseigne» de la boutique VI, 14 après sa restauration.

reposant sur un pied, col allongé se terminant par un bec pincé, anse surélevée. Cette forme renvoie à des récipients en bronze, en céramique ou en verre ${ }^{43}$. Les couleurs employées - vert, bleu, rouge, blanc, possible rappel des

verte d'une inscription électorale (Pagano 1987) - paraît en fait imputable tant aux dégâts causés par l'éruption de 79 qu'à ceux occasionnés par les fouilles du XVIII ${ }^{\mathrm{e}}$ siècle.

${ }^{41}$ GSE 1961 : « 18 agosto. [...] Sulla sinistra dell'ingresso, sulla faccia esterna ed a metri 1.70 dalla banchina del decumano massimo, è stato rilevato un quadro di pubblicità dipinto su stucco non molto fine [...]». Voir également la description faite par A. Maiuri dans ses carnets personnels (cit. in Pagano 1988: 209-210 ; Monteix 2006: 67)

${ }^{42}$ Pagano 1988: 211-212.

${ }^{43}$ Pagano 1988: 212-213. 
factiones - interdisent toutefois toute qualification du matériau de ces brocs. Sous chacun d'entre eux est mentionné un prix en asses, indiqués par ordre décroissant de gauche à droite ${ }^{44}$. Notons enfin que ces quatre indications ont été surpeintes d'un coup de pinceau plus sombre, pouvant signifier qu'elles n'étaient plus en valeur au moment de l'éruption. Malgré l'interprétation proposée par G. Guadagno, il me semble, suivant en cela M. Pagano, qu'il ne s'agit pas du prix des cucumae représentées, mais bien du liquide contenu par celles-ci, d'un volume probable d'un sextarius ${ }^{45}$ : cette fresque permettrait ainsi de caractériser un marchand de vin au cotyle, interprétation que l'absence de tout objet pertinent à l'activité commerciale dans le local aurait autrement interdite ${ }^{46}$. Pourtant, mettre l'accent sur ces données ne me paraît rendre compte qu'incomplètement de l'intérêt premier de cette représentation. En effet, la majeure partie de la surface picturale est occupée par la représentation du dieu. Les informations économiques et commerciales ne sont ici qu'accessoires. En dépit de l'unicité de cette représentation de Semo Sancus, la première image perçue par le passant et l'éventuel client de cette boutique est qu'un dieu protège ce commerce: la tête découverte et couronnée désigne déjà une divinité, avec la redondance du sacré représentée par l'acte

${ }^{44}$ La lecture de M. Pagano (1988: 214) a été corrigée par A. Varone (2000: 279).

${ }^{45}$ G. Guadagno (1993: n. 112 p. 88-89, contra Pagano 1988: 213-215) estime, en se fondant sur une première analyse proposée par S. Tassinari (1979: n. 13 p. 240), que les récipients sont en bronze et que leur prix est indiqué sous chacun d'eux. Cette interprétation peut être rejetée pour l'essentiel en raison du fonctionnement du commerce des objets en bronze: selon S. Tassinari (1993: 208), ces derniers auraient été vendus au poids. Sur le relief de la collection Farnese conservé au MANN (Inv. n 6575) représentant un atelier de bronzier, une balance se trouve en évidence, sur la gauche, au-dessus d'un probable client et d'un enfant (cf. Zimmer 1982: cat. n 121, p. 185-186). En revanche, sur la fresque des Praedia Juliae Felicis (MANN Inv. $n^{\circ}$ 9063), une scène représente la vente d’objets métalliques; parmi ceux-ci, aucune balance ne peut être clairement distinguée.

${ }^{46}$ Deux objets seulement ont été mis au jour dans cette boutique, une lampe en bronze (Inv. n ${ }^{\circ}$ E2386=77682, cf. Conticello De Spagnolis - De Carolis 1988: cat. $\mathrm{n}^{\circ} 22$ p. 56) - qui pourrait provenir de l'extérieur du local, seule la façade de celui-ci ayant alors été mis au jour, cf. GSE 1961 : de libation ${ }^{47}$. Seule la volonté didactique du commanditaire permet de connaître le dieu ici évoqué, par le rajout - maladroit ${ }^{48}$ - de son nom. L'épiclèse dius fidius généralement accolée à son nom ne doit pas conduire à des débordements d'interprétation. En effet, M. Pagano considère que seules les vertus traditionnellement accordées au dieu - protection des serments et donc des transactions commerciales - permettrait d'expliquer son utilisation comme "réclame ${ }^{49}$. Pourtant, Semo Sancus, dieu du Latium, n'est certainement pas assez attesté en Campanie pour permettre un lien aisé entre sa représentation et son identification. L'important reste ici de montrer le lien entre l'activité commerciale et la présence d'un dieu, dont le caractère divin est immédiatement reconnaissable. En revanche, il serait impropre de trancher entre un acte de dévotion personnelle de la part du boutiquier et une volonté de placer son commerce sous la protection de la divinité, ces deux approches n'étant pas exclusives l'une de l'autre. La présence d'une figure divine en façade reste plus importante que la liste des prix en vigueur.

La seconde «enseigne » connue à Herculanum est beaucoup moins porteuse d'informations. Tout d'abord, sa date de découverte ne peut qu'être évaluée soit à juin 1933, soit aux environs d'octobre $1938^{50}$. Elle n'est jamais mentionnée

18 agosto - et une statuette en marbre représentant une tête de Bacchus (Inv. n E2387=77683).

${ }^{47}$ Selon P. Veyne (1990), les images de dieux se livrant à des libations sont des tautologies qui soulignent d'autant le caractère divin du personnage représenté.

${ }^{48}$ La lisibilité du nom est particulièrement faible, avec les deux dernières lettres insérées en minuscules dans le $C$; l'ensemble se situait originellement à $3,55 \mathrm{~m}$ du sol. Une lecture rapide s'avère source d'erreur, en dépit d'une position actuelle de la fresque plus basse que lors de sa mise au jour. Voir par exemple A. Wallace-Hadrill (1994: 177182), qui fonde un raisonnement sur le statut du propriétaire de la Casa del salone nero en utilisant une lecture "ad sanctum».

49 «Il dio era garante dei giuramenti e quindi della buona fede negli affari [...] e a ragione lo troviamo raffigurato come divinità protettrice (ma anche come réclame) nella nostra bottega ercolanese» (Pagano 1988: 211).

50 Les environs de la fontaine "d'Hercule», située à quelques mètres au sud de cette représentation ont été exhumés en deux temps: une première fois lors des dégagements du cardo V (GSE 1933: " 5 giugno. Sul V Cardine, lato Nord, lavoro fatto dalla Ditta privata, a m. 84 dall'angolo 
dans les journaux de fouilles, malgré sa première publication parmi les illustrations d'A. Maiuri ${ }^{51}$. Ce n'est qu'à la suite du colloque commémorant le $250^{\mathrm{e}}$ anniversaire du début des fouilles d'Herculanum qu'elle est prise en considération par G. Guadagno, puis publiée par M. Pagano ${ }^{52}$. Partiellement détruite par l'éruption, en lente dégradation depuis après sa découverte jusqu'à sa chute définitive, cette fresque n'offre que peu de renseignements. Ainsi, seuls deux brocs, assez similaires à ceux de la boutique VI, 14 sont discernables. Ils reposent sur un parallélogramme plus clair, simplement destiné à ne pas les laisser flotter dans le vide, mais difficilement interprétable comme un comptoir en perspective ${ }^{53}$. Il serait inutile de tenter d'insérer cette fresque dans les questions liées à l'interprétation des brocs représentés - sont-ils eux-mêmes à vendre ou bien seul leur contenu l'est-il ? - puisqu'elle n'apporte guère de donnée supplémentaire. La disparition de sa partie supérieure empêche de déterminer si une divinité y était figurée. L’inverse serait étonnant. En effet, lorsque l'on prend en compte les « enseignes » pompéiennes, on note que non seulement les représentations divines sont omniprésentes, mais surtout qu'elles sont primordiales.

Comme je ne saurai proposer ici une étude exhaustive du lien existant à Pompéi entre les peintures considérées comme des «enseignes» et les représentations divines, il me semble judicieux d'utiliser comme point de départ les peintures de façade représentant des métiers ou dotées d'une valeur partiellement commerciale.

del giardino della Casa $\mathrm{N}^{\circ} 1$ è stata sterrata una fontana di travertino bianco, lunga m. 2.20, larga m. 1.50 ed alta $\mathrm{m}$. $0.75[\ldots] »)$, puis lors de l'ouverture des travaux sur le decumanus maximus (juillet-septembre 1937, e.g. GSE 1937: "18 settembre. Si scava in trincea, per poter mettere alla luce il pavimento del Decumano Massimo »). Cette seconde date paraît la plus probable pour cerner la date de mise à jour de cette représentation, associée à la nécessité de contenir les terres surplombant le decumanus maximus.

${ }^{51}$ Maiuri 1958 b: fig. 51 p. 55.

${ }^{52}$ Guadagno 1993: n. 112 p. 88-89 et tav. XVI, 2 ; Pagano 1989.

${ }^{53}$ Contra Pagano 1989: 268.

${ }^{54}$ Une erreur d'interprétation du bâton situé entre les jambes de chaque personnage et le tour fait réfuter à A. Maiuri (1954 b: 91) l'idée qu'il puisse s'agir d'une représentation de confection d'objets céramiques. Il préfère interpréter ce bâton comme celui de voyageurs ou de clients d'une caupona, installés à une table. Le même instrument
Deux exemples permettent d'illustrer le rapport entre les dieux et une activité artisanale. Tous deux représentent un atelier de céramique à divers stades de fonctionnement. Le premier, mis au jour en 1940 sur le montant sud de la porte I 8,10, est mal conservé. Il se divise en deux champs. À gauche, l'espace est divisé en quatre parties, chacune comportant une étape du tournage d'un broc céramique à l'aide d'un tour à bâton ${ }^{54}$. Très lacunaire, le champ de droite est occupé par un autel sur lequel brûlent des offrandes. À la droite de celui-ci se tient un personnage dont seules les jambes sont visibles. Il aurait été vêtu comme un xoanon, tenant une verge dont la partie inférieure est conservée. Il est possible qu'il s'agisse de Minerve, déesse protectrice des activités artisanales, éventuellement figurée en tant que statue ${ }^{55}$. Si les lacunes de cette fresque rendent inutile tout commentaire d'ensemble, l'association entre une vue de métier - fût-elle un témoin d'activités largement antérieures à l'éruption - et une divinité reste notable. Elle est encore plus frappante sur la peinture mise au jour en façade de l'îlot II 3 (fig. 16). Sur le montant gauche de l'entrée $9^{56}$ sont représentés Mercure et Minerve, à peine perceptibles $^{57}$. Sur l'autre montant, Vulcain ou Héphaïstos semble accueillir ceux qui franchissent la porte. Dans son dos, un potier, assis devant son tour, le bâton permettant de le manipuler posé sous le volant, façonne des vases ${ }^{58}$. Malgré son importance du point de vue de l'histoire des techniques ${ }^{59}$, et bien que cet atelier de

est pourtant visible sur la fresque mise au jour en façade de II 3, 9 (Pompéi, Antiquarium, Inv. n²1631), bien que le volant soit plus bas. Sur l'interprétation de ces deux représentations et sur l'usage du tour à bâton ou à main durant l'Antiquité romaine, cf. Desbat 2004, part. 138-142.

${ }^{55}$ Maiuri 1954 b: 91 ; Fröhlich 1991: 51, 64.

${ }^{56}$ La position de la porte encadrée par les deux peintures varie selon les auteurs et les publications. Selon M. Della Corte (1965: $\mathrm{n}^{\circ} 814 \mathrm{a}$; cf. CIL IV, 7574), elle se trouverait sur le côté est de l'îlot, en II 3, 7. L'annuaire d'H. Eschebach (1993: 91-92) les place au sud, autour de II 3, 8. Dans le rapport des NSc (1939: 198-200, n 434 p. 313), A. Maiuri et M. Della Corte les signalent de part et d'autre de l'entrée II 3, 9. À la suite de Th. Fröhlich (1991: 313), je conserve cette localisation.

${ }^{57}$ NSc 1939: 313.

${ }^{58}$ Fröhlich 1991: 51-52, 313.

${ }^{59}$ Desbat 2004: 140-142. 


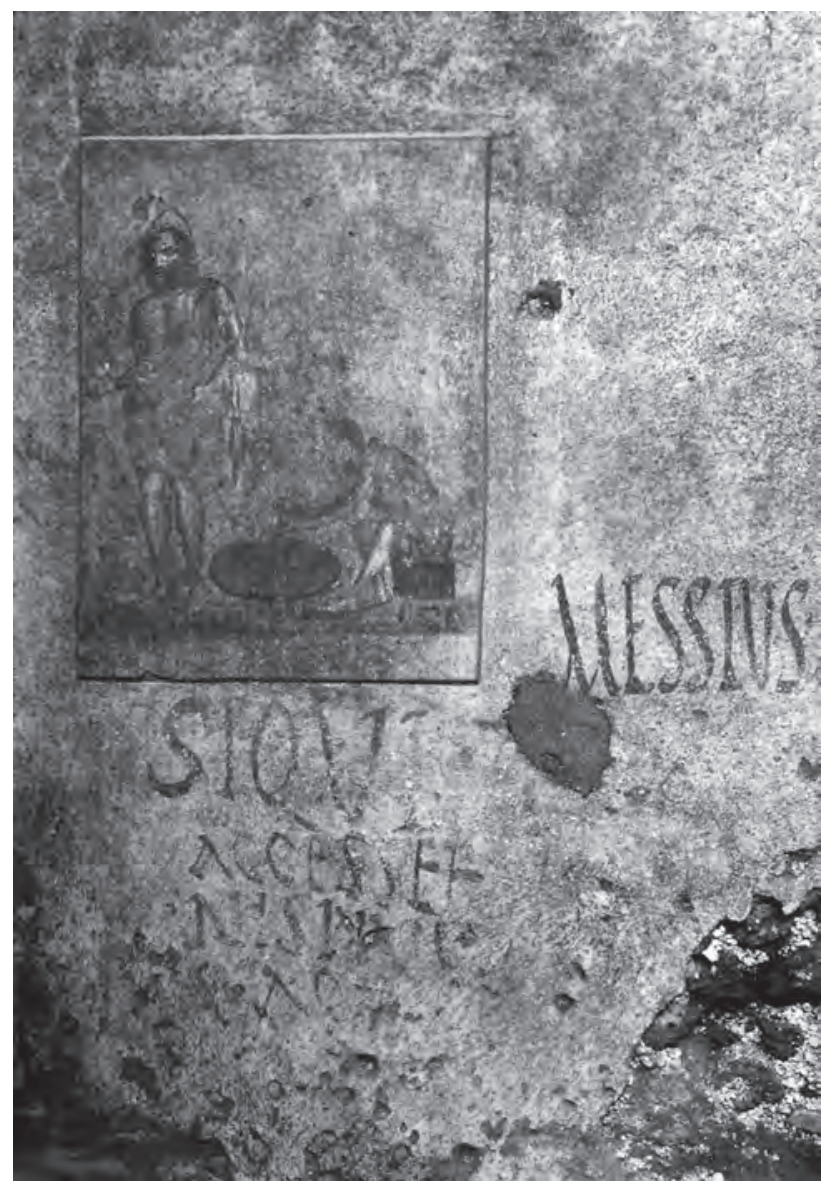

Fig. 16 - «Enseigne» sur la façade sud de l'îlot II 3 représentant la confection de vases grâce au tour à bâton sous la protection de Vulcain.

céramique n'ait pas été fonctionnel au moment de l'éruption ${ }^{60}$, cette fresque montrant trois divinités en rapport direct avec les activités de production $^{61}$ - Minerve protectrice des artisans, Vulcain protecteur des arts du feu, Mercure du commerce - est d'abord une manifestation reli-

\footnotetext{
${ }^{60}$ Cette absence de toute trace d'atelier fonctionnel dans le jardin rend l'interprétation de l'inscription CIL IV, 7574 [Si qui(s) / accesset / nisi ius / (h)ab(eat?)] délicate. Je ne saurais déterminer si cet avis est associé au fonctionnement de l'atelier ou à la dernière phase de cet espace. La présence de Mercure dans la fresque de façade semble impliquer de possibles transactions commerciales. Toutefois, il peut ne s'agir que de l'écoulement de la production, à d'éventuels intermédiaires, plutôt qu'une vente directe au consommateur final. Voir également Peña - McCallum 2009: 59-60,
} 76.

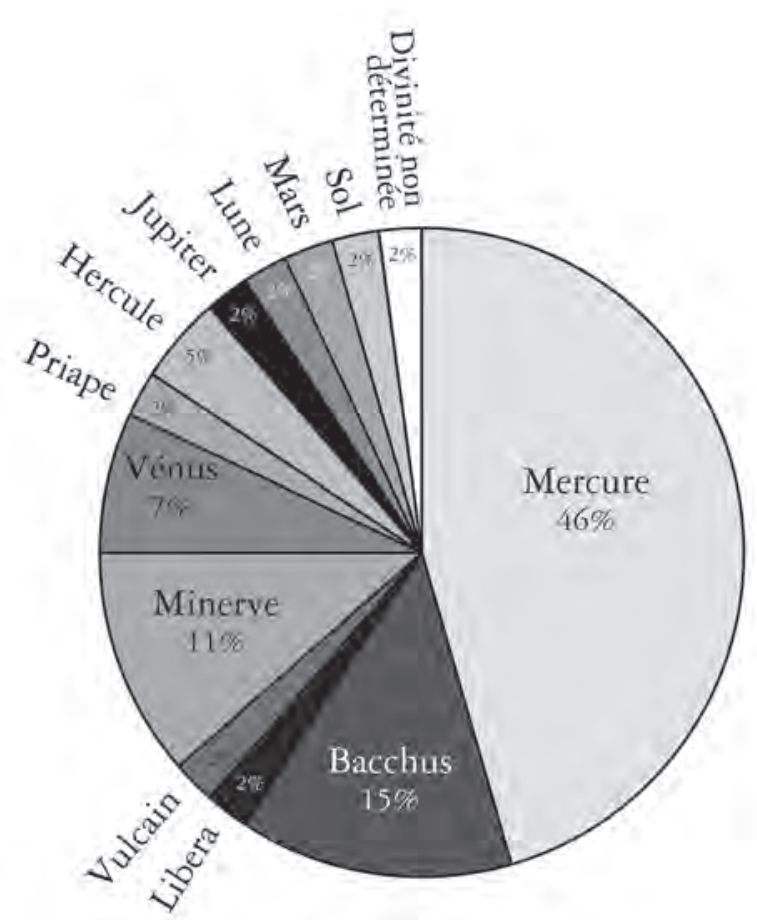

Fig. 17-Diagramme de répartition des divinités représentées sur vingt-six «enseignes » des boutiques de Pompéi. Chaque figuration est comptabilisée, même lorsque plusieurs ont été peintes sur la même façade.

gieuse. Comme dans la fresque de Semo Sancus à Herculanum, les informations sur la nature des activités s'étant déroulées dans le local restent d'importance secondaire ${ }^{62}$.

Ce trait transparaît plus encore si l'on prend en considération les représentations mises au jour en façade de locaux artisanaux ou commerciaux (fig. 17) ${ }^{63}$. Ainsi, parmi les 39 fresques de cette sorte, $26(67 \%)$ présentent au moins une

${ }^{61}$ Fröhlich 1991: 49-52.

${ }^{62}$ Des remarques identiques, donnant la prépondérance au fait religieux sur la représentation des activités, peuvent être effectuées à propos des fresques situées en façade de VI 7, 8-12 (cf. Fröhlich 1991: 319-320), de VI 13, 6.8-9 (cf. Fröhlich 1991: 322-323) et de IX 7, 7 (cf. Fröhlich 1991: 333-335). Sur cette dernière, cf. infra, p. 187-189.

${ }^{63}$ Ces fresques ne constituent pas l'intégralité de celles qui ont été découvertes lors des fouilles pompéiennes: seules celles bénéficiant d'une reproduction - dessin ou photographie - ont été considérées. 
divinité. Parmi ces dernières, seules 5 (19\%) sont également associées à une représentation des activités s'étant déroulées dans le local. Parmi les différentes occurrences (38) de dieux seuls ou en groupes, Mercure reste de loin le plus présent (18 figurations, 46\%). Cette surreprésentation n'est en rien étonnante, tant le dieu représente la médiation mercantile dans le monde romain $^{64}$. Si une bourse, supposé symbole du profit mercantile, est presque toujours tenue par Mercure, ce dernier peut également être muni de son caducée, qui renvoie au lucrum, "surcroît inattendu ${ }^{65}$. L'association entre cette forme de profits inespérés et la représentation de Mercure en façade des boutiques interdit de suivre A. Maiuri lorsqu'il décrit les boutiquiers pompéiens uniquement âpres au gain ${ }^{66}$. De plus, le fait que ce dieu ne soit pas omniprésent montre que la protection d'un ou plusieurs dieux est plus recherchée pour l'activité commerciale ou artisanale dans son ensemble que pour les seules entrées d'argent. Par ordre d'importance, vient ensuite Bacchus, représenté à sept reprises - en incluant Libera -, parfois en lien avec Mercure ou d'autres divinités ${ }^{67}$. Il n'est pas possible, en l'état actuel des connaissances sur les locaux disposant d'une telle fresque de déterminer si la présence de ce dieu est liée au commerce s'y déroulant - vente ou production de vin - ou bien s'il ne s'agit que d'un choix propre au tenancier. Le troisième groupe de représentations inclut Minerve et Vulcain, deux divinités protégeant traditionnellement l'artisanat. À chaque fois

${ }^{64}$ Voir sur ce point les remarques de B. CombetFarnoux (1980, part. p. 383-431) concernant l'évolution sous la République.

${ }^{65}$ Combet-Farnoux 1980: 429.

${ }_{66}$ «[... La cité restait entre les mains des nouveaux riches [...] dominés par une unique angoisse, par une seule fièvre ardente: l'argent: Salve lucrum. [...] Désormais descendu de l'Olympe, Mercure se transforme en ministre des plus humbles négoces humains [...] finissant par apparaître dégradé en une grotesque caricature sur la porte d'un thermopolion» (Maiuri 1943: 105-106).

${ }^{67}$ Pour simplifier, les représentations de Liber Pater ont été assimilées à celle de Bacchus. Sur les variations dans la représentation, cf. Fröhlich 1991: 129-132.

${ }^{68}$ Les deux locaux I 8, 10 et II 3, 7-9 paraissent, au vu de leur enseigne, avoir été des ateliers de production céramique. Leur inactivité au moment de l'éruption transparaît des éléments mis en évidence lors de la fouille (cf. Casti- qu'il a été possible de déterminer les activités de production se déroulant dans un local - au moment de l'éruption ou dans une phase antérieure -, les divinités représentées en façade leur sont liées ${ }^{68}$.

L'utilisation conjointe d'images de divinités avec des phallus rejoint cette observation. Priape, dans sa représentation humaine ou par son seul attribut, est censé avoir une valeur apotropaïque ${ }^{69}$. Il peut ainsi participer à la protection de la boutique. L'exemple le plus intéressant est constitué par le Mercure peint en façade de la boutique IX 12, $1^{70}$. Uniquement vêtu d'un pagne, tourné vers la gauche, il tient une bourse dans sa main droite. Le bras gauche légèrement replié soutient le caducée. Ithyphallique et couronnée de fleurs, cette divinité est une habile combinaison entre l'apparat traditionnel de Mercure et l'attribut de Priape. Selon une interprétation iconologique simpliste, la personne occupant le local IX 12, 1 se trouverait de la sorte protégée contre le mauvais œil, mais pourrait attirer les gains du lucrum. Cette fonction apotropaïque apparaît particulièrement importante dans les édifices commerciaux ou artisanaux. D'autres exemples méritent d'être signalés. Ainsi, la vasque de teinturerie située en IX 7, 2 expose deux phallus, dont l'un ailé et figuré dans un temple précédé de degrés ${ }^{71}$. À Herculanum, une boutique située dans la parcelle de la Casa del telaio $(\mathrm{V}, 3)$ voit son linteau orné d'un phallus, conservé en place même une fois la fonction commerciale de ce

glione Morelli - Vitale 1989: 198; Jashemski 1979: 176). Le local VI 7, 8 aurait été occupé en 79 par des menuisiers (AdI 1838: 168-169; Fiorelli 1875: 109). Aucun élément ne permet de déterminer les activités se déroulant en IX 3, 14, dont l'entrée est ornée par une représentation de Minerve et de Mercure (GdS 1870: 164, 211; GdS 1871: 212, 218; Fiorelli 1875: 396). Enfin, le local IX 11, 17 n'a pas été fouillé, seule son enseigne est connue: la présence de Minerve correspondrait à la première des trois phases de cette représentation (Spinazzola 1953: 163-166; Fröhlich 1991: 337-338).

${ }^{69}$ Herter 1938: 1733-1744.

${ }^{70}$ MANN, sans numéro d'inventaire. Cf. Spinazzola 1953: 251-252, fig. 213 p. 173, fig. 281 p. 252 (sur cette dernière, le phallus a pudiquement été masqué par de la peinture); Fröhlich 1991: 338.

${ }^{71}$ Cf. Spinazzola 1953: 251-252 et fig. 280. 


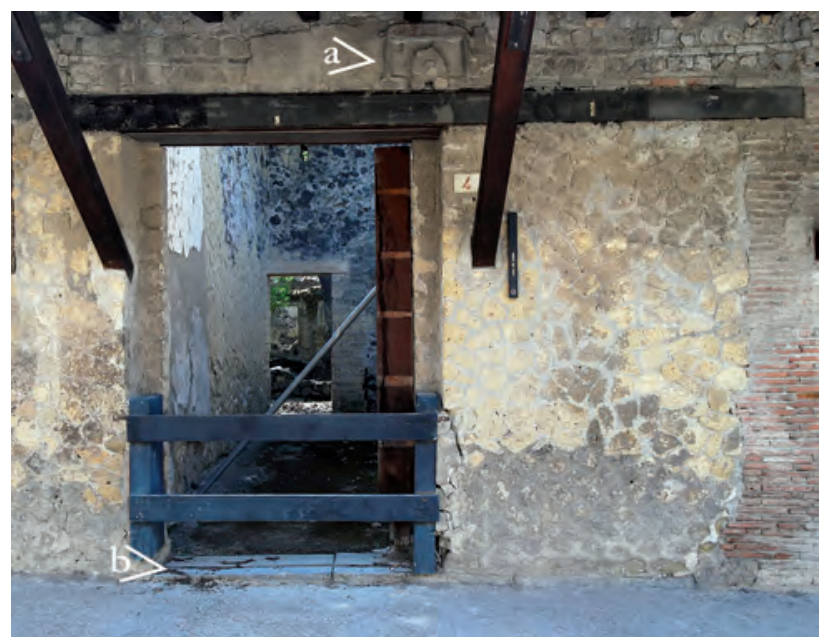

Fig. 18 - «Entrée » V, 4 de la Casa del telaio. En (a), un phallus sculpté au-dessus du linteau d'une boutique condamnée. En (b) la pierre de seuil de cette boutique, laissée en place.

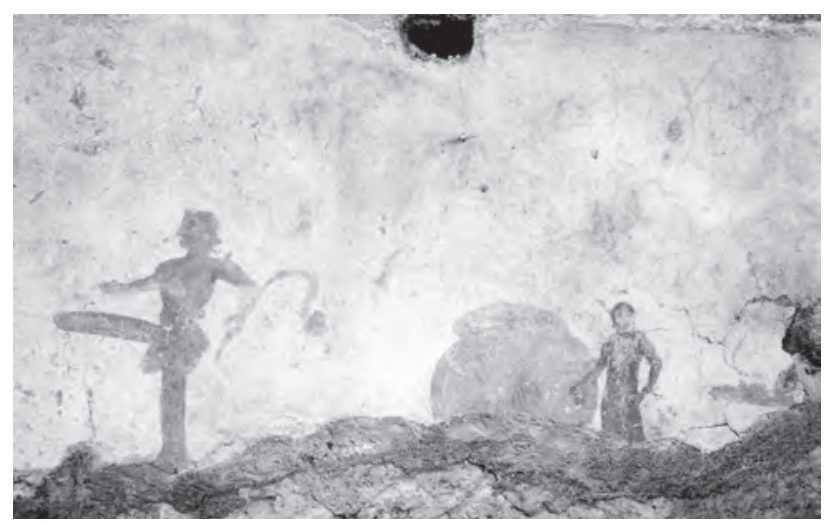

Fig. 19 - Représentation de Priape et d'un dolium à l'arrière du comptoir de la boutique IV, 17.

local abandonnée (fig. 18). Dans les boulangeries, ce sont les fours qui sont protégés par un phallus. Ainsi, en Or. II, 8 (cat. $\mathrm{n}^{\circ} 42$ ), juste

${ }^{72}$ Cf. infra fig. 73-74, p. 155 .

73 VI 6, 17-21; VI 14, 32; VIII 4, 26-29; IX 1, 3.33. L'hypothèse de B. J. Mayeske (1972: 26), qui estime que ce type de décoration montre une association entre le phallus et le pain, tous deux considérés comme "staff of life», ne saurait être suivie. Sans extrapoler outre mesure les exemples cités ci-dessus ou celui du four de la boulangerie Or. II, 8 à Herculanum, il conviendrait de vérifier la concomitance entre ces représentations de phallus et les restaurations liées aux séismes ayant frappé la région durant les années 60-70. Un rapide examen initial laisse en effet supposer que les reliefs de phallus ont été apposés sur des aménagements au-dessus de la bouche se trouvent deux de ces reliefs apotropaïques, réalisés en mortier. Le doublement pourrait paraître redondant, mais il est vraisemblablement à mettre en relation avec les conséquences d'une destruction partielle du four: après un probable séisme, la partie antérieure s'est fissurée et vraisemblablement effondrée ${ }^{72}$. Lors de la reconstruction, les deux reliefs auront certainement constitué un gage de protection supplémentaire. À Pompéi, il est plus délicat de déterminer la fréquence de telles représentations, à cause des restaurations qui les ont affectées. Toutefois, les fours d'au moins quatre boulangeries sont ainsi protégés ${ }^{73}$.

La recherche d'une protection pour le lieu d'exercice d'un métier peut apparaître non seulement en façade, mais également à l'intérieur même du local. Ainsi, le commerce alimentaire IV, 17 (cat. $\mathrm{n}^{\circ} 11$ ) présente sur le mur situé derrière le comptoir une fresque très dégradée mais sur laquelle on reconnaît la silhouette d'un Priape (fig. 19). Derrière lui, à droite, se trouvent un dolium et un second personnage - d'exécution plus fine - qui paraît tenir une bourse dans sa main droite. Une fois encore, outre la protection contre le mauvais œil, l'attraction du lucrum est revendiquée. Les fresques ne sont pas les seuls moyens utilisés par les boutiquiers pour être protégés. Dans la boutique "d'Asellina» (IX 11, 2), une lampe en bronze est suspendue aux bourses d'un pygmée ithyphallique $^{74}$. Une amulette phallique ainsi que six clochettes de dimensions variées sont également accrochées - probablement par des chaînettes - en divers points de son corps (fig. 20) ${ }^{75}$. Ces clochettes - tintinnabula - ont également vocation à repousser le mauvais œil ${ }^{76}$. On les retrouve isolées ou regroupées dans différents

- fours, montants de portes - restaurés, suite à une destruction potentiellement liée aux secousses telluriques.

${ }^{74}$ Sur la valeur apotropaïque et déplacée du pygmée, cf. Levi 1941: 224-225. Voir également Clarke 2003: 192-196 sur le rôle du rire comme ferment de la valeur apotropaïque des pygmées.

${ }_{75}$ Mis au jour le 11 décembre 1911, ces différents éléments ont été répertoriés sous le numéro d'inventaire Inv. ${ }^{\circ} \mathrm{P} 1098$. Les chaînes qui relient les clochettes, la lampe et l'amulette au pygmée ont été restaurées. Toutefois, les anneaux d'attache situés sur le corps sont antiques.

${ }^{76}$ Espérandieu 1912; Herzog Hauser 1937. 


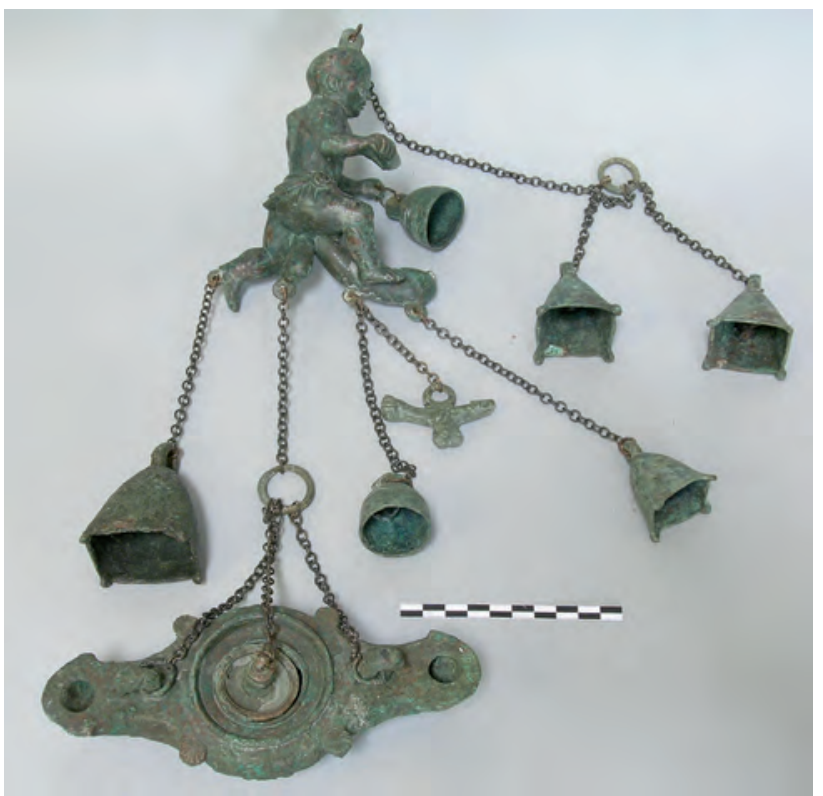

Fig. 20 - Lampe en bronze suspendue aux bourses d'un pygmée ithyphallique provenant de la boutique dite "d'Asellina » (IX 11, 2) à Pompéi.

locaux commerciaux d'Herculanum, parfois dans des pièces annexes, parfois dans le local principal ${ }^{77}$. Ces représentations et objets à valeur apotropaïque, mis en évidence pour constituer une revendication à l'usage de l'occupant mais aussi des clients, ne sont toutefois nullement une pratique propre aux boutiquiers, comme le montrent des exemples issus de vastes domus $^{78}$ : la volonté d'écarter le fascinum transcende les différentes couches de la société.

${ }^{77}$ Trois clochettes ont été trouvées dans la pièce 7 de la maison IV, 12-13.15-16, en lien avec le commerce alimentaire situé en IV, 15-16 (Inv. n E734-735, E740=76011-76012, 76017, mis au jour le 11 février 1932; cf. infra n. 146). Dans l'atelier Or. II, 10, une cloche a été exhumée dans la pièce principale et dans l'arrière-boutique. Toutes deux devaient avoir été suspendues, étant donné qu'elles ont été mises au jour à 15 et $80 \mathrm{~cm}$ du sol (Inv. $\mathrm{n}^{\circ} \mathrm{E} 1115=76392$, pièce principale, 19 juillet 1933; Inv. $\mathrm{n}^{\circ} \mathrm{E} 1622=76900$, arrièreboutique, 17 août 1936).

${ }^{78}$ La fresque montrant Priape à l'entrée de la Casa dei Vettii, trop souvent interprétée - à tort, cf. Kastenmeier 2001 - comme une marque de mauvais goût, participe de ce phénomène, tout comme les onze clochettes suspendues dans l'ambulacre de la Casa del rilievo di Telefo (Or. I, 2-3) [Inv. $\mathrm{n}^{\circ} \mathrm{E} 1229-1232=76507-76510$ et E1280 = 76558].

${ }^{79}$ Mercure tient une bourse et le caducée (cf. NSc 1899: fig. 4 p. 343); Vénus tient un timon et s'appuie sur un amour
La protection des aménagements artisanaux n'est pas nécessairement laissée aux seuls soins de Priape et des tintinnabula. Dans le commerce alimentaire V 4, 6-8, une partie des denrées vendues est produite sur place, grâce non seulement à un four à pain, mais aussi au huit dolia partiellement enterrés, destinés à la maturation du vin pressé dans une pièce voisine. Cet équipement est placé sous la triple surveillance de Vénus pompéienne, de Mercure et de Bacchus, représentés sur les montants encadrant l'entrée de la pièce et sur le mur ouest ${ }^{79}$. Le choix de ces dieux correspond pleinement aux activités exercées dans le local: vente (Mercure) notamment d'un vin produit sur place (Bacchus); Vénus renverrait alors à la divinité tutélaire de la cité ${ }^{80}$. Cette association entre des représentations de divinités et des aménagements artisanaux est particulièrement notable: il serait ainsi possible de considérer que ces fresques à motif religieux situées en façade - ou à proximité d'aménagements artisanaux - correspondent aux Pénates propres à l'exercice du métier pratiqué dans le local. Toutefois, il paraît peu probable de considérer que ces "enseignes » aient été directement impliquées dans des rites.

Plus que «l'esprit du temps» qui mettrait le commerce sous l'égide de la religion - «business under the aegis of religion »-, tel que l'a proposé M. Rostovtseff, ces « enseignes » montrent un lien étroit entre l'exercice d'un commerce ou d'une activité artisanale et la religion ${ }^{81}$. Ces représentations en façade des boutiques ne sont que

(cf. NSc 1899: fig. 5 p. 344); Bacchus tient le thyrse et verse un liquide dans la gueule de la panthère qui se tient à ses pieds; il est accompagné par la Ménade (cf. NSc 1899: fig. 6 p. 345). La position de ces trois peintures donnée par A. Sogliano est erronée, puisqu'il les place dans la pièce a, située au nord de l'entrée V 4, 6, sans plus de précision (NSc 1899: 344). A. Mau décrit les peintures dans la salle du pressoir (MDAIR 1902: 314-315). R. Paribeni renvoie au texte d'A. Sogliano, sans indiquer leur position au fil de sa description (NSC 1902: 375-378). Les restes de ces peintures encore en place donnent foi au texte d'A. Mau (cf. PPM III: fig. 4-5 p. 1058).

${ }^{80} \mathrm{Je}$ remercie particulièrement W. Van Andringa pour ses remarques sur ces différents problèmes religieux.

${ }^{81}$ SEHRE $^{2}$ : 100, commentaire à la pl. XVI. J.-P. Morel (1987: 144; 1992: 293-291) propose une interprétation, à mon sens exagérée, de cette expression: il en déduit des liens topographiques étroits entre les édifices religieux et les implantations commerciales. 
rarement de véritables enseignes à destination exclusivement commerciale. Sur les 33 représentations pompéiennes, trois seulement ont cette fonction. La première, située sur un mur perpendiculaire à la rue entre les locaux IX 11, 4 et IX 11, 5 représente divers objets en bronze: un cratère, des œnochoés et un entonnoir ${ }^{82}$. Sa position la rend particulièrement visible pour les passants allant vers l'est de la ville en empruntant la Via dell'Abbondanza. Les deux autres pourraient donner le nom des établissements en façade desquels elles se trouvent, sans avoir de valeur strictement religieuse: la caupona « du phénix » (I 11, 10-11) ${ }^{83}$ et l'hospitium «de l'éléphant»(VII 1, 44-45) ${ }^{84}$.

À l'exception de ces trois cas, le terme d'enseigne est donc largement usurpé pour ces représentations principalement religieuses. $\mathrm{Si}$ Mercure, divinité du commerce et des gains réalisés par le biais de celui-ci est fréquemment dépeint, le choix de la divinité figurant sur la façade s'étend à d'autres dieux. Les croyances personnelles du boutiquier, tout autant que l'image qu'il veut renvoyer à ses clients, ont nécessairement influé sur de tels choix ${ }^{85}$. À la place de ces fresques religieuses, ou combinés avec elles, des images et objets apotropaïques sont également présents, en façade, bien en vue à l'intérieur ou sur des aménagements de grande importance pour les activités se déroulant dans ces locaux. Si cette dernière pratique correspond à une volonté de se protéger soi- même et le lieu de son travail du mauvais œil, l'interprétation des fresques de façade reste délicate. Montrent-

82 Contrairement aux deux représentations d'Herculanum, il est délicat de trancher en faveur d'une interprétation de cette enseigne. Il peut s'agir d'une boutique vendant des objets en bronze aussi bien que du vin: tous les objets représentés semblent réalisés dans ce métal et peuvent avoir été utilisés pour la consommation de cette boisson (Spinazzola 1953: 246 et fig. 273 p. 257). Contrairement à ce qui est proposé par G. Spano (NSc 1912: 112 et fig. 3 p. 29), il est hautement improbable que cette enseigne ait servi à la boutique dite «d'Asellina ( (IX 11, 2).

${ }^{83}$ Pompéi, Antiquarium, Inv. n 2195 . Sous la représentation d'un phénix - réalisée soit en prenant comme modèle un lophophore resplendissant (Lophophorus impejanus), selon Ansaloni et al. 2007, soit en s'inspirant du faucon égyptien divinisé selon A. Tammisto (1986) - figure l'inscription CIL IV, 9850: Phoenix felix / et tu. Les amphores mises au elles des Pénates? Ont-elles une fonction autre qu'une demande d'intercession pour la protection des locaux? Comment s'intègrent-elles au culte domestique? Comment sont-elles perçues par les passants, clients potentiels? À défaut de pouvoir répondre à ces questions, il faut souligner deux points. Tout d'abord, les images de métier pouvant accompagner ces représentations religieuses restent exceptionnelles et doivent donc être interprétées comme telles: le boutiquier ou l'artisan qui se mettent ainsi en scène se trouvent dans un processus qui est significatif par et pour lui-même. Enfin, la rareté de ces scènes de métier en façade et la variété des divinités représentées - qui ne peuvent être associées à un négoce particulier - font que ces «enseignes » n'apportent qu'une contribution marginale à l'identification des activités se déroulant dans les locaux commerciaux et artisanaux.

\section{I.2.2 Les systèmes d'ouverture}

Un second élément de la façade permettrait d'indiquer la nature commerciale ou artisanale des activités se déroulant dans un local: son système de fermeture. L'absence d'indication d'un commerce par le biais de l'affichage en façade - ou du moins sa rareté - n'a-t-elle pas été palliée par un moyen plus pragmatique, permettant aux clients potentiels de se rendre compte directement des activités pratiquées dans chaque boutique ou atelier? Si des études ponctuelles à l'échelle d'un îlot ont pu être menées sur les fermetures des pièces, il n'existe actuellement

jour dans ce local permettent de considérer qu'il était tenu par un caupo appelé Euxinus (AE 1967, 86d: Pompeis / ad amphitheatr(um)/Euxino coponi). Selon A. Baldi (1964: 798), l'enseigne pourrait avoir eu une valeur néo-pythagoricienne.

${ }^{84} \mathrm{La}$ fresque représente un éléphant et un pygmée. Au-dessus se trouve la légende CIL IV, 806: Sittius restituit / elefantu(m). En dessous est peinte l'annonce CIL IV, 807: hospitium hic locatur / triclinium cum tribus lectis / et comm(odis).

${ }^{85}$ C. Potts (2009) aboutit à des conclusions similaires en se fondant sur le seul exemple de la façade entre les portes IX 7, 1 et IX 7, 2. En revanche, on ne saurait la suivre sur son identification de collegia professionnels à Pompéi, fondée sur une lecture très discutable d'une inscription électorale (Potts 2009: 67-69). 
aucune recherche exhaustive sur ce point pour l'aire vésuvienne. C'est pourquoi j'ai choisi de me référer de préférence aux travaux d'A. Bouet sur Olbia-de-Provence ${ }^{86}$.

Les seuils mis au jour à Herculanum sont réalisés en tuf, en lave, en calcaire blanc, voire - dans de rares cas - en marbre. Quel que soit le type d'ouverture, un nombre important de seuils $(44,31 \%)$ n'a pas été décrit lors de la fouille, ce qui signifie que ceux-ci ont été emportés. Ces disparitions sont à mettre sur le compte des méthodes de fouilles du XVIII siècle. Actuellement, le seuil de la boutique V, 6 (cat. $n^{\circ} 12$ ) est restauré en béton de tuileau moderne: seul subsiste du seuil antique un bloc ne comportant que la rainure longitudinale, disposé devant la boutique sur le trottoir ${ }^{87}$. Il est possible que l'utilisation du bois pour confectionner des seuils n'ait pas été réservée aux seuls étages ${ }^{88}$. Par delà ces absences, l'usage différencié des pierres utilisées pour les seuils permet de mettre en évidence une volonté de monumentaliser ou du moins de rehausser l'aspect de certaines entrées. L'accès principal à une maison privée de plain-pied est fréquemment réalisé en calcaire blanc ou en marbre: les deux entrées de la Casa del salone nero sont distinguées par le type de matériau utilisé, calcaire blanc pour celle donnant dans l'atrium, tuf pour l'entrée secondaire. L'accès aux étages peut également être différencié par le matériau. Ainsi, immédiatement au nord de la boutique

${ }^{86}$ Une étude des systèmes de fermeture a été menée à propos de l'îlot I 10 de Pompéi (Ling 1997 b). La recherche effectuée par Y. Hori (1992), quoique concernant exclusivement Pompéi, ne saurait être qualifiée d'exhaustive, ne serait-ce que par son absence de prise en compte dans sa typologie des seuils marqués par une pierre, mais dépourvus de porte. Ce type de séparation est en revanche étudié par A. Bouet (1995: type A, p. 10-15).

${ }^{87}$ GSE 1933: «6 maggio. L'Ambiente $\mathrm{N}^{\circ} 1$ della Casa n. 6 , sul IV Cardine, lato Est, è stato svuotato. [...] Il vano esterno è largo m. 3 ed alto m. 2.47, la soglia manca [...]».

${ }^{88}$ Les seuils en bois à l'étage sont attestés tant dans les journaux de fouilles (cf. GSE 1929: «27 maggio. [...] La stanza n. 1 misura m. 4.75 x 4.95, vi si sale mediante la scala che si trova nella bottega d'angolo n. 10 [...]. La soglia è di legno carbonizzato ed è rimasta in sito ", à propos du seuil situé à l'étage de la boutique III, 10, donnant accès à l'espace situé au-dessus de la pièce 2) que par la découverte de crapaudines en bronze isolées. Toutefois, dans sa description de la boutique «d'Asellina » à Pompéi (IX 11, 2),

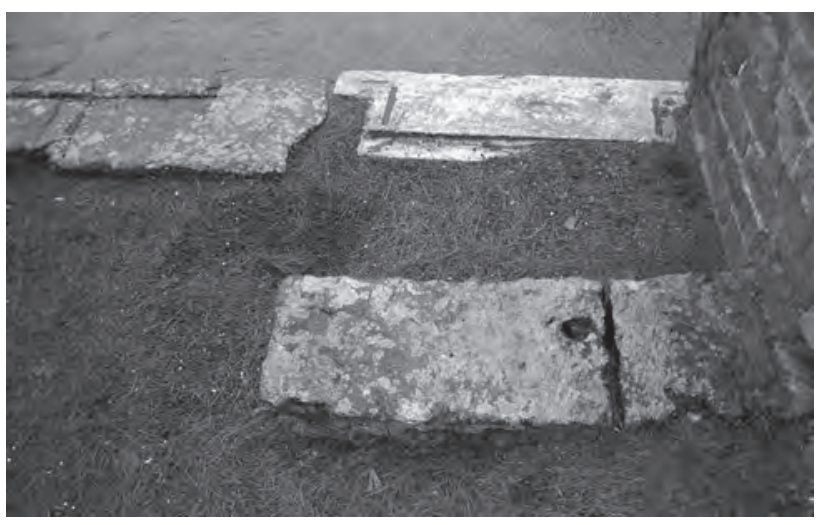

Fig. 21 - Seuils en façade de l'Insula Orientalis $I I^{a}$. À gauche, seuil de la boutique Or. II, 1 en tuf gris. À droite, seuil en calcaire permettant l'accès à l'étage Or. II, $1 \mathrm{~b}$ (cliché pris de l'est).

Or. II, 1 (cat. $\mathrm{n}^{\circ} 38$ ) se trouve une entrée indépendante menant à l'étage (Or. II, 1b). Le seuil du local commercial est en tuf, tandis que celui de l'appartement est en calcaire (fig. 21) ${ }^{89}$. Outre cette différenciation matérielle, les seuils de boutiques ont un fonctionnement caractéristique permettant de créer une vaste ouverture et donc un accès important pour la clientèle. Ils ont un pas étroit et un double système de fermeture. D'un côté, un vantail mobile permet d'accéder au local en dehors des heures de fonctionnement du commerce. Le long de la majeure partie

G. Spano déclare avoir observé un seuil en bois, entre l'espace de vente et la rue: "Il termopolio, di cui diamo qui la pianta e la veduta aveva il vano di ingresso largo m. 2,67 e la soglia di legno che ci è attestata dalla impronta " (NSc 1912: 113).

${ }^{89}$ GSE 1932: « 7 aprile. [...] Il quarto ed ultimo vano al lato sud è lungo m. 4.96 e la soglia per m. 1.36 è di travertino bianco [cette mesure inclut la portion de seuil prise sous la maçonnerie], per m. 1.44 di pietra vulcanica, per m. 1.36 di tufo e per m. 0.78 di travertino. L'ingresso aveva due porte. La prima, estremità nord, è lungo m. 0.97 costruita con due battenti, i quali erano attaccati agli stipiti di legno larghi m. 0.23 e dello spessore di m. 0.03 mediante cornice di bronzo. La seconda porta si presenta ad un sol battente largo m. 0.23 e la rimanenza con incavo sulla soglia $[\ldots]$ ». Contrairement à ce que propose A. Maiuri (1958 b: 455), il me semble nécessaire de considérer l'accès à l'étage comme indépendant de la boutique. Ce doublement du vantail mobile est inutile si l'accès à la boutique donne également accès à l'étage. 


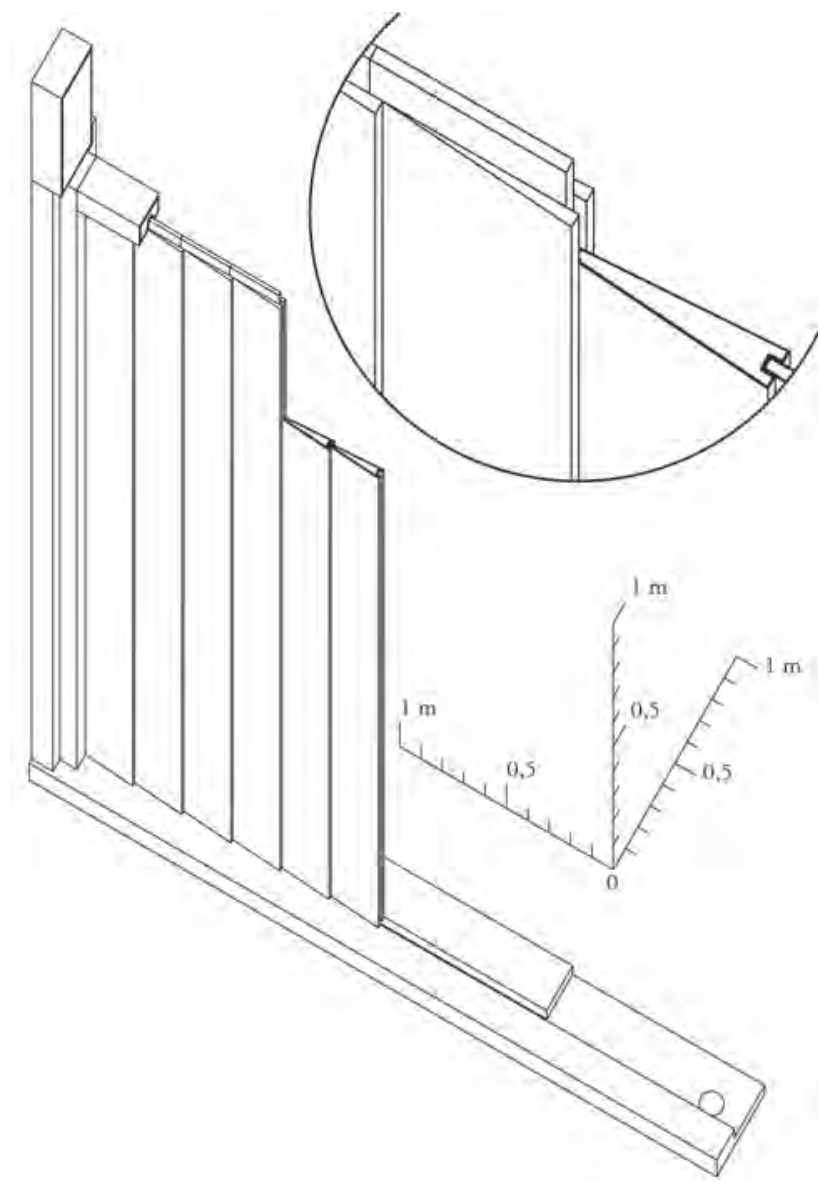

Fig. 22 - Restitution isométrique du système d'encastrement des planches fermant la boutique DM 4E à Herculanum (échelle 1/40; détail encadré, échelle 1/10).

${ }^{90}$ Ces seuils correspondent aux types D1a (vantail à droite, rainure à gauche) et $\mathrm{D} 1 \mathrm{~b}$ (vantail à gauche, rainure à droite) de la typologie développée par A. Bouet (1995: 3034).

${ }^{91}$ Seules deux attestations de ces rainures d'architrave sont connues, en dépit de la fréquente observation de ces pièces de bois à Herculanum. Elles concernent la boutique IV, 7 (GSE 1928: «27 novembre. [...] Un terzo vano sempre nel medesimo lato [«lato est del II cardine» correspondant au côté est du cardo IV] è apparso è largo m. 2.70 e alto $\mathrm{m}$. 2.34. L'architrave è alto $\mathrm{m}$. 0.15 . Il vano appartiene ad un magazzino. Difatti sulla soglia di travertino si nota l'incasso che serviva per contenere le tavole. Il medesimo incasso notasi nell'architrave carbonizzato [...]») et la porte de boutique partiellement rebouchée en V, 4 (GSE 1931: 22 agosto, cf. infra $\mathrm{n}$. 101).

92 Cf. Spinazzola 1953: fig. 749 p. 768. Les planches permettant de fermer la boutique située à l'arrière du $4^{\mathrm{e}}$ pilastre du côté nord du decumanus maximus ont été ainsi décrites par les GSE 1961: «8 agosto. [...] Sulla sinistra dell'ingresso accenni di porta a pulisse formata da numero 6 doghe a sezione trapezoidale con incastro a coda di rondine. du seuil, partant de la feuillure excavée pour permettre l'articulation du vantail, se trouve une rainure longitudinale ${ }^{90}$. Le rassemblement d'éléments épars provenant tant d'Herculanum que de Pompéi permet de comprendre la structure et le fonctionnement de ces portes (fig. 22). À la rainure longitudinale du seuil répond, directement creusée dans le linteau, une rainure similaire $^{91}$. Elles permettent de glisser des planches qui sont encastrées les unes dans les autres par un système d'enture à enfourchement, comme le montrent les lattes mises au jour dans la partie nord du decumanus maximus d'Herculanum ou les moulages réalisés en IX 7, 7 et en IX 7, 10 à Pompéi ${ }^{92}$. La partie externe du système de fermeture a été observée dans la fullonica de Stephanus $(\mathrm{I} 6,7)$ et dans le probable accès à l'atelier de feutre de Verecundus (IX 7, 7). Chacune des planches constituant la partie démontable de la porte est munie d'un anneau en fer. Une fois le vantail mobile refermé, deux barres coudées à l'une de leurs extrémités s'insèrent dans les anneaux, d'abord du côté des planches puis du côté du vantail ${ }^{93}$. Les deux becs de canne s'unissent et sont maintenus assemblés par un cadenas ${ }^{94}$. Ce dernier permet au boutiquier de fermer sa porte une fois à l'intérieur de son local, si celui-ci lui sert également d'habitation. Ce système d'ouverture modulable présente toutefois l'inconvénient d'occuper une partie de

Le doghe sono larghe metri 0.18-0.19 e sono spesse da un lato cm 1 e cm 5 all'incastro [...]». L'emploi du terme de queue d'aronde est abusif: un tel tenon empêcherait la désolidarisation des planches lors de leur démontage. Les mesures reportées sur la figure 22, prises sur les planches conservées sur place dans un local voisin (DM, 4 E), diffèrent un peu.

${ }^{93}$ Selon V. Spinazzola (1953 : fig. 751 p. 769 ), la pointe de chacune des barres est supposée s'insérer dans le montant en bois. Pourtant, les deux exemples dont il montre les photos (Spinazzola 1953: fig. 221 p. 190, 749 p. 768), ne permettent pas une telle conclusion: les deux barres s'arrêtent avant d'atteindre le montant. Toutefois, la barre située du côté du vantail semble, d'après les photos de fouille, être également fixée à celui-ci par des anneaux.

${ }^{94} \mathrm{La}$ clé - caractéristique d'un système à glissement ou à double poussée - permettant de fermer la porte de la fullonica de Stephanus a été mise au jour à proximité de la porte (NSc 1912: fig. 2 p. 247), ce qui laisse supposer que l'un des occupants a cherché à se protéger à l'intérieur de cet atelier au moment de l'éruption. Sur le fonctionnement des serrures durant la période romaine, cf. Ciurletti 1996, part. p. 76 . 
la boutique avec les planches démontées lorsque le commerce fonctionne: dans le cas de la boutique IV, 7 à Herculanum, quelques 18 planches larges de $10 \mathrm{~cm}$, longues de près de $2,4 \mathrm{~m}$ et épaisses de $2 \mathrm{~cm}$ devaient être entreposées à l'intérieur. Malgré ce problème de rangement et de manutention, de telles ouvertures permettent de laisser voir l'ensemble des activités se déroulant dans la boutique ou dans l'atelier, rendant presque inutile toute enseigne figurant cette information. La boutique s'ouvrant au nord de la Casa con giardino (V, 32 ; cat. $\left.\mathrm{n}^{\circ} 24\right)$ dispose d'un seuil en tout point singulier. En effet, aucun des trois blocs de tuf qui la composent ne présente de crapaudine permettant d'insérer et d'articuler un vantail ${ }^{95}$. L'absence de rainure longitudinale et la largeur du pas obligent à restituer deux vantaux articulés, se repliant sur eux-mêmes et sur les montants de l'ouverture et l'absence de gâche laisse supposer un système de barre transversale pour assurer la fermeture de la porte ${ }^{96}$.

Les seuils des lieux de métier ne sauraient toutefois se limiter aux portes à coulisse. Ainsi, l'atelier VI, 30 (cat. $n^{\circ} 27$ ) présente un seuil à pas étroit et à deux vantaux mobiles en tuf gris. Les cavités de deux paires de crapaudines sont visibles à sa surface, indiquant un remploi. Le seuil ne permet donc évidemment pas à lui seul de caractériser un atelier. Il convient cependant de se demander la raison de l'absence d'une ouver-

${ }^{95} \mathrm{Il}$ est possible que cette disparition des crapaudines soit due à la restauration des deux montants de la porte, qui débordent très largement sur le pas. Ils auraient ainsi englobé ces dernières, en dépit d'un espace ménagé de part et d'autre du seuil, large d'une trentaine de centimètres, destinés à servir de première assise à ces montants.

${ }^{96}$ Conformément la typologie d'A. Bouet (1995:15-19), j'ai défini ce seuil à pas large et vantaux articulés comme de type B3.

${ }^{97}$ Un local situé en face de VI, 30, en VII, 12 montre un système de fermeture étroite assez proche. Un seuil à rainure longitudinale - appartenant vraisemblablement à une phase précédente - a été partiellement englobé dans la maçonnerie, ne laissant comme ouverture que la partie accueillant le vantail. Les aménagements internes de cette boutique, observés depuis la rue à cause de travaux de restauration en cours, laissent supposer la présence d'un atelier de nettoyage des toisons au cours de la dernière phase. N'était le contre-exemple du local Or. II, 18, il serait possible de considérer que ce type de locaux se dispense d'ouverture large. Sur ces ateliers, cf. infra, p. 170-175. ture large à l'entrée de ce local. Cela peut être dû à un faible lien avec la clientèle: ne recherchant pas de contact direct et fréquent avec celle-ci, l'artisan y œuvrant n'aurait ainsi pas eu besoin d'ouvrir largement son local pour faire connaître ses activités ${ }^{97}$. Une autre hypothèse tient à l'histoire même de cet atelier: inséré tardivement dans un espace interstitiel des thermes, l'utilisation d'un seuil préexistant aurait alors été préférée aux travaux de percement d'une ample ouverture.

À l'inverse, une large porte ne détermine pas nécessairement un local commercial. Ainsi, le seuil III, 2 de la Casa dell'albergo (III, 1-2.18-19) ne se présente pas comme un seuil à pas étroit et rainure longitudinale. En effet, aucune cavité courant sur toute la longueur des blocs de tuf n'y est visible. Deux crapaudines en calcaire creusées à proximité des montants n'indiquent en rien l'utilisation de planches mobiles pour assurer la fermeture. Bien au contraire, il faut certainement considérer que des vantaux articulés permettaient de clore ce vaste espace, interprétation également appuyée par l'absence de creusement pour la gâche ${ }^{98}$. Dès lors, il faut tenter de revenir sur l'interprétation de ce local comme une boutique, visiblement motivée par la seule largeur du seuil ${ }^{99}$, sans que les objets ou aménagements découverts à l'intérieur ne permettent de conforter cette hypothèse ${ }^{100}$. Dès lors, en dépit

${ }^{98}$ Type C1b, cf. Bouet $1995: 20$.
${ }^{99}$ Ruggiero 1885 : XLVII.
${ }^{100}$ Lentrée du journal de fouille concernant cet espace est la suivante: "Ercolano 13 giugno 1830. Un nuovo edifizio le cui pareti esteriori sono adorne di finte bugne e che si distende lungo la strada antica già nota, si è in questa settimana principiato a restituire al giorno. Il suo ingresso mena ad un cortile dipinto d'un turchino che muore nel nero, ed un lungo corridoio sormontato da qualche cenacolo o stanza superiore conduce nell'interno dell'abitazione. Sul lato opposto della strada si comincia a scoprire una bottega e qualche dietrostanza, tutte vagamente decorate. Tra gli oggetti ivi recentemente rinvenuti e di cui sto compilando l'analogo verbale si deve distinguere una gamba e porzione del petto di un cavallo di bronzo, un candelabro e qualche utensile di cucina dello stesso metallo. Bonucci » (Ruggiero 1885: 564). Selon M. Ruggiero (1885: 564 [renvoi à la pl. XII, $\left.\mathrm{n}^{\circ} 19\right]$ ), dont l'hypothèse a été reprise par A. Maiuri (1958 b: 267), cette façade serait celle de la Casa dello scheletro, de telle sorte que la boutique située sur le côté opposé de la rue serait soit l'entrée II, 2 de la Casa d'Argo, 
des assertions de M. Ruggiero, le local III, 2 ne paraît pas avoir eu de fonction commerciale.

Enfin, avant de caractériser les activités se déroulant dans un local par le seuil dont celui-ci est pourvu, il est nécessaire de prendre en compte la dimension diachronique. Un exemple est constitué par les deux ouvertures de la boutique IV, 15-16 (cat. $n^{\circ} 10$ ): dans les deux cas, le bloc le plus à droite présente, outre l'extrémité de la rainure permettant de faire coulisser des planches, la trace de deux paires de crapaudines. Ces creusements très clairs indiquent qu'après avoir été utilisé pour une fermeture à deux vantaux mobiles, le pas a été démaigri et sa largeur réduite pour permettre le creusement de la rainure. Ces aménagements pourraient indiquer l'existence d'une porte "d'habitation privée » dans une phase antérieure. Inversement, l'exemple de la Casa del telaio montre le bouchage partiel d'une large ouverture de boutique afin de la transformer en lieu d'habitation. Dans une phase précédant l'éruption, un local commercial s'ouvrait en devanture de la Casa del telaio, en lieu et place de l'entrée $[\mathrm{V}, 4]$. Le linteau de cette large ouverture a été conservé, ainsi que le bas-relief en forme de phallus inséré dans la maçonnerie au-dessus

soit l'entrée II, 3 de la Casa del genio. Cette interprétation du texte de $\mathrm{C}$. Bonucci est problématique: aucune de ces deux entrées ne pourrait avoir été prise pour un commerce. Si en revanche la façade décrite appartient à la Casa del genio - ce que la description de l'organisation des pièces autoriserait -, il est alors possible que la bottega décrite corresponde à l'entrée III, 2 de la Casa dell'albergo. Dans les deux hypothèses, aussi peu étayée l'une que l'autre, il reste étonnant que les colonnes précédant la Casa del genio et la Casa d'Argo ne soient pas décrites. Leur découverte n'est indiquée que le 30 septembre 1830 (Ruggiero 1885: 565).

${ }^{101}$ GSE 1931: « 22 agosto. Il vano numero 4 che trovasi sul $3^{\circ}$ cardine $[=$ cardo IV] lato est è stato sterrato per $\mathrm{m}$. 1.10. Il pilastro lato sud è di opera incerta ed è alto $\mathrm{m}$. 2.36. La faccia interna è coperta da tegole di terracotta. Lo stipite di legno carbonizzato è dello spessore di m. $0.20 \mathrm{e}$ largo m. 0.30. L'architrave è alto m. 0.20 per 0.30 . La faccia esterna dell'architrave è coperto per tutta la sua altezza da un tavola dello spessore di m. 0.02. All'estremità inferiore dell'architrave la tavola fa gomito e gira nella parte interna e termina all'orlo di una rozza scanalatura profonda $\mathrm{m}$. 0.023 e larga m. 0.043. All'estremità sud dell'architrave sostenuto allo stipite vi è infisso un cardine di ferro. Anche la soglia presenta la stessa scanalatura, perciò l'ambiente doveva essere una bottega. Nessun trovamento ».

102 GSE 1931: " 5 settembre. Il vano numero 4 lato esterno della Casa sannitica sterrata in parte il 22 agosto de celui-ci (fig. 18). De la même façon, le seuil en tuf gris a été laissé en place avant que la porte ne soit bouchée. Seule la partie nord, comportant une rainure longue de 1,72 m, est restée dégagée de tout appareil. En l'état actuel, ce seuil ne peut avoir été fonctionnel durant la dernière phase de la cité: aucune crapaudine n'y a été ménagée pour permettre la mobilité d'un vantail; des planches insérées dans la rainure n'auraient pas pu en être extraites. Seul un étonnant cardine en fer est mentionné par les GSE, pris dans le linteau ${ }^{101}$. La description finale de cette porte de boutique, murée au sud avec de la maçonnerie, au nord par des planches fixes, est erronée ${ }^{102}$. En effet, rien ne permet de considérer avec les rédacteurs de ce rapport que la porte était formée de deux battants. De plus, l'argument des cabochons qui ne seraient utilisés que sur des portes de case private est peu décisif et contredit par l'exemple de la porte de la boutique III, 15 (cat. $\left.\mathrm{n}^{\circ} 6\right)^{103}$. L'absence de crapaudine oblige à considérer que la porte était murée avec des panneaux de bois au moment de l'éruption. Si une telle pratique est difficile à expliquer, elle témoigne toutefois du remploi d'un seuil de boutique à l'endroit de son utilisation première.

è ora completamente libera del materiale che lo copriva. È alto m. 2.97 e largo m. 1.72. La muratura che si sviluppa sopra l'architrave è alta m. 0.42 ed è fatta da un filare di mattoni, ed un altro ad opera incerta alternandosi fino all'altezza citata. Benché l'architrave e la soglia presentava struttura di porta di magazzino pur tuttavia essa era formata a due battenti. Difatti era il vano una volta lungo m. 3.80, attualmente il carbone per detta lunghezza è tutto in sito, ma poscia ebbe la sua trasformazione e rimpicciolirono l'apertura rimanendo lo stesso architrave e la stessa soglia e trasformarono la sola porta e per fare sì che i battenti non fossero obbligati ad entrare sia nella scanalatura soprastante che sottostante aggiunsero un rialzo di 2 centim. di legno all'architrave (descrizione del 22.8.31) da formare battito. Se tanto poi non fosse sufficiente per dimostrare la trasformazione della porta basta guardare alcune borchie di ferro che ornavano la parte inferiore dei battenti. (La parte superiore era spezzata da cunicoli borbonici). Ornamenti usati solamente da porte di case private».

${ }^{103}$ GSE 1928: " 27 dicembre. [...] Il terzo vano è largo m. 2.50, e alto m. 2.26. La soglia è di pietra di piperno. Quest'ultimo vano appartiene ad un magazzino. Difatti per m. 0.70 a lato nord è chiuso da una porticina di legno carbonizzato con decorazione di borchie di ferro. Numero 7 ve ne sono attualmente attaccate alla porta [...]». 
En théorie, la façade des locaux commerciaux et artisanaux pouvait être ornée de fresques à motifs essentiellement religieux mais comportant occasionnellement des représentations directement associées avec les activités pratiquées-objets en vente ou fonctionnement de l'atelier. Rares, ces représentations des artisans ou des boutiquiers dans le cadre de l'exercice de leur métier n'en sont que plus précieuses pour l'histoire des techniques. Outre ces fresques, le système de fermeture à vantail mobile et panneaux coulissants paraît avoir été largement dominant dans les locaux commerciaux, au point que sa mise en évidence constitue un indice remarquable pour identifier ces derniers. Toutefois, ces seuils ne sauraient constituer le seul marqueur: réutilisés en place, ils n'indiquent plus une boutique; certains ateliers, installés dans des locaux ne permettant pas la mise en place d'une large ouverture, sont dépourvus de ce type d'accès. Il faut donc chercher à caractériser d'autres éléments pertinents au commerce ou à l'artisanat.

\section{I.3 Les aménagements internes}

Par le traitement de leur façade - décoration extérieure, seuil -, les locaux commerciaux ont pu présenter des signes distinctifs, même si cette pratique n'a pas nécessairement été généralisée. Il faut maintenant déterminer s'il existe un traitement particulier de l'architecture intérieure des lieux de métier permettant de les distinguer des autres espaces de la maison, que cela concerne les différents revêtements - sol et murs - ou les aménagements en bois ${ }^{104}$.

\section{I.3.1 Le traitement du sol et des murs}

Contrairement à la majeure partie des espaces domestiques qui bénéficie d'un pavement maçonné, décoré ou non, de nombreuses boutiques - quand leur sol a été complètement dégagé ${ }^{105}$ - montrent une utilisation de la terre battue. Dans le local VI, 15 (cat. $\mathrm{n}^{\circ}$ 30), la mise en

${ }^{104}$ Les aménagements maçonnés, qui permettent de caractériser des occupations spécifiques, sont traités séparément dans les chapitres consacrés à ces métiers.

105 Certaines boutiques paraissent n'avoir pas été fouillées intégralement. La mise en évidence d'une strate de matériel éruptif sur le sol de la boutique VI, 15 a amené en 2002 à achever sa mise au jour (Monteix 2003). Des évidence de travaux en cours au moment de l'éruption empêche de préciser si cet état était destiné à durer ou non. Dans le local voisin VI, 14, des traces de rubéfaction observées le long de sa paroi occidentale sur le sol en terre battue montrent qu'il a été en usage avant son ensevelissement. D'autres boutiques témoignent de la même absence de recherche. Dans la boutique V, 34 (cat. $n^{\circ} 25$ ), une simple couche de béton gris sans aucun rehaussement décoratif constitue le niveau de circulation. Parfois, même lorsque le sol a bénéficié d'une amorce de traitement particulier, il présente des caractéristiques techniques qui le différencient nettement de ceux des autres espaces de la maison et, d'une façon générale, un moindre soin.

Il est très fréquent que les lieux de métier soient implantés dans des espaces préexistants qui conservent leurs caractéristiques originelles en dépit d'un changement d'usage. La pièce dans laquelle se développe la boutique IV, 14 (cat. $\mathrm{n}^{\circ}$ 9) au moment de l'éruption a ainsi été conçue pour une toute autre destination. Son pavement est un signinum orné d'un tapis de tesselles délimité par un filet droit et formant un quadrillage oblique de filets dentelés (fig. 23). Au centre de

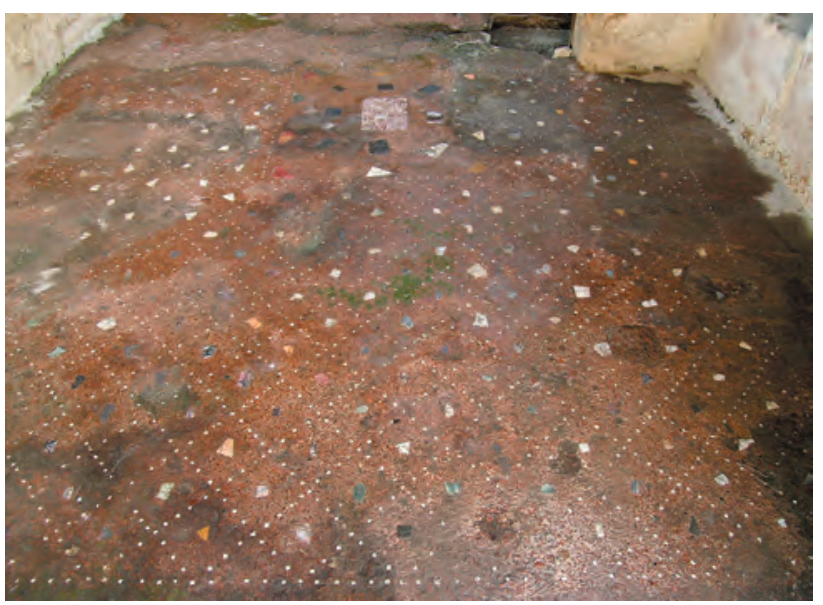

Fig. 23 - Pavement de la boutique IV, 14. Le sol a été découpé dans une phase postérieure pour permettre l'installation d'une latrine dans l'angle sud-ouest (cliché pris du nord).

tentatives de nettoyage d'autres boutiques se sont également soldées par un échec, dès lors qu'il s'est avéré que les fouilleurs avaient créé un niveau artificiel. Par exemple, la partie antérieure de la boutique VI, 25 reste encore, au moment j'écris ces lignes, ensevelie sous une couche d'enduits peints détachés de la paroi (Monteix 2006: 38-39). 
chaque carré sur pointe a été inséré un fragment de marbre. Sur l'axe médian nord-sud mais dans la moitié méridionale de celui-ci se trouve un carré dont le centre est occupé par un fragment de marbre rectangulaire. Neuf autres fragments rayonnent à partir de ce rectangle, séparés sans régularité par des croisettes de cinq tesselles quatre blanches et une noire au centre. Un rang de croisettes identiques sépare ces fragments de triangles de marbre tendant vers l'isocèle. L'angle sud-ouest a été tronqué dès l'origine. La présence du motif décentré permet de supposer que ce pavement a été prévu pour accueillir des couches de repas, ce qui en aurait fait à l'origine un triclinium. La transformation de ce local en boutique pourrait être advenue après le second séisme ${ }^{106}$. Divers travaux sont effectués, outre le bouchage des portes permettant la communication avec la maison IV, 12-13.15-16 et la mise en place d'un étage indépendant: une latrine est percée dans l'angle sud-ouest et divers creusements pratiqués le long des parois est et ouest ${ }^{107}$. En ce qui concerne la décoration pariétale, la cloison maçonnée alors créée pour séparer la latrine du local est enduite d'un socle ocre, tandis que la moitié supérieure est peinte en blanc et rehaussée de lignes rouges aux angles, de façon à s'insérer dans la décoration préservée de la phase précédente ${ }^{108}$. Un second exemple de ce type de récupération d'une pièce pour la transformer en boutique est visible dans la façade nord de la Casa del colonnato tuscanico (VI, 16; cat. $n^{\circ} 31$ ). En effet, la paroi orientale est ornée d'une fresque en III $^{\mathrm{e}}$ style de transition, représentant Hercule accomplissant un rite de fondation de ville ${ }^{109}$. Le sol est composé d'un pavement d'opus sectile polychrome présentant une alternance de carrés sur pointe inscrits dans des carrés formés par des triangles isocèles. La transformation en boutique de cette pièce, qui ne s'ouvrait à l'origine que sur l'atrium, pourrait s'inscrire parmi les conséquences du séisme de 62 ap. J.-C., comme semble l'indiquer la conso-

${ }^{106}$ Cf. infra, p. 311.

${ }^{107}$ Ces creusements ont été comblés lors de la restauration de la boutique. Seule leur forme pouvant désormais être distinguée, il est difficile de déterminer leur rôle exact.

${ }^{108}$ Sur le mur sud, deux épaisseurs d'enduit peint ont été mises au jour. Il est impossible de déterminer si la lidation de son montant oriental en tuf avec des briques. Dans ce cas encore, les travaux effectués pour l'installation de la boutique sont minimaux. Toutefois, même lorsque les aménagements sont plus importants, la réfection du pavement et de la décoration pariétale n'est pas ressentie comme une nécessité: quand une boutique a été ouverte en V, 6, une mezzanine, un comptoir maçonné, deux tables de cuisson, une évacuation d'eau et des casiers à amphores ont été mis en place; la décoration des murs, également en $\mathrm{III}^{\mathrm{e}}$ style de transition, n'a pas été martelée ou changée.

Il arrive néanmoins que l'installation d'une boutique ou d'un atelier entraîne une transformation radicale du sol ou des revêtements pariétaux. Ainsi, le commerce alimentaire V, 9-10 (cat. $\mathrm{n}^{\circ} 13$ ) présente une importante unité de conception: un nouveau pavement en cocciopesto est mis en place dans l'ensemble du local. À l'est du comptoir qui est alors construit, ce sol est décoré par un semis régulier de grosses tesselles noires. De la sorte, la division entre l'espace destiné à la clientèle et celui propre au boutiquier - déjà matérialisée par le comptoir - est accentuée. Cet enrichissement destiné aux clients est également perceptible dans la décoration de marbre du comptoir: les faces orientale et frontale - ainsi que l'angle nord-est, biseauté - sont rehaussées d'une plinthe et de fragments rectangulaires striés verticalement qui donnent l'illusion de pilastres engagés. Lors de ces travaux, une première décoration pariétale est mise en place. Au cours d'une phase successive, elle est refaite. Le pavement, éventré pour installer une canalisation d'eau sous pression, est seulement restauré, sans prendre la peine d'insérer de nouveau les cabochons dans la partie endommagée. Cette adaptation du local aux activités s'y déroulant est également perceptible dans le cadre de contraintes techniques. Ainsi, les trois ateliers qui ont été consacrés, à un moment de leur histoire, au nettoyage des toisons - VI, 30;

seconde a été mise en place après la création de la boutique ou si elle constitue une transformation de la décoration du triclinium.

${ }^{109}$ Manni 1974: 12-16; Coralini 2001: 84. 
Or. II, 5 (cat. $\mathrm{n}^{\circ} 40$ ) et Or. II, 18 (cat. $\mathrm{n}^{\circ} 50$ ) - présentent une caractéristique commune audelà des équipements nécessaires à leur bon fonctionnement: tous les trois sont dotés d'un sol exclusivement constitué de bipedales posées à plat ${ }^{110}$. Quand, dans une phase successive, l'utilisation du local change, ce revêtement de sol peut être conservé - comme en Or. II, 5 - ou bien partiellement oblitéré par un béton sans doute plus en adéquation avec la nouvelle activité, comme en VI, $30^{111}$.

Il n'y a donc que rarement un traitement des sols ou des murs propre aux lieux de métier ${ }^{112}$. L'économie de moyens par la réutilisation de pavements ou de fresques préexistants semble être la façon la plus courante d'aménager ces locaux. Cette conservation d'éléments qui ne sont pas directement associés à la boutique proprement dite ou à l'atelier qui s'installe rend délicate l'interprétation de ces locaux par la seule analyse de la décoration, qu'elle soit pariétale ou au sol. L'usage fréquent de sols de terre battue ou en béton simple montre une absence de recherche dans le traitement qui tendrait sans qu'il faille s'en étonner - à rejeter les boutiques vers les espaces de service. Si des impératifs techniques ont pu amener à des transformations dans le traitement du sol et des murs - comme c'est le cas, à Herculanum, des ateliers liés au

${ }^{110}$ Cette caractéristique paraît propre à Herculanum: les ateliers de nettoyage des toisons de Pompéi ne présentent pas ce sol en tuiles.

${ }^{111}$ Sur les transformations du local Or. II, 5, cf. infra, p. 190-191. Dans l'atelier VI, 30, il reste délicat de déterminer si le béton mis en place dans la partie orientale du local est antique ou bien issu de la restauration effectuée dans les années 1930.

112 Les remarques formulées par A. Wallace-Hadrill (1994: 155-158) sur la rareté de la décoration dans les boutiques - qui serait liée selon lui à la fonction commerciale ou à la pauvreté supposée des boutiquiers - doivent être tempérées. En effet, le manque d'intérêt flagrant lors des fouilles pour les boutiques explique pour partie la carence actuelle de toute trace de décoration. Il apparaît en effet, à chaque fois que des vestiges de la décoration mise en place en coordination avec la boutique subsistent, que les schémas iconographiques ne peuvent être comparés avec la décoration des espaces résidentiels. Toutefois, cette différence pourrait être davantage due à des questions fonctionnelles qu'à des problèmes de pauvreté ou de statut social. L'histoire contemporaine des deux sites interdit malheureusement toute recherche en ce sens. travail de la laine - la réalisation de programmes unitaires lors de la transformation d'un espace en boutique reste rare. Néanmoins, dans ce cas, la distinction matérielle entre la zone réservée à la clientèle et celle propre au boutiquier est particulièrement marquée.

\section{I.3.2 Comptoirs, étagères et mezzanines}

Parmi les aménagements des locaux commerciaux, le comptoir devrait être l'un des plus récurrents. Pourtant, ce n'est pas le cas: en suivant le décompte proposé par A. Maiuri, $26 \%$ des espaces commerciaux présentent un comptoir maçonné et pas un seul comptoir en bois ${ }^{113}$. Le faible nombre d'exemples signalés de ces aménagements ligneux rend périlleuse toute tentative de restitution formelle. En Or. II, 9 (cat. $\mathrm{n}^{\circ} 43$ ), des fragments de bois mis au jour dans la partie septentrionale du local ont été interprétés par les fouilleurs comme les restes d'un comptoir ${ }^{114}$. Le sol de la boutique ne conserve aucune trace de cet aménagement, ce qui laisse penser qu'il s'agissait d'un meuble et non d'un aménagement fixe. Les fouilles effectuées dans la seconde moitié des années 1960 sur le côté nord-est du decumanus maximus d'Herculanum ont également mis au jour un comptoir en bois dans le local DM, 8 E. En l'état, il est difficile-

${ }^{113}$ Ce décompte se fonde sur les données présentées dans le volume de 1958 sur les Nuovi Scavi. Il ne prend donc pas en considération l'angle nord ouest de l'insula VI. Selon cette publication, sur les 46 boutiques et ateliers d'Herculanum, 12 présentent un comptoir. Un comptoir en bois est seulement décrit comme une hypothèse pour la boutique Or. II, 9 (Maiuri 1958 b: 462). En ajoutant les locaux de l'insula VI, mais en retranchant les 4 locaux dont l'interprétation commerciale ou artisanale me semble erronée, le pourcentage de boutiques et ateliers présentant un comptoir reste identique (26\%), parmi lesquels $2 \%$ (1) correspondent à ceux en bois. Faute de pouvoir tous les étudier de la même façon, les locaux commerciaux se développant sur le côté nord du decumanus maximus n'ont pas été pris en compte.

${ }^{114}$ GSE 1936: « 31 dicembre. [...] La casa n. 9 è composta di due ambienti terranei e due piani superiori. L'ambiente n. 1 è un magazzino. A destra di chi entra vi è la cucina e la latrina, mentre a sinistra vi era il banco di vendita di legno, pochi avanzi a suo tempo furono sterrati ». 
ment étudiable. En effet, les journaux de fouilles de cette période sont absents des archives de l'Ufficio Scavi ou de celles de la Surintendance à Naples. Aucune des photos prises durant ce chantier ne permet de voir sa structure. Seule la trace en négatif du bois - non préservé - dans un bloc de matériel éruptif permet d'établir son existence. Un renfoncement à l'angle oriental permet de supposer la présence d'un montant de section quadrangulaire sur lequel auraient pu être fixées des planches. Les restaurations effectuées à sa base empêchent de déterminer s'il s'agissait d'un meuble pouvant être déplacé.

À Pompéi, l'attestation de comptoirs en bois dans les commerces a longuement été postulée en se fondant sur la fresque mise au jour dans le tablinum de la maison VII 3, 30 ${ }^{115}$. Elle représente un homme vêtu en toge blanche qui tend un pain de sa main droite à un groupe de trois personnages, deux adultes et un enfant. Après de longues variations interprétatives dans l'historiographie, Th. Fröhlich a récemment démontré que la lecture proposée par G. Fiorelli est partiellement justifiée: loin de représenter une scène de vente, cette scène témoigne de la libéralité de l'occupant de la maison VII 3, 30 au cours d'une distribution de pains ${ }^{116}$. Tout en considérant cette interprétation parfaitement valide, il semble opportun de reprendre l'étude de cette fresque pour caractériser avec précision la nature de l'aménagement en bois, trop souvent considéré comme un comptoir (fig. 24) ${ }^{117}$ : en

\footnotetext{
${ }^{115}$ Mise au jour en 1864, cette fresque a immédiatement été détachée pour être conservée au MANN (Inv. ${ }^{\circ}$ 9071).

116 Fröhlich 1991: 236-241. G. Fiorelli (1875: 208) voyait des appariteurs parmi les personnages situés au premier plan.

${ }^{117}$ A. MacMahon (2005 b: 74) espère ainsi trouver dans cette scène la seule représentation d'un comptoir en bois pompéien.

${ }^{118}$ Trois de ces poteaux sont visibles sur la partie antérieure de cette construction. Leur section en $\mathrm{T}$ se déduit de la position des clous - deux par extrémité de planche -, alignés verticalement à faible distance de la partie visible des poteaux. Une double rangée de clous est également perceptible sur le côté droit. Toutefois, la figuration d'un poteau à cet endroit peut prêter à discussion.

${ }^{119}$ Le détail des planches utilisées pour constituer la partie supérieure de cette estrade n'est pas représenté.

120 À partir d'un dessin effectué avant le détachement de la paroi, W. Helbig la décrit en ces termes: "In
}

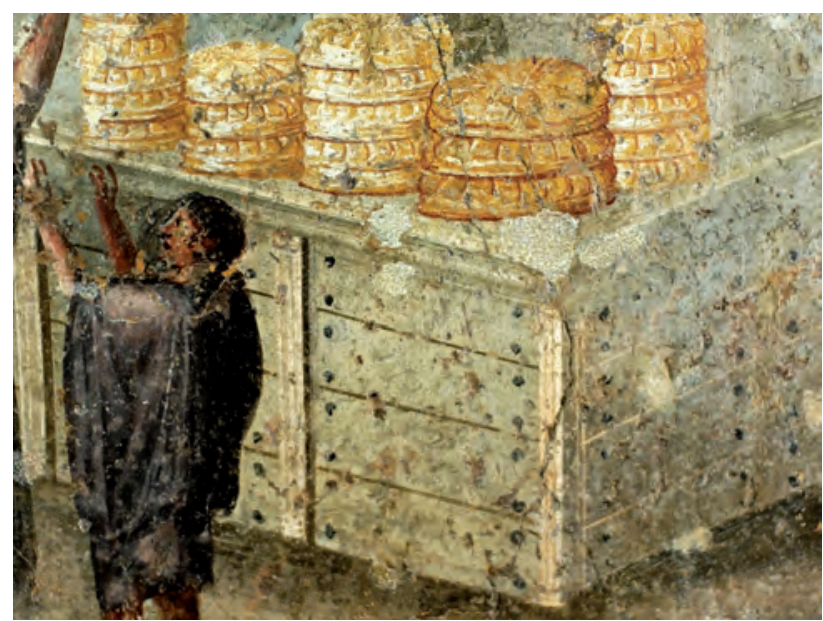

Fig. 24 - Détail de la fresque représentant une distribution de pains, découverte dans la maison VII 3, 30 à Pompéi.

un sens, la lecture de cette représentation tient pour l'essentiel à la valeur accordée à cette construction en bois. Sa structure pourrait être constituée par une trame de poteaux périphériques ayant une section en $\mathrm{T}$, sur laquelle des planches sont assemblées de chant ${ }^{118}$. L'ensemble est recouvert par un plancher sur lequel est assis le personnage en toge blanche ${ }^{119}$. La position assise de ce dernier ne fait aucun doute: remarquée dès les premières descriptions ${ }^{120}$, elle est perceptible par l'excroissance des genoux, placés en avant du corps. De ce fait, le «magistrat » faisant una specie di banco siede una giovane fornaia vestita d'un abito lungo bianco, che presenta colla destra un pane alle persone collocate di sotto » (BdI 1864: 119). G. de Petra, en faisant la recension de l'ouvrage d'O. Jahn (1868) consacré à la représentation de l'artisanat dans la peinture murale, signale l'incohérence de cette interprétation: "In vero, se come l'Helbig ed il Jahn ritengono, la scena è una bottega, il suggesto su cui siede il voluto panettiere dev'essere un pancone; ma considerando tutte le botteghe di Pompei, non una fa sorgere l'idea che il pancone servisse di sedile al venditore [...]»(GSPomp, n.s. 1, 1, 1868: 10). Finalement, G. Fiorelli corrige la première description de cette façon: «Di fronte evvi il tablino, già adorno di un quadretto esprimente un edile o altro magistrato municipale, che vestito di bianca toga e seduto in un suggesto, fa al popolo una gratuita distribuzione di pane [...]»(Fiorelli 1875: 208). 
preuve de libéralité se tiendrait dans la position du tailleur, assis jambes croisées et repliées. Derrière lui est installé un présentoir en bois sur lequel sont disposés des pains. La position de cet éventaire est clairement indiquée sur la droite: la ligne d'intersection entre le plancher et le montant droit est soulignée, accentuée par la différence chromatique entre ces deux éléments. Dès lors, comme le personnage principal et l'éventaire reposent sur le plancher, il ne saurait être question de considérer cet aménagement comme un comptoir, derrière lequel le vendeur est censé se tenir debout. Dans cette scène, c'est donc une estrade - suggestum - qui est représentée ${ }^{121}$

Un autre témoignage de l'existence d'un comptoir en bois dans une boutique pompéienne est supposé se trouver dans le commerce alimentaire I 6, 8-9. Un léger creusement du sol en équerre est situé dans la moitié orientale du local principal (fig. 25) ${ }^{122}$. Dans sa continuité, au sud, se trouvent deux dolia pris dans un massif maçonné. Dès la fouille, cette trace a été interprétée comme caractéristique d'un comptoir en bois $^{123}$. Cette interprétation a ensuite été reprise dans le compte rendu d'A. Maiuri ${ }^{124}$. Le comptoir de cette boutique était pourtant, comme c'est fréquemment le cas dans les commerces alimentaires, non pas en bois mais maçonné: la trace laissée dans le sol, qui s'élargit à l'extrémité sud du bras rentrant, indique très claire-

${ }^{121}$ Cette représentation peut être rapprochée des scènes de congiaires impériaux (cf. Virlouvet 1995: fig. 9, 15-16, 25-26 et s.v. suggestum). Toutefois, outre l'évidente différence d'échelle de distribution, cette fresque se distingue de l'iconographie impériale par la position du personnage qui donne les pains: il est assis en tailleur et non sur un siège curule. De ce fait, il est possible que cette libéralité ne soit pas due à un magistrat, mais plutôt à un simple citoyen éventuellement candidat à une élection: la représentation d'édile pompéien C. Vestorius Priscus le montre sur un siège curule, signe de sa charge (cf. Mols - Moormann 1994: 29-30, 43-44).

${ }^{122}$ Outre dans le local I 6, 8-9, S. Ellis (2004a: 45 et n.7) considère que des comptoirs en bois se trouvaient en II 2, 3 et en IX 2, 25. Dans cette boutique, G. Fiorelli (1875: 388) décrit un aménagement mixte: «[...] un banco di tavole sostenute da tre poggiuoli», ce qui laisse supposer l'existence de pieds de table, probablement maçonnés, actuellement détruits. Concernant le commerce II 2, 3, dans sa publication des graffites, M. Della Corte (NSc 1927: 100)

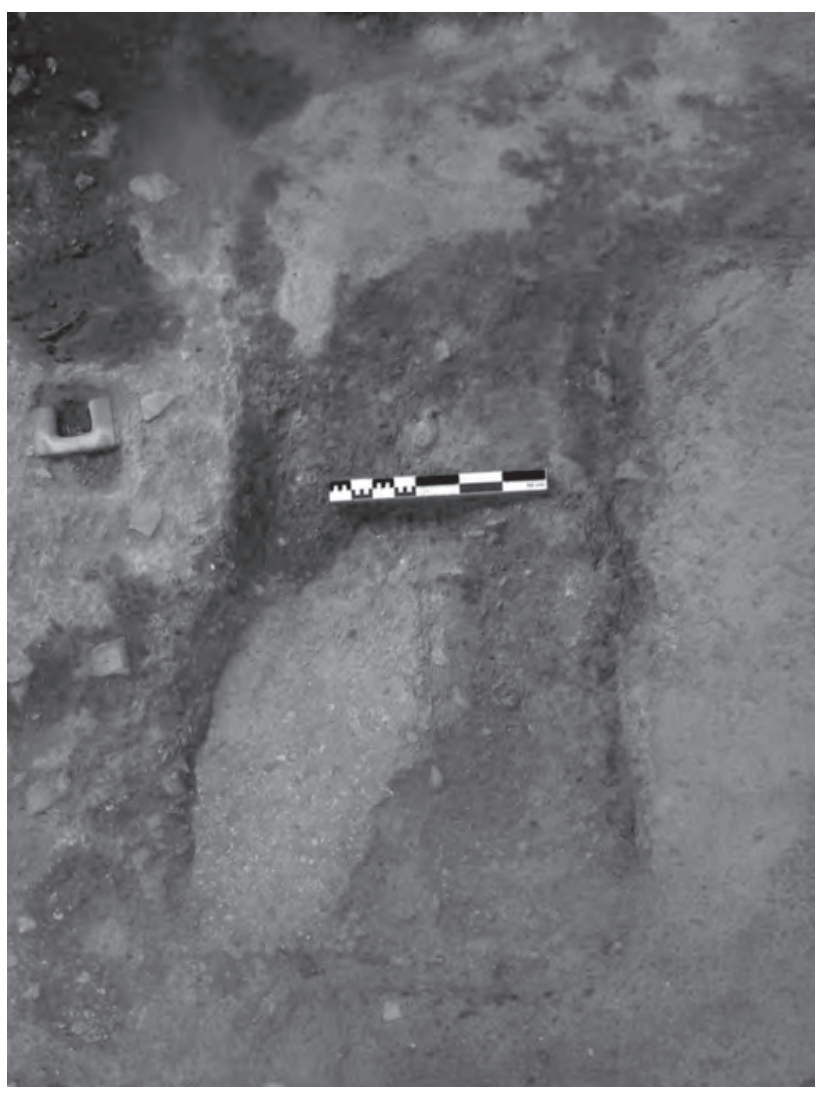

Fig. 25 - Empreinte du creusement pour un comptoir maçonné, détruit ou en cours de reconstruction. Pompéi, local I 6, 7 (cliché pris du sud).

signale: "Termopolio, del cui banco di vendita in legno restano chiarissime impronte nell'angolo $\mathrm{NE}$ ». L'état actuel de ce local ainsi que la disparition des GSP concernant la fouille complète de cette boutique, après guerre, empêche toute vérification de cette indication.

${ }^{123}$ GSP 1927 : « 24 agosto. Oggi è stato portato a termine lo scavo dell'ambiente $n^{\circ} 39$ in pianta, il quale è formato da una bottega a due porte. Presso il vano orientale di questa vedesi sul suolo la traccia del banco di vendita in legno, formato dal solito podio ad angolo retto, del quale uno dei due lati parallelo alla soglia. In continuazione della parte interna del podio vi sono due dei soliti dolii congiunti da muratura e che lasciano uno stretto passaggio tra essi e l'estremità del banco di vendita. Le pareti sono di grezzo signino. La parte della bottega verso occidente reca sulla parete del medesimo lato, dei segni di colore nero, forse conti del bottegaio, e tanto questa parete che quella di fronte recano dei fori per gattoni, sostegni di due mensole $[\ldots] \gg$.

${ }^{124}$ NSc 1929: 392; cf. également Allison 2004: 112. 
ment la présence d'un chauffe-eau / fourneau, peu compatible avec un aménagement en bois ${ }^{125}$. De plus, de nombreux signes indiquent que des travaux étaient en cours dans cette boutique et la maison à laquelle elle appartient, comme le montre le matériel de construction mis en évidence dans l'angle sud-est de la pièce $14^{126}$. À proximité, dans le péristyle i, ont également été trouvés une table en marbre démontée et six dolia; stockés dans la partie arrière de la maison, ils doivent être mis en relation avec le creusement observé dans le local principal ${ }^{127}$. Bien qu'il soit difficile de préciser si ces dolia sont le signe d'une restauration - éventuellement due à un séisme de peu antérieur à l'éruption ${ }^{128}$ - ou d'un changement d'activité alors en cours, leur fond pointu et la trace d'un chauffe-eau doivent de toute façon être interprétés comme autant de facteurs plaidant en faveur d'un comptoir maçonné et non en bois ${ }^{129}$.

${ }^{125}$ Concernant la définition formelle et fonctionnelle à donner aux chauffe-eau / fourneaux et sur les spécificités des aménagements des commerces alimentaires, cf. infra, p. $97-102$.

126 GSP 1927: «2 giugno. [...] Nell'angolo sud-est dell'ambiente in corso di scavo [«nord est del grande peristilio segnato in pianta col $n^{\circ} 20 »=$ péristyle 16 de la maison I 6,11$]$ sono stati trovati una quantità di frammenti di anfore e di materiale edilizio, ivi depositato dagli antichi stessi $[\ldots]$ ». La pièce 14 appartient à la maison I 6, 11 qui communique avec I 6, 8-9.

Au début de la fouille a également été mis au jour un tas de sable pouvant indiquer des travaux de maçonnerie interrompus par l'éruption. L'absence de toute donnée sur la cote de cette découverte empêche de déterminer si l'interprétation donnée par les fouilleurs - un apport de sable dû aux explorations de récupération en 79 ap. J.-C. - est fiable. GSP 1927 : «18 aprile. [...] I lavori di scavo continuano nella casa immediatamente a nord di quella segnata col $\mathrm{N}^{\circ} 13$ della Reg. I Ins. VI, ed ivi si è constatato che dagli antichi cercatori fu qui depositata una quantità di sabbia marina e fluviale, del che non vedesi la ragione $[\ldots] »$.

${ }^{127}$ GSP 1927 : «16 agosto. [...] Oggi si è anche completamente liberato dal materiale eruttivo l'ambulacro settentrionale del piccolo peristilio ( $\mathrm{n}^{\circ} 22$ in pianta), di cui si parlò il giorno 18 del scorso mese di giugno. Dietro il pluteo di detto ambulacro sono stati trovati sei grandi dolii di terracotta e sotto la parete nord del ricordato ambulacro, si sono rinvenuti: [Description de trois pieds de table en marbre, inventoriés sous le $\mathrm{n}^{\circ}$ 3921]».

L'absence dans la boutique ou dans l'atrium - partiellement occupé par une table de cuisson - de tout matériel de préparation culinaire ou de vaisselle de table indique
Si ces remarques contredisent les arguments fréquemment avancés pour caractériser le mode de construction des comptoirs en bois, elles ne constituent pas une affirmation de l'absence d'un tel aménagement dans les boutiques et les ateliers, comme en témoigne un document iconographique en façade de l'atelier de feutre de Verecundus (IX 7, 7) à Pompéi. Sur le montant gauche, sous une représentation de Mercure dans le pronaos d'un temple ${ }^{130}$, une scène de vente de chaussures - réalisées en feutre selon V. Spinazzola ${ }^{131}$ - est peinte, partiellement recouverte par des programmes électoraux. La vendeuse se trouve derrière une table en bois à quatre pieds. Devant elle, les produits à vendre sont exposés sur une table et sur un présentoir. D'autres sont enfermés dans une armoire posée sur la table. Derrière la commerçante se trouve un meuble qui ne peut pas être atteint par le client vêtu d'une toge verte qui attend sur

également que ce commerce alimentaire n'était pas fonctionnel au moment de l'éruption. Enfin, dans l'atrium de la maison I 6, [8-9.]11, un verre céramique - "fritillus» - contenant des pigments a été mis au jour le 7 septembre 1927 (Inv. nº P3991).

${ }^{128}$ Sur l'hypothèse d'un séisme dans l'année précédant l'éruption de 79, cf. infra, p. 233 et suivantes.

${ }^{129}$ La présence de comptes inscrits sur la paroi ouest et les empreintes d'étagères dans les murs ouest et sud (cf. GSP 1927: 24 agosto, cit. supra, n. 123) me font toutefois préférer la première hypothèse d'une remise en état d'un commerce alimentaire. A. Maiuri (NSc 1929: 395) considère que les dolia faisaient partie des marchandises (mercanzie) de la boutique, voulant probablement signifier que ces conteneurs entreposés dans le péristyle étaient fonctionnels au moment de l'éruption ou du moins directement associés au commerce. P. Allison (2004: www.stoa.org/pompeianhouseholds) estime quant à elle que la maison était au moins partiellement inoccupée avant l'éruption. En dépit des nombreux signes pertinents à la conduite de travaux dans l'ensemble I 6, 8-9.11, l'hypothèse d'une restauration de la boutique n'a jamais été évoquée. Seuls E. La Rocca, M. et A. De Vos (1994: 198) signalent des travaux de réparation en cours.

${ }^{130}$ Spinazzola 1953: 207; Fröhlich 1991: 64, 334-335.

131 Le lien entre cette représentation d'une scène de commerce et l'atelier de feutre a été fait par V. Spinazzola (1953: 207-208). Toutefois, l'absence de connaissance sur la division des espaces au-delà de la façade oblige à un minimum de prudence. Il est possible que cette fresque renvoie non pas à l'atelier de feutre mais à la boutique immédiatement voisine (IX 7, 8). 
un long siège. Le "comptoir " n'est guère plus qu'une simple table - deux pieds verticaux non ouvragés reliés par des traverses d'entrejambes sont visibles -, similaire à l'une de celles représentées sur le mur ouest de la pièce annexe du commerce VI 10, 1.19. Malgré la déformation induite par la représentation perspective, le comptoir apparaît en position centrale et permet de distinguer deux espaces, l'un accessible à la clientèle, l'autre non.

Ce détournement de meubles utilisés comme comptoir paraît fréquent, à en juger par les représentations sculptées. Sans commenter l'ensemble de ces reliefs, certains d'entre eux méritent une attention particulière. Un sarcophage de Portus présente deux scènes sur l'une de ses faces, dont seule celle de droite est pertinente à mon $\operatorname{propos}^{132}$. Elle se déroule chez un marchand de vin, pouvant proposer des services de restauration. À gauche, au-dessus d'un fourneau, des récipients sont disposés sur trois niveaux. Le patron, tourné vers la droite, apporte une consommation à deux clients situés de l'autre côté d'un aménagement en bois ajouré. Ce dernier est constitué par trois pieds, reliés par deux entre-jambes de dimensions plus réduites. Les pieds extérieurs sont liés à la table par un assemblage en onglet. L'espace propre au commerçant est très nettement distingué de celui réservé à la clientèle par ce meuble. Toutefois, la position assise du client de droite et le déplacement du commerçant suggèrent plus une table utilisée par la clientèle qu'un comptoir proprement dit. D'autres exemples donnent une attestation plus claire de l'utilisation de meubles comme comptoir. Ainsi, sur un relief d'Arlon, une même forme de comptoir est attestée à deux reprises, dans des scènes l'une de vente de tissu et l'autre de comptes ${ }^{133}$. Sa face latérale présente deux panneaux à plate-bande simple, séparés par un montant intermédiaire. Un panneau similaire est figuré sur la face postérieure, du côté du

\footnotetext{
${ }^{132}$ Ce sarcophage a été découvert en 1931 dans l'Isola Sacra à Portus (Museo Ostiense, Inv. n 1340, cf. NSc 1931: 531).

${ }^{133}$ Espérandieu 4043 (V, p. 233-235).

${ }^{134}$ Espérandieu 4295 (V, p. 388-389). Il est possible que cette différence de conception soit due à une simplification de la part du sculpteur, en dépit de la finesse de réalisation des pâtisseries exposées.
}

commerçant. Les pieds sont carrés. Paraissant dépourvu de tout système de rangement - aucune porte n'est visible - ce comptoir n'aurait d'autre fonction que celle de démarquer l'espace propre au commerçant du reste de la boutique, ainsi que de présenter les marchandises. De conception plus simple, le comptoir d'un possible vendeur de pâtisserie figuré sur un relief de Metz est construit de la même façon ${ }^{134}$. Il est utilisé pour les mêmes fonctions de division de l'espace et d'exposition des marchandises. Bien que mutilé, un bloc provenant du monument funéraire d'un marchand de vin de Trèves montre également un meuble utilisé comme comptoir ${ }^{135}$. Sa face latérale présente au moins un panneau à platebande simple. La table proprement dite déborde du meuble et semble avoir été délimitée par un cadre en ressaut.

Ce bref excursus hors d'Herculanum appelle quelques remarques. Aucune activité ne détient d'exclusivité sur la présence d'un comptoir. Cet aménagement doit donc être perçu comme foncièrement générique et ne peut pas, par sa seule présence ou son absence, permettre l'identification des activités se déroulant dans un local. Les deux fonctions principales qui émergent de l'analyse de ces représentations iconographiques sont d'une part l'exposition des produits à vendre, d'autre part la création d'une limite matérielle entre l'espace pour l'accueil de la clientèle et celui où le commerçant évolue seul. L'iconographie représente majoritairement des comptoirs en bois $^{136}$, tandis que les attestations archéologiques de ceux-ci restent peu nombreuses, que ce soit à Herculanum ou à Pompéi. Cela rejoint les remarques faites précédemment sur l'absence de délimitation claire dans le traitement du sol des locaux commerciaux. Le comptoir en bois, élément mobile parmi les aménagements de la boutique, rend l'espace intérieur de la boutique complètement modulable en fonction des besoins du commerçant. Cette caractéris-

\footnotetext{
${ }^{135}$ Espérandieu 7591 (X, p. 208).

${ }^{136}$ Tout du moins, à chaque fois que les détails sont suffisamment précis pour permettre l'identification du matériau employé par l'analyse des techniques d'assemblage, l'utilisation du bois paraît prépondérante. Dans le cas de représentations simples ou non détaillées, il est impossible de trancher entre comptoir maçonné ou comptoir en bois.
} 


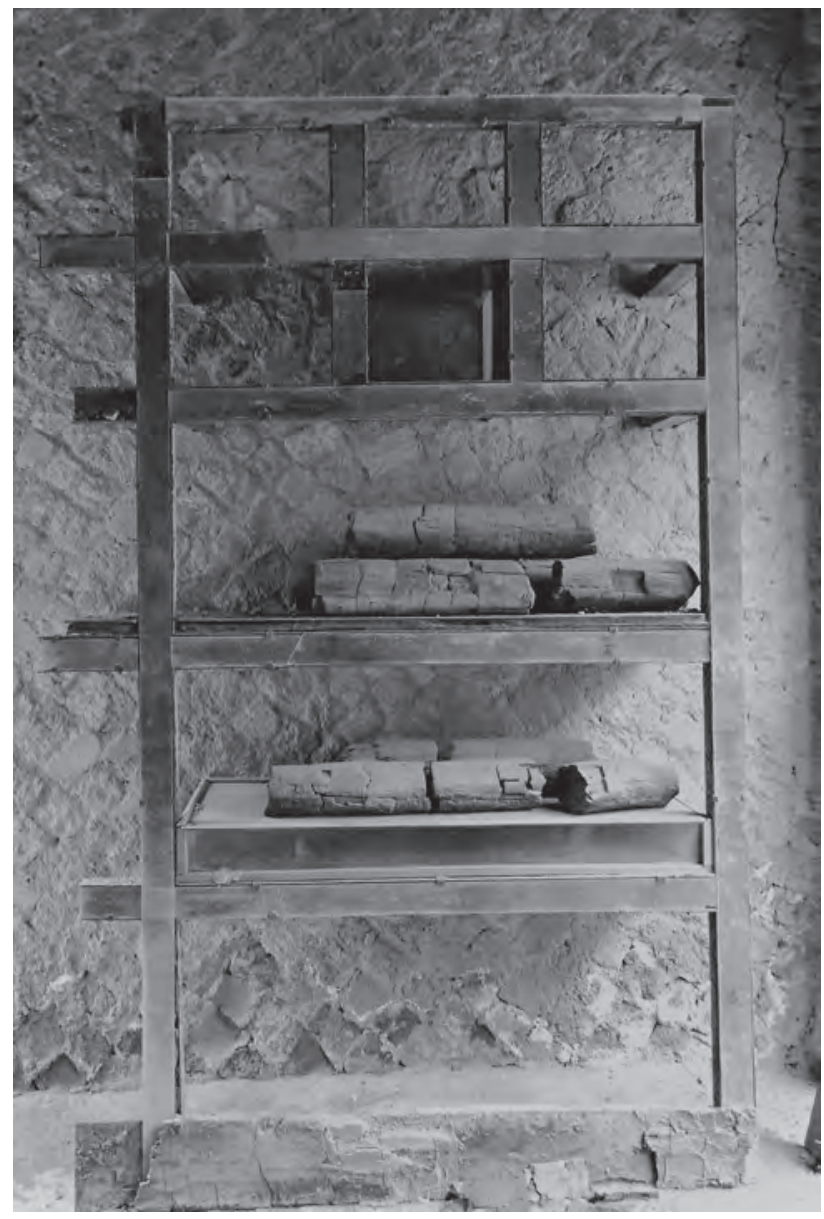

Fig. 26 - Étagère murale dans la boutique V, 12 (cliché pris de l'est).

tique fait que la nature d'un local peut changer du tout au tout sans que sa structure globale ne s'en trouve affectée. Dès lors, l'interprétation des

${ }^{137}$ Cf. infra, p. 92-97.

${ }^{138}$ Pour les aménagements en bois spécifiques à certains métiers - textile, boulangerie -, je renvoie aux chapitres qui leurs sont consacrés.

139 GSE 1939: «22 marzo. Nel magazzino n. 12 della casa 11 posta sul Decumano Massimo Insula V, nella parete ovest si è sterrato uno scaffale di legno carbonizzato. È alto m. 2.18 e largo attualmente m. 2.22, ma era più largo perché alle due estremità è rotto. Si compone di quattro scomparti [...]». Suivent des mesures qui ne correspondent que difficilement aux vestiges actuellement visibles. Un relevé intégrant les restaurations est proposé par S. Mols (1999: pl. 155).

${ }^{140}$ Le mode d'assemblage des montants aux supports n'est pas explicité par S. Mols (1999: 62). activités se déroulant dans les locaux dépourvus d'aménagements spécifiques ne peut se faire si aucun matériel n'a été mis au jour. Si je n'ai pas mentionné les comptoirs maçonnés jusqu'à présent, c'est parce qu'en raison de leur nombre et de la fréquence avec laquelle ils sont associés à des éléments particuliers, ils méritent un développement plus important $t^{137}$.

Outre le comptoir, dont les traces sont particulièrement ténues, d'autres aménagements en bois ont été utilisés dans les locaux commerciaux ou artisanaux. En premier lieu, se trouvent les étagères, situées dans la boutique ou dans l'ate$\operatorname{lier}^{138}$. Une seule d'entre elles, mise au jour en 1939, a été parfaitement conservée en façade de la Casa dell'Apollo citaredo, en V, 12 (cat. n 14; fig. 26) ${ }^{139}$. Elle se compose de huit supports alignés horizontalement deux à deux et chacun encastré dans le mur ouest du local. Ils sont fixés à deux battants verticaux ${ }^{140}$. Quatre tablettes reposent sur les supports ${ }^{141}$; deux montants verticaux divisent les deux espaces supérieurs en trois compartiments. Des fagots de paille ont été mis au jour sur l'une des tablettes ${ }^{142}$. L'hypothèse proposée par A. Maiuri faisant de cette étagère murale un présentoir pour ce qui était vendu ne saurait pour autant être rejetée ${ }^{143}$. En revanche, l'absence de tout autre artefact dans cette boutique implique soit que le stock du magasin a été emporté lors de la fuite précédant l'éruption, soit que la mise en place de celui-ci n'était pas encore achevée ${ }^{144}$. Cet aménagement, récurrent dans les locaux artisanaux ou commerciaux, reste l'un des rares à avoir été préservé: malgré la bonne conservation du bois à Herculanum, toutes les étagères n'ont pas été retrouvées intactes. Dans la plupart des

${ }^{141}$ Telle qu'elle se présente actuellement, une cinquième tablette repose sur la plinthe. Son absence dans la description des GSE et l'analyse de S. Mols (1999: pl. 155) permettent d'y voir une restauration.

142 GSE 1939: " 11 aprile. Oggi è stato svuotato lo scaffale di legno carbonizzato sterrato il 22 marzo ultimo scorso nell'ambiente 12 della casa 11 Decumano Massimo Insula V. Nell'interno conservava quattro ramazze di paglia. Parte di esse sono conservate discretamente [...]».

${ }^{143}$ Maiuri 1958 b: 252.

${ }^{144}$ Il ne saurait être question de supposer un déplacement de ces objets par le flux pyroclastique: en ce cas, les fagots de paille auraient également été déplacés. 
cas, seules les empreintes des supports muraux ont pu être identifiées. Une configuration identique à celle de la boutique $\mathrm{V}, 12$ pourrait avoir existé dans le local VI, 18 (cat. $\mathrm{n}^{\circ}$ 32): les traces de six supports sont actuellement visibles dans le mur ouest de la boutique. Elles pourraient indiquer une étagère à deux ou trois tablettes ${ }^{145}$. Dans la pièce 7 , servant selon toute vraisemblance de dépôt pour le commerce alimentaire IV, 15-16, seule une tablette a été mise au jour le long du mur ouest $^{146}$. Parmi les objets entreposés sur celle-ci, certains - un pain, une tasse céramique ${ }^{147}$ - pourraient directement être liés avec le commerce se déroulant en devanture ${ }^{148}$. Ces étagères ne constituent toutefois pas une spécificité des boutiques. Que leurs montants soient maçonnés - comme en $\mathrm{V}, 6-7$ et V, $17^{149}$ - ou que l'ensemble soit en bois, ces aménagements ont fréquemment été mis en évidence dans différentes maisons d'Herculanum, dans des pièces servant de dépôt à l'étage ${ }^{150}$ ou au rez-de-chaussée ${ }^{151}$. Il faut donc certainement y voir un aménagement commun, servant à entreposer toute sorte d'objets, réutilisés dans certaines boutiques comme présentoir ou dans les arrièreboutiques comme rangement ${ }^{152}$.

${ }^{145}$ Dans la laconique description de la fouille exécutée dans ce local, aucune mention n'est faite de ces supports encastrés (GSE 1961 : «19 settembre. [...] L'ambiente misura metri 2.85 per 2.85 , sulla parete destra si notano tracce di stucco bianco, sulla parete in fondo si rileva un vano che immette nell'atrio del colonnato toscano [...]»). Comme ce mur a été intégralement reconstruit (cf. Nég. Ufficio Scavi di Ercolano, n 173, 09/1961), il reste possible que les fragments de support soient des intégrations modernes.

${ }^{146}$ GSE 1932: " 11 febbraio. Nella casa n. 6 ambiente n. $7 \mathrm{sul} 4^{\circ}$ cardine lato ovest a m. 1.40 dal pavimento sopra una tavoletta di legno carbonizzato sostenuta da 2 traverse di forma rettangolare di $\mathrm{m}$. 0.04 per 0.07 conficcati nella parete ovest posta in maniera da formare una massa è stato raccolto: [Description des objets inventoriés $n^{\circ}$ E734$740=76011-76017] »$.

${ }^{147}$ Tous les objets ont été mis au jour le 11 février 1932. Outre le pain (Inv. ${ }^{\circ}$ E732=76009) et la tasse à paroi fine (Inv. $\mathrm{n}^{\circ} \mathrm{E} 738=76015$; type Atlante II [Ricci] 1/23, p. 250), quatre clochettes (cf. supra, n. 77), un anneau en argent (Inv. $\mathrm{n}^{\circ} \mathrm{E} 736=76013$ ) et une monnaie (Inv. $\mathrm{n}^{\circ} \mathrm{E} 737=76014$ ) ont été mis au jour sur cette tablette.

${ }^{148}$ A. Maiuri (1958 b: 434) signale que des étagères de ce type se seraient trouvées dans le local IV, 15-16 mais auraient été détruites par les tunnels du XVIII ${ }^{\mathrm{e}}$ siècle.

${ }^{149}$ Dans la pièce 5 de la Casa di Nettuno e Anfitrite, la supposée table de cuisson $\mathrm{f}^{2}$ (Maiuri 1958 b: 402) s'est avérée être, après nettoyage, une étagère dont les montants sont maçonnés: au-dessus de la couche correspondant
Une variante spécialisée de ces meubles fixés aux murs n'est attestée que dans certains commerces. Il s'agit vraisemblablement de porte-amphores que l'on ne trouve que dans les commerces alimentaires - qu'ils pratiquent seulement la vente de vin ou non (fig. 27). La forme

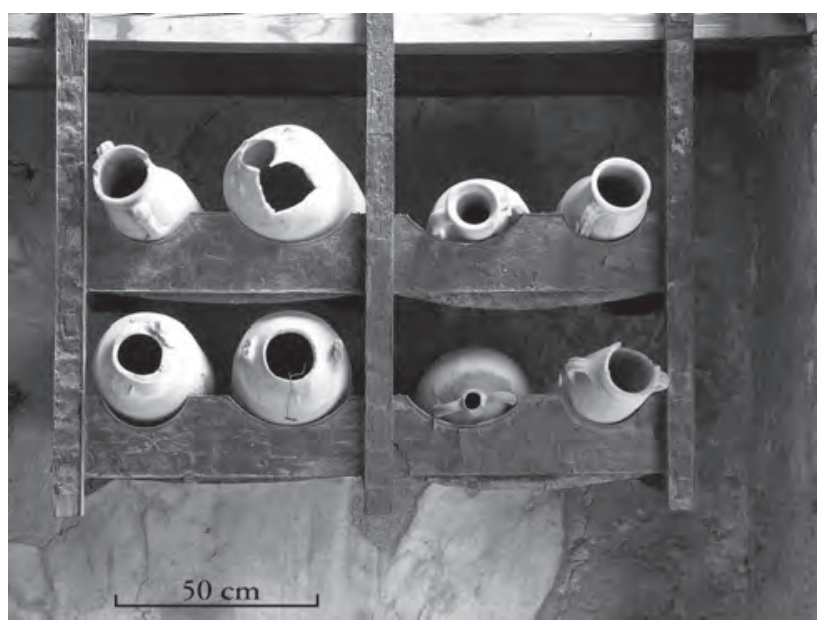

Fig. 27 - Porte-amphores de la boutique située en façade de la Casa di Nettuno e Anfitrite (V,6). Les amphores actuellement présentées ne proviennent pas de ce local (cliché pris du nord).

aux premières surges de l'éruption, des petits fragments de charbon de bois ont été mis en évidence. Une étagère similaire se situe dans le local V, 17.

${ }^{150}$ Casa d'Argo (cf. Maiuri 1958 b: 361 ; Mols 1999: 231); Casa dello scheletro (GSE 1927: 6 giugno; cf. Mols 1999: 240); Casa del tramezzo di legno (GSE 1869: 13 maggio; cf. Ruggiero 1885: 587; Mols 1999: 232); Casa del salone nero (GSE 1939: 29 settembre; cf. Mols 1999: 259).

${ }^{151}$ Casa dei cervi (GSE 1930: 24 novembre; cf. Mols 1999: 247-248); Casa del mobilio carbonizzato (GSE 1933: Aprile [«Descrizione della Casa $n^{\circ}$ 5, sul IV Cardine, lato Est. [...] Ambiente $\mathrm{n}^{\circ} 12$ »]; pièce 3 [contra Maiuri 1958 b: 260, n. 56 p. 472]); V, 19 (GSE 1938: aprile [«Casa 22. 23. 24. Decumano Massimo Insula V. Descrizione»]; description d'une cloison en bois ayant également servi d'étagère; cat. $\mathrm{n}^{\circ} 18$ ); Casa del salone nero (GSE 1939: 3 giugno; cf. Mols 1999: 258 [une faute typographique empêche de connaître la cote des empreintes: 1,60 m à partir du sol]; Casa di M. Pilus Primigenius Granianus (GSE 1940: 3 marzo; cf. Mols 1999: 260); Casa della gemma (GSE 1934: 22 aprile; cf. Mols 1999: 253).

${ }^{152}$ Une éventuelle distinction pourrait être faite, du point de vue morphologique, entre les étagères utilisées comme présentoir et les autres. Les descriptions des GSE n'indiquent jamais, pour les étagères situées dans les maisons ou les arrière-boutiques, la présence de montants assemblés avec les supports. Toutefois, le fait que ces pièces de bois verticales ne laissent aucune trace sur le sol limite l'application de cette interprétation en dehors de l'exemple mis au jour en $\mathrm{V}, 12$. 
de ces étagères est la même que celle des précédentes, à ceci près que les montants ne vont pas jusqu'au sol et qu'ils sont fixés aux solives supportant le plafond. La partie antérieure est fermée par une planche dans laquelle une découpe semicirculaire a été pratiquée. Cet arrondi est le seul argument permettant de préciser la fonction de ces étagères suspendues. En effet, sur les trois exemplaires mis au jour, aucune amphore n'a été retrouvée en place ${ }^{153}$. Une quatrième attestation de cet aménagement, dont seules des traces ont été mises en évidence dans la boutique IV, 17, permettrait toutefois de supposer qu'il servait effectivement à entreposer des amphores: des conteneurs fracassés - découverts remplis de fèves - ont été mis au jour dans l'arrière-boutique (a), tandis que des traces d'encastrement de support sont visibles sur son mur nord ${ }^{154}$. Notons enfin que si ces porte-amphores ne sont attestés que dans des boutiques, ils peuvent - comme tout autre aménagement antérieur - avoir été conservés même en cas de changement d'activité. Ainsi, celui qui se trouve dans l'atelier de métallurgie du plomb VI, 12 (cat. $n^{\circ} 28$ ) apparaît comme un vestige d'une phase antérieure: lors de l'éruption, son utilité serait limitée au stockage du bois.

${ }^{153}$ Ce type d'étagère a été mis au jour en V, 6, en Or. II, 9 et en VI, 12. Aucune amphore, entière ou fragmentée n'a été mise au jour dans la boutique V, 6 (sur ce point, cf. supra, p. 22-23). En Or. II, 9, quatre amphores sont attestées - plus une cinquième à l'étage -, mises au jour le 6 et 10 février 1936 à proximité de la porte de communication vers l'arrière-boutique. Si aucune indication précise n'est donnée quant à leur altitude de découverte, l'absence de toute description de l'étagère avant le résumé final (GSE 1936: 31 dicembre) laisse supposer qu'elles n'ont pas été trouvées en position. Enfin, en VI, 12, seule la moitié nord a été mise au jour intact. Du bois utilisé par l'artisan pour fondre du plomb y était entreposé (GSE 1961: «12 luglio. [...] Nello spazio compreso fra la mensola e la fiancata si è notato molto legno carbonizzato spaccato e duro. Evidentemente legna da ardere [...]»). En revanche, des amphores brisées auraient été mises au jour à la verticale de la moitié sud, détruite. Elles ne sont mentionnées que lorsque deux inscriptions furent découvertes après leur nettoyage (sur ces inscriptions, cf. Pagano 2004 : fig. 6-7 p. 358-359). On peut compter au moins six amphores sur plusieurs clichés pris dans cet atelier après restauration (cf. cliché Ufficio Scavi di Ercolano D802, pris en 1961 et Pagano 2004 : fig. 3 p. 355).

${ }^{154}$ Les empreintes pour l'encastrement ne sont visibles que sur le mur nord, ce qui interdit de penser à une mezzanine - qui serait par ailleurs inaccessible - postulée par le rédacteur des GSE (1932: «12 marzo. [...] A m. 1.38
Le dernier type d'aménagement que l'on rencontre dans certaines boutiques est constitué par les mezzanines. Par ce terme, j'entends distinguer les surfaces additionnelles mises en place dans un volume prédéfini - visibles notamment dans certains locaux de l'Insula Orientalis $I^{a 155}$. Contrairement à la pergula telle que la définit F. Pirson ${ }^{156}$, la mezzanine ne recouvre pas l'ensemble de la surface du local. De même, toujours en opposition à ce type d'appartement de taille réduite fréquemment associé aux boutiques, elle réduit la hauteur sous plafond là où elle se développe; cette réduction est à double effet: la hauteur est diminuée sous l'aménagement, mais elle est également faible entre le niveau créé et le plafond de la boutique. Ainsi, dans le seul exemple parfaitement conservé de mezzanine, mis au jour dans la boutique $\mathrm{V}, 6$, les poutres $\mathrm{du}$ premier étage se situent à $2,89 \mathrm{~m}$ de hauteur ${ }^{157}$. Le plancher de la mezzanine est à $1,90 \mathrm{~m}$ audessus du sol, ne laissant guère plus d'un mètre pour y circuler ${ }^{158}$. Ces deux caractéristiques - couverture incomplète de l'espace et réduction partielle de la hauteur sous plafond - sont celles qui définissent le mieux cet aménagement. D’un point de vue structurel, l'exemple de la Casa di

dall'estremità superiore del podio sulla parete nord vi sono sei alveole con altrettanti travi di legno carbonizzato a forma rettangolare della larghezza di m. 0.08 per 0.08 che sostenevano un ammezzato. I suddetti travi sono disposti da nord a sud»). Cette étagère paraît avoir contenu des amphores qui ont chuté au cours de l'éruption, se rompant et versant leur contenu: au moins sept d'entre elles ont été mises au jour dans la pièce.

Cf. GSE 1931: 15 dicembre [SNI], 24 dicembre [fragments de deux amphores, SNI]; GSE 1932: 13-14 gennaio [fragments de quatre amphores SNI, les deux premières présentant l'une un timbre (Della Corte 1958: n² 260 p. 261) l'autre deux inscriptions peintes (CIL IV, 10770 a), les deux dernières contenant des fèves (Inv. ${ }^{\circ}$ E708=75985)]. M. Della Corte (1958: $n^{\circ} 179-181$ p. 260 et $n^{\circ} 258-259$ p. 261) mentionne au total six amphores provenant de cette maison, dont deux seraient de la forme Schoene VIII, soit de probables amphores de vin crétois.

${ }^{155}$ Cf. infra, p. 270-271.

${ }^{156}$ Pirson 1999: 19-20.

${ }^{157}$ Voir fig. 47 p. 114.

${ }^{158}$ GSE 1934: "[Description finale de V, 6-7, insérée à la fin du journal de juin] [...] L'ambiente è alto m. 2.89 e il solarino è sostenuto da otto travi. A m. 1.90 di altezza dal pavimento ed a m. 2.50 dal vano d'ingresso vi è un ammezzato di legno carbonizzato chiuso dalla parte anteriore da transenne di legno [...]». 
Nettuno e Anfitrite devrait également permettre de définir son mode de construction, n'étaient les problèmes induits par la description faite au moment de la fouille puis lors de la restauration. Ainsi, selon les rédacteurs des GSE, l'ensemble serait constitué par un double système de solives majoritairement orientées est-ouest, une seule étant en sens nord-sud ${ }^{159}$. Pourtant, cette description rend l'ensemble non fonctionnel: si, comme les GSE l'indiquent, les deux solives passantes nord-sud s'appuyaient sur les solives est-ouest, celles-ci flotteraient sans appui autre que la cloison de bois qui ne s'étend pas sur toute la largeur du local. Considérons donc que les solives est-ouest s'appuient sur celle qui est fixée dans les murs nord et sud. Le système employé pour la restauration - l'insertion du bois originel dans des poutrelles métalliques - empêche de vérifier la nature exacte de cet aménagement, d'autant que divers éléments non décrits dans les journaux de fouilles y ont été ajoutés - comme le poteau de section quadrangulaire dans l'alignement d'une paroi en opus craticium -, tandis que la charpente de soutien a été simplifiée ${ }^{160}$.

On connaît à Herculanum d'autres attestations d'un tel aménagement, même si seules les empreintes dans les murs soient conservées. La

${ }^{159}$ GSE 1933: «1 febbraio. [...] I travi che sostengono tutto il peso partono dalla parete est e sono a forma rettangolare della larghezza m. 0.14 e dello spessore di m. 0.05 . Altri travi sono piazzati da sud a nord e misurano m. 0.09 per m. 0.19 e poggiano sopra i primi, i quali dato il peso e la lunghezza dovevano certamente essere sostenuti dai piedi, per ora nessuna traccia vi è apparsa, perché non ci siamo inoltrati con lo sterro $[\ldots]$ ».

${ }^{160}$ La paroi en opus craticium située sur le côté nord de la table de cuisson sud-est n'est jamais décrite. Le poteau de section quadrangulaire qui se situe dans l'alignement de cette paroi est également absent des GSE. Ces manques peuvent être dus au laconisme des descriptions une fois la majeure partie de la mezzanine et de sa cloison de bois mises au jour, voire à l'intervention préférentielle des restaurateurs en lieu et place des fouilleurs. Actuellement, le plancher repose directement sur la solive passante nord-sud, sans qu'aucune des solives est-ouest n'ait été restaurée ou suggérée. Leur maintien dans la description finale, rédigée une fois la restauration achevée, n'est due qu'à la copie, à peine retouchée, de l'entrée du $1^{\text {er }}$ février 1933.

${ }^{161}$ Les traces correspondant à cette vaste mezzanine n'ont pas été reconnues comme telles par A. Maiuri (1958 b: 221-222). L'ouverture qui aurait servi de passage entre les deux pièces de la mezzanine a ainsi été interprétée comme boutique III, 4 (cat. $\mathrm{n}^{\circ}$ 2) dispose d'une mezzanine passablement étendue, qui constituerait presque un demi-étage et se développe au moins au-dessus de la pièce annexe 17 et pour partie dans le local principal ${ }^{161}$. En V, 28 (cat. ${ }^{\circ} 23$ ), c'est également dans la pièce annexe que se développe cette surface additionnelle. Construite dans une seconde phase, elle ne semble pas avoir d'extension au sud du mur de refend qui divise l'arrière-boutique en deux parties inégales ${ }^{162}$. De la même façon, deux phases successives de plancher sont visibles dans la pièce 18-4 de l'atelier Or. II, 18. Dans un premier temps, un plancher est mis en place, par le biais de sept solives nordsud reposant sur une solive passante est-ouest, dans le tiers méridional de la pièce 18-2/4. Après la construction du mur de refend divisant cet espace, la mezzanine est abaissée et sa surface réduite: l'accès se fait désormais par une trémie ménagée en son milieu. De tels planchers secondaires se rencontrent également dans certaines pièces des domus sans aucun lien avec une activité commerciale ou artisanale. Ainsi, la partie orientale de la cuisine 14 de la Casa del tramezzo di legno est-elle surplombée par une mezzanine. Dans la pièce C de la Casa del salone nero, c'est presque la totalité de la surface de la pièce qui est ainsi doublée ${ }^{163}$. L'absence de découverte d'objet

une fenêtre. Une série de poutres est pourtant visible sur toute la longueur du mur oriental de la pièce principale.

${ }^{162}$ Ce mur est abattu jusqu'à la racine actuellement. L'installation de cette mezzanine dans une seconde phase se déduit notamment de l'insertion d'une des solives dans la niche creusée dans le mur nord. L'accès à ce plancher ne pouvait se faire que depuis la partie sud de l'arrière-boutique, vraisemblablement au moyen d'une échelle mobile.

163 GSE 1939: " 2 giugno. È incominciato lo sterro di un ambiente posto ad ovest della cucina. Doveva essere un ripostiglio, poiché quasi all'altezza di m. 1.60 dal pavimento sulla parete nord si notano delle alveole con delle tracce di travicelli a forma rettangolare di m. 0.05 per 0.039 che potevano contenere delle tavole per deporre gli oggetti o provviste». Si les restaurations effectuées dans le mur nord ne permettent pas d'appréhender l'ensemble du système de poutres, l'accès paraît avoir été ménagé par le percement d'une trémie à la verticale de la fenêtre donnant sur le puits de lumière $(\mathrm{F})$. Contrairement à ce que proposent le rédacteur du compte rendu puis A. Maiuri (1958 b: 240), les dimensions des solives rendent peu crédible l'hypothèse d'une étagère: les mesures indiquées dans les GSE sont erronées, la section des encastrements actuellement visibles varie d'un minimum de 12 x $12 \mathrm{~cm}$ à un maxium de $20 \times 15 \mathrm{~cm}$. 
sur ces planchers empêche de caractériser avec sûreté leur fonction: les amphores installées sur la mezzanine de la boutique V, 6 ne correspondent qu'à une mise en scène de la fouille ${ }^{164}$. La présence de ces planchers dans les lieux de métier peut se justifier par la nécessité d'entreposer le stock des denrées commercialisées ou la matière première nécessaire à la production. Si une seule interprétation devait être proposée, celle-ci paraîtrait la plus solide en raison de la présence de ces aménagements dans les domus à proximité des cuisines: ces planchers permettent notamment d'éloigner les denrées entreposées de l'humidité du sol, tout en offrant une extension de la surface. Toutefois, ces espaces pourraient également, dans certains cas, constituer le lieu de repos des esclaves tenant la boutique: l'espace y est suffisant pour jeter une paillasse et dormir, à défaut d'offrir une grande liberté de mouvement ${ }^{165}$.

Dans les boutiques et les ateliers, les fonctions de présentation et de stockage sont assurées par des meubles - fixés aux murs ou non - que l'on retrouve également dans les espaces de service de la sphère domestique ${ }^{166}$. La rémanence des empreintes qu'ils peuvent laisser dans les murs et l'usage multiple d'aménagements similaires rendent difficile leur appréhension. Quand les activités se déroulant dans un local ont varié, il est particulièrement délicat d'attribuer une étagère ou une mezzanine à une phase déterminée. C'est pourquoi, de même que l'utilisation de motifs spécifiques dans le traitement du sol ou des murs est rare, les différents aménagements présents dans les lieux de métier ne permettent pas nécessairement de les caractériser avec précision.

\section{I.4 De l'étude des artefacts à la caractérisation des locaux}

Les différents éléments généraux étudiés jusqu'à présent, pris isolément, ne permettent

${ }^{164}$ Cf. supra, p. 22-23.

${ }^{165}$ Une telle utilisation est notamment possible en III, 4 et en V, 6. Cela semble plus difficile pour la boutique V, 28 ou pour l'atelier Or. II, 18. Sur l'utilisation de paillasses pouvant être posées n'importe où dans la maison, cf. Apul., que difficilement de caractériser l'existence de lieux de métier. Une telle définition paraît possible en prenant en considération les objets mis au jour dans ces locaux. La mise en évidence de concentrations d'artefacts permet l'identification des activités spécifiques se déroulant dans ces locaux. Je ne chercherai toutefois pas à dépasser dans ce chapitre des considérations générales. Il faut ainsi définir des cadres interprétatifs qui seront utilisés dans les chapitres suivants et pour compléter un premier aperçu global du tissu des métiers à Herculanum. C'est pourquoi je me suis astreint à ne prendre en considération que les boutiques théoriquement nombreuses et facilement identifiables, celles se trouvant au bout de la chaîne de la commercialisation.

I.4.1 Les artefacts, vecteurs d'identification du commerce

Les objets mis au jour dans les locaux commerciaux devraient largement contribuer à la détermination des activités s'y déroulant. Toutefois, une première précaution quant aux données disponibles s'impose: faute de ramassage exhaustif du moindre tesson, une part très importante des objets a disparu. À ce problème lié aux méthodes de fouille, il faut évidemment ajouter les perturbations occasionnées par les tunneliers du XVIII ${ }^{e}$ siècle. La conjonction de ces deux facteurs fait que le nombre d'objets provenant des boutiques est particulièrement peu élevé: seulement 563 objets ont été inventoriés pour les 59 locaux interprétés par A. Maiuri comme dédiés au commerce. Le nombre moyen de ces objets par local est inférieur à 10, et s'approche de 6 si l'on ne prend en considération que la partie principale de la boutique ou de l'atelier (fig. 28). Comme seule une concentration d'artefacts ayant des caractères communs - usage, matière, forme, origine - peut conduire à une identification, les possibilités de préciser

Met., 2, 15. Sur la question de la localisation des esclaves à l'intérieur des domus, cf. George 1997.

${ }^{166}$ Pour des exemples de meubles que l'on trouve tant en contexte commercial que dans des espaces domestiques, cf. Mols 1999: 135. 


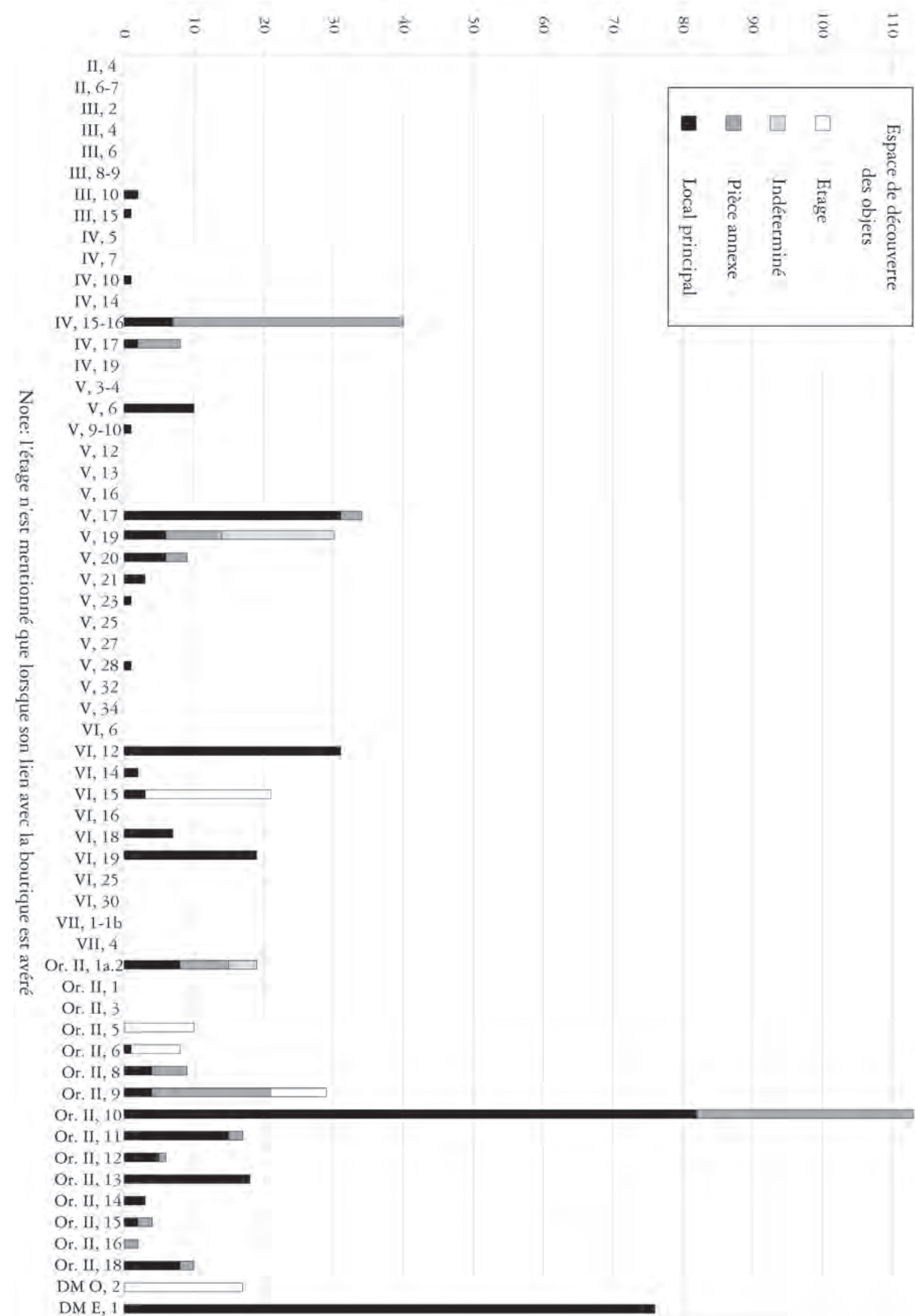

Fig. 28 - Distribution des objets découverts dans les locaux commerciaux et artisanaux d'Herculanum ou interprétés comme tels par A. Maiuri en fonction de leur espace de provenance. 
les fonctions exercées dans ces locaux sont peu importantes. Faute de point de comparaison, qu'il soit archéologique ou textuel, il est impossible de donner de seuil à partir duquel une concentration devient pertinente. Il va de soi que le contexte de découverte est décisif: à titre d'exemple, la plus grande concentration de lampes - 1085 exemplaires - a été mise au jour dans les thermes du forum à Pompéi, ce qui ne saurait attester une pratique commerciale ${ }^{167}$. Dans le cas du local V, 17, ce sont 19 lampes de terre cuite qui sont découvertes dans une caisse de bois ${ }^{168}$. Si elles avaient été mises au jour dans une boutique, elles auraient pu constituer un indice de l'activité commerciale s'y déroulant. L'étude architecturale de ce local montre qu'il n'est en fait qu'un appartement de plain-pied ${ }^{169}$. Toutefois, la présence de cette caisse pourrait conduire à considérer que son occupant pouvait être lié avec la distribution de ces luminaires, qu'il les vende à d'autres commerçants ou à des particuliers - dans une boutique non identifiée ${ }^{170}$. Les 19 lampes, dont deux en bronze, provenant du local Or. II, 10 (cat. $\mathrm{n}^{\circ} 44$ ) ne permettent pas non plus d'identifier un commerce dédié à l'éclairage, malgré la réelle concentration qu'elles indiquent, particulièrement si on les rapporte à la surface de ce local ${ }^{171}$. Les 20 pierres semi-précieuses et

${ }^{167}$ Ces découvertes massives de lampes sont reportées en trois occasions lors de la fouille des thermes: le 7 août 1824, 307 lampes à un bec sont découvertes (PAH II: 111); le 23 août, 134 (PAH II: 112-113); le 12 septembre 1824, 394 autres (PAH II: 114); finalement le 4 décembre 1824, les 250 derniers exemplaires (PAH II: 121).

${ }^{168}$ GSE 1938: 1 marzo, cit. infra n. 248.

${ }^{169}$ Cf. infra, p. 83-87.

${ }^{170}$ Cette situation n'est pas sans rappeler la caisse en bois mise au jour dans le tablinum de la maison VIII 5, 9 à Pompéi. Celle-ci contenait 90 bols de céramique sigillée provenant de La Graufesenque, accompagnées par 37 lampes pour partie fabriquées dans le nord de l'Italie (NSc 1881: 300-302; BdI 1883: 174-175; Atkinson 1914: 27-28). La fouille des boutiques en façade de cette maison a eu lieu entre le 30 novembre 1840 et le 3 juillet 1841 (PAH II: 387399). L'absence de localisation des endroits où se déroulent les travaux - au-delà de la mention «a destra della strada de'Mercadanti »- empêche une plus grande précision dans les dates. De ce fait, il n'est pas possible d'affirmer que ces bols et lampes étaient destinés à une vente dans un de ces locaux. Cette hypothèse est toutefois la plus probable. Outre la nature des objets empaquetés dans la caisse, la seule différence avec la situation en V, 17 tient dans l'im- objets travaillés au tour qui y ont été trouvés, associés à des instruments en bronze désignent de façon plus convaincante un atelier où le principal outil est un tour. De la même façon, les deux lingots de plomb trouvés en VI, 12 indiquent un atelier de plombier parce qu'ils ont été découverts avec des conteneurs en plomb et avec des objets en bronze ou des poids en marbre nécessitant une réparation ${ }^{172}$. Il ne saurait en revanche être question d'interpréter de la même façon la maison pompéienne VIII 6, 1.9-11 où un lingot a également été mis au jour: son rez-de-chaussée comporte une boulangerie ${ }^{173}$. Ces quelques exemples soulignent la nécessité de prendre en compte l'ensemble des éléments disponibles pour déterminer les activités se déroulant dans les locaux commerciaux.

Théoriquement, l'ultime maillon de la commercialisation des objets manufacturés - quand ils ne sont pas produits dans un atelier disposant d'un espace de vente - devrait être la boutique. A priori, les cités ensevelies par le Vésuve devraient permettre d'étudier ces commerçants, petits revendeurs de proximité, qui écoulent de la marchandise d'origines éventuellement diverses. En effet, dans la plupart des autres sites, les informations ne concernent que la consommation finale - ou plutôt ses vestiges

possibilité d'avancer une hypothèse sur le lieu de vente dans ce dernier cas. Sur l'interprétation de cette caisse, cf. infra, n. 248 p. 86 .

${ }^{171}$ Les 19 lampes permettent d'éclairer un local d'une surface de $56 \mathrm{~m}^{2}$. À titre de comparaison, 24 lampes dont une en bronze ont été découvertes dans la maison de C. Julius Polybius (IX 13, 1-3), d'une surface totale de $1184 \mathrm{~m}^{2}$ (rezde-chaussée: $890 \mathrm{~m}^{2}$; étage: $294 \mathrm{~m}^{2}$ ); 47 lampes proviennent de la Casa del Menandro (I 10, 4.14-17) dont la surface (hors péristyle) est d'environ $1600 \mathrm{~m}^{2}$. Le nombre de lampes trouvées dans ces maisons pompéiennes est issu de la base de données de P. Allison (www.stoa.org/pompeianhouseholds).

${ }^{172}$ Sur cet atelier, en attendant la publication définitive des fouilles effectuées en 2004 et 2005, cf. Monteix 2004 a, 2004 b, 2005, 2006: 19-23, 2007 b et Monteix - Pernot - Coutelas 2008.

${ }^{173}$ CIL X, 8339; cf. Domergue 1984: 200-201, 210. Le lingot a été trouvé dans un réduit ménagé sous un escalier (cf. NSc 1882: 82; BdI 1882: 184). Dans les pièces souterraines situées au nord de la maison, aucun élément ne permet de supposer l'existence d'un espace de production artisanale. La présence de ce lingot ne s'expliquerait que par d'éventuels travaux en cours nécessitant la présence d'un plombier sur place. 
- appréhendée d'une façon très générale. S'il est ainsi possible de définir des axes commerciaux à travers les importations, l'organisation de la dernière étape nous échappe encore en grande partie. Existe-t-il des « concessionnaires », revendeurs spécialisés dans les produits provenant d'une région particulière, voire d'un producteur spécifique? Ou bien au contraire, le stock de ces commerces est-il spécialisé dans une matière, la nature précise des objets vendus dépendant de ce que des négociants peuvent acheminer jusqu'à Herculanum ou Pompéi?

Seuls quelques rares exemples d'Herculanum permettent de proposer une première réponse à ces questions. En raison des dégâts causés d'abord par l'éruption puis par les fouilles du XVIII ${ }^{e}$ siècle, conjugués avec les limitations de l'enregistrement effectué durant les dégagements du $\mathrm{XX}^{\mathrm{e}}$ siècle, la culture matérielle de cette ville reste d'un abord délicat. L'étude des objets découverts dans une boutique partiellement fouillée sur le decumanus maximus offre un exemple très détaillé. Mis au jour sur une profondeur d'environ $1,80 \mathrm{~m}$, pour permettre de construire un mur de soutènement, ce local montre le système de fermeture à vantail mobile et rainure longitudinale, majoritaire dans les commerces $^{174}$. À l'intérieur, quelque 63 objets ont été découverts, comportant une écrasante majorité en verre $(73 \%, 46$ pièces), divisée entre de la vaisselle de table $(76 \%, 35$ pièces $)$ et des

${ }^{174}$ GSE 1961: 8 agosto, cit. supra, n. 92.

175 Selon les études menées par E. de Carolis (2006) à partir d'exemples de la regio I de Pompéi, le pourcentage d'objets en verre, quelle que soit l'extension de l'unité domestique oscille entre 35 et $45 \%$. En publiant ce matériel, A. de Franciscis (1963: 139) se demandait quelle interprétation donner au local: commerce de proximité, la caisse indiquant une réception de marchandise, ou bien intermédiaire procédant à la redistribution des objets emballés vers d'autres lieux de vente.

176 De Franciscis 1963: 137; Scatozza Höricht 1986: 22. E. M. Stern (1999: 471; 2006: 52) va encore plus loin, considérant que la "vaisselle en verre [...] [est] répartie en paquets distincts selon la forme des objets. Par conséquent, on vend des services complets de vaisselle de table en verre $[\ldots] »$.

177 GSE 1961: «8 agosto. [...] Parte del vetro rappresentante coppette è stato rinvenuto avvolto in stoffa o nelle casse $[\ldots] »$.

${ }^{178}$ Selon A. de Franciscis (1963: 137, 139), plusieurs bouteilles sont à ce nom dans la boutique au lieu d'une conteneurs à onguents (24\%, 11 pièces). La comparaison avec les inventaires des maisons de Pompéi donne à cette surreprésentation de la verrerie une interprétation évidente: ce local est celui d'un revendeur spécialisé dans les objets fabriqués dans cette matière ${ }^{175}$.

Bien que cette boutique n'ait été que partiellement fouillée et que tous les objets qu'elle contenait n'aient pas été découverts, une rapide analyse des mécanismes d'approvisionnement permet de comprendre l'insertion du commerçant dans la chaîne économique. Depuis la première publication de cette boutique par A. de Franciscis, les informations la concernant sont quelque peu erronées. Ainsi, tant le successeur d'A. Maiuri que ceux qui ont par la suite étudié ce matériel considèrent que l'ensemble de la vaisselle de verre a été mise au jour emballée dans de la paille et dans des morceaux d'étoffe ${ }^{176}$. Pourtant, à défaut d'avoir pu retrouver les photos mentionnées dans les GSE, ceux-ci sont catégoriques: seule une partie des coupes a été découverte emballée dans les caisses ou dans des fragments d'étoffe ${ }^{177}$. De la même façon, une seule bouteille présente sur son fond un timbre au nom de P. Gessius Ampliatus, indiqué au génitif, déjà connu par ailleurs dans la région ${ }^{178}$. Faire de ce probable verrier un Pompéien, unique producteur de l'ensemble de la vaisselle découverte dans ce local, est une exagération peu fondée ${ }^{179}$.

seule (Inv. $\mathrm{n}^{\circ}$ E2362 = 77658). Une correction est proposée ensuite (de Franciscis 1973: 311). Deux exemplaires de ce timbre ont été inventoriés. L'un provient des Monts Albains (CIL X, 8062, 5 a), l'autre vraisemblablement de Pompéi (CIL X, 8062, 5 b). L. A. Scatozza Höricht (1991 : 76) signale deux autres attestations à Pompéi, l'une sur une bouteille (Isings 50, Inv. $\mathrm{n}^{\circ} \mathrm{P} 13512$ ), l'autre sur un bocal quadrangulaire (Isings 62, Inv. $\mathrm{n}^{\circ} \mathrm{P} 933$ ). L'emploi du génitif sur les exemplaires provenant d'Herculanum et de Pompéi plaide en faveur de l'interprétation de ce nom comme désignant celui du producteur du contenant (sur les timbres apposés sur le matériel en verre, cf. Sternini 1993, part. 81-85 et 8893).

${ }^{179}$ Mettant l'accent sur la nécessité de ne pas confondre lieu de découverte et lieu de production, J.-P. Morel (1979: 262) a réfuté cette interprétation faisant de P. Gessius Ampliatus un artisan pompéien. Pourtant, dans son étude sur la verrerie d'Herculanum, L. A. Scatozza Höricht (1986: 80-81) la reprend à son compte, tout en étendant sa production à l'ensemble des objets mis au jour. Dans une étude postérieure (Scatozza Höricht 1991, part. 78), elle 
Avant d'examiner ce cas particulier, précisons certains points concernant l'industrie verrière dans l'Antiquité. Durant tout le Haut Empire, la matière première est issue d'ateliers primaires situés en Orient: le sable proviendrait des côtes de Palestine, tandis que le natron, utilisé comme fondant pour abaisser la température de fusion, est originaire d'Égypte. Le verre serait préparé sous forme de blocs acheminés par voie maritime vers l'Occident. Si les analyses de composition ont permis d'arriver à une telle conclusion, elles empêchent toute détermination plus fine du lieu de production des objets en eux-mêmes ${ }^{180}$. Celle-ci ne paraît pouvoir se faire que par le biais de comparaisons formelles et techniques, à l'échelle d'une région. La connaissance de sites de production ou d'épaves aide bien évidemment à distinguer une production locale d'une production importée ${ }^{181}$.

Dans le cas de la boutique d'Herculanum, la problématique est autre: il s'agirait de distinguer l'existence ou non de plusieurs ateliers fournissant le local. Les 46 objets mis au jour se répartissent selon 9 formes générales. Si l'on s'en tient aux techniques de fabrication, deux ensembles se dégagent, entre la fabrication par simple soufflage $(34 / 74 \%)$ et celle par soufflage au moule $(12 / 26 \%)^{182}$. Il serait difficile de ne se fonder que sur ce critère pour distin-

sous-entend que P. Gessius Ampliatus serait un affranchi de Gessii installés à Pouzzoles qui auraient pu être impliqués dans l'essor de l'artisanat du verre en Campanie. Cette hypothèse oublie cependant la seconde estampille (CIL X, 8062, 5 a: P(ublius) Gessius Ampliatus P(ublii) f(ilius) [fecit]) ou bien oblige à considérer que ces deux personnages sont distincts: le Publius Gessius Ampliatus de la seconde estampille serait alors le fils du précédent, luimême affranchi selon cette suggestion. La même idée a été de nouveau présentée ensuite, sans emporter la conviction (cf. Scatozza Höricht 2000).

180 Des analyses effectuées sur des objets en verre découverts en contexte de production à Lyon, et comparés avec d'autres, provenant de Saintes, d'Aoste, de Rome et de Jalame (Israël) ont montré qu'un même sable, provenant des côtes de Palestine a été utilisé dans ces différents sites. La matière première était donc importée d'Orient après conditionnement en blocs réalisés dans des ateliers primaires, pour être distribuée aux ateliers secondaires d'Occident (cf. Nenna - Vichy - Picon 1997, Picon - Vichy 2003). Le même type d'analyse, conduit sur des fragments de verre pompéien a conduit au même résultat (cf. Vallotto - Verità 2002; Verità 2006). guer des lieux de production différents. En effet, les fouilles de fours de verriers menées à Lyon montrent la coexistence dans un même quartier de plusieurs ateliers durant la seconde moitié du $\mathrm{I}^{\text {er }} \mathrm{s}$. de notre ère. Les techniques employées, identifiables tant avec les rebuts de cuisson qu'avec les restes d'outils - moule, probable pontil - ressortent tant du soufflage simple que du soufflage au moule. Dans ces ateliers lyonnais, l'existence conjointe de deux techniques apparaît possible ${ }^{183}$. La couleur des objets ne constitue pas non plus un critère, tant elle peut être influencée par les arrivages de matière première. Seul le timbre de P. Gessius Ampliatus permet quelques réflexions: en dépit des transformations de la forme des lettres - relevant vraisemblablement d'un changement de moule -, on le trouve sur deux types de récipients, bouteille de forme Isings 50 et bocal de forme Isings 62. La conception générale de ces deux conteneurs - obtenus par soufflage dans un moule constitué par cinq plaques de pierre ${ }^{184}$ - ne varie que dans l'élargissement de l'ouverture pour former ou non un col. Contrairement à ce que postule L. A. Scatozza Höricht, rien ne permet d'affirmer que cet atelier était l'unique fournisseur du verre à Herculanum ${ }^{185}$ : des récipients de forme similaire ont été mis au jour dans la ville, dépourvu de ce timbre qui reste le

181 Sur les problèmes de détermination des origines, voir les remarques de D. Foy et M.-D. Nenna (2003 b, part. 227-229). Les différentes contributions sur la question des productions et importations données lors du colloque de l'A.F.A.V. de 2001 mettent en évidence ce problème de la caractérisation du lieu de fabrication (cf. Foy - Nenna 2003 a: 139-296).

182 Sur la différence entre ces deux techniques, cf. Stern 2006: 53-57.

${ }^{183}$ Il faut toutefois noter que les formes de verre moulé mises en évidence sont considérées comme ayant été importées et que les lacunes dans la connaissance des implantations, dues au caractère préventif des fouilles, empêchent de séparer nettement les différents ateliers présents sur ce site. Cf. Motte - Martin 2003.

${ }^{184}$ Un exemple de ce type de moule a été mis au jour dans les fouilles de la Montée des Buttes à Lyon (cf. Motte - Martin 2003: 316 et fig. 21,5 p. 317).

185 "Tale unica officina riforniva in epoca flavia apparentemente tutta Ercolano, come è attestato dalla perfetta analogia di forme e motivi decorativi fra i vetri del gruppo di Ampliatus e quelli rinvenuti, invece, nelle case della cittadina vesuviana » (Scatozza Höricht 1986: 80). 
seul indicateur du producteur ${ }^{186}$. Ce postulat ne s'appuie en fait que sur l'assertion fausse selon laquelle toute la marchandise aurait été mise au jour emballée. En ce qui concerne l'approvisionnement de ce local, la démonstration de l'existence de plusieurs fournisseurs ne pourrait toutefois être obtenue que par la découverte, dans la même boutique, d'autres bouteilles de même forme, sans timbre ou avec un timbre différent.

Bien que dans l'incapacité de le démontrer formellement, il me semble hautement improbable, au vu de la diversité des formes vendues et des techniques employées, qu'un seul atelier ait vendu sa production à ce commerçant. Quant à la caisse, son contenu, uniquement constitué de coupelles, paraît indiquer une livraison effectuée dans ce local par un producteur. La détermination exacte des pièces constituant ce chargement, rendue impossible par leur destruction partielle lors de l'éruption, aurait constitué un exemple unique de boutique connue par son stock et ses fournisseurs. En l'état, ce local montre égale-

${ }^{186}$ Forme Isings 50: Scatozza Höricht 1986, cat. n 77 à 92 (seule la bouteille ${ }^{\circ}$ E2362 $=77658$ [cat. $n^{\circ}$ 93] porte ce timbre à Herculanum); Forme Isings 62: Scatozza Höricht 1986, cat. $n^{\circ} 246$ à 249 (aucun de ces bocaux ne porte de timbre).

${ }^{187}$ Rappelons que dans ce cas, la vente au détail de verrerie est induite de la multiplicité des formes dans un unique matériau. Dans un exemple pompéien (VII 5, 29), l'écrasante majorité des objets mis au jour est en verre: «Il 27 febbraio [1829] [...]. Si eseguì quindi uno scavo in una bottega sulla strada detta del tempio di Augusto; [...] vi si rinvennero. Vetro. 550 caraffinette, 11 unguentarj e lagrimatoi diversi, un vasetto rotondo a due anse e a collo stretto di forrna assai elegante, altre 55 boccettine, varie pastiglie rotonde per collana. Bronzo. Monete 31 di diverso modulo, due guantiere circolari, due pezzi per guarnizione di porta, un piccolo peso. Terracotta. Due pignatte, un picciolo oliario, un vasettino circolare della bellissima forma di un calice, e fregiato nel giro di una picciola ghirlanda di edera [...]. Il dì 9 marzo [...] si eseguì poscia una ricerca finale nella stessa bottega incominciata a sgombrarsi innanzi a S.M. il Re di Baviera, e vi si raccolsero i seguenti oggetti. Bronzo. 12 monete di diverso modulo, un bel candelabro. Vetro. 120 caraffinette di diversa grandezza » (PAH II, 219). Cependant, comme le remarque J.-P. Brun (Brun - Monteix 2009: 123124), la forme des objets - pour peu détaillée qu'elle soit comme il arrive dans les comptes rendus de fouille - permet de considérer qu'il ne s'agissait pas d'un marchand de verrerie, mais bien d'un détaillant en parfums.

188 «13 giugno [1818] - [...] Nel decorso di questa settimana, nello sterro dietro l'ultimo tempio esastilo nel Foro e propriamente in una bottega si sono trovati i seguenti oggetti. Terracotta. Una lucerna a due luminelli di straordinaria forma ment une spécialisation du commerce par matériau $^{187}$.

Ce cloisonnement dans le commerce de proximité est confirmé par l'examen des locaux de vente de céramique à Pompéi. Ainsi, trois commerces probables de céramique ont été mis au jour dans le quartier du forum, autour du macellum. Deux d'entre eux ne peuvent être situés avec précision en raison du manque de détail dans les rapports de fouilles du début du XIX $^{\mathrm{e}}$ siècle. Le premier devrait se trouver sur le côté occidental du marché, alors que la fouille du vico degli Augustali n'a pas encore commencé. Sur les 105 objets mis au jour, seuls trois ne sont pas en céramique; les autres sont répartis entre cinq catégories - lampes, vases à anse, petits vases, tasses et jarres à huile - dont les appellations sont trop imprécises pour permettre une caractérisation fine ${ }^{188}$. Le mois suivant, sur le côté nord du macellum, au début du vico degli Augustali, un probable revendeur spécialisé dans les luminaires est identifié: dans sa boutique, 42 lampes sont découvertes ${ }^{189}$. Le

e misura, lunga pal. 1 ed once 2, larga once 91/2, rappresentante una testa di vitello. Dieciannove lucerne ordinarie. Vasetti con manico e senza trentacinque. Tazze di varie forme ventotto. Oliari sei. Vasettini piccioli tredici. Marmo. Una testolina e due pesi, une piccolo, l'altro più grande [...]»(PAH I, 3: 205). Le même inventaire, rédigé par R. Amicone, est reporté dans le dernier tome de la $P A H$ (III: 15), en date du 11 juin 1818.

${ }^{189}$ La localisation de cette boutique est sujette à variations. Selon le rédacteur du journal de fouille, elle pourrait se trouver sur le côté ouest du macellum : « 1 Agosto - [...] Il giorno 28 dello scorso mese, in una bottega laterale al Foro, ad Oriente, di rincontro al tempio esastilo si rinvennero i seguenti oggetti. Bronzo. Una conca con un sol manico dissaldato, e rotta in parte. Terracotta. Quarantadue lucerne ordinarie» (PAH I, 3: 209).

Selon R. Amicone, elle se trouverait sur le côté nord: «1 Agosto - Nell'abitazione in seguito della descritta [« in una abitazione su la dritta della stradetta alle spalle del detto tempio ", (PAH III: 16)], si è rinvenuto. [suit la même liste d'objets]» (PAH III: 16).

La boutique immédiatement à côté ne paraît pas devoir être interprétée comme celle d'un revendeur d'objets céramiques, en dépit du fait que seuls des objets de ce type ont été trouvés: "18 Luglio - [...] Il giorno 14 nel travaglio al lato orientale del tempio esastilo, si rinvennero. Terracotta. Una lucerna sferica ad un luminello, di diametro once 7. Altra lucerna più piccola. Otto vasi di diverse forme. Sette piccoli vasettini di diverse forme " (PAH I, 3 : 208). En effet, surtout si l'on compare avec l'exemple précédent (cf. supra, n. 188), le nombre d'objets paraît moins important en valeur absolue. Il serait nécessaire de pouvoir retrouver ces derniers pour confirmer cette impression. 
troisième local est identifiable grâce à la plaque de terre cuite située sur le montant occidental de sa porte, figurant deux hommes portant une amphore (VII 4, 15-16). En dépit de l'absence d'un décompte précis des objets mis au jour, il s'agit vraisemblablement d'un négoce d'objets céramiques variés ${ }^{190}$. Un quatrième exemple plus détaillé se situe en VII 2, 52. Selon la liste des objets mis au jour, il s'agirait d'un marchand se consacrant à la céramique de cuisine et de service, en l'absence probable de toute céramique fine ${ }^{191}$. Le matériel trouvé dans ces quatre locaux mériterait d'être autopsié de façon à déterminer l'origine des objets vendus ${ }^{192}$. Notons, en attendant, la diversité du commerce de la céramique à Pompéi observée à travers ces quatre exemples: le stock de quatre revendeurs permet de reconnaître deux vaisseliers généralistes, le troisième spécialisé dans les lampes, le dernier dans la céramique commune. Dans les deux premiers

190 «23 settembre [1818] - [...] Nella bottega che resta alle spalle del Tempio di Giove, e proprio quella ove si vedono due facchini, che portano un'anfora su le spalle, nell'approntarsi, si rinvennero una quantità di oggetti di creta, consistenti in lucerne di varie forme, pignatti, coverchiole, tegami ed altro»(PAH III: 17). Cette fouille de "préparation", préalable à la visite de deux ministres le 26 septembre (PAH III: 18), n'est mentionnée que par R. Amicone. Sur ces préparations précédant les visites officielles, la lecture des journaux de fouille de Pompéi au $\mathrm{XIX}^{\mathrm{e}}$ siècle est parfois édifiante. Il semble en effet que la venue de visiteurs donnait fréquemment lieu à une fouille anticipée, voire à un véritable maquillage, certains «beaux objets » pouvant être remis en place - dans un autre endroit - au moment opportun. Il arrive cependant parfois que les objets soient replacés dans leur pièce d'origine. L'exemple le plus flagrant de cette pratique est donné par E. Falkener (1852: 74-75), qui décrit la découverte, le repositionnement puis la destruction partielle lors d'une visite officielle du nez d'une statue de Bacchus dans la Casa di Marco Lucrezio (IX 3, 5.24) en 1847.

L'analyse détaillée de la $P A H$, où sont mentionnées les visites officielles, permettrait certainement de cerner l'importance accordée à tel visiteur en fonction du nombre d'objets découverts. En croisant ces données avec l'histoire diplomatique du royaume, il serait certainement possible de mieux discerner comment Pompéi a servi de vitrine aux Bourbons mais également d'évaluer quelle fraction du site a été offerte en sacrifice sur l'autel des bonnes relations internationales.

${ }^{191}$ GSP 1862: «A' 14 [agosto]. [...] all'ingresso della 3a bottega a sinistra del Vicolo di Augusto, a contare dall'altro vicolo che si prolunga con quello delle Terme, [...] si è raccolto: Terracotta. 47 pignattini ad un manico [...] - Altri cas, à partir des données connues sur la production céramique locale, les boutiques semblent nécessairement constituer le point d'aboutissement de plusieurs producteurs: l'atelier de potier situé en I 20, 3 n'aurait fabriqué que des lampes et des fritilli, tandis que l'un des deux situés au-delà de la porta di Ercolano aurait au moins fabriqué des marmites ${ }^{193}$.

Pour d'autres produits, on trouve une spécialisation beaucoup plus évidente. Ainsi, toutes les amphores découvertes dans la boutique IV, 14 à Herculanum proviennent de Crète et ont contenu du vin. Contrairement à ce que propose A. Maiuri, qui voudrait, certainement poussé en cela par l'inscription VASA peinte à l'extérieur de la boutique, y voir une taberna vasaria spécialisée dans le commerce des produits céramiques, seules des amphores ont été mises au jour dans ce local ${ }^{194}$. Les études d'A. Marangou-Lerat ont montré que ces amphores - de type VIII dans

due pignattini ad un manico a forma di bicchiere [...] -4 tazzette [...] - Altre cinque [...] - Altri tre frammenti di tazzette simili $[\ldots]-13$ piattini con vernice rossa $[\ldots]-$ Altri cinque piattini rotti [...] - Una scodella [...] - Altre due [...] - Altre tre [...] - Due piccole caldaie [...] - 8 coperchi di diversa dimensione $[\ldots]$-Altri tre più piccoli $[\ldots]-4$ oleari diversi $[\ldots]$ - Tre pignatte ad un manico [...] - Altre due senza manichi $[\ldots]$.

A' 19 [agosto] [...] Terracotta - Una conca a tre manichi - 3 piccole caldaie di divesi dimensioni - 7 pentole della quali una sola col manico - 12 arette diverse - Una lagena a due manichi - Un pignattino ad un manico - 104 coperchi diversi - una tazzetta con vernice rossa ».

${ }^{192}$ Une telle étude est cependant d'une difficulté insurmontable. Ces objets sont conservés au MANN dans le meilleur des cas, s'ils n'ont pas été offerts au visiteur ayant assisté à leur découverte. Les livres d'inventaire ne permettent pas de créer une passerelle vers la description de la $P A H$.

${ }^{193}$ Sur ces ateliers, cf. Peña - McCallum 2009: 64-76; Cerulli-Irelli 1977; Annechino 1977: 106-107; Fulvio 1879: 280; Fiorelli 1875: 416.

${ }^{194}$ Maiuri 1958 b: 436. CIL IV, 10527 : vASA. L'apographe inclus dans les GSE (1932: 2 febbraio), bien que reproduit par leurs rédacteurs et donc éventuellement moins fiable que la lecture de M. Della Corte, est difficilement intelligible mais ne paraît pas se limiter à ces quatre lettres en raison de plusieurs ligatures. En ce qui concerne les objets mis au jour dans cette boutique, les GSE 1932 ne mentionnent que 28 amphores: «25 gennaio. Nella casa n. 8 ambiente n. 1 posta all'estremità del decumano minore lato sud, ambiente che fa parte della casa n. 6 , addossato alla parete ovest a m. 0.50 dal vano d'ingresso è stato trovato un deposito di piccole anfore. 4 ne sono state sterrate, altre sono ancora 
la typologie de R. Schoene - correspondaient à des amphores vinaires crétoises ${ }^{195}$. Les 36 conteneurs découverts correspondent au type AC2 ou à sa variante de demi volume AC4 ${ }^{196}$. Les différentes inscriptions portées sur le col permettent d'esquisser l'organisation du commerce de ce vin entre la Crète et la Campanie. La majeure partie des amphores de IV, 14 (34 sur 36) portent le nom de K.E. Zosimos ${ }^{197}$. Dans un seul cas, reporté uniquement dans les GSE, ce nom est accompagné par celui de Ti. Claudius Epaphroditus, en alphabet grec, au génitif ${ }^{198}$. Deux amphores portent ce même nom, seul ${ }^{199}$. Ce personnage est attesté sur d'autres amphores crétoises à Herculanum ou à Pompéi ${ }^{200}$. Si cette transcription par les rédacteurs des GSE n'est pas erronée ${ }^{201}$, ce dernier personnage peut être considéré comme le négociant en vin, probable exportateur entre la Crète et Herculanum, tandis que K.E. Zosimos serait producteur ou intermédiaire ${ }^{202}$. De la sorte, l'écrasante majorité des amphores mises au jour dans cette boutique auraient transité par le biais de Ti. Claudius Epaphroditus. Ce dernier ne constitue cependant pas nécessairement l'unique source d'approvisionnement du boutiquier:

in sito coperte di materiale vulcanico e ciascuna porta una iscrizione fatta con pittura nera. [Description de 4 amphores pourvues de six inscriptions peintes] [...] 30 gennaio. Nella casa n. 8 ambiente n. 1 si sono sterrate parecchie anfore di terracotta. [Description de 24 amphores et cols d'amphores pourvus d'inscriptions peintes]. Altre anfore sono ancora nell'ambiente ma non è possibile sterrarle per il momento per la cattiva conservazione delle pareti ».

${ }^{195}$ Marangou-Lerat 1995, part. 130-146 sur Pompéi et Herculanum.

${ }^{196}$ Le nombre exact de ces vases est délicat à établir: A. Maiuri (1958 b: 436) et M. Della Corte (1958: $n^{\circ} 185-240$ p. 260) en dénombrent 35 , tandis que les GSE n'en indiquent que 28 (cf. supra, n. 194), tout en signalant que d'autres sont encore ensevelies. Au moins une inscription relevée dans les GSE ne figure ni dans l'article sur Herculanum, ni dans le supplément du $C I L$ consacré à la ville. Le nombre de 36 amphores crétoises reste un minimum, obtenu uniquement par le biais des marques peintes. Les éventuelles amphores non marquées ne peuvent pas être dénombrées.

${ }^{197}$ Le corpus et A. Maiuri proposent un kappa, corrigé en epsilon par A. Marangou-Lerat (1995: P87 p. 146)

198 GSE 1932: 25 gennaio [quatrième inscription décrite].

${ }^{199}$ CIL IV, 10889 a-b.

200 À Herculanum, une autre amphore portant son nom a été trouvée en Or. II, 9 (CIL IV, 10890, mise au jour le l'une des amphores ne peut lui être rattachée de façon certaine ${ }^{203}$. Cette incertitude permet de proposer une spécialisation pour le commerçant en IV, 14, celle de revente de vin crétois. Toutefois, bien qu'au moment de l'éruption l'essentiel de son stock semble provenir d'un unique négociant, il parait s'être fourni chez d'autres importateurs, constituant en cela un relais des marchands grecs - crétois? - en général, mais non le «concessionnaire » de l'un d'entre eux en particulier. Avec toute la prudence nécessaire pour ce type d'hypothèse, le boutiquier de IV, 14 pourrait avoir été le principal - sinon l'unique - revendeur de vin crétois d'Herculanum.

Ces quelques exemples de commerce de proximité de biens manufacturés montrent à quel point, même dans les cités ensevelies par le Vésuve, une recherche sur l'organisation commerciale est tributaire de facteurs variés. La limitation principale aux résultats que l'on peut obtenir en se fondant sur les artefacts tient aux destructions infligées à cette source par l'éruption puis par les générations successives de fouilleurs. À défaut de permettre une conclusion de portée générale, les cas étudiés montrent la diversité des situations dans un

6 février 1936). À Pompéi, ce négociant est attesté à six reprises (CIL IV, 5942, 6356, 6408, 9764, 9765, 10443; cf. Marangou-Lerat 1995: 135).

${ }^{201}$ Quels que soient les défauts reconnus au travail de M. Della Corte (cf. Solin 1973, Mouritsen 1988: 13-27), l'absence de cette amphore dans la retranscription de ses carnets reste surprenante (Della Corte 1958).

${ }^{202}$ Cette interprétation soutient également la comparaison avec les deux amphores portant le nom de L.R. Antigonius (CIL IV, 10802 = Marangou-Lerat 1995: P85 p. 145 et CIL IV, 10806 = Marangou-Lerat 1995: P84 p. 145). Dans les deux cas, il est associé avec un nom ou surnom en grec. L'un d'eux (CIL IV, 10806) est exclusivement mentionné pour un cru de Lyttos (cf. Marangou-Lerat 1995 : P7-P8 p. 132).

${ }^{203}$ CIL IV, 10795 (= Marangou-Lerat 1995: P87 p. 146): I / MIN. Le texte de cette amphore AC2 reste énigmatique: la numération de première ligne est interprétée par comme une indication de capacité ou comme un système d'inventaire de la marchandise (cf. Marangou-Lerat 1995: 146). Selon A. Łos (1997, part. 67-70), la plupart des noms de citoyens lus sur les amphores de vin crétois doit être interprétée non pas comme des Crétois ayant obtenu la citoyenneté romaine, mais comme des Italiens, probables affranchis impériaux. 
contexte de fort cloisonnement entre les différentes productions. On peut supposer plusieurs sources d'approvisionnement pour le commerce $\mathrm{du}$ verre, mais sans localisation envisageable. Si la caisse contenant des objets empaquetés était bien un arrivage de produits, elle pourrait provenir d'un unique atelier. En revanche, en ce qui concerne la distribution du vin crétois, elle paraît avoir été assurée à Herculanum par un unique revendeur, s'approvisionnant auprès de plusieurs revendeurs qui se fournissaient dans plusieurs chais. La structure de la distribution finale de ces produits - son fort cloisonnement et ses variations dans la spécialisation - apparaît comme un reflet probable du système de production. Ce reflet ne permet toutefois pas de cerner les éventuels intermédiaires au niveau local et dissimule une partie de ceux des niveaux régionaux et interrégionaux. L'étude du contenu des boutiques pour caractériser la chaîne de commercialisation s'avère, dans le cas des cités ensevelies par le Vésuve, une impasse faute de données suffisantes ${ }^{204}$. Seule une étude diachronique, aux échelles régionale et interrégionale, comprenant les espaces de production et les sites de consommation peut permettre d'aboutir à des résultats globaux, même s'ils risquent de laisser dans l'ombre l'avant dernier maillon qu'est le fournisseur du boutiquier ${ }^{205}$.

${ }^{204}$ La destruction par un incendie d'une boutique de céramique à Poitiers au $\mathrm{III}^{\mathrm{e}}$ siècle permet d'illustrer ce commerce de proximité de façon plus précise que ce qu'il a été possible de faire avec les exemples pompéiens. Il s'agissait d'une boutique exclusivement tournée vers la vaisselle de table et de préparation, où 320 individus ont été inventoriés. Les productions sont régionales: Lezoux pour la céramique sigillée, un nombre indéterminé d'ateliers en l'état actuel pour la céramique commune (Wittman - Jouquand 2003).

${ }^{205}$ Une telle étude menée sur la céramique sigillée du centre de la Gaule a permis de caractériser différents schémas de distribution possibles en fonction de la distance entre le centre de production et celui de consommation (Delor Ahü 2004, part. 88-94). Il semble délicat de reproduire une telle analyse sur d'autres productions pour lesquelles les sites de production ne sont que grossièrement localisés comme la céramique commune par exemple ou difficilement localisables comme pour le verre.

${ }^{206}$ Pour les locaux fouillés durant les années 1960-1961, j'ai considéré soit l'interprétation proposée par A. Maiuri
I.4.2 L’interprétation des «boutiques » d'Herculanum

Au terme de ces réflexions d'ordre général sur les boutiques, il faut reconsidérer tous les locaux qui ne bénéficient pas d'une interprétation précise dans la somme écrite par A. Maiuri, en mettant en évidence les facteurs permettant ou non de les considérer comme des lieux de métier. Quelque 54 locaux ont été décrits comme pouvant être associés à une activité artisanale ou commerciale ${ }^{206}$. Parmi ceux-ci, 5 $(9 \%)$ seraient des ateliers ${ }^{207}$. Le raisonnement déployé pour ces interprétations est toujours le même: en l'absence de toute trace de comptoir maçonné ou en bois, le local ne pourrait être que destiné à une production qui n'est jamais spécifiée ${ }^{208}$. Les locaux Or. II, 15 (cat. $\mathrm{n}^{\circ} 48$ ) et Or. II, 16 (cat. $\mathrm{n}^{\circ} 49$ ) sont interprétés soit par comparaison planimétrique avec l'atelier Or. II, 10, soit grâce à la présence d'un fourneau ${ }^{209}$. La caractérisation d'un atelier est donc pour A. Maiuri une interprétation par défaut qui ne saurait être suivie: aucun élément architectural général ne permet de distinguer un atelier d'une boutique. Ni le seuil, ni la forme du local ne sont suffisamment spécifiques pour favoriser une telle distinction entre une activité de vente et celle de production - qui peuvent par ailleurs

dans ses carnets personnels (VI 12 et VI, 14), soit l'interprétation donnée par G. Cerulli-Irelli (1974) concernant les boutiques liées à la Casa del colonnato tuscanico (VI, 16; VI, 18 et VI, 25). Bien que mis au jour dans les années 1930, l'atelier VI, 30 n'est jamais mentionné. Pour le commerce alimentaire VI, 19, en se fondant sur les GSE (1961: 25 settembre), j'ai considéré qu'il aurait été appelé termopolio et donc assimilé à un commerce alimentaire. Les boutiques situées sur le côté nord du decumanus maximus n'ont pas été prises en compte.

${ }^{207}$ Locaux II, 4 ; III, 15 ; V, 32 ; Or. II, 14 ; Or. II, 15.

${ }^{208}$ L'exemple le plus développé concerne la Casa a graticcio (III, 15): "[...] La mancanza di qualsiasi apprestamento in muratura o in legno di un banco di vendita e le tracce di decorazione a stucco bianco e a fasce lineari, inducono a supporre che qui fosse allogata la bottega di un artigiano che avesse bisogno, per l'esercizio della propria arte, degli ambienti retrostanti per piccola officina e per deposito» (Maiuri 1958 b: 414).

${ }^{209}$ Maiuri 1958 b: 465-466. 
être présentes dans un même local. En l'absence d'élément permettant une identification précise, abandonnons l'idée que ces locaux aient été occupés par des artisans; je proposerai plus loin de nouvelles interprétations. Certains locaux (21/39\%) sont considérés comme des boutiques dont l'activité n'est pas spécifiée, sans qu'il soit loisible de restituer le raisonnement ayant conduit à cette qualification. Ainsi, la boutique V, 13 (cat. $\mathrm{n}^{\circ} 15$ ) n'est mentionnée qu'au détour d'une phrase dans un paragraphe discutable sur l'évolution des accès à l'étage de la Casa del bicentenario: elle est appelée bottega sans explication supplémentaire ${ }^{210}$. D’une façon générale, dès lors qu'une boutique appartient à une domus - à "plan traditionnel» ou non - elle n'est indiquée que très rapidement comme local commercial, sans détailler. Une réflexion plus approfondie est fournie pour les botteghe con abitazioni ${ }^{211}$. Toutefois, en matière d'interprétation, une fois constatée l'absence d'aménagement maçonné et de comptoir, le postulat d'une activité commerciale est posé sans autre clarification.

À la suite du processus de révision que j'ai effectué, certains locaux, déjà interprétés comme des boutiques par A. Maiuri, restent, faute de tout élément concluant, de potentiels locaux commerciaux dont l'activité est ignorée. En V, 29, la largeur de la porte et la présence d'une mezzanine dans la salle annexe permettent de supposer l'existence d'une boutique. La pierre

${ }^{210}$ Maiuri 1958 b: 228.

${ }^{211}$ Maiuri 1958 b: 432-449.

${ }^{212}$ Le 31 juillet 1933, ont été découverts un col d'amphorisque (SNI, timbre AAR) et un fond de plat sigillé (SNI, timbre sans correspondance dans le CVArrII). Le 8 août 1933, un balsamaire (Inv. $\mathrm{n}^{\circ} \mathrm{E} 1131=76408$; cf. ScatozzaHöricht 1986: cat. $\mathrm{n}^{\circ} 185$, pl. XXXV) et un second fond de plat sigillé (SNI, timbre d'Acceptus [CVArrII 19, 1]).

${ }^{213}$ GSE 1927: " 26 aprile. [...] Nello scavo a cunicolo del decumano minore è stato completamente posto in luce, al lato sinistro ed a cm. 80 dall'ultimo vano della Palestra delle Terme un vano di una bottega che misura m. 2.60 di altezza per m. 2.60 di larghezza. L'architrave carbonizzato è rimasto in sito ». Entre le 11 juin et le 5 juillet 1928, l'intérieur de la boutique est fouillé. Aucun objet n'est mis au jour.

214 En dépit de la description laconique des GSE, A. Maiuri (1958 b: 109) considère qu'aucune trace d'installation commerciale ou artisanale n'est perceptible. La transformation du local en boutique de souvenirs semble avoir joué un rôle non négligeable dans cette interprétation. de seuil ayant disparu, il est en revanche impossible de déterminer si le système de fermeture prenait la forme caractéristique d'une porte à coulisse. Les rares objets qui y ont été découverts ne permettent guère de confirmer ou d'infirmer cette proposition ${ }^{212}$. À titre d'hypothèse, je considèrerai l'espace V, 29 comme un lieu de métier. En ce qui concerne le local VI, 6 (cat. n²6), son interprétation comme boutique ne se fonde que sur les mentions des GSE, tant les restaurations successives et surtout sa transformation en boutique de souvenirs puis en dépôt rendent impossible toute étude plus approfondie ${ }^{213}$. Faute de découverte de matériel, aucune précision ne peut être apportée; A. Maiuri pour sa part refuse d'y voir un commerce ${ }^{214}$. En dépit de certaines réinterprétations, 17 locaux ne peuvent bénéficier d'un nouvel apport de données et il est donc impossible de confirmer ou non l'hypothèse selon laquelle il s'agit de boutiques ${ }^{215}$. L'absence de tout aménagement extérieur ou intérieur, ainsi que le nombre faible ou inexistant d'objets découverts limitent la réflexion au seul seuil à pas étroit et rainure longitudinale ou, quand ce dernier a été emporté, à la largeur de l'ouverture sur la rue $e^{216}$.

Toutefois, pour 17 autres locaux, l'utilisation des archives de fouille et des observations sur le site permet de revoir les suppositions d'A. Maiuri, en précisant la fonction de boutiques non interprétées spécifiquement ${ }^{217}$, en révisant les liens de certains locaux avec les métiers du textile ${ }^{218}$ ou

${ }^{215}$ Ces locaux sont les suivants: III, 4 ; III, 08-09; V, 13 ; V, 16 (cat. $\mathrm{n}^{\circ} 17$ ); V, 20 (cat. $\left.\mathrm{n}^{\circ} 19\right)$; V, 23 (cat. $\mathrm{n}^{\circ} 21$ ); V, 27 (cat. $\mathrm{n}^{\circ} 22$ ); V, 28; V, 32; VI, 6; VI, 16; VI, 18; VI, 25 (cat. $\mathrm{n}^{\circ} 34$ ); VII, 1-1a (cat. $\mathrm{n}^{\circ} 35$ ); Or. II, 1 ; Or. II, 3 (cat. $\mathrm{n}^{\circ} 39$ ); Or. II, 14 (cat. $\mathrm{n}^{\circ} 47$ ).

${ }^{216}$ Seul le local VI, 25 reste problématique: son seuil, emporté, ne mesure que 1,4 m de large ce qui reste peu important par rapport aux autres boutiques. Aucun objet n'a été mis au jour selon les trois entrées des GSE (1960: 13, 22, 23 dicembre). Cette situation peut être due au caractère incomplet de la fouille (cf. supra, n. 105). La relative étroitesse du seuil pourrait être liée à l'évolution de cette pièce par rapport à la Casa del colonnato tuscanico: jusqu'au séisme de 62, la partie nord de ce local a été occupée par un escalier permettant d'accéder au premier étage depuis la rue (cf. infra, p. 336).

${ }^{217}$ III, 02 ; V, 19; V, 34 ; VI, 15 ; VI, 30 ; Or. II, 16

${ }^{218}$ Les maisons ou boutiques suivantes ont été considérées par A. Maiuri comme des ateliers associés au textile: III, 10; IV, 5; IV, 19; V, 3 ; Or. II, 5. Cf. chapitre IV pour le détail de ces changements d'interprétation. 


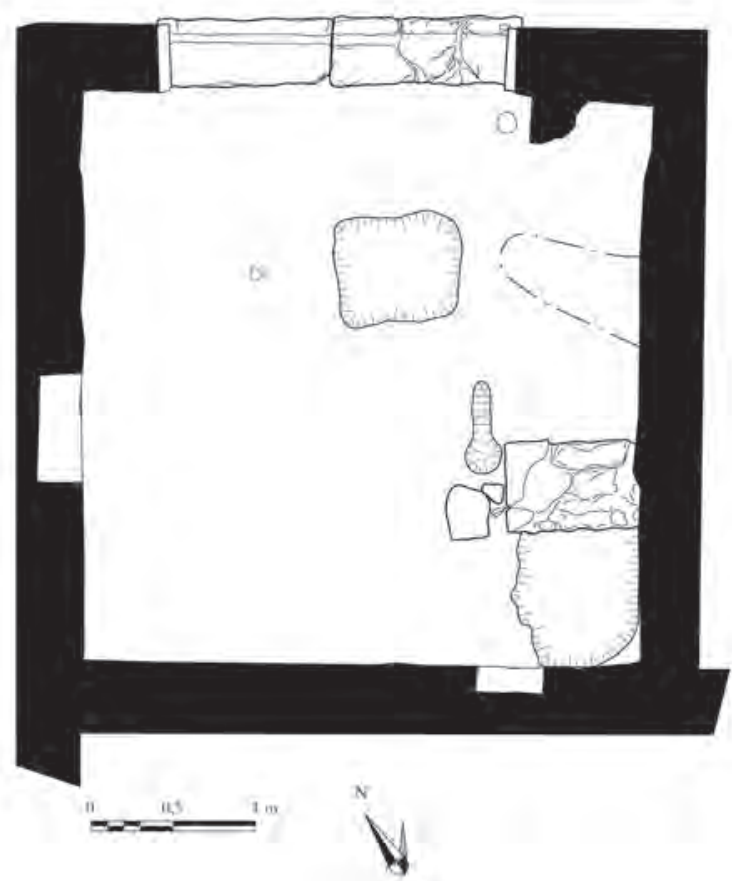

Fig. 29 - Plan de la boutique VI, 15 dans son état au moment de l'éruption. La fosse quadrangulaire au centre de la pièce a été comblée de matériel éruptif; dans l'angle sud-est, entre la marche maçonnée et le mur, se trouve le conduit de la citerne (échelle 1/60).

encore en requalifiant des artisanats présumés. De nouvelles hypothèses peuvent être avancées. Ainsi, peu d'espaces ont été reconnus comme étant en travaux au moment de l'éruption ${ }^{219}$. Pourtant, au moins trois boutiques n'étaient pas fonctionnelles en 79 ap. J.-C. La première d'entre elles se situe en façade de la Casa del salone nero: différents éléments indiquant des travaux

${ }^{219}$ Seuls la Casa dell'albergo et les thermes suburbains sont reconnus comme ayant été en travaux au moment de l'éruption (Maiuri 1958 b: 153, 324). Pour la domus, il s'agirait des conséquences du séisme de 62 ap. J.-C.

${ }^{220}$ Pour les comptes rendus des différentes campagnes effectuées dans ce local, cf. Monteix 2007 b qui inclut et rappelle la bibliographie précédente.

${ }^{221}$ Cette fosse apparaît sur le plan dressé lors de la restauration de la Casa del gran portale (Papaccio 1990: fig. 17 p. 223), sans qu'aucune explication ne soit donnée.

${ }^{222}$ D'une manière générale, peu d'objets ont été mis au jour dans la Casa del gran portale. La boutique V, 34 n'est jamais mentionnée, pas même dans la description finale insérée dans les GSE à la fin du mois de janvier 1933.

${ }^{223}$ Contra Maiuri 1958 b: 413 et Jansen 1991: 152 et n. 12 p. 164. dans le local VI, 15 - non vus lors de la fouille incomplète effectuée en 1961 - ont été mis en évidence $^{220}$. Le principal d'entre eux, qui aurait perturbé toute activité commerciale, est une fosse inscrite dans un rectangle de $0,50 \mathrm{~m}$ sur $0,70 \mathrm{~m}$ environ située au milieu de la boutique (fig. 29). Ouverte au moment de l'éruption, elle a été exclusivement colmatée par les flux pyroclastiques. Outre ce creusement de destination indéfinie, il semble que la cloison en pan de bois devant fermer la cage d'escalier n'était pas encore en place. Enfin, une amphore fracturée contenant des pigments a été mise au jour dans la citerne. Provenant vraisemblablement de l'étage, elle signale également une réfection de la décoration. Bien que d'une netteté moindre, la boutique V, 34 située en devanture de la Casa del gran portale $(\mathrm{V}, 35)$ pourrait avoir été dans une situation similaire. Grâce à un nettoyage partiel, une fosse aux contours irréguliers, encore partiellement remplie de matériel éruptif a été remise au jour ${ }^{221}$. Si sa position dans le local est moins dangereuse pour une éventuelle clientèle que dans le cas de VI, 15, il paraît improbable que cette boutique ait été alors en fonctionnement. L'absence de tout signalement d'objet au cours des fouilles pourrait également aller dans ce sens ${ }^{222}$. Enfin, le troisième local (III, 15) se situe en façade de la Casa a graticcio (III, 13-15). Le treuil et la corde qui y ont été mis au jour ne peuvent pas correspondre à un système de levage de puits ${ }^{223}$, que l'on dresse la comparaison avec l'autre exemplaire connu de ce type d'appareil - découvert mis au jour en IV, 13 et de taille considérablement plus réduite 224 ou que l'on

${ }^{224}$ Le coefficient de multiplication des forces par un treuil correspond - sans prendre en compte le coefficient de frottement - au rapport de la longueur de la manivelle par le rayon du tambour (cf. Adam 1995: 45). Pour le treuil mis au jour en III, 15, il vaut un peu plus de $2(35 / 17=2,1)$. Le tambour de l'entrée IV, 13 a un coefficient multiplicateur proche de $1(40 / 30,6=1,3)$, si l'on considère qu'il était actionné en manipulant directement le disque latéral. Dès lors, le premier permet de soulever une charge deux fois supérieure à la force exercée, tandis que le second ne facilite pas beaucoup le levage.

La description de son contexte de découverte apporte d'autres éléments. GSE 1932: «2 marzo. Nella casa n. 9 posta all'estremità est del decumano minore lato sud a m. 4 dal pilastro d'ingresso lato ovest a m.2.20 di altezza dal pavimento dell'ambiente è stato sterrato un argano di legno 
prenne en compte l'absence d'orifice de puisage dans la boutique où il a été trouvé225. De plus, ce dernier a été mis au jour en place au-dessus d'une bouche de citerne. La présence d'un appareil de levage ne paraît se justifier que par la conduite de travaux, en dépit de l'absence de toute notation sur la présence de matériel de construction à proximité. En revanche, un tas de chaux a été mis en évidence à l'extrémité occidentale de la Casa a graticcio, dans la pièce 13 et une réserve de tuiles dans la pièce $11^{226}$. L'existence d'un lien fonctionnel entre la boutique et l'espace artisanal qui se développe à l'ouest autour des vasques est difficile à démontrer ${ }^{227}$, mais la conduite de travaux qui rendaient ce local non opérationnel en 79 ne fait guère de doute. Ces transformations arrêtées par l'éruption du Vésuve apportent une information essentielle sur la vitalité commerciale de la cité: aucun lieu de métier ne paraît complètement abandonné, quel que soit l'événement ayant pu entraîner leur réfection - volonté du propriétaire ou secousse sismique -, contrairement à ce qui a été observé en plusieurs points de Pompéi ${ }^{228}$.
Parmi les petits locaux de plain-pied pouvant, par leur situation au sein d'une parcelle, être considérés comme des boutiques, seul V, 25 est interprété comme un espace d'habitation. Toutefois, cette identification est effectuée par défaut plus que sur des fondements précis: il s'agit exclusivement d'une appréciation générale ${ }^{229}$. Aucun élément ne permet d'approfondir cette intuition qui paraît aussi raisonnable que probable. La documentation concernant la fouille de ce local est indigente et les vestiges fortement dégradés: le seuil très étroit a disparu, seuls deux objets ont été mis au jour ${ }^{230}$. Ce type d'interprétation doit s'appliquer à d'autres supposées boutiques. L'exemple permettant le plus d'approfondissement est constitué par le local V, 17 et l'appartement accessible par l'escalier V, 18. Selon A. Maiuri, il s'agirait d'une boutique et de son logement, malgré une hésitation sur sa destination:

Bottega senza banco di vendita, ma con le sue installazioni ben riconoscibili e che [...] doveva avere merce non troppo commune; o forse il proprietario o locatario esercitava qualche professione più nobile della mercatura. È comunque uno degli interni più singolari ed evidenti di bottega ${ }^{231}$. carbonizzato [...]». L'absence d'excroissance - manivelle ou bras - permettant la manipulation du treuil et son altitude de découverte invitent à le considérer non pas comme un véritable treuil mais plutôt comme une poulie permettant une démultiplication minimale afin de faciliter l'extraction du seau.

${ }^{225}$ GSE 1929: « 5 gennaio. [...] A m. 1.90 dall'estremità della soglia del vano n. 15, a m. 1.15 dalla parete nord, ed a m. 0.90 di altezza dal pavimento della casa è stato raccolto: Vegetale. Corda carbonizzata m. 4.00, spessore m. 0.017. Inventario n. 393. All'estremità di un capo di un nodo notasi un pezzo di legno carbonizzato a guisa di pinoli. E poichè [...] si notano avanzi di piccole assicelle piazzate a forma di croce con altri pinoli può darsi che era un argano al quale era avvolta la corda. Le assicelle sono lunghe m. 0.37 e larghe m. 0.09, se ne contano n. 2. Si spera di poterne ricavare tutti i pezzi, per poterlo ricostruire». La seule bouche de citerne mise en évidence dans la Casa a graticcio se situe dans le puits de lumière 4.

${ }^{226}$ Le tas de chaux, dont des restes sont encore difficilement visibles dans la pièce 13 , et la réserve de tuiles ne sont mentionnés qu'au cours de la description finale de la maison. GSE 1929: «23 febbraio [...] Percorrendo il corridoio lato nord in fondo ad esso in un ristretto spazio vi sono 3 vasche con qualche avanzo di calce un piccolissimo portico, ed all'altezza di m. 2.10 dal pavimento della casa nell'angolo nord est una latrina [...]. In quest'ambiente [n ${ }^{\circ} 15=$ Maiuri 11] furono raccolti 4 piedi di letto di legno carbonizzato ed una quantità di tegole con coppi. Dato la presenza dei fossi con avanzi di calce e delle tegole con i rispettivi coppi può darsi che la casa o era in riparazione oppure stava per essere modificata [...]. ».

227 Sur l'interprétation des différentes vasques situées dans la pièce 13, cf. infra, p. 203-205.

${ }^{228}$ Sur les locaux transformés en espaces de culture après l'un des séismes, cf. supra, n. 46 p. 8. Quelques dépotoirs ont été mis en évidence, notamment dans les parcelles I 6, 13-14 (NSc 1929: 430-436; Maiuri 1942 a: 160); VII 11, 16-17 (Fiorelli 1875: 281); VIII 6, 3 (BdI 1884: 135137 [indiqué comme VIII 7, 5]; Maiuri 1942 a: 160 [indiqué comme VIII 6, 2-3]); IX 3, 21-22 (Fiorelli 1875: 399; Maiuri 1942 a: 160). VIII 5, 36 (thermes républicains; cf. Maiuri 1942 a: 160 ; Maiuri 1950 c: 135-136).

229 «[...] Quello invece minore con una porta piuttosto angusta d'ingresso e un podio da un lato, ha più il carattere di abitazione terranea accanto alla fauce, che di bottega o di officina di lavoro " (Maiuri 1958 b: 444).

${ }^{230}$ GSE 1933: « 4 agosto. Sul battuto del piano inferiore della Casa $\mathrm{N}^{\circ}$ 9, V Cardine, lato Ovest, a m. 1.45 dalla soglia del vano ed a m. 0.37 dalla parete Nord, è stato raccolto: [Description de l'objet inventorié $n^{\circ} 1123$ et d'un fond de vase sigillé]». Cette entrée du journal des fouilles est la seule concernant ce local.

${ }^{231}$ Maiuri 1958 b: 238. 


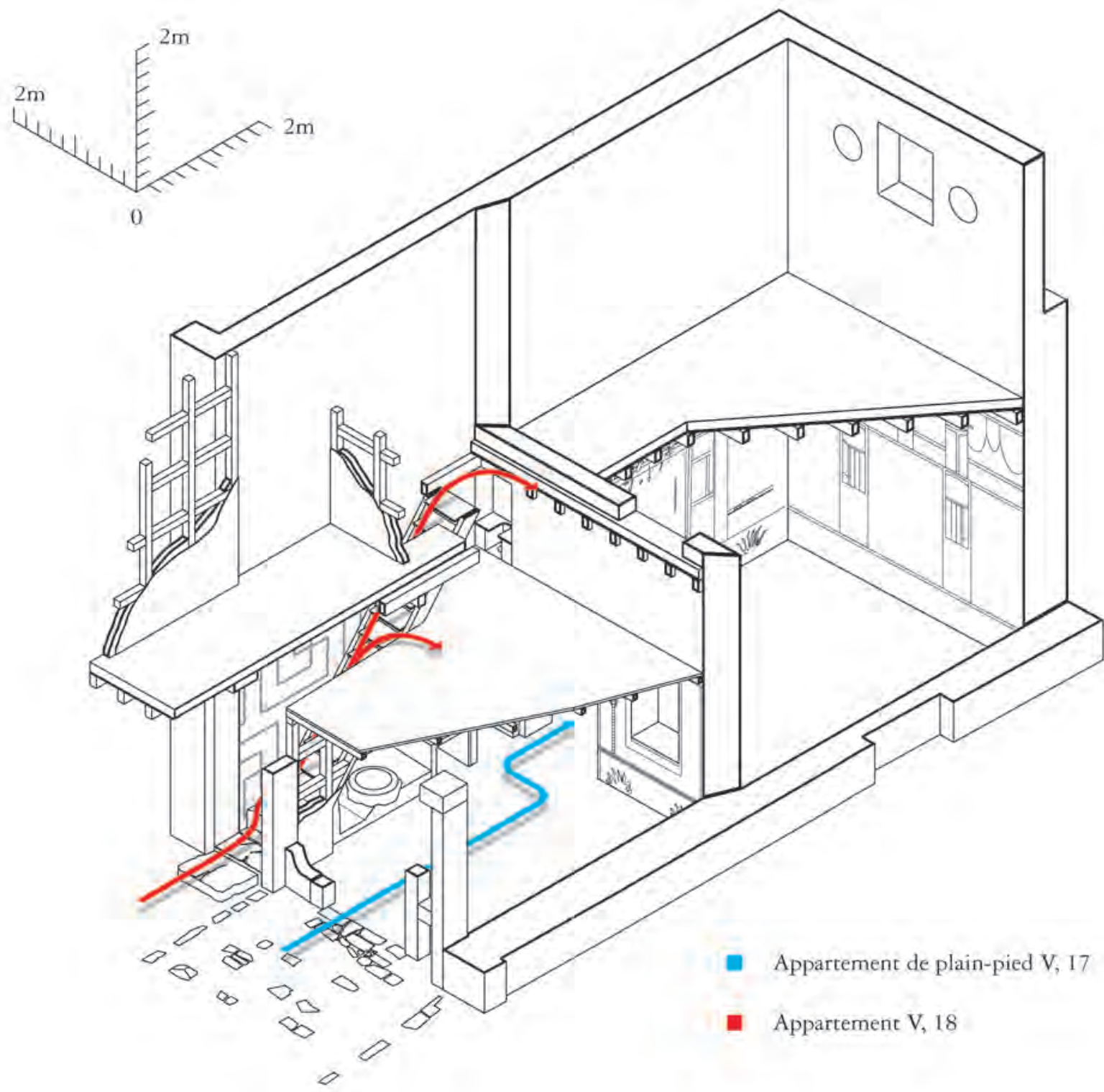

Fig. 30 - Restitution isométrique des appartements V, 17 et V, 18. L'unique porte donnant accès à V, 17 devait être à double battant (échelle 1/100).

L’analyse détaillée des éléments préservés et des objets mis au jour permet de supposer l'existence non d'un local commercial, mais de deux appartements distincts, l'un au rez-de-chaussée, le second à l'étage, ne communiquant pas entre eux (fig. 30). L'élément premier de cette interprétation tient dans le seuil. En l'état actuel, la

${ }^{232}$ Ce marquage du trottoir, qui permet essentiellement une distinction par rapport avec la Casa del bicentenario, façade est percée d'une large ouverture limitée par deux pilastres de briques. Un montant en bois - moderne - distingue l'entrée V, 18 de $\mathrm{V}, 17$. Le trottoir devant cette dernière est rehaussé de fragments de marbre encadrés par des plaques alignées dans le sens nord-sud ${ }^{232}$. Contrairement à ce que l'on pourrait attendre

mais aussi entre l'appartement de l'étage et le local V, 17, a été interprété par F. Pirson comme un signe que ces deux 
pour une boutique, aucun seuil à rainure longitudinale, aucune empreinte de ce seuil dans le sol n'est visible ${ }^{233}$. En revanche, quatre fragments de marbre situés au centre de l'ouverture sont parfaitement alignés sur leur côté sud et sont positionnés non pas en concordance avec le parement externe des pilastres, mais avec le parement interne. Si un seuil avait dû se trouver encastré dans le sol, il se serait trouvé à la place de ces fragments. Celui d'entre eux qui se situe le plus à l'est présente plusieurs cavités dont l'une revêt la forme d'une crapaudine, tandis que le fragment au centre est dégrisé. Il faudrait ainsi restituer un seuil centré, à vantail mobile sans rainure longitudinale. Ce type d'huisserie implique également la restitution d'une paroi de part et d'autre de cette porte, réduisant ainsi l'ouverture de $3 \mathrm{~m}$ à $1 \mathrm{~m}$ ou $1,40 \mathrm{~m}^{234}$. Il est probable que cette paroi était constituée de blocs de tuf ${ }^{235}$.

Les autres éléments architectoniques de cet espace permettent de conforter cette restitution. Deux trous de poteaux ont été mis en évidence le long du dé de l'escalier permettant d'accéder à l'appartement V, 18: il n'y aurait pas de marche entre le local et l'échelle de meunier, mais une cloison en pan de bois. Cette partition de l'espace transparaît également dans la décoration. La paroi occidentale est enduite d'une fresque de $\mathrm{IV}^{\mathrm{e}}$ style à motifs architecturaux qui se poursuit

unités constituaient une propriété distincte de la domus voisine. Les autres facteurs permettant cette interprétation seraient la nette séparation de l'avancée des étages - en dépit de leur reconstruction moderne - et le fait qu'une porte entre la Casa del bicentenario et la seconde pièce du rez-de-chaussée ait été murée (cf. Pirson 1999: 71-73).

${ }^{233} \mathrm{Il}$ reste probable que le sol en béton de tuileau visible en devanture de ce local et une partie de celui situé à l'intérieur soient des restaurations modernes.

${ }^{234}$ La distance entre le pilastre de briques ouest et le montant de la porte d'accès à l'étage est de $3 \mathrm{~m}$. Les fragments de marbre constituant le seuil sont groupés et alignés sur une distance de près d'un mètre. Un morceau isolé peut également être comptabilisé parmi eux, ce qui porte le seuil à une largeur de $1,40 \mathrm{~m}$. Toutefois, il est possible que ce fragment ait été déplacé pour assurer la fixation de la porte restaurée.

${ }^{235}$ La description des GSE (1938: «3 gennaio. È incominciato lo sterro dell'ingresso principale della casa n. 25, Decumano Massimo Insula V [V, 17; voir plan P637 à l'Archivio disegni de la SANP à Pompéi]. I pilastri del vano sono ensuite dans la pièce annexe $\mathrm{e}^{236}$. Entre ces deux pièces, l'unité figurative est complète, en dépit des dégradations survenues dans la pièce principale, qu'il s'agisse de l'effacement progressif des motifs ou de la destruction de la partie supérieure, qui pourrait avoir été malmenée dès avant l'éruption, lors de la mise en place de la mezzanine ${ }^{237}$. En revanche, la paroi orientale présente, au nord du faux limon, deux lignes de méandres dessinés selon un schéma dérivant des zebra patterns. L'utilisation de cette technique indiquerait un espace de passage, la zébrure soulignant la vitesse de déplacement dans cet escalier ${ }^{238}$. La séparation entre la cage d'escalier et le local est ainsi fortement matérialisée malgré la disparition de la cloison entre ces deux espaces ${ }^{239}$. Passé l'escalier, la décoration de l'étage redevient de IV style, mais plus simple et moins unitaire. Dans la première pièce, la paroi est partagée entre un haut socle rouge et une partie supérieure animée de colonnes. Dans la seconde pièce, située audessus de la pièce annexe de IV, 17, seule la décoration de la paroi nord a été conservée. Au centre se situe le cadre sur bois représentant des amours autour d'un trépied apollinien ${ }^{240}$. La décoration de la partie supérieure montre un édicule en vue frontale pourvu d'un fronton ${ }^{241}$. La différence de style entre l'appartement V, 18 et le local V, 17 est au moins aussi frappante que l'unité du rez-de-chaussée. completamente abbattuti, ma essi erano fatti di blocchi di tufo [...]») indique des montants en blocs de tuf. Ceux qui sont actuellement visibles sont constitués de briques, éventuellement partiellement remontés mais qui ne sauraient être une construction intégralement moderne. Les blocs de tuf décrits par les GSE seraient ainsi ceux constituant la cloison de façade.

${ }^{236}$ Sur les motifs architecturaux de la pièce annexe, cf. Eristov 1994 : cat. $n^{\circ} 98$.

${ }^{237}$ Les motifs sont dégradés notamment à cause de l'éruption, le rouge ayant viré au jaune sous l'effet de la chaleur. La partie supérieure a complètement disparu. La portion de mur sur laquelle elle aurait été fixée a été intégralement restaurée.

${ }^{238}$ Laken 2003, part. 172-173.

${ }^{239}$ Cette différence de traitement a été notée par A. Maiuri (1958 b: 238), mais considérée comme deux moments de la décoration.

${ }^{240}$ Cf. Maiuri 1938. La figure 1 p. 483 est la seule représentation publiée de la paroi nord.

${ }^{241}$ Édicule type 1.2.1.1 (Eristov 1994: 78, fig. 52 p. 79). 
L'observation des aménagements réalisés permet également de conclure à la nette distinction de ces deux espaces. Ainsi, une mezzanine se développe au-dessus d'une grande partie de la pièce principale. La destruction partielle de la fresque située sur la paroi occidentale et la restauration de cette dernière empêchent de connaître précisément son extension ${ }^{242}$. Elle donne notamment accès à une latrine creusée dans la partie supérieure du mur de refend entre les pièces nord et $\operatorname{sud}^{243}$. Une seconde latrine a été ménagée dans le même mur, mais au rez-de-chaussée, accessible depuis la seconde pièce. L'autre aménagement doublé est la cuisine. Au rez-de-chaussée, le long du mur se trouve une table de cuisson, à côté d'une armoire maçonnée ${ }^{244}$. En dépit de l'absence de toute description ou de vestiges, une cuisine est indiquée au premier étage. Mentionnée pour la première fois en novembre 1937, cette pièce sert ensuite de repère topographique pour la poursuite de la fouille de l'étage ${ }^{245}$. L'analyse de ces évocations permet de situer cet espace dans la moitié nord de l'appartement. La redondance des latrines et de la cuisine plaide définitivement pour une séparation de ces deux appartements. Enfin, la partie supérieure d'un dolium est visible au rez-de-chaussée, le long du mur est. Selon A. Maiuri, il aurait contenu les denrées mises en vente dans la supposée boutique ${ }^{246}$. En fait, un

\footnotetext{
${ }^{242}$ Sur le mur nord, au dessus du linteau moderne, l'enduit a été conservé. Il s'agit d'un simple fond blanc rythmé par des bandes verticales rouge sombre qui ne saurait constituer la partie supérieure de la décoration observée sur le mur occidental.

${ }^{243}$ Ces latrines ne sont pas mentionnées par G. Jansen (1991: n. 18-20 p. 165).

${ }^{244}$ GSE 1938: « 8 aprile. Nell'ambiente 1 della casa 25, Decumano Massimo Insula V, il dolio che trovasi incassato sul pavimento presso la cucina tiene il seguente bollo: [OPTATVS.BIRRI; cf. Łos 2000: 261]». Cette table de cuisson est considérée par A. Maiuri (1958 b: 438) comme « un focolare basso e minuscolo, il più piccolo focolare che siè rinvenuto finoggi ad Ercolano ».

245 GSE 1937: «9 novembre. Nel terzo ambiente, cucina, del piano superiore della casa 25, Decumano Massimo insula V, presso la parete nord, e a metri 0.97 dalla parete est si è sterrato: [Description des objets inventoriés $\left.\mathrm{n}^{\circ} \mathrm{E} 1782-1784=77062-77064\right]$; « 16 dicembre. In un ambiente del piano superiore, e precisamente quello posto a sud della cucina della casa 25, Decumano Massimo insula $\mathrm{V},[\ldots] »$.
}

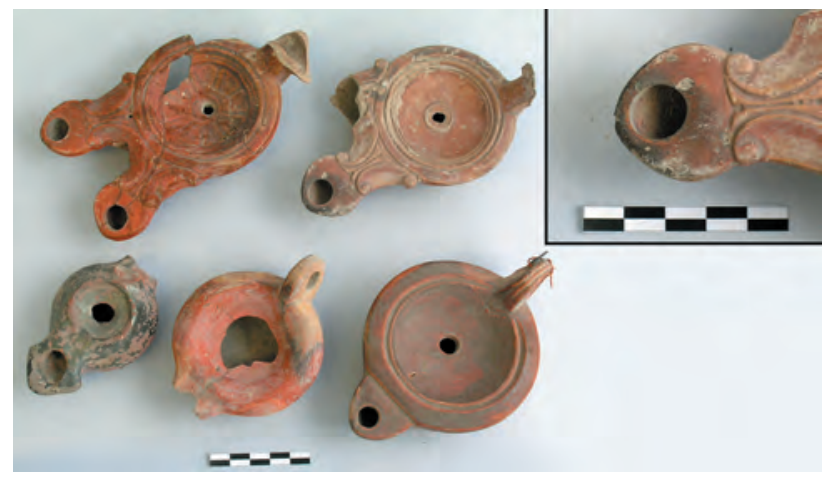

Fig. 31 - Cinq des dix-neuf lampes provenant d'une caisse trouvée en V, 17. Les douze autres ont disparu. En encadré, traces de carbonisation sur le bec d'une des lampes, ce qui exclut son utilisation à des fins de revente.

nettoyage de l'intérieur de ce conteneur - encore partiellement rempli de matériel éruptif-montre qu'il ne s'agit que de la moitié supérieure d'un dolium, insérée dans un conduit de maçonnerie et utilisé comme bouche de citerne ${ }^{247}$. Enfin, le matériel mis au jour ne permet pas de conclure à la présence d'une structure commerciale, à moins de considérer, pour reprendre les termes d'A. Maiuri, que des lampes constituent une "merce non troppo commune» : la seule concentration d'objets est constituée par les 19 lampes mises au jour dans une caisse de bois (fig. 31) ${ }^{248}$.

${ }^{246}$ Maiuri 1958 b: 238.

${ }^{247}$ Un seau en bronze, ayant pu être utilisé pour prélever l'eau, a été mis au jour dans la pièce annexe (GSE 1938: 14 aprile, Inv. ${ }^{\circ} \mathrm{E} 1906=77186$ ).

${ }^{248}$ GSE 1938 : " 1 marzo. Nella casa 25, ambiente 1 piano terraneo, Decumano Massimo Insula V, a m. 2.80 dal vano d'ingresso e a 0.45 dalla parete est, in un cassetto di legno a forma rettangolare, lungo m. 0.38 , alto m. 0.25 e largo m. 0.20 vi era: Terracotta. 17 lucerne monolichne discretamente conservate. Esse sono di diverse grandezze. [Inv. $\left.\mathrm{n}^{\circ} \mathrm{E} 1883=77163\right]$. Terracotta. 2 lucerne bilichne col rostro accorciato in buono stato di conservazione [Inv. $\mathrm{n}^{\circ} \mathrm{E} 1884$ $\mathrm{a}-\mathrm{b}=77164 \mathrm{a}-\mathrm{b}]$ ».Sur les 19 lampes indiquées dans les GSE, seules cinq sont encore conservées à Herculanum, tandis que le livre d'inventaire a été gratté et le nombre réécrit. Il n'existe aucune uniformité dans les types et donc dans les provenances. L'une de ces lampes fait figure de pièce de collection, puisqu'elle remonte à la fin du $\mathrm{II}^{\mathrm{e}}$ siècle av. J. - C. (Inv. $n^{\circ}$ E1883 c=77163 c, cf. Bisi Ingrassia 1977: type IIB, p. 75-76). De plus, une autre (Inv. $\mathrm{n}^{\circ} \mathrm{E} 1884 \mathrm{~b}=77164 \mathrm{~b}$ ) présente des traces de carbonisation sur l'un de ses becs, indiquant un objet déjà utilisé et non une livraison empa- 
Les autres artefacts ne forment guère plus un assemblage pertinent à une activité commerciale ou artisanale. Ils constituent seulement le témoignage d'activités domestiques primaires comme la préparation culinaire et sa consommation. Tous ces éléments, du seuil aux objets mis au jour en passant par la décoration constituent autant d'indices convergents pour mettre en évidence non pas un local commercial mais un appartement de plain-pied en V, 17, distinct de celui qui est accessible par l'escalier V, 18.

Une autre supposée boutique peut être interprétée de la même façon. Le local II, 4, qui comporte quatre pièces a été interprété par A. Maiuri comme une boutique. Pourtant, déjà J. Beloch le considérait comme une maison de modestes dimensions. Aucun élément, ni le seuil - emporté - ni les rares objets mis au jour, ne pointe vers un local commercial. Bien au contraire, la niche d'encastrement d'un lit dont des fragments ont été mis au jour - indique clairement que la pièce $b$, qui n'est pas formellement séparée des autres, servait pour dormir ${ }^{249}$.

\section{COMMENT RECONNAîTRE LES LIEUX DE MÉTIER:} UN BILAN

L'étude du mot taberna a montré la vacuité des excès d'hypercritique contre l'emploi de ce terme pour désigner, de façon générale, un lieu de métier. Les exemples d'inscriptions pompéiennes où ce mot est employé dans un contexte matériel connu permettent de continuer légitimement à appeler tabernae les pièces largement ouvertes sur la rue et dont le système de fermeture est constitué par des planches. Par extension, il devient également possible d'utiliser les sources littéraires mentionnant ces tabernae pour obtenir une vision plus large de la société romaine. En revanche, archéologiquement, des différents éléments constitutifs des lieux de métier, aucun, pris isolément, ne permet une identification définitive. Les représentations figurées, qui parfois indiquent la nature des activités pratiquées dans

quetée. Cette caisse serait donc à associer à un mode de rangement plutôt qu'à une quelconque pratique commerciale.

${ }^{249}$ Sur cet appartement de plain-pied, cf. Beloch 1890: 236 (= Beloch 1989: 270); contra Maiuri 1958 b: 445-446. une boutique ou un atelier, restent trop rares -2 pour au moins 52 locaux à Herculanum ${ }^{250} ; 7$ pour plus de 600 locaux à Pompéi - pour permettre une étude exhaustive des locaux commerciaux et artisanaux. De plus, leur rémanence en façade d'espaces ayant parfois changé de fonction entre le moment de la décoration et l'éruption rend leur interprétation délicate. Soulignons de nouveau que la majeure partie de ces fresques ne représente pas à proprement parler des enseignes mais des manifestations religieuses, plus caractéristiques des croyances personnelles du tenancier que d'un métier en particulier. La présence d'éléments indiquant la nature de l'activité se déroulant dans le local reste également soumise au choix de son occupant. Les aménagements intérieurs en bois - comptoirs, étagères, mezzanines - sont également trop fréquents dans les espaces domestiques de service pour permettre la caractérisation d'une boutique ou d'un atelier. En ce qui concerne enfin les assemblages concentrés d'objets permettant d'identifier un revendeur spécialisé dans la commercialisation finale d'objets manufacturés, ils sont étrangement peu nombreux, leur faible fréquence pouvant être imputée dans une large mesure - difficilement estimable - aux techniques de fouille utilisées depuis la redécouverte des villes ensevelies par le Vésuve. Seul le seuil à vantail mobile et rainure longitudinale paraît permettre de reconnaître aisément un local commercial. Il ne saurait toutefois constituer l'unique élément d'interprétation, certains ateliers en étant dépourvus. La fréquente disparition des pierres de seuil à Herculanum ne permet pas non plus d'aboutir à des conclusions définitives: une large ouverture ne doit pas nécessairement être associée à un lieu de métier. Dans cette première approche générale, un constat amer doit être dressé: sur les 49 locaux pouvant être considérés comme des boutiques ou des ateliers, 19 ne bénéficient d'aucune interprétation précise. Leur participation à la vie commerciale d'Herculanum reste hypothétique.

\footnotetext{
${ }^{250}$ En tenant compte de trois des locaux situés sur la portion nord du decumanus maximus, dont seuls deux ont été partiellement fouillés.
} 



\section{CHAPITRE II}

\section{LES COMMERCES ALIMENTAIRES : RESTAURATION ET VENTE AU DÉTAIL}

"Telle est la disposition de cette boutique. Il n'est pas difficile de deviner ce que l'on y vendait; car la forme du comptoir, où l'on remarque un fourneau, de grandes amphores scellées dans le massif, et trois gradins pour poser de petites mesures de capacité pour les liquides, semble indiquer un de ces lieux où l'on vendait des comestibles de toute espèce, et des aliments cuits ».

F. Mazois, Les ruines de Pompéi dessinées et mesurées par F. Mazois... $2^{e}$ partie, Firmin Didot, Paris, 1822-1824, p. 43-44.

Parmi les aménagements très fréquents dans les locaux commerciaux, tant à Herculanum qu'à Pompéi, se trouvent les comptoirs maçonnés dans lesquels sont incorporées des jarres en terre cuite. Depuis le début du XIX ${ }^{\mathrm{e}}$ siècles, ces locaux ont été l'objet d'une attention particulière. Ils paraissent comme caractéristiques de boutiques qui sont ainsi interprétées avec un automatisme souvent déconcertant dans les journaux et comptes rendus de fouille. À travers l'analyse des interprétations proposées pour ces locaux, il est possible d'esquisser un schéma historiographique qui tend à se confondre avec celui, plus général, des boutiques. Au cours de cette évolution, un seul élément est constant: ces locaux ont assumé la fonction essentielle de nourrir la population ou du moins une partie de celle-ci.

À lui seul, le nombre de ces espaces commerciaux justifie une analyse détaillée; à Herculanum ou Pompéi, ils représentent environ un quart des boutiques découvertes. Que cet ouvrage traite principalement de la situation herculanéenne

\footnotetext{
${ }^{1}$ La définition exacte de la paternité de cette introduction ne peut être déterminée, tant les dates exactes de publi-
}

ne saurait justifier la relégation des plus de 150 exemples pompéiens et de leur grande variété, parfois masquée par l'emploi abusif de l'appellation discutable de "thermopolium ». En dépit de la répétition continuelle - dans des travaux s'étalant sur plus d'un siècle - de descriptions identiques et souvent inadaptées, il m'a semblé utile de revenir sur la nature des aménagements présents dans ces locaux, leur juste compréhension permettant d'appréhender les facettes variées d'un même métier.

Il convient au préalable de revenir rapidement sur l'historiographie concernant ces locaux. Avec une préséance que les liens tissés entre eux rend inextricable, il revient à François Mazois et à William Gell d'avoir introduit les termes de «thermopolium» et d' "oinopolium» dans la littérature archéologique pour désigner les établissements pourvus d'un comptoir maçonné, de dolia et d'un système pour chauffer les liquides ${ }^{1}$. Cet excès d'érudition qui a fait entrer un jeu de mots de Plaute dans les descrip-

cation des fascicules de l'ouvrage de F. Mazois sont difficiles à établir avant leur réunion en volume en 1824. De plus, les 
tions de Pompéi a eu dans un premier temps un destin variable selon les publications auxquelles on se réfère ${ }^{2}$. Si aucun stéréotype n'apparaît encore, à l'exception de l'association avec la prostitution, d'abord timide mais implacable, le mythe commence à se construire tout au long du premier $\mathrm{XIX}^{\mathrm{e}}$ siècle ${ }^{3}$. Il est essentiellement fondé sur les commerces proches de la porta di Ercolano (VI 1, 2-4; VI 17, 1-2 et VI 17, 3-4), la "taverne de Fortunata» (VI 3, 18-20) et le local en façade de la Casa di Sallustio (VI 2, 5) ou de la Casa di Pansa (VI 6, 1.8.12-13) ${ }^{4}$. À partir des années 1860, autour de la figure de G. Fiorelli, alors que les études sur Pompéi et Herculanum sortent des principes de la recherche antiquaire, l'emploi du mot « termopolio » commence à s'imposer, parfois en alternance avec caupona, sans réel automatisme ${ }^{5}$. Il revient à A. Mau d'avoir le premier dressé une interprétation des locaux présentant des comptoirs fondée pour partie sur la terminologie latine. De leur côté, Th. Mommsen et J. Marquardt ont successivement employé le

liens entre les deux savants ont certainement permis des échanges au moins lors de leurs séjours à Naples (cf. British Library, Add 50135 f92, lettre de F. Mazois à W. Gell datée de 1819). Si F. Mazois ne mentionne jamais W. Gell dans son ouvrage, ce dernier est d'abord laudatif (Gell - Gandy 1821: X-XI, 120, n. 2 p. 125) avant de porter des accusations d'emploi abusif de dessin à son encontre (Gell 1832: 37). La comparaison entre la planche de W. Gell (1832: pl. XI p. 37) et celle de F. Mazois ([Gau] 1829: pl. VII) montre que cette accusation est discutable.

${ }^{2}$ Sur le possible jeu de mots contenu dans le terme thermipolium, cf. Monteix 2007 a: 117.

${ }^{3}$ La découverte, en 1830, des fresques ornant l'arrièreboutique du local VI 10, 1.19 facilite ce lien entre prostitution et «thermopolium», comme le montrent les commentaires de W. Gell (1832, II: 12): "It would be a curious speculation to discover whether, in Pompeii, a thermopolium was generally understood to be also a lupanare, or whether there is something peculiar in the house in question $[\ldots]$ ».

${ }^{4}$ Pour C. Bonucci (1827: 86-87, 109, 100), ces locaux sont respectivement considérés comme termopolio, taverna, osteria. Pour E. Breton (1855: 218-219, 206), qui ne mentionne pas les locaux situés près de la porte, la taverne de Fortunata est un "thermopole», tandis que la boutique en façade de la Casa di Pansa sert à la vente les produits des terres du propriétaire. De tels exemples pourraient être multipliés à l'infini; j'en signalerai un cependant, description non interprétative d'un comptoir, sous la plume de G. Minervini : cf. BullArchNap (n.s., I) 1853: 59

${ }^{5}$ Le terme de caupona paraît alors plus réservé à un hôtel, éventuellement associé à un local présentant un terme de popina pour désigner des restaurants ${ }^{6}$. Parallèlement à ces classifications érudites, l'usage de l'italianisme termopolio devient de plus en plus automatique dans les relations de fouille. Il faut cependant attendre le début du $\mathrm{XX}^{\mathrm{e}}$ siècle et la découverte en 1911-1912 de la boutique "d'Asellina» (IX 11, 2) pour que le seul comptoir maçonné devienne le vecteur d'interprétation d'un local comme termopolio ${ }^{7}$. Le mélange entre l'érudition et la pratique du terrain finit par générer un désordre évident. Cependant, une règle paraît s'établir: un commerce pourvu d'un comptoir maçonné, dans lequel sont pris des dolia, peut revêtir n'importe laquelle des appellations latines ou pseudo-latines qui indiquent des bars, éventuellement des restaurants, de toute façon des lieux de perdition mal famés en raison de la prostitution qui y règnerait ${ }^{8}$.

À partir des années 1950, notamment en raison du ralentissement des fouilles, des essais de synthèse commencent à être publiés sur cette question. Le premier est dû à Tönnes Kleberg

comptoir, qu'à une boutique en elle-même (Fiorelli 1873: 8). Pour désigner un commerce, il utilise le terme de taberna cauponia (Fiorelli 1873: 28). Plusieurs termopolii sont reconnus dans les nouvelles fouilles effectuées entre 1861 et 1875: IX 1, 6; I 4, 3 (Fiorelli 1873: 61, 65); VII 4, 4 (Fiorelli 1875: 213). Ils s'ajoutent aux trois autres mis au jour et étudiés dans les périodes précédentes: VI 1, 2 ; VI 4, 1 et VI 10, 1.19 (Fiorelli 1875: 76, 95, 139).

${ }^{6}$ DP IV : 198 [II : 205]; Marquardt 1892, II: 99-100 [II: 470-471].

${ }^{7}$ GSP 1911: «Dicembre (en 1911 et jusqu'en mai 1912, les journaux de fouilles ne sont pas rédigés tous les jours, mais vraisemblablement en fin de mois; le texte est ensuite à peine remanié pour publication dans les NSc). [...] Il vano $\mathrm{n}^{\circ} 2$ - Reg. IX Ins. XI, come è provato da un banco di vendita che comincia a mostrarsi immediatemente dopo la soglia è un termopolio $[\ldots]$ ».

À Herculanum, la pratique est identique dans les journaux de fouilles. La boutique IV, 15-16 est appelée termopolio avant que le comptoir ne soit décrit (GSE 1931: 24 novembre). Les commerces suivants sont également interprétés de cette manière à cause de la présence d'un comptoir maçonné: IV, 10 (GSE 1929: 27 settembre; cf. cat. $\mathrm{n}^{\circ}$ 8); V, 6 (GSE 1933: 6 maggio, cit. infra n. 35); V, 9-10 (GSE 1938: 5 settembre); Or. II, 6 (GSE 1933: 6 settembre). L'automatisme de l'interprétation transparaît dans toute sa force en 1961, lors de la description du local VI, 19: «[...] L'ambiente in oggetto viene denominato termopolio per l'esistenza di banchi con doli [...]» (GSE 1961: 25 settembre).

${ }^{8}$ Outre les peintures «obscènes » du local VI 10, 1.19, l'étude du vocabulaire romain et en particulier du mot 
qui, après une analyse fine - mais discutable $e^{9}-\mathrm{du}$ vocabulaire latin de la restauration dans laquelle il conclu à l'inexistence du thermipolium, a tenté d'associer chacun de ces termes avec un type de local. Utilisant les sources littéraires comme point de départ, il détermine deux groupes, chacun subdivisé en deux sous classes: d'un côté les locaux ayant pour fonction principale l'hôtellerie - cauponae/hospitia et stabula -, de l'autre les restaurants (popinae) et débits de boisson (tabernae $)^{10}$. Cette étude reste, pour ses définitions des termes latins, un point de référence pour les synthèses postérieures: très fréquemment citée, elle n'a cependant guère été suivie ${ }^{11}$. En 1970, une étape importante est franchie par H. Eschebach, qui publie un premier «annuaire» des maisons et autres édifices mis au jour à Pompéi, dressant une synthèse des appellations déjà attribuées à chaque local ${ }^{12}$. Avec justesse, mais sans explica-

popina a facilité la mise en place d'un lien entre commerce alimentaire et prostitution. Les commentaires sur la boutique «d'Asellina» (IX 11, 2) - fouillée en 1912 - sont caractéristiques de cette interprétation. En raison de plusieurs programmes électoraux lus en façade et qui mentionnent des noms de femmes comme rogatores, dont un recouvert de peinture blanche, M. Della Corte (NSc 1911: 432) a estimé qu'il fallait y voir une marque infamante et a suggéré plus tard que de la prostitution pouvait s'y tenir (Della Corte 1935: 25-26). Si la mise au jour d'une plaque de marbre permettant d'étaler les onguents (Inv. $\left.\mathrm{n}^{\circ} \mathrm{P} 1159\right)$ pourrait effectivement renvoyer à une présence féminine dans ce local, rien n'incite à les considérer comme prostituées. Comme le fait remarquer Th. McGinn (2004: n. 72 p. 285), l'interprétation de ce local comme lupanar tient du sous-entendu répété de publication en publication.

${ }^{9}$ Pour quelques remarques concernant l'analyse de ces termes latins par T. Kleberg (1957), cf. Monteix 2007 a: 117-119.

${ }^{10}$ Kleberg 1957: 26-44.

${ }^{11}$ Une exception est constitutée par l'étude de J. Packer (1978) qui a tenté de donner une vision archéologique plus détaillée des types de locaux mis en évidence par T. Kleberg. Il donne la description des aménagements correspondant aux stabula (I 1, 6.8-9 et VII 12,34-35; ibid., p. 7-12), hospitia (I 2, 24; I 11, 16 et VI 9, 1.14; ibid., p. 12-30), popinae et tabernae (I 10, 13; V 2, 13; VI 14, 35-36; V 1, 13; ibid., p. 30-43). L'utilisation de ces appellations reste assertorique: aucune explication n'est jamais donnée sur les raisons du choix de tel ou tel terme latin. La déclaration de principe de suivre les interprétations de T. Kleberg n'est pas effective: J. Packer ne recourt pas au terme de caupona.

${ }^{12}$ Eschebach 1970: 115-179.

${ }^{13} \mathrm{La}$ "caupona d'Euxinus» et le «thermopolium du Phénix» ne sont qu'un seul et unique local (I 11, 10-12; tion, les popinae disparaissent. Certains locaux sont affublés de deux appellations, comme "thermopolium» et caupona ${ }^{13}$. Considérée à tort comme une étude fournissant des interprétations sûres, cet annuaire, simple synthèse des appellations données dans la bibliographie antérieure, a servi de fondement à la création d'une base de données informatique développée dans les années 1980 autour du Consorzio Neapolis. Reprenant de nouveau l'ensemble des données publiées sans chercher nécessairement à y mettre de l'ordre, les collaborateurs de ce catalogue ont dénombré chacune des supposées interprétations proposées pour ces locaux, après avoir tenté un bref essai de définition ${ }^{14}$. Ainsi, 27 locaux sont à la fois qualifiés comme «thermopolia » et comme caupona ${ }^{15}$.

Au-delà des débats sur l'utilisation de tel ou tel terme latin ${ }^{16}$, une interprétation générale

cf. Eschebach 1970: 120, 165, 179). La première appellation renvoie aux amphores mises au jour dans le jardin de cette boutique qui mentionnent un copo dont le nom est Euxinus (AE 1967, 86d; cit. supra, n. 83 p. 56), tandis que la seconde fait référence à l'enseigne trouvée en façade de cette boutique, représentant un phénix (CIL IV, 9850; cit. supra, n. 83 p. 56). M. Della Corte appelle ce local caupona Euxini (et Iusti) (NSc 1958: n²5-29 p. 83).

14 «Per hospitium si intende un edificio per il ricovero dei forestieri; cauponae e thermopolia sono locali ove veniva servito da mangiare e da bere; per un esame approfondito della terminologia dei locali di questo genere, si veda KLeBerg [1957], pp. 1-25» (La Torre 1988: n. 14 p. 92). Le renvoi à l'ouvrage de $\mathrm{T}$. Kleberg est d'autant plus inadéquat que ce dernier non seulement a refusé catégoriquement l'usage du terme de thermipolium (Kleberg 1957: 24-25). De surcroît, sa propre typologie rassemble hospitia et cauponae d'une part, popinae et tabernae de l'autre (Kleberg 1957: 31). La popina est ici absente.

${ }^{15}$ La Torre 1988: 78. La situation est alors telle qu'elle suscite ce jugement définitif de la part d'A. Wallace-Hadrill (1995: 46): «[...] No firm typology has been established, and the labels are applied with apparent indifference, sometimes to the same establishments. To state that there were 120 cauponae and 89 thermopolia [...] is to elevate these vagaries of modern usage into a fantasy statistic ».

${ }^{16}$ A. Wallace-Hadrill (1995: 46) a réintroduit le terme de popina en remplacement de "thermopolium». Si je partage pleinement le constat d'insurmontable désordre dans la compréhension des commerces liés à l'alimentation à Pompéi, il semble délicat de suivre l'analyse des transformations successives de popina en latin ou de considérer que ce terme peut être employé dans le contexte pompéien. Cf. Monteix 2007 a: 117-119. 
reste acquise pour tous: les locaux pourvus de comptoirs maçonnés offrent des services de restauration et de débit de boissons, avec l'imposition progressive de l'idée que seule de la nourriture préparée est vendue dans ces boutiques. Pourtant, même les synthèses du XIX ${ }^{\mathrm{e}}$ siècle, si floues sur le rapport entre terminologie latine et vestiges archéologiques, exposaient le principe qu'une partie de ces locaux pouvaient vendre des denrées non cuisinées, écoulant la marchandise produite dans les villas de certains propriétaires de boutiques ${ }^{17}$. Seule L. Eschebach a réintroduit cette hypothèse en proposant, pour des boutiques souvent laissées par ailleurs sans interprétation, une fonction de Lebensmittelgeschäft ${ }^{18}$. En 2005, S. Ellis, refusant d'employer la terminologie antique, sort de la redoutable mise en adéquation des termes latins et des vestiges archéologiques. Toutefois, il substitue à ce maelström d'identifications peu ou pas interprétatives le terme de bars qui renvoie à une réalité trop contemporaine et cantonnée aux seuls débits de boissons ${ }^{19}$.

Pour éviter ce risque de confusion j'ai préféré adopter l'expression au sens très large de « commerces alimentaires ». À partir d'une exploration exhaustive des deux sites, complétée par la consultation des archives de fouille - publiées et non publiées -, j'ai recensé 13 commerces disposant d'un comptoir ou d'alignement de dolia à Herculanum et 166 dans le périmètre intra-urbain de Pompéi ${ }^{20}$. Pour l'essentiel, j’ai pris en compte les comptoirs maçonnés en euxmêmes - et parfois l'absence de maçonnerie -, les éléments de stockage (dolia et amphores) et les

\footnotetext{
${ }^{17}$ Cette interprétation est souvent justifiée par la comparaison avec les pratiques des propriétaires de Florence au $\mathrm{XIX}^{\mathrm{e}}$ siècle. Cf. e.g. Mazois 1824 b: 75; Bonucci 1827: 100; Gell 1828: 70; Breton 1855: 206.

18 Eschebach 1993: 489. La forme de cet annuaire empêche de développer les interprétations et de les justifier. La liste dressée mériterait certainement d'être vérifiée et expurgée.

${ }^{19}$ Si S. Ellis (2004 b: 371-373) emploie une précaution initiale définissant les bars comme "food and drink outlets », le sens de débit de boissons reste l'acception courante dès lors qu'il s'agit de désigner un lieu de commerce. Cf. The new shorter Oxford english dictionnary, s.v. bar, Oxford, Clarendon Press, 1993); Dictionnaire de l'Académie française, s.v. bar, $9^{\mathrm{e}}$ éd., Paris, Fayard - Imprimerie nationale éditions, 2001).
}

éventuels aménagements associés à la cuisson. J'ai cherché à accorder une certaine importance aux objets mis au jour dans ces locaux, tant ils semblent constituer un indispensable complément à une étude strictement architecturale ${ }^{21}$. La somme de ces données permet de répartir ces locaux selon une typologie fonctionnelle qui autorise à voir une variété de pratiques laissée insoupçonnée par la terminologie latine.

\section{II.1 Les différents aménagements des commerces alimentaires (comptoir, dispositifs de cuisson et de stockage)}

Le principal sinon l'unique moyen de reconnaissance des commerces alimentaires est constitué par le comptoir maçonné dans lequel peuvent être insérés des dolia. Il serait toutefois trop réducteur de limiter ainsi les aménagements présents dans ces locaux. Des tables de cuisson et des fourneaux, ainsi qu'une variété de moyens de stockage des denrées participent également à la définition des activités s'y déroulant.

\section{II.1.1 Particularités des comptoirs maçonnés}

Compte tenu de leur supposée spécificité fonctionnelle, dans le chapitre précédent, j'avais écarté les comptoirs maçonnés de la discussion sur les aménagements permettant de séparer l'espace accessible à la clientèle de celui réservé au commerçant. Tous les comptoirs maçonnés n'indiquent pas nécessairement des commerces alimentaires, mais cette relation se vérifie dans la majorité des cas $^{22}$. L'usage de la maçonnerie

\footnotetext{
${ }^{20}$ À Herculanum, les commerces alimentaires partiellement fouillés, situés dans l'insula VII ou dans les édifices bordant le côté nord du decumanus maximus, ont été pris en compte en dépit de données lacunaires qui empêchent une réelle comparaison avec celles des autres locaux. Pour Pompéi, les cinq locaux situés au-delà de la Porta di Ercolano ont été exclus faute de pouvoir les inclure dans un discours topographique comparatiste. Pour une description rapide de ces locaux, cf. infra n. 204 p. 128.

${ }^{21} \mathrm{La}$ répartition des objets a été analysée dans l'ensemble des commerces alimentaires d'Herculanum. En revanche, comme je n'ai utilisé Pompéi que comme point de comparaison et de référence, ma recherche y est loin d'être exhaustive.

${ }^{22}$ Cet avis est également partagé par S. Ellis (2004 a: 45 ; 2004 b: 373-375) bien qu'il n'indique jamais précisé-
} 
pour construire cette délimitation spatiale est un choix fait par le commerçant pour des besoins spécifiques, notamment en termes de résistance. Les techniques de construction utilisées pour ces comptoirs s'écartent de celles utilisées pour les murs: quand ils sont visibles, les parements sont constitués de moellons de tout venant, mais des tuiles peuvent être également utilisées, comme pour le remplissage des espaces interstitiels entre les dolia du bras ouest dans le comptoir de la boutique IV, 15-16. Les comptoirs ne sont donc guère plus que des murets posés sur le sol sans réelle fondation ${ }^{23}$. À Herculanum, ces aménagements ont fréquemment été laissés dans un état fragmentaire par le passage des tunnels lors des fouilles du XVIII ${ }^{\mathrm{e}}$ siècle. Seule une faible portion, aujourd'hui disparue, a été décrite en 1929 dans le local III, 6 (cat. $\left.n^{\circ} 3\right)^{24}$. De la même façon, en V, 21 (cat. $\mathrm{n}^{\circ} 20$ ), seul le bras occidental subsiste alors qu'au minimum un second bras orienté est-ouest doit être restitué. À Pompéi, certains comptoirs ont pu être détruits depuis leur mise au jour. Les trois dolia qui sont actuellement visibles dans le local VII 4, 17, alignés le long du mur est, ont pu être à l'origine englobés dans un massif de maçonnerie ${ }^{25}$. Cette situation se retrouve dans la boutique VII 12, 9 à Pompéi où quatre dolia sont disposés en équerre, trois le long du mur oriental, le quatrième en retour au nord, du côté de l'ouverture du local ${ }^{26}$.

ment quels sont les commerces qu'il considère comme n'étant pas des bars. Pour quelques hypothèses concernant les «comptoirs » maçonnés - qu'il faudrait parfois appeler établi - non associés à des commerces alimentaires, cf. infra, p. 127.

${ }^{23}$ Voir l'exemple déjà traité (supra, p. 65-66) du comptoir maçonné - détruit avant l'éruption - en I 6, 8-9 à Pompéi. Le creusement préparatoire à l'installation est à peine supérieur à $3 \mathrm{~cm}$ par endroits.

${ }^{24}$ GSE 1929: 27 maggio.

${ }^{25}$ La mise en place d'un tel massif n'est pas une nécessité absolue, comme le montre le relief de la collection Nanni (cf. infra n. 89).

${ }^{26}$ Ces locaux dépourvus de toute trace de maçonnerie englobant les dolia n'ont pas été pris en compte par S. Ellis (2004 b: fig. 1 p. 374). Un doute subsiste quant à l'antiquité de l'implantation des dolia visibles en VII 4, 17 : ils ne sont pas mentionnés par G. Fiorelli (1875: 214). En ce qui concerne VII 12, 9, la description du local en 1875 laisse un doute quant à l'existence d'un enrobage de maçonnerie:
En moyenne, ces comptoirs ont une hauteur située entre 65 et $70 \mathrm{~cm}$. Si une largeur moyenne de $90 \mathrm{~cm}$ peut être observée, elle varie en fonction de l'insertion ou non de dolia: en raison du fort diamètre de ceux inclus dans le comptoir situé en VI, 19 (cat. $\mathrm{n}^{\circ}$ 33) sa largeur est supérieure, jusqu'à $113 \mathrm{~cm}^{27}$. Inversement, le comptoir de la boutique IV, 17 (Casa del priapo) est plus étroit: les jarres contenant les denrées préparées dans ce local en sont séparées, réparties entre la pièce principale et l'une des pièces annexes ${ }^{28}$. La forme des comptoirs est relativement peu variée. Deux dispositions principales émergent à Pompéi: en équerre simple (110 locaux, 70\% du total) ou double - en « U» - (31 locaux, $20 \%$ du total $)^{29}$. À Herculanum, avec un nombre bien moins important de locaux (13 contre 158), les deux types présentent le même nombre d'attestations $(5,38 \% \text { du total })^{30}$. Si le plan en équerre ne permet pas de contenir tous les dolia nécessaires, l'ajout d'un troisième bras, éventuellement séparé du comptoir proprement dit, permet d'accroître la capacité de stockage, à l'exemple du local VI, 19 où, outre les sept jarres implantées dans le comptoir principal, deux autres sont détachées le long du mur oriental ${ }^{31}$. Quel que soit le plan adopté, une constante demeure: l'un des bras est toujours parallèle à l'ouverture sur la rue, très fréquemment il bloque partiellement celle-ci. De la sorte, la clientèle peut acheter ou consommer sans

«[...] l'altra [bottega ha] quattro dolii di terracotta fabbricati nel suolo» (Fiorelli 1875: 282).

${ }^{27}$ Le dolium situé dans l'angle nord-ouest du comptoir est large de 1,10 m; cf. GSE 1961: 25 settembre.

${ }^{28}$ Sur ce local et la dispersion de ses aménagements, cf. infra, p. 108-112.

29 Les comptoirs constitués par une barre simple sont représentés par 8 locaux (4\% du total); 9 comptoirs mentionnés dans les archives mais actuellement recouverts ou détruits sont de forme inconnue. Seul le comptoir de la boutique I 14, 15 présente une forme de plan en « M », pour s'adapter à l'articulation du local.

${ }^{30}$ Le comptoir du local III, 6 pourrait n'avoir été qu'une barre simple. Le comptoir du local V, 19 est de forme indéterminé. En Or. II, 9, les restes d'un comptoir en bois ont été mis au jour, sans spécifier sa forme (cf. supra, p. 63); en dépit de cet aménagement cette boutique doit être considérée comme un commerce alimentaire (cf. infra, p. 125126).

${ }^{31}$ Cf. fig. 41 p. 103. 
entrer dans le local, tout en utilisant le comptoir comme appui. Cette disposition permet d'utiliser l'espace public du trottoir pour agrandir la surface utilisée par la boutique, sans que cela ne constitue une violation flagrante des règlements en vigueur sur ce point. Un léger retrait peut être ménagé pour faciliter la mise en place des planches pour fermer la boutique, comme en Or. II, 13 (cat. $\left.\mathrm{n}^{\circ} 46\right)$ à Herculanum. Le retrait peut également être plus important, comme en I 8, 15-16 à Pompéi: dans ce cas, la clientèle ne consomme pas à partir du trottoir, mais bien dans le local; des contingences de circulation interne ont pu jouer dans l'adoption de cette disposition ${ }^{32}$. Dans certains cas, l'emplacement du comptoir pourrait avoir été dicté par la recherche d'une visibilité maximale depuis la rue. S. Ellis a établi une corrélation entre le sens de circulation dans les rues de Pompéi et le côté du seuil choisi pour installer le comptoir. À partir de l'exemple de la portion méridionale de la via Stabiana, où les comptoirs sont disposés dans la moitié nord des commerces alimentaires, il en a déduit une recherche de visibilité maximale pour attirer les clients venant de l'extérieur de la ville ${ }^{33}$.

Outre la disposition du comptoir, son aspect peut également avoir été utilisé pour rendre le local plus attirant pour les clients. À Herculanum, les données sur ce point sont parti-

32 Un second exemple pompéien est constitué par le local I 11, 16. Le comptoir disposant d'un dolium, de trois degrés d'exposition et d'un chauffe-eau / fourneau se situe au centre la maison, accessible à la clientèle après le franchissement d'un couloir. De façon générale sur cette maison, interprétée comme un hospitium, cf. Miele 1989.

${ }_{33}^{3}$ Ellis 2004 b: 381-383. Cette intéressante hypothèse, qui donne une forte importance à la clientèle venant de l'extérieur de la ville, ne saurait cependant être considérée comme l'unique facteur d'explication à la localisation des commerces alimentaires (cf. Monteix 2010).

${ }^{34}$ GSE 1933: «6 settembre. [...] L'ambiente $\mathrm{N}^{\circ}$ 6, V Cardine, insula Occidentale è un termopolio. Il banco di vendita è quasi distrutto dai cunicoli borbonici, così anche i dolii $[\ldots]$.

13 settembre. [...] Il podio era rivestito di stucco a fondo rosso per tutta l'altezza e di marmo, frammenti, la larghezza $[\ldots]$ »

${ }^{35}$ L'exemple de la boutique V, 6 est assez éclairant en ce sens. GSE 1933: «6 maggio. L'Ambiente $\mathrm{N}^{\circ} 1$ della Casa n. 6, sul IV Cardine, lato Est, è stato svuotato. È un termopolio [...]. La seconda [cucina] che trovasi all'estremità Nord del banco di vendita è alto m. 0.79, largo m. 1.04 e culièrement peu nombreuses. Ainsi, seuls deux locaux présentent une décoration spécifique pour les faces verticales. En Or. II, 6 (cat. $n^{\circ} 41$ ), les journaux de fouilles mentionnent un enduit rouge sur les parties visibles par la clientèle; cependant, sa conservation partielle empêche de déterminer si la décoration était plus complexe ${ }^{34}$. Le second comptoir à l'aspect élaboré se situe dans la boutique V, 9-10: ses deux faces tournées vers les clients sont rehaussées de pièces de marbres donnant l'illusion de pilastres engagés. Presque tous les comptoirs actuellement visibles à Herculanum disposent sur leur face supérieure d'un tapis de fragments de marbre colorés fréquemment imbriqués sans ordonnancement particulier. Les quelques exceptions s'expliquent par leur reconstruction ${ }^{35}$. L'étude détaillée de ce traitement de surface est inutile: outre les restauration consécutives à la fouille, il s'agit de matériel de récupération, très certainement non retravaillé et qui ne demande pas de compétence particulière pour sa mise en œuvre ${ }^{36}$. À Pompéi, la situation est similaire. Quand une description précise permet de déterminer l'état des comptoirs lors de leur mise au jour, ils sont également, sauf restauration abusive ${ }^{37}$ et à de rares exceptions près, décrits comme recouverts par ce type de mosaïque en marbre de récupération. En ce qui concerne la décoration des parois verti-

lungo m. 1.10. Quest'ultimo si è dovuto rifare completamente perché rotta da cunicoli borbonici [...]».

${ }^{36}$ A. Mac Mahon (2005 b: 73-74) estime que des artisans spécialisés dans l'agencement de ces fragments de marbre auraient été employés pour la construction des comptoirs. Pourtant, ils sont mis en œuvre sans ajustement particulier, souvent espacés de plusieurs millimètres à un centimètre environ.

${ }^{37}$ La façade du local I 8, 8 a d'abord été mise au jour en 1912-1913 par V. Spinazzola, tandis que le reste du local n'a été fouillé qu'entre janvier et juin 1939. Lors des fouilles de la via dell'Abbondanza, deux dolia situés côté rue, à l'est, ont été mis au jour. Immédiatement restaurée, cette portion du comptoir n'a pas laissé apparaître ces deux jarres: un plan de travail en fragments de marbre a été recréé à la place. Ce n'est qu'après juin 1939 que les autres dolia ont été réintégrés, à l'exception des deux les plus à l'est; comparer les figures 1 et 2 publiées dans le PPM (I: 804). L'étude de ce comptoir sans prendre en compte ces données d'archives ferait croire à l'existence de deux phases antiques successives, la seconde comportant une condamnation de ces deux dolia . 


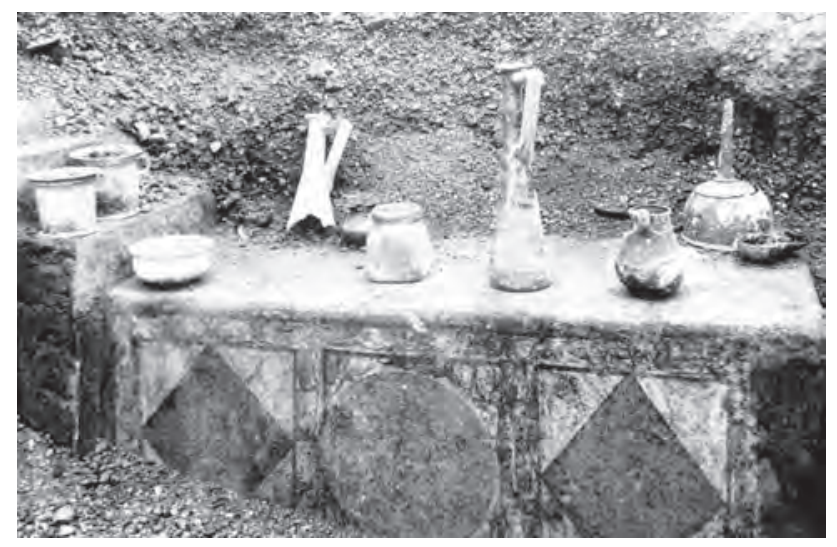

Fig. 32 - Décoration du comptoir du local I 19, 1-2, peint, reprenant des motifs d'opus sectile; les objets photographiés ont été découverts sur sa surface en juin 1933.

cales, Pompéi présente une plus grande variété qu'Herculanum. La majorité des comptoirs préservés présentent sur leurs faces visibles des assemblages de marbre identiques à ceux des plans de travail. D'autres motifs plus élaborés existent: l'alternance de carrés sur pointe et de cercles inscrits dans des carrés, reprise directe des motifs de l'opus sectile des pavements, peut être réalisée soit en marbre (V 4, 7), soit en peinture imitant cette pierre (I 19, 1-2) (fig. 32); l'alternance de carrés sur pointe inscrits dans des carrés formés par des triangles isocèles (I 11, 1) ou des mélanges de rectangles et de disques $(I 8,8)$ sont également attestés ${ }^{38}$. Une fresque pouvant évoquer les mets vendus dans la "caupona Pherusae» (III 6,1) était située sur son comptoir, côté rue: des grappes de raisin, des pommes, des poissons, des légumes et des gazelles y étaient représentées jusqu'en 1943 (fig. 33) ${ }^{39}$. Certaines de ces fresques peuvent n'avoir aucun rapport avec les denrées en vente. Ainsi, celui du local V 2, 19 est orné d'une représentation de Thétis avec les armes d'Achille ${ }^{40}$. Un autre exemple particulièrement intéressant

${ }^{38}$ Spinazzola 1953 : fig. $275-278$ p. $248-250$. L'imitation peinte de fragments de marbre sur le comptoir de la boutique II 1, 1 (II, IV, 1 dans les légendes de V. Spinazzola) n'est plus visible actuellement.

${ }^{39}$ Pour la description de cette boutique ainsi que la seule photo montrant le comptoir avant destruction, cf.

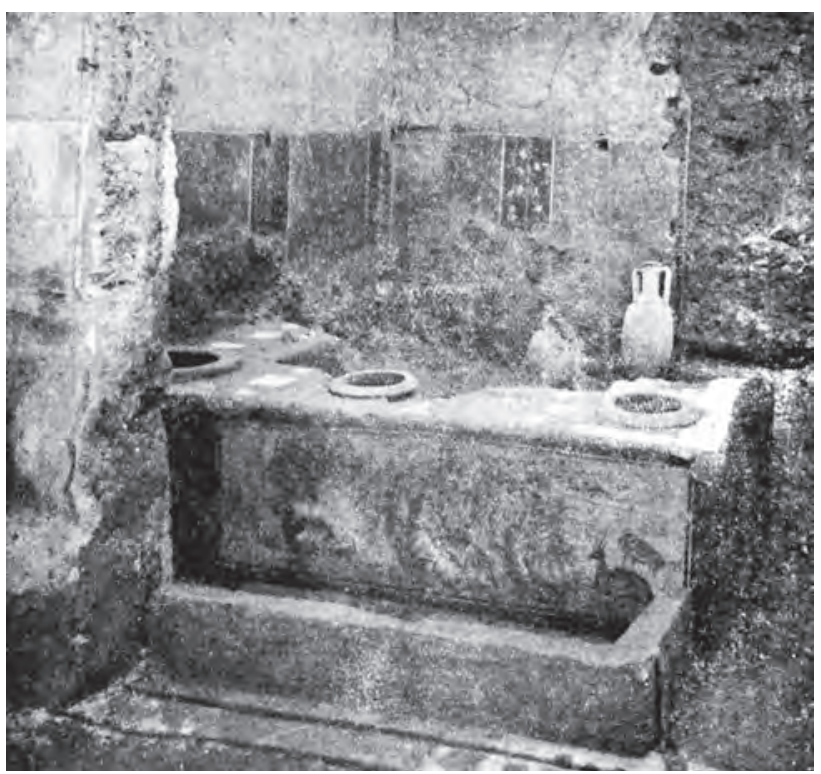

Fig. 33 - Comptoir de la boutique «de Pherusa ( (III 6, 1). Le bombardement de 1943 a détruit l'ensemble (comptoir, fresque et aménagement en terre crue).

est constitué par le comptoir en équerre de la boutique «de Sotericus» (I 12, 3), dépourvu de dolium, mais comprenant à son extrémité sud un chauffe-eau. La face nord, donnant sur la via dell'Abbondanza, est décorée par des carrés sur pointe dessinés avec des fleurs stylisées. La face orientale du bras rentrant reprend des motifs décoratifs issus du $\mathrm{III}^{\mathrm{e}}$ style de transition: dans une trame d'édicules rendus sans perspective flottent des animaux - oiseau, panthère et cygne. Des dolia sont incorporés dans un bras indépendant situé dans l'atrium, le long du mur ouest. Au-dessus de ces cinq jarres, la paroi peinte imite un revêtement de plaques de marbre. La face verticale du bras est également peinte, en jaune uni. Ces variations dans la décoration des différentes faces visibles par les clients paraissent directement liées à la position de ces faces par rapport au local. Le côté nord donnant sur la

NSc 1936: 310-316, part. p. 310-312 et fig. 3. À propos des dégâts du bombardement de 1943, cf. García y García 2006 : 19-30, 60 .

${ }^{40}$ NSc 1877: 251. 
rue tranche nettement par la recherche décorative qu'il montre, tandis que les deux autres faces tendent à s'insérer dans la décoration des murs à l'intérieur de ce vaste commerce. Un dernier exemple montre cette distinction des différentes faces du comptoir. Dans le local I 7, 13-14, la face donnant dans la boutique aurait porté une imitation de plaques de marbres peintes. En revanche, le côté donnant sur la rue montre un Priape ithyphallique entouré par deux cadres dans lesquels figurent des lions ${ }^{41}$. Dans ce cas, le comptoir remplace la façade pour mettre en avant une expression qui, à défaut d'être religieuse au sens le plus strict, exprime les croyances du boutiquier. De la même façon, les symboles bacchiques qui se trouvent sur la face nord du comptoir situé en I 8, 1 pourraient remplacer les peintures religieuses destinées à protéger le commerce, habituellement situées en façade à l'extérieur ${ }^{42}$.

Ces décorations et leurs variations ne sont pas une démonstration de la richesse ou du statut des boutiquiers ${ }^{43}$, mais bien plus un moyen d'attirer des clients. Comme les «enseignes», ces décorations des faces verticales renvoient plus aux goûts personnels du tenancier qu'à une quelconque mode. Sur la surface horizontale, les fragments de marbre permettent, outre leurs couleurs chatoyantes, de disposer d'un plan de travail et de service pratique, résistant et facile à nettoyer ${ }^{44}$. Enfin, il faut noter la présence dans certains

${ }^{41}$ GSP 1936: « 28 febbraio. [...] L'ambiente ha un largo vano d'accesso dal vicolo meridionale e nell'interno si è delimitato il banco di vendita a gomito, il cui braccio interno appare dipinto ad imitazione di lastre marmoree [...].

5 marzo. [...] Si è portato a compimento lo scavo del termopolio $\mathrm{n}^{\circ} 14$ eseguendo una diligente esplorazione del banco di vendita. [...] Del banco di vendita è notevole il fronte prospiciente il vicolo, esibente al centro un priapo itifallico dipinto riquadrato da un motivo floreale; lateralmente due riquadri a fondo giallo ed in ognuno campeggia un piccolo leone con la testa rivolta verso il quadro centrale. Il braccio interno ed il rivestimento marmoreo del banco sono malandati ed incompleti [...]». Cf. également Stefani 2005 c: 101.

${ }^{42}$ Selon V. Spinazzola (1953: 250), de part et d'autre d'un bouclier comportant une tête de Méduse, un Pan et une probable Diane sont représentés. Dans le registre inférieur, une hydrie et un cratère servent de support à des thyrses. Sur la vocation religieuse des «enseignes» de façade, cf. supra, p. 49-53.

${ }^{43}$ A. Mac Mahon (2005 b: 74-75) suppose en revanche une course effrénée entre les tenanciers de boutiques pour commerces de gradins, disposés en général le long du mur contre lequel est appuyé le comptoir. Cet aménagement est loin d'être présent dans tous les locaux: seuls trois (25\%) à Herculanum et 36 (23\%) à Pompéi disposent d'au moins un de ces gradins, sans que la nature des aliments vendus dans ces commerces n'influe sur leur présence. Leur longueur et leur nombre varient selon les boutiques, mais il s'agit en général de marches hautes et profondes d'une dizaine de centimètres. Ils auraient servi à ranger des ustensiles utiles au bon fonctionnement du commerce ou à exposer des denrées en vente, comme le montre l'exemple de la boutique di Stabilio Oenoclio (I 19, 1-2), où deux vases en verre y ont été découverts (fig. 32) ${ }^{45}$. Cette pratique est également visible sur un sarcophage trouvé dans l'Isola Sacra à Portus: des verres et une marmite sont disposés sur des gradins situés derrière le tenancier ${ }^{46}$.

Trois fonctions caractérisent les comptoirs maçonnés des commerces alimentaires. Par leur disposition, ils permettent de dresser des limites d'une part entre la boutique et l'extérieur, d'autre part entre l'espace de la clientèle et celui réservé au tenancier. Leur décoration répond tout autant à la nécessaire attraction de la clientèle qu'à des besoins pratiques dans le cas du revêtement en fragments de marbre. Qu'ils disposent ou non de gradins, les comptoirs permettent également d'exposer les produits mis en vente. Finalement,

décorer leurs comptoirs avec des fragments de marbre. Cette assertion ne peut pas être démontrée, faute de toute donnée chronologique précise sur la mise en place de ces aménagements.

${ }^{44} \mathrm{La}$ pierre ponce (Inv. $\mathrm{n}^{\circ} \mathrm{P} 1117$ ) trouvée dans la «boutique d'Asellina » (IX 11, 2) pourrait avoir servi à cette fonction de nettoyage: demie sphère d'un diamètre de $7,5 \mathrm{~cm}$, elle tient parfaitement dans la main et présente une surface plane permettant une abrasion du revêtement du comptoir (NSc 1912: 117, contra Stefani 2005 c: 121).

${ }^{45}$ Selon les journaux de fouilles, cette photo n'aurait pas été mise en scène. GSP 1933: «19 giugno. [...] L'esplorazione condotta con speciale oculatezza ci ha restituito il banco cosparso di un notevole gruppo di oggetti, qui sottoelencati, i quali sono stati fotografati al loro preciso posto secondo il rinvenimento [suit la liste des objets Inv. $\mathrm{n}^{\circ} \mathrm{P} 5634$ à P5645]».

${ }^{46}$ Museo Ostiense, Inv. ${ }^{\circ} 1340$ (lors de la rédaction de ce texte, le sarcophage était conservé au Museo delle navi à Fiumicino), cf. NSc 1931: 531. 
ils constituent l'épine dorsale de ces commerces, particulièrement lorsqu'ils sont utilisés comme infrastructure pour la mise en place des aménagements de cuisson et de stockage comme nous le verrons plus loin.

\section{II.1.2 Les aménagements pour la cuisson}

Parmi les éléments freéquemment associés aux comptoirs maçonnés se trouvent deux types d'aménagements liés à la cuisson d'aliments ou au chauffage de l'eau. Le premier d'entre eux est spécifique à ce type de commerce, tandis que le second, qui constitue un fourneau classique, est également attesté en contexte domestique. À Herculanum, les chauffe-eau/fourneaux (CE/F) sont particulièrement mal conservés, puisque seuls les locaux Or. II, 6 et Or. II, 13 en présentent quelques vestiges. Pour cerner la forme et le fonctionnement de ce type de système de cuisson, il est plus aisé d'étudier celui de la boutique «d'Asellina» à Pompéi (IX 11, 2) (fig. 34). Une excroissance maçonnée longue de $1,2 \mathrm{~m}$ domine l'extrémité nord du bras rentrant du comptoir ${ }^{47}$. Deux parties peuvent être distinguées. La première se trouve dans l'immédiate continuité du comptoir proprement dit. Un parallélépipède permet l'encastrement définitif d'un récipient en bronze dont le col dépasse audessus du massif maçonné ${ }^{48}$. Lors de la fouille, le couvercle de ce récipient, découvert en place, était décoré de deux dauphins opposés servant d'anses et pourvu d'une chaînette ${ }^{49}$. Sous cette chaudière, un vide a été ménagé, dans lequel des dépôts de carbone ont pu être observés. Enfin, à l'angle sud-ouest du massif maçonné se trouvait un cylindre en terre cuite permettant l'évacuation de la fumée créée dans la chambre de combustion. Une petite ouverture est ménagée dans la paroi nord ${ }^{50}$. La chaudière en bronze n'est associée à aucun système de remplissage ou de vidange de son contenu. Au nord de ce massif une petite plateforme est ménagée, encadrée par deux murets ${ }^{51}$. Son plan horizontal
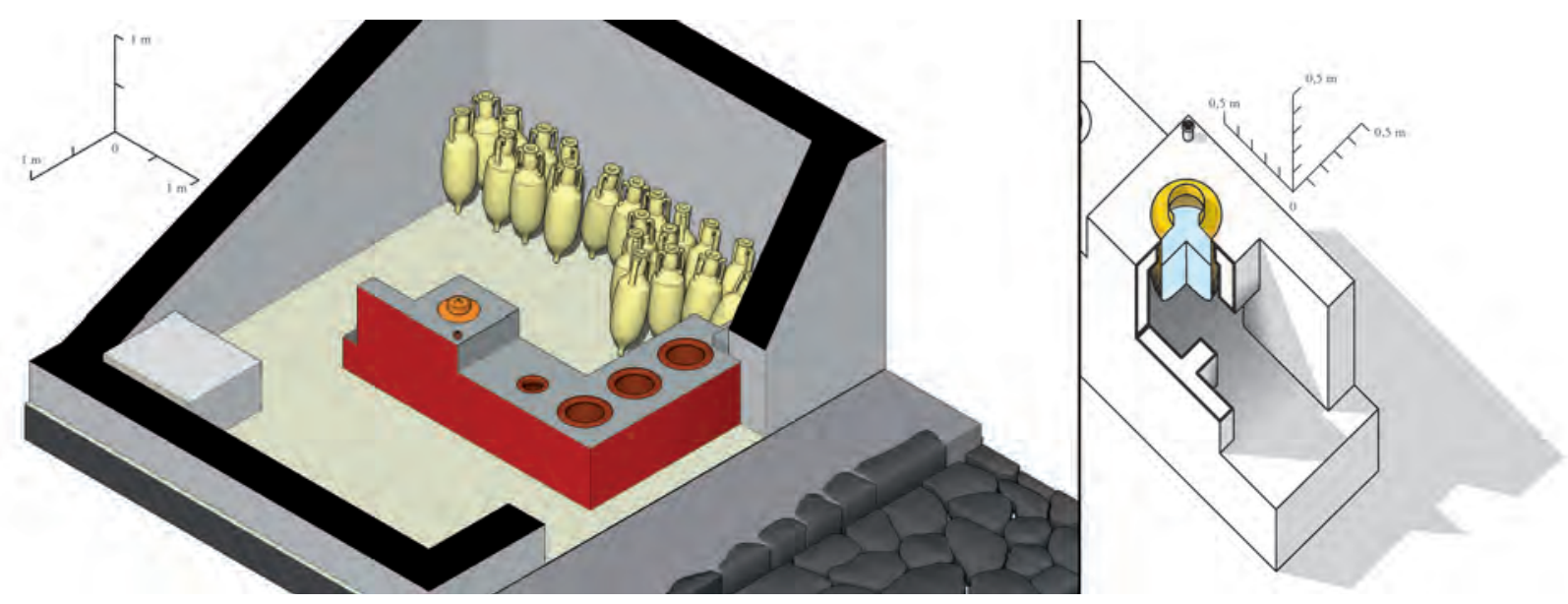

Fig. 34 - Restitutions de la boutique «d'Asellina» (Pompéi, IX 11, 2). À gauche, isométrie de l'ensemble du local; le chauffe-eau / fourneau constitue une excroissance dans le comptoir (échelle: 1/100). À droite, axonométrie en éclaté de l'extrémité du bras occidental du comptoir: en avant de la chaudière, une plateforme permet de disposer d'un espace de cuisson minimal (échelle: 1/50).

${ }^{47}$ Le comptoir est haut de $64 \mathrm{~cm}$, tandis que le sommet de la maçonnerie contenant le $\mathrm{CE} / \mathrm{F}$ s'élève $21 \mathrm{~cm}$ audessus.

${ }^{48}$ Le parallélépipède de maçonnerie est haut de $85 \mathrm{~cm}$, large de $74 \mathrm{~cm}$ et long de $71 \mathrm{~cm}$. Le récipient est haut de $42 \mathrm{~cm}$ et son col large de $19 \mathrm{~cm}$. Il pourrait correspondre au type V1100 des formes en bronze publiées par S. Tassinari (1993: 102).

\footnotetext{
${ }^{49}$ Il est visible sur les photos prises lors de la fouille. Inv. ${ }^{\circ}$ P18667. Cf. NSc 1912: 114-115; Tassinari 1993: vol. **, p. 277 ; Stefani 2005 c: 116.

${ }^{50}$ Hauteur: $27 \mathrm{~cm}$; largeur: $31 \mathrm{~cm}$.

${ }^{51} \mathrm{La}$ plateforme se trouve à $32 \mathrm{~cm}$ du sol. Le muret occidental est haut de $53 \mathrm{~cm}$, le second n'est conservé que sur une dizaine de centimètres
} 
est recouvert de béton laissant apparaître des tuiles fragmentées. La fonction de cet aménagement est double: d'une part, la chaudière en bronze permet de faire chauffer et de maintenir au chaud de l'eau pouvant être utilisée pour la consommation du vin ${ }^{52}$; d'autre part, la plateforme permet de placer du bois ou du charbon sous la chaudière mais aussi et surtout d'avoir une petite surface $-c a \cdot 0,4 \mathrm{~m}^{2}$ - permettant le dépôt d'un lit de braises utilisé pour faire cuire des aliments dans l'une des différentes marmites découvertes dans ce local. Cette cuisson s'effectuait au moyen d'un trépied en fer remisé lors de l'éruption sur les étagères qui couraient le long du mur oriental du local ${ }^{53}$.

En dépit de la clarté de cet exemple, il n'en reste pas moins un cas rare, tout autant par sa conservation que par l'emploi d'une chaudière en bronze. Des descriptions beaucoup plus nombreuses indiquent l'utilisation de récipients en plomb, essentiellement dans les dernières décennies du $\mathrm{XIX}^{\mathrm{e}}$ comme dans le cas du commerce V 1, 13 à Pompéi ${ }^{54}$. Les différentes caractéristiques de ces chaudières sont indi-

52 Le vin est normalement consommé coupé d'eau (Tchernia - Brun 1999: 36), ce qui a donné lieu à de nombreux sarcasmes quant au rapport entre les deux liquides, en particulier quand le vin est jugé trop dilué (CIL IV, 3948: Talia te fallant/ utinam medacia copo/ tu ve $<n>$ des acuam et / bibes merum / <cervum $>$ ) ou pas assez (Mart. 1, 56; 2, 51). Les attestations d'utilisation d'eau chaude ou froide abondent sans qu'il ne soit possible de mettre en évidence une pratique plus développée dans un sens ou dans l'autre. Le graffite ajouté sur l'un des cadres de la boutique VI 10, 1.19 qui montre une femme en train de servir un client ne permet pas d'interprétation univoque. Le texte (CIL IV, 1291) indique da fridam pusillum - que l'on peut traduire par «donne-moi un peu d'eau froide »-, ce qui peut indiquer tout autant une envie de refroidir du vin que de le couper d'eau froide.

${ }^{53}$ Ce trépied (Inv. ${ }^{\circ} \mathrm{P} 1188$; absent des dépôts en mai 2004), a été mis au jour le 16 janvier 1912, sur les amphores appuyées contre le mur est du local. Étrangement, il ne figure pas dans la liste du matériel découvert reportée dans les NSc (1912: 116-120). Il ne fait pas de doute qu'il se trouvait sur les étagères dont les empreintes sont visibles sur la paroi (cf. NSc 1912: 117-118 sur l'existence de ces étagères). D'autres découvertes confirment cette interprétation, comme la boutique VI 15, 15 «Il banco terminava in un focolaretto, sul quale si rinvenne il 29 novembre un tripode di ferro" (NSc 1897: 461). Un trépied a également été découvert dans la boutique I 10,13. Lors de l'éruption, quées: un récipient rectangulaire, alimenté en eau sous pression par un tuyau. Deux systèmes de récupération de l'eau chaude sont envisagés: une ouverture sommitale circulaire et un second tuyau. À ma connaissance, aucune de ces chaudières trouvées dans des commerces alimentaires, n'est actuellement conservée dans les dépôts de Pompéi ou d'Herculanum ${ }^{55}$. En revanche, d'autres exemples de ce système de chauffe sont conservés in situ dans les murs diaphragmes des boulangeries ${ }^{56}$. Un tel chauffeeau, découvert dans la Villa des Mystères permet de saisir leur conception (fig. 35$)^{57}$. Il est constitué de deux feuilles de plomb, la première ayant été découpée en croix dont chacun des bras a été replié pour former le corps du récipient. Ces parois ont été soudées entre elles par une coulée de métal puis la partie supérieure a été ajoutée. Malgré l'absence de toute trace d'implantation de tuyau, les restes de carbonisation sur sa face inférieure et les dépôts calcaires à l'intérieur indiquent une fonction de chauffeeau. La légère déformation du fond, sensiblement affaissé et convexe au centre, renvoie il se trouvait sur le sol, avec un récipient en terre cuite posé à son sommet, comme le décrivent les GSP (1932: « 7 luglio. [...] Sul pavimento presso la parete sud si è rinvenuto e lasciato in situ un trepiedi di ferro alto m. 0,16 con fascia circolare nella parte superiore su cui poggia il fondo di un vaso di terracotta [...]»). Cf. NSc 1934: 341.

54 «Nell'angolo a d. dell'ingresso evvi una specie di focolare, formato da due sostegni coperti d'una lastra di mattone sovrapposta ad una tavola di legno, e sopra questa una cassetta di piombo addossata all'anta dell'ingresso ed incastrata nel materiale in maniera da lasciar sotto di essa lo spazio per accendere il fuoco. La cassetta ha di sopra un'apertura tonda col margine rivolto in su; due fistule, in diversa altezza, si dirigono da essa verso l'ingresso $(\mathrm{N})$, attraversando il materiale che la sorregge» ( $B d I$ 1877: 135). La description d'un dispositif similaire a également été faite pour le local V 2, 19 (MDAIR 1894: 57).

${ }^{55} \mathrm{Il}$ est possible que certaines des chaudières découvertes entre 1860 et le début du XX $\mathrm{XX}^{\mathrm{e}}$ siècle aient été transférées au MANN.

${ }^{56}$ Cf. infra, p. 157.

${ }^{57}$ Ce chauffe-eau a été mis au jour le 13 mars 1930 dans la pièce 50 de la Villa des Mystères (Inv. $n^{\circ}$ P4496), qui se situe entre le pressoir et les autres espaces consacrés à la production vinicole, encore non fouillés (Maiuri 1960: 40-45). Les dimensions de ce chauffe-eau lui donnent une contenance maximale de 16 litres. 


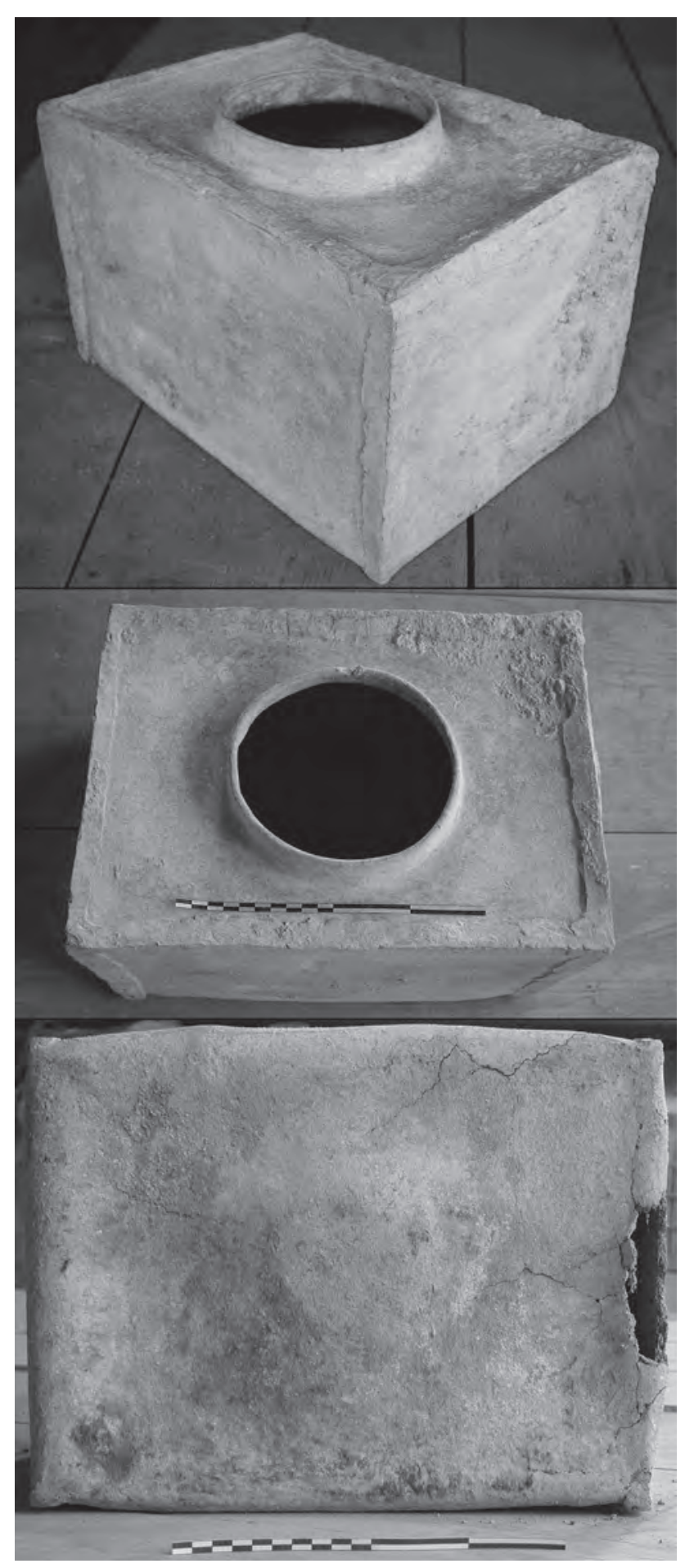

Fig. 35 - Chauffe-eau en plomb provenant de la Villa des Mystères (pièce 55). De haut en bas, vue cavalière, vue de dessus et vue du fond. Les soudures visibles sur les côtés et au sommet permettent de comprendre la conception de l'ensemble. également à une utilisation de la chaleur ${ }^{58}$. Dans certains cas, cette déformation a été évitée en plaçant une plaque de bronze sous la chaudière en plomb ${ }^{59}$. L'alimentation en eau sous pression de ces chaudières est seulement une possibilité, dépendant d'abord de la connexion au réseau d'approvisionnement hydraulique. Ainsi, dans la boutique en façade de la Casa di Nettuno e Anfitrite (V, 6), bien que seule la conduite d'eau ait été observée, il est possible de restituer un chauffe-eau installé sur la table de cuisson située à l'extrémité septentrionale du comptoir $^{60}$. Ces aménagements peuvent atteindre un haut degré de raffinement. Selon la description des journaux de fouilles, dans la cour 8 dépendant du commerce I 1, 6.8-9, une chaudière en plomb reliée à un dispositif en bronze et insérée dans un massif maçonné a été découverte ${ }^{61}$. Cet exemple reste toutefois exceptionnel.

Lorsque cet aménagement a disparu, d'autres éléments morphologiques permettent de supposer son existence. Le CE/F doit prioritairement être cherché à l'extrémité libre de l'un des bras du comptoir. Dans le local dit «de Sotericus» (I 12, 3), l'extrémité méridionale est plus large que le reste du comptoir de $32 \mathrm{~cm}$. On retrouve en plan une disposition similaire à celle de la boutique "d'Asellina»: une chambre circulaire ronde est suivie, après un léger étré-

${ }^{58}$ En dépit de la basse température de fusion du plomb l'utilisation de ce métal au-dessus d'un feu ne pose pas de problème: la chaleur se répartit dans l'eau, ce qui évite d'atteindre des températures trop élevées. La présence de calcaire sur les parois internes permet de supposer une utilisation aux environs de $100^{\circ} \mathrm{C}$, ce qui rend le métal d'autant plus malléable qu'il est soumis au poids de l'eau.

${ }^{59}$ Selon la description des journaux de fouilles, ce dispositif aurait été employé pour le CE/F du local VI 1, 18.20: « 1789 - 12 marzo - Si sono evacuate due stanze: la prima è una bottega col bancone di fabbrica con tonica dipinta rossa, il pavimento di mattoni pesti, e l'intera tonica bianca con liste rosse [...] Si è trovato in questa stanza. [...] Piombo. Un vaso, ossia un cassone di piombo col suo coperchio forato in mezzo, ed il fondo di rame lungo pal. $2 \frac{1}{2}$, largo $1 \frac{1}{2}$, alto $1 \frac{1}{1 / 4}[\ldots] »(P A H \mathrm{I}, 2: 44-45)$.

${ }^{60}$ GSE 1933: "6 maggio. L’Ambiente $\mathrm{N}^{\circ} 1$ della Casa n. 6, sul IV Cardine, lato Est, è stato svuotato. E' un termopolio. [...] Sul pavimento si osserva una conduttura di piombo che è spezzata presso il banco di vendita. [...]».

${ }^{61}$ GSPomp n.s. 2, $1873: 426$. 
cissement dû à la présence d'une porte, par une plateforme rectangulaire (fig. 36). Cet élargissement reste visible, même quand le comptoir est arasé, comme dans le local I 6, 8-9 (fig. 25). Lors des descriptions effectuées au cours de la fouille, il arrive parfois que seule la plateforme ou la chambre de chauffe subsistent et soient mentionnées $^{62}$. En Or. II, 13, un massif sensiblement cubique se trouve au bout du bras méridional du comptoir ${ }^{63}$. Il est recouvert d'une grande brique carrée posée à plat, probable tegula mammata, correspondant à la plateforme de cuisson. L'ensemble, qui déborde sur le côté sud du comptoir d'une quinzaine de centimètres, correspond parfaitement à un chauffeeau/fourneau. Il est possible que le $\mathrm{CE} / \mathrm{F}$ soit un

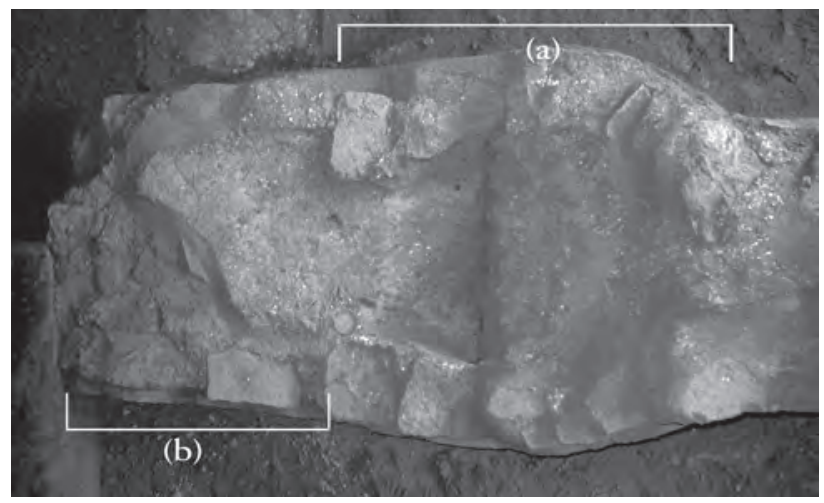

Fig. 36 - Comptoir du commerce alimentaire «de Sotericus» (I 12, 3). Vestige d'un chauffe-eau inclus dans la maçonnerie. En (a), la chambre de chauffe; en (b), la plateforme de cuisson.

${ }^{62}$ La description du chauffe-eau du local VI 16, 12 est exemplaire: «Il banco di vendita, in muratura, [...] forma il solito angolo o gomito terminante con un poggiuolo rivestito superiormente con una tegola e cocci » (NSc 1908: 60). Bien que très dégradés, les vestiges actuellement visibles, mis en parallèle avec cette descritpion ne laissent guère de doute quant à la fonction de chauffe-eau/fourneau de cet appendice du comptoir.

${ }^{63}$ Les journaux de fouilles indiquent deux aménagements de cuisson. La plateforme terminant le comptoir pourrait correspondre au plus petit d'entre eux. Il ne reste rien du second actuellement. GSE 1936: «22 ottobre. La casa n. 13 è un negozio. Vi sono dei dolium, avanzi murati e la cucina. Quest'ultima è formata da un fornello piccolo ed uno grande $[\ldots] »$. ajout postérieur, correspondant à une transformation des activités se déroulant dans un local; il est alors simplement accolé au comptoir ${ }^{64}$. Un autre système, moins fréquent, a été employé à Herculanum, dans le local $\mathrm{n}^{\circ} 8$ du decumanus maximus côté oriental (DM E, 8) (fig. 37) ${ }^{65}$. Coincé entre le montant droit de l'entrée et le mur oriental, un petit massif sert de support à trois tuiles. Deux sont disposées de chant, la troisième, une tuile à douille récupérée, est disposée à plat. La tuile constituant la face nord est percée d'une ouverture semi circulaire d'environ $30 \mathrm{~cm}$ qui a dû servir de gueule pour alimenter le foyer. La douille aurait alors servi de support à la vaisselle utilisée pour la cuisson, voire de chauffeeau employant un récipient céramique.

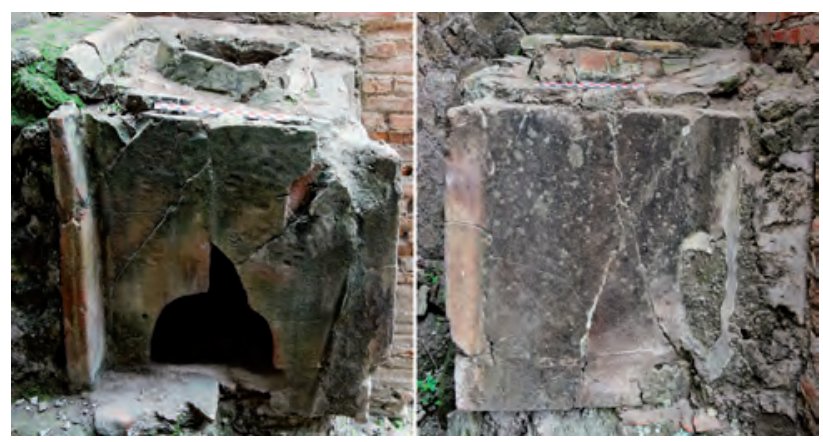

Fig. 37 - Aménagement pour la cuisson construit avec des tuiles dans le local DM 8E (vue des faces septentrionale et occidentale).

${ }^{64}$ Deux locaux pompéiens présentent cette caractéristique: I 6, 5 et II 4, 5. Dans les deux cas, le CE/F forme une excroissance du comptoir, tant dans la longueur que dans la largeur.

${ }^{65}$ Si l'on suit la chronologie-parfois hasardeuse-reportée sur les fiches photographiques conservées à l'Ufficio Scavi d'Herculanum, ce local aurait été fouillé en décembre 1968. Toutefois selon les livres d'inventaire, il faudrait considérer que l'excavation de ce commerce a eu lieu entre décembre 1967 et janvier 1968: bien que les données ne soient pas claires, il s'agirait de la bottega 4, nuovo scavo decumano massimo. Les journaux de fouilles de cette période ont disparu. Malgré le nombre important d'objets trouvés dans ce local, il n'a pas été intégré à ce corpus, comme les autres commerces situés dans la partie nord du decumanus maximus. 
Quel que soit le dispositif employé, la fréquence de ces chauffe-eau qui peuvent également offrir des possibilités - réduites mais non nulles - de cuisson est notable à Pompéi: 91 des 157 commerces alimentaires (58\%) en disposent. À Herculanum en revanche, seuls quatre boutiques possèdent un tel aménagement (30\%), sans que cette différence ne trouve d'explication évidente. Quant à l'utilité de ces dispositifs, il semble clair que la possibilité de faire tiédir de l'eau permet au minimum de couper le vin. Toutefois il ne faut pas limiter leur utilisation à ce seul breuvage: il n'est pas exclu que la préparation de certaines décoctions implique non pas la cuisson des feuilles mais leur simple infusion dans de l'eau préalablement chauffée. Enfin, disposer de liquide au moins tiède permet de réduire le temps de cuisson des bouillies.

Le second grand groupe de constructions destinées à cuire les aliments n'est pas propre aux commerces alimentaires. Les tables de cuisson constituent au contraire la forme la plus répandue de ces aménagements dans l'architecture domestique des cités ensevelies par le Vésuve ${ }^{66}$. Dans leur forme la plus simple et la plus courante, il s'agit de tables maçonnées, hautes de 60 à 80 centimètres. Leur face antérieure est souvent percée et voûtée, de façon à déposer dans cet espace le bois utilisé comme combustible lors de la cuisson. Généralement accolées à au moins deux murs, elles peuvent être bordées sur les côtés libres par un rebord construit avec des imbrices prises dans un cordon de béton. Ce rang de tuiles permet de générer un lit de braises sur lequel les récipients sont déposés soit directement, soit avec l'intermédiaire d'un trépied en fer, soit encore avec des petits murets maçonnés. Dans son utilisation commerciale, cet aménagement ne présente que rarement des spécificités. Toutefois, trois locaux ont conservé les vestiges d'une utilisation particulière de ces

${ }^{66}$ Sur ces tables de cuisson ou fourneaux, voir d'une façon générale Fulvio 1879: 275-277; Salza Prina Ricotti 1980: part. 239-273; Foss 1997 qui s'attache essentiellement au rapport entre nourriture et religion. Pour la localisation des espaces consacrés au service en général et à la cuisine en particulier, on se reportera désormais à l'ouvrage de

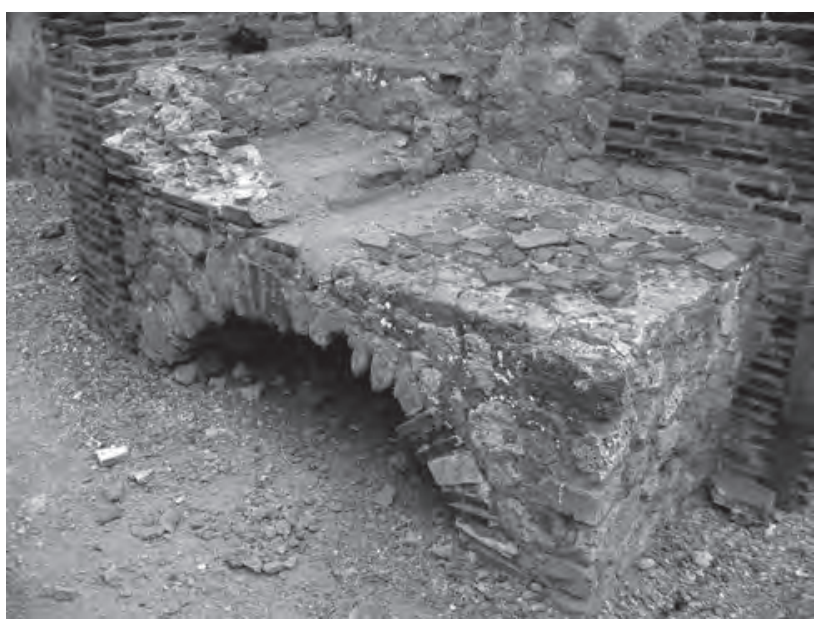

Fig. 38 - Table de cuisson dans l'arrière-boutique du local VII 9, 30-31 à Pompéi. Toute la partie gauche est occupée par les vestiges d'un support de chauffe-eau, probablement en plomb (cliché pris du sud-est).

tables de cuisson. Ainsi, en VII 9, 30-31, une table de cuisson dont la forme et les dimensions sont comparables à celles des autres fourneaux domestiques se trouve dans la pièce immédiatement au sud du local principal, accolée à l'angle nord-est (fig. 38). À son extrémité septentrionale subsiste un quadrilatère maçonné haut de $9 \mathrm{~cm}$, ceint sur trois côtés par un muret haut de $22 \mathrm{~cm}$ et large de $20 \mathrm{~cm}$. Ce dernier ne peut avoir été utilisé que comme support pour une chaudière, vraisemblablement parallélépipédique et en plomb. De la sorte, ce fourneau inclut un chauffe-eau. Une telle disposition réduit le nombre de foyers dans le local, les braises du fourneau pouvant être utilisées pour réchauffer l'eau ${ }^{67}$. Dans la Casa di Nettuno e Anfitrite (V, 6), une canalisation en plomb alimentait le fourneau situé à l'extrémité septentrionale du comptoir, ce qui autorise à restituer la présence d'une chaudière, peut-être placée sur deux moellons

P. Kastenmeier (2007: 60-61 pour la description des fourneaux; 69-90 pour la description de l'usage des cuisines)

${ }^{67}$ Un aménagement similaire, bien que de taille inférieure se situe immédiatement à l'entrée de la boutique VI 10, 1.19. 
disposés de chant (fig. 39) ${ }^{68}$. Bien que l'espace disponible pour préparer des plats cuisinés soit restreint par l'installation de ces chauffe-eau, il reste supérieur à celui des plateformes des $\mathrm{CE} / \mathrm{F}$ installés en extrémité de comptoir ${ }^{69}$. L'insertion de chauffe-eau sur les tables de cuisson paraît constituer un dispositif exceptionnel.

La présence des aménagements de cuisson dans les commerces alimentaires disposant d'un comptoir maçonné est très importante: à Herculanum, au moins 8 de ces boutiques (62\%) - 128 à Pompéi (81\%) - et disposent d'un fourneau ou d'un chauffe-eau, voire des deux ${ }^{70}$. En ce qui concerne les $\mathrm{CE} / \mathrm{F}$, soulignons que seule la présence d'une plateforme autorise à les considérer comme permettant de faire cuire des aliments.

II.1.3 Le stockage des denrées et la fonction des dolia

Au-delà des aspects strictement formels des comptoirs maçonnés, l'insertion de jarres en terre cuite - dolia - en leur sein permet de proposer une fonction de commerces alimentaires pour ces locaux. Il est admis que ces récipients étaient destinés à recevoir des denrées alimentaires. La nature exacte de ces dernières soulève en revanche un débat qui n'est pas dénué d'importance. Selon les chercheurs, du vin, de l'huile ou des aliments en vrac ont pu y être conservés. En considérant l'ensemble de la documentation disponible concernant ces locaux, mais aussi en étudiant les différentes solutions employées pour la conservation des aliments hors de ces commerces, il me semble possible non pas de trancher, mais du moins de proposer une hypothèse raisonnable.

\footnotetext{
${ }^{68}$ Ces moellons sont actuellement écartés de $27 \mathrm{~cm}$, ce qui donne une assise assez importante à la chaudière qui s'y serait trouvée. La justesse de ces dimensions reste discutable, puisqu'il s'agit d'une restauration. La distinction entre le chauffe-eau et les moellons ou murets utilisés pour servir d'appui aux casseroles (Fulvio 1879: 276-277; Salza Prina Ricotti 1980: 242-244; Kastenmeier 2007: 61) ne paraît devoir se faire que sur le critère de distance entre les blocs de support, à comparer avec les dimensions connues des vaisselles de cuisson. Dans le cas de la boutique liée à la Casa di Nettuno e Anfitrite, la présence de la canalisation d'eau sous pression est un indice probant.

${ }^{69}$ La surface disponible sur la table de cuisson du local VII 9, 30-31 est de $1 \mathrm{~m}^{2}$. En VI 10, 1.19, le fourneau occupe
}

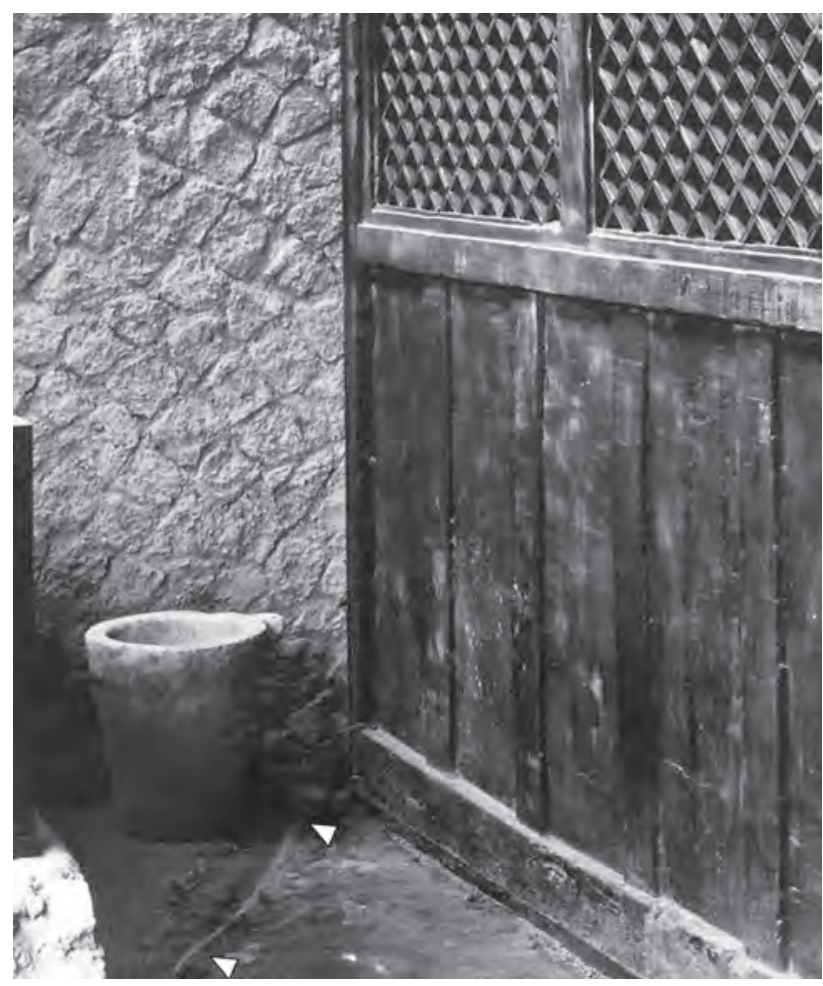

Fig. 39 - Canalisation en plomb visible au moment des fouilles en retrait du comptoir de la boutique située en façade de la Casa di Nettuno e Anfitrite (V, 6). Ce tuyau, provenant du couloir d'entrée devait alimenter un chauffeeau disposé sur le comptoir.

Il convient de souligner tout d'abord certaines lacunes fondamentales de la documentation disponible. J'ai recensé 47 dolia à Herculanum et quelque 375 à Pompéi dans les commerces alimentaires ${ }^{71}$. Une partie d'entre eux n'est plus visible actuellement, parfois en raison d'une absence de restauration: selon les GSE, au moins deux dolia ont été mis au jour

une surface identique, dont $0,7 \mathrm{~m}^{2}$ reste libre pour la cuisson. À titre de comparaison, la surface utile du CE/F de la boutique "d'Asellina» est de $0,38 \mathrm{~m}^{2}$; dans le restaurant «de Sotericus» (I 12, 3), la plateforme s'étend sur 0,3 $\mathrm{m}^{2}$.

${ }^{70}$ Rien ne permet de définir si les locaux III, 6 et V, 21 présentaient ou non ces aménagements destinés à la cuisson. Faute de mieux, j'ai estimé qu'ils en étaient dépourvus.

${ }^{71}$ Ce recensement est un nombre minimal, dressé pour les seuls commerces alimentaires - hors boulangeries. N'ont pas été comptabilisés les dolia en remploi (comme en V, 17 à Herculanum, cf. supra, p. 86), ou ceux utilisés dans les villas et dans les maisons hors de toute structure de vente. 
dans le local Or. II, 13 à Herculanum ${ }^{72}$. Tel que l'on peut l'observer désormais, le comptoir ne présente aucune trace de ces deux jarres. Il n'existe aucune recension complète et encore moins de typologie de ces récipients pour la région ensevelie par le Vésuve. Pourtant, dans un même local, les variations de taille et de forme sont souvent importantes. Les neuf jarres du local VI, 19 sont toutes de forme cylindrique mais leur diamètre varie de 60 à 110 centimètres (fig. 40). À Pompéi, trois de ces jarres sont actuellement visibles dans le local VII 4, 17. Elles ne sont comparables ni par leur forme, ni par leurs dimensions (fig. 41). Dans les commerces alimentaires, ces différences de type ont nécessairement une signification, même sans prendre en compte l'officine de production ${ }^{73}$. De plus, il existe une remarquable différence de taille entre les dolia utilisés dans les villas pour amener le vin à maturation et ceux qui sont insérés dans les comptoirs (fig. 42) $7^{74}$. A priori, rien ne permet de supposer qu'un lien fort existe entre la forme et le contenu. Proposer une hypothèse de contenu dans le cas des commerces alimentaires ne signifie évidemment pas interpréter l'usage des

${ }^{72}$ GSE 1936: " 24 settembre. Si lavora nelle case n. 13 e 14 poste nel $\mathrm{V}$ cardine $2^{\circ}$ Insula orientale. Nella prima è stato sterrato un dolium murato in un banco di vendita. [...] Non si è raccolto nessun oggetto. [...] 22 ottobre. La casa n. 13 è un negozio. Vi sono dei dolium, avanzi murati e la cucina. Quest'ultima è formata da un fornello piccolo ed uno grande. La soglia d'ingresso è di pietra di lava vulcanica. Le pareti sono di opera reticolato. Poco stucco si conserva sulle pareti ed è a fondo rosso. Il pavimento è marcito, ma doveva essere di calcestruzzo. Nessun trovamento ». On ne peut que noter le passage du singulier au pluriel pour caractériser les dolia de ce local. Rien ne permet de déterminer si ce sont seulement deux dolia ou plus qui ont été mis au jour.

${ }^{73}$ Le Corpus recense 21 estampilles lues sur les dolia pompéiens (CIL X, 8047), qui ne proviennent toutefois pas tous du périmètre urbain.

${ }^{74}$ Les dolia dont les dimensions sont publiées sont peu nombreux: mesures précises pour 10 des 18 jarres mises au jour dans la villa Regina de Boscoreale (De Caro 1994: fig. I p. 68); dimensions moyennes des 72 dolia sur les 84 mis au jour dans la villa de la Pisanella à Boscoreale (Pasqui 1897 : 486); hauteur moyenne estimable (Amodio 1873) pour les dolia provenant de la villa Musigno à Scafati (BullArchNap 7, 1859: 81), déplacés après la fouille dans les locaux VII 4, 13 et 14 (Fiorelli 1875: 214; NSc 1892: 122). Bien que conscient des implications d'approximation impliquées par la non prise en compte des volumes, j'ai été contraint de comptabiliser chaque dolium comme une unité fixe sans tenir compte des fréquentes variations observées. dolia en toute circonstance.

La question de la porosité de ces récipients est de première importance. Dans sa synthèse

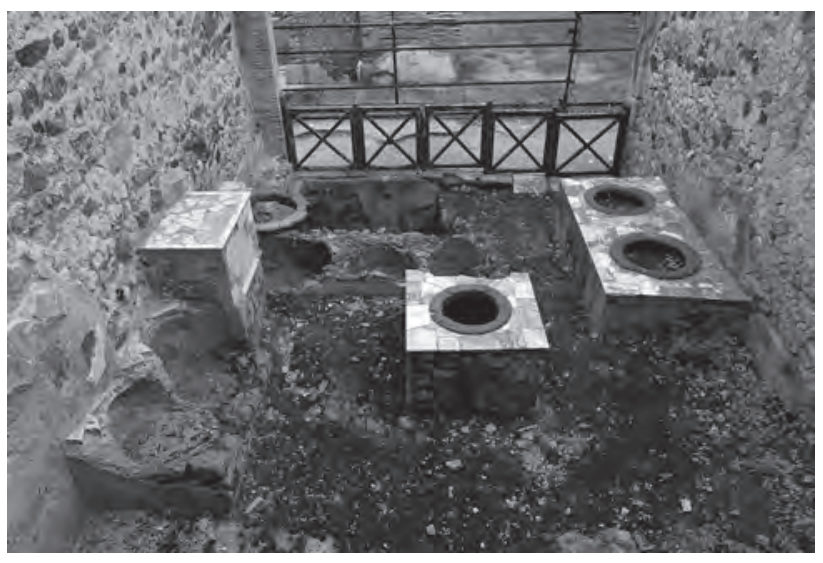

Fig. 40 - Commerce alimentaire VI, 19. Sept dolia sont encastrés dans le comptoir principal, deux dans un bras annexe. (cliché pris du sud).

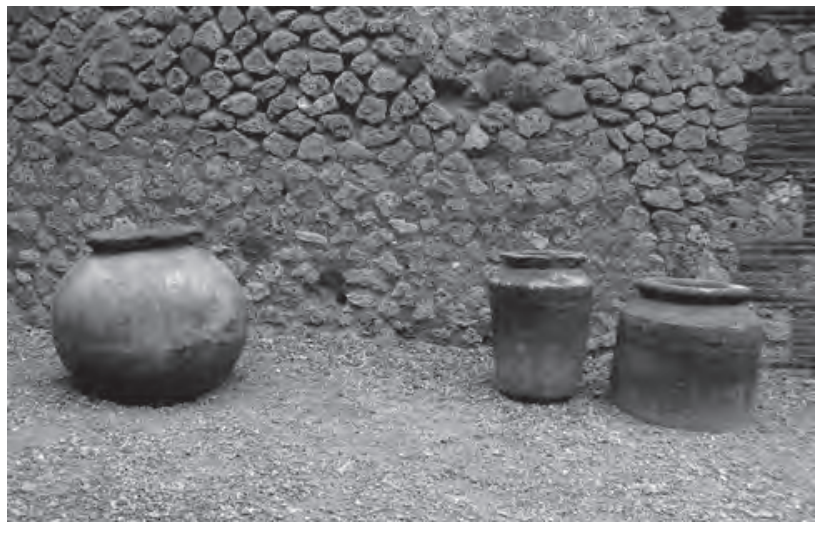

Fig. 41 - Dolia dans le probable commerce alimentaire VII 4, 17 (cliché pris de l'ouest).

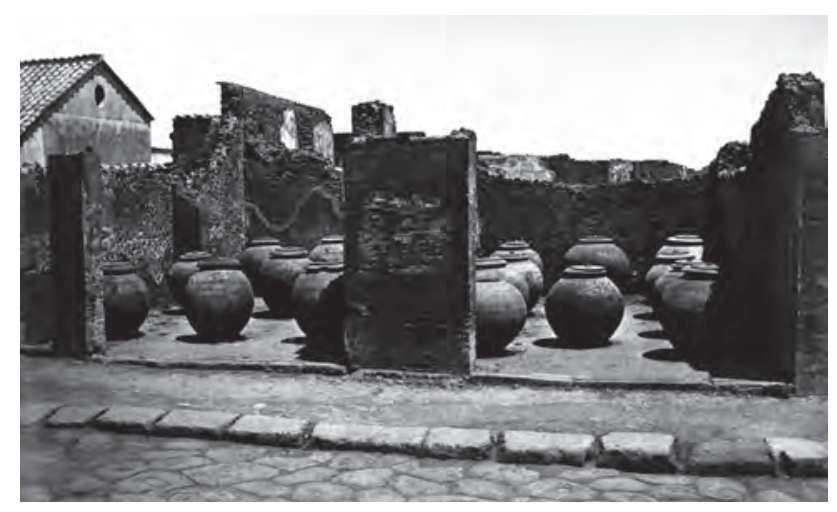

Fig. 42 - Dolia provenant de la villa Musigno à Scafati, temporairement stockés dans les locaux VII 4, 13 et 14. 
pionnière et érudite sur le vin dans l'Antiquité, R. Billiard souligne cette caractéristique des dolia en indiquant que sans poissage de leur surface intérieure, il aurait été impossible qu'ils conservassent leur contenu liquide ${ }^{75}$. Les pertes ont été démontrées par une expérience qu'il a réalisée, avec et sans poissage d'une amphore ${ }^{76}$. Largement attestée dans la littérature agronomique antique, cette pratique paraît avoir été fortement répandue pour la maturation et la conservation du $\operatorname{vin}^{77}$. Vraisemblablement à partir de ces attestations littéraires - pourtant non citées -, J. Packer a considéré que l'ensemble des dolia insérés dans les comptoirs maçonnés étaient visiblement dépourvus d'un revêtement de poix et donc impropres au stockage de liquide: il en a conclu à une utilisation exclusive pour contenir des denrées solides ${ }^{78}$. En dépit de propositions de solutions alternatives au stockage du vin en dolia sans poissage, cette interprétation a été acceptée depuis ${ }^{79}$. Pourtant, l'absence de trace de poix dans ces dolia ne saurait être un élément déterminant: les jarres scellées découvertes des villas orientées vers une production vinicole - donc contenant du vin mis à vieillir -, ne présentent pas de marques visibles du poissage ${ }^{80}$. En effet, seul le noircissement du fond, dû à l'allumage d'un feu à l'intérieur pour étaler la poix, serait observable à l'œil $\mathrm{nu}^{81}$. La seule alternative serait d'effectuer des analyses

\footnotetext{
${ }^{75}$ "Les vaisseaux de terre, quels qu'ils fussent, n'étaient point employés tout bruts et tels qu'ils sortaient des mains du potier. Mal cuits à cause de leurs grandes dimensions, n'ayant aucune couleur vernissée, leur porositéles eût rendus impropres à tenir un liquide quelconque, le vin surtout qui, à cause de sa nature alcoolique, était plus volatil. Il fallait donc avant de s'en servir et pour leur donner l'imperméabilité qui leur faisait défaut, leur faire subir une préparation, c'était le poissage, picatio [...]»(Billiard 1913: 474).

${ }^{76}$ Billiard 1913: 474-475.

${ }^{77}$ Parmi les auteurs latins recommandant cette pratique, cf. Cat., Agr., 23, 1 et 69, 1; Colum., 12, 18, 5.

${ }^{78}$ Packer 1978: 47-48.

${ }^{79} \mathrm{~S}$. Ellis (2004 a: 47) a proposé l'utilisation d'une outre ou d'un second récipient, insérés dans le dolium. Aucune de ces deux propositions n'est attestée archéologiquement ou dans les textes.

${ }^{80}$ Stefani 2006: 157-160.

${ }^{81}$ Brun 2001: 86.

${ }^{82}$ Cf. infra n. 126.

${ }^{83}$ Dans divers objets provenant de Pompéi, des restes d'huile ont été découverts. Toutefois, l'identification de cette substance a toujours nécessité la réalisation d'analyses.
}

aussi complexes que coûteuses ${ }^{82}$. En dépit de la validité théorique des arguments soulevés par J. Packer, la présence ou l'absence de poix dans ces récipients ne peut pas être déterminée. Il est donc impossible de prendre en compte ces remarques pour la détermination du contenu des dolia.

L'analyse directe des matières et objets mis au jour dans ces jarres ne permet pas de préciser leur fonction. En effet, aucune trace de matière organique n'a été découverte dans les dolia des commerces d'Herculanum ou de Pompéi, qu'il s'agisse de vin, d'huile ou d'aliments en $\operatorname{vrac}^{83}$. L'identification, dans les villas, des dolia utilisés comme conteneurs destinés à la maturation du vin s'est toujours faite par déduction à partir des aménagements de production: la présence d'un pressoir à raisin indiquant fort justement que les dolia, ou au moins une partie d'entre eux, ont servi à la fermentation vinaire. Au sein de ces villas, quelques-uns des récipients ont été retrouvés contenant de la farine, des pignes, des olives ou du grain, en plus de ceux destinés au $v^{8}{ }^{84}$. Enfin, en dépit de la présence - exceptionnelle - de vin dans certains récipients tels que des amphores mais également une onochoe, la rareté de toute trace similaire dans les dolia montre à quel point les conditions de conservation n'ont pas été uniformes pendant et après l'éruption de $79^{85}$. L'étude des représentations

Les quantités mises au jour sont faibles et l'huile apparaît comme fréquemment contenue dans des récipients en verre (cf. Borgongino 2006: cat. $\mathrm{n}^{\circ} 503-520$, p. 148-151). Une "substance grasse » a été mise au jour dans deux dolia de la villa de la contrada Iossa à Scafati (NSc 1892: 122).

${ }^{84}$ Stefani 2006: 159-160. Je signalerai cependant que dans la villa de la contrada Iossa à Scafati - fouillée seulement en partie -, A. Sogliano (NSc 1892: 122) ne mentionne pas de pressoir; douze des dix-sept dolia ont été trouvés vides.

${ }^{85}$ Trois exemples de restes de vin dans des amphores ont été répertoriés par M. Borgongino (2006: cat. n 521523, p. 151), deux provenant d'Herculanum, un de Pompéi. Il convient d'ajouter la matière carbonisée à structure spongieuse figée observée à l'intérieur et sur une partie de la panse de l'oenochoe (Inv. $n^{\circ}$ E703=75980) mise au jour dans la pièce 9 associée à la boutique IV, 17. Ce résidu pourrait être du vin. Enfin, S. De Caro (1994: 68) signale de traces résiduelles de vin dans trois des dolia $\left(n^{\circ} 9,14\right.$ et 18$)$ de la villa Regina de Boscoreale. La rareté de telles attestations dans les dolia pourrait être due aux conditions de fouille des autres villas. 
iconographiques et des textes permet d'apporter des précisions quant à l'utilisation des dolia comme conteneurs à vin ${ }^{86}$. Dans les textes, les dolia sont plus fréquemment mentionnés dans un contexte de confection du vin que de vente en boutique $^{87}$. Si plusieurs représentations iconographiques italiennes montrent des dolia en cours d'utilisation, une seule pourrait renvoyer à de la vente de vin en vrac ${ }^{88}$; les autres sont trop imprécises ou lacunaires pour permettre une détermination ${ }^{89}$. Aucune de ces représentations iconographiques ne montre de façon assurée un dolium utilisé pour contenir des denrées alimentaires solides; aucun de ces exemples n'autorise une interprétation définitive quant au liquide éventuellement contenu dans les jarres: ni l'huile ni le vin ne peuvent être exclus. Ces remarques semblent difficilement conciliables avec les attestations littéraires qui ne mentionnent guère l'usage du dolium dans le commerce de proximité du vin: le seul témoignage concernant sa vente en vrac, extraite du réquisitoire de Cicéron contre Pison, associe le vin non à des dolia mais à la cupa, qu'il faudrait comprendre comme un tonneau et non comme une cuve ${ }^{90}$.

${ }^{86} \mathrm{Il}$ ne saurait être question de renvoyer dans le détail à l'ensemble des occurrences de dolium dans la littérature latine, en particulier agronomique; cf. $T L L$, s.v.

${ }^{87}$ Cependant, dans une glose sur un passage de Neratius concernant l'instrumentum des tabernae cauponiae, Paul évoque la présence de dolia. Cf. Paul., ad Sab., 4 (Dig. 33, 7, 13 pr.). Le contenu des jarres ne saurait être déterminé: les activités du négoce mentionné renvoient tant à la restauration qu'au débit de vin.

${ }^{88} \mathrm{La}$ brique taillée mentionnant Lucifer Aquatarius provenant de l'Isola Sacra (Museo Ostiense, Inv. n 5858) montre une boutique dans laquelle sont disposées des cruches et des conteneurs, probables représentations d'amphores de type "gauloise 4 ». Il ne faudrait cependant pas considérer que le cognomen d'Aquatarius renvoie à un vendeur d'eau, fonction improbable pour une boutique permanente dans une ville bénéficiant d'un raccord à l'eau sous pression. Cf. Floriani Squarciapino 1958: cat. $n^{\circ} 9$ p. 192-193; Zimmer 1982: cat. $n^{\circ} 176$ p. 218.

89 Une seconde brique, provenant d'Ostie est trop lacunaire pour se prêter à l'interprétation. Le relief est situé sur la façade du cassegiato di Annio (III, XIV, 4). Cf. Floriani Squarciapino 1958: cat. n 16 p. 196-197; Zimmer 1982: cat. $n^{\circ} 174$ p. 217 . Un relief funéraire provenant de la collection Nanni à Preturo montre une série de quatre dolia disposés en équerre à même le sol, sans figuration de la maçonnerie ayant pu les grouper - ce qui peut être une convention iconographique utilisée pour laisser visibles les dolia et faciliter ainsi la compréhension de la scène repré-

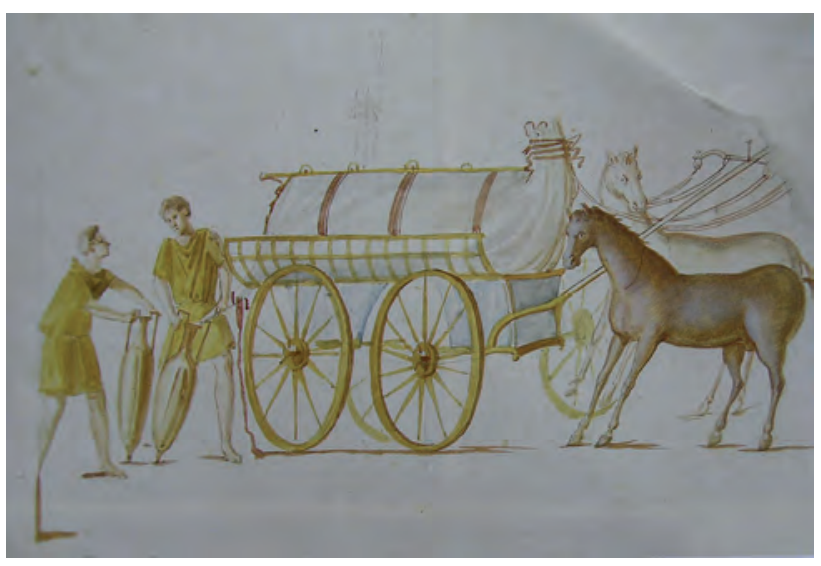

Fig. 43 - Reproduction par G. Marsigli d'une fresque disparue, découverte dans la pièce annexe du local VI 10, 19.

$\mathrm{Si}$, à Herculanum et Pompéi, les attestations de vin dans les dolia des locaux commerciaux sont absentes - et rarissimes dans les tonneaux de stockage ${ }^{91}-$, la fresque provenant du local VI 10, 1.19 constitue un témoignage intéressant sur le devenir du vin après sa sortie du chai (fig. 43). Elle dépeint un chariot à quatre

sentée. Si le boutiquier tient un objet à la main, les mutilations de l'épitaphe empêchent toute détermination du négoce représenté. Cf. Studi Miscellanei 10, 1966, pl. XXVI, 63; Zimmer 1982: cat. n 173 p. 216-217; Segenni 1985: n 11 p. 200-201, pl. XLVI, 2.

${ }_{90}$ Cic., Pis., 67: [...] pistor domi nullus, nulla cella; panis et vinum a propola atque de cupa [...]. "[...] Chez lui pas de boulanger, pas de cave; le pain et le vin viennent du revendeur et de la cupa $[\ldots]$ ».

L'interprétation de ce passage comme témoin de la vente de vin en vrac est due à A. Tchernia $(1986$ : 33 ; 2000: 207). Le sens de cupa comme cuve paraît assez improbable: il contredirait l'idée que Pison ne produit pas son propre vin. Dans son étude sur le tonneau, E. Marlière (2002 : 2728) estime, sans prendre en compte ce passage, que les premières mentions du tonneau sont liées à la guerre des Gaules. Cette apparition plus précoce du tonneau en Italie semble également être confirmée par un passage de Varron (de vita populi romani, 1) rapporté par Nonius Marcellus $(15,544 M)$. Des représentations de tonneau sur stèles funéraires existent dès le $\mathrm{I}^{\mathrm{er}} \mathrm{s}$. de notre ère, dans le cadre du transport du vin: le foudre est monté sur un char. Cf. en particulier celle de Q. Veiquasius Optatus conservée au Museo di Antichità de Turin (Inv. 450, cf. Mercando - Paci 1998: cat. $\mathrm{n}^{\circ} 45$, pl. LXIV)

${ }^{91}$ Concernant les faibles attestations de vin dans les dolia, cf. supra, n. 85. Un tonneau a été découvert en I 7, 5 : "[...] Avanzi di un botticello cilindrico di legno, alto m. 0,20 di m. 0,33 circa di diametro. Era fatto di tante doghe tratte- 


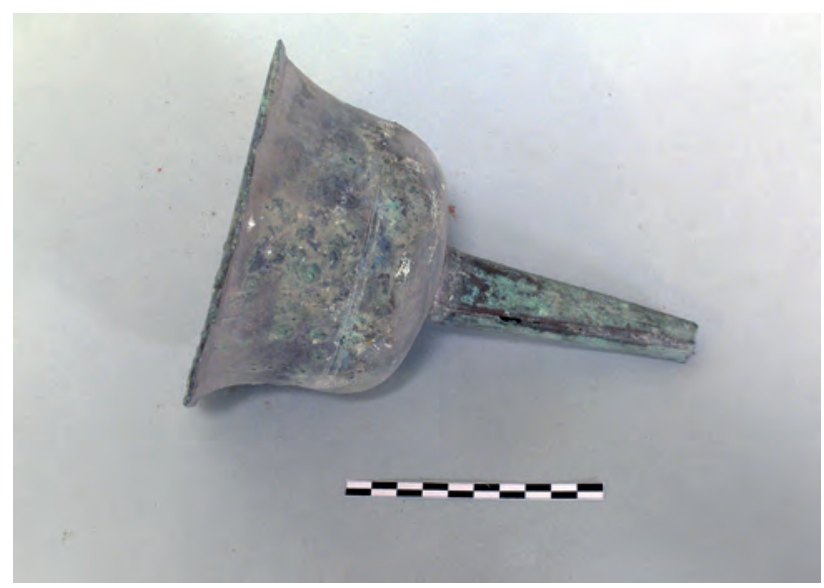

Fig. 44 - Entonnoir en bronze provenant de la boutique dite "d'Asellina » (Pompéi, IX 11, 2), découvert sur le comptoir, en avant du chauffe-eau, associé à un aménagement en bois.

roues sur lequel est disposée un culleus, outre en peau de bœuf aux proportions imposantes ${ }^{92}$. Deux personnages stationnent à l'arrière de ce véhicule, chacun muni d'une amphore. Celui qui est situé le plus près du chariot paraît la remplir avec le contenu de l'outre. Cette fresque ne montre pas le remplissage des cruches à l'intérieur du local, ce qui empêche de déterminer si ces amphores remplies de vin en vrac ont été transvasées dans des dolia ou non. Tout au plus est-il possible de se référer à la frise de l'oecus q de la Casa dei Vettii, où deux Amours tirent

nute sotto e sopra da due cerchioni esterni di ferro a nastro, e di due fondi certamente anch'essi di doghe di legno: nel bel mezzo dell'altezza v'è un cannello di bronzo esternamente munito di otturatore circolare a cerniera, aprendo e chiudendo il quale vuotavasi o trattenevasi il liquido contenuto nel recipiente» (NSc 1912: 67).

92 Sur le vocabulaire et l'utilisation des outres, cf. Marlière 2002: 13-25, part. 22-23.

${ }^{93}$ Les entonnoirs sont conçus à partir de deux feuilles de bronze. Leur tuyau est tronconique, long et fin. Ils correspondent à la catégorie $\mathrm{R}$ de la typologie de $\mathrm{S}$. Tassinari (1993: 88-89).

${ }^{94}$ Ces locaux sont les suivants:

Boutique dite "d'Asellina» (IX 11, 2), NSc 1912: 117. «Parimente sul bancone, però dinanzi al rialzo che esso forma sul fornello, vennero trovati gli avanzi di una specie di cassettina di legno, la quale doveva essere munita di un foro nel mezzo, in cui veniva fissato il tubo rastremato di un imbuto [di bronzo (Inv. ${ }^{\circ}$ P1151)].

«Caupona» dite «de Q. Poppaeus Eros» (I 10, 13), GSP 1932: «7 luglio. [...] Si è portato a compimento lo scavo du vin directement depuis une amphore pour le faire goûter. Cette vraisemblable utilisation préférentielle des amphores pour le stockage du vin peut se déduire également des différents entonnoirs mis au jour dans certains de ces commerces alimentaires (fig. 44) ${ }^{93}$. En effet, si le vin avait été conservé dans les dolia, il aurait été nécessaire que des louches fussent à disposition. Dans les trois locaux intégralement fouillés sur les quatre où de tels entonnoirs ont été mis au jour, des amphores ont également été découvertes $^{94}$. Celui situé en VI 16, 32-33 est d'autant plus intéressant que son comptoir est dépourvu de dolium encastré et que le dispositif de chauffage est également détaché, et a été installé dans l'atrium. Les deux entonnoirs ont été mis au jour dans une pièce latérale, dans une armoire contenant également divers objets en bronze utilisés pour le service, dont trois brocs, ainsi qu'un chaudron. Au total, six amphores ont été découvertes, dont deux dans le local commercial $^{95}$. À Herculanum, aucun entonnoir ne paraît avoir été découvert. En revanche, la présence d'amphores vinaires soit dans le local principal, soit dans les pièces annexes rend l'utilisation des dolia comme conteneurs à vin assez ambiguë. Ainsi, une série d'amphores vinaires provenant de l'Égée a été mise au jour dans la pièce $7 \mathrm{du}$ commerce IV, 15-16 ${ }^{96}$. Le remplissage des dolia de la pièce principale avec du vin ne ferait-il pas double emploi avec ces amphores?

della bottega all'angolo sud est dell'isola [...]. A pochi centimetri (10 a 15) dal piano del banco nel lapillo integro si è raccolto: [...] Bronzo ([Inv. $\left.\left.{ }^{\circ} \mathrm{P}\right] 5055\right)$ Un imbuto a campana con l'orlo internamente rigato ed avente il tubo d'emissione staccato. [...] Nell'interno del banco si sono lasciati in situ due anfore di terracotta [...]». Cf. NSc 1934: 340-341.

Boutique «de Stabilio Oenoclion» (I 19, 1-2), GSP 1933: "19 giugno. [...] Si è messo in luce un magnifico banco di vendita [...]. L'esplorazione condotta con speciale oculatezza ci ha restituito il banco cosparso di un notevole gruppo di oggetti, qui sottoelencati [...]. BRonzo ([Inv. $\left.\left.\mathrm{n}^{\circ} \mathrm{P}\right] 5636\right)$ Imbuto a recipiente emisferico col fondo staccato, cannula conica laminare accartocciata staccata $[\ldots]$. Ce local n'a été fouillé qu'en devanture, ce qui empêche de déterminer la présence d'amphores. Cf. NSc 1933:320321.

Boutique VI 16, 32-33: cf. note suivante.

${ }^{95}$ NSc 1908: 287-298.

${ }^{96}$ GSE 1932: «25 gennaio. [...] Nello stesso ambiente [n. 7 della casa n. 6 sul $4^{\circ}$ cardine lato ovest] alcuni frammenti di anfora portano la seguente dicitura in pittura 
Outre ces différentes attestations de l'utilisation préférentielle des amphores, d'autres éléments incitent à reconsidérer l'emploi des dolia des commerces alimentaires pour le stockage du vin. Parmi les rares objets mis au jour dans ces jarres, des pièces de monnaie sont fréquemment mentionnées: à Herculanum, dans trois des commerces alimentaires, de telles découvertes ont eu lieu, ce qui rend difficile l'hypothèse de leur transport par le flux pyroclastique $^{97}$. À Pompéi, des trésors monétaires ont été mis au jour dans au moins trois commerces de ce type. Deux d'entre eux sont d'une importance toute relative ${ }^{98}$. Dans le dolium central de la caupona di L. Vetutius Placidus (I 8, 8), 1611 pièces de bronze avaient été déposées ${ }^{99}$. La valeur de ce dépôt - environ 585 sesterces - paraît trop importante pour constituer les recettes de la boutique, d'autant plus que seules des pièces

rossa: ЕПI [CIL IV, 10878]». Cette inscription ne se rencontre à Pompéi et Herculanum que sur des amphores de type Schoene XIII = Agora 198, ayant contenu du vin et de provenance égéenne (cf. Panella 1986: n. 14 p. 618). Sur les autres amphores de cette boutique, conservées à l'étage, cf. infra n. 208.

${ }^{97}$ Ces découvertes de monnaies ont eu lieu en IV, 15-16 (GSE 1932: « 29 febbraio. Nello svuotare i dolium che sono murati nel termopolio numero 6 sul $4^{\circ}$ cardine lato ovest, nel fondo del terzo dolium a cominciare dall'estremità sud si sono raccolte due monete di bronzo: [Inv. $\mathrm{n}^{\circ}$ E780-781= 76057-76058]. Nel quarto dolium anche è stato raccolto: [Description des monnaies Inv. $\left.\left.\mathrm{n}^{\circ} \mathrm{E} 782=76059\right] »\right)$, en Or. II, 6 (GSE 1933: «13 settembre. [...] Frammenti di cinque dolii sono in sito, di misure diverse. Nel secondo dolio sul fondo è stato raccolto. [Description de la monnaie Inv. $\left.\left.\mathrm{n}^{\circ} \mathrm{E} 1135=76412\right] »\right)$ et en VI, 19 (GSE 1961: «25 settembre. [...] Durante la rimozione dei frammenti di dolium restaurabili tra il materiale di risulta è stato rinvenuto [Description de 17 monnaies Inv. n E2461=77758]»). Dans ce dernier cas, la mention, en plus de ces 17 monnaies, de deux crapaudines en bronze (Inv. $n^{\circ}$ E2462=77759) et d'un urceus (Inv. $n^{\circ}$ E2463=77759), ainsi que les conditions de fouille laissent un doute quant au stockage de ces pièces dans le fond d'un des dolia. En revanche dans les deux autres exemples, le dépôt volontaire de ces pièces dans les jarres est hautement probable. À tout le moins, il est impossible que ces pièces soient tombées d'une étagère surplombant les comptoirs.

98 Vingt-deux pièces, pour moitié de bronze, pour moitié d'argent ont été découvertes dans le local VII 4, 4, cf. NSc 1886: 132-133. Aucune précision n'est donnée quant à la provenance exacte de ce trésor dans le local commercial. Dans la boutique "d'Asellina» (IX 11, 2), huit pièces ont été découvertes déposées dans deux des dolia ; 34 de bronze sont présentes, celles d'argent ayant probablement été emportées ${ }^{100}$ : les $25 \mathrm{~kg}$ de monnaies de bronze ont pu être cachées dans ce local faute de pouvoir les emporter commodément. En revanche, trois autres dépôts plus petit, découverts dans trois dolia distincts du comptoir, pourraient constituer la caisse du commerçant ${ }^{101}$. Ces monnaies, qu'elles correspondent à la recette de l'ultime journée, à un fond de caisse ou à un dépôt de thésaurisation, s'accommodent plutôt mal avec la présence de liquide, vin ou huile, dans les jarres où elles sont contenues. Leur manipulation semblerait plus aisée avec des denrées solides.

Enfin, du point de vue de la conservation du vin, les dolia ne constituent pas la meilleure des solutions. Lorsque, dans les villas, ils servent à la vinification, ils sont dotés d'un couvercle de façon à limiter les échanges avec l'air. En céra-

autres proviennent du comptoir (27 pièces) et des étagères (7 pièces); cf. NSc 1912: 117-118 et 120.

${ }^{99}$ GSP 1939: « 27 maggio. Si procede al ripulimento della parte interna del banco di vendita del termopolio $\mathrm{n}^{\circ} 8$ [...]. Nel dolio centrale del braccio presso il vano nel togliere il lapillo penetratovi, si è rinvenuto un numeroso gruppo di monete del peso di kg. 25 ; così distinte: BRONZO (Inv. [n ${ }^{\circ} \mathrm{P}$ ]6942) $\mathrm{N}^{\circ} 374$ monete di grande modulo in buono stato di conservazione. Bronzo (Inv. [n $\left.{ }^{\circ} \mathrm{P}\right] 6943$ ) $\mathrm{N}^{\circ} 1237$ monete di medio modulo in maggioranza concrezionate». Ce dépôt est conservé au MANN. Il est apparu incomplet lors de sa récente étude (Castello - Oliviero 1997: 94-95): 223 monnaies sont reportées manquantes.

${ }^{100} \mathrm{Cf}$. Andreau 2008: 214. Une première remarque allant dans ce sens avait déjà été faite par R. Vitale (Castiglione Morelli - Vitale 1989: 220). Sur la valeur du dépôt, cf. Castiello - Oliviero 1997: 95. V. Castiglione Morelli (Vitale 1989: 196) et A. d'Ambrosio (1996: 112) considéraient qu'il s'agissait de la recette des dernières journées.

${ }^{101}$ GSP 1939: " 30 maggio. Seguitando il ripulimento dei dolii nel banco, nel dolio d'angolo NE si è rinvenuto: Bronzo (Inv. [ ${ }^{\circ} \mathrm{P}$ ]6952) Gruppo di $\mathrm{n}^{\circ} 35$ monete concrezionate di grande e medio modulo, tutte dalle impronte irriconoscibili [...].

31 maggio. In giornata è stato ultimato lo svuotamento del lapillo dai doli di terracotta murati nel banco di vendita del termopolio $n^{\circ} 8$. Nel secondo dolio a contare da $\mathrm{N}$, del braccio interno più lungo, si è rinvenuto: Bronzo (Inv. [n P]6956) Gruppo di ${ }^{\circ} 10$ monete di medio modulo concrezionate. Terracotta [SNI] Due vasettini - Un oleare - una lucerna monolychne ordinaria [...].

10-15 giugno. [...] Al disotto dei dolî sprofondati del lato frontale siè rinvenuto: Bronzo (Inv. 6986) Gruppo di $\mathrm{n}^{\circ} 22$ monete di bronzo delle quali 17 di medio modulo e 5 di piccolo modulo, tutte erose e irriconoscibili. ». 
mique ou plus rarement en pierre, ces couvercles sont des disques d'un diamètre variant de 40 à $60 \mathrm{~cm}$ environ, munis d'une poignée de préhension sur leur face supérieure et parfois de trois ou quatre ergots destinés à empêcher leur déplacement latéral une fois positionnés sur des dolia. Ils sont rarement mentionnés dans les commerces alimentaires ${ }^{102}$. En dépit de ces rares attestations, même en considérant que tous les dolia mis au jour à Herculanum et Pompéi ont bénéficié d'un tel couvercle - disparu faute d'enregistrement - ces jarres ne sont que peu propices à la conservation du vin. Pour la vinification, il est nécessaire que le moût fermente en milieu anaérobie. L'isolation entre le raisin et le milieu extérieur est obtenue par le scellement du couvercle sur le dolium ${ }^{103}$. En l'absence d'une fermeture étanche, le vin se dégrade: la fermentation malolactique tend à le changer en vinaigre dans un processus aérobie ${ }^{104}$. À moins de supposer une consommation très importante de cette boisson, qui permettrait une rotation rapide du contenu des dolia, ces récipients ne sont guère adaptés au stockage du vin dans le dernier maillon de la chaîne de consommation.

Les différents arguments avancés permettent à tout le moins de douter du stockage du vin dans ces jarres. Force est d'admettre que les arguments positifs en faveur du stockage de denrées solides sont peu nombreux ${ }^{105}$. Comme cela a déjà été évoqué, les découvertes de céréales dans des dolia indiquées par A. Maiuri pour la

${ }^{102}$ Dans le local I 8, 8 de Pompéi, des fragments d'un disque en marbre qui pourrait avoir servi de couvercle ont été trouvés dans l'une des jarres, cf. GSP 1939: «29 maggio. [... $] \mathrm{Nel} \mathrm{I}^{\circ}$ dolio, da occidente, del braccio frontale si è recuperato un tondo di marmo grigio in frammenti, restaurabili, che risulta del diametro di metri 0,57 ». À Herculanum, si aucun de ces couvercles n'est documenté dans les journaux de fouilles, plusieurs exemplaires sont visibles sur le site, exposés ou remisés dans des espaces sans lien évident avec leur provenance originelle qui reste indéterminée.

${ }^{103}$ Cette observation a été faite dans le chai de la villa de la Pisanella à Boscoreale: "Sulla bocca del dolio riposava il coperchio piano, ansato sopra, e stuccato in giro con cemento » (Pasqui 1897: 486).

${ }^{104}$ Selon E. Marlière (2002: 188), le problème est le même avec les tonneaux qui sont adaptés au transport, mais pas assez étanches pour permettre un bon vieillissement.

${ }^{105}$ Pour les attestations issues des villas, une recension a été dressée par G. Stefani (2006: 157-160).
Casa di Nettuno e Anfitrite (V, 6) sont erronées ${ }^{106}$. Toutefois, la boutique IV, 17 offre un exemple pertinent ${ }^{107}$. Pour bien en cerner la portée, il faut prendre en compte l'ensemble de la Casa del priapo (IV, 17-18) (fig. 45, a). Construite selon un plan centré sur un puits de lumière tétrastyle - dont l'entrecolonnement est fermé par un muret -, elle peut être divisée en deux secteurs principaux. Le premier correspond aux pièces 1 à 8 qui s'ouvrent sur la cour B. Bien que de surfaces différentes, l'absence de communication de ces pièces entre elles - selon un plan qui se répète partiellement à l'étage - semble être un indice suffisant pour proposer que cette maison ait servi d'hôtel, recevant des hôtes payants dans ces chambres dont l'état d'achèvement au moment de l'éruption est incertain ${ }^{108}$. Le second secteur, constitué des pièces 9,10 , a et de la boutique IV, 17 constituerait un complément à cette probable activité hôtelière: un service de restauration, ouvert tant à une clientèle de passage sur le cardo IV - autour du comptoir et dans la salle a - qu'aux hôtes y séjournant, dans la pièce 10. Dans la boutique, qui s'ouvre sur le cardo IV, une table de cuisson et un dolium globulaire partiellement enterré sont disposés à l'entrée, sur la droite. Sur la gauche, un comptoir maçonné simple se développe sur la moitié de la largeur du local. Selon les journaux de fouilles, les seuls objets découverts dans cette boutique sont une monnaie, un broc en bronze et un nombre indéterminé d'amphores, dont

${ }^{106}$ Cf. supra, p. 22-23.

${ }^{107}$ Contra Stefani 2006: 160.

${ }^{108}$ Les informations concernant les pièces 1 à 8 ne sont constituées que par la description finale de la maison une fois la fouille achevée (GSE 1932: 12 marzo), ce qui empêche de développer l'interprétation de ce secteur "hôtelier » audelà de la seule remarque planimétrique. Un seul objet est signalé pour cette partie de la maison, un mortier en marbre (Inv. $n^{\circ}$ E726=76003), mis au jour dans la pièce 3, à l'entrée d'un tunnel du XVIII ${ }^{\mathrm{e}}$ siècle (GSE 1932: 26 gennaio). En ce qui concerne l'état d'achèvement de cette maison, outre sa création tardive - après le second séisme, cf. infra, p. 309 311 - l'absence dans toutes les pièces ou peu s'en faut d'un revêtement autre que blanc pourrait laisser supposer des travaux encore en cours. Cette situation expliquerait l'absence de tout objet dans le secteur "hôtelier». En revanche, la boutique était en fonctionnement au moment de l'éruption. 


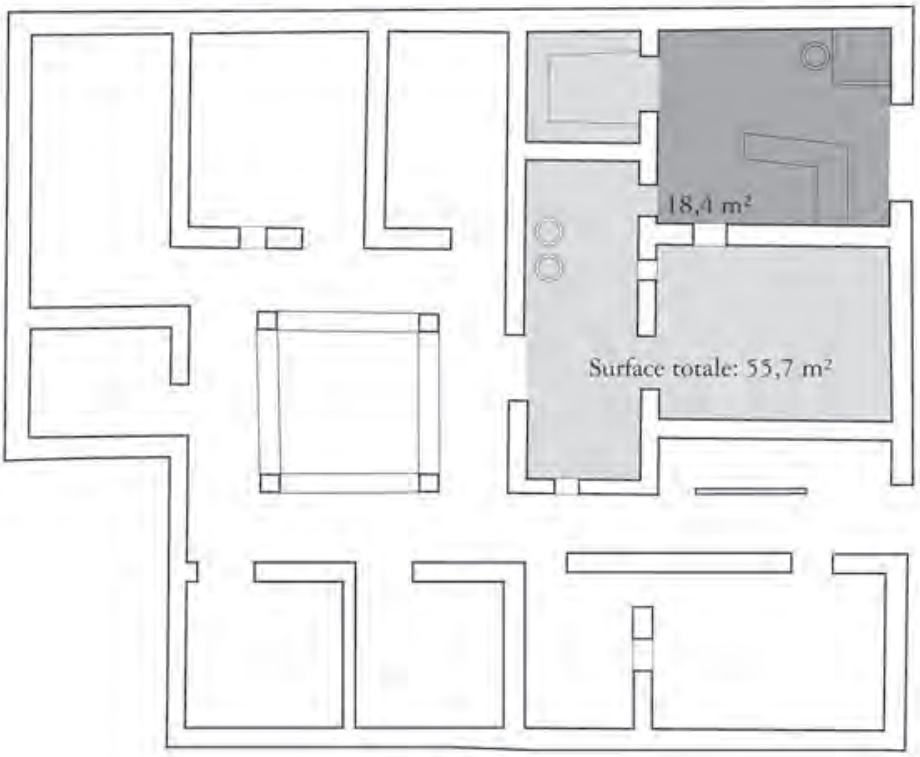

a) IV, 17-18
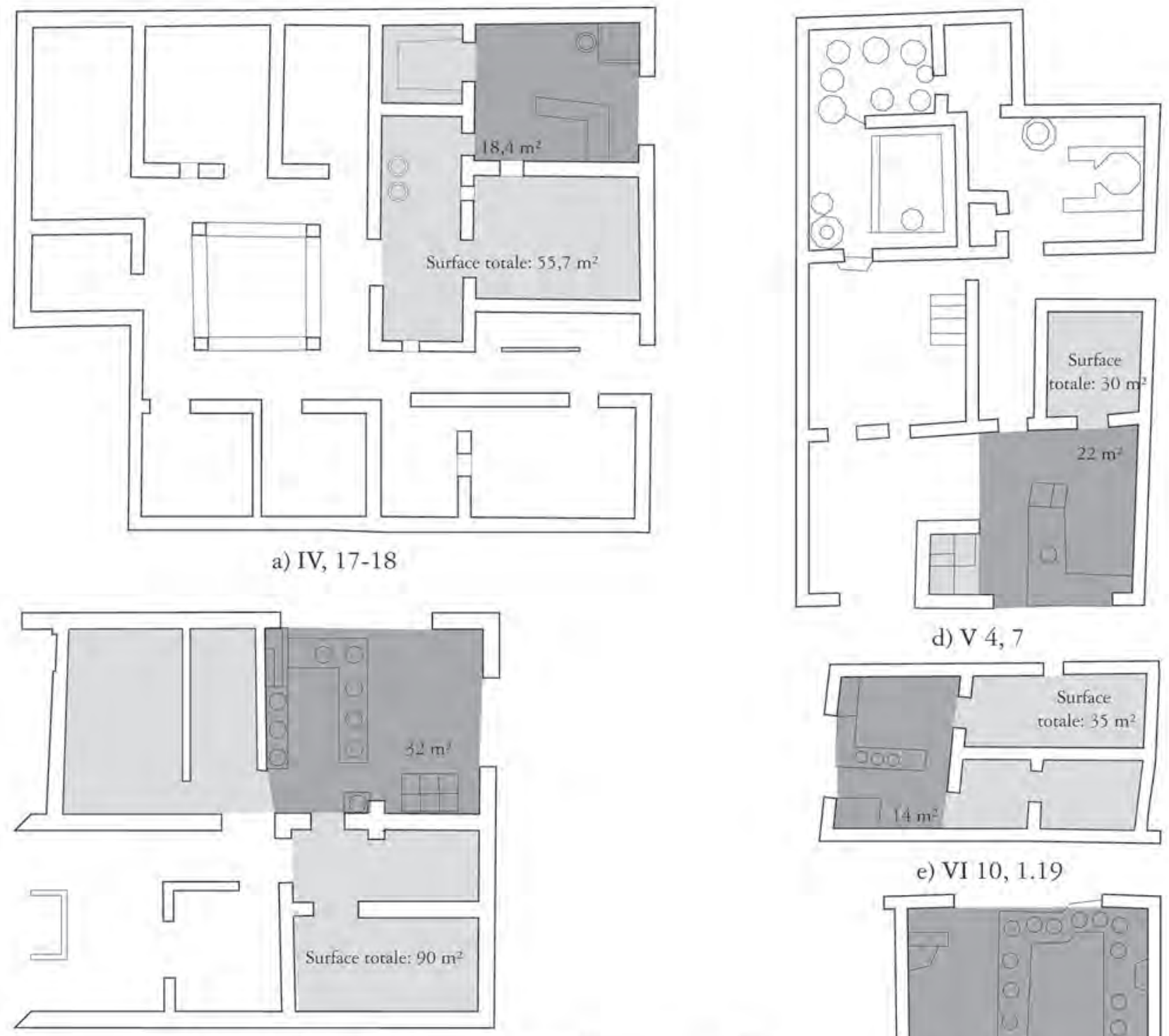

d) V 4, 7

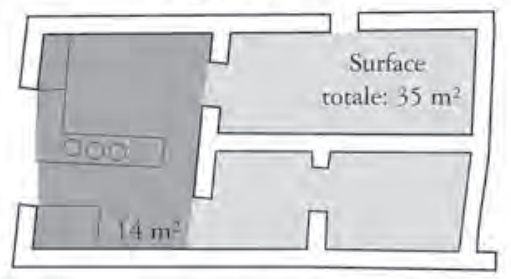

e) VI $10,1.19$

b) IV, $15-16$
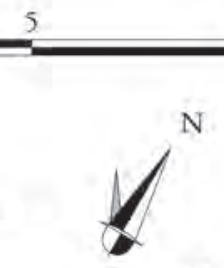

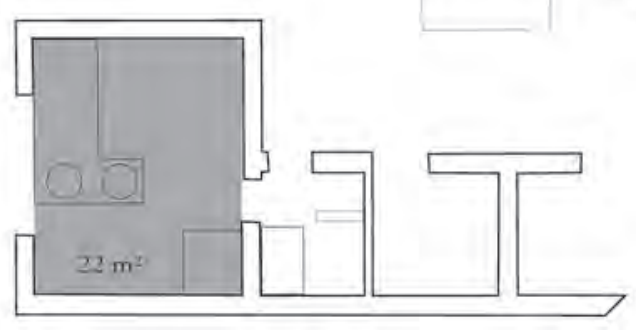

c) V, 6
Herculanum

Pompéi

N
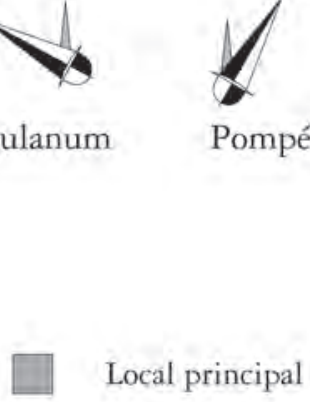

$\square \quad$ Pièce(s) annexe(s)

Fig. 45 - Comparaison entre les commerces alimentaires d'Herculanum et de Pompéi. Les pièces annexes comprennent les espaces d'accueil de la clientèle et de stockage (échelle 1/200). 
une seule présentait une inscription non intelligible $^{109}$. Derrière le comptoir, un Priape ithyphallique est représenté à proximité d'un dolium sur le mur sud; on voit un serpent sur la paroi nord $^{110}$. Dans la petite pièce a qui s'ouvre dans le mur ouest de la boutique, un banc maçonné est disposé sur trois côtés, vraisemblablement destiné à accueillir la clientèle. Les empreintes visibles sur le mur nord autorisent la restitution d'un porte-amphores, conteneurs dont de nombreux exemplaires ont été trouvés ${ }^{111}$. Parmi celles-ci, une amphore vinaire crétoise et deux autres indéterminées contenant $15 \mathrm{~kg}$ de fèves ${ }^{112}$. Bien qu'aucune vaisselle n'y ait été trouvée, cette pièce a servi de salle de restauration pour les clients venant directement de la rue, mais aussi de zone de stockage pour une partie des denrées consommées dans le local. La pièce 9 est d'autant plus intéressante qu'elle se trouve à un croisement non seulement planimétrique mais également fonctionnel: cette pièce met en communication le secteur de restauration avec la partie «hôtelière » de la maison. Elle s'ouvre tant sur la boutique IV, 17 que sur la

${ }^{109}$ La monnaie (Inv. $n^{\circ}$ E719=75996) et le broc (Inv. $\left.\mathrm{n}^{\circ} \mathrm{E} 720=75997\right)$ ont été mis au jour le 20 janvier 1932. Pour les amphores, les journaux de fouilles (GSE 1932) indiquent ceci: « 26 febbraio. Nella casa n. 5 nell'ambiente n. 12 vi erano molte anfore di terracotta completamente frammentate, un solo avanzo di vaso è stato raccolto [suit l'apographe de l'inscription, incompréhensible]».

${ }^{110}$ Pour le Priape, cf. Maiuri 1958 b: fig. 483 p. 438. Le serpent n'est plus visible mais est décrit dans les GSE (1932): « 12 marzo. [...] Sulla parete nord a m. 0.56 di altezza dal pavimento vi è dipinto un serpente agatodemone $[. .$.$] ».$

${ }^{111}$ Sur le banc et la présence d'étagères dans cette pièce, cf. Maiuri 1958 b: 437. Pour les traces d'étagères, cf. GSE 1932: «12 marzo. [...] A m. 1.38 dall'estremità superiore del podio sulla parete nord vi sono sei alveole con altrettanti travi di legno carbonizzato a forma rettangolare della larghezza di m. 0.08 per 0.08 che sostenevano un ammezzato $[\ldots] »$.

${ }^{112}$ Amphore crétoise (type Schoene VIII) : CIL IV, 10770 c. Pour les fèves, cf. GSE 1932: «14 gennaio. Nella casa n.5 ambiente $n .4$ posta sul $4^{\circ}$ Cardine lato ovest nell'angolo sud ovest vi erano due grosse anfore di terracotta completamente frammentate esse contenevano: [Description de l'objet inventorié $\left.\mathrm{n}^{\circ} \mathrm{E} 708=75985\right]$ ); cf. également Borgongino 2006: cat. $n^{\circ} 94$ p. 80 .

${ }^{113}$ Cette cloison est décrite comme étant constituée par deux portes par les GSE (1932: «12 marzo. [...] L'ambiente è diviso in due mediante porte di legno completamente rovinate da cunicoli borbonici. La prima porta a misura m. 2.75 cour à portique ou la pièce 10 . Toutefois, selon les journaux de fouilles, cette pièce en longueur aurait été divisée au moyen d'une cloison de bois nécessairement orientée est-ouest ${ }^{113}$. Cette division est également perceptible dans le traitement du sol: la partie centrale qui relie directement la cour à la pièce 10 est pavée avec un béton à dominante rouge, obtenue par le broyage de céramiques. En revanche, les deux parties nord et sud ont un revêtement obtenu en pilant des fragments de tuf, qui donnent au sol une tonalité jaune. Les zones de service, consacrées au rangement de denrées et d'objets, sont matériellement démarquées du couloir de passage, au sol et en élévation. Plusieurs aménagements de stockage ont été prévus. Contre la paroi sud, sur une mezzanine ou une étagère profonde, reposant sur deux ou quatre poutrelles ${ }^{114}$, un vase contenant des noix, un plat - de service ou de cuisson - et une casserole, tous trois en bronze, ont été découverts ${ }^{115}$. Dans un espace difficile à circonscrire, mais dans cette même pièce 9 , se trouvait un dolium, reposant directement sur le sol $^{116}$. Il contenait $1 \mathrm{~kg}$ de noix, attribué de façon

di lunghezza, la seconda m. $3.30[\ldots] »)$. Toutefois, les mesures correspondant à la longueur totale de la pièce (GSE 1932: «12 marzo. [...] L'ambiente misura m. 6.05 di lunghezza per m. 2.30 di larghezza [...]»), il faut supposer une erreur de rédaction et considérer l'existence d'une cloison, percée ou composée de deux vantaux, orientée est-ouest.

${ }_{114}$ GSE 1932: " 12 marzo. [...] Una ammezzato sostenuto da 4 travicelli carbonizzati a forma rettangolare di m. 0.9 per 0.10 trovano sulla parete ovest ed est all'estremità sud dell'ambiente e sopra essi poggiavano delle tavole di legno dello spessore di m. 0.015 servivano per deposito di provviste $[\ldots]$ ». Actuellement, seules deux empreintes sont visibles dans la paroi orientale, qui ne semble pas avoir été restaurée.

${ }^{115}$ Le vase en bronze (Inv. $\left.{ }^{\circ} \mathrm{E} 693=75970\right)$ a été trouvé à 1,4 m du sol (GSE 1931: 10 dicembre), indiquant clairement qu'il devait avoir été stocké sur cette étagère. Les noix ne sont pas mentionnées dans le catalogue de M. Borgongino (2006: 199). Le plat en bronze (Inv. ${ }^{\circ}$ E694=75971) et la casserole (Inv. n E695=75972) ont été mis au jour sur le sol ou sans indication d'altitude, à la verticale de l'étagère (GSE 1931: 10-11 dicembre).

116 GSE 1931: « 21 dicembre. Nella casa n. 5 posta sul $4^{\circ}$ cardine lato ovest nell'ambiente numero 2 aderente alla parete sud e a m. 0.30 da quella ovest è stato sterrato un dolio ridotto in vari pezzi contenente noci $\mathrm{kg} 1$. Il tutto è rimasto in sito ». Les indications données pour localiser le lieu de découverte doivent être erronées, à moins de considérer que la fouille s'est arrêtée le 11 décembre 1931 à 
erronée par A. Maiuri à la jarre de la boutique ${ }^{117}$. Enfin, des amphores et de la vaisselle en bronze de service et de cuisson étaient stockées dans cette pièce: une oenochoe ayant contenu du vin carbonisé lors de l'éruption - et un chaudron ${ }^{118}$.

L'examen de l'architecture et des objets découverts dans le secteur oriental de la Casa del priapo (IV, 17-18) montre que les quatre pièces sont étroitement liées et forment un ensemble intégré voué à des activités de restauration. La préparation culinaire se déroule dans la boutique IV, 17. Les plats qui y sont conçus sont servis aux clients assis dans la pièce a ou bien à ceux qui sont installés dans la pièce 10 , qui communique avec la boutique par une fenêtre passe-plat ${ }^{119}$. Les quelques rares éléments connus de la vaisselle de préparation et de table employée dans ce local ont été retrouvés répartis entre la boutique et la pièce 9 . Les réserves d'aliments - noix et fèves - sont divisées entre les pièces a et 9 , soit dans des amphores, soit dans un dolium - éventuellement deux. Excepté le «couloir» conduisant de la cour à la pièce 10 , l'ensemble de la pièce 9

$7 \mathrm{~cm}$ du dit dolium (GSE 1931: «11 dicembre. Nella casa n. 5 ambiente numero 2 sul pavimento lato sud a m. 0.20 dalla parete sud e a 0.37 da quella ovest è stato raccolto: [Description de l'objet Inv. $\mathrm{n}^{\circ}$ 695=75972]). Le nettoyage du sol de cette pièce, effectué au printemps 2004 n'a pas permis de voir la trace d'un éventuel creusement destiné à accueillir cette jarre. Contrairement à l'assertion de G. Stefani (2006: 160), ce dolium n'était donc pas partiellement enterré. Il a seulement été mis au jour brisé. Dans la description finale de cette pièce, les GSE mentionnent deux dolia. Le second aurait contenu des fèves (GSE 1932: «12 marzo. [...] Due grossi dolium di terracotta ed anfore furono sterrati nell'angolo sud ovest. In una vi erano noci e nell'altra fave [...]»). Il faut considérer que cette indication est une erreur. Les rédacteurs auront vraisemblablement confondu les fèves trouvées dans une amphore dans la pièce a (cf. supra, n. 112) avec les deux conteneurs à noix de la pièce 9 .

${ }^{117}$ Maiuri 1958 b: 437 et fig. 384 p. 438 . Cf. Borgongino 2006: cat. $n^{\circ} 343$ p. 118 .

118 Sur l'œenochoe (Inv. $\mathrm{n}^{\circ} \mathrm{E} 703=75980$ ), cf. supra, n. 85. Le chaudron (Inv. $\mathrm{n}^{\circ}$ E704=75981) est visible sur la photo des objets supposés issus du local IV, 17, présentée par A. Maiuri (1958 b: fig. 383 p. 438). Ces deux objets ont été mis au jour le 29 décembre 1931. Le même jour, une amphore a été découverte. D'autres conteneurs indéterminés ont également été trouvés dans cette pièce le 17 décembre 1931. L'un d'eux porte l'inscription CIL IV, 10726.

119 L'hypothèse formulée par A. Maiuri (1958 b: 437) sur le rôle de cette fenêtre, qui aurait permis au propriétaire de surveiller le fonctionnement de son commerce, paraît devoir être abandonnée. est dans la dépendance directe des activités de restauration se déroulant en IV, 17. L'argument utilisé par G. Stefani pour réfuter la pertinence de l'exemple que constitue cette boutique doit dès lors être écarté: le dolium contenant des noix, bien que non inclus dans la maçonnerie du comptoir, est un des éléments du commerce alimentaire se déroulant dans ce local ${ }^{120}$. Il en va de même pour le dolium situé le long du mur nord de la boutique, dont le contenu reste inconnu. L'un et l'autre n'ont pas été intégrés au comptoir faute de place: le comptoir est trop étroit pour accueillir deux jarres en son sein ${ }^{121}$. Cette séparation entre le comptoir et les jarres tient à la forme et à la disposition des lieux: le local en lui même est de dimensions modestes, notamment en comparaison avec des locaux du même type (fig. 45) ${ }^{122}$. Cependant, d'autres exemples montrent une séparation partielle des dolia par rapport au comptoir, sans présenter ces problèmes de surface ou de disposition; leur disqualification comme commerce alimentaire n'a par ailleurs jamais été évoquée ${ }^{123}$. La

120 « È tuttavia documentato che in un dolio nella bottega annessa ad un casa di Ercolano (IV, 17 Casa del priapo), si rinvenne una notevole quantità di noci, destinate di certo alla vendita [...] ma tale dolio non era inglobato nel bancone di vendita ma addossato alla parete sud dell'ambiente 9 , in parte interrato nel pavimento. [Quel] caso citato [...] non è del tutto pertinente [...]» (Stefani 2006: 160).

${ }^{121}$ Le bras nord du comptoir mesure $52 \mathrm{~cm}$ de large, le bras oriental $62 \mathrm{~cm}$. Le diamètre interne du dolium situé le long du mur nord est de $80 \mathrm{~cm}$. Les dimensions de celui qui a été mis au jour dans la pièce 9 ne sont pas mentionnées dans les GSE.

${ }^{122}$ En ne comptant que le local principal - sans la pièce annexe (a) accessible aux clients -, la boutique IV, 17 dispose d'une surface de $18 \mathrm{~m}^{2}$. À titre de comparaison, tous les locaux de type 1 (cf. infra, p. 113-117 pour la définition de ce type) ont des surfaces plus importantes: II, 6-7 $\left(24 \mathrm{~m}^{2}\right.$; cf. infra p. 377 et fig. 204); IV, 15-16 (32 m²); V, 6 $\left(22 \mathrm{~m}^{2}\right)$. À Pompéi, la situation paraît similaire: I 8, 8 $\left(32 \mathrm{~m}^{2}\right)$; V 4, 7 (22 $\left.\mathrm{m}^{2}\right)$; VII 6, 2 (32 $\left.\mathrm{m}^{2}\right)$. Le local VI 10, 1.19 est d'une superficie inférieure $\left(14 \mathrm{~m}^{2}\right)$; il dispose toutefois de trois dolia intégrés dans le comptoir. Cette variation est due à une utilisation différente de la surface disponible: le local pompéien accorde moins de place aux clients dans la pièce principale, mais leur en présente plus dans les pièces annexes.

${ }^{123}$ La boutique de Sotericus à Pompéi (I 12, 3) présente un comptoir en équerre, muni d'un chauffe-eau. Les cinq dolia de ce local sont intégrés dans une maçonnerie disposée le long du mur occidental de l'atrium. 
séparation matérielle entre le comptoir et les jarres ne permet en rien de les dissocier d'un point de vue fonctionnel: leur contenu - qui reste inconnu - devait être utilisé dans le cadre des activités de restauration se déroulant dans cette boutique. En définitive, et en dépit de son unicité, la boutique IV, 17 constitue un exemple bien documenté de commerce alimentaire dont un des dolia a contenu des aliments en vrac.

Cet unique exemple de dolium contenant des denrées alimentaires sèches pousserait à s'intéresser aux autres formes possibles de stockage à Herculanum et Pompéi. Une étude en ce sens, publiée par ailleurs ${ }^{124}$, a permis de mettre en évidence la très faible quantité de denrées alimentaires découvertes lors des fouilles. Pour Pompéi en particulier, il convient notamment de souligner qu'au cours du $\mathrm{XX}^{\mathrm{e}}$ siècle, presque aucun dépôt de denrées n'a été mis au jour (fig. 46). Sur l'ensemble des deux sites, en dépit de la richesse globale des macro-restes végétaux extraits des dépôts éruptifs, il faut souligner que l'on ne pourra jamais comprendre de manière exhaustive les techniques de conservation. Tout au plus un aperçu partiel est-il possible. Il donne à observer, en fonction des quantités requises par chaque unité domestique, des vasques maçonnées, de petits conteneurs céramiques ou en matériaux périssables. Les conditions d'ensevelissement ont été telles dans ces deux villes que la conservation des matériaux organiques a été bonne - excellente comparée à d'autres sites - mais non parfaite. La très faible fréquence des découvertes de denrées alimentaires dans des dolia ne constitue en rien un argument définitif permettant de repousser l'hypothèse sur laquelle s'appuie la suite de mes réflexions sur les commerces alimentaires.

L'idée que les 422 dolia découverts dans les aires urbaines d'Herculanum et de Pompéi en association à des comptoirs aient tous contenu du vin - ou même de l'huile - me semble peu crédible. Reprenons les arguments et exemples développés dans les paragraphes qui précèdent. L'absence très fréquente de couvercles sur les dolia aurait favorisé une dégradation rapide de

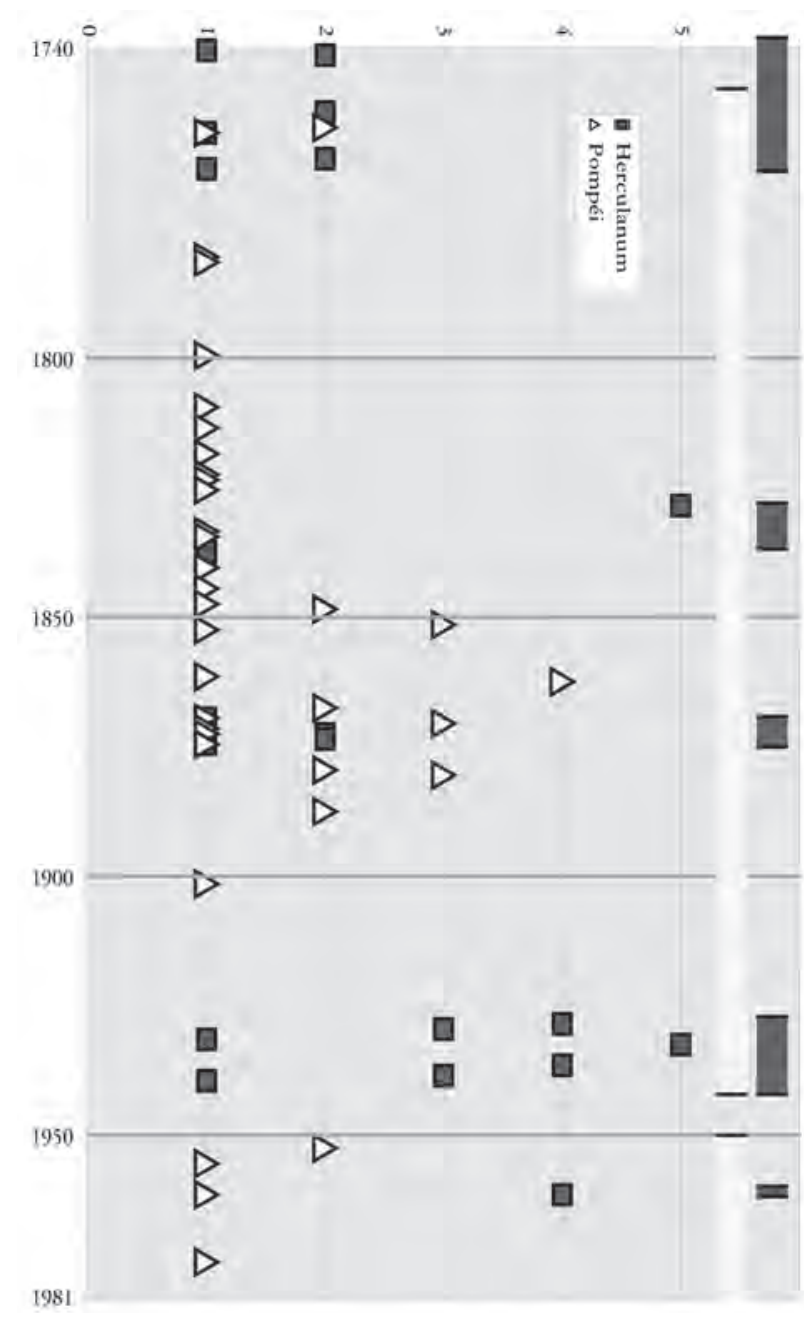

Fig. 46 - Chronologie des découvertes de céréales et de légumineuses à Herculanum et Pompéi. Les quantités renvoient aux numéros d'inventaire créés; les bandes indiquent les périodes de fouille dans les deux sites.

cette boisson au contact de l'air. L'utilisation de ces jarres comme tiroir-caisse me semble également incompatible avec la présence de vin. Enfin, la présence fréquente d'amphores vinaires dans les locaux munis de comptoirs et les quelques attestations d'entonnoirs permettant de transvaser le vin de ces amphores vers des pichets rendent inutile l'utilisation des dolia pour le stockage de cette boisson, même lors-

${ }^{124}$ Monteix 2008; les données d'inventaires exploitées dans cet article se fondent sur les recensions dressées par M. Borgongino (2006). 
qu'il s'agit de vin en vrac transporté depuis son lieu de production dans une outre et extrait de cette dernière grâce à des amphores selon l'iconographie.

La principale difficulté pour considérer que les dolia de ces commerces alimentaires urbains ont servi à conserver des denrées alimentaires solides reste le très faible nombre d'attestations de cette pratique. Un seul exemple est connu et pertinent, le dolium contenant des noix dans la boutique liée à la Casa del priapo à Herculanum. L'absence de presque tout reste organique dans les dolia doit rester un argument à employer avec prudence. Les attestations de céréales ou de farine dans les boulangeries sont particulièrement rares, sans que cela n'entraîne la disqualification de ces locaux comme lieux de production du pain ${ }^{125}$. Le processus interprétatif conduisant à considérer les dolia comme des conteneurs d'aliments solides est identique: comment pourrait-on autrement justifier la présence de tables de cuisson, de fourneaux, souvent d'une conséquente batterie de cuisine et de vaisselle de table dans une partie de ces commerces alimentaires? La difficulté à mettre en évidence des structures de stockage des denrées plus conséquentes que des amphores ou les quelques rares vasques maçonnées peut s'expliquer raisonnablement par le grand nombre de dolia répartis dans les commerces alimentaires de la ville.

Le seul moyen pour démontrer que les dolia insérés dans les comptoirs ou associés à ceux-ci ont contenu du vin serait de pratiquer des analyses qui amèneraient à caractériser les restes organiques des contenus ${ }^{126}$. En attendant que de telles analyses soient pratiquées et donnent un résultat positif, je considèrerai que les jarres incluses dans les comptoirs ont essentiellement servi au stockage de denrées alimentaires solides.

${ }^{125}$ Stefani 2006: 160. Sur les problèmes de localisation des stocks de céréales utilisées dans les boulangeries, cf. infra n. 189 p. 167.

${ }^{126}$ La détermination d'un contenu organique peut se faire par la recherche des molécules piégées dans la paroi du conteneur, en caractérisant d'abord la classe chimique (lipides, polyphénols, terpènes, etc.), puis en identifiant les molécules spécifiques. Quant à l'existence d'une imperméabilisation par la poix, si un examen visuel peut amener à

\section{II.2 Propositions pour une typologie des commerces alimentaires à Herculanum et Pompéi}

En utilisant les différents éléments se rapportant au commerce alimentaire, il est possible de proposer une classification de ces locaux. Avant de présenter les six types mis en évidence - dont seuls cinq renvoient effectivement à la vente de nourriture préparée ou non - quelques clarifications sur ma démarche s'imposent. Je ne saurai trop souligner que le premier objectif de la typologie proposée est d'organiser les commerces de bouche en fonction des aménagements dont ils disposaient dans le local principal. Ce postulat amène deux remarques. Tout d'abord, il m'a été impossible d'analyser l'ensemble du matériel découvert dans ces 179 locaux. Tous les objets provenant des locaux des nuovi scavi d'Herculanum (1927-1961) et inventoriés ont été étudiés. Seuls quelques exemples pompéiens ont fait l'objet des mêmes soins. Comme second point, insister sur le local principal permet d'éviter une trop grande dispersion: les salles annexes, en tout cas celles destinées à la réception de la clientèle, n'ont été que survolées. Je n'aborderai que brièvement la question des salles à manger, et ne mentionnerai pas les problèmes posés par l'hôtellerie. En revanche, j'ai étudié les pièces annexes participant au bon fonctionnement du commerce par leur fonction de stockage ou de préparation.

Tous les locaux présentant ou ayant présenté un comptoir maçonné en leur sein ont été pris en compte. Ce premier recensement a nécessairement achoppé sur la dégradation du site depuis sa mise au jour. Certains locaux qui ont pendant un temps été pourvus d'un comptoir sont complètement vides actuellement. Comme développé plus haut, la présence de plusieurs dolia

l'identification d'une zone de combustion au fond du dolium - caractéristique du poissage -, la recherche des composants chimiques de la poix paraît la plus adaptée. Sur les différentes méthodes employées pour caractériser la présence de matière organique dans les récipients céramiques, cf. Brun 2004 a: 28-35. Outre le coût de telles analyses, l'inévitable risque de "faux négatifs», induit par la détérioration de la matière organique depuis la mise au jour des dolia pompéiens, rend l’opération périlleuse. 
alignés dans un local commercial m'a fait considérer ce dernier comme consacré à l'alimentation, même quand des restes de maçonnerie ne sont plus visibles ou ne sont pas rapportés sur les plans les plus anciens ${ }^{127}$. Avec ce critère de sélection, 13 espaces commerciaux ont été analysés à Herculanum et 166 à Pompéi. Leur classification a été effectuée de façon à souligner dans un premier temps les réserves de denrées alimentaires solides, perceptibles par la présence de dolia. Les deux groupes ainsi obtenus ont ensuite été subdivisés en trois catégories selon qu'ils présentaient ou non des aménagements propres à la cuisson ou au chauffage des aliments.

II.2.1 Type 1: les restaurants utilisant une table de cuisson

La première catégorie des commerces alimentaires regroupe tous ceux qui disposent non seulement de dolia mais également d'une table de cuisson. Certains présentent également en plus de ce fourneau un chauffe-eau. En se plaçant du point de vue des aménagements construits, le plus bel exemple est constitué par le local situé en façade de la Casa di Nettuno e Anfitrite (V, 6). Outre le comptoir qui occupe les deux tiers de l'ouverture sur la rue, deux fourneaux, des casiers à amphores et une mezzanine en bois ont été découverts (fig. 47). Les tables de cuisson se trouvent aux angles nord-ouest et sudest du local. Elles occupent chacune une surface supérieure à un mètre carré. Celle située contre la paroi septentrionale présentait également un chauffe-eau dont seule l'alimentation en eau sous pression a été découverte. La disposition des lieux est telle que les clients ne pouvaient que consommer debout, soit depuis la rue, soit en stationnant dans le maigre espace laissé libre entre le second fourneau, le comptoir et le casier

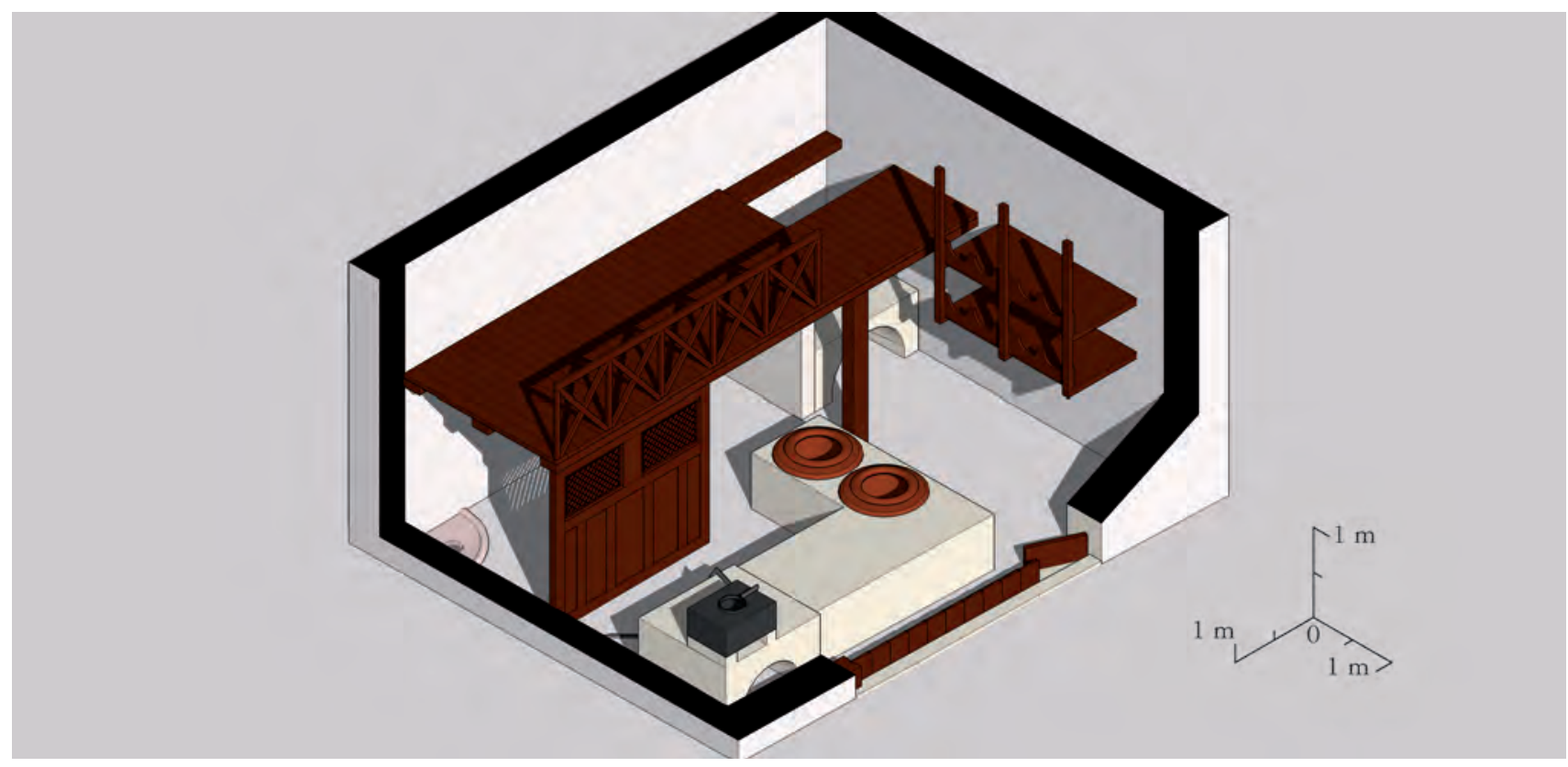

Fig. 47 - Restitution isométrique du commerce alimentaire V, 6 (échelle: 1/100).

${ }^{127}$ Seuls deux locaux posent un problème en ce sens. Le premier est situé en VII 4, 17 ; les dolia qui s'y trouvent actuellement pourraient y avoir été transportés après la fouille. Le second $(I \quad 4,17)$ est actuellement vide de tout vestige.
Toutefois, la description donnée par G. Fiorelli (1875: 67) est suffisamment claire pour admettre la présence de deux dolia: «17. Qui si vendeva farina mollita, ch'era serbata in due grandi dolii di terracotta, fabbricati nel suolo». 
à amphores. La zone située sous la mezzanine derrière le panneau en bois pourrait avoir été utilisée tant pour la préparation que pour le nettoyage des plats: dans l'angle nord-est, le sol est occupé par un avaloir maçonné en arc de cercle (fig. 48). En revanche, contrairement à ce que propose A. Maiuri, il ne faut pas considérer la pièce 5 comme un espace annexe à la boutique; le commerce a été limité au seul local principal $^{128}$. Si les constructions en bois ont été remarquablement conservées, il n'en va pas de même pour les objets utilisés pour la préparation et le service. La fonction de préparation culinaire est attestée par la découverte d'une marmite et d'un ramequin en bronze; la vaisselle de table reste inconnue ${ }^{129}$. Seuls deux gobelets "fritilli »- ont été trouvés, laissant supposer que du vin était vendu, ce qui s'accorde tant avec la présence du chauffe-eau qu'avec celle du porteamphores, bien que ce dernier ait été découvert vide $^{130}$.

À Pompéi, la boutique «de L. Vetutius Placidus» $(\mathrm{I} 8,8)$ présente des aménagements comparables, mais dans une disposition et à une échelle sensiblement différentes. Ainsi, le comptoir en double équerre qui occupe la majeure partie du local, ne laissant libre qu'un passage à l'ouest, n'inclut pas moins de 13 dolia ${ }^{131}$. Outre ces jarres, les capacités de stockage ont été augmentées par l'adjonction d'une

${ }^{128}$ A. Maiuri (1958 b: 402 et fig. 330 p. 394) considérait que la pièce 5 dépendait partiellement du commerce, en raison de l'identification douteuse d'un fourneau dans cet espace.

${ }^{129}$ La marmite (Inv. $\mathrm{n}^{\circ} \mathrm{E} 1004=76281$ ) et le ramequin (Inv. ${ }^{\circ} \mathrm{E} 1005=76282$ ) ont été découverts le 4 février 1933, sur le sol au sud du comptoir.

${ }_{130}$ Ces deux récipients, l'un piriforme (Inv. $n^{\circ}$ E1014=76291), l'autre ovoïde (Inv. n E1015=76292) ont été trouvés, avec deux pièces de monnaies (Inv. $\left.\mathrm{n}^{\circ} \mathrm{E} 1011-1012=76288-76289\right)$, une lampe en terre cuite (Inv. $\mathrm{n}^{\circ} \mathrm{E} 1013=76290$ ) et son support en bronze (Inv. $\mathrm{n}^{\circ} \mathrm{E} 1016=76293$ ), le 14 février 1933, derrière la cloison en bois. L'interprétation de ces récipients céramiques reste discutée. Pour M. Annecchino (1977), il s'agit de gobelets à boire parfois également utilisés comme cornets à dés. En revanche, C. Pavolini (1980: part. 1009-1013) tempère cette interprétation, en faisant remarquer la difficulté d'utiliser certains de ces récipients comme instruments de jeu ou l'absence de pied de soutien pour d'autres formes. Dans ce contexte particulier, l'utilisation de ces deux récipients comme

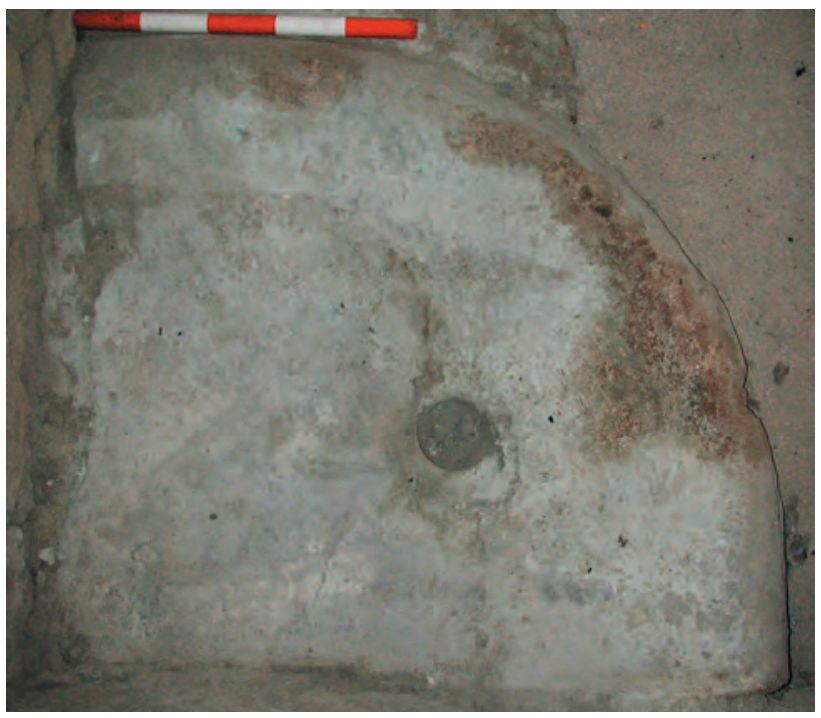

Fig. 48 - Casa di Nettuno e Anfitrite (V, 6), angle nord-est de la boutique. Aménagement maçonné permettant l'évacuation de l'eau.

cave dont l'accès se situe derrière le comptoir. Aucun élément ne permet de définir ce qui était conservé dans cette petite pièce souterraine ${ }^{132}$. Le dispositif de cuisson, situé dans l'angle nordouest du local, est brièvement et sans grande précision décrit par les journaux de fouilles ${ }^{133}$. Il reste impossible de définir si «l'acquario» correspond à un chauffe-eau ou non, hypothèse

verre à boire semble hautement probable. Sur les différences entre le matériel réellement découvert et les objets réputés provenant de la boutique, cf. Monteix 2009: 186-187.

${ }^{131}$ La surface du local principal est de $31 \mathrm{~m}^{2}$. Le comptoir et le fourneau occupe $21 \mathrm{~m}^{2}$, ne laissant que $10 \mathrm{~m}^{2}$ pour le passage et le stationnement des clients.

132 Cette cave a d'abord été repérée grâce à l'effondrement du bras occidental du comptoir. GSP 1939: «1015 giugno. Durante i lavori di rimozione del banco sprofondato [...], al disotto del braccio interno si è scoperto un ripostiglio in muratura rustica di m. 2,70 x 1,95, profondità m. 1,03 con pavimento battuto in calcestruzzo. La copertura era in legno, di cui si osserva l'impronta della tenuta sul lato orientale, con massetto sovrastante su cui poggiava la parte interna del banco. L'apertura a botola, situata nell'angolo $\mathrm{SE}$, è delle dimensioni approsimative di $\mathrm{m} .0,60$ x 0,45. Dal piccolo ambiente sotteraneo si è estratto materiale rimescolato ed uno strato inferiore di lapillo vergine alto m. 0,50».

133 GSP 1939: "25 maggio. [...] Nell'angolo NO vi è l'impianto in muratura di un fornello con vaschetta ed acquario[...]». 
très probable que l'observation des vestiges ne permet pas de vérifier. L'utilisation d'eau est avérée par la mise au jour d'une ciste en plomb, située lors de sa découverte dans le local principal, entre la porte menant vers le reste de la maison et le laraire peint ornant le mur sud ${ }^{134}$. Habituellement situés à proximité des bouches de citernes, ces récipients servaient de réserve d'eau quotidienne, évitant ainsi d'incessants puisages. Outre la préparation culinaire, l'eau devait également être utilisée pour allonger le vin servi dans la boutique. Une soixantaine d'amphores vinaires a été découverte, répartie entre l'arrière de la maison et l'étage ${ }^{135}$. Peu de matériel a été mis au jour, éventuellement en raison des perturbations postérieures à l'ensevelissement ${ }^{136}$. Parmi ce qui a pu être utilisé dans le cadre des activités commerciales, seule une coupe de céramique sigillée italique a été mise au jour ${ }^{137}$. En revanche, dans la pièce 2 , située au sud du local et communiquant avec celui-ci, divers récipients en bronze ont été découverts ${ }^{138}$. Si l'on prend également en considération la découverte des pieds d'un lit dans cette même pièce dont le pavement - mis en place dans une phase antérieure ${ }^{139}$ - renvoie à la disposition des triclinia, cette salle aura servi à recevoir une partie de la clientèle après l'installation de la boutique $^{140}$.

Par la présence d'une table de cuisson, ces locaux - au nombre de 6 à Herculanum et 36 à Pompéi ${ }^{141}$ - pourraient avoir offert une certaine variété ou du moins une certaine quantité de plats cuisinés. Les conditions d'accueil de la clientèle restent toutefois variables: le local situé en V, 6 ne semble avoir permis à ses clients qu'une
134 GSP 1939: «23 maggio. [...] A destra del dipinto larario, addossato allo stipite del vano, si è messo in luce un serbatoio di piombo, alto m. 0,75 , deformato dalla pressione del materiale [SNI] ». Cette ciste est conservée dans la maison où elle a été découverte, mais dans une autre pièce que celle d'origine. Sur la peinture associée au culte domestique, de notable importance, cf. Fröhlich 1991: 252-253.

135 V. Castiglione Morelli et R. Vitale (1989: 197) ne signalent que 21 amphores. M. Della Corte (NSc 1946: 96-100) en recense 30 qui portent des inscriptions. Mon décompte de 59 amphores s'appuie sur les listes données par les journaux de fouilles, la majeure partie de ces amphores provenant du jardin mis au jour entre le 17 et le 23 août 1939. La reprise de l'étude de ces amphores, réalisée par M.-B. Carre et E. Botte dans le cadre de l'analyse exhaustive des archives de fouilles de l'ilôt I 8 menée sous la direction de $\mathrm{Ph}$. Borgard, permettra d'affiner ce dénombrement et l'identification des conteneurs.

${ }^{136}$ Sur les mentions des perturbations voir, par exemple, GSP 1939: « 7 marzo. Lo scavo sistematico si conduce nella parte alta della zona che confina a $\mathrm{N}$ con la via dell'Abbondanza. La stratificazione è tutta rimaneggiata per l'intera superficie investita, avendo perduto il carattere della naturale sovrapposizione del materiale vulcanico [...]». Cette description correspond à la partie surplombant le local I 8, 8. Sur ce type de perturbations postérieures à l'éruption, cf. Berry 1997 b: 187; Allison 2004: 179-182.

${ }^{137}$ D'autres récipients ont été mis au jour dans l'un des dolia, vraisemblablement tombés depuis une étagère, le 31 mai 1939 (cf. supra, n. 101). Étonnamment, les mêmes objets sont trouvés le lendemain, toujours dans l'une des jarres. GSP 1939: " $\mathrm{I}^{\circ}$ giugno. [...] Nella taberna $\mathrm{n}^{\circ} 8$ si è terminato lo svuotamento del materiale volcanico dai dolî murati nel braccio interno più lungo del banco, rivenendovi : Terracotta. Due vasettini; un oleare ed una lucerne monolychne $[\mathrm{SNI}]$ ». Il fort probable que cette seconde décou- verte soit une erreur de rédaction. De toute façon, aucun de ces objets céramiques découverts dans le local n'ayant été inventorié, il est impossible, faute de photo de fouille, de déterminer avec exactitude leur forme ou leur rôle. Les vasettini peuvent être des gobelets et l'oleare une cruche.

${ }^{138}$ Inv. n P6979; 6981; 6982 (?); 6983 trouvés le 3 juin 1939 à proximité de la porte donnant vers la boutique.

${ }^{139}$ La décoration tant du pavement que des parois a été interprétée comme de III ${ }^{\mathrm{e}}$ style II B (30-45 ap. J.-C.) (PPM I: 802-803 et fig. 4-8 p. 806-808). Les journaux de fouilles indiquent le creusement caractéristique des têtes de lit dans le mur occidental. Dans un second temps, cet aménagement a été aboli (GSP 1939: 3 giugno). De plus, selon Th. Fröhlich (1991: 94-95), les fresques du local commercial seraient de IV ${ }^{\mathrm{e}}$ style, tandis que de façon plus précise le laraire aurait été peint dans les dernières années précédant l'éruption. Ces différents éléments permettent de considérer que la boutique a annexé la pièce 2 lors de sa création, au plus tôt dans la seconde moitié du $\mathrm{I}^{\mathrm{er}} \mathrm{s}$. de notre ère.

140 Trois pieds de lit (deux en fer et bois, le troisième décoré en os) ont été mis au jour le long de la paroi méridionale de la pièce 2 le $1^{\text {er }}$ juin 1939 (Inv. n P6977). Un tel lit pourrait indiquer un service de restauration couché. En plus des récipients de service, la découverte de fragments de serrure à proximité de la porte ouest de la pièce 2 (SNI, cf. GSP 1939: 29 maggio) pourrait également indiquer une volonté de séparation nette entre cette salle et le reste de la maison.

${ }^{141}$ Le local II 5, 1, n'a bénéficié que d'une fouille partielle, permettant la découverte d'un comptoir disposant d'un dolium. La présence d'un triclinium dans le jardin II 5, 4, probablement lié à cette boutique, permet de lui restituer des fonctions de restauration, en plus de la consommation du vin produit sur place (cf. Jashemski 1973 : 40-41 et Rossiter - Haldenby 1989), et donc le faire figurer dans le groupe 1. 
consommation debout ou la vente à emporter, tandis que la boutique «de L. Vetutius Placidus» aurait offert l'alternative d'une salle de restauration avec l'usage possible de couches. Les conditions générales de préservation de ces locaux interdisent une étude plus fine des pratiques de préparation et de consommation alimentaires.

\section{II.2.2 Type 2: des locaux entre le restaurant} et le débit de boissons

La seconde catégorie de commerces alimentaires regroupe tous ceux qui disposent uniquement comme système de cuisson d'un chauffeeau/fourneau, généralement incorporé au comptoir pourvu de dolia. À Herculanum, un seul local peut être rattaché à ce groupe. Il s'agit de la boutique Or. II, 6 qui présente un $\mathrm{CE} / \mathrm{F}$ arasé à l'extrémité du bras méridional du comptoir. Cinq dolia ont été mis en évidence en dépit des destructions causées par les tunnels du XVIII ${ }^{\mathrm{e}}$ siècle. L'ensemble se compose de trois pièces au niveau de la rue, et au moins trois à l'étage, directement accessible depuis l'intérieur de la boutique $^{142}$. Le pavement du rez-de-chaussée a subi un traitement unitaire - des fragments de marbre pris dans un cocciopesto - qui ne permet

\footnotetext{
${ }^{142}$ Le mur de refend nord-sud situé au premier étage comporte deux portes. Comme il semble peu probable que les deux mêmes pièces communiquent avec deux portes distinctes, il paraît opportun de restituer au moins une cloison est-ouest. En l'absence de toute trace de chaînage arraché sur les parois nord-sud, je proposerai la restitution d'au moins une cloison en pan de bois.

143 GSE 1933: "6 settembre. [...] L'ambiente $\mathrm{N}^{\circ}$ 6, V Cardine, insula Occidentale è un termopolio. [...] Sulla parete Est, vi è una scena di caccia $[. .$.$] ». Cette description$ est trop lapidaire pour tenter un quelconque rapprochement avec les scènes figurées sur le comptoir de la boutique III 6, 1 à Pompéi.

${ }^{144}$ GSE 1933: « 17 marzo. Nell'ambiente n. 1 della casa $\mathrm{N}^{\circ} 6$, posta sul $5^{\circ}$ cardine, lato est, sulla parete nord, vi è un quadro con la figura di Dioniso. La divinità tiene il braccio sinistro poggiato sulla spalla di un altro uomo, il quale con la mano destra stringe un vaso. Pampini e grossi grappoli di uva sono tesi intorno a Dioniso ». Malgré l'absence de niche ou de tout reste d'autel portatif, il est tentant de rattacher cette peinture aux Pénates de la boutique.

${ }^{145}$ Découverte le 6 septembre 1933, non inventoriée, cette assiette n'est connue que par la retranscription du timbre qu'elle présente. Il s'agirait de la marque C.P.P, in planta pedis dextrorsum correspondant à C. $\mathrm{P}() \mathrm{P}($ isanus)
}

pas de différencier l'utilisation des espaces. En revanche, les rares fragments de décoration pariétale décrits lors de la fouille - aujourd'hui disparus - pourraient constituer un écho des probables activités de restauration et de consommation de boisson ayant eu lieu dans ce local : une scène de chasse a été identifiée sur le mur est ${ }^{143}$, tandis que l'ensemble de la boutique paraît avoir été placée sous la protection de Bacchus, représenté derrière le comptoir ${ }^{144}$. La préparation et la consommation de nourriture ne semblent guère faire de doute, attestées par la découverte d'une assiette en céramique arétine ${ }^{145}$. En revanche, il est plus délicat de percevoir la consommation de vin dans ce local, aucune amphore n'y ayant été découverte. Les deux coupes arétines pourraient palier cette absence ${ }^{146}$. De plus, l'ensemble de la vaisselle de service qui a été mise au jour provient du premier étage, ce qui rend son interprétation difficile ${ }^{147}$. Il est impossible de déterminer si elle était stockée là comme vaisselle utilisée dans le cadre de l'unité domestique ou des activités commerciales.

Un exemple pompéien permet de mieux définir les pratiques correspondant aux aménagements caractéristiques de ce second groupe. Il s'agit de la boutique «d'Asellina » (IX 11, 2),

(CVArrII 1342, 14-16). Les principales attestations de ces timbres correspondent à des assiettes et coupe de forme Conspectus 3.2, B2.7 et B3.17.

${ }^{146}$ Deux coupes ont été trouvées le 18 février 1933. La première porte le timbre L.R.PI in planta pedis dextrorsum, indicateur de la production de L. Rasinius Pisanus. Les dimensions du timbre données dans les GSE correspondent à CVArrII 1690, 42 encore non attesté dans les cités ensevelies par le Vésuve. Il s'agirait d'une coupe de forme Conspectus B3.14-15, en raison de la mention d'un haut pied par les GSE. L'utilisation d'un tel récipient pour boire est sujette à caution, certaines " coupes » ayant pu être utilisées comme assiette. La seconde coupe porterait un timbre in planta pedis dextrorsum avec les lettres ACCE (lecture incertaine), sans comparaison dans le CVArrII.

${ }^{147}$ Le 18 février 1933, dans la moitié occidentale de l'étage ont été trouvés une bouteille en verre (Inv. n E1020=76297), un gobelet céramique (Inv. $\mathrm{n}^{\circ} \mathrm{E} 1021=76298$ ) et deux amphorisques (Inv. $\mathrm{n}^{\circ}$ E1022-1023=76299-76300). Le 21 septembre 1933, seuls des objets en bronze ont été découverts: un chaudron (Inv. $n^{\circ}$ E1136=76412) et deux cruches (Inv. $\left.\mathrm{n}^{\circ} \mathrm{E} 1137-1138=76413-76414\right)$. Selon les indications des jours précédents, ils proviendraient d'une pièce appelée "ambiente 2 », pouvant se situer dans la moitié orientale de l'étage. 


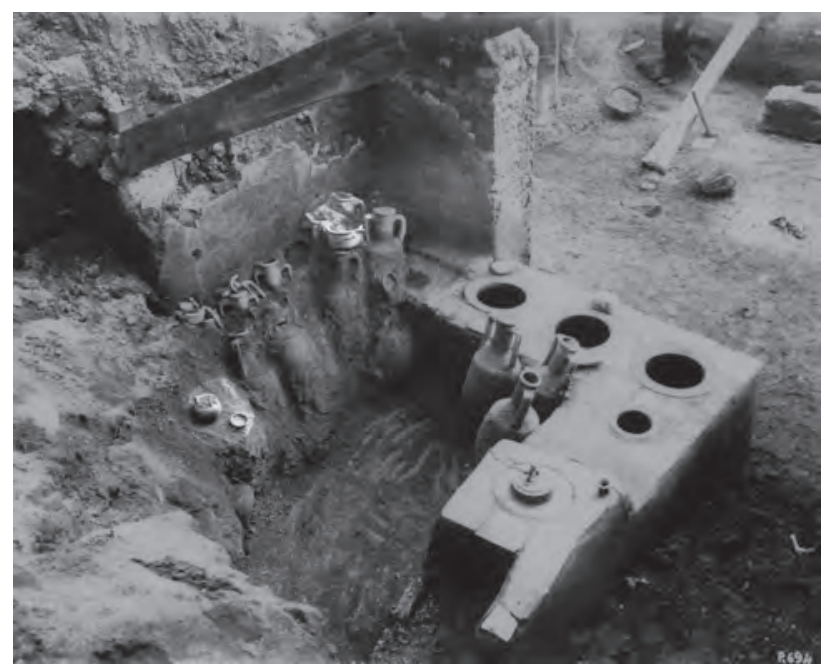

Fig. 49 - Boutique «d'Asellina» (Pompéi, IX 11, 2) en cours de fouille. Les deux cercles plus clairs soulignent des objets découverts dans le local mais non inventoriés. On note également l'excroissance du chauffe-eau / fourneau au nordouest du comptoir.

fouillée entre 1911 et 1912 (fig. 34) ${ }^{148}$. Je ne reviendrai pas sur la description de son chauffeeau disposant d'une plateforme de cuisson qui termine le bras occidental du comptoir, dans lequel quatre dolia sont insérés. Seul un étroit passage est ménagé le long de son côté ouest, essentiellement pour permettre l'accès au premier étage. L'espace réservé à la clientèle en

148 Outre le compte rendu publié dans les NSc (1912: 111-120), on consultera la présentation du matériel lors d'une exposition à l'Antiquarium de Boscoreale (Stefani 2005 b).

${ }^{149}$ Ce décompte s'appuie sur la photo prise lors de la fouille (fig. 49) qui montre 13 amphores, dix le long du mur oriental, trois appuyées contre le comptoir. Les douze autres sont encore en place dans la boutique, entre l'extrémité occidentale du comptoir et la paroi est ou dans l'angle nord-est. Il est possible que deux de ces amphores correspondent à celles qui sont également visibles sur la photo. Si la majorité de ces conteneurs paraît être d'origine italienne, un ou deux exemplaires pourraient correspondre au type Pompei 6 d'origine égéenne (cf. Panella - Fano 1977: 153 et Panella 1986: n. 12 p. 617).

150 «Parimente sul bancone, però dinanzi al rialzo che esso forma sul fornello, vennero trovati gli avanzi di una specie di cassettina di legno, la quale doveva essere munita di un fòro nel mezzo in cui veniva fissato il tubo rastremato di un imbuto [...]» (NSc 1912: 117). Ce type de dispositif n'est pas sans rappeler celui qui est sculpté sur deux reliefs conservés au musée de Dijon [Espérandieu 3469 (IV, p. 387- est réduit aux $5 \mathrm{~m}^{2}$ situés sous l'escalier. En dépit des destructions et des disparitions d'objets depuis la fouille, la consultation des archives et l'étude des ustensiles trouvés permet de reconstituer la majeure partie des activités culinaires qui se sont déroulées dans ce local (fig. 49). La première de celles-ci est la consommation de vin. En effet, au moins 23 amphores ont été trouvées alignées le long de la paroi est ou appuyées dans l'angle intérieur du comptoir. Il semble qu'il n'y ait eu que des conteneurs à vin de type Dressel $2-4^{149}$. Le vin contenu dans ces amphores était transvasé par le biais d'un entonnoir fixé, selon la description de G. Spano, à une forme en bois probablement percée en son centre ${ }^{150}$. Les vases de service probablement destinés à recevoir ce vin, additionné d'eau réchauffée grâce au CE/F, sont de plusieurs formes. Deux d'entre eux sont des cruches affectant respectivement la forme d'un chien et d'un coq (fig. 50) ${ }^{151}$. Parmi les différents récipients provenant de ce local, neuf autres peuvent avoir été utilisés pour verser du vin (fig. 51) ${ }^{152}$. Aucun reste organique n'a été découvert lors de la mise au jour de ce local. Néanmoins, plusieurs éléments de la batterie de cuisine permettent non seulement d'obtenir l'assurance que cette boutique n'était pas exclusivement vouée au débit des boissons, mais également de préciser certains des mets préparés. Les ustensiles de préparation sont peu nombreux,
388 ) et 3608 (IV, p. 442-443)] où l'on voit un haut comptoir, probablement en bois, à travers lequel sont fixés des entonnoirs qui permettent au client de remplir une cruche.

${ }^{151} \mathrm{La}$ cruche en forme de chien est conservée dans les magasins de Pompéi (Inv. n P1099). En revanche, celle en forme de coq a été détruite lors du bombardement de 1943 (Inv. $\left.\mathrm{n}^{\circ} \mathrm{P} 1100\right)$. Toutes deux ont été trouvées le 12 décembre 1911, sur le comptoir. Cf. NSc 1912: fig. 12 p. 114.

${ }^{152}$ Parmi les plus susceptibles d'avoir été utilisés dans le service du vin, une amphore (Inv. $n^{\circ} \mathrm{P} 1107$ ) et une oenochoe (Inv. $\mathrm{n}^{\circ} \mathrm{P} 1149$ ) en bronze, ainsi qu'une lagoena en céramique (Inv. $\mathrm{n}^{\circ} \mathrm{P} 1186$ ), trouvée sur le fourneau. Deux autres de format plus réduit (Inv. n $\mathrm{P} 1101$ et P1194 - non mentionnée dans les GSP ou dans les NSc, trouvée le 16 janvier 1912), ont été respectivement découvertes sur le comptoir et sur les amphores. L'utilisation de ces deux vases pour le service du vin peut être déduite de l'une des fresques provenant de la boutique VI 14, 35-36 (MANN Inv. n 111482 , cf. Fröhlich 1991: 211-214). Un broc (Inv. n 1190) a été trouvé sur le comptoir (cf. NSc 1912: 116). Enfin, deux autres récipients céramique (Inv. n ${ }^{\circ} \mathrm{P} 1141-1142$; cf. NSc 1912: 119) ont également pu être utilisés de cette façon. 


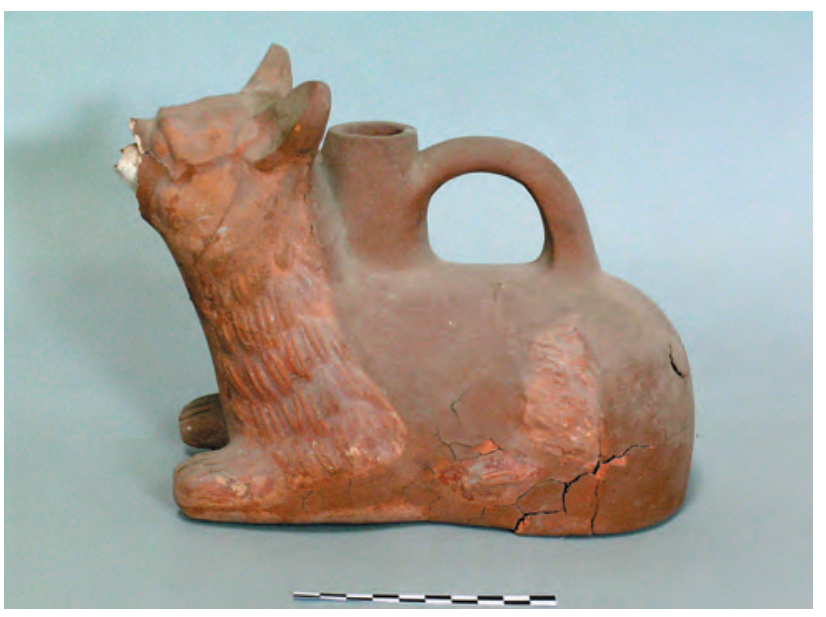

Fig. 50 - Cruche en forme de chien provenant de la boutique «d'Asellina» (Pompéi, IX 11, 2).

signe probable de la faible diversité des plats confectionnés. Notons tout d'abord l'absence complète de tout instrument de broyage, qu'il s'agisse de petite meule manuelle ou de mortier, bien que dans ce dernier cas le bois ait pu être employé. Seuls un ramequin en bronze - à fonctions certainement multiples - et une feuille de boucher renvoient à cette première étape (fig. 52) ${ }^{153}$. Pour la cuisson, un trépied en fer a été découvert sur les amphores, tombé de l'étagère du mur oriental ${ }^{154}$. Il pouvait servir d'appui à une marmite et un pot en terre cuite utilisés pour la cuisson d'aliments sur la plateforme du $\mathrm{CE} / \mathrm{F}^{155}$. La céramique n'est pas la seule matière utilisée pour cuisiner: un "seau» en bronze a été trouvé dans la boutique, dont les pieds en plomb semble interdire son utilisation comme chaudron: il aurait uniquement permis le maintien au chaud de plats de consistance liquide ${ }^{156}$.

En ce qui concerne la vaisselle de consommation, la majeure partie est constituée par des

${ }^{153}$ Le ramequin (Inv. ${ }^{\circ} \mathrm{P} 1150$ ), traditionnellement - et improprement - appelé «stampo» ou «forma per pasticceria» (cf. infra, p. 150), a été trouvé comme le couteau (cf. n. suivante) au-dessus des amphores. Ils devaient être rangés sur l'étagère au moment de l'éruption. Le couteau (Inv. n P1191, non mentionné dans les GSP ou les NSc) est intégralement constitué en fer. La lame, de forme triangulaire, est longue de $22 \mathrm{~cm}$ (la pointe est cassée) et large de $10,5 \mathrm{~cm}$. Aucun reste osseux de découpe n'est signalé dans

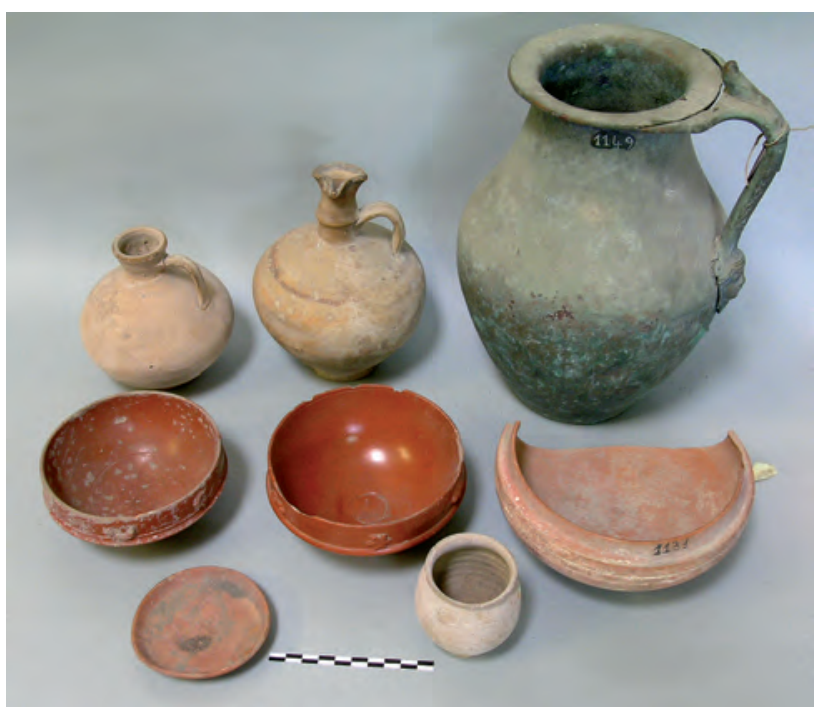

Fig. 51 - Echantillon de la vaisselle provenant de la boutique "d'Asellina» (Pompéi, IX 11, 2). En haut, cruches céramiques et en bronze. Au centre, vaisselle de table: coupes arétines et écuelle à couvercle.

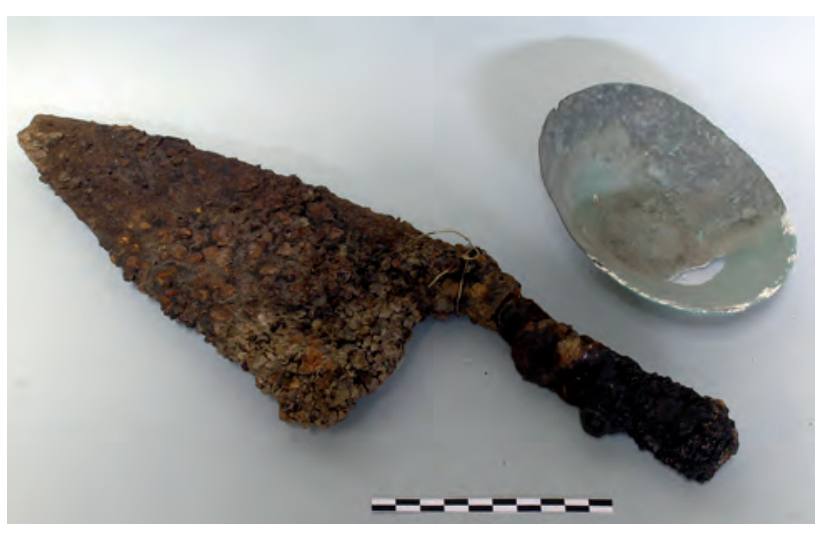

Fig. 52 - Instruments de préparation culinaire provenant de la boutique «d'Asellina » (Pompéi, IX 11, 2): couteau en fer et ramequin en bronze, considéré comme stampo.

le compte rendu de fouille. Sur l'usage de ces couteaux, cf. Monteix 2007 c: 189-190.

${ }^{154}$ Cf. supra, n. 53 p. 98.

${ }^{155}$ La marmite (Inv. $n^{\circ} \mathrm{P} 1143$ ) et le pot (Inv. $\mathrm{n}^{\circ} \mathrm{P} 1185$ ) ont été trouvés sur les amphores (cf. fig. 49).

${ }^{156}$ Inv. n P1115; cf. Tassinari 1993: 108 (forme X1100). Sur l'inadéquation du terme de seau, cf. Tassinari 1996: 118. 
gobelets et des tasses pour la boisson. Les formes et les matières employées sont d'une grande diversité, sans que l'idée d'un service puisse être évoquée: une tasse à dépression en céramique à paroi fine côtoie gobelets, tasses et coupe en terre cuite ou en verre (fig. 51) ${ }^{157}$. En revanche, les quelques éléments destinés à la consommation des aliments sont plus homogènes. Passons rapidement sur une assiette à engobe dont la taille est très réduite ${ }^{158}$. Trois coupes en céramique arétine ont été mises au jour, une sur le comptoir ${ }^{159}$, deux provenant des étagères ${ }^{160}$. Bien que le terme avec lequel elles sont caractérisées renvoie à la boisson, elles peuvent avoir été utilisées pour contenir des aliments. Une dernière écuelle, d'un volume à peine supérieur aux coupes précédentes, présente la particularité d'avoir une lèvre remontant vers l'intérieur destinée à faciliter la pose d'un couvercle ${ }^{161}$. Ce dispositif devait permettre de faciliter la conservation de la chaleur des aliments. Il est possible que d'autres écuelles, en bois, aient été utilisées. Parmi les différents récipients trouvés dans la boutique, un seul peut avoir servi à conserver les denrées solides nécessaires aux préparations culinaires. Il s'agit d'un bocal en verre, vide lors de sa mise au jour ${ }^{162}$. Bien que représentant une fraction mineure de la vaisselle, deux marmites attestent incontestablement que la plateforme

157 Les sept récipients pour la consommation des liquides sont les suivants: Inv. $\mathrm{n}^{\circ} \mathrm{P} 1102$, tasse en paroi fine à dépressions; Inv. $\mathrm{n}^{\circ} \mathrm{P} 1123$, gobelet céramique; Inv. $\mathrm{n}^{\circ} \mathrm{P} 1146$, tasse céramique; Inv. $\mathrm{n}^{\circ} \mathrm{P} 1104$, coupe en verre; Inv. ${ }^{\circ} \mathrm{P} 1155$ verre à dépressions en verre (détruit lors du bombardement de 1943); Inv. $n^{\circ} \mathrm{P} 1184$ tasse en verre.

${ }^{158}$ Inv. $n^{\circ} \mathrm{P} 1145$, trouvée sur les amphores, provenant de l'étagère du mur oriental.

${ }^{159}$ Inv. $\mathrm{n}^{\circ} \mathrm{P} 1114$, timbre in planta pedis dextrorsum de Cn. At(eius) A(...) (CVArrII 279, 2), forme Conspectus 34.1.

${ }^{160}$ Inv. $\mathrm{n}^{\circ} \mathrm{P} 1147$, timbre in planta pedis dextrorsum de L. Rasinius Pisanus (CVArrII 1690, 48), forme Conspectus 34.1; Inv. $\mathrm{n}^{\circ} \mathrm{P} 1148$, sans timbre, forme Conspectus 34.1.

${ }^{161}$ Inv. $n^{\circ} \mathrm{P} 1131$. Le couvercle n'a pas été mis au jour. Aucune trace de carbonisation n'est visible sur le pied ou la panse, ce qui contredit l'interprétation comme "padella o bassa pignatta » proposée par G. Spano.

${ }^{162}$ Inv. $\mathrm{n}^{\circ} \mathrm{P} 1111$, mis au jour sur le comptoir. J'ai volontairement exclu les petits récipients permettant de conserver des produits en quantité trop restreinte pour qu'ils puissent constituer les réserves de la boutique. Parmi ceux-ci se trouvent des unguentari (Inv. $\mathrm{n}^{\circ} \mathrm{P} 1105-1106, \mathrm{P} 1112$ et P1124) et les petits récipients en verre (Inv. n P1153-1154, P1156). du $\mathrm{CE} / \mathrm{F}$ a servi à préparer des plats cuisinés. Dès lors, à moins de supposer que les ingrédients pour ces derniers étaient disposés dans des sacs derrière le comptoir, seuls les dolia subsistent comme système de conservation.

En combinant le rôle des aménagements construits avec la vaisselle de cuisine et de table, il est possible de proposer une image très générale des fonctions de cette boutique. La majeure partie de la vaisselle de service et de table renvoie plus à la consommation de vin qu'à celle d'aliments. Ces derniers ne sont toutefois pas exclus. Les marmites sont peu nombreuses, mais devaient être suffisantes pour préparer des bouillies, que l'on peut supposer confectionnées à partir de grains et de graines conservés sous forme de farine dans les dolia. De la viande devait être débitée et consommée, probablement bouillie, dans ce local, sans que cette pratique ne soit généralisable à l'ensemble des boutiques de ce groupe ${ }^{163}$. La spécificité de cette catégorie de commerces est de se situer entre le restaurant et le débit de boissons. Cette situation est également perceptible à travers le local I 6, 5: la nombreuse vaisselle souligne clairement des capacités de préparation culinaire, tandis que la décoration du comptoir côté rue - un flacon de verre à moitié rempli de vin - indique le débit de boissons $^{164}$.

${ }^{163}$ Sur la préparation de la viande, cf. André 1981 : 146148. Ce couteau reste exceptionnel en raison de son statut d'unicum dans le matériel des boutiques alimentaires étudié ou aperçu par la consultation des archives. Il est possible que cette rareté des couteaux soit imputable en partie aux conditions des fouilles et au faible intérêt porté aux instruments en fer. Pour une hypotèse quant au fonctionnement du marché de la viande à Pompéi, cf. Monteix 2007 c: 191 194.

164 Une importante partie du matériel contenu dans cette boutique était rangée sous l'escalier et a été mise au jour le 9 juillet 1912. Le reste de la boutique a fait l'objet d'une fouille jusqu'au 27 juillet 1912 (cf. NSc 1912: 256257). La décoration du comptoir est décrite dans les NSc (1912: 250): «Sulla parete esterna del banco, all'angolo, è dipinto un fiasco di vetro monoansato ad orlo trilobato, per circa una quarta parte ripieno di vino (liquido rosso) [...]». Des 18 objets trouvés, seuls trois ont reçu un numéro d'inventaire: "Il secondo [...] [andito era] adibito a deposito di stoviglie. Vi si sono rinvenuti molti vasi di terracotta, alcuni dei quali dal fondo annerito pel contatto col fuoco: pignatte circolari senza anse, a fondo bombato, quattro; sferoidali biansate, due; ovoidali senz'anse, due, ovoidale biansate, 
II.2.3 Type 3: la vente de produits alimentaires non préparés

Les boutiques regroupées dans la troisième catégorie présentent un comptoir dans lequel sont insérés des dolia mais aucun dispositif de cuisson pouvant avoir été utilisé dans le cadre des activités commerciales. À Herculanum, le nombre de ces locaux est assez important: quatre qui représentent $30 \%$ des commerces alimentaires connus. Cette forte représentation doit toutefois être relativisée. Deux d'entre eux ont été particulièrement endommagés entre l'ensevelissement de la ville et sa fouille en aire ouverte, à tel point que leur comptoir est inévitablement incomplet, entraînant une incertitude quant au type auquel les rattacher ${ }^{165}$. Les deux seuls locaux pour lesquels l'insertion dans cette catégorie est hors de doute sont situés en façade de la Casa dell'Apollo citaredo (V, 9-10) et de la Casa del colonnato tuscanico (VI, 19).

Cette dernière boutique est composée d'une unique pièce, large de 4,90 $\mathrm{m}$ et longue de $8,04 \mathrm{~m}$. La majeure partie des murs a été retrouvée abattue lors de la fouille ${ }^{166}$. Au fond du local se développe sur toute sa largeur un

una; boccali monoansati, due, piatti rustici, due; piccole scodelle aretine, due [Inv. $\left.\mathrm{n}^{\circ} \mathrm{P} 1369\right]$; una pelvi [...], una grossa lucerna monolychne [...] [Inv. n P1368]; e con le descritte terrecotte, un vaso di bronzo [...] [Inv. $\left.\mathrm{n}^{\circ} \mathrm{P} 1367\right] »$ (NSc 1912: 250-251). Une partie a été exposée sur place (cf. Inventario mobile del materiale archeologico in situ, conservé dans les archives de Casa Bacco) probablement jusqu'au début des années 1980.

${ }^{165}$ Ces deux locaux sont situés en III, 6 et en V, 21. Voir p. 93 et 102 .

166 GSE 1961: «25 settembre. [...] le pareti laterali del Termopolio sono state trovate quasi del tutto abbattute $[\ldots]$ ».

${ }^{167}$ Cerulli Irelli 1974: 68.

${ }^{168}$ L'hypothèse d'une cave reste possible: non mentionné dans les GSE (1961: 25 settembre), l'enduit hydraulique actuellement visible pourrait être de restauration (Monteix 2006: 34, 71). Un aménagement similaire, quoique beaucoup plus profond, a été observé lors des fouilles de la boutique VI, 15 (Monteix 2007 b: 171-175); en fonction du premier quart du $\mathrm{I}^{\mathrm{er}}$ s. ap. J.-C. au séisme de 62, sa fonction reste indéterminée. Deux autres exemples existent à Herculanum, de taille plus réduite: l'un non fouillé devant le comptoir V, 9-10, le second dans la boutique IV, 17. Ce dernier exemple pose problème: il n'a pas été mis au jour par A. Maiuri, comme le montre son absence sur la photo escalier en deux volées qui permet d'accéder à l'appartement se développant au-dessus de la boutique mais également sur le front nord de la Casa del colonnato tuscanico ${ }^{167}$. Le principal aménagement de ce local est constitué par un comptoir en double équerre dans lequel sont insérés sept dolia. Un bras secondaire est appuyé contre le mur oriental. Il comporte deux jarres supplémentaires. Contre la paroi ouest s'élève un podium recouvert de plaques de marbre et probablement destiné à servir de présentoir pour une partie des denrées en vente. Aucun dispositif de cuisson, chauffe-eau ou table de cuisson, n'a été mis en évidence lors de la fouille. En plus du comptoir, le seul aménagement de cette boutique est constitué par une fosse profonde de 1,45 m, longue de 2,30 m et large de 1,30 m, située immédiatement à droite du seuil (fig. 53). Dans chacune de ses parois nord et sud, deux encastrements de solives ont été observés. Ils permettaient de disposer un plancher pour couvrir ce creusement. La fonction de cette fosse reste délicate à établir ${ }^{168}$. Enfin, au-delà du seuil se trouve un bloc de lave quadrangulaire évidé en son centre, servant de bouche à un puits ou à une citerne $\mathrm{e}^{169}$.

publiée (Maiuri 1958 b: fig. 383 p. 438). Il est possible que le trou qui se trouve devant le comptoir soit un sondage non rebouché et non publié.

À Pompéi, de tels creusements n'ont été pour l'instant aperçus que dans des phases antérieures à l'éruption, lors de fouilles récentes. S. Ellis et G. Devore (2008: 314-316), s'appuyant sur une liste de ces aménagements fréquemment situés en avant de locaux commerciaux, proposent un lien avec la transformation des poissons et mentionnent une datation au $\mathrm{I}^{\mathrm{er}} \mathrm{s}$. de notre ère. Enfin, un système approchant mais non excavé se trouvait devant le comptoir de la boutique III 6, 1: un muret en terre crue aurait servi d'enclos à volailles selon M. Della Corte (NSc 1936: 310-312). Il convient certainement de distinguer les fosses ayant un accès relativement aisé, éventuellement destinée à la conservation des denrées, de celles dont la profondeur empêche un accès facile et qui pourraient, si un revêtement hydraulique a été prévu, avoir servi dans le cadre de la transformation du poisson. Pour un bilan des aménagements liés à cette pratique, voir Botte 2009: 71-104.

${ }^{169}$ Les puits sont beaucoup plus fréquents à Herculanum qu'à Pompéi, en raison de la proximité de la nappe phréatique (Jansen 1991: 161-162). L'absence de fouille empêche de déterminer à quel dispositif hydraulique cette bouche est liée. 


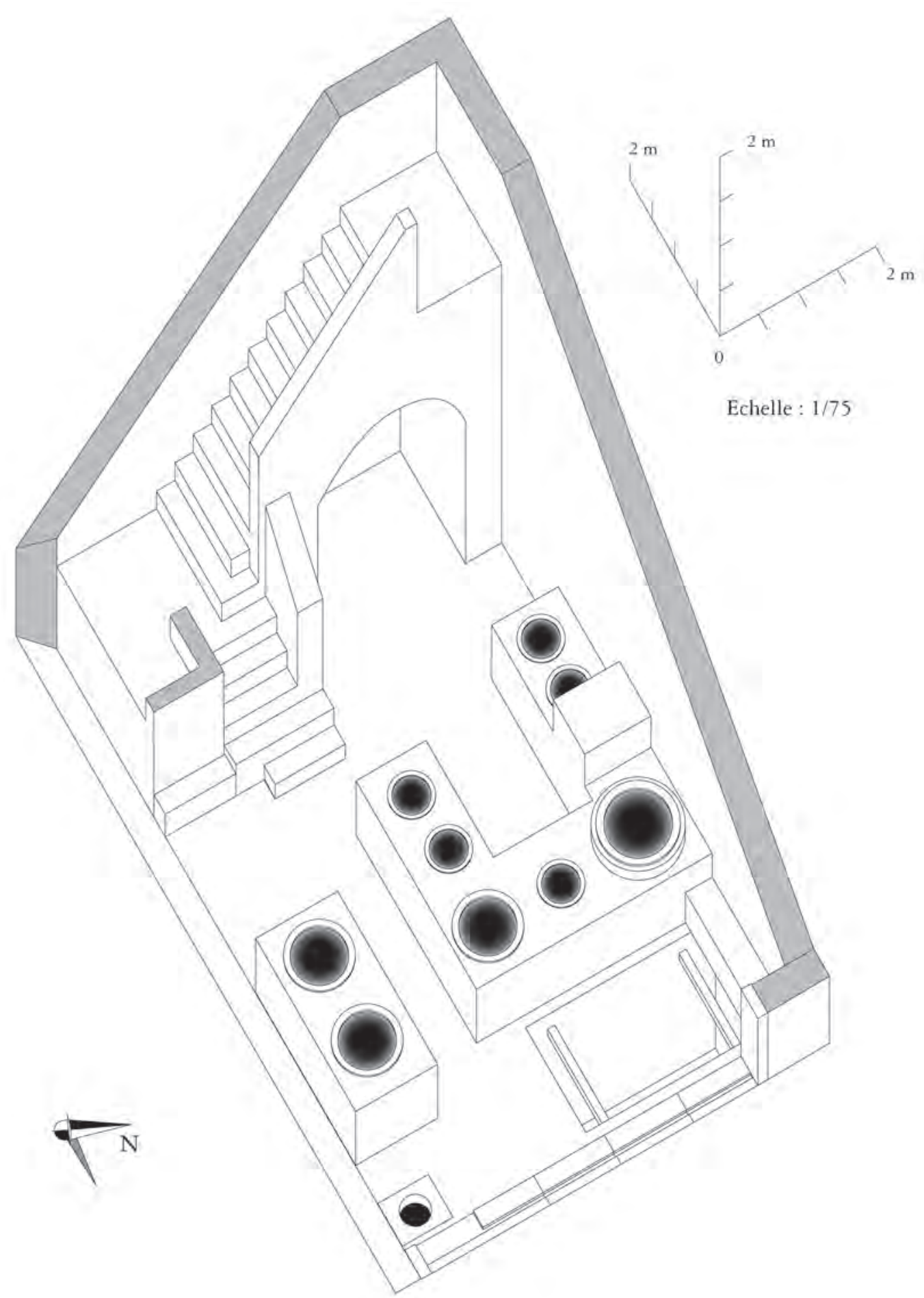

Fig. 53 - Restitution axonométrique de la boutique VI, 19 à Herculanum (échelle : 1/75). 
La boutique V, 9-10 située à l'angle nordouest de la Casa dell'Apollo citaredo présente des aménagements similaires ${ }^{170}$. En l'état actuel, ce local dispose de huit dolia: cinq sont partiellement enterrés dans l'aile sud, tandis que les trois autres sont insérés dans le comptoir. Il faudrait porter ce total à neuf en ajoutant le dolium non restauré dans le comptoir, voire à douze avec les trois jarres enterrées le long du mur oriental de l'atrium de la Casa dell'Apollo citaredo ${ }^{171}$. Dans la boutique, les destructions ne semblent pas avoir touché le bras oriental du comptoir si l'on se fie au maintien de l'enduit rouge sur la paroi verticale de son extrémité sud. Aucun chauffe-eau ne s'y serait donc trouvé. Sur la paroi sud, trois rangées superposées de trous pour l'encastrement de supports indiquent la présence d'une étagère, sans qu'il soit possible de définir une éventuelle spécialisation comme porte-amphores (fig. 54). Contrairement à ce que propose A. Maiuri, aucune trace ne permet de supposer l'existence d'une mezzanine ou d'un accès à l'étage lors de la dernière phase ${ }^{172}$. Une canalisation contenant un tuyau en plomb traverse la boutique d'ouest en est. Son installation tardive a obligé à détruire partiellement le pavement, sans restaurer sa décoration. Ce tuyau passe ensuite dans un autre conduit, également utilisé pour convoyer les eaux de pluie dans la citerne dont la bouche se situe dans la boutique ${ }^{173}$. Aucun élément ne permet de déterminer son point d'arrivée dans la maison. Enfin, en devanture du comptoir se trouve une fosse - non fouillée - de taille plus réduite que celle de VI, 19. Elle s'étend sur 1,28 m de longueur

${ }^{170}$ Sur la décoration de ce local, cf. supra, p. 62.

${ }^{171}$ GSE 1938: « 5 settembre. L'ambiente 32 della casa 31 è un termopolio. Il banco di vendita è spezzato all'estremità ovest. Conserva due doli ben conservati e altri quattro, così divisi: due nel banco e due sul pavimento rotti. Il podio è rivestito di marmi colorati, asportati dagli scavatori borbonici ». Cette description ne concerne que le comptoir, sans mentionner les dolia enterrés au sud de celui-ci. Rien ne permet d'expliquer l'absence de restauration des trois jarres qui ne sont pas insérées dans cet aménagement actuellement.

${ }^{172}$ Maiuri 1958 b: 251.

${ }^{173}$ Cette façon d'utiliser des conduites maçonnées pour installer des canalisations en plomb d'eau sous pression

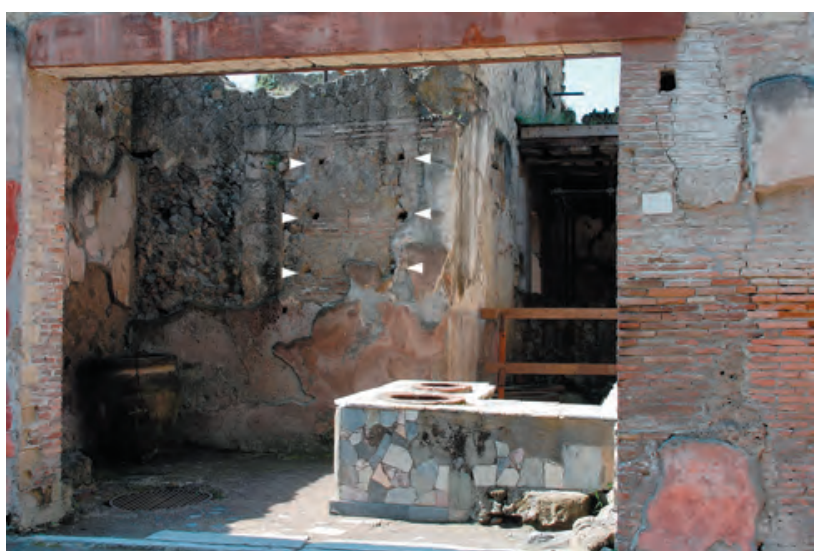

Fig. 54 - Commerce alimentaire (V, 9-10) en façade de la Casa dell'Apollo citaredo. Sur le mur du fond, six encastrements (soulignés par des flèches) devaient servir de support soit à une étagère, soit à un porte-amphores (cliché pris du nordouest).

pour $0,33 \mathrm{~m}$ de largeur. Ses parois internes sont recouvertes d'un enduit rosé pouvant avoir des propriétés hydrauliques. Contrairement à celle de VI, 19, elle pourrait avoir été protégée du côté de la rue par un petit muret.

Les caractéristiques de ces deux locaux sont très proches. Dans les deux cas, aucun dispositif de cuisson n'a été identifié, ce qui interdit toute interprétation comme restaurant. Ces deux boutiques n'ont pas permis la découverte d'objets permettant de compléter les informations fournies par les aménagements construits ${ }^{174}$. Toutefois, cette situation pourrait être le fruit combiné du hasard, des différentes destruc-

paraît courante à Herculanum. Un autre exemple se situe dans la Casa di Nettuno e Anfitrite (V, 6-7). Ladduction d'eau, également tardive, utilise le conduit de trop-plein de l'impluvium pour traverser l'atrium vers le nymphée et la pièce 6 , probable salle de bains. Dans ce cas comme dans celui de la Casa dell'Apollo citaredo, la conduite maçonnée sert tout autant à faire circuler l'eau de pluie qu'à faciliter la mise en place de l'eau sous pression.

${ }^{174}$ Un seul objet a été inventorié dans la boutique V, 9-10: une lampe à deux mèches (Inv. n E1948=77228), découverte à proximité du comptoir. Pour le local VI, 19, cf. GSE 1961: 25 settembre, cit. supra, n. 97. 
tions survenues depuis le processus d'ensevelissement et des méthodes de fouille. L'existence d'un point d'eau sous la forme d'une citerne ou d'un puits ne peut pas nécessairement être mise en relation avec la nature des activités commerciales: un tel accès peut avoir été utilisé pour des besoins domestiques ${ }^{175}$. En revanche, le nombre de dolia est relativement important dans ces deux locaux. Cette caractéristique se retrouve également à Pompéi : la moyenne des dolia dans les 158 commerces alimentaires de la ville est de 2,4 jarres par boutique; si l'on ne considère que les 26 du troisième type, cette moyenne s'élève à 4 dolia par local. À quelques exceptions près, c'est également dans cette catégorie que l'on retrouve les locaux disposant du plus grand nombre de ces conteneurs en valeur absolue ${ }^{176}$. D'une façon générale, en suivant l'hypothèse proposée quant au contenu de ces jarres, il faut considérer ces locaux comme des commerces alimentaires de denrées en vrac, non cuisinées. Le plus grand nombre de dolia en moyenne renverrait ainsi à une plus grande variété d'aliments vendus.

II.2.3 Type 4: les débits de boissons sans service de restauration

La quatrième catégorie de cette proposition de typologie, tout comme les deux suivantes, inclut des locaux qui sont dotés d'un comptoir

\footnotetext{
${ }^{175}$ La bouche de citerne de la boutique V, 9-10 constitue le seul point d'accès à une réserve d'eau pour l'ensemble de la Casa dell'Apollo citaredo. En ce qui concerne VI, 19, le point d'eau n'aurait servi qu'à l'appartement situé au-dessus du local. Pour un autre exemple à Herculanum de citerne dans un commerce bénéficiant d'une unité domestique à l'étage, cf. Monteix 2006: 34-37.

${ }^{176}$ La boutique (VI 8, 8) en façade de Casa del poeta tragico qui appartient au premier groupe des restaurants dispose de 16 dolia; la boutique "de L. Vetutius Placidus» (I 8, 8), située dans la seconde catégorie, dispose de 13 de ces jarres.

${ }^{177}$ Bien que celle-ci ne soit pas indiquée dans les GSP, il est impossible qu'elle se soit limitée aux $35 \mathrm{~cm}$ restaurés.

${ }_{178}$ Une assiette (Inv. $\mathrm{n}^{\circ} \mathrm{P} 5990$, portant le timbre in planta pedis dextrorsum de Cn. Ate(ius) $\mathrm{Ma}$ ( ) [CVArrII 298,1], de forme Conspectus 3) et une coupe (Inv. n P5991, sans timbre, détruite lors du bombardement de 1943, mais dont la description correspond au type 34 du Conspectus: «Frammenti di un cratere con motivo di festoni e fiori a rilievo all'esterno") en céramique arétine ont été découvertes dans ce local le 28 février 1936. Ces deux objets
}

maçonné mais dépourvus de tout dolium. Dès lors, leur lien avec le commerce alimentaire pourrait être remis en question. Les boutiques du groupe 4 disposent toutefois d'un unique aménagement pour la cuisson, constitué par un chauffe-eau. Aucun local de cette sorte n'ayant été mis en évidence à Herculanum, il faut se tourner vers Pompéi. Des 26 boutiques de ce type que l'on trouve dans cette ville, celle située en I 7, 13-14 permet une étude approfondie. Les restaurations qui y ont été effectuées se sont appuyées sur les maigres vestiges ayant subsisté, sans toutefois lui redonner son élévation originelle ${ }^{177}$. De la même façon, le chauffe-eau situé à l'extrémité nord, reconnaissable à l'excroissance qu'il occasionne dans la largeur du comptoir, n'a pas été reconstruit. Il est trop endommagé pour permettre sa reconnaissance complète et vérifier la présence ou non d'une plateforme de cuisson. Le matériel découvert tant dans le local que dans d'autres parties de la maison permet de préciser les activités conduites dans cette boutique. Toute la vaisselle qui est décrite renvoie majoritairement au service ou à la consommation de boissons ${ }^{178}$. Par ailleurs, des amphores en nombre indéterminé ont été trouvées dans le local proprement dit ${ }^{179}$. Il faudrait également leur ajouter celles rangées renversées à l'étage en deux files superposées: il s'agit du stock d'amphores vides de la boutique conservées en

pourraient provenir du premier étage ou être tombés d'une étagère. En dépit de l'absence de numéro d'inventaire et des problèmes d'appellation dans les GSP, les objets découverts le 5 mars 1936 renvoient à la vaisselle de service ou de consommation de boisson. Cf. GSP 1936: « 5 marzo. [...] Sul pavimento dietro al banco si è rinvenuto: [...] Vetro. Frammenti di vasoio, bottiglia e bicchiere non restaurabile. Terracotta. Anfora ovoidale, alt. m. 0,65 [...]».

${ }^{179}$ GSP 1936: « 27 febbraio. [...] Nell'ambiente rustico a sud comunicante col vano $\mathrm{n}^{\circ} 13$ incominciano ad affiorare anfore ed un'iscrizione dipinta col carbone sull'intonaco laterizio della parete est [...].

2 marzo. [...] Le ricerche condotte in profondità in detta bottega vanno restituendo alla luce un ampio termopolio, di cui si è nettamente delimitato il banco di vendita con anfore in deposito ed una stanzetta laterale in servizio del commercio che vi era esercitato [...]». M. Della Corte en recense huit de forme Schoene VIII pouvant être des amphores crétoises (NSc 1946: n 12-20 p. 86-87) et une de forme Schoene XIII (NSc 1946: n $^{\circ} 11$ p. 86). Ces conteneurs et un dixième ont été inventoriés (Inv. $n^{\circ}$ P6016-6025) sans être mentionnés dans les GSP. 
attendant d'être remplies de nouveau (fig. 55) ${ }^{180}$. Celles qui se situent encore sur place sont essentiellement de type Dressel 2-4. D'autres, non mentionnées dans les comptes rendus de fouilles et dont la localisation originelle au sein du local reste à déterminer, seraient, selon les livres d'inventaire de forme Schoene VIII, fréquemment assimilables à des amphores vinaires crétoises $^{181}$. Ces éléments forment un faisceau convergent de données qui permet d'interpréter cette boutique comme un débit de boissons, à l'exclusion de toute activité de préparation culinaire. Les 26 locaux de type 4 formeraient ainsi les seuls «bars» de Pompéi.

\section{II.2.5 Type 5: des restaurants aux capacités} de stockage incertaines

Cette cinquième catégorie des commerces disposant d'un comptoir maçonné comporte tous ceux qui sont dépourvus de dolium mais présentent pourtant au minimum une table de cuisson, à laquelle est éventuellement adjoint un chauffe-eau. Le local Or. II, 9 à Herculanum - théoriquement exclu de cette typologie car présentant un comptoir en bois à la place d'un te aménagement maçonné182 - est un exemple de cette situation. À côté de la latrine, une table de cuisson a été aménagée contre une porte murée,

${ }^{180}$ GSP 1935: « 25 novembre. [...] Lo scavo completo del luogo ha messo in luce un interessante deposito di anfore di terracotta collocate capovolte in due filari sovrapposti al disotto della anzidetta tettoia. Per quanto è possibile si liberano i vasi dalla cenere compatta lasciandoli in situ e se ne esegue un rilievo fotografico di un gruppo di diciotto [...]». Ces amphores sont effectivement restées en place jusqu'à l'écroulement du plancher les supportant. Sans une étude complète de cet amas de tessons, il est impossible de les dénombrer. L'hypothèse, proposée de façon très générale par A. Varone (2008: 351), faisant de ces amas d'amphores des réservoirs destinés à stocker de l'eau en l'absence de fonctionnement de l'aqueduc paraît devoir être repoussée, au moins dans ce cas.

${ }^{181}$ Cf. Marangou-Lerat 1995: 131-132.

${ }^{182}$ GSE 1936: 31 dicembre, cit. supra, n. 114 p. 63.

${ }^{183}$ Ce ramassage incomplet s'expliquerait par l'état des amphores lors de leur découverte. Cf. GSE 1936: «13 febbraio. [...] Nell'ambiente 2 della casa 9 posta sul V cardine Insula orientale vi sono moltissime anfore sia sul solaio del piano superiore che a quello inferiore, ma quasi tutte ridotte in pezzi da non potersi raccogliere e restaurare. Dette anfore servivano per conservare olio, vino e altro occorrente al termopolio posto nell'ambiente precedente».

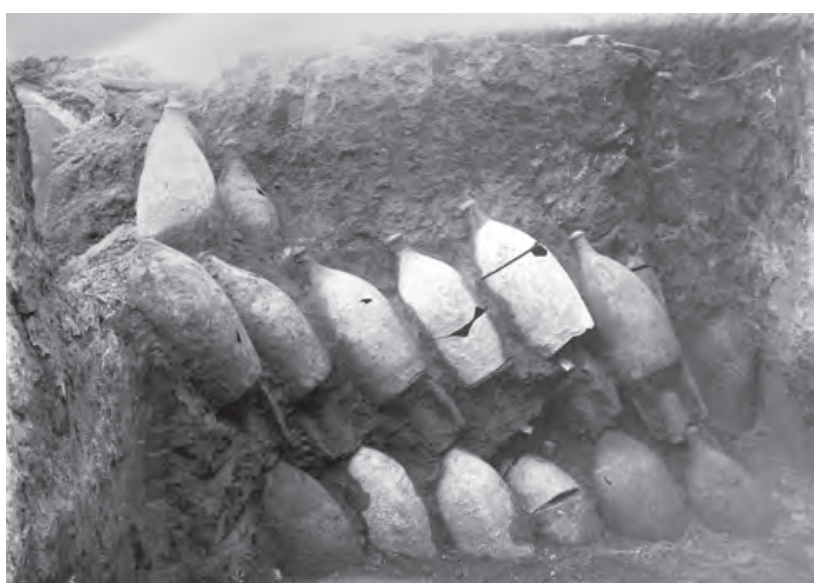

Fig. 55 - Amphores stockées tête-bêche à l'étage de la boutique I 7, 13-14. Toutes celles qui sont identifiables sur la photo sont des amphores vinaires de type Dr. 2-4.

mais aucun dolium n'est mentionné dans les GSE ou visible actuellement. Des amphores, essentiellement vinaires, ont été mises au jour tant dans le local principal que dans la pièce annexe ou à l'étage accessible depuis la boutique, et partiellement prélevées ${ }^{183}$. Une erreur de transcription dans les journaux de fouilles indique pour certaines d'entre elles le local Or. II, 5 comme lieu de découverte ${ }^{184}$. À partir des inscriptions

${ }^{184}$ À la date de découverte, le local Or. II, 5 a déjà été intégralement fouillé. La dernière mention explicite du local Or. II, 5 remonte au 23 janvier 1933. Pour des raisons pratiques, il est difficilement crédible que ce local n'ait pas été intégralement fouillé en mars 1936, alors que la pièce à abside de la "Palestre » a été mise au jour. Enfin, après l'entrée du 30 juin 1936, un résumé des travaux effectués au cours de l'année écoulée est dressé. Cf. GSE 1936: «Dal 1 luglio 1935 al 30 giugno 1936 si sono eseguiti i seguenti lavori di sterro. Quattro gruppi tra case ed edifici si sono posti alla luce [...] Quarto gruppo. Ambienti numero 6, 7 e 8 posti sul $\mathrm{V}$ cardine nella $2^{\circ}$ Insula orientale [...]». Cette mention pourrait renvoyer aux locaux dont la fouille a été presque achevée entre le $1^{\text {er }}$ juillet 1935 et le 30 juin 1936. De cette façon, l'entrée «[...] Nella casa n. 5 posta sulla $2^{\circ}$ Insula orientale, ambiente 2 , sul solarino abbattuto [del piano superiore] si è raccolto [Description d'un col d'amphore pourvu de l'inscription peinte CIL IV, 10722]» (GSE 1936: 24 marzo) ainsi que celles des deux jours suivants ne renverraient pas au local Or. II, 5 mais à la boutique Or. II, 9. Les notes de M. Della Corte (1958: n $^{\circ}$ 587, 589-590 p. 283) sont éclairantes sur ce point. Pour chacune de ces amphores, vues lors de sa visite sur le site du 8 avril 1936, il considère qu'elles proviennent d'Or. II, 9. 
relevées et de la détermination des conteneurs, quand c'est possible, le vin paraît avoir été le produit le plus fréquemment conservé, essentiellement dans des amphores égéennes ${ }^{185}$. Certaines d'entre elles portent un nom pouvant être interprété comme renvoyant au tenancier de cette boutique de vente de vin ${ }^{186}$, avec éventuelle consommation au détail sur place: M. Livius Alcimus ${ }^{187}$. L'autel du culte domestique situé dans le mur nord de la pièce principale représente les Pénates - Mercure, Bacchus et Hercule - et des serpents autour d'une niche. Lassociation des deux premiers renvoie au commerce du vin tandis que le troisième serait la divinité tutélaire de la cité ${ }^{188}$. Par ailleurs, sous plusieurs objets en céramique arétine, majoritairement retrouvés dans la boutique, on trouve le nom de M. Livius Alcimus - au génitif -, probable marque de propriété de ces éléments de service. Si trois des quatre cas sont d'interprétation difficile ${ }^{189}$, le quatrième est identifiable avec une assiette, retrouvée dans l'ambulacre de la « Palestre ${ }^{190}$.

185 Les amphores sont soient des crétoises AC2 (CIL IV, 10794 [= Marangou-Lerat 1995 : cat. ${ }^{\circ}$ P88], 10881, 10882a-b, 10890 [= Marangou-Lerat 1995: cat. n P22], 10913), soit proviennent de Chios (CIL IV, 10722), soit sont de type Schoene XIV = Pompei 6 (CIL IV, 10784). Certains fragments restent de forme indéterminée (CIL IV, 10761, 10785-10786, 10877, 10899).

${ }^{186}$ C'est déjà ainsi qu'A. Maiuri (1958 b: 462) a interprété cette boutique, qu'il appelle taberna vinaria.

${ }^{187}$ Des deux amphores de type Schoene XIV = Pompei 6 portant ce nom complet au génitif (Della Corte 1958: cat. $\mathrm{n}^{\circ} 298$ p. $265=C I L$ IV, 10787 et cat. $\mathrm{n}^{\circ} 587$ p. $283=$ CIL IV, 10784), une a été retrouvée dans les dépôts d'Herculanum (Inv. n E2596=77893). Bien que l'inscription soit fortement dégradée et en dépit des critiques formulées par H. Solin (1973) à l'encontre des lectures de M. Della Corte, celle-ci est juste. Trois autres amphores ont été trouvées dans la boutique et portent ce nom incomplet (CIL IV, 10784-10786). D'autres exemplaires ont été mis au jour en V, 5 (CIL IV, 10787) et en Or. II, 11 (CIL IV, 10788).

188 GSE 1936: "14 luglio. Sulla parete Nord dell'Ambiente 9 , sul V Cardine, lato est, è stato sterrato un quadro con tre soggetti mitologici. Al centro vi è Bacco seduto su una sedia, che con la mano destra tiene un recipiente curvo verso terra e da esso scorre un liquido che si versa sopra un animale (pantera ?). Di fronte alla divinità vi è un Mercurio che porge a Dioniso la borsa con la mano destra mentre la sinistra stringe il caduceo. Alle spalle dell'idolo pare che vi sia Ercole [...]». Cf. Maiuri 1958 b: 362. Sur le rôle d'Hercule dans la peinture à Herculanum, cf. Coralini 2001 : cat. $\mathrm{n}^{\circ}$ E001 p. 235.
En considérant que l'inscription portée sur les amphores indique le tenancier de ce local et qu'il s'agit de la même personne dont le nom est incisé sous la vaisselle de service, il faut supposer que le local Or. II, 9 dépasse les fonctions de simple débit de boissons et a également proposé un minimum de restauration. La question du stockage des denrées alimentaires très probablement cuisinées dans cette boutique reste ouverte, faute de reste de matière organique dans la pièce principale ou dans les annexes. En l'absence de tout dolium, il faut donc proposer que la nourriture ait été entreposée en sacs ou en amphores à l'étage. Vingt-quatre locaux pompéiens peuvent appartenir à cette catégorie: sans aménagement de stockage reconnaissable, mais dotés de structures de cuisson dépassant le $\mathrm{CE} / \mathrm{F}$ isolé, pointant vers des fonctions de restauration ${ }^{191}$. Si aucune explication à cette absence de structure maçonnée pour la conservation des denrées ne peut être proposée, les considérer comme des restaurants paraît l'unique interprétation possible.

${ }^{189}$ Un premier exemplaire a été trouvé en Or. I, 1 le 16 février 1934. Il porte le timbre in planta pedis dextrorsum de Cn. Ate(ius) $\mathrm{Ma}$ ( ) (CVArrII 298, 2 / 8) qui peut se trouver sur des assiettes (Conspectus 20.4/3) ou sur des coupes (Conspectus 37 / 34). L'intégration de l'inscription incisée au revers proposée par M. Della Corte reste sujette à caution [CIL IV, 10859: M(arci) Livi Alcimi so(dalis?)]. Un second exemple provient du chemin situé au sud de l'insula Orientalis II ${ }^{a}$ (GSE 1935: 14 giugno). Le timbre reporté dans les journaux de fouilles est difficilement lisible et reste sans correspondance dans le CVArrII. Au revers a été incisée l'inscription CIL IV, 10857 [M(arci) Livi Alcimi]. La troisième attestation de ce marquage provient de la "Palestre » (GSE 1936: 8 gennaio). Il présente le timbre in planta pedis dextrorsum de S[extius] M[urrius] F[estus] (CVArrII 1212, 42 / 43) qui n'est attesté que sur des coupes de forme Conspectus 34.1 ou B4.1-10. Au revers se trouve l'inscription CIL IV, 10858 b [M(arci) Livi Alcimi].

${ }^{190}$ Seul le fond a été conservé. Il porte à l'intérieur la marque inversée in planta pedis sinistrorsum de Fortu(natus) (CVArrII 848, 1). De très nombreux exemplaires de cette assiette de forme Conspectus 3 ont été mis au jour à Pompéi (Pucci 1977: 14-15). Au revers, le nom M(arci) Livi Alcimi (CIL IV, 10858 a) a été incisé.

${ }^{191}$ Dans la boutique «de Stabilio Oenoclion » (I 19, 1-2), seule la partie du comptoir donnant sur la rue a été mise au jour, sans que des dolia ou des aménagements de cuisson ne soient trouvés. Les objets mis au jour empêchent de la considérer comme un commerce non alimentaire (supra, n. 94 et fig. 32). Toute autre forme de détermination étant impossible, je l'ai placée par défaut dans le groupe 5. De la même 
II.2.6 Type 6: des commerces non alimentaires

La dernière catégorie de cette typologie comporte tous les locaux disposant de comptoirs maçonnés mais dépourvus de moyen de stockage de denrées et d'aménagement pour la cuisson. Si aucun exemple de ce type ne se trouve à Herculanum, l'atelier de plombier VI, 12 a été affublé de l'appellation termopolio au début de sa fouille à cause de la présence d'un comptoir maçonné. Cette première interprétation a eu des conséquences importantes, cet aménagement ayant été restauré en équerre, pour mieux se conformer aux supposées caractéristiques classiques de ces boutiques, au mépris de la situation de découverte ${ }^{192}$. Des présupposés identiques ont amené certains locaux à être considérés comme des bars, en particulier ceux situés en VII 3, 13, VII 3, 23 et VII 5, 28 seraient des bars ${ }^{193}$. Tous trois présentent un comptoir dont la partie supérieure est constituée par des blocs de calcaire en remploi. La similtude d'agencement avec l'atelier VI, 12 a permis d'envisager à titre d'hypothèse que les activités de ces locaux aient été tournées vers la métallurgie - peut-être du plomb ${ }^{194}$ : cette proposition a été confirmé en VII 5, $28^{195}$.

Dans d'autres exemples, comme le local II 2, 3, la présence d'un comptoir en bois et l'appellation de termopolio donnée par M. Della Corte ne suffisent pas à transformer la boutique en commerce alimentaire ${ }^{196}$. Bien au contraire,

façon, le local situé en VIII 4, 25 présente un comptoir fortement dégradé, réduit à une maigre portion ne comportant plus que les gradins et les restes d'une vasque maçonnée. G. Fiorelli (1873: 7) a proposé que la suite du comptoir de ce «termopolio» soit en bois. Faute d'autres données et à défaut d'avoir cherché les traces de l'extension du comptoir, j'ai considéré que le local s'inscrivait par défaut dans le type 5 , sachant qu'il pourrait correspondre à n'importe lequel des quatre premiers types. Les deux locaux I 1, 1.1a.10 et I 1, 3-5 ont été interprétés selon un même schéma. Disposant tous deux d'un comptoir pourvu d'un chauffe-eau, ils auraient dû être considérés comme des débits de boissons. Toutefois, le matériel mis au jour permet de supposer des fonctions de restauration et donc de les compter parmi les restaurants où les denrées ne sont pas stockées dans des dolia. La présence d'une meule manuelle dans le local I 21, 4-5 qui dispose d'un chauffe-eau détaché du comptoir - qui est presque arasé - permet d'y restituer des fonctions de restauration. Le raisonnement est identique pour la boutique VII 7, 11 (cf. Sorgente - Fiorelli [1860]: B5 ; Fiorelli 1875 : 246-247). l'absence simultanée d'aménagement pour la cuisson ou pour le stockage appelle à ce que cette classification soit démontrée. Le doute peut toutefois subsister quant à ce local. En effet, plusieurs graffites renvoient à des repas ou à une consommation de vin ${ }^{197}$. Seule l'étude du matériel permettrait de réintégrer ce local parmi les commerces alimentaires, dans la catégorie 5 le cas échéant.

\section{Perspectives pour L'étude des commerces ALIMENTAIRES}

Dans les choix effectués lors de cette étude des commerces alimentaires, la présence d'un comptoir a été déterminante. Pourtant, ce critère très commode est finalement le moins significatif. En effet, les 8 commerces pompéiens placés dans la sixième catégorie comportent un tel aménagement mais ne présentent guère les autres éléments indispensables à leur qualification parmi les restaurants, débits de boissons ou boutiques de denrées alimentaires en vrac: le comptoir, qu'il soit maçonné ou non, n'est en rien caractéristique des tabernae ${ }^{198}$. En recensant à Pompéi 166 boutiques pourvues d'un comptoir, dont 158 sont liées à l'alimentation - soit plus du quart des locaux commerciaux de cette ville selon le dénombrement de V. Gassner ${ }^{199}$ - j'ai bien conscience de ne pas atteindre une quelconque exhaustivité: il est hautement probable que des aliments aient été vendus dans

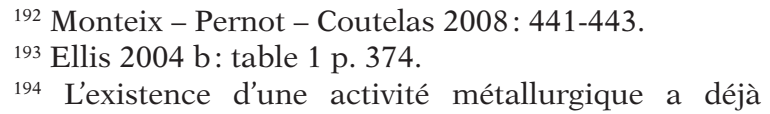
été proposée par L. Eschebach (1993: 267) pour le local VII 3, 13.

${ }^{195} \mathrm{La}$ fouille a permis de mettre en évidence trois ateliers successifs au moins partiellement tournés vers la métallurgie du plomb en VII 5, 28. Le nettoyage de VII 3, 23 n'a pas permis de conclure: soit le sol de circulation en usage en 79 a été emporté par les premiers dégagements, soit il était en cours de finition au moment de l'éruption. Sur ces deux locaux, cf. Monteix - Rosso 2008: 244-247.

${ }^{196}$ NSc 1927: 100.

${ }^{197}$ CIL IV, 8489: Oliva condita / XVII K(alendas) novembres; CIL IV, 8490: Avete, utres sumus / cot [pro quod] estis, (a)ere voluimus / Quando venistis (a)ere exi(vi)mus; CIL IV, 8491 : Dea nolo cenam v(e)nde(re) / chirograp (h)um s...

${ }^{198}$ Contra Mac Mahon 2005 b: 70, 85; 2005 a: 48.

199 V. Gassner (1986: 83) recense 577 boutiques à Pompéi. 
des locaux dépourvus de comptoir maçonné ou de stockage dans des dolia - sans même évoquer les boulangeries et le commerce ambulant. Certaines mentions dans les archives de fouilles permettent d'en reconnaître certains sans toutefois pouvoir toujours les localiser avec précision. Plusieurs exemples peuvent être évoqués brièvement. La mise au jour d'un vase contenant des noix dans une boutique de l'îlot VIII 5 pourrait indiquer le premier commerce alimentaire de cette insula ${ }^{200}$. Une quantité non précisée de grain et de graines identifiées comme du chanvre a été trouvée dans une boutique située à l'ouest de l'îlot VII 13 ${ }^{201}$. Les 113 amphores découvertes en IX 2, 9, boutique dépourvue de comptoir maçonné, pourraient caractériser un débit de boissons (type 4) ou un commerce de vente de vin comme en IV, 14 à Herculanum ${ }^{202}$. Enfin, le local I 7, 4 pourrait être considéré comme un restaurant, comme le suggèrent les pots en verre contenant des denrées, le réchaud en fer trouvé sur un podium maçonné. La difficulté est ici de déterminer la fraction des objets découverts ayant eu un usage commercial et non domestique $^{203}$.

Les différents types que j'ai définis sur des fondements prioritairement architecturaux renvoient à une large palette de fonctions, autrefois regroupées sous l'appellation inadéquate de «thermopolium». Cette analyse détaillée

200 «21 Giugno [1841] - Il travaglio seguita sempre nel descritto modo, cioè [...] nell'approntare le stanze nelle abitazioni a dritta la strada de' Mercadanti, e proprio quelle subito il vicoletto dei 12 Dei. Nel secondo dei nominato travagli, in un vaso in frammenti di terracotta, si sono raccolte varie noci carbonizzate» (PAH II: 398-399).

201 « 6 ottobre [1821] - Nel disterrarsi una bottega alla dritta della strada sita al lato opposto del Foro civile, si sono rinvenuti i seguenti oggetti [...] Dippiù una quantità di grano, ed altra di seme di canapa abbruciata. E finalmente un pezzo che sembra pane, anche abbruciato [...]» (PAH II : 40-41). Il est peu probable que cette boutique soit le local VII 13, 24, qui pourrait n'avoir été fouillé que durant le mois de novembre 1821 (PAH II : 43-44).

${ }^{202}$ GSP 1862: 23-24 settembre. Sur le local IV, 14, cf. supra, p. 78-79.

${ }^{203}$ Les pots en verre, contenant des dattes, des figues et "une matière grasse » ont été trouvés lors de la mise au jour de la Via dell'Abbondanza, avec un entonnoir (NSc 1912: 66-67; cf. aussi Borgongino 2006: cat. $n^{\circ} 74$ et 166). La reprise des fouilles en avril 1924 a amené à la découverte complète du local et de sa cuisine: «Al muro perimetrale des systèmes de cuisson permet de donner une image plus précise de la variété des pratiques du commerce alimentaire ${ }^{204}$ : la distinction fonctionnelle entre aliments cuisinés, nourriture vendue en vrac et débits de boissons permet non seulement d'appréhender les variations dans la pratique culinaire, mais également de cerner certains aspects de la répartition de ces locaux dans la ville. Quel que soit le destin de l'hypothèse formulée ci-dessus, qui voudrait considérer les dolia des commerces alimentaires plus comme des conteneurs à denrées solides que comme des récipients à liquides, la typologie que j'ai proposée ne changerait guère, ses fondements étant les aménagements observés. En revanche, dans le cas d'une infirmation - même partielle - de cette proposition, les interprétations fonctionnelles de chaque groupe devraient être revues.

Cette approche typologique ne va toutefois pas sans poser de problèmes: dans certains cas, l'application stricte des critères architecturaux peut générer des difficultés, notamment entre les types 4 et 5 : la découverte d'un objet propre à la préparation alimentaire - sous réserve de son utilisation commerciale, difficilement démontrable - suffit à faire basculer un local d'une catégorie à l'autre. Il faudrait également réussir à intégrer une dimension diachronique à ce classement, ne serait-ce que pour prendre

di ovest è appoggiata una cucina in muratura con suvvi un treppiede» (NSC 1927: 15; cf. également GSP 1924: 3-12 aprile).

${ }^{204}$ Cette variété va au-delà de la répartition typologique proposée par S. Ellis (2004 b: 373-375). Il recense 158 locaux pourvus d'un comptoir et estime qu'au moins $128(81 \%)$ étaient impliqués dans la vente de boissons et de nourriture. Pour avoir la même base de calcul que lui, il faudrait ajouter les cinq boutiques situées de part et d'autre de la via dei Sepolcri, écartées car situées en dehors du périmètre urbain et donc sans comparaison possible à Herculanum. Dans le bâtiment situé au nord-est de la rue, quatre commerces alimentaires sont reconnaissables. Au $\mathrm{n}^{\circ} 1$, le comptoir comporte 4 dolia mais pas de dispositif de cuisson (type 3); un $\mathrm{CE} / \mathrm{F}$ est installé entre les deux piliers qui bordent le $\mathrm{n}^{\circ} 2$ (type 4 ou 5); le même aménagement se trouve au milieu des locaux situés aux $n^{\circ} 4$ et 5 , probable vestige d'un comptoir ayant pu comporter des dolia (type 2, 4 ou 5). En façade de la "Villa de Cicéron», un comptoir maçonné présente un orifice circulaire, pouvant être un dolium (type 3 ?). Sur ces locaux, cf. Mazois 1824 a: 55 et pl. XXXVIII; Sorgente - Fiorelli [1860]: tav. A1. 
en compte les variations liées aux événements sismiques des dernières années de ces cités ${ }^{205}$. Le trépied découvert en I, 9, 11 pourrait ne s'être trouvé que casuellement dans ce local en rénovation, que ce soit en raison des éventuelles transformations d'activités en cours ou pour un usage domestique ${ }^{206}$. D’une manière générale, une étude aussi précise qu'exhaustive du matériel retrouvé dans ces commerces alimentaires permettrait de vérifier la validité de cette typologie. L'absence d'amphore ou la découverte de vaisselle de préparation culinaire dans des locaux réputés de type 4 obligerait à revoir intégralement cette catégorie. Inutile de masquer la difficulté d'une telle entreprise: sans évoquer les boutiques fouillées avant les années 1860 dont les objets ne sauraient que très difficilement être retrouvés dans les réserves du MANN, les choix d'inventaire lors des travaux conduits au $\mathrm{XX}^{\mathrm{e}}$ siècle ne facilitent guère la tâche $\mathrm{e}^{207}$.

Outre ces difficultés propres à la création d'une typologie, quelques pistes devraient être explorées pour l'approfondir. Un premier point serait d'analyser plus en détail les pièces annexes, pour tenter de distinguer les espaces de préparation, de consommation - pour les seuls restaurants et débits de boissons - et de stockage en dehors du local principal. Une étude rapide du commerce IV, 15-16 montre les problèmes de ce type d'analyse (fig. 56). L'espace de préparation est bien délimité à la pièce 8 où se situe la table de cuisson. Une partie des capacités de stockage est évidemment située dans le local principal avec les dolia, mais également à l'étage où de nombreuses amphores ont été mises au jour ${ }^{208}$. Proposer une fonction aux pièces 6,7 et 9, qui

${ }^{205}$ L'exemple de la boutique I 9, 11 est caractéristique. Tels que l'on peut les voir actuellement, les aménagements de ce local indiquent qu'il appartient au type 4 : un comptoir en équerre dépourvu de dolium dispose d'un chauffe-eau à son extrémité. La consultation des archives lors des fouilles de l'université de Reading a fait ressortir des travaux lors de l'éruption (Berry 1997 a). Cependant, un trépied en fer s'y trouvait, pouvant indiquer des possibilités de préparation culinaire normalement absentes de ce type de local.

${ }^{206}$ Dans la pièce 9 de la maison I 9, 11-12 se trouve une cuisine, dans laquelle des niveaux de cendres ont été mis en évidence, mais qui ne présentait que très peu de matériel de préparation culinaire (Berry 1997 a: 120).

${ }^{207}$ Cf. supra, n. 164 p. 120 pour l'exemple du devenir des objets découverts dans la boutique I 6, 5 .

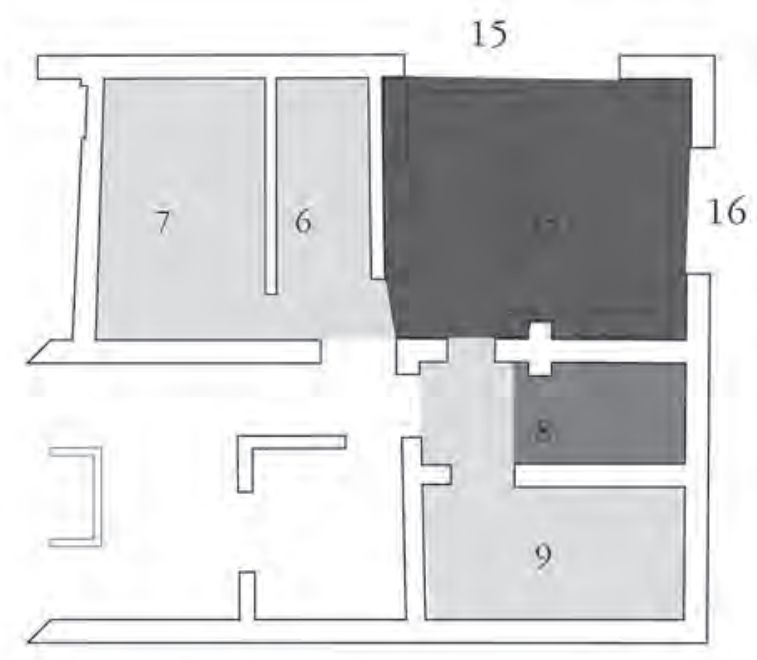

$\square$

Local principal

Espace de préparation

Pièces de stockage et

d'accueil de la clientèle

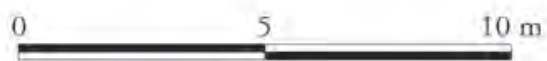

Fig. 56 - Fonction des pièces dans la boutique IV, 15-16 (échelle: 1/200).

peuvent être associées à ce commerce, paraît plus complexe. Ainsi, de nombreux graffites ont été lus sur les parois de la pièce 6, parmi lesquels un apophtegme de Diogène ${ }^{209}$. Si l'on exclut le local principal, les murs de cette salle sont les seuls à avoir servi d'écritoire. Il pourrait ainsi s'agir

${ }^{208}$ GSE 1931: «24 novembre. [...] Sul solarino del secondo piano lato ovest del Termopolio d'angolo del $4^{\circ}$ cardine [correspondant au cardo $\mathrm{V}$ actuel] è stato sterrato un deposito di anfore. Sette se ne sono recuperate in buono stato le altre erano completamente frammentate». Parmi ces amphores, trois présentent des inscriptions peintes (CIL IV, 10766-10767 et 10896; les hypothèses de P. Ciprotti dans le corpus à leur propos doivent être abandonnées). D'autres ont été mises au jour les 18 et 22 décembre 1931: 9 urcei portant les inscriptions CIL IV, 10831-10832 (la provenance IV, 19 est une erreur de la part de M. Della Corte [1958: $\mathrm{n}^{\circ} 171$ p. 259] lors de la relecture de ses notes), un pied d'amphore portant un timbre (Della Corte 1958: $\mathrm{n}^{\circ} 178$ p. 259).

${ }^{209}$ CIL IV, 10528-10545. 
d'une salle d'accueil de la clientèle. Toutefois, les différents objets qui y ont été mis au jour - des assiettes (fig. 57), des vases de service et un plat de cuisson - paraissent réfuter cette hypothèse, sauf à considérer qu'une même pièce serve à plusieurs usages en dépit de sa taille réduite ${ }^{210}$. Un même raisonnement peut être conduit pour la pièce 7 dans laquelle différents éléments de service ont été trouvés. La découverte, au centre de cet espace, d'une marmite contenant de l'orge pourrait toutefois y autoriser la présence de clients ${ }^{211}$. Ces deux pièces, en dépit de l'étroitesse de la $\mathrm{n}^{\circ} 6$, paraissent ainsi avoir eu une fonction double, tout à la fois zone de stockage pour la vaisselle, mais aussi une partie des denrées, et espace d'accueil de la clientèle. Rien n'a été trouvé dans la pièce 8 , toutefois une situation similaire est hautement probable.
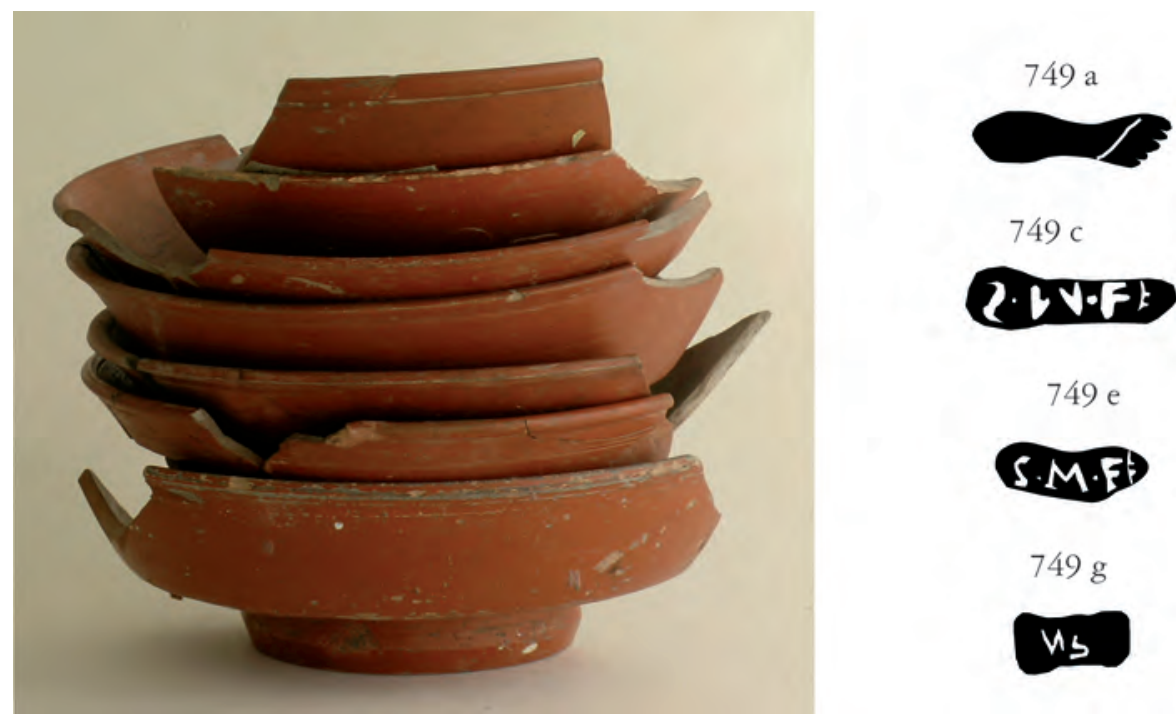

De la sorte, non seulement le local principal d'une surface importante: $32 \mathrm{~m}^{2}$ - permettait le séjour des clients, mais trois des quatre pièces annexes offraient la même opportunité. La difficulté réside néanmoins dans la possibilité d'un usage mixte, à la fois privé et commercial de ces pièces annexes, comme dans le cas de la pièce annexe du local Or. II, 9 qui peut tout autant avoir constitué un appartement qu'une salle à manger destinée à la clientèle.

Le second point devant être développé est pour partie le corollaire du premier. Une fois les espaces d'accueil de la clientèle définis, il faut chercher à comprendre les modes de consommation des denrées ou boissons proposées. Dans la boutique de la Casa del priapo (IV, 17), trois positions sont offertes pour le repas: debout au comptoir, assis sur le banc maçonné de la pièce a

Fig. 57 - Assiettes en céramique sigillée provenant de la pièce 6 du commerce alimentaire IV, 15-16. À droite, les différents timbres moulés sur le fond des assiettes (échelle 1/1).

${ }^{210}$ Les objets mis au jour dans la pièce 6 sont les suivants: sept assiettes en céramique arétine de forme Conspectus 3.2, présentant les timbres de cinq producteurs différents (CVArrII 848, 1212 et probablement 1586; deux timbres hors CVArrII) (Inv. $n^{\circ}$ E749=76026); un plat à engobe rouge pompéien (forme Goudineau [1970] 2830, cf. Scatozza-Höricht 1988) (Inv. $\left.n^{\circ} \mathrm{E} 750=76027\right)$; une cruche à une anse (Inv. $\left.\mathrm{n}^{\circ} \mathrm{E} 751=76028\right)$; une seconde cruche à une anse (forme Gasperetti [1996] 1252a)
(Inv. $\left.\mathrm{n}^{\circ} \mathrm{E} 752=76029\right)$; une cruche en bronze dont le col est manquant (Inv. $\mathrm{n}^{\circ} \mathrm{E} 753=76030$ ).

${ }^{211}$ GSE 1932: « 25 gennaio. [...] Nell'ambiente $\mathrm{n}$. 7 della casa n. 6 sul $4^{\circ}$ cardine lato ovest sul pavimento [...] è stato raccolto: Bronzo. Pentola col fondo distaccato contenente una piccola quantità di orzo [...] [Inv. $n^{\circ}$ E724=76001]».

Cf. également Borgongino 2006: cat. n 366 p. 123, qui ne donne pas le lieu de provenance. 


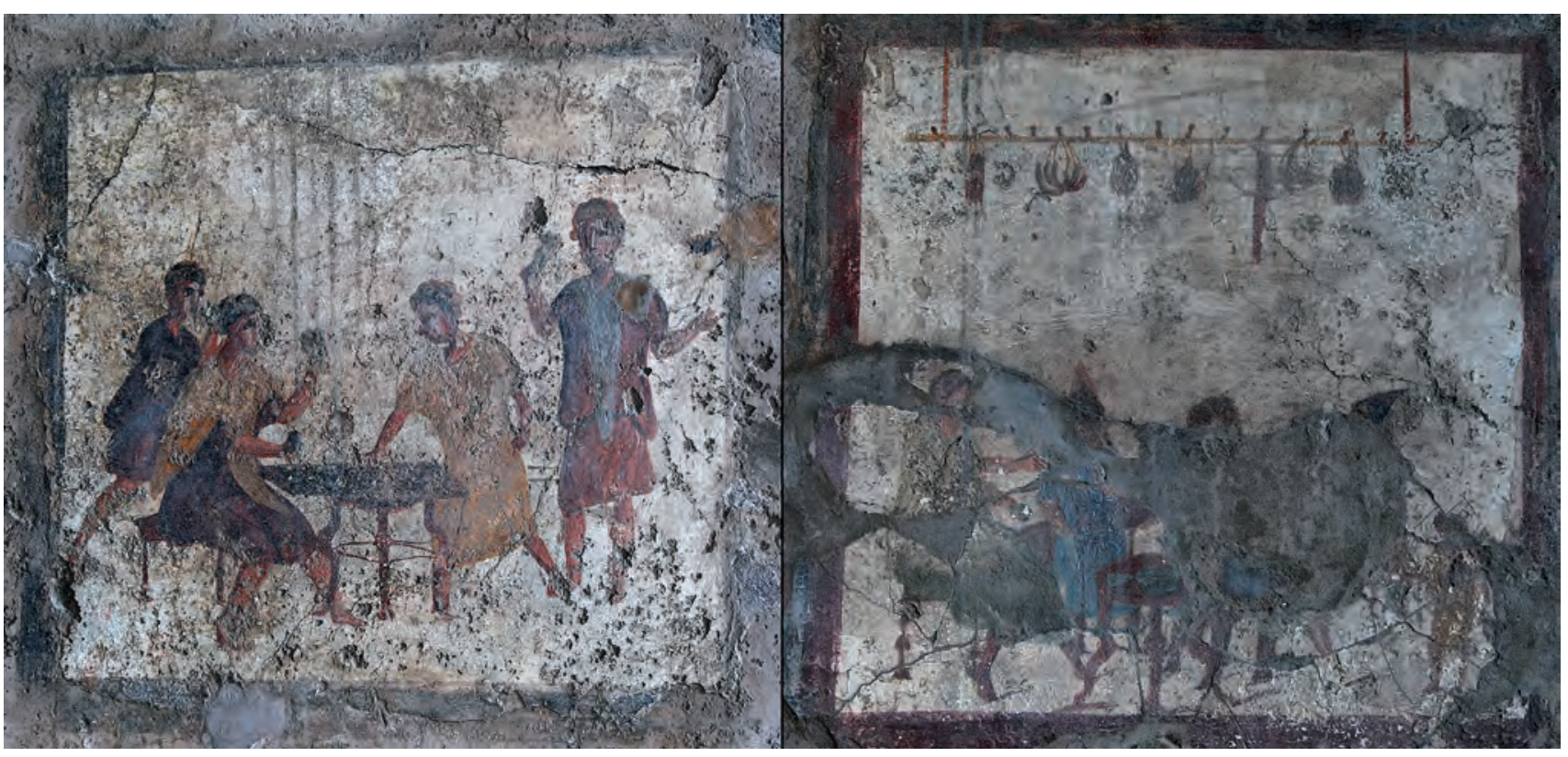

Fig. 58 - Scènes de vie peintes dans la pièce annexe du commerce alimentaire VI 10, 1.19. (a), scène de jeu : tout en consommant des boissons, les deux clients attablés jouent aux dés; (b): scène de repas (?), au-dessus des quatre personnages attablés, pendent des saucisses et autres cochonnailles.

ou couché en 10. Cette dernière façon de prendre son repas reste hypothétique dans le cadre des restaurants. Les textes littéraires donnent une vision contrastée de ces pratiques ${ }^{212}$. Les rares représentations de l'intérieur des commerces alimentaires indiquent l'usage de tables et de chaises plutôt que de lits. Dans la «caupona della via di Mercurio»(VI 10, 1.19), la pièce annexe située au nord-est du local principal porte encore sur ses murs la majeure partie des fresques mises au jour. Différentes scènes de vie sont représentées: les personnages qui jouent ou tiennent des gobelets sont figurés assis autour d'une table, alors même que la possibilité de se nourrir est rappelée par diverses cochonailles suspendues au-dessus de leur tête (fig. 58) $)^{213}$.

${ }^{212}$ Pour les textes littéraires, les remarques ironiques de Martial (5, 70, 3), qui mentionne des sellariolae popinae fréquentées par Syriscus, pourraient indiquer que l'on y mange assis mais aussi constituer un jeu de mots sur l'éventuelle présence de prostituées dans ces lieux. En revanche, Juvénal, lorsqu'il dépeint les frasques de Lateranus (Sat. 8, 173), indique clairement une position couchée.

${ }^{213}$ Sur ces fresques ainsi que sur la bibliographie antérieure, cf. Fröhlich 1991 : 214-222, part. 214-216.
Les codes de représentations des clients sont les mêmes sur les fresques provenant de la caupona «de Salvius»(VI 14, 35-36) ${ }^{214}$. Malgré ces attestations iconographiques, l'utilisation de couches pour manger dans certains de ces restaurants est vraisemblable, en particulier dans le restaurant dépendant des thermes des Praedia Iuliae Felicis (II 4, 7), en alternance avec des bancs maçonnés. Outre ces considérations sur la position des clients, la détermination du contenu de leurs assiettes paraît constituer une intéressante piste de recherches, à mener non pas seulement avec les restes végétaux, trop peu nombreux dans les boutiques, mais aussi avec les différentes listes de prix inscrites sur les parois de certains murs qui révèlent la place

\footnotetext{
${ }^{214}$ Ces fresques provenant de la boutique VI 14, 35-36 sont conservées au MANN (Inv. $\mathrm{n}^{\circ} 111482$ ). Cf. Fröhlich 1991 : 211-214. Ces deux séries de peintures ont récemment été interprétées par J.Clarke (2003: 160-170), qui y voit des scènes d'un comique irrévérencieux, déformant les codes de l'élite, dans la Caupona "de Salvius », et un miroir de la vie de ces commerces dans la boutique VI 10, 1.19.
} 
importante du pain ${ }^{215}$. Enfin, il serait nécessaire, en étudiant les types de vaisselle de préparation trouvés dans ces commerces, de déterminer les gestes culinaires déployés afin de pouvoir appréhender les types de pratiques alimentaires mis en œuvre.

En dépit de ces quelques remarques et des inévitables besoins d'approfondissement, cette esquisse typologique permet d'obtenir une première vision globale sur le commerce alimentaire dans les deux villes ensevelies par le Vésuve. La principale caractéristique d'Herculanum est de ne présenter aucun débit de boissons (type 4), ce qui laisse supposer que la consommation de vin se faisait essentiellement dans les restaurants (types 1 et 5). Ce constat doit cependant être tempéré: deux locaux (IV, 14 et VI, 14) pourraient s'être consacrés au commerce du vin. Rien ne permet toutefois de déterminer si la consommation dans ces boutiques était possible, faute d'objet ou d'aménagement permettant d'aboutir à une telle conclusion. En comparant la situation des deux villes, la surreprésentation relative des locaux vendant des denrées en vrac (type 3 ) à Herculanum est saisissante: $38 \%$ des commerces alimentaires (5 locaux) paraissent avoir eu cette fonction contre seulement 16\% à Pompéi (25 boutiques) (fig. 59). Rappelons toutefois que cette spécificité pourrait découler directement des données de fouilles, particulièrement lacunaires en ce qui concerne Herculanum. En revanche, la proportion de restaurants est sensiblement équivalente dans les deux villes ${ }^{216}$. Sans même évoquer la différence d'échelle, la disparité qualitative et quantitative entre les deux échantillons rend la comparaison difficile (pl. Iv, h.t.).

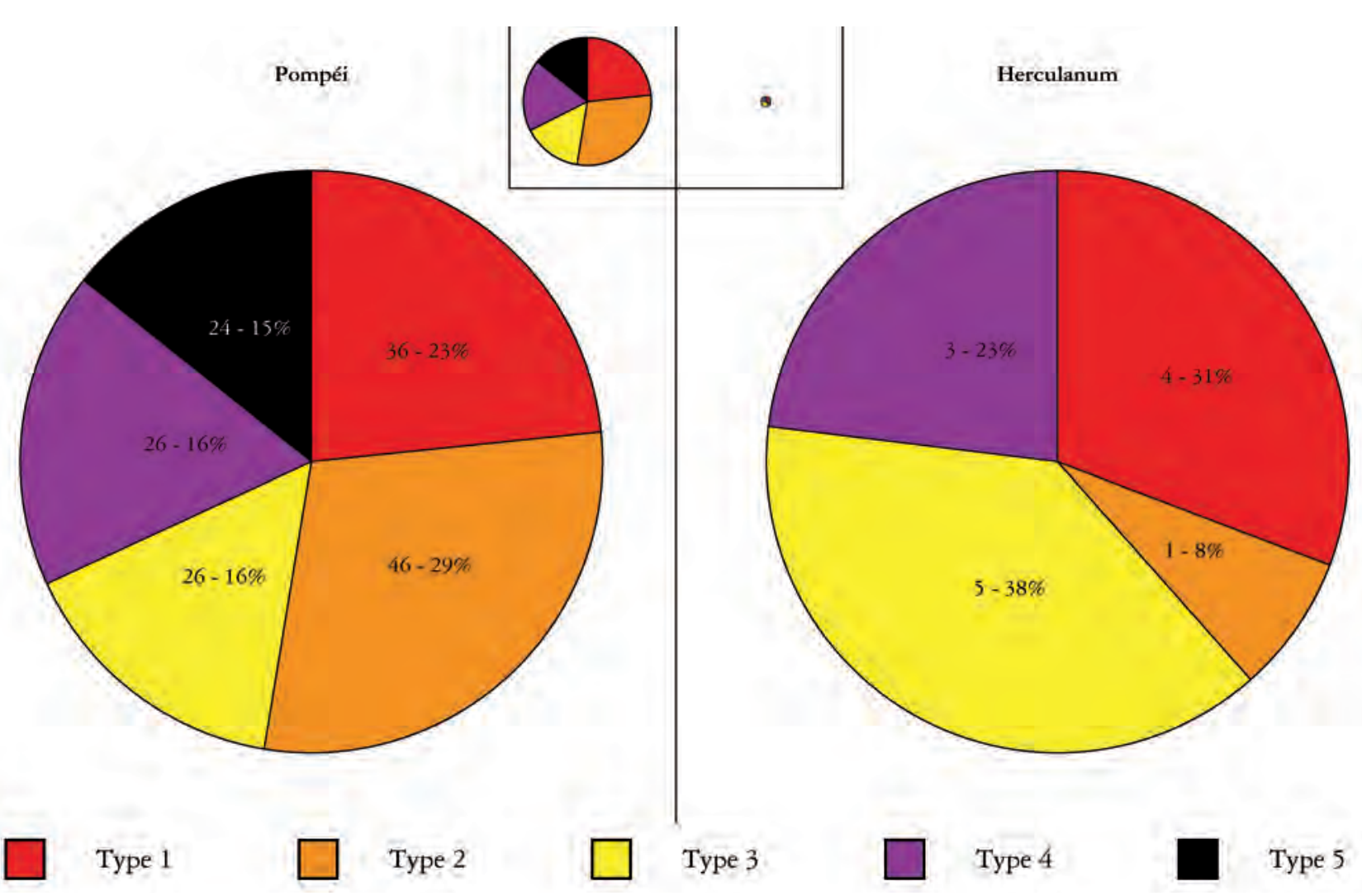

Fig. 59 - Répartition des commerces alimentaires à Herculanum et Pompéi en fonction de leur type. En encadré, les mêmes données, corrélées au nombre d'espaces commerciaux ( $1 \mathrm{~mm}$ de diamètre $=10$ locaux).

${ }^{215}$ Les trois principales inscriptions donnant une liste de denrées avec des prix en regard mentionnent le pain parmi celles-ci (CIL IV, 4888, 5380 et 8561). De ces trois listes, la plus intéressante pour un tel propos est celle provenant de l'atrium de la maison IX 7, 24-25 (CIL IV, 5380; cf. NSc
1880: 396; BdI 1882: 138): elle mentionnerait les produits achetés pour le fonctionnement de la boutique.

${ }^{216} 62 \%$ des commerces alimentaires (8 locaux) d'Herculanum sont des restaurants au sens large (types 1, 2 et 5). Cette proportion est de 66\% (103 boutiques) à Pompéi. 


\section{CHAPITRE III}

\section{BOULANGERIES ET CONFECTION DU PAIN}

\begin{abstract}
«Méthode pour faire le pain - Vous mettez la quantité de farine que vous voulez [...]; faites une fontaine au milieu, et vous mettez dans cette fontaine un demi-quarteron ou plus de levure, faites votre détrempe à l'eau tiède, [...] travaillez bien votre pâte en y joignant deux onces de sel fin délayé dans un peu d'eau tiède, couvrez-là chaudement afin qu'elle puisse fermenter et lever; [...] puis chauffez le four, et lorsqu'il est bien nettoyé vous divisez la pâte en autant de partie que vous voulez et formez des pains de la forme qu'il vous plaira. Vous placerez ces pains dans le four le plus promptement possible $[\ldots]$ »
\end{abstract}

A. Dumas, Le grand dictionnaire de cuisine, Paris, C. Tchou, 1965, p. 373.

Selon l'affirmation de Pline l'Ancien, la boulangerie ne se serait développée qu'à partir de 171 av. J.-C. à Rome. De la sorte, et plus particulièrement si l'on ne prend pas en compte la capitale de l'Empire, les céréales cuites sous forme de pain seraient longtemps restées l'apanage des couches les plus riches de la population ${ }^{1}$. Le mode le plus fréquent pour cuisiner ces dernières est resté celui de la bouillie, éventuellement vendue dans les commerces alimentaires étudiés au chapitre précédent. Même si l'on peut supposer que la puls a continué d'être préparée dans une large part de la population humble, les pains carbonisés mis au jour dans les villes ensevelies par le Vésuve indiquent l'émergence ou l'ancrage de cette forme de consommation

\footnotetext{
${ }^{1}$ Comme le fait remarquer J. André (1981: 62), l'affirmation de Pline (NH 18, 107-108) est contestable, comme l'indiquent certaines mentions dans l'œuvre de Plaute (Asin., 200-201: Quom a pistore panem petimus, uinum ex oenopolio, / si aes habent, dant mercem [...]; "Quand nous
}

des céréales dans le troisième quart du $\mathrm{I}^{\mathrm{er}}$ siècle de notre ère. La fresque découverte dans le tablinum de la maison VII 3, 30, où un notable - à défaut d'être indiscutablement un magistrat - distribue du pain à des personnages habillés comme des voyageurs, montre à elle seule l'importance croissante du pain dans l'alimentation ${ }^{2}$. Létude des lieux de préparation de ce pain à Herculanum permet de compléter l'analyse de l'artisanat alimentaire initiée dans le chapitre précédent.

Deux boulangeries ont été mises au jour à Herculanum, situées dans l'Insula Orientalis $I I^{a}$ (1a et 8). En dépit des informations disponibles sur ces deux locaux, il m'est apparu utile d'étendre cette étude aux 36 locaux pompéiens

allons chercher du pain chez le boulanger, du vin chez le cabaretier, ils ne lâchent leur marchandise que s'ils tiennent l'argent » [trad. CUF]).

${ }^{2}$ Pour une analyse de cette fresque, cf. supra, p. 64-65. 
pour avoir une approche plus générale. Je ne reviendrai pas sur les questions associées au stockage du grain, ce problème ayant déjà été évoqué ${ }^{3}$. De façon très générale, la confection du pain se déroule selon trois étapes principales. La première est la mouture, qui transforme les grains de céréale panifiable en farine, dont la finesse et la qualité conditionnent largement le produit final. Dans un second temps, cette farine est additionnée d'eau, de levain et d'éventuels autres ingrédients. Ce mélange doit être pétri jusqu'à homogénéisation puis laissé à reposer pour que les ferments du levain donnent à la pâte sa structure aérée. Enfin, les pains façonnés sont cuits dans un four. À chacune de ces trois étapes correspondent un ou plusieurs aménagements dont les variations sont tout autant liées au contexte local qu'à l'évolution technique.

\section{III.1 La mouture du grain}

Depuis le début des fouilles à Pompéi, les boulangeries en général et les meules en particulier n'ont cessé de susciter admiration et curiosité, comme l'attestent les quelques pages consacrées par Fr. Mazois à la description de la boulangerie VI 3, 3.27-28 à la découverte de laquelle il a participé 4 . Malgré l'importance, au moins d'un point de vue strictement archéologique, des instruments de broyage utilisés dans ces locaux, plusieurs opérations prennent place avant la mouture: quel qu'ait été le nettoyage des grains effectué sur le lieu de récolte, il est impératif de le compléter afin d'éviter la présence de déchets - pierres, balles des grains, plantes ayant poussé en même temps que le blé. Les indications sur la façon dont ce nettoyage est effectué restent peu nombreuses, les sources littéraires

\footnotetext{
${ }^{3}$ Sur la question du stockage des denrées périssables et du grain en particulier, cf. supra, p. 112.

${ }^{4}$ Mazois 1824 b: 56-61.

${ }^{5}$ Plin., NH 18, 97-98: De ipsa ratione pisendi Magonis proponemus sententiam: triticum ante perfundi aqua multa jubet, postea evalli, dein sole siccatum pilo repeti [...].

«Sur les procédés de pilage, nous allons exposer l'avis de Magon: il veut qu'on arrose d'abord le blé à grande eau, puis qu'on le débarrasse de sa balle, qu'on le fasse sécher au soleil et qu'enfin on le remette sous le pilon » (trad. CUF).

${ }^{6}$ Apul., Met., 9, 23, 2: Tunc uxor [...] exsangui formidine trepidantem adulterum alveo ligneo, quo frumenta contusa
}

sont vagues et contradictoires sur ce point. Pline ne mentionne de nettoyage préalable que pour le grain pilé au mortier: il reprend un conseil de l'agronome carthaginois Magon, qui indique un mouillage du grain avant d'en retirer les balles et de finalement le piler ${ }^{5}$. Apulée, narrant le séjour de Lucius transformé en âne dans une boulangerie, évoque incidemment d'autres actions préparatoires: il signale que le blé - frumentum - est nettoyé après avoir été pilé. Ce nettoyage se ferait dans une auge en bois, suffisamment grande pour cacher l'amant de la femme du boulanger 6 . Que ce soit à Pompéi ou à Herculanum, aucun mortier ayant une capacité suffisante pour permettre le pilage d'une importante quantité de grains n'a été découvert.

La question du nettoyage du grain avant sa mouture ne peut être intégralement résolue avec les représentations iconographiques. Par exemple, la frise située au sommet du tombeau de M. Vergilius Eurysaces ne montre pas cette étape préparatoire. Sur le côté méridional, qui présente les premières actions opérées dans un pistrinum, le contrôle de l'arrivée du grain est immédiatement suivi par la mouture (fig. 60, a ) ${ }^{7}$. Le relief du caisson de P. Nonius Zethus, provenant d'Ostie, montre sur une de ses faces un animal en train d'actionner une meule (fig. 61) ${ }^{8}$. Sur l'autre face, trois modii, un objet en vannerie, une planche striée de canaux et un cylindre - large, de faible hauteur et dont le fond est perforé d'une multitude de trous - sont exposés contre un mur, soit accrochés, soit sur des étagères ${ }^{9}$. Une corbeille est posée sur le sol. Les modii sont reconnaissables à leur iconographie caractéristique: un tronc de cône qui repose sur deux ou trois pieds et dont le sommet est ouvert ${ }^{10}$. Leur utilisation intervient au début du processus de boulangerie, quand il

purgari consuerant, temere propter jacenti suppositum abscondit.

"Alors la femme cache son amant blême de peur et tremblant sous un alveus en bois dans lequel on avait l'habitude de nettoyer le blé pilé et qui traînait là par hasard» (trad. CUF remaniée).

${ }^{7}$ Sur ce relief en général, cf. Ciancio Rossetto 1973. Concernant l'interprétation du côté méridional, cf. Ciancio Rossetto 1973: 45 et pl. XXVII, 2-XXVIII, 1-2.

${ }^{8}$ Vatican, Museo Chiaramonti, Inv. ${ }^{\circ} 1343$.

${ }^{9} \mathrm{G}$. Zimmer (1982: 114) interprète les étagères comme des racloirs (rutilla). 

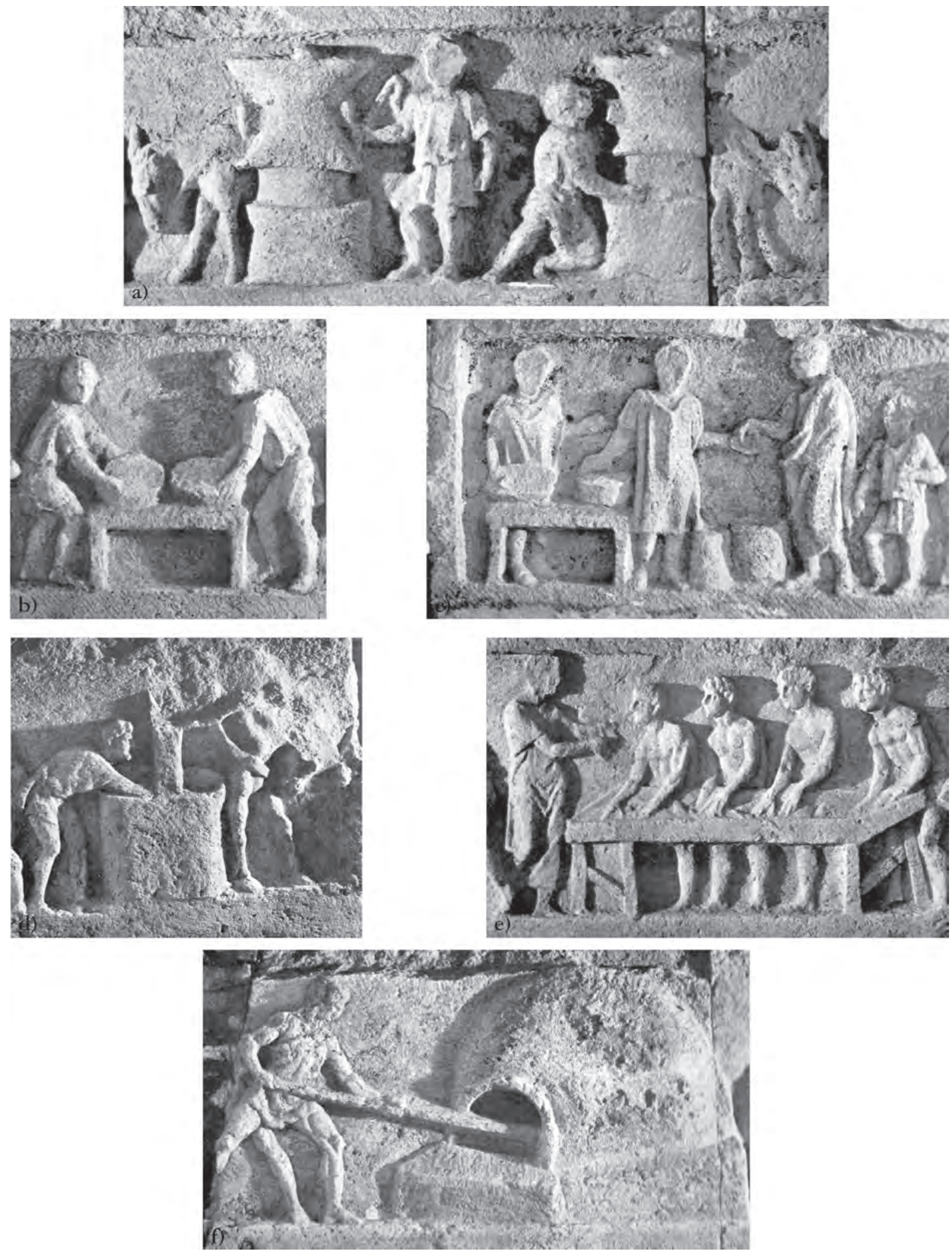

Fig. 60 - Frise du mausolée de M. Vergilius Eurysaces (Rome, Porta Maggiore). Les scènes sont présentées sur les faces sud et nord du monument, de droite à gauche; ici, la sélection de représentations est organisée dans un sens dextroverse. (a) mouture du grain; les meules sont actionnées par des équidés; un homme est préposé à chaque meule, pour fouetter l'animal ou pour ramasser la farine; (b): blutage de la farine moulue, deux hommes utilisent des tamis au-dessus d'une table; (c): contrôle de la qualité de la farine après le blutage, probablement par M. Vergilius Eurysaces (ultime représentation de la frise sud); (d) pétrissage de la pâte: le pétrin est actionné par un équidé tandis qu'un homme manipule la pâte lors du frasage; (e) façonnage des pains effectué par quatre hommes sous le contrôle d'un surveillant; (f) enfournement des pains dans un four dépourvu de mur-diaphragme. 


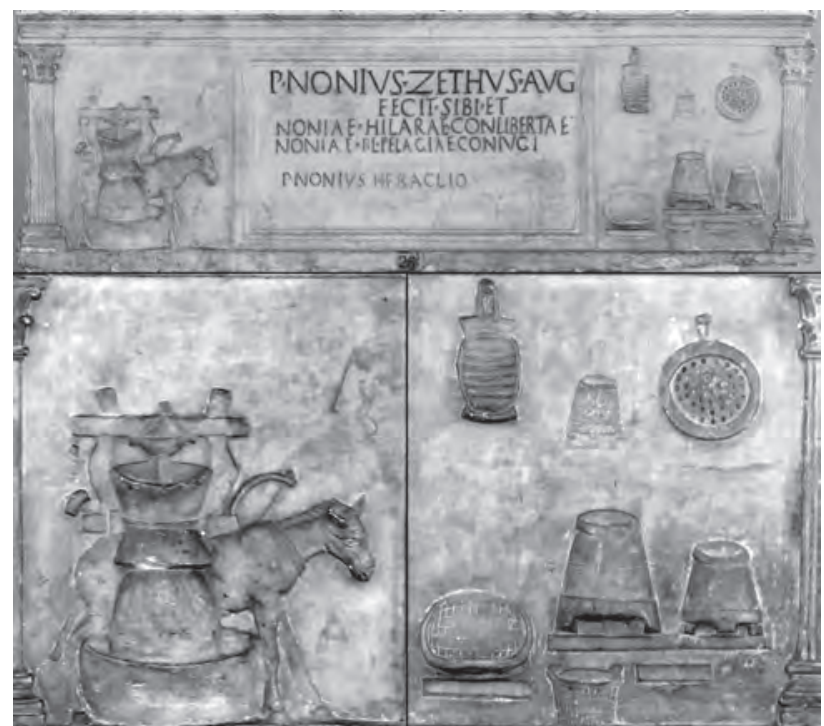

Fig. 61 - Relief du caisson de P. Nonius Zethus (Ostie). À gauche, équidé actionnant une meule; à droite, modii et objets en vannerie utiles lors des premières phases du nettoyage du grain.

s'agit de mesurer la quantité de blé à moudre. Comme l'autre scène représentée sur ce relief est justement la mouture, l'ensemble des instruments figurés pourrait renvoyer au criblage du grain: l'objet en vannerie situé sur la gauche, qui ne paraît pas avoir de volume et qui ne saurait donc être interprété comme une corbeille, pourrait

${ }^{10}$ Voir entre autres exemples la mosaïque de la statio mensorum sur la place des Corporations d'Ostie; cf. également Virlouvet 1995: fig. 17, 19, 42, 43.

${ }^{11} \mathrm{G}$. Zimmer (1982:114) interprète cet objet comme une corbeille. Pourtant, outre son absence de volume, rendue en ne gravant pas d'ouverture à son sommet, sa forme, en particulier l'avancée de la partie inférieure qui repose sur l'étagère, indique un objet souple, avachi. Un van est représenté sur un relief fragmentaire provenant de Mayence (Junkelmann 1997: fig. 53 p. 111). Il a la forme d'un arc de disque avec des bords relevés et munis de poignées dans la partie la plus étroite. Rien ne permet de déterminer si cette scène se déroule dans une exploitation agricole - qui montrerait alors le premier nettoyage du grain - ou bien dans une boulangerie.

${ }^{12}$ L. Ammann (1925: 77-78) décrit de la façon suivante l'un des principes de nettoyage du grain avant mouture: "On peut, au moyen d'un tamis à trous de diamètre judicieusement calculé, séparer les impuretés plus grosses ou plus petites que le blé lui-même [...]». Ce premier nettoyage implique l'emploi de deux tamis différents. être un van, destiné à faire s'envoler les éléments les plus légers pris dans la masse de grains ${ }^{11}$. Le cylindre suspendu en haut à droite de cette face constituerait un crible, tamis dont les trous sont d'une taille voisine de celle des grains de façon à ne conserver que les éléments les plus gros qui peuvent être rejetés ${ }^{12}$. Quant au dernier élément accroché, je ne saurai en proposer une interprétation $^{13}$. L'ordre du nettoyage ne peut pas être précisé à partir des éléments rassemblés sur ce relief. Aucun objet pouvant rappeler ceux qui y sont représentés n'a été découvert à Herculanum ou à Pompéi. Le dernier traitement que l'on peut faire subir au grain avant de le moudre consiste à le mouiller ou à l'immerger. Selon Pline, la mise en œuvre de cette pratique dépendrait d'un compromis entre le rendement et la blancheur de la farine ${ }^{14}$. Une immersion permettrait en fait de nettoyer les grains, tout en les préparant à la mouture ${ }^{15}$; si un tel procédé était en usage à Herculanum ou Pompéi, il faut supposer l'existence de baquets en bois, faute d'aménagement hydraulique permanent lié à un tel objectif dans les pièces consacrées à la mouture.

À la suite du nettoyage, les grains sont prêts à être broyés avec une mola. Les meules sont constituées de deux éléments, une meta, qui sert de surface de trituration fixe, la partie dormante de l'instrument, et un catillus, qui prend généralement la forme d'une clepsydre qui tourne autour de la meta. L'origine de ces

13 G. Zimmer (1982: 114) y voit un alveus. Si l'ensemble des objets représentés est bien sensiblement à la même échelle, la taille de ce dernier ne semble pas compatible avec la description qui est faite de cet instrument par Apulée (Met., 9, 23, 2; cit. supra, n. 6 p. 134).

14 Plin., NH 18, 87: Nam quae sicca moluntur, plus farinae reddunt, quae salsa aqua sparsa, candidiorem medullam, verum plus retinent in furfure.

«En effet, les grains que l'on moud à sec donnent plus de farine; ceux qu'on arrose d'abord d'eau salée donnent une farine plus blanche, mais il en reste davantage dans le son » (trad. CUF).

15 «Les blés secs ont, en effet, une écorce cassante, qui se pulvériserait sous la meule [...] et qui se mélangerait à la farine; une humectation légère rendra, au contraire, cette écorce plus élastique. [...] Le traitement des blés par l'eau s'applique surtout aux blés durs [...] qui doivent être toujours fortement humecté avant d'entrer en travail» (Ammann 1925: 116-117). 
deux éléments en roche volcanique a longtemps soulevé des débats. Depuis le début des années 1980 avec les travaux de D.S. Peacock et la mise en évidence de carrières situées dans le nord du Latium pour ce type de roche, il est désormais acquis qu'une partie des meules pompéiennes a été façonnée près d'Orvieto et non avec les roches locales ${ }^{16}$. L'observation des instruments de meunerie pompéiens, corrélée à leur usure et à leur situation dans les boulangeries, permet de proposer que la roche locale est progressivement remplacée par les importations d'Ombrie ${ }^{17}$. Plusieurs formes ont été individualisées dans cette vaste catégorie des "meules pompéiennes » en forme de clepsydre. Selon l'étude de D.S. Peacock, ces différences formelles recouvrent une variation dans la provenance: le type 3 , de forme plus allongée, est de loin le plus fréquent; il correspondrait aux meules du Latium ${ }^{18}$. Audelà de ces questions typologiques, dont l'intérêt sera maximal une fois atteinte l'exhaustivité, la question du mode d'utilisation de ces moulins rotatifs est primordiale. D’une manière générale, que ce soit pour les quatre exemplaires d'Herculanum ou les 86 de Pompéi, ces meules sont très fortement endommagées. Dans la majeure partie des cas, seule la meta est encore en place, les catilli ayant été cassés avant ou pendant l'éruption voire depuis leur mise au jour ${ }^{19}$. Cet état - probablement dû aux effets d'un séisme de peu antérieur à la catastrophe finale ${ }^{20}$ - n'empêche toutefois pas de connaître le fonctionnement de ces meules. La description faite par Fr. Mazois de l'une d'entre elles, située en VI 3, 3.27-28 est éloquente:

[...] Je fus assez heureux pour retrouver, au moment de la fouille, ces moulins garnis encore de tous leurs ferre-

16 L'extraction des meules pompéiennes dans le Latium a tout d'abord été proposée comme hypothèse par D.S. Peacock $(1980 ; 1989)$. Une étude pétrologique menée à l'échelle de l'empire romain a permis la détermination de 16 sites de production pour ces meules (Williams-Thorpe 1988). Des analyses similaires n'ont pas encore été effectuées sur l'ensemble des meules pompéiennes. Toutefois, de premiers résultats indiquent trois sites d'extraction: Orvieto, le Vésuve et la région de l'Etna (Buffone - Lorenzoni - Pallara - Zanettin 1999).

17 Cette première hypothèse a été formulée par S. Longepierre, dans le cadre du programme d'étude des boulangeries de l'Italie romaine, commencé en 2008.

${ }^{18}$ Peacock 1989: 210-211.

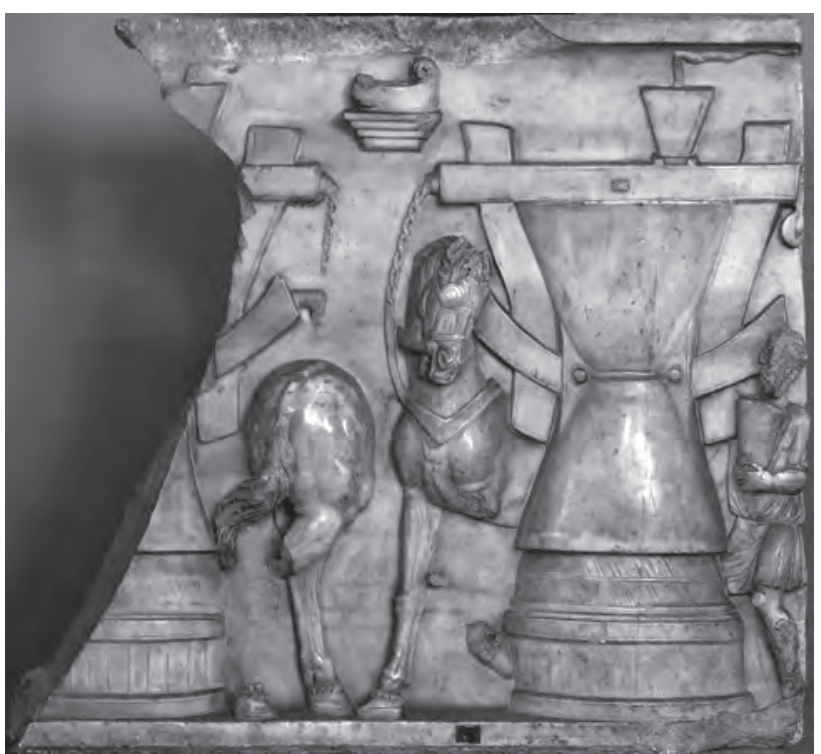

Fig. 62 - Relief de la Porta San Giovanni. Deux équidés actionnent des meules. Au sommet de celles-ci, on observe un cône servant de réserve à grain à droite, un personnage tient un récipient.

ments, totalement détériorés, il est vrai par l'oxydation [...]. La meule mobile était garnie, à son étranglement interne, d'une espèce de moyeu en fer, et tournait sur un pivot scellé dans la meule fixe. Le grain passait par quatre trous ménagés dans le moyeu et cette armature se rattachait, par des liens de fer, aux bras de bois à l'aide desquels on mettait le moulin en action ${ }^{21}$.

La forme du bras qui permet d'actionner la meule est en revanche plus délicate à définir: sur les représentations iconographiques de meule entraînée par un âne, le châssis de bois est complexe. Sur le sarcophage provenant de la Porta San Giovanni, six pièces de bois le composent (fig. 62) ${ }^{22}$. Deux barres horizontales sont

19 À Herculanum, les deux catilli de la boulangerie Or. II, 1a ont été mis au jour sur place, mais fortement endommagés. Un seul sur les deux du local Or. II, 8 a été découvert. À Pompéi, les emplacements de 86 meules peuvent être localisés dans des locaux commerciaux. Huit sont complètement arasés, 50 ne présentent plus que leur meta en place. Un seul local semble avoir eu une productivité nulle au moment de l'éruption (VI 14, 33, cf. NSc 1877 : 105). Ces chiffres sur Pompéi ne renvoient pas aux destructions depuis la fouille, mais à l'état décrit par les archives.

${ }^{20}$ Cf. infra, p. 236.

${ }^{21}$ Mazois 1824 b: 57-58.

${ }^{22}$ Vatican, Museo Chiaramonti, Inv. n 1370. 
situées de part et d'autre du catillus au niveau de son étrécissement médian, fixées par des tenons qui traversent la pierre et le bois. Une autre traverse se situe au sommet de la pièce mobile, posée sur celle-ci. En son centre, un tenon dépasse, signe que cette traverse est fixée à une pièce verticale, vraisemblablement une extension du moyeu ${ }^{23}$. Les deux barres transversales sont liées par deux montants encastrés de part et d'autre du catillus: le tout forme un cadre fermement associé à la meule. L'équidé qui entraîne cette dernière, les yeux occultés, est tenu par un collier dont la représentation détaillée permet de comprendre qu'il est formé de corde et de tissu, ce qui correspond également à la description qui en est donnée par Apulée ${ }^{24}$. Chaque extrémité de ce collier est fixée à l'une des barres transversales. Ce système est représenté, parfois avec moins de détails sur d'autres reliefs funéraires (fig. 63) ${ }^{25}$. Seul le tombeau de M. Vergilius Eurysaces est trop sommaire en ce qui concerne les meules pour montrer le châssis (fig. 60, a) ${ }^{26}$. Sur la majeure partie de ces reliefs est également représenté, au sommet de l'assemblage en bois, un trapèze inversé ou un triangle ${ }^{27}$. Il s'agit du réservoir de grains constitué, selon la restitution proposée à Ostie par J.Th. Bakker, par un récipient ayant la forme d'un tronc de cône inversé, percé à sa base. Dans cet orifice venait se loger une tige en fer ayant la forme d'une lance: en soulevant le récipient, le grain se déversait dans le catillus ${ }^{28}$. À partir de ces données, il est possible de revoir tant la description proposée par Fr. Mazois que les restitutions graphiques généralement publiées: le cadre

${ }^{23}$ Contrairement à ce que prétend J. Mayeske (1972: 17), l'écrasante majorité des metae comporte une excavation quadrangulaire à leur sommet, permettant l'insertion d'une tige en fer de section carrée ou rectangulaire. Sans celle-ci, il ne serait pas possible de fixer le catillus.

${ }^{24}$ Apul., Met., 9, 12, 1: [...] Iamque maxima diei parte transacta defectum alioquin me, helcio sparteo dimoto, nexu machinae liberatum adplicant praesepio. «La plus grande partie du jour étant écoulée, et j'étais d'ailleurs épuisé, quand on m'enleva mon collier de halage en fibre et, libéré de la machine où j'étais attaché, me mit à la mangeoire » (Trad. CUF).

${ }^{25}$ Sarcophage de la vigna Sassi à Porta Latina (Rome, Sepolcro degli Scipioni, Inv. ${ }^{\circ}$ 523/24); relief sur brique provenant de la tombe de Ti. Claudius Eutychus sur l'Isola Sacra à Portus (cf. Floriani Squarciapino 1956: cat. n 7 ;

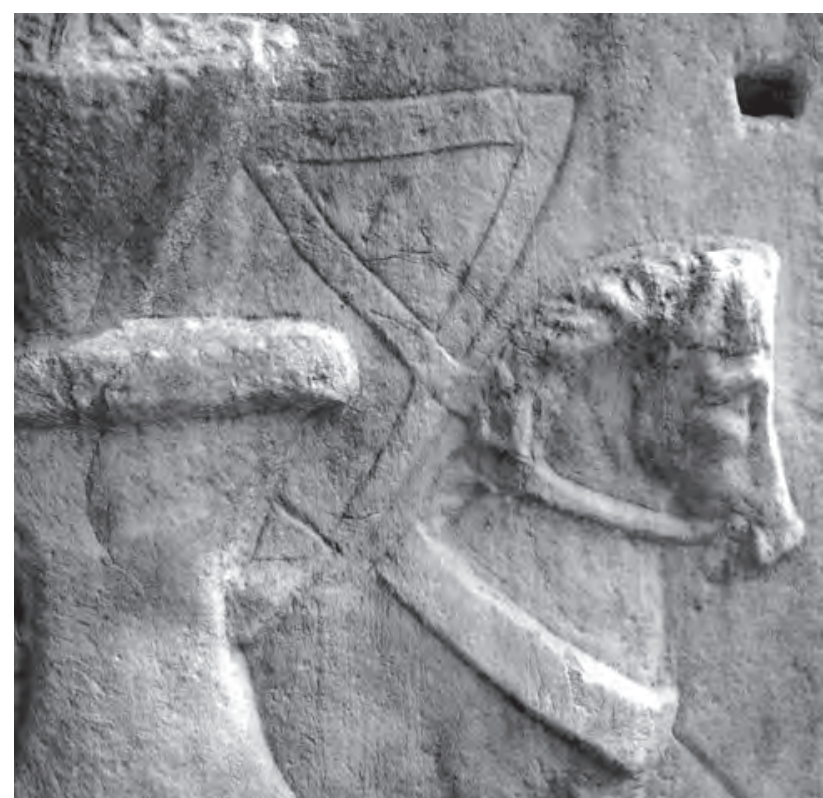

Fig. 63-Détail du sarcophage de la Villa Médicis représentant une scène de meunerie. La meule, pourvue d'un réservoir à grain, est actionnée par un équidé. Le collier permettant la traction et le mors paraissent reliés à la partie supérieure de la meule.

extérieur est le soutien du catillus par le biais d'un manche vertical - probablement en bois - qui s'insère dans le tenon situé au sommet de la meta; le «moyeu » décrit plus haut n'est qu'un simple filtre pour les grains et n'aurait aucun rôle mécanique ${ }^{29}$. De plus, dans le cas d'une rotation par la force animale, la présence d'un bras inférieur dépassant largement de la base de la meule est inutile: le système de collier souple permet de se passer de cette excroissance ${ }^{30}$.

Zimmer 1982: cat. $\left.n^{\circ} 24\right)$; sarcophage de la Villa Médicis (Cagiano de Azevedo 1951: cat. n 126 p. 87-88; Zimmer 1982: cat. $\left.\mathrm{n}^{\circ} 20\right)$; conteneur à urne de P. Nonius Zethus trouvé à Ostie.

${ }^{26}$ Ciancio Rossetto 1973: pl. XXVIII.

${ }^{27}$ Aux reliefs indiqués à la note 25 , il faut ajouter une plaque en marbre conservée à Bologne (cf. Zimmer 1982: cat. $\left.n^{\circ} 19\right)$. Elle n'apporte aucune information supplémentaire quant au système de châssis, non représenté. En revanche, un grand réservoir conique a été figuré au-dessus du catillus. Pour des problèmes de place, il est placé devant le four dans le champ immédiatement supérieur.

${ }^{28}$ Bakker 1999: 56-57.

${ }^{29}$ Bakker 1999: 6.

${ }^{30}$ Contra Adam 1995: fig. 735 et 737 p. 347-348. 
Jusqu'à présent, nous avons considéré que ces meules étaient entraînées par des équidés ${ }^{31}$. À l'appui de cette considération, la majorité des reliefs figurant des moulins rotatifs présente un équidé attaché au châssis quand celui-ci est indiqué. L'utilisation d'un animal avec ce type d'appareillage pourrait ne pas être la seule solution: sur le sarcophage d'Annius Octavius Valerianus, conservé au Museo Gregoriano Profano, bien que proportionnellement plus petit et dépourvu d'un catillus en forme de clep- sydre, un appareil similaire est actionné par deux personnages (fig. 64) ${ }^{32}$. Que ce soit à Herculanum ou à Pompéi, la présence de ces animaux est attestée dans certaines boulangeries. Selon A. Maiuri, des ossements de chevaux ou d'ânes ont été mis au jour dans le local Or. II, 1a (cat. $n^{\circ} 37$ ), mais aucun en Or. II, $8^{33}$. Dans une partie des boulangeries pompéiennes, la présence de ces animaux peut être déduite de la découverte d'ossements $^{34}$ ou d'éléments de harnachement ${ }^{35}$. Toutefois, le nombre de ces attestations est parti-

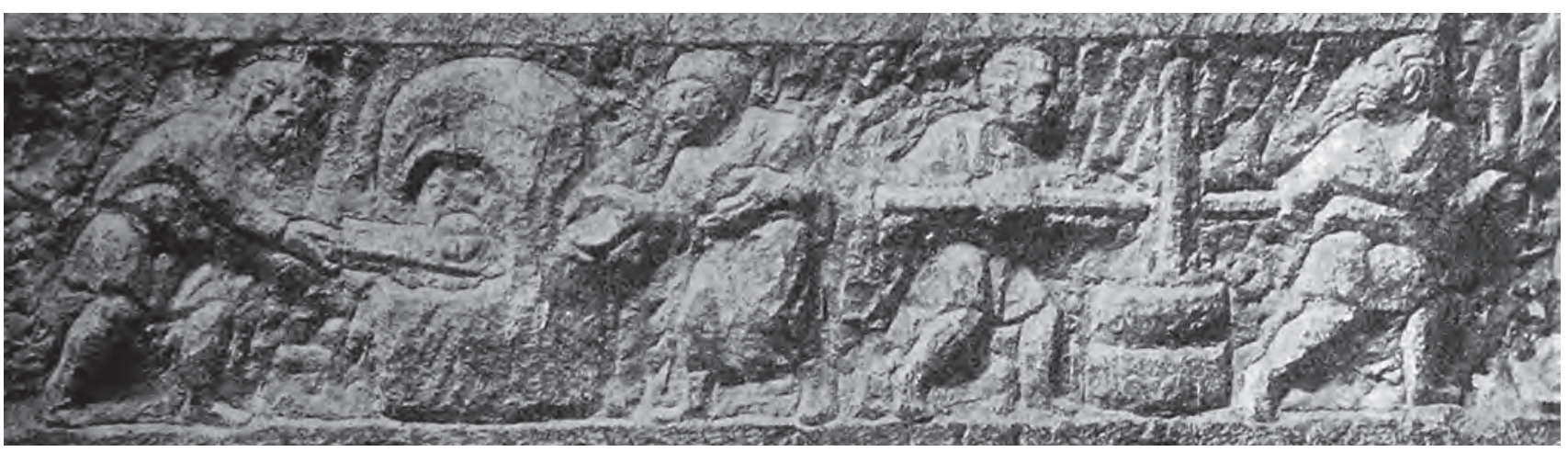

Fig. 64 - Sarcophage d'Annius Octavius Valerianus (Rome, Via Appia). À droite, deux hommes entraînent une meule à bras. À gauche, deux autres s'affairent autour d'un four.

\begin{abstract}
${ }^{31}$ Apulée, narrant les mésaventures de Lucius mentionne des ânes: Apul., Met., 7, 15, 3-5 et 9, 10, 5 - 9, 14,5.

32 À rebours de ses prédécesseurs et sans réelle discussion, A. Mau (1886: 47) a interprété ce cylindre comme un pétrin actionné à bras d'homme. Pourtant, le cylindre est très nettement divisé en deux parties, ce qui renvoie à la distinction entre la meule dormante et la moitié rotative de trituration. Il ne s'agirait donc pas d'une meule "pompéienne» dont le catillus est en forme de clepsydre, mais d'une meule à corps cylindrique, comme on peut en observer un exemplaire en I 8, 15-16 à Pompéi. Sur ce relief conservé au Museo Gregoriano profano, cf. Garrucci 1861: 52-54, part. 53, pl. XXXII; Blümner 1912: fig. 9 p. 25.

${ }_{33}$ Maiuri 1958 b: 453. Quant aux ossements mis au jour en Or. II, 1a, il précise qu'ils correspondent à un animal mort attaché à sa meule. Cette mention pourrait être un des effets du goût dramaturgique d'A. Maiuri. Les GSE (1935: «9 agosto. Nell'ambiente n. 1 della casa 1 posta nel vicoletto che si trova all'estremità sud del V cardine si sono sterrati due mulini discretamente conservati. Sul pavimento si è raccolto [Description d'un fond de vase sigillé] Nessun trovamento ») ne mentionnent aucun ossement, que ce soit lors de la découverte des meules ou pendant le reste de la fouille de cette boulangerie. Toutefois, les os présentés dans la pièce $\mathrm{B}$ au moins peu après la fin des restaurations (cf. cliché Ufficio scavi di Ercolano, $\mathrm{n}^{\circ} \mathrm{E} / \mathrm{C} 360$, daté de 1936) pourraient provenir de ce local sans avoir été mentionné lors des comptes rendus de fouille. Une autre possibilité ne
\end{abstract}

doit pas être négligée: ces os pourraient provenir d'un autre endroit, déplacés dans la boulangerie selon la pratique déjà mentionnée des mises en scène. Des ossements d'animaux ont ainsi été découverts dans la Casa dell'atrio a mosaico (IV, 1-2, cf. GSE 1929: 4 marzo, 31 luglio) mais surtout dans le local 11 de l'insula Orientalis IIa (GSE 1936: 30 settembre).

${ }^{34}$ I 12, 1-2 (GSP 1961: "14 marzo [...]. Si scava anche nell'area dei molini sito a sinistra il II ambiente del vano $\mathrm{n}^{\circ} 2$ [...] Durante lo scavo ai pie' delle due mete di molino si rinvengono alcuni residui di ossa di animali probabilmente ossa di cavallo oppure di asino»); VI 3, 3.27-28, cf. Mazois 1824 b: 59; VII 2, 3.6 («30 [maggio 1868]. [...] Nell'ultima stanza a dritta del peristilio dell'anzidetta casa, [...] sonosi raccolte molte ossa di animali forse buoi o cavalli [...]» [GSPomp, n.s. 1, 2, 1868: 48]); IX 12, 6, cf. Varone 1989: 232-233.

${ }^{35}$ Un mors a été découvert en V 4, 1-2 (cf. NSc 1890: 357). Le 13 novembre 1890, un second objet associé à l'harnachement des animaux a été mis au jour dans une pièce au nord est de l'atrium, pouvant correspondre à la salle des meules: "una museruola per asino, coi due montanti relativi, lunga m. 0,19» (NSc 1890: 392). En I 12, 1-2, dans la même pièce que les ossements évoqués à la note précédente, deux muselières ont été mises au jour le 13 mars 1961 (GSP 1961: «13 marzo [...]. Si scava anche nell'area dei molini e precisamente nell'angolo Nord Est. Del detto ambiente, durante lo scavo si è rinvenuto [...] alcuni elementi di bronzo adibito a briglia di cavallo [...] [Inv. n P13219 a-b, inscrit le 15 mars 1961 sur les registres]»). 
culièrement réduit, ce qui peut être dû à la faible qualité des journaux de fouilles quand la majeure partie de ces locaux, situés dans la zone centrale de Pompéi, a été mise au jour ${ }^{36}$. L'utilisation de pavements en blocs de lave autour des meules est un autre indice qui signale la présence des animaux: la mise en œuvre d'un tel aménagement permet d'éviter une trop rapide détérioration du sol là où il est piétiné en permanence ${ }^{37}$. Toutefois, il ne saurait constituer le seul indicateur: dans les deux boulangeries d'Herculanum, le sol apparaît constitué par un simple béton, alors même que la distance entre les meules et les murs permet le passage d'un animal et que des ossements pourraient attester l'usage de ces bêtes en Or. II, $1 \mathrm{a}^{38}$.

L'exemple le plus complet est constitué par la boulangerie située en IX 12, 6, exhumée durant les années 1980. Deux squelettes d'équidés ont été trouvés dans la salle g, également utilisée comme fournil, et cinq autres dans la pièce $p$, qui s'ouvre sur la rue mais communique avec l'intérieur de la maison ${ }^{39}$. Cette boulangerie comporte quatre meules - dont une ou deux en fonctionnement au moment de l'éruption - autour desquelles le sol est pavé ${ }^{40}$. Les sept animaux dont le squelette a été découvert laissent supposer soit un roulement dans leur utilisation pour actionner les meules, soit une utilisation comme animaux de bât. Il faut noter que même avant la destruction partielle de ces moulins, l'utilisation simultanée de quatre d'entre eux aurait requis une coordination parfaite entre les animaux de façon à ce qu'ils ne se gênent pas les uns les

${ }^{36}$ Sur les 29 espaces disposant de meules, 14 ont été mis au jour après 1861 .

${ }^{37}$ Ce type de pavement n'est cependant pas obligatoire: la quatrième meule de la boulangerie I 12, 1-2 n'en dispose pas, son pourtour est revêtu de simple terre battue.

${ }^{38}$ Sur ces ossements, cf. supra, n. 33. Sur le problème de la largeur des animaux employés, cf. infra.

${ }^{39}$ Varone 1989: 231-237.

${ }^{40}$ Dans le premier rapport de fouilles, A. Varone (1989: 233) signale qu'une seule des meules est entière, qu'un catillus aurait été détruit par les tunnels de récupération antiques, tandis que les deux autres avaient été utilisés avant l'éruption pour préparer de la chaux. En revanche, dans une publication ultérieure, il se contente d'indiquer que l'un des catilli a été retrouvé brisé sur le sol (Varone 1995: 29), ce qui pourrait indiquer un dommage survenu pendant l'éruption et non lors d'un séisme antérieur. autres. Pour obtenir cette synchronisation, des guides humains ont pu être utilisés. Sur quatre des reliefs représentant des meules en fonctionnement, un personnage s'active autour des animaux attelés: sur la brique sculptée provenant de l'Isola Sacra, il fouette la bête (fig. 65); sur la plaque de marbre de Bologne, il tend la main vers le sommet de la meta, comme pour actionner le réservoir de grains (fig. 66); sur le sarcophage de la Porta San Giovanni, il tient un récipient (fig. 62). En revanche, sur celui provenant de la Vigna Sassi, aucune action ne peut lui être attribuée. Loin de laisser les ânes tourner en rond sans intervention, il était nécessaire de les accompagner pendant leur mouvement, tant pour éviter les accrochages, quand les meules sont rapprochées les unes des autres, que pour assurer la logistique des moulins.

En dépit des assertions de L. A. Moritz qui développe une longue série d'arguments pour réfuter l'existence de meules actionnées par l'homme, cette pratique n'est pas complètement inexistante $^{41}$. Face à l'absence patente de toute mention de cette pratique dans les textes, sauf à une période tardive, il est déjà possible de renvoyer au relief conservé au Museo Gregorio Profano (fig. 64) ${ }^{42}$. Comme l'indique L. A. Moritz, le meilleur facteur pour supposer l'existence de telles meules est leur proximité avec les murs ${ }^{43}$. Selon les manuels regroupant des mensurationstypes à destination des architectes contemporains, la largeur d'un âne serait de $40 \mathrm{~cm}^{44}$. Bien que cette mesure reste seulement indicative - ne serait-ce que parce qu'elle ne tient pas compte

${ }^{41}$ Moritz 1958: 97-102; Mayeske 1972: 170-171.

${ }^{42}$ Une mesure de Constantin datée de 319 concernant des condamnés pour des faits sans gravité mentionne l'utilisation de force humaine pour faire fonctionner les pistrina de l'Vrbs (Cod. Theod. 9, 40, 3). Aucun élément ne permet de déterminer le moment à partir duquel se développe ce type de châtiment. Je remercie C. Virlouvet de m'avoir indiqué cette référence. Sur le relief, cf. supra, n. 32.

43 "[...] The monuments show clearly that animals were in antiquity harnessed so close to their mills that their use could only be ruled out if the distance between wall and mill were smaller than the width of the animal. This is nowhere the case» (Moritz 1958: 98). Jamais L. A. Moritz ne donne la largeur de ces animaux.

${ }^{44}$ Neufert 1966: 205. Parmi les ossements d'animaux tués lors l'éruption, aucun âne n'a été clairement identifié. A. King (2002: 421-422) signale des ossements d'âne pour des niveaux 


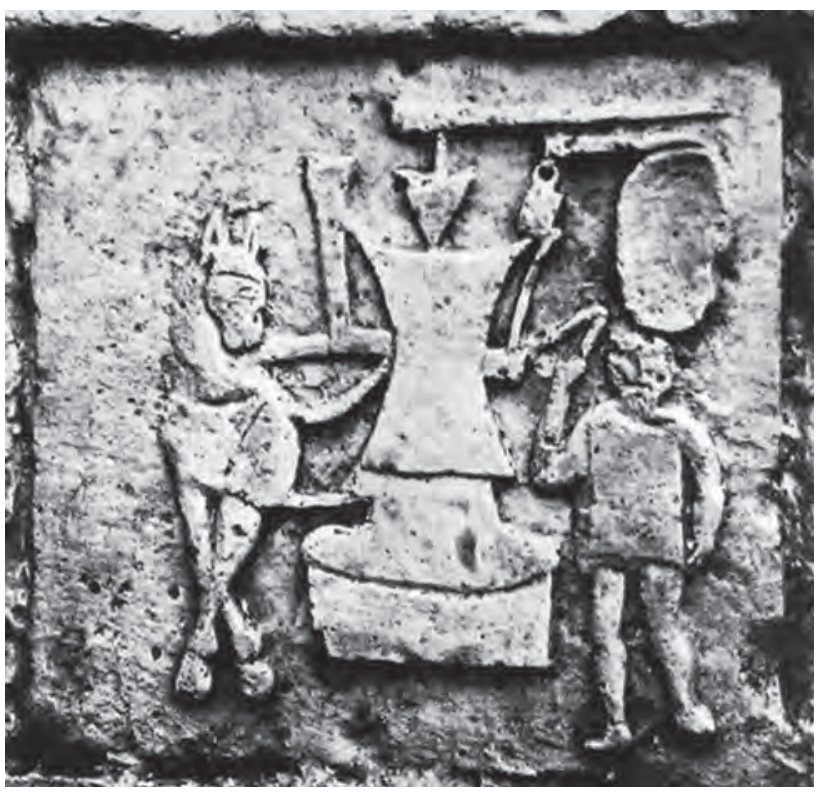

Fig. 65 - Plaque funéraire provenant de la tombe de Ti. Claudius Eutychus dans l'Isola Sacra et représentant une scène de meunerie: la meule, actionnée par un équidé dispose d'un réservoir à grain. Un homme se tient à proximité, un fouet à la main; derrière lui, se trouve un possible van.

des variations de taille propre à cette espèce -, elle permet de considérer qu'en dessous de cette distance entre la base de la meule et les murs l'entourant, un âne ne peut avoir été utilisé comme force motrice. Ainsi, une cinquantaine de centimètres sépare l'une des meules située en Or. II, 1a des murs nord et est, ce qui permet sans grande marge - d'utiliser des animaux ${ }^{45}$. La situation est toutefois telle que les restaurateurs ont cru bon de rogner partiellement le montant ouest de la porte menant vers la pièce $b^{46}$. Dans

$\mathrm{du} \mathrm{VI}^{\mathrm{e}}$ au $\mathrm{IV}^{\mathrm{e}}$ siècle av. J.-C., mais aucune attribution sûre ne peut être donnée pour le $\mathrm{I}^{\mathrm{er}} \mathrm{s}$. de notre ère. Les données archéozoologiques ne permettent que difficilement de faire la différence entre un cheval et ses hybrides - mule ou bardot. Le squelette d'équidé remonté et exposé en I 8, 12 - qui pourrait, selon A. King (2002: 422), être une mule - permet d'obtenir un exemple de mesures pour Pompéi, à l'exception de la cage thoracique trop endommagée. Sur les problèmes de distinction entre âne et cheval, notamment dans le cas de la région ensevelie par le Vésuve, cf. King 2002: 421-426.

${ }^{45}$ La base maçonnée des meules en Or. II, 1a n'est plus visible actuellement. Toutefois, en reportant les dimensions

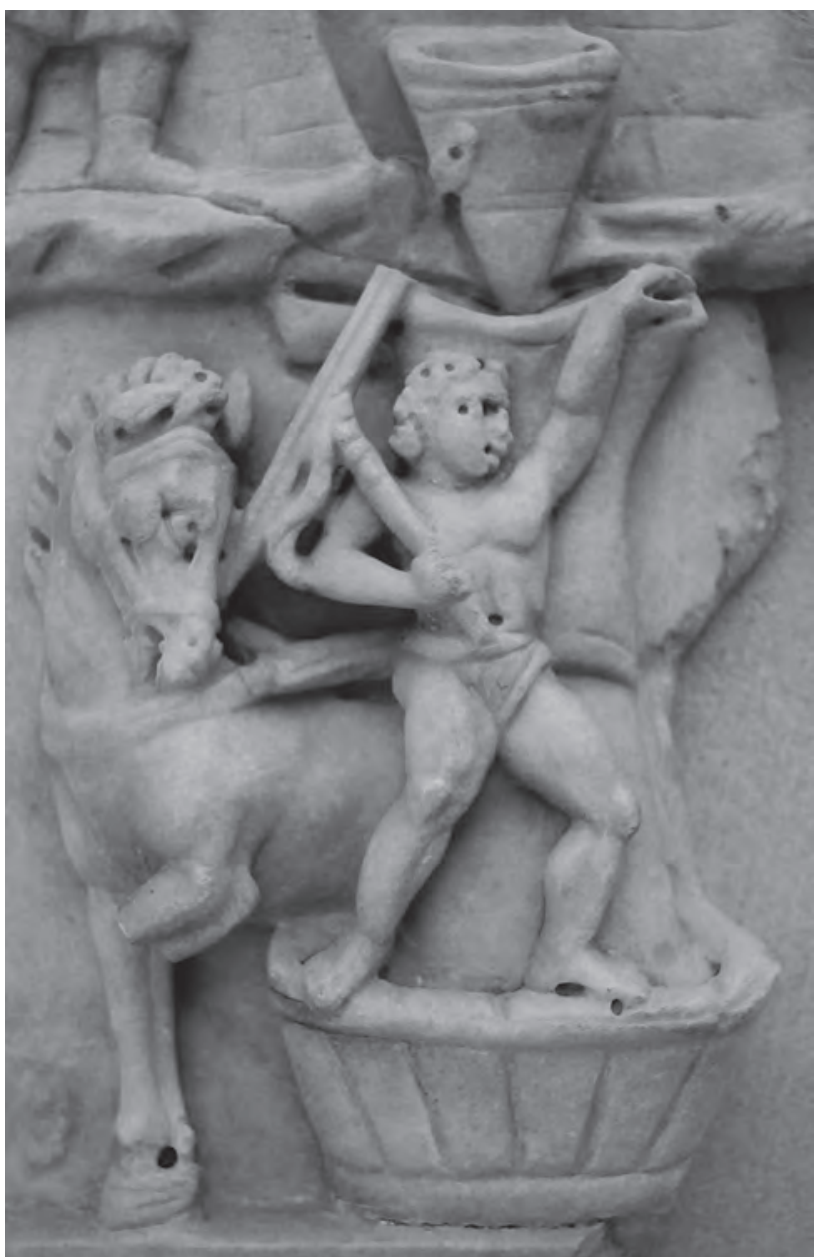

Fig. 66 - Détail du relief représentant une scène de boulangerie, conservé au Museo Civico Archeologico de Bologne: la meule est actionnée par un équidé, accompagné par un homme qui tient un fouet d'une main et tend la seconde vers le sommet de la meta.

de celles d'Or. II, 8 ou en évaluant la largeur de cette base sur les photos faites après la fouille, il est possible d'évaluer leur emprise au sol à un cercle ayant un diamètre de 120 centimètres. De la sorte, la distance entre la meule - base comprise - et le mur oriental est de 50 centimètres.

46 Les comptes rendus de fouille concernant cette boulangerie sont particulièrement peu détaillés. Il est impossible de déterminer si cet arasement correspond à une situation observée avant réfection du pan de mur ou bien s'il s'agit d'une pure invention. 
les boulangeries pompéiennes, la distance mesurée entre le mur et la base de la meule n'est jamais inférieure à $40 \mathrm{~cm}^{47}$. Toutefois, ce constat ne permet pas pour autant le rejet définitif de l'utilisation de la force humaine pour broyer le grain. En effet, deux types de meules sont trop bas pour permettre une rotation animale. Le premier est de forme cylindrique. La hauteur maximale du bras permettant la rotation est de $45 \mathrm{~cm}^{48}$. Le second type reprend la forme en clepsydre des meules pompéiennes mais de taille réduite: l'exemplaire complet situé en VII 2, 22 est haut de $84 \mathrm{~cm}$, son bras se situant à $50 \mathrm{~cm} \mathrm{du} \mathrm{sol} \mathrm{(fig.} \mathrm{67)}{ }^{49}$. Ces meules actionnées par une main-d'œuvre humaine sont peu nombreuses, toutefois, rien ne permet de douter de leur emploi à Pompéi, en dépit de leur rendement inférieur.

Jusqu'à présent, je n'ai mentionné que les parties en pierre volcanique de ces meules. La base de la meta est toujours enrobée par un aménagement maçonné dont la hauteur varie de 30 à $40 \mathrm{~cm}$, pour une largeur de 15 à $20 \mathrm{~cm}$. Le sommet de cette excroissance constitue la surface sur laquelle la boulange se dépose une

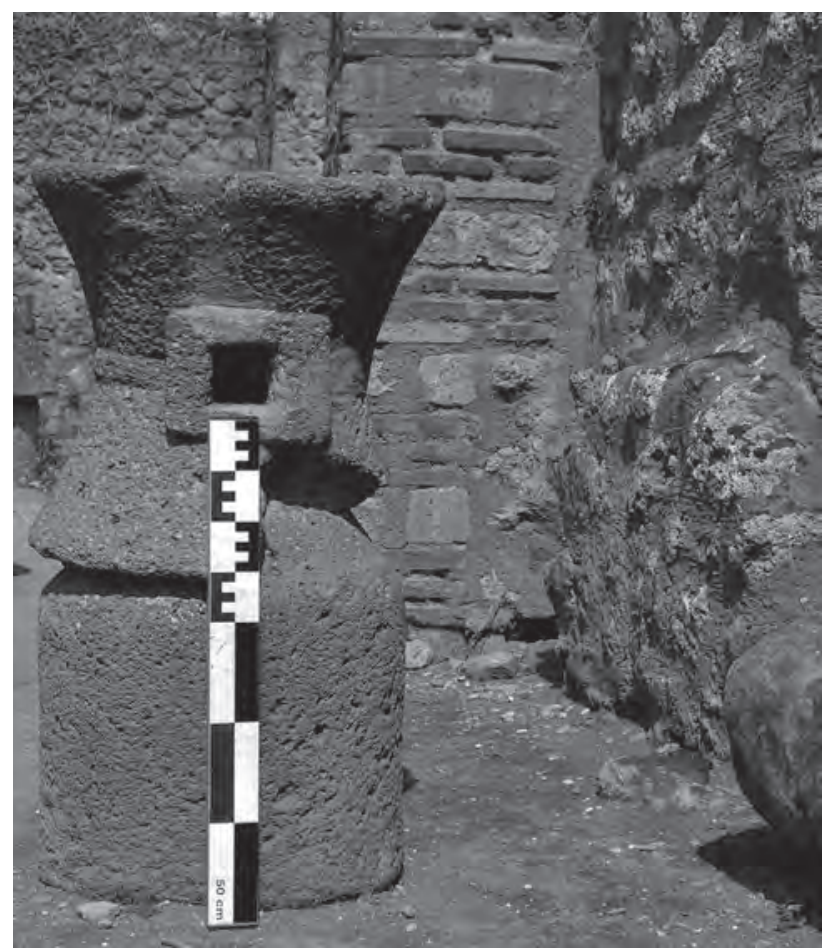

Fig. 67 - Meule provenant de la boulangerie VII 2, 22 à Pompéi. Bien que reprenant la forme des moulins à sang à rotation animale, celle-ci ne peut avoir été manipulée que par un homme.
47 Les distances les plus faibles entre les meules et les murs ont été relevées dans les boulangeries suivantes: VI 2, 6 (mur ouest - meule ouest: $44 \mathrm{~cm}$ ); VI 6, 17-21 (mur est - meule sud-est: $45 \mathrm{~cm}$ ); VII 2, 3.6 (mur ouest - meule sud-ouest: $48 \mathrm{~cm}$ ). Dans toutes les autres boulangeries, les meules sont situées à au moins $50 \mathrm{~cm}$ des murs.

${ }^{48}$ Cette meule correspond au type 1 de la typologie proposée par D.P.S Peacock (1989: 206-207). Aux cinq exemplaires étudiés par cet auteur, qui, comme il l'indique, ne se situent pas dans des boulangeries, il faut ajouter les deux qui se situent en I 8, 15-16. Ces deux meules ont pour dimensions les mesures suivantes: hauteur totale 62 et $34 \mathrm{~cm}$; diamètre 60 et $36 \mathrm{~cm}$; hauteur du catillus 33 et $20 \mathrm{~cm}$; hauteur de la barre 45 et $22 \mathrm{~cm}$. Ce local n'est pas spécialisé dans la production de pains, comme l'indiquent tant le comptoir maçonné situé en I 8, 15 que le dispositif recouvert de feuilles de plomb situé dans la pièce annexe. Toutefois, la présence d'un four à voûte de dimension réduite le long du mur nord de ce même espace indique une possible production boulangère et permet de le considérer parmi les pistrina. L'interprétation de ce local comme destiné à la production de pigments, proposée par M. Della Corte (NSc 1946: 113) et suivie par V. Castiglione Morelli (Castiglione Morelli - Vitale 1989: 207-208) paraît hautement improbable: alors que l'ensemble du matériel mis au jour dans l'arrière-boutique indique des activités de prépara- tion culinaire - au moins du pain, les pistes en plomb étant peut-être à associer avec une production de fromages - il serait étonnant que le four seul soit destiné à la production de pigments dont aucune trace n'a été mise en évidence.

${ }^{49}$ Ces meules correspondent au type 3a de la typologie proposée par D.P.S. Peacock (1989: 210). Six exemplaires ont été observés à travers la ville. Deux sont situés dans la boulangerie VII 2, 22 (cf. PPM VI: 659-664, part. fig. 1-8). En I 4, 12 - boutique associée à la boulangerie I 4, 12-17 - se situe une meta qui ne peut avoir reçu qu'un catillus de ce type. En VI 14, 32, un catillus de cette forme a été mis en place sur une meta normalement destinée à recevoir des pièces de dimensions supérieures. Enfin, deux autres exemplaires proviennent des commerces alimentaires VI 8, 8 et VII 4, 4. Quatre de ces exemplaires proviennent donc de boulangeries, en dépit des assertions de D.P.S. Peacock (1989: 210) qui refuse de les associer à ces locaux. Conservant également la forme de la clepsydre, mais en plus trapue, les meules de type 2d (Peacock 1989: 209) paraissent avoir été manipulées à la force des bras. Au seul exemplaire de meta dépourvue de son catillus signalé par ce chercheur en VIII 6, 1.9-11, il convient d'ajouter celui - complet - qui se trouve en VII 16, 5-6. En dépit du pavement qui entoure son catillus - dépourvu de socle maçonné - la hauteur du bras, $55 \mathrm{~cm}$, semble interdire l'utilisation d'un animal. 
fois les grains broyés. L'étude de cette surface est rendue délicate par les fréquentes restaurations qui ont pu affecter ce massif maçonné ${ }^{50}$. Le principal traitement qui a pu leur être appliqué est de recouvrir le sommet légèrement concave du muret par une feuille de plomb martelée et rabattue sur les côtés ${ }^{51}$. Quant aux gestes nécessaires au bon ramassage de la boulange s'amoncelant dans cette cavité, ils peuvent à peine être restitués avec les sources iconographiques. Sur le relief de la Porta San Giovanni (fig. 62), le personnage qui accompagne l'animal tient un récipient le long de son torse avec son bras gauche. Ce récipient peut contenir tout autant des grains avec lesquels il s'apprête à remplir le réservoir situé au-dessus de la meta que de la boulange. En revanche, sur le tombeau de M. Vergilius Eurysaces, le personnage à proximité de la meule de droite se penche en pliant le genou gauche vers la base de cette dernière. Son bras droit est en extension, comme pour rassembler la farine à peine broyée (fig. 60, a ) 52 . Sa posture générale ne paraît pas s'adapter avec un âne en mouvement; un arrêt de la meule aurait ainsi été nécessaire pour ramasser au fur et à mesure la farine produite. Une telle pratique, tout comme l'installation des moulins en batterie et leur fonctionnement simultané, ne pouvait que requérir d'impressionnants talents de coordination entre les tandems homme-animal.

La boulange, résultat du broyage, contient la farine, des gruaux et le son, enveloppes des grains. Avant de pouvoir utiliser la farine, il est nécessaire de bluter l'ensemble, afin de la séparer des éléments plus grossiers. Le blutage s'accomplit avec un tamis, l'opération devant

\footnotetext{
${ }^{50}$ Un exemple de ces restaurations est particulièrement visible sur le cliché d'une boulangerie non spécifiée publié par T. Warscher (1930: fig. 1 p. 103).

${ }^{51}$ Ce revêtement est encore visible sur une meule en I 12, 1-2 et sur une autre en IX 12, 6. La même technique est attestée en VII 2, 3.6 au moment des fouilles sur l'une des trois meules en état de fonctionnement: "Quivi si notano anche tre molae per sfarinare il grano, avendo una di esse la base ricoverta da una lamina di piombo [...]» (GSPomp, n.s. 1, 3, 1868: 60). Aucune information ne peut être obtenue à partir des deux exemples d'Herculanum: la base des deux meules du laboratoire Or. II, 8 a été fortement endommagée, tandis que celle d'Or. II, 1a paraît avoir été reconstruite.

${ }^{52}$ Cf. Ciancio Rossetto 1973: 42 et pl. XXVIII, 1.
}

être renouvelée plusieurs fois pour extraire le maximum de farine. Ainsi, selon Pline, trois opérations successives de blutage sur du blé barbu permettent d'obtenir une augmentation de rendement de $7 \%$ dans la quantité finale de pain $^{53}$. Il ne donne aucune description des instruments utilisés, sauf pour mentionner des inventions non romaines, comme celles de l'Égypte, de la Gaule ou de l'Espagne ${ }^{54}$. À défaut de proposer une description précise de ces blutoirs, ce texte permet une première approche. Ainsi, il ne faudrait pas voir cet instrument comme percé de trous assez larges, mais comme utilisant une maille resserrée, obtenue avec du tissu, du papyrus ou des crins de cheval. Une mention de Caton renvoie également à un cribrum farinarium tissé. Dans la recette de la placenta qu'il propose, il indique qu'après avoir égoutté le fromage frais de brebis mis à macérer, il faut le pétrir dans un mortier, puis, après l'avoir émietté, le passer dans un tamis ${ }^{55}$. Le but de cette opération n'est pas de réduire le fromage en fragments minuscules, mais bien de lui enlever toute son eau, en le pressant sur un tamis à maille serrée ${ }^{56}$. Cette utilisation d'une surface de tissu vraisemblablement tendue sur un tambour de bois, manœuvrée par une seule personne a perduré au moins jusqu'au $\mathrm{XVII}^{\mathrm{e}}$ siècle, avant une première forme de mécanisation.

Les interprétations généralement proposées pour certains reliefs donnent une vue sensiblement différente. Un fragment isolé du relief de Bologne montre un homme de dos, debout devant une table, seulement vêtu d'un pagne qui soulève au-dessus de lui un large cylindre de 59-60.

${ }^{53}$ Plin., NH, 18, 89-90. Sur ce passage, cf. André 1981 :

${ }^{54}$ Plin., NH, 18, 108: Cribrorum genera Galliae saetis equorum invenere, Hispaniae lino excussoria et pollinaria, Aegyptus papyro atque iunco.

"Quant aux diverses sortes de tamis, les Gaules ont inventé ceux en crin de cheval; les Espagnes, les tamis et les blutoirs en lin; l'Égypte, ceux en papyrus et en jonc» (trad. CUF).

${ }^{55}$ Cat., Agr., 76, 3.

${ }^{56}$ Comme le note J. André (1981: 155), quoi que sans faire proprement référence à ce texte, «sec et réduit en poudre, le fromage remplaçait la farine dans de nombreuses recettes de gâteaux ». 


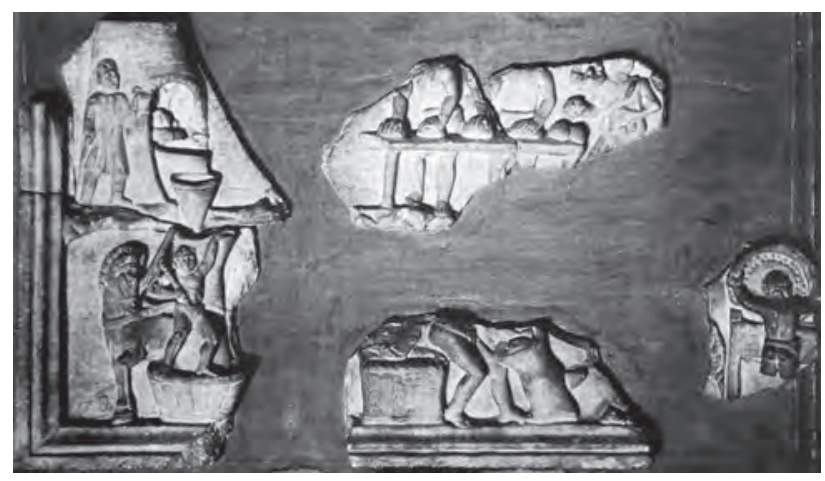

Fig. 68 - Relief représentant une scène de boulangerie, conservé au Museo Civico Archeologico de Bologne. En dépit des lacunes, les différentes étapes de la confection du pain sont figurées de droite à gauche et de bas en haut. Le fragment représentant le tamisage du grain (en bas, à droite) a disparu.

hauteur réduite (fig. 68). Deux rangées concentriques de trous sont figurées, ce qui suggère un instrument en métal. La position de ce fragment est incertaine ce qui rend délicate son interprétation. Toutefois, si la restitution actuelle qui le place dans le champ inférieur est juste, la scène renverrait à la préparation du grain ${ }^{57}$. Il est ainsi fort probable que ce cylindre large et de faible hauteur soit un crible et non un blutoir, comme dans le cas du caisson de P. Nonius Zethus évoqué plus haut (fig. 61) ${ }^{58}$. En revanche, un relief très mutilé, conservé à Ostie, pourrait montrer un crible dans un laboratoire (fig. 69) ${ }^{59}$. Un personnage tient un plat de ses deux bras. Derrière lui, à sa gauche, sont disposés sur une étagère deux types de pains. Sur le mur, deux

${ }^{57}$ Cette hypothèse a été proposée par O. Jahn (1861: 343). Seul l'angle inférieur gauche du relief est conservé intégralement. On y voit la meule déjà décrite et au-dessus le four. La lecture de ce relief se ferait ainsi de bas en haut, de droite à gauche puis de gauche à droite. Il faudrait également se poser la question de la place du fragment dans le champ inférieur. Tel qu'il est présenté actuellement (cf. Zimmer 1982: fig. 19 p. 109), il est placé à droite des opérations de vidage des sacs. Si le personnage tenant son tamis passe les grains au crible, il faudrait positionner ce fragment à droite de la mouture. L. A. Moritz (1958: 167) considère que tant le relief de Bologne que celui de Zethus renvoient au blutage. Concernant ces deux interprétations, G. Zimmer (1982: 109) reste circonspect.

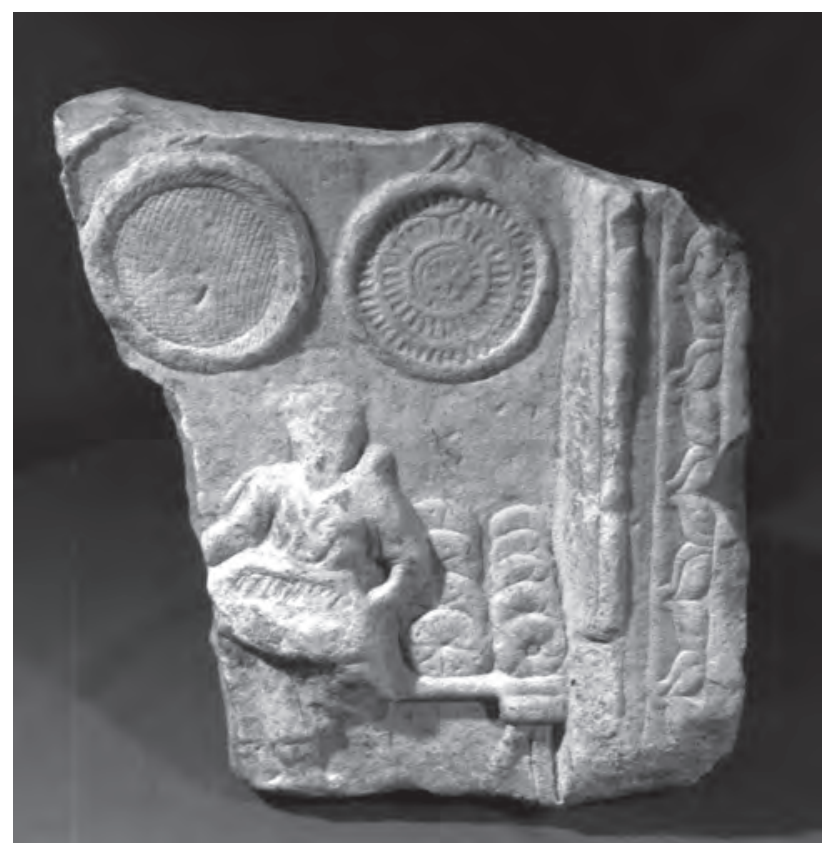

Fig. 69 - Relief fragmentaire conservé à Ostie. Suspendus au mur, deux probables tamis utilisés pour bluter la farine.

objets circulaires sont suspendus; le fond de celui de gauche est comme quadrillé tandis que celui de droite montre deux cercles concentriques dans lesquels des rainures rayonnantes ont été creusées; au centre se situe une forme d'étoile. G. Zimmer a interprété le premier comme un tamis, le second comme un moule ${ }^{60}$. La façon dont ces objets sont gravés renvoie au mode de rendu de la vannerie ${ }^{61}$. Il pourrait ainsi s'agir de deux tamis différents - plutôt que d'un tamis et d'un moule ${ }^{62}-$, utilisés pour

${ }^{58}$ Cf. supra, p. 134.

${ }^{59}$ Museo Ostiense, Inv. n 137. Cf. Zimmer 1982: cat. $\mathrm{n}^{\circ} 28$.

${ }^{60}$ Zimmer 1982: 116.

${ }^{61}$ Lobjet de gauche pourrait ainsi être conçu en fibres tissées, tandis que celui de droite pourrait être réalisé en matériaux rigides, comme de l'osier. Le motif au centre serait la transposition précise d'un départ croisé à montants rayonnants. Je remercie vivement M. Cullin-Mingaud de ses remarques sur les représentations de ces objets en vannerie.

${ }^{62}$ L'usage de la vannerie pour faire des blutoirs est par ailleurs confirmé par Pline (NH, 18, 108; cit. supra, n. 54). 
bluter la farine ${ }^{63}$. Enfin, certains reliefs exposent clairement la façon d'utiliser ces tamis. Sur la frise méridionale du tombeau de M. Vergilius Eurysaces, à gauche des meules - dans la suite chronologique de la mouture -, une même scène est représentée à deux reprises (fig. 60, b-c ). Deux garçons manipulent des récipients cylindriques au dessus d'une table. Dans la scène la plus à gauche, un personnage en toge récupère quelque chose dans la main de l'un des garçons. Selon l'interprétation de P. Ciancio Rossetto, il s'agirait de deux moments distincts du blutage: après avoir été passée une première fois dans un tamis, la farine serait de nouveau blutée avec un instrument à mailles plus fines; le résultat étant alors inspecté par Eurysaces en personne. La farine serait stockée dans des récipients cylindriques posés au sol au pied de la table ${ }^{64}$.

De ces premières interventions sur le grain pour obtenir de la farine, peu de vestiges ont subsisté. Les vans éventuellement utilisés pour le nettoyage des grains, puis les blutoirs servant à l'affinage de la farine n'ont pas été conservés en raison de l'utilisation de matériaux périssables - bois, tissu, vannerie. Si les instruments de certains reliefs, interprétés comme des tamis à bluter, pourraient indiquer des cribles en métal, aucun objet de cette sorte n'a été découvert à Pompéi ou Herculanum. La nécessité de mouiller tout ou partie des grains entraîne l'obligation de disposer d'installations hydrauliques à proximité des meules, probablement des baquets en bois. Finalement, de toutes ces opérations préliminaires, la mouture est la mieux connue. Les meules utilisées à cet usage sont - hors problèmes liés aux travaux en cours au moment de l'éruption - les mieux conservées, au point de suffire pour indiquer une boulangerie. Une partie de ces meules était actionnée par des animaux, mais pas toutes. Cet usage de la force animale rend obligatoire la présence d'écuries qu'il faudrait identifier. Après le blutage, la farine est prête à être employée pour la confec-

${ }^{63} \mathrm{La}$ finesse de la farine dépend du blutage et a des conséquences importantes sur la qualité du pain. La présentation d'un tamis à bluter sur un relief funéraire, au-dessus de pains cuits pourrait ainsi être une affirmation du savoirfaire du boulanger.

${ }^{64}$ Ciancio Rossetto 1973: 42, 48-50 et pl. XXIX. tion de pains. Des différents sous-produits de la mouture, seul le son est alors perdu pour les opérations de boulangerie mais peut être utilisé pour la nourriture des animaux.

\section{III.2 Pétrissage et façonnage du pain}

En dépit des propos de Pline, les opérations de pétrissage qui succèdent à la mouture ont une certaine importance: la confection de la pâte par le mélange de la farine avec différents ingrédients conditionne la forme et la qualité du pain ${ }^{65}$. Les différentes étapes peuvent être retracées en analysant les reliefs montrant des scènes de boulangerie. Ainsi, sur la frise du tombeau de M. Vergilius Eurysaces, les actions situées sur le côté septentrional se situent dans la suite de la vérification de la farine (fig. 60, de). Elles s'achèvent brutalement - en raison de la destruction partielle du monument lors de son incorporation partielle à la muraille aurélienne - par l'enfournement d'une miche de pain. Comportant de fortes similitudes avec les opérations de mouture et de blutage, une partie des actions représentées est doublée. À l'extrémité droite, un équidé est harnaché autour d'un objet cylindrique dont émerge un pieu. À gauche de celui-là, un homme est courbé; son avant-bras droit disparaît dans l'orifice supérieur de l'objet cylindrique. Après des divergences d'interprétation, voulant tout d'abord faire de cette scène une nouvelle représentation de mouture, il a été admis qu'il s'agissait d'une machine destinée au pétrissage $^{66}$.

C'est à A. Mau que l'on doit le rapprochement entre ces scènes et les cylindres en pierre fréquemment mis au jour dans les boulangeries pompéiennes. Il a exposé les principes généraux du fonctionnement de ces équipements en deux temps, d'abord en 1886 suite à l'observation du pétrin mis au jour en VI 14, 33, puis dans sa synthèse sur Pompéi. Depuis, ses conclusions ont été répétées à de nombreuses reprises, sans

\footnotetext{
${ }^{65}$ Plin., NH, 18, 105 : [...] Summa laus siliginis bonitate et cribri tenuitate constat.

«L'excellence [du pain] dépend de la qualité de la farine et de la finesse du tamis » (trad. CUF).

${ }^{66}$ Sur le débat concernant cette portion du relief, cf. Mau 1886: 47-48, avec la bibliographie antérieure.
} 
variation sensible et sans susciter d'étude plus approfondie. Il convient donc de partir de ses observations comme préalable. Selon lui, les pétrins seraient formés d'un cylindre de lave évidé en son centre, d'un diamètre de 45 à $60 \mathrm{~cm}$. La paroi du fond présente une crapaudine en fer - parfois fixée par une coulée de plomb -, de forme carrée avec un évidement semi-circulaire au centre. Dans deux cas (VI 14, 33 et VII 2, 22), une barre en fer horizontale, pliée vers le haut à ses extrémités distales a été observée peu après la fouille. L'exemple de VII 2, 22 présentait également une bande de fer repliée sur elle-même pour former un carré. En son centre, une pointe en fer recevait l'axe de rotation de la machine. Des témoins de la mise au jour effectuée en VI 14, 33 ont expliqué à A. Mau la présence de nombreux fragments de bois à l'intérieur au moment de la découverte. Si, par analogie avec le relief du tombeau de M. Vergilius Eurysaces, il propose à fort juste titre d'interpréter l'ensemble comme des pétrins, certains éléments restent obscurs dans un premier temps, en particulier les trous qui percent les parois du cylindre. En revanche, il signale, au moins pour l'exemple de VI 14, 33, la présence d'une poutre fixée dans les murs entourant le pétrin et qui passe au-dessus de son centre. L'axe vertical s'y serait inséré ${ }^{67}$. Dans sa synthèse portant sur l'ensemble du site, il revient rapidement sur la question des pétrins avec plusieurs divergences quant à son article précédent. D'une part, la poutre à peine évoquée n'est plus mentionnée, tandis que le mystère des perforations parait résolu: il s'agit d'emplacements permettant l'insertion de fiches en bois qui servent à bloquer la pâte devant être pétrie. Surtout, il propose une restitution complète de l'ensemble: selon lui, dans l'axe vertical seraient fichées des planches formant un plan seulement

\footnotetext{
${ }^{67}$ Mau 1886.

68 " The dough was placed in a round pan of lava a foot and a half or two feet in diameter. In this a vertical shaft revolved, to the lower part of which two or three wooden arms were attached (three in Fig. 224); the one at the bottom was strengthened by an iron crosspiece on the under side, the projecting centre of which turned in a socket below » (Mau 1899: 384).
}

interrompu pour permettre le passage des fiches lors du mouvement rotatif. Il en vient ainsi à considérer que la lame en fer située au fond du pétrin ne sert qu'à renforcer la structure en bois - axe et planches encastrées - qui seule assure le pétrissage $^{68}$. Cette interprétation a depuis toujours été acceptée dans l'ensemble des ouvrages traitant de la boulangerie ou de l'alimentation en général ${ }^{69}$. Seul V. M. Strocka, dans son analyse de la Casa del labirinto (VI 11, 8-10) propose une variante à ce modèle: au lieu de restituer des planches insérées dans l'axe central, il suggère que ce soient des fiches, ce qui permet de laisser plus de place à la pâte devant être malaxée $\mathrm{e}^{70}$.

L'étude détaillée du pétrin de la boulangerie des casti amanti (IX 12, 6) permet de préciser les observations réalisées par A. Mau sur l'exemple de la boulangerie VII 2, 22, désormais réduit à la seule crapaudine et aux amorces du bras ${ }^{71}$. Ce pétrin se présente sous la forme d'un cylindre, très légèrement évasé à l'extérieur, réalisé en roche volcanique locale trachytique. Deux creusements quadrangulaires perforent ses parois. $\mathrm{Au}$ centre, une crapaudine en fer est scellée dans la masse de pierre par une coulée d'alliage à base de plomb. Plusieurs pièces métalliques ont été découvertes en lien avec cette crapaudine: un grand clou à tige de section carrée et tête hémisphérique qui se positionne dans la cavité de la crapaudine; il perfore une plaque carrée rivetée à une grande barre dont les extrémités sont repliées à angle droit vers le haut. La barre transversale, la plaque carrée et l'extrémité métallique de l'axe forment un bloc solidaire, amovible de la crapaudine. Pour comprendre le fonctionnement de ce mécanisme, il faut le compléter avec une pièce en bois verticale, plantée sur le clou axial. Cette poutre était enserrée à sa base par une frette en

\footnotetext{
${ }^{69}$ Voir par exemple Mayeske 1972 : 22 ; Curtis 2001 : 363365; Thurmond 2006: 64-67; Bakker 1999: 78, sur Ostie.

${ }^{70}$ Strocka 1991: 61 et fig. 38 p. 61.

${ }^{71}$ L'étude des pièces métalliques du pétrin de la boulangerie des Chastes Amants a été réalisée par A. Duvauchelle et C. Loiseau. Qu'ils trouvent ici l'expression de ma gratitude pour les discussions animées que nous avons eues autour des pétrins.
} 
fer qui servait tout à la fois de maintien contre l'éclatement mais aussi et surtout qui permettait d'entraîner la lame dans le mouvement initié par la rotation de l'axe. En se fondant sur les remarques d'A. Mau, qui rapporte que des fragments de bois ont été observés par les fouilleurs sur la frette du pétrin découvert en VII 2, 22, il est possible de restituer la base de l'axe en bois ${ }^{72}$. Elle aurait été taillée en tenon, lui-même probablement parcouru longitudinalement par une rainure permettant d'enserrer la barre horizontale sur laquelle l'axe repose. Dans sa première étude, A. Mau avait fort justement noté la présence d'un axe horizontal fixé au-dessus du centre du pétrin. Il est regrettable qu'il ait oublié cet élément dans sa synthèse ultérieure. En effet, mécaniquement, l'axe vertical - qui, dans sa partie inférieure est simplement appuyé dans une crapaudine - ne peut être fonctionnel sans être maintenu à son extrémité supérieure. Il doit donc nécessairement s'insérer dans une poutre disposée orthogonalement à celui-ci. Des encastrements de poutres ont systématiquement été observés dans les salles disposant d'un pétrin; ils permettent d'ailleurs fréquemment de retrouver la position originelle du pétrin après son déplacement $^{73}$. L'assemblage entre l'axe vertical et la poutre de maintien paraît devoir être restitué sans élément métallique. En effet, aucune pièce de ce type n'a été signalée dans les rapports de fouille. Il convient donc de considérer que l'axe vertical était à section quadrangulaire dans sa partie inférieure et à section circulaire dans sa partie supérieure, sans pièce de liaison.

Revenons sur son emploi du pétrin pour fraser les ingrédients constitutifs de la pâte à

72 «Al fero osservato nel[l'esempio] n. 3 [soit le pétrin de VI 14, 33, actuellement muni seulement de la barre transversal, mais dépourvu de frette] [...] è sovrapposto un ferro quadrato di circa m. 0,17 di ogni lato, che ha nel mezzo un incavo di m. 0,11 in ogni lato, nel centro una punta di ferro [...] Avanzi di legno si osservano tanto nell'incavo quanto sul marginee che vi rimane intorno. Se ne deduce che l'asse dell'apparechio era grossa m. 0,17, e nell'estremità si restringeva a m. 0,11 e con questa estremità, quadrata era fissata nell'incavo suddetto e sulla punta che ne forma il centro» (Mau 1886: 47).

${ }^{73}$ À titre d'exemple, le pétrin de IX 3, 19-20 a été observé posé dans l'angle sud-ouest de la pièce 119. L'enduit du mur sud conservait l'empreinte d'une poutre présentant un axe sud-sud-ouest / nord-nord-est, tandis que le mur avait été pain. Selon l'hypothèse d'A. Mau, des «dents» horizontales en bois auraient été insérées dans l'axe vertical, avec des espaces correspondants aux fiches enchâssées dans les trous prévus à cet effet dans la paroi en pierre. Des observations effectuées sur l'ensemble des pétrins permettent de réfuter cette interprétation et d'en proposer une autre. Les mesures des trous de fixation des fiches interdisent la restitution proposée: la différence entre le sommet de la fiche la plus basse et la base de la fiche qui lui est immédiatement supérieure en hauteur est souvent faible, quand elle n'est pas nulle ou négative. Dans la boulangerie VII 2, 22, exemple employé par A. Mau, les quatre fiches présentent des différences nulles quand elles sont appariées deux à deux dans l'ordre croissant de hauteur par rapport au fond. À partir de ce constat, nous devons donc considérer que le bras horizontal n'est autre que le fraseur, ou lame de pétrissage qui, par sa rotation permet de mélanger les ingrédients de la pâte. Les fiches - très probablement en bois permettent quant à elles d'aider au malaxage en constituant autant d'obstacles à la pâte en cours de confection.

Une autre solution consiste à pétrir la pâte à la main. Si Caton expose cette technique en dehors du cadre d'une production importante ${ }^{74}$, l'absence de pétrin mécanique dans une majeure partie des boulangeries plaide en faveur d'un fort développement du pétrissage manuel. À Herculanum, une seule (Or. II, 1a) des deux boulangeries dispose d'un pétrin en pierre. À Pompéi, vingt-six de ces appareils ont été mis au jour, répartis entre vingt-deux locaux ${ }^{75}$. À Ostie, dans les trois boulangeries dont l'étude a été

reconstruit en correspondance. Le nettoyage de l'ensemble de la pièce a permis de mettre en évidence un creusement destiné à recevoir la base du pétrin, dans l'alignement de l'encastrement de poutre. Quand les deux parois se faisant face ont été restaurées, il devient impossible de déterminer l'emplacement initial du pétrin sans procéder à un nettoyage du sol.

${ }^{74}$ Cat., Agr., 74.

${ }^{75}$ Le laboratoire de la Casa del marinaio (VII 15, 1.2-15) présente deux pétrins. La situation est identique en I 12, 1-2, avec un pétrin remployé comme aménagement hydraulique. Deux pétrins ont été vus hors des boulangeries, l'un au carrefour de la via degli Augustali et du vico del lupanare, le second dans la nécropole de la Porta di Ercolano. B. Mayeske (1972: 169) n'en recense que huit au total dans la ville. 
dirigée par J.Th. Bakker, des pétrins mécaniques sont présents, mais leur nombre n'apparaît pas lié aux meules mises en évidence ${ }^{76}$. Une unique représentation permet de connaître l'aspect des aménagements permettant le pétrissage manuel pour la période antique: un relief redécouvert récemment à Rome montre trois personnages debout, courbés devant un coffre, les mains plongées à l'intérieur ${ }^{77}$. Ce relief montre un système également attesté par plusieurs exemples dans l'iconographie moderne: les planches de l'Encyclopédie montrent une grande auge rectangulaire, munie d'un couvercle - appelé tour - et divisée en plusieurs compartiments à l'intérieur ${ }^{78}$. Au début du $\mathrm{XX}^{\mathrm{e}}$ siècle, ces pétrins sont encore employés; ils peuvent également être de section trapézoïdale ou semi-circulaire ${ }^{79}$. Aucun récipient en bois ainsi conçu n'a été identifié, ni à Herculanum, ni à Pompéi.

Parmi les ingrédients contenus dans le pain, outre la farine, l'eau est indispensable. À l'exception d'une mention lapidaire de la part de Pline l'Ancien, aucun des textes mentionnant les procédés de panification n'indique clairement le rapport entre ces deux ingrédients ${ }^{80}$.

${ }^{76}$ Dans le Cassegiato dei Molini (I, III, 1-2), 5 pétrins pour 10 meules (Bakker 1999: 59); dans le Molino (I, XIII, 4), 5 pétrins pour 8 meules (Bakker 1999: 78); au moins 1 pétrin pour au moins 1 meule dans le Cassegiato delle fornaci (II, VI, 7) (Bakker 1999: 88).

${ }^{77}$ Wilson - Schörle 2009, part. fig. 4.

${ }^{78}$ Encyclopédie, t. 19, p. 12, pl. 1, fig. 1A.

${ }^{79}$ Ammann 1925: 363-365.

${ }^{80}$ Plin., NH, 18, 67: Lex certa naturae [...] sicut optimum frumentum esse quod in subactum congium aquae capiat.

"C'est une loi naturelle bien établie [...] que le meilleur blé est celui qui absorbe un congius d'eau lorsqu'on le pétrit» (trad. CUF). Si l'on considère que le volume de blé est d'un modius $(8,76 \mathrm{~L})$, le rapport ainsi décrit est d'environ 2,6 volumes de blé pour un volume d'eau. À titre de comparaison, L. Ammann (1925: 370) donne le rapport suivant: "On peut dire que, approximativement, une bonne farine absorbe le tiers de son poids d'eau; les farines inférieures absorbent seulement le quart». Cette comparaison doit être considérée avec prudence: de la sorte, la farine antique serait de meilleure qualité que la farine contemporaine, ce qui est peu probable en raison de son manque de pureté, dû notamment à la présence de son (sur ce point, cf. André 1981: 66-67).

81 «Le gluten du blé est la seule des matières azotées contenues dans les céréales qui jouisse de la propriété de se souder sous l'action d'un malaxage en présence de l'eau, en donnant une pâte élastique et plastique» (Ammann 1925: 50). Sur le rapport entre la quantité de gluten, la qualité
Cette absence est largement justifiable: la quantité d'eau dépend tout d'abord de la qualité de la farine. L'obtention d'un pain levé est liée au gluten contenu dans le blé. Plus une farine contiendra de gluten, meilleure sera sa qualité, mais aussi plus importante sera la quantité d'eau qu'elle peut absorber ${ }^{81}$. En outre, l'adjonction d'eau est également conditionnée par le type de pâte - et donc de pain - que l'on cherche à obtenir. Les quelques annotations de Pline sur les différentes sortes de pain, particulièrement celui qu'il appelle "parthique» ou «aquatique» constituent une corroboration empirique de ces remarques ${ }^{82}$. Du sel est également ajouté dans la pâte, soit dans l'eau qui sert au pétrissage - notamment dans le cas où de l'eau de mer est utilisée - soit dans le levain selon Pline $^{83}$. Ce dernier élément est d'une importance particulière, puisqu'il s'agit du principe actif de fermentation qui permet de donner une structure aérée au pain ${ }^{84}$. La pâte fermentée depuis la veille peut être utilisée à ce dessein, ce qui évite le développement d'une acidité nuisible à la formation de bulles de gaz ${ }^{85}$. Enfin, d'autres ingrédients peuvent être ajoutés, pour donner

de la farine et la quantité d'eau nécessaire à l'obtention de la pâte, cf. Ammann 1925: 315, 370-371 et la note précédente.

${ }^{82}$ Plin., NH, 18, 105: [...] Non pridem etiam e Parthis invecto quem aquaticum vocant, quonima aqua trahitur ad tenuem et spongiosam inanitatem, alii Parthicum.

"[...] Depuis peu on a même importé de Parthie un pain qu'on appelle aquatique, parce qu'en l'étendant d'eau on lui donne une consistance ténue et spongieuse; d'autres l'appellent parthique» (trad. CUF).

${ }^{83}$ Plin., NH, 18, 68: Marina aqua subigi, quod plerique in maritimis locis faciunt occasione lucrandi salis, inutilissimum.

«Pétrir le pain avec de l'eau de mer, comme on le fait souvent sur les côtes pour économiser le sel, est une pratique très nuisible» (trad. CUF).

Plin., NH, 18, 104: Nunc fermentum fit ex ipsa farina quae subigitur priusquam addatur sal, ad pultis modum decocta et relicta, donec acescat. Vulgo vero nec suffervefaciunt, sed tantum pridie adservata materia utuntur [...].

"Aujourd'hui, on fait le levain avec la farine elle-même, qu'on pétrit avant d'y ajouter le sel, qu'on fait cuire jusqu'à consistance de bouillie, et qu'on laisse aigrir. Mais d'ordinaire, on ne la fait pas chauffer, et on se contente d'utiliser de la pâte gardée de la veille [...]» (trad. CUF).

${ }^{84}$ Pour l'historique des différentes recettes utilisées pour faire lever la pâte, cf. André 1981: 65-67.

${ }^{85}$ Plin., NH, 18, 104, cit. supra, n. 83. 
du goût au pain ${ }^{86}$. Une fois la pâte pétrie de façon homogène ${ }^{87}$, deux opérations doivent se succéder: le façonnage des pains et la fermentation panaire ${ }^{88}$.

Parmi les reliefs sur lesquels sont figurées des scènes de boulangerie, deux montrent la formation des pains. Sur la frise d'Eurysaces, cette étape est dédoublée, comme dans le cas du blutage. Derrière deux tables se situent quatre personnages au torse nu dont les mains, quelles que soient les variations dans leur position corporelle, sont jointes en avant sur la table. Celle-ci paraît dotée d'un rebord vertical qui la ferait ressembler à une auge de faible profondeur. Entre les deux tables, se trouve un personnage vêtu d'une tunique et non d'une toge (fig. 60, e $)^{89}$. La composition est similaire à celle où la farine est tamisée. Toutefois, le vêtement ne paraît pas désigner M. Vergilius Eurysaces lui-même, mais plutôt un de ses assistants ${ }^{90}$. La seconde table représenterait ainsi l'exécution des conseils prodigués par ce surveillant. Ce principe de succession des opérations se perçoit également à travers la représentation de la matière manipulée par les quatre personnages. Sur la table de droite, la plasticité de la pâte est figurée par l'utilisation d'un rendu proche de celui d'un drapé ${ }^{91}$. En revanche, sur la table de gauche, la pâte n'est plus étirée, les miches sont presque formées. La pratique représentée sur le relief de Bologne est assez différente (fig. 70). Seuls deux personnages se situent derrière la

86 André 1981: 67, avec les références des textes mentionnant ces ajouts.

${ }^{87} \mathrm{Je}$ ne reviendrai pas sur les gestes du pétrissage manuel qui sont largement décrits pour la période contemporaine (Ammann 1925: 368-373), mais dont les différentes phases ne peuvent être que difficilement restituées pour l'Antiquité. Le malaxage de la pâte - dépourvue de levain - est décrit de façon assez détaillée par le Pseudo-Virgile:

Moretum, 42-46: [...] Levi tum protinus illam/componit tabula, tepidas super ingerit undas / contrahit admixtos nunc fontes atque farinas, / transversat durata manu liquido que coacto, / interdum grumos spargit sale. (éd. Teubner)

«Il dépose la farine sur une planche lisse et verse pardessus de l'eau tiède. Il mélange alors l'eau et la farine confondues et les pétrit d'une main sans faiblesse et, quand la pâte liquide a pris de la consistance, il en saupoudre de sels les morceaux» (trad. André 1981: 63).

Les gestes devaient à la fois être plus nombreux et plus variés pour une pâte devant lever.

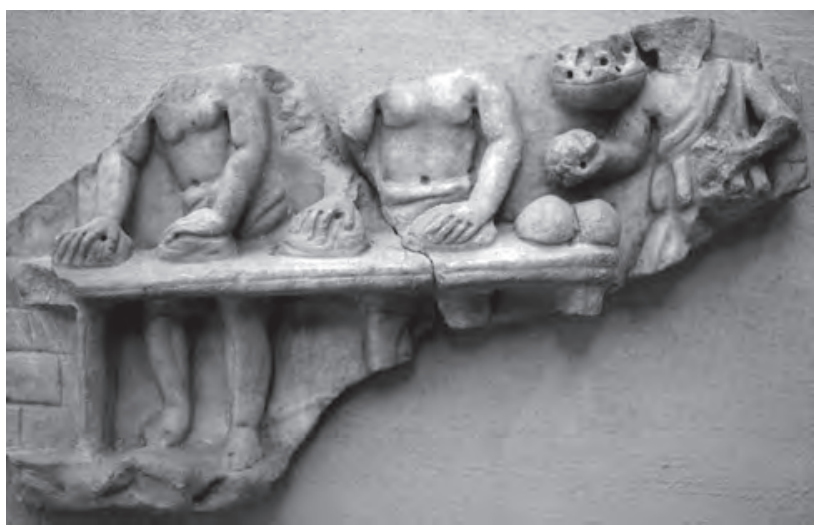

Fig. 70 - Détail du relief représentant une scène de boulangerie, conservé au Museo Civico Archeologico de Bologne: tandis que les deux personnages de gauche, torses nus, façonnent des miches, le troisième, à droite, est situé sous une balance et présente ce qui semble être une boule de pain pesée.

table, torses nus, éventuellement surveillés par un troisième homme vêtu d'une tunique ${ }^{92}$. Ils paraissent malaxer une miche dans chacune de leur main. Cette représentation est étrange, surtout si on la compare au relief d'Eurysaces où les personnages qui façonnent les pains ont les deux mains occupées par une seule miche. Dans les boulangeries pompéiennes, le lieu de façonnage est aisément reconnaissable dans de nombreux cas. Ainsi, majoritairement dans des pièces situées sur l'un des côtés du four, se trou-

\footnotetext{
${ }^{88}$ Dans la boulangerie contemporaine, cette phase se situe avant et après la mise en forme: une première fermentation légère - le pointage - a lieu, puis la fermentation véritable se déroule (Ammann 1925: 363, 441-446).

${ }^{89}$ Concernant cette partie de la frise septentrionale, cf. Cianco Rossetto 1973: 43, 56-58, pl. XXX, 2 - XXXI, 1.

${ }^{90}$ De la sorte, une plus grande importance est donnée au blutage, sous la surveillance directe du maître des lieux. Cette primauté se comprend tant la qualité finale du pain dépend de cette première étape.

${ }^{91}$ Ce rendu permettrait également de se demander si la scène de la première table n'est pas plus proche de la finition du pétrissage que du début du façonnage.

${ }^{92}$ L'extrême mutilation de ce relief empêche toute certitude. Cependant, le troisième personnage semble situé sous une possible balance dont un plateau est visible. Cet assistant du boulanger (?) serait-il chargé de peser les pâtons?
} 
vent des bases maçonnées ou en pierre, hautes d'une soixantaine de centimètres, larges d'une vingtaine et profondes de 90 à $100 \mathrm{~cm}$. Parfois au centre de la salle, elles peuvent avoir été plaquées contre l'un des murs. Ces bases sont au moins au nombre de deux. Elles constituent les supports de tables en bois sur lesquelles les pains étaient façonnés. À Herculanum, les importantes destructions constatées dans les deux boulangeries font qu'un seul de ces pieds a été mis au jour, dans la pièce 8-5 en Or. II, $8^{93}$.

Avant d'abandonner le façonnage, il faut se consacrer aux "moules à pâtisserie » supposés être associés à cette opération précédant la fermentation. Plusieurs types sont fréquemment mentionnés. Le premier d'entre eux, la forma di cucina des journaux de fouilles, se présente sous la forme d'une feuille de bronze prenant la forme d'un coquillage. Certains modèles disposent d'un système de préhension, sous la forme d'anses disposées de part et d'autre de la coquille, ou d'attaches en anneau. Un seul exemplaire a été mis au jour à Herculanum, dans la Casa di Marco Pilo Graniano Primigenio (Or. I, 1a), en dehors de tout contexte de cuisine ${ }^{94}$. Les 23 exemplaires conservés à Pompéi ne proviennent pas de cuisines, quand leur lieu de découverte est connu ${ }^{95}$. Selon S. Tassinari, ces récipients en forme de coquillage ne seraient absolument pas utilisés comme moules de cuisson,

${ }_{93}$ Ce support se trouve actuellement dans la pièce du four. Toutefois, il est visible avant déplacement sur un dessin publié par A. Maiuri (1958 b: fig. 415 p. 461). Une première interprétation de ces supports comme tables associées à la préparation du pain a été proposée par A. Mau (1886: 45).

${ }^{94}$ GSE 1940: « 29 aprile. [...] Nell'ambiente n. 3 presso la parete ovest, a m. 2.25 dal vano d'ingresso ed a m. 0.18 di altezza dal pavimento si è rinvenuto: [...] Bronzo. Utensile da cucina a forma di conchiglia con ansa distaccata, lunghezza m. 0.21. Inventario n. 2067 ». Deux autres objets en forme de coquille ont été mis au jour à l'entrée d'un cunicule (cf. infra n. 104). Enfin, rangé dans une armoire au premier étage de la Casa di Nettuno e Anfitrite (V, 6-7), insérée dans une "casserole», un dernier exemplaire de ce type d'objet a été découvert (Inv. n E936=76213).

${ }^{95}$ Ces objets correspondent au type $\mathrm{N}$ du classement des objets en bronze réalisé par S. Tassinari (1993: 81-82).

${ }^{96}$ Tassinari 1993: 232.

${ }^{97}$ GSE 1932 : « 4 febbraio. Nella casa $\mathrm{N}^{\circ} 6$ sul IV cardine lato est, sul pavimento a m. 0.40 dal banco di vendita, lato sud ed a m. 1.38 dal vano d'ingresso è stato raccolto: mais plutôt pour pratiquer des ablutions ou du moins pour verser un liquide ${ }^{96}$. Une seconde catégorie d'objet, beaucoup plus fréquente tant à Pompéi - 65 exemplaires conservés sur place - qu'à Herculanum - 18 exemplaires - est d'interprétation plus délicate. Il s'agit de récipients dont le fond est elliptique et les parois rectilignes et obliques; cette forme récurrente existe selon des modules variables (fig. 52). La découverte de l'un d'entre eux derrière le comptoir du commerce alimentaire V, 6 pourrait suggérer une utilisation en lien avec la préparation culinaire ${ }^{97}$. Toutefois, l'absence de dépôt de carbone sur la partie externe rend improbable une fonction de moule. Beaucoup plus fréquemment, ce type de récipient en bronze est découvert avec des objets divers, hors de tout contexte de préparation culinaire. Bien que ne donnant pas d'interprétation définitive, S. Tassinari propose d'y voir des récipients destinés à l'ablution ou à contenir de la pâte ou du savon ${ }^{98}$. Il me semble hautement probable que de tels «stampi » aient pu avoir des fonctions diverses, tant dans les cuisines que, comme le propose S. Tassinari, pour la toilette. Malgré cette incertitude, un fait demeure: aucun récipient de ce type n'a été mis au jour dans les boulangeries d'Herculanum ou dans celles de Pompéi ${ }^{99}$. Le troisième exemple de ces supposés moules à pâtisserie provient pour l'essentiel de la situation herculanéenne.
Bronzo. Forma per pasticceria lunga m. 0.18 e del diametro al centro di m. 006. È divisa in due parti. Inventario 1004 [=76281]». Le 18 janvier 1932, un autre objet du même type a été mis au jour à l'étage du commerce alimentaire IV, 15-16 (Inv. n E718=75995). Rien ne permet de l'associer avec une forme de préparation culinaire, quelle qu'elle soit.

98 Tassinari 1993: 233. Ces objets sont regroupés, sans sous-classement en fonction des petites variations de forme de l'ellipse ou d'ouverture, dans la série O2000 (Tassinari 1993: 84).

${ }^{99}$ Sur les boulangeries de Pompéi, notre affirmation ne saurait être définitive. Dans le corpus étudié par S. Tassinari, figurent deux boulangeries (I 12, 1-2 et V 4, 1-2), où aucun ramequin $\mathrm{O} 2000$ n'a été inventorié. Pour certaines boulangeries qu'elle interprète comme des pistrina dulciaria, B. Mayeske cite parfois à l'appui de son hypothèse des passages de littérature postérieure à la fouille qui mentionnent des «forme di pasticceria ». Les descriptions proposées ne correspondent pas à ces ramequins (e.g. Mayeske 1972: 119, à propos de la supposée boulangerie VII 4, 29). 

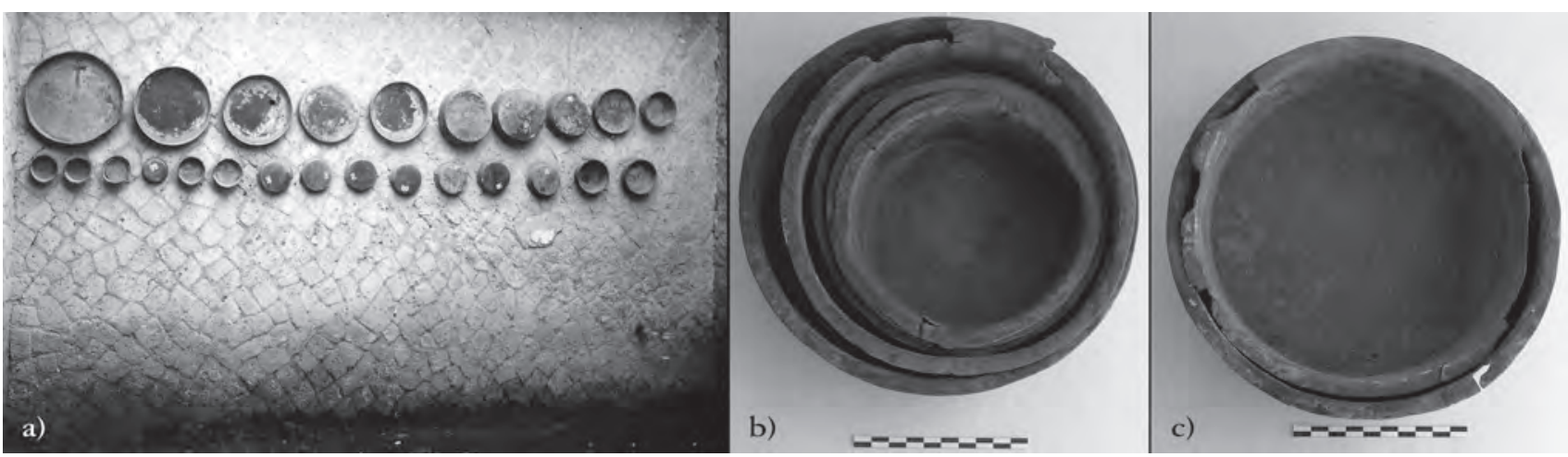

Fig. 71 - Plats en bronze provenant de l’appartement indépendant situé au-dessus de la boulangerie Or. II, 8. (a) : présentation des vingt-cinq plats dans l'arrière-boutique du pistrinum Or. II, 8 en 1957; (b-c): sept de ces plats en bronze, découverts le 19 août 1936.

En effet, selon A. Maiuri, vingt-cinq plats circulaires à bords relevés auraient été mis au jour dans l'arrière-boutique de la boulangerie Or. II, 8 (fig. 71) ${ }^{100}$. Ce lieu de découverte permettrait une compréhension immédiate de leur rôle: "[Queste] 25 teglie in bronzo [...] dovevano contenere stacciate e pizze da cuocere al forno e da ammannire calde e fumanti alla clientela abituale e d'occasione ${ }^{101}$. Une première correction s'impose immédiatement: ces plats ont effectivement été mis au jour dans le local Or. II, 8, mais à l'étage et non dans la pièce annexe. Le lien avec le laboratoire est alors d'autant moins évident que l'étage surplombant ce local n'est pas accessible depuis la boulangerie ${ }^{102}$. Une telle concentration d'objets est par ailleurs suspecte, surtout si l'on compare ce nombre avec les plats similaires à ceux mis au jour à Pompéi. En effet, selon l'étude de $\mathrm{S}$. Tassinari, seuls quatre plats à bords relevés y sont conservés, aucun ne prove-

${ }^{100}$ Ces 25 objets n'ont bénéficié que de six numéros d'inventaire $(1625 \mathrm{a}-\mathrm{l}=76903 \mathrm{a}-\mathrm{l} ; 1626 \mathrm{a}-\mathrm{e}=76904 \mathrm{a}-\mathrm{e} ; 1627$ $\mathrm{a}-\mathrm{f}=76905 \mathrm{a}-\mathrm{f} ; 1628=76906 ; 1629 \mathrm{a}-\mathrm{b}=76907 \mathrm{a}-\mathrm{b} ; 1630$ = 76908), ce qui permet de comprendre qu'ils ont été mis au jour groupés en six lots différents. Certains d'entre eux sont marqués par des timbres: MARI; Q.CELER; QUAR. CAP. Aucun de ces timbres n'a été pour l'instant identifié à Pompéi, particulièrement sur ce type de récipient (cf. Tassinari 1993: 203-207).

${ }^{101}$ Maiuri 1958 b: 457-458.

${ }^{102}$ Sur ce point, cf. infra, p. 282-283.

${ }^{103}$ Tassinari 1993: 83-84; vol.**, p. 174. nant d'une boulangerie ${ }^{103}$. Enfin, étrangement, cette entrée des journaux de fouilles est la seule concernant l'étage du local Or. II, 8. Bien que cela ne soit pas clairement indiqué dans les $G S E$, il est possible que cet amas de vaisselle de bronze soit un vestige des fouilles en tunnel du XVIII ${ }^{\mathrm{e}}$ siècle $^{104}$. Quelle que soit l'interprétation que l'on donne au contexte dans lequel ces 25 plats ont été trouvés, ils ne peuvent pas avoir été matériellement utilisés dans le cadre de la boulangerie située en Or. II, 8. Enfin, l'observation des quelques plats qui n'ont pas encore été nettoyés et restaurés montre que des traces de carbonisation se situent sur le fond mais aussi sur les parois, à l'extérieur. Ces traces indiquent clairement que ces plats étaient utilisés partiellement enfoncés dans un lit de braise, ce qui est incompatible avec le fonctionnement d'un four à pain ${ }^{105}$. Leur intégration dans la description de ce local faite par A. Maiuri n'est due qu'à leur

${ }^{104}$ Des amas d'objets en bronze sont parfois mentionnés à l'entrée de tunnels. GSE 1928 «31 agosto. Nello scavo del II cardine [= cardo IV], all'ingresso di un cunicolo si è trovato: [Description de deux forme di pasticceria en bronze, Inv. $\mathrm{n}^{\circ}$ E304 a-b et E305 = 75580 a-b et 75581]».

${ }^{105}$ Ces traces sont visibles sur les objets inventoriés Inv. $\mathrm{n}^{\circ} \mathrm{E} 1628=76906, \mathrm{E} 1629 \mathrm{~A}-\mathrm{B}=76907 \mathrm{~A}-\mathrm{B}$. Provenant de la mezzanine d'une boutique située sur le decumanus maximus - sans lien a priori avec une boulangerie -, le plat Inv. $n^{\circ} E 2913=78250$ présente exactement les même traces situées sur le fond et sur les parois, à l'extérieur. 
accrochage sur le mur est de l'arrière-boutique ${ }^{106}$. Il est possible que certains produits des boulangeries aient été cuits en utilisant des plats ou des moules; en l'état actuel des connaissances sur le matériel provenant de ces locaux, la forme de ces derniers ne peut être précisée.

Bien que l'iconographie et surtout les textes invitent à considérer l'existence de nombreuses formes de pains, ceux qui ont été mis au jour dans les villes ensevelies par le Vésuve paraissent tous conçus de la même façon. Les neuf pains découverts durant les Nuovi scavi à Herculanum ne diffèrent que par de légères variations dans leurs dimensions ${ }^{107}$. Ronds, leur diamètre oscille entre 14 et $18 \mathrm{~cm}$. Leur surface est striée de trois à quatre incisions rayonnantes pratiquées avant la fermentation, comme l'indique la boursouflure affectant chaque secteur ainsi défini. Le diamètre est aussi marqué par un étrécissement médian, également réalisé avant que la pâte ne lève, probablement avec des cordelettes ${ }^{108}$. Parmi les manipulations effectuées durant le façonnage, se trouve l'éventuel marquage du pain.

${ }^{106}$ Maiuri 1958 b: fig. 411 p. 458. Sur ces manipulations - involontaires - des données de la fouille, cf. supra, p. $20-23$ et $32-35$.

${ }^{107} 2$ fragments de pains provenant de la Casa dello scheletro (III, 3; Inv. $\left.\mathrm{n}^{\circ} \mathrm{E} 24=75300\right) ; 2$ pains découverts dans la fouille du decumanus inférieur, provenant d'un bâtiment non identifié (Inv. $\left.\mathrm{n}^{\circ} \mathrm{E} 112=75388\right) ; 1$ pain provenant de la pièce 1 de la Casa dell'ara laterizia (III, 17; Inv. ${ }^{\circ} \mathrm{E} 411=75688$ ); 1 pain provenant de l'étage de la Casa dei cervi ou de la Casa della stoffa (IV, 21 ou IV, 19-20; Inv. ${ }^{\circ}$ E574=75851); 1 pain trouvé sur une étagère de la pièce annexe $7 \mathrm{du}$ commerce alimentaire IV, 15-16 (Inv. $\mathrm{n}^{\circ} \mathrm{E} 739=76016$ ); 1 pain dans l'abside de la «Palestre» (Or. II, 4; Inv. n E1493 = 76771); 1 pain provenant de l'étage de la boutique DM 1E, au nord du decumanus maximus (Inv. $\mathrm{n}^{\circ} \mathrm{E} 2322=7$ 7618).

108 Si ces incisions avaient été pratiquées après la fermentation, elles laisseraient apparaître la structure alvéolaire de la mie mise au jour et non l'aspect lissé que l'on peut observer. Le fait que chacun des rayons soit parfaitement rectiligne, même lorsqu'il est sensiblement décalé par rapport au centre, ainsi que certaines traces sur le côté du pain laissent supposer que ce sont des cordes qui ont été utilisées pour marquer la pâte lors de la fermentation. L'irrégularité de la partie inférieure indique quant à elle que ces pains n'étaient pas moulés.

${ }^{109}$ Sur ce pain, mis au jour le 10 mai 1748, généralement considéré comme provenant de la Casa dei cervi (IV, 21), et sur les difficultés pour retracer son origine, cf. Tran Tam Tinh 1988: 123-124.

${ }^{110}$ CIL X, 8058, 18: cELERIS Q(uinti) GRANI/VERI $S E R(v i)$. Contrairement à ce que prétend B. Mayeske
Deux pains présenteraient une telle marque de fabrique pour les deux villes. Le premier a été trouvé à Herculanum durant les fouilles du XVIII ${ }^{\mathrm{e}}$ siècle, ce qui empêche de déterminer son origine précise ${ }^{109}$. L'inscription, probable positif d'un sceau en bronze, indique que ce pain appartient à Celer, esclave de Q. Granius Verus ${ }^{110}$. L'impression de cette marque avant la fermentation ne fait guère de doute: réalisée une fois la pâte levée, l'application du sceau ne pourrait que conduire à un aplatissement du réseau de bulles de dioxyde de carbone donnant l'aspect gonflé au pain ${ }^{111}$. Cela est confirmé par le pain mis au jour dans la Casa dell'ara laterizia (III, 17)

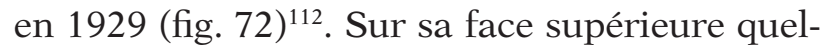
ques lettres d'un sceau sont lisibles. Initialement, elles ont dû s'étendre sur la majeure partie du diamètre. Toutefois, tant l'incision des rayons que la levée du pain ont décalé les lettres imprimées et les ont partiellement effacées ${ }^{113}$.

Il est difficile de déterminer si le pointage, première fermentation avant façonnage, était effectuée ou non dans la boulangerie romaine ${ }^{114}$.

(1972: 189), ce pain n’a pas été trouvé dans la boulangerie VII 1, 36-37 de Pompéi.

${ }^{111}$ Par une mention sibylline, G.C. Boon (1987: 370) tend à réfuter cette idée. Un certain "Mr Evans», non mentionné ailleurs dans son article ou dans les notes, aurait effectué deux essais expérimentaux de marquage de pain. Le premier aurait été un échec, le timbre devenant illisible suite à la levée du pain. Le second, réalisé sur du pain sans levain avec de la farine complète, aurait permis une bonne lecture du timbre. Faute de détail, il est impossible de déterminer où le sceau a été appliqué. Les deux exemples d'Herculanum montrent la faisabilité de ce marquage.

${ }^{112}$ GSE 1929: « 4 aprile. Il n. 2 [pièce 1 selon la numérotation d'A. Maiuri] della casa n. 17 è completamente sterrato [...]. Nell'angolo nord-ovest sul pavimento è stato raccolta un'anfora mancante della parte superiore e nell'interno di essa eravi una discreta quantità di fave carbonizzate. A m. 0.25 dall'anfora s'è rinvenuto: Commestibile. Pane a forma circolare in basso e schiacciato in alto. La parte superiore è divisa in sei triangoli, i cui vertici finiscono tutti al centro del pane. Il diametro della base è di m. 0.14 , e quello superiore è di m. 0.13. Inventario n. $411[=75688]$ [...]».

${ }^{113}$ L'empreinte de ce sceau est inédite à ce jour. Elle ne correspond à aucun des sceaux en bronze mis au jour dans la ville. Seules deux lettres parmi les premières restent lisibles. En considérant que l'impression est un positif et que les lettres peuvent se lire directement, je proposerai cette lecture: --]VM[----]O(?)[.

${ }^{114}$ La présence dans certaines boulangeries de jattes en céramique pourrait correspondre au pointage: la pâte y serait déposée pour une première levée avant façonnage. Un premier 


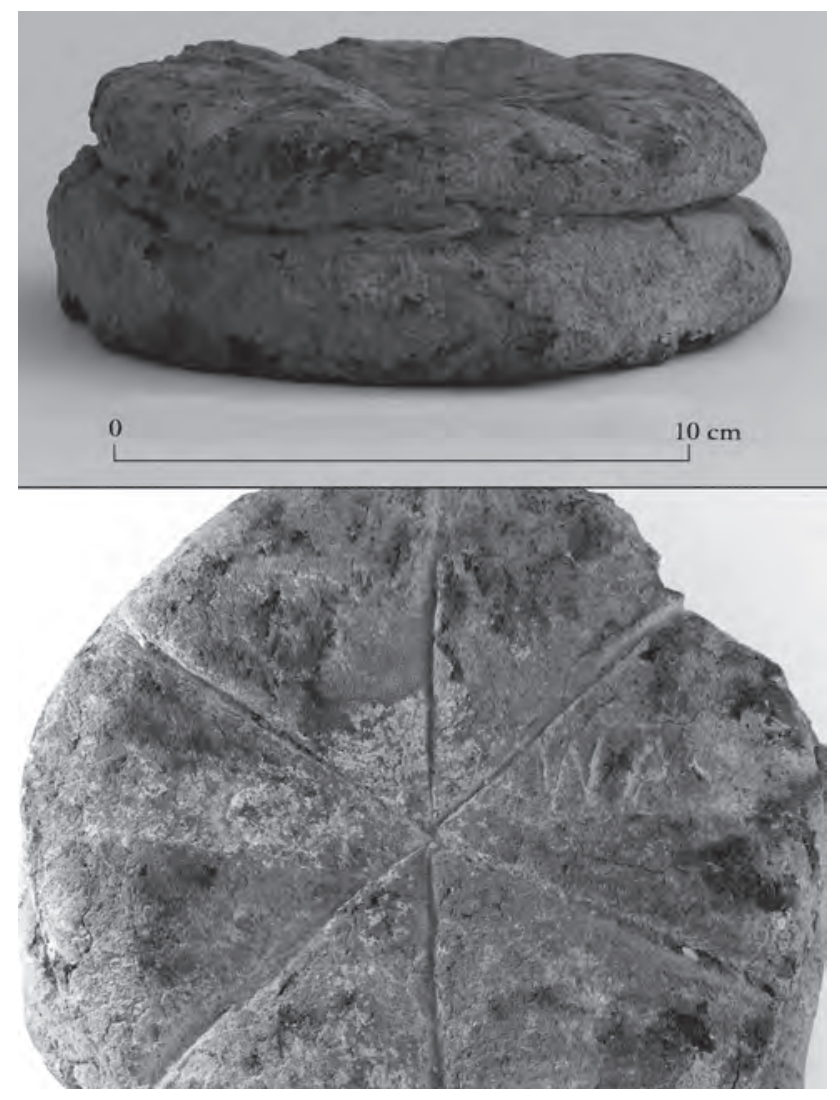

Fig. 72 - Pain provenant de la Casa dell'Ara laterizia (III, 17). Outre la division de la surface supérieure en six portions, l'incision médiane laisse supposer l'utilisation d'une cordelette pour modeler la pâte lors de la levée. Un cachet illisible a été appliqué sur la surface supérieure.

En revanche, certains aménagements permettent de déterminer l'endroit où la fermentation principale, la plus longue et la plus importante avait lieu. Cette reconnaissance n'est guère possible à Herculanum où les murs ont été fortement reconstruits, suite à leur destruction

inventaire des locaux où ces jattes sont visibles comporte les boulangeries suivantes: V 3, 8; VI 3, 3.27-28; VI 11, 8-10; VII 15, 1-2.15; IX 1, 3.33; IX 3, 19-20; IX 5, 4; IX 12, 6.

${ }^{115}$ Des marques observées sur le mur nord permettent de restituer la profondeur des planches à environ $50 \mathrm{~cm}$. En ce qui concerne les deux poteaux en bois insérés dans la maçonnerie au sol, utilisés pour séparer les étagères, ils ont, du nord au sud, les dimensions suivantes: diamètre $24 \mathrm{~cm}$; largeur (est-ouest) $26 \mathrm{~cm}$, longueur $40 \mathrm{~cm}$.

116 Toutes ces empreintes ont une section rectangulaire d'environ $10 \times 5,5 \mathrm{~cm}$.

${ }^{117}$ Estimation maximale, calculée en considérant que les tablettes se poursuivent au-delà des supports. Il faudrait par les tunneliers du XVIII ${ }^{\mathrm{e}}$ siècle. À Pompéi, l'exemple le plus détaillé et le plus intéressant est constitué par le local I 12, 1-2. Dans la pièce située immédiatement au sud du four, là où se trouve le pétrin, le mur oriental présente trois séries d'empreintes d'étagères, séparées par deux avancées de mur ayant pu correspondre à de très courtes parois ${ }^{115}$. Dans chacun des espaces ainsi délimités, trois étagères sont disposées à environ $1,20 \mathrm{~m}, 1,60 \mathrm{~m}$ et 1,90 $\mathrm{m}$ du sol; chaque tablette est soutenue par deux supports dont l'empreinte dans le mur donne la dimension ${ }^{116}$. L'ensemble forme un rayonnage de $16,3 \mathrm{~m}$ linéaires ${ }^{117}$. Un tel positionnement permet d'éviter une trop longue manipulation des pains une fois qu'ils sont façonnés: les deux tables servant à cette opération sont situées devant les étagères. De plus, la proximité du four ne peut que faciliter la fermentation ${ }^{118}$ : le conduit de chaleur qui transperce le mur nord n'a pas que le rôle - traditionnellement alloué à ces aménagements - d'évacuation de la fumée et d'aide au tirage ${ }^{119}$, il facilite ainsi les échanges de chaleur du four vers le fournil. Dans tous les cas où la conservation $\mathrm{du}$ four est suffisante et où l'identification du fournil - facilitée par la présence du pétrin, des tables de façonnages ou des étagères de fermentation - est possible, ce petit conduit de tirage est dirigé vers le panificium ${ }^{120}$. Une fois le pain suffisamment levé, sans qu'aucune précision ne puisse être apportée quant au temps nécessaire, il peut être cuit dans le four.

Les informations concernant les différentes étapes de la transformation de la farine en pain prêt à cuire sont assez fragmentaires, bien que l'aspect général de la chaîne opératoire soit connu en particulier grâce aux sources iconogra-

éventuellement ajouter à ce métrage de rayonnages les deux étagères situées sur le mur occidental (longueur cumulée: 4,4 m).

${ }^{118}$ Les levures qui participent à la fermentation panaire se développent d'autant plus qu'elles sont à température élevée, à condition que celle-ci ne dépasse pas les $50{ }^{\circ} \mathrm{C}$ (Ammann 1925: 433).

${ }^{119}$ Fulvio 1879: 285-286.

120 Même dans le cas du four situé en Or. II, 8 à Herculanum, on retrouve cet arrangement. Le tuyau de terre cuite permettant le tirage est orienté vers le nord où se situe le fournil et ce bien que cette pièce ne se trouve pas en contact direct avec le four. 
phiques. L'utilisation de pétrins mécaniques ne paraît pas avoir été généralisée. Comme souvent, ceux en bois n'ont guère laissé de trace, à l'exception d'un relief représentant une scène de boulangerie. Les aménagements associés au façonnage ont été mieux préservés, qu'il s'agisse des bases maçonnées des tables utilisées pour cette opération, ou des étagères dont les empreintes restent visibles sur les murs. La mise au jour de pains tant à Herculanum qu'à Pompéi a permis de restituer certains gestes effectués durant leur confection. Un important manque vient de la disparition ou de l'absence d'enregistrement des outils présents dans ces laboratoires. Bien que certains aient certainement été en bois, des instruments en métal devaient également être utilisés. Enfin, je n'ai pas mentionné le problème des réserves - d'eau ou de farine - dont l'existence doit être postulée, à défaut de toujours pouvoir les caractériser. Je reviendrai sur ce point plus loin, après avoir abordé l'étape de la cuisson, certainement la mieux documentée de toutes d'un point de vue archéologique.

\section{III.3 Utilisation des fours pour la cuisson $d u$ pain}

La cuisson du pain permet de figer les filets de gluten qui se sont formés au cours de la fermentation. Durant ce processus, les bulles de gaz contenues dans le pain se dilatent sous l'effet de la vaporisation de l'eau ${ }^{121}$. Si l'utilisation d'un four à pain constitue le procédé qui est le plus courant pour la boulangerie dès lors qu'elle passe du stade domestique à une production artisanale, d'autres modes de cuisson sont attestés tant archéologiquement

${ }^{121}$ Ammann 1925: 454.

${ }^{122}$ CIL IV, 677: Trebium aed(ilium) o(ro) v(os) f(ecit) / clibanari rog(ant). La définition du clibanus est extraite de l'ouvrage de J. André (1981: 67).

${ }^{123}$ Pour des exemples de ce type de four en Gaule, cf. Barberan - Piquès - Raux - Sanchez 2006.

${ }^{124}$ Sen., Ep. , [14], 90, 23. Cette absence d'attestation ne signifie en rien une disparition de ce type de cuisson.

${ }^{125}$ Ammann 1925: 462. De façon plus spécifique, il s'agit de l'avancée située face à la gueule de la chambre de cuisson.

${ }^{126}$ Seuls trois fours présentent un tel massif circulaire: à Herculanum en Or. II, 1a; à Pompéi en I 3, 1 et en V 3, 8. Dans chacun de ces cas, cette forme paraît s'expliquer par l'exiguïté du local ou des problèmes de circulation: un que par les textes littéraires. Dans les villes ensevelies par le Vésuve, seul un graffite mentionne, à travers leurs revendeurs, les clibani, «galette[s] obtenue[s] en plaquant la pâte à cuire sur la paroi extérieure d'un vase de terre ou de métal à l'intérieur ou autour duquel était entretenu un feu ${ }^{122}$. Bien que ce soit une enquête méritant d'être approfondie, aucun de ces fours en cloche ne semble avoir été découvert ${ }^{123}$. De la même façon, la cuisson sous la cendre de pains non levés, mentionnée par Sénèque citant Posidonius n'est pas attestée par les restes carbonisés provenant d’Herculanum ou de Pompéi124. En fonction des aménagements supplémentaires à la chambre de cuisson, il est possible de déterminer deux types de fours utilisés dans les boulangeries, chacun d'entre eux étant représenté à Herculanum. La comparaison avec les fours de Pompéi permet de préciser certains aspects mais également de distinguer les pratiques des deux villes.

D'une manière très générale, un four à pain est constitué au minimum de trois éléments: un massif maçonné, une coupole reposant sur celui-ci et l'autel, débord frontal du massif par rapport à cette dernière dans la terminologie contemporaine $^{125}$. Le massif est très fréquemment quadrangulaire, mais peut être, en de rares exceptions, circulaire ${ }^{126}$. Vraisemblablement selon la période d'installation mais aussi selon les ressources disponibles, il est construit avec les mêmes types d'opus que les autres éléments de l'architecture privée. À Herculanum, la base des fours situés en Or. II, 1a et en Or. II, 8 a été érigée en opus reticulatum ${ }^{127}$. En revanche, à Pompéi, certains exemples peuvent être soit en opus incertum, soit en opus testaceum ${ }^{128}$.

massif quadrangulaire aurait considérablement empiété sur l'espace disponible pour le fournil dans les deux exemples pompéiens, et aurait compliqué les déplacements à Herculanum.

${ }^{127}$ Sur la définition des différents types d'opus employés dans la construction à Herculanum, cf. infra, p. 226-230. La typo-chronologie qui peut s'appliquer à ces modes de parement lors de leur utilisation dans l'architecture domestique ne paraît pas être fonctionnelle dans le cas de ces fours, construits l'un comme l'autre après le séisme de 62 (cf. infra, p. 281-283).

${ }^{128}$ L'ensemble du massif du four situé en IX 12, 6 est parementé de briques, tandis que celui situé en VI 5, 15 est intégralement construit en opus incertum, fortement restauré depuis le dégagement. 


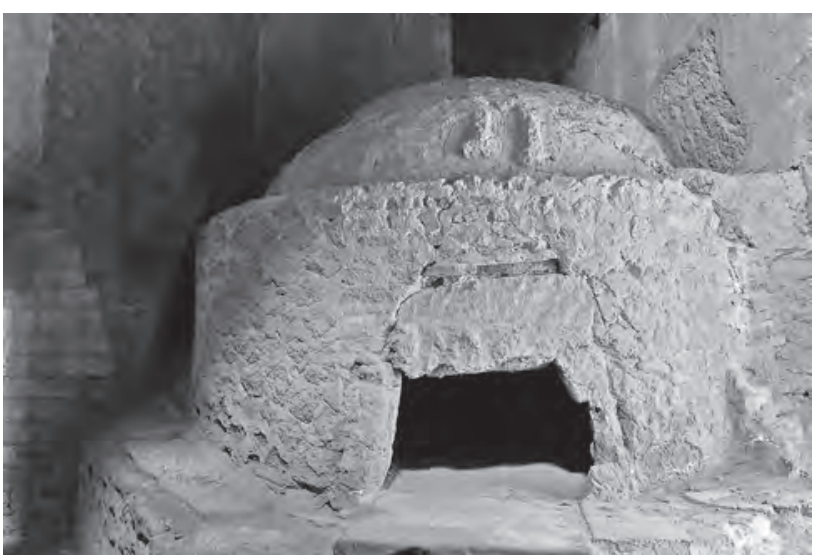

Fig. 73 - Four de la boulangerie Or. II, 8 à Herculanum. En plus des éléments constitutifs d'un four, l'autel - qui s'étend sur tout le pourtour - et la coupole, on distingue des réparations effectuées à la suite de l'effondrement de la «façade » de cet aménagement de cuisson. L'éventualité d'une répétition de cet évènement a été conjurée par l'apposition de phallus apotropaïques (cliché pris de l'ouest).

Quel que soit le mode de parement utilisé, les fours tendent à s'appuyer au moins sur un mur. Selon les observations faites durant la fouille en Or. II, 1a, corroborées par celles de L. Fulvio à Pompéi, la partie supérieure du massif comprendrait une couche de sable, qui permet - selon cet ingénieur des fouilles pompéiennes - d'empêcher la dispersion de la chaleur. Sur celle-ci repose la sole, constituée de tuiles mises à l'envers ${ }^{129}$.

La coupole, qui, reposant sur le massif, constitue à proprement parler la chambre de cuisson, présente de nombreuses variantes particulièrement dans les techniques de mise en œuvre. La remarquable conservation du four situé en Or. II, 8 permet d'étudier ce type de construction

129 GSE 1935: «11 luglio. Un ambiente non ancora numerato perché in corso di sterro, tiene il pavimento di grosse tegole di terracotta che poggiano sopra uno spessore di metri 0.40 di sabbia marina. Non è accertato ancora il motivo di tale costruzione. Nessun trovamento ». À Pompéi, selon L. Fulvio (1879: 285), l'épaisseur de sable employé ne serait que d'une dizaine de centimètres. Les tuiles retournées sont attestées dans certains fours, parfois remplacées par des briques carrées de 55,60 cm de côté.

130 Deux moellons ont été mis en évidence dans la première assise de la coupole. L'un est associé à une réparation de la partie ouest, effondrée au cours d'un séisme.

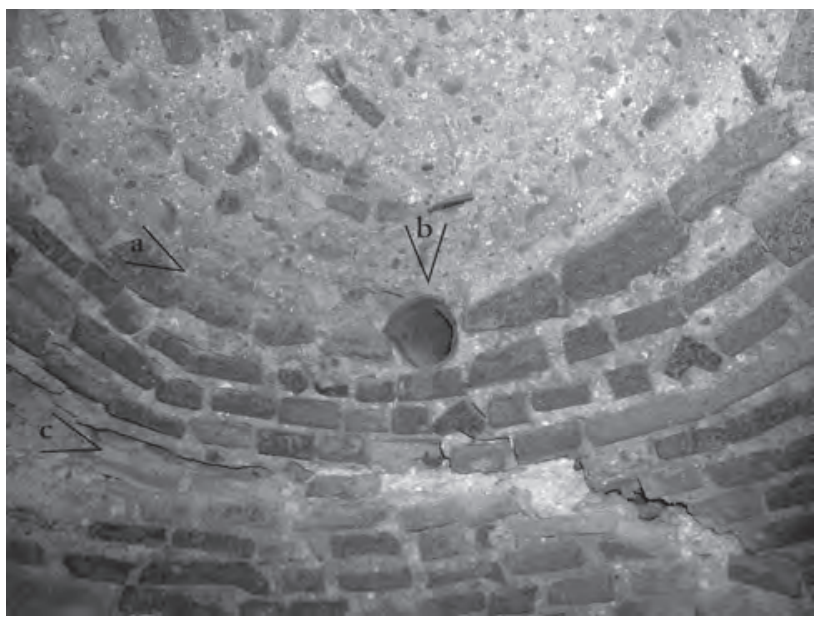

Fig. 74 - Intérieur du four de la boulangerie Or. II, 8 à Herculanum. Le sommet de la coupole, au lieu de bénéficier d'un parement de tuiles, a été réalisé en jetant du béton sur une forme circulaire. La limite (a) entre les deux formes de maçonnerie est très nette. Une amphore (b) a été insérée pour ménager un conduit d'aération. Une ligne de fracture (c), correspondant à l'effondrement de la partie antérieure du four, est également visible (cliché pris du sud/sud-est).

en détail. La gueule, qui permet d'introduire les boules de pâte levée, est constituée par trois blocs de tuf gris, deux verticaux, le troisième en guise de linteau. Tout le reste de la coupole est construit en maçonnerie (fig. 73). Le parement interne ne présente que des fragments de tuiles, contrairement à la pratique récurrente à Pompéi, où la première assise est en moellons de lave, disposés en anneau ${ }^{130}$. Ces tuiles sont disposées en assises régulières présentant un léger encorbellement, la tranche restant toutefois toujours orientée vers le centre du four. À 1,27 m de la sole, au nordnord-ouest de la coupole, un col d'amphore fracturé est inclus dans la maçonnerie et constitue un tuyau d'aération (fig. 74, b). Au-dessus de ce

Le second paraît avoir été présent dès la construction originelle du four. Sa position, guère remarquable, échappe à toute interprétation. La première assise du four situé en Or. II, 1a est constituée par des moellons de tuf, qui peuvent correspondre aux travaux de restauration effectués sur cet aménagement. À Pompéi en revanche, selon L. Fulvio (1879: 285), l'utilisation d'une ghirlanda de moellons de lave, haute d'une vingtaine de centimètres, permettrait à la coupole de résister aux coups de pelle en bois lors de l'enfournement. Cette hypothèse paraît peu convaincante. L'explication la plus probable semble devoir être cherchée soit dans les techniques de construction - cette assise donne une base 
niveau, la coupole n'est plus parementée, laissant supposer l'utilisation d'une forme sur laquelle le béton est jeté pour achever cette construction ${ }^{131}$. Dans les nombreux exemples pompéiens, cette partie supérieure est celle qui est la plus sujette à des variations techniques. En effet, si quelques fours montrent l'utilisation de ce même procédé de coulée de béton, il est beaucoup plus fréquent que le sommet de la coupole soit constitué par un

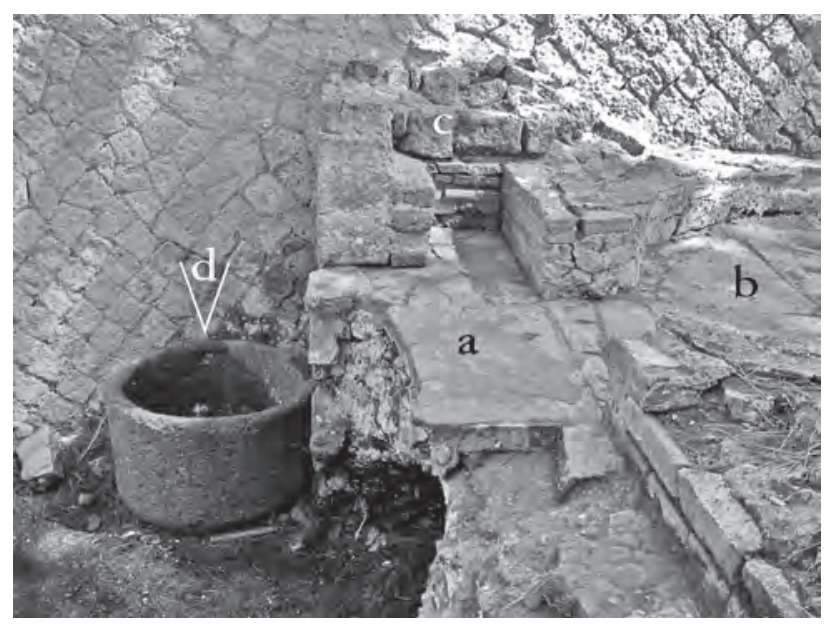

Fig. 75 - Four de la boulangerie Or. II, 1a à Herculanum. Bien que fortement dégradées, les principales composantes de cet aménagement ont été conservées. L'autel (a) est revêtu de tuiles plates, comme la sole (b). Les vestiges du mur-diaphragme permettent d'envisager la présence d'un chauffe-eau (c), pourtant indiqué dans les journaux de fouilles de l'autre côté de la gueule. Devant le four, un bloc de roche volcanique a été taillé en cylindre (d), peut-être pour recueillir les braises entre deux fournées (cliché pris de l'ouest). assemblage en encorbellement de tuiles ou par l'utilisation d'une unique tuile plate ou encore un fragment de récipient en terre cuite ${ }^{132}$. Ces pratiques font que, comme le remarquait déjà L. Fulvio, la coupole n'est pas parfaitement sphérique mais a une forme tendant de façon plus ou moins accentuée vers le cône ${ }^{133}$. Enfin, la paroi extérieure de ces fours est parfois simplement constituée par un massif cylindrique qui entoure la base de la coupole, tandis que sa partie supérieure conserve son aspect de calotte. Cet aspect simple correspond tant au four situé en Or. II, 8 qu'à celui de $14 \%$ de ceux de Pompéi ${ }^{134}$. Notons toutefois que les exemples pompéiens incluent la partie inférieure de la coupole dans un massif de forme carrée. Pour fermer la gueule du four, des portes en fer ont été mises au jour dans la plupart des boulangeries, que ce soit à Pompéi ou à Herculanum ${ }^{135}$. Composées de plusieurs bandes de fer qui s'entrecroisent perpendiculairement, ces portes ne sont pas prises dans la maçonnerie: deux poignées permettent de la manipuler entre les phases de chauffage ${ }^{136}$.

Le dernier élément constitutif des fours est l'autel, plateforme située en avant de la gueule du four. Dans le cas de la boulangerie Or. II, 8, il est uniquement revêtu d'une tuile dans la continuité de la sole et se développe sur toute la longueur accessible du four. En Or. II, 1a, l'autel est parfaitement horizontal et revêtu de briques (fig. 75). Il présente différents aménagements sur ses côtés: la partie centrale est ouverte, tandis que les deux côtés sont occupés par des montants construits en opus vittatum qui sont distants de $33 \mathrm{~cm}$ de la façade du four proprement dite: en dépit de

${ }^{133}$ Fulvio 1879: 285 et pl. II,4.

${ }^{134}$ Les cinq locaux dont le four est dépourvu de mur

stable à l'ensemble de la coupole, plus simple à réaliser en moellons qu'en appareil de tuiles - soit dans la thermodynamique - l'assise servant à emmagasiner de la chaleur et à la restituer au cours de la cuisson.

${ }^{131}$ L. Fulvio (1879: 288) signale que les traces des planches de bois utilisées pour former ce coffrage de support étaient visibles dans le four situé en VII 16, 9. Dans de nombreux fours pompéiens, la construction paraît avoir été réalisée en disposant les tuiles en encorbellement, avant d'être retaillées en biseau.

132 Quelques exemples de ces variations techniques: sommet de la coupole maçonné sans parement en I 12, 1-2 et en V 3, 8; bourrage de tuiles en VI 14, 32 et en VII 1, 36-37; utilisation d'une tuile posée à plat en V 4, 6-8 et en VII 12, 7 ; utilisation d'une jatte retournée en IX 5, 4. diaphragme sont les suivants: I 3, 1 ; I 8, 15-16; VI 5, 15 ; VII 12, 7; VII 12, 13.

135 Une porte a été mise au jour en Or. II, 1a à Herculanum (cf. infra n. 137). À Pompéi, elles ont été signalées dans les boulangeries suivantes: I 12, 1-2; VII 1, 36-37. Bien que la proportion de signalement de ces portes par rapport au nombre de boulangeries soit très faible, chaque four doit nécessairement en disposer, pour éviter les pertes de chaleur.

${ }^{136}$ Une description de ces plaques a été effectuée par L. Fulvio (1879: 286). Actuellement, seule celle de la boulangerie I 12, 1-2 est encore en place. 
leur arasement partiel, ils permettent de restituer une paroi s'élevant en avant du four. À gauche - à l'est - se trouvent deux appuis en briques qui débordent du montant en tuf et de la paroi $\mathrm{du}$ four; la partie occidentale est trop endommagée pour permettre de discerner une construction similaire. De la sorte, l'autel est ici divisé en trois parties: un plan horizontal devant la gueule et deux niches latérales qui l'encadrent. Selon les journaux de fouilles, un récipient en plomb aurait été inséré sur le côté ouest - à droite de la gueule $^{137}$. En dépit de leur état de conservation très dégradé, les aménagements inclus autour de l'autel peuvent être restitués à partir des exemples pompéiens. En I 12, 1-2, la partie gauche de l'autel est occupée par un récipient quadrangulaire en plomb, reposant sur deux montants maçonnés (fig. 76, b). Situé à $30 \mathrm{~cm}$ au-dessus de la surface de l'autel, il a une capacité de 109 litres $^{138}$. Il s'agit en effet d'un chauffe-eau directement associé au four. Son approvisionnement est assuré par l'un des deux tuyaux sectionnés visibles dans le mur

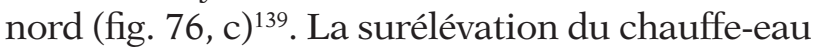
par rapport à l'autel permet d'y glisser en dessous des braises ou du bois provenant du four. Bien qu'un tel appareillage ne soit pas directement employé lors de la cuisson du pain, il permet, par la concentration des structures de chauffage en un seul point, une économie de combustible: l'eau tiède ou chaude peut servir lors du pétrissage ${ }^{140}$. De telles installations paraissent assez fréquentes, dès lors qu'un mur diaphragme est construit en avant du four et de l'autel ${ }^{141}$. Quand la disposition des murs autour du four le permet - et quand cela présente une réelle utilité pour les différentes

${ }^{137}$ GSE 1935: "13 luglio. Il pavimento di tegole ieri accennato appartiene, a quanto pare, a un forno. La bocca di ferro è ancora in sito, mentre la muratura è bassa. Al lato ovest tiene una vaschetta di piombo murata con mattoni, serviva per conservare acqua. Nessun trovamento». En l'état actuel, non seulement ce récipient a disparu, mais la restauration effectuée laisserait plutôt supposer qu'il se trouvait de l'autre côté, à l'est. Enfin, ce conteneur est absent des rares photographies prises durant la fouille.

${ }^{138}$ Ses dimensions ( $\mathrm{P} \times \mathrm{l}$ x h) sont de $46 \times 54$ x $44 \mathrm{~cm}$. Sa face supérieure est percée d'une ouverture circulaire d'un diamètre de $20 \mathrm{~cm}$.

${ }^{139}$ Le second tuyau devait servir à tirer de l'eau depuis le chauffe-eau, par l'extérieur du four, sans interférer avec les boulangers occupés devant la gueule.

${ }^{140}$ Les boulangeries du début du $\mathrm{XX}^{\mathrm{e}}$ siècle présentent un dispositif similaire. L. Ammann (1925: 458) conseille

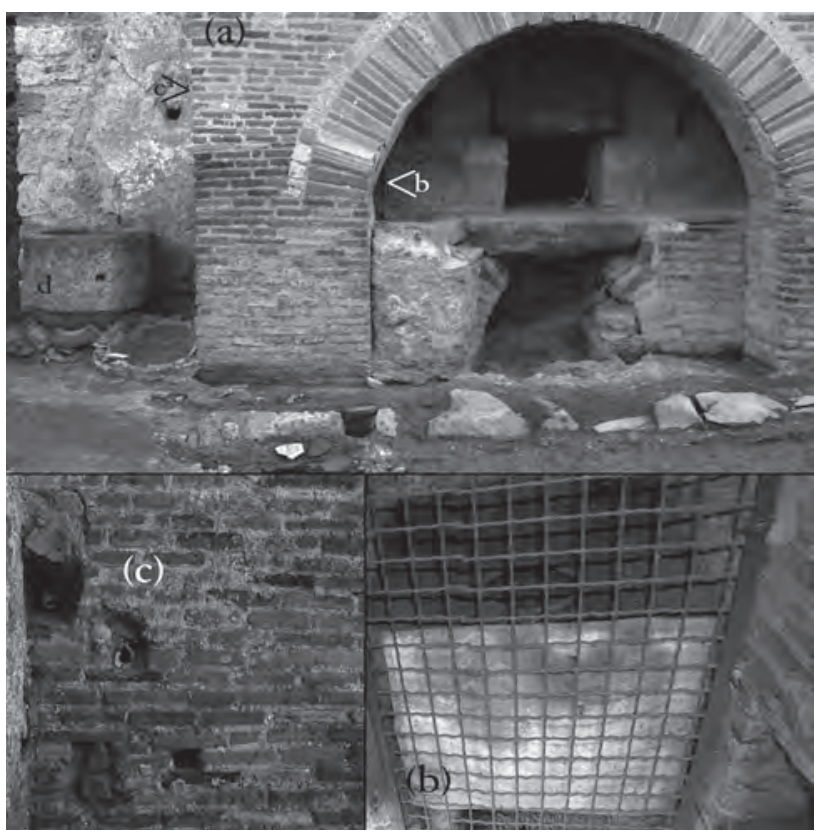

Fig. 76 - Four de la boulangerie I 12, 1-2 à Pompéi. Le mur diaphragme (a) permet de contenir différents aménagements utiles lors de la préparation des pâtons. Un chauffe-eau (b), alimenté par un tuyau d'eau sous pression (a) est inséré à gauche de l'arcade. Le second tuyau permet de récupérer de l'eau chaude, qui se déverse dans un pétrin en remploi (d).

manipulations du pain -, un passage peut être ouvert dans l'autre montant. Un plan incliné est souvent disposé entre cette ouverture et la bouche du four. Comme cela a été interprété par L. Fulvio, et à sa suite par tous ceux qui se sont intéressé aux boulangeries, cette ouverture permet de faire passer les miches levées du fournil à l'autel, pour les y enfourner ${ }^{142}$. Enfin, sous certains autels, des niches sont ménagées, éventuellement pour stocker le combustible nécessaire à la cuisson.

ainsi l'installation d'une chaudière à proximité de la gueule du four.

${ }^{141}$ L'incertitude quant à la présence ou à l'absence de ces chauffe-eau inclus dans la maçonnerie tient tout d'abord à l'indigence des rapports de fouille du $\mathrm{XIX}^{\mathrm{e}}$ siècle qui ne les signalent que rarement ainsi qu'à leur éventuelle récupération. Dans son article de synthèse sur les fours, L. Fulvio (1879: 287) signale la présence de chauffe-eau en VI 14, 32 (indiqué 30), VII 12, 11 et VIII 4, 26-29 (indiqué 27).

142 Fulvio 1879: 287; Mau 1900: 383-384; Mayeske 1972: 173-174; Varone 1989: 232-233. En revanche, l'hypothèse faite par L. Fulvio que les pains cuits repassent également par cette ouverture est invraisemblable: la manipulation des miches chaudes avec la pelle ne permet guère de remonter le plan incliné. 
En ce qui concerne cette dernière opération, il est possible de comparer les principes généraux transmis par l'ingénierie moderne avec les structures des fours et des expérimentations menées en Allemagne. La cuisson du pain doit s'effectuer dans une chambre hermétique pour éviter l'échappement de la vapeur qui seule donne une certaine élasticité à la miche. De cette façon, le four n'est ventilé que lors de la phase de préchauffage ou de réchauffement. La température idéale pour la fixation des filaments de gluten s'échelonne entre 200 et $250^{\circ} \mathrm{C}^{143}$. À partir des expérimentations menées à Saalburg, il est possible de préciser certains aspects de cette cuisson: le préchauffage a permis d'atteindre une température idéale après une douzaine d'heures; pour éviter tout refroidissement, les pains sont introduits le plus rapidement possible, à raison de deux à trois par pelletée. Chaque fournée a cuit pendant une durée variant entre une demi-heure et trois quarts d'heure. Entre chacune d'entre elles, des bûches ont été ajoutées pour réchauffer le four ${ }^{144}$. Grâce à la découverte de 81 pains dans le four situé en VII 1, 36-37, certains points non exposés dans cette expérience peuvent être clarifiés. En particulier, les dimensions de la sole sont telles que le nombre de miches mises à cuire ensemble a atteint un maximum, compte tenu des dimensions de chacune d'elles - à peine plus d'une vingtaine de centimètres de diamètre ${ }^{145}$.

${ }^{143}$ Ammann 1925 : 462, 454.

${ }^{144}$ Le fondement de cette expérimentation est l'un des fours à pain construits dans le fort de Saalburg vers 135 ap. J.-C. par la $\mathrm{II}^{\mathrm{e}}$ cohorte des Rhètes. Il s'agit d'un four dans sa plus simple expression, dépourvu de tout aménagement particulier de l'autel. Cette expérience a été menée par P. Knierriem et E. Löhnig (1997) entre 1993 et 1996. Lors des fouilles du fort, au moins 44 fours de ce type ont été mis au jour, organisés en plusieurs batteries (sur ce point, cf. Jacobi 1930: 10-19 et pl. I-II; Jacobi 1937: 24-25 et pl. $\mathrm{V}, 4)$.

${ }^{145}$ GSP 1862: «A’ 9 [agosto]. [...] Nell'atrio di sopra indicato si è palesato un forno con chiusura di ferro a due anse nel quale sonosi raccolti ottantuno pani, quasi tutti della medesima forma circolare» (cf. BdI 1862: 315; Fiorelli 1873 : 16-17; Fiorelli 1875: 171-172). La majeure partie de ces pains a été détruite au retour d'une exposition à Florence en 1930 puis lors du bombardement de l'Antiquarium par l'aviation alliée (cf. Borgongino 2006: cat. n 457-462 et García y García 2006: 181-200, part. 195, avec une erreur sur la provenance des pains). Désormais, seuls six de ces pains
Dès lors, au cours de la cuisson, le combustible devait nécessairement être retiré du four ${ }^{146}$.

Les différentes phases de cuisson sont les suivantes. Le feu est allumé alors que la porte en fer est retirée et le conduit inséré dans la paroi de la coupole n'est pas obturé. Ce dernier permet non seulement d'améliorer le tirage, mais également d'utiliser au mieux la chaleur sortant du four. C'est pourquoi le fournil se trouve très fréquemment à l'autre extrémité de ce tuyau d'aération: l'air chaud provenant du four permet d'augmenter sensiblement la température de cette pièce où les miches sont laissées à lever, ce qui facilite d'autant le levage. Une fois la température idéale atteinte - dont la mesure est laissée à l'expérience de la personne chargée de l'enfournement -, le trou d'aération est rebouché et le combustible cède sa place aux pâtons. En fonction de la position de l'autel - qui permet de stocker temporairement les miches, pendant que la personne chargée de l'enfournement officie - par rapport au fournil, les boules de pâte peuvent transiter par le «passe-pain». La forme de l'outil permettant le transport des pâtons et leur introduction dans le four est essentiellement connue par l'iconographie ${ }^{147}$ : le relief de M. Vergilius Eurysaces montre ainsi sur sa face septentrionale un homme vêtu d'une tunique en train d'enfourner ou de défourner. Il manipule un manche plus long que lui n'est haut, dont existent encore, dont un réduit en morceaux (Borgongino 2006: cat. $n^{\circ}$ 463-467). Leurs dimensions, quand elles sont connues, oscillent entre 19 et $23 \mathrm{~cm}$ de diamètre. La sole du four est une ellipse large de 2,62 m, profonde de 2,55 m. De la sorte, les 81 pains pourraient y trouver place, avec un écart entre eux variant de 2 à $5 \mathrm{~cm}$. Avec un tel nombre de pains, la capacité maximale du four est atteinte.

${ }^{146}$ Dans le cadre de l'expérimentation de Saalburg, les auteurs précisent que la première bûchée est la plus importante en volume et donc en énergie déployée, tandis que celles de réchauffement ont entraîné une moindre consommation (Knierriem - Löhnig 1997 : 136). Ils n'indiquent pas s'ils ont retiré ou non les braises du four au cours de la cuisson.

${ }^{147}$ Une pelle à pain antique en bois a été découverte dans un puits dans le vicus lié au fort de Zugmantel (Allemagne). Elle est visible sur l'une des planches de l'ouvrage de M. Junkelmann (1997: pl. XV. 4). Une autre pelle a été mise au jour dans un puits du fort de Saalburg (Jacobi 1930: 17 et pl. I). Sa longueur totale est de $186 \mathrm{~cm}$. Le fer - en bois - mesure $39 \mathrm{~cm}$ de longueur pour $25 \mathrm{~cm}$ de largeur. 
aucun détail de l'extrémité n'est visible (fig. 60, e $)^{148}$. En revanche, sur le relief de Bologne, bien que très mutilée, la scène d'enfournement est représentée alors qu'un pain est enfourné ou défourné à l'aide d'une pelle (fig. 77) ${ }^{149}$. De telles pelles en bois ont dû être utilisées également à Herculanum ou Pompéi, sans toutefois laisser de trace $^{150}$. Une fois le four rempli, la porte de fer est remise en place le temps de la cuisson.

Parmi les aménagements nécessaires tout au long de ce processus on trouve en particulier les conduits d'évacuation de la fumée. Dans les fours ne comportant qu'un simple autel, comme en Or. II, 8, rien de tel n'est prévu. L'inévitable fumée créée par la combustion s'échappe dans la pièce où se trouve le four. En revanche, dans le cas des fours plus complexes, différents procédés ont été prévus pour évacuer cette fumée. L'état de conservation du four situé en Or. II, 1a empêche toute détermination du système employé. Dans les fours pompéiens disposant d'un mur diaphragme, une cheminée est percée au-dessus de l'autel: soit elle se prolonge directement jusqu'à l'extérieur, soit elle aboutit dans une chambre à fumée ménagée au-dessus de l'extrados de la coupole ${ }^{151}$. Enfin, dans la proximité du four, on trouve parfois deux types de récipients, comme dans la boulangerie Or. II, 1a: de part et d'autre de l'autel se trouvent d'un côté un cylindre taillé dans de la roche volcanique et de l'autre côté au moins un dolium (fig. 75, d) ${ }^{152}$. L'intérieur du premier conteneur, haut d'une quarantaine de centimètres, est excavé en tronc de cône; il se rencontre avec une fréquence assez peu élevée dans les boulangeries pompéiennes ${ }^{153}$. Il convient tout d'abord de distinguer ces récipients des aménagements hydrauliques, quand bien même ces derniers seraient également réalisés en roche volcanique. Le principal point de distinction est que les récipients servant à contenir de l'eau présentent

${ }^{148}$ Cf. Ciancio Rossetto 1973: 51 et Pl. XXXI, 2.

${ }^{149}$ Sur ce relief, cf. supra, n. 27 p. 138 et fig. 68.

${ }^{150}$ Une pelle en fer a été mise au jour dans la boulangerie V 4, 1-2, au pied du four (NSc 1901: 257). Il est possible que cet instrument ait servi à la manipulation des pains.

${ }^{151}$ Sur les différentes attestations de ces systèmes, cf. Fulvio 1879: 288-290.

${ }^{152}$ Selon les journaux de fouilles, deux dolia se trouvaient disposés dans la proximité du four. GSE 1935: tous un conduit d'évacuation. Un des meilleurs exemples est constitué par le pétrin en remploi situé au nord du four de la boulangerie I 12, 1-2: la majeure partie des trous servant à l'insertion des fiches a été bouchée avec du béton hydraulique, cependant l'un d'entre eux est resté ouvert pour permettre à ce réservoir de se vider dans l'avaloir situé immédiatement à proximité. Il est probable que ces "récipients", disposés en façade des fours soient pour l'essentiel des metae en remploi. Une interprétation pour expliquer la conservation de ces blocs taillés, alors qu'ils ont perdu leur fonction originelle - et en dépit de leur possible réutilisation comme pétrin-, est de considérer qu'ils servaient de brasero, entendu comme réserve de combustible en cours de calcination, entre deux fournées. Quant aux autres

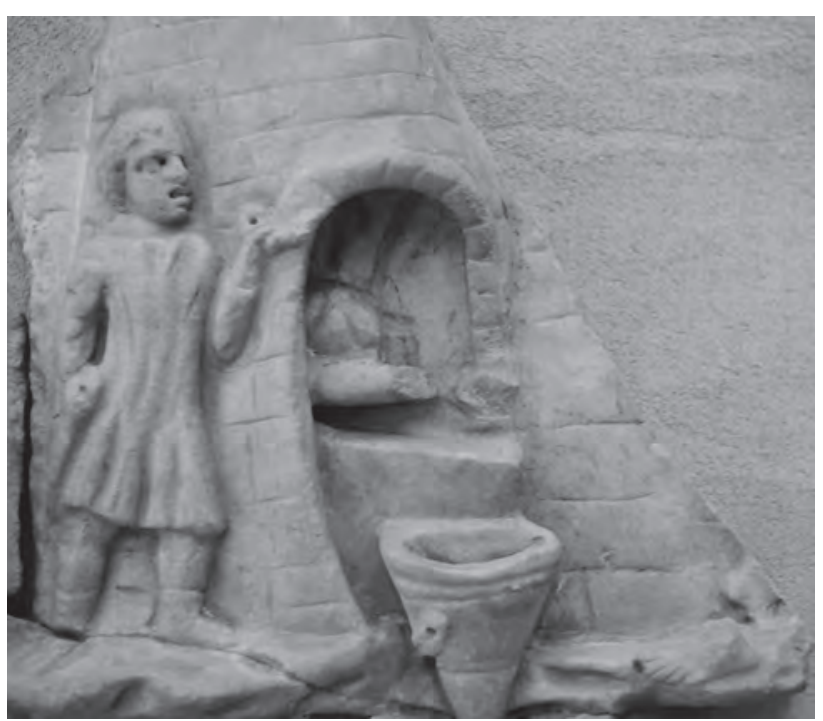

Fig. 77 - Détail du relief représentant une scène de boulangerie, conservé au Museo Civico Archeologico de Bologne: l'enfournement ou le défournement du pain, au moyen d'une pelle, est réalisé par un personnage dont seul subsiste le pied gauche.

«22 luglio. Due dolium si sono sterrati nella casa n. 1 posta nel vicoletto che trovasi all'estremità sud del V cardine, lato nord. Uno è in buono stato di conservazione e l'altro è rotto. Non si è raccolto nessun oggetto ».

${ }^{153}$ On rencontre ce type de conteneur dans les boulangeries suivantes: VI 11, 8-10; VI 14, 33 (?); VII 1, 36-37; IX 12, 6 . 
récipients, réalisés dans des matériaux divers - céramique, maçonnerie -, parfois insérés dans le sol, ils correspondent souvent aux vestiges du système hydraulique.

À partir de ces différentes données, les fours à pains de l'aire vésuvienne peuvent être répartis en deux séries distinctes: d'une part les plus simples, dépourvus de toute forme d'aménagement de l'autel; d'autre part ceux qui disposent d'un mur diaphragme en façade qui leur permet d'abriter divers aménagements accessoires chauffe-eau; passe-pain; conduit d'évacuation de la fumée. La chronologie de ces deux groupes d'implantations devrait être approfondie. Deux bornes peuvent être fixées par le biais de l'iconographie. Le relief de M. Vergilius Eurysaces représente sur sa face septentrionale un four dépourvu d'aménagement de l'autel: seul le massif de la sole et la coupole sont représentés. Selon P. Ciancio Rossetto, ce tombeau aurait été construit vers 30-20 avant notre ère ${ }^{154}$. À l'autre extrémité de l'arc chronologique durant lequel les fours auraient été dotés d'un mur diaphragme se trouve le sarcophage de la Villa Médicis: sur la scène d'enfournement qui y est figurée, la bouche du four est en retrait d'une paroi maçonnée, qui n'est représentée que sur un côté ${ }^{155}$. Selon M. Cagiano de Azevedo, ce sarcophage daterait de la fin du III $^{\mathrm{e}}$ de notre ère ${ }^{156}$. Ces bornes chronologiques peu nombreuses et très larges témoignent difficilement du passage d'une forme de four à l'autre. Tout au plus

${ }^{154}$ Ciancio Rossetto 1973: 67

155 Cette représentation asymétrique pourrait être uniquement due à des considérations de techniques de gravure: le boulanger en train d'enfourner un pain recouvre partiellement la zone où le montant droit du mur diaphragme aurait dû apparaître. Pour se simplifier la tâche, le sculpteur n'a pas jugé bon de le figurer.

${ }^{156}$ Cagiano de Azevedo 1951: 88.

157 Selon A. Maiuri, les boulangeries mises en place à la suite du séisme de 62 sont les suivantes: VI 3, 3.27-28; VII 1, 36-37; VII 2, 3.6; VIII 4, 26-29 (Maiuri 1942 a: 98-99; $164-165$; 167-168; 169-170; 172-173). L'ambiguïté persiste en ce qui concerne la boulangerie (VI 2, 6) flanquant la Casa di Sallustio (VI 2, 3-5.30-31): aucune datation claire n'est proposée pour la mise en place de la boulangerie (Maiuri 1942 a: 98-99). Selon V. M. Strocka (1991: 70), la boulangerie de la Casa del labirinto aurait également installée après le tremblement de terre.

${ }^{158}$ Varone 1989: 233; Varone 1995: 30.

159 Un autre exemple de four comportant un mur diaphragme pouvant avoir été construit avant le séisme permettent-elles d'avoir un point de repère maximal pour l'adoption de la représentation des fours pourvus d'un mur diaphragme. Si l'on suit les indications données par A. Maiuri, il est possible de déterminer une phase de transition plus resserrée. Selon ce dernier, au moins quatre boulangeries auraient été implantées après le séisme de 62 ap. J.-C. à Pompéi, auxquelles il faudrait ajouter celle située dans la Casa del labirinto (VI 11, 8-10) ${ }^{157}$. Ces cinq fours sont tous du type le plus complexe, avec mur diaphragme et accessoires incorporés. Selon A. Varone, il faudrait considérer la construction du four de la Casa dei casti amanti (IX 12, 6.8) comme antérieure à cette catastrophe: une première réparation, attribuable au séisme de 62 , est recouverte par du noir de fumée, tandis que l'ensemble du local a été mis au jour dans un état de destruction avancée - signe trahissant l'existence d'un second tremblement de terre peu avant l'éruption $^{158}$. Partant de ces données, il serait ainsi possible de considérer la seconde moitié du $\mathrm{I}^{\mathrm{er}}$ s. ap. J.-C. comme la période durant laquelle la construction de fours à pain disposant d'un mur diaphragme se généralise et tend à s'imposer ${ }^{159}$. Toutefois, l'absence d'uniformité dans ce processus est patente. En effet, sans développer l'exemple du limes rhénan outre mesure, il montre clairement la pérennité d'une forme plus simple de fours pendant les deux derniers tiers du $\mathrm{II}^{\mathrm{e}}$ de notre ère ${ }^{160}$. Dans un contexte beaucoup plus proche, le cas d'Herculanum

de 62 est celui de la Casa del Menandro (I 10, 4.14-17), qui servait également de chauffage pour le balnéaire. En l'état actuel des recherches, il aurait été érigé avant le séisme (Ling 1997 a: 95, 102-103). Toutefois, l'évolution de la question concernant le probable second tremblement de terre et les dégâts causés dans cette maison pourrait amener à abaisser cette chronologie.

${ }^{160}$ Les quelques cinquante fours mis au jour dans le fort de Saalburg sont tous de type simple (cf. Jacobi 1937: 2425). Ils ont été construits vers 135 ap. J.-C. et utilisés jusque vers $233\left(260\right.$ ?), soit au cours des $4^{\mathrm{e}}$ et $5^{\mathrm{e}}$ phases de ce fort (Schallmayer 1997: 111-117). Une installation aussi tardive de ce système simple paraît s'expliquer par le contexte particulier de leur mise en œuvre. Ainsi, l'intérêt principal du mur diaphragme est de permettre l'installation d'un système d'évacuation de la fumée, potentiellement dérangeante en milieu clos et urbain. Dans le cas des fours de Saalburg, installés en extérieur, l'utilisation de ce système est inutile. 
réduit également la portée de ce schéma évolutif. Le four de la boulangerie Or. II, 8 paraît avoir été construit immédiatement après 62 : les deux accès à la pièce où se trouve ce four sont liés à des remaniements postérieurs à ce séisme. La porte menant vers le fournil au nord a été ménagée en cassant un mur de refend, tandis que l'accès depuis la boutique aurait été réparé à la suite de l'un des deux tremblements de terre. Le four en lui-même oblitère un passage remontant au plan originel de l'édifice dans lequel il s'insère ${ }^{161}$. Ce contre-exemple interdit de caractériser de façon précise l'évolution des aménagements associés aux fours de boulangerie dans la région ensevelie par le Vésuve. Par ailleurs, il serait, d'une façon plus générale, nécessaire de dater la mise en place des pistrina dans ces deux villes et de définir en particulier la chronologie des fours simples.

\section{Les boulangeries d’Herculanum et de Pompéi: ESSAI DE SYNTHÈSE}

L'étude de la succession des opérations présidant à la réalisation du pain a permis de mettre en évidence trois types d'espaces au sein des boulangeries. L'espace dévolu à la meunerie est celui qui paraît s'insérer dans les boulangeries avec le moins de contrainte, tant qu'il reste peu développé: en Or. II, 1a, les deux meules se situent dans la même pièce que le four. Leur position est telle qu'elles ne gênent pas la circulation pendant leur fonctionnement: seule la vraisemblable écurie $\mathrm{B}$ reste inaccessible à ce moment. De la même façon, en Or. II, 8, les deux meules n'empêchent aucun déplacement, que ce soit vers le four ou vers les latrines. Cette insertion des molae n'est toutefois facilitée que tant qu'elles ne sont pas plus de deux. Au-delà, il faut prévoir un espace dégagé plus important qui, s'il peut se situer à proximité du four ${ }^{162}$, constitue fréquemment une pièce indépendante ${ }^{163}$.

${ }^{161}$ Sur l'existence de deux séismes, mais aussi sur la typo-chronologie des modes de construction à Herculanum, cf. infra, p. 233 et suivantes.

${ }^{162}$ Les trois meules de la boulangerie VI 6, 17-21 sont disposées en équerre devant le four. Un espace important a toutefois été ménagé devant la bouche de celui-là.

${ }^{163}$ En I 12, 1-2, les quatre meules sont disposées dans
Les liens entre la zone de meunerie et les autres pièces paraissent réduits à la seule continuité du travail: la proximité topographique n'est pas une nécessité164. En revanche, le fournil - second espace très défini dans lequel se déroulent généralement le pétrissage et le levage de la pâte - paraît toujours conçu et disposé selon des critères plus stricts. En Or. II, 8, il se situe dans la pièce la plus au nord, seulement accessible depuis le four. En Or. II, 1a, il est accolé au four, mais un parcours assez long doit être effectué pour passer de l'un à l'autre. Cette proximité topographique se justifie par l'utilisation de la chaleur du four dans le fournil lors de l'allumage du feu ou de sa réanimation. L'état de conservation du four situé en Or. II, 1a empêche de bien cerner ses relations exactes avec le fournil - ou du moins avec la pièce dans laquelle se trouve le pétrin. Toutefois, il est fort probable que le conduit d'aération ait plutôt débouché à l'est - vers le fournil - que nulle part ailleurs. Dans bon nombre d'exemples pompéiens, cette relation de proximité - pour exploiter au maximum la chaleur issue du four - se double d'une économie de déplacement. Le fournil dispose ainsi d'un accès simplifié au four, que ce soit par le biais d'un passe-pain ou par une proximité physique qui évite de longs détours. Ce choix peut non seulement s'accorder avec des problèmes strictement techniques - manipuler le moins possible les pâtons pour éviter d'endommager la structure du gluten - mais aussi avec des questions logistiques. De cette façon, les mitrons qui passent les pains ne gênent pas celui qui est chargé de l'enfournement. D'un point de vue très global, la compréhension que l'on a des parcours - du grain au pain cuit - dans la boulangerie fait que ces derniers peuvent ne pas avoir de cohérence linéaire. En revanche, une cohérence technique est perceptible. Deux blocs sont coordonnés mais ne nécessitent pas de lien matériel direct: d'une part la meunerie

une unique pièce, séparée de l'entrée principale de la maison et des autres espaces consacrés à la confection du pain.

${ }^{164}$ En ce sens, l'exemple le plus marquant est la boulangerie située en VI 5, 15. Les deux meules se trouvent à l'entrée du local. Un couloir long de plus de 15 mètres les sépare du fournil et du four. 
et ses annexes - stockage du grain, écurie pour les éventuels animaux; d'autre part le fournil et le four.

Sans atteindre les excès reconnus pour les commerces alimentaires, l'utilisation de la nomenclature latine a causé des dégâts pour la compréhension de ces locaux. En effet, certains pistrina sont considérés comme "dulciaria», ce qui laisse entendre que leur production est notamment, si ce n'est exclusivement, tournée vers la pâtisserie. Ce terme est d'un emploi rare: il n'existe que deux occurrences de la locution pistor dulciarius pour les deux premiers siècles de notre ère ${ }^{165}$. La première est due à Martial, dans le titre d'une épigramme qui évoque la confection de gâteaux au miel ${ }^{166}$. La seconde apparaît dans les Métamorphoses d'Apulée, quand l'âne est vendu à deux esclaves cuisiniers, dont l'un est notamment spécialisé dans la confection de pâtisseries ${ }^{167}$. Pour autant que ces deux mentions permettent d'en juger, le métier de pistor dulciarius ne constitue guère plus qu'une extension des capacités techniques d'un pistor, par les ingrédients qu'il emploie tout particulièrement le miel - mais aussi par les ustensiles à sa disposition; rien ne permet de supposer l'existence d'aménagements construits différents de ceux utilisés par un simple pistor $^{168}$. Dans un premier temps, les justifica-

${ }^{165}$ Les autres attestations de dulciarius sont dues à des gloses tardives (cf. TLL, s.v.)

${ }^{166}$ Mart., 14, 222: Pistor dulciarius / Mille tibi dulces operum manus ista figuras / extruet: huic uni parca laborat apis.

"Pistor dulciarius / Cette main dressera pour toi mille formes agréables de gâteaux: c'est pour celui-ci seul que travaille l'abeille économe» (trad. CUF).

${ }^{167}$ Apul., Met., 10, 13, 3: At illorum alter pistor dulciarius, qui panes et mellita concinnabat edulia [...].

"L'un des deux, pistor dulciarius, fabriquait des pains et des gâteaux au miel» (d'après trad. CUF).

La mention de panes simples montre que dans ce cas, la spécification des capacités de l'esclave par l'adjectif dulciarius n'est qu'un complément à son activité première de pistor. De la sorte, il serait plus proche du boulangerpâtissier que du spécialiste des seules pâtisseries.

168 Cette remarque se justifie non seulement par la mention des vasae variis usibus transportés par l'âne dès lors qu'il est employé par les deux esclaves cuisiniers (Apul., Met., $10,13,4)$, mais également par les indications données dans les recettes de cuisine: les recettes pâtissières impliquent nécessairement l'utilisation d'une batterie de cuisine plus diversifiée par les gestes qu'elles supposent que la confection du simple pain (sur les pâtisseries antiques, cf. André 1981: 210-215). tions apportées aux interprétations de pistrina «dulciaria» sont presque inexistantes. Ainsi, des trois premiers locaux considérés de cette façon par G. Fiorelli, seul l'un d'eux bénéficie d'une ébauche d'explication ${ }^{169}$. Reprenant une interprétation proposée par E. Breton, il considère que le four situé en VII 4, 29 est un four "à réverbération" composé de deux chambres. La première, s'ouvre au niveau du sol et aurait servi à contenir le combustible qui par un conduit aurait permis de chauffer indirectement la sole de la seconde chambre située au niveau supérieur ${ }^{170}$. Cette interprétation a été rejetée par L. Fulvio, qui préfère y voir l'illustration du four permettant de préparer des pigments noirs, semblable à celui que décrit Vitruve ${ }^{171}$. Si cette seconde interprétation est extrêmement délicate à suivre, la forme de cet aménagement n'est en rien celle d'un four à pain, ce qui rend d'autant plus difficile l'intégration de ce local au nombre des pistrina ${ }^{172}$. Ce n'est que pour la mise au jour de la boulangerie située en V 1, 14-16 que G. Fiorelli propose une interprétation se rapprochant de la spécialisation qui transparaît dans les textes. Ainsi, une forte concentration de «forme di pasticceria», découvertes avec d'autres instruments propices à la découpe de la pâte l'incite à considérer cette boulangerie comme celle d'un pistor dulciarius ${ }^{173}$. Comme

${ }^{169}$ Les deux boulangeries I 4, 13 et VII 12, 7 sont dénommées "pistrina dulciaria» sans aucune justification par G. Fiorelli $(1873$ : 68, 18; 1875: 66-67, 282). Le seul dénominateur commun entre ces deux locaux est de se trouver dans des îlots qui n'ont été fouillés que partiellement par G. Fiorelli. La boulangerie I 4, 13 a été dégagée à partir de 1853; celle située en VII 12, 7 en 1845 (BullNap 1845: 5, 90) puis en 1863 ( $B d I$ 1864: 115). Aucune explication ne peut être proposée pour cette interprétation de locaux qui diffèrent par l'absence de meule en VII 12, 7 et par la forme du four, muni d'un mur diaphragme en I 4, 13.

${ }^{170}$ Breton 1955: 275; Fiorelli 1875: 217.

${ }^{171}$ Fulvio 1879: 282-283. Cf. Vitruv., 7, 10, 2.

${ }^{172} \mathrm{La}$ mise au jour de petites meules manuelles et de pâtisseries carbonisées, mentionnée par E. Breton (1855: 275) n'est pas non plus suffisante pour caractériser une boulangerie. De telles meules peuvent servir dans un cadre domestique. Contrairement à ce que propose B. Mayeske (1972: 118-119), il semble nécessaire de réfuter l'association de l'entrée VII 4, 29 avec un pistrinum.

173 «Non è improbabile che fosse questa l'abitazione di un pistor dulciarius, poichè [...] vi si trovò il 16 dello stesso mese [di febbraio] in presenza del Principe ereditario di Baden una quantità d'istrumenti di bronzo, atti a tagliar 
nous l'avons vu plus haut, ces supposés moules à pâtisserie pourraient n'avoir qu'un lien ténu avec la production boulangère, étant vraisemblablement plus destinés à la préparation culinaire en général sinon aux ablutions ${ }^{174}$. Ce local dépendait intégralement de farine moulue à l'extérieur car aucune meule n'y a été mise au jour. Dès lors, le fait que cette boulangerie ait disposé de deux fours à pain, pourrait indiquer une forme de spécialisation, l'un de ces deux aménagements destinés à la cuisson pouvant être utilisé plus spécifiquement pour la réalisation de pâtisseries ${ }^{175}$. Par la suite, les autres boulangeries découvertes ne sont pas considérées comme utilisées par un pistor dulciarius. Cette variation dans les appellations empêche de vérifier que la quantité et la qualité de la vaisselle de bronze sont les principaux critères employés pour distinguer les types de boulangeries ${ }^{176}$.

Dans sa synthèse sur les boulangeries pompéiennes, B. Mayeske propose un autre schéma interprétatif pour considérer certains locaux comme dédiés aux pâtisseries. Selon elle, l'absence de meule pourrait indiquer une telle spécialisation $^{177}$. Elle indique ensuite une liste de 10 établissements correspondant à sa définition $^{178}$. Avant de se pencher sur cette proposition, il faut discuter le nombre de ces locaux, sans revenir sur le four situé en VII 4, 29 qui ne peut que difficilement s'accorder avec une production boulangère. Contrairement à son assertion, le local VI 5, 15 a disposé d'au moins deux meules,

le paste in varie guise, dando loro svariata forma ( $N S c$ 1876: 27). C'est L. Viola (1879: 27) qui emploie le terme de «forme di pasticceria » à propos des objets mis au jour dans ce local. A. Mau accepte ensuite cette interprétation (BdI 1877: 129-134, part. 134).

${ }^{174}$ Cf. supra, p. 150-152.

175 Une étude des objets en bronze découverts dans ce local serait d'autant plus intéressante pour la mise en évidence d'éventuels véritables moules à pâtisserie.

${ }^{176}$ Les cinq autres locaux ayant une activité au moins partielle de boulangerie ont été fouillés après les années 1880. Tous ont été considérés soit comme des pistrina simples, soit comme un atelier de préparation des pigments (I 8, 15-16; NSc 1946: 210). Ils sont situés en I 12, 1-2 (Mayeske 1988), V 3, 8 (NSc 1902: 207-208), V 4, 1-2 (NSc 1901: 255-257), IX 12, 6 (Varone 1989: 232-234),.

${ }^{177}$ Mayeske 1972: 171-172. Cette interprétation pourrait provenir d'une part d'une remarque de T. Warscher, à

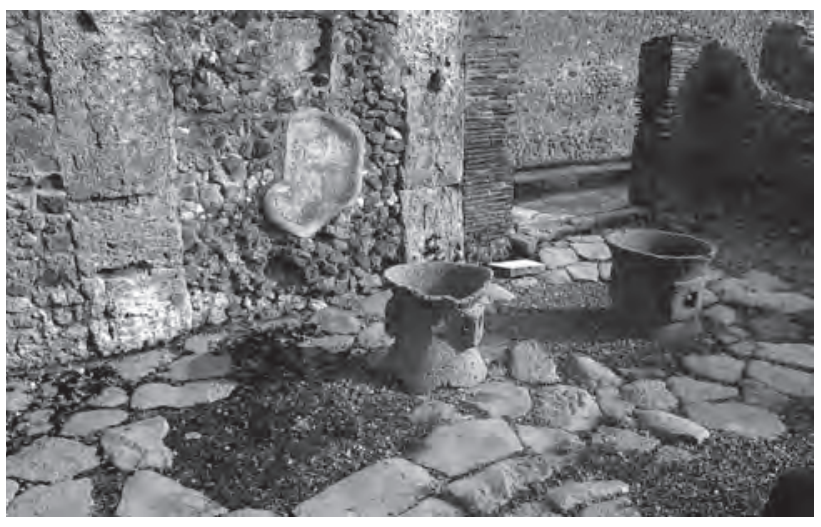

Fig. 78 - Boulangerie VI 5, 15 à Pompéi. Cette pièce, ouverte sur la rue disposait avant l'éruption de deux meules, comme le signalent très distinctement les deux empreintes dans le dallage de basalte, ainsi que les deux catilli (cliché pris du nord-est).

installées immédiatement après l'entrée. Si les deux metae ont disparu, leur empreinte reste perceptible au milieu du dallage en basalte qui s'y développe (fig. 78) ${ }^{179}$. Enfin, un troisième local ne doit pas être intégré à ce groupe de boulangeries dépourvues de meules. En effet, en I 4, 12-17 se développe un ensemble qui a la particularité d'être doté de deux fours, situés dans deux pièces séparées mais qui appartiennent à une même propriété. L'absence de meule directement associée au plus petit des deux fours ne suffit pas à le considérer comme une unité de production autonome. En revanche, comme

propos de la boulangerie située en VI 5, 15: «a small bakery without mills, perhaps of a pistor dulciarius » (cit. in Mayeske 1972: 98 ; cette citation est extraite d'un appendice consacré aux boulangeries, inséré dans le Codex Topographicus Pompejanus rédigé vers 1930, cf. Mayeske 1972: IX; García y García 1998: 1220-1223). D'autre part, l'interprétation de la boulangerie V 1,14-16, elle aussi dépourvue de meules, a dû jouer un rôle non négligeable.

178 Il s'agit des locaux suivants: I 3, 1; I 4, 12-17; V 1, 14-16; VI 5, 15; VI 6, 4-5; VII 4, 29; VII 12, 1-2.36; VII 12, 7; VII 12, 11 et VII 12, 13.

${ }^{179}$ Lors de mes observations sur le site en mai 2005, deux catilli étaient également disposés sur cette aire dallée. Ils n'auraient pas été présents en 1971 (Mayeske 1972: 9798). Toutefois, bien que dans une pièce située plus près du four, G. Fiorelli (1875: 100) mentionnait déjà la présence de meules, sans en indiquer le nombre. 
pour l'exemple déjà signalé de la boulangerie V 1,14-16, ce doublement des aménagements de cuisson pourrait effectivement permettre de considérer qu'une partie de la farine moulue a pu être destinée à de la pâtisserie. Enfin, un dernier local est plus délicat à interpréter. En VII 12, 11, aucune meule n'a été trouvée en fonction lors de la fouille. Toutefois, comme l'indique G. Fiorelli, dans une phase antérieure, la mouture du grain pouvait s'y dérouler ${ }^{180}$ : un catillus brisé en deux a été remployé dans le massif de fondation d'un départ d'escalier. Finalement, seules sept boulangeries ne sont pas équipées d'instrument de broyage du grain ${ }^{181}$. Cette seule absence les différencie des autres locaux: leur four et l'organisation de leurs espaces de production ne présentent aucune particularité telle qu'elles puissent être considérées comme dédiées à la pâtisserie. D'un point de vue économique, que la meunerie puisse être dissociée de la confection du pain est particulièrement intéressant. Cela implique en effet que certaines boulangeries ont eu une production de farine suffisamment importante pour dégager des surplus par rapport à leur capacité de stockage et de cuisson. La présence d'un catillus brisé en VII 12,11, sans que les signes pouvant indiquer une volonté de réparation n'aient été observés, est en ceci un signe remarquable d'évolution: cette transformation

180 «[VII 12,] 11. Un antico pistrinum nel quale a quanto pare erasi dismessa la molitura del grano [...]» (Fiorelli 1875: 283).

181 Pistrina dépourvus de meule: I 3, 1; V 1, 14-16; VI 6, 4-5; VII 12, 1-2.36; VII 12, 7; VII 12, 11 et VII 12, 13. Cette dernière présente cependant un catillus dépourvu de meta, à proximité du pétrin; seul un nettoyage complet de la boulangerie permettra de déterminer si la phase de mouture s'y est déroulée ou non.

${ }^{182}$ La situation apparaît identique à Ostie, en dépit du changement d'échelle (cf. Bakker 1999: part. fig. 29 p. 114-115). Il serait toutefois indispensable de déterminer la provenance des meules trouvées éparpillées à travers la ville.

183 Les 12 boulangeries de type A, comprenant des meules, un fournil, un four et une boutique sont les suivantes: I 4, 12-17; I 8, 15-16; V 4, 1-2; VI 5, 15; VI 6, 17-21; VII 2, 22; VII 16, 9; VIII 4, 26-29; IX 1, 3-33; IX 3, 10-12; IX 3, 19-20; IX 12, 6.

${ }^{184}$ Les 7 boulangeries de type A1, comprenant un fournil, un four et une boutique sont les suivantes: I 3, 1 ; V 1, 14-16; VI 6, 4-5; VII 12, 1-2.36; VII12, 7; VII 12, 11 ; VII 12, 13 . trahit un choix important de la part du pistor qui, en ne reconstruisant pas sa meule, a estimé pouvoir maintenir son activité en se procurant de la farine broyée par certains de ses concurrents. Inversement, aucun local n'est uniquement pourvu de meules: le meunier n'existe pas en tant que tel à Pompéi ou à Herculanum ${ }^{182}$.

Afin de mieux comprendre les relations non seulement entre les boulangeries, mais aussi entre ces locaux et le reste de la ville, une esquisse typologique peut être proposée. La principale différence entre les deux pistrina d'Herculanum tiendrait à l'existence - pas en Or. II, 1a mais éventuellement en Or. II, 8 - d'une salle au moins partiellement dévolue à la vente. À Pompéi, la situation est identique. Après avoir renoncé à la dichotomie entre des boulangeries simples et d'hypothétiques pâtisseries, il semble que le seul critère efficient est la présence d'un espace de vente au public (fig. 79). De la sorte, je définirai deux groupes. Le premier - type A - regroupe les boulangeries présentant une boutique sur leur devanture. Dans ces boulangeries, l'ensemble de la chaîne de production, de la meunerie à la vente est assurée, sans intermédiaire et dans un unique lieu ${ }^{183}$. À l'intérieur de cet ensemble, il est possible de dégager les locaux - type A1 - qui sont dépourvus de meule ${ }^{184}$. Ils doivent donc s'approvisionner en farine dans d'autres boulangeries ${ }^{185}$.

${ }^{185} \mathrm{Si}$ de nombreuses villas parmi celles mises au jour autour de Pompéi paraissent avoir été munies de fours et parfois de meules, rien ne permet de supposer une production de farine destinée à la ville dans ces exploitations agricoles: le nombre maximal de meules, toujours associées à un four, est de deux, à la villa de Gragnano (cf. NSc 1923: 275-280, part. 280; White 1970: 437-438). Des aménagements de panification ont été mis au jour dans les villas suivantes (entre parenthèses, le numéro d'inventaire de chaque villa - selon la mise au net d'Asaka 1993 -, suivi du nombre de meules): Boscoreale, contrada Pisanella ( $\left.\mathrm{n}^{\circ} 13 ; 1\right)$; Boscoreale, contrada Giuliana ( ${ }^{\circ} 14$; $1)$; Boscoreale, piazza Mercato/Vargas ( $\left.{ }^{\circ} 15 ; 0\right)$; Scafati, contrada Spinelli ( $\left.{ }^{\circ} 19 ; 0\right)$; Boscotrecase, contrada Setari $\left(\mathrm{n}^{\circ} 23 ; 1\right)$; Boscotrecase, contrada Cività-Giuliana $\left(\mathrm{n}^{\circ} 26\right.$; $1)$; Boscoreale, fondo d'Ancuzo ( $\mathrm{n}^{\circ} 28 ; 0$ ?); Boscoreale, contrada Pisanella ( $\mathrm{n}^{\circ} 29 ; 1$ [pas de four mis au jour]); Gragnano, contrada Carità $\left(\mathrm{n}^{\circ} 34 ; 2\right)$; Scafati, contrada Spinelli $\left(\mathrm{n}^{\circ} 35 ; 1\right)$; Scafati, contrada Crapolla $\left(\mathrm{n}^{\circ} 36 ; 0\right)$; Scafati, contrada Acquavitrara $\left(n^{\circ} 39 ; 0\right)$; Valle di Pompei $\left(n^{\circ} 41 ; 0\right)$. 


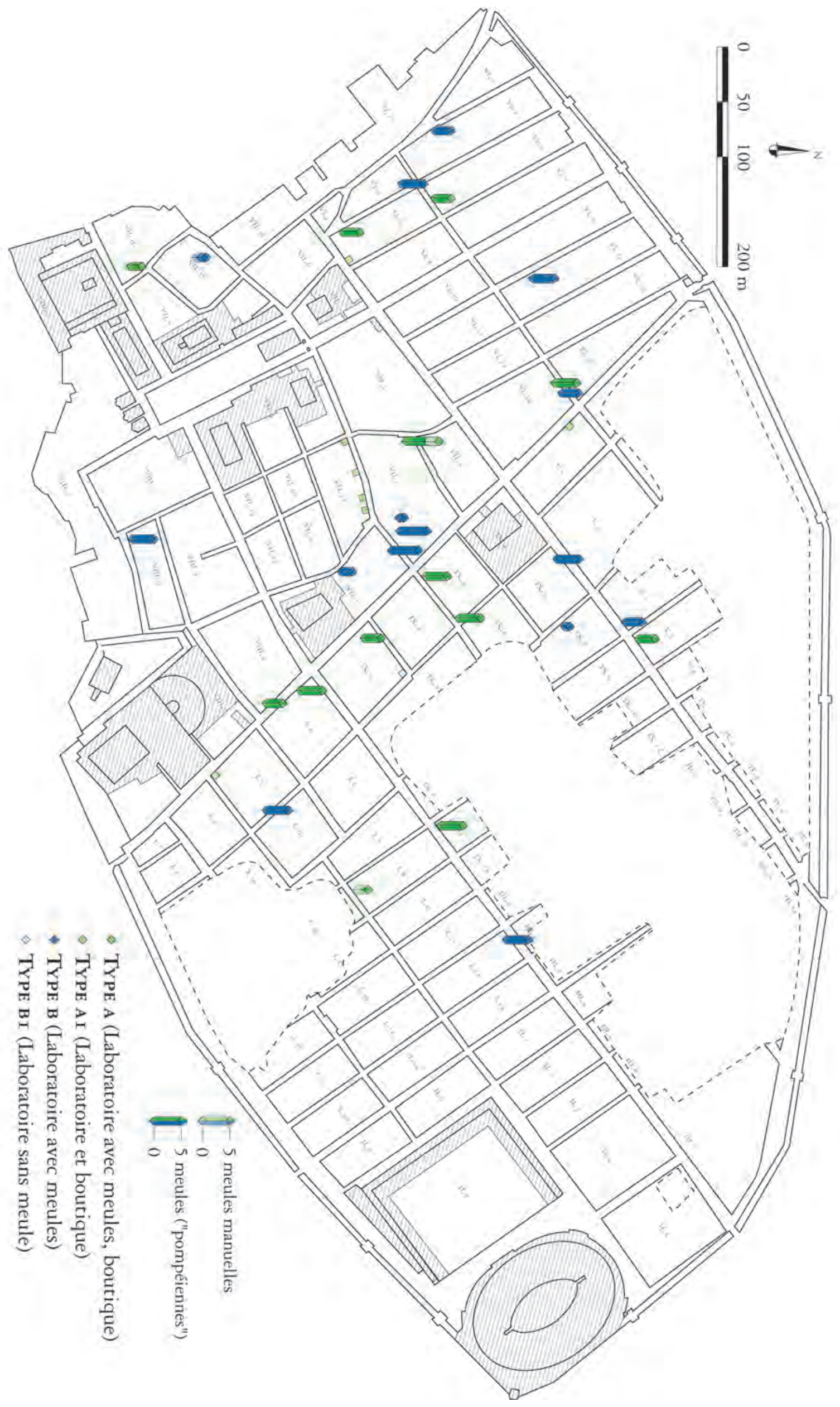

Fig. 79 - Répartition des espaces voués à la boulangerie à Pompéi, visibles mais non nécessairement fonctionnels au moment de l'éruption (échelle: 1/5000). 
Il convient de noter qu'à une exception près ${ }^{186}$, aucun four à pain n'est isolé, ce qui limite la chaîne possible des intermédiaires: aucun boulanger qui achète de la farine n'a recours à la vente indirecte de sa production. Cette solution d'écoulement du pain par le biais d'un intermédiaire entre le boulanger et le consommateur - dans des lieux et selon des formes restant à déterminer - concerne les boulangeries de type $\mathrm{B}$. Ces dernières comportent toujours des meules, un fournil et un four ${ }^{187}$. Complètement dissocié de tout espace de vente, le local Or. II, 1a à Herculanum appartient à ce groupe. En revanche, la situation est éventuellement plus complexe pour la boulangerie Or. II, 8 . Ce local dispose d'un seuil à rainure longitudinale et vantail mobile, caractéristique des implantations commerciales. Aucun élément ne s'oppose à l'utilisation d'ânes comme force motrice dans cette boulangerie: en considérant que ceux-ci occupaient un espace de 50 à $60 \mathrm{~cm}$ autour de la base des meules, cela ne laisse qu'une bande large de 1,53 m entre la partie occupée par les animaux et le mur nord de la pièce. Cette zone, relativement étroite, reste de surcroît le point de passage obligé pour se rendre dans la pièce du four et par là dans le fournil. Ces différents éléments la rendent particulièrement peu propice à l'accueil de la clientèle de la boulangerie. Par ailleurs, aucun aménagement d'exposition de la marchandise n'est visible, que ce soit sur les murs ou par d'éventuelles traces laissées au sol. La même conclusion pouvant être donnée pour la pièce annexe $B$, par ailleurs vraisemblablement occupée par une mezzanine ${ }^{188}$. Dès lors, il faut considérer que la boulangerie Or. II, 8 devrait s'insérer dans le groupe B (locaux dépourvus d'espaces de vente), en dépit de son seuil caractéristique des boutiques - qui a certainement été maintenu depuis une phase précédente.

\footnotetext{
${ }^{186}$ Cette exception est constituée par la seule boulangerie représentant le groupe $\mathrm{B} 1$, pourvue d'un four à pain mais pas de meule, située en IX 1, 22.29. Des fragments de deux catilli distincts sont visibles dans la maison. Il est possible qu'il faille donner un traitement particulier à cette boulangerie, en l'associant à celle de la maison VII 1, 25.46-47, à celle de la Casa del marinaio (VII 15, 1.2-15) et à celle de la Casa del centenario (IX 8, 6.3.a). Ces quatre espaces de boulangerie pourraient n'avoir eu qu'une production à vocation domestique.
}

Le circuit de distribution du pain paraît moins diversifié à Herculanum qu'à Pompéi, puisque rien ne permet de supposer l'existence de boulangeries vendant directement leur production au public. Il faut donc considérer une segmentation plus marquée pour cette activité: faute de vente directe au détail, devaient exister des intermédiaires - qu'ils soient vendeurs ambulants ou tenanciers de commerces alimentaires - entre les producteurs de pain et les consommateurs. Bien évidemment, cette conclusion doit être perçue avec toutes les précautions nécessaires au contexte d'Herculanum: seules deux boulangeries ont été mises au jour; le tissu urbain n'est connu qu'à hauteur de 25 à $30 \%$. Enfin, d'une façon plus générale, en revenant sur les procédés de production et sur le métier de boulanger, il faut souligner un aspect non dénué d'importance. Par un glissement sémantique difficile à appréhender à travers les seuls exemples d'Herculanum ou de Pompéi, le pistor, supposé spécialiste de la mouture du grain - au moins étymologiquement -, apparaît parfois comme un boulanger au sens contemporain du terme: un artisan dont le métier est de confectionner du pain. Les procédés de panification peuvent, dans la pratique et jusqu'à un certain point, être détachées des activités de meunerie. Il est vraisemblable que cette dissociation partielle n'est due qu'au développement de la consommation de pain alors en cours. Il est frappant de constater que dans les représentations iconographiques, au contraire, l'accent est toujours mis sur la mouture du grain, même à des périodes plus tardives que le $\mathrm{I}^{\mathrm{er}} \mathrm{s}$. de notre ère: aucun relief intégral représentant des activités boulangères n'omet complètement l'obtention de la farine.

Au-delà de cette définition variable du métier de pistor, quelques problèmes restent en suspens. Ainsi, la définition de l'utilisation des

${ }^{187}$ Les 16 boulangeries de type B sont les suivantes: I 3, 27; I 12, 1-2; V 3, 8; VI 2, 6; VI 3, 3.27-28; VI 11, 8-10; VI 14, 32;VI 14, 33; VII 1, 25.46-47; VII 1, 36-37; VII 2, 3.6; VII 2, 51 ; VII 15, 1.2-15; VIII 6, 1.9-11; IX 5, 4 ; IX 8, 3.6.a.

${ }^{188}$ Les aménagements de cette pièce sont toutefois difficiles à discerner, la majeure partie des murs ayant été reconstruite. 
pièces annexes des boulangeries nous échappe souvent. En dépit des assertions - rarement fondées - que l'on trouve dans les descriptions des fouilles, sur de supposés horrea, la localisation des réserves de grains et, dans une moindre mesure, de farine, reste délicate à déterminer ${ }^{189}$. De la même façon, aux rares exceptions des pièces où des squelettes d'animaux ont été trouvés, les écuries ne sont pas identifiables. Il serait ainsi nécessaire de déterminer quelles traces d'aménagements permettent de reconnaître ces espaces particuliers. D'autres voies peuvent également être explorées, comme de tenter de mesurer les capacités de production de ces locaux ${ }^{190}$, que ce soit en mesurant précisément l'ensemble des fours ou les étagères des fournils ${ }^{191}$.

Avec ce chapitre s'achève l'exploration des espaces de production et de commercialisation de denrées alimentaires en ville, activité indispensable s'il en est. Le chapitre suivant sera consacré à un autre versant des transformations de produits agricoles dans l'espace urbain, la filière textile.
${ }^{189}$ Dans les deux boulangeries d'Herculanum, aucun élément organique n'a été mis au jour. À Pompéi, si l’on excepte le grain et la farine conservés dans des amphores découvertes en VI 3, 3.27-28 (cf. Mazois 1824 b: n. 1 p. 56), la matière première utilisées dans ces locaux nous échappe complètement.

${ }^{190}$ Un essai en ce sens, prenant en considération les meules, a été mené par J.Th. Bakker (1999: 13-15) : il aboutit à un ratio d'une meule pour 90 habitants. Il me semble toutefois peu concluant pour deux raisons. La première est qu'il utilise le chiffre discutable et discuté de la population pompéienne, estimée ici à 10.000 habitants et que les meules qu'il dénombre ne correspondent qu'à la surface de la ville mise au jour. La seconde raison est qu'il considère que l'ensemble de la population consomme du pain et que seules les boulangeries en produisent (sur la consommation de grain en bouillie dans les commerces alimentaires, cf. supra, p. 120). Une expérience similaire de calcul a été tentée par M. Leduc (2008: 488-496) sur les boulangeries de Volubilis, en fondant son raisonnement sur les capacités des pétrins découverts.

${ }^{191}$ Ces deux mesures, en les comparant avec la dimension connue des pains pompéiens, peuvent donner une approximation ponctuelle - par fournée - des capacités de production de ces locaux. Cette problématique, ainsi que les différents problèmes laissés en suspens, sera explorée dans le cadre du programme de recherches "pistrina - études des boulangeries de l'Italie romaine », initié par l'École française de Rome et le Centre Jean-Bérard en septembre 2008. 


\section{CHAPITRE IV}

\section{TISSER, NETTOYER, TEINDRE: LES LIEUX DE L'ARTISANAT TEXTILE}

\begin{abstract}
[Megadore]. «[...] Mais, cela, c'est encore bien beau au prix des autres dépenses. À votre porte, vous avez le dégraisseur, le brodeur, le bijoutier, le tisseur de lin, puis toute la troupe des marchands, frangiers, chemisiers, teinturiers en orange, teinturiers en violet, teinturiers en jaune, tailleurs de robes à manches, les parfumeurs de chaussures, les revendeurs de lingerie, les bottiers; les cordonniers en chaussures de ville qui travaillent assis, sans compter les cordonniers en sandales, sans compter les teinturiers en mauve. Il faut donner aux dégraisseurs, il faut donner aux raccommodeurs. Puis ce sont les fabricants de soutiengorge, ce sont avec eux les fabricants de ceintures ».
\end{abstract}

Plaute, Aulularia, v. 507-516., trad. A. Ernout, CUF, 1932.

De toutes les formes de l'activité économique en ville, celles liées à la production et à la transformation du textile ont certainement été parmi les plus étudiées. La raison d'un tel intérêt est assez aisée à discerner. Fortement dépendante de la laine, et donc de l'élevage, la "filière» textile permet de dresser un pont entre les activités rurales et les activités urbaines. Derrière la toison, se cacheraient les principaux rouages de l'économie antique, ou du moins les réponses aux questions permettant de distinguer les productions domestiques des "industrielles», les activités rurales de celles du monde urbain, mais également de tenter d'écrire une histoire de l'Antiquité dans le temps moyen. Il ne saurait être question ici de reprendre ce débat initié

1 Cf. Finley 1975. Les conséquences des débats qui ont suivi la parution de cet ouvrage ont été analysées par J. Andreau (1995). Voir également mes remarques sur la situation pompéienne (Monteix 2010). depuis plus de trente ans, quand M. I. Finley a écrit son Économie antique ${ }^{1}$. En se cantonnant simplement à la situation des villes ensevelies par le Vésuve, les ouvrages de W. Moeller puis de W. Jongman constituent des synthèses - antagonistes - dont le but est d'utiliser les données issues de Pompéi pour proposer des modèles économiques ${ }^{2}$. Il serait prématuré de projeter d'intégrer Herculanum à ce débat ex abrupto. En effet, la définition des lieux où se déroule l'activité textile reste, à de rares et récentes exceptions près, fondée sur des données incomplètes ou dont l'actualisation reste à faire, particulièrement dans le cas d'Herculanum. Pour suggérer des pistes de comparaison entre le fonctionnement économique des deux cités, au moins

\footnotetext{
${ }^{2}$ Cf. Moeller 1976, contra Jongman 1988.
} 
du point de vue de la production textile, il m'a semblé nécessaire de reprendre l'intégralité des activités urbaines de cette "filière ", en suivant pas à pas les différentes étapes se succédant en ville après la tonte. Du filage au foulage, du nettoyage des toisons à l'utilisation d'une presse pour lustrer les habits, il faut synthétiser les connaissances sur le textile à Pompéi pour permettre de distinguer les pratiques de production propres à Herculanum ${ }^{3}$.

\section{IV.1 De la laine à l'étoffe, des officines de lavage des toisons au métier à tisser}

Pour mesurer l'étendue et la variété de la « filière » textile à Herculanum, il faut en premier lieu recenser les différents lieux dans lesquels se sont déroulées les premières phases du travail de la laine. Trois d'entre elles peuvent être reconnues archéologiquement: le nettoyage des toisons, le filage et le tissage ${ }^{4}$. Toutefois, entre la reconnaissance d'une activité et la qualification de sa production, des difficultés peuvent apparaître.

\section{IV.1.1 Les officines de lavage des toisons}

Dans son ouvrage consacré au marché de la laine à Pompéi, W. Moeller a mis en évidence des ateliers formant un ensemble cohérent par les aménagements dont ils disposent ${ }^{5}$. Dans une réponse parfois acerbe à cette étude, $\mathrm{W}$. Jongman a notamment critiqué le terme "d'officinae lanifricariae» par lequel ces ateliers ont été appelés. $\mathrm{Si}$ la justesse de ce refus d'employer cette expression - forgée sur un probable jeu de mots à consonances graveleuses - ne saurait être mise en cause, l'idée générale de W. Moeller doit être conservée ${ }^{6}$. En effet, 24 ateliers pompéiens présentent des caractéristiques similaires ${ }^{7}$.

La principale d'entre elles est une longue table maçonnée accolée à un mur, pouvant être pourvue d'un retour, haute d'une soixantaine de centimètres et large d'environ 1,10 mètre. $\mathrm{Au}$ centre de cette table se trouve au moins une chaudière "basse", reconnaissable à son plan circulaire et à son sommet biseauté. Cette disposition permet l'insertion d'un bassin tronconique en plomb, dont certains sont encore conservés en place ou attestés par les journaux de fouilles ${ }^{8}$. À l'arrière de ce bassin, une cheminée est percée dans la table pour faciliter le tirage du foyer. Enfin, des vasques maçonnées sont systématiquement disposées à proximité, souvent à l'extrémité de la table ${ }^{9}$. L'interprétation de ces aménagements a été détaillée par Ph. Borgard: il s'agit d'ateliers qui permettent de dégraisser
${ }^{3}$ Ce chapitre a bénéficié de la relecture méticuleuse de F. Médard, ce qui m'a évité de trébucher sur l'écheveau du vocabulaire technique du textile, ce dont je la remercie chaleureusement.

${ }^{4}$ La finition des vêtements par leur nettoyage en foulerie pourrait être intégrée dans ces premières phases. Toutefois, la difficulté de différenciation - si tant est qu'une telle distinction soit fondée dans la pratique - entre les fouleries destinées au premier lavage et celles consacrées à l'entretien et à l'avivement des couleurs (cf. Wilson 2003: 443) m'a fait préférer l'étude groupée de toutes les fullonicae ensemble.

${ }^{5}$ Moeller 1976: 13, 30-35.

6 L'appellation "officina lanifricaria» vient d'une mention peinte à proximité d'un de ces ateliers, sur une affiche en façade du commerce alimentaire VII 12, 15-16. Entre le texte rappelant un munus offert par A. Suettius Certus et l'indication des peintres de cette annonce, l'un d'entre eux a ajouté la mention «lanifricari dormis » (CIL IV, 1190). Comme le signale W. Jongman (1988: 167), il est très possible que cela s'adresse à l'un des clients du commerce alimentaire. Dans sa thèse sur la langue vernaculaire à Pompéi, V. Väänänen (1958: 93) indique qu'il s'agit d'un hapax sans toutefois comprendre le jeu entre les mots lana et fricare. Les explications présentées récemment par
Ph. Borgard et M.-P. Puybaret (2004: 51-52) montrent cette boutade sous un jour nouveau.

${ }^{7}$ Aux 24 établissements d'identification sûre, s'ajoutent trois autres possibles (soulignés): I 3, 15; I 3, 16; I 3, 30; I 4, 26; I 8, 19; VI 16, 3-4; VII 2, 27; VII 3, 24; VII 4, 39-40; VII 9, 41; VII 9, 43; VII 9, 44; VII 10, 13; VII 11, 3; VII 11, 5; VII 12, 17; VII 12, 22; VII 12, 25; VII 12, 30; VII 13, 21; VII 14, 5.17-19; VIII 4, 1.53; VIII 4, 2-6.49-50; VIII 4, 35; VIII 4, 37; IX 3, 13; IX 3, 14.

${ }^{8}$ Le bassin est encore visible dans l'officine VII 12, 17 (Moeller 1976: pl. 1; Borgard - Puybaret 2003: fig. 23, 7 p. 317-318). Une description de celui situé dans l'atelier I 3, 15 est proposée dans les GSP (1869: «6 [febbraio] All'entrata della terza bottega, posta sul lato destro della succennata strada, a contare dall'angolo sulla via di Stabia, si è raccolta una piccola vasca di piombo tutta ammaccata, rotta nel fondo e nel giro, con manici di bronzo, uno dei quali è mancante; un piccolo peso di piombo, ed una quantità di terra rossastra, che sembra essere colore»; cit. in GSPomp, n.s. 1, 1868: 246).

9 Pour une description plus détaillée de ces aménagements, cf. Borgard - Puybaret 2003: 304-306; Borgard - Puybaret 2004: 49-52. 
la laine brute. Les chaudières «basses » servent à faire tremper les toisons dans de l'eau tiède pour les débarrasser de leurs impuretés après la tonte, en particulier pour dissoudre le suint, graisse imprégnant les toisons ${ }^{10}$. Une évolution de l'organisation de ces ateliers est perceptible dans trois cas: au lieu de disposer d'une table maçonnée accolée au mur, un banc de pierre est utilisé pour l'étalage des toisons, ce qui autorise deux ouvriers à travailler simultanément sur une même toison et donc permet d'augmenter la productivité. La chaudière se transforme également: elle devient une forme fermée, un tronc de cône emmuré dans un bloc maçonné ${ }^{11}$.

De telles séries d'aménagements se retrouvent également à Herculanum, avec quelques variantes. Au cours du $\mathrm{I}^{\mathrm{er}}$ siècle de notre ère, au moins quatre officines peuvent y être identifiées, sans qu'il ne soit toujours possible de se déterminer sur leur coexistence ou leur succession. $\mathrm{Au}$ moment de l'éruption, seules deux sont en activité. Celle qui est la mieux conservée se situe en Or. II, 18. Identifiée par A. Maiuri comme une teinturerie, l'ensemble des éléments à peine décrits s'y retrouve ${ }^{12}$. Sur le côté nord du local principal largement ouvert sur la rue, est disposée une table maçonnée, longue de $5,56 \mathrm{~m}$, large de 1,07 $\mathrm{m}$ et haute de 0,77 m (fig. 80). Le sol comme la surface de la table sont recouverts de tuiles posées à plat. L'ouverture du foyer a été détruite, seul un bloc de lave subsiste sur le côté ouest. Aucun objet qui puisse se rapporter à l'activité qui s'y exerçait n'a été découvert. Les trois autres pièces sont d'interprétation difficile, ne présentant aucun aménagement particulier. La partie sud de la pièce 18-4 est encombrée par une glissière maçonnée qui a servi à recevoir les eaux

${ }^{10}$ Sur cette interprétation, cf. infra n. 223 p. 217.

${ }^{11}$ Deux de ces laveries ont été étudiées par Ph. Borgard (- Puybaret 2004: 57-58). Situées en I 8, 19 et en VII 14, 5.17-19, elles sont associées à des teintureries de grand teint. Il paraît nécessaire d'ajouter à cette série l'atelier VI 16, 3-4 qui est en revanche associé avec une foulerie. Une chaudière similaire pourrait s'être trouvée en VI 14, 21-22, également en lien avec une foulerie. Enfin, dans la Casa dei Postumii (VIII 4, 2-6.49-50), dans la pièce 22, un banc maçonné, détaché du mur et recouvert d'un bloc de calcaire blanc, construit à côté d'une "chaudière basse " 'classique', a été interprété comme un espace de boucherie (Dickmann

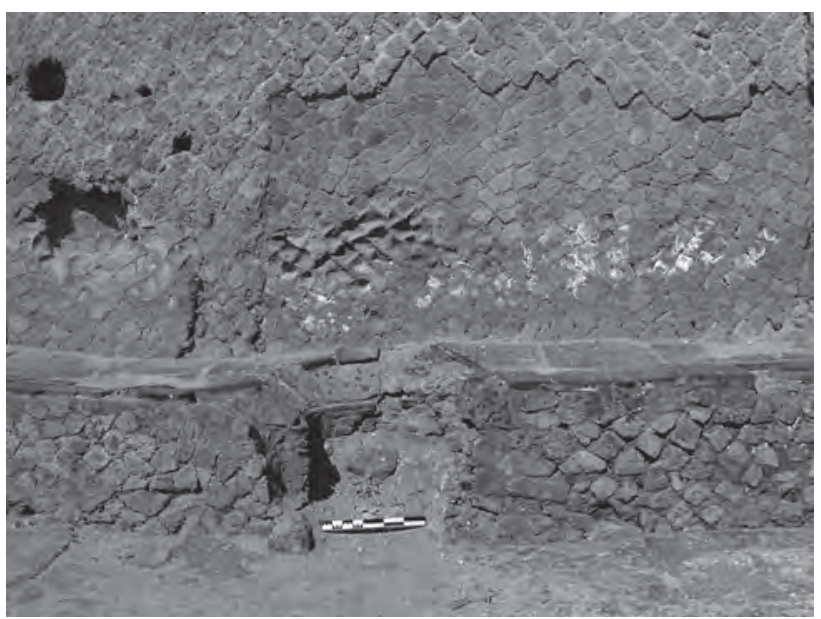

Fig. 80 - Table maçonnée dans l'atelier Or. II, 18 à Herculanum. En dépit des importantes restaurations qui ont touché cette table, la structure de la chaudière «basse» au centre permet d'identifier cet atelier comme une officine de nettoyage des toisons (cliché pris du sud).

collectées dans les étages et acheminées jusqu'à l'égout grâce à un tuyau constitué par des cylindres de terre cuite emboîtés. Insérée dans une phase postérieure à la construction initiale de l'Insula Orientalis $I I^{a}$, cette colonne d'évacuation des eaux n'a pas de rapport direct avec les activités artisanales de ce local. Aucune trace de séchoir n'a été mise en évidence. Les deux séries d'encastrements de solives dans la pièce 18-4 semblent correspondre à deux aménagements successifs de mezzanine. De même, aucun bassin maçonné n'a pu être identifié ${ }^{13}$. La seconde officine en fonction lors de l'éruption se trouve en VII, 12, sur le versant ouest du cardo III. Découverte en 1960, le compte rendu de sa fouille est particu-
- Pirson 2000 : 454-455; contra Kastenmeier 2007: 30-31), en dépit de l'inadéquation d'une table en marbre pour la découpe bouchère: la dureté du matériau ne saurait qu'abîmer le fil des couteaux. Il est assez probable que la chaudière ait été entourée par deux tables dont l'une aurait perdu son plan de travail en calcaire blanc.

${ }^{12}$ Maiuri 1958 b: 466-467.

13 Cette absence d'un bassin pourrait être due aux destructions provoquées par les tunnels du XVIII ${ }^{\mathrm{e}}$ siècle: les restaurations autour de la table maçonnée sont particulièrement nombreuses à en juger par la qualité des maçonneries. 
lièrement laconique ${ }^{14}$. Longtemps encombré par les débris provenant de la désagrégation du talus occidental des fouilles, ce local a bénéficié en 2006 d'un nettoyage permettant de confirmer l'interprétation comme officine de nettoyage des toisons ${ }^{15}$. La création de ce local paraît relativement tardive, à en juger par l'obturation partielle de la vaste ouverture sur la rue par une cloison en opus craticium $^{16}$ : la pierre de seuil, indiquant à l'origine une boutique d'aspect traditionnel et comportant le vantail mobile, a été récupérée et déplacée du sud au nord; les autres blocs sont restés en place.

$\mathrm{Au}$ moins deux autres ateliers similaires peuvent être identifiés par les maigres empreintes qu'ils ont laissées ${ }^{17}$. Le premier se situe en VI, 30. Inscrit dans la parcelle des thermes et s'ouvrant sur le cardo III - en face de l'officine VII, 12 -, il a la particularité de n'être jamais mentionné dans le texte d'A. Maiuri, ou sur les plans que ce dernier propose pour l'insula VI ou les thermes ${ }^{18}$. Composé de deux pièces, il présente une série d'aménagements maçonnés dans la principale d'entre elles (fig. 81). En entrant à gauche se trouve une vasque rectangulaire, dont le large rebord à l'ouest est notamment constitué par un seuil en remploi et dont les parois internes

${ }^{14}$ GSE 1960: «26 ottobre. Continuando lo sterro all'interno del vano ieri menzionato si sono messi in luce due ambienti, il primo sicuramente una bottega di metri 4.30 per 3.40, a sinistra vi è un focolare con banco di metri 3.40 per 1.10 , il secondo vano si sviluppa a nord del primo con una luce di metri $1.20[\ldots]$ ».

15 Ce nettoyage a été réalisé par l'Herculaneum Conservation Project. Les aménagements visibles depuis la rue montrent que la table maçonnée est en équerre; une chaudière basse y est incluse.

${ }^{16}$ GSE 1960: «25 ottobre. [...] Si è messo in luce il vano di un nuovo ambiente sempre sul III cardo, che prende il numero 12. Tale ambiente in origine doveva avere una luce maggiore di quella di costruzione, una tompagnatura alla beneventana restringendo in tal modo il vano nella misura di metri 1.30 di luce e metri 2.70 di altezza. Nessun rinvenimento ». Cette paroi a été restaurée avec des blocs de tuf.

${ }^{17}$ Le nettoyage partiel du sol effectué en Or. II, 15 par l'Herculaneum Conservation Project en 2006 pourrait permettre d'y identifier un cinquième atelier. Le long du mur nord, au sol, les vestiges d'un fourneau probablement circulaire ont été mis en évidence. Il serait toutefois nécessaire d'étendre ce nettoyage pour confirmer cette interprétation. Enfin, la pièce 13 de la Casa a graticcio présente des aménagements relativement proches de ceux d'une laverie de toisons (cf. infra, p. 203-205). sont enduites de mortier hydraulique. Un avaloir creusé dans sa paroi sud permet l'évacuation de son contenu. Immédiatement à l'est de cette vasque, une large table maçonnée haute de $60 \mathrm{~cm}$ s'étend sur toute la longueur du local, construite après l'arasement partiel d'un mur. Cette table a été fortement endommagée par l'un des tunnels qui a transpercé l'atelier. Ces dégâts permettent toutefois de discerner un évidement dont le côté nord est semi-circulaire. Au centre, on peut observer des fragments de briques épaisses de deux à trois centimètres, utilisées comme comblement lors de l'abolition de ce qui paraît avoir été une chaudière "basse». Le sol de la moitié est du local est recouvert de tuiles posées à plat. Enfin, notons la présence dans la pièce annexe, des empreintes de quatre petites poutres circulaires, situées à 1,80 m du sol, qui ne décrivent pas un plan strictement horizontal, ce qui rend leur interprétation comme mezzanine délicate. La destruction dans une seconde phase exceptée ${ }^{19}$, la similitude de ces aménagements avec ceux que l'on trouve en Or. II, 18 ou dans les laveries de toisons pompéiennes est frappante ${ }^{20}$. Elle l'est également en Or. II, 5, quand, dans une phase antérieure à celle de l'éruption, le local comprenait une laverie de

${ }^{18}$ Bien que ce local a été fouillé entre 1927 et 1958 , le plan général et la planimétrie des thermes laissent un vide sans numérotation à son emplacement (cf. Maiuri 1958 b: fig. 68 p. 32 ; tav. IV A). Avant 1958, il n'est représenté qu'une seule fois, sur le plan général des édifices mis au jour, en 1936 (Maiuri 1936 a/b: pl. h.t.). Sa première identification comme atelier est due à G. Guadagno (1993: fig. XVIII p. 97). Les journaux de fouilles ne permettent pas de pallier cet oubli. Il est fort probable qu'il ait été fouillé par une entreprise privée chargée de dégager le cardo III et mentionnée durant cette période (cf. GSE 1932: 5 luglio). Sur ce point, cf. Monteix 2006: 23-27.

19 Dans une seconde phase, un bloc de maçonnerie carré, haut d'au moins $0,60 \mathrm{~m}$, a été construit au centre du local; sa construction oblitère l'ouverture de la chaudière basse. Je ne saurais proposer aucune interprétation d'emploi pour ce probable four.

${ }^{20}$ La porte de l'espace VI, 30 a été réduite à un moment non spécifiable de son histoire. Faut-il y voir une similitude avec la situation observée en VII, 12 et dans les officines pompéiennes? Selon M. Flohr (2007 a: 136), la réduction de la largeur de l'espace d'entrée serait caractéristique de ces locaux. Sans y proposer d'explication, je signalerai cependant que les deux locaux situés dans l'Insula Orientalis $I I^{a}$ n’ont pas bénéficié de ce resserrement de l'accès. 


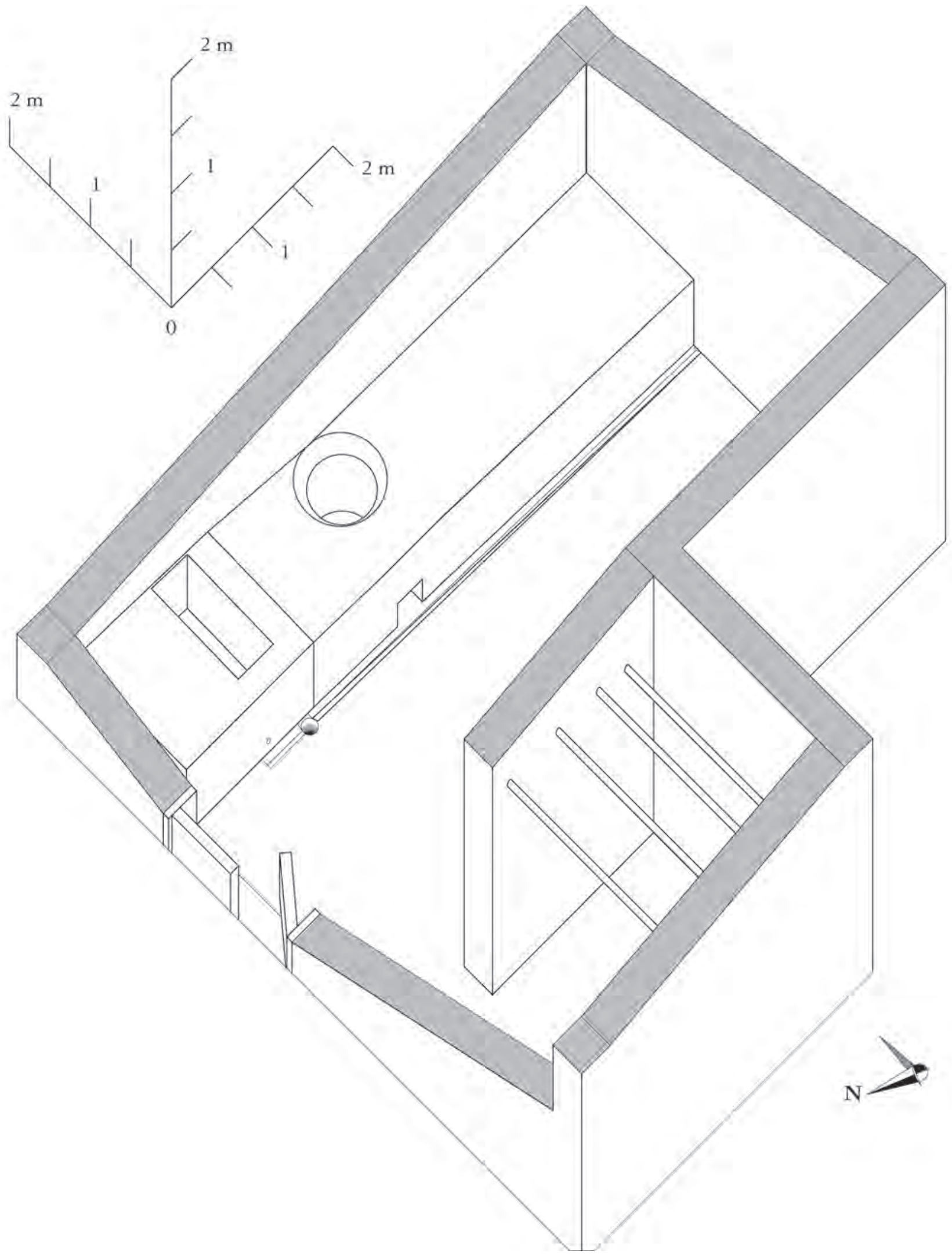

Fig. 81 - Proposition de restitution axonométrique de l'atelier de nettoyage de toisons VI, 30 à Herculanum (échelle 1/50). 


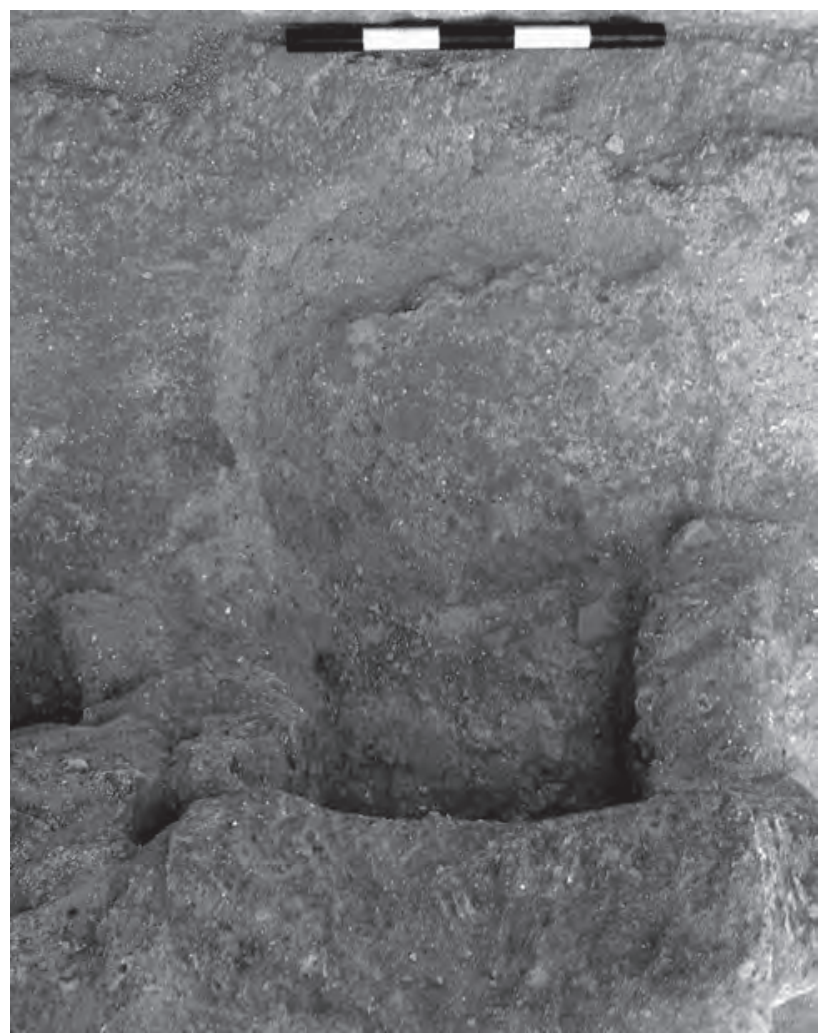

Fig. 82 - Vestiges de la chaudière «basse» dans l'atelier Or. II, 5. La table maçonnée a été découverte complètement arasée. Dans une phase antérieure à l'installation d'une probable activité de feutre dans ce local, la table comportait une chaudière basse dont l'empreinte circulaire a été conservée. Le linteau en roche volcanique est resté en place (vue zénithale prise du nord).

toisons ${ }^{21}$. Cette dernière était constituée d'une table maçonnée plaquée contre la paroi sud du local, après l'oblitération d'une porte donnant sur l'accès principal à la «Palestre »(Or. II, 4). Large de 1,15 m, cette table disposait d'une chaudière «basse » dont seule l'empreinte circulaire est encore visible, ainsi que le linteau en pierre de l'ouverture du foyer (fig. 82). À son extrémité ouest, immédiatement à droite de l'entrée se trouve le fond de ce qui semble avoir été un bassin de taille relativement réduite $(0,62$ x $0,60 \mathrm{~m}$ ), sous lequel se trouve l'orifice permettant l'évacuation des eaux vers les égouts. Un

21 Sur les différentes transformations subies par ce local, cf. infra, p. 190-191.

22 À Pompéi, selon un recensement rendu difficile par la stratification moderne recouvrant les sols, seule la

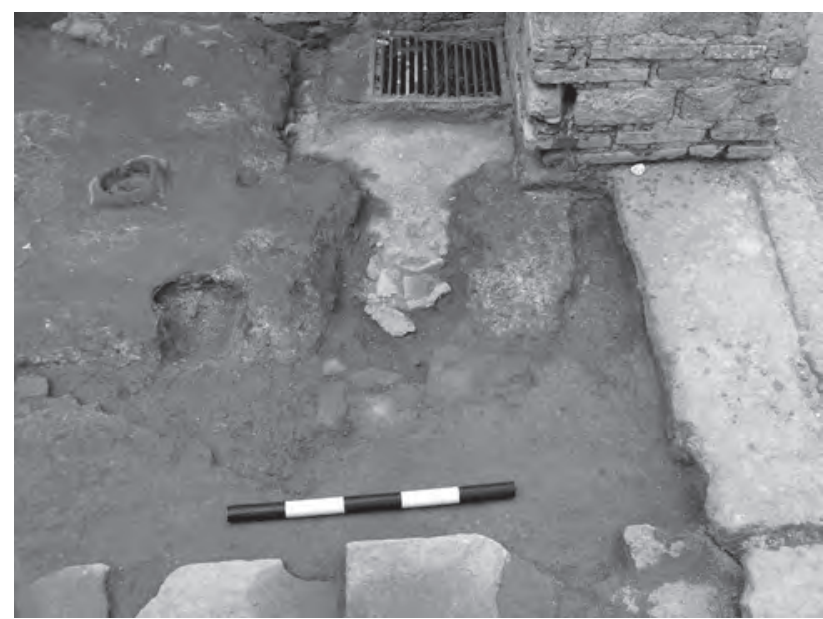

Fig. 83 - Table maçonnée arasée dans l'atelier Or. II, 5. Cette table est percée à sa base par un avaloir qui se déverse dans l'orifice de collecte vers le vide sanitaire courant sous l'îlot. L'ensemble du sol de cet atelier est couvert de tuiles posées à plat (cliché pris du nord).

avaloir taille la table pour se connecter à cet orifice (fig. 83). Dans la pièce annexe située au sud-est, des empreintes de solives se trouvent à $1,50 \mathrm{~m}$ du sol. Contrairement à l'aménagement similaire en VI, 30, elles forment un plan sensiblement horizontal, ce qui empêche de réfuter la présence d'une mezzanine. Enfin, sur le côté nord du local, il n'est pas possible de déterminer si une seconde table a été construite ou non. L'arrêt très net du pavement en tuiles posées à plat, qui ne semble pas pouvoir être associé aux travaux effectués durant la phase suivante, pourrait plaider pour une telle interprétation.

Les caractéristiques des officines de nettoyage des toisons à Herculanum sont, du point de vue des aménagements maçonnés, identiques à celles que l'on trouve à Pompéi avec cependant quelques variations de détails. En particulier, leur sol est systématiquement constitué par des tuiles ou des briques bipedales ${ }^{22}$. Dans les deux établissements ensuite oblitérés, un espace de séchage peut être restitué dans les pièces annexes. Enfin, je constaterai le maintien dans le temps du nombre de ces officines: bien que la proxi-

laverie intégrée à la "cuisine» 22 de la Casa dei Postumii (VIII 4, 2-6.49-50) présente un sol fait de briques bipedales correspondant parfaitement aux aménagements maçonnés (Dickmann - Pirson 2000: 455). 
mité topographique puisse induire en erreur, et en tenant compte des approximations liées aux datations ${ }^{23}$, la mise en fonction des ateliers situés en Or. II, 18 et en VII, 12 semble correspondre à l'arrêt de ceux respectivement localisés en Or. II, 5 et en VI, 30. Une telle succession confirmerait l'importance de ces ateliers pour la filière textile, sans toutefois faire d'Herculanum un important centre de production.

\section{IV.1.2. Le fil invisible}

Une fois les toisons nettoyées, elles doivent être transformées en fil. Si le matériel utilisé pour cette opération est relativement bien connu, la localisation de cette activité est beaucoup plus malaisée. La quenouille, généralement tenue dans la main gauche est longue d'une trentaine de centimètres. On y dispose les fibres animales ou végétales nettoyées et peignées. L'autre main tient le fuseau, lesté d'une fusaïole, disque perforé donnant de l'inertie lors du mouvement rotatif. Le filage consiste à tirer les fibres stockées sur la quenouille et à les tordre avec le fuseau ${ }^{24}$. La rareté des quenouilles en fouille est largement compensée par les découvertes de fuseaux et de fusaïoles. Alors même que cette opération, goulet d'étranglement de la «filière " textile, requérait une main d'œuvre importante en comparaison des suivantes, les instruments utilisés pour le filage restent peu nombreux à nous être parvenus ${ }^{25}$. À Herculanum, un faible

${ }^{23}$ Cf. infra, p. 244-253.

${ }^{24}$ Sur les gestes effectués lors du filage, cf. Wild 1970: 31-40, part. 35-37.

${ }^{25}$ Sur le rapport - estimé à cinq contre un - entre les fileurs et les tisseurs, cf. Wild 2002: 8-9.

${ }^{26}$ Quant au faible nombre d'outils liés au filage, deux explications non concurrentes peuvent être avancées: les matériaux périssables les constituant et leur taille réduite ont pu les faire disparaître lors des fouilles; l'extrême légèreté des fusaïoles, associée à la violence du premier flux éruptif, a pu, à Herculanum, entraîner leur déplacement hors des espaces d'utilisation.

27 GSE 1927: 14 dicembre. Inv. n E104-105=7538075381. Sur les quatre fuseaux, un seul a été découvert avec la fusaïole insérée.

${ }^{28}$ GSE 1928: 17 febbraio. Inv. n E171=75447. Six fragments ont été conservés.

${ }^{29}$ GSE 1930: 22 ottobre. Inv. n E568=75845.

30 Une synthèse de localisation a été proposée par P. M. Allison (2004: 146-148; 2006: 396-397) dans un nombre de ces objets a été mis au jour sur l'ensemble du site ${ }^{26}$. Un premier ensemble, composé de quatre fuseaux intégraux, a été découvert dans la pièce 6 de la Casa del tramezzo di legno (III, 4-6.8-9.11) ${ }^{27}$. Des morceaux permettant de restituer un ou deux fuseaux proviennent d'une armoire au premier étage de la Casa a graticcio $(\text { III, 14 })^{28}$. Enfin, trois fusaïoles ont été mises au jour dans la Casa dei cervi (IV, 21) ${ }^{29}$. L'inventaire de telles découvertes doit encore être mené à Pompéi ${ }^{30}$. Signalons toutefois que les locaux les plus divers peuvent avoir abrité une telle activité. Le commerce alimentaire I 6, 6 a livré deux fuseaux. Ils ont été découverts au rez-dechaussée, dans le local principal ${ }^{31}$. En revanche, dans la maison dite "de Pinarius Cerialis" (III 4, b), au moins un fuseau et trois fusaïoles ont été découverts ${ }^{32}$. Il est probable qu'ils constituent une production réalisée sur place: l'une des fusaïoles est inachevée, tandis que des déchets de débitage de métapodes de bœuf ont également été trouvés ${ }^{33}$. Ces exemples dispersés restent cependant moins intéressants que l'inscription provenant de la maison VI 13, 6.8-9. Sur l'une des colonnes du péristyle, une liste de douze lignes donne la comptabilité de produits confectionnés par dix personnes. Le texte est toujours conçu selon le même modèle: un nom, suivi de la mention d'un poids pensum - soit écrit $p e(n) s a$, soit abrégé $p(e n s a)^{34}$ - à laquelle trois termes peuvent être associés (trama, stamen ou suptemen $)^{35}$. Ces trois derniers indiquent

échantillon de trente maisons pompéiennes puis dans l'insula I 10.

${ }^{31}$ Inv. ${ }^{\circ} \mathrm{P} 1447 \mathrm{a}-\mathrm{b}$ et P1462.

${ }^{32}$ Le fuseau (Inv. ${ }^{\circ}$ P2734 a) a été découvert le 20 juin 1918 dans la pièce $\mathrm{D}$, tandis que les deux fusaïoles (Inv. $\left.\mathrm{n}^{\circ} \mathrm{P} 2721 \mathrm{a}-\mathrm{b}\right)$ ont été trouvées le 12 juin de la même année, dans la pièce $C$.

${ }^{33}$ Les déchets de débitage ont été découverts avec des charnières à des stades diversement avancés de fabrication (Inv. ${ }^{\circ}$ P2736) dans la pièce D, le 20 juin 1918. La fusaïole inachevée (Inv. $\mathrm{n}^{\circ} \mathrm{P} 2740 \mathrm{~b}$ ) trouvée le 10 juillet 1918 provient de la pièce I.

34 Sur l'abréviation de pensum en pe(n)sum, cf. Väänänen 1958: 68 .

${ }_{35}$ CIL IV, 1507: Vitalis trama pes V/Florentina pesa III / Amaryllis pes v trama et stamen / Ianuaria supte(men) pesa II (vel III) et sta(men) pes duas / Heracla pes Vstamen / Maria p(esa) III stamen / Lalage pes stamen / Ianuaria p(esa) II trama / Florentina pes $V$ trama / Damalis trama pes $V /$ Serv (o)la trama pes $V /$ Paptis (vel Baptis) pes V trama / Doris pes V stamen. 
des qualités de fil différentes, correspondant à la trame et à la chaîne, suptemen pouvant soit être un terme générique pour qualifier du fil, soit un synonyme de trame ${ }^{36}$. Comme souvent avec ce type de liste, il est impossible de déterminer la raison ayant poussé à son inscription et encore moins la durée sur laquelle ce relevé d'une production de fil s'étend. Dans cet exemple, la main d'œuvre est essentiellement féminine $^{37}$. En considérant que le décompte de production reporté constitue un ensemble clos, il est intéressant de signaler que le poids de fil de trame est supérieur à celui de fil de chaîne ${ }^{38}$. Si à travers cet exemple, certes ponctuel, une activité de filage impliquant une dizaine de personnes dans un espace domestique peut être induite, les éléments permettant de mesurer l'ampleur de tels procédés restent trop peu nombreux. En revanche, le tissage peut être perçu de façon moins sommaire.

IV.1.3 Les attestations de métiers à tisser à Herculanum et Pompéi

Parmi les débats qui ont fait couler le plus d'encre dans l'histoire des techniques textiles, le type de métier à tisser employé dans l'Antiquité romaine semble se situer aux meilleures places. De façon schématique, deux métiers auraient coexisté durant la période impériale. L’un comme

36 W. Moeller (1969: n. 29 p. 566) considère que suptemen est synonyme de trame, sans pour autant trouver d'explication à l'utilisation de deux mots pour désigner une production comparable.

${ }^{37}$ W. Moeller (1969: 566) considère que les dix noms indiquent tous des femmes. Il est délicat d'être aussi affirmatif, Vitalis et Baptis (ou Paptis) pouvant tout autant désigner des hommes. Il est également impossible de supposer l'existence d'une activité de tissage, effectué par des hommes, associée au filage comme cela a été proposé par W. Moeller (1976: 40), à la suite des lectures de M. Della Corte (1965: $\mathrm{n}^{\circ} 185$ p. 120-121). Cette interprétation se fonde sur la liste de noms masculins dispersée sur certaines colonnes du même péristyle (CIL IV, 1493-1506 et 1508-1509). Tous ces noms sont au mieux seuls, sinon accompagnés par la mention de leurs prouesses sexuelles. La faiblesse de cette reconstitution a déjà été soulignée par W. Jongman (1988: 163-164).

${ }^{38}$ La différence qualitative entre les deux types de fil peut tenir à leur grosseur respective. 27 poids de trame ont été filés, contre seulement 16 de chaîne. Si l'on considère que la première ligne, sans indication de nature, renvoie à l'autre sont dits "verticaux ${ }^{39}$. Dans le premier, dont l'apparition remonte au Néolithique, le métier est constitué de deux montants réunis à leur sommet par une barre; trois baguettes - l'une fixe, les deux autres mobiles - sont disposées à des hauteurs différentes pour fixer les fils verticaux de chaîne, les ouvrir pour le passage des fils de trame (baguette de séparation) et les ordonner (baguette de lices). Les fils de chaîne sont rassemblés et tendus par une série de pesons qui donnent leur nom à ce type de métier vertical ${ }^{40}$. À chaque passage de la navette, la barre de lices doit changer de position pour permettre l'alternance des nappes. Enfin, le tissage progresse du haut vers le bas (fig. 84). La principale différence avec le second type, qui est dit "à deux traverses horizontales", tient au système d'ourdissage de la chaîne. Les pesons ne sont plus nécessaires: le fil de chaîne est disposé en une longue spirale tubulaire entre les deux traverses ${ }^{41}$. Ce système permet de gagner un temps appréciable lors du montage du métier. Le métier à deux barres horizontales est d'une utilisation strictement verticale contrairement à son prédécesseur, nécessairement incliné et en appui contre une paroi. Ultime différence notable, le tissage s'effectue de bas en haut, ce qui permet à la personne travaillant au métier d'être assise (fig. 85) ${ }^{42}$. En déterminant le ou les type(s) de métier utilisé(s) à Herculanum et

du fil de chaîne, tout comme le terme suptemen, on obtient 21 ou 22 poids de ce type de fil. Il ne faudrait pas déduire de cette différence un rapport dans la densité de fils tissés.

${ }^{39}$ Cette appellation se fait par opposition au métier horizontal sur bâti dont l'apparition ne daterait que de l'Antiquité tardive. La mise au point la plus récente et la plus claire sur ce débat a été présentée par J.-M. Carrié (2004: 21-22) avec une importante bibliographie.

40 Ces métiers «à pesons» sont en fait utilisés à l'oblique, généralement appuyés contre un mur. L'étude la plus complète sur ce type de métier est proposée par M. Hoffmann (1983), en se fondant sur l'exemple ethnographique de la Norvège dans les années 1950. Voir également la description proposée par A. Ferdière (1984: 218-222) pour la Gaule centrale.

${ }^{41}$ Il est également possible de monter la trame sur une corde qui sera elle-même fixée à la seconde traverse. Cf. Cizuk - Hammarlund 2008: 124-125.

${ }^{42}$ Selon R.J. Forbes (1956: 202), le métier vertical à deux traverses horizontales serait venu en Occident depuis la Palestine, supplantant progressivement le métier à pesons. Le fonctionnement du métier vertical à deux traverses a 


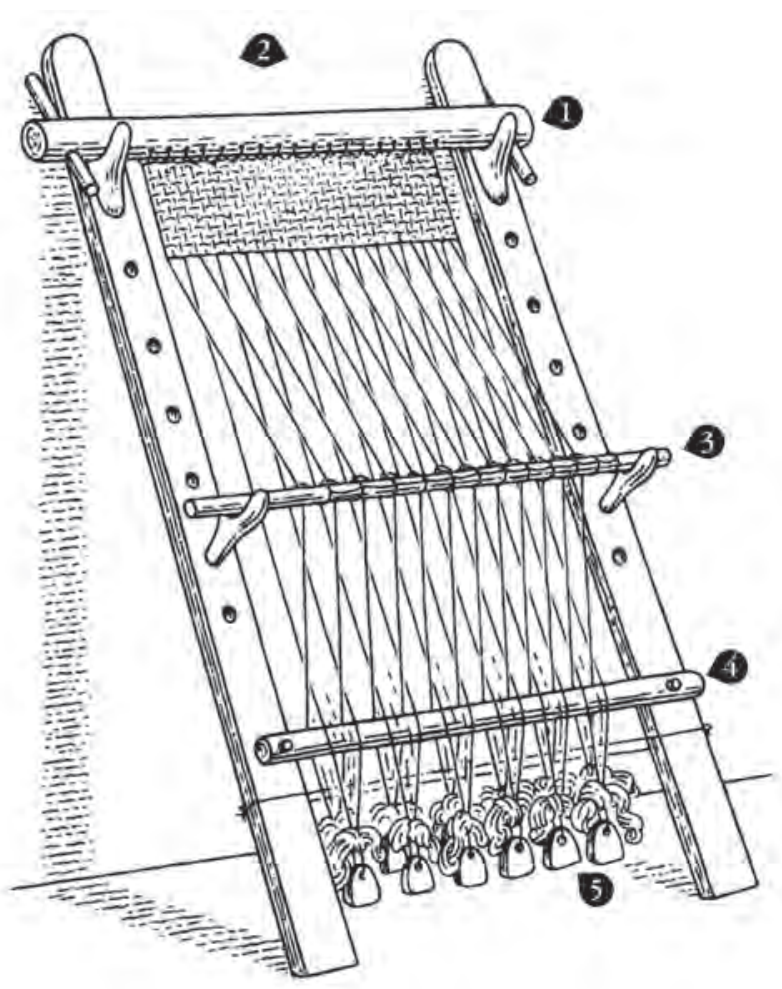

Fig. 84 - Nomenclature d'un métier vertical à pesons. (1): ensouple, barre horizontale soutenue par une fourche à laquelle sont fixés les fils de chaîne; (2): montants; (3): baguette de lice, sa translation permet d'ouvrir et de fermer les fils de chaîne pour laisser passer la navette; (4): baguette de séparation; (5): pesons.

Pompéi et en les localisant, il est possible d'avoir un aperçu des moyens de production textile dans ces deux villes.

À Herculanum, seuls deux possibles métiers à tisser ont été individualisés: le premier à partir de pesons de tisserands dans la boutique VII 1a, le second dans la Casa del telaio $(\mathrm{V}, 3)^{43}$. Une seule source crédible concerne ce dernier avant sa «restauration »: le dessin réalisé par F. Ferrajoli

été d'abord expliqué, à partir d'exemples ethnographiques et pour l'Âge du Fer danois, par M. Hald (1980: 210-217). Notons également que la description des différences de fonctionnement entre ces deux types de métiers telle qu'elle vient d'être faite est simplifiée à l'extrême. La mobilité et l'utilisation de la baguette de lices et de celle de séparation varient considérablement entre l'un et l'autre, bien que la nomenclature soit identique. Les explications les plus

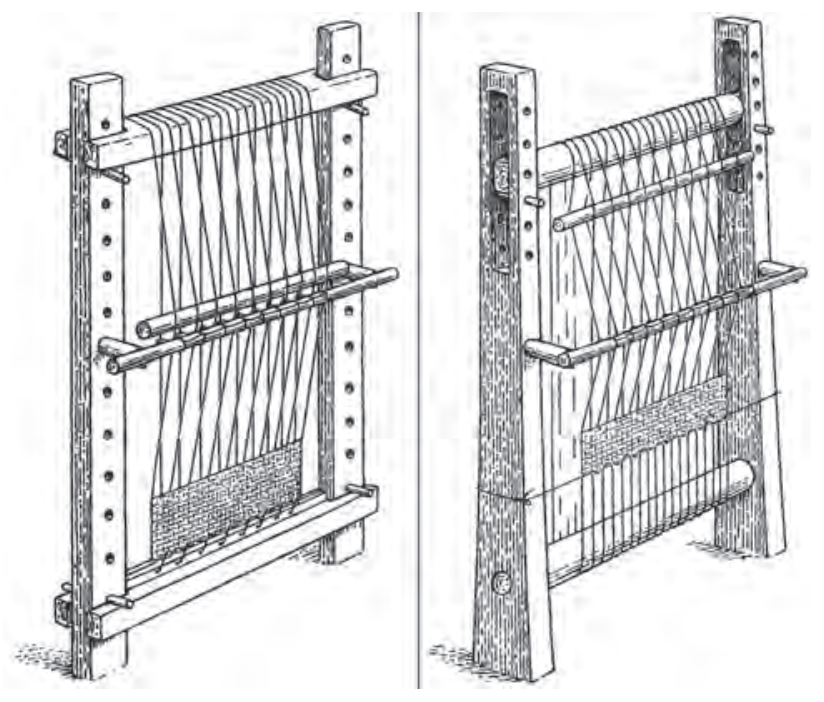

Fig. 85 - Deux types de métiers verticaux sans peson. La chaîne de celui de gauche est fixé à une cordelette, tandis que pour celui de droite, la chaîne est tubulaire; dans les deux cas, le tissage commence par en bas.

(fig. 86). Il s'agit d'un croquis schématique qui reporte la position respective des différentes pièces de bois découvertes ainsi que l'indication de leurs dimensions : les indications cotées alternent mètres et centimètres; les rapports de taille restent schématisés, particulièrement pour la profondeur. Huit pièces ont été dessinées. Les deux premières sont des montants verticaux dont la cotation n'est que partielle. Celui de droite a une section de $4 \times 10 \mathrm{~cm}$ et est percé de deux séries verticales de trous. Pour le second, seule la hauteur préservée est indiquée $(1,12 \mathrm{~m})$. Entre ces deux pièces se trouve une traverse, longue de 2,25 m, large $8 \mathrm{~cm}$ et dont l'épaisseur n'est pas précisée. Bien que les quatre traits délimitant sa face inférieure soient représentés, elle paraît s'encastrer dans le montant droit grâce à une encoche; le dessin manque ici de clarté; rien n'interdit formellement de considérer que cette

synthétiques sur le fonctionnement de différents types de métier ont été données par M. Ciszuk et L. Hammarlund (2008).

${ }^{43}$ Sur les vicissitudes du métier à tisser de la Casa del telaio, cf. supra, p. 20-22. Pour ce qui est des pesons de tisserands découverts dans la boutique VII 1a, leur nombre (8, cf. Ruggiero 1885: LI, 640, 656) paraît insuffisant pour aboutir à la restitution d'un métier à tisser. 


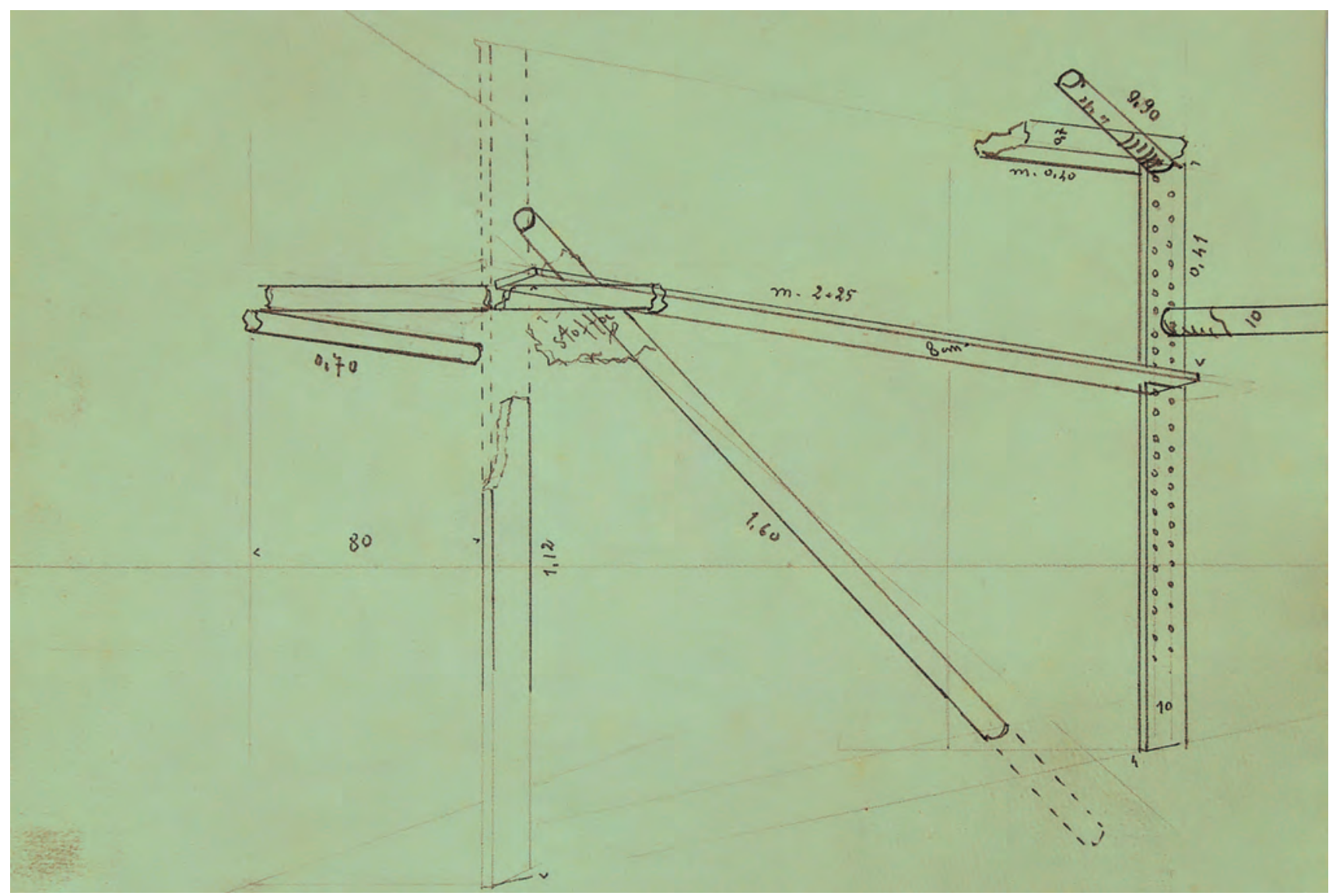

Fig. 86 - Dessin en perspective des restes d'un métier à tisser vertical, sans peson. Réalisé par F. Ferrajoli lors de la découverte à Herculanum dans la Casa del telaio (V, 3) en janvier 1933.

traverse se trouve en avant du montant droit. En considérant que le rapport de hauteur est juste, elle se situerait au-dessus de la partie conservée du montant gauche. Enfin, au sommet du montant droit se trouve une seconde barre large de 40 (?) $\mathrm{cm}$ et épaisse de $7 \mathrm{~cm}$ selon les indications reportées. Toutes les autres pièces sont de section circulaire, sans que leur diamètre ne soit indiqué. L'une d'elle, positionnée en biais, a une longueur conservée de 1,60 [m]. À son extrémité gauche est fixé un fragment d'étoffe. Une seconde baguette, brisée en trois morceaux se trouve en avant de la précédente. Une seule dimension est

44 Le premier est dépourvu de toute mention de longueur, tandis qu'une longueur de $9($ ?), $90 \mathrm{~cm}$, qui ne correspond pas aux proportions du dessin, est indiquée pour le second morceau. indiquée, pouvant correspondre à la longueur $(0,70[\mathrm{~m}])$ de l'un de ces fragments. Enfin, accolés au montant droit se trouvent deux autres morceaux de baguettes, l'un proche de la barre horizontale, le second à proximité du sommet ${ }^{44}$. La représentation de stries, qui pourraient être incisées sur ces deux fragments, permettrait de reconstituer une unique pièce. Ces différents éléments me paraissent représenter les restes d'un métier vertical à deux traverses horizontales. Une première indication tient à l'absence de signalement de peson ${ }^{45}$. L'état et la position des fragments permettent également cette inter-

${ }^{45}$ Cet argument doit être considéré avec précaution: le métier à tisser lui-même n'a pas été immédiatement signalé lors de sa découverte, mais seulement lors du résumé mensuel (cf. supra, n. 118 p. 20). De plus, un seul peson 
prétation. L'indice le plus probant tient aux deux montants qui semblent avoir été trouvés dans une parfaite verticalité: le métier à pesons était manipulé en position oblique, en appui contre une paroi. La baguette sur laquelle des fragments d'étoffe ont été trouvés serait alors la traverse inférieure. L'ensouple pourrait être constituée par la barre de section circulaire présentant des stries. Les encoches visibles dans le montant droit permettraient de déplacer la lice au fur et à mesure de l'avancement du tissage ${ }^{46}$. Ce très probable métier à deux traverses horizontales, correspond à la seule attestation du tissage à Herculanum: contrairement aux interprétations proposées par A. Maiuri, aucune trace de production textile n'a été mise en évidence dans la Casa delle stoffa (IV, 19-20), qui ne tire son nom que de la découverte de morceaux d'étoffe à l'étage ${ }^{47}$.

Avant de procéder à l'examen des attestations d'activités de tissage à Pompéi, il convient de confronter cette éventuelle attestation d'un métier à tisser à deux traverses horizontales

figure dans les inventaires d'Herculanum pour la période 1927-1961 (Inv. n E2115=77396, de provenance inconnue). Comme pour Pompéi, il est hautement probable que ces objets n'aient pas été mentionnés dans les comptes rendus de fouilles. En revanche, étant donné la largeur minimale de ce métier, indiquée par la longueur de la barre encastrée dans le montant droit $(2,25 \mathrm{~m})$, si il avait été de type «à pesons », une quantité importante de ces derniers auraient été mis au jour et - peut-on espérer - inventoriés.

${ }^{46}$ Une structure similaire, quoi que plus complexe, est visible sur le plus ancien métier vertical conservé (IX ${ }^{\mathrm{e}}$ siècle ap. J.-C.), trouvé à Oseberg (cf. Hoffmann 1983: fig. 137 p. 331). Pour des propositions de restitution de métiers à deux barres horizontales, cf. Wild 1970: 69-72.

${ }^{47}$ Maiuri 1958 b: 426. GSE 1931: «11 novembre. Nel terreno alto della casa n. 2 sul $4^{\circ}$ cardine lato ovest è stato raccolto: Stoffa. Vari pezzi ben conservati. Inventario $674[=75951] »$.

${ }^{48}$ "A way to account for the paucity of loomweights in Britain would be to argue that the two-beam loom began to displace, but not fully replace, the warp-weighted loom here by the second century. There is literacy authority for such a change in Italy» (Wild 2002: 11). Voir également, sans détail, Rast-Eicher 2005: 77.

${ }^{49}$ Sen., Ep., [14,] 90, 20: Ecce posidonius, ut mea fert opinio, ex is qui plurimum philosophiae contulerunt, dum vult describere primum, [...] deinde quemadmodum tela suspensis ponderibus rectum stamen extendat, quemadmodum subtemen insertum, quod duritiam utrimque conprimentis tramae remolliat, spatha coire cogatur et iungi, aux acquis sur ce point d'histoire des techniques. Traditionnellement, on considère que l'apparition de ce métier se substituant à celui à pesons remonte au courant du $\mathrm{I}^{\mathrm{er}} \mathrm{s}$. de notre ère $^{48}$, en se fondant sur un passage d'une lettre de Sénèque ${ }^{49}$. Dans celle-ci, le philosophe s'exprime sur la position des sages vis-à-vis des techniques; volontiers polémique, il cherche à différencier sa perception de celle de Posidonius d'Apamée. Il moque les descriptions techniques non actualisées de l'Apaméen - ce dernier ayant pu renvoyer à des détails archaïsants à dessein ${ }^{50}$ - en les comparant avec celle d'Ovide, qui aurait, elle, des traits 'modernes' ${ }^{51}$. Dans la logique du texte de Sénèque, le tissage tel que décrit par Ovide présenterait une «innovation technique» (subtilius genus). Si le poète ne mentionne pas, au contraire du philosophe, le montage des fils de chaîne sur les pesons, rien ne permet d'affirmer que l'évolution présentée soit celle de l'apparition du métier vertical à deux traverses horizontales. Bien au contraire, les deux vers précédents d'Ovide (Met. 6, 53-54) - non repris

textrini quoque artem a sapientibus dixit inventam, oblitus postea repertum hoc subtilius genus [...]

«Voici Posidonius, un des hommes envers qui la philosophie a, selon moi, le plus d'obligations: il décrit [...] comment ensuite la toile, à l'aide de poids suspendus, s'étire en une chaîne droite, comment la trame introduite pour amollir la tension de la chaîne qui la serre de part et d'autre s'unit et s'incorpore à elle par la pression de la lame; il conclut en attribuant au sage jusqu'à l'invention des procédés techniques de la tissanderie, oubliant qu'on a découvert depuis un mécanisme plus ingénieux » [trad. CUF].

${ }^{50}$ Chaumartin 1988: 25.

${ }^{51}$ La citation d'Ovide ici reportée est plus longue de trois vers - indiqués entre les accolades - que celle faite par Sénèque, probablement de mémoire, comme en témoigne la légère variation dans le texte (mentionnée en romain entre crochets droits). Ovid., Met. 6, 55-60): \{Haud mora, constituunt diversis partibus ambae/et gracili geminas intendunt stamine telas:/] tela iugo vincta est, stamen secernit harundo, / inseritur medium radiis subtemen acutis, / quod \{digiti expediunt, atque inter stamina ductum/percusso\} [lato] paviunt insecti pectine dentes.

"\{Aussitôt elles dressent, chacune de son côté, deux métiers et les tendent avec les fils déliés de chaîne;] le métier est joint à l'aide de la traverse; la lice [litt. le roseau] sépare les fils de chaîne; dans l'intervalle, à la suite de la navette aiguë, s'insère la trame, \{que dévident les doigts et qui, conduite à travers la chaîne, est\} serrée par les dents taillées dans le peigne, chaque fois qu'on le frappe » [d'après trad. CUF]. 
par Sénèque - peuvent s'interpréter comme le montage des fils de chaîne sur l'ensouple seule, reliés à des pesons non mentionnés, la seconde traverse étant alors celle décrite au v. 55, début de la citation de Sénèque. En ce sens, l'opposition montrée par Sénèque entre la description archaïsante de Posidonius et celle «moderne» d'Ovide porterait plus sur les outils associés au tissage: soit la navette que seul le poète évoque; soit, et cela semble beaucoup plus probable, celui servant à resserrer la trame - Posidonius mentionne un battant (spatha) tandis qu'Ovide décrit un peigne ${ }^{52}$. Si aucun de ces deux textes, par ailleurs datés autour du changement d'ère, ne semble renvoyer à un métier à deux traverses, un papyrus daté de 54 ap. J.-C. comporte la description de ce type d'appareil ${ }^{53}$. Certaines représentations iconographiques de la fin du $\mathrm{I}^{\mathrm{er}}$ siècle de notre ère indiquent également cet usage: le duel entre Arachné et Minerve illustré sur les frises du forum transitorium constitue la première et la mieux datée de ces figurations ${ }^{54}$. Le relief de Forlì, daté du $\mathrm{II}^{\mathrm{e}}$ siècle et généralement interprété comme représentant les activités d'un foulon, pourrait également montrer un métier à tisser à deux traverses, plutôt qu'un

${ }^{52}$ Sur la difficulté à reconnaître ces objets en fouille, cf. Wild 2002: 11 et n. 68-70.

${ }^{53}$ P. Oxy. II, 264 (cf. Johnson 1936: cat. $\mathrm{n}^{\circ} 300$ p. 475). Ce contrat de vente a pour objet un métier à tisser: deux

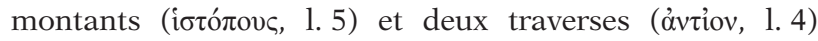
servent à le caractériser. L'absence de mention de pesons autorise à considérer ce métier à tisser comme vertical à deux traverses.

${ }^{54}$ Construit par Domitien, inauguré par Nerva, le forum transitorium présente, à son extrémité orientale un temple consacré à Minerve. Le duel de tissage entre la déesse et Arachné est figuré sur une frise; on y voit trois métiers à tisser. En outre, une quatrième représentation est détachée de la figuration du mythe. Cf. Wild 1970: 69; D’Ambra 1993 : 116-119, 123-125 et pl. 57-59, 74, 80.

${ }^{55}$ On comparera avec profit le relief de Forlì avec le relief de Sens qui représente bien, lui, une foulerie. Dans la moitié inférieure de ce dernier, un drap est disposé sur une traverse tenue par un poteau cranté; sa partie basse semble flotter, non retenue. En revanche, sur le relief de Forlì, le drap (le fil de trame?) forme comme une large courroie entre les deux traverses soutenues par deux poteaux. À gauche, le personnage, masqué en dessous de la taille, paraît manipuler ou montrer un tissu déployé devant lui. Quoi qu'il en soit, ses bras ne sont pas dans la position tendue du foulon qui cherche à se maintenir pendant le saltus fullonicus. Le seul élément pouvant éventuellement renvoyer à la foulerie est constitué séchoir à linge ${ }^{55}$. Pour conclure sur ce point, si des attestations, papyrologique et probablement archéologique à Herculanum, font du métier à tisser vertical à deux traverses une réalité du $\mathrm{I}^{\mathrm{er}} \mathrm{s}$. de notre ère, rien ne permet d'estimer sa période d'apparition, en Italie ou ailleurs. De plus, même une fois largement diffusé, il ne remplace pas complètement le métier à pesons ${ }^{56}$.

Cette cohabitation des métiers autorise donc, en dressant une cartographie des pesons, à obtenir un aperçu, même partiel, des activités de tissage dans les villes ensevelies par le Vésuve. Ce type d'objet prend généralement la forme de troncs de pyramide en terre cuite, de taille et de poids variable ${ }^{57}$. Si leur usage le plus commun, tendre les fils de chaîne, ne soulève guère de question, un point cependant doit être noté. Lors du fonctionnement du métier, les pesons sont disposés sur au moins deux rangées, de façon à séparer les fils pairs et impairs de la chaîne. Il n'est pas possible de considérer qu'un seul peson permette de mettre en évidence un métier à tisser ${ }^{58}$. Dans le cas de Pompéi, où, en dépit des perturbations diverses, on peut s'attendre à retrouver tous les pesons d'un métier, un nombre minimal - arbitrairement fixé à 20 - doit

par la cage tressée située en haut du relief mutilé. Voir Zimmer 1982: cat. n 43 p. 128-129; Lovén 2001: 48-49. L'un comme l'autre supposent une activité de foulerie, reprenant en cela l'interprétation proposée par G. Susini (1958: 202-205).

56 Wild 2008: 470-472. Pour la bibliographie concernant la disparition progressive des pesons dans l'Occident romain, cf. Wild 2002: n. 72 p. 11.

${ }^{57}$ Les découvertes de pesons seraient relativement nombreuses selon A. Ferdière (1984: 222), tempéré par J.-C. Béal (1996: n. 7 p. 122). Toutefois, dans les publications les concernant, la supposée banalité de ces objets fait qu'ils ne sont que rarement décrits et encore moins pesés. L'existence de formes et de modules différents apparaît très nettement (cf. Ferdière 1984: 222-223). Il convient de noter que, si le tronc de pyramide est la forme la plus fréquente pour la période romaine, d'autres existent.

58 Dans son ouvrage sur les maisons pompéiennes, P. Allison (2004: 146-148) considère que des activités de tissage se sont déroulées dans 18 des demeures qu'elle a étudiées, parmi 20 montrant des objets liés au textile (sur un échantillon de 31). Pourtant, l'examen détaillé du nombre de pesons trouvés permet de réfuter cette assertion. À trois exceptions près (VI 16, 19.26-27 - 60 pesons; I 10, 8 - 53 pesons; VI 15, 8 - 54 pesons), toutes les autres maisons n'ont livré que de maigres concentrations, plus souvent des découvertes isolées. Ces dernières seraient à reprendre pour déterminer la fonction de ces pesons hors de leur usage premier. 
avoir été découvert dans une pièce pour caractériser une véritable fonction dans la production textile ${ }^{59}$. D'une façon générale, de telles concentrations dans une même pièce sont particulièrement rares. Les livres d'inventaire dressant la liste des objets conservés à Pompéi, essentiellement pour la période entre 1890 et les années 1960, ne mentionnent au total que 177 pesons, recouvrant 90 numéros d'inventaire. Au-delà des mentions de pesons isolés, les seuls groupes proviennent de la fouille de la décharge située au sud-est de l'îlot VIII 2, à l'extérieur de la ville ${ }^{60}$. Dans les fouilles plus anciennes, les mentions des pesons sont également rares ou floues: " una quantità di pesi da telaio » a été découverte dans la cuisine de la maison IX 7, 19 en 1881, mais sans précision quant au nombre ${ }^{61}$. Dans la description qu'il donne des objets découverts au cours des fouilles entre 1862 et 1873, G. Fiorelli n'indique aucun peson céramique parmi les «arnesi, serviti alle transazioni dei pubblici e privati negozi ${ }^{62}$. Cependant, le plomb apparaît comme une alternative à la terre cuite: ces pesons en forme de tronc de pyramide ont suscité la curiosité à la fin du $\mathrm{XIX}^{\mathrm{e}}$ siècle en raison des inscriptions que certains présentent sur leurs faces. Des trois séries mises en évidence, deux sont mentionnées dans le Corpus: la première porte les inscriptions $E M E$ ( «achète moi») et HABBEB [IS] ( "tu m'auras»), écrite de trois façons différentes (fig. 87); la seconde FVR CAVE // MALVM («voleur, crains le mauvais œil ») ${ }^{63}$; la troisième
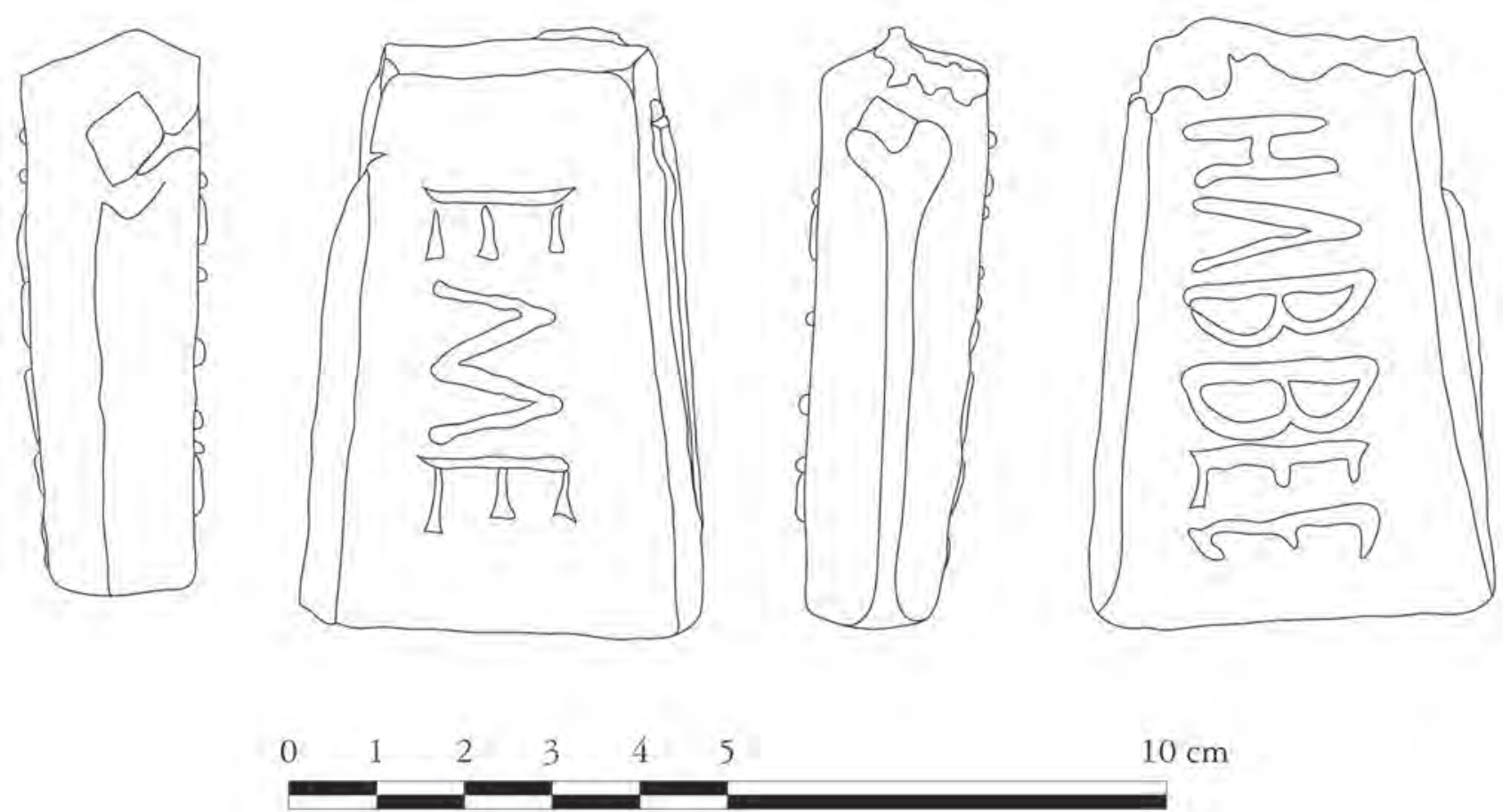

$10 \mathrm{~cm}$

Fig. 87 - Peson en plomb provenant de la maison I 9, 10. L'inscription $E M E$ / HABBEB[IS] inciterait à l'achat, probablement du tissu confectionné grâce à ce type de pesons.

\footnotetext{
${ }^{59}$ Dans sa remarquable analyse des restes d'un métier à tisser datant du Hallstatt B (-1100/-700) découvert à Gars Thunau (A) à partir de la position de 36 pesons, I. Schierer (1987: 29-37) dresse un catalogue des exemples similaires: la découverte de deux groupes de quatre pesons à Oberleiserberg (A) est exclue des métiers à tisser, (Schierer 1987: 39), tandis que celle de 20 pesons pyramidaux à Marbøgger (DK) est incluse (Schierer 1987: 40).

${ }^{60} 70$ pesons y ont été découverts, en 6 groupes distincts (Inv. $\mathrm{n}^{\circ} \mathrm{P} 8760-8778,8821-8835,8876-8885,8897-8914$, 8968-8977, 9273-9278).
}

${ }^{61} \mathrm{NSc} 1881: 196$.

${ }^{62}$ Fiorelli 1873: 169-172. En revanche, 211 pesons en plomb sont indiqués (ibid., p. 170).

${ }^{63}$ Le volume $\mathrm{X}$ du $C I L$ donne trois formes de cette inscription: EME//HABEBIS (CIL X, 8067.5.c.d), EME//HABEBBI(s) (CIL X, 8067.5.e.f.h) et EME//ET HABEBIS (CIL X, 8067.5.g). Ces variations ne sont pertinentes qu'à un changement de moule. CIL X, 8067.6 a: (f) VR.CAVE // ( $m$ ? $)_{A L V M}(M A N N$, Inv. $\mathrm{n}^{\circ} 64521$ et 74520$)$ et $C I L \mathrm{X}, 8067.6$ b: FVR.CA(ve) // MALV (m) (GSPomp, n.s. 3, 1877: 137). 
reste inédite et mentionne l'atelier de production: EX OFF. M. // BADELVS. Diverses interprétations ont été données pour l'utilisation de ces pesons. La première a été proposée par S. De Luca: selon lui, la grande variabilité de masse empêche de les considérer comme adaptés à la pesée avec une balance, tandis que la présence d'un trou longitudinal permettant le passage d'un fil et la suspension indiquerait soit des fils à plomb, soit des enseignes ${ }^{64}$. Th. Mommsen a considéré que la masse des pesons est trop éloignée de la livre romaine $(327,45 \mathrm{~g})$ pour qu'ils ne correspondent pas à une utilisation de la mine attique $(436,6 \mathrm{~g})$. Face à la distorsion entre le poids mesuré et la valeur théorique de la mine attique (près de $60 \mathrm{~g}$ ), l'article est conclu par une évocation peu amène de la malhonnêteté des boutiquiers romains ${ }^{65}$. Une dernière contribution à ce débat a été fournie par E. Pernice qui réfute tous les arguments précédents et qui, partant de la constatation non justifiée que l'ensemble de ces pesons auraient été découverts dans des boutiques, en conclut à des sceaux dont les inscriptions seraient autant d'avertissements ou d'incitations à l'égard de la clientèle ${ }^{66}$.

Deux découvertes permettent de définir le rôle de ces poids en plomb. La première a eu lieu dans une pièce à l'angle nord-ouest l'atrium de la maison VI 16, 19.26-27. Le même jour, 32 pesons de même forme mais sans inscription y ont été découverts, accompagnés par 28 pesons en terre cuite ${ }^{67}$. Une telle concentration, en dépit du mélange des matières, ne peut qu'indiquer un métier à tisser. La seconde découverte effectuée dans la boutique I 6, 10 est encore plus précise et concerne des poids portant pour partie l'inscription EME // HABEBIS. Dans la description qu'il

${ }^{64}$ De Luca 1866: 68-70. Il évoque rapidement la possibilité que ce soient des contrepoids utilisés dans le tissage et propose également qu'ils aient servi à tracer des lignes sur les murs. Dans un second article publié quelques années plus tard, il soumet les mêmes interprétations et signale sa surprise lors de la mise au jour d'un peson en terre cuite (De Luca 1880: 413-417).

65 "Schlechte und nicht zum Vortheil des Käufers gereichende Justierung ist allen römischen Budengewichten eigen» (Mommsen 1881: 318).

${ }^{66}$ Pernice 1890: 44-45. Ces variations dans les usages prêtés à ces objets pourraient être dues à la compréhension tardive du rôle des pesons, même en terre cuite. Selon

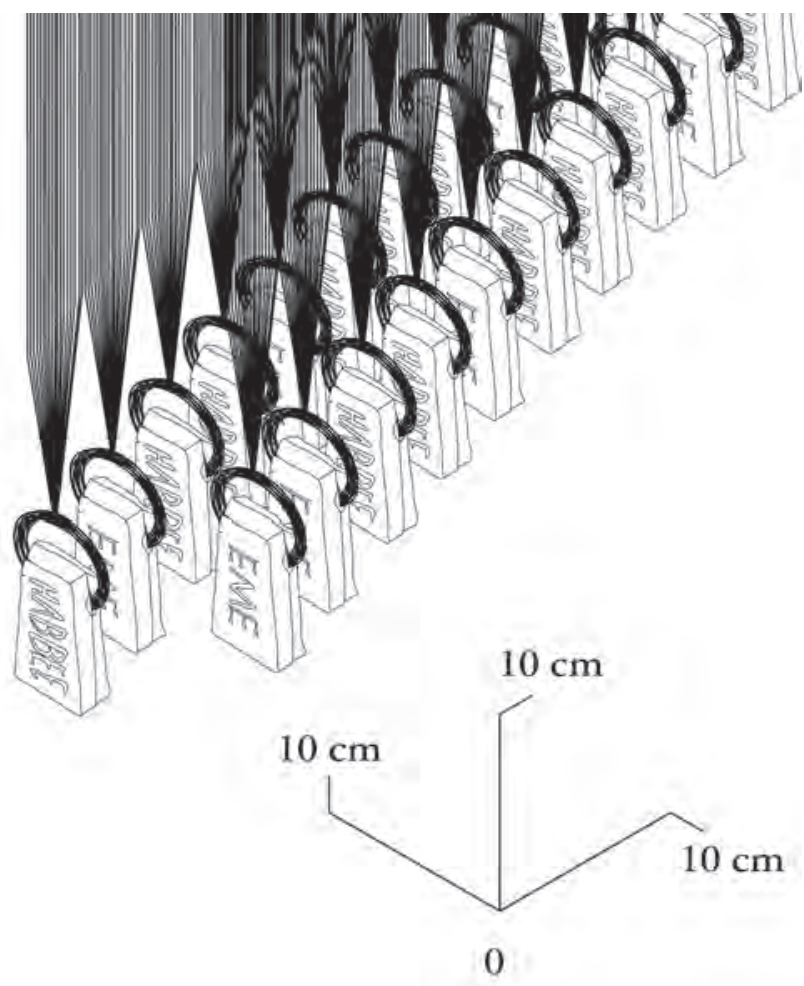

Fig. 88 - Proposition de restitution isométrique de la disposition des pesons en plomb employés dans un métier à tisser. L'écartement des pesons est hypothétique. On note que, grâce à cette disposition, l'inscription reste lisible (échelle 1/5).

en fait dans les Notizie degli scavi, A. Maiuri rend compte de la disposition des restes d'un métier à tisser tels que fossilisés par l'éruption du Vésuve (fig. 88) ${ }^{68}$. En dépit de cette remarquable découverte pour laquelle est soulignée la linéarité de la disposition des pesons - ne manque que le détail
A. Ferdière (1984: 223), ce ne serait qu'à la fin du XIX ${ }^{\mathrm{e}}$ que leur utilisation au cours du tissage aurait été fixée.

${ }^{67}$ Ces 60 pesons ont été mis au jour le 21 décembre 1904 ; ils ne sont pas mentionnés dans les NSc (1908: 184 sq.). Ceux en plomb ont d'abord été inventoriés sous le $\mathrm{n}^{\circ} 3585$ (Inv. $\mathrm{n}^{\circ} \mathrm{P} 56118-56149$ ), ceux en terre cuite sous le $\mathrm{n}^{\circ} 3584$.

68 «Nello scavo completo della bottega e del retrobottega si raccolse la seguente suppellettile: [Inv. $\left.\mathrm{n}^{\circ} \mathrm{P}\right](4097)$ una lunga serie di pesi di piombo (n. 72) di forma trapezoidale si rinvenne quasi regolarmente allineata lungo il lato orientale della bottega $\mathrm{m}$, come se fosse originariamente sospesa ai due lati del bancone di legno che doveva occu- 
indiquant la présence de deux rangées ou plus -, il serait possible d'objecter que ces pesons en plomb sont trop lourds pour un tel usage. Cependant, le poids absolu des pesons n'est pas un argument pertinent: l'important est que les fils soient tous soumis à une tension équivalente; en accrochant plus de fils aux pesons en plomb, on peut obtenir une tension par fil comparable à celle résultant de l'emploi de pesons céramiques. De la même façon, les variations de poids qui ont permis les spéculations sur l'usage de ces pesons ne constituent pas une gêne dans leur emploi dans un métier à tisser. L'exemple ethnographique scandinave montre que si le poids des pierres utilisées comme pesons est mesuré avant d'installer le métier, il ne s'agit que d'une estimation pour obtenir une bonne répartition de la tension des fils entre la rangée avant et la rangée arrière, sans avoir besoin d'une équivalence au gramme près ${ }^{69}$. Bien au contraire, la relative standardisation des pesons en plomb permet de réduire les écarts de poids et donc de simplifier l'installation des fils de chaîne ${ }^{70}$. Un

pare quel lato della bottega. Ciascun peso è forato superiormente; misura metri 0,065 x m.0,042, e varia dal peso di gr. 396 al peso di gr. 356 ; su alcuni pesi si legge a caratteri molto corrosi da uno dei lati, la consueta iscrizione: EME » (NSc 1929: 402). La lecture des GSP (1927: 15 settembre) ne donne pas ces précisions: les objets découverts ce jour sont énumérés sans aucun détail de localisation. Cependant, avec la première découverte, effectuée en 1912, de huit pesons, il est possible d'avancer que le métier à tisser se trouvait contre le mur occidental: "A circa $1 \mathrm{~m}$ dalla soglia e verso lo stipite destro, nel vano n. 10, si sono trovati otto panelli di piombo, di forma rettangolare rastremata, alti m. 0,065 , forati nel lato più corto per tenerli sospesi » (NSc 1912: 217).

69 "The stones varied in weight and size from five to eighteen marks (250 gm). An old steelyard was brought in, and every stone weighed. There had to be two stones of approximately equal weight to maintain a balance between the front threads and the back threads» (Hoffmann 1983: 42).

${ }^{70}$ La pesée de 35 des 41 pesons découverts en I 9, 10 (Inv. P9919) donne une variation de poids de 353 à $390 \mathrm{~g}$ (moyenne: $375 \mathrm{~g}$; écart type: $10 \mathrm{~g}$ ). Pour les 36 pesons de Gars Thurnau, pesés par I. Schierer (1987: 32-37), la variation de poids est de 80 à $304 \mathrm{~g}$ (moyenne: $209 \mathrm{~g}$; écart type: $48 \mathrm{~g})$.

${ }^{71}$ La majeure partie de ces sites a été trouvée en consultant les livres d'inventaire conservés à Pompéi. Les autres ont été répertoriés au gré de la consultation des archives les plus anciennes, en particulier la $P A H$. Ce dépouillement, encore non exhaustif, permettra à terme de compléter ce premier relevé - encore partiel - de telles séries de pesons en plomb, inscrits ou non, permet d'identifier seize métiers à tisser à travers Pompéi (fig. 89) ${ }^{71}$. Parmi ces séries, une seule, provenant de la maison VI 16, 19.26-27, est de composition mixte, mélangeant les pesons en plomb à ceux en terre cuite ${ }^{72}$.

Certains graffites semblent également indiquer des ateliers de tissage. Parmi les séries d'inscriptions renvoyant à de telles activités, une seule constituerait un indice d'artisanat textile. Sur le mur sud du péristyle de la Casa dei capitelli figurati (VII 4, 29.57), trois graffites se succèdent à une vingtaine de centimètres d'intervalle. Tous sont conçus selon le même modèle: un nom, au génitif sauf faute de déclinaison, suivi du terme locus $^{73}$. La seule mention permettant de rattacher cette série d'emplacements nominatifs à l'activité textile est l'inscription TEXE qui précède l'une de ces indications, selon C. Zangemeister ${ }^{74}$. En revanche, les graffites découverts dans la maison I 10, 8 ne doivent pas, contrairement aux propositions de M. Della Corte, être néces-

premier aperçu. La localisation de ces métiers est donnée ci-après, avec soit la date de découverte, soit la référence bibliographique, suivie par le nombre de pesons.

I 2, 27-29 (GSPomp n.s. 3, 1874: 93; 30); I 6, 10 $(13 / 05 / 1912$ et $15 / 09 / 1927 ; 80)$; I $9,10(23 / 12 / 1952 ; 41)$; I $10,8(02 / 11 / 1932 ; 53)$; I 13, $02(14 / 12 / 1955 ; 50) ;$ II 3,3 (13 et $16 / 01 / 1953 ; 33)$; III 4 , a/b $(12 / 06 / 1918 ; 41) ; \mathrm{V} 4,13$ (23/05/1903; 42); VI 1,7 (?) (PAH I, $1: 248 ; 38)$; VI 9, 7 (BdI 1830: 121 et $P A H$ II: 236); VI 15, 8 (30/03/1898; 54); VI 16, 19.26-27 (21/12/1904; 32); VII 9, 47(PAH II: 28 et PAH III: 26; 20); VII 15, 8 (GSPomp n.s. 2, 1873 : 416; 50); VII 16,19 (16/01/1962; 37); IX 2, 5 (GSPomp n.s. 2, 1873: $170 ; 36)$.

${ }^{72}$ Selon les NSc (1906: 186), les deux séries de pesons ont été découvertes le 22 décembre 1904 dans la pièce $\mathrm{E}$ de la maison VI 16, 19.26-27 (cf. NSc 1906: fig. 1 p. 181). La date de découverte diffère d'un jour dans les livres d'inventaire. Les pesons en plomb ont été inventoriés 3584 lors de leur mise au jour, puis inventoriés de nouveau sous les numéros P56118 à P56149. Les pesons céramiques (inventaire originel 3585) n'ont pas bénéficié de ce nouvel inventaire, ils sont considérés comme manquants.

${ }^{73}$ CIL IV, 1569: TIBVRTINVS LOCVS; 1571: ERATI LOCVS; 1572: CRESCENTIS LOCVS.

${ }^{74}$ CIL IV, 1570. Dans son commentaire, C. Zangemeister indique: "Locus texenti assignatus videtur intelligendus esse ». Selon la description de cette maison rédigée par M. F. Avellino (1837: 31-32, 62-76), aucun objet n'a été mis au jour dans cette portion du péristyle. Sur cette inscription, voir les remarques sceptiques de W. Jongman (1988: 164). 


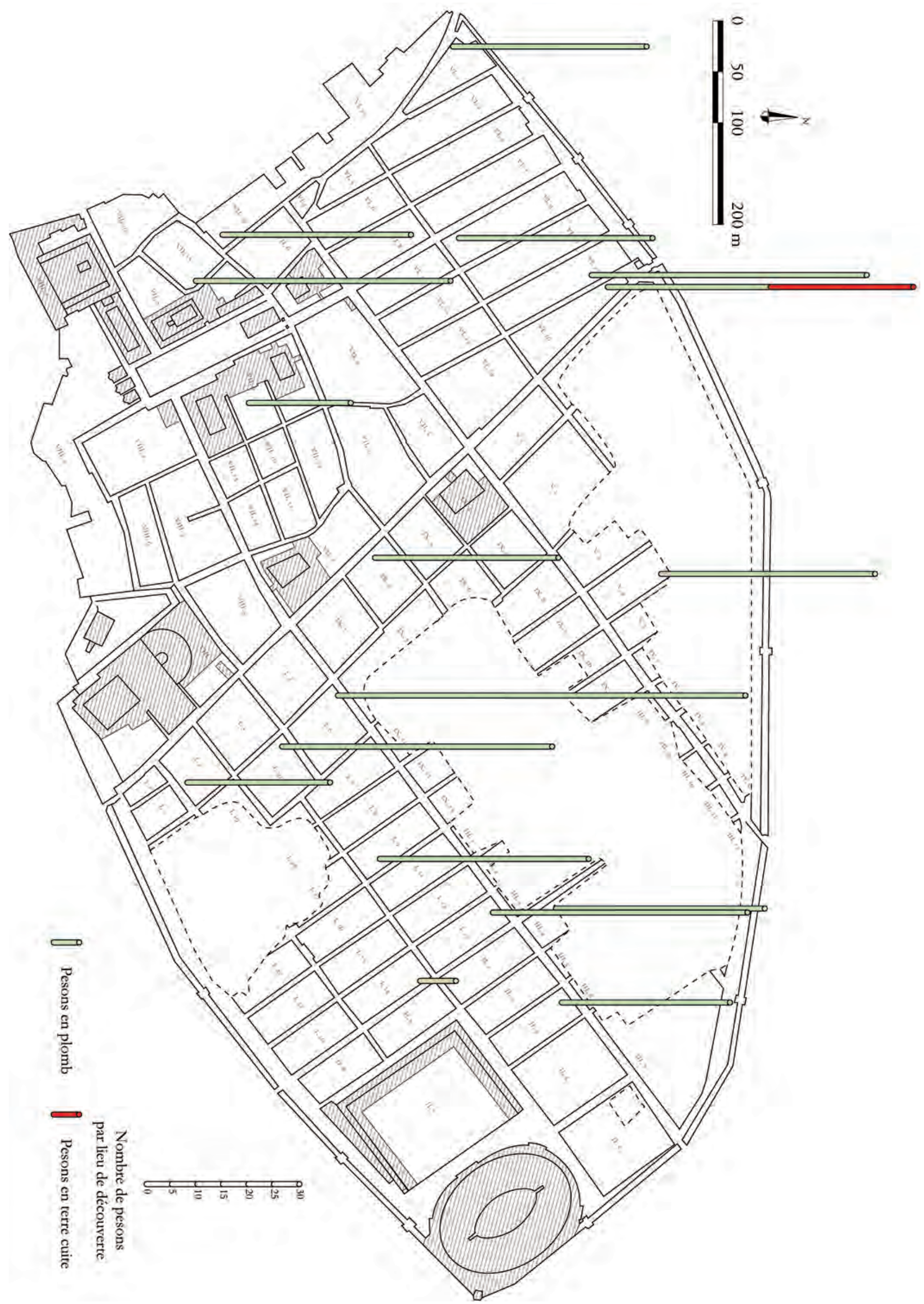

Fig. 89 - Répartition des groupements de pesons en plomb, parfois associés à des pesons en terre cuite, pouvant indiquer des métiers à tisser à Pompéi (échelle: 1/5000). 
sairement associés aux tisserands œuvrant sur le métier à tisser dont 53 pesons en plomb ont été retrouvés ${ }^{75}$. En effet, ces inscriptions ont été gravées sur les parois de la pièce 3, située au nord-est de l'atrium, tandis que les pesons ont été mis au jour un mètre à l'ouest de l'impluvium $^{76}$. Deux autres ateliers de tissages sont supposés se trouver en IX 12, 1-2 et IX 12, 3-577. Les arguments permettant d'aboutir à une telle conclusion sont pourtant maigres. En façade de IX 12, 1-2, sous une représentation de Mercure, se trouverait - avec une erreur probable - un graffite rappelant le début d'un tissage ou d'un filage $^{78}$. À l'intérieur, sur le mur ouest de cette boutique, le prix d'une tunique, probablement achetée, la veille des Nones de juillet ${ }^{79}$. La représentation de Mercure en façade ne peut pas être associée à un commerce particulier et le graffite inscrit en dessous de celle-ci ne saurait être considéré comme rédigé par l'artisan ou le commerçant travaillant dans ce local ${ }^{80}$. Enfin, les mentions d'achat de tunique se trouvent également dans des locaux sans rapport avec le textile $^{81}$. En ce qui concerne la maison voisine IX 12, 3-5, le seul argument étant la similitude avec IX 12, 1-2, il convient de ne pas la prendre en compte parmi les ateliers textiles ${ }^{82}$.

\section{IV.1.4 Bilan sur la production textile}

Les remarques qui précèdent expliquent pourquoi la production textile est si difficile

${ }^{75}$ CIL IV, 8380-8381, 8384. Cf. NSc 1934: 317 et Della Corte 1965: n607-613 p. 301. Rien ne permet d'affirmer comme le fait W. Moeller (1976: 39) que les noms inscrits correspondent à des textores ou à des quasillariae. Sur ces pesons, voir également Allison 2006: cat. $\mathrm{n}^{\circ} 1599$. Les GSP (1932: 28 novembre) et les livres d'inventaire indiquent 53 pesons; 57 sont actuellement inventoriés sous le $\mathrm{n}^{\circ} \mathrm{P} 5165$.

${ }^{76}$ GSP 1932: 28 novembre.

${ }^{77}$ Della Corte 1965 : n 656 p. 321-322.

${ }^{78}$ CIL IV 9109: scripsi coeptum stamen decembre, VII K(alendas) Ianuarias. La première publication de ce graffite indique qu'il a été trouvé sur le montant droit de la boutique I 6, 1 (NSc 1912: n 72 p. 222).

Sur la fresque en façade de IX 12, 1-2, cf. Spinazzola 1953: 166 et fig. 206 p. 167.

${ }^{79}$ CIL IV, 9108: Prid(ie) nonis Iulis tunica SH XV.

${ }^{80}$ Par ailleurs, les objets découverts à l'étage ne correspondent pas, contrairement aux suppositions de M. Della Corte (1965: 321-322), à des éléments associés au travail à comprendre. Le filage n'a laissé que peu de traces, exception faite de certains artefacts dont l'inventaire doit encore être dressé et la localisation déterminée. Toutefois, l'exemple des inscriptions trouvées dans le péristyle de la maison VI 13, 6.8-9 indique que le filage, "goulot d'étranglement de la production textile » pour reprendre les mots de J.-P. Wild ${ }^{83}$, pouvait donner lieu à une élaboration urbaine, que je me garderai bien de qualifier quantitativement. En ce qui concerne le tissage, l'interprétation du métier à tisser de la Casa del telaio $(\mathrm{V}, 3)$ à Herculanum comme un métier vertical à deux barres transversales a des conséquences mitigées. Du point de vue de l'histoire des techniques, cela renforce les attestations papyrologiques montrant une utilisation de ce type de métier dès la première moitié du $\mathrm{I}^{\mathrm{er}}$ siècle de notre ère. En revanche, pour l'identification des espaces de production textile, cette interprétation ne peut amener qu'à un constat simple: il ne sera jamais possible d'avoir une estimation correcte du nombre de métiers à tisser en fonction à Pompéi en 79. L'utilisation simultanée de métiers à pesons ne pallie pas ce manque: les pesons en terre cuite ont été trop mal consignés dans les rapports de fouilles pour permettre une approximation de leur répartition dans la ville. L'inventaire des pesons en plomb autorise - en l'état actuel de son avancement - à identifier 16 métiers à tisser. Si seulement trois d'entre eux se trouvent dans des édifices à destination commerciale - les boutiques I 6, 10,

du textile, à l'exemple de l'imposante volière provenant du balcon (NSc 1912: 102-103). Seul un peson a été trouvé à l'étage (NSc 1912: 146).

${ }^{81}$ CIL IV, 10664 : III idus Septembr(es) pro tunica (empta) (denarium) I a(sses) VII. Ce graffite a été lu dans l'atelier Or. II, 10 à Herculanum. Pourtant, les activités se développant dans cet espace n'ont aucun rapport avec le textile: considéré comme gemmarius par A. Maiuri (1958 b: 463464), le matériel découvert et la comparaison avec la maison de Pinarius Cerialis à Pompéi (III 4, b) laissent en revanche supposer une activité plus générale, liée à la manipulation d'un tour, allant de l'incision de pierres semi-précieuses à la production d'objets tournés, en os (Inv. n ${ }^{\circ} 2736$ en particulier) ou en nacre (Inv. ${ }^{\circ}$ E1643=76921).

${ }^{82}$ Della Corte 1965: nº 657 p. 322; Moeller 1976: 4041.

83 "Spinning, in fact, was a production bottleneck» (Wild 2002: 8). 
VI 16,19 et IX 2, $5^{84}$ - la localisation des autres ne permet pas de trancher la question de la production domestique à possible vocation commerciale ou purement commerciale. Faute de pouvoir déterminer le nombre de personnes impliquées dans ce type de travail, que ce soit par l'épigraphie ${ }^{85}$, ou par la répartition des métiers à tisser, la réponse à un tel problème ne saurait être apportée. Comment proposer un seuil à partir duquel un métier installé dans un atrium, un péristyle ou une cour $-88 \%$ des cas relevés - perd son statut d'activité domestique pour devenir une entreprise commerciale? La seule solution pour comprendre l'étendue de la production textile dans les villes ensevelies par le Vésuve est de quantifier la place, la répartition et l'importance des officines consacrées au lavage des toisons. En effet, ce travail est non seulement primordial, mais il a également laissé des traces nombreuses et assez aisément reconnaissables, particulièrement depuis les travaux de W. Moeller et de Ph. Borgard.

\section{IV.2 Teinturerie et confection du feutre à travers deux exemples d'Herculanum}

La teinture peut se dérouler à trois moments différents de la transformation de la laine en vêtement: soit directement sur la toison propre, donc immédiatement après le passage de cette dernière dans une laverie, soit après le filage, soit après tissage. En revanche, les attestations concernant la confection du feutre sont beaucoup moins nombreuses. Toutefois, comme l'un des ateliers d'Herculanum pourrait avoir eu ces deux fonctions, il m'a paru opportun de traiter ces deux types d'officines ensemble, malgré leur absence de conjonction a priori.

IV.2.1 Teinture et feutre: les ateliers de Pompéi

Les études de $\mathrm{Ph}$. Borgard ont montré la différence existant entre les officines effectuant une teinture ex novo et celles se contentant de

${ }^{84}$ Selon le GSPomp (n.s. 2, 1873: 170), 36 pesons en plomb ont été découverts dans l'arrière-boutique de IX 2, 5 ( Stanza in fondo alla bottega segnata col n. 52 sulla Stabiana »).

${ }^{85}$ Les estimations de W. Moeller (1976: 81), qui estime entre 700 et 1000 personnes le nombre d'individus impli- rafraîchir les teintes. Les premières doivent être qualifiées d'officinae infectoriae, teintureries de grand teint, tandis que les secondes sont des offcinae offectoriae, teintureries de petit teint. Les aménagements de ces types d'ateliers diffèrent sensiblement. Ainsi, dans les officinae infectoriae, l'une des chaudières est toujours différente des autres par sa taille - supérieure - et par sa position isolée (fig. 90). Il s'agirait de cuves de mordançage, qui permettent de préparer les fibres aux opérations de teinture. Les exemples pompéiens montrent que ce type de cuve est remarquablement standardisé dans sa conception. Elles se présentent en général sous la forme d'un cylindre maçonné à l'intérieur duquel des supports en briques permettent de soutenir une cuve en plomb au-dessus de la chambre de chauffe. Les autres chaudières de ces locaux sont construites de la même façon, mais sont de taille plus réduite et regroupées. En outre, dans certaines des teintureries de grand teint, il est possible de mettre en évidence des chaudières de forme tronconique et non cylindrique. Il s'agit d'aménagements destinés à des teintures par fermentation - e.g. pourpre, indigo - nécessitant un apport moindre de chaleur mais une plus grande interaction avec l'air. Dans les teintureries de petit teint, on retrouve des chaudières cylindriques semblables à celles des officinae infectoriae, mais regroupées par deux ou trois (fig. 91). Pour résumer ces données proprement pompéiennes, les ateliers de teinture de grand teint disposent d'une grande chaudière cylindrique de mordançage, éventuellement d'une chaudière pour la teinture de fermentation, et d'une série de trois chaudières pour la teinturerie de petit teint. Les officinae offectoriae se caractérisent quant à elles par des groupes de deux ou trois chaudières, sans que des cuves de mordançage ou de teinture par fermentation ne soient présentes. Dans chacun de ces types d'établissement, on trouve également des vasques maçonnées permettant probablement le rinçage des toisons ou des pièces de tissus après leur teinture ${ }^{86}$.

qués dans cette production, ont été critiquées sur des fondements raisonnables avec beaucoup de justesse par W. Jongman (1988: 161-165).

${ }^{86}$ Ces éléments permettant de caractériser les différents types de teinturerie en fonction des aménagements dont elles disposent sont tous issus des articles de $\mathrm{Ph}$. Borgard 


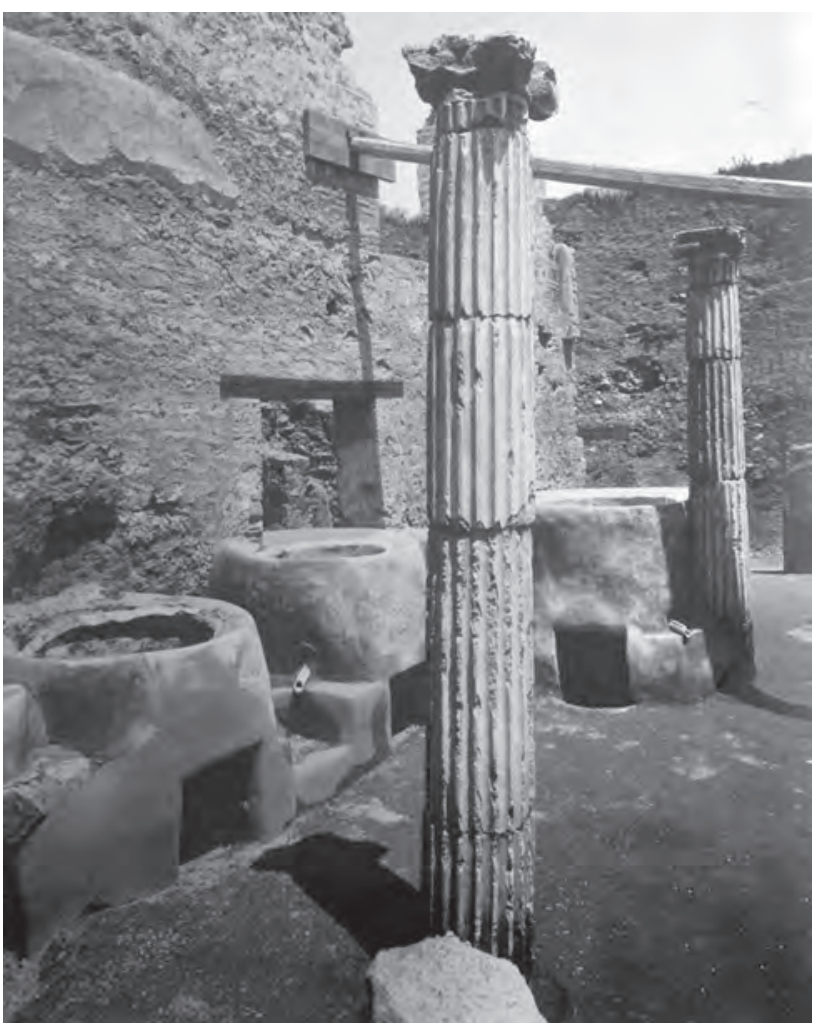

Fig. 90 - Teinturerie à Pompéi (I 8, 19). Dans cette officine de teinture de grand teint, la cuve de mordançage est repérable par son isolement - à droite - et par ses dimensions supérieures aux trois autres qui sont groupées.

En ce qui concerne les ateliers de feutre, leur identification est beaucoup plus délicate. Le feutrage s'obtient en entremêlant des fibres de laine à la force des mains. L'humidité et la chaleur permettent de faciliter ce processus d'agglomération des fibres entre elles ${ }^{87}$. L'unique mention littéraire des procédés de fabrication vient de Pline l'Ancien:

La laine pour elle-même permet de faire des habits de feutre, et, si l'on ajoute du vinaigre, ces dernières résistent

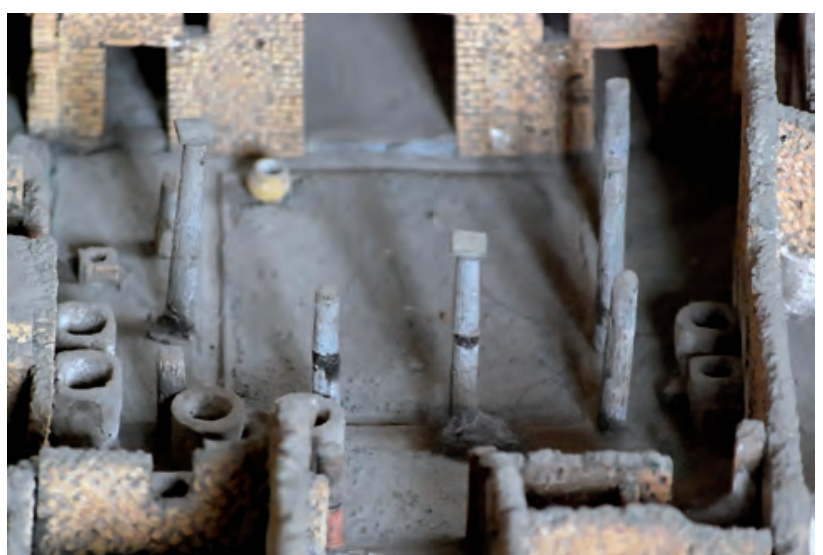

Fig. 91 - Atelier de teinturerie à Pompéi (VII 2, 11) représenté sur la maquette en liège du MANN. Répartis autour du péristyle, trois groupes de trois chaudières destinées à la teinture de petit teint.

même au fer, et, mieux encore, au feu par le dernier apprêt qu'ils subissent. C'est en effet des chaudrons à polir qu'on l'extrait pour en faire des matelas, invention qui, je pense, nous vient des Gaules [trad. CUF $]^{88}$.

La seule expression aenis polientium extracta implique que la laine est baignée dans des chaudrons, avant ou lors de sa trituration. Aucune autre explication n'est indiquée dans les textes ${ }^{89}$. La fresque peinte en façade du local IX 7, 5-7 permet de préciser une partie de la fabrication Commençons par la décrire, sans préjuger ni de son sens de lecture, ni de son interprétation. Il s'agit d'une bande de faible hauteur, située sous un cadre représentant la procession de Vénus Pompeiana portée par un quadrige tiré par des éléphants (fig. 92). Entre ce cadre et la fresque, une inscription électorale a été peinte par des feutriers, coactiliari $^{90}$. Huit personnages sont représentés, répartis en quatre ensembles

bus novissimo sui purgamento. Quippe aenis polientium extracta in tomenti usum veniunt, Galliarum, ut arbitor, invento [...].

${ }^{89}$ Bien que la technique la plus simple pour obtenir du feutre soit d'agglomérer les fibres sans transformation préalable, le feutrage à partir de pièces déjà tissées ne saurait être exclu: à titre d'exemple ethnographique, les chéchias tunisiennes sont fabriquées par feutrage d'un bonnet de laine tricotée, le kabous.

90 CIL IV, 7838: VETTIVM FIRMUM AED(ilis) QVACTILIARI ROG(ant). 


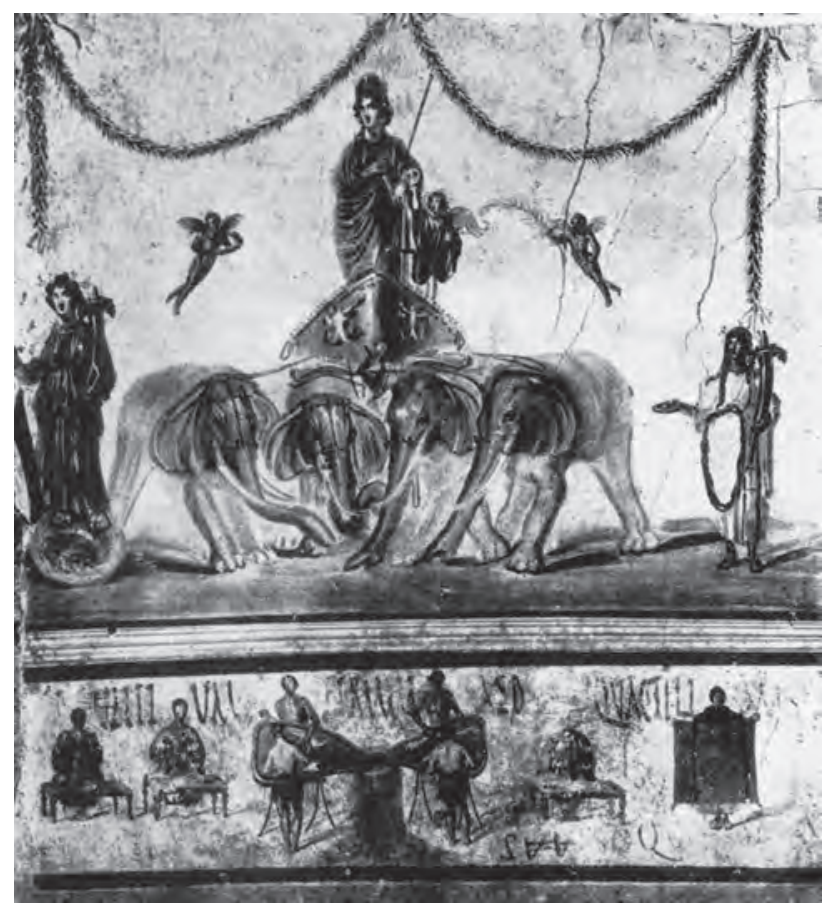

Fig. 92 - Fresque située en façade de l'atelier de feutre «de Verecundus» (Pompéi, IX 7, 5-7). Sous la procession de Vénus Pompeiana, les opérations de confection du feutre sont représentées.

distincts. À gauche, le premier groupe comporte deux personnages dans une attitude et une situation similaires. Vêtus, ils sont assis sur un tabouret bas derrière une table sur laquelle divers outils sont disposés. Leur position est figée: ils enserrent de leurs pieds nus une forme quadrangulaire - plus large à son sommet qu'à sa base - qui est recouverte d'une matière colorée; leurs mains sont jointes au sommet de cette forme, tenant un instrument constitué de plusieurs dents effilées parallèles ${ }^{91}$. La matière qu'ils tiennent est fermement plaquée contre la forme quadrangulaire; le reste est visible de part et d'autre de la forme, lâché en plis de drapé. Le second groupe est constitué par quatre hommes. Torses nus, seulement vêtus d'un pagne, ils s'affairent deux à deux de part et d'autre d'un four-

${ }^{91}$ Seules les mains de l'ouvrier de gauche sont très clairement visibles. L'outil ne paraît tenu qu'avec ses deux index, ses autres doigts semblant plus serrer la forme et la matière colorée. neau. Celui-ci est cylindrique, relativement haut - son sommet se trouve au-dessus de la taille des ouvriers - est percé de deux ouvertures. Celle de sa base occupe presque l'intégralité de la hauteur; elle s'achève en arc; des morceaux de bois en émergent. Celle du sommet est circulaire. Elle paraît contenir un conteneur de forme circulaire: un anneau, indiquant le marli de celui-ci est très nettement dessiné. Devant les personnages, une forme trapézoïdale dont les bords sont surélevés repose sur deux tréteaux. La plus petite extrémité s'achève au dessus du fourneau; elle est dépourvue de bord. Les quatre hommes manipulent une matière blanchâtre, à l'exception d'un d'entre eux - situé de face, à gauche qui tient en plus plusieurs fils de couleurs différentes dans sa main droite; celui qui lui fait face semble verser un liquide sur la matière blanche déposée devant lui ${ }^{92}$. La troisième partie de cette fresque reprend un personnage seul, dans une posture et avec des instruments similaires aux deux premiers: assis derrière une table, à maintenir une forme quadrangulaire entre ces quatre membres. Il dispose également d'outils sur sa table. Enfin, le dernier personnage est debout, tenant de ses deux mains écartées une pièce comportant deux bandes de couleur sur les côtés. Cette pièce dispose d'une certaine souplesse: des plis de drapé en arc concave sont dessinés au milieu. Cette production, de forme quadrangulaire, dispose à ses deux extrémités inférieures de deux pompons. Sous ce personnage est inscrit le nom de Verecundus ${ }^{93}$.

La première interprétation de cette fresque a été proposée par V. Spinazzola, avec une description très précise, en particulier concernant les ouvriers assis ${ }^{94}$. L'ordre dans lequel il décrit les différents groupes constitue en lui-même une interprétation: il commence par les trois personnages assis puis mentionne les quatre autres travaillant autour du foyer avant de passer à Verecundus. Il considère que l'instrument tenu par les ouvriers qui se tiennent derrière une table est un peigne, ce qui l'amène à voir en eux des pectinarii chargés de démêler la laine et de

\footnotetext{
${ }^{92}$ Angelone 1986: 47.

${ }^{93}$ CIL IV, 7839.

${ }^{94}$ Spinazzola 1953: 189-195.
} 
la peigner avant tout traitement. Cette interprétation a été ensuite largement reprise par tous ceux qui ont étudié l'artisanat textile à Pompéi, avec toutefois des ajustements mineurs ${ }^{95}$, à l'exemple de J.P. Wild qui estime que le peigne n'est pas autonome mais attaché à l'extrémité d'une planche ${ }^{96}$. Ces différentes remarques ne résistent pourtant pas à l'examen de la fresque. Tout d'abord, la présence d'un second peigne sur la table du premier des ouvriers, ainsi que la double rangée de dents qu'il présente, en fait un instrument indépendant, non serti dans une pièce de bois. Un tel peigne a été mis au jour à Herculanum, sur la plage: il s'agit d'une plaque de fer partiellement sciée de façon à libérer deux rangées de dents; rien n'autorise à supposer sa fixation sur un manche ${ }^{97}$. De plus, sur la fresque de Verecundus, il ne fait aucun doute que la matière qui est peignée se trouve entre le peigne et la forme en bois. Cette dernière ne saurait être de la laine en cours de préparation. Le peignage est supposé être une des premières opérations effectuées avant tout autre traitement après la tonte: ce qui est manipulé par les trois ouvriers assis est teint et donc a déjà subi les opérations de préparation des toisons ${ }^{98}$. Surtout, la possibilité qu'a cette matière d'être appliquée en tension contre un guide probablement en bois, et de flotter avec des plis de drapé pour les parties non tenues rend très peu crédible l'hypothèse d'une toison. Dès lors, ces trois ouvriers ne seraient pas en train de préparer de la matière première avant sa transformation en feutre, mais ils seraient plutôt au stade de la finition du feutre. Les différents instruments dont ils disposent et le sens de lecture de la fresque viennent en soutien à cette hypothèse. Les différents couteaux à lame courbe ne paraissent d'aucune utilité dans le processus de nettoyage initial ${ }^{99}$.

${ }^{95}$ Moeller 1976: 15, 54; Angelone 1986 : 44-48; Borgard - Puybaret 2003: 311-312. Étonnamment, R. J. Forbes (1956: 132) interprète cette fresque comme une représentation de teinturerie

${ }^{96}$ Wild 1970: 25

${ }^{97}$ Inv. n ${ }^{\circ}$ E3309=78606, découvert le 4 novembre 1982. Sa longueur totale est de $27,5 \mathrm{~cm}$; il est large de $12 \mathrm{~cm}$. Environ cinquante dents ont été ménagées de chaque côté.

${ }^{98}$ La teinture sur toison est possible, particulièrement dans le cas d'un atelier de feutre qui ne saurait être teint une fois mis en forme. Sur les attestations de teinture sur toison, cf. Wild 1970: 80 et n. 2 .
Bien au contraire, leur forme semble tout à fait adaptée pour la tonte du feutre, la coupe des fibres mal intégrées. La répétition à droite du fourneau d'un personnage assis empêche de considérer cette fresque comme une frise à lecture unidirectionnelle. Bien que situé à l'extrême droite, Verecundus, dont l'importance est soulignée par l'apposition de son surnom, se détache des ouvriers. Ceux qui sont assis sont en retrait par rapport au fourneau. Cette fresque représenterait d'une part le fonctionnement de l'atelier, avec un effet de répartition spatiale dans la profondeur - le feutrage serait situé sur le devant pour évacuer la chaleur et la finition sur l'arrière -, et d'autre part le propriétaire ou le tenancier de ce local qui exhibe fièrement sa marchandise.

Les différents éléments de cette fresque ont permis à W. Moeller de proposer un inventaire des possibles ateliers de feutre à Pompéi, toutefois, les vestiges construits proches des aménagements représentés sont particulièrement peu nombreux et d'interprétation délicate. Outre l'atelier de Verecundus, la répétition du terme de quactiliari sur une affiche électorale à proximité l'amène à considérer le local IX 7, 1 - non fouillé - comme un atelier consacré à la même production $^{100}$. Pourtant, rien ne permet d'avoir la certitude que les rogatores peignent nécessairement leur appui électoral en façade de leur lieu de domicile ou d'activité ${ }^{101}$. Ces quactiliari pourraient être les mêmes que ceux de l'atelier de Verecundus. Les autres locaux qu'il propose d'interpréter comme impliqués dans la préparation du feutre disposent tous d'un fourneau central, tel que celui représenté sur la fresque. Se rapportant aux descriptions de M. Della Corte, il infère de la présence d'un fourneau au centre du local IX 3, 16 un atelier de feutre. Actuellement,

\footnotetext{
${ }^{99}$ Sur les différentes formes de couteaux identifiées sur la fresque, cf. Spinazzola 1953 : 190-194 et fig. 227 p. 194.

100 Moeller 1971; Moeller 1976: 52. CIL IV, 7809: Herennivm et Svettivm/Aedilis quactiliari rogant D(igni) R(ei) P(ublicae).

101 Pour vérifier une telle hypothèse, il est nécessaire de connaître la nature de l'activité se déroulant dans le local concerné. S'il existe une certaine conjonction entre les mentions de caupones et les commerces alimentaires (Monteix 2007 a: 119-121), ce rapport étroit n'a pas la valeur d'automatisme donnée par M. Della Corte et W. Moeller pour les activités textiles.
} 
cet aménagement est détruit, ce qui empêche toute vérification, alors que les descriptions proposées par G. Fiorelli sont trop sibyllines ${ }^{102}$. Un dispositif proche de celui représenté en façade de l'atelier de Verecundus a été mis au jour en I 12, 4: un fourneau de faible hauteur se trouve au milieu du local; il a été découvert fortement détruit et a été restauré103. Peut-être conviendrait-il d'ajouter le local VII 11, 7, qui dispose en son centre de ce que G. Fiorelli a appelé un focolare ${ }^{104}$. Les indices de l'artisanat du feutre à Pompéi sont extrêmement minces hors de la fresque de Verecundus.

IV.2.2 Les ateliers Or. II, 5 et Or. II, 11 à Herculanum

Les différents éléments rassemblés à propos de Pompéi sont autant de facteurs discriminants qui concourent à l'interprétation de certains locaux d'Herculanum. Selon A. Maiuri, deux teintureries se seraient trouvées dans l'Insula Orientalis $I I^{a}$, aux entrées 5 et 11 . Un nouvel examen des aménagements qui y ont été mis au jour amène à revoir ou à approfondir ces interprétations. La fonction du local Or. II, 5 est inférée de la présence d'un dolium dépourvu de fond - complètement emmuré dans une maçonnerie épaisse d'une dizaine de centimètres, à l'exception d'une ouverture rectangulaire à sa base - ainsi que sur le sol, constitué de tuiles "per un più commodo lavaggio». En outre, il estime qu'une latrine se développe dans l'angle sud-ouest et qu'un escalier court le long du mur nord pour permettre d'atteindre l'appartement situé au premier étage ${ }^{105}$. W. Moeller

${ }^{102}$ Les deux descriptions que G. Fiorelli (1873 : 52 ; 1875 : 396) donne de ce local sont identiques. Il se contente de signaler la présence d'un fourneau et d'un départ d'escalier. Sur le plan reporté à la fin du volume sur les fouilles de 1862 à 1872 , le fourneau est représenté avec un rond d'un diamètre de 1,1 m. Il apparaît isolé dans la moitié sud du local.

${ }^{103}$ Moeller 1971; Moeller 1976: 51-52. Voir les remarques de W. Jongman (1988: 165-166) à ce propos.

${ }^{104}$ Le local VII 11, 7 a été interprété comme commerce alimentaire par S. Ellis (2004 b: table 1 p. 374). Pourtant, la forme du fourneau central n'a rien à voir avec les autres installations que l'on trouve habituellement dans ce type de locaux (cf. supra, p. 97-102). Cette interprétation est en fait a repris cette interprétation, précisant toutefois qu'il s'agirait, en l'absence de batterie de chaudières, d'une officina offectoria ${ }^{106}$. Le seul aménagement visible actuellement dans ce local est un dolium pris dans de la maçonnerie, s'appuyant sur une table maçonnée et sur la chaudière basse, caractéristiques d'une laverie de toisons (fig. 93) ${ }^{107}$. Haute de $1,10 \mathrm{~m}$, cette jarre en remploi est dépourvue de fond et englobée dans un muret épais de $8 \mathrm{~cm}$. Les photos effectuées peu de temps après la fouille montrent que cette construction recouvrait complètement la table maçonnée, doublant presque la hauteur de celle-ci et dépassant l'ouverture de la jarre ${ }^{108}$. Sur le côté ouest, un orifice quadrangulaire a été ménagé. À l'intérieur, aucune préparation n'a été effectuée. En revanche, des incisions verticales ont été pratiquées sur toute la hauteur interne du col. Leur forme quadrangulaire permet de les considérer comme des encoches pour insérer les pattes de support d'un objet installé sur l'ouverture. Peu d'objets ont été mis au jour dans ce local, fortement détruit par les tunnels du XVIII ${ }^{\mathrm{e}}$ siècle ${ }^{109}$. En dépit de cette absence, la similitude entre l'aménagement de ce dolium en remploi et le fourneau dépeint sur la fresque de l'atelier de Verecundus est frappante. Sa position n'est certes pas centrale; toutefois, le rehaussement de la table maçonnée se substitue au plan incliné sur tréteaux. De plus, la grande hauteur entre le foyer et le probable récipient posé au sommet du dolium facilite l'entretien d'une chaleur suffisamment peu élevée pour ne pas dégrader la laine. Un atelier de fabrication de feutre aurait donc pu se trouver dans ce local au cours de ses dernières phases.

due à G. Fiorelli (1875: 278): «[...] il podio ed il focolare che [la bottega n.7] ha nel mezzo accennano ad un'osteria $[\ldots] »$.

${ }^{105}$ Maiuri 1958 b : 455 .

${ }^{106}$ Moeller 1976: 112.

${ }^{107}$ Supra, p. 172-174.

${ }^{108}$ Voir Maiuri 1958 b: fig. 406 p. 455.

${ }^{109}$ GSE 1932: " 30 aprile. Il vano numero 5 che trovasi sul IV cardine lato est a nord del tempio a m. 0.25 dalla soglia e a 1.37 dalla parete sud sul pavimento è stato raccolto: [Description des objets Inv. $n^{\circ}$ E822-E824=76099-76101]. La muratura delle pareti dell'ambiente è di opera reticolata completamente schiacciata e forata da cunicoli». 


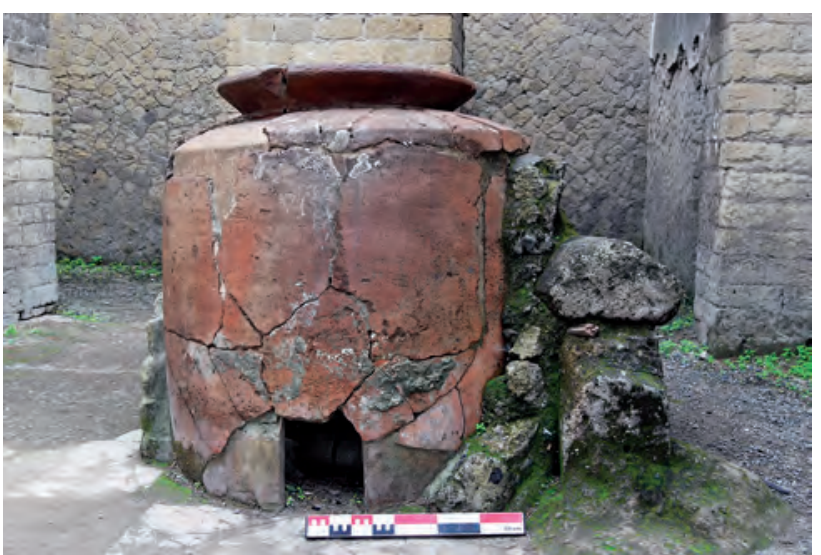

Fig. 93 - Dolium emmuré pour être utilisé comme fourneau dans l'atelier Or. II, 5. À droite, il s'appuie sur la table maçonnée préexistante, destinée au nettoyage des toisons, et la recouvre partiellement (cliché pris de l'ouest).

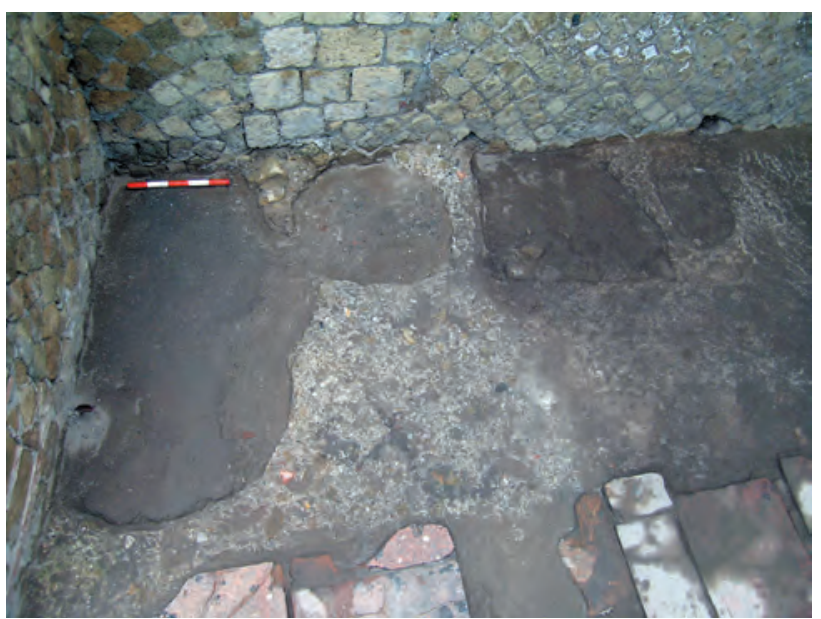

Fig. 94 - Fosses remblayées au nord de l'atelier Or. II, 5. La plus grande pourrait être le résultat de la disparition des limites entre deux fosses circulaires. La fosse trapézoïdale conserve, au sud, l'amorce d'un parement en opus reticulatum (cliché pris du sud).

les constructions dont seules les empreintes sont visibles, leur destruction est antérieure à l'éruption de 79 et aux dégâts liés à l'ensevelissement. Il est ainsi probable que ce local se trouvait partiellement en travaux quand le Vésuve a recouvert la ville. Rien ne permet de déterminer si ces installations ont fonctionné ou non avec la laverie de toisons, mais elles ont pu être contemporaines de l'installation du dolium emmuré ${ }^{112}$.

Quelques mètres plus au nord, se trouve le local Or. II, 11 (cat. $\mathrm{n}^{\circ} 45$ ) qui serait, selon A. Maiuri, également d'une teinturerie: des dolia auraient été fixés dans un podium maçonné et utilisés comme chaudières ${ }^{113}$. W. Moeller dresse quant à lui un parallèle entre les vestiges visibles et les aménagements des laveries de toison, bien que, détachés du mur, ils se trouveraient dans une situation "atypique ${ }^{114}$. Aucune de

Sa situation isolée trouverait des parallèles avec les aménagements des officinae infectoriae, toutefois son diamètre très réduit par rapport aux trois autres autoriserait à écarter cette proposition. Au cours de l'avant dernière phase précédant l'éruption, le local Or. II, 5 aurait ainsi eu la double fonction de teinturerie et d'atelier de feutre. En revanche, seule cette dernière activité semble avoir été effective au moment même de l'éruption.

${ }^{113}$ Maiuri 1958 b: 464.

${ }^{114}$ Moeller 1976: 112.

\footnotetext{
la dernière fosse corresponde également à une chaudière. printemps 2004 avec l'amicale collaboration de J. Andrews ;

${ }^{111}$ Dans le sens des aiguilles d'une montre, les diamètres restituables sont de 70,100 et $80 \mathrm{~cm}$

${ }^{112}$ Bien que seule l'empreinte issue de leur destruction soit connue, une hypothèse de restitution peut être proposée. Le plan de ces installations est particulièrement proche de celui des teintureries pompéiennes. Il s'agirait
}

${ }^{110}$ Cette description fait suite à un nettoyage effectué au 
ces interprétations n'est réellement satisfaisante mais les archives et l'état actuel des aménagements construits ne permettent qu'une relecture très limitée. Des chaudières, seules subsistent de une à trois assises en opus reticulatum formant deux murets circulaires. La restitution proposée par R. Oliva montre en revanche un aménagement maçonné rectangulaire dans lequel deux cavités cylindriques sont percées sur le dessus ainsi que deux autres sur la face sud ${ }^{115}$. Pour que cette construction puisse correspondre à une laverie de toison, une table maçonnée permettant d'étaler les toisons et une vasque de rinçage seraient nécessaires. Ni l'une ni l'autre ne sont visibles ou décrites dans les journaux de fouilles. Si l'on ne tient pas compte de la restitution graphique publiée par A. Maiuri, la forme des vestiges peut se rapprocher des fondements de chaudières "hautes » employées dans les teintureries. Toutefois, la mention de grilles en fer lors de la description générale des locaux Or. II, 10-12 semble récuser cette hypothèse ${ }^{116}$. Cet aménagement, désormais disparu mais utilisé pour séparer le récipient à chauffer du foyer, ne se rencontre dans aucune des teintureries pompéiennes. En revanche, ces grilles sont attestées dans une restitution proposée par L. Fulvio dans sa recension des aménagements de chauffage à Pompéi: il interprète ce dispositif comme une variante des tables de cuisson; cependant, le texte illustré par ce dessin n'est pas d'une grande clarté quant à la localisation de la construction reproduite ${ }^{117}$. L'étude des objets découverts n'apporte guère plus d'informations. À l'exception de deux outils qui pourraient indiquer des travaux en cours au moment de l'éruption, aucun objet ne dénote d'un environnement partiellement domestique, pourtant révélé architecturalement par la pièce annexe à

${ }^{115}$ Maiuri 1958 b: fig. 422 p. 464.

116 GSE 1936: "16 ottobre. [Il magazzino numero 11] è formato da un grande ambiente che affaccia sulla strada. In esso vi è presso la parete nord un banco a forma rettangolare con due fornaci chiuse al centro da gratiglie di ferro. Doveva essere una tintoria». Toutes les autres entrées concernant ce local, fouillé entre le 13 juillet 1933 et le 17 octobre 1936, ne donnent aucun élément descriptif, seulement des indications concernant la découverte d'objets. vivre (11-2) ${ }^{118}$. En l'état actuel, il est impossible de trancher entre ces différentes propositions, dont aucune n'est pleinement satisfaisante. Le premier élément qu'il conviendrait de vérifier est la structure du sol dans ce local: l'emploi de tuiles favoriserait une interprétation dans les activités textiles et un nettoyage de l'ensemble de la surface permettrait certainement de mettre au jour d'autres aménagements arasés.

À Herculanum, le décompte des ateliers pouvant être impliqués dans la teinturerie est particulièrement maigre. Aucun local ne peut être considéré comme tel de façon certaine au moment de l'éruption: la présence d'une teinturerie - démantelée à l'automne 79 - en Or. II, 5 reste conjecturale, tandis que l'espace Or. II, 11 n'est au mieux qu'un atelier possible, sinon un local sans aucun rapport avec la filière textile. Cette relative absence des teintureries à Herculanum peut n'être due qu'aux limitations de l'espace urbain fouillé mais pourrait également permettre de mesurer a contrario la spécialisation de l'opération de teinture.

\section{IV.3 Le nettoyage des vêtements dans les fouleries}

Des différentes opérations de la chaîne opératoire du textile, la foulerie est à la fois la dernière et celle qui est supposée se répéter après la vente de l'étoffe. En effet, le lavage du tissu peut non seulement avoir lieu après le tissage et la teinture, mais également ensuite pour raviver les couleurs ou redonner de l'éclat au blanc. Bien que très éparpillées, les données concernant cette activité, au moins indirectement, sont assez nombreuses. Pourtant, la mise en adéquation des sources textuelles et iconographiques avec les vestiges archéologiques reste problématique. Je ne reprendrai pas l'intégralité de ce

${ }^{117}$ Fulvio 1879: tav. I, 4 et p. 277. Le dessin proposé pourrait - sans aucune certitude - être la restitution d'un aménagement situé dans le commerce alimentaire VII 12, 15-16. Toutefois, aucun des vestiges visibles actuellement ne permettrait une telle reconstruction.

${ }^{118}$ La tête d'une massette (Inv. $\left.{ }^{\circ} \mathrm{E} 1677=76955\right)$ et une sorte de pied-de-biche (Inv. $\left.\mathrm{n}^{\circ} \mathrm{E} 1678=76956\right)$ ont été découverts le 22 septembre 1936 dans la pièce principale. 
dossier, certains de ses versants restant éloignés de ma préoccupation principale: actualiser et réviser les interprétations des espaces consacrés à l'artisanat textile à Herculanum ${ }^{119}$.

IV.3.1 La reconstitution du processus de lavage

Des reconstitutions, fondées sur l'analyse des textes et des vestiges archéologiques ont été proposées par H. Blümner, R. J. Forbes, J. P. Wild et finalement W. Moeller ${ }^{120}$. Avant de détailler les différents témoignages concernant ce procédé, revenons sur son intérêt dans la longue chaîne opératoire textile. Une fois tissée, la pièce de vêtement n'est pas encore prête à l'emploi: il faut la débarrasser de la graisse qui a pu servir au filage, resserrer l'intrication des fils de chaîne et de trame et la traiter dans son ensemble pour en améliorer l'aspect. Dans le cadre du nettoyage consécutif à l'usage des vêtements, ce traitement permet de les débarrasser des saletés accumulées.

119 Volontairement, je n'ai pas pris en considération la majeure partie des fragments du Digeste concernant les fouleries. Les nombreuses attestations des fullones dans les textes juridiques ne permettent pas d'avoir plus de détails sur la nature des opérations conduites dans ces ateliers. En effet, la relative importance numérique des foulons, parmi les métiers mentionnés dans le Digeste, paraît plus être due à un exercice de rhétorique qu'à des demandes issues de la pratique. La foulerie aurait ainsi constitué un exemple riche pour le développement de la casuistique juridique. Parmi les discussions qui semblent avoir eu pour cadre les fouleries et le travail qui y est effectué, se trouvent tant des réflexions sur les questions de vol que sur la nature du contrat liant l'artisan à son client. Cf. not. Labeo, Post. a Iav. epit., 5 (Dig., 19, 2, 60, 2); Iav. Ex post. lab., 9 (Dig., 47, 2, 91 pr.); Ulp. ad ed., 28 (Dig., 14, 3, 5, 6; Dig., 14, 3, 5, 10), 29 (Dig., 14, 4, 1, 1; Dig., 47, 2, 12 pr.), 32 (Dig., 12, 7, 2 ; Dig., 19, 2, 13, 6); ad Sab. 29 (Dig., 47, 2, 12 pr.); Gai. Ad ed. provinc., 5 (Dig., 4, 9, 5 pr.), 10 (Dig., 19, 2, 25, 8); Inst., 3, 142; 3, 162; 3, 205; Paul. Sent., 2 (Dig., 47, 2, 83 pr.), ad Ed. 22 (Dig., 9, 1, 2 pr.); Alfen. Dig., a paulo epit., 5 (Dig., 19, 2,31 ). Hors sources juridiques, mais sur des problèmes de droit impliquant les foulons, voir Tran 2007.

${ }^{120}$ Blümner 1912: 170-190, part. 182-183 ; Forbes 1956: 81-90, 93-95; Wild 1970: 82-86; Moeller 1976: 18-28, part. 26-27. Les fondements scientifiques de ces propositions ont été raillés par M. Bradley, qui considère qu'il ne s'agit là que de reconstitutions idéalisées: «idealised reconstructions have been a hallmark of fulling archaeology» (Bradley 2002: 24-25). Toutefois, l'un des principaux problèmes de l'article de M. Bradley reste qu'il se contente de rejeter toutes les
Les textes littéraires décrivent une partie des opérations de foulerie, sans que leur ordre ne soit toujours clairement identifiable. Ainsi, dans un extrait de son Histoire Naturelle, alors qu'il traite des différents types d'argile, Pline l'Ancien décrit avec peu de détails les grandes étapes des procédés de foulerie ${ }^{121}$. À partir de cette description, R. Robertson a cherché à caractériser d'un point de vue géologique les différentes terres mentionnées par Pline l'Ancien ${ }^{122}$. Il en ressort que la première phase utilise un détergent plus ou moins violent selon que l'étoffe est teinte ou non: les tissus blancs sont passés sous l'action de la sarda (montmorillonite de calcium), tandis que les tissus teints sont traités avec des argiles ne contenant que peu de montmorillonite, dont Pline ne donne pas le nom, sauf de façon générale. Ensuite, quelle que soit l'étoffe, elle est soumise à l'action du soufre ${ }^{123}$. Pour ce faire, une cage en osier est utilisée: la description qui en est faite par Apulée lorsque l'amant d'une femme de foulon y est caché se passe de tout commentaire $^{124}$. Enfin, le traitement s'achève

interprétations antérieures, sans en proposer de nouvelle. Les points de vue très discutables de cet auteur ont donné lieu à deux réponses dans le volume suivant du JRA (Wilson 2003, Flohr 2003). Leurs auteurs ont notamment rectifié les nombreuses approximations de M. Bradley concernant les structures archéologiques des fouleries ou la place des foulons dans la société romaine. Je soulignerai enfin qu'en 2006 et 2007, M. Flohr (2007 b, 2008) a procédé au nettoyage de plusieurs fouleries pompéiennes, prélude à une réinterprétation complète du dossier.

${ }^{121}$ Plin., NH, 35, 196-198.

122 Robertson 1949.

${ }^{123}$ Plin., NH, 35, 175: Alterum genus appellant glaebam, fullonum tantum officinis familiare. Tertio quoque generi unus tantum est usus ad lanas suffiendas, quoniam candorem mollitiam que confert; "La seconde espèce [de soufre] est appelée glaeba, particulièrement commune dans les ateliers de foulons. De même la troisième espèce n'a qu'un seul usage: purifier la laine par fumigation car ce procédé lui apporte blancheur et moelleux» (trad. CUF).

La proximité des deux utilisations est soulignée par le terme quoque. Toutefois, il nous semble que la légère distinction qui existe entre les deux types de soufre pourrait tenir à un emploi de la "troisième espèce» de soufre non dans les fouleries, mais avant le tissage, une fois la laine nettoyée.

${ }^{124}$ Apul., Met., 9, 24, 2 : Ergo nostra repente turbata praesentia, subitario ducta consilio, eundem illum subiectum contegit viminea cauea, quae fustium flexu teret $<i>$ in rectum aggerata cumulum lacinias circumdatas suffusa candido fumo sulpuris inalbabat, eo que iam ut sibi videbatur tutis- 
par une application manuelle (desquamere) soit d'un autre détergent pour les tissus blancs (le saxum, de la bentonite, ou montmorillonite de sodium), soit d'une argile kaolinitique, parmi lesquelles se distingue la creta Umbrica, pour les pièces teintes. Il ne semble pas, dans ce dernier cas, qu'un rinçage particulier soit nécessaire. $\mathrm{Au}$ contraire, toujours selon R. Robertson, les argiles kaolinitiques se fixent dans les fibres et donnent ainsi un lustre particulier au vêtement. À cet usage des différentes variantes de la terre à foulon, il convient d'ajouter celui de l'urine, dont la nature alcaline en fait un remarquable agent détergent. Les références à cet emploi sont assez fréquentes, que ce soit chez Pline qui en vante les capacités médicales ou les origines exotiques $^{125}$, ou chez Martial qui évoque le bris d'une amphore pleine d'urine par un foulon ${ }^{126}$.

La nature même du texte encyclopédique de Pline fait qu'il a plus particulièrement insisté sur les matières utilisées par les foulons. Au-delà des manques manifestes de cette description et de la très faible mention des opérations de rinçage

sime celato mensam nobis cum secura participat; " Troublée soudain par notre présence, et avisant sur le champ, elle le dissimule sous une cage d'osier faite de baguettes flexibles, disposées en cercle et allant se rejoindre au sommet, sur laquelle on étendait les pièces d'étoffes pour les blanchir à la fumée du soufre. L'autre ainsi caché, pensait-elle, en lieu sûr, elle vient sans inquiétude s'associer à notre repas » (Trad. CUF).

${ }^{125}$ Plin., NH, 28, 66: Virilis podagris medetur argumento fullonum, quos ideo temptari eo morbo negant; "L'urine d'homme guérit la goutte, à preuve les foulons qu'on dit ignorer cette maladie pour cette raison » (trad. CUF).

Plin., NH, 28, 174: Utilior [...] urina [...] fullonia vetus, calfactae vapore per lagoenae collum subeunte [...]; «Plus efficace [contre les maladies des oreilles] est la vieille urine de foulons, mise dans une bouteille qu'on chauffe jusqu'à ce que la vapeur s'échappe par le goulot» (trad. CUF).

Plin., NH, 28, 91 : [...] Urinam [cameli] fullonibus utilissimam esse tradunt [...]; "On dit que l'urine de chameau est très utile aux foulons » (trad. CUF).

126 Mart., 6, 93, 1-2: Tam male Thais olet quam non fullonis avari / testa vetus, media sed modo fracta via [...]; "Thaïs sent plus mauvais qu'une vieille jarre de foulon avare qui vient de se briser au milieu de la rue» (trad. CUF). Sur la difficulté de suivre l'interprétation traditionnelle de ce passage, cf. Wilson - Flohr à paraître. Je remercie vivement M. Flohr de m'avoir communiqué cet article avant parution.

127 Titinius, Fullones, 5 (21-22) [Non., 369 L]: Terra istaec est, non aqua, ubi tu solitu's argutarier/Pedibus, cretam dum compescis, vestimenta qui laves; "C'est ici la et de séchage, elle constitue le seul texte d'approche technique sur le sujet. Les autres sources littéraires donnent une image plus mouvementée des travaux des foulons en mettant l'accent sur leur façon de travailler: le foulage au pied du linge. Un extrait d'une comédie au titre évocateur écrite par Titinius renvoie le foulon à son seul langage, celui du bruit de ses pieds pendant son travail ${ }^{127}$. Sénèque propose étonnamment de voir les mouvements de foulage comme un excellent exercice pour donner au corps une saine fatigue ${ }^{128}$. Cette utilisation des pieds ressort aussi d'un texte de Pline qui estime que l'urine protège les foulons de la goutte ${ }^{129}$. Enfin, la dernière étape des vêtements dans les fouleries paraît être celle du pressage des vêtements pour leur donner un aspect lustré, feutré. Cette opération est mentionnée indirectement sans beaucoup de détails par Martial qui en exalte le résultat ${ }^{130}$. Sénèque y voit quant à lui un luxe aux antipodes de la simplicité stoïcienne, donnant ce faisant l'explication la plus claire quant à l'utilisation de la presse ${ }^{131}$.

terre et non l'eau où tu as l'habitude de jacasser avec tes pieds, pendant que tu foules la craie pour laver les vêtements » (trad. CUF).

${ }^{128}$ Sen., Ep., [2,] 15, 4: Sunt exercitationes et faciles et breves, quae corpus et sine mora lassent et tempori parcant, cuius praecipua ratio habenda est: $[\ldots]$ saltus $[. .$.$] ut contu-$ meliosius dicam, fullonius [...]; «Il y a des exercices simples et brefs, qui fatiguent ton corps sans délai, tout en préservant ton temps, ce dont il faut tenir compte: [ainsi] le saut, comme on dit outrageusement, du foulon» (trad. CUF).

${ }^{129}$ Plin., NH, 28, 66. Cit. supra, n. 125.

${ }^{130}$ Mart., 2, 43, 6: [...] sic tua suppositis collucent prela lacernis [...]; «De même tes presses brillent de tes manteaux superposés $[\ldots] »($ trad. CUF).

Mart., 11, 8, 5: [...] de Palatinis dominae quod serica prelis [...]; «[Des senteurs] de la soie sortie des presses de la maîtresse du Palatin [...]» (trad. CUF).

Deux autres attestations plus tardives de l'usage d'un prelum ou d'un pressorium pour décrire un traitement des vêtements se trouvent chez Ammien Marcellin $(28,4,19)$ et Claudien (Carmin. min., 25, 101).

${ }^{131}$ Sen., Tranq., 1, 5: Tenet me summus amor parsimoniae, fateor: placet [...] non ex arcula prolata vestis, non ponderibus ac mille tormentis splendere cogentibus expressa, sed domestica et vilis, nec servata nec sumenda sollicite; «J'ai un profond amour de la simplicité je l'avoue: ce que j'aime, $[\ldots]$ ce ne sont point des vêtements que l'on tire du fond d'un coffre, que l'on torture sous des poids et des vis sans nombre pour les obliger à prendre du lustre, mais un costume ordinaire et grossier, qu'on entretienne sans souci et qu'on porte sans scrupule» (trad. P. Veyne). 
Les rares autres mentions des opérations techniques qui se déroulent dans les fouleries sont dépourvues de contexte, ce qui rend délicate leur insertion à un moment de la chaîne opératoire. Ainsi, quand Frontin expose les évolutions de la législation sur l'adduction en eau à Rome, il signale que le surplus des aqueducs pouvait être utilisé par les foulons contre paiement d'une redevance ${ }^{132}$. L'utilisation de l'eau est partiellement évidente et a déjà été mentionnée pour le foulage proprement dit. Toutefois, la question du rinçage et de sa situation dans l'enchaînement des opérations reste posée, j'y reviendrai. Un autre problème associé à l'utilisation de l'eau est soulevé par un extrait des Questions naturelles de Sénèque. Le philosophe, alors qu'il étudie la formation des phénomènes lumineux, utilise l'une des étapes du travail des foulons pour illustrer son propos. Il expose ainsi que ces artisans forment des arcs-en-ciel lorsqu'ils crachent de l'eau sur des étoffes disposées sur des cordes ${ }^{133}$. Un troisième moment est indirectement décrit par les textes, sans que son contexte ne soit toutefois spécifié. Il s'agit du peignage des étoffes avec des peignes pourvus d'épines, mentionné à trois reprises par Pline l'Ancien ${ }^{134}$. En théorie, l'utilisation de cette brosse pourrait intervenir tout autant avant le foulage comme première étape de nettoyage, ou après celui-ci, pour préparer l'étoffe au lustrage

132 Frontin., Aq. 94, 3-4: Apud antiquos omnis aqua in usus publicos eroga<ba>tur et cautum ita fuit: "ne quis privatus aliam <aquam > ducat, quam quae ex lacu humum accidit» - haec enim sunt verba eius legis - id est quae ex lacu abundavit; eam nos caducam vocamus. Et haec ipsa non in alium usum quam in balnearum aut fullonicarum dabatur, erat que vectigalis statuta mercede quae in publicum penderetur; "Chez les Anciens, toute l'eau était distribuée pour l'usage public ainsi que prescrit: "Aucun particulier ne tirera d'eau autre que celle qui est tombée du lacus humus» - tels sont les termes de cette loi - c'est-à-dire l'eau qui a débordé du bassin, que nous appelons trop-plein. Et même cette eau là n'était pas donnée pour d'autres usages que les bains ou les fouleries et encore y avait-il une redevance à payer» (trad. CUF).

${ }^{133}$ Sen., Nat., 1, 3, 2: Idem videbis accidere, si quando voleris observare fullonem: cum os aqua implevit et vestimenta tendiculis diducta leviter aspergit, apparet varios edi colores in illo aere asperso, quales fulgere in arcu solent; "Regarde aussi un foulon à l'ouvrage, tu verras le même fait se produire: quand il a rempli d'eau sa bouche et qu'il sous la presse. Les seuls textes n'éclairent pas sur ce point.

Il est possible de compléter cette séquence inachevée et partiellement désordonnée des opérations de foulerie par le biais des représentations de cette activité. À Pompéi, deux fresques montrent le travail des foulons ou les instruments qu'ils utilisent. Parmi les nombreuses activités notamment artisanales représentées sur la frise de l'oecus q de la Casa dei Vettii (VI 15, 1.27), dans l'angle nord-est, sur la paroi orientale, des amours sont occupés à fouler des vêtements ${ }^{135}$. Du nord au sud, ce tableau est divisé en six petites scènes qui semblent se succéder. Dans la première (fig. 95, a), deux amours piétinent de concert dans un bac en bois peu profond, mais terminé à ses deux extrémités par un haut montant aveugle. Une amphore est posée contre le montant gauche, tandis qu'une masse informe de couleur blanchâtre, pouvant être une pile de tissu, gît à droite. La scène suivante (fig. 95, b), immédiatement à droite, montre un amour en train de manipuler - de frotter? - une étoffe orange, disposée devant lui, dans un bac posé sur une petite table. Un troisième amour (fig. 95, c) se tient de dos. Devant lui est installé un grand séchoir composé de quatre montants verticaux - trois seulement sont visibles - réunis par des traverses horizontales. À peine en dessous de celles-ci, une autre traverse soutient une pièce

en humecte légèrement les vêtements déployés au moyen de cordelettes, on voit apparaître dans l'air aspergé des couleurs variées, semblables à celles qui brillent ordinairement dans l'arc-en-ciel» (trad. CUF).

${ }^{134}$ Plin., NH, 27, 91: Hippophaeston nascitur in spinis, ex quibus fiunt aenae fulloniae; "L'hippophaeston croît dans les épines dont sont faits les peignes des foulons» (trad. CUF).

Plin., NH, 24, 111: Vulgaris quoque haec spina, ex qua aenae fulloniae inplentur; "On emploie également la racine de l'épine commune dont on garnit les peignes des foulons » (trad. CUF).

Plin., NH, 16, 244: Quaedam enim in terra gigni non possunt et in arboribus nascuntur. [...] quod vero in spina fullonia hippophaeston [...]; «En effet, certains végétaux ne peuvent venir dans la terre et naissent sur les arbres. [...] Ce qui croît sur le chardon à foulon se nomme hippophaeston $[\ldots] »($ trad. CUF).

Sur l'aenia fullonia, instrument utilisé pour le brossage des tissus selon Pline, cf. Wild 1968: 141-142.

${ }^{135}$ Sur cette fresque, cf. PPM V : 468-572, part. 541-565. 
de tissu jaune clair. De sa main gauche, l'amour soulève cette dernière, tandis que sa main droite la frotte, avec un instrument de forme carrée. Le quatrième amour (fig. 95, d) transporte un tissu bleu vers deux possibles psychés qui sont juchées en position assise sur un petit podium (fig. 95, e). Celui de gauche observe une étoffe rouge, tandis que celui de droite se penche sur le tissu bleu qui est disposé sur ses jambes. Enfin, une psyché, également assise sur une chaise posée sur un podium paraît plier avec beaucoup de soin une pièce de tissu blanc (fig. 95, f). Cette seule fresque permet de résoudre l'un des points laissés en suspens: la brosse est passée sur les vêtements après le foulage; elle sert donc à préparer l'éventuel lustrage sous presse qui n'est pas montré ici. De plus, les deux premières scènes montrent également la variété des gestes associés au foulage: les pieds ne sont pas seuls à être employés durant cette phase, une manipulation manuelle a également lieu.

La seconde fresque pompéienne apportant des informations complémentaires sur les procédés de foulerie provient de la fullonica de L. Veranius Hypsaeus (VI 8, 2.20-21), fouillée entre 1825 et 1827 . Les différents aménagements correspondant aux étapes du nettoyage des vêtements sont répartis autour du péristyle. Directement associés à ces constructions propres aux fouleries, deux piliers encadrant la fontaine située à l'est du péristyle présentent des fresques à fond rouge sur trois de leurs côtés ${ }^{136}$. Sur le pilier sud se trouve une peinture de laraire avec les deux serpents affrontés audessus d'un autel. Les autres faces portent les représentations de Bacchus et d'Apollon ${ }^{137}$. Sur le pilier nord, à l'ouest, est peinte une Vénus qui, selon Th. Fröhlich, ne saurait être Vénus Pompeiana $^{138}$. Les deux autres faces montrent quatre des opérations du traitement des étoffes dans une foulerie, dans des cadres distincts. Sur le côté sud, on voit, de bas en haut, quatre personnes vêtues de tuniques en train de nettoyer des pièces d'étoffe par piétinement et manipulation dans des stalles (fig. 96, a). Au dessus, dans un cadre séparé, du tissu est en train de sécher

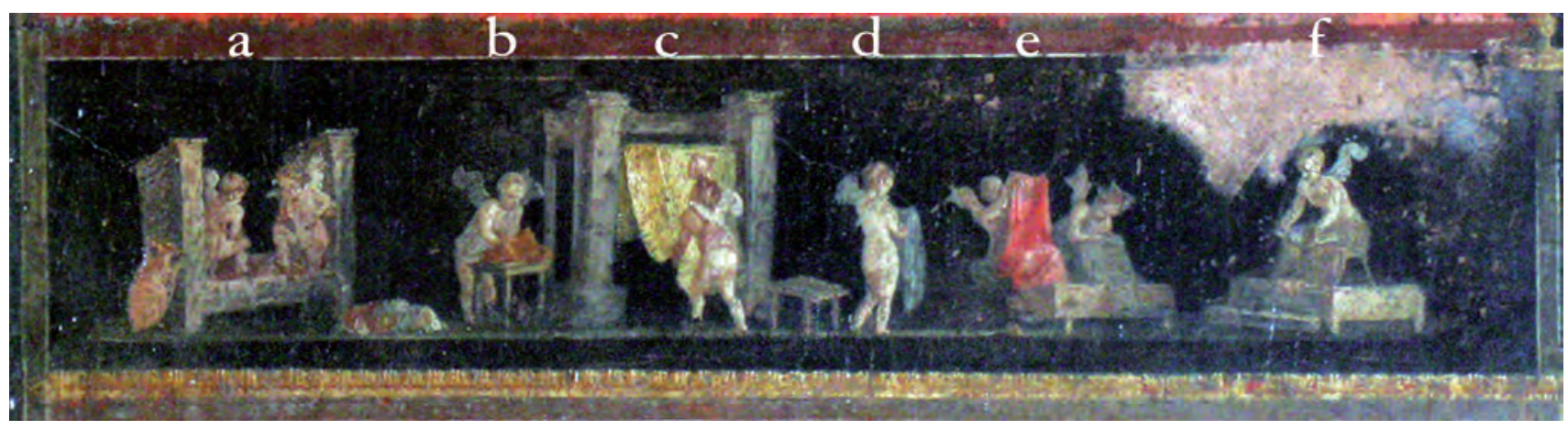

Fig. 95 - Fresque de l'oecus q de la Casa dei Vettii (VI 15, 1.27), paroi est. Cette partie de la frise médiane représente des Amours impliqués dans l'artisanat textile. (a): foulage des vêtements; (b): nettoyage à la main d'une étoffe; (c): extension du linge sur un séchoir; (d-e): un Amour transporte un morceau d'étoffe pour qu'il soit reprisé (?); (f): ultime vérification du linge et pliage.

${ }^{136}$ MANN, Inv. n 9774. Sur cette peinture en général, voir tout particulièrement les remarques de Th. Fröhlich (1991 : 229-236), qui donne une bibliographie conséquente sur ces fresques. Plus récemment, elle a été incorporée par J.R. Clarke dans son étude sur l'art des "Romains ordinaires» (Clarke 2003: 112-118).

137 «Sulla faccia orientale de'suddeti due pilastri e poggetti vedonsi simili porzioni d'intonaco, similmente dipinte a rosso; in una è rappresentata un'ara con due grossi serpenti ravvolti in varie spire; nell'altra un Bacco a chiaroscuro; nella terza un Apollo» (PAH II: 145). Dans la description du Museo Borbonico, il est fait mention en plus d'un fleuve représenté au-dessus de la fontaine située entre les deux piliers (MB 4, 1827 : XLVIII-L, 9). Selon G. Fiorelli (1875: 124), ce fleuve serait la personnification du Sarno. Le pilier sud a été détruit par le temps, n'ayant pas bénéficié du transport au Real Museo Borbonico en 1827 (PAH III : 74).
${ }^{138}$ Fröhlich 1991: 232-233. 
Fig. 96 - Fresque découverte dans la fullonica de L. Veranius Hypsaeus (VI 8, 2.20-21). Ce pilier, originellement situé à l'extrémité orientale du péristyle, a été déposé pour être conservé au MAAN. Les différents cadres sont présentés selon l'ordre de la chaîne opératoire et non comme sur le pilier; les échelles varient en raison de la différence de largeur des deux faces. La première étape de la foulerie est représentée en bas de la face sud (a): quatre hommes sont installés dans des stalles pour y fouler le linge déposé dans des bassines. Dans le cadre au-dessus, les étoffes nettoyées sont peignées et soufrées (b). Sur la face orientale, une presse a été représentée (fig. 105); en dessous est peinte la fin du processus,

la rétrocession des vêtements à leur propriétaire (c).

sur une barre attachée par des cordes, tandis qu'un personnage le peigne (fig. 96, b). À droite, une seconde personne transporte une cage - en osier? - et un petit seau supposé contenir du soufre. C'est du moins ce que l'on peut inférer de la description d'Apulée: le vêtement, après avoir été étalé sur l'armature, est soumis aux vapeurs de soufre, pour décolorer les étoffes blanches ${ }^{139}$. Dans l'angle inférieur gauche, une femme et une servante manipulent une petite pièce tissée ${ }^{140}$. Enfin, sur le côté est, deux cadres présentent la dernière opération du nettoyage - le pressage des étoffes pour leur donner du lustre ${ }^{141}$ - puis, en dessous, la redistribution des vêtements propres à leurs propriétaires (fig. 96, c). Les informations apportées par la fresque de la Casa dei Vettii permettent de définir la succession de ces quatre panneaux. La représentation du brossage sert ici de point de repère, postérieur au foulage. Le panneau sud doit donc être lu de bas en haut - foulage puis les trois autres opérations du panneau supérieur à ordonner -, tandis que le panneau oriental se lit de haut en bas: presse et remise du vêtement au client. La succession des opérations peintes sur le second

${ }^{139}$ Apul., Met., 9, 24, 2, cit. supra, n. 124. Cf. Moeller 1976: 23-24.

${ }^{140}$ Leur taille, plus réduite que celle des deux hommes en train de travailler sur les tissus, serait explicable, soit par un problème de manque d'espace, soit par une importance moindre. Cette association de la maîtresse et de la servante correspondrait, selon Th. Fröhlich (1991: 234), à un schéma courant dans les reliefs funéraires classiques et hellénistiques.

${ }^{141}$ Cf. fig. 106, a, p. 209.
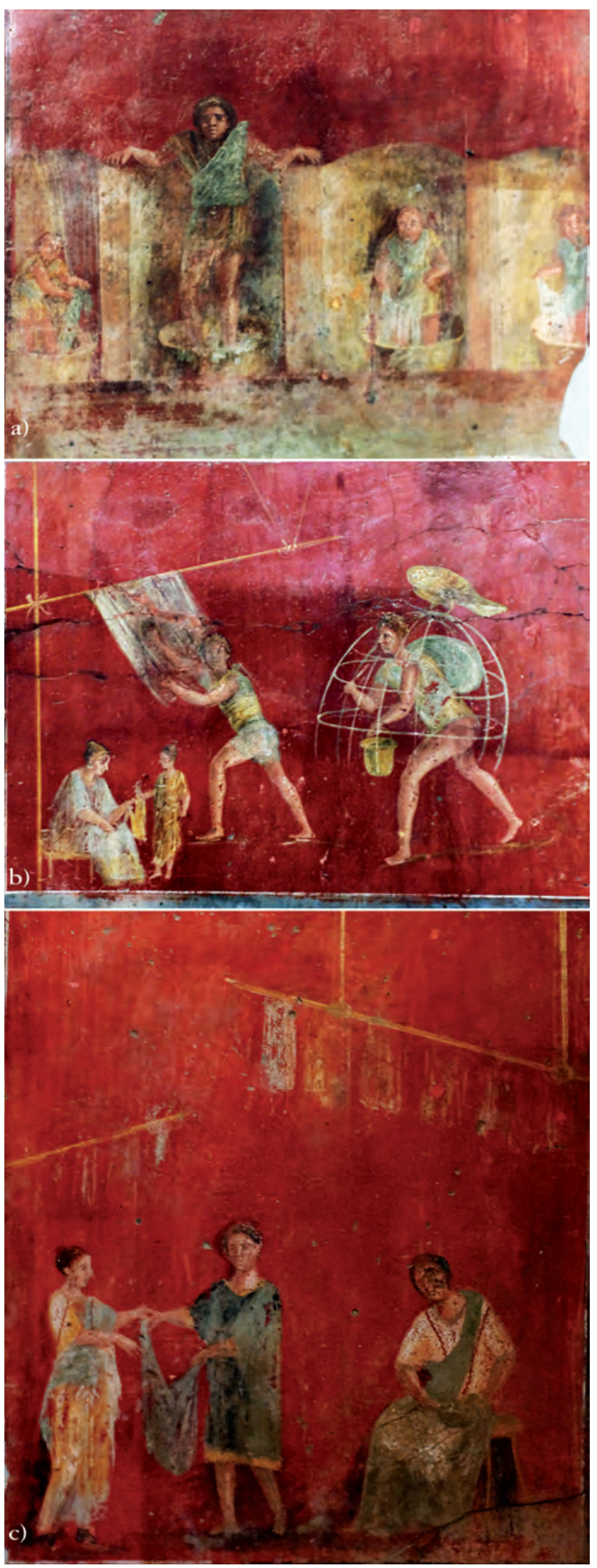
panneau ne saurait être déterminée. Selon les auteurs, le brossage suit le soufrage et inversement, sans aucune justification ${ }^{142}$. Des arguments aussi variés que l'économie de déplacement des étoffes, le sens de marche du porteur de la cage en osier ou l'influence possible de l'humidité du tissu sur l'action du soufre pourraient être invoqués pour aboutir à des conclusions opposées: il n'existe aucun moyen de trancher. En revanche, les attestations littéraires et iconographiques permettent de définir la séquence grossière des opérations se déroulant dans les fouleries: nettoyage des étoffes en les piétinant avec des solutions alcalines; soufrage et brossage - ou inversement - pour redonner de l'éclat aux couleurs et favoriser le feutrage; éventuel passage sous presse pour achever de lustrer le vêtement. Au-delà de la chaîne opératoire, soulignons que de toutes ces opérations, le piétinement est ressenti - ou exprimé - comme la plus caractéristique du métier de foulon ${ }^{143}$.

IV.3.2 Du foulage au lustrage: architecture des fouleries

Que ce soit à Pompéi ou à Herculanum, des fouleries de tailles diverses ont été mises au jour, ou du moins des locaux ont-ils été interprétés en ce sens. Ces espaces artisanaux sont supposés permettre la réalisation des différentes opérations décrites précédemment, à l'exception de la mise sous presse des vêtements pour les lustrer

142 R.J. Forbes (1956: 86) décrit le panneau sud de gauche à droite et de haut en bas, faisant donc suivre le brossage par le soufrage puis par le foulage. J.P. Wild (1970: 83) indique que l'utilisation du soufre se déroule avant celle de l'aena. W. Moeller (1976: 22-24) restitue pour sa part une succession brossage-soufrage. A. Wilson $(2001: 273)$ ne mentionne pas le brossage.

${ }^{143}$ Un relief de Sens (Espérandieu 2768 [IV p. 11-13]), interprété comme le relief funéraire d'un drapier, montre dans sa moitié inférieure un homme en pagne dans un caisson en bois se tenant à une rambarde, illustration gauloise du saltus fullonius.

${ }^{144}$ La liste principale des fouleries est due à W. Moeller (1976: 41-51), complétée par M. Flohr (2007 a); je n'ai pas retenu la foulerie située en IX 13, 5, non fouillée et uniquement identifiée par des inscriptions électorales. Dans la liste qui suit, les fouleries d'interprétation incertaine sont indiquées entre crochets droits: I 4, 7; [I 4, 26]; I 6, 7 ; I 10, 6; qui pourrait n'être qu'un traitement supplémentaire. Les différentes représentations iconographiques de l'activité des foulons montrent toutes des stalles dans lesquelles le foulage est effectué, possible marqueur minimal et indispensable de l'activité.

Commencer parl'étude des locaux pompéiens permetd'utiliserun répertoire deformeséminemment plus varié que ce qu'offre Herculanum: Pompéi disposerait de treize fouleries ayant des aménagements en partie communs ${ }^{144}$. Toutes présentent un système de construction similaire pour les stalles dans lesquelles les foulons piétinent le tissu pour le laver. La version minimale de ces aménagements est constituée par deux murets séparés d'une soixantaine de centimètres, toujours appuyés contre une paroi, de façon à constituer un rectangle fermé sur trois côtés ${ }^{145}$. Les parois de l'espace ainsi délimité sont recouvertes de mortier hydraulique. La partie appuyée contre le mur est systématiquement en pente douce, tandis qu'un bourrelet constitué de béton de tuileau peut être disposé en avant, constituant une barrière pour éviter l'ennoiement des stalles ou que le liquide qu'elles contiennent ne se répande dans le local lors de la manipulation des étoffes. À l'intérieur, une dépression est généralement observée. Selon les descriptions de fouilles, des récipients métalliques y ont été découverts dans la fullonica de L. Veranius Hypsaeus (VI 8, 2.20-21), probablement semblables à celles qui sont représentées

V 1, 2; V 3, 1-2; VI 8, 2.20-21; VI 14, 21-22; VI 15, 3; VI 16, 3-4; VI 16, 6; VII 2, 41; IX 6, a.1. Il est probable que cette liste soit sujette à variation et expansion dans les prochaines années grâce aux travaux de M. Flohr.

${ }^{145}$ Les stalles situées dans la première pièce donnant sur la rue de la foulerie VI 14, 21-22 sont actuellement fermées sur leurs quatre côtés. Le muret qui les ferme à l'est est une restauration, comme le confirme la description donnée au moment des fouilles. Cf. GSP 1875: «1 [aprile]. [...] A sinistra è un podio di fabbrica con un vaso infisso accanto a due muretti addossati alla parete» (cit. in GSPomp, n.s. 3, 1874: 171). Si un mur avait fermé les stalles, le terme de vasca aurait certainement été employé. Le nettoyage de surface effectué en 2007 par M. Flohr (2008: 8-10) en a apporté la vérification, en plus de la mise au jour d'un pavement en cocciopesto rehaussé de tesselles formant la parole salve ainsi qu'une représentation du caducée et d'une corne d'abondance. 


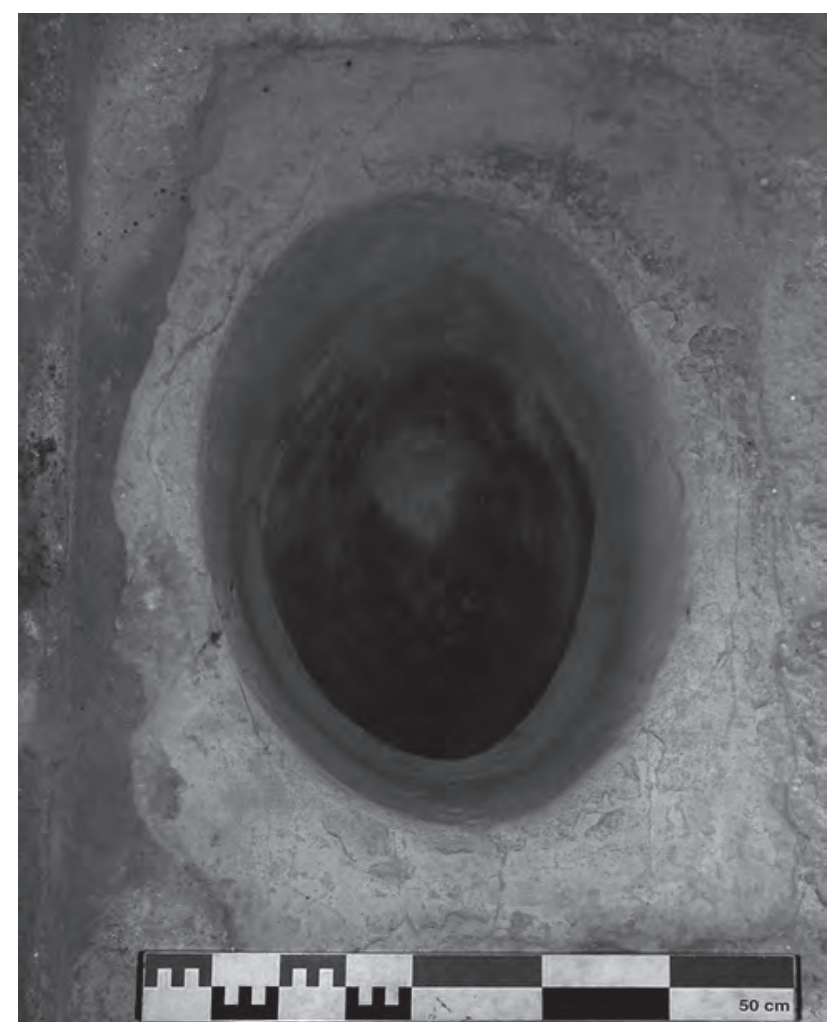

Fig. 97 - Bassine en calcaire dans l'une des stalles de foulage de la fullonica "de Stephanus » à Pompéi (I 6, 7).

sur la fresque ${ }^{146}$; deux de ces stalles ont livré des bassines concaves en calcaire dans la fullonica de Stephanus (I 6, 7) (fig. 97) $)^{147}$. Toutefois, dans la majorité des exemples observés, seule l'empreinte de ce récipient est conservée, empêchant ainsi de déterminer son matériau de fabrication ou sa forme (fig. 98; 99, c-d). L'exemple d'Ostie montre également que des récipients céramiques ont été utilisés pour cela ${ }^{148}$. En association étroite avec ces stalles, se trouvent toujours des conteneurs céramiques englobés dans la maçon-

${ }^{146}$ MB 4, 1827 : XLVIII-L, 14. La mention de ces bassines métalliques est tellement rapide qu'il est impossible de déterminer s'il s'agit juste inférence par rapport à la fresque ou si de tels récipients ont effectivement été mis au jour. La septième stalle, remise au jour par M. Flohr (2008: fig. 6 p. 4), est en calcaire blanc.

${ }^{147}$ Le plan de ce réceptacle est elliptique, long de $51 \mathrm{~cm}$, large de 39. Sa profondeur est de $33 \mathrm{~cm}$.

148 Pietrogrande 1976: 11, 33-39, 62, 81-85; De Ruyt 1996: 7 ; De Ruyt 2001 : fig. 2-3 p. 187.

${ }^{149}$ MB 4, 1827 : XLVIII-L, 14; De Luca 1878.

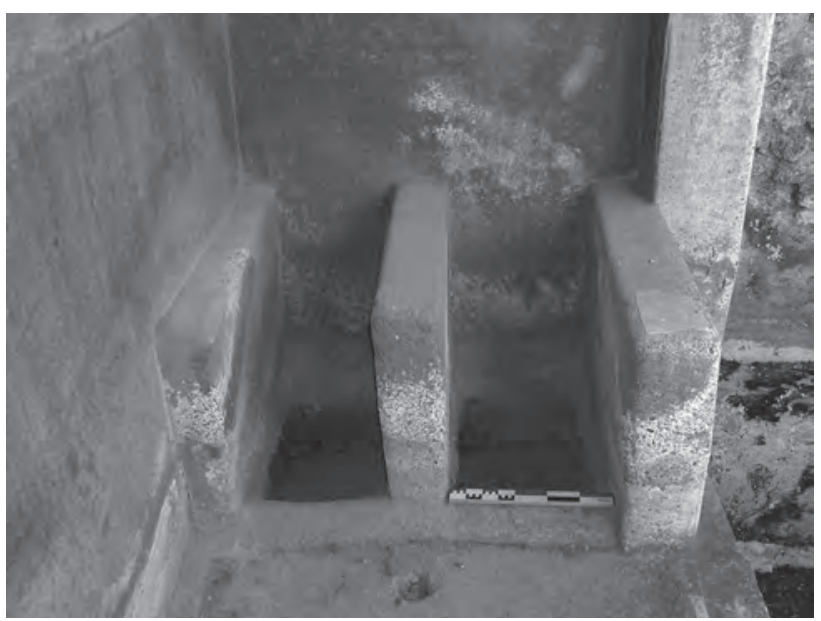

Fig. 98 - Stalles de foulage de la fullonica VI 14, 21-22 à Pompéi. Contrairement à la fullonica «de Stephanus», les bassines en calcaire n'ont pas été conservées. On note également la présence d'un bourrelet de maçonnerie en avant des stalles (cliché pris de l'est).

nerie, dans le muret latéral ou à l'extrémité de la rangée de ces stalles (fig. 99, e). Dans certains de ces récipients, une substance blanchâtre a été découverte, interprétée et analysée comme de la terre à foulon ${ }^{149}$. Ces amphores ou ces dolia constituaient donc une réserve de dégraissant utilisée lors du foulage. Le seul problème de cet aménagement est constitué par sa vidange, particulièrement lorsque la vasque est en calcaire. Faute de tout orifice permettant l'évacuation des liquides utilisés, il faut supposer que le tissu devait servir d'éponge et qu'aucune vidange n'était nécessaire en fin de traitement. Une première distinction peut être effectuée entre les ateliers en fonction du nombre de stalles disponibles, soit entre les locaux disposant de deux d'entre elles et ceux qui en ont au moins trois ${ }^{150}$.

${ }^{150}$ Les locaux suivants disposent de deux stalles: I 4, 7 ; I 10, 6; V 1, 2; V 3, 1-2; VI 15, 3; VI 16, 6; IX 6, a.1. En revanche, les ateliers dont la liste suit en possèdent au moins trois: I 6, 7 (5); VI 8, 2.20-21 (7); VI 14, 21-22 (7+3); VI 16, 3-4 (3). Le décompte proposé par V. Spinazzola (1953: 770) pour la fullonica de Stephanus ne prend en considération que les trois stalles disposées le long du mur oriental, pas les deux autres - dépourvues de vasque en calcaire blanc - situées le long du mur ouest. M. Flohr (2008: 3-4) a remis au jour une septième stalle en VI 8, 2.20-21. 


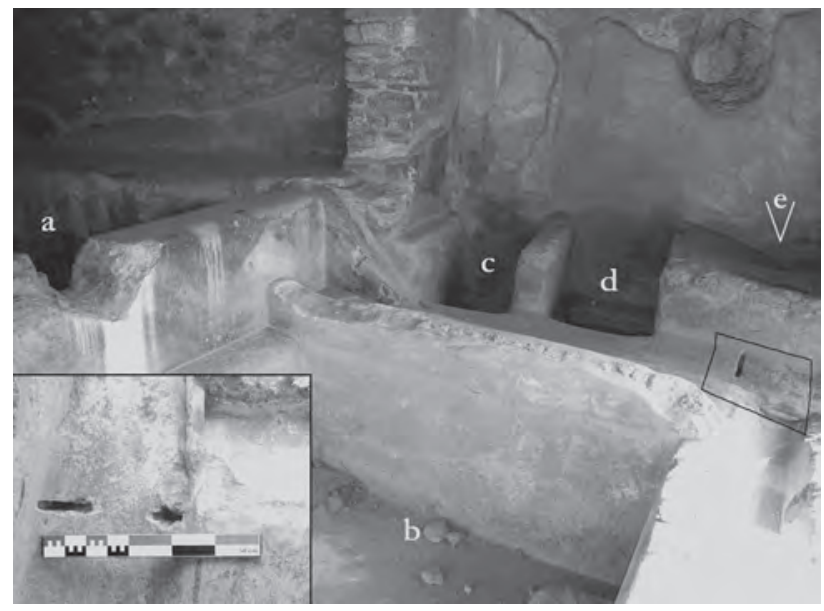

Fig. 99 - Fullonica "de Stephanus» (I 6, 7) ; angle sudouest de la zone de foulerie. Le bassin (a) sert de réservoir pour alimenter ceux qui sont utilisés pour le rinçage (b). À proximité des stalles de foulage (c, d), deux vases sont encastrés dans la maçonnerie pour contenir la terre à foulon (e). Une rigole passe devant ces stalles. Une encoche permet d'insérer une planche (cf. encadré) et d'éviter l'ennoyement permanent de ces dernières (cliché pris du nord est).

Outre ces stalles, certains de ces ateliers présentent plusieurs bassins, disposés en batterie par deux, ou plus fréquemment par trois. Pour autant que mes observations ont permis de

${ }^{151}$ En ce qui concerne le local VI 16, 3-4 (NSc 1906: 348350), la description faite lors de sa découverte ne permet pas de déterminer si des tuyaux en plomb ont été observés ou non; le raccordement au système d'adduction en eau reste hautement probable. En VI 8, 2.20-21, le tuyau de plomb servant à alimenter le bassin situé le plus au sud a été restitué par M. Flohr (2008: 2) qui en a observé l'empreinte.

${ }^{152}$ Un quatrième bassin a priori non lié au rinçage a été mis en évidence par M. Flohr (2008: 3).

${ }^{153}$ Ce système de vidange n'est pas décelable en I 6, 7 . Les trois bassins principaux de VI 8, 2.20-21 disposent chacun d'une bonde propre et se vident par le biais d'un drain qui débouche dans le Vico della fullonica (Flohr 2008: 2-5). Selon A. Sogliano (NSc 1906: 348), les orifices de vidange des bassins de VI 16, 3-4 se jettent dans un collecteur qui se verse dans la rue.

${ }^{154}$ Les volumes en litres des bassins sont les suivants (les astérisques renvoient aux mesures données par Ph. Borgard et M.-P. Puybaret [2003: 310-311]):

\begin{tabular}{|c|c|c|c|c|}
\hline & I 6, 7 & VI 8, 2.21-22* & VI 14, 21-22 & VI 16, 3-4* \\
\hline Premier bassin & 4572 & 4350 & 4169 & 2850 \\
\hline Deuxième bassin & 1887 & 2950 & 3431 & 4000 \\
\hline Troisième bassin & 2802 & 2950 & 3103 & - \\
\hline Total & 9261 & 10250 & 10703 & 6850 \\
\hline
\end{tabular}

le constater, tous ces bassins sont alimentés grâce à des conduites d'eau sous pression ${ }^{151}$. Ils communiquent toujours entre eux, par le biais d'un tuyau en plomb ou en terre cuite souvent inclinés, ce qui fait que le remplissage du deuxième et de l'éventuel troisième bassin se fait par surverse depuis le premier ${ }^{152}$. Dans certains cas, un orifice de vidange est également prévu sur le fond ${ }^{153}$. L'aménagement hydraulique de la fullonica de Stephanus permet de supposer que l'eau était en renouvellement constant: en avant de la surverse, le fond du second bassin est fortement dégradé, signe d'une érosion beaucoup plus importante liée à l'écoulement de l'eau (fig. 100). Le dernier bassin se vide toujours à perte pour conserver un niveau constant. Avec un tel fonctionnement, la quantité d'eau utilisée pour alimenter les bassins était très importante: environ 10.000 litres pour le seul remplissage, le reste de la consommation étant étroitement lié au débit des canalisations à l'arrivée dans chacune des fullonicae ${ }^{154}$. En dépit de son absence de mention dans les textes, l'utilisation de ces bassins ne soulève guère de problèmes. La présence de marches maçonnées en facilite l'accès, dans une masse d'eau généralement haute d'une cinquantaine de centimètres ${ }^{155}$. Les foulons pouvaient donc y porter et en retirer les

Ces volumes correspondent au remplissage maximal compte tenu de la hauteur de la surverse et non au volume maçonné.

155 L'interprétation des marches comme bancs de travail pour le processus de rinçage, proposée par M. Flohr (2005 a: 60-61), ne semble guère fondée. En effet, les «bancs» courent toujours le long d'une portion infime des bassins. S'ils avaient été construits uniquement pour s'asseoir, ils auraient eu une longueur supérieure ou les bassins auraient été réduits. Il reste toutefois possible qu'ils aient servi d'abord de marches et éventuellement de bancs, mais aucune trace ne permet de s'en assurer. La seule exception à cette omniprésence de marches est constituée par le premier bassin de la fullonica de Stephanus qui n'est pas facilement accessible. Sa hauteur d'eau maximale est de $93 \mathrm{~cm}$. Selon Ph. Borgard et M.-P. Puybaret (2003: 310), il s'agirait d'une réserve d'eau plus que d'un bassin de rinçage. Il me semble que la raison d'être de cette réserve doit être cherchée dans l'éloignement par rapport aux châteaux d'eau secondaires et aux éventuelles chutes de pression - et donc d'alimentation - pouvant en résulter. 
vêtements mis à rincer, l'eau courante, éventuellement suppléée par un brassage manuel, facilitant ce processus. Par ailleurs, le renouvellement constant permet d'éviter la concentration progressive des substances détergentes et donc d'améliorer la qualité du rinçage ${ }^{156}$. En revanche, aucune information ne peut être obtenue ni sur la durée du rinçage, ni sur l'alternance de cette opération avec le foulage.

Les autres aménagements susceptibles d'avoir été présents dans ces ateliers - presses exceptées -, tels que les cages en osier, les espaces de séchage et de brossage des vêtements n'ont guère laissé de traces. Avant de voir quelques combinaisons avec d'autres activités liées au textile dans certains de ces ateliers, il faut revenir sur les différentes fouleries qui ne disposent pas de bassin. En effet, la seule présence des stalles très standardisées a laissé plus d'un auteur dubitatif quant à la réelle destination des locaux dans lesquels elles ont été découvertes ${ }^{157}$. Pourtant, ces constructions, dûment pourvues d'une réserve de terre à foulon, et parfois d'une arrivée d'eau clairement signalée, sont les seules traces permettant d'identifier une foulerie $a$ minima ${ }^{158}$. En effet, les bassins peuvent avoir été constitués par des baquets en bois, qui offrent des qualités de rinçage certainement inférieures à celles des bassins maçonnés mais permettent tout de même cette opération ${ }^{159}$. Les presses paraissent n'être présentes que dans les plus

${ }^{156}$ Voir sur ce point les remarques de M. Flohr (2005 a: $60)$ qui suppose un rinçage par paliers successifs remontant le cours des bassins.

${ }^{157}$ Le meilleur exemple est constitué par le local I 10, 6, qui présente deux stalles, dont l'interprétation n'a cessé de soulevé des doutes et des précautions, que ce soit de la part d'O. Elia (NSc 1934: 276), de R. Ling (1997 a: 147) et même de W. Moeller (1976: 43).

${ }^{158}$ Dans la très discutable remise en cause des procédés de foulerie qu'il a menée, M. Bradley (2002: 26-27) dresse une liste de critères permettant la distinction de ces ateliers. La majeure partie des éléments qu'il indique est soit optionnelle (presse), soit susceptible de n'avoir laissé aucune trace, même à Herculanum ou Pompéi (jarres pour récolter l'urine, restes de soufre ou de terre à foulon). M. Flohr (2005 a: 5960 ), après avoir avancé d'autres critères - priorité des bassins sur les stalles et réduction des fouleries pompéiennes à six -, guère plus satisfaisants, est revenu sur cette interprétation et propose désormais également de distinguer les fouleries une fois les stalles dûment identifiées (Flohr 2007 b: 132).

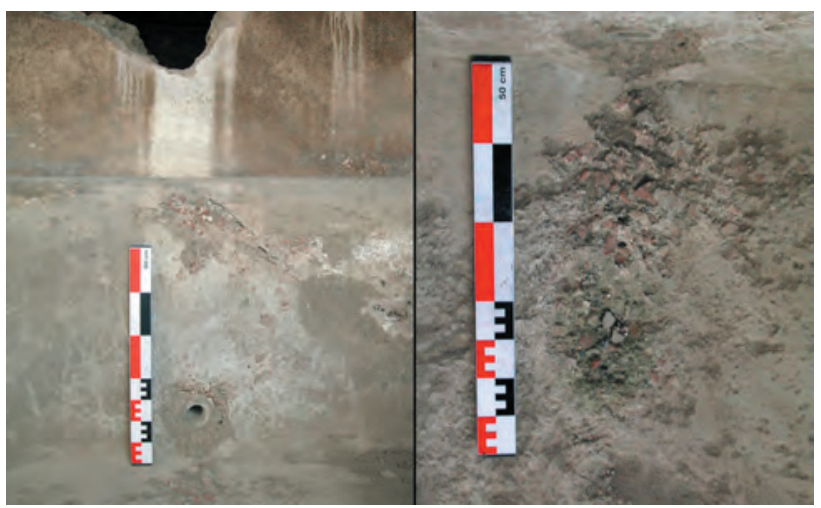

Fig. 100 - Fullonica «de Stephanus» (I 6, 7), paroi sud et fond du second bassin de rinçage. La paroi sud est percée d'une surverse (à gauche, en haut) et d'une conduite en plomb, à probable débit continu comme l'indique l'importante érosion du fond du bassin en correspondance du tuyau (à droite).

grands établissements pourvus de plusieurs bassins - exception faite du local VI 16, 3-4 $4^{160}$. Les rares sources littéraires mentionnant leur utilisation montrent qu'elles ne sont pas une étape obligatoire dans les différents traitements auxquels le linge est soumis. La meilleure illustration de cette simplicité des aménagements minimaux est procurée par le local VI 14, 21-22. Dans la boutique 21, une partie de la paroi méridionale est occupée par trois stalles et un récipient emmuré pouvant avoir contenu les détergents utilisés. D'autres activités probablement liées au textile se déroulaient également dans ce

${ }^{159}$ La recherche de vasques maçonnées de dimensions réduites serait pourtant nécessaire. Ainsi, dans sa description du local VI 16, 6, A. Sogliano (NSc 1906: 350) signale non seulement les deux stalles, mais également «gli avanzi di una bassa vasca » en avant de ces dernières. Ce petit bassin n'est pas mentionné sur le plan (NSc 1906: fig. 1 p. 346). Lors de l'étude de la Casa degli amorini dorati, F. Seiler (1992: fig. 511) a remis au jour cette vasque. Toutefois, sa profondeur reste non mentionnée. Il n'est guère douteux que des nettoyages systématiques des sols des fullonicae permettraient d'avoir une vision plus claire sur ce problème, comme l'a démontré M. Flohr (2007 b: 133 et map 2 p. 132) en étudiant en détail le bassin, les stalles et le système d'évacuation des eaux en VI 15, 3.

${ }^{160}$ Sur les presses dans les fouleries, cf. infra, p. 208213. Selon M. Flohr (2008: 12), une presse se serait trouvée en VII 2, 41. Cependant, les traces qu'il mentionne paraissent par trop éloignées des seules qui sont encore observables, en I 6, 7. 
local selon les journaux de fouilles ${ }^{161}$. L'espace considéré comme faisant partie de la fullonica a longtemps supposé être cantonné au péristyle occupé par les bassins et aux stalles situées au sud-ouest et au sud-est de ce dernier ${ }^{162}$. Il apparaît au contraire que le doublement de ces installations traduit une extension progressive des activités de foulerie: d'une première officine simple dans la boutique, cette implantation textile s'est considérablement développée avec l'installation à l'arrière de la maison de quatre autres stalles et des trois bassins, sans pour autant démanteler les premiers aménagements, avant de s'agrandir encore par l'ajout de trois autres stalles au sud-est du péristyle ${ }^{163}$.

Pour compléter cette rapide analyse des fouleries pompéiennes, il faut encore mentionner le cas de l'atelier situé en VI 16, 3-4 qui présente, dans la pièce située au sud, trois vasques de foulage et deux bassins de rinçage. Lors de sa création, après le séisme de 62 selon F. Seiler ${ }^{164}$, d'autres équipements liés au textile ont été construits. Il s'agit de deux chaudières "basses» 'évoluées', dont une seule est bien conservée avec son récipient en plomb, d'un bassin et de tables maçonnées qui ne sont pas collées au mur et permettent ainsi le travail de plusieurs ouvriers en même temps; autant d'aménagements à rapprocher de la salle souterraine de l'atelier I 8, 19. Le local VI 16, 3-4 disposait ainsi des éléments initial et final de la transformation de la laine en vêtement: le lavage des toisons et les travaux de finition sur le tissu ${ }^{165}$.

Ces différents éléments du travail en foulerie permettent de discerner les locaux d'Herculanum pouvant avoir été impliqués dans l'ars fullonia. Le premier d'entre eux se trouve dans une maison qui doit son nom à cette activité, la Casa della fullonica (IV, 5-7; cat. $\mathrm{n}^{\circ} 7$ ). Les informations concernant son dégagement sont inexistantes ou peu s'en faut. Fouillée entre le 23 novembre 1928 et le 29 mars 1932, seules
${ }^{161}$ GSP 1875: «1 [aprile]. Essendosi eseguito uno scavo straordinario nella Reg. VI, Is. 14a, lato orientale, bottega n. 21, si è raccolto: Bronzo. Due secchie, un vaso cilindrico, una lagena, una misura, una stadera, e quattro placche rettangolari, ognuna a doppia lamina, frammezzo alla quali è un tessuto di lana: formavano forse una macchina che serviva per la confezione di qualche tessuto. Sopra una delle placche er auna figurina di Cerere con cornucopia giacente in una conchiglia, di sotto alla quale vedesi un toro. Insieme alle placche fu rinvenuto un cilindro di piombo. [...] Ferro. Una specie di forchetta con corto manico e con quindici denti molto sottili, e una grande forbice. Piombo. Un peso con la leggenda ЕмE ed наввев. Sul pavimento della medesima bottega vedesi a musaico il motto salve e due falli. A dritta è praticato nel pavimento un incavo, che serviva per l'imbasamento di qualche sostruzione di legno [...]» (cit. in GSPomp, n.s. 3, 1874: 171; cf. supra, n. 145). Les objets découverts les 29-30 janvier et le 12 février 1875 n'apportent pas d'informations supplémentaires sur les activités effectuées (cf. GSPomp, n.s. 3, 1874: 167-168). Cette description donnée à la fin de la fouille de la boutique VI 14, 21 suggère, notamment par les outils en fer, un travail du textile autre que celui de la foulerie. En revanche, les plaques en bronze double enfermant de la laine devraient être observées avant de conclure, comme l'a fait M. Flohr (2005 b: 59), qu'elles témoignent de la présence d'une presse. Tout au moins ces plaques ne semblent pas s'insérer dans un tel instrument tel qu'il est possible de le restituer à partir des autres exemples pompéiens (cf. infra, p. 210 sq.).

${ }^{162} \mathrm{Ph}$. Borgard et M.-P. Puybaret (2003: 311) ne dénombrent ainsi que les sept stalles situées autour des bassins, en suggérant cependant leur augmentation de quatre à sept en deux phases. M. Flohr (2005 b: 59) signale bien des activités de productions dans cette boutique, mais limitées à la seule finition des vêtements, en dressant un parallèle avec la fullonica de Stephanus, dans l'entrée de laquelle se trouve la presse, mais où aucune vasque n'est présente.

${ }^{163}$ Cette interprétation planimétrique et fonctionnelle a été confirmée par le nettoyage effectué par M. Flohr (2008: 8-9). Son étude des rapports entre le sol mosaïqué (cf. supra, n. 145), les stalles, l'enduit peint et l'ouverture d'une porte donnant sur l'atrium montre qu'après une boutique présentant l'inscription en mosaïque, s'installe une première foulerie. Ce n'est que dans un troisième temps, après le séisme de 62 (Flohr 2005 b: 58-59), que les bassins et quatre stalles sont installés dans le péristyle, concomitamment avec l'ouverture d'une porte entre l'atrium et l'ancienne foulerie.

${ }^{164}$ Seiler 1992: 83, pl. 96.

165 Cette association entre ces deux activités est plus étonnante que celle entre le nettoyage des toisons et la teinturerie observée en I 8, 19 (cf. Borgard - Puybaret 2004: 57-58): la teinture sur toisons permettait ainsi de livrer un produit semi-fini pour le filage, sans intermédiaire. Il serait nécessaire d'approfondir l'étude du local VI 16, 3-4. La vaste pièce $G$, d'une surface supérieure à la somme des deux autres, ne présente aucun aménagement. Le compte rendu de sa fouille ne propose aucun élément supplémentaire (NSc 1906: 348-350). Qu'une telle surface ait été laissée inoccupée est pour le moins curieux. Peut-être faudrait-il y restituer un espace de filage et de tissage, faisant de ce local un ensemble textile intégré, du nettoyage des toisons à la finition des vêtements. 
l'avancée de son étage sur la rue et les trois portes ouvrant sur le cardo IV sont décrites de façon un peu détaillée ${ }^{166}$. Au total, trois objets y ont été inventoriés et un nombre indéterminé d'amphores mis au jour ${ }^{167}$. Une interprétation ne peut être proposée qu'en se fondant sur les aménagements maçonnés subsistant. Le long du mur nord de la pièce principale située immédiatement après l'entrée IV, 6 , les vestiges de deux stalles sont encore visibles, en dépit de l'effondrement partiel entre 1998 et 2002 de la paroi sur laquelle elles s'appuient. Les trois murets constituant leurs côtés sont larges de 23 à $28 \mathrm{~cm}$ et longs de $81 \mathrm{~cm}$ et sont recouverts d'enduit de tuileau. Le muret occidental est conservé en élévation, sur une hauteur minimale de $85 \mathrm{~cm}$. Les deux autres comportent chacun un long vase emmuré. L'empreinte du premier est seulement perceptible, mais le fond du second est encore en place. Dans celui-ci, sous une faible épaisseur de matériel éruptif subsistant, une substance blanchâtre a été observée (fig. 101). Une photo d'archive montre également que les deux stalles étaient protégées par un bourrelet couvert d'une imbrex, ainsi que deux pentes qui se rejoignent pour faciliter la vidange (fig. 102). L'interprétation proposée par A. Maiuri est parfaitement justifiée : ces deux stalles correspondent bien à l'équipement minimal permettant de caractériser une foulerie ${ }^{168}$. En revanche, le fait que les deux conteneurs emmurés aient contenu de l'urine, comme proposé par W. Moeller, est peu probable ${ }^{169}$ : à titre d'hypothèse, en attendant d'éventuelles analyses, je considérerais plutôt que ces vases ont contenu de la terre à foulon. Remarquable attestation d'une foulerie - bien que fort endommagée -, l'atelier de la Casa della fullonica paraît isolé si l'on s'en tient aux propositions d'A. Maiuri.

${ }^{166}$ La date du 29 mars 1932 correspond à la dernière mention de travaux dans les GSE. Celui-ci a pourtant dû se prolonger ensuite, le relevé des dégagements publié par A. Maiuri (1932: pl. h.t. [p.58-59]) dans son ouvrage sur Herculanum montrant un plan incomplet pour cette maison.

${ }^{167}$ Un pot céramique très ouvert a été découvert dans l'entrée IV, 6 (Inv. n E399=75675). Une clochette en bronze (Inv. $\left.{ }^{\circ} \mathrm{E} 402=75679\right)$ a été trouvée en IV, 5. Des amphores

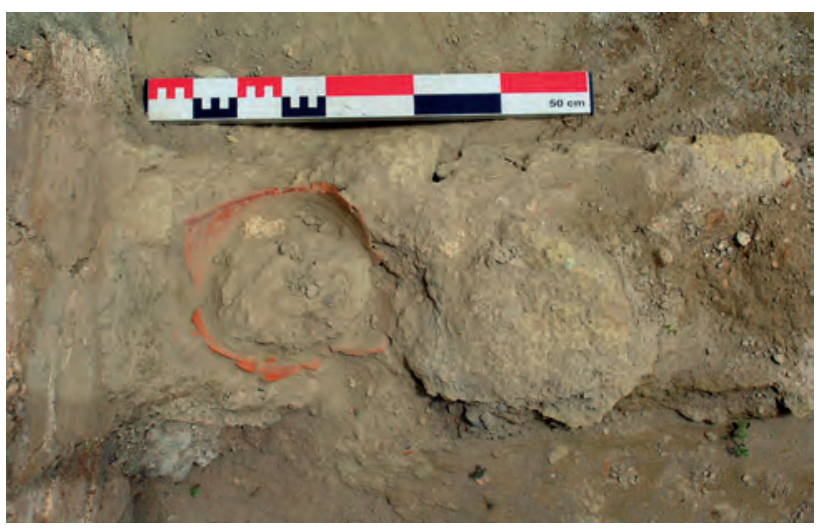

Fig. 101 - Casa della fullonica (IV, 7), pièce 9. Vestiges de l'appui oriental de la seconde stalle de foulage. Le fond du vase ayant contenu de la terre à foulon est encore en place. Sous le matériel éruptif, une substance blanche apparaît, probablement de l'argile utilisée pour le nettoyage des vêtements.

Deux autres locaux pourraient avoir abrité des officines similaires. Dans la boutique V, 34, immédiatement au nord de la fosse ouverte lors des travaux initiés avant l'éruption, appuyé non seulement contre l'enduit correspondant à la création cette boutique, mais également contre un muret, se trouve un second muret large d'au moins une quinzaine de centimètres. Un vase a été inséré dans cette construction, contre la paroi occidentale. Pour endommagé et limité qu'il soit, cet ensemble pourrait constituer le témoignage d'une foulerie encore inachevée en 79. Ma seconde hypothèse semblerait presque plus hasardeuse. La pièce située à l'extrémité occidentale de la Casa a graticcio (III, 13-15) dispose de trois bassins qui lui ont donné son premier

en nombre indéterminé, dont l'une porte l'inscription VINO (non reportée dans le Corpus; cf. GSE 1931: 18 dicembre), proviennent d'un espace indéterminé situé au-delà de la porte IV, 5. Enfin, une monnaie de bronze a été découverte le 16 mars 1932 (Inv. n E795=76072).

${ }^{168}$ Maiuri 1958 b: 422 . Le refus de cette interprétation par M. Bradley (2002: 25 et fig. 7 p. 25) tient certainement à l'état dans lequel il a vu ces stalles, envahies de végétation.

${ }^{169}$ Moeller 1976: 113. 


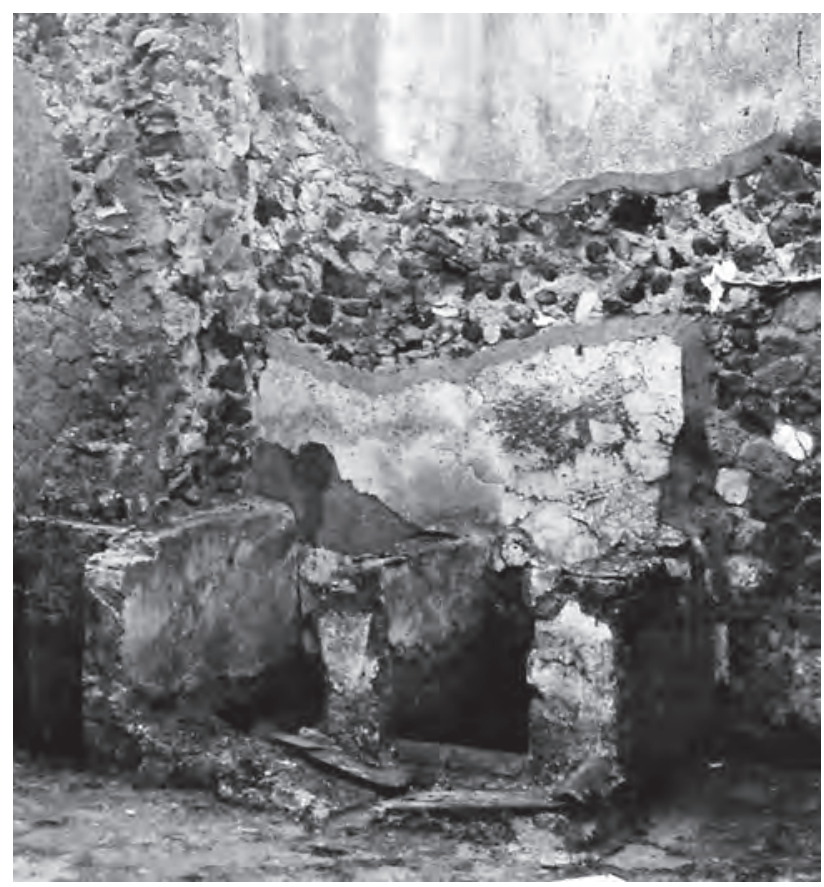

Fig. 102 - Casa della fullonica (IV, 7), pièce 9. Sur ce cliché pris en 1941, les deux stalles sont intactes. Outre l'ouverture d'un vase à l'extrémité nord de l'appui central, on note la présence d'un bourrelet maçonné fermant la stalle de droite. Un plan incliné a été aménagé en avant de ces deux équipements (cliché pris du sud-est).

nom lors du dégagement ${ }^{170}$. Aucune mesure n'est jamais donnée mais ces bassins sont représentés sur les plans publiés par A. Maiuri ${ }^{171}$. Parmi les autres aménagements présents dans cette pièce on observe la bouche d'une citerne et le fond d'une petite vasque maçonnée, situé dans l'angle nord ouest ${ }^{172}$. Des restes de béton

${ }^{170}$ GSE 1927: «14 ottobre. [...] Nello scavo C s'è incominciato lo svuotamento degli ambienti terranei. In quello che trovasi alle spalle del lato sinistro della Casa dello scheletro numero $\mathbf{M}$ per terra trovasi una vasca a forma bislunga. Nessun trovamento.

17 ottobre. [...] Nello scavo C numero M una seconda vasca è stata trovata nello stesso ambiente. Esse non sono state ancora liberate dal materiale di risulta e quindi nessuna dimensione può descriversi ».

Le lendemain, 18 octobre, cette partie de la Casa a graticcio devient la "casa chiamata provvisoriamente delle vasche». Lors de la description finale de la maison, les bassins sont devenus trois (GSE 1929: «23 febbraio. [...] Percorrendo il corridoio lato nord in fondo ad esso in un ristretto spazio vi sono 3 vasche con qualche avanzo di calce

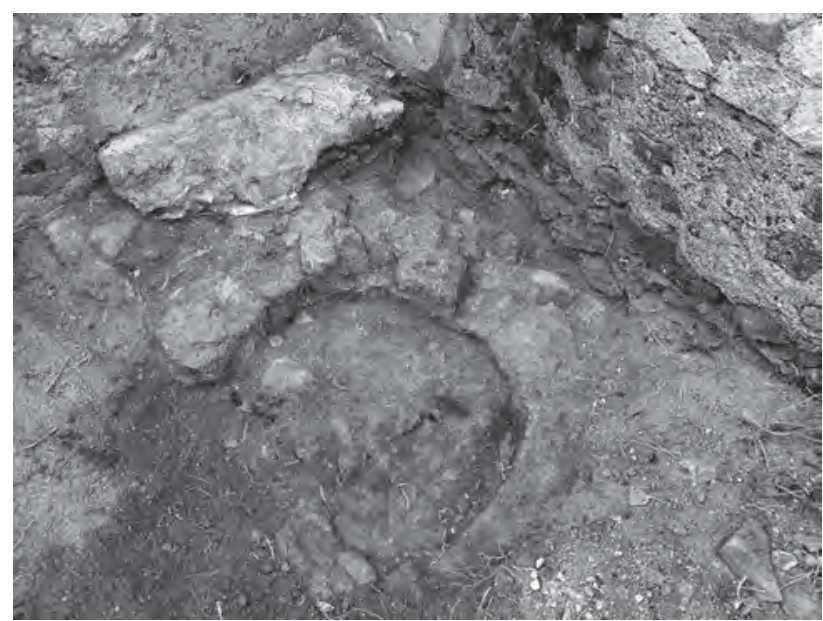

Fig. 103 - Casa a graticcio (III, 13-15), pièce 13. Vestiges de deux aménagements dans l'angle nord-ouest de la pièce au sud de laquelle trois grandes vasques ont été mises au jour. Contre le mur ouest, le fond d'un petit bassin, est reconnaissable grâce à l'emploi d'un béton de tuileau. Dans sa continuité, à l'est, un aménagement circulaire ressemble à la base d'une chaudière «basse » (cliché pris du sud-est).

hydraulique peuvent encore être observés tant sur le mur nord que sur le fond proprement dit. Cette vasque se trouve à l'extrémité de ce qui semble être une table maçonnée - arasée - dans laquelle une cavité circulaire a été ménagée (fig. 103). Ces différents aménagements ne sont pas sans rappeler l'équipement "standardisé» des laveries de toisons, si l'on est prêt à considérer la cavité circulaire comme l'empreinte d'une chaudière. Néanmoins, aucune de ces officines, à Herculanum ou Pompéi n'est dotée de véritables bassins, qui semblent plutôt carac-

un piccolissimo portico, ed all'altezza di m. 2.10 dal pavimento della casa nell'angolo nord est una latrina $[\ldots]$ ».

${ }^{171}$ Maiuri 1958 b: 416 et fig. 345 p. 407.

${ }^{172}$ La cavité circulaire correspondant probablement à une chaudière fait $75 \mathrm{~cm}$ de diamètre. La vasque est incomplète, ses dimensions minimales sont de $30 \mathrm{~cm}$ de large et $70 \mathrm{~cm}$ de long. Ces deux éléments ont été décrits lors de la fouille.

GSE 1927: "20 ottobre. Nello scavo C e precisamente nella casa delle vasche I al lato sinistro di chi entra attaccato tra il muro di questa casa e quello del peristilio che trovasi al lato nord è uscito una piccola vasca semicircolare essa si sopraeleva dalle altre per m. 0.70 e nell'interno di essa è stata trovata una quantità di polvere di stucco? Detta vasca misura m. 0.50 di diametro. Alla distanza di m. 1 attaccato 
téristiques des plus grandes fouleries. En l'état, il est impossible de se prononcer de façon définitive; proposer qu'une activité liée au textile se soit déroulée dans la Casa a graticcio reste une hypothèse de travail.

En partant des sources littéraires, complétées par les représentations iconographiques, j’ai restitué les différentes opérations des processus de foulerie et tenté de les replacer dans leur contexte spatial par la compréhension des vestiges matériels. Quelques points flous subsistent néanmoins dans cette reconstitution. Le foulage dans des stalles avec des détergents minéraux et animaux est au cœur de ces opérations, précédant ou alternant avec le rinçage dans des bassins dont la taille et la conception dépendent de l'extension des activités. Il est probable que le lustrage avec brosses vienne ensuite, une fois le tissu sec et peut-être ravivé dans ses couleurs par sulfuration. L'examen des ateliers de Pompéi a montré une remarquable dichotomie entre les plus grands, disposant de nombreuses stalles, de bassins et d'une presse, et les autres, seulement pourvus du matériel minimal: deux à trois stalles et parfois une petite vasque maçonnée. Cette distinction ne se retrouve pas à Herculanum, où la seule officine clairement identifiée est d'envergure modeste. Quand bien même les deux hypothèses proposées $(\mathrm{V}, 34$ et III, 14) viendraient à être démontrées, elles ne constitueraient pas des ateliers de grande ampleur. Cette division très stricte entre les fouleries implique une différence à la fois quantitative et qualitative sur le plan des vêtements traités. Bien que jamais le nombre de stalles ne soit équivalent à celui que l'on trouve

alla parete est è uscita un'altra vasca di forma circolare avente il diametro di m. $0.40[\ldots]$ ». Deux erreurs sont à signaler dans cette description. La pièce I est censée correspondre au jardin de la Casa del tramezzo di legno; toutefois la mention de la Casa delle vasche renvoie à la Casa a graticcio. La première vasque décrite ne paraît pas semi-circulaire mais rectangulaire.

${ }^{173}$ Maiuri 1932: 60 et fig. p. 58. Un second pressoir à vis en bois a été mis au jour dans le Fayoum. Il est exposé au musée d'Alexandrie. Selon J.-P. Brun (1993 b: 545), il daterait du $\mathrm{II}^{\mathrm{e}}$ siècle de notre ère. R.J. Forbes (1955: 137) le décrit comme possédant deux vis et identique à la description faite au livre III, 19 du traité de mécanique de Héron d'Alexandrie, au milieu du $\mathrm{I}^{\text {er }} \mathrm{s}$. de notre ère. Pour des traductions française et anglaise de ce texte, assorties d'un commentaire de A.G. Drachmann, cf. Drachmann 1963: 126-133, Carra de Vaux 1988: 207-211, 293-298. à Ostie, plus celui-ci augmente, plus les possibilités de rotation des vêtements - et donc de production élevée - deviennent importantes. De la même façon, la présence, dans les plus grands établissements pompéiens, d'une presse pour le lustrage final est un indice de la qualité du nettoyage effectué.

\section{IV.4 Une réinterprétation de la presse "à vête- ments » de l'atelier III, 10 à Herculanum}

Le constat que les fouleries d'Herculanum étaient peu nombreuses et plutôt de taille réduite, pourrait être remis en cause par le pressoir découvert en juin 1928 dans la boutique III, 10, située à l'angle nord-est de la Casa del tramezzo di legno (cat. $\mathrm{n}^{\circ}$ 5). Jusqu'à présent, il a été interprété comme utilisé dans le cadre de l'artisanat textile, pour lustrer les étoffes à la fin du processus de nettoyage. Pourtant, A. Maiuri n'a guère approfondi cette hypothèse dans les différentes publications concernant les nuovi scavi. Dans son premier ouvrage sur Herculanum, il se contente de proposer que cette presse ait pu servir «à plier et à étirer les draps et les étoffes que l'on exposait ensuite sur les rayons de simples étagères ", après avoir insisté sur la conservation et la restauration de cet objet unique dans l'Occident romain, et ce malgré une probable première interprétation comme presse à huile ${ }^{173}$. Dans sa synthèse de 1958, il reprend cette description sans en exposer les fondements, autrement que par une comparaison entre ce pressoir et celui représenté sur la fresque mise au jour dans la fullonica de L. Veranius Hypsaeus (VI 8, 2.20-21)
La première interprétation comme presse à huile est clairement indiquée dans un article du Times, en date du 7 décembre 1928 (p. 15): "Interesting also is a wooden oil press used for crushing olives and of a type identical with those used to this day". Selon I. C. McIlwaine (1988: n 3.545 p. 383), cette interprétation serait également reproduite dans le numéro du 20 décembre 1928 du Telegrafo della Sera. En revanche, le Times, dans son édition du 6 novembre 1931, dans l'article intitulé « Ancient secrets. The search for the keys» (p. 16), qui fait suite à un article d'A. Maiuri (1931 b), la presse est indiquée comme ayant été utilisée pour des pièces d'étoffe. Ce changement dans l'interprétation est ensuite repris, sans explication, dans le guide des fouilles (Maiuri 1936: 34). 
à Pompéi ${ }^{174}$. Une telle comparaison, tant d'un point de vue morphologique que fonctionnel pose plusieurs problèmes.

La presse découverte en juin 1928 dans la boutique III, 10, située à l'angle nord-est de la Casa del tramezzo di legno, est un cadre en bois formé par deux montants de $12 \mathrm{~cm}$ de large pour $27 \mathrm{~cm}$ d'épaisseur; leur hauteur conservée est de $150 \mathrm{~cm}^{175}$. Aucune précision n'est donnée quant à leur mode de fixation dans le sol ${ }^{176}$. Ces jumelles sont reliées par un banc horizontal long de $105 \mathrm{~cm}^{177}$. L'assemblage précis de ces différentes pièces entre elles est difficile à établir à cause des restaurations modernes. Toutefois, la description des GSE indique clairement qu'une mortaise a été ménagée dans chaque jumelle. Le maintien du banc aux jumelles paraît avoir été assuré par l'enfoncement de coins ${ }^{178}$. Au centre de cette pièce horizontale, un écrou permettant le passage d'une vis de $9 \mathrm{~cm}$ de diamètre a été creusé. Bien que les journaux de fouille décrivent un banc monoxyle, il est en fait constitué par

174 «[... Il suo carattere e la sua destinazione ci sono fortunatamente attestati [...] da un torchio di legno che, come diremmo in seguito [je souligne], per la sua forma e le sue dimensioni, non può essere altro che un pressorium per i panni [...]» (Maiuri 1958 b: 220). Dans la note qui est supposée éclairer ce passage, il renvoie aux ouvrages de J. Overbeck et de V. Spinazzola pour affirmer la ressemblance entre les deux pressoirs (Maiuri 1958 b: n. 33 p. 471).

${ }^{175}$ Selon les journaux de fouille, cette hauteur est minimale: sans qu'aucune explication ne soit fournie, les deux piliers ne touchent pas le sol. GSE 1928: «20 luglio. [...] Il congegno di legno carbonizzato è stato isolato e risulta una pressa. I due pilastri esterni sono attualmente alti m. 1.50 ma erano ancora più alti, perché la parte inferiore ora non tocca il pavimento ».

${ }^{176}$ Lors de la description finale de la Casa del tramezzo di legno, effectuée après la restauration, les données métriques de la presse ont subi quelques modifications. Les piliers font désormais $171 \mathrm{~cm}$ de haut, leur écartement est porté de $84 \mathrm{~cm}$ à $90 \mathrm{~cm}$. Ces transformations sont certainement à mettre en relation avec les « véritables cages vitrées » (Maiuri 1932: 60) utilisées pour protéger la presse.

${ }^{177}$ Hauteur: $21 \mathrm{~cm}$; épaisseur: $23 \mathrm{~cm}$. La description faite dans les GSE n'est pas en adéquation avec la reconstitution visible actuellement sur le site: GSE 1928: «20 luglio. [...] A m. 0.26 dall'estremità superiore si trova un incasso nel quale è fissato un traversone che è lungo m. 1.05 pari alla distanza che passa dai due estremi dei pilastri. [...] Al centro di esso e cioè a m. 0.26 dalla faccia interna di ciascun pilastro vi è piazzato un cilindro superficialmente circondato da una spirale [...]». Tel qu'il est décrit, le banc ne devrait deux traverses assemblées grâce à deux bardes en métal disposées de part et d'autre de l'écrou, encore visibles en dépit de la corrosion. La vis est haute de $93 \mathrm{~cm}$, mais son amplitude maximale est limitée à environ $60 \mathrm{~cm}$, à cause de l'augmentation de son diamètre à sa base. Le plateau de transmission de la pression est une planche carrée de $62 \mathrm{~cm}$ de côté, épaisse de $7 \mathrm{~cm}$. La maie est monoxyle et épaisse de $10 \mathrm{~cm}$. Deux rainures longitudinales de section quadrangulaire ont été pratiquées sur sa face supérieure (fig. 104). Comme le font très justement remarquer les rédacteurs des GSE, ces deux saignées permettent l'écoulement d'un liquide ${ }^{179}$. Aucun élément n'aide à définir le mode de fixation de la maie aux jumelles, faute de description ou de mise au jour d'une pièce de bois transversale permettant de fermer le cadre dans lequel est inséré la vis. L'ensemble paraît avoir été fixé par rapport aux murs par le biais de plusieurs poutrelles d'un diamètre de $6 \mathrm{~cm}^{180}$. Enfin, bien qu'obstrués, les deux orifices orthogonaux servant de logement

pas dépasser des jumelles dont l'écartement, mesuré à l'extérieur, serait justement de $105 \mathrm{~cm}$. Pourtant, avec les indications qui sont données quant à la localisation de l'écrou un rapide calcul amène à réduire cet écartement des jumelles: $2 \times 26 \mathrm{~cm}$ (distance interne des jumelles - écrou) $+6 \mathrm{~cm}$ diamètre de la vis $+2 \times 12 \mathrm{~cm}$ (épaisseur des jumelles) $=82$ $\mathrm{cm}$. Il s'ensuit que soit le banc a été coupé au remontage - il devrait dépasser d'environ $10 \mathrm{~cm}$ de chaque côté des jumelles - soit l'indication de la mesure entre l'écrou et les jumelles est erronée. En corrigeant cette dernière - de 26 à $36 \mathrm{~cm}$ - et en rectifiant le diamètre de la vis à $9 \mathrm{~cm}$ - tel que mesuré sur place - les dimensions sont de nouveau en accord avec la première mention d'écartement des jumelles. Il semble peu probable que cette erreur soit liée à un problème d'écriture.

178 GSE 1928: «20 luglio. [...] All'estremità esterna superiore di ciascun pilastro eravi un travicello, quello al lato sinistro era a guisa di maniglia e l'altro era inclinato nell'interno, in maniera che in alto formavano un angolo acuto [...]». Cette description reste passablement incompréhensible. L'observation détaillée des vestiges en place n'a pas permis de la clarifier.

${ }^{179}$ GSE 1928: "24 luglio. [...] Il pezzo superiore che serviva come pressa ed era attaccato alla vite, mediante un perno di ferro non fisso era lungo m. 0.62 , e lo spessore $\mathrm{m}$. 0.07, il secondo pezzo di legno che formava la base della pressa aveva la medesima lunghezza del primo ma lo spessore era di m. 0.10. Sulla faccia superiore di quest'ultimo pezzo si notano dei piccoli canaletti larghi m. 0.02, essi servivano forse per far colare il liquido [...]».

${ }^{180}$ GSE 1928: «20 luglio. [...] Per mantenere fissa la pressa vi erano dei travicelli del diametro di m. 0.06 che erano a mo' di puntello alle fauci laterali [...]». Les importants travaux de 


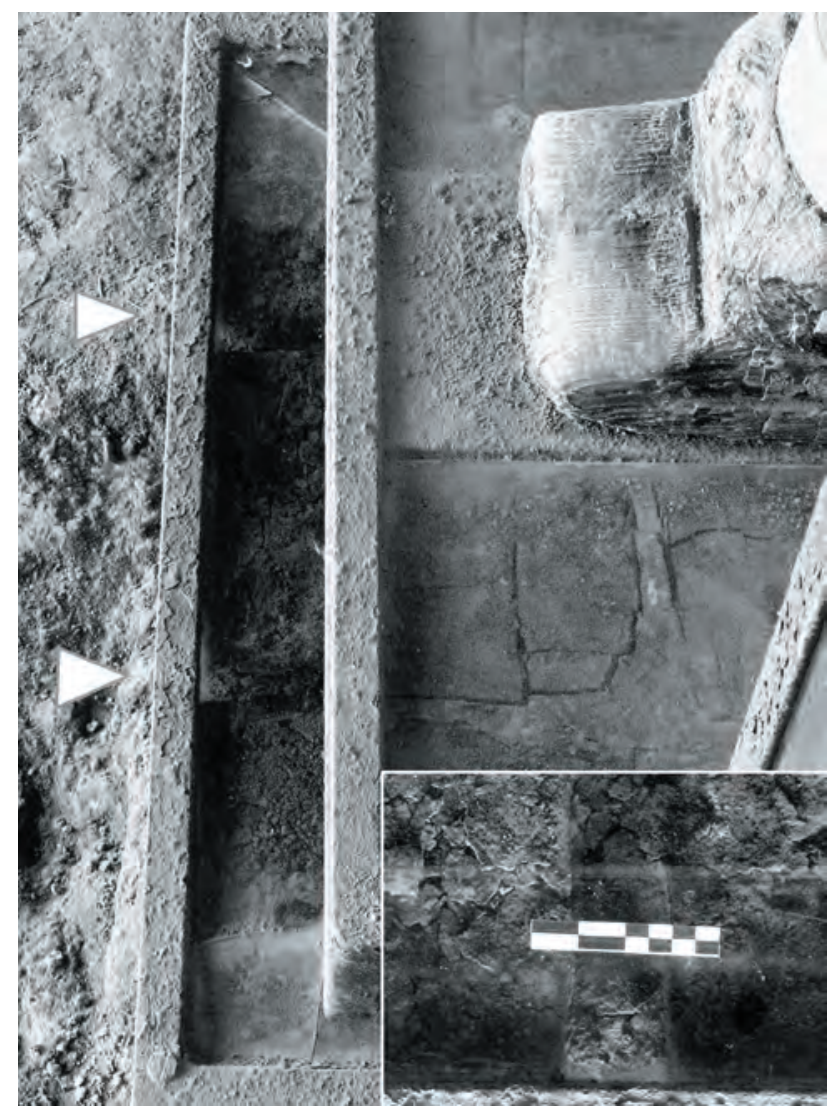

Fig. 104 - Boutique III, 10, vue du plateau et de la maie de la presse. Les flèches indiquent les rainures excavées sur la surface supérieure de la maie. En encadré, vue zénithale d'une des rainures.

à la barre de manœuvre sont encore visibles. Ils se situent dans la partie élargie de la vis. Pour compléter la description de ce dispositif, il faut mentionner la fosse excavée sous le pressoir: si ses dimensions ne sont jamais indiquées dans les GSE, elle contenait une matière noire non identifiée lors de sa mise au jour ${ }^{181}$. En l'état actuel, il est impossible d'observer cette cuve: après sa consolidation, la presse a été repositionnée très exactement à l'endroit où elle a été découverte.

Pour synthétiser cette description, je me contenterai de rappeler les caractéristiques prin-

restauration des murs qui se sont déroulés dans cette boutique empêchent de cerner le point de fixation de ces poutrelles. De la même façon, le coffrage en bois et en verre entourant la presse ne permet pas de confirmer - ou d'infirmer - le lien que ces dernières pouvaient entretenir avec celle-ci.

181 GSE 1928: «20 luglio. [...] A quanto pare sotto la pressa si trova una vaschetta in muratura, le dimensioni non

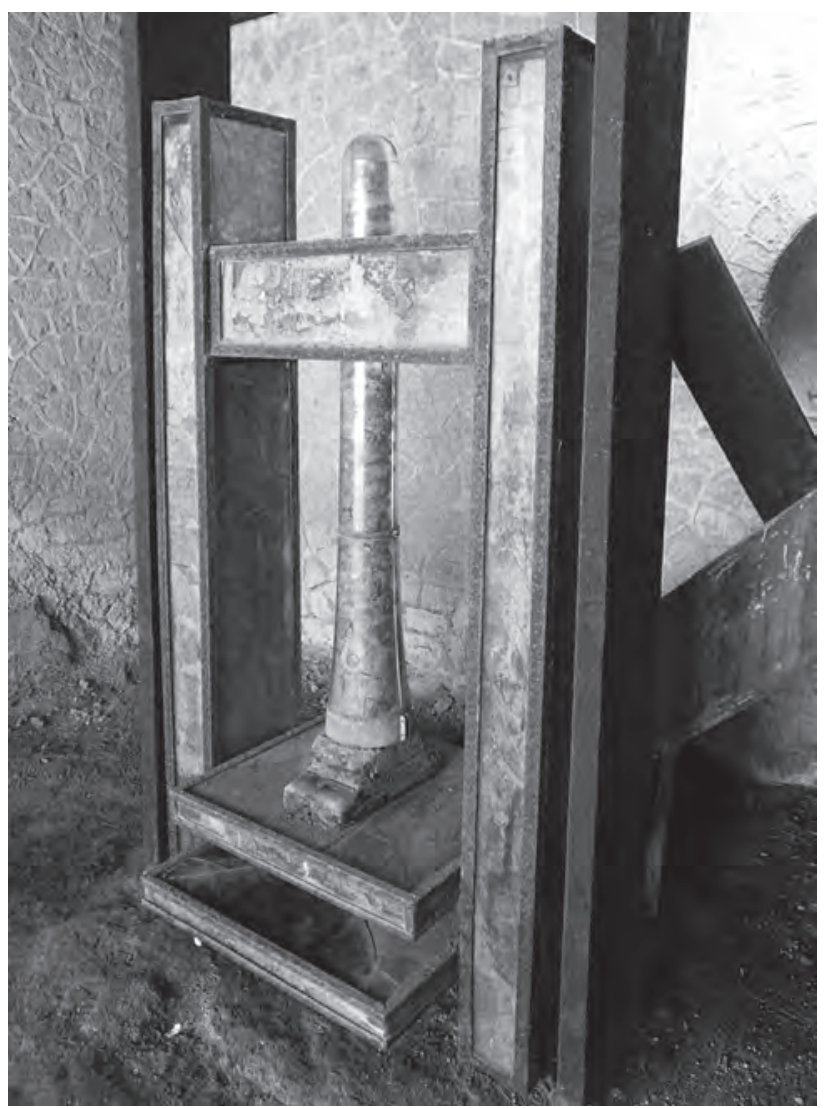

Fig. 105 - Boutique III, 10, vue de la presse telle qu'elle a été restaurée (cliché pris du nord-ouest).

cipales de la presse découverte dans la boutique III, 10 (fig. 105): elle présente une unique vis centrale; sa maie, carrée, en bois, présente sur sa face supérieure deux canaux de section quadrangulaire, probablement destinés à l'écoulement d'un liquide qui était recueilli dans une vasque maçonnée. En dépit de la destruction de sa base par les fouilleurs du XVIII ${ }^{\mathrm{e}}$ siècle, il faut considérer que la presse était fixée au sol par l'enfoncement des montants, ce qui oblige à restituer une seconde traverse pour soutenir la maie ${ }^{182}$.

sono ancora conosciute perché non del tutto sterrata [...]»; "24 luglio. [...] Nelle cunetta è stato raccolto materia nera che deve essere esaminata [...]»; GSE 1929: «27 maggio. [...] Nella cunetta fu raccolto materia nera [...]».

${ }^{182}$ Pour une typologie des pressoirs à vis - dans ce cas le type C1 -, cf. Brun 1986: 124-125, 127-129. 
Avant de définir l'usage du pressoir herculanéen, un point doit être fait sur les attestations pompéiennes. La presse figurée sur la fresque provenant de la fullonica de L. Veranius Hypsaeus (VI 8, 2.20-21) présente de subtiles différences avec celle du local III, 10 à Herculanum (fig. 106, a): deux vis permettent d'abaisser la traverse utilisée pour presser le linge, au lieu d'une unique vis centrale. Quoique les bras permettant d'actionner ces vis aient pu être dessinés sans grand réalisme dans leur dimension ${ }^{183}$, les lanternes dans lesquelles ils s'enfilent sont de couleur grise, avec des reflets métalliques et présentent - du moins à droite - une seconde perforation décalée par rapport à celle qui contient la barre de manœuvre (fig. 106, b). La représentation simple d'une surépaisseur à leur base interdit de se prononcer sur l'articulation entre le tambour et la traverse. Pour l'assemblage du cadre, deux mortaises sont ménagées aux extrémités du banc, de façon à pouvoir y encastrer le sommet des jumelles, dont la partie supérieure est taillée pour servir de tenon (fig. 106, c). Ce détail permet d'induire la représentation d'un banc monoxyle, contrairement à celui de la presse d'Herculanum ${ }^{184}$. L'ombre portée du banc signale qu'il est en débord par rapport aux jumelles ${ }^{185}$. La fixation au sol du cadre semble assez légère: les jumelles s'enfilent dans deux blocs posés au sol qu'une

${ }^{183}$ En dépit d'une nécessaire schématisation due à la représentation perspective, La représentation des barres de manœuvre enfilées dans les lanternes est loin d'être aussi schématique que ce que leur taille réduite pourrait laisser croire.

${ }^{184}$ Aucune barde métallique enserrant le banc n'est visible, ce qui confirme cette situation. La seule difficulté technique à résoudre lors de la conception de la presse se situe alors dans le creusement des deux écrous (cf. infra).

${ }^{185}$ Sur les divers dessins effectués depuis la découverte de cette fresque, cette ombre portée a toujours été omise. Par ailleurs, les faces antérieures des deux jumelles présentent trois rectangles démaigris n'ayant d'autre fonction que décorative (cf. not. $M B, 4,1827$ : L; Mau 1899: 387 ; Moeller 1976: 25). En fait, seuls deux rectangles sont dessinés, dans la moitié inférieure et au milieu de chaque jumelle. Le banc quant à lui présente trois rectangles creusés à sa surface.

${ }^{186}$ D'un point de vue technique, le principe d'une maie «flottante», ne reposant pas directement sur le sol est un non sens. En effet, la pression exercée se reporterait alors principalement sur les fixations de la maie aux jumelles, les amenant de la sorte à rompre. subtile nuance chromatique autorise à considérer comme réalisés en pierre, probable artifice de finition graphique qui permet de positionner la presse dans le champ pictural en ménageant un jour entre le sol et la maie ${ }^{186}$. La presse a été peinte en cours de fonctionnement: une pile d'étoffes pliées est représentée par des lignes horizontales. En termes de maniement, les deux vis sont représentées avec des pas antagonistes, ce qui autorise une unique personne à effectuer le pressage: le plateau descend en faisant tourner les tambours vers l'intérieur ${ }^{187}$. Une partie du linge est cachée par une planche montrée en perspective, enchâssée à la base de la presse comme le souligne un effet de perspective sur la gauche. Cette pièce de bois constitue la maie. Son avancement en biais pourrait correspondre à une adaptation aux exigences d'un dessin réalisé de face, qui complexifie le rendu des objets situés dans un plan orthogonal à celui de la représentation ${ }^{188}$. Enfin, la partie supérieure montre - à gauche - une tablette permettant de poser un objet et - à droite - une forme rappelant un flacon au corps globulaire, interprétée comme un flacon d'huile ${ }^{189}$. Cet évident souci du détail permet accessoirement de souligner une seconde différence majeure avec la presse mise au jour à Herculanum: lors du fonctionnement de la presse représentée dans la foulerie, aucun liquide ne s'écoule ${ }^{190}$.

\footnotetext{
${ }^{187}$ Cet ingénieux système permet d'éviter que le plateau ne se retrouve dans une position non horizontale faute de coordination entre les manœuvres, ce qui pourrait entraîner des dégâts dans la structure de la presse.

188 Cette forme de représentation participe des différentes techniques utilisées par le peintre pour donner autant que possible l'impression du relief, tout comme les ombres portées du banc, des vis et des montants sur le mur de fond. Labsence d'ombrage porté du plateau ne saurait être interprétée comme une largeur moindre de celui-ci par rapport à la maie, mais plutôt comme une simplification du dessin.

${ }^{189}$ Selon Th. Fröhlich (1991 : 235), la minutieuse reconstitution de ces deux objets serait un indice supplémentaire pour considérer que la presse a été peinte d'après nature.

${ }^{190}$ Autant la représentation des ombres portées demande une certaine recherche picturale, autant celle d'un liquide s'écoulant est relativement banale, qu'elle soit réalisée par de simples traits verticaux - comme dans la fresque de la Casa del centenario figurant Bacchus effectuant une libation avec une oenochoe - ou par un traitement chromatique - à l'instar de la presse à coins en train de fonctionner dans
} 
Les nombreuses précisions fonctionnelles reportées sur cette fresque - et en dépit de certaines approximations - laissent peu de doute quant à l'existence d'un exemplaire dont ce serait inspiré le peintre, vraisemblablement situé dans la foulerie en elle-même. Dans le rapport sur les fouilles daté du 30 juin 1826, se trouvent, parmi le matériel mis au jour au cours de la quinzaine écoulée les objets suivants: «Ferro. [...] Due pezzi di legno foderati di ferro ${ }^{191}$. Le manque de détails des rapports de fouille empêche de déterminer avec précision la pièce dans laquelle elles ont été mises au jour. Toutefois, la proximité de la fullonica apparaît suffisante pour considérer qu'elles en proviennent ${ }^{192}$. Si la description de l'atelier rédigée par G. Bechi dans le Real Museo Borbonico n'indique pas d'espace pour localiser cette presse, G. Fiorelli considère qu'elle

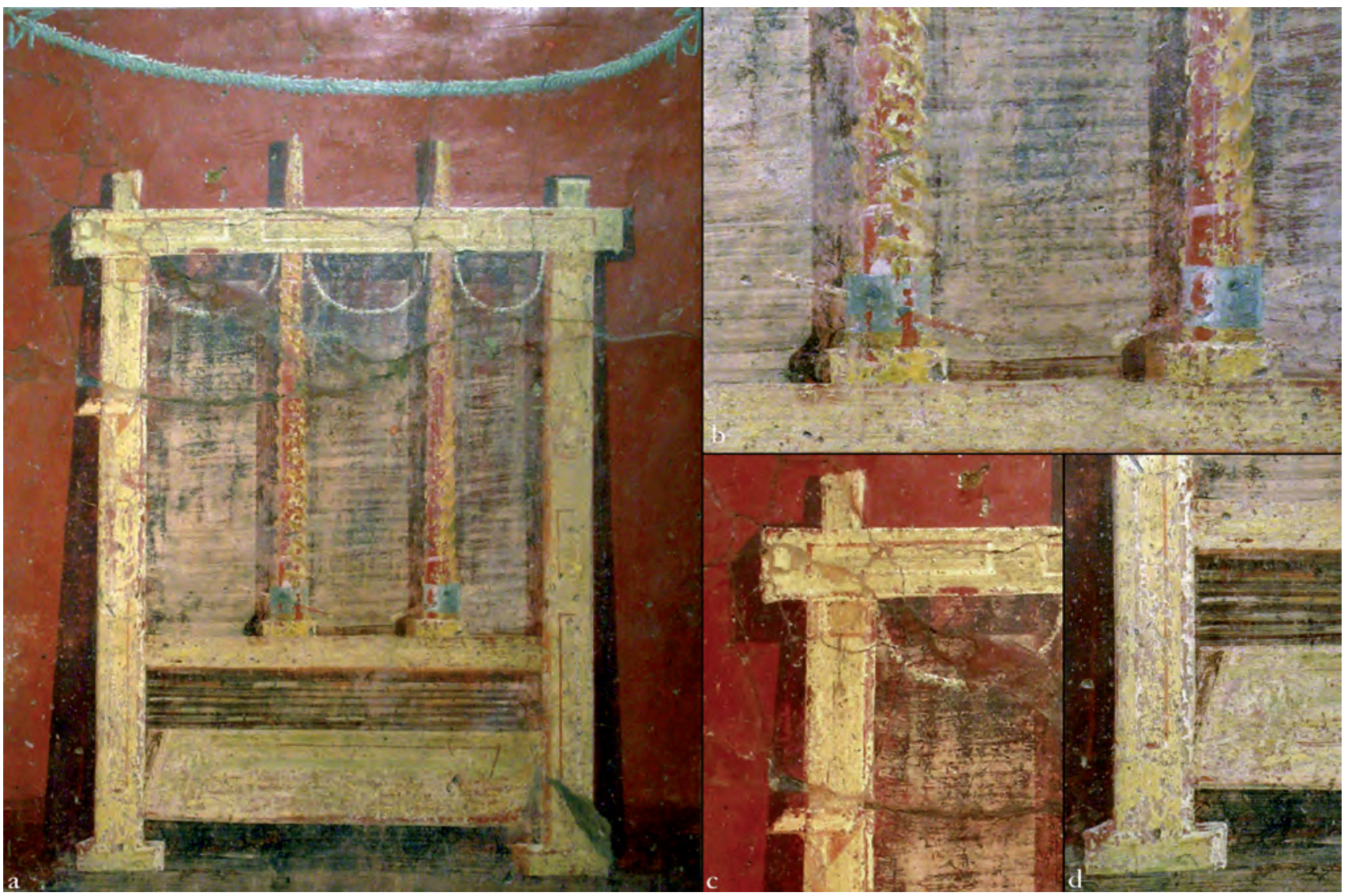

Fig. 106 - Représentation de la presse à vêtements sur la fresque de la fullonica de L. Veranius Hypsaeus, vue générale (a) et détails du cadre supérieur du montant oriental. (b): articulation entre le tambour et la traverse; (c): encastrement du banc monoxyle dans les montants et ombre portée de l'assemblage; (d): effet de perspective de la maie et linge en train d'être pressé.

l'oecus q de la Casa dei Vettii. Cette observation permet accessoirement de réfuter la possibilité que les pièces d'étoffes placées dans ce pressoir aient été gorgées d'eau au départ; sur l'état du linge lors de son passage sous presse, cf. infra n. 209 et p. 213.

${ }^{191}$ PAH II: 165.

192 À partir d'octobre 1825, la publication des minutes de fouille cesse, remplacée par l'édition d'un Giornale degli
Scavi dont le premier numéro est daté du 28 avril 1826. Cette publication se voulant plus synthétique présente l'avancée des travaux avec moins de détails, et sans toujours respecter l'ordre de mise au jour, comme des comparaisons avec le journal de R. Amicone - publié dans le volume III de la $P A H$ - permettent de s'en rendre compte. De plus, deux secteurs sont alors ouverts: la via di Mercurio au nord du forum et «lo scavo della Regina» au sud du forum. En fonction des 
se serait trouvée au nord-est du péristyle ${ }^{193}$. À défaut de pouvoir situer leur origine avec précision, les lanternes enchâssant le tambour des vis de la presse ont été retrouvées dans l'atelier VI 8, 2.20-21. Elles auront probablement servi de modèle à la fresque qui ornait les piliers orientaux du péristyle.

Le problème de localisation est identique en VI 14, 21-22: la description des deux lanternes qui y ont été découvertes en mai 1877 correspond aux exemplaires conservés provenant de la fullonica de Stephanus et permet donc d'y voir les restes d'une presse à vêtements ${ }^{194}$. Montée sur un cylindre de bois moderne, cette lanterne est constituée de deux frettes en fer, assemblées par quatre plaques toutes percées d'un trou circulaire. À la hauteur de ces perforations, la plaque s'élargit, de façon à conserver une largeur minimale de $3 \mathrm{~cm}$ autour de ces œillets ${ }^{195}$. Leur ressemblance avec les éléments représentés sur la fresque, mais aussi avec les parties métalliques subsistant de la presse mise au jour dans la fullonica de Stephanus (I 6, 7), permet de considérer qu'il s'agit des renforts métalliques insérés dans la partie inférieure du tambour des vis et facilitant l'introduction de la barre de manœuvre ${ }^{196}$.

L'étude des découvertes survenues dans la fullonica I 6, 7 dite de Stephanus permet de mieux comprendre le fonctionnement d'un tel instrument. Après plusieurs jours de dégagement de la pièce d'entrée de cet atelier situé sur la via dell'Abbondanza, une interprétation est proposée pour les objets métalliques découverts le 8 juillet 1912: ils constitueraient les éléments en fer d'une presse à vêtements, similaire à celle représentée dans la fullonica de L. Veranius Hypsaeus. Bien que les pièces de bois n'aient pas été conservées, leur empreinte dans le sol a été partiellement relevée: les jumelles, enfoncées découvertes qui se font dans chacun de ces secteurs, l'un peut bénéficier d'un plus long développement que l'autre. Bien que l'essentiel de la fouille du portique de la fullonica ait eu lieu entre octobre 1825 et avril 1826, certaines pièces sont fouillées plus tardivement, notamment la pièce ornée d'un cadre représentant Thésée tuant le Minotaure, seulement décrite le 3 juin 1826 (PAH II: 162; cf. PPM IV), ou encore la pièce 19 décrite le 15 juin 1826 (PAH II: 164). Faute de découvertes importantes, la liste des objets peut être compilée un certain temps après leur mise au jour, et sans signalisation précise. De la sorte, l'imposante liste d'objets décrite dans le fascicule 9 du Giornale degli Scavi (PAH II: 164-166), associée à la mise au jour de la «troisième» entrée de la fullonica (VI 8, 22, Casa della fontana grande), pourrait provenir en fait du secteur nord oriental de l'atelier.

193 «[... In quello [portico] a settentrione [erano] varie nicchie, per le conche di bronzo dentro cui i fulloni pigiavano i panni, tenendosi con le mani poggiati ai murriciuoli che le dividono; e poi un altro lavatoio, una cella pel pressoio, l'adito che univa l'officina ad una casetta contigua, e finalmente l'armario che serbava i panni mondati dalle sozzure [...]» (Fiorelli 1875: 123). De la sorte, il se serait trouvé à l'extrême fin du parcours des étoffes devant être lavées. L'état de dégradation avancé des murs entourant la pièce 32 (cf. PPM IV: fig. p. 604; Flohr 2008: fig. 1 p. 1) a empêché tout nettoyage pour vérifier cette hypothèse.

${ }^{194}$ L'information sur cette découverte est donnée sans localisation précise dans les NSc (1877: 117): «Da alcuni frammenti di ferro rinvenuti della fullonica al num. 22, isola 14 , regione VI risultarono due argani formati ciascuno a due cerchi, del diametro di met. 0,38, concatenati alla distanza di met. 0,35 mediante quattro fasce, inognuna delle quali travasi un foro circolare in corrispondenza dell'altra fascia che è di contro, dove introducevasi la sbarra per servire di leva, tirando i pesi ». La description provenant des inventaires n'est guère plus précise, même si elle signale les restaurations liées à la présentation des objets dans l'antiquarium du site: «Inv. 106. 23 maggio 1877. Un argano che presente due cerchi del diam. di cent. 38 concatenati alla distanza di 35 centimetri mediante quattro fasce in ognuna delle quali sta un foro circolare in corrispondenza dell'altra fascia che è di contro, dove introducevasi la sbarra per servire di leva, tirando pesi. I due cerchi stanno intorno ad un fusto di legno che è stato sostituito con quello moderno; Museo pompeiano.

Inv. 107; 23 maggio 1877. Altro simile al sudetto, restaurato senza il legno; Museo pompeiano» (Casa Bacco, Lib. 16, p. 6-7). Il est probable que ces deux objets aient changé de numéro d'inventaire une fois insérés dans les collections de l'Antiquarium. Les premiers registres donnent ainsi les numéros 92 et 94 et une description plus réduite: «92. Argano di ferro antico con cilindro di legno moderno. Diametro m. 0,38, alto m. 0,45 ». Bien que non daté, ce livre d'inventaire, signé par A. Ausiello, C. Lembò et N. Pagano, ne saurait être antérieur à 1872. Conservés dans les 'Granai' du forum, ces deux objets ont désormais comme numéro d'inventaire Antiquarium, Inv. nº $1219(126 / 3)$ et 1220 (127).

${ }^{195}$ Les frettes ont un diamètre extérieur de $39 \mathrm{~cm}$, une hauteur de $5 \mathrm{~cm}$. Le métal - corrodé - a une épaisseur variant de 1,5 à $2 \mathrm{~cm}$. Les plaques sont hautes de $33,5 \mathrm{~cm}$, larges de $4 \mathrm{~cm}$, sauf autour de l'œillet ou la largeur globale est de $9 \mathrm{~cm}$. L'œillet a un diamètre intérieur de $4 \mathrm{~cm}$. L'ensemble a une hauteur de 43,5 cm. Les différentes pièces de métal sont assemblées par rivetage.

${ }^{196}$ Sur ces éléments pertinents à la presse de la fullonica de Stephanus, cf. infra, p. 211. 
dans le sol de $50 \mathrm{~cm}$ ont une section de $30 \mathrm{~cm}$ par $50 \mathrm{~cm}$ (fig. 107, a) ${ }^{197}$. Dans le mur est, les traces de quatre solives rectangulaires sont visibles (fig. 107, c) ${ }^{198}$. Dans sa description, M. Della Corte indique la présence d'un renfoncement entre les jumelles ${ }^{199}$ : un simple creusement qui a consisté à enlever la dernière strate de pavement sur une épaisseur de 2 à $3 \mathrm{~cm}$. Sa limite ouest correspondant avec la face occidentale des jumelles, il faut l'interpréter comme le négatif de la maie en bois. Parmi les différents objets métalliques mis au jour à proximité de cette presse, les seuls à avoir été prélevés, conservés et décrits sont deux lanternes ajourées en fer comportant des œillets opposés deux à deux et situés sur des plans différents (fig. 107, b) ${ }^{200}$. D'une forme et d'une conception rigoureusement similaire à celles considérées provenant de la fullonica VI 14, 21-22, elles ont des dimensions à peine inférieures ${ }^{201}$.

Une restitution de cette presse a été proposée par V. Spinazzola (fig. 108) ${ }^{202}$. Elle est particulièrement discutable sur de nombreux points, qu'il s'agisse du fonctionnement ou de l'adéquation avec les traces observées dans la fullonica de Stephanus ${ }^{203}$. Bien que la fresque de la fullonica de L. Veranius Hypsaeus soit censée n'avoir été utilisée que comme "guide» ${ }^{204}$, le dessin proposé semble plutôt une copie de celle-

${ }^{197}$ NSc 1912: 248-249. Lors d'une vérification sur le site effectuée en mai 2005, il s'est avéré que seule la jumelle méridionale a été moulée avec du plâtre, son empreinte étant restée sur place. Elle mesure $49 \mathrm{~cm}$ de long pour $32 \mathrm{~cm}$ de large. En revanche, il ne reste aucune trace de la jumelle nord: le pavement est fortement endommagé là où elle aurait dû se situer.

${ }^{198}$ Les quatre empreintes de poutrelles ont pour dimensions $10 \mathrm{~cm}$ en hauteur, 12 en largeur. Groupées par deux, elles sont distantes de $36 \mathrm{~cm}$ dans le sens vertical et de $145 \mathrm{~cm}$ dans le sens horizontal. Les deux solives les plus basses se situent à $156 \mathrm{~cm}$ du sol.

${ }^{199}$ NSc 1912: 249.

${ }^{200}$ D'autres fragments métalliques sont visibles sur la photo de la découverte, sans qu'ils ne soient mentionnés dans le texte ou qu'ils n'aient été conservés (cf. NSc 1912: fig. 4 p. 249). Seuls les fils de fer destinés à maintenir les deux objets antiques dans leur position de découverte sont en revanche visibles sur la même photo recadrée et publiée par V. Spinazzola (1953: fig. 764 p. 777).

${ }^{201}$ Les deux exemplaires provenant de la fullonica de Stephanus sont beaucoup plus corrodés que ceux conservés dans les granai. Les frettes ont un diamètre extérieur de

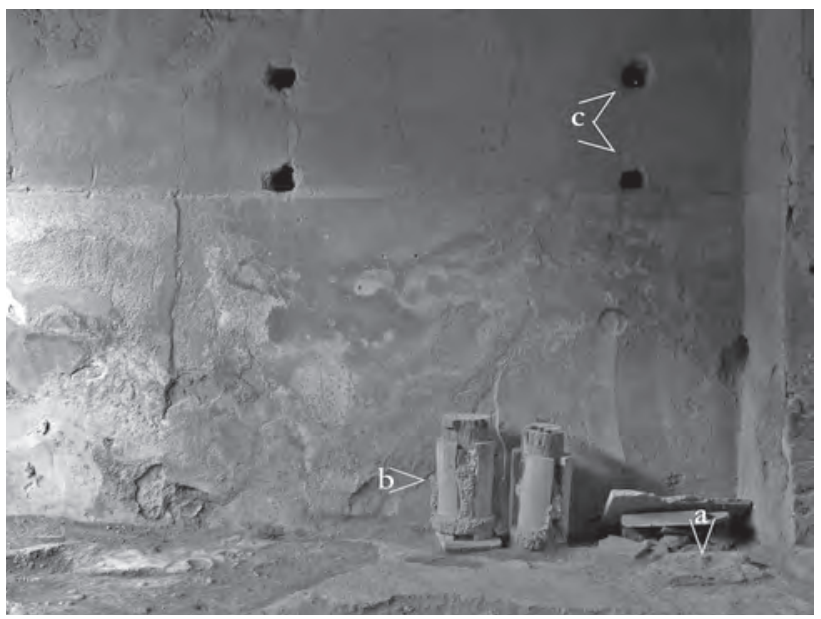

Fig. 107 - Fullonica «de Stephanus », entrée, mur oriental, traces de la presse à vêtements. (a): empreinte en plâtre du montant méridional. (b) : lanternes en fer restaurées sur des billots de bois moderne; (c): empreinte des poutrelles de maintien du banc (cliché pris de l'ouest).

ci à laquelle quelques éléments techniques non fonctionnels ont été ajoutés. Pour bien cerner les différences structurelles entre la représentation peinte et ce que l'on peut restituer de la presse de Stephanus à partir des traces conservées, les quatre empreintes de poutrelles du mur sont de première importance. Leur position est telle que

$25 \mathrm{~cm}$, une hauteur de $5 \mathrm{~cm}$. L'épaisseur du métal n’a pas pu être mesurée. Les plaques sont hautes de $32 \mathrm{~cm}$, larges de $3 \mathrm{~cm}$, sauf autour de l'œillet ou la largeur globale est de $9 \mathrm{~cm}$. L'œillet a un diamètre intérieur de $3,5 \mathrm{~cm}$. L'ensemble a une hauteur de $43 \mathrm{~cm}$. La distance entre les lanternes aurait été, au moment de la découverte (NSc 1912: fig. 4 p. 249), d'un peu moins de $50 \mathrm{~cm}$.

${ }^{202}$ Spinazzola 1953: 777, fig. 764-766.

${ }^{203}$ Sans donner trop de détails, je signalerai les principales inexactitudes ou inadéquation avec le lieu de découverte: d'un dessin à l'autre, les éléments ne sont pas cohérents entre eux; les bras de manœuvre sont insérés dans le bois et non dans les œillets des lanternes; les jumelles ne sont pas enfoncées dans le sol; les poutrelles insérées dans le mur situé en arrière de la presse ne sont pas à la bonne place. Un important contresens technique rend très critiquable cette restitution: les vis, le plateau et la maie sont en retrait par rapport au cadre alors que l'une des raisons d'être de celui-ci est de former un système plan et fermé.

204 «[...] Il «torcular fullonicum» $[. .$.$] è da noi rico-$ struito in disegno sulle tracce dei resti esistenti e sulla guida che la pittura della fullonica di Via Mercurio ne fornisce» (Spinazzola 1953: 777). 


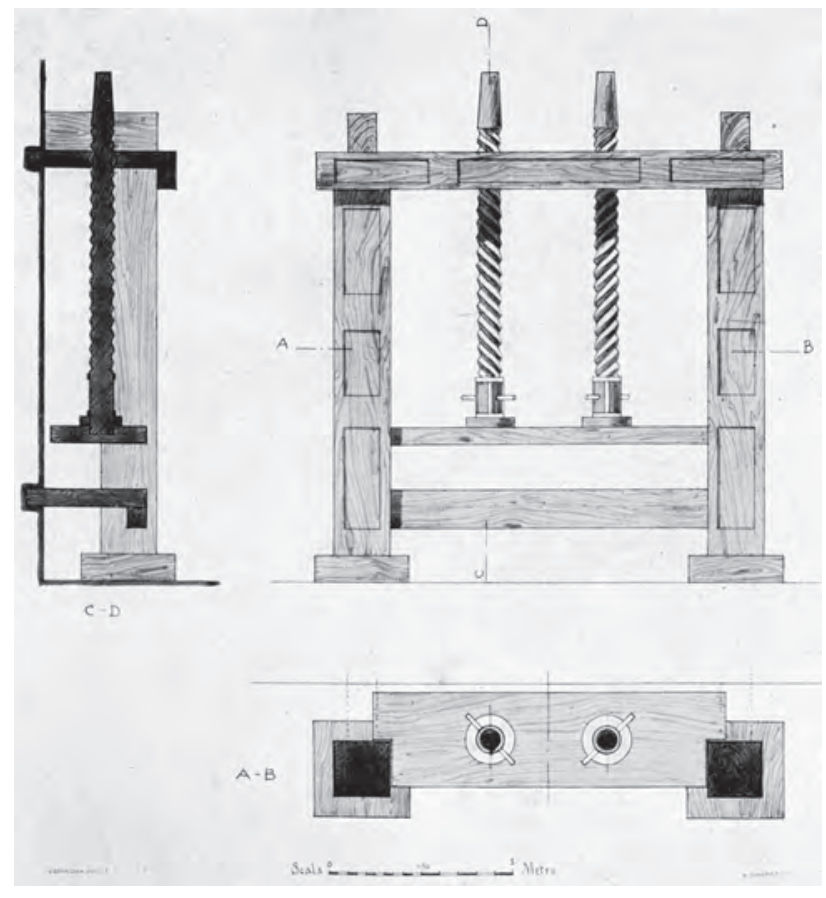

Fig. 108 - Restitution de la presse de la fullonica «de Stephanus» proposée par V. Spinazzola, inspirée de la fresque de la fullonica de L. Veranius Hypsaeus. ces pièces de bois ne peuvent qu'avoir été encastrées dans les jumelles. En considérant leur hauteur, elles auraient alors eu un rôle étroitement lié au banc: les deux poutrelles inférieures lui servant de support, les deux supérieures empêchant qu'il ne s'élève lors de l'utilisation des vis, compensant ainsi leur poussée verticale $^{205}$. Un second point de distorsion entre la fresque et les traces observées dans la fullonica de Stephanus est constitué par l'ancrage au sol: les empreintes des jumelles dans le sol et le creusement entre celles-ci plaident en faveur d'une maie reposant sur le pavement et non «flottante» comme elle est peinte. Si le problème de l'articulation entre les vis et le plateau ne paraît guère pouvoir être résolu autrement que par des hypothèses ${ }^{206}$, il reste à discuter de la réalisation des deux écrous dans le banc. La représentation figurée en VI 8, 2.20-21 indique un banc monoxyle. Le texte d'Héron d'Alexandrie expose comment creuser deux écrous à chaque extrémité du banc ${ }^{207}$. Une autre solution suppose, comme dans le cas de la presse d'Herculanum,
${ }^{205}$ Sur la fresque de la fullonica de L. Veranius Hypsaeus, les poutrelles, si elles existaient sur le modèle dont s'est inspiré le peintre, ne sont pas représentées. En fonction de ce qui est visible, un tel assemblage entre le banc et les jumelles n'aurait amené qu'à une dislocation complète de la presse à sa première utilisation. Il ne s'agit certainement que d'une adaptation de la réalité lors de sa figuration. En dépit de l'ombrage et de la perspective donnée à la maie, qui donnent tous deux un effet de relief, la presse est représentée en vue frontale, ce qui rend difficile le dessin des éventuelles poutrelles, dont seul l'encastrement dans les jumelles aurait été visible. De plus, il ne faut pas perdre de vue que, bien que montrant une relative fidélité technique - essentiellement en ce qui concerne les pas de vis -, cette fresque a dans son ensemble une fonction première qui est décorative et pour partie religieuse: l'étroite association sur ces piliers entre les serpents, génies protecteurs du lieu, les Pénates - Vénus, Bacchus, Apollon, un fleuve personnifié - et les scènes de travail suppose une volonté religieuse de placer l'activité de l'atelier sous la protection de certaines de ces divinités.

${ }^{206}$ En se fondant sur la fresque de L. Veranius Hypsaeus, qui montre un anneau en bois entre le tambour et le plateau, deux solutions sont possibles, selon que cet anneau serve à communiquer la pression au plateau ou à permettre sa remontée une fois le pressage effectué: dans le premier cas l'anneau est fixé à la vis, dans le second au plateau.

${ }^{207}$ La presse à olives décrite par Héron d'Alexandrie est munie de deux vis $(M e c ., 3,19)$. Contrairement à la presse de la fullonica d'Hypsaeus, il n'y a pas de banc à proprement parler, une poutre qui s'abaisse en fait office: "Nous prenons une poutre équarrie dont la longueur est de 6 spithame $[=138,7 \mathrm{~cm}]$, dont la largeur n'est pas moindre de 2 pieds [grecs $=62 \mathrm{~cm}$ ], et dont l'épaisseur n'est pas moindre de 1 pied $[\mathrm{grec}=31 \mathrm{~cm}][\ldots]$; nous l'appelons la table [...]. Après cela, nous prenons une poutre équarrie et longue dont la longueur est la même que celle de la poutre inférieure dans laquelle les vis sont montées. Cette poutre est forée de deux trous cylindriques qui pénètrent dans son épaisseur et qui ressortent de l'autre côté [...]. À l'intérieur de ces deux trous est sculptée une rainure hélicoïdale, qui fait d'eux les écrous des deux vis, en sorte que cette poutre s'abaisse lorsqu'on tourne les deux vis [...]. Nous expliquerons plus loin la manière de sculpter la rainure hélicoïdale. La longueur et l'épaisseur de cette poutre doivent [...] se mesurer à la longueur et à l'épaisseur de la table; mais sa largeur doit être inférieure d'un quart à celle de cet organe » [Trad. B. Carra de Vaux].

L'assemblage permettant de creuser l'écrou dans la poutre est exposé au paragraphe 3, 21. A. G. Drachmann (1936) en a proposé une restitution, validée par l'expérimentation qu'il a réalisée. Je renvoie à cette étude pour plus de détails (cf. également Drachmann 1963: 137-140 = Carra de Vaux 1988: 301-304). Il est cependant opportun de souligner les dimensions similaires de la poutre devant être creusée dans le texte d'Héron (épaisseur supérieure ou égale à $31 \mathrm{~cm}$ ) et dans la fullonica de Stephanus (distance verticale entre l'empreinte des poutrelles sur le mur est: $36 \mathrm{~cm}$ ). Bien que la description d'Héron se rapporte à une presse à huile, elle autorise la restitution d'un banc monoxyle pour la presse de la fullonica de Stephanus. 
que le banc ait été au préalable coupé en deux dans le sens de la longueur ${ }^{208}$. Ces deux parties seraient maintenues assemblées par des frettes. L'absence de représentation de ces rubans métalliques sur la fresque de la fullonica d'Hypsaeus permet toutefois de préférer un banc monoxyle.

La conjonction entre les vestiges observés dans la fullonica de Stephanus et la fresque de L. Veranius Hypsaeus autorise une restitution de la presse en I 6, 7, ce qui permet de comparer cet instrument avec le pressoir découvert à Herculanum en III, 10 (fig. 109). Par-delà les variations les plus évidentes - dimensions, nombre de vis -, la principale différence entre les deux instruments est que celui de la foulerie ne présente aucune fosse entre les jumelles: le léger creusement qui s'y trouve ne constitue qu'une préparation à la mise en place de la maie. L'interprétation fonctionnelle de la presse d'Herculanum tient à la fosse qui a été découverte sous la maie. Pour mieux comprendre l'utilisation des presses à vêtements, il faut les réinsérer dans le cadre des opérations de foulerie. Qu'il ait été juste soumis à une aspersion d'eau, envoyée par la bouche du fullo, ou qu'il vienne de subir un second traitement avec de la terre à foulon, le vêtement à presser n'était pas gorgé d'eau ${ }^{209}$. Dès lors, l'usage de la presse ne sert qu'à donner du lustre au vêtement, pas à l'essorer. Après ce passage sous presse, le vêtement est finalement prêt à être utilisé, que ce soit pour être rendu à son propriétaire - scène visible sur le pilier de la fullonica VI 8, 2.20-21-, ou porté, resplendissant de lumière - signe vraisemblable du lustrage - et

${ }^{208}$ Cette solution est également envisagée par Héron d'Alexandrie $(M e c ., 3,15)$ pour la réalisation d'une presse à huile comportant un long écrou attaché à un contrepoids fixe. Sur la reconstitution de ce pressoir, cf. Amouretti - Comet - Ney - Paillet 1984 : 402-408.

${ }^{209}$ Je n'ai pas réussi à trouver, dans les procédés de foulerie, une place définitive au texte de Sénèque (Nat., 1 , 3 , 2, cit. supra, n. 133) décrivant un arc-en-ciel lorsqu'un foulon crache de l'eau. À titre d'hypothèse, je proposerai que cette légère humidification ait lieu avant le pressage, pour détendre les fibres.

${ }^{210}$ Mart. 2, 43, 6 et 11, 8, 5, cit. supra, n. 130.

211 Ces fresques proviennent de la Casa dei Vettii (VI 15, 1 ; oecus q; PPM V: 541-565), de la Casa di Trittolemo (VII 7, 2.5.14-15; uniquement conservée sur un dessin du XIX ${ }^{\mathrm{e}}$ siècle; cf. Mattingly 1990: 74-75), de la Casa dei cervi à Herculanum (conservée au MANN, Inv. 9179; cf. Tran Tam Tinh 1988: 52-66, part. p. 62; Mattingly 1990: 77-79). La de parfum si l'on suit Martial ${ }^{210}$. Ces considérations sur l'état du linge avant sa mise en presse sont en adéquation avec les aménagements découverts dans la fullonica de Stephanus, où aucune fosse ou rigole de collecte n'a été mise en évidence autour des jumelles exhumées en 1912. Dès lors, la presse herculanéenne ne saurait être destinée aux vêtements: tant les canaux creusés dans la maie que la fosse décrite sous celle-ci désignent un instrument conçu pour extraire des liquides, probablement une presse à huile.

Une telle interprétation pourrait s'affaiblir en regard des principales attestations d'huilerie à Pompéi. En effet, dans un article consacré à la production de parfums à Pompéi, D. J. Mattingly avait mis en évidence la forte prégnance des presses à coins dans les représentations figurées des parfumeurs, à partir des quatre exemples de fresque provenant de Pompéi et d'Herculanum ${ }^{211}$. Cependant, les révisions archéologiques opérées à Paestum et Pompéi par J.-P. Brun laissent de la place à l'emploi de pressoirs à vis en parfumerie $^{212}$. L'utilisation des presses à coin dans l'iconographie pourrait alors n'être qu'un code pour éventuellement distinguer la parfumerie de la production d'huile moins fine et notamment alimentaire, mais aussi un décalage dans l'adaptation de nouveaux schémas de représentation alors que l'innovation technique est en voie de diffusion ${ }^{213}$. Si la réinterprétation de la presse d'Herculanum se marie les rares sources textuelles et épigraphiques, elle peut cependant se justifier. Le premier obstacle fonctionnel auquel cette révision se heurterait est la maie: l'usage

dernière est conservée au Fitzwilliam Museum de Cambridge et son origine serait pompéienne (Mattingly 1990: 75-77).

${ }^{212}$ Sur les fouilles de la parfumerie de Paestum, cf. Brun 1998 et Brun 2000: part. 291-295. Pour celles de Pompéi, cf. Borgard - Brun - Leguilloux - Tuffreau-Libre 2002: 472-473, Brun 2003: 9-13. Une révision des interprétations proposées dans ces comptes rendus de fouille est présentée dans Brun - Monteix 2009: 124-128.

${ }^{213}$ À ce propos, les remarques de D. J. Mattingly (1990: 79-80) sur la familiarité des sujets représentés en peinture restent d'une grande pertinence. Les fresques seraient plus à considérer comme l'exemplification d'associations connues entre un objet et une production - la presse à coins du parfumeur - que de simples représentations techniques. Fruit d'une évolution technique récente, la représentation d'une presse à vis serait porteuse d'un message moins clair, surtout pour des dessins observés en passant.

${ }^{214}$ Brun 1993 a: 525. 

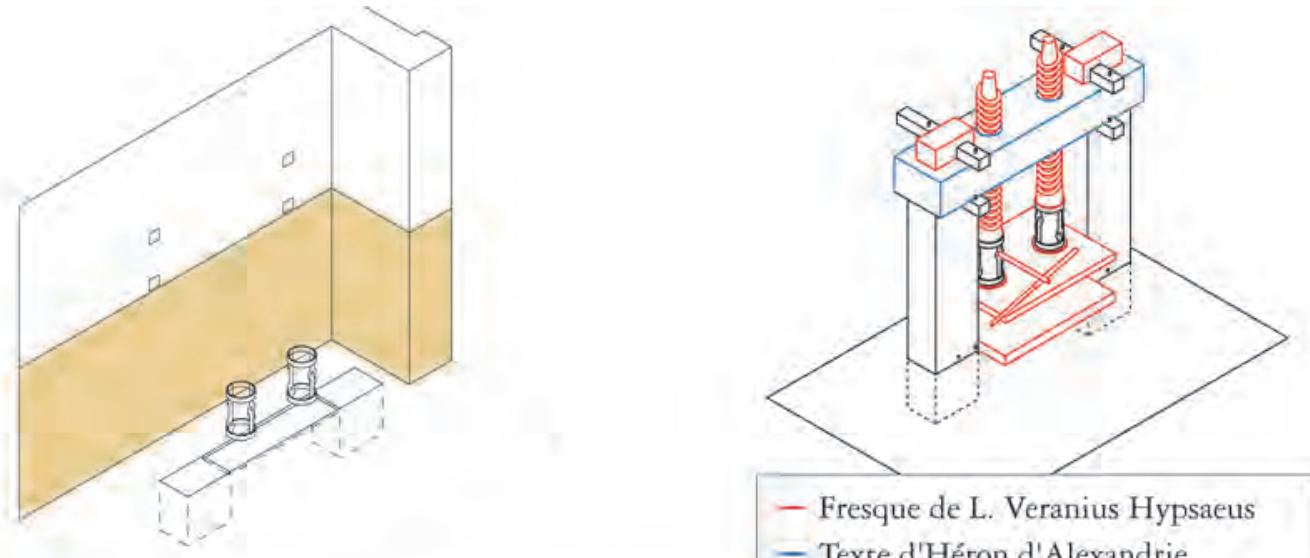

- Fresque de L. Veranius Hypsaeus

- Texte d'Héron d'Alexandrie

a

- Fouille de la fullonica de Stephanus

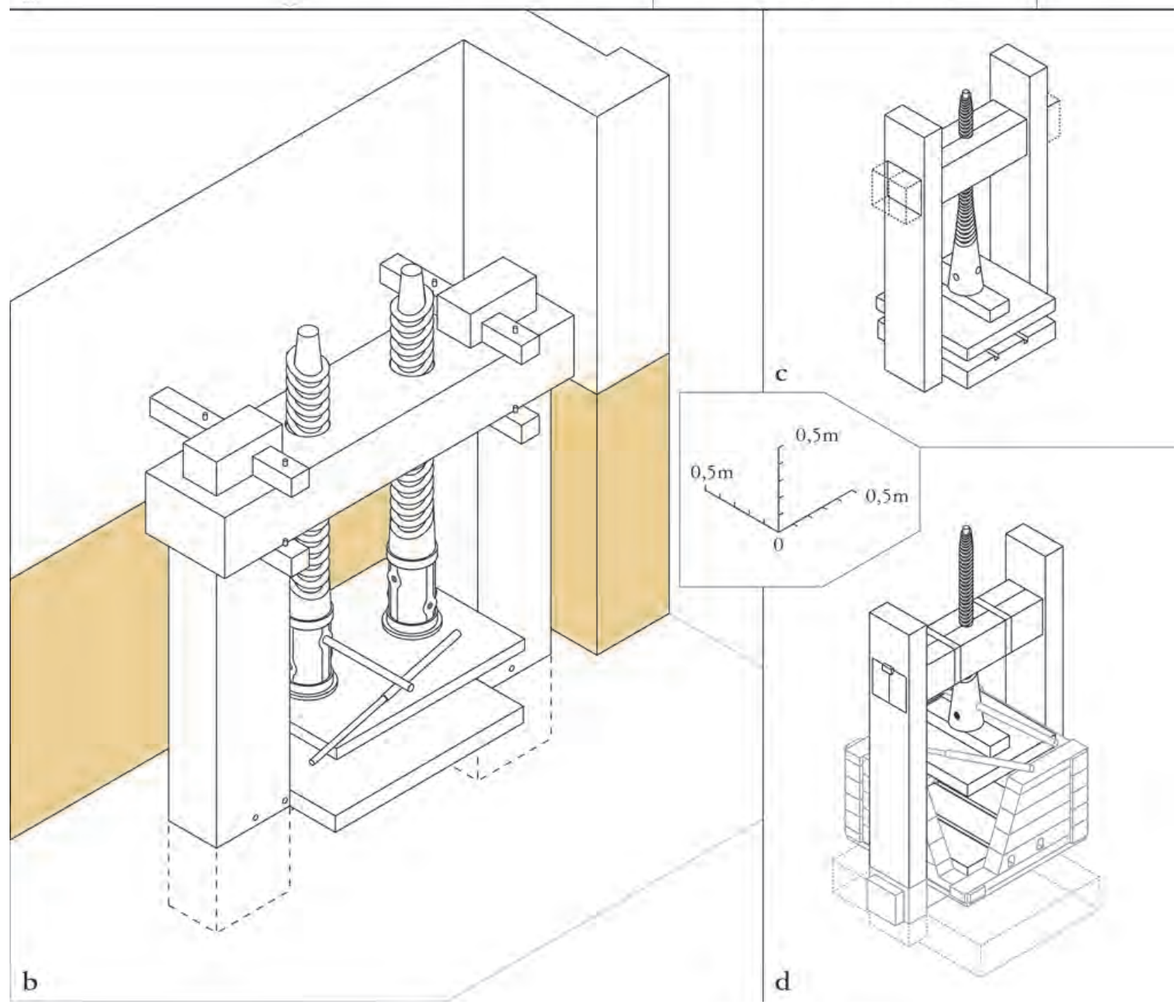

Fig. 109 - Restitutions isométriques des presses à vis de la fullonica de «Stephanus» et de la boutique III, 10. Pompéi: (a), éléments de la presse mis au jour lors de la fouille et justification de la restitution (échelle: 1/100); (b) presse restituée (échelle: 1/40); Herculanum: (c), représentation de la restauration actuelle; (d), proposition de restitution selon les indications fournies par les journaux de fouilles et le texte d'Héron d'Alexandrie (les éléments restitués sont tracés en gris; échelle: 1/40). 
de la pierre serait prépondérant ${ }^{214}$ et les attestations archéologiques de maies en bois rares hors d'Herculanum. De plus, les canaux d'écoulement sont rectilignes et parallèles dans ce cas précis. La majeure partie des vestiges d'huilerie, que la maie soit constituée par une pierre ou qu'un sol bétonné soit utilisé en ce sens, présente des rainures circulaires dont le diamètre est à peine supérieure à celle des scourtins écrasés. Une autre solution peut être envisagée: la presse découverte en III, 10 ayant été partiellement écourtée lors de sa restauration ${ }^{215}$, l'usage des scourtins - associés à un système de rainurage circulaire - peut être écarté. Un écart de $10 \mathrm{~cm}$ entre la presse sortie de sa gangue et sa version restaurée permet de postuler l'existence d'un espace entre la maie et les jumelles qui autorise l'insertion d'un coffre en bois contenant les fruits à presser, semblable à celui décrit par Héron d'Alexandrie (galeagra) ou par Pline l'Ancien et Columelle (regulae) ${ }^{216}$.

${ }^{215}$ Les archives concernant les restaurations effectuées en 1928 ne se trouvent pas parmi les GL conservés à l'Ufficio Scavi d'Herculanum. Les GSE donnent tout d'abord un écartement de $105 \mathrm{~cm}$ entre les jumelles, correspondant à la longueur du banc. Le coffrage en verre utilisé pour protéger la presse a obligatoirement nécessité qu'elle soit complètement démontée. Le banc mesure actuellement $87 \mathrm{~cm}$ de longueur. Il a donc été écourté de $18 \mathrm{~cm}$ au remontage. Celui-ci a d'ailleurs été effectué en plusieurs temps, comme le montre l'absence de la partie sommitale de la vis sur la photo publiée par A. Maiuri (1958 b: fig. 172 p. 220). Enfin, comme dernier problème de restauration, notons que les deux pièces de bois actuellement visibles entre le tambour de la vis et le plateau, non protégées par les plaques de verre, paraissent n'être que du bois moderne à peine carbonisé en surface.

${ }^{216}$ Héron, Mec. 3, 16-17; Plin., NH, 15, 5 : [...] quin et ex eo prima unda preli lautissima ac deinde per deminutiones, sive in sportis prematur sive, ut nuper inventum est, exilibus regulis pede incluso.

«[...] Et même, dans cette huile, la première coulée du pressoir est la plus belle, puis la qualité décroît, que l'on presse en cabas ou, selon un procédé d'invention récente, en enfermant la pulpe dans de minces réglettes » (trad. CUF).

Columelle préconise l'utilisation des regulae, soit pour l'obtention d'huile à partir d'olives vertes $(12,52,10)$, soit pour extraire de l'huile à parfums $(12,54,2)$. Il indique que cette utilisation d'un coffrage à la place de scourtins n'est pas adoptée partout - si consuetudo erit regionis $(12,52,10)$ - mais sans donner une répartition de cette technique. Sur les différences d'usage entre scourtins et coffre, cf. Brun 1986: 47-48.

Quoique d'une période plus tardive, un socle en pierre mise au jour à Karanis (Égypte) apporte quelques infor-
L'adoption de ce système de coffrage sans bec verseur sortant de la maie implique l'installation d'une fosse pour recueillir le produit du pressage, laissé à décanter ${ }^{217}$. Si les exemples des parfumeries de Pompéi, Paestum ou Délos, pourvues de maies en pierre avec bec verseur, suggèrent l'utilisation d'un récipient mobile pour faire décanter l'huile, des fosses de petites tailles sont attestées dans une huilerie de Jordanie ${ }^{218}$. Il ne manque qu'une observation directe de la fosse signalée lors de la fouille de l'atelier III, 10 pour affirmer qu'elle a servi à la décantation des produits issus du pressage des olives.

Ces différentes observations et confrontations, en dépit de la part non négligeable laissée à la restitution autorisent une révision fonctionnelle de la presse découverte en III, 10. Vers le milieu du I ${ }^{\text {er }}$ s. ap. J.-C., Héron d'Alexandrie - qui a pourtant signalé l'usage de la presse à coins par les parfumeurs ${ }^{219}$ - décrit une presse

mations métriques sur la technique du pressage en coffre: la maie rectangulaire - 44 x $88 \mathrm{~cm}$ - est entourée par un canal finissant en bec verseur. Le creusement périphérique mesure 3 à $4 \mathrm{~cm}$ de largeur. Sur la datation de cette pierre et les conditions de sa découverte, cf. Brun 2004 b: 175178. Les mesures ont été obtenues à partir de l'axonométrie présentée p. 178.

${ }^{217}$ Lors de l'extraction d'huile à partir d'olives - et plus particulièrement d'olives vertes, très riches en eau végétale -, il est nécessaire de la laisser décanter, de façon à ce que la différence de densité avec l'eau sépare les deux produits. L'huile surnageant est ensuite récupérée avec des coupelles (cf. Brun 1986: 47-53). Dans la fresque conservée au Fitzwilliam Museum, l'amour accroupi à côté de la presse pourrait être en train de procéder à la récupération de l'huile après décantation (Mattingly 1990: 77).

${ }^{218}$ Dans une huilerie de Khirbet Edh-Dharih (Jordanie), datant du $\mathrm{I}^{\mathrm{er}}$-II $\mathrm{I}^{\mathrm{e}}$ siècle ap. J.-C., utilisant deux pressoirs à levier, F. Villeneuve (1988: 464) décrit ainsi ces fosses de décantation: "L'huile s'écoule, pour première décantation, dans deux recettes cylindriques couvertes d'une margelle en pierre». Le plan publié montre que ces fosses sont d'une taille à peine inférieure aux margelles, qui mesurent $77 \mathrm{~cm}$ de côté (Villeneuve 1988: fig. 3).

Sur une gravure sur cuivre réalisée par Johannès Stradan $\left(\mathrm{XVI}^{\mathrm{e}}\right.$ siècle) montrant l'intérieur d'un moulin, la fosse de décantation est située juste en dessous de la maie (Amouretti - Comet - Ney - Paillet 1984: fig. 1 p. 383).

${ }^{219}$ Héron, Mec., 2, 4: «La quatrième machine simple [...] est celle appelée le coin. Elle rend de grands services dans les presses pour les parfumeries et pour produire l'adhésion des parties disjointes dans certains ouvrages de menuiserie» (trad. B. Carra de Vaux, corrigée par Pappos, cf. Carra de Vaux 1988: 243-244). 
ressemblant à s'y méprendre avec celle, restituée, d'Herculanum: "Il existe un autre instrument à une seule vis. Pour le construire, on fixe sur la table deux pieds portant la poutre transversale dans laquelle est creusé l'écrou; cet écrou se trouve au milieu de la poutre; on y introduit la vis, et on la tourne à l'aide de pieux qui sont dans le tambour; elle s'abaisse sur la planche placée dans le coffre [galeagra] et, en la refoulant, fait couler les sucs $»^{220}$.

En conclusion, il faut définitivement abandonner le lien, proposé par A. Maiuri, entre le pressoir situé en III, 10 et l'artisanat textile. L'argumentaire fondé sur les similitudes avec les presses à vêtements découvertes dans les fouleries de Pompéi se limite au seul fonctionnement à vis ${ }^{221}$. L'interprétation du local III, 10 comme une huilerie est raisonnable. Quant à pousser jusqu'à y voir un atelier de parfumerie, seule l'absence de fourneau maçonné pour l'enfleurage pourrait constituer une objection ${ }^{222}$.

\section{ESSAI DE COMPARAISON DES ACTIVITÉS TEXTILES À Herculanum et Pompéi}

À partir du panorama des activités textiles esquissé pour Herculanum et Pompéi, une approche comparative entre les deux villes peut être proposée (pl. Iv, h.t.). Un premier constat montre qu'Herculanum dispose de toute la palette des ateliers impliqués dans la production textile, à l'exception notable de la teinturerie, des doutes subsistant sur la localisation de cette activité en Or. II, 11. Les premières étapes de fabrication du tissu - filage et tissage - peuvent être écartés de cette comparaison: la localisation de ces activités se fonde fortement sur les découvertes d'objets - pesons ou fusaïoles. À Herculanum, les dégâts provoqués par les fouilles en tunnel du XVIII ${ }^{\mathrm{e}}$ siècle sont trop importants pour autoriser à dresser un inventaire représen-

${ }^{220}$ Héron, Mec., 3, 20 (trad. B. Carra de Vaux).

${ }^{221}$ Déjà W. Moeller, bien que prompt à associer la presse d'Herculanum au processus de foulerie (Moeller 1976: 26), s'est montré finalement circonspect face à l'absence de structure liée à cet artisanat en III, 10: "The only disquieting feature of this 'find' is that the press came to light in a shop that shows no other signs of fulling» (Moeller 1976: 113). tatif. Notons toutefois que dans les deux villes, le filage et le tissage se déroulent majoritairement - exclusivement à Herculanum, mais avec une seule attestation probante - dans des contextes supposés appartenir à la sphère domestique, et non dans des espaces conçus pour une activité commerciale ou artisanale. Cette observation n'autorise cependant pas à cantonner ces productions au milieu.

La comparaison de l'équipement des deux villes en laveries de toison est plus indicative. Si deux de ces officines paraissent se maintenir tout au long du I ${ }^{\text {er }}$ siècle ap. J.-C. à Herculanum - sans prendre en compte les déplacements au sein de la ville - ce sont entre 24 et 27 de ces établissements qui ont été pour l'instant identifiés à Pompéi. Au-delà de la triviale supériorité en valeur absolue, la prise en compte des chaudières montre une concentration certaine à Pompéi : contre une moyenne oscillant entre 1,28 et 1,32 chaudière par atelier pompéien, toutes les officines d'Herculanum ne disposent toujours que d'une unique vasque pour dégraisser les toisons. De plus, le progrès technique, sensible à Pompéi avec l'apparition d'équipements permettant une meilleure productivité, est inexistant à Herculanum. Quel que soit le moment d'observation choisi durant le ${ }^{\text {Ir }}$ siècle, les aménagements n'y évoluent pas, toujours centrés sur la table maçonnée accolée au mur et dans laquelle sont insérés chaudière et bassin.

Les fouleries offrent également des perspectives de comparaison appréciables. Tout d'abord, des deux types de fullonicae identifiés, seul celui n'offrant que des capacités réduites de nettoyage a été identifié formellement à Herculanum. Les dix à douze fouleries pompéiennes se répartissent en deux groupes, le premier composé de six à huit officines ayant des capacités identiques à celles d'Herculanum; le second composé de quatre grandes fouleries qui sont équipées de

\footnotetext{
222 Certains des points délicats dans cette interprétation ne pourront jamais être éclaircis, vues les destructions occasionnées par les premiers fouilleurs du site. En revanche, une nouvelle mise au jour de la fosse de décantation permettrait certainement de confirmer l'hypothèse faisant de cette presse une presse à huile.
} 
bassins maçonnés à flux d'eau continu et parfois également d'une presse à lustrer, ce qui pourrait traduire une production qualitativement et quantitativement supérieure. Une observation plus détaillée montre également que le nombre moyen de stalles par fullonica est plus important à Pompéi (3,3) qu'à Herculanum (2).

Deux dernières remarques permettent de compléter ce tableau. À Herculanum, les différents lieux de la production textile sont tous spécialisés et différenciés, dédiés à une seule des opérations de la filière. En revanche, à Pompéi, des signes de concentration verticale sont discernables en plus de la concentration horizontale évoquée pour les fouleries (la fullonica VI 14, 21-22 en serait le meilleur exemple avec ses dix stalles cumulées): les ateliers I 8, 19 et VII 14, 5.17-19 combinent teinture et nettoyage des toisons, tandis que l'officine VI 15, 3 inclut dégraissage de la laine brute et foulerie, voire peut-être filage et tissage. Enfin, en considérant que les laveries de toisons sont le reflet à peine déformé - mais perceptible, au contraire du filage ou du tissage - de la production de tissu brut en milieu urbain, le rapport entre ces acti-

\footnotetext{
${ }^{223}$ Il conviendrait toutefois d'approfondir les interrogations sur l'interprétation de ces locaux, telle que proposée par W. O. Moeller (1976: 13) et validée ensuite par les travaux de Ph. Borgard (- Puybaret 2003: 311-312). Si W. Jongman (1988: 167-170) l'a contestée sur des questions formelles, sans proposer d'autre hypothèse, rappelons que l'une des premières explications à ces aménagements est due à A. Sogliano (NSc 1898: 388-391; 1903: 339). Suite à la découverte de nombreux ossements animaux (en particulier des têtes) à proximité des ateliers VII 9, 43 et VII 9, 44, il a proposer d'y voir des officines de triperies (cajonzari en napolitain). Une telle interprétation liant ces ateliers au travail de la viande a été proposée de nouveau par J.-A. Dickmann et F. Pirson (cf. n. 11 p. 171) puis par M. Flohr (2007 b: 132 et n. 26 p. 145), qui se fonde sur la découverte d'ossements dans les ateliers I 3, 16 et I 3, 15 . Dans ce dernier espace, de possibles pigments ont également été trouvés à proximité de la chaudière (cf. n. 8 p. 170).
}

vités et celles "de transformation" - teinturerie et foulerie - est plus important à Pompéi qu'à Herculanum, ce qui indiquerait une possible surproduction textile dans la Colonia Cornelia Veneria Pompeianorum ${ }^{223}$.

Ces quelques observations doivent être considérées avec prudence, Herculanum étant relativement plus mal connue que Pompéi. Cependant, elles permettent un tableau plus nuancé et plus relatif des activités textiles dans ces deux villes que ceux proposés par W. Moeller ou W. Jongman. Herculanum aurait ainsi un panorama des activités textiles banal, au sens où aucune spécialisation dans la production n'émerge. En revanche, à Pompéi, la répartition des différents types d'atelier et leur concentration tant verticale qu'horizontale indiquerait une forme de spécialisation pour une partie des activités textiles, ce qui pourrait confirmer de façon synchronique le tableau diachronique dressé par Ph. Borgard: Pompéi aurait été une ville drapière lors de l'éruption de $79^{224}$. Il serait toute fois nécessaire de multiplier les comparaisons avec d'autres villes pour mieux cerner ces aspects de la production textile à Pompéi.
Faute d'éléments suffisamment probants (le dépôt d'ossements à proximité du macellum pourrait être une décharge liée à cet édifice ou au temple situé en façade sur le forum; il faudrait connaître la nature des ossements découverts en I 3), il me paraît raisonnable de suivre les interprétations de $\mathrm{Ph}$. Borgard fondées sur la comparaison avec des aménagements modernes, quitte à soulever une série de questions problématiques que je laisse volontairement sans esquisse de réponse: où était stockée la laine à Pompéi? Les stocks étaient-ils suffisants pour une activité pérenne tout au long de l'année? Si non, à quoi servaient ces espaces lorsqu'ils ne lavaient pas des toisons?

${ }^{224}$ Les grands traits de l'évolution de la production textile à Pompéi - qui passerait au cours du I ${ }^{\mathrm{er}} \mathrm{s}$. de notre ère de ville lainière à ville drapière - ont été présentés par $\mathrm{Ph}$. Borgard au séminaire d'A. Tchernia, le 28 novembre 2002, puis indiqués en conclusion de son dernier article traitant de ce problème (Borgard - Puybaret 2004 : 58-59). 



\section{LES LIEUX DE MÉTIER, ESPACES DE VENTE ET DE SAVOIR-FAIRE}

Au terme de cette recension et de cette série d'interprétations - nouvelles ou confirmées - il convient de dresser un bilan sur la notion de métier et sur ses lieux d'exercice. Définir l'espace privilégié de certaines activités relève d'une gageure, faute de source. À Herculanum, la dichotomie entre le petit commerce de proximité et les autres métiers, bien qu'elle eût certainement comblé d'aise Cicéron ${ }^{1}$, reste le résultat d'un effet de distorsion provoqué par la disparition - pour des questions de conservation ou de méthodes de fouilles - des vestiges de ces activités. À de trop rares exceptions près, la boutique des simples revendeurs fait office de chaînon manquant dans notre compréhension des phénomènes économiques allant de la production à la consommation, pour ne même pas envisager ceux qui semblent dépourvus d'un local fixe et qui n'ont laissé de trace que par l'inscription de leur nom de métier ou par leur représentation sur certaines fresques, comme celle des Praedia Juliae Felicis ${ }^{2}$.

Les exemples des métiers de bouche commerces alimentaires et boulangerie - et du textile permettent diverses constatations. $\mathrm{La}$ première d'entre elles touche à l'absence d'espace spécifique: la boutique ou l'atelier s'installe dans n'importe quelle partie de l'espace domestique. Le besoin d'être visible depuis la rue pour attirer de la clientèle fait préférer les locaux situés de part et d'autre du ou des accès à la domus. Toutefois, ces espaces ne sont pas les seuls à être

\footnotetext{
${ }^{1}$ Cic., Off., 1, 150 : Sordidi etiam putandi, qui mercantur a mercatoribus, quod statim vendant.

«Le commerce est sordide si c'est un petit commerce où l'on n'achète que pour revendre directement » (trad. CUF).

2 Sur le commerce ambulant, voir Magaldi 1930; la
}

occupés. Dans un pragmatique souci d'éviter la multiplication des travaux en gros œuvre, des pièces prévues pour un autre usage - péristyles, atriums, salles de réception, fractions d'édifices publics - sont fréquemment détournées de leur vocation première et employées en guise d'ateliers. Il faudra revenir sur ce point en adoptant une vision diachronique.

Cette forme d'opportunisme spatial pourrait être une caractéristique importante de l'organisation du travail dans le monde romain. La répétition, parfois troublante, des aménagements propres à chacun des métiers étudiés a permis la restitution des processus qui sont caractéristiques de ces activités. Pourtant, en dépit de cette forme extrêmement systématique de succession des tâches, aucune uniformité n'apparaît dans l'agencement ou le choix des espaces de travail. Dans le cas de la production du pain par exemple, les boulangeries d'Herculanum et de Pompéi disposent toutes - aux légères variations dues à des problèmes de conservation près - d'une batterie d'aménagements identiques: éventuelles meules, pétrin et four. Pourtant, au-delà des problèmes d'échelle, aucun de ces pistrina n'est identique à l'autre. Les dispositions optimales pour ces aménagements, suivant l'ordre de la chaîne opératoire, semblent recherchées sans être toujours atteintes, tant s'en faut. Dès lors, les boulangeries, mais il en va de même pour les lieux des autres métiers envisagés, se définissent plus comme un

fresque des praedia de Julia Felix a été récemment étudieee par S. Nappo (1989) et P.G. Guzzo (2005). Pour une proposition sur le rôle des commerçants ambulants dans la distribution des produits de boucherie, cf. Monteix 2007 c: 191197. 
rassemblement passablement organisé d'infrastructures de travail - d'outils que nous percevons essentiellement sous leur forme maçonnée - que comme un espace strictement rationalisé.

À partir de cette définition en termes d'espaces de production variables, il est possible de s'extraire des lieux pour atteindre les métiers en eux-mêmes. La capacité d'exercer un de ces métiers tient à la faculté d'utiliser convenablement les outils, instruments et aménagements. Seule la maîtrise d'un savoir-faire technique compte et fait l'atelier. Une telle définition du métier permet d'étendre la réflexion au-delà des champs traditionnels de l'«artisanat $»^{3}$. Pour reprendre l'exemple des caupones - terme unique définissant, dans les sources littéraires, celui qui accueille ses clients comme des hôtes payants - l'adéquation entre les textes et les données archéologiques est pour une fois troublante. Pour tous les grands types que j’ai définis à Pompéi, il existe toujours au moins un exemple qualifiant le tenancier de caupo ${ }^{4}$. En ne prenant en compte que ces catégories, le seul facteur commun entre ces établissements - outre la nature alimentaire des produits vendus - se limite au savoir-faire de leurs tenanciers: l'accueil de la clientèle.

Les métiers seraient donc ubiquistes, leur implantation uniquement limitée-et discernablepar les aménagements nécessaires à leur pratique. Latelier ou la boutique ne seraient alors que des assemblages fluctuants d'instruments et d'outils pouvant être utilisés hors de tout cadre systématiquement défini, le seul facteur de cohésion restant les capacités de l'homme de métier. Cette définition ne doit pas pour autant cacher deux écueils, tous deux émergeant des sources à disposition. Le premier tient à la possibilité de définir positivement un savoir-faire. La nature même des vestiges archéologiques fait que l'instrument et le résultat de la maîtrise technique sont presque toujours dissociés: les informations sur le détail

\footnotetext{
3 Les définitions traditionnellement proposées pour circonscrire l'artisanat excluent volontairement l'alimentation et ses processus de transformation (cf. e.g. Ferdière 2001: 3 ; Santoro 2004: 24, 26, 35).

${ }^{4}$ L'inscription CIL IV, 494 est peinte sur le côté ouest du restaurant VII 5, 14 (type 2), en face de VII 6, 22 (restaurant de type 1); CIL IV, 537 se trouve en façade d'un commerce de type 4 (VII 5, 17); CIL IV, 1048 a été lue en devanture du local IX 1, 16, revendeur de denrées en vrac (type 3). Cf. Monteix 2007 a: fig. 1, p. 120.
}

des productions du probable parfumeur de la Casa del tramezzo di legno seront toujours nulles; les connaissances sur cet homme de métier resteront toujours limitées à l'un des ses outils, la presse. Tout au plus cet instrument trouvera sa place dans une longue histoire des techniques, impossible à écrire dans les villes ensevelies par le Vésuve qui n'offrent au mieux qu'un instantané très déformé. Le second écueil est constitué par la trompeuse uniformité du savoir technique. La définition d'un atelier comme la somme des connaissances qui y sont mises en pratique ne doit pas faire oublier la présence d'une hiérarchie dans ces équipes. Derrière le maître-artisan se cachent de nombreux tâcherons qui ne peuvent être assignés à d'autres tâches que les plus répétitives. La transmission du savoir-faire technique ou son absence sont deux champs qui doivent encore être explorés 5 .

La vision adoptée jusqu'à présent a été essentiellement synchronique, concentrée sur l'état du tissu commercial tel qu'il a été scellé par l'éruption du Vésuve à l'automne 79. Cependant, cette description des lieux de métier en fonctionnement, quelque idéale qu'elle puisse être, correspond à la dernière étape du développement commercial à Herculanum. Pour appréhender complètement le phénomène de l'insertion des boutiques et des ateliers dans l'espace urbain, il faut doublement changer d'échelle: non seulement pour étudier le rapport de ces locaux avec les maisons en façade desquelles ils s'installent généralement, mais également pour cerner les rythmes de cette installation. L'impossibilité dans laquelle on se trouve actuellement de bénéficier de données diachroniques, consécutives à des fouilles stratigraphiques dans l'ensemble des boutiques et des ateliers ne saurait constituer un obstacle: le recours à l'archéologie du bâti, qui permet de suivre l'évolution des structures conservées en élévation, autorise à pallier ce manque.

5 Sur la transmission du savoir artisanal, voir les recherches en cours de N. Tran. Quant à l'absence de savoirfaire, elle est résumée dans ce long et sarcastique graffite (CIL IV, 10150): de[d]uxisti octies tibi supere(s)t ut (h)abeas sedecies coponium fecisti cretaria fecisti salsamentaria fecisti pistorium fexisti agricola fuisti aere minutaria fecisti propola fuisti languncularia nunc facis si cunnu(m) linx\{s\}e\{e\}ris consummaris omnia. 


\section{DEUXIÈME PARTIE}

\section{LA PLACE DES BOUTIQUES AU SEIN DES PROPRIÉTÉS URBAINE: ESSAI D'ARCHÉOLOGIE DU BÂTI}




exemple de ces boutiques dans lesquelles les propriétaires faisaient vendre, pour leur compte, les productions de leurs biens ruraux. C'est ce qu'indique la porte de communication de cette boutique avec l'atrium; d'ailleurs, elle était située dans une rue qui devait être peu passagère, et par conséquent peu recherchée des marchands; il ne pouvait y avoir que le propriétaire de la maison qui pût trouver son compte à pareil établissement ».

F. Mazois, Les ruines de Pompéi dessinées et mesurées par F. Mazois... $2^{e}$ partie, Firmin Didot, Paris, 1822-1824, p. 49.

«Tutto il presente studio si fonda [...] sull'esame dei sistemi costruttivi ».

G. Lugli, «Studi topografici intorno alle antiche ville suburbane», Boll. Com., 55, 1927, p. 145.

Pour comprendre l'importance du tissu commercial à Herculanum, il faut réussir à définir les espaces voués à une activité commerciale ou artisanale et proposer des interprétations pour ces locaux. Toutefois, cela limite la compréhension de ces phénomènes à une fraction de la seule sphère de la production et de la commercialisation, laissant dans l'ombre l'évidente interaction entre ces lieux de métier et les autres formes d'espace. De la même façon, en étudiant les boutiques et les ateliers à la seule échelle du local, les relations que l'on peut espérer restituer sont celles du commerçant avec sa clientèle.

Pour une compréhension générale des phénomènes liés au commerce de proximité et à l'artisanat urbain, les locaux ne doivent plus être analysés pour eux-mêmes mais à travers les relations qu'ils entretiennent avec les autres édifices en devanture ou au sein desquels ils sont implantés. Toutefois, une telle recherche n'a d'in- térêt que si l'on quitte la dimension synchronique de l'état de la ville au moment de l'éruption du Vésuve, tel que restitué après les fouilles. Il serait ainsi possible de suivre l'évolution des implications dans le commerce en analysant les transformations subies par les lieux de métier. Pour être complète, cette démarche devrait prendre en compte autant que possible l'ensemble des données disponibles et donc considérer tous les édifices connus à Herculanum. Cependant, dans une ville où la détermination de l'extension du patrimoine immobilier, et plus encore des propriétaires de ces fonds, est une gageure, j'ai choisi de ne pas prendre en considération les fractions d'îlots n'ayant jamais présenté de boutique ou d'atelier, à moins que les transformations qu'ils ont subies ne les aient amenés à être liés à des lieux de métier. De cette façon, je déterminerai quelles étaient les fractions de la population impliquée dans le commerce de proximité et dans la production urbaine. 
Une première limite à cette réflexion doit être posée. Ma démarche se fonde d'abord et essentiellement sur l'interprétation des vestiges construits encore en élévation au moment de l'éruption de 79. C'est dire que les sources à disposition sont fortement lacunaires, que ces lacunes soient simplement dues aux processus «normaux » de transformation du bâti - fondés sur la destruction partielle et le remploi des aménagements tombés en désuétude - ou aux destructions liées à l'éruption ou aux premières fouilles. De plus, la richesse d'Herculanum en documents épigraphiques, pour être certaine, n'est d'aucun secours dans une telle recherche. En effet, malgré la découverte du probable album des citoyens ou de nombreux documents issus de la pratique juridique, aucune inscription, aucun graffito, aucune tablette de cire ne permet de faire le lien entre un local commercial et son occupant ou son tenancier ${ }^{1}$. De la sorte, les quel- ques remarques ayant trait à la société herculanéenne que je ferai n'atteindront pas le niveau de précision, ne serait-ce qu'en terme de statut social, que l'on pourrait obtenir par une étude épigraphique $^{2}$. De ce fait, sans même chercher pour l'instant à revoir les interprétations proposées sur ce sujet par A. Maiuri, je ne pourrai pas, par exemple, déterminer l'importance des affranchis dans le milieu social commerçant à Herculanum. Tout au plus me sera-t-il possible de suggérer quelques hypothèses quant à la position sociale - relative - de tel résidant dans une domus dont la façade est occupée par des locaux commerciaux. Ces remarques ne pourront toutefois être formulées qu'après une étude de l'évolution des différents édifices en façade desquels des boutiques ou des ateliers ont été mis en évidence, recherche parfois fastidieuse mais néanmoins indispensable.

\footnotetext{
${ }^{1}$ Le supposé album des Augustales (CIL X, 1403) a été récemment réinterprété par G. Camodeca (2000) comme la liste des citoyens d'Herculanum, en raison du nombre beaucoup trop important de noms mentionnés sur cette liste pour une si petite ville. Les huit lots d'archives mis au jour à Herculanum se rapportent essentiellement au procès en ingénuité de Petronia Justa, aux contentieux de
}

L. Cominius Primus, aux archives de L. Venidius Ennychus et à cinq autres groupes d'importance moindre. Toutes ces tablettes sont en cours de relecture et de réédition par G. Camodeca (2002, part. n. 1-2 p. 257).

${ }^{2}$ Une étude sur le milieu commercial des environs du forum romanum, fondée sur l'analyse de données provenant d'inscriptions lapidaires, a été menée par E. Papi (2002). 


\section{CHAPITRE V}

\section{FONDEMENTS D'UNE ARCHÉOLOGIE DU BÂTI À HERCULANUM}

La méthode consistant à définir les phases d'évolution d'un bâtiment en observant les variations de ses techniques de construction n'est en rien nouvelle. Son emploi a été systématisé à Pompéi au début des années 1980 par R. Ling et son équipe dans l'îlot I 10 avant de devenir le point de départ de toute recherche archéologique dans les villes ensevelies par le Vésuve et d'être également utilisée dans d'autres sites, à Rome ou à Ostie par exemple ${ }^{1}$. Un exposé de cette méthode et de la façon dont j'ai tenté de l'appliquer à Herculanum est rendu nécessaire pour bien cerner les possibilités qu'elle offre, mais également ses limites d'application. La principale difficulté reste le basculement d'une

\footnotetext{
${ }^{1}$ Sur l'emploi de cette méthode à Pompéi, cf. not. Dobbins 1994, Ling 1997 a, Guidobaldi - Pesando 1998, Coarelli - Pesando 2006: 15-21, Santoro 2007: 77-180. À Rome, les travaux menés dans la Vigna Barberini se sont pour partie appuyés sur l'étude du bâti (Villedieu 2007,
}

\begin{abstract}
«Tout le principe de la construction tient et se résume en une seule chose: réunir avec ordre et assembler avec art de nombreux matériaux - pierres de taille, moellons, bois ou tout ce que tu voudras d'autre - afin d'en tirer une construction solide et, autant que possible, entière et bien liée.

[...] Il faut donc examiner quelles sont les parties principales de la construction, quelles sont leurs lignes et quel est l'ordre selon lequel elles se succèdent. Les parties de la construction à exécuter ne sont guère obscures [...] Mais tout le monde ne saisit pas ce qui est propre à chaque partie ni ce qui la distingue des autres ".
\end{abstract}

Leon Battista Alberti, De re aedificatoria, III, 1 (édition et traduction P. Caye et F. Choay, "Sources du savoir», Paris, éd. du Seuil, 2004, p. 139).

chronologie relative, obtenue par l'observation des relations stratigraphiques entre les différentes formes de mise en œuvre, à une chronologie absolue permettant de discerner à grands traits l'évolution du tissu commercial dans la ville.

Je préciserai d'emblée un point de sémantique. J'ai intentionnellement utilisé le terme d'archéologie «du bâti», plutôt que «de la construction». Une définition de cette seconde expression a été proposée par H. Dessales dans le volume consacré à l'étude des châteaux d'eau d'Ostie $^{2}$. Il s'agit d'une extension de la définition de l'archéologie du bâti, débordant le seul cadre de l'étude matérielle d'un édifice, pour tendre

part. 22). Pour Ostie, voir le travail T. L. Heres (1982) et surtout les recherches menées autour du château d'eau de la Porta Romana (Bukowiecki - Dessales - Dubouloz 2008).

${ }^{2}$ Bukowiecki - Dessales - Dubouloz 2008: 19-24. 
à la restitution des gestes, de l'organisation du chantier, etc. Ce glissement donne des objectifs plus larges, conduisant finalement à une histoire des techniques appliquée à la construction maçonnée, que la simple expression d'archéologie du bâti, dont je limiterais l'extension à l'étude des formes de maçonnerie, avec pour principal objectif de définir des rapports chronologiques. Dans certains cas, notamment pour les murs réparés ou construits après 62, quelques-unes de mes remarques peuvent tendre vers l'archéologie de la construction. Toutefois, dans l'ensemble, je ne chercherai pas à tirer de conclusions économiques ou sociales par les techniques de construction en elles-mêmes.

\section{V.1 Les techniques de mise en ouvre dans la cons- truction à Herculanum}

L'utilisation des formes de construction pour comprendre les rythmes de la vie urbaine à Herculanum s'inscrit dans une tradition remontant à A. Maiuri. Ce n'est pourtant pas avant la fin des années 1980 qu'une étude systématique a été développée par Th. Ganschow, ensuite revue et amendée sur certains points par une équipe néerlandaise conduite par R. de Kind et M.C. van Binnebeke ${ }^{3}$. Mon étude s'est fondée en très grande partie sur ces recherches, malgré quelques désaccords sur certains points de détail qui seront signalés chemin faisant.

\section{V.1.1 Généralités}

La mise en œuvre dans le monde romain se caractérise par l'emploi de matériaux divers qui sont liés avec des mortiers de chaux. Outre un massif de fondation, un mur se caractérise par deux ensembles formant, après séchage, un bloc concrétionné: le cœur, opus caementicium ou maçonnerie de blocage, enserré entre deux parements. Dans les conditions de préservation qui sont celles d'Herculanum, l'étude du

\footnotetext{
3 Cf. Maiuri 1958 b: 62-74; Ganschow 1989; Hoppenbrouwers - Vermeulen 1996.

${ }^{4}$ Pour d'évidentes raisons de temps et de moyens techniques, l'homogénéité de chaque type de parement présenté ne saurait être qualifiée autrement que comme une estimation de visu. Si certaines formes de mise en œuvre ne se caractérisent que par l'uniformité des matériaux employés,
}

blocage est rigoureusement impossible, sauf lorsque le mur s'écroule. Pour les quelques rares parois qui n'ont pas été restaurées dans leur élévation antique, une chape de béton empêche également une telle étude. Quand bien même une autopsie du blocage serait possible, elle n'apporterait que peu d'informations utilisables pour déterminer une chronologie: les fragments utilisés dans cette portion des murs sont généralement du tout-venant, débris de taille, tessons, etc., sans choix ni organisation, à l'exception des limites de banchées correspondant aux rythme des arrêts dans la construction. Dès lors, seuls les parements permettent de définir un «style» de construction. D’une façon générale, leur définition repose sur l'homogénéité - de matériaux, de dimensions et d'assemblage des moellons - qu'ils présentent ${ }^{4}$. Les matériaux utilisés à Herculanum sont sensiblement différents de ceux de Pompéi, bien que leur nature volcanique domine largement ${ }^{5}$. Le calcaire dit «du Sarno » est complètement absent d'Herculanum. En revanche, différents types de lave ont été employés, de sa forme compacte de couleur gris-bleu à sa forme plus aérée, "spongieuse », la cruma, de couleur rouge-violet. Parmi les matériaux volcaniques, le tuf a été particulièrement utilisé à Herculanum. Trois grandes catégories sont visibles: le tuf gris, dit de Nocera, essentiellement utilisé pour les seuils et colonnes; le tuf "rougeâtre» dont la couleur varie du brun au rosé, plus facile à travailler mais moins résistant que le précédent; le tuf jaune enfin. Ce dernier est certainement le matériau le plus employé dans la ville. La localisation des gisements utilisés à Herculanum reste à préciser dans les Champs Phlégréens. Le tuf jaune alors employé se caractérise par ses faibles inclusions basaltiques et surtout par une coloration jaune à reflets verts, au contraire du tuf utilisé lors des restaurations qui est jaune légèrement orangé et montre de nombreuses inclusions de basalte, ce qui facilite parfois la distinction des murs antiques de

\footnotetext{
d'autres pourraient en revanche être étudiées différemment. Il serait ainsi possible de mesurer les moellons d'opus reticulatum pour préciser les variations de leur régularité et de leurs dimensions (cf., pour Ostie, Bukowiecki - Dessales - Dubouloz 2008 : 36-39).

5 Sur ces matériaux de construction, cf. Ganschow
} 1989: 23-28 et pl. 1-3. 
ceux qui ont été reconstruits lors de la fouille ${ }^{6}$. En ce qui concerne la restauration, rappelons un point central: les travaux de reconstruction précèdent souvent la fouille et se caractérisent par un remploi fréquent mais non systématique des moellons provenant de la destruction des éléments instables de la maçonnerie antique. Si certaines parois sont restaurées en utilisant une technique similaire à celle de la construction d'origine, il reste impossible de se fier aux éléments reconstruits. Enfin, la distinction entre les constructions antiques et les restaurations modernes peut s'effectuer en analysant les photos réalisées lors de la fouille, alors que le mortier moderne est encore frais, mais également par certaines différences de matériaux (moellons et mortier) ou de traitement des joints.

\section{V.1.2. Typologie des mises en œuvre}

Huit grands types de construction ont été mis en œuvre pour l'élaboration des murs, à partir de la première version d'une typologie valable à Herculanum proposée par A. Maiuri puis modifiée entre les années 1980 et $1990^{7}$. Les premiers relèvent de la catégorie de l'opus incertum. Depuis les travaux de G. Lugli, ce nom est donné aux murs dont le parement est constitué de moellons pas ou peu retaillés, généralement assemblés avec une forte quantité de mortier ${ }^{8}$. En fonction de la nature des matériaux employés et du travail de taille effectué, quatre principaux types ont été identifiés. Le premier (opus incertum A, abrégé en Inc. A) est constitué de blocs et de moellons de lave, généralement

\footnotetext{
${ }^{6}$ Le tuf photographié par Th. Ganschow (1989: pl. 1) provient d'un mur restauré. Une autre caractéristique de ce matériau de restauration est qu'il semble avoir une résistance à l'érosion moindre que celui provenant des filons antiques.

${ }^{7}$ Sur la genèse de cette typologie, étroitement liée aux recherches d'A. Maiuri à Pompéi ainsi qu'aux travaux de G. Lugli, cf. supra, p. 17.

${ }^{8}$ Lugli 1957 : 446-449.

${ }^{9}$ Maiuri 1958 b: 64-65; Ganschow 1989: 37.

${ }^{10}$ A. Maiuri (1958 b: 65-66) n'a identifié que l'opus incertum B sans distinguer les autres sous-types. Th. Ganschow (1989: 38-40) distingue trois sous-catégories (Inc. Ba, Inc. Bb, Inc. Bc). La dernière est très peu courante et n'est reconnue par ce chercheur que dans la Casa del telaio
}

non retaillés. La taille de ces pierres est telle que les caementa sont pratiquement inexistants. La différence entre les rares murs construits de cette façon qui subsistent et les murs en pierres sèches tient dans un emploi très abondant de mortier comme liant dans le premier cas ${ }^{9}$. Le second type (opus incertum B, abrégé en Inc.B) se caractérise également par l'emploi de moellons de lave. Toutefois, contrairement au type précédent, ils sont sélectionnés et retaillés. Leur taille varie entre 10 et $25 \mathrm{~cm}$. Des sous-types ont été identifiés en fonction de la nature de la roche volcanique qui domine dans les parements. Le type Inc.B correspond à l'emploi de lave pas ou peu poreuse, de couleur bleue ou grise. En revanche, dans le type $I n c . \mathrm{B}^{1}$, les moellons sont essentiellement en ponce de couleur rouge. Quant à l'Inc. $\mathrm{B}^{2}$, il reprend les caractéristiques de l'Inc.B mais se distingue de ce dernier par son mortier très sableux qui présente de nombreux nodules de chaux adhérant mal aux moellons ${ }^{10}$. Le troisième type d'opus incertum (Inc C) correspond à l'introduction du tuf rossiccio et du tuf jaune dans la construction. Les moellons du premier sont de taille moyenne à grande (jusqu'à une vingtaine de centimètres), tandis que les seconds sont plus petits $(10-15 \mathrm{~cm})$ mais irréguliers ${ }^{11}$. Enfin, l'opus incertum D (Inc.D) se caractérise par des moellons d'origines volcaniques assez diverses, associés à des morceaux de béton de tuileau ou des fragments de tuiles, briques et autres objets céramiques. Le mortier est, encore plus que celui qui compose l'Inc. $\mathrm{B}^{2}$, riche en chaux. Il déborde largement d'entre les blocs mal taillés ${ }^{12}$.
(IV, 3), sur une portion de mur particulièrement dégradée constituant la paroi nord de la pièce G. Les types décrits ont été identifiés par l'équipe néerlandaise (Hoppenbrouwers - Vermeulen 1996: 180-182).

11 Contrairement à ce que propose Th. Ganschow (1989: 41), je n'ai observé aucun exemple où le tuf rossiccio et le tuf jaune auraient été mélangés. Comme l'avait déjà noté A. Maiuri (1958 b: 66): «È un opus incertum a tessitura regolare, composto esclusivamente di elementi in tufo giallo di Napoli $o$ tufo rossiccio locale [...]». Dans un seul cas, des moellons de cruma sont associés au tuf rossiccio, dans le mur nord de la pièce 4 de la Casa del papiro dipinto (IV, 8-9).

12 Ganschow 1989: 42; Hoppenbrouwers-Vermeulen 1996: 182-183, 185. 
La seconde grande catégorie de construction des murs tire son nom de l'aspect des parements: les moellons, taillés plus ou moins grossièrement en forme de pyramide à base sensiblement quadrangulaire, forment, une fois assemblés, comme un filet ${ }^{13}$. L'opus reticulatum n'est réalisé à Herculanum qu'avec du tuf - jaune ou rossiccio. Le premier type constitue une transition formelle entre l'Inc.C et l'opus reticulatum achevé. Les moellons constituant l'opus reticulatum grossier tendent à une certaine régularité, sans avoir toutefois la forme de véritables carrés sur pointe: ils sont plus proches du trapèze et leur alignement reste passablement irrégulier. Notons toutefois que la distinction entre ce type de mise en œuvre et l'Inc.C est parfois assez délicate à faire, à tel point qu'A. Maiuri a réfuté son existence ${ }^{14}$. En revanche, la différence entre les opera reticulata A (Ret.A) et B (Ret.B) est beaucoup plus sensible. Dans le premier, les carrés sur pointe sont taillés très régulièrement et leurs dimensions visibles sont toujours inférieures à $10 \mathrm{~cm}$ de côté. Les moellons sont disposés en rangs serrés, laissant des joints rarement supérieurs à $1 \mathrm{~cm}$. Dans quelques cas, certains moellons ne sont pas en tuf, mais en ponce rouge, de façon à dessiner des motifs polychromes ${ }^{15}$. Le Ret.B se caractérise en revanche par des quadrilatères plus grossiers - 10 à $13 \mathrm{~cm}$ de côté - en rangs moins serrés ${ }^{16}$. Enfin, la dernière façon de construire des murs est la technique du pan de bois hourdé, l'opus craticium. Essentiellement

\footnotetext{
487-490.

${ }^{13}$ Sur les origines de l'opus reticulatum, cf. Lugli 1957:

${ }^{14}$ Maiuri 1958 b: 68. Contra Ganschow 1989: 44-45.
} Le terme d'opus quasi reticulatum a été critiqué à fort juste titre par F. Coarelli (1977: 10) qui s'appuie en cela sur la terminologie vitruvienne où seuls l'opus incertum et l'opus reticulatum sont indiqués. La technique de mise en œuvre qualifiée ici d'opus reticulatum grossier correspond à l'opus quasi reticulatum tel que défini par Th. Ganschow. Je remercie vivement $H$. Dessales de ses remarques sur ce point.

${ }^{15}$ Sur le Ret.A, cf. Maiuri 1958 b: 70-71 et Ganschow 1989: 47-48. Les occurrences de la variante polychrome se limitent à la face sud de la Casa di Aristide (II, 1), à la façade de la Casa d'Argo (II, 2), à une fraction de celle de la Casa del tramezzo di legno (III, 4-12) et à quelques éléments de la Casa dei due atri (VI, 28-29). Si cette variante mérite d'être signalée, elle ne saurait être considérée comme un type propre tant elle est peu répandue.

${ }^{16}$ Maiuri 1958 b: 70-71 et Ganschow 1989: 49. utilisé pour des cloisons non porteuses et dans les étages, ce type de construction aurait eu des vertus parasismiques. Dans les différents exemples restaurés à Herculanum, ces cloisons apparaissent souvent dénuées de sablière basse: les poteaux reposent directement sur le sol, parfois plantés, comme dans le cas de l'appartement V, 17. L'exemple de la pièce 5 de la Casa di Nettuno e Anfitrite (V, 6-7) pourrait toutefois autoriser la restitution d'une telle sablière. Des entretoises, disposées entre les poteaux définissent des espaces qui sont hourdés avec une maçonnerie en tout-venant ${ }^{17}$.

Outre les types de construction utilisés pour les parois, plusieurs opera n'ont été utilisés que pour l'encadrement des portes et fenêtres. Les matériaux utilisés sont sensiblement les mêmes que pour les murs. Le tuf rossiccio et parfois le tuf gris sont employés comme montant de portes. Taillé en blocs larges de 40 à $60 \mathrm{~cm}$, de hauteur variable, il est plus particulièrement associé avec des parois en opus incertum ${ }^{18}$. Aucun mur n'a été érigé avec un tel opus quadratum, toutefois, des blocs de tufs sont parfois insérés comme piliers corniers, ou comme support des solives d'un compluvium dans le cas de la Casa dell'Apollo citaredo $(\mathrm{V}, 9-12)^{19}$. Dans quelques rares exemples, des blocs de taille plus réduite sont utilisés comme montants de fenêtre ${ }^{20}$.

Avec le développement de l'utilisation du tuf jaune, apparaissent trois formes de maçonnerie majoritairement employées comme

17 Sur cette technique de mise en œuvre, cf. Maiuri 1958 b: 74; Ganschow 1989: 50; Adam 1995: 132-135. Sur ses possibles caractéristiques parasismiques, cf. Papaccio 1993. Ces spécificités sont toutefois largement contrebalancées par l'extrême facilité avec laquelle de telles cloisons prenaient feu selon Vitruve $(2,8,20)$.

${ }^{18}$ Cette utilisation préférentielle de l'opus quadratum comme montant de portes percées dans des parois en opus incertum présente quelques exceptions. Ainsi, la porte située à l'étage de la Casa della fullonica (IV, 5-7), entre les pièces 2 et 4 , voit son montant sud érigé en Inc. A, comme le reste de la maçonnerie environnante.

${ }^{19}$ Cette maison constitue le seul exemple à Herculanum d'association entre des piliers en opus quadratum et des parois en Ret.B. Sur l'opus quadratum, cf. Maiuri 1958 b: 63-67; Ganschow 1989: 51; Hoppenbrouwers -Vermeulen 1996: 183.

${ }^{20}$ Une des occurrences de cette technique est constituée par la fenêtre murée, située au ras du sol au moment de l'éruption, qui se trouve percée dans le mur séparant la boutique VI, 25 de son arrière-boutique. Selon un procédé 
montants de portes et fenêtres. La première est l'opus vittatum (Vit.): elle se compose de moellons équarris, assemblés en assises régulières, formant un appareil isodome ou quasi isodome de taille réduite. Les moellons sont hauts et épais de 8 à $10 \mathrm{~cm}$, longs de 8 à $30 \mathrm{~cm}$. Ils peuvent être utilisés pour former des arcs de décharge, insérés dans des parois construites en opus incertum ou en opus reticulatum, comme dans la façade des thermes - au-dessus de la porte VI, 9 - ou dans celle de la Grande taberna, entre IV, 14 et IV, $15^{21}$. Notons qu'aucune paroi n'est intégralement construite en opus vittatum: si certains pans de murs n'emploient que cette technique de construction, ils constituent toujours des montants dont la largeur a été quelque peu allongée. Deux variantes de cette technique existent: elles consistent à alterner une ou plusieurs assises de briques avec les moellons en tuf. Cet opus vittatum mixtum $(\mathrm{Vm})$ doit être strictement divisé en fonction du nombre d'assises de briques employées $^{22}$ : sauf en cas de reconstruction abusive, ils ne sont jamais employés ensemble. Pour bien comprendre la répartition de cette mise

similaire à celui qui a été observé à Pompéi, de tels blocs peuvent également avoir été employés pour confectionner des chaînes verticales utilisées pour délimiter des parcelles (cf. Guidobaldi - Pesando 1998)

21 Maiuri 1958 b: 66, 70; Ganschow 1989: 52-53; Hoppenbrouwers - Vermeulen 1996: 183. Notons que l'arc est souvent inclus dans une autre maçonnerie, sans constituer à proprement parler une phase d'opus vittatum. Des exemples de cette pratique peuvent notamment être observés aux endroits suivants: Casa d'Argo, passage entre la pièce 1 et le jardin (II, 2; opus reticulatum A); Grande taberna con abitazione (entre IV, 14 et IV, 15; opus incertum D; cf. infra, p. 370); Casa del bel cortile, passage entre les pièces 3 et 4 $(\mathrm{V}, 8$; opus reticulatum $\mathrm{B}$ et opus vittatum mixtum à deux assises de briques); au dessus des entrées VI, 8 (opus reticulatum A) et VI, 9 (opus incertum C/opus quasi reticulatum) des thermes; façade de la Casa dei due atri (VI, 29; opus reticulatum A); Insula Orientalis $I I^{a}$, entrée 19, passage entre l'Aula superiore et la loggia (opus reticulatum B). Un exemple - unique - d'arc construit en alternant un moellon de tuf avec deux briques se situe au-dessus de l'entrée V, 2 de la Casa sannitica. Enfin, un seul arc de décharge en briques dans une construction privée se trouve dans la Casa di Aristide (II, 1), pris dans le mur de refend entre les pièces 11 et 4. sur l'intérêt de l'emploi des arcs de décharge dans une maçonnerie, cf. Fulvio Giuliani 2002: 83-85.

${ }_{22}$ Th. Ganschow (1989: 55-56) signale l'existence de ces deux variantes, sans les distinguer clairement. Cf. également Hoppenbrouwers -Vermeulen 1996: 183-184. en œuvre, j’ai jugé préférable de la distinguer de l'opus vittatum mixtum à plusieurs assises alternées de briques $\left(V^{2}\right)$. Des terres cuites architecturales ont également été employées, dans la construction privée, essentiellement pour l'érection de montants ${ }^{23}$. Les autres attestations de l'emploi de cette technique d'opus testaceum ont été observées pour des chaînages ou pour des reconstruction d'angles. L'emploi des briques et des tuiles ne se limite pas aux seuls montants des portes et fenêtres, mais peut avoir été étendu à certaines colonnes et piliers.

Un dernier type de maçonnerie doit être mentionné: le remplissage par coffrage ${ }^{24}$. Cette mise en œuvre se distingue par son absence de parement maçonné et donc l'impossibilité de la rattacher aux opera précédents: du béton avec des inclusions de natures très diverses (moellons, tessons, fragments de sol, etc.) est jeté dans des coffrages de planches. Cette technique est fréquemment utilisée pour condamner portes et fenêtres. Elle peut également être employée pour des parois ou pour une seule face d'un mur, l'autre étant appareillée plus régulièrement.

${ }^{23}$ L'utilisation d'un terme aussi vague pour définir les éléments de cette forme de maçonnerie tient à la difficulté de la distinction entre briques et tuiles, sans compter que ces deux matériaux peuvent être mélangés dans certains montants (Ganschow 1989: 56; Hoppenbrouwers -Vermeulen 1996: 184). Par commodité rédactionnelle, le terme de brique a été adopté dans la suite du texte. La limitation à la construction privée est volontaire: seuls certains édifices publics intègrent des parois intégralement construites en opus testaceum. Dans certains cas, sans constituer une paroi complète, des assises de 3 à 6 briques peuvent courir sur toute la longueur d'une paroi, comme au nord de la Casa dei cervi (IV, 21), éventuellement alternées avec une assise de moellons en tuf, à l'exemple de la façade méridionale de la Casa di Aristide (II, 1). Prises dans une paroi en réticulé, ces assises d'opus mixtum à panneaux permettent de stabiliser la maçonnerie et de limiter la création de fissures obliques dans des murs ainsi construits.

${ }^{24}$ Les coffrages laissent souvent leur empreinte, particulièrement si les planches qui les constituent n'ont pas été assemblées de façon jointive. En remplacement de ces dernières, la porte devant être condamnée peut être laissée en place. Le meilleur exemple de cette ultime technique est constitué par les deux communications entre l'atrium de la Casa del salone nero (VI, 11.13) et l'atelier VI, 12: du côté de la domus, l'empreinte des portes est encore visible. 
V.1.3 Principes de chronologie relative: l'exemple de la façade nord-est de la Casa del tramezzo di legno (III, 8-10)

À partir de la définition de ces différents types d'opera, on doit esquisser les rapports chronologiques qui existent entre eux. Quelle que soit la durée d'utilisation de chacune de ces mises en œuvre, il nous faut considérer que, dans un même édifice, l'emploi d'une technique donnée correspond à une unique phase de travaux. L'analyse des relations stratigraphiques de ces différentes portions de maçonnerie, soit la détermination de la façon dont elles s'appuient les unes aux autres, permet de proposer une chronologie relative par pan de mur, puis par édifice. Il va de soi que la contemporanéité dans l'emploi d'une technique de construction peut céder le pas à des anomalies stratigraphiques: deux phases d'utilisation de l'opus reticulatum B peuvent ainsi être distinguées dans l'atelier Or. II, 18. Le but de cette analyse n'étant pas de proposer une réflexion sur l'histoire des techniques de construction, il n'est pas question de dresser la «micro-stratigraphie» qui corres-

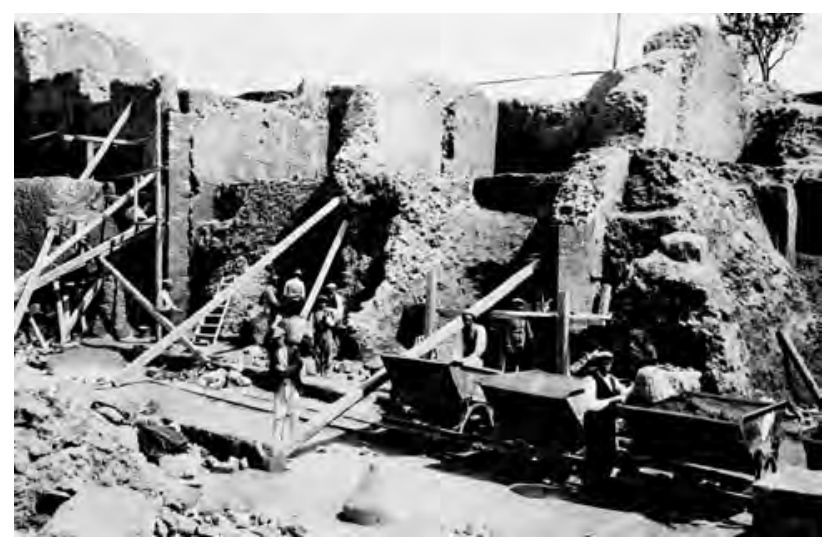

Fig. 110 - Façade de l'Insula Orientalis $I I^{a}$ en cours de fouille. Les éléments de maçonnerie fragilisés par les tunnels du $\mathrm{XVIII}^{\mathrm{e}}$ siècle sont soutenus par des étais le temps de leur reconstruction.

${ }^{25}$ La paroi s'étendant à l'ouest du montant occidental de la porte 8 n'a pas été prise en considération: le montant - en briques - et le mur en opus incertum $\mathrm{C}$ sont des restaurations modernes. Cette portion de la Casa del tramezzo di legno a été mise au jour dans les années 1870. pondrait aux opérations successives d'un même chantier.

Au titre d'illustration de ces principes, l'étude de la façade s'étendant sur le côté nord-est de la Casa del tramezzo di legno, entre l'entrée 8 d'une probable boutique communiquant avec la domus et l'atelier III, 10 constitue un exemple fécond ${ }^{25}$. Comme souvent à Herculanum, la proportion de maçonnerie restaurée est extrêmement élevée: sur une surface de $38 \mathrm{~m}^{2}$, ce sont près de $24 \mathrm{~m}^{2}(63 \%)$ qui paraissent avoir subi une restauration moderne perceptible notamment par l'utilisation de tuf jaune très vif, assemblé en moellons serrés. L'insertion après la fouille de linteaux en béton armé ou en bois, en remplacement des pièces antiques, est visible non seulement par les matériaux en eux-mêmes, mais également par la présence d'un arc naturel de rupture au-dessus de la position précédemment occupée par linteau, toujours rempli de maçonnerie de restauration. Le mode opératoire des travaux de consolidation des murs lors de la fouille explique la forme parfois absurde que peuvent revêtir les unités construites: les photos d'archives montrent toujours une forêt d'étais empêchant les murs de tomber ou de se renverser (fig. 110).

Sept types différents de maçonnerie supposés antiques ont été identifiés (fig. 111). Le premier n'est discernable que par les quelques moellons préservés situés dans l'entrée III, 9: des blocs de lave bleue subsistent sous le montant occidental de la porte et à l'emplacement où aurait dû se trouver le seuil. Ce sont toutefois majoritairement les pierres utilisées dans le blocage qui sont visibles, laissant planer un doute pour une identification correcte du type utilisé, que l'on supposera être de l'opus incertum B. La majeure partie de la façade correspondant à la porte 9 est construite en opus reticulatum B (Ret.B), le côté oriental de l'entrée ainsi que trois des quatre montants des deux fenêtres percées dans cette paroi sont en opus vittatum. Selon les statistiques dressées par Th. Ganschow, ces deux types d'opera sont très fréquemment associés ${ }^{26}$. La

${ }^{26}$ Th. Ganschow (1989: fig. 7b p. 113) rapporte que sur les 361 emplois recensés de l'opus reticulatum B, 152 sont associés avec de l'opus vittatum. 

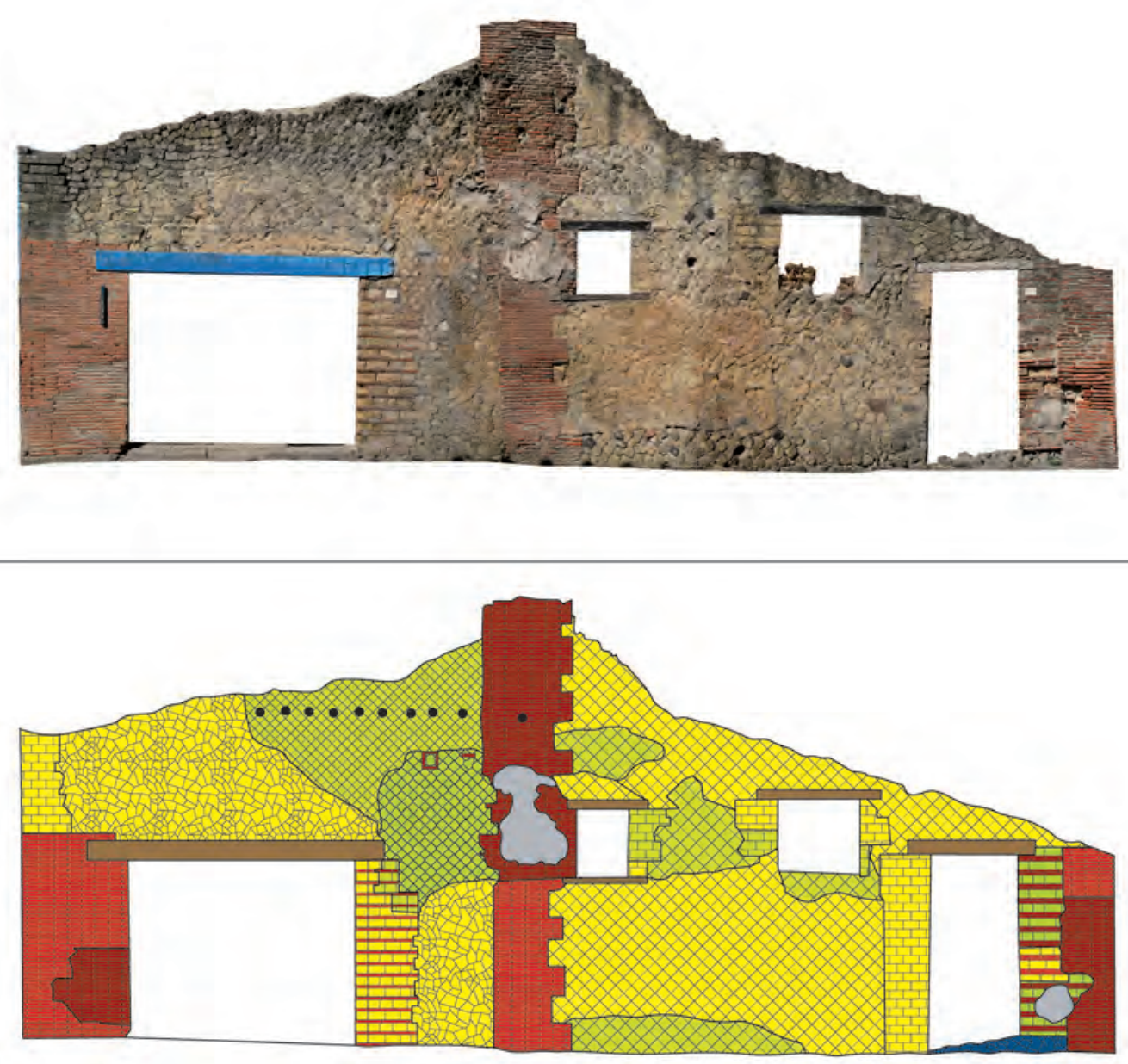

Est

0

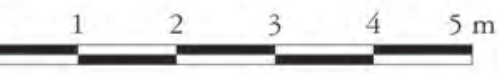

Ouest

$\begin{gathered}\text { Maçonnerie } \\ \text { antique }\end{gathered}$
Opus incertum B reticulatum B
Opus reticulatum A
Opremière phase
Opus vittatum mixtum
une assise de briques

$\begin{gathered}\text { Maçonnerie } \\ \text { antique } \\ \text { Opus reticulatum A } \\ \text { deuxième phase } \\ \text { Opus vittatum mixtum } \\ \text { deux assises de briques } \\ \text { Opus testaceum }\end{gathered}$
Opus incertum C
Enduit peint

Fig. 111 - Façade nord-orientale de la Casa del tramezzo di legno (III, 9.10). En haut, mosaïque d'orthophotographies (redressement numérique à partir d'un nuage de points relevés sur la façade). En bas, schéma d'interprétation des différents types de maçonnerie identifiés dans la façade (échelle : 1/100). 
réalisation de cet opus reticulatum B est parfois proche du reticulatum grossier, en particulier dans les 45 premiers centimètres de l'élévation, où des moellons de lave et un fragment de céramique remplacent par endroits les carrés sur pointe en tuf. Deux autres formes de construction ont en revanche été utilisées pour la façade de la boutique III, 10, pour autant que l'on puisse en juger, puisque seul le côté occidental a été partiellement épargné par les galeries du $\mathrm{XVIII}^{\mathrm{e}}$ siècle et les restaurations du $\mathrm{XX}^{\mathrm{e}}$ siècle. La partie principale de la paroi est construite avec un appareil d'opus reticulatum A présentant quelques irrégularités ${ }^{27}$. Au sommet de la partie conservée se trouvent deux encastrements de poutres, délimités par des briques ou des tuiles. Le montant occidental semble presque intégralement reconstruit. Deux assises de briques encadrant une assise de moellons de tuf jaune ont toutefois été préservées de la destruction, autorisant les restaurateurs à effectuer la restitution d'un montant intégralement construit en opus vittatum mixtum à un seul rang de briques. Au-dessus de cette première forme d'opus reticulatum A s'en trouve une seconde, plus nette et plus régulière dans sa mise en œuvre. La limite entre les deux reste relativement simple à distinguer, en dépit de sa ligne arrondie et irrégulière. À $3,88 \mathrm{~m}$ du trottoir, neuf empreintes rondes d'encastrements ont été identifiées à intervalles réguliers ${ }^{28}$. Le sixième type de mise en œuvre est constitué par l'opus testaceum. Il a été employé en deux endroits différents: comme montant occidental pour les entrées III, 8 et III, 10; comme parement externe en correspondance du mur de refend séparant les espaces III, 9 et III, 10, sur toute la hauteur préservée de la façade. Un détail de mise en œuvre doit être noté: le côté oriental est sensiblement régulier et passablement rectiligne, tandis que des chaînages crénelés avec le mur en opus reticulatum B ont été ménagés sur le côté occidental. Enfin, l'opus vittatum mixtum à deux rangs de briques $\left(\mathrm{Vm}^{2}\right)$ sert de montant occidental à la porte III, 9.

Pour comprendre la succession des phases de transformation de cette façade, il faut prendre en considération les rapports entre ces différents appareils. Pour l'essentiel, ils se discernent facilement, la simple superposition permettant de déterminer quelle mise en œuvre est postérieure à quelle autre ${ }^{29}$ : l'opus reticulatum A très régulier s'appuie sur la construction de même type moins régulière, il lui est donc postérieur. L'opus incertum B, n'est physiquement couvert que par le $V m^{2}$; il passe à travers le seuil de la porte III, 9 et pourrait donc s'être prolongé sous le mur construit en Ret.B. Deux relations doivent être explicitées plus particulièrement. La première concerne le bloc vertical construit en briques. Trois liens différents sont perceptibles. À l'ouest, la relation avec l'opus reticulatum B est assurée par un chaînage crénelé: tous les $30 \mathrm{~cm}$ environ, les briques débordent sur le Ret. B de 27 à $30 \mathrm{~cm}$. Comme le réticulé est ici associé principalement à l'opus vittatum, les assises de briques paraissent lui être postérieures, de telle façon que la paroi en Ret.B a été partiellement retaillée pour accroître sa cohésion avec les briques. Le même principe a été appliqué dans les relations entre la paroi en briques et le mur en Ret.A peu régulier. Toutefois, au lieu de construire des chaînes régulières et sensiblement carrées, l'accroche entre les deux types d'appareils suit une ligne sinusoïdale ${ }^{30}$. À peine la limite entre les deux opera reticulata A est-elle dépassée que l'extrémité orientale de la paroi en briques devient presque verticale. Cette situation empêche de déterminer avec certitude les rapports de succession entre les briques et le Ret.A très régulier. Toutefois, comme la paroi en opus reticulatum A
${ }^{27}$ Le dessin des «mailles» du filet n'est pas toujours strictement linéaire. Toutefois, les moellons ont des dimensions visibles toujours inférieures ou égales à $10 \mathrm{~cm}$. Cette forme d'opus reticulatum A reste très proche des caractéristiques générales de l'opus reticulatum B. Elle se distingue toutefois très nettement de la façade de III, 9, permettant l'individualisation d'une phase différente de construction.

${ }^{28}$ L'entraxe de ces empreintes est d'environ $27 \mathrm{~cm}$. Chacune a un diamètre de 7 à $8 \mathrm{~cm}$. Une dixième est située dans le bloc de maçonnerie en briques immédiatement à l'ouest.

${ }^{29}$ L'opus reticulatum B est associé avec l'opus vittatum. De la même façon, l'opus reticulatum A peu régulier a été mis en place en même temps que l'opus vittatum mixtum à une assise de briques.

${ }^{30}$ Dans la partie inférieure du mur, la restauration moderne n'a pas reproduit cette forme de chaînage. 
peu régulier est antérieure à ce dernier et aux briques, et comme une série de poutrelles est disposée sur les briques et sur le Ret.A, celui-ci est soit contemporain des briques, soit à peine postérieur à celles-ci. Le second point tient aux relations du montant situé entre les portes 8 et 9. Alors que le côté oriental du pilier en briques est relativement régulier, à $66 \mathrm{~cm}$ du trottoir, il est creusé sur $33 \mathrm{~cm}$, comme s'il avait été rogné pour faciliter l'accrochage de l'opus vittatum mixtum à deux assises de briques. L'observation rapprochée des mortiers différents de ces deux montants permet de confirmer que le $V m^{2}$ s'appuie sur les briques.

Une chronologie relative peut dès lors être esquissée. Rien ne peut être dit de la première phase caractérisée par l'opus incertum B, trop peu conservé. Au cours de la phase suivante, le premier mur est arasé. À sa place, une paroi en opus reticulatum $\mathrm{B}$ est construite: deux fenêtres et la porte 9 y sont percées; leurs montants sont en opus vittatum. Dans une troisième phase, une boutique est créée à l'emplacement de III, 10. Ses parois sont en opus reticulatum A peu régulier, les deux montants de la porte en opus vittatum mixtum à une assise de briques. L'étage est doté d'une avancée sur la rue comme en témoignent les poutres quadrangulaires encastrées. La transformation successive est caractérisée par l'insertion d'un pilier en briques dans la façade. Dans la partie supérieure, l'avancée sur la rue est démantelée et un nouvel opus reticulatum A plus régulier est disposé. Dans ces deux nouveaux murs, on insère des poutrelles rondes qui plus sont caractéristiques d'un appentis que d'une nouvelle avancée sur la rue. Au cours des même travaux, le montant oriental - et peut-être également celui situé à l'ouest - de la porte 8 est (re)construit en briques. Enfin, la dernière phase est marquée par la seule reconstruction du montant ouest de la porte 9 en opus vittatum mixtum à deux assises de briques. Je reviendrai plus loin sur l'interprétation à donner à cette

${ }^{31}$ Cf. infra, p. 244-253.

${ }^{32}$ En raison des travaux de restauration menés par l'Herculaneum Conservation Project, cet îlot a été inaccessible pendant la majeure partie de mes recherches. De plus, aucune boutique ou local artisanal n'y a été identifié. succession de travaux et sur leur insertion dans une chronologie «absolue ${ }^{31}$.

La forme d'analyse détaillée développée pour la façade nord-est de la Casa del tramezzo di legno a été menée sur l'ensemble du site - façades et espaces internes -, à l'exception de l'Insula Orientalis $I^{a 32}$. Pour éviter un développement fastidieux lors de la présentation synthétique de ces résultats, les données ne seront pas autant détaillées, sauf sur des points importants ou pouvant appeler une discussion.

\section{V.2 Herculanensis oppidi pars ruit (Sen., Nat., 6, 1, 2): questions sismiques}

Parmi les facteurs nécessaires à la compréhension de l'évolution du bâti à Herculanum, les problèmes sismiques sont parmi les plus importants. En effet, le séisme de 62 ap. J.-C. est l'un des jalons majeurs de l'histoire des deux villes ensevelies par le Vésuve ${ }^{33}$. Leur situation serait, estime-t-on en général, radicalement modifiée après qu'elles ont subi des destructions plus ou moins importantes: en 62 commencerait l'ultima fase, derniers moments de vie marqués par d'importants travaux de restauration, toujours en cours lors de l'éruption de 79. De la sorte, les dix-sept dernières années correspondraient pour certains chercheurs - à un ralentissement et même à une décadence de l'économie et de la société des deux cités, radicalement transformées par la catastrophe. En se cantonnant au seul domaine architectural, les dégâts provoqués par le séisme seraient des témoins de ces changements: les travaux réalisés indiqueraient les nouvelles orientations prises par les sociétés de ces deux villes, mais offriraient également à rebours un cadre de compréhension à la situation «d'avant». Depuis quelques années, cette vision a été modifiée par des contributions ponctuelles, essentiellement sur Pompéi, rassemblées au cours d'un colloque qui s'est tenu en 1993, tendant toutes à suggérer l'existence d'au moins

\footnotetext{
${ }^{33}$ Bien que désormais unanimement admise, la date de 62 ap. J.-C. a suscité un long débat, dû à des divergences entre la longue description de Sénèque (Nat., 6, 1, 1-2) et le bref récit de Tacite $(A n n ., 15,22)$. Sur les jalons de sa résolution, cf. Adam 1986: n. 9 p. 68.
} 
un second tremblement de terre entre 62 et $79^{34}$. L'analyse de ces données récentes et la mesure de leur portée éventuelle pour l'évolution d'Herculanum restent à effectuer.

V.2.1 Les attestations littéraires et épigraphiques des phénomènes sismiques

Les commentaires de Sénèque sur les phénomènes sismiques constituent l'une des sources les plus détaillées sur le séisme antérieur à l'éruption:

Pompeios, [...] consedisse terrae motu vexatis quaecumque adiacebant regionibus, [...] audivimus, et quidem hibernis diebus[...]. Nonis Febuariis hic fuit motus Regulo et Verginio consulibus, qui Campaniam [...] magna strage vastavit: nam et Herculanensis oppidi pars ruit dubiequestant etiam quae relicta sunt [...]. Neapolis quoque privatim multa, publice nihil amisit leviter ingenti malo perstricta $[\ldots]^{35}$.

À propos du même phénomène, Tacite se contente de souligner qu'un tremblement de terre a frappé Pompéi, sans indiquer les autres villes alentour ${ }^{36}$. Cependant, les termes employés par Sénèque laissent peu de doutes quant à l'ampleur des dégâts à Herculanum. L'année 64 est marquée par un second séisme, attesté à Naples par Suétone: Néron donnait un

${ }^{34}$ Les actes de ce colloque ont été édités par Th. Fröhlich et L. Jacobelli en 1995. L'importance de cette question est brillamment exposée dans l'introduction de ces actes par L. Jacobelli (1995).

35 Sen., Nat., 6, 1, 1-2: «Nous avons entendu que Pompéi, [...] vient d'être renversée en plein hiver par un tremblement de terre dont ont souffert toutes les contrées avoisinantes; c'est le jour des nones de Février, Regulus et Verginius étant consuls, qu'eut lieu ce séisme qui frappa la Campanie [...] avec une force considérable. Herculanum s'est en partie écroulé et ce qui reste debout n'est pas sans inquiéter. [...] L'affreux fléau a légèrement touché Naples où des particuliers ont subi des pertes, mais non la cité $[\ldots]$ » (d'après trad. CUF).

36 Tac., Ann., 15, 22: Isdem consulibus [P. Mario et L. Afinio] [...] et motu terrae, celebre Campaniae oppidum Pompei magna ex parte proruit.

"Lors du consulat des mêmes (Publius Marius et Lucius Afinius, en 62 ap. J.-C.), un tremblement de terre a détruit en partie Pompéi, célèbre ville de Campanie» (d'après trad. CUF).

${ }^{37}$ Suet., Nero, 20, 3: Et prodit Neapoli primum ac ne concusso quidem repente motu terrae theatro ante cantare destitit, quam incohat absolveret nomon. récital dans le théâtre qui s'est écroulé à la fin de la représentation, manquant de peu d'y perdre la vie ${ }^{37}$. La seule présence de l'empereur a rendu cet événement digne de figurer dans les annales. L'ampleur de cette possible secousse ne peut pas être mesurée, laissant ouverte la question d'éventuels dégâts à proximité du Vésuve. Jusqu'en 79, aucune source littéraire ne mentionne d'autres séismes. En revanche, dans sa lettre à Tacite, Pline le Jeune indique très clairement qu'il s'agit de phénomènes courants en Campanie et que la région en a souffert avant l'éruption ${ }^{38}$. Pour ces secousses précédant l'éruption, ni la magnitude, ni les dégâts subis et encore moins leur répartition dans le temps ne peuvent être déterminés. Il faut souligner cependant que Pline habitait alors à Misène, à proximité des Champs Phlégréens, zone susceptible d'engendrer des séismes. Quand bien même il englobe toute la Campanie dans son témoignage, son vécu, qui fait l'intérêt majeur de ce récit, reste attaché à une zone sismique relativement éloignée du Vésuve.

Pour les éventuels tremblements de terre postérieurs à celui de 62 , la principale attestation épigraphique provient d'une inscription découverte à Herculanum. Trouvée dans l'entrée de la «Palestre»(Or. II, 4), cette plaque commé-

«Ce fut à Naples qu'il débuta et, quoiqu'un tremblement de terre eût tout à coup ébranlé le théâtre, il ne cessa de chanter qu'après avoir terminé son morceau» (trad. CUF).

Tac., Ann., 15, 34, 1 : Illic, plerique ut arbitrabantur, triste ut ipse, providum potius et secundis numinibus, evenit: nam, egresso qui adfuerat populo, vacuum et sine ullius noxa, theatrum conlapsum est.

"Là survint un incident, que la plupart jugeraient sinistre, mais Néron plutôt providentiel et dû à la faveur des dieux: quand le public en fut sorti, une fois vide, et sans dommage pour personne, le théâtre s'écroula" (trad. CUF).

Il faut souligner que Tacite ne mentionne pas de cause à l'écroulement du théâtre, ce qui laisse la possibilité que cet édifice ait été endommagé lors du séisme de 62, en dépit des remarques de Sénèque (Nat., 6, 1, 2, cit. supra) sur l'absence de dégâts aux monuments publics à Naples.

${ }^{38}$ Plin., Ep., 6, 20, 3: Praecesserat per multos dies tremor terrae minus formidolosus, quia Campaniae solitus [...].

«Pendant plusieurs jours on avait eu comme préliminaire des secousses de tremblements de terre moins effrayantes, parce que habituelles en Campanie» (d'après trad. CUF). 
more des réparations effectuées par Vespasien dans le temple de Magna Mater:

Imp(erator) Caesar Vespasianus aug(ustus) pont(ifex) max(imus) / trib(unicia) pot(estate) VII imp(erator) XVII p(ater) p(atriae) co(n)s(ul) VII design(atus) vIII / Templum matris deum terrae motu conlapsum restituit [CIL $\mathrm{X}, 1406]$.

En s'appuyant sur le contexte de découverte mentionné très précisément dans les journaux de fouilles du XVIII ${ }^{e}$ siècle, G. Guadagno a identifié le temple avec la partie intérieure de la «Palestre» ${ }^{39}$. Les mesures prises en faveur d'Herculanum par Vespasien sont rappelées par une seconde inscription, trouvée en plusieurs fragments mais restituée dans le local à l'angle nord-ouest de l'aedes Augustalium (VI, 20-24) ${ }^{40}$. La comparaison entre ces inscriptions et celles qui ont été réalisées à la suite des séismes ayant accompagné l'éruption de 79 montre que le pouvoir impérial a su réagir rapidement, en moins de deux années, à l'exception de Nocera, qui a attendu une intervention de la part de Domitien dans la seconde moitié de $82^{41}$. G. Guadagno estime donc que les deux interventions impériales à Herculanum - d'une portée matérielle limitée, mais à forte valeur démonstrative - ne peuvent pas correspondre, comme le voudrait l'historiographie, à des réparations tardives du séisme de 62 . Il en conclut donc à l'existence d'un événement autonome, qui se serait produit dans la première moitié des années $70^{42}$.

En utilisant ces données textuelles, des sismologues ont retracé les événements telluriques des années 62 à 79 autour du Vésuve en utilisant le séisme du 5 février 62 comme point de départ. Ils concluent que l'épicentre a dû se trouver au

${ }^{39}$ Sur les variations d'A. Maiuri pour interpréter cette plaque, cf. supra, n. 143 p. 24. Sur la découverte de la plaque, cf. infra, p. 263-264.

${ }_{40} A E$ 1979, 170 (cf. Guadagno 1978: 134) relue en 1995 (Guadagno 1995: 119; AE 1996, 409): Imp (erator) C[a]<esar V>espas[ianus] Aug(ustus) pont(ifex) max(imus) trib(unicia) pot(estate) VII i[mp(erator) XVIII p(ater)] $p$ (atriae) c[o(n)s(ul) vII des(ignatus) VIII] / ce<nsor $>$ gen [ium] municipi herculane [i terrae motu conlapsum] r(estituit). Les rédacteurs de l'Année Épigraphique ont des doutes quant à certains détails restitués dans la titulature ainsi qu'envers le développement $R$ (estituit). nord-ouest de Pompéi, provoquant des dégâts importants à Pompéi et Herculanum. Surtout, ce tremblement de terre serait de nature volcanique - et non tectonique -, ce qui permettrait de dresser un lien entre ce premier événement et l'éruption de 79. Dès lors, pour reprendre leurs termes, la secousse de 62 serait une pointe énergétique dans un contexte pré-éruptif. Ces analyses rendent donc possible, du point de vue des sciences de la terre, un ou plusieurs séismes, d'ampleur potentiellement moindre que pour celui de 62 , au cours des 17 dernières années précédant la catastrophe finale ${ }^{43}$. Parmi ces secousses, l'une d'entre elles aurait été plus forte à Herculanum dans la première moitié des années 70, permettant à l'empereur de démontrer sa largesse en finançant des restaurations. À ce contexte éruptif s'ajoute, à Herculanum, la mise en évidence d'une activité bradysismique, caractérisée par une alternance de mouvements de subsidence et de remontées du sol. Le dernier événement enregistré par les géologues ayant travaillé sur ce phénomène est une subsidence ayant entraîné un changement du niveau de la mer de 2,5 $\mathrm{m}$ dans les années 60 de notre ère ${ }^{44}$. Comme l'a montré la crise dans les Champs Phlégréens entre 1982 et 1984, ces variations du niveau du sol peuvent être associées à des secousses sismiques.

\section{V.2.2 Retour sur L'ultima fase edilizia di} Pompei

Dans son ouvrage sur la dernière phase édilitaire de Pompéi, A. Maiuri dresse un inventaire très complet des espaces en travaux lors de l'éruption et des réparations déjà effectuées ${ }^{45}$. Cependant, certaines données invalident la thèse

${ }^{41}$ G. Guadagno (1995: 122-124) fonde ses analyses sur deux inscriptions anciennes (CIL X, 1481; AE 1902, 40) et sur trois autres de découverte plus récente.

${ }^{42}$ Guadagno 1995: 122, 124-126. Contra Maiuri 1958 b: 72.

${ }^{43}$ Sur ces considérations sismologiques, cf. Marturano - Rinaldis 1995.

${ }^{44}$ Sur le phénomène de bradyséisme à Herculanum, cf. Cinque - Irollo 2008.

${ }^{45}$ Maiuri 1942 a. Une mise à jour exhaustive de ces données serait nécessaire, mais une telle recherche déborde largement du cadre du présent propos. 
défendue dans L'ultima fase edilizia di Pompei voulant que les travaux inachevés observés au cours des fouilles à Pompéi soient consécutifs au séisme de 62 .

L'hypothèse d'un second séisme a tout d'abord été proposée par K. Schefold, ce qui lui permettait d'expliquer plusieurs problèmes chronologiques liés au IV ${ }^{\mathrm{e}}$ style pompéien ${ }^{46}$. Parmi les données permettant de valider partiellement cette proposition, se trouvent celles recueillies dans la boulangerie de la Casa dei casti amanti (IX 12, 6.8), fouillée à partir de 1987. Comme plusieurs autres espaces consacrés à la même activité, celle-ci a été retrouvée dans un état tel que sa productivité ne pouvait qu'être diminuée avant l'éruption: une seule des quatre meules était alors en état de marche, disposant de son catillus en place sur la meta, tandis que deux autres étaient à terre, avec leur surface interne recouverte d'une couche de mortier, remployées pour faire lever la pâte à pain. Au-delà de ces bouleversements, qu'on pourrait à la rigueur interpréter comme consécutifs au séisme de 62 , le four offre un témoignage particulièrement notable. Son angle nord-est présente une fissure sur toute la hauteur du mur diaphragme, réparée par l'insertion de fragments de briques et de tuiles. Sur cette réparation, un enduit blanc a été appliqué, qui a eu le temps d'être noirci par la fumée se dégageant du four. Cette situation suggère trois phases: fissure du four provoquée par un séisme ${ }^{47}$, réparation, suivie d'une réutilisation. Il s'ensuit que les travaux en cours dans la boulangerie au moment de l'éruption ne peuvent pas être interprétés comme consécutifs au séisme de $62^{48}$. Ces travaux scellés par l'éruption ne sauraient être considérés comme résultant de la secousse décrite par Sénèque. En

\footnotetext{
${ }^{46}$ Schefold 1957: 152-153.

${ }^{47}$ Sur les dégâts caractéristiques des séismes, cf. infra, p. 237.

48 Varone 1995: 29-30. D’autres éléments provenant de cette même maison conduisent à un résultat identique. Dans le triclinium dont les fresques donnent son nom à la domus, un tas de chaux a été trouvé, signe indubitable de travaux en cours en 79 . Les parois sont couvertes par un cycle décoratif de III ${ }^{\mathrm{e}}$ style final (35-45 ap. J.-C.). Une partie de la paroi orientale sur laquelle se trouve ce décor n'est pas en opus incertum mais en pan de bois hourdé. Sur cette
}

revanche, l'hypothèse d'un second tremblement de terre de peu antérieur à l'éruption semble parmi les plus probables.

Avec parfois des données moins spectaculaires, ce type d'interprétation constitue la conclusion de la majeure partie des interventions du colloque de Boscoreale. Dans les thermes du Sarno, après avoir constaté un nombre élevé de réparations, A. Koloski Ostrow concluait qu'il était impossible de les lier toutes au séisme de 62. Elle proposait ainsi qu'une partie des dégâts seulement soit liée à ce premier événement. Ils auraient affaibli la structure de l'édifice et auraient facilité un effondrement plus tardif, sous le coup d'un second séisme ${ }^{49}$. En étudiant les peintures de l'atrium de la Casa degli amorini dorati (VI 16, 7.38), F. Seiler a mis en évidence l'existence de dégâts postérieurs à la réparation de ceux causés par le séisme de $62^{50}$. Un autre système d'interprétation a été proposé par S.C. Nappo, en se fondant sur l'étude de maisons concentrées dans la zone sud-est de la Regio I. Selon lui, les restaurations consécutives au séisme de 62 auraient été conduites à leur terme, mais un second séisme aurait ensuite amené de profondes transformations des conditions économiques et sociales, perceptibles par des changements dans la fonction des pièces. Enfin, il attribue les travaux en cours à un dernier séisme antérieur de peu à l'éruption ${ }^{51}$. Les transformations observées dans la maison I 9, 11-12 par J. Berry lui permettent d'aboutir à une conclusion similaire: après l'amorce de travaux de restauration à la suite des dégâts de 62 , cette activité est suspendue dans certaines pièces, qui sont partiellement abandonnées ou dont l'usage est radicalement transformé - d'espace de réception à zone de stockage. Peu avant

portion de mur, la fresque présente des différences physiques - moindre épaisseur de l'enduit - et surtout stylistiques, trahissant une création postérieure au reste du décor, par une autre main, ayant déjà intégré les schémas du IV style. Dans cette pièce, comme dans le cas du four, une première restauration a été effectuée, mais une seconde était en cours en 79 (Varone 1995: 30-32).

${ }^{49}$ Koloski Ostrow 1990: 50.

${ }^{50}$ Seiler 1992: 83-86, part. 84.

${ }^{51}$ Nappo 1995, part. 52-54.

${ }^{52}$ Berry 1997 a, part. 122-124. 
l'éruption, de nouveaux dommages réduisent encore les espaces habités mais aussi les activités commerciales, comme la destruction du comptoir situé en I 9, 11 le montrerait. Toutefois, des signes de reprise ont également été perçus, interrompus par l'éruption ${ }^{52}$. Ces exemples, déjà nombreux, incitent à modifier les interprétations concernant le retrait de l'élite foncière hors de la ville pendant les 17 années s'étendant entre 62 et $79^{53}$. En l'état actuel, il est difficile, faute de datation absolue des séismes postérieurs à 62, de déterminer si cette deuxième vague de réparations constatée en différents points de la ville résulte d'un même événement ou si la ville a été frappée par une activité sismique continuelle («on-going seismic activity») provoquant des dégâts espacés dans le temps ${ }^{54}$.

Avant d'étudier la validité de cette proposition à Herculanum, il faut considérer les éventuels modes de construction particuliers employés à Pompéi pour effectuer les réparations consécutives à ces secousses. Une étude de J.-P. Adam a esquissé un catalogue des formes de dommages subis par les constructions pompéiennes en 62 , permettant de cerner les points des édifices plus particulièrement sensibles aux secousses sismiques ${ }^{55}$. Il en ressort que les dégâts les plus fréquents correspondent à des lézardes et des fissures dues aux mouvements des parois. Parfois corrélés à ces désordres, des gîtes ou des séparations de parois perpendiculaires entre elles ont été observées. Les effondrements partiels de murs peuvent suivre des lignes diversement inclinées, horizontales quand seule la partie supérieure est tombée, verticales quand un pan entier a disparu, ou obliques. Les déplacements latéraux des parois survenant en cas de séisme rendent particulièrement fragiles certaines parties des édifices. Ainsi, les angles

${ }^{53}$ Maiuri 1942 a: 162-163; contra Lepore 1950.

${ }^{54}$ L'idée d'une activité sismique continuelle a été développée par P. Allison (1995). Les contributions les plus récentes sur cette question tendent à proposer un séisme relativement violent - mais moins fort qu'en 62 - dans l'année précédant l'éruption (cf. Varone 2005: 322).

${ }^{55}$ Adam 1986: 72-79.

${ }^{56}$ Ling 1995 : 201, 207. Le terme employé est emergency repairs. sont fréquemment détruits par un effet de bélier d'une paroi contre l'autre. Les portes constituent l'autre point délicat: là où s'interrompt la maçonnerie, les montants continuent leur mouvement, provoquant en réponse l'effondrement du linteau. Pour les réparations, les fissures sont bouchées par l'insertion de matériaux hétérogènes, souvent des terres cuites architecturales, plus facilement fractionnables. Les murs peuvent avoir été reconstruits avec les moellons provenant de leur destruction, mélangés avec les différents débris - tessons céramiques, fragments de béton de sol, etc. - jonchant le sol sur lequel ils ont été ramassés. Ce type de reconstruction, appelée "d'urgence » par R. Ling, offre une grande visibilité dans les murs, tant le contraste est saisissant par rapport aux opera "classiques» bâtis avec des matériaux sélectionnés et ordonnés ${ }^{56}$. Outre l'utilisation de tout-venant comme moellons, une autre caractéristique de ces constructions est leur utilisation d'un mortier très sableux, pauvre en chaux ou dont la chaux a été mal gâchée, et se présente sous la forme de nodules non écrasés. Pour pallier la gîte des murs, des contreforts ont été construits, avec un usage de la brique particulièrement développé ${ }^{57}$. Parmi les autres techniques de maçonnerie qui voient alors leur utilisation s'intensifier, signalons l'opus vittatum mixtum, notamment employé pour la construction d'une nouvelle porte à la Porta di Ercolano, après le séisme de 62 selon l'hypothèse de Th. Fröhlich ${ }^{58}$.

Deux dernières remarques doivent être faites avant de définir les dommages liés au(x) séisme(s) à Herculanum. Tout d'abord, dans son étude précise sur les éventuelles secousses multiples ayant pu marquer l'insula du Ménandre à Pompéi (I 10), R. Ling estime que seul le double emploi dans un même mur de réparations d'ur-

\footnotetext{
${ }^{57}$ Sur les techniques mises en œuvre après le séisme, cf. Maiuri 1942 a: 189-202, part. 198-201 pour l'emploi de la brique.

${ }^{58} \mathrm{Th}$. Fröhlich réfute la datation tardo-républicaine de cette porte en invalidant l'ensemble des arguments traditionnellement présentés. Cela lui permet de proposer, pour Pompéi, une chronologie d'utilisation de l'opus vitattum mixtum entre 50 et 79 ap. J.-C. Cf. Fröhlich 1995 : part. 157158.
} 
gence différentes pourrait permettre de caractériser deux séismes ${ }^{59}$. Stricto sensu, cette précaution est très raisonnable et parfaitement justifiée. Elle doit toutefois être nuancée par l'utilisation de mises en œuvre "classiques» lors des réparations: ces dernières ne sont pas uniquement effectuées avec des débris ramassés sur la zone d'écroulement des murs. Une seconde remarque porte sur les interprétations proposées par A. Maiuri. En effet, ce dernier, à la fin de son catalogue des réparations et transformations, dresse la liste des techniques mises en œuvre pour réparer les dégâts du séisme de 62. Suivant son raisonnement selon lequel la situation de Pompéi au moment de l'éruption n'est liée qu'à la durée des travaux de restauration, il considère que les techniques de l'ultima fase correspondent toutes à des réparations ${ }^{60}$. En revanche, dans son texte décrivant presque une à une les demeures où des dommages ont été mis en évidence, mais également dans sa conclusion générale, il interprète ces techniques, dans le cas des boutiques et des ateliers, comme de nouvelles constructions. Elles constitueraient des transformations profondes effectuées par le ceto mercantile pompéien qui aurait profité du retrait des propriétaires fonciers sur leurs terres pour envahir les domus. C'est certainement en voulant impérativement appliquer cette théorie fondée sur les hypothèses de M. Rostovtseff qu'A. Maiuri est passé à côté d'un des aspects fondamentaux pour cette situation perturbée en raison du séisme: la nécessité de distinguer les deux types de constructions successives à la catastrophe. Il faut d'une part dissocier les restaurations d'urgence effectuées immédiatement après le séisme des nouvelles constructions, et d'autre part mettre en évidence les transformations marquant seulement le

\footnotetext{
59 «To my mind the proponents of the second-earthquake theory need to substantiate their case by producing examples of houses with two (or more) successive phases of emergency repairs. Only this form of evidence can offer a valid argument for successive episodes of earthquake damage » (Ling 1995 : 201). Lors de la publication du second volume consacré à cet îlot, R. et L. Ling (2005: 35, 169-170) signalent des indices permettant de conclure à l'existence d'un second séisme ayant affecté la maison du Ménandre. Il s'agirait toutefois d'une secousse d'une portée moindre par rapport à celle de 62 .

${ }^{60}$ Maiuri $1942 \mathrm{a}: 188-208$. Les termes qu'il emploie sont essentiellement rifacimento et tecnici di restauro.
}

retour au continuum de la vie urbaine. Une telle distinction est d'autant moins évidente que les transformations ont pu se dérouler en même temps que les réparations, même si cette situation n'était pas systématique.

De cette brève incursion dans Pompéi entre 62 et 79 , je retiendrai les faits suivants. Tout d'abord, repoussant la trop grande importance accordée jusque là aux sources littéraires, l'existence de plusieurs événements sismiques, d'une magnitude probablement inférieure à celle de la catastrophe de 62, semble largement fondée. Aucun élément ne permet cependant de déterminer la chronologie de ces secousses. Si cette situation offre une explication simple aux nombreuses maisons encore en travaux en 79, elle complexifie considérablement l'étude globale de la ville dans ses dernières années. En l'absence de trace claire d'un second grand événement sismique qui aurait frappé uniformément Pompéi, il devient plus délicat de proposer un schéma valide pour l'intégralité de la ville.

V.2.3 Transformations des techniques de construction à Herculanum entre 62 et 79

Les remarques d'A. Maiuri sur la question du tremblement de terre dans sa synthèse de 1958 sont floues et quelque peu paradoxales. Il estime que les réparations observées sont sans rapport avec la description des dégâts rapportée par Sénèque, à moins d'ajouter à celles-là les nombreux désordres et ruines observés au moment de la fouille, comme à Pompéi. Pourtant, il souligne également la force particulièrement brutale de l'éruption à Herculanum, réduisant la portée de sa remarque précédente ${ }^{61}$. Dans le reste de son ouvrage, le séisme et ses conséquences

\footnotetext{
${ }^{61}$ «Ma questi ed altri parziali restauri [...] non ci darebbero un esatto quadro della grave situazione edilizia che il terremoto dell'anno 62 dové creare ad Ercolano e non giustificherebbero la testimonianza di Seneca, se non si tenesse conto [...] che lo stato di rovina e di disordine di molti edifici all'atto della scoperta è da spiegare più in conseguenza dei danni non riparati del terremoto che di quelli prodotti dall'eruzione del 79. Ciò vale anche per Ercolano, pur tenendo debitamente presente che ad Ercolano agirono sul crollo degli edifici [...] le forze più violente di avulsione e di trasporto determinate dall'alluvione fangosa " (Maiuri 1958 b: 73).
} 
sont à peine mentionnés, sauf pour donner de l'ampleur à son interprétation de l'invasion de la ville par les marchands et les affranchis ${ }^{62}$. Il s'en tient à l'idée d'une unique catastrophe en 62 dont les dommages n'ont pas été complètement réparés en 79. Sans mentionner de façon claire plusieurs secousses, Th. Ganschow avait déjà signalé la rapide succession des réparations dans les dernières phases de la vie d'Herculanum ${ }^{63}$. L'interprétation de G. Guadagno, proposant un second événement sismique à Herculanum dans la première moitié des années 70 , a été globalement bien accueillie par les chercheurs travaillant sur Pompéi ${ }^{64}$. Les sismologues sont quant à eux très prudents quant à l'éventuelle concomitance des séismes à Pompéi, Herculanum et Naples durant cette période: au-delà du tremblement de terre de 62, les hypothétiques secousses successives auraient été moins fortes et donc moins susceptibles de toucher l'ensemble du golfe de Naples. Il s'agirait de phénomènes localisés, dont l'un d'eux a été suffisamment important toutefois pour qu'une restauration soit entreprise par Vespasien à Herculanum. Rien ne permet en revanche de supposer que le probable séisme qui a frappé Pompéi peu avant l'éruption ait également touché Herculanum ${ }^{65}$.

En suivant les interprétations de G. Guadagno, je considère qu'un séisme a frappé le bâtiment constituant l'Insula Orientalis $I I^{a}$, abritant notamment un temple voué à la Magna Mater, au cours de la première moitié des années 70 . Les dégâts alors causés ont été réparés par une intervention du pouvoir impérial en 76. L'étude des types d'appareils employés dans ce bâtiment devrait donc permettre d'individualiser une partie des formes de mise en œuvre correspondant à cette période. La construction homogène

${ }^{62}$ Sur ce point, cf. supra, p. 4-5.

${ }^{63}$ Ganschow 1989: 101.

${ }^{64}$ Sur les réactions à l'hypothèse de G. Guadagno, cf. Fröhlich - Jacobelli 1995: 129-130. M. Pagano a exprimé ses critiques sur cette hypothèse au cours de l'une des discussions du colloque de Boscoreale (Fröhlich - Jacobelli 1995: 200) et dans un article consacré à la "Palestre» (Pagano 1996 a: n. 87 p. 243): sans explicitement nier la possibilité d'un second séisme, il refuse qu'il ait pu avoir une influence forte sur la région, sans développer son argumentation.

${ }^{65}$ Telles semblent être les conclusions que l'on peut prudemment inférer des remarques d'A. Marturano et de de cet édifice a déjà été largement soulignée par A. Maiuri dans la description qu'il en donne ${ }^{66}$. De fait, et sans développer immédiatement certains détails liés à la maçonnerie originelle, l'intégralité de cet îlot a été bâti en employant l'opus reticulatum B pour les parois et l'opus vittatum simple pour les chaînages d'angles et les montants d'ouvertures ${ }^{67}$. Deux autres formes de maçonnerie sont présentes à divers endroits de l'édifice: l'opus testaceum et l'opus vittatum mixtum à deux assises de briques $\left(V^{2}\right)$. La localisation de ces deux types d'appareils est très particulière et très caractéristique (fig. 112). Très fréquemment, ils sont employés dans des montants de portes - en particulier sur la façade occidentale donnant sur le cardo $\mathrm{V}$ - et dans des éléments porteurs comme les colonnes du péristyle inférieur. Toutefois, ces appareils ne sont pas utilisés de façon systématique pour l'ensemble de ces portions soumises à des tensions particulières: les montants latéraux de l'abside de l'Aula absidata - qui supportent le poids du cul-de-four et une partie du poids de la voûte - sont érigés en opus vittatum simple (fig. 113). Par ailleurs, le chaînage de certaines portions en $V m^{2}$ avec le reste de la maçonnerie est peu soigné, en ceci qu'il semble s'adapter à un pan de mur préexistant dont la limite n'est pas verticale (fig. 114). Ces différents éléments conduisent à interpréter l'utilisation de ces deux appareils dans l'Insula Orientalis $I I^{a}$ comme des réparations consécutives aux séismes.

L'analyse des rapports entre ces réparations permet de proposer une chronologie relative dans leur emploi, au moins dans le cadre de cet édifice. Ainsi, bien que les endroits où les deux appareils ont été employés successivement soient peu nombreux, leur étude permet une

V. Rinaldis (1995: 133-134 et Fröhlich - Jacobelli 1995: 200).

${ }^{66}$ Maiuri 1958 b: 113-143, part. 116-117.

${ }^{67} \mathrm{Je}$ reviendrai dans le chapitre suivant sur l'histoire de cet édifice en proposant notamment une explication pour les quelques portions de murs construites en opus vittatum mixtum qui appartiennent certainement à la construction initiale. Dans cette première vision très générale, je ne prends pas en considération les transformations faites à l'intérieur des boutiques s'ouvrant sur le cardo V qui renvoient également à des épiphénomènes, même si certaines ont été réalisées à la suite des séismes. 
Opus vittatum mixtum

une assise de briques

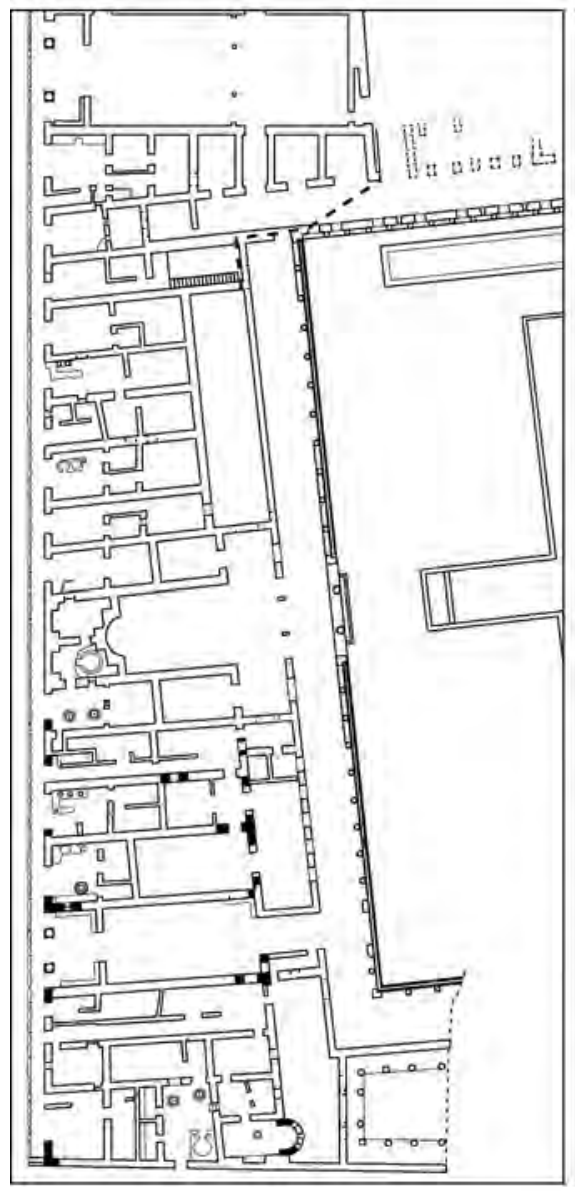

Opus testaceum

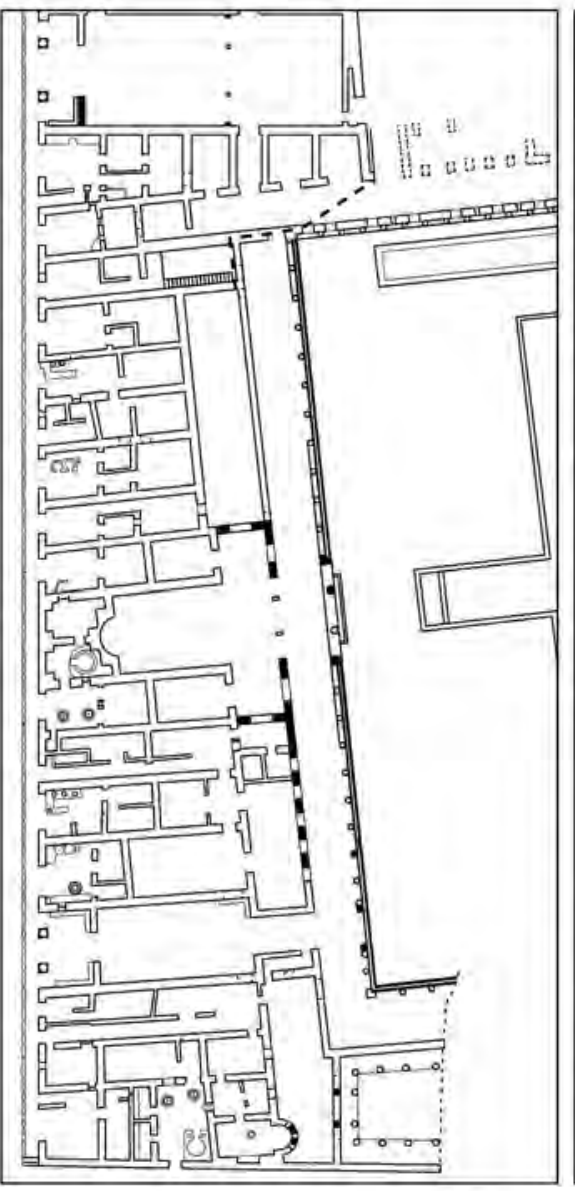

11 $\quad 10 \quad 20 \quad 40 \mathrm{~m}$
Opus vittatum mixtum

deux assises de briques

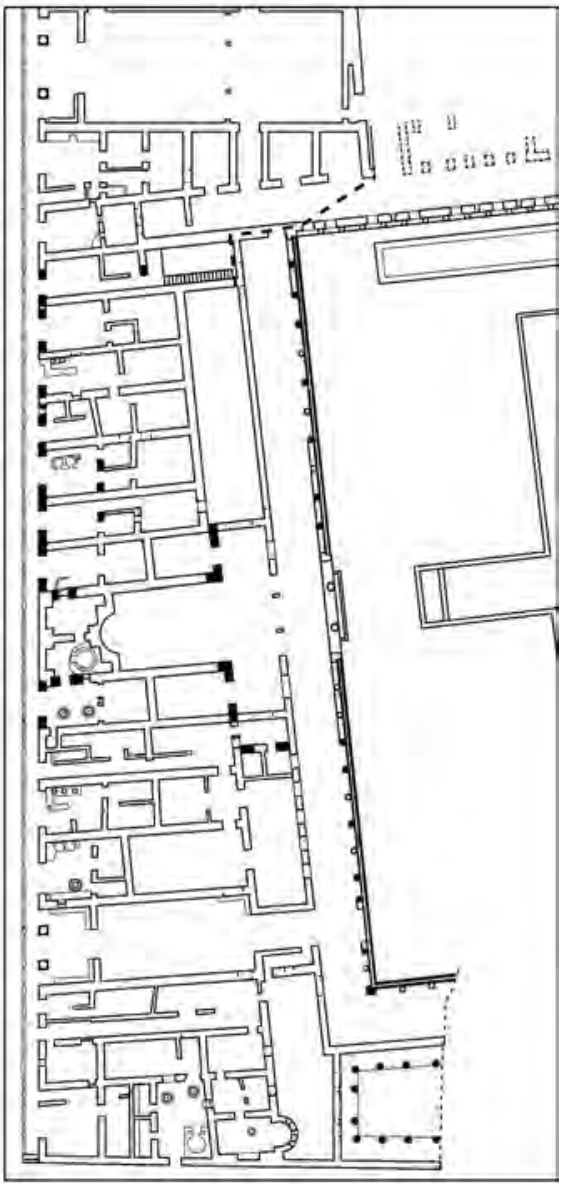

Fig. 112 - Répartition des différents types de maçonnerie dans l'Insula Orientalis $I^{a}$ (échelle: 1/1000).

distinction claire. Le principal témoignage de cette succession est constitué par l'abolition de la communication entre le pronaos précédant les salles I à III et la pièce L, surtout en l'observant depuis cette dernière salle (fig. 115). Le socle en opus incertum ainsi que les premières assises des montants de la porte ont été restaurés. Ces derniers sont construits en opus testaceum jusqu'à la hauteur du linteau, dont on devine l'empreinte. À l'est, le montant s'achève en opus vittatum mixtum à deux assises de briques. La situation semble plus complexe à l'ouest: la portion située contre le reste du bâtiment est érigée en $V m^{2}$ tandis que le montant de la porte bouchée est en opus testaceum. Pourtant, la portion en $\mathrm{Vm}^{2}$ s'appuie sur, ou plutôt s'in- sère sous le montant en briques. Cette situation s'explique par la fonction architecturale de cette partie de paroi en opus vittatum mixtum: il s'agit de la façade de la pièce III. La restitution des phases clarifie ces observations (fig. 116). Dans un premier temps, la salle L communique avec le pronaos. Probablement après le séisme de 62, les deux montants sont reconstruits avec des briques, matériau non employé au cours des phases précédentes de cet édifice. Le second tremblement de terre détruit non seulement le sommet de la paroi où se trouve cette porte, mais également les angles de la façade des pièces I et III. Le montant ouest de la porte est épargné, tandis que le montant oriental est partiellement endommagé, mais reste debout. Les maçon- 


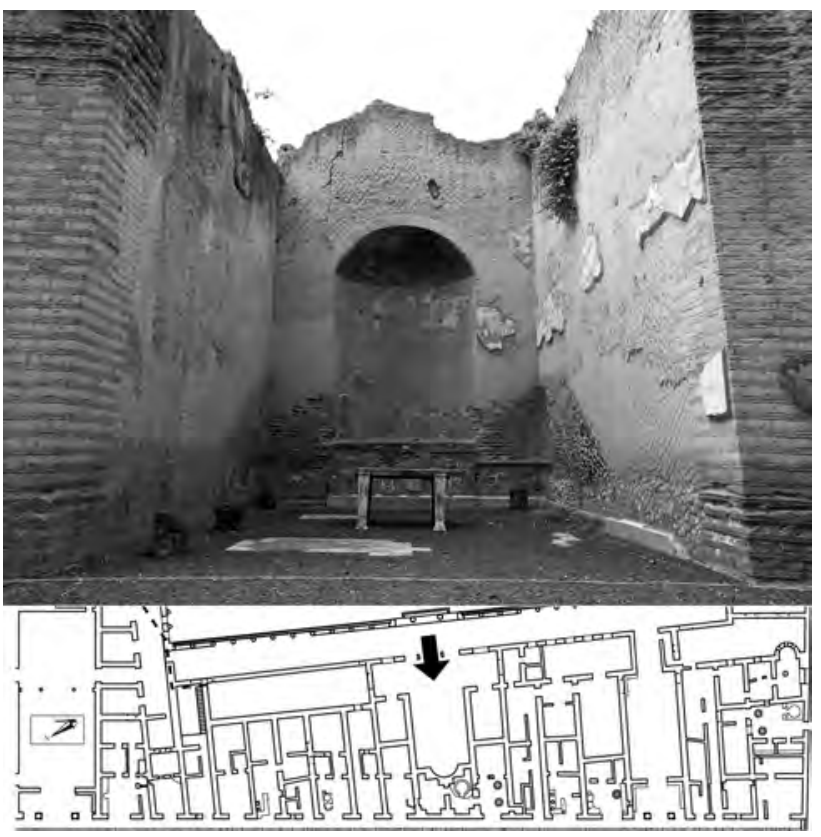

Fig. 113 - Aula absidata dans la "Palestre». Labside et le mur du fond sont construits en opus reticulatum B et en opus vittatum. À gauche et à droite, les montants des salles II et III ont été restaurés dans une phase successive en opus vittatum mixtum à deux rangs de briques.

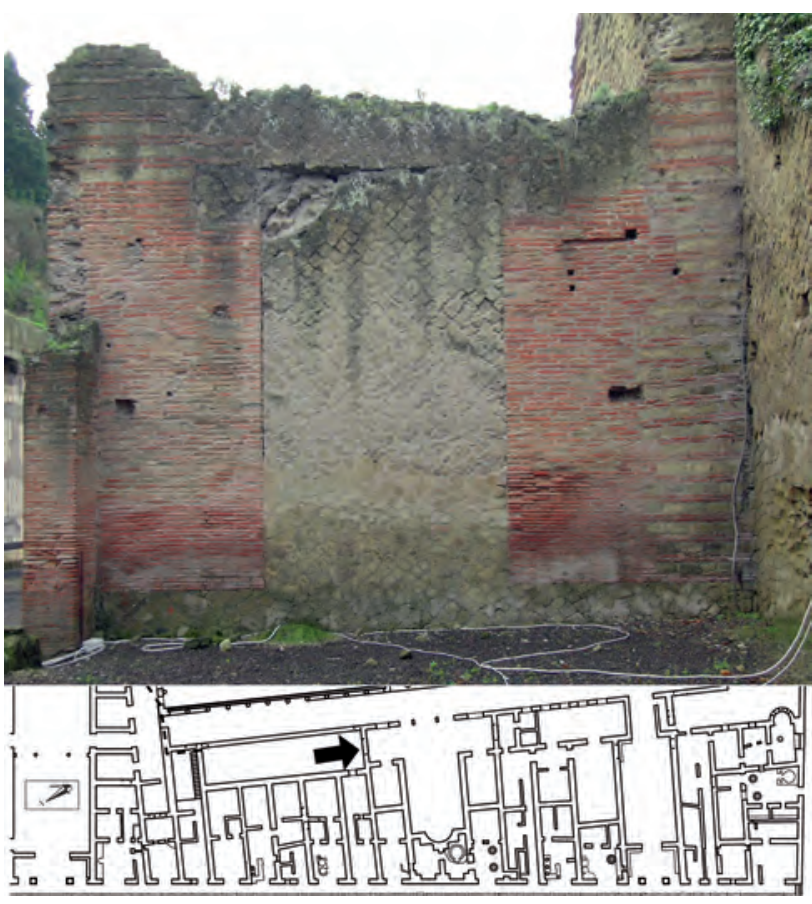

Fig. 115 - Mur de séparation entre le pronaos et la salle L dans l'Insula Orientalis $I I^{a}$. Trois phases de construction peuvent être identifiées: une première réparation des montants effectuée en briques; une seconde réparation de la partie supérieure et du montant de façade de la pièce III (en haut, à droite); le bouchage de la porte.

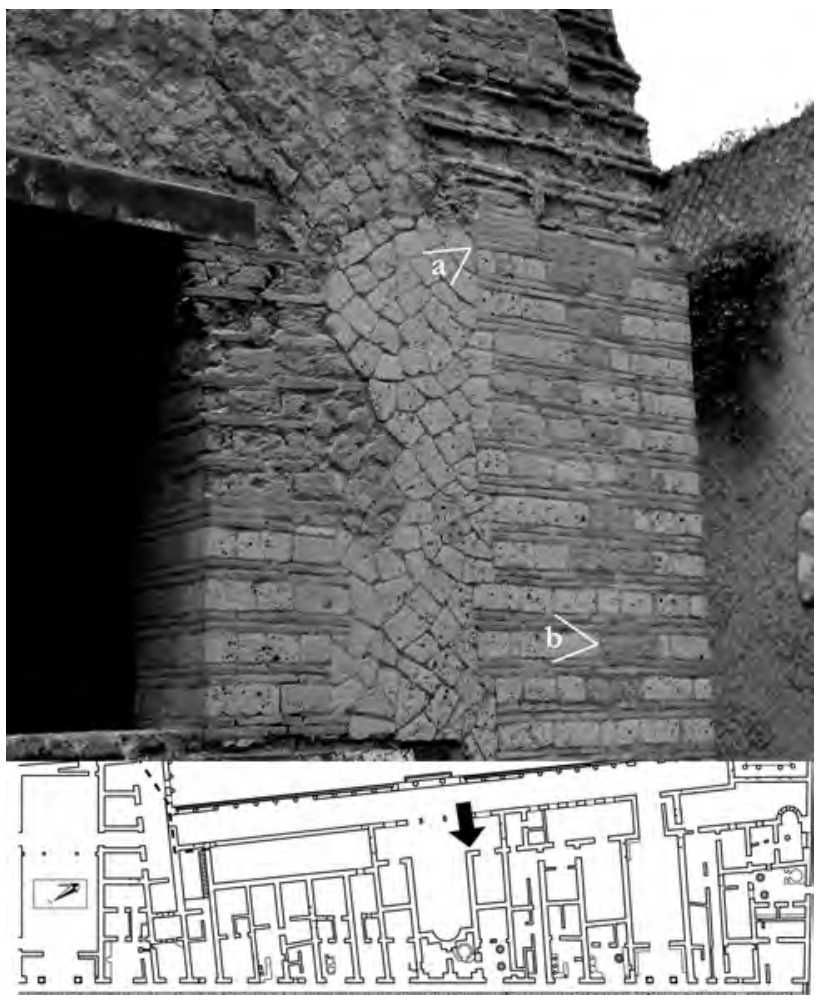

Fig. 114 - Montant nord est de la pièce II dans la « Palestre». La différence de couleur du tuf souligne les parties restaurées des parties antiques: (a), rangs de briques pouvant indiquer une première réparation avant celle effectuée en opus vittatum mixtum; (b), moellons de maçonnerie antique incorporés dans la reconstruction moderne.

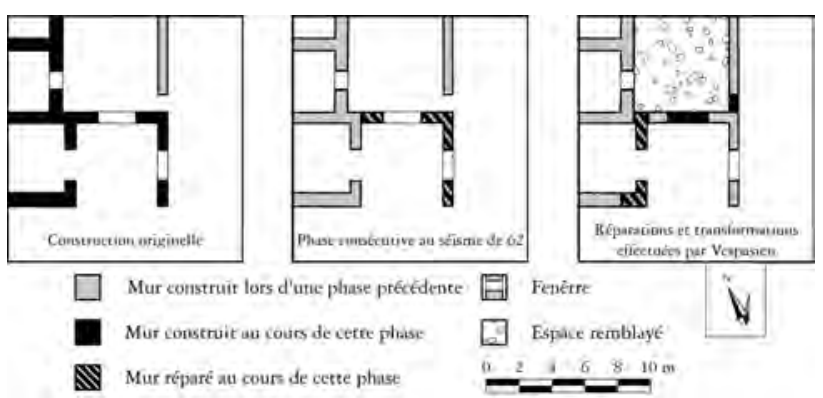

Fig. 116 - Évolution des relations entre la salle L et le pronaos de l'Aula absidata. 


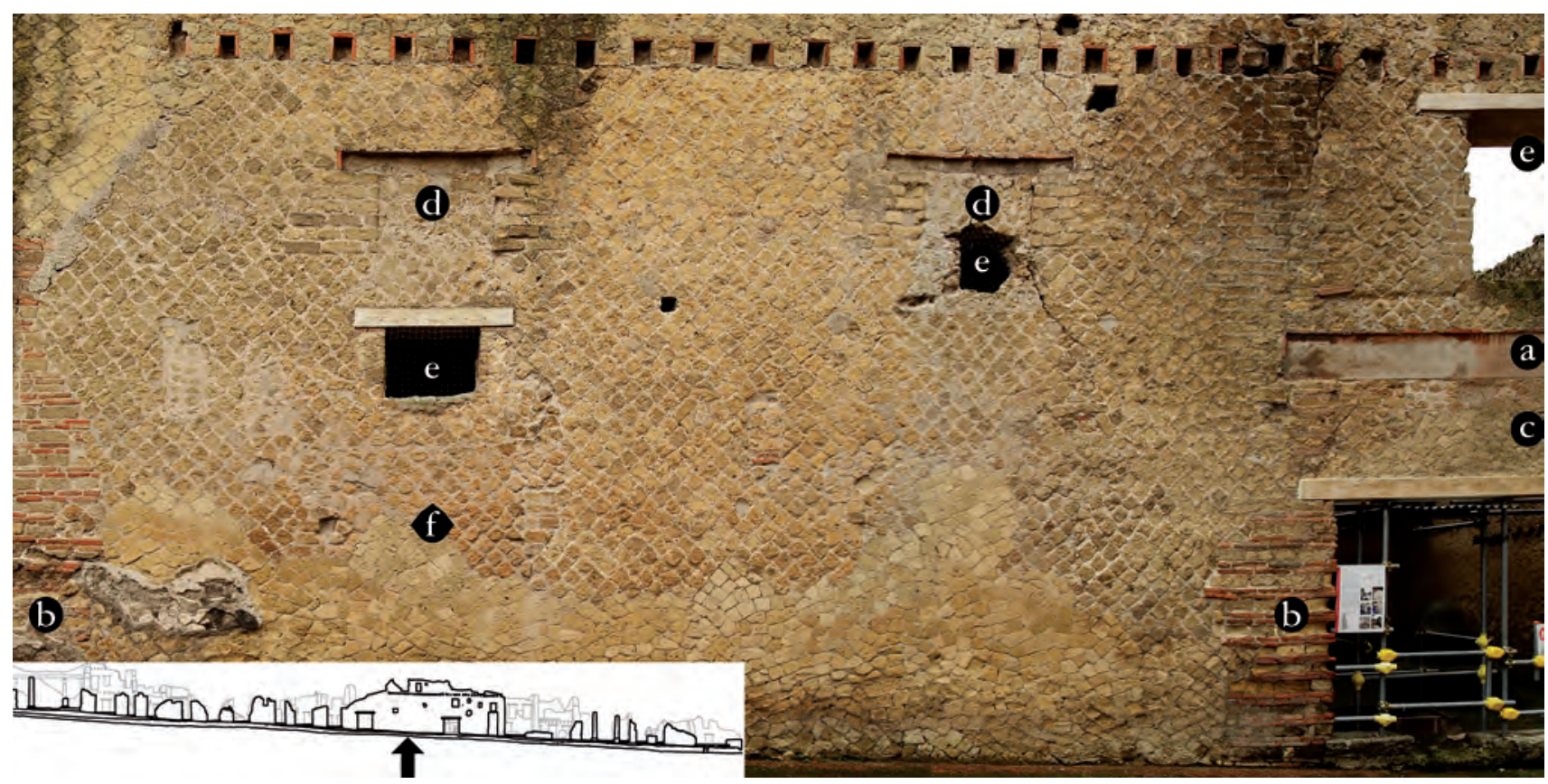

Fig. 117 - Façade de l'Insula Orientalis $I I^{a}$ entre les locaux Or. II, 8 et Or. II, 9. Les travaux effectués par Vespasien, essentiellement des consolidations et une réduction de la portée des ouvertures, sont clairement discernables sur cette façade. (a): linteau correspondant à la hauteur originelle des deux portes; (b): pilier reconstruit en opus vittatum mixtum $\left(\mathrm{Vm}^{2}\right)$; (c): bouchage de l'espace résiduel après réduction de la hauteur du linteau; (d): fenêtres bouchées dans le cadre des mêmes travaux; (e): fenêtre bricolée dans une phase ultérieure. Le seul vestige de porte bouchée perceptible entre les deux locaux 8 et 9 correspond à un probable passage de chantier (f), comblé avant l'achèvement des travaux initiaux.

neries saines sont conservées, tandis qu'une seconde série de restaurations est effectuée, en employant l'opus vittatum mixtum à deux rangs de briques. La porte est ensuite condamnée par un bouchage en opus reticulatum $\mathrm{B}$, tandis que la pièce L est complètement remblayée ${ }^{68}$. Si l'on applique cette interprétation - associer les réparations en opus testaceum au séisme de 62 et celles en opus vittatum mixtum à deux rangs de briques $\left(V m^{2}\right)$ au second séisme - à l'ensemble de l'édifice, on dresse le constat que les secondes sont plus nombreuses que les premières. Toutefois, cela ne permet pas de supposer que

${ }^{68}$ Sur le remblaiement de cet espace, cf. Maiuri 1958 b: 126-127 et GSE 1936: «2 dicembre. L'ambiente n. 10 posto a nord dell'abside è un lungo corridoio a forma rettangolare. Dal materiale sterrato in esso, oltre a quello eruttivo, appare che fu colmato prima dell'ultima eruzione. Difatti molti frammenti di anfora e cocci di vasi di terracotta aretina si sono raccolti, e fra essi ve ne sono alcuni con iscrizioni e bolli seguenti: [les marques sur les amphores le deuxième tremblement de terre a été plus violent que le premier: il est possible d'une part que certaines réparations en briques aient été reprises en $\mathrm{Vm}^{2}$; d'autre part, pour peu que des parties de la maçonnerie aient été jugées affaiblies, leur reconstruction intégrale a pu être envisagée. D’une manière générale, les ouvertures de la façade occidentale ont alors été généralement reconstruites et surtout réduites, comme le montrent les locaux Or. II, 8 et 9 (fig. 117). Après les réparations, et en plus de celles-ci, ce sont donc des travaux de mise en sécurité qui auraient été effectués par Vespasien. Je revien-

correspondent aux inscriptions CIL IV, 10897, 10904, 10910 et 10911, dont la provenance est erronée dans le corpus; des trois timbres de vases sigillés recopiés, un seul peut être identifié: CVArrII 1839, 9, timbre d'un Secundus ayant exercé à Pouzzoles]». D'autres fragments de céramique arétine - illisibles - ont été découverts dans cet espace les 5 et 6 février 1937. 
drai plus loin sur l'utilisation, avant 62, des deux types de maçonneries associées aux réparations des séismes dans l'Insula Orientalis $I I^{a}$. Notons toutefois d'ores et déjà que la chronologie relative entre l'opus testaceum et l'opus vittatum mixtum paraît fixe lorsqu'ils sont utilisés successivement dans une même paroi: les portions en briques semblent plus fréquemment employées les premières ${ }^{69}$.

Ces deux formes de mise en œuvre ne sont pas les seules à avoir été employées pour effectuer des réparations après les séismes. Sans chercher à comparer la violence subie par les deux villes, les localisations des dégâts sont les mêmes à Herculanum qu'à Pompéi: fissures, lézardes, montants des portes et des fenêtres, angles, parois diversement effondrées. Les techniques de construction alors déployées sortent de tout cadre typologique, à l'exception des opera incerta $\mathrm{B}^{2}$ et $\mathrm{D}$ qui apparaissent, à la suite des travaux de Th. Ganschow et de l'équipe néerlandaise, caractéristiques de cette période troublée: ils constituent en fait la récupération de murs écroulés, reconstruits avec leurs moellons, mais sous une forme bâclée, en insérant des fragments divers en plus ${ }^{70}$. Une technique qui semble également avoir été utilisée pour reconstruire des murs effondrés est celle du coffrage ou plutôt du demi-coffrage. Quelques arguments seulement permettent de considérer que ce mode de construction appartient au groupe des techniques employées plus spécifiquement pour réparer les dégâts créés par les secousses sismiques. Le principal d'entre eux provient de la Casa del colonnato tuscanico (VI, 16-18.26-27). L'ensemble de l'aile ouest de cette maison semble avoir souffert du séisme de 62. Après une première restauration, des modifications substantielles de plan ont été effectuées. Les deux montants de la porte d'accès à la pièce 19 ont été restaurés avec des techniques différentes. De toute évidence, l'ouest correspond parfaitement aux réparations d'urgence: les moellons compo-

\footnotetext{
${ }^{69}$ Les mêmes observations conduites casuellement à Pompéi ne montrent pas cette uniformité: les briques seules peuvent y avoir été employées avant ou après le $V^{2}$. En revanche, Th. Ganschow (1989: fig. 7b-c p. 113-114) indique que dans le meilleur des cas, ces deux types d'opus sont utilisés conjointement (4 occurrences), sinon les
}

sant cette partie du mur correspondent, par leur forme et leur nature, aux opera incerta B et B1, soit de la lave bleue et de la cruma; toutefois, le mortier est employé en abondance, et parmi les inclusions se trouvent des fragments de béton de sol et de céramique. L'ensemble correspond parfaitement à l'opus incertum D. En revanche, le montant oriental, à l'exception de sa base restaurée en opus incertum $\mathrm{C}$, se présente sous la forme d'un bloc monolithique de béton. Aucun parement n'a été dressé, les caementa semblent peu nombreux mais comportent des éléments très hétérogènes, noyés dans un mortier très abondant et incluant de nombreux nodules de chaux non écrasés. Cette différence de technique pour un même pan de mur, fût-il percé d'une porte, incite à percevoir deux phases distinctes. Au cours de la première, le montant occidental a été reconstruit avec le tout-venant constitué par les éléments jetés à terre lors du premier séisme. En revanche, après la seconde secousse, un choix différent a été opéré: les restaurations ont été réalisées par coffrage. Une technique proche, mais présentant un certain raffinement de rationalisation, a été employée dans des conditions similaires pour construire ex novo la majeure partie des murs de refend de la Casa del priapo (IV, 17-18), probablement après les réparations du second séisme. Chacun des murs concernés a été construit en au moins quatre opérations successives. Une première banchée est réalisée sur 1,85 m de hauteur, correspondant à l'emplacement des linteaux de portes. Un côté du mur est coffré, tandis que l'autre est parementé en opus incertum C; les angles des montants sont réalisés en opus vittatum. Dans cette construction très systématique, le coffrage est toujours situé à l'intérieur des pièces, le parement appareillé du côté de l'atrium. Après l'insertion des linteaux, une seconde banchée est mise en place, sur une hauteur de $0,90 \mathrm{~m}$, sans utilisation de coffrage cette fois : toute l'élévation est construite en opus incertum $\mathrm{C}$. Un deuxième arrêt permet de poser

briques seraient employées après le $V m^{2}$ (8 occurrences). Ces données ne sont pas plus détaillées, toutefois les exemples exposés, ainsi que celui de la façade nord de la Casa del tramezzo di legno, (cf. supra, p. 230-232) les contredisent.

${ }^{70}$ Ganschow 1989: 118; Hoppenbrouwers -Vermeulen 1996: 185. 


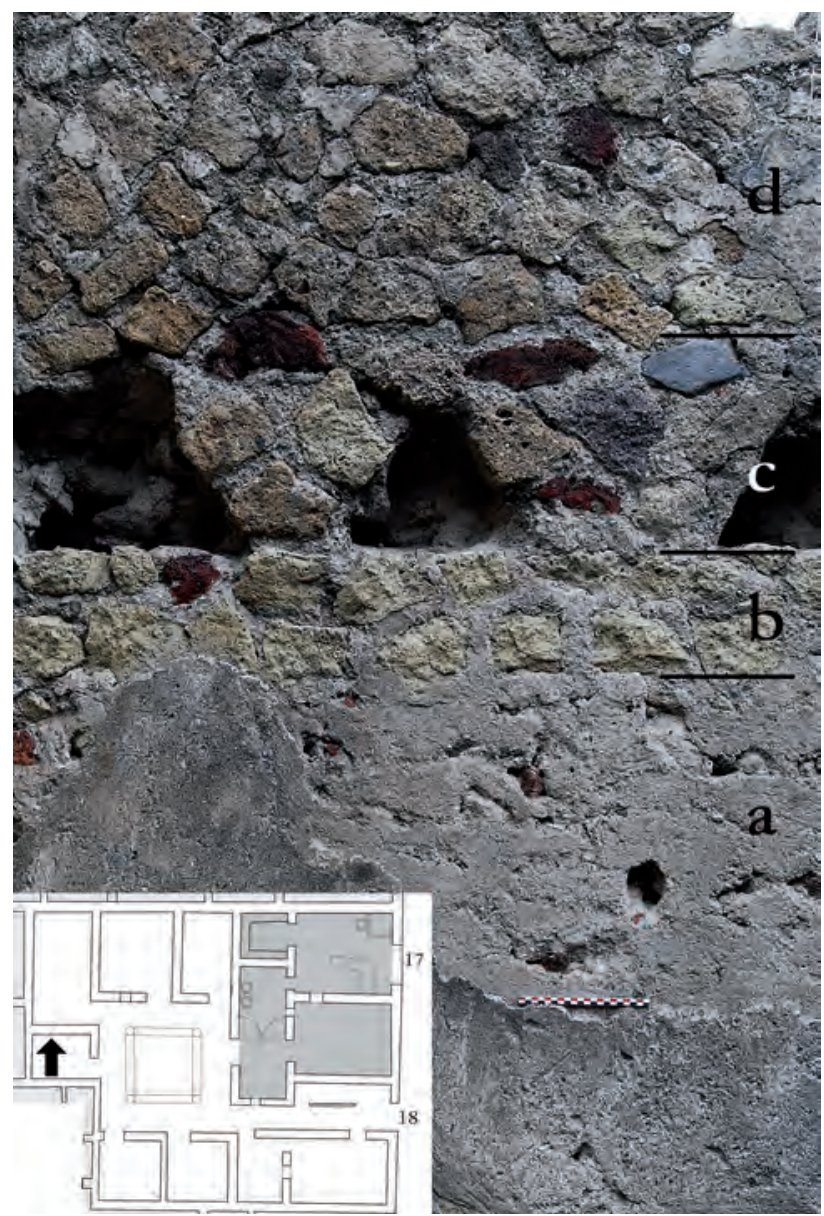

Fig. 118 - Étapes de la construction d'un mur dans la Casa del priapo (IV, 17-18). (a): maçonnerie coulée dans un coffrage; (b) seconde banchée appareillée; (c) insertion des solives; (d): reste de l'élévation, appareillée.

les solives de l'étage et de la galerie de circulation autour de l'atrium: les interstices entre les pièces de bois sont ensuite remplis par des moellons de tuf (fig. 118). Le choix de l'emplacement pour le développement de la cage d'escalier, qui implique un nombre moindre de solives, correspond justement à l'angle sud-ouest de l'atrium, touché par les séismes; peut-être faut-il y voir un lien de cause à effet ${ }^{71}$. Le reste de l'élévation - les parois de l'étage - est érigé avec des moellons

${ }^{71}$ Contrairement à ce que suggère A. Maiuri (1958 b: 437-438), l'escalier d'accès à l'étage ne se situe pas dans l'entrée IV, 17 au nord de la paroi en opus craticium mais dans en tuf, dont l'appareillage s'approche de l'opus reticulatum grossier. Cette technique de mise en œuvre qui utilise le coffrage ne semble pas avoir été beaucoup employée.

Une observation attentive des parois non reconstruites à la suite des fouilles permet de mettre en évidence de nombreuses réparations dans les maçonneries. L'identification du séisme auquel ces réparations constituent une réponse est souvent malaisée, ne serait-ce qu'en raison de l'emploi de techniques moins caractéristiques après celui de 62. Seule l'analyse fine de cette micro-stratigraphie qui ne s'étend que sur 17 années permet d'aboutir à une vision d'ensemble. Les réparations d'urgence effectuées en remployant les moellons des parois effondrées peuvent correspondre aux deux séismes, même s'il semble que cette technique ait été principalement employée après le premier. L'utilisation du coffrage pourrait correspondre majoritairement aux réparations et transformations postérieures au second tremblement de terre. Par ailleurs, l'exemple de l'Insula Orientalis $I I^{a}$ montre que l'usage de l'opus testaceum correspondrait plutôt aux réparations de 62 , tandis que l'emploi de l'opus vittatum mixtum à deux assises serait lié aux travaux ultérieurs. Il ne saurait toutefois être question d'utiliser ces éléments chronologiques de façon systématique. En effet, si ces techniques ont été mises en œuvre massivement lors des 17 dernières années de la vie d'Herculanum, il convient non seulement de voir quels sont leurs emplois antérieurs, quand ils existent, mais également de ne pas oublier que les autres appareils ont continué à être employés.

\section{V.3 Éléments pour une chronologie «absolue»}

Pour dépasser le cadre limité de la chronologie relative induite par l'analyse des stratigraphies verticales, des points d'ancrage "absolus " doivent être déterminés. C'est seulement avec ceux-ci qu'il est possible d'évaluer la durée d'emploi des différentes techniques de mise en œuvre et par là de proposer une esquisse de l'évolution

l'angle sud-ouest de l'atrium, seul endroit où une absence de solive permet de restituer la cage d'escalier. Il serait étonnant que deux escaliers aient permis d'accéder à l'étage. 
du tissu commercial à Herculanum. Trois types de sources peuvent contribuer à cet affermissement chronologique: les inscriptions, les résultats des fouilles stratigraphiques pratiquées à Herculanum et les styles décoratifs.

\section{V.3.1 Les inscriptions des édifices publics}

Des différents édifices publics connus par des inscriptions, seuls quatre ont été suffisamment mis au jour pour mettre en rapport le texte et sa datation avec les techniques de construction mises en œuvre. Inutile de revenir sur le temple de Magna Mater qui constitue une partie de l'Insula Orientalis $I I^{a}$ : l'inscription concerne les réparations du second séisme et non la fondation du bâtiment.

Le théâtre d'Herculanum propose un dossier épigraphique permettant de suggérer une date de construction. Plusieurs inscriptions mentionnent d'une part M. Nonius Balbus, d'autre part Ap. Claudius Pulcher. Éventuel 'fondateur' du municipe d'Herculanum, ce dernier a été consul en 38 av. J.-C. et acclamé imperator en 32 avant notre ère ${ }^{72}$. La date de sa mort est inconnue alors qu'elle aurait constitué un terminus ante quem précieux pour dater le théâtre, en raison d'une dédicace post mortem qui y a été découverte ${ }^{73}$. La dédicace du tombeau de M. Nonius Balbus, situé devant les thermes suburbains, mentionne des honneurs similaires rendus à ce personnage $^{74}$. Tous les deux ont certainement terminé

${ }^{72}$ G. Guadagno (1982: 197-204) estime que la mention d'Ap. Claudius Pulcher dans l'inscription CIL X, 1453 [Appius Pulcher C(ai) f(ilius) co(n)s(ul) imp (erator) VI[I]vir epulon(um)] ne peut pas renvoyer à la construction du théâtre et doit donc - en l'absence de toute postérité du gentilice Claudius dans l'onomastique d'Herculanum - amener à considérer celui-ci comme un personnage ne s'étant pas établi dans la ville, mais ayant toutefois mérité des honneurs insignes. Il faudrait donc voir en lui le fondateur du municipe. Cette interprétation concorde avec les remarques d'A. Degrassi (1960: 144-145) qui considérait, à partir d'une inscription remployée dans un pavement de la Casa del rilievo di Telefo (Or. I, 2-3) mentionnant un duovir primus, que la création du municipe n'aurait été effective qu'entre César et Auguste (Della Corte 1958: n $284=A E$ 1960, $277=$ Guadagno 1978: n 53: Laribus sign[um]/ Marcius Phi[lippus] / duovir prim[us?] / [f]aciundum [cur(avit)] / [i]sdemque pro[bavit]). leur vie dans le courant du règne d'Auguste, ce qui offre une fourchette acceptable pour la datation du théâtre. Dégagé mais maintenu sous une enveloppe de matériel éruptif - renforcée par des piliers en tuf construits au XVIII ${ }^{\mathrm{e}}$ siècle -, le théâtre a récemment bénéficié d'une campagne d'étude et de relevés, qui permet de définir les techniques employées pour sa construction ${ }^{75}$. La structure porteuse est construite en briques et en opus reticulatum. La répartition de ces deux types d'appareils est particulièrement remarquable. Les deux ordres de la façade extérieure, scandés par 19 arcades, sont érigés en opus testaceum, tout comme le mur de scène. Toutes les autres structures rayonnantes sont construites en opus reticulatum, avec des terminaisons en opus vittatum. Seule exception dans cette construction très unitaire, les extrémités des murs soutenant les versurae sont construites en opus vittatum mixtum ${ }^{76}$.

Une seconde datation fondée sur l'épigraphie est suggérée par l'aedes Augustalium (VI, 20-24). Selon une étude menée par G. Guadagno, la construction de cet édifice remonterait au plus tard à l'année 11 de notre ère, date de la plus haute attestation des Augustales: une statue dédiée à Auguste paré du titre de divus a été ajoutée contre l'une des colonnes à l'intérieur, en recouvrant la décoration originelle ${ }^{77}$. De toute façon, cet édifice a été érigé avant 14 de notre ère. Les techniques de construction employées sont peu nombreuses: l'essentiel de la structure

${ }^{73}$ CIL X, 1424 = ILS, 890: Ap (pio) Claudio C(ai) f(ilio) Pulchro/co(n)s(uli) imp(eratori)/Herculanenses post mort (em).

${ }^{74} A E 1947,53=A E 1976,144,1.8-9$.

${ }^{75}$ Pour des relevés détaillés et une étude architecturale du théâtre, cf. Balasco 2000 a et b.

${ }^{76}$ M. Pagano (1993 a: 150) y voit les seules restaurations effectuées, se fondant non sur la technique de construction mais sur les changements dans la décoration, qui y est réalisée en IVe style. A. Balasco (2000 b: 78) en signale d'autres, réalisées avec des briques brisées, pour renforcer certaines structures affaiblies. Les descriptions données par A. Balasco ne permettent pas de déterminer si l'opus vittatum mixtum employé comporte une ou deux assises de briques. De la même façon, l'opus reticulatum n'est pas défini avec plus de précision. Il semble toutefois s'agir d'une version très régulière de type $\mathrm{B}$.

${ }^{77}$ CIL X, 1412 = ILS, 74a: Divo Augusto / Augustales. Cf. Guadagno 1983: 172-173. 
du bâtiment est constitué par une série d'arcs aveugles érigés en briques, remplis d'opus reticulatum B. En revanche, la façade septentrionale présente deux piédroits construits en opus vittatum mixtum à deux assises de briques qui encadrent l'entrée de l'espace VI, $20^{78}$. Les études de T. Najbjerg ont montré que les quatre piliers qui rythment la façade de l'Aedes Augustalium doivent être associés chronologiquement avec la construction du portique qui s'étend au nord de celui-ci; tous sont construits en briques ${ }^{79}$. La dichotomie entre la conception organique et les appareils employés permet de conclure que l'opus vittatum mixtum à deux assises de briques est postérieur à la construction du portique et probablement attribuable à une phase de restauration associée à l'un des événements sismiques. En revanche, à cette exception près, aucune autre trace de réparation n'est discernable dans les maçonneries.

La troisième série d'inscriptions concerne un édifice essentiellement connu par les relevés effectués au XVIII ${ }^{\mathrm{e}}$ siècle par J.-Ch. Bellicard puis par P. de Bardet ${ }^{80}$. Il s'agit, selon une récente réinterprétation, d'une porticus se développant au nord des îlots VI et VII, auparavant appelée forum ou basilique. L'étude de cet édifice, dont quelques restes ont été dégagés durant les fouilles des années 1960, et surtout de son programme décoratif, a permis à T. Najbjerg de proposer une date de construction à peine antérieure à 49 de notre ère ${ }^{81}$. Le cycle décoratif représentant la famille impériale a ensuite été modifié sous Vespasien, par l'adjonction des statues des femmes de la dynastie flavienne ${ }^{82}$. Les maçonneries d'un édifice daté avec une

${ }^{78}$ G. Guadagno (1983: 165 et n. 25) les signale comme construits en opus vittatum dans son texte mais donne fort justement la description de l'opus vittatum mixtum en note.

${ }^{79}$ Najbjerg 2002: 143-146; sur ce portique, cf. infra.

${ }^{80}$ Sur ces relevés, cf. Pagano 1996 a : 229-230 et Najbjerg 2002: 133-136.

81 Najbjerg 2002: 147-148. Une telle datation avait déjà été proposée - élargie au règne de Claude - par A. Allroggen-Bedel (1974: 108), puis affinée à l'année 49 comme terminus ante quem probable par M. Pagano (1996 a: 242). L'ensemble de ces interprétations se fonde sur la datation des bases de statues financées majoritairement par L. Mammius Maximus (CIL X, 1413, 1417-1418), telle précision sont importantes pour ce propos. Les différentes parties qui n'ont pas été reconstruites lors de la fouille sont, pour le gros œuvre, en opus testaceum. Selon Th. Ganschow, aucune réparation consécutive ne serait perceptible, tandis que T. Najbjerg mentionne de telles réparations, mais en renvoyant à des adjonctions ${ }^{83}$. Faute d'argument dans un sens ou dans l'autre, il faut considérer que dès le milieu du $\mathrm{I}^{\mathrm{er}}$ siècle, la brique a été employée pour cette porticus.

En dépit de dégagements parfois partiels, les monuments d'Herculanum offrent une vision homogène de la construction publique entre le règne d'Auguste et celui de Claude. Le gros œuvre paraît toujours édifié en combinant opus testaceum et opus reticulatum, tandis que les rares réparations reconnues, et éventuellement attribuables à l'un des séismes qui ont touché la ville, sont réalisées en employant de l'opus vittatum mixtum, à deux rangs de briques quand l'étude le précise.

\section{V.3.2 Le résultat des fouilles}

Outre les inscriptions, qui permettent d'obtenir des datations précises, ou du moins des termini post ou ante quos, peu tributaires des évolutions de la recherche archéologique, les rares sondages effectués dans la ville sous les niveaux ensevelis par l'éruption participent pleinement à l'élaboration d'une chronologie absolue. Les premières fouilles stratigraphiques ont été effectuées par V. Tran Tam Tinh durant les années 1970; une partie d'entre elles reste inédite ${ }^{84}$. Les autres concernent essentiellement la Casa dei cervi (IV, 21), dont le jardin

qui se trouvaient dans les niches du portique, ainsi que sur celle de la statue en bronze de Claude (CIL X, 1416) portant la titulature de 49 ap. J.-C.

${ }^{82}$ CIL X, 1419 et 1422; Allroggen-Bedel 1974: 108; Pagano 1996 a: 242 ; Najbjerg 2002: 148.

83 Ganschow 1989: 89; Najbjerg 2002: 148-149. La proportion de restauration moderne dans les quelques parties visibles de cet édifice est tellement importante qu'il serait vain de tenter de discerner des réparations antiques.

${ }^{84}$ Cf. Pagano 1996 b: 189, à propos d'un sondage dans la Casa del colonnato tuscanico. D'autres sondages peuvent être signalés dans la Casa del priapo et dans la Casa della stoffa. 
a été exploré. Les données apportées par ces fouilles sont toutefois peu nombreuses en ce qui concerne les possibilités de proposer une datation pour certains types d'opus: les seules structures véritablement dégagées, construites en opus incertum A, ont été interprétées comme ayant été détruites et abandonnées lors du séisme de $62^{85}$.

Fréquemment en lien avec des travaux de restauration ou de transformation du parc archéologique, une série de sondages a été effectuée par M. Pagano à la fin des années 1980 et dans le courant des années 1990. Deux sondages ont été implantés dans l'entrée Or. II, 4 de la "Palestre». Leur stratigraphie ainsi que le matériel mis au jour - des tessons de céramique sigillée (italique et de Campanie), des fragments d'enduit peint de $\mathrm{III}^{\mathrm{e}}$ style - permettent d'aboutir à la conclusion que cet édifice a été construit sur un espace dénué de constructions antérieures, avec d'importants travaux de remblaiement, dans une fourchette chronologique oscillant entre la période augustéenne et le règne de Tibère $^{86}$. Les fragments d'enduits proviendraient d'édifices environnants détruits sous Auguste ${ }^{87}$. Cette première datation est rehaussée au début de la période augustéenne après un nouveau sondage effectué dans l'entrée Or. II, 19 de l'édifice. Il a permis de définir qu'avant l'érection de la «Palestre», le decumanus maximus continuait vers l'est. Une fosse remplie de déblais consécutifs au séisme de 62 a également été identifiée $^{88}$. En dépit des légères variations d'une

${ }^{85}$ Tran Tam Tinh 1977, part. 41. La théorie développée par cet auteur, qui placerait la construction de la Casa dei cervi après le séisme de 62 a été vivement rejetée par Th. Ganschow (1989: 184-215) et critiquée par R. Ling (1992: 333-336). Une reprise de l'étude de cette maison serait cependant nécessaire en prenant en compte l'existence d'un second séisme. Un rapide examen des maçonneries de cette maison, notamment du côté de la Casa della stoffa (IV, 19-20) laisse supposer au minimum des restaurations très importantes en lien avec le séisme de 62, si ce n'est une construction ex nihilo à ce moment.

${ }^{86}$ Un sondage réalisé en 2006 le long de la façade sud de la «Palestre », dans le cadre de l'Herculaneum Conservation Project, oblige à réviser partiellement cet aperçu général. En effet, un mur érigé en opus incertum aurait été arasé pour construire les fondations de la «Palestre». Ce mur originel aurait perforé un niveau de sol (US 93) daté entre les règnes d'Auguste et de Tibère (Wallace-Hadrill - Guidobaldi publication à l'autre, ces trois sondages donnent une fourchette chronologique pour l'utilisation des opera reticulatum B et vittatum, principales techniques de construction de la «Palestre». Ces explorations ne se sont pas limitées aux édifices publics. Du sondage effectué dans le jardin de la Casa del colonnato tuscanico (VI, 16-18.26-27), il ressort que l'extension de cette domus au sud de sa parcelle primitive s'est déroulée durant la période augustéenne ${ }^{89}$. L'analyse des structures maçonnées correspondant à cette extension montre une utilisation massive de l'opus reticulatum B et de l'opus vittatum. Signalons également qu'une fosse profonde de 2,55 m a été creusée en avant de cette maison, pour y couler un massif de béton, destiné, selon les interprétations de M. Pagano, à stabiliser la domus après le séisme de 62. Deux couches de remplissage colmatant cette fosse auraient livré un abondant matériel encore inédit ${ }^{90}$.

Enfin, une série de sondages a été réalisée dans les boutiques situées en façade de la Casa del salone nero (VI, 11-15) au cours de deux campagnes qui se sont déroulées en 2004 et 2005; sans détailler le résultat de ces fouilles, un point mérite d'être souligné ${ }^{91}$. Le sondage réalisé sur toute l'extension de l'arrière-boutique du local VI, 12 constitue un témoignage de l'utilisation relativement tardive de l'opus quadratum pour réaliser des montants de porte. Après l'arasement des murs constituant la plus ancienne occupation observée en ce point, un épais remblai a été déposé pour permettre la construction de la

- Camardo - Moesch 2008: 420-421). L'analyse des données provenant de ce sondage tendrait à remettre en cause l'unité de construction de l'édifice, pourtant largement étayée par l'étude des techniques constructions, des fresques de première phase (cf. infra) et des sondages réalisés dans les années 1980-1990, et à abaisser drastiquement la date de construction.

${ }^{87}$ Pagano 1990; Pagano 1993 a: 598-599. Cette destruction a été attribuée, lors d'une communication ultérieure, à un hypothétique séisme survenu durant la période augustéenne (Cf. Fröhlich - Jacobelli 1995: 200).

${ }^{88}$ Pagano 1996 b: 189.

${ }^{89}$ Pagano 1993 a: 597-598; contra Cerulli Irelli 1974: 73.

${ }^{90}$ Pagano 1996 b: 190 et fig. 5 p. 192.

${ }^{91}$ Pour les résultats de ces sondages, voir Monteix 2005 et surtout Monteix 2007 b. 
partie septentrionale de la Casa del Salone nero ${ }^{92}$ - entrée VI, 13, atrium et pièces l'entourant. Lors de la fouille, l'empreinte du pilier utilisé comme piédroit de la porte menant de la pièce $12^{\prime}$ à l'atrium a été observé reposant sur ces remblais datés de l'époque augustéenne ${ }^{93}$. Rien ne permet de déterminer le type de maçonnerie utilisé en élévation: le mur a été détruit lors du séisme de 62 et le bloc utilisé comme piédroit remployé dans la même position.

Bien que la fiabilité des données ainsi recueillies soit moindre que celle provenant de la corrélation entre les inscriptions et le bâtiment auquel elles se rapportent, la chronologie des techniques de construction a été sensiblement précisée. Le principal problème des datations induites des sondages est qu'elles restent tributaires d'études céramologiques parfois incomplètes ou imprécises. Une troisième option est de compléter cette périodisation par l'examen des styles décoratifs et des maçonneries qui leur sont associées.

\section{V.3.3 Les styles décoratifs}

Je ne saurais proposer ici une synthèse, fûtelle très restreinte, ni de l'évolution des styles décoratifs - entendus comme un ensemble cohérent entre la décoration pariétale et le pavement-, ni des problèmes chronologiques posés par cette dernière. L'acuité de ces derniers est d'autant plus forte que mon propos reste cantonné à Herculanum, jusqu'à présent moins

92 Ces travaux de terrassement ont également été observés dans la fouille de la boutique VI, 14, où ils atteignent une épaisseur supérieure à $43 \mathrm{~cm}$ : perçus grâce à la fosse qui les a coupés, la hauteur totale de ces remblais ne saurait être déterminée, la fosse n'ayant pas été intégralement fouillée pour des raisons de sécurité.

${ }^{93}$ Les différentes US composant le remblai ont notamment livré une coupe en vernis noir à profil sinusoïdal (Morel [1981: 202-203], série 2654 e) produite dans la seconde moitié du I ${ }^{\mathrm{er}} \mathrm{s}$. av. J.-C.; un fragment de céramique sigillée caractéristique de la production A de la baie de Naples (cf. Hedinger - Schneider - Soricelli 1994) et un fragment d'amphore de Bétique (Dressel 7-11). L'ensemble permet de circonscrire la datation de cet exhaussement du sol à la période augustéenne. Ces différents éléments proviennent de l'étude menée par B. Chiaretti sur l'ensemble du matériel de la fouille. Qu'elle trouve dans l'utilisation de ces données toute l'expression de ma reconnaissance. explorée que Pompéi par les spécialistes de peinture romaine, pour ne pas mentionner les pavements ${ }^{94}$.

L'un des principaux problèmes pour utiliser les styles décoratifs comme indicateur chronologique des techniques de construction reste que les fresques masquent les maçonneries. De ce fait, de nombreuses parois ne renseignent que sur le style de peinture qu'elles portent. Il s'ensuit que les données sur de telles parois restent limitées à la seule période durant laquelle elles ont été enduites: dans la majeure partie des cas, les fresques subsistent autour des perforations du XVIII ${ }^{\mathrm{e}}$ siècle, le reste du mur ayant été reconstruit lors de la fouille. A contrario, quand l'enduit est partiellement tombé, il devient difficile de déterminer le style auquel le rattacher, faute d'éléments caractéristiques suffisamment nombreux. Ce type de problème est inexistant pour les pavements, mais le faible nombre de publications rend les attributions délicates. Les seuls volumes de synthèse détaillée sur les pavements de Pompéi restent ceux d'E. Pernice et de M.E. Blake, qui ne sont que d'une utilité réduite pour notre analyse ${ }^{95}$. En effet, alors qu'une chronologie relativement fine serait utile, les datations proposées sont assez larges, pour dresser, conformément aux buts de cet ouvrage, une évolution des décorations de sol sur la longue durée. De plus, et cet aspect est également valable pour les fresques, les schémas décoratifs employés à Herculanum n'ont que des parallèles parfois minces avec ceux de Pompéi. Cette particularité,

${ }^{94}$ Les décors auraient dû être inclus dans le second volume d'A. Maiuri sur les fouilles d'Herculanum, non publié suite à sa disparition. Certaines parois d'Herculanum ont fait l'objet d'études particulières ou sont mentionnées dans des synthèses thématiques. D'une manière globale, l'étude de la peinture d'Herculanum est cependant longtemps restée cantonnée, comme l'ensemble du site, au rôle d'exemple, en contrepoint ou en appui de la situation pompéienne. Dans les années 2000, la thèse de doctorat de D. Esposito (2005) a comblé cette lacune. En revanche, les études sur les pavements sont encore limitées aux brèves remarques d'A. Maiuri et aux deux monographies sur les peintures de la Casa dell'atrio a mosaico et de la Casa del colonnato tuscanico (Cerulli Irelli 1971; Manni 1974).

${ }^{95}$ Cf. Blake 1930 et Pernice 1938. 
qui pourrait être simplement liée à l'existence d'ateliers locaux, complique la détermination stylistique en s'appuyant sur des parallèles, et ce en dépit de monographies récentes ${ }^{96}$.

Pour dépasser les débats chronologiques des spécialistes de cette question, il serait possible d'utiliser, à la suite de ce qu'a fait Th. Ganschow, des attributions larges de style et de déterminer sur quels types de maçonnerie ils sont présents $^{97}$. Cela permettrait de poser des jalons chronologiques - diffus - pour leur mise en œuvre. Une telle démarche est toutefois contrariée par les restaurations "à l'identique», ou peu s'en faut, de certaines parois avant l'éruption de 79. Un exemple permet d'illustrer cette situation. E. Moormann a étudié les différentes fresques de la Casa del mobilio carbonizzato. Dans deux pièces, celle au sud du tablinum et le couloir d'entrée, il inscrit la décoration dans un $\mathrm{IV}^{\mathrm{e}}$ style encore proche structurellement du $\mathrm{III}^{\mathrm{e}}$, mais ayant probablement été retouché après le séisme de $62^{98}$. La décoration de la pièce 8 est interprétée comme relevant du IV ${ }^{\mathrm{e}}$ style comportant quelques éléments caractéristiques du $\mathrm{III}^{\mathrm{e}}$, comme la division horizontale de la paroi sans liaison verticale ou les motifs des frises. Il considère que cet ensemble a été exécuté avant le séisme de $62^{99}$. La maçonnerie des parois occidentale et méridionale présentent des signes distinctifs de restauration: les deux montants de la porte permettant d'accéder à cette pièce ont été reconstruits en briques, tout comme le montant droit de la fenêtre occidentale et la partie inférieure de la fenêtre centrale ${ }^{100}$. La différence de réalisation des fresques entre les murs restaurés et la paroi septentrionale est essentiel-

96 Le constat des différences entre les façons de peindre à Herculanum et à Pompéi a déjà été suggéré par A. Allroggen-Bedel (1991). La série "Häuser in Pompeji » (e.g. Strocka 1991, Seiler 1992) ou encore les études menées sur l'îlot I 10 à Pompéi (Ling 1997 a; Ling - Ling 2005) montrent pourtant tout le parti que l'on peut tirer d'une étude exhaustive et concomitante des peintures et des structures maçonnées. Un bilan détaillé de l'état des études sur la peinture à Herculanum en 1990 a été dressé par M. Manni (1990), désormais remplacé par le travail de D. Esposito (2005).

${ }^{97}$ Ganschow 1989: 101-102.

98 Moormann 1987: 128, 133.

${ }^{99}$ Moormann 1987: 130, 133. lement perceptible dans les bordures ajourées et dans la finesse de la frise de glyphes séparant la zone médiane de la zone supérieure. La paroi nord présente une finesse supérieure aux deux autres ${ }^{101}$. Cet exemple incite à relativiser la chronologie obtenue sur fondements stylistiques.

Ce type de réfection tardive, souvent liée aux réparations post-sismiques, est attesté pour tous les styles. Ainsi, A. Laidlaw signale d'une part une dizaine d'exemples de restauration de parois en $\mathrm{I}^{\mathrm{er}}$ style après la date originelle de mise en œuvre et d'autre part des imitations tardives de ce style, dues à l'affect attaché à cette forme décorative ${ }^{102}$. Sans revenir sur les autres exemples déjà évoqués à Pompéi - qui concernent le III ${ }^{\mathrm{e}}$ style -, notamment ceux de la Casa dei casti amanti et de la Casa degli Amorini dorati, signalons que ce type de restauration a également été mis en évidence dans la Casa di Paquio Proculo (I 7, 1.20) ${ }^{103}$. Toutes ces interventions ont une conséquence importante sur la façon dont une chronologie des types de maçonnerie peut être établie. Les principes posés par Th. Ganschow sont techniquement justes: la datation des fresques devrait donner un terminus ante quem pour l'utilisation du type de maçonnerie sur lequel cette décoration est appliquée ${ }^{104}$. Cependant, les diverses formes de restauration peuvent faire devenir ce terminus post quem: il convient de rester prudent pour déterminer les rapports chronologiques entre la décoration et son suppport. Enfin, je soulignerai un dernier point: le fait que le décor soit intégralement refait ne signifie pas que les murs ont été construits au même moment; un changement de décor n'implique pas nécessairement une transformation des volumes architecturaux.

100 Th. Ganschow (1989: 266) considère que les montants de la porte ont été reconstruits après la fouille, tandis que la partie inférieure de la fenêtre centrale aurait été construite dans une variante d'opus testaceum.

${ }^{101}$ Il est plus délicat de déterminer à quel groupe appartient la paroi orientale, beaucoup plus endommagée et donc moins lisible.

${ }^{102}$ Les exemples de restauration sont donnés dans Laidlaw 1985: n. 15 p. 42; pour les imitations tardives mais également pour les parois conservées durant un laps de temps important, cf. Laidlaw 1985: 44-46.

${ }^{103}$ Cf. supra, p. 236 et Ehrhardt 1995.

${ }^{104}$ Ganschow 1989: 101-102. 


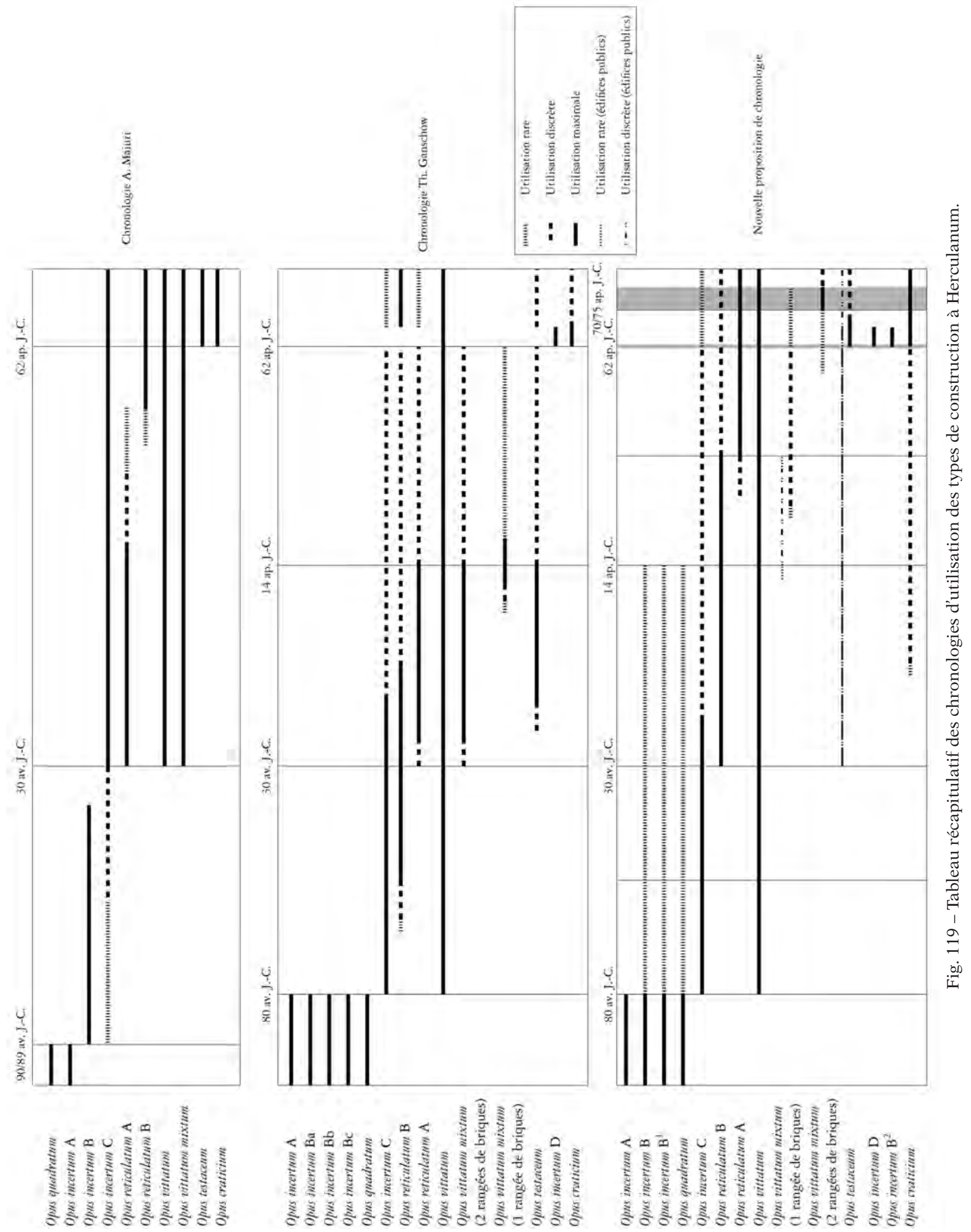


DE LA CHRONOLOGIE DES TYPES DE CONSTRUCTION À L'ÉVOLUTION DU BÂTI À HERCULANUM

Les éléments présentés permettent de dresser une esquisse de chronologie pour l'utilisation des différents types d'opera à Herculanum. Dans ses grandes lignes, elle ne diffère que peu de celle proposée par Th. Ganschow. Ces différences ne sont pas négligeables, puisqu'elles conditionnent la trame chronologique que j'ai établie pour l'ensemble de la ville. Afin d'expliquer le tableau synoptique que j'ai dressé, je ne commenterai que les points de divergence avec celui de Th. Ganschow (fig. 119).

Des différentes données qui autorisent à poser des jalons chronologiques, les bâtiments publics - dont la période ou la date de construction sont connues soit par les inscriptions, soit par le résultat des fouilles - constituent les témoignages les plus intéressants. Leur mise en œuvre s'échelonne entre la période augustéenne et la moitié du I ${ }^{\text {er }}$ s. de notre ère. Pour le gros œuvre, ils présentent une unité technique qui est remarquable: leurs parois de première phase sont systématiquement érigées en opus reticulatum $\mathrm{B}$. En revanche, les autres parties diffèrent sensiblement: la brique est employée dans tous les bâtiments étudiés, à l'exception de l'Insula Orientalis $I I^{a}$. Cette différence tient à la conception même de ces édifices: le théâtre, l'aedes Augustalium et le portique situé au nord du decumanus maximus sont tous les trois construits en utilisant des arcs comme structure porteuse, au contraire de l'édifice contenant le temple de Magna Mater dans lequel les murs ont été fortement épaissis

${ }^{105}$ La description de la voûte étoilée de l'entrée Or. II, 4 n'est pas assez précise pour déterminer si elle était constituée en briques ou non (cf. Ruggiero 1885 : 233-234). Aucun élément n'est connu quant à la couverture de la cella $\mathrm{I}$. Le cryptoportique au nord de la "Palestre » est voûté en béton non parementé.

${ }^{106}$ Dans le cas de l'aedes Augustalium, cette seconde fonction est mise en évidence par le fait que le remplissage des arcades n'est pas réalisé sur l'ensemble de leur profondeur: les arches restent visibles.

${ }^{107}$ Dans son tableau de correspondance entre les peintures et les types de construction, Th. Ganschow (1989: 103, 125) considère à tort, que la fresque située sur les parois nord et sud du tablinum de la Casa dei due atri (VI, 28-29) est de $\mathrm{III}^{\mathrm{e}}$ style. La composition générale et les éléments de pour permettre un développement en hauteur, tandis que les quelques voûtes conservées sont toutes en béton coffré105. Dans les attestations connues d'emploi des terres cuites architecturales à Herculanum, l'intérêt de leur emploi est donc uniquement de permettre la construction aisée d'arcs qui servent tout autant à répartir les charges qu'à avoir une fonction esthétique ${ }^{106}$. En suivant ce constat, nous devons donc limiter l'érection de murs en opus testaceum, dans la construction privée, à la période postérieure à 62 de notre ère. En effet, dans les domus, l'utilisation de la brique est toujours limitée à des parties fortement susceptibles d'avoir été endommagées en cas de secousse sismique. Les quelques exemples de peintures pouvant donner une datation plus haute montrent systématiquement des traces de réfection qui soulignent également les dégâts liés au tremblement de terre ${ }^{107}$. Une date aussi tardive pourrait s'expliquer par la différence dans le rapport coût/facilité de mise en œuvre longtemps plus favorable au tuf dans une région particulièrement riche de ce matériau. Le développement de l'opus vittatum mixtum $(V m)$ à un puis deux rangs de briques participe de cette évolution qui tend à augmenter la part de la brique. Comme le remarque très justement Th. Ganschow, le $V m$ simple est peu employé dans le temps et son utilisation reste fortement liée à l'édification de la "Palestre » ${ }^{108}$. Quant au $V m^{2}$, il paraît employé préférentiellement pour les réparations du second séisme, tout du moins à chaque fois qu'il est en relation avec des parois en briques. Toutefois, il paraît plus raisonnable de le cantonner à la période 62-79 ${ }^{109}$. la zone médiane sont de IV ${ }^{\mathrm{e}}$ style. Selon les recherches de D. Esposito (2005: 168-169), cette maison serait un exemple du IV ${ }^{\text {e }}$ style flavien à Herculanum. Cf. également Maiuri 1958 b: 276; Bastet - de Vos (1979: 139) qui n'intègre pas la maison dans leur liste des attestations de $\mathrm{III}^{\mathrm{e}}$ style hors de Pompéi.

${ }^{108}$ Ganschow 1989: 129-130. En revanche, il est difficile de s'expliquer le choix de chronologie qu'il propose dans son tableau synoptique, où il limite l'utilisation maximale de ce type de construction au règne d'Auguste (Ganschow 1989: fig. 8 p. 135).

${ }_{109}$ Il est possible que, comme à Pompéi (cf. supra, p. 237), l'opus vittatum mixtum à deux assises de briques ait été utilisé avant le séisme de 62. Aucun exemple parmi ceux que j'ai observés à Herculanum n'est probant en ce sens. 
Quant aux autres correctifs que je propose à la chronologie de Th. Ganschow, ils sont d'une portée moindre. Ainsi, l'extension de l'usage de l'opus quadratum jusqu'à la période augustéenne, fondée sur les fouilles réalisées dans l'atelier VI, 12, reste sans grande conséquence. Cela n'est guère plus qu'un épiphénomène, une probable utilisation tardive d'une technique ancienne, qui souligne juste que même après la guerre sociale, même une fois qu'Herculanum est devenu un municipe, les opera préromains d'A. Maiuri peuvent encore être utilisés ${ }^{110}$. Une situation similaire a récemment été mise en évidence à Pompéi. Un mur en opera $a$ telaio a été daté de la fin du $\mathrm{I}^{\text {er }}$ s. av. J.-C. par M. Fulford et A. Wallace-Hadrill lors des fouilles en I 9,11-12. Cette datation ne permet pas de remettre en cause l'usage massif de ce type d'opus au cours des $\mathrm{III}^{\mathrm{e}}$ et $\mathrm{II}^{\mathrm{e}}$ siècles avant notre ère ${ }^{111}$. Pour en revenir à Herculanum, des blocs de tuf gris ont également été utilisés en remploi comme montant de portes après 62 en VI, 12 et en VI, $15^{112}$. Il me semble également nécessaire de repousser la date d'utilisation de l'opus reticulatum A, dont le début et la période maximale d'emploi correspondrait, selon Th. Ganschow, au règne d'Auguste, en raison d'une interprétation très douteuse du tablinum de la Casa dei due atri (VI, 28-29), mais également d'une erreur d'appréciation des phases de construction des

${ }^{110}$ A. Maiuri (1958b: 68) semble utiliser la période de 89-80 av. J.-C. comme basculement de la cité samnite à la cité romaine, marquée par «l'adozione dell'opus incertum in tufo e l'abbandono quasi completo dei materiali lavici [...] segnano un nuovo periodo [...] avvenuto lentamente durante il cinquantennio che va dall'espugnazione della città e della sua sua costituzione in municipium romano all'avento di Augusto ». Th. Ganschow (1989: 98-101) quant à lui reporte cet événement à 80 av. J.-C. L'obtention du statut de municipe semble se situer vers la fin des années 30 av. J.-C., très certainement en lien avec la présence d'Ap. Claudius Pulcher dans la cité (cf. supra, n. 72). De toute façon, le lien entre le statut légal de la ville et l'évolution des techniques de construction semble bien difficile à établir. Les techniques de construction employées dans la Casa del salone nero pourraient n'être que l'un des ultimes soubresauts des mises en œuvre les plus anciennes.

${ }^{111}$ Fulford - Wallace-Hadrill 1998. R. Laurence (JRS 88, 1998: 202) a tenté d'utiliser cette datation pour proposer un abaissement général de la chronologie de ce type de construction. La réponse donnée par R. et L. Ling (2005: 174) à ce propos est irréprochable du point de vue de la méthode: «[...] The chronology of building techniques is a general good thermes «du forum »113. Cet opus n'apparaît guère plus qu'un raffinement de l'opus reticulatum B. Il se développerait uniquement dans une phase successive. Son absence d'utilisation dans les bâtiments publics construits durant la période augustéenne et connus par les fouilles s'avère un argument suffisant pour considérer que son usage ne se développe que durant le $\mathrm{I}^{\mathrm{er}} \mathrm{s}$. de notre ère.

Pour reprendre l'exemple développé plus haut, les transformations de la façade nordorientale de la Casa del tramezzo di legno sont les suivantes. Après avoir longtemps conservé un mur périmétrique nord construit en opus incertum B, des travaux sont effectués lors de la période augustéenne: le mur est arasé et remplacé par une construction en opus reticulatum B qui prévoit un accès par la porte 9 . Il est possible que dès ce moment une boutique soit ouverte en 8 . Aucun élément ne peut être relevé pour la boutique 10. Au cours de la phase successive, probablement la première post-augustéenne, des remaniements importants transforment l'angle nord-est. La boutique III, 10 est créée et séparée de l'espace accessible par la porte 9 en construisant un mur de refend. L'appartement à l'étage, qui déborde sur la pièce (a) et le vestibule (III, 11) de la Casa del tramezzo di legno, dispose d'une avancée sur la rue $^{114}$. Les travaux ont été réalisés en employant

guide but should often be regarded as offering only termini post quos; the various rubblework techniques, in particular, may recur in broadly similar forms over long periods of time, and in these circumstances it is wise to retain a certain flexibility when using them as dating tools ». Les fouilles dirigées par F. Coarelli et F. Pesando (2006: 19, 312-316) ont permis de confirmer que l'utilisation initiale et principale de l'opera a telaio doit être située au $\mathrm{III}^{\mathrm{e}}$ siècle avant notre ère.

112 Pour le détail du raisonnement permettant d'aboutir à cette conclusion, voir Monteix 2007 b: 169-175.

${ }^{113}$ Sur la Casa dei due atri, cf. Ganschow 1989: 125, 127 et supra, n. 107. À propos des thermes, Th. Ganschow (1989: 93-95) considère qu'ils ont été intégralement construits en opus reticulatum A, suivant en cela l'analyse d'A. Maiuri (1958 b: 93). Pourtant, une première phase, en opus incertum $\mathrm{C}$, est visible, au moins dans la moitié nord de la façade orientale. Seules les transformations successives, et l'extension des bâtiments thermaux - essentiellement de la moitié dite des thermes féminins - au sud-est, le long de la palestre, ont été réalisées en opus reticulatum A.

${ }^{114} \mathrm{La}$ présence d'une porte dont les montants sont en opus vittatum entre la pièce qui surplombe la boutique 10 et celle qui se développe au-dessus de la pièce (a) de la Casa 
une forme irrégulière d'opus reticulatum A pour les parois, et l'opus vittatum mixtum à un rang de briques pour les montants. Le séisme de 62 provoque des dégâts assez importants. Le mur de refend entre la boutique III, 10 et l'espace III, 9 fait bélier contre la façade, l'endommageant fortement. L'angle nord-est de la boutique s'effondre, emportant le montant oriental et une grande portion de la façade. Enfin, très probablement, les deux montants de la boutique III, 8 sont également endommagés. Les premières reconstructions sont effectuées en utilisant de la brique pour les montants et l'opus reticulatum A pour les parois. Une conduite d'eau est insérée dans le mur de refend entre III, 9 et III, 10, permettant la mise en place d'une latrine à l'étage de III, 10 et au rez-de-chaussée de III, 9. L'appartement d'angle perd son extension sur la rue. Un auvent est ménagé à la place. Le second séisme provoque des dégâts moindres: seul le montant occidental de la porte III, 9 doit être remplacé.

Cet exemple développé dans le détail montre les limites des réflexions possibles grâce à l'archéologie du bâti, même dans un site bénéficiant de conditions de conservation exceptionnelles. Ces incertitudes quant à l'insertion dans une chronologie absolue ne me semblent pouvoir être éclaircies que ponctuellement. En effet, le contexte troublé et destructif des dernières années de vie d'Herculanum fait qu'une partie importante du palimpseste maçonné a été effacée. Les questions soulevées ne sauraient guère plus être résolues par la fouille, ne seraitce que parce que les datations que l'on peut obtenir avec les céramiques fines ne sont pas assez précises pour permettre de distinguer les débris provenant de l'un ou de l'autre séisme.
Une part d'incertitude restera nécessairement sur les hypothèses qui seront formulées.

$$
\text { * } *
$$

Dans les chapitres suivants, je présenterai le résultat de mes observations sur l'ensemble des vestiges mis au jour à Herculanum. J'ai dressé un relevé - sommaire ${ }^{115}$ - des parois des différentes domus de façon à définir une chronologie relative de leurs transformations ainsi que des éventuelles créations ou fermetures de liens avec les édifices voisins. À partir de ces études par maison, j'ai procédé à une mise en phase sur tout le site, en utilisant les jalons que je viens de poser. D'un point de vue architectural, les seuls moments bien datés sont d'une part la période augustéenne - avec le flou que comporte ce laps de temps -, d'autre part les deux séismes, puis l'éruption. Pour les phases intermédiaires, il m'a semblé plus opportun de ne pas recourir à une précision illusoire, que ce soit en suivant les règnes des empereurs ou les datations des styles décoratifs. J'ai donc divisé arbitrairement la première moitié du $\mathrm{I}^{\mathrm{er}}$ siècle, s'étalant entre la mort d'Auguste et le séisme de 62, en deux phases successives dont la limite médiane est volontairement non spécifiée. En ce qui concerne les phases les plus anciennes de la ville, elles ne sont que peu visibles dans les murs en élévation. Sans recourir aux fouilles stratigraphiques, je suis convaincu qu'il n'est pas possible de présenter une évolution fine en deçà du ${ }^{\text {er }} s$. avant notre ère. J'ai donc arbitrairement divisé la période pré-augustéenne en deux phases: la première correspond sensiblement à la situation samnite ou immédiatement postérieure à la guerre sociale, la seconde montre les évolutions successives. del tramezzo di legno pourrait indiquer que cet étage existait déjà lors de la phase antérieure. Il aurait été accessible depuis l'espace III, 9.

${ }^{115}$ Idéalement, il aurait été nécessaire, tout à la fois dans un but documentaire et argumentatif, de distinguer chacune des unités stratigraphiques qui renseignent l'évolution du bâti à Herculanum, en les positionnant sur un relevé exhaustif des parois, dessinées à échelle constante. Une telle entreprise n'aurait pas pu être effectuée par une seule personne dans le cadre d'une thèse de doctorat. La vision que je présente ne saurait être qu'impressionniste. Toutefois, elle me semble suffisante pour comprendre l'évolution de la ville et en particulier celle des structures commerciales et artisanales. 



\section{CHAPITRE VI}

\section{L'INSULA ORIENTALIS II ${ }^{A}$ : ARCHITECTURE, FONCTION ET ÉVOLUTION D'UN BÂTIMENT PUBLIC}

Quel que soit l'angle d'approche sous lequel on se place, l'Insula Orientalis $I I^{a}$ est un édifice imposant, hors-normes, particulièrement si on le situe dans le contexte de la ville somme toute petite qu'est Herculanum. Sa seule emprise au sol, alors que le bâtiment n'a pas été fouillé intégralement, est fort impressionnante: près de $9000 \mathrm{~m}^{2}$ peuvent être restitués - dont au moins $4000 \mathrm{~m}^{2}$ sont construits sur deux à trois niveaux -, pouvant être portés à $13600 \mathrm{~m}^{2}$ si l'on suit les reconstitutions fondées sur les relevés du XVIII ${ }^{\mathrm{e}}$ siècle proposées par M. Pagano ${ }^{1}$. Selon les auteurs, cet édifice aurait servi de champ d'exercice pour la jeunesse herculanéenne ou constituerait une adaptation romaine de la palestre

1 Pagano 1996 a: 243-248. À titre de comparaison, l'emprise au sol des thermes de Caracalla est supérieure à $24.000 \mathrm{~m}^{2}$. La palestre de Pompéi se déploie sur environ $15.500 \mathrm{~m}^{2}$, toutefois il ne s'agit que d'un vaste enclos avec
«Pur escluendo ogni carattere di aedes sacra, l'impianto non è troppo dissimile da quello di un tempio a cella tripartita preceduto da un vestibolo e da un pronao, o dallo schema tripartito che si riscontra in alcune aule della Domus Aurea neroniana ».

A. Maiuri, Ercolano. I nuovi scavi, vol. I, Roma, Istituto poligrafico dello Stato, 1958, p. 122.

«Prenons garde que cet ensemble d'Herculanum [...] ne saurait en aucun cas constituer [un] prototype de l'habitat collectif de Rome ou d'Ostie».

P. Gros, L'architecture romaine du début du III siècle av.

J.-C. à la fin du Haut-Empire. 2, Maisons, palais, villas et tombeaux, "Manuels d'art et d'archéologie antiques», Paris, Picard, 2001, p. 110.

grecque. Toutefois, une de ses nombreuses particularités reste la file de boutiques et d'ateliers qui se situent sur sa façade occidentale, surplombée par des appartements.

Initier une synthèse sur l'évolution du tissu commercial à Herculanum par cet édifice tient tout d'abord à la présence de quatorze boutiques et ateliers au moment de l'éruption, soit près du quart des lieux de métier d'Herculanum. Fondé sur des remblais contenant du matériel augustéen, ce bâtiment est un point de référence important pour les techniques de construction dans la ville: l'ensemble est construit en opus reticulatum $\mathrm{B}$, avec des angles en opus vittatum, parfois en opus vittatum mixtum à un rang de

un portique interne, sans autre espace présentant une architecture plus élaborée. La surface du portique de l'Insula Orientalis $\mathrm{II}^{a}$ est de $4800 \mathrm{~m}^{2}$. 
briques. Létude du glissement d'une technique à l'autre devrait permettre d'étalonner les repères chronologiques avec plus de précision. L'unité de l'ensemble et son caractère public le distinguent des domus et des lieux traditionnels d'implantation des boutiques et ateliers, obligeant alors à l'isoler des autres bâtiments.

\section{VI.1 Restitution du projet initial}

Avant de déterminer l'aspect initial de l'Insula Orientalis $I I^{a}$, quelques éléments doivent être précisés quant à son site d'implantation, tant ils ont vraisemblablement conditionné une partie des choix opérés lors de la construction. $\mathrm{La}$ «Palestre » se situe à l'extrémité orientale du promontoire sur lequel la ville d'Herculanum s'est installée et constitue la dernière construction identifiée avant la mer $^{2}$. Le site présente une importante déclivité essentiellement orientée vers le $\operatorname{sud}^{3}$, particulièrement sensible sur les 106 mètres qui constituent la longueur connue du bâtiment: une différence d'altitude de près de 6 mètres sépare l'entrée Or. II, 19 de la boutique Or. II, $1^{4}$. Il convient également de souligner la position de l'édifice par rapport aux

\footnotetext{
2 Cette installation sur un promontoire est tirée d'une remarque de L. Cornelius Sisenna, au livre IV de ses Histoires de L. Cornelius Sisenna, citée par Nonius ([Non., p. 304, 22L] 84: Quod oppidum tumulo in excelso loco propter mare parvis moenibus inter duas fluvios infra Vesuvium collocatum; "Cette place-forte [d'Herculanum] située sur un promontoire élevé près de la mer, avec de petits remparts, entre deux fleuves au pied du Vésuve » [éd. et trad. CUF]). Déjà, F. La Vega (1797, cit. in Maiuri 1958 b: fig. 31 p. 29), dans la restitution qu'il proposait du site, avait indiqué la "Palestre» comme limite orientale de la ville, en laissant toutefois une certaine distance entre celleci et la mer. La publication du plan mis à jour de la ville par M. Pagano (1996 a: 230-234, fig. 1-3 p. 231-233) propose un tracé pour la ligne de côte qui serait nettement plus proche de l'Insula Orientalis $I I^{a}$. Les analyses géomorphologiques réalisées dans le cadre de l'Herculaneum Conservation Project (Cinque - Irollo 2008: 425-431) confirment ce tracé le long de l'Insula Orientalis $I^{a}$, suggérant que celle-ci se serait développée au-dessus d'une ria, avec cependant deux inflexions par rapport au plan précédemment cité. D’une part, en 79 , la mer aurait été plus proche du front méridional de la ville; d'autre part, le second fleuve mentionné par Sisenne ne se situerait pas entre Herculanum et la villa des Papyri mais plus à l'ouest de cette dernière.
}

axes de circulation: si les deux entrées Or. II, 4 et Or. II, 19 sont sensiblement dans la continuité des decumani inférieur et maximus, seule la seconde est strictement dans l'alignement de l'axe viaire. Par ailleurs, le cardo V a été modifié par la construction de l'Insula Orientalis $I I^{a}$ : un décalage de quelques degrés par rapport au premier tracé fait que la rue s'élargit au fur et à mesure de la descente vers la mer, jusqu'à l'Insula Orientalis $I^{a}$ à l'angle de laquelle elle

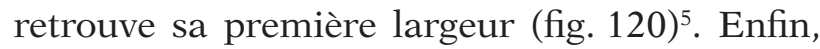
ce complexe est articulé en trois ensembles distincts - par-delà les éventuelles communications ayant pu exister entre eux ${ }^{6}$. Le cœur de l'édifice paraît constitué par la vaste aire entourée d'un portique, dans laquelle on trouve un bassin cruciforme qui se développe en arrière de la façade. Des salles s'ouvrent sur ce portique à l'ouest, tandis qu'un cryptoportique se situe au nord (pl. v, h.t.). Le second ensemble correspond aux différentes salles qui se trouvent au-dessus du cryptoportique, accessibles par l'entrée Or. II, 19. Elles donnent notamment accès à une terrasse surplombant le portique et son bassin. La façade occidentale, avec ses boutiques et ses appartements, constitue le troisième ensemble.

\footnotetext{
${ }^{3}$ Faute de point précis correspondant aux environs de la côte au-delà de la "Palestre», juger de la déclivité vers l'est est épineux, mais il est fort probable que l'orientation générale soit sensiblement au sud-est.

${ }^{4}$ Le sol de la boutique Or. II, 1 se trouve à $5,95 \mathrm{~m}$ en dessous de celui de l'entrée Or. II, 19 et à 0,70 m sous celui de l'entrée Or. II, 4. Le dénivelé de la rue est encore plus important: selon les plans publiés par M. Pagano (1996 a: fig. 13-14 p. 258-259), le cardo V passe de 23,00 m s.l.m. (au point de jonction avec la rue bordant l'Insula Orientalis $I I^{a}$ au nord) à 19,80 m s.l.m. (devant l'entrée Or. II, 19), puis à 14,30 m s.l.m. devant l'entrée Or. II, 4.La légère différence de déclivité est due au rattrapage partiel de celle-ci par la construction de terrasses à l'emplacement de l'Insula Orientalis $I I^{a}$.

${ }^{5}$ A. Maiuri (1958 b: 39-40, 173) mentionne un retrait de la façade et la volonté d'imposer un nouveau plan régulateur pour la partie orientale de la ville. Contrairement à ce qu'il indique, il ne s'agit pas d'un retrait constant, mais bien d'une orientation différente. Sur l'inadéquation entre le supposé plan hippodaméen de la ville revendiqué par A. Maiuri (1958 b: 27) et l'orientation réelle des rues, cf. Guadagno 1993: 83-87.

${ }^{6}$ Maiuri $1958 \mathrm{~b}: 116$.
} 


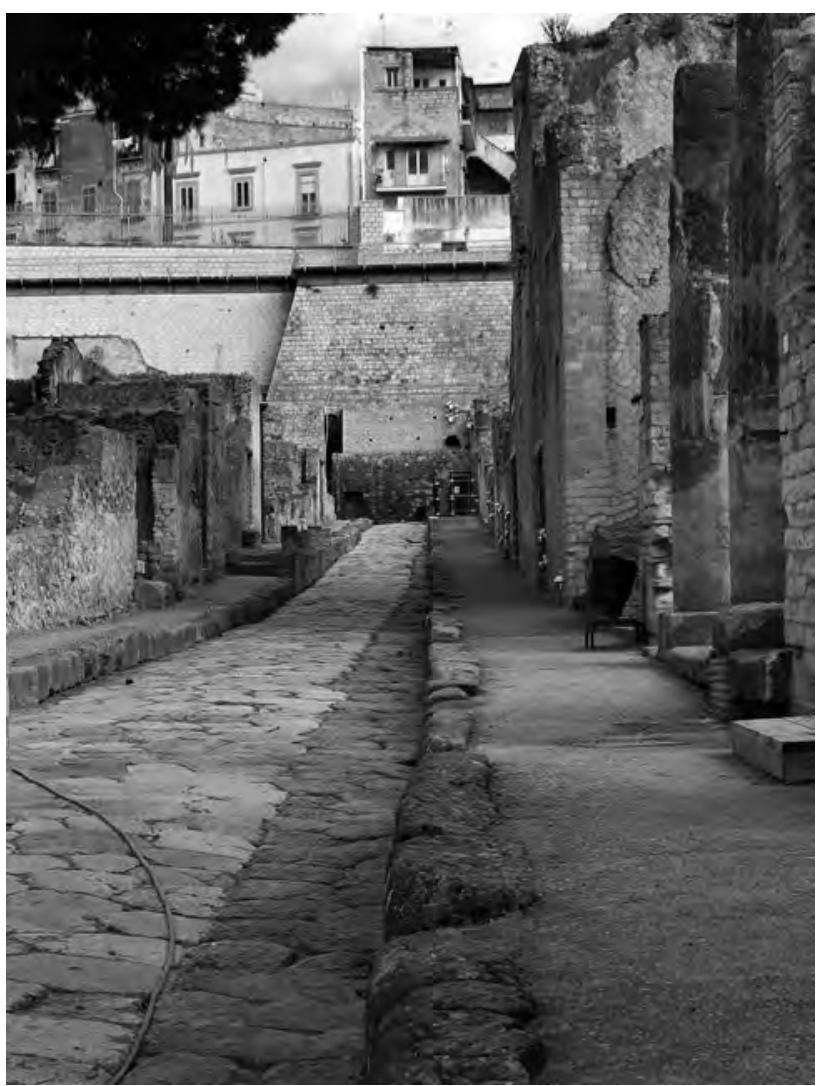

Fig. 120 - Cardo V vu depuis le sud-est. En correspondance de l'Insula Orientalis $I I^{a}$, la rue est sensiblement plus large mais va en se resserrant au fil de la montée vers le decumanus maximus. Le pavement dans la partie droite de la chaussée souligne ce changement d'alignement.

\section{VI.1.1 Date et techniques de construction}

La détermination de la datation - déjà définie dans ses grandes lignes au cours du chapitre précédent ${ }^{7}$ - et l'étude des différentes techniques de construction sont deux problèmes étroitement liés. La principale question reste de définir la période de construction, son éventuelle durée et surtout de mettre en évidence l'existence d'une unité ou non dans le projet initial. En effet, A. Maiuri d'abord puis F. Yegül à sa suite ont

\footnotetext{
${ }^{7}$ Cf. supra, p. 244-253.

${ }^{8}$ Maiuri 1958 b: 118, 134-135. F. Yegül (1993: 371-372, 374-376), dans un premier temps prudent par rapport à cette interprétation, finit par l'adopter. Cette interprétation a été également reprise par D. Camardo (Wallace-Hadrill - Guidobaldi - Camardo - Moesch 2008: 417-418).
}

postulé que l'édifice avait été construit en deux temps, d'abord la terrasse supérieure, le cryptoportique et la terrasse inférieure avec un premier bassin, suivis par la façade occidentale ${ }^{8}$. Les arguments en faveur de cette hypothèse sont peu nombreux. Le premier d'entre eux tient à l'observation des techniques de construction employées pour les ouvertures du cryptoportique vers l'esplanade inférieure. Selon A. Maiuri, ces dernières, qui sont des fenêtres au moment de l'éruption, auraient d'abord été des portes, partiellement condamnées lors de la seconde phase de l'édifice (fig. 121). Cette interprétation est sujette à caution, suite aux travaux de M. Pagano. Les variations que l'on peut observer ne sont dues qu'à un changement de technique dans l'édification de la base du cryptoportique, construite d'ouest en est. Les deux premières fenêtres reposent sur un unique mur construit en opus reticulatum $\mathrm{B}$, sur lequel des montants en opus vittatum ont ensuite été posés. Le troisième et le cinquième entrecolonnements sont aveugles, la troisième fenêtre qui s'insère entre eux est construite selon les principes précédents. Ce n'est que pour le sixième entrecolonnement, qui présente une fenêtre, que cette technique change. À la place d'un mur bahut en réticulé, deux montants sont construits et l'espace entre eux est ensuite comblé par des moellons de tuf de forme hétérogène. Ce procédé a été employé pour toutes les autres fenêtres qui suivent. S'il n'est pas interdit d'évoquer des problèmes de statique, l'adoption de cette technique n'est qu'un artifice de construction: les montants des fenêtres projetées ont été construits avant que leur partie inférieure ne soit comblée ${ }^{9}$, probablement pour laisser un "passage de chantier». Le second argument suggéré par A. Maiuri est que les ailes orientale et occidentale du portique inférieur s'appuient sur le cryptoportique. Ce point a également été rejeté par M. Pagano: une limite verticale - visible depuis la terrasse inférieure et depuis la loggia sépare en deux, au niveau du portique occidental

\footnotetext{
${ }^{9}$ Comme le souligne M. Pagano (1996 a: 244), si une première phase avait effectivement existé avec des portes et non des fenêtres, l'enduit recouvrant celles-là aurait été laissé en place au moment du bouchage, or aucun enduit n'est visible.
} 


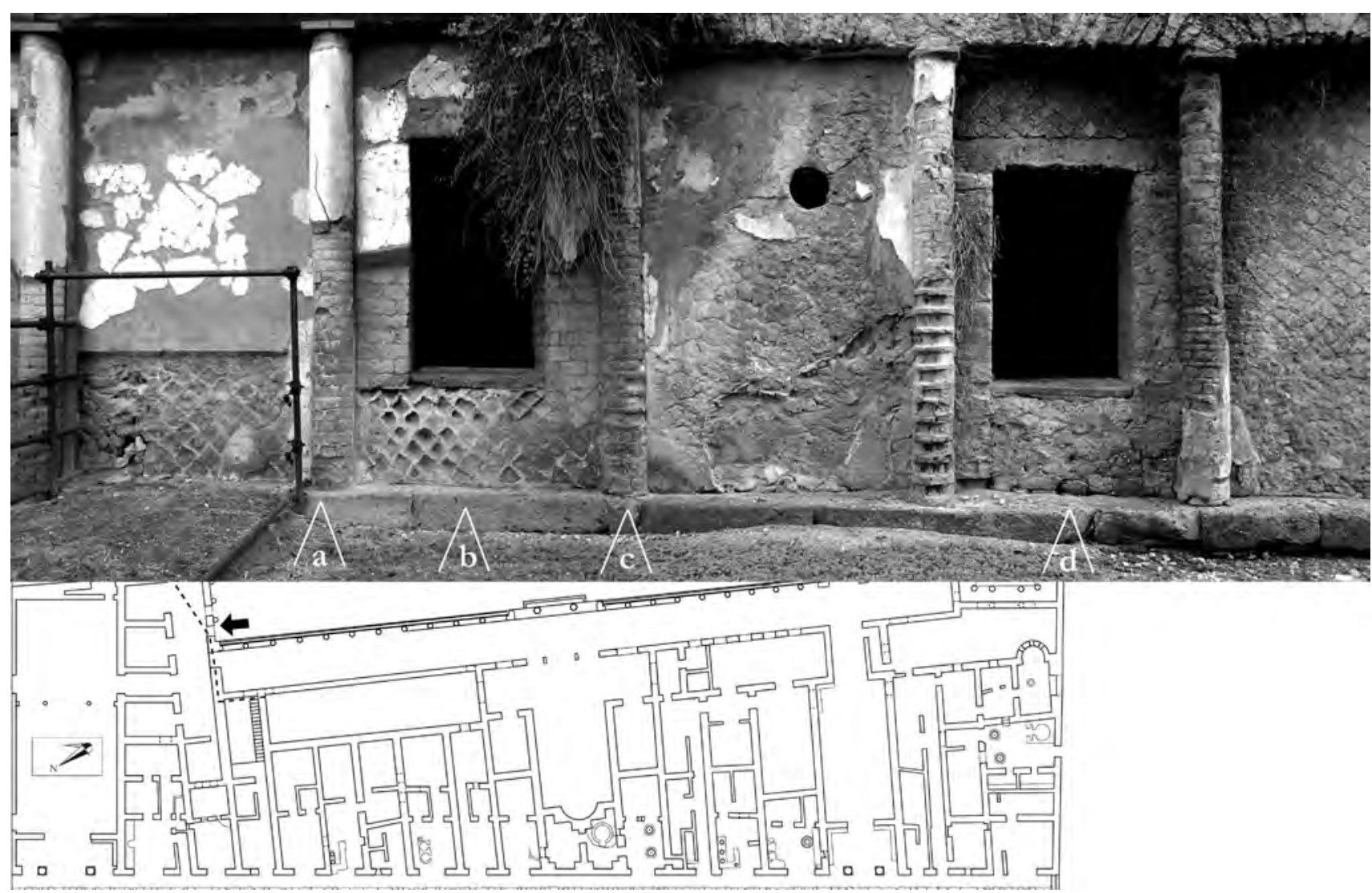

Fig. 121 - Partie ouest du cryptoportique donnant sur de la terrasse inférieure de l'Insula Orientalis II ${ }^{a}$. Les variations dans les maçonneries ne caractérisent pas des changements de phase mais l'emploi progressif de techniques différentes de mise en œuvre. D'abord construites en opus vittatum (a), les colonnes s'appuient sur un massif en opus reticulatum B continu à la base des fenêtres (b). Elles sont ensuite construites en opus vittatum mixtum à une assise de briques (c), alors que la base des fenêtres n'est plus construite de façon continue, mais dans un second temps du chantier (d).

inférieur, la loggia. Cette césure, signe d'un adossement, implique que la partie occidentale de cet espace a été construite avant son développement vers l'est ${ }^{10}$. Cette division est également visible depuis la terrasse supérieure (fig. 122). F. Yegül soutient l'hypothèse de deux édifices successifs en mentionnant la continuité de la corniche du cryptoportique au-dessus de l'aile ouest de la colonnade ${ }^{11}$. Cependant, on ne saurait recourir à une corniche intégralement reconstruite dans les années 1950 pour justifier deux phases. De plus, d'un point de vue strictement formel, l'arrêt

${ }^{10}$ Pagano 1996 a: 244 ; contra Maiuri 1958 b: 135.

11 "The continuation of the cryptoporticus cornice behind the west colonande indicates that the construction brutal de la corniche aurait été particulièrement inesthétique. Enfin, l'étude des peintures menée par D. Esposito a montré que les fresques découvertes dans les pièces de la loggia et dans celles flanquant l'Aula absidata sont contemporaines et comportent des éléments renvoyant aux phases $\mathrm{Ib} / \mathrm{Ic}$ du III ${ }^{\mathrm{e}}$ style (10 av. J.-C. / 25 ap. J.-C.) ${ }^{12}$. Je considère donc que, faute d'arguments probants, l'unité de conception entre les différents ensembles ne fait pas de doute, et qu'on ne saurait restituer un premier bâtiment limité au cryptoportique et à la loggia.

of the north wing preceded the others » (Yegül 1996: 376 et fig. 12 p. 378).

${ }^{12}$ Esposito 2005: 123-126. 


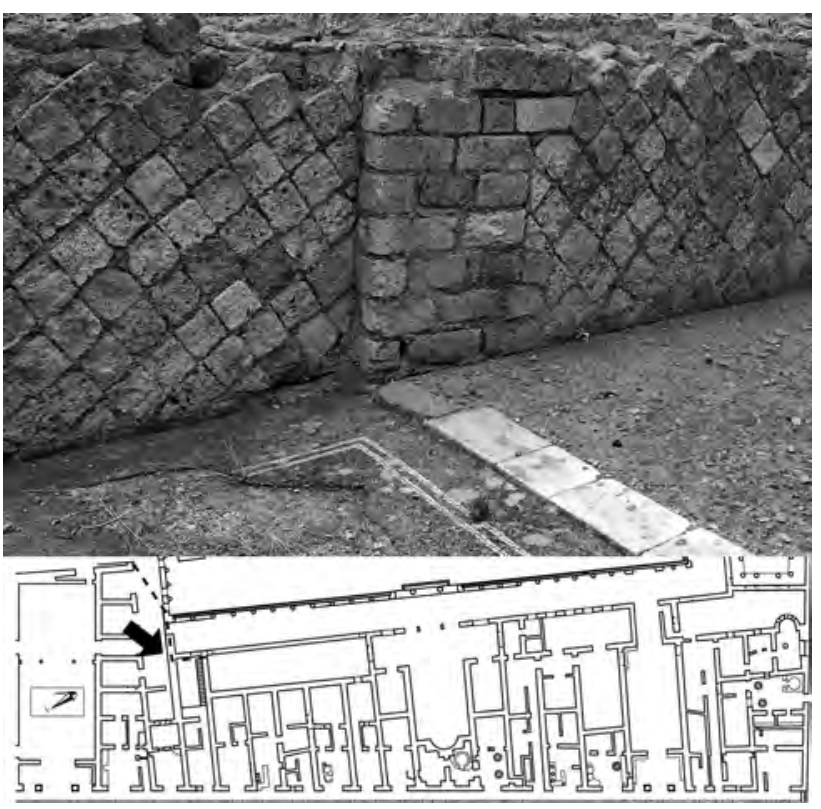

Fig. 122 - Pièce 19-3, loggia de l'Insula Orientalis $I^{a}$, mur sud. Limite verticale dans la maçonnerie originelle montrant que le cryptoportique s'appuie sur les constructions constituant l'angle nord-ouest de la «Palestre» (cliché pris du nord-est).

Avant d'esquisser les rythmes du chantier et de proposer une restitution du projet initial, il convient de revenir sur la question de la datation. Les sondages effectués dans le vestibule Or. II, 4 et dans l'entrée Or. II, 19 indiquent que les travaux de terrassement préalables à la construction contenaient du matériel remontant à la période augustéenne ${ }^{13}$. Une étude des terres cuites architecturales découvertes au cours du dégagement de l'Insula Orientalis $I I^{a}$ a fait proposer à M. Pagano le terminus ante quem de 29 ap. J.-C. pour la pose de la toiture. Cette suggestion est liée aux nombreuses tuiles augustéennes employées, parmi lesquelles certaines provenant des figlinae supposées appartenir à Livie $^{14}$. Si les tuiles découvertes sont essentiellement augustéennes, il convient de rester prudent: l'année 29, date de la mort de Livie, peut n'avoir aucun rapport avec la production de ces tuiles et encore moins avec leur mise en

\footnotetext{
${ }^{13}$ Pagano 1993 a: 598-599; Pagano 1996 b: 189.

${ }^{14}$ Pagano 1990: 172; Pagano 1996 a: 243. Dix tuiles portent des timbres indiquant un lien avec Livie: 5 sont marquées Abdae Liviae (CIL X, 8042, 41, a); deux Damae Liviae (CIL X, 8042, 41, b-c); trois Hilari Liviae.
}

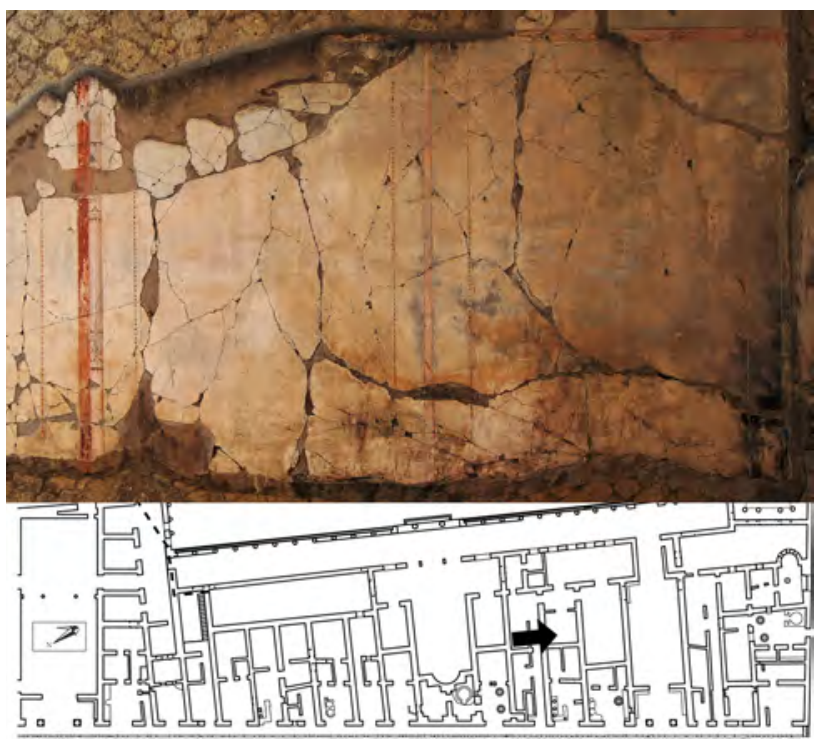

Fig. 123 - Insula Orientalis $I I^{a}$, pièce B, mur sud. Vestiges d'une fresque de III ${ }^{\mathrm{e}}$ style correspondant à la décoration du projet initial (cliché pris du nord).

œuvre. Toutefois, cette datation pour la finition du bâtiment correspond sensiblement aux informations apportées par les peintures correspondant à la première phase du bâtiment. Peu de parois ont conservé leur décoration. Outre les éléments renvoyant à la loggia et aux pièces flanquant l'Aula absidata déjà cités, deux pièces tout à la fois suffisamment préservées et également comparables dans leurs styles permettent de proposer une datation. La première est la pièce A, située au sud de l'Aula absidata. L'enduit est essentiellement conservé sur les murs ouest et sud (fig. 123) ${ }^{15}$. Seule cette dernière paroi permet encore une identification stylistique pour les zones médiane et supérieure. La partie médiane est divisée en panneaux par des colonnes blanches décorées d'anneaux sécants et de colliers à dents de loup. Ces colonnes semblent s'appuyer sur un pilastre rouge. Dans chaque panneau, un cadre est délimité par des guirlandes rectilignes.

\footnotetext{
${ }^{15}$ Sur le mur nord, seuls des fragments de la partie basse sont conservés, désormais illisibles.
} 
La zone supérieure n'est conservée que dans l'angle supérieur droit du mur sud. Deux guirlandes, l'une tendue, l'autre pendante partent d'un édicule dont les contours sont désormais effacés. La seconde pièce, 1a-8 (Maiuri F), se situe dans la portion méridionale du bâtiment, accessible depuis l'entrée Or. II, 2 et, au moment de l'éruption, depuis la boulangerie Or. II, 1a. Sur le mur ouest, le socle est relativement bien conservé. Sur un fond noir, des lignes se croisent en formant des croix prises dans des carrés sur pointe (fig. 124). La zone médiane est divisée en panneaux par des colonnes dont les motifs ont disparu. Dans ces panneaux, des cadres sont dessinés par une ligne blanche sur une bande peut-être noire. Enfin, dans ces deux pièces le premier pavement est composé par des tesselles noires, fines (inférieures à 7-8 mm) en rang oblique. Deux lignes de trois tesselles blanches en rang rectiligne forment une bordure ${ }^{16}$. Le cadre médian est également composé d'une ligne de trois tesselles blanches. Ces différents éléments décoratifs renvoient tous au $\mathrm{III}^{\mathrm{e}}$ style, plus particulièrement à sa phase IIa selon la typologie de L.F. Bastet et M. de $\operatorname{Vos}^{17}$. La décoration de la pièce voisine 1a-7 (Maiuri D) a également été attribuée à la phase $\mathrm{II}$ du $\mathrm{III}^{\mathrm{e}}$ style par E. Moormann, après avoir restitué la fresque à partir de fragments emportés lors des fouilles du XVIII ${ }^{\mathrm{e}}$ siècle $^{18}$. Cette interprétation permet de proposer une datation vers 25-35 ap. J.-C. pour la fin du chantier.

Bien qu'il soit impossible de déterminer avec précision à quel moment a été entrepris ce chantier, inscrit dans la période augustéenne, il s'est nécessairement agi d'une opération longue, que l'on considère le terminus ante quem de M. Pagano ou la datation suggérée par les fourchettes stylistiques. En déterminant que l'ensemble de l'édifice avait été construit en une seule période, des adaptations dans les techniques de mise en œuvre ont déjà été notées. Outre les petites transformations dans

${ }^{16}$ Dans la salle B du corps central, ces tesselles n'ont été observées que sur quelques rangs en raison de la pose d'une couche de béton lors d'une phase successive. La restitution des lignes en tesselles blanches sur le bord est hautement probable.

${ }^{17}$ En ce qui concerne les deux pavements en mosaïque,

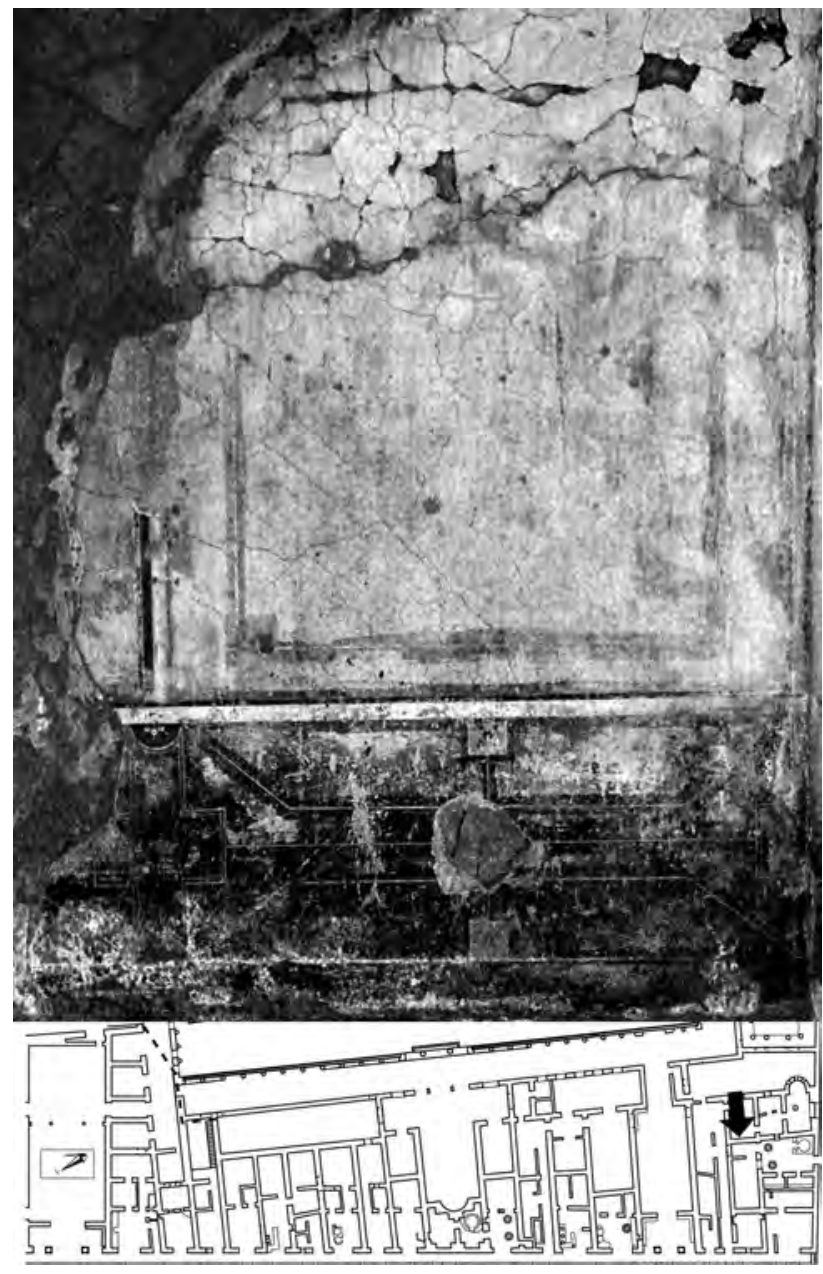

Fig. 124 - Insula Orientalis $I I^{a}$, pièce $1 \mathrm{a}-8$, mur ouest. Fresque de $\mathrm{III}^{\mathrm{e}}$ style correspondant à la décoration du projet initial, préservée dans une boulangerie au moment de l'éruption.

la confection des fenêtres du cryptoportique, un changement plus conséquent peut être mis en évidence: l'adoption partielle de l'opus vittatum mixtum à un rang de briques pour la construction de certains montants de portes ou de fenêtres. En effet, les utilisations de ce type de mise en œuvre sont particulièrement concentrées. À

on notera l'inversion de couleur, avec une dominante noire au lieu de blanche (Bastet - de Vos 1979: 110). Pour les caractéristiques de la phase IIa, cf. Bastet - de Vos 1979: 53-61.

18 Moormann 1986, part. 131. Cf. également Esposito 2005 : 133-134. 
l'exception des colonnes partiellement engagées en façade du cryptoportique, aucun emploi de cet opus n'est connu au nord de l'Aula absidata (fig. 112 et 120). Cette absence pourrait être due au recours, après le second séisme, à l'opus vittatum mixtum à deux rangs de briques pour effectuer des réparations. En plus de cette répartition concentrée à l'échelle de l'édifice, deux autres faits sont intrigants. Tout d'abord, tous les montants de la zone sud ne sont pas construits selon cette technique. Au rez-de-chaussée, seuls les angles situés à l'extérieur du bloc méridional (Or. II, 1a-3) sont érigés de cette façon. Entre l'entrée Or. II, 4 et l'Aula absidata, la répartition est identique, à l'exception de la porte au nord de la pièce $\mathrm{A}$, je vais y revenir. De plus, c'est également dans cette partie du bâtiment que le $V m$ simple est attesté dans les étages, sans schéma de répartition strict, non seulement sur les façades mais également pour certains murs de refend. Le second point problématique se situe dans la pièce $B$. Le mur nord est percé de deux ouvertures dont les montants sont, au rezde-chaussée, en opus vittatum mixtum simple et, à l'étage, en $V m^{2}$ et en $V m$ simple. Dans le chapitre précédent, j'ai assigné l'utilisation de deux assises de briques aux restaurations consécutives au second séisme. Telles qu'elles peuvent être observées, ces deux ouvertures sont actuellement bouchées. Seule celle du rez-de-chaussée peut avoir été une porte: à l'étage, les encastrements pour les solives correspondant au plancher de circulation ne sont visibles que sur la face nord du mur, mais pas à l'intérieur de la pièce A (fig. 125-126). Le montant oriental de la porte est partiellement recouvert d'un enduit qui, bien qu'il soit très dégradé, ne peut que correspondre à la décoration déjà décrite pour cette pièce, soit une fresque de $\mathrm{III}^{\mathrm{e}}$ style réalisée à la fin des travaux.

Dans cette situation particulière, deux hypothèses peuvent être présentées. La première correspond au postulat minimal - mais pouvant être amendé - de l'archéologie du bâti : à chaque type de maçonnerie correspond une phase de transformation ou de réparation dans un édifice. Cette suggestion implique que peu après la construction initiale, avant qu'une décoration ne soit mise en place - si tant est qu'elle ait laissé des traces - le bâtiment a subi une première transformation importante. Cette hypothèse

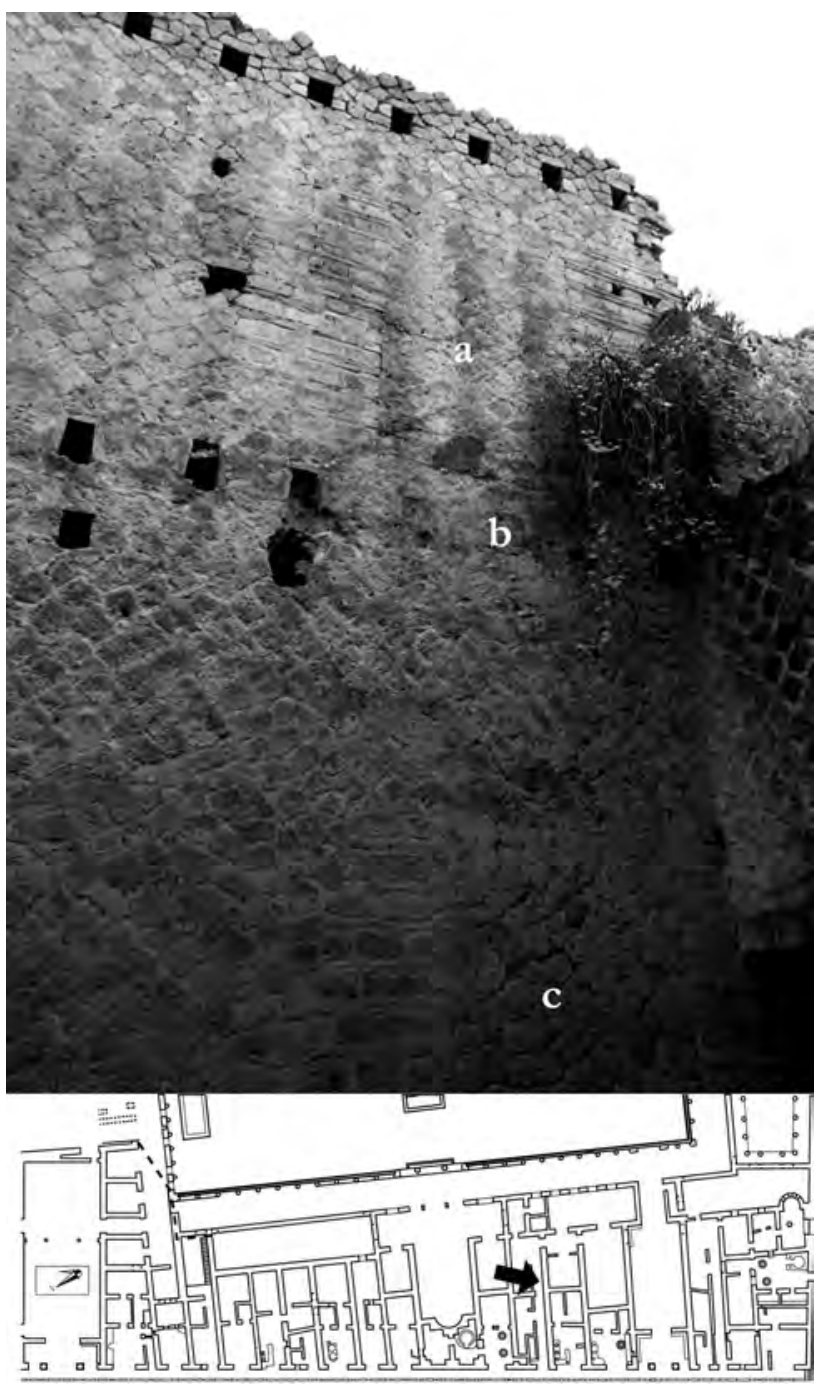

Fig. 125 - Insula Orientalis $I I^{a}$, pièce 7-4, mur sud. De haut en bas, fenêtre donnant sur la pièce A, bouchée lors de la dernière phase (a); ligne de solives soutenant le plancher (b) ; porte bouchée constituant une révision du projet initial avant qu'il ne soit mené à terme (c).

semble délicate à suivre, tant les données provenant des sondages et de la datation des styles picturaux sont cohérentes, même si elles impliquent un chantier de longue durée. Une seconde interprétation plus raisonnable, d'autant qu'elle permet de prendre en compte toutes les utilisations de l'opus vittatum mixtum simple dans ce bâtiment, peut être proposée. Ainsi, on pourrait considérer que l'utilisation partielle de cette mise en œuvre pourrait être le fait d'un changement de technique propre à une autre équipe de maçons, intervenue dans la seconde partie de la 


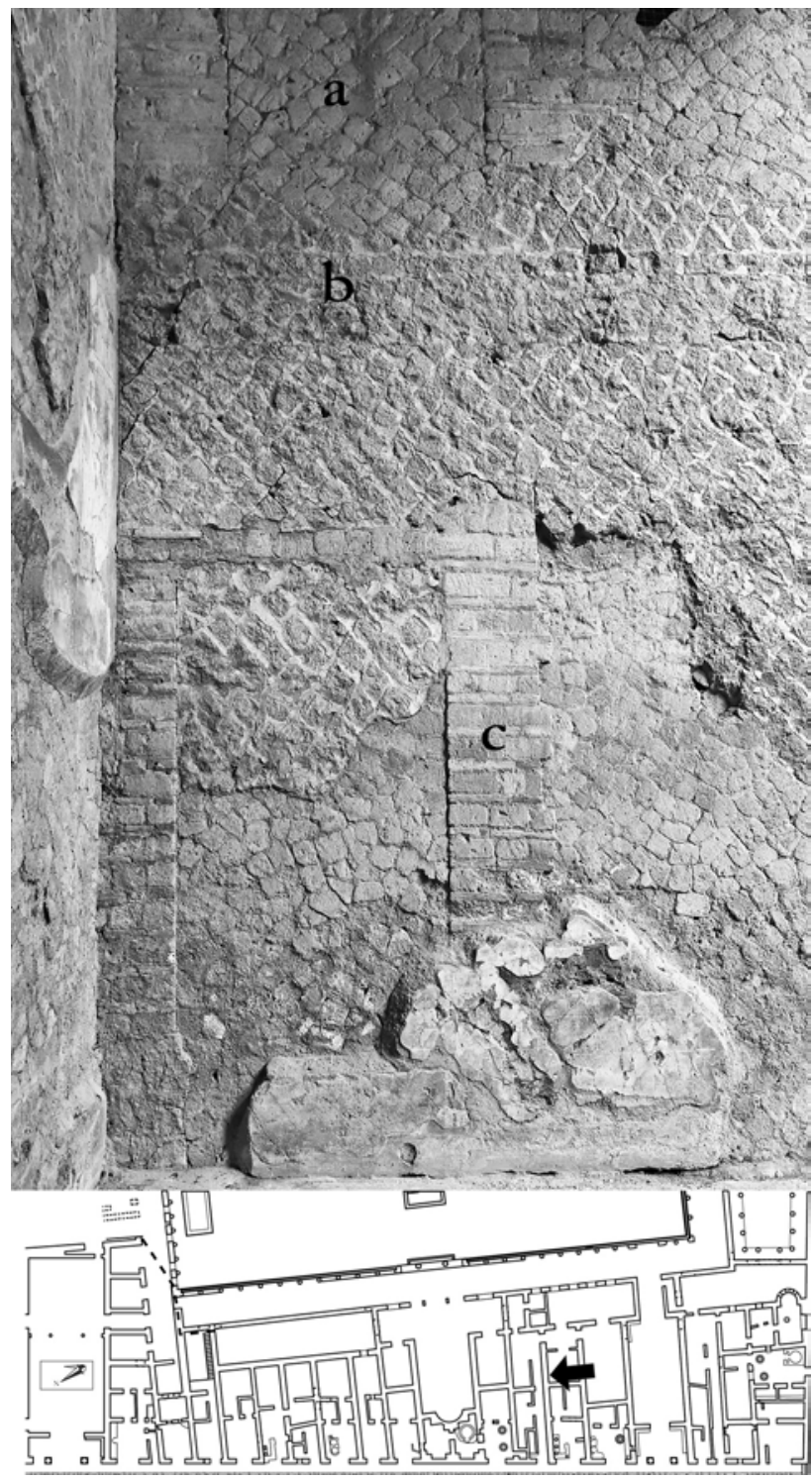

Fig. 126 - Insula Orientalis $I I^{a}$, pièce A, mur nord. Même paroi que dans la figure précédente, vue de l'autre côté. On notera que sous la fenêtre (a), aucune solive ne soutient le plancher en (b). En bas, le montant oriental de la porte (c) est recouvert d'un enduit correspondant à la décoration initiale, indice de révision du projet initial.

construction. À l'appui de cette idée, je citerai principalement le changement de technique de construction pour les colonnes partiellement engagées en façade du cryptoportique. De plus, la porte dans le mur nord de la pièce A pourrait être attribuée à un léger remaniement de certains détails du projet d'ensemble, peu avant sa finition. En effet, rien, exception faite de sa

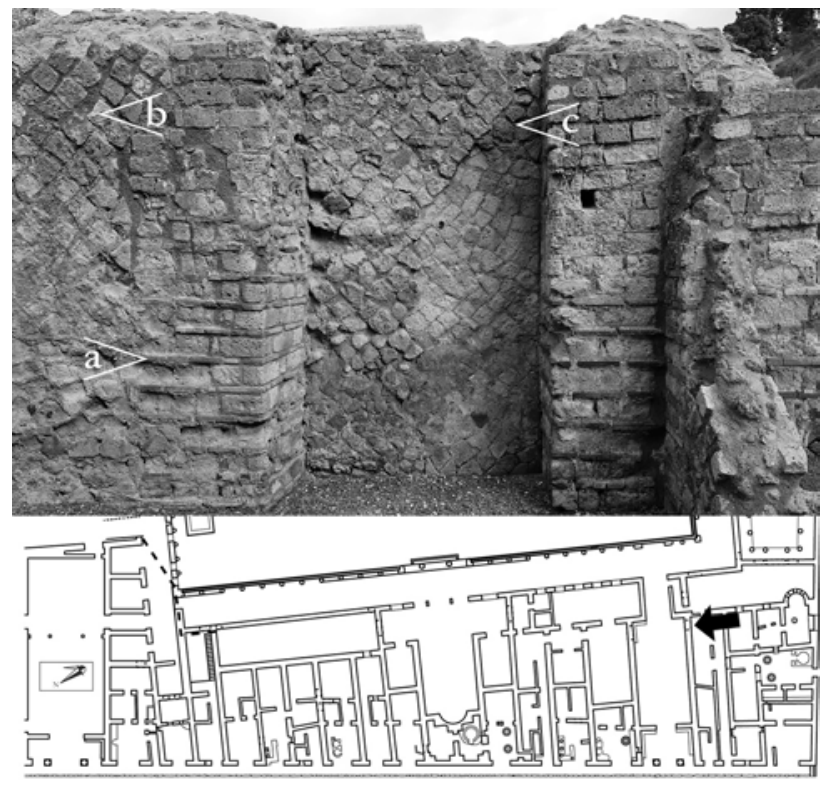

Fig. 127 - Insula Orientalis $I I^{a}$, pièce 1a-10, mur nord. Le montant occidental est construit, dans sa partie inférieure, en opus vittatum mixtum à une seule rangée de briques et dans sa partie supérieure en opus vittatum (a). On note une différence d'aspect entre l'opus reticulatum B de la paroi (b) et celui du bouchage de la porte (c), signe que cette fermeture s'est déroulée dans une phase postérieure à la construction initiale.

position, ne permet de distinguer l'opus reticulatum B qui bouche cette porte de celui qui a été employé pour réaliser le reste du mur. Les autres cas observés de bouchage, quand ils sont réalisés sans utiliser du tout-venant, montrent toujours une différence entre les moellons du mur initial et ceux qui ferment le passage (fig. 127). Il ne faudrait pas considérer ce remaniement du projet comme un simple passage «de chantier». Si tel avait été le cas, si l'ouverture avait été destinée à être complètement bouchée à l'achèvement des travaux, seul le linteau aurait bénéficié d'un support aménagé, comme c'est le cas dans la façade entre les entrées Or. II, 8 et Or. II, 9 (fig. 117, f).

Au-delà de la précision apportée à l'utilisation de l'opus vittatum mixtum simple, qui tout en appartenant à l'unique phase de construction de cet édifice, peut être assignée à la première phase post-augustéenne pour le reste de la ville, ces éléments autorisent à retracer les grandes lignes du chantier. Dans la zone dégagée de l'édifice, le point de départ apparaît être l'en- 
trée Or. II, 19: elle seule se situe en situation d'alignement avec un axe viaire préexistant; les étapes de construction mises en évidence par M. Pagano dans la façade du cryptoportique indiquent également qu'elle été construite la première. À l'est, ces premiers travaux incluent le squelette du cryptoportique, sans toutefois que ne soient alors érigées les colonnes engagées audelà de la quatrième. Il est probable que la voûte du cryptoportique soit également construite durant cette tranche. En revanche, les éléments se développant sur l'extrados de cette voûte, soit la loggia, les pièces 19-6, 19-7 et les espaces se développant à l'est de celles-ci sont construits ultérieurement. La seconde tranche des travaux comporte la construction de l'aile occidentale, avec l'excavation d'une fosse septique à l'ouest de cette aile; les nouvelles constructions s'appuient sur le premier bloc et se développent vers le sud ${ }^{19}$. C'est à environ la moitié de ces travaux qu'est introduite la nouvelle technique de l'opus vittatum mixtum à un rang de briques. Enfin, la dernière tranche de gros œuvre correspond à l'édification de l'aile nord, soit la loggia proprement dite et les salles connues se développant à l'est de l'entrée Or. II, 19. C'est au cours de cette ultime fraction des travaux que les dernières colonnes du cryptoportique sont érigées et que la partie basse des fenêtres est bouchée. Après l'édification de la majeure partie du gros œuvre, des transformations concernant les accès et le plan de circulation ont été entreprises, amenant ainsi à la fermeture de certaines portes. Finalement, entre la fin des années 20 et le début des années 30 de notre ère, le système décoratif a été achevé après avoir été réalisé du nord au sud, si l'on peut se fier aux légères différences d'attributions stylistiques observées de part et d'autre d'une ligne située au sud de l'Aula absidata.

\footnotetext{
${ }^{19}$ Les observations effectuées par D. Camardo (WallaceHadrill - Guidobaldi - Camardo - Moesch 2008: n. 19) dans la fosse septique qui se développe sous la façade de l'îlot s'accordent avec ce point: l'aile occidentale a été construite du nord au sud.

${ }^{20}$ L'évolution des interprétations d'A. Maiuri concernant cet îlot est exposée supra, p. 23-24.

${ }^{21}$ Cit. supra, p. 235.

${ }^{22}$ Comptes rendus de C. Weber datés du 19 juillet 1757 et du 5 novembre de la même année (cit. in Ruggiero 1885: 231-232, 245). Après la découverte du 18 juillet, les autres
}

VI.1.2 Réflexions sur la fonction du bâtiment public

L'Insula Orientalis $I I^{a}$ a été interprétée de plusieurs manières depuis sa découverte partielle au XVIII ${ }^{\text {e }}$ siècle. La détermination des fonctions d'un bâtiment qui ne saurait recevoir de réponse univoque dépasse de loin le cadre de ce travail. Toutefois, les faits disponibles permettent de réfuter définitivement l'interprétation proposée par A. Maiuri qui donne un rôle principal de palestre à l'édifice. Certains éléments et une partie du raisonnement ayant conduit ce dernier à proposer cette identification ont déjà été présentés ${ }^{20}$. Je me contenterai donc de reprendre ici les arguments principaux pour voir leur adéquation avec les faits archéologiques et surtout épigraphiques.

L'essentiel du problème tient à l'inscription CIL X, 1406 qui évoque des réparations effectuées par Vespasien dans le temple de la Magna Mater $^{21}$. Le lieu de découverte de cette plaque est signalé avec une remarquable précision par les comptes rendus, d'autant plus que des plans schématiques accompagnent le texte:

De priessa doy parte á V.S. como ayer á la tarde se ha empezado descubrir en el palacio de la Vénere y propiamente en la misma cámara continuando la grutas sin plano, en aire ó $1^{\circ}$ apartamento encima las grutas viejas caitando todo de paranza, una famosa inscripcion que se ha descubierto una porcion o pedazo como sigue con bellos caracteres grandes y se va descubriendo el restante hasta medio dia que son dos otros pedazos [...].

En la masseria de Bisogno toda la roba encontrada estava en el Templo positivamente dentro y al lado que mira al mar, però al ciel de la tercera gruta una encima de la otra que sera cerca 21 pal. en aire encima del plano conforme la Venere, Mercurio y inscripcion, ninguna cosa estava en el plano todo se hallava en alto $^{22}$.

fragments ont été extraits le 20 juillet (cf. Ruggiero 1885: 232). L'entrée Or. II, 4 est décrite dans un long rapport daté du 6 août 1757 (cit. in Ruggiero 1885: 233-234), accompagné d'un schéma indiquant la position des fragments de l'inscription, alors signalés sans précision d'altitude, mais en mentionnant qu'ils sont au niveau du deuxième étage: "quando se havrá acavado quitar todo de paranza, iremos enzima del astrago, donde esperamos ser un $2^{\circ}$ orden ó apartamiento, y viene ser de que la isncripcion quedará á los pies de los escavadores ». 
Transposées sur le site tel qu'il a été mis au jour dans les années 1930, ces données permettent de déterminer que l'inscription a été découverte en quatre morceaux, peu distants les uns des autres, à environ 5,50 $\mathrm{m}$ de hauteur par rapport au sol de l'entrée dans le vestibule Or. II, 4. Si l'on suit les schémas insérés par M. Ruggiero, les fragments proviennent de la portion occidentale du vestibule, alors appelée antetempio. En effet, ils ont été trouvés immédiatement au-delà de la salle voûtée dont le plafond était décoré de 956 étoiles, dont certains fragments ont été mis au jour en 1931, dans la deuxième salle après l'entrée Or. II, $4^{23}$. Comme l'a fort justement fait remarquer G. Guadagno, le refus de l'identification de l'Insula Orientalis IIa avec le templum Matris deum par A. Maiuri tient exclusivement à une erreur d'appréciation des comptes rendus concernant l'état de la voûte décorée d'étoiles ${ }^{24}$. Alors que les fouilleurs du XVIII ${ }^{\mathrm{e}}$ siècle l'ont découverte déjà abattue comme l'indique l'expression boveda caida, A. Maiuri suppose dans son texte que ce sont eux qui l'ont mise à bas:

Purtroppo di questo monumentale ingresso, dopo il malaugurato scavo che se ne fece negli 1757-1758, non ci resta che lo scheletro, oltre alle molte confuse descrizioni e alle assurde denominazioni dei rapporti di scavo, mentre l'edificio era ancora per la robustezza delle sue strutture intatto, tanto che il Weber poté, in quelle tenebre, numerare le 956 stelle dipinte sulla volta $[\ldots]^{25}$.

Dans son raisonnement, il avait pourtant suggéré, en note, la seule interprétation que l'on puisse donner à cette inscription :

L'iscrizione fu rinvenuta nelle parti alte dell'edificio [... citation des différents comptes rendus et schémas ...]. Lepigrafe dunque si sarebbe trovata al di sopra dell'architrave della porta, in funzione di vera e propria epigrafe dedicatoria e commemorativa [je souligne]; ma poichè il muro del pronao della grande aula si rinvenne abbattuto e il Weber, pur tanto diligente, nulla ci dice della incassatura in cui avrebbe dovuta essere contenuta,

${ }^{23}$ GSE 1931: "3 dicembre. Nello sterro del tempio della dea madre si sono raccolti numero tre stelle di stucco che decoravano le volte». Cf. également Maiuri 1958 b: 120. Dans sa remarquable étude, sur laquelle toutes mes remarques se fondent, G. Guadagno (1981 : 135-136 ; 1995 : 120-122) estime que la plaque inscrite aurait été trouvée « $a$ conttato con la porta di comunicazione tra portico monumentale e vestibolo interno", soit au dessus de la porte du vestibule comportant la voûte étoilée. Peut-être le point dobbiamo dedurne che l'iscrizione già frammentata fosse trasportata in quel luogo dalla corrente alluvionale che aveva defluito a più riprese lungo il $5^{\circ}$ cardine $[\ldots]^{26}$.

M. Pagano, qui refuse sans explication les interprétations de G. Guadagno, a proposé deux hypothèses pour expliquer cette découverte ${ }^{27}$. D’une façon générale, il exclut le transport par les flux pyroclastiques. Sa première hypothèse consiste à supposer une présence temporaire en attendant une remise en place. Pour justifier ce point de vue, il dresse un parallèle avec l'inscription $C I L \mathrm{X}, 932$, attribuée à Pompéi, mais dont les travaux de G. Guadagno ont montré qu'elle avait été découverte appuyée contre un mur en attendant d'être remise en place ${ }^{28}$. Une telle interprétation ne saurait s'appliquer à une plaque découverte à plus de 5 mètres du sol. M. Pagano propose une seconde hypothèse, qu'il écarte immédiatement pour sa faiblesse, selon son propre aveu: l'inscription aurait été insérée dans la maçonnerie pour faire référence à un édifice situé ailleurs, en raison d'une visibilité plus grande. Refermons la question concernant la position et l'interprétation de cette inscription en citant G. Guadagno:

Una volta per tutte si deve affermare senza mezzi termini che il testo epigrafico è stato trovato ancora nel suo contesto e che il templum Matris deum, inserito nel programma vespasianeo di interventi di restauro dei danni da terremoto, è da identificare con il complesso gravitante intorno alla vasta area porticata interna alla Ins. Or. $I I^{29}$.

Les données épigraphiques et de fouilles permettent d'inscrire un temple de Cybèle dans l'Insula Orientalis $I I^{a}$. Il convient cependant de préciser certains points dérivant de l'interprétation de l'ensemble comme une palestre. Le premier élément à discuter est le rapport avec la palestre de Pompéi. Comme souvent, A. Maiuri n'expose que de façon diffuse les points de

de découverte peut-il être décalé de quelques mètres vers l'ouest.
${ }^{24}$ Guadagno 1995: 120.
${ }^{25}$ Maiuri 1958 b: 118 .
${ }^{26}$ Maiuri 1958 b: n. 59 p. 190.
${ }^{27}$ Pagano 1996 a: 245-246 et n. 87 p. 243.
${ }^{28}$ Guadagno 1981: n 67 p. 131-132.
${ }^{29}$ Guadagno 1995: 122. 
comparaison entre les deux édifices, bien que la découverte de la palestre pompéienne ait eu une influence décisive sur l'interprétation de l'édifice d'Herculanum ${ }^{30}$. Il souligne la similitude de plan: une aire découverte, entourée par un portique, bénéficiant d'une piscine en son milieu. Certains détails architecturaux sont également comparés, comme la présence d'un fronton surélevé en position centrale, la différence d'altitude entre le sol de l'aire découverte et le portique - pour corriger l'aspect massif des colonnes - et enfin la présence d'arbres. Les quelques différences ne seraient dues qu'à la configuration du terrain et à un léger décalage temporel dans la construction $^{31}$. Ces rapprochements restent discutables. Si la surélévation d'un fronton central se retrouve dans les deux édifices, il souligne une petite salle de $52 \mathrm{~m}^{2}$ à Pompéi tandis qu'il donne accès à l'Aula absidata et aux deux salles qui la flanquent à Herculanum $\left(266 \mathrm{~m}^{2}\right.$, au moins 11,30 m sous la voûte). Les difficultés de rapprochement entre les deux édifices ne se résument pas seulement à un problème de grandeur: la palestre de Pompéi dispose d'une surface découverte $\left(13.490 \mathrm{~m}^{2}\right)$ largement supérieure à celle d'Herculanum $\left(3700 \mathrm{~m}^{2}\right)$. La seule présence des différentes constructions autour du portique herculanéen suffit à montrer un usage différent. La forme en croix et la faible profondeur du bassin sont suffisantes pour souligner une

${ }^{30}$ Cf. supra, p. 23.

${ }^{31}$ Maiuri 1958 b: 116, 136, 142 et n. 75, 77 p. 191.

32 "A differenza della Palestra di Pompei, dove la gran vasca quadrangolare centrale, con il fondo digradante, ha il carattere di una vera e propria natatio, la piscina della Palestra ercolanese non poteva invece avere altro uso all'infuori di quello d'una frigida lavatio [...]» (Maiuri 1958 b: 137). Les bras du bassin à Herculanum sont de $55 \mathrm{~m}$ (nordsud) et $35 \mathrm{~m}$ (est-ouest). Leur largeur est de 5,80 m, leur profondeur à peine supérieure à $1 \mathrm{~m}$. La piscine pompéienne mesure $22 \mathrm{~m}$ de large pour $34 \mathrm{~m}$ de long. Sa profondeur varie de 1 à 2,6 m (NSc 1939: 186-190). Bien que conservant l'interprétation d'A. Maiuri, F. Yegül (1993: 380) souligne l'absence de véritable parallèle - au-delà d'une description générale - entre la «Palestre» d'Herculanum et celle de Pompéi.

${ }^{33}$ Contra Maiuri 1958 b: 116-117; Yegül 1993 : 383-389; Pagano 1996 a: 243-246.

${ }^{34}$ AE 1947, 53 = AE 1976, 144: [Qu]od M(arcus) Ofillius Celer IIviriter (um) v(erba) f(ecit) pertinere at municipi / dignitatem meritis $M$ (arci) Noni Balbi respondere d(e) e(a) r(e) i(ta) c(ensuerunt) / [cu]m M(arcus) Nonius Balbus quo hac différence majeure entre les deux édifices: celle d'Herculanum ne permettait pas la natation, mais seulement des ablutions ${ }^{32}$. Sans même mentionner l'inscription à l'entrée du complexe, écartés quelques lointains rapprochements formels, les deux édifices ne sauraient guère être comparés du point de vue de leur fonction. L'Insula Orientalis $I I^{a}$ n'a certainement pas eu de rôle de palestre ou de campus permettant la réunion de la juventus d'Herculanum ${ }^{33}$.

Le second point qui mérite d'être discuté n'est qu'une conséquence secondaire de cette interprétation. En effet, la découverte en 1942 du monument contenant les cendres de M. Nonius Balbus $^{34}$ a permis à A. Maiuri de justifier l'existence d'une palestre sur le modèle grec à Herculanum. Parmi la liste des honneurs rendus à la mémoire de l'évergète, on trouve la mention de ludi gumnici (l. 9): au cours de la célébration de ceux-ci, une journée aurait été dédiée à M. Nonius Balbus. Rien ne permet cependant de placer leur déroulement dans l'Insula Orientalis $I I^{a}$ comme l'a fait A. Maiuri, ou encore d'impliquer la juventus dans leur organisation ${ }^{35}$. Les seuls points de topographie mentionnés sont d'une part le monument sur lequel est apposée l'inscription - qui deviendrait le point de départ de la procession faite au cours des Parentalia, fête des morts se déroulant dans la neuvaine s'achevant le 21 février (1. 8-9) ${ }^{36}$-, et d'autre part

vixerit parentis animum cum plurima liberalitat(e) / singulis universisque praistiterit placere decurionibus statuam equestrem ei poni quam / celeberrimo loco ex pecunia publica inscribique M(arco) Nonio M(arci) f(ilio) Men(enia) Balbo pr(aetori) proco $(n) s(u l i)$ patrono universus /ordo populi Herculanie(n)ssis ob merita eius item eo loco quo cineres eius conlecti sunt aram / marmoream fieri et constitui inscribique publice $M$ (arco) Nonio $M$ (arci) f(ilio) Balbo exque eo loco parentalibu(s) / pompam duci ludisque gumnicis qui soliti erant fieri diem edici unum in honorem eius et cum in Theatro / ludi fient sellam eius poni c(ensuerunt).

${ }^{35}$ Maiuri 1942 b: 277-278.

${ }^{36}$ A. Maiuri (1942 b: 277) considère qu'il s'agirait de l'anniversaire du décès. L'absence de mention de la date reste étonnante; l'association entre ces Parentalia et la fête romaine semblerait plus probante, nonobstant le caractère privé des rites associés à cette fête: décrété patron de la cité par cette même inscription, la relation entre l'ensemble des citoyens et M. Nonius Balbus permettrait alors de faire cette procession. Je remercie vivement N. Laubry pour les discussions que nous avons eues sur cette inscription et sur les Parentalia. 
le théâtre mentionné comme espace de déroulement d'autres ludi, sous-entendus scaenici (1. 9-10). Aucune indication spatiale n'est donnée pour les ludi gumnici. Enfin, je soulignerai également le paradoxe qu'il y aurait à donner des jeux dans un bâtiment pas nécessairement achevé: selon L. Schumacher, il faut identifier M. Nonius Balbus avec le tribun de la Plèbe de 32 av. J. - C.; la date de sa mort, inconnue, est toutefois à placer avant la fin du règne d'Auguste, vraisemblablement vers le changement d'ère ${ }^{37}$. Quand bien même ce personnage serait mort une fois la construction terminée, la mention explicite de l'existence des jeux avant que ces honneurs ne lui soient décernés-ludis gumnicis qui soliti erant fieri (1. 9) - rend l'association entre l'Insula Orientalis $I I^{a}$ et les ludi moins évidente que ne le suggère A. Maiuri. En rejetant l'interprétation de la terrasse inférieure de cet édifice comme lieu des ludi, certaines identifications proposées par A. Maiuri, souvent reprises par la suite, deviennent également caduques. Ainsi, la table en marbre découverte dans l'Aula absidata ne saurait avoir été utilisée comme «mensa agonistica », destinée à l'exposition des prix décernés lors des ludi gumnici ${ }^{38}$. De la même façon, considérer la loggia qui s'ouvre sur la terrasse inférieure comme le lieu de concentration du public venu regarder les jeux est une idée sans fondement autre que l'interprétation de l'édifice comme palestre ${ }^{39}$.

37 Outre les remarquables considérations prosopographiques de L. Schumacher (1976: 165-170), les études stylistiques de G. Schörner (1995: 75) tendraient à confirmer cette datation et l'indentification avec le tribun de la Plèbe de 32 avant notre ère. En raison de l'inscription CIL X, 1425 qui mentionne les (re)constructions effectuées par M. Nonius Balbus dans la basilique, ainsi qu'à l'enceinte - interprétées comme consécutives au séisme de 62 -, A. Maiuri (1942 b: 263-264, 266) considérait la mort de ce personnage comme antérieure de peu à l'éruption et le voyait comme petit-fils du tribun de la Plèbe. En dépit des analyses de L. Schumacher, V. Tran Tam Tinh (1988: 126130) estime que M. Nonius Balbus aurait été le propriétaire de la Casa dei cervi (IV, 21) et maintient l'idée de sa mort sous les Flaviens, se fondant sur l'inscription incomplète CIL X, 1420 - dédicace en l'honneur de Vespasien faite par un M. Noniu[---. Dans l'album de la ville (CIL X, $1403+$ $A E 1978,119)$, vraisemblablement rédigé entre la seconde
Abandonnée l'hypothèse de la palestre, quelques éléments d'identification doivent être proposés. L'articulation générale du plan d'ensemble a déjà été notée. La façade ouest transforme sensiblement le tracé du cardo $\mathrm{V}^{40}$. En revanche, la terrasse inférieure, le cryptoportique et l'Aula absidata flanquée de ses deux salles constituent un ensemble cohérent, sans influence d'aucune sorte de la part des autres monuments de la ville ou des axes viaires. Pour cette partie du bâtiment, la place centrale de l'Aula absidata est évidente. Elle est ainsi soulignée tant par l'alignement avec le bras de la piscine que par l'accès depuis le portique, matérialisé par un fronton tétrastyle dont deux colonnes in antis ${ }^{41}$. L'accès principal à ces trois pièces répond aux ouvertures du portique. Une pièce barlongue $(18,80$ x $5 \mathrm{~m}$ ) précède les trois salles. Les rares vestiges du pavement, fortement endommagé par les galeries du XVIII ${ }^{\mathrm{e}}$ siècle, permettent de restituer une individualisation des trois espaces: la salle principale, au centre, est décorée de carreaux de marbre de couleurs variés du vestibule à l'abside ; les deux autres pièces sont, dans le vestibule, soulignées par l'adoption de carrés de taille plus réduite, disposés en file oblique. La bichromie y est assurée par l'alternance de marbre jaune et de bardiglio $^{42}$. En revanche, à l'intérieur de ces deux pièces, le pavement est constitué par un tapis de tesselles blanches rehaussées d'éclats de marbre. Dans la salle principale, outre la table

moitié des années 60 et le début des années 70 de notre ère (Camodeca 2008: 89), quelques vingt-cinq M. Noni sont attestés, dont onze ingénus, signe d'une implantation déjà ancienne.

${ }^{38}$ Maiuri 1958 b: 125, 142-143.

${ }^{39}$ Maiuri 1958 b:143; Yegül 1993 : 389; Pagano 1996 a : 243.

${ }^{40}$ Aucune explication n'a été proposée pour cette différence d'alignement entre la rue et le trottoir en façade de l'Insula Orientalis $I I^{a}$. Il ne s'agit pas d'un élargissement du cardo V (supra, n. 5 p. 256): le décalage semble trop faible pour pouvoir être expliqué par une adaptation aux courbes de niveaux. Peut-être faut-il y voir une erreur de relevé au début du chantier?

${ }^{41}$ Le fronton est une restitution proposée par A. Maiuri (1958 b: 130).

${ }^{42}$ Sur les pavements en opus sectile de ces salles, cf. Maiuri 1958 b: 124; Guidobaldi - Olevano 1995: 234. 
en marbre à pattes d'aigle disposée au milieu, le mur du fond est percé d'une abside. Aucune statue n'y a été mise au jour, bien qu'une telle disposition la suggère fortement. Cette disposition architecturale tripartite et axiale fait songer à un édifice cultuel. A. Maiuri l'a signalé, mais a immédiatement écarté cette interprétation, difficilement conciliable avec l'identification d'une palestre $^{43}$ : le rapprochement avec l'inscription mentionnant un templum Matri deum au-dessus de l'accès principal à la terrasse inférieure est inévitable. Comme je le soulignais plus haut, l'interprétation proposée par G. Guadagno me semble parfaitement raisonnable et ne souffre guère la discussion: le bassin cruciforme et les trois salles à l'ouest du portique sont le templum indiqué par l'inscription ${ }^{44}$. L'identification des fonctions des salles du cryptoportique est en revanche beaucoup plus malaisée, notamment en raison de leur fouille partielle, rapide et peu détaillée dans les journaux de fouilles. De la même manière, les salles accessibles depuis l'extérieur qui se développent au sud et au nord de l'entrée Or. II, 4, ou encore celles qui se situent à proximité de l'entrée Or. II, 19 et qui donnent sur la loggia, échappent à toute identification ${ }^{45}$. En revanche, en suivant les relectures des documents de fouilles du XVIII ${ }^{\mathrm{e}}$ siècle proposées par M. Pagano, à la fonction cultuelle notamment dédiée à Cybèle pourraient s'être ajoutés des cultes aux divinités égyptiennes, notamment

\footnotetext{
${ }^{43}$ Maiuri 1958 b: 122, cit. supra, p. 255 en exergue. Audelà de cet extrait, A. Maiuri ne cesse, tout au long de sa description de la terrasse inférieure de l'Insula Orientalis $I I^{a}$, d'associer l'Aula absidata à des pratiques religieuses au détour d'une phrase, hypothèse rapidement repoussée pour rappeler la juventus et son entraînement dans la palestre. C'est ainsi qu'il considère que "L'abside era indubbiamente destinata ad accogliere une grande statua di culto o onoraria $[\ldots]$ », ou encore à propos de la table en marbre: «Nessun dubbio per tanto che questa mensa e per le sue inusitate dimensioni e per la sua austera eleganza di forme [...] e, infine, per la sua ubicazione e ben calcolata distanza dall'abside, avesse una funzione essenziale e non semplicemente decorativa; fosse insomma destinata a ceremonie e a riti che si tenevano in questa sala " (Maiuri 1958 b: 124, 125). Finalement il conclue par ces termes: «[...] La grande aula absidata e [le] due sale ad essa adiacenti nel portico occidentale costitu[iscono] il centro religioso architettonico dell'edificio [...]. La grande aula doveva essere consacrata al culto della divinità $\mathrm{o}$, più probabilmente dell'impe-
}

Atoun, dans un second espace religieux situé au nord-est du bâtiment. Récemment, A. Borlenghi, en se fondant sur l'analyse détaillée des inscriptions et du mobilier sculpté retrouvés dans l'Insula Orientalis $I I^{a}$, a suggéré qu'au culte originel de Cybèle ait été associé, sous Vespasien, celui d'Isis et celui de la maison impériale ${ }^{46}$. Enfin, un hypothétique établissement thermal pourrait également se situer dans la frange nord encore ensevelie, à proximité de l'entrée septentrionale de l'édifice ${ }^{47}$.

Je ne saurai proposer en l'état une définition plus précise des différentes fonctions se déroulant dans ce vaste bâtiment. L'interprétation comme palestre doit être abandonnée. La portion connue de cet îlot, du moins sa terrasse inférieure avec le bassin cruciforme, ne peut être identifiée que comme le temple de Cybèle. D'autres cultes ont pu être célébrés dans la partie septentrionale, éventuellement avec d'autres fonctions qui restent délicates à définir.

\section{VI.1.3 L'aile occidentale}

Le second ensemble de cet édifice est constitué par sa façade occidentale. Au moment de l'éruption, elle se présentait comme une file ininterrompue de boutiques et d'ateliers, avec deux accès permettant de se rendre aux appartements situés à l'étage. L'étude des différentes formes de maçonnerie permet de restituer l'as-

ratore o dei principi imperiali sotto la cui protezione era posata l'associazione della Juventus ercolanese» (Maiuri 1958 b: 142).

${ }^{44}$ G. Guadagno (1995: n. 25 p. 127) signale également que selon lui, l'inscription CIL X, 929 (Iulia Hygia / ex visu) correspondrait à la base d'une statue d'Esculape - fréquemment identifiée comme celle d'Isis (cf. Tran Tam Tinh 1971: cat. $n^{\circ} 11$ p. 63). Une telle identification, associée à Cybèle, permettrait d'interpréter le bassin avec sa fontaine en bronze - représentant une hydre enroulée autour d'un arbre - comme une piscina où seraient pratiquées des ablutions dans une eau disposant de vertus médicinales. Cette interprétation de l'inscription CIL X, 929 a été critiquée par M. Pagano (1996 a: 246-247) qui suggère d'y voir plutôt une copie de l'Aphrodite de Daphni.

${ }^{45}$ Sur l'aspect de ces salles lors du projet initial, cf. infra, p. 272.

${ }^{46}$ Borlenghi 2006: 257-258.

${ }^{47}$ Pagano 1996 a: 245. 
pect initial de cette construction, qui a subi plus de transformations que ne l'a supposé A. Maiuri $(\text { pl. I, h.t. })^{48}$.

La restitution que je propose ici se fonde sur un relevé des maçonneries en opus reticulatum B, en opus vittatum et en opus vittatum mixtum à une assise de briques. Les passages qui ont été fermés dans une seconde phase sont relativement aisés à percevoir grâce à la conservation des montants. En revanche, en plusieurs points, j'ai considéré qu'une portion de mur continuait dans le projet originel là où une ouverture a été mise en évidence lors de la fouille: fréquemment de telles fenêtres et portes se sont avérées être des percements réalisés sans soin et surtout sans assurer l'ouverture par la mise en place de montants particuliers. L'exemple le plus clair est constitué par l'entrée Or. II, 2: que l'on tienne ou non compte des restaurations effectuées au moment de la fouille, le montant sud de la porte est exclusivement construit en opus reticulatum B, maçonnerie peu propice au maintien des montants (fig. 128). Il s'agit donc d'une porte aménagée dans un second temps. Certains de ces aménagements tardifs et non soignés peuvent être dus à des restaurations modernes. Par exemple, les communications entre les boutiques Or. II, 10 et 11 ne constituent qu'une régularisation d'une galerie du XVIII ${ }^{\mathrm{e}}$ siècle $^{49}$. À partir de ces observations, l'aspect de l'aile occidentale lors de sa construction est restituable ${ }^{50}$.

${ }^{48}$ A. Maiuri (1958 b: 117-118) estime que les transformations ne concernent que les boutiques en elles-mêmes, à l'exception de deux fermetures de portes donnant sur la terrasse inférieure.

${ }^{49}$ La trace d'un tunnel est visible dans la paroi orientale du couloir reliant les pièces 10-1 et 10-3. Les montants de la supposée porte de communication entre Or. II, 10 et Or. II, 11 sont très nettement des constructions de restauration moderne. Il semble donc que, lors de la restauration du site, les maçons aient pérennisé une ouverture percée au XVIII ${ }^{\mathrm{e}}$ siècle.

${ }^{50}$ Pour faciliter la compréhension des différentes évolutions de l'Insula Orientalis $I I^{a}$, la nomenclature des pièces reprend celle de la dernière phase: la pièce $1 \mathrm{a}-1$ correspond au premier espace accessible depuis l'entrée Or. II, 1a, soit, au moment de l'éruption, à la pièce dans laquelle se trouvent le four et les meules de la boulangerie Or. II, 1a.

${ }^{51}$ La conjugaison des effets de la pente et des destructions occasionnées lors de l'éruption fait que l'étage n'est que difficilement étudiable dans cette partie, et de toute façon
Je commencerai la description de cet état initial par le bloc situé au sud de l'entrée Or. II, $4^{51}$. Une seule boutique se situe dans l'angle sud-est, correspondant à la boutique Or. II, $1^{52}$. L'ensemble des autres parties de cette fraction méridionale est vraisemblablement destiné à un usage public. On y accède soit par le cardo $\mathrm{V}$ avec l'unique entrée Or. II, 3, soit, de l'intérieur, par deux

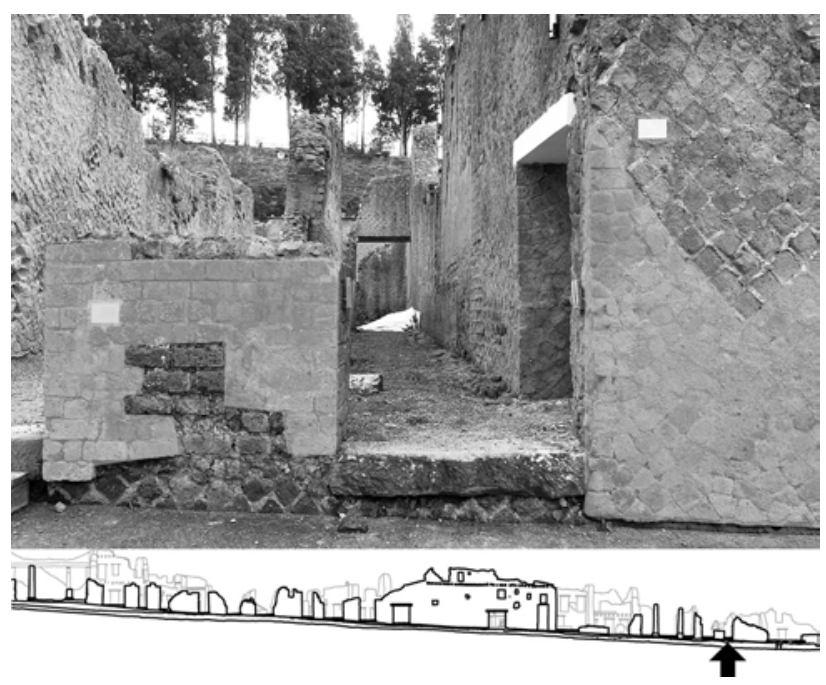

Fig. 128 - Façade de l'entrée Or. II, 2. Les restaurations modernes sont soulignées en grisé. L'opus reticulatum B qui constitue le montant droit a été taillé après la construction initiale pour percer cette porte. sans liaison perceptible avec tout le reste de la façade. Dès lors, le bloc méridional apparaît comme un isolat, coupé de la partie centrale par l'entrée Or. II, 4.

${ }^{52}$ Des solives protégées par des tuiles - indice clair de construction originelle - témoignent de l'existence d'un étage, correspondant à l'étage discontinu, au-dessus des pièces $1-1,1-2$ et 2-2. Le seuil de l'entrée Or. II, 1 b qui permet cet accès au moment de l'éruption, est en calcaire alors que tous les autres seuils - y compris ceux donnant accès à la loggia ou à la terrasse inférieure - sont en tuf gris. Cette anomalie est fortement contrebalancée par l'absence de toute trace d'arrachement de maçonnerie dans l'opus vittatum qui constitue l'angle nord-ouest de la boutique. $\mathrm{Si}$, dès l'origine, il n'y avait pas eu cet accès à un appartement indépendant, une trace d'arrachement aurait été visible dans la maçonnerie. De plus, comme l'absence de réaménagement du système de poutraison permet de considérer que l'escalier n'a pas subi de transformation, j'estime que l'entrée Or. II, 1b fait partie du plan originel. La pierre de seuil aura été changée à un moment indéterminé. 
ouvertures, l'une ménagée à l'extrémité orientale du vestibule menant à la terrasse inférieure, l'autre dans l'angle sud-est du portique. L'entrée occidentale s'ouvre sur une longue pièce partagée en deux par un mur de refend longitudinal. Au sud de celui-ci, il est possible qu'un escalier ait été disposé pour permettre d'accéder à l'étage. Trois groupes de pièces peuvent être identifiés au sud de la pièce d'accès principal. Le premier, à l'ouest, comporte cinq espaces accessibles par une volée restituée de trois marches: une soixantaine de centimètres sépare la pièce $1 \mathrm{a}-11$ des espaces 1a-1 à 5 (fig. 129). Le seul aménagement de première phase discernable dans cet ensemble de pièces est constitué par les deux latrines 1a2 et 1a-3, séparées par un mur. Les pièces constituant le second groupe (1a-6 à 8) sont toutes orientées est-ouest, voûtées et décorées de fresques décrites plus haut. Toutes les trois s'ouvrent sur la pièce 1a-12, soit par une fenêtre surmontée d'un œil-de-bœuf (1a-6 et 8), soit par une baie à plan en abside dans laquelle trois ouvertures ont été ménagées (1a-7). Contrairement à ce que suggère A. Maiuri, rien ne permet de supposer que ces espaces aient jamais été dévolus au rôle d'habitation ${ }^{53}$. Le fait qu'ils soient accessibles depuis le vestibule et la terrasse inférieure suppose au contraire une fonction publique, indéterminée. Enfin, le troisième groupe s'étend à l'est des deux premiers. Il comporte au moins la pièce 1a-12 ainsi que le péristyle qui se développe au sud de la terrasse inférieure. La paroi orientale de cet espace est percée de deux baies. La première est une porte qui donne sur le portique, tandis que la seconde est beaucoup plus large et rythmée par deux colonnes, intégrées dans une phase successive à la maçonnerie (fig. 130). En ce qui concerne le péristyle, il est impossible de déterminer à quels autres espaces il est relié. En effet, la zone située dans sa continuation à l'est reste inconnue, non fouillée ${ }^{54}$. En l'état actuel, dix colonnes ont été mises au jour, sans que ce nombre n'en constitue nécessairement la totalité: l'absence de colonnes centrales du côté oriental

\footnotetext{
${ }^{53}$ Maiuri 1958 b: 452-454.

${ }^{54}$ Les mentions concernant la fouille de ce péristyle se réduisent à une entrée. GSE 1935: « 4 luglio. L'atrio o peri-
} stilio della casa a monte del vicoletto è largo metri 12.60

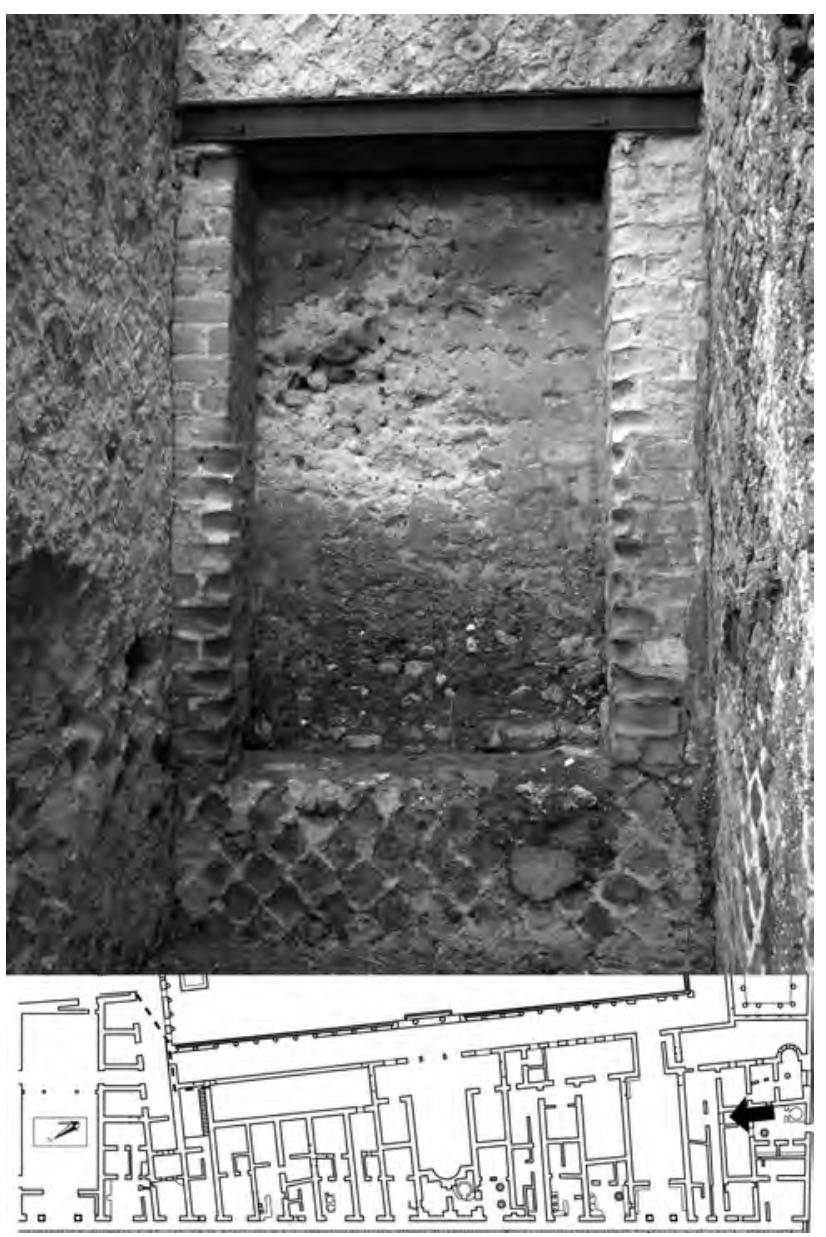

Fig. 129 - Porte bouchée dans la paroi nord de la pièce 1a-4 de l'Insula Orientalis $I I^{a}$. Ouverte lors du projet initial, cette porte permettait le passage entre les pièces $1 \mathrm{a}-11$ et $1 \mathrm{a}-4$ grâce à une volée de trois marches.

inciterait plutôt à considérer que le péristyle se poursuit sous le matériel éruptif.

Les pièces de la partie centrale de l'édifice présentent certaines caractéristiques communes dans leur conception architecturale qui permettent d'éviter une répétitive description pièce par pièce. Notons tout d'abord que tous les accès sur le cardo $\mathrm{V}$ existant au moment de l'éruption paraissent avoir été conçus dès la phase initiale. Seuls quelques changements mentre il giardino o impluvio è di metri 7. La lunghezza non può sapersi perché in corso di sterro. La parete lato ovest è senza stucco, mentre quella sud e nord sono completamente abbattute. Non si è raccolto nessun oggetto ». 


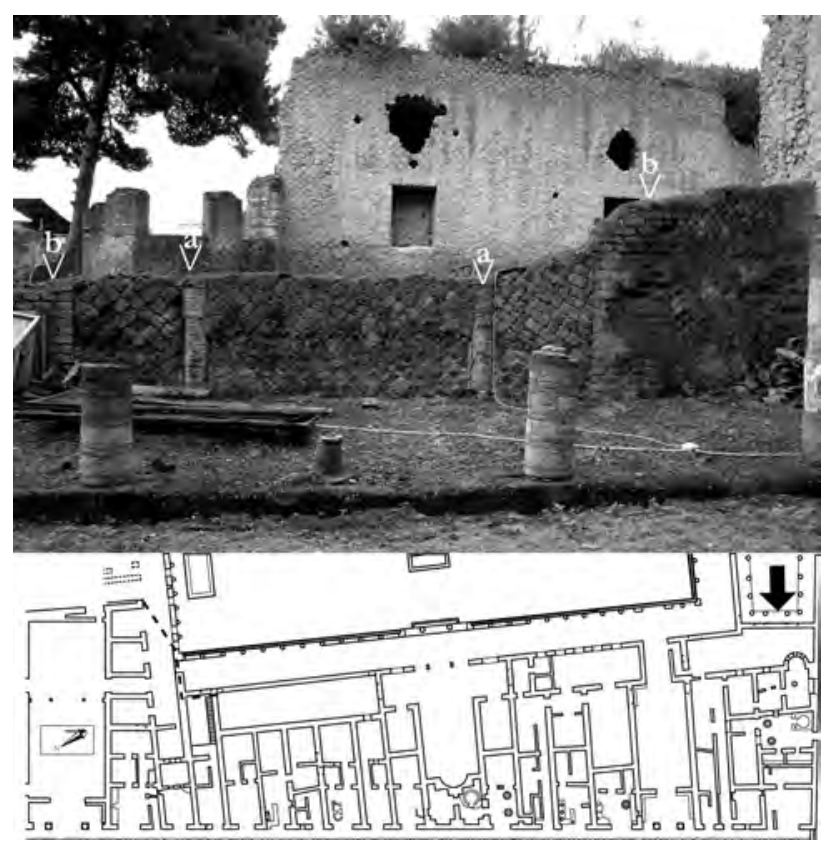

Fig. 130 - Insula Orientalis $I I^{a}$, péristyle méridional, mur ouest. Ouverte dans le projet initial, cette baie, rythmée par deux colonnes (a) et dont les montants (b) sont en opus vittatum, permettait la circulation entre le péristyle méridional et la pièce 4-4.

sur lesquels je reviendrai ont pu affecter l'extension de certaines ouvertures. La largeur et la profondeur de ces différentes pièces varient grandement d'un espace à l'autre, sans qu'un module particulier ne puisse être distingué. Les variations de profondeur sont dues à deux facteurs distincts. Le premier est la divergence entre l'alignement de la rue et l'orientation de la terrasse inférieure: plus l'espace se situe vers le sud, plus il peut, potentiellement, être profond. Le second facteur est encore plus contraignant.

${ }^{55}$ Seuls trois locaux disposent de deux murs de refend: Or. II, 10; Or. II, 11 et Or. II, 18. Ce sont les locaux d'une longueur supérieure à 50 pieds romains $(14,80 \mathrm{~m})$.

${ }^{56}$ L'absence de tuiles pour marquer les encastrements des solives au niveau de la mezzanine qui se développe en Or. II, 11 laisse supposer qu'elle n'a été installée que dans un deuxième temps. Les architectes qui ont conçu le projet auront jugé la hauteur sous plafond trop faible pour permettre l'installation de deux niveaux, tandis que ceux qui ont transformé le local l'ont considérée suffisante.

${ }^{57}$ Cet étage n'est pas assez préservé au-dessus des locaux Or. II, 5 et 6 pour permettre la restitution de ses ouvertures et communications.
En effet, l'extension de chacun de ces espaces qui s'ouvrent sur la rue est limitée par l'emprise, à l'est, des espaces publics: toutes ces pièces, qu'elles soient des boutiques ou destinées à d'autres fonctions, s'installent dans les parties laissées vacantes par la terrasse à portique et ses dépendances. Cette adaptation aux conditions dictées par la partie la plus importante du bâtiment ainsi que la nécessité de se conformer à la pente font que chaque local est particulier. Toutefois, une unique solution a été déployée et déclinée, soulignant d'autant plus l'unité de construction: en fonction de la longueur, un ou deux murs de refend ont été installés, percés par deux ouvertures - soit une porte et une fenêtre, soit deux portes ${ }^{55}$. L'implantation des étages suit les mêmes principes. Pour compenser la déclivité, à partir d'Or. II, 10 en descendant vers le sud, des mezzanines - qui ne couvrent pas toute la surface du local - puis des étages complets sont installés à une altitude constante ${ }^{56}$. L'encastrement dans lesquelles les solives viennent se loger - aménagé avec des tuiles fracturées (fig. 123-b) - permet de restituer la structure initiale des différents niveaux. Le premier étage au-dessus des espaces Or. II, 5 à 10 n'a pas d'équivalent en première phase dans les locaux Or. II, 11 à 18. En revanche, le premier étage qui se développe au-dessus d'Or. II, 11 à 18 correspond au second étage des pièces Or. II, 5 à 10 (pl. I, h.t. $)^{57}$. Cet étage continu sur toute la longueur du bâtiment est doublé, du côté de la rue par un balcon permettant d'accéder aux différents appartements ${ }^{58}$. L'accès depuis le rez-de-chaussée semble s'être effectué depuis deux ou trois escaliers. Le premier est situé en Or. II, 7, probablement dans le quart nord-est du local ${ }^{59}$. Un possible second escalier a pu se

${ }^{58}$ À la suite d'A. Maiuri (1958 b: 450-451), je ne saurais déterminer si ce balcon courait ou non tout au long de la façade de l'Insula Orientalis $I^{a}$.

${ }^{59} \mathrm{La}$ définition de l'aspect du local Or. II, 7 est assez délicate dans cette première phase. En effet, la majeure partie des parois est trop restaurée pour permettre une analyse rigoureuse des transformations: l'ouverture entre cet espace et la boulangerie Or. II, 8 a été intégralement restaurée, ce qui empêche de déterminer si cette porte correspond à une ouverture tardive ou au projet initial. La redécouverte de deux murs de refend nord-sud arasés - observés lors de nettoyages effectués dans ces deux locaux (fig. 138) - m'inciterait à considérer que le local Or. II, 7 
trouver en Or. II, $12^{60}$. Enfin, le troisième escalier se trouvait en Or. II, $17^{61}$.

Ces caractéristiques générales souffrent quelques exceptions. Si la majorité de ces locaux n'est constituée que d'une enfilade de pièces dans le sens est-ouest, certains présentent dès la phase initiale des communications nord-sud. Les deux premiers sont situés de part et d'autre de l'Aula absidata: l'espace situé à l'ouest de l'abside étant particulièrement sensible en raison des contraintes de statique, il a été divisé en deux par un épais mur porteur et réparti entre les locaux Or. II, 8 et Or. II, 9, plutôt que de percer deux ouvertures en façade (fig. 117) ${ }^{62}$. L'autre exception est caractérisée par les locaux Or. II, 11 à 13 qui paraissent communiquer entre eux par le biais de portes ménagées en opus vittatum, deux entre les espaces 11 et 12 , une entre 12 et 13 . Bien qu'il soit probable que ce grand espace n'ait eu que deux accès sur la rue - en 11 et en 13 - l'absence de mur de refend est étonnante. Tout au plus supposerais-je une division entre espace commercial et espace d'habitation, ce qui permettrait d'expliquer cette taille. En effet, la seule entrée qui a été élargie dans une phase ultérieure est celle d'Or. II, 13 (fig. 131). Elle pourrait donc, lors de son état initial, ne pas avoir été conçue comme une entrée de boutique mais comme un accès particulier, ouvrant sur un appartement de plainpied. Le rapport de l'entrée 12 avec ces différents espaces est plus délicat à établir. En effet, le mur de refend est-ouest, percé d'une porte donnant accès à des latrines, semble ne s'être étendu

était, au cours de la première phase, non seulement indépendant d'Or. II, 8, mais également des pièces A, B et C situées au sud de l'Aula absidata. L'absence de solives dont l'encastrement serait protégé par des tuiles dans les deux tiers occidentaux d'Or. II, 7 m'incite également à considérer que l'escalier qui s'y trouvait ne devait permettre d'atteindre que l'étage discontinu (le premier étage dans ce local).

${ }^{60}$ Une telle hypothèse permettrait d'expliquer la multiplication des accès au local unique se développant entre les portes Or. II, 11 et Or. II, 13.

${ }^{61}$ Dans cette première phase, le mur de refend est-ouest séparant l'entrée Or. II, 17 du local Or. II, 18 n'existe pas, ou du moins n'est-il pas construit en maçonnerie, comme l'indique la ligne d'enduit qui se trouve entre le mur de façade et le refend.

62 Les contraintes mécaniques rendant cette zone sensible sont perceptibles par l'utilisation dès la première que sur le tiers occidental du local. Toutefois, le percement d'une seconde porte dans une phase ultérieure empêche de déterminer les limites de son extension originelle. L'absence d'un seuil large donnant sur la rue interdit de restituer un espace commercial ${ }^{63}$. À titre d'hypothèse, j'ai restitué ici un mur en retour qui permet de fermer la pièce unique 12-2/3 à l'est. De la sorte, cette entrée aurait permis d'accéder à l'étage.

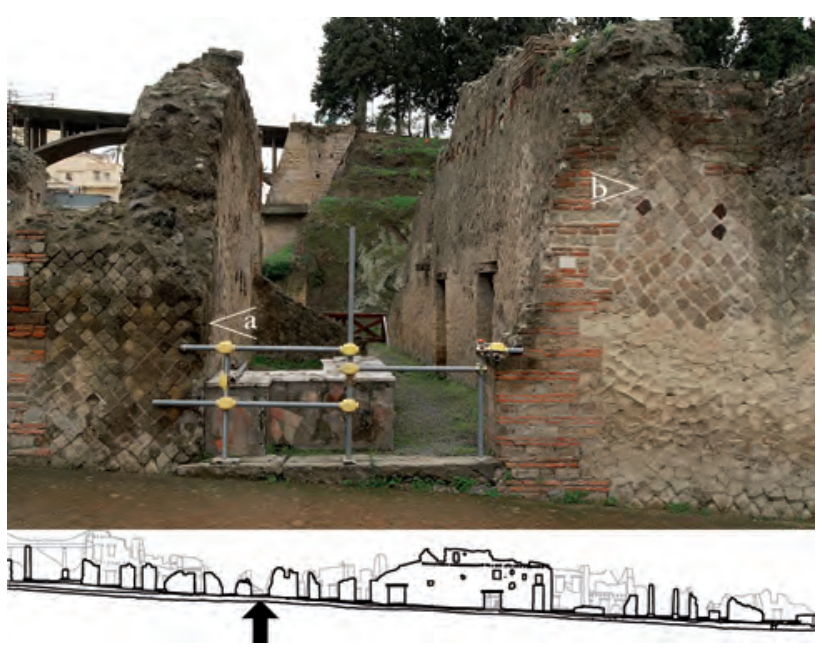

Fig. 131 - Façade du local Or. II, 13. Le montant gauche de la première phase a été remplacé par une paroi en opus reticulatum A lors des travaux effectués par Vespasien (a), comme la comparaison avec la maçonnerie originelle (b) permet de le constater. L'absence de moellons isodomes dans le montant nord révèle que l'entrée était beaucoup plus réduite tant lors du projet initial qu'après les travaux terminés en 76. L'ouverture de cette boutique ne serait alors qu'un bricolage précédant de peu l'éruption.

phase de piliers de renforcement à chacun des angles de l'espace situé à l'ouest de l'abside. Il s'agit du seul point de tout l'édifice dans lequel cette pratique a été observée. La seule ouverture ayant été percée dans cette façade est un passage de chantier menant dans la pièce $8-5$, rebouché avant l'achèvement des travaux.

${ }^{63}$ Les maçonneries visibles de la façade présentent deux phases. La partie principale du mur est constituée d'opus reticulatum $\mathrm{B}$ - caractéristique de la construction initiale -, tandis que les montants sont en opus vittatum mixtum à deux assises de briques, attribuable aux réparations effectuées par Vespasien. L'extension de l'opus reticulatum est telle qu'il est impossible qu'un montant en opus vittatum définissant un seuil plus large ait été présent lors de la première phase. Dans ce cas comme dans d'autres, les montants construits ou réparés lors des travaux financés par Vespasien sont essentiellement des reconstructions à l'identique (cf. infra, p. 278-280). 
Tout comme dans la partie méridionale, le projet initial donne une part importante aux espaces publics, en lien soit avec la terrasse inférieure, soit avec la loggia. En dépit de sa très large ouverture qui pourrait faire penser à une boutique, l'espace Or. II, 18 ne présente aucun aménagement permettant de l'interpréter comme un espace commercial. Bien plus, la pièce à l'est de ce local (18-4) est en communication avec la pièce 19-4 qui donne sur la loggia. De la même façon, comme cela avait déjà été perçu par A. Maiuri, l'espace Or. II, 15 a tout d'abord été un moyen d'accès à la terrasse inférieure: la pièce 15-4 comporte un escalier qui permet de franchir les 4,15 m de hauteur séparant ce local du portique ${ }^{64}$. Il est délicat de définir si un tel accès était communément emprunté pour se rendre à la terrasse inférieure, ou s'il s'agissait seulement d'un local de service. Dans ce même secteur nord-occidental, au cours de la phase initiale, la boutique Or. II, 16 est dépourvue de local annexe. La pièce 16-2 est en effet exclusivement rattachée par deux portes à la pièce 19-5 puis à la loggia. Une différence de niveau de $50 \mathrm{~cm}$ existe entre les deux espaces. Enfin, les trois pièces A, B et $\mathrm{C}$ situées au sud de l'Aula absidata ne paraissent pas avoir été accessibles par l'entrée Or. II, 7 durant cette phase, mais uniquement par la porte située au nord-est du vestibule Or. II, 4 : la structure de la maçonnerie permet de considérer que le passage visible au moment de l'éruption entre les pièces 7-1 et 7-4 a été ménagé après la construction initiale $^{65}$. Ces différentes observations font que seuls huit espaces commerciaux paraissent avoir été prévus dès la réalisation de cet ensemble. Trois groupes peuvent être constitués, en fonction de la présence de pièces annexes ou d'accès à l'étage

\footnotetext{
${ }^{64}$ Maiuri 1958 b: 118, 466. La largeur actuelle visible
} de l'escalier est inférieure à sa largeur originelle, comme en témoigne l'absence de parement au nord des piliers de soutènement.

${ }^{65}$ Le montant septentrional ne peut servir de point de repère, il a été intégralement restauré. En revanche, l'absence d'arc de décharge et de montant méridional plaide pour une ouverture ménagée de façon moins soignée et postérieure à la construction initiale.

${ }^{66}$ Un indice permettant de cerner le caractère subsidiaire des espaces utilisés par des particuliers par rapport aux espaces d'utilité publique pourrait être apporté par la fosse septique qui se développe le long de la façade ouest de l'Insula Orientalis $I I^{a}$. En effet, les travaux réalisés par l'Herculaneum (fig. 132). Dans le premier, seul l'espace Or. II, 16 se présente comme un local commercial simple, dépourvu de pièce annexe ou d'accès à l'étage. Parmi les boutiques disposant de pièces annexes mais limitées au seul rez-de-chaussée, les situations changent fortement d'un local à l'autre. Les surfaces des quatre locaux - Or. II, 6, 8, 11.13 et 14 - varient 49 à $150 \mathrm{~m}^{2}$. Le troisième groupe, composé des boutiques Or. II, 5, 9 et 10 paraît plus homogène: chacune dispose de pièces annexes et d'un accès à l'étage. Toutefois, dans le détail de la répartition des différentes surfaces, l'hétérogénéité prime également. Même en prenant en considération l'ensemble des huit locaux, les variations de la surface consacrée aux activités commerciales ou artisanales sont importantes, de 21 à $31 \mathrm{~m}^{2}$. Notons enfin qu'aucun indice n'est perceptible quant à la nature de ces activités.

L'absence d'uniformité de plan et de répartition des surfaces entre les locaux commerciaux montre à quel point leur insertion dans ce bâtiment ne saurait être interprétée autrement que comme une utilisation des espaces interstitiels laissés libres par les fonctions publiques de l'édifice. La topographie générale du site d'implantation a également eu un rôle non négligeable pour empêcher toute uniformité par-delà quelques caractéristiques générales. À l'origine, les espaces commerciaux ou donnant accès à des appartements sont largement minoritaires: en ne prenant en considération que l'aile occidentale et sans mesurer la surface occupée par les étages, la partie publique de l'édifice correspond à $77 \%$ de la surface disponible (fig. 133). Si les boutiques sont alors tributaires de l'espace non utilisé par le bâtiment public, cette subsidiarité est moins aisée à matérialiser pour les étages mais existe probablement ${ }^{66}$. L'ensemble de ces

Conservation Project ont permis de démontrer que l'espace voûté situé contre le mur de façade, entre les entrées Or. II, 14 et Or. II, 1, n'était pas un égout comme l'avait supposé A. Maiuri, mais une fosse septique destinée à recevoir le contenu des conduites d'évacuation des latrines situées dans les appartements de l'étage et dans les boutiques (WallaceHadrill - Guidobaldi - Camardo - Moesch 2008: 415-420). Le fait qu'il ait été nécessaire, lors de la dernière phase, d'installer un conduit en terre cuite dans la paroi méridionale de la pièce 18-4 tendrait à montrer que les espaces situés à l'étage dans l'aile nord n'était pas, avant le second séisme, équipés de latrine. On pourrait inférer de ce constat que les étages de la partie septentrionale de l'Insula Orientalis $I I^{a}$ pourraient avoir eu, jusqu'au milieu des années 70 , un usage public. 


\begin{tabular}{|c|c|c|c|c|c|c|c|c|}
\hline \multicolumn{6}{|c|}{ Phase I: de l'achèvement du projet initial (ca. 25-35 ap. J-C.) au séisme de 62 } \\
\hline & Boutique & $\begin{array}{c}\text { Pièce } \\
\text { annexe }\end{array}$ & étage & $\begin{array}{c}\text { Surface } \\
\text { commerciale }\end{array}$ & $\begin{array}{c}\text { Surface } \\
\text { annexe }\end{array}$ & $\begin{array}{c}\text { Surface } \\
\text { au sol }\end{array}$ & $\begin{array}{c}\text { Surface } \\
\text { étage }\end{array}$ & $\begin{array}{c}\text { Surface } \\
\text { totale }\end{array}$ \\
\hline Or. II, 16 & $\mathrm{X}$ & & & 24 & 0 & 24 & 0 & 24 \\
\hline Or. II, I4 & $\mathrm{X}$ & $\mathrm{X}$ & & 31 & 32 & 63 & 0 & 63 \\
\hline Or. II, I1, 13 & $\mathrm{X}$ & $\mathrm{X}$ & & 25 & 137 & 162 & 0 & 162 \\
\hline Or. II, 8 & $\mathrm{X}$ & $\mathrm{X}$ & & 22 & 40 & 63 & 0 & 63 \\
\hline Or. II, 6 & $\mathrm{X}$ & $\mathrm{X}$ & & 28 & 22 & 40 & 0 & 49 \\
\hline Or. II, I & $\mathrm{X}$ & $\mathrm{X}$ & & 33 & 19 & 52 & 0 & 52 \\
\hline Or. II, 10 & $\mathrm{X}$ & $\mathrm{X}$ & $\mathrm{X}$ & 21 & 33 & 55 & 11 & 66 \\
\hline Or. II, 9 & $\mathrm{X}$ & $\mathrm{X}$ & $\mathrm{X}$ & 23 & 37 & 60 & 30 & 90 \\
\hline Or. II, 5 & $\mathrm{X}$ & $\mathrm{X}$ & $\mathrm{X}$ & 29 & 16 & 45 & 46 & 91 \\
\hline Totaux & 9 (9) & 8 & 3 & 237 & 336 & 573 & 87 & 660 \\
\hline
\end{tabular}

\begin{tabular}{|c|c|c|c|c|c|c|c|c|}
\hline \multicolumn{8}{|c|}{ Phase II: du séisme de 62 au second tremblement de terre (ca. 70-75) } \\
\hline Or. II, 16.18 & $\mathrm{X}$ & $\mathrm{X}$ & & 55 & 53 & 108 & 0 & 108 \\
\hline Or. II, II. I3-I4 & $\mathrm{X}$ & $\mathrm{X}$ & & 60 & 174 & 234 & 0 & 234 \\
\hline Or. II, 8 & $\mathrm{X}$ & $\mathrm{X}$ & & 23 & 39 & 62 & 0 & 62 \\
\hline Or. II, 6 & $\mathrm{X}$ & $\mathrm{X}$ & & 28 & 22 & 49 & 0 & 49 \\
\hline Or. II, I & $\mathrm{X}$ & $\mathrm{X}$ & & 33 & 39 & 72 & 0 & 72 \\
\hline Or. II, 10 & $\mathrm{X}$ & $\mathrm{X}$ & $\mathrm{X}$ & 21 & 33 & 55 & 11 & 66 \\
\hline Or. II, 9 & $\mathrm{X}$ & $\mathrm{X}$ & $\mathrm{X}$ & 23 & 37 & 60 & 30 & 90 \\
\hline Or. II, 5 & $\mathrm{X}$ & $\mathrm{X}$ & $\mathrm{X}$ & 29 & 16 & 45 & 46 & 91 \\
\hline Totaux & $8(10)$ & 8 & 3 & 272 & 413 & 684 & 87 & 771 \\
\hline
\end{tabular}

\begin{tabular}{|c|c|c|c|c|c|c|c|c|}
\hline \multicolumn{8}{|c|}{ Phase III: des réparations de Vespasien à l'éruption du Vésuve (76-79) } \\
\hline Or. II, 18 & $\mathrm{X}$ & $\mathrm{X}$ & & 28 & 55 & 83 & 0 & 83 \\
\hline Or. II, I6 & $\mathrm{X}$ & $\mathrm{X}$ & & 22 & 14 & 36 & 0 & 36 \\
\hline Or. II, 15 & $\mathrm{X}$ & $\mathrm{X}$ & & 21 & 48 & 69 & 0 & 69 \\
\hline Or. II, 8 & $\mathrm{X}$ & $\mathrm{X}$ & & 23 & 63 & 85 & 0 & 85 \\
\hline Or. II, 3 & $\mathrm{X}$ & $\mathrm{X}$ & & 9 & 18 & 27 & 0 & 27 \\
\hline Or. II, I & $\mathrm{X}$ & $\mathrm{X}$ & & 33 & 18 & 52 & 0 & 52 \\
\hline Or. II, 19 & $\mathrm{X}$ & $\mathrm{X}$ & & 40 & 153 & 193 & 0 & 193 \\
\hline Or. II,14 & $\mathrm{X}$ & $\mathrm{X}$ & $\mathrm{X}$ & 29 & 31 & 60 & 13 & 72 \\
\hline Or. II, 13 & $\mathrm{X}$ & $\mathrm{X}$ & $\mathrm{X}$ & 27 & 57 & 84 & 10 & 94 \\
\hline Or. II, 11 & $\mathrm{X}$ & $\mathrm{X}$ & $\mathrm{X}$ & 25 & 41 & 66 & 14 & 80 \\
\hline Or. II, 10 & $\mathrm{X}$ & $\mathrm{X}$ & $\mathrm{X}$ & 23 & 32 & 55 & 23 & 78 \\
\hline Or. II, 9 & $\mathrm{X}$ & $\mathrm{X}$ & $\mathrm{X}$ & 22 & 18 & 40 & 24 & 64 \\
\hline Or. II, 6 & $\mathrm{X}$ & $\mathrm{X}$ & $\mathrm{X}$ & 27 & 22 & 49 & 49 & 98 \\
\hline Or. II, 5 & $\mathrm{X}$ & $\mathrm{X}$ & $\mathrm{X}$ & 27 & 17 & 44 & 46 & 90 \\
\hline Totaux & $14(14)$ & 13 & 7 & 356 & 587 & 943 & 179 & 1122 \\
\hline
\end{tabular}

Fig. 132 - Tableau de répartition des boutiques de l'Insula Orientalis $I^{a}$ en fonction des espaces dont elles disposent. Ordonnancement par phase. Les surfaces sont indiquées en mètres carrés. 
Phase initiale

(2e phase post-augustéenne)
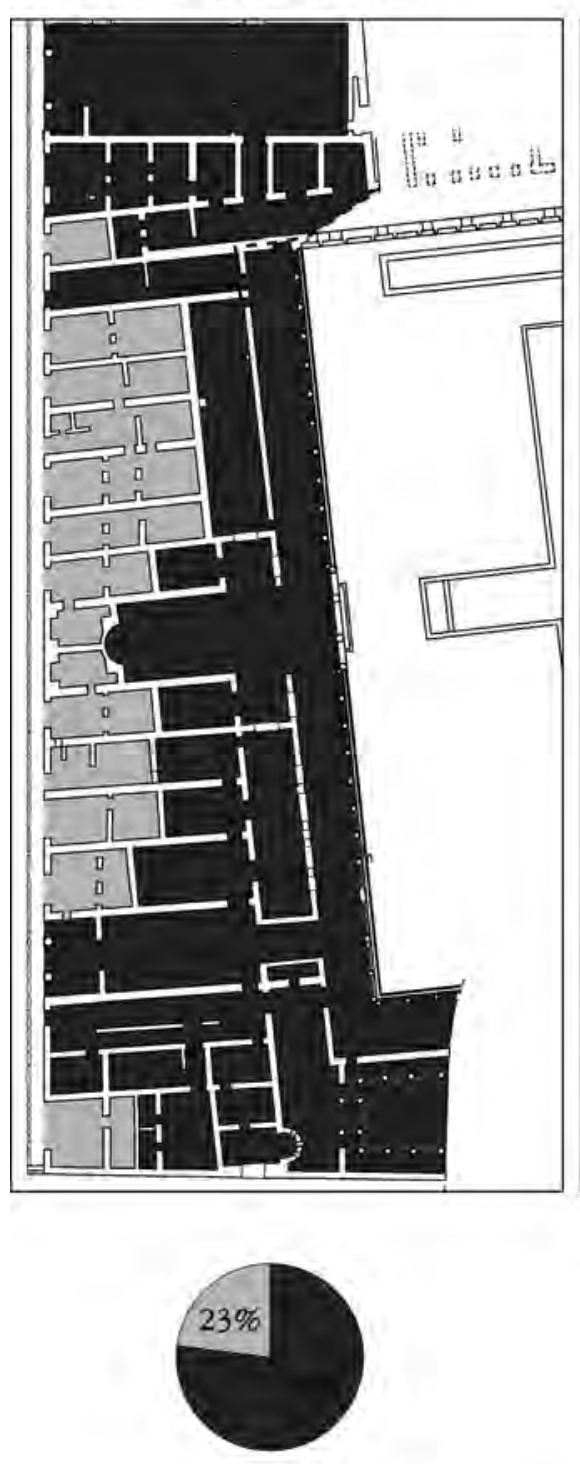

Phase II

(62- ca. 75)
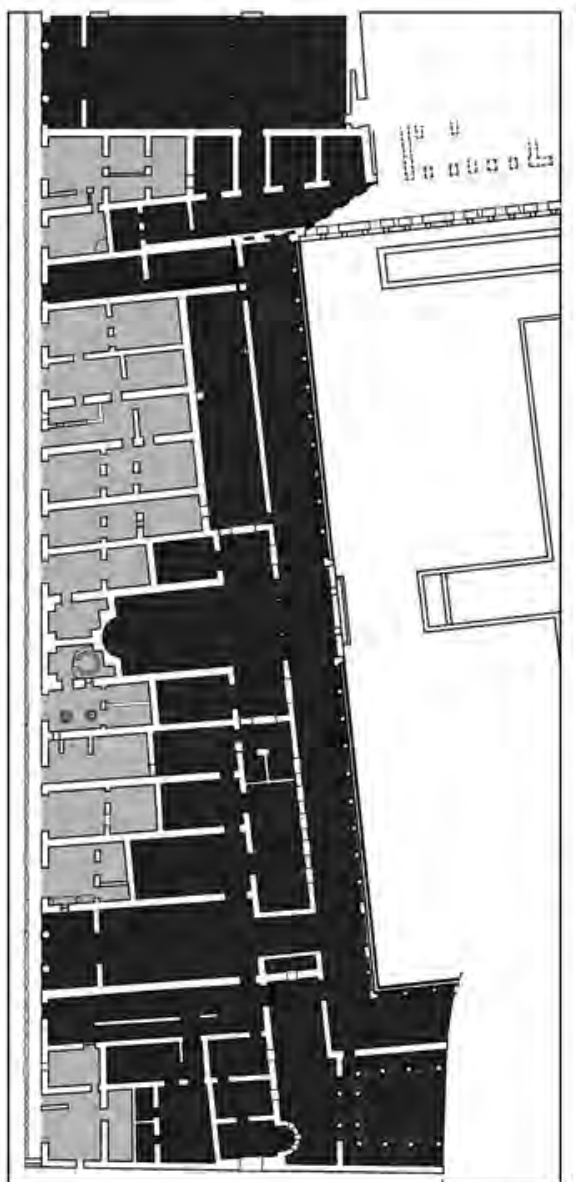

$40 \mathrm{~m}$
Phase III

(76-79)

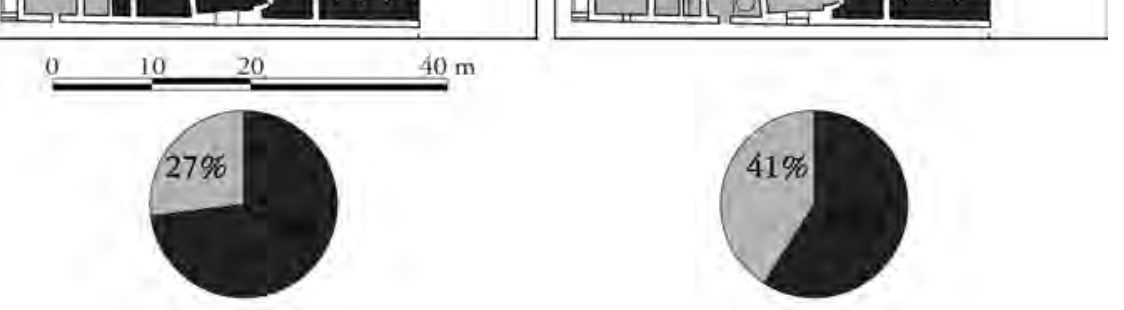

Espaces publics

Espaces commerciaux et accès aux appartements

Fig. 133 - Évolution des fonctions des différents espaces de l'aile occidentale de l'Insula Orientalis II (échelle: 1/1000). 
données semble difficilement conciliable avec l'idée d'A. Maiuri qui aurait voulu faire de l'Insula Orientalis $I I^{a}$ le prototype des immeubles de rapport qui se développent au $\mathrm{II}^{\mathrm{e}}$ siècle à Ostie ${ }^{67}$.

\section{VI.2 Les transformations successives}

L'étude des transformations et des réfections de la maçonnerie laisse proposer une évolution de l'aile ouest de l'Insula Orientalis $I I^{a}$. Avant de décrire ces changements, il convient de noter une nouvelle fois que les résultats présentés restent fondés sur l'analyse de rapports stratigraphiques. J'ai considéré que l'emploi d'une même technique de mise en œuvre correspond à une seule phase de travaux. Parfois, notamment dans le cas des portes bouchées avec une maçonnerie non appareillée, aucun élément intrinsèque ne permet d'attribuer une transformation à une phase particulière. C'est alors le seul critère de vraisemblance qui m'a amené à proposer une interprétation. D'une manière générale, j'ai mis en évidence deux phases principales, correspondant aux travaux réalisés à la suite des deux séismes attestés dans cet édifice. Toutefois, il est important de conserver à l'esprit que ces deux périodes doivent être subdivisées en deux phases principales. Dans les deux cas, la première correspond aux réparations effectuées à l'identique, tandis que la seconde est une période durant laquelle des aménagements sont apportés aux différents locaux. Ces transformations peuvent être la conséquence directe du séisme, sans que cela ne soit pour autant la règle. Enfin, à l'exception des réparations proprement dites, les changements observés dans les différents locaux, quand ils sont assignés à une même phase, ne sont pas nécessairement strictement contemporains. Cette remarque s'applique d'autant plus à la phase qui s'étend entre 62 et la première moitié des années 70 .

VI.2.1 Le séisme de 62 et les premières transformations de l'Insula Orientalis $I^{a}$

Le relevé des dégâts subis par l'Insula Orientalis $I I^{a}$ lors du séisme de 62 aurait tendance à réfuter le constat désastreux dressé par Sénèque (fig. 134). Si les parois endommagées sont alors restaurées en utilisant l'opus testaceum $^{68}$, l'emploi de cette technique de maçonnerie reste relativement circonscrit. La portion de l'édifice la plus sévèrement touchée est le pronaos qui se développe en avant des pièces I à III. Sur trois côtés, les murs ont été intégralement reconstruits, en maintenant les hautes ouvertures donnant sur le portique à l'est, sur la pièce $\mathrm{L}$ au nord et sur la pièce 7-6 au sud. De la même façon, les montants des fenêtres orientales de la pièce $\mathrm{D}$ ont tous été réparés en briques. Le portique ne semble pas avoir été trop endommagé: seules les colonnes supportant l'hypothétique fronton entre l'Aula absidata et le bassin paraissent être tombées, ainsi que les deux piliers qui soulignent l'aboutissement du vestibule Or. II, 4. Dans ce dernier, la colonne nord pourrait s'être effondrée, comme le suggèrent les briques utilisées pour réparer l'angle sud-est de sa base. Au sud, les deux colonnes marquant le passage de la pièce 4-4 au péristyle méridional ont été reconstruites en briques, ainsi que deux des montants de la baie à plan en abside dans la pièce 1a-7. Enfin, au nord, le montant sud de l'accès Or. II, 19 a été relevé.

Cette répartition des dégâts reste ardue à interpréter. Tout d'abord, il s'agit d'un relevé minimal: sans autre possibilité d'investigation que l'observation des murs en élévation lors de l'éruption, nul ne saurait déceler des murs ou portions de murs qui, ayant subi le choc des deux séismes, ont été reconstruites coup sur coup, la seconde réparation faisant disparaître la première. Ensuite, les éléments de restitution des parties hautes manquent à une vision plus complète des dégâts subis par l'ensemble du bâtiment. En effet, si les deux colonnes entre le péristyle méridional et la pièce 4-4 ont pu s'effondrer sans entraîner l'écroulement de la maçonnerie située au-dessus du linteau qu'elles ont supporté, je ne saurais déterminer avec précision la conséquence de la chute d'une des colonnes du vestibule Or. II, 4 sans avoir au préalable reconstitué le système de couverture

\footnotetext{
${ }^{68}$ Cf. supra, p. 239-243.
}

${ }^{67}$ Contra Maiuri 1958 b: 113; Yegül 1993: 384, 389. 


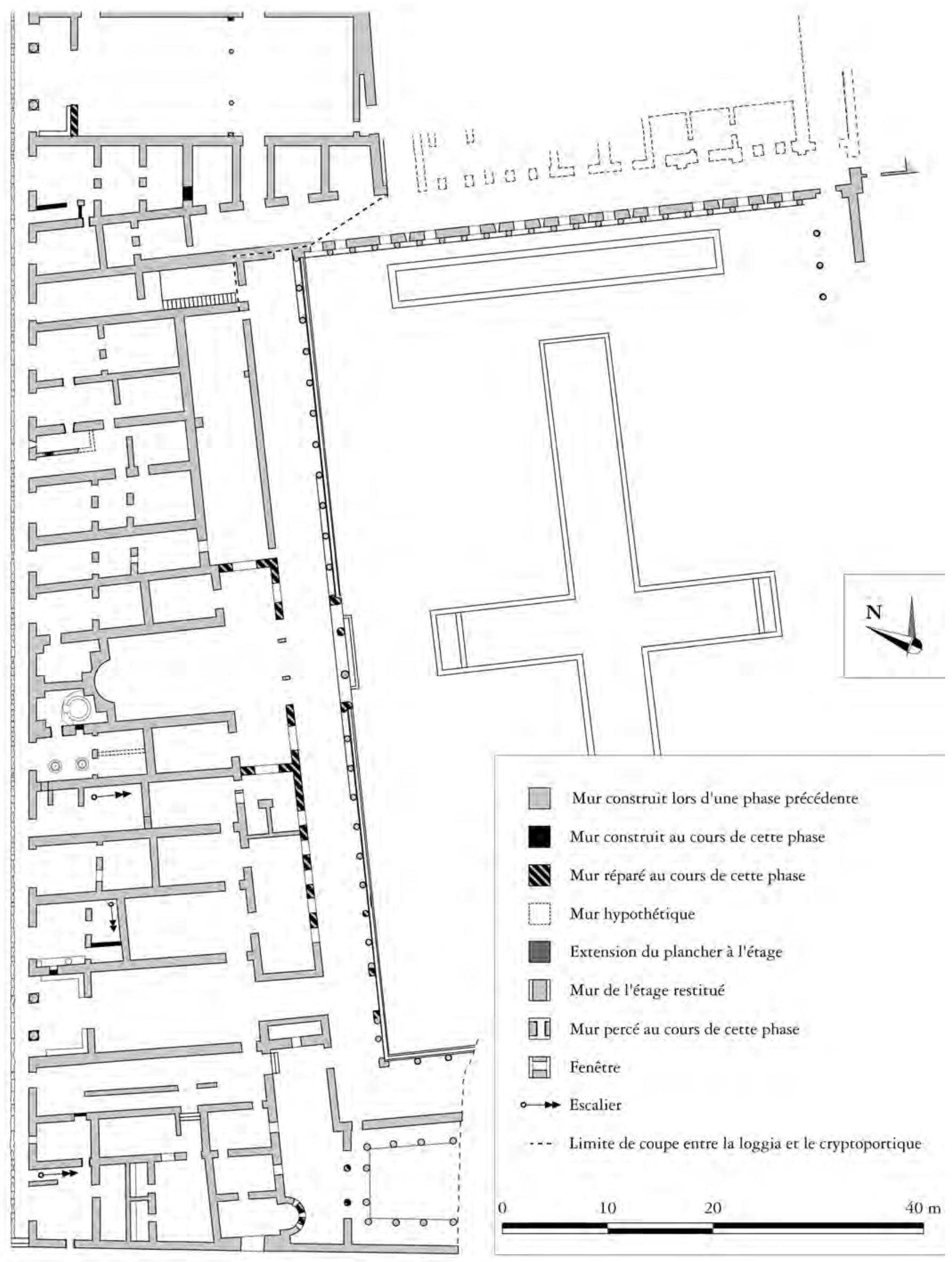

Fig. 134 - Insula Orientalis $I I^{a}$ - transformations consécutives au séisme de 62 (échelle: 1/500). 
de cette pièce ${ }^{69}$. En revanche, la moitié sud du portique s'est probablement effondrée à la suite des destructions occasionnées dans le pronaos et dans les pièces 7-6, 7-7 et $\mathrm{D}$.

Quelle qu'ait été l'importance des dommages consécutifs à cette première secousse, les changements apportés à la structure d'ensemble sont peu nombreux. Une amorce de réduction des espaces strictement publics tend à se dessiner. Le local Or. II, 18 devient une boutique ou un atelier suite à la fermeture de la porte entre les pièces 18-5 et 19-4 (fig. 135) ${ }^{70}$. Ce basculement d'une utilisation publique vers un espace commercial pourrait également trouver une confirmation dans la construction d'un mur de cage au nord de l'escalier Or. II, 17. La surface située sous cet accès à l'étage est alors utilisée comme pièce de service par l'aménagement d'une porte donnant dans le local principal. La nature exacte des activités se déroulant dans ce dernier ne peut pas être déterminée. Notons toutefois la création d'une mezzanine dans le tiers méridional de la pièce $18-2 / 4^{71}$. Par ailleurs, une porte est percée vers le local Or. II, 16 au sud. L'autre exemple de cette réduction de l'espace public provient de la boutique Or. II, 1, qui s'étend d'une pièce vers le nord: une porte est ménagée entre cet espace et la pièce 2-2, tandis que l'ouverture vers le couloir 2-1 est obturée. Si ces transformations réduisent quelque peu la surface utilisée à des fins publiques, elles ne constituent pas un changement radical: la proportion entre les différentes fonctions ne varie alors que peu dans l'aile occidentale, où seuls $27 \%$ de la surface au sol sont utilisés par des espaces commerciaux. Profitant de la fermeture de la porte entre la boutique Or. II, 5 et le vestibule Or. II, 4, deux bancs en équerre sont installés au nord et au sud de celui-ci ${ }^{72}$.

Parmi les transformations que l'on peut constater dans la façade occidentale, signalons

${ }^{69}$ Par exemple, si la façade présentait un arc de décharge - au-dessus des colonnes et du linteau en bois qu'elles ne devaient pas manquer de supporter -, il aurait certainement permis d'éviter un effondrement trop important malgré la chute de la colonne.

${ }^{70}$ La datation de ce bouchage après le séisme de 62 tient à plusieurs éléments. Le premier d'entre eux, dont l'importance est toute relative, est lié aux matériaux employés comme caementa. La forte proportion de cruma rouge et la surabondance de mortier laissent en effet supposer le remploi de moellons provenant de la destruction d'autres édifices. En

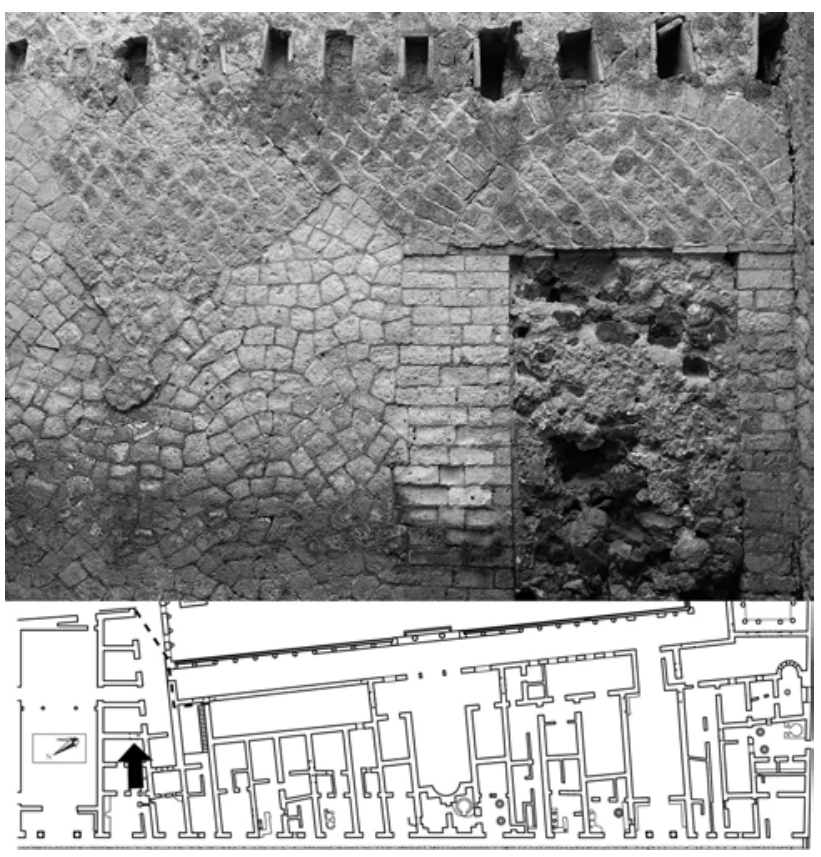

Fig. 135 - Insula Orientalis $I I^{a}$, pièce 18-5, mur est. Porte bouchée vers la pièce 19-4. Lors de la construction initiale, ce passage permettait de passer du local Or. II, 18 aux pièces de la loggia.

l'extension de l'espace Or. II, 11.13 à la boutique Or. II, 14 par le percement d'un passage dans le mur sud de cette dernière. Par ailleurs, ce vaste ensemble paraît également s'approprier la latrine située dans la pièce 12-2, grâce à l'ouverture d'une porte entre celle-ci et la boutique Or. II, 13. Dans deux locaux, il est possible de déterminer quelles sont les activités qui se développent alors: en Or. II, 5, la fermeture de la porte donnant sur le vestibule Or. II, 4 permet l'installation le long du mur sud d'une table maçonnée dans laquelle est insérée une chaudière basse, caractéristique des officines dédiées au nettoyage des toisons ${ }^{73}$. Le sol est alors également recouvert de tuiles. Un mur

revanche, l'existence de deux phases d'aménagements et de modifications des relations avec le local Or. II, 16 m'a incité à placer cette transformation d'un accès au bâtiment public en espace commercial après le séisme de 62 .

${ }^{71}$ Pour une description du système de solives employé dans cet espace, cf. supra, p. 71.

${ }^{72}$ Déjà A. Maiuri (1958 b: 118) considérait l'installation de ces bancs comme l'un des travaux appartenant à une seconde phase de l'édifice.

${ }^{73}$ Sur ce type d'atelier, cf. supra, p. 170-175, part. 171172. 
de refend est disposé de façon à scinder la pièce $5-2 / 3$. Six poutrelles y sont encastrées, probablement pour servir de séchoir. En Or. II, 8, une boulangerie s'installe. Le four est construit dans la pièce $8-4$, bouchant la porte de communication originelle entre cet espace et le local principal 8-1. Un nouvel accès est ménagé à l'ouest du premier ${ }^{74}$. Deux meules sont installées en 8-1. La pièce 8-2 paraît avoir été coupée en deux par un mur de refend; une mezzanine est alors mise en place dans la moitié méridionale ${ }^{75}$ (fig. 136). Il est possible que les activités des autres locaux commerciaux aient également changé au cours de cette phase; cependant aucun élément ne permet de déterminer leur nature.

L'impact général du séisme de 62 apparaît comme peu important dans l'Insula Orientalis $I I^{a}$. À l'exception du pronaos qui a vraisemblablement subi des dommages sérieux, ainsi que le portique, les dégâts semblent relativement limités. Quant aux transformations consécutives à cette secousse, elles s'avèrent également peu nombreuses et ne donnent pas l'impression d'une transformation radicale de l'édifice. En comparaison, les suites du second séisme sont beaucoup plus marquées.

VI.2.2 Du second séisme (ca. 70-75 ap. J.-C.) à l'éruption du Vésuve

L'inscription CIL X, 1406 apporte le témoignage de réparations achevées en 76 et financées par Vespasien, consécutives à un second séisme qu'il convient de placer au cours de la première moitié des années 70 selon les études de G. Guadagno. Ces réparations sont notam-

\footnotetext{
${ }^{74}$ Rien ne permet de dire si cet accès a été aménagé en prenant soin de construire des montants ou non. En effet, les consolidations effectuées dans la phase suivante ont notamment été constituées par l'érection de deux montants en opus vittatum mixtum à deux assises de briques. Pour justifier l'installation de cette boulangerie au cours de cette phase consécutive au séisme de 62, soulignons que la coupole du four a subi des dommages caractéristiques de ceux qui se produisent en cas de secousse sismique. De plus, le four s'appuie sur une porte bouchée qui appartient au projet initial: le montant oriental est construit en opus vittatum. La boulangerie n'appartient donc pas à la première phase mais a été frappée par un séisme: elle doit donc s'inscrire dans la phase II (62 - ca. 75 ap. J.-C.).

${ }^{75}$ L'empreinte de six solives de section circulaire peut être observée sur la paroi sud de la pièce 8-2. Dénuées de délimitation en tuile, elles ne peuvent correspondre qu'à une phase
}

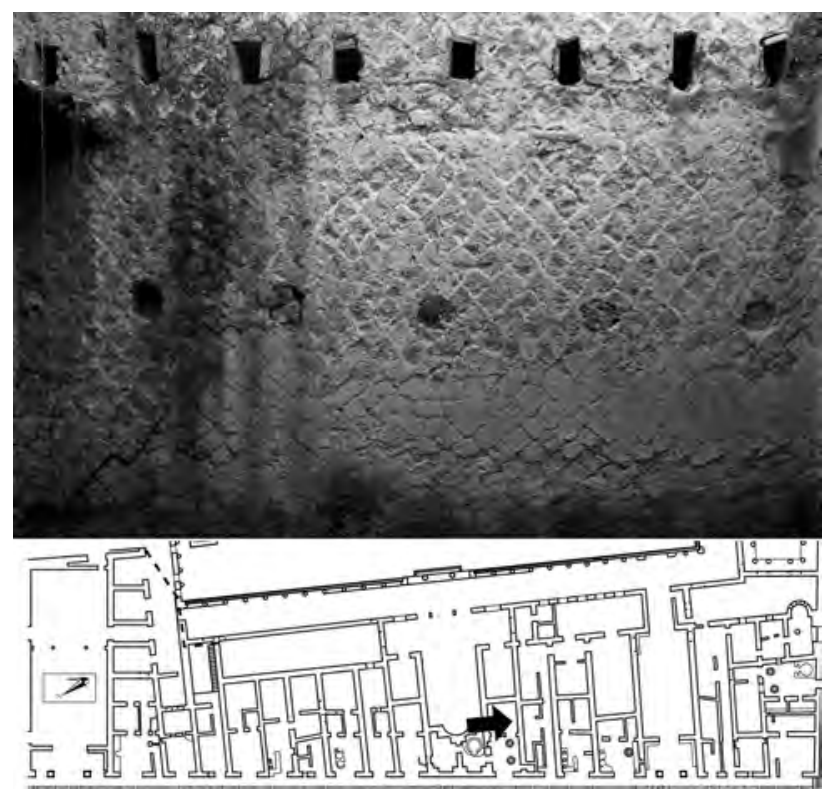

Fig. 136 - Insula Orientalis $I I^{a}$, pièce 8-2, mur sud. Les empreintes de solives rondes suggèrent l'installation d'une mezzanine non prévue dans le projet initial.

ment marquées par l'utilisation de l'opus vittatum mixtum à deux assises de briques ${ }^{76}$. En dépit de l'emploi de cette technique de construction particulière, la distinction entre la phase de simple réparation et celle de transformation successive est moins aisée que lors des travaux qui ont suivi le séisme de 62. En effet, il apparaît que les réparations financées par l'empereur débordent du seul cadre de la remise en état de l'édifice: d'importantes modifications paraissent avoir été réalisées en même temps (pl. II, h.t.; fig. 137) $)^{77}$.

postérieure à la construction. Ces empreintes ne sont pas visibles sur le mur nord, fortement restauré, mais qui aurait pu conserver la cavité correspondant à la deuxième solive depuis l'ouest. Dans le mur oriental, aucune trace correspondant à une solive passante de soutien n'est visible. Il faut alors nécessairement restituer un mur orienté est-ouest au centre de la pièce.

76 Sur l'existence d'un second séisme qui peut être inféré de cette inscription, cf. supra, p. 234-235. En ce qui concerne l'emploi de l'opus vittatum mixtum à deux assises de briques, cf. supra, p. 239 sq.

${ }^{77}$ De ce fait, dans l'évolution présentée sur la pl. h.t. II, la trame utilisée pour indiquer les réparations signale en fait toutes les transformations vraisemblablement effectuées par Vespasien, et non les seules remises en état employant l'opus vittatum mixtum à deux assises de briques. La carte de répartition de cette technique de construction est présentée à la figure 112 . 


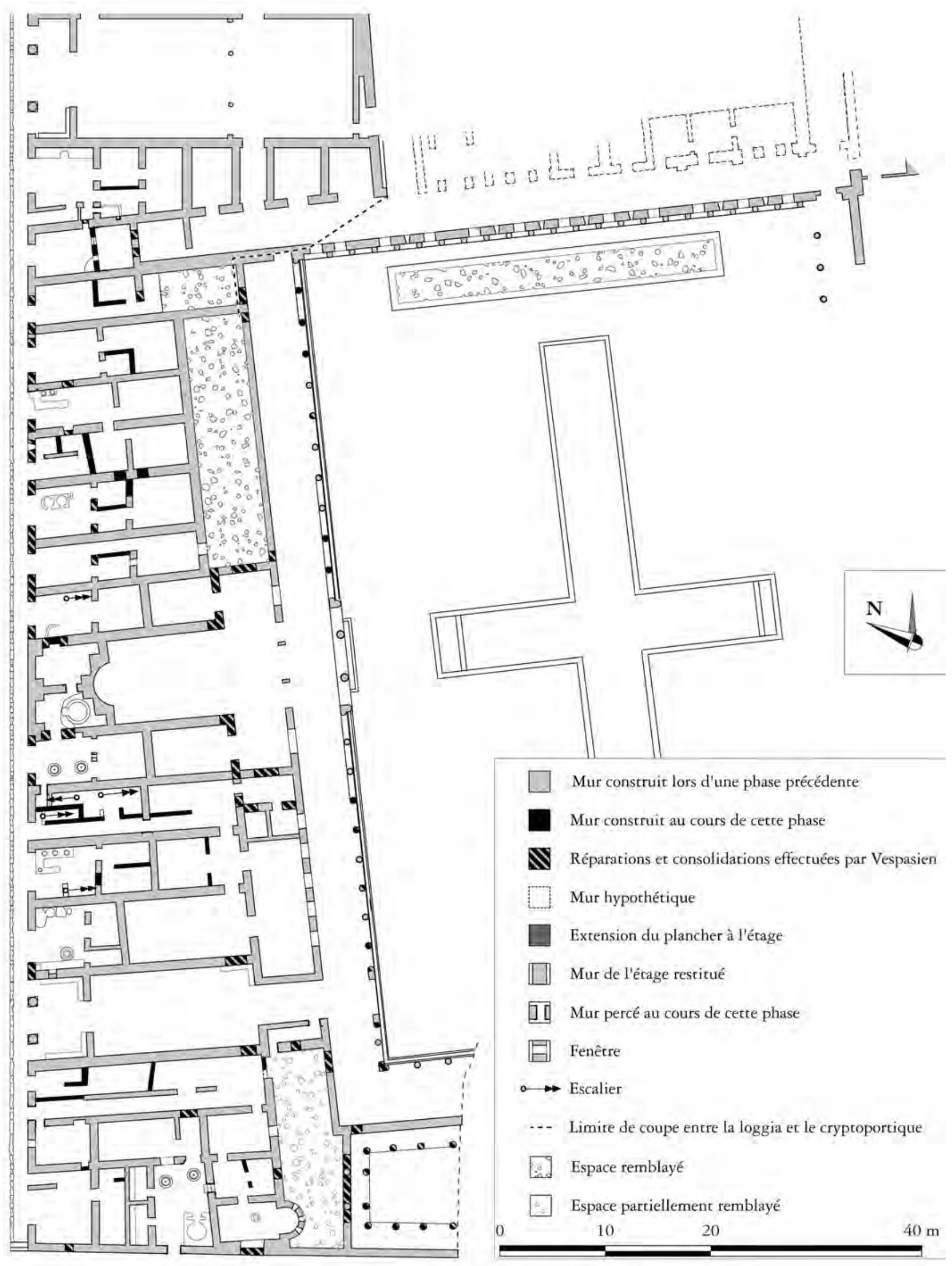

Fig. 137 - Insula Orientalis $I I^{a}$ - transformations consécutives au second séisme (ca. 70/75; échelle: 1/500). 
L'intervention impériale apparaît centrée autour de la consolidation d'un édifice malmené par deux secousses sismiques - qui ont montré des erreurs de conception - mais également par certains aménagements peu soignés effectués après le projet initial. De ce fait, le $V m^{2}$ ne peut pas servir de guide pour déterminer l'impact du second séisme sur le bâtiment. Il a en effet été employé en des endroits qui n'ont pas nécessairement été endommagés par le tremblement de terre. La façade de la boulangerie Or. II, 8 donne une illustration de cet emploi préventif d'une forme de maçonnerie adaptée aux montants, portion particulièrement fragile en cas de secousse tellurique (fig. 117). Les montants originels sont en opus vittatum au nord et en opus vittatum mixtum à une rangée de briques au sud. Le linteau disposé au sommet de cette première ouverture est d'une épaisseur imposante, quelque $40 \mathrm{~cm}$. Telle qu'elle peut être observée actuellement, la partie inférieure des deux montants est réalisée en $V m^{2}$. La limite entre cette technique de construction et les précédentes est marquée par un second linteau, situé $1,08 \mathrm{~m}$ sous le premier. Son épaisseur est moindre de moitié. L'espace entre les deux linteaux a été rempli par de la maçonnerie. Le maintien en place du premier linteau et la préservation des deux techniques de construction correspondant au projet originel indique clairement que les montants n'ont pas été détruits lors du second séisme. Dès lors, l'utilisation du $\mathrm{Vm}^{2}$ correspond à un remplacement volontaire effectué en même temps que la réduction de hauteur de la porte. Comme le faisait déjà remarquer A. Maiuri, à

${ }^{78}$ A. Maiuri (1958 b: 117-118) mentionne cet abaissement à la suite d'un paragraphe consacré aux réparations qui ont suivi le séisme de 62. Il ne lie toutefois pas de façon explicite les deux faits.

${ }^{79}$ Les deux portes percées dans les murs nord et sud de la boutique Or. II, 13 pourraient avoir été obturées à ce moment.

${ }^{80}$ La façade entre les boutiques Or. II, 8 et 9 montre que les fenêtres correspondant à l'étage aboli - se développant auparavant au-dessus des pièce 8-4 et 8-5 - ont été complètement murées. Les baies donnant sur le pronaos ont été comblées, tout comme celle s'ouvrant depuis l'étage sur la salle A. La largeur de la fenêtre correspondant au premier étage de l'espace Or. II, 7 a été réduite. La fenêtre donnant de la pièce 1a-6 sur l'espace 4-4 a également été bouchée.

${ }^{81}$ Sur ce point, cf. supra, p. 239-242. chaque fois que les murs conservent une élévation suffisante, cette réduction de la hauteur des portes peut être observée, en particulier sur la façade occidentale ${ }^{78}$. La mise en œuvre déployée pour cette réduction de l'embrasure est toujours l'opus vittatum mixtum à deux assises de briques. D’une façon générale, la majeure partie des travaux de Vespasien semble avoir eu pour objectif de réduire les vides dans la maçonnerie, considérés comme autant de points faibles pouvant engendrer des destructions. Ces travaux de précaution ont donc amené à la fermeture de certaines portes hâtivement percées sans emploi de montants particuliers ${ }^{79}$, à l'abolition de l'étage se développant au-dessus des pièces 8-4 et 8-5, au bouchage ou à la réduction de l'ouverture de certaines fenêtres ${ }^{80}$, mais surtout au remblaiement de plusieurs pièces: la pièce $\mathrm{L}$ a été intégralement comblée après la réparation des montants de l'accès à la salle III; la baie donnant sur le pronaos ainsi que des accès au portique ont été bouchés ${ }^{81}$. La pièce 15-4, auparavant utilisée comme escalier de liaison entre la terrasse inférieure et le cardo $\mathrm{V}$, a également été remblayée, une fois murée la porte donnant sur le portique ${ }^{82}$. Ces deux remblaiements doivent être liés à des problèmes de structure de l'ensemble du bâtiment. En effet, compte tenu de la pente naturelle sur laquelle est implantée l'Insula Orientalis $I I^{a}$, la création de la terrasse et du portique a nécessairement impliqué d'importants travaux de terrassements. La différence d'altitude entre la rue et la pièce 15-4 est de 4,15 m, alors même que cet espace n'est pas couvert avec une voûte, contrairement au

${ }^{82}$ Maiuri 1958 b: 466. Cf. GSE 1937: « 30 giugno. Si è sospeso lo spianamento del terreno e si lavora ad ovest del grande portico, e precisamente nell'angolo nord ovest. Nessun oggetto si è raccolto.

1 luglio. Nell'ambiente posto a nord ovest del grande portico, nel terreno di riempimento si è raccolto un fondo di coppa aretina col bollo seguente: [Description d'un timbre in pianta pedis] [...].

7 luglio. È terminato il lavoro nell'ambiente a nord ovest del portico. Come già feci noto l'ambiente una volta aveva d'ingresso nell'ambulacro lato ovest, poi fu chiuso e vi si entrava dalla casa n. 15 posta nel V cardine II insula orientale». Les différents timbres sur fonds de vases sigillés découverts dans le remblai entre le $1^{\text {er }}$ et le 6 juillet 1937 ne permettent pas de spécifier la date de fermeture de cet espace. 
cryptoportique. Dès lors, cette pièce et la salle $\mathrm{L}$ constituent, dans le plan originel, deux vides au-dessus desquels se développent les portions les plus élevées de l'édifice. Leur remblaiement sert de contrefort et empêche d'éventuels mouvements dangereux dans la maçonnerie. Au contraire de ce qui a été avancé par A. Maiuri et M. Pagano, j'interprète le remplissage du bassin rectangulaire selon le même schéma ${ }^{83}$ : les effets conjugués de la proximité du bâtiment au nord et de la profondeur du bassin génèrent un risque non négligeable d'affaissement au niveau des fondations du cryptoportique. Là encore, le remblaiement permet d'assurer une plus grande stabilité à l'ensemble et d'éviter de laisser ouvert un vide dangereux ${ }^{84}$.

Par-delà de ces travaux, essentiellement concentrés en façade, autour de l'Aula absidata et dans les espaces remblayés, il devient plus difficile de déterminer si les changements de plan que l'on peut observer appartiennent aux consolidations effectuées par Vespasien. En effet, parmi les transformations les plus importantes se trouve une modification radicale du plan de circulation et d'accès à certaines parties publiques au préalable. Si le remblaiement des espaces L et 15-4 constitue déjà une réduction des espaces publics, ainsi qu'une modification de l'accès à la terrasse inférieure, les changements

${ }^{83}$ A. Maiuri (1958 b: 135) estime, comme un élément de son interprétation distinguant deux phases de construction à la «Palestre» (sur ce point, cf. supra, p. 257-258), que le bassin rectangulaire fonctionnait dans le premier état du cryptoportique, quand il s'ouvrait sur la terrasse. Le remblaiement aurait eu lieu une fois l'extension du bâtiment et le bassin cruciformes construits. M. Pagano (1996 a : 245), bien que refusant l'idée de deux phases pour le bâtiment, considère également que le bassin rectangulaire a pu être remblayé à la suite de la construction de la natatio cruciforme.

${ }^{84}$ Le bassin rectangulaire se trouve à 6 mètres au sud du cryptoportique. Sa profondeur est de 2,35 mètres (Maiuri 1958 b: 137). Les journaux de fouilles correspondant à la mise au jour de ce bassin sont, comme pour l'ensemble des travaux effectués dans la "Palestre» après guerre, lacunaires et lapidaires. La seule mention de cette découverte est brève et peu détaillée. Cf. GSE 1956: «Dal 1 al 12 agosto. [...] Si è dato inizio allo svuotamento dei materiali accumulati nella natatio esistente in linea parallela al fronte esterno del Criptoportico. Le pareti di essa sono ricoperte di signino e fino a questo momento i materiali in essa accumulati sono tutti materiali di riporto, il che lascia adito alla sont plus importants encore au sud de l'Aula absidata et dans le bloc méridional. Dans ce dernier, la communication entre le péristyle et la pièce 4-4 est définitivement obturée. La différence de niveau actuelle laisse supposer que cette pièce a été partiellement remblayée, une fois bouchée la porte menant vers l'angle sud-ouest du portique. Il semble également que le lien vers l'ouest et vers l'espace $1 \mathrm{a}-9$ ait été obturé ${ }^{85}$. Loin d'être complètement clos, l'espace 4-4 bénéficie d'un passage vers le vestibule conduisant à la terrasse inférieure. Le remblaiement partiel permet de rattacher les travaux effectués dans cette pièce à l'intervention de Vespasien. En ce cas, il convient également de considérer que la transformation radicale de tout le bloc méridional a été effectuée au même moment. Au terme de ces travaux, tous les espaces se développant entre les entrées 1a - qui est alors percée - et 3 sont d'usage privé et non plus partiellement public. Une boulangerie s'installe en Or. II, 1a, profitant non seulement des trois pièces situées au niveau du vicolo meridionale, mais également en s'étendant à l'est dans la partie surélevée, par le percement d'une porte dans le mur porteur ${ }^{86}$. Les autres changements sont d'importance moindre. La boutique Or. II, 1 retrouve son aspect originel, perdant l'accès à la pièce 2-2. Celle-ci est désormais reliée à l'entrée Or. II, 2, créée à ce moment (fig. 128).

supposizione che detta vasca venne abolita dagli antichi stessi. Di particolare rilievo è il fatto che anche la natatio venne esplorata dagli scavatori borbonici, data la presenza di un cunicolo lungo il muro nord di essa. Lo scavo di detta natatio è stato però sospeso per adibire gli operai allo sbancamento dei materiali verso oriente $[\ldots .$.$] ». Rien ne permet$ de déterminer ce qui est advenu des tessons éventuellement découverts lors de cette fouille.

${ }^{85}$ En l'état actuel, le mur qui clôt la pièce 1a-9 à l'est apparaît incomplet et fortement dégradé (cf. fig. 3-31). Comme il ne présente pas de fin vers le sud, il me semble, à titre d'hypothèse, nécessaire de le prolonger afin de clore complètement le passage entre les deux pièces. Seuls les vestiges visibles sont reportés sur les différents plans publiés par A. Maiuri (1958 b: fig. 91 p. 114 et pl. IV, B).

${ }^{86}$ Une telle pratique semblerait en contradiction complète avec les grandes lignes du schéma de réparation et de consolidation réalisé par Vespasien. Toutefois, l'ouverture pratiquée entre les pièces $1 \mathrm{a}-1$ et $1 \mathrm{a}-6$ reste de taille réduite, d'une hauteur inférieure à 1,50 m (cf. Maiuri 1958 b: pl. XXXIX), limitant d'autant la portée des atteintes à la maçonnerie. 
Cette entrée devrait avoir servi d'accès à l'escalier menant à l'étage. Enfin, par la création de deux murs de refend, un petit espace, probable boutique d'interprétation incertaine, est ménagé en Or. II, $3^{87}$.

Les autres transformations plus radicales, du plan de circulation et des fonctions de l'Insula Orientalis $I I^{a}$ se situent autour de l'entrée Or. II, 7 et des pièces A, B et D. Avant d'étudier les changements survenus en Or. II, 7, qui concernent tout autant l'accès aux étages qu'au rez-de-chaussée, il me faut décrire le nouveau plan des salles A, B et $\mathrm{D}$. La pièce $\mathrm{B}$ ne subit qu'une transformation: l'accès au vestibule 4-1 est désormais fermé, obligeant alors à modifier l'ensemble du plan de circulation. La pièce $\mathrm{D}$ reste inchangée; ses ouvertures sur le portique sont maintenues et ne paraissent pas avoir souffert lors du second séisme. Les modifications les plus importantes concernent la salle A. Son sol, auparavant en fines tesselles noires et blanches, est refait, la mosaïque étant alors recouverte d'une épaisse couche d'opus signinum non décoré. Un mur de refend est créé au nord et sud, de façon à ménager un accès central tout en réduisant la longueur de la salle. La partie antérieure - pièce 7-9 - ainsi créée est un espace de distribution qui permet d'accéder aux salles A, B et $\mathrm{D}$. Au nord de cette dernière, la pièce 7-8 est condamnée, tandis que l'ouverture de la pièce 7-7 est réduite. Enfin, la pièce 7-6 voit la baie

${ }^{87}$ La présence d'un seuil à rainure de type D1a (cf. supra, p. 57-58) tend à faire de cet espace une boutique. Les données de fouilles concernant ce local sont très peu nombreuses, rendant délicate son interprétation. Cf. GSE 1932: « 7 aprile. [...] Il secondo vano lato sud è lungo $\mathrm{m}$. 1.77 e largo m. 0.49. La soglia è di pietra lavica. Sopra esso per $\mathrm{m}$. 1.18 vi è una scanalatura larga $\mathrm{m}$. 0.04 fatta nella medesima maniera di quella della soglia delle botteghe e per m. 0.59 senza scanalatura ciò dimostra che lo spazio minore occupato da una porticina, mentre la rimanenza era chiuso da tavole scorrevoli [...].

14 aprile. [...] Nel vano numero 2 dello stesso tempio a m. 0.90 dal pilastro lato sud vi è un muro largo m. 0.45 ed alto attualmente m. 0.55 e il pavimento che passa tra essi è di tegole di terracotta. Sopra detto spazio eravi poggiato un fondo di dolium di terracotta senza nessun bollo». La présence de ce dolium pourrait autoriser la restitution d'un petit commerce alimentaire. Il convient toutefois d'être prudent au vu de la faiblesse des éléments supportant cette interprétation. s'ouvrant sur le pronaos condamnée. Comme A. Maiuri, je considèrerai que ces différentes transformations n'ont pas fait perdre leur caractère public à ces pièces, sans cependant chercher à en déterminer l'usage précis ${ }^{88}$. Les adaptations survenues dans les pièces situées dans le prolongement de l'entrée Or. II, 7 - qui devient alors le seul point d'accès aux salles $\mathrm{A}, \mathrm{B}$ et $\mathrm{D}$ - sont plus délicates à exposer en raison des nombreuses restaurations modernes. Seule l'étude fine du système de poutres et l'observation des liens entre les pièces 7-2 et 7-3 permettent de saisir les modifications survenues dans cette partie de l'Insula Orientalis $I I^{a}$. Un nettoyage effectué à l'extrémité de la pièce 7-2 m'a permis de discerner deux phases de construction de part et d'autre d'un mur de refend orienté est-ouest (fig. 138, b). Au nord, le mur de refend nord-sud apparaît arasé, certainement dès avant l'éruption; une pierre est disposée à plat devant ces restes de maçonnerie, constituant une probable marche (fig. 138, a et d). Au sud, un mur dont les éléments - mortier et caementa - sont différents est également arasé (fig. 138, c). Je proposerai simplement qu'il n'ait pas été restauré en élévation; il aurait constitué la limite orientale de l'espace 7-2, cage d'escalier dont la première marche est un bloc de tuf ${ }^{89}$. Tel qu'il est visible actuellement, le mur de refend est-ouest qui se développe au sud des pièces 7-2 et 7-3 a été presque intégralement reconstruit lors des

\footnotetext{
${ }^{88}$ A. Maiuri (1958 b: 128) refuse la pire des transformations, celle qui aurait conduit ces espaces à avoir une utilisation commerciale: «[...] il loro stesso impianto e la loro ubicazione non consentivano che potessero trasformarsi in una comune casa d'abitazione o, peggio, in locali d'industria o di bottega». En revanche, faute de tout élément épigraphique ou autre permettant d'appuyer son hypothèse d'une association religieuse ou professionnelle liée à l'institution de la juventus, il me semble nécessaire de rejeter cette dernière.

${ }^{89}$ Tant l'arasement du mur que la destruction partielle de l'escalier sont dus au passage d'un tunnel creusés par les fouilleurs du XVIII ${ }^{e}$ siècle. Cf. GSE 1936: " 8 luglio. Nella casa $\mathrm{n} .7$ posta sul $\mathrm{V}$ cardine $2^{\circ}$ Insula orientale a sinistra di chi entra vi è una scala di legno carbonizzato che serviva per salire ai piani superiori esterni. I primi scalini mancano completamente perché in detto sito ci passava un cunicolo. Ogni scalino misura m. 0.25 di larghezza e m. 0.22 di altezza e m. 0.80 di lunghezza. Il traversone è alto m. $0.20 \mathrm{e}$ m. 0.05 di larghezza. Nessun trovamento».
} 


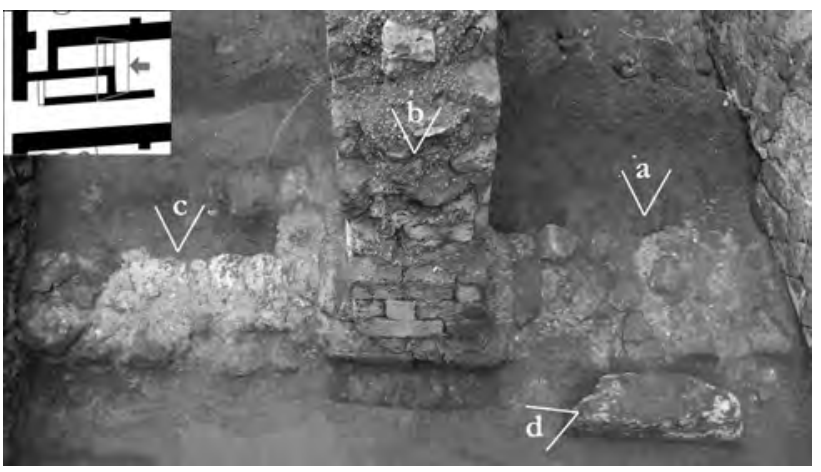

Fig. 138 -Insula Orientalis $I I^{a}$, pièce 7-3, côté ouest. Vestiges de maçonneries non restaurées lors de la fouille. a: mur de refend appartenant à la première phase de l'édifice, arasé au moment de l'éruption; b: mur de refend nord-sud construit lors de la dernière phase, fortement restauré; c: mur construit lors de la dernière phase qui se distingue du mur a par son mortier; d: bloc de pierre utilisé comme première marche d'un escalier est-ouest accessible depuis la pièce 73. Le mur (c) a servi de piédroit d'échiffre à l'escalier ouestest accessible depuis la pièce 7-2.

fouilles. Un bref retour de maçonnerie antique vers le nord a toutefois été préservé (fig. 139, b). Il autorise la restitution d'un passage entre la pièce $7-1$ et la pièce $7-3^{90}$. L'étude des empreintes de solives permet de compléter la compréhension de l'articulation de ces espaces. La paroi nord montre deux séries de cavités. La première, à l'est, comporte quatre solives de petites dimensions et une cinquième de section plus importante. Elles sont toutes encadrées par des tuiles, signe de leur mise en œuvre dans le projet initial, et trouvent leur répondant dans la paroi sud (fig. 139, c). En revanche, dans la partie ouest de la paroi nord, quatre solives ont été insérées, sans que leur cavité ne soit entourée de briques et sans disposer d'une seconde extrémité dans la paroi sud; elles décrivent pourtant un plancher qui donne accès à l'étage situé au-dessus des pièces 8-1 à 3. Ces différents éléments permettent de proposer une restitution de la fonction de ces différentes pièces. L'espace 7-2 est une cage d'escalier permettant d'accéder au second étage, grâce à une seconde volée de marches. Le couloir 7-1 permet soit de rejoindre les salles

${ }^{90} \mathrm{Il}$ serait nécessaire de nettoyer l'intégralité du sol de cette pièce pour permettre de vérifier cette hypothèse.

91 Cette division de l'étage fait que l'appartement surplombant la boulangerie Or. II, 8 n'est aucunement lié

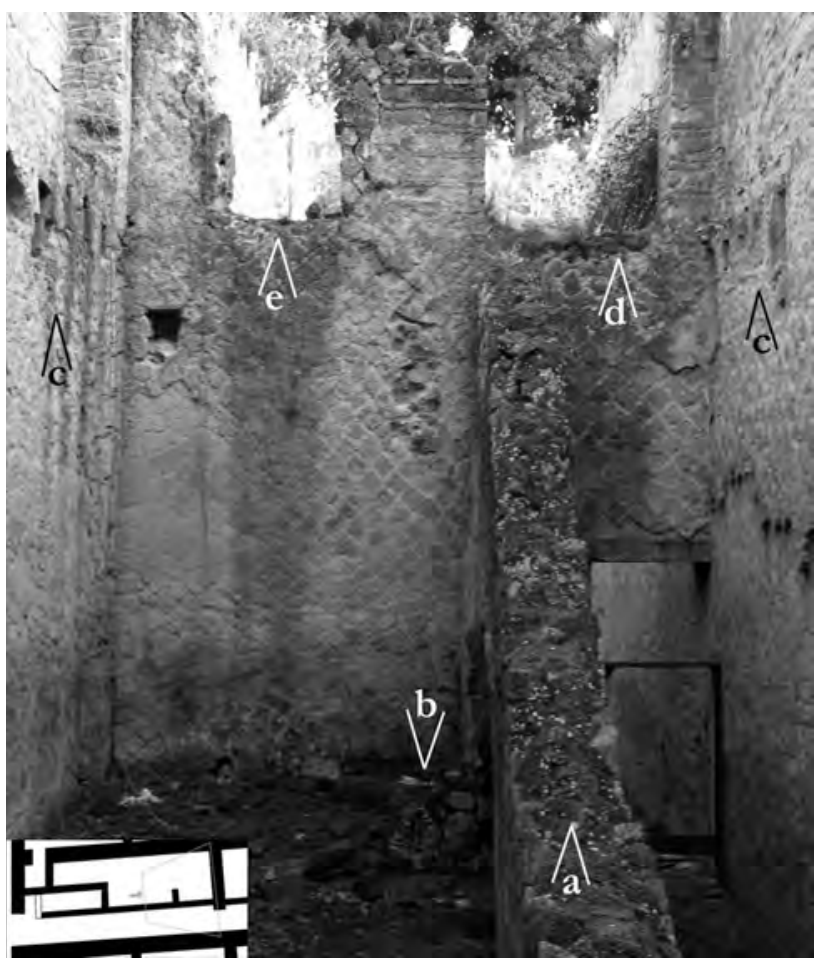

Fig. 139 - Insula Orientalis $I^{a}$, pièce 7-3, mur est. a: mur de refend intégralement reconstruit lors de la fouille, sans respecter toutes les maçonneries visibles; b: montant oriental d'un passage entre le couloir 7-1 et la pièce 73, partiellement restauré; c: solives encadrées de tuiles supportant l'étage partiel dès la première phase; $d$ : porte donnant accès à l'étage surplombant les pièces 7-4 et 7-5, incluse dans la construction originelle; e: porte percée sans soin lors de la dernière phase.

publiques $\mathrm{A}$, $\mathrm{B}$ et $\mathrm{D}$, en passant par la pièce $7-4$, soit d'accéder au premier étage par la pièce 7-3. Dans cette dernière, deux escaliers sont disposés. Le premier est orienté vers l'est; il donne accès à l'étage situé au-dessus des pièces 7-4 et 7-5. Le second, orienté vers l'ouest donne accès à l'étage surplombant la boulangerie. Lors de la construction initiale, ces deux appartements communiquaient par une porte percée entre 82 et 7-3. Elle a été bouchée, vraisemblablement lors des travaux de réparation et de consolidation (fig. 140) ${ }^{91}$.

avec cet espace de panification. Dès lors, les moules en bronze provenant de cet appartement ne sauraient être associés avec la production de pain se déroulant au rez-dechaussée (sur ce point, cf. supra, p. 151-152). 


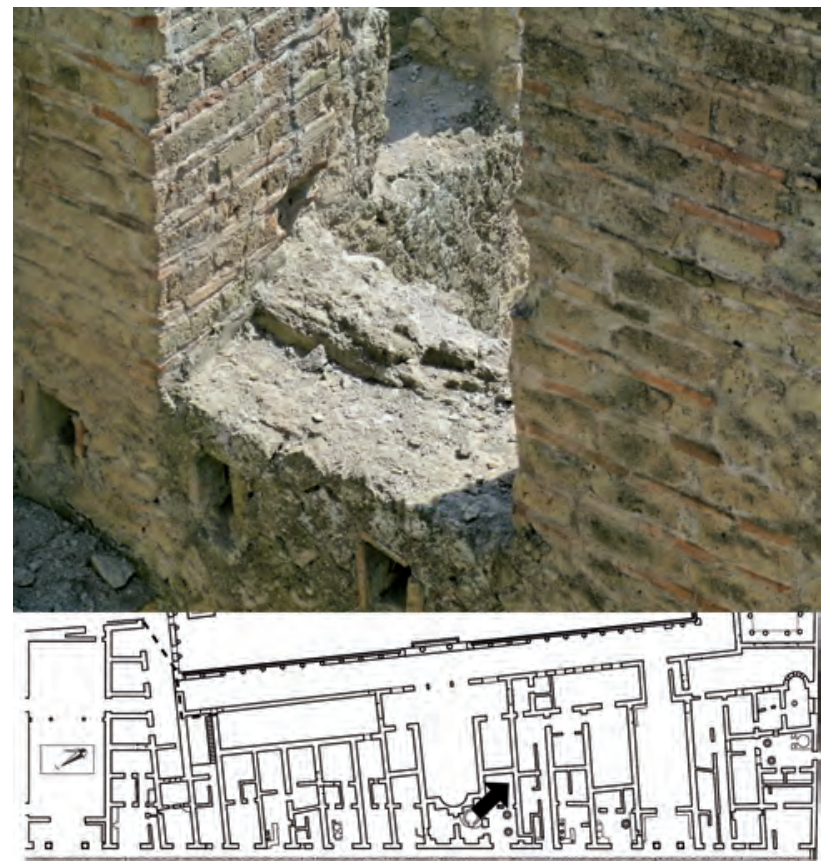

Fig. 140 - Insula Orientalis $I I^{a}$, pièce 8-2, étage, angle sudest. La porte percée dans le mur sud donne accès à l'étage qui surplombe la portion orientale de la pièce 7-3 lors de la première phase. Au moment de l'éruption, elle a été bouchée.

Enfin, une dernière série de transformations pourrait être attribuée aux travaux réalisés par Vespasien. Elle concerne les locaux Or. II, 16 et Or. II, 18. Tout d'abord, le passage percé entre ces deux locaux lors de la phase précédente est obturé. De plus, il semble que le mur de refend entre la boutique Or. II, 16 et les pièces accessibles depuis la loggia ait été détruit lors du séisme. Sa reconstruction, qui pourrait ne pas faire partie des réparations financées par le pouvoir impérial, a été effectuée avec un léger décalage vers l'ouest: le nouveau mur de refend s'appuie sur les vestiges du précédent, comme le souligne une couche d'enduit partiellement recouverte par la marche permettant de passer de la pièce 16-1 à la pièce 16-2 (fig. 141). En lien

\footnotetext{
${ }^{92}$ Il semble difficile que le bouchage de ces deux portes ne soit pas attribué aux travaux financés par Vespasien. En revanche, la reconstruction du mur de refend nord-sud pourrait faire partie des transformations successives à ces travaux.
}

avec cette reconstruction, les deux portes de communication entre les pièces 19-5 et 16-2 sont bouchées $^{92}$. De cette façon, la boutique Or. II, 16 est devenu un local indépendant disposant d'une pièce annexe gagnée sur l'espace public. En Or. II, 18, un tuyau destiné à recueillir les eaux usées est inséré dans le mur sud de la pièce 18-4. Pour faciliter l'évacuation, plutôt que de creuser le pavement, on a ménagé une gouttière maçonnée. Elle se déverse dans la latrine de la pièce 18-3, après avoir traversé le mur (fig. 142). L'importance de cette installation dans l'économie générale de l'édifice semble suffisante pour l'assigner aux travaux de Vespasien. En revanche, la construction d'un refend séparant les pièces $18-2$ et $18-4$, sur lequel est installé une mezzanine correspond aux dernières transformations dans ce local, comme l'installation d'une officine de nettoyage des toisons.

Avec ceschangements dansl'accèsauxespaces publics, la recension des travaux effectués par Vespasien est complète. À la suite de ces réparations et consolidations, d'autres transformations sont survenues dans l'Insula Orientalis $I I^{a}$. Elles concernent tant l'installation de certaines activités dans les locaux commerciaux que le redimensionnement de ceux-ci, au rez-de-chaussée ou à l'étage. Les travaux qui sont menés à ce moment sont d'autant plus intéressants qu'ils prennent parfois l'exact contre-pied des réalisations impériales. Ainsi, l'étage surplombant les pièces 8-4 et 8-5 a été condamné, ainsi que les fenêtres donnant sur le cardo V. Pourtant, entre 76 et 79 , la porte de communication entre le local Or. II, 9 et la pièce $8-5$ est bouchée, tandis que le mur séparant cet espace de la pièce 8-4 est percé d'une porte. De cette façon, la boulangerie Or. II, 8 s'agrandit d'une pièce vers le nord. Une fenêtre est ménagée dans la paroi occidentale (fig. 117, e). De la même façon, une porte est creusée dans le mur sud du local principal pour permettre un accès aux latrines disposées en $8-3^{93}$. Les autres transformations concernent essentiellement les conditions de loge-

\footnotetext{
${ }^{93}$ Il est probable que ce creusement ait été effectué lors des transformations survenues dans le local Or. II, 7.
} 


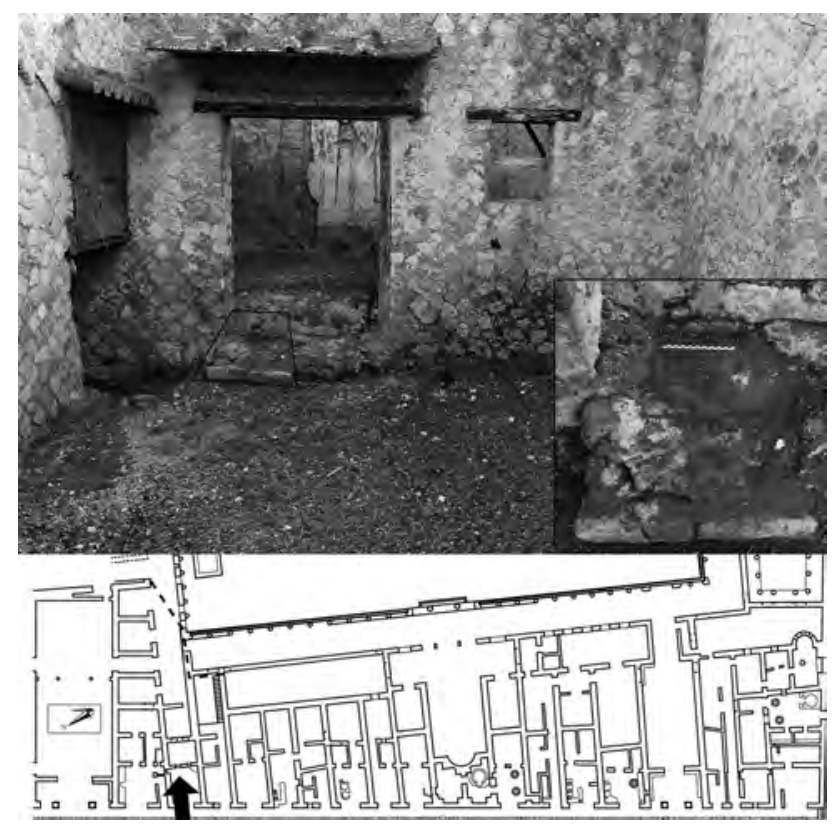

Fig. 141 - Boutique Or. II, 16, local principal. Le mur de refend qui sépare cette boutique de la pièce annexe s'appuie sur un mur antérieur partiellement arasé, comme en témoigne l'enduit laissé sur ce dernier, englobé dans la marche (encadré).

ment dans ces boutiques et ateliers. Le local unique Or. II, 11.13-14 est subdivisé en trois. En Or. II, 13, un comptoir maçonné est installé en réduisant l'emprise du montant nord de l'entrée, vraisemblablement restauré par Vespasien. L'abolition des portes donnant dans les pièces 11-2 et 11-4 permet l'installation d'une chambre au rez-de-chaussée du local Or. II, 11. Comme en Or. II, 10 et en Or. II, 14, cette nouvelle pièce est formée par la mise en place de cloisons reliant les murs de refend du projet initial. Des mezzanines sont également installées au-dessus de ces pièces, si elles n'existaient pas. Les trois boutiques Or. II, 10, 11 et 14 prennent alors un aspect très proche, à l'exception des aménagements propres aux activités s'y développant: outre le

${ }^{94}$ La conception de cette pièce est également différente: elle n'est pas créée en construisant une cloison entre deux murs de refend, mais en édifiant une cloison en équerre qui s'appuie sur le mur de refend préexistant. Sur l'usage de cette pièce comme chambre, cf. Maiuri 1958 b: 466.

${ }^{95}$ Maiuri 1958 b: 466 . La partie orientale de cette pièce, dont le pavement correspondait au sommet du remblai oblitérant l'accès vers la terrasse inférieure, a été décrite de façon trop sommaire pour que l'on puisse déterminer les

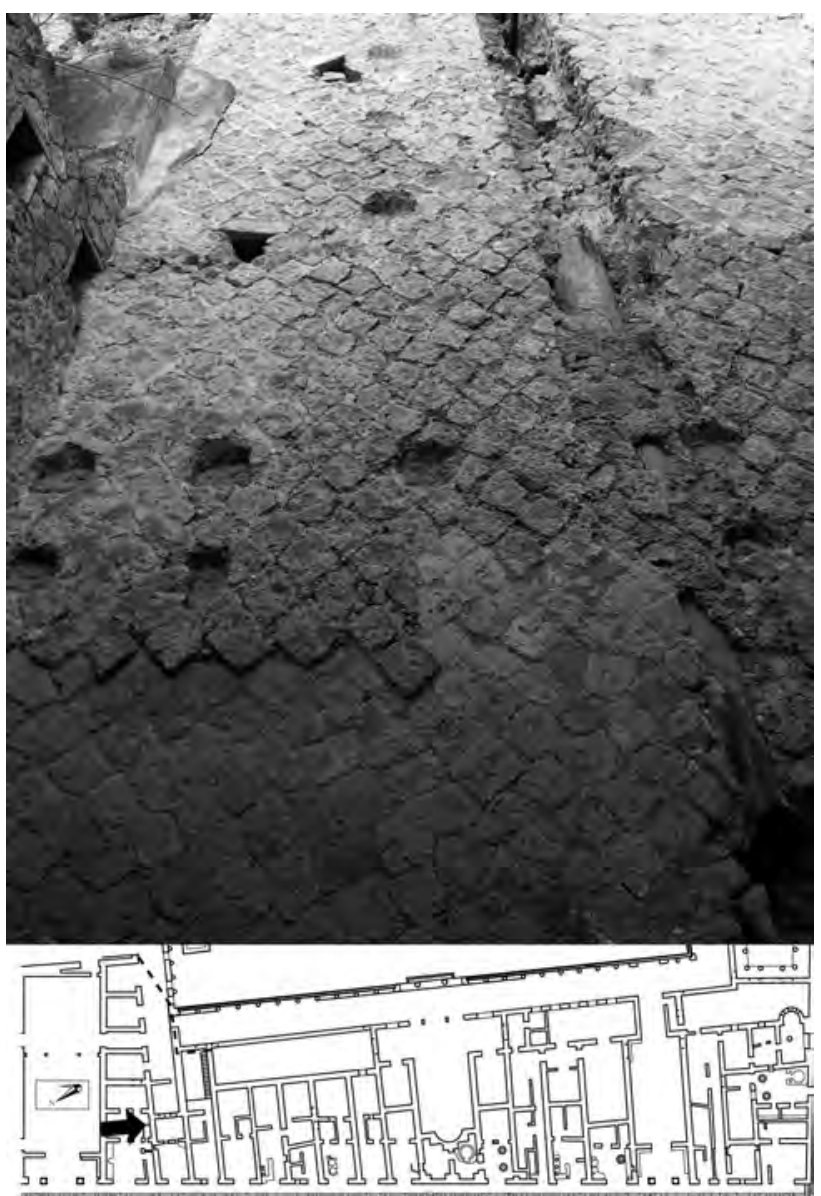

Fig. 142 - Atelier Or. II, 18, pièce 18-4, mur sud. L'installation de la descente de latrine ne saurait remonter à la première phase de l'édifice: elle coupe la maçonnerie originelle.

local principal, on y trouve une chambre, longée par un couloir ou un espace qui permet d'accéder à une pièce annexe. La boutique Or. II, 15 tend également à se conformer à ce nouveau modèle de boutique. Toutefois, la pièce 15-3 ne doit pas nécessairement être interprétée comme une chambre ${ }^{94}$. La pièce 15-4 sert de cuisine, tout du moins sa partie occidentale ${ }^{95}$.

activités s'y déroulant. Cf. GSE 1937: « 29 aprile. L'ambiente 3 della casa 15 è a forma rettangolare. Misura metri 3.75 di lunghezza per 9.30 di larghezza. La parete è del tutto distrutta, mentre le altre sono poco sviluppate. È da supporsi che nella parete est doveva starci qualche finestra per avere la luce dal grande peristilio, poiché pochissima ne poteva avere dal vano che affaccia nel V cardine data la sua lontananza. Aveva il piano superiore». 
La boutique Or. II, 9 a subi des changements liés indirectement aux conséquences du second séisme: à cause de la réduction de la hauteur de son entrée et de l'abolition de l'étage surplombant la pièce 8-5, il a été nécessaire de réduire la surface de la mezzanine disposée dans le local principal pour permettre à la lumière de continuer à entrer dans la pièce annexe. L'ensemble du local est décoré à neuf, en particulier la pièce 9-2 qui bénéficie alors d'un plafond suspendu et d'un revêtement pariétal de $\mathrm{IV}^{\mathrm{e}}$ style. La boutique Or. II, 6 profite de la redistribution de l'espace disponible à l'étage: un escalier est créé pour accéder à l'appartement surplombant l'ensemble du local. En Or. II, 5, la principale transformation concerne les activités qui s'y déroulent. La laverie de toison est remplacée par un probable atelier de feutre, éventuellement complété dans un premier temps par une installation de teinturerie. Cette dernière est démantelée avant l'éruption ${ }^{96}$. Enfin, le local Or. II, 12 a également subi de profondes transformations. D’abord séparé de la boutique Or. II, 13 au nord par le bouchage d'un passage, puis à l'est par l'érection d'un mur de refend, son interprétation reste délicate. En effet, selon A. Maiuri, il aurait présenté un escalier ${ }^{97}$, et aurait ainsi constitué le pendant des entrées Or. II, 2, 7 et 17 utilisées comme point d'accès aux appartements de l'étage. Aucune trace d'un tel aménagement n'est cependant visible.

Ces différents travaux font qu'au moment de l'éruption, le rapport entre les formes d'utilisation de ce bâtiment a été considérablement transformé. La part des activités commerciales ou domestiques s'est particulièrement accrue, passant, pour l'aile occidentale, de $27 \%$ à $41 \%$. Toutefois, bien que ce développement des commerces et des appartements se déroule à la suite du second séisme, rien ne permet de discerner un lien de cause à effet entre ces deux phénomènes, tout au moins en ne prenant en compte que la seule Insula Orientalis II ${ }^{a}$. En effet,

${ }^{96}$ Parmi les problèmes qui restent irrésolus se trouve l'accès à l'appartement se développant au-dessus du local Or. II, 5. Selon A. Maiuri (1958 b: 455), l'escalier se serait trouvé contre la paroi nord, là où ont été mises en évidence les fosses interprétées comme d'éventuels vestiges de tein- la multiplication - et la réduction de la taille des appartements ne saurait être comprise qu'à l'échelle de la ville ${ }^{98}$.

\section{L'INSULA ORIENTALIS II ${ }^{A}$ ENTRE FONCTIONS PUBLIQUES ET VIE COMMERCIALE}

$\mathrm{Au}$ terme de cette description de l'évolution de l'Insula Orientalis $I I^{a}$, plusieurs points méritent d'être soulignés. Tout d'abord, l'analyse des maçonneries démontre clairement que ce complexe a été érigé en un seul chantier, éventuellement divisé en plusieurs phases, et qu'il comportait dès son origine les différents éléments révélés par la fouille: une terrasse inférieure bordée d'un portique et au milieu de laquelle se développent deux bassins, l'un rectangulaire, l'autre cruciforme; au nord de cette terrasse, un cryptoportique surplombé par une loggia; une aile occidentale, présentant du côté du portique une série de salles publiques et sur le cardo $\mathrm{V}$ des boutiques et des accès aux étages. L'architecture particulière de ce complexe, et en particulier le subtil jeu de répartition des étages, tient à la topographie originelle du site de construction qui présente une forte pente orientée vers le sud et vers l'est. Les quelques variations dans les techniques de mise en œuvre et les transformations mineures de certains espaces ne permettent pas de remettre en cause l'unité de cette réalisation. Tout au plus soulignent-elles la durée du chantier de construction vraisemblablement achevé au cours du deuxième quart du $\mathrm{I}^{\mathrm{er}}$ siècle de notre ère.

Ensuite, je ne saurai trop insister sur la fonction initiale et principale de cet édifice qui reste avant tout un espace cultuel, dédié à la Magna Mater. De l'inscription célébrant les réparations effectuées par Vespasien disposée dans le vestibule à l'orientation des axes architecturaux - qui sont autonomes par rapport au reste de la trame urbaine - en passant par la position centrale de l'Aula absidata et du bassin cruciforme, tous les

turerie. Jusqu'à ultérieure vérification, il faut considérer que cet escalier se trouvait dans la pièce 5-2.

${ }^{97}$ Maiuri 1958 b: 466.

${ }^{98}$ Cf. infra, p. $353 s q$. 
éléments disponibles indiquent que le cœur de l'édifice est constitué par la terrasse inférieure et ses dépendances. Dans le fond, mon étude des espaces commerciaux qui se développent progressivement le long de la façade ouest du bâtiment ne constitue guère plus qu'une focalisation sur une des parties annexes de ce complexe. En effet, si, dès le projet initial, des boutiques et des appartements sont inclus, ils n'occupent que des espaces interstitiels, la surface qui leur est concédée étant tributaire des besoins publics.

Parmi les locaux commerciaux ou artisanaux dont on peut suivre l'évolution de façon satisfaisante, soit les lieux de métier dont les aménagements maçonnés facilitent - hors contexte de fouille stratigraphique - l'identification, je noterai en premier lieu le développement tardif des boulangeries qui n'apparaissent guère avant les années 60 . Bien évidemment, ce constat reste limité par le fait que certaines implantations de ce type de production peuvent être encore ensevelies. À propos du textile, je soulignerai de nouveau le maintien au cours des deux dernières phases d'une unique officine de lavage de toisons ${ }^{99}$. Son déplacement dans l'îlot ne saurait toutefois signifier qu'il s'agit du même artisan qui a changé de cadre de travail ${ }^{100}$. Aucun commentaire en revanche ne peut être fait sur les commerces alimentaires: si celui qui se trouve au moment de l'éruption en Or. II, 14 est une installation tardive, aucun élément ne permet de dater avec précision la création de celui qui se trouve en Or. II, 6.

Au-delà de ces particularités d'activités, il convient de dresser un bilan de l'évolution des implantations de commerces en façade de cet édifice. Une première solution consiste à suivre la répartition des fonctions. Chacune des phases voit une réduction progressive mais très nette

${ }^{99}$ Cf. supra, p. 171-175.

${ }^{100}$ Cette remarque ne tient pas compte de la possible laverie de toison située, au moment de l'éruption, en Or. II, 15; cf. supra, n. 17 p. 172.

${ }^{101}$ La surface totale utilisée diminue à la suite des travaux de consolidation menés par Vespasien, notamment avec le remblaiement de la salle L. Pour les deux premières phases, elle s'élève à environ $3640 \mathrm{~m}^{2}$, tandis que seuls $3500 \mathrm{~m}^{2}$ sont utiles à partir de la troisième phase. L'évolution en pourcentage correspond au rapport entre les espaces publics et les autres, incluant non seulement les commerces et leurs des espaces publics au profit des surfaces destinées aux activités commerciales. À surface au sol presque constante, la part des commerces et de leurs dépendances dans l'aile occidentale a cru, entre le projet initial et l'éruption, de $23 \%$ à $41 \%{ }^{101}$. Dans un cadre aussi général, je ne proposerai pas d'explication trop poussée à ce constat: il conviendrait de suivre en parallèle les évolutions des espaces publics et de déterminer la fonction des pièces qui ont été progressivement remplacées par des espaces commerciaux.

En revanche, cette évolution schématique masque des disparités d'une phase à l'autre. Ces dernières peuvent être mises en évidence en étudiant le nombre de locaux individualisés dans chaque phase, sans oublier de prendre en compte la surface occupée par les dépendances, qu'elles soient consacrées au travail ou à l'habitation (fig. 132). Après le séisme de 62, on observe ainsi une densification des locaux commerciaux. En effet, si leur nombre en valeur absolue ne varie que peu avec la création d'un commerce en Or. II, 18 qui fait passer le nombre de boutiques de 9 à 10, le nombre d'unités architecturales indépendantes ${ }^{102}$ diminue et la surface moyenne augmente - de 25 à $34 \mathrm{~m}^{2}$. Cette concentration s'explique en partie par les modifications induites à la suite de la secousse sismique: les deux locaux Or. II, 16 et Or. II, 11.13 s'adjoignent chacun une autre boutique. Cet effet de concentration est également accentué par la disparité des surfaces disponibles: le plus petit local - Or. II, 6 - se développe sur seulement $49 \mathrm{~m}^{2}$, tandis que les deux boutiques Or. II, 11.13-14 disposent avec leurs annexes d'une surface cumulée de $234 \mathrm{~m}^{2}$. Inversement, au cours de la phase suivante, ce phénomène disparaît complètement. Le nombre de boutiques - qui sont toutes des unités architecturales indépendantes - augmente de façon

dépendances, mais également les espaces d'accès aux appartements. Calculée de cette façon, la surface «non publique» passe de $840 \mathrm{~m}^{2}$ à $1420 \mathrm{~m}^{2}$ entre le projet initial et l'éruption du Vésuve. En revanche, si l'on prend en compte les espaces commerciaux, leurs annexes - d'habitation ou de travail - et les éventuels étages, la surface double presque au cours de la même période, passant de $660 \mathrm{~m}^{2}$ à $1122 \mathrm{~m}^{2}$.

102 Par unité architecturale, j'entends un ensemble unitaire, comportant une ou plusieurs pièces commerciales, éventuellement liées à des espaces d'habitation. 
assez importante, passant de 10 à 14. La surface moyenne strictement commerciale est réduite de 34 à $25 \mathrm{~m}^{2}$, tandis que les surfaces annexes ou d'habitation tendent à s'harmoniser ${ }^{103}$, notamment avec la création de mezzanines ${ }^{104}$. Cette dernière phase est donc marquée par une véritable parcellisation des espaces commerciaux. Cette violente inversion de tendance s'explique certainement par l'action menée par le pouvoir impérial: la majeure partie des travaux financés par Vespasien a consisté en une réduction des risques de destruction par le renforcement des maçonneries affaiblies par des ouvertures souvent trop importantes ou bricolées. Toutefois, quelques exemples montrent que certaines parois ont été percées sans art ni précaution lors de ces mêmes travaux ou immédiatement après. Dès lors, l'intervention impériale a pu constituer un moment de redéfinition des espaces pour mieux adapter cet édifice aux besoins alors ressentis, que ce soit en termes d'infrastructures commerciales ou surtout de logements.

Un dernier point doit être abordé pour conclure cette étude d'un édifice où les fonctions publiques et privées sont si étroitement mêlées et en concurrence permanente au fil de son évolution: la détermination de son propriétaire. Selon A. Maiuri, cette construction aurait été réalisée par le municipe d'Herculanum afin de donner un siège à certaines institutions comme celle de la juventus. L'aile occidentale aurait ainsi permis d'obtenir des revenus locatifs contribuant aux finances municipales ${ }^{105}$. Cette hypothèse semble très plausible, aux détails près concernant la présence de la juventus et des ludi, directement induite de l'interprétation de l'édifice comme une palestre. Toutefois, l'exemple d'Ostie permet de suggérer une autre possibilité. Lîlot du sanc-

\footnotetext{
${ }^{103}$ La seule exception à cette harmonisation des surfaces commerciales est constituée par la boulangerie Or. II, 1a, qui s'étend au total sur $193 \mathrm{~m}^{2}$. La surface moyenne est de $80 \mathrm{~m}^{2}$ durant cette phase; elle est réduite à $71 \mathrm{~m}^{2}$ si l'on ne prend pas en compte cette boulangerie.

${ }^{104}$ Entre les deux phases, la surface des étages associés aux boutiques a doublée, de $87 \mathrm{~m}^{2}$ à $179 \mathrm{~m}^{2}$. Ceci est dû non seulement aux créations de mezzanines dans les locaux situés au nord de l'Aula absidata, mais également au rattachement d'appartements auparavant indépendants à des boutiques. Notons que sans prendre en compte le lien avec les boutiques, la surface des étages dans l'aile occidentale reste constante tout au long de l'évolution de l'Insula
}

tuaire d'Hercule (I, XIv) montre, dans son évolution entre la fin de la République et le $\mathrm{II}^{\mathrm{e}}$ siècle de notre ère, des caractéristiques similaires: un espace sacré progressivement empiété par des constructions d'usage privé, mais vraisemblablement toujours tenu par un même propriétaire et dont les revenus auraient été gérés par une association religieuse ${ }^{106}$. Le sanctuaire de Sérapis serait d'un parallélisme encore plus frappant: comme dans l'Insula Orientalis $I I^{a}$, dès le projet originel, le sanctuaire aurait été associé à d'autres bâtiments comprenant des boutiques, des appartements, des thermes ${ }^{107}$. Faute de tout témoignage épigraphique permettant de choisir entre l'une ou l'autre hypothèse, il faudra se considérer que l'ensemble de la gestion de ce bâtiment devait être publique.

Pour conclure, contrairement à ce que proposait F. Yegül, l'Insula Orientalis $I I^{a}$ n'est pas un nouveau type architectural, adaptation romaine du gymnase grec. Il s'agit avant tout d'un espace partiellement consacré au culte de Cybèle, dont certains espaces ont été utilisés pour d'autres fonctions publiques non déterminées. Une probable gestion publique ou du moins collective - sans chercher à identifier l'entité véritablement propriétaire de cet édifice - a conduit à insérer des boutiques et des appartements le long de la façade ouest, pour en tirer des revenus locatifs. L'accroissement très sensible de ces espaces tout au long du $\mathrm{I}^{\mathrm{er}}$ siècle, recadré de façon assez stricte après les travaux financés par Vespasien, pourrait n'être qu'un épiphénomène uniquement lié à ce bâtiment. Seule l'étude des autres édifices - moins sensibles à des interventions du pouvoir municipal ou impérial - ayant accueilli des boutiques peut permettre de clarifier ce point.

Orientalis IIa. L'étage discontinu dispose d'environ $350 \mathrm{~m}^{2}$ dans le projet initial et au moment de l'éruption, en dépit des fermetures et réductions de surfaces qui surviennent autour des entrées Or. II, 7 à 9 .

${ }^{105}$ Maiuri 1958 b: 116-117.

106 Je remercie J. Dubouloz d'avoir attiré mon attention sur le possible parallélisme entre ces deux îlots à Ostie et l'Insula Orientalis $I I^{a}$ d'Herculanum. Sur le sanctuaire d'Hercule et les bâtiments qui lui sont associés, cf. Mar 1996, part. p. 148-152 pour les liens entre association religieuse et propriété urbaine.

${ }^{107}$ Sur l'histoire de cet îlot, cf. Bloch 1959, Mar 1995 et Mar 1996: 136-138. 


\section{ESSAI DE RESTITUTION DES IMPLANTATIONS COMMERCIALES EN FAÇADE DES DOMUS D'HERCULANUM}

Des dix îlots identifiés au sud du decumanus maximus grâce aux fouilles en tunnel du XVIII siècle, huit ont désormais au moins partiellement été mis au jour. Toutefois, les connaissances sur les insulae I, II et VII sont extrêmement limitées. En effet, seule la frange méridionale donnant sur la mer de l'insula I a été mise au jour lors des fouilles de la Villa dei Papiri. Quant aux insulae II et VII, leur bord occidental donnant sur le cardo III est connu, au niveau de la Casa d'Argo, sur la moitié de leur largeur sinon seules les boutiques ont été - partiellement -

1 Dans la pièce $\mathrm{D}$ de la Casa del rilievo di Telefo (Or. I, 2-3), un petit four, installé dans l'angle nord-ouest est encore visible, quoi que dans un état de conservation inférieur à celui qu'il présentait lors de la fouille (cf. Maiuri 1958 b: fig. 290 p. 360). Guère mentionné dans les journaux de fouilles, l'interprétation de cet aménagement est
«Tutto il carattere del pianterreno ci rivela un'abitazione originariamente signorile, appartenuta al patriziato della città dall'età di Augusto fino almeno all'età di Claudio ; è la casa d'impianto tipicamente patrizio, quale si riscontra più frequentemente a Pompei che non ad Ercolano dove l'evoluzione edilizia e l'avviamento verso le forme della casa d'affitto con più quartieri e più alloggi, avvengono più rapidamente e decisamente.

[...] Ma verso la fine del regno di Claudio e il principio dell'età neroniana, $[. .$.$] la casa dové passare ad altre mani:$ da quelle di un patrizio ercolanese, a quelle di un liberto e di un mercante arricchito, probabilmente nelle stesse mani del procurator di un tempo, più accorto e sagace del suo imprevidente e prodigo signore ».

A. Maiuri, «Inventio crucis», Pompei ed Ercolano fra case e abitanti, Padova, Le Tre Venezie, 1950 (Itinerari del Sud, 2), p. 253-254.

dégagées. Faute de pouvoir bénéficier pour ces trois îlots de données comparables avec celles des insulae III à VI, je ne les ai pas incluses dans mon étude. De la même façon, j'ai écarté l'Insula Orientalis $I^{a}$, composée de deux maisons pouvant se rapprocher des villas urbaines mais dépourvues de tout espace destiné à la production ou à la commercialisation ${ }^{1}$. D'une manière générale, les analyses détaillées ne portent que sur les espaces ayant disposé d'une partie dévolue au commerce ou à la production à un moment quelconque de leur histoire, même si ce n'était

délicate. Selon A. Maiuri (1958 b: 359-360), il s'agirait d'un four associé à une boutique située dans la pièce $\mathrm{B}$. Si son état de conservation interdit toute interprétation, il ne s'agirait de toute façon pas d'un aménagement inséré dans le cadre d'une production urbaine pérenne. 
pas le cas au moment de l'éruption. Bien que réduite de la sorte, mon analyse va porter sur les quatre îlots qui ont été intégralement fouillés, essentiellement par A. Maiuri, entre 1927 et 1961. Afin de mieux cerner les évolutions non pas d'un point de vue global mais en se focalisant sur des parcelles ayant pu constituer des ensembles de propriétés, je procéderai îlot par îlot. De la sorte, je proposerai une interprétation des évolutions propres à chaque insula ${ }^{2}$.

\section{VII.1 Évolution des insulae III et IV}

Les deux îlots méridionaux connus intégralement sont, d'une manière générale, très semblables. L'un et l'autre paraissent avoir été originellement allotis en les divisant selon une ligne médiane orientée dans le sens de la longueur. Surtout, au moment de l'éruption, plus de la moitié de ces deux insulae est occupée par de vastes demeures, une dans l'insula III, deux dans l'insula IV. Toutefois, en dépit de ces caractères généraux relativement proches, ces deux îlots présentent des formes d'habitation dissemblables tout au long de leur histoire.

VII.1.1 Les transformations des implantations commerciales dans l'insula III: la Casa del tramezzo di legno (III, 4-12) et la Casa a graticcio (III, 13-15)

Le faible nombre de boutiques présentes en façade de l'insula III rend son étude rapide (pl. vI, h.t.). En effet, seules la Casa del tramezzo di legno (III, 4-12) et la Casa a graticcio (III, 13-15) disposent, au moment de l'éruption, de lieux de métier en devanture ${ }^{3}$. Dans le cas des autres maisons, aucun élément ne permet de distinguer d'éventuels locaux commerciaux qui auraient été abolis dans un second temps ${ }^{4}$. À ce point, je soulignerai que l'étude des phases qui précèdent le séisme de 62 est particulièrement délicate dans cet îlot. En effet, la Casa del tramezzo di legno est l'une des rares maisons fouillées en deux temps: d'abord à la fin du XIX ${ }^{\mathrm{e}}$ siècle, puis par A. Maiuri. Il s'ensuit que les restaurations modernes sont nombreuses et souvent très difficiles à identifier. La majeure partie du corps central, autour de l'atrium, a ainsi été soit reconstruite - de façon à pouvoir reconstituer le compluvium - soit de nouveau enduite, ce qui empêche toute analyse de la maçonnerie. Enfin, les dégâts occasionnés par les secousses sismiques de la seconde moitié du ${ }^{\text {er }}$ siècle de notre ère ont entraîné d'importantes reconstructions, qui empêchent de percevoir l'évolution de ce bâtiment. La situation est pire dans la Casa a graticcio, où seuls des fragments de maçonnerie peuvent être attribués à la période antérieure à 62 , sans qu'une ébauche de plan ne puisse être proposée.

Pour ces différentes raisons, je ne m'attarderai pas sur les phases les plus anciennes. Reprenant une hypothèse brièvement exposée par W. Johannowsky, R. de Kind a proposé une restitution du système originel de découpage des îlots d'Herculanum en lots ${ }^{5}$. L'un comme l'autre suggèrent que l'insula III aurait été partagée à l'origine selon une ligne médiane nord-sud, permettant la création d'au moins dix lots rectangulaires et d'une parcelle trapézoïdale $^{6}$. Les portions de maçonnerie permettant de définir l'aspect originel de la Casa del tramezzo di legno sont peu nombreuses (fig. 143). Tout

\footnotetext{
${ }^{2}$ Durant une importante partie du travail effectué sur le site pour préparer ce travail, j'ai trouvé en J. Andrews (University of Reading), qui préparait alors son $P h D$ sur l'utilisation des étages à Herculanum et Pompéi, un interlocuteur de grande valeur. Les nombreuses discussions menées avec lui à Herculanum ont alimenté une partie des réflexions présentées ici. En dépit des divergences d'interprétation que nous avons pu parfois avoir, qu'il trouve ici l'expression de mes plus vifs remerciements.

${ }^{3}$ Sur la Casa del tramezzo di legno, cf. Maiuri 1958 b: 207-222; sur la Casa a graticcio, Maiuri 1958 b: 407-420 et supra, p. 26-35, 82-83.

${ }^{4}$ Il faudrait sinon que la maçonnerie n'en ait pas conservé la trace. La présence en élévation de techniques de
}

construction "préromaines » en façade de la Casa dell'erma di bronzo (III, 16) exclut cette domus de telles recherches. Seule la façade occidentale de la Casa dello scheletro pourrait - de façon très hypothétique - permettre la mise en évidence, pour la période tardo-républicaine, d'une boutique, qui aurait été complètement oblitérée au cours de travaux effectués durant le $\mathrm{I}^{\mathrm{er}}$ siècle de notre ère.

${ }^{5}$ Johannowsky 1982: 148-149; de Kind 1993; de Kind 1998.

${ }^{6}$ Aucune donnée ne permet de définir la façon dont l'espace occupé par la Casa dell'albergo était découpé à l'origine. 

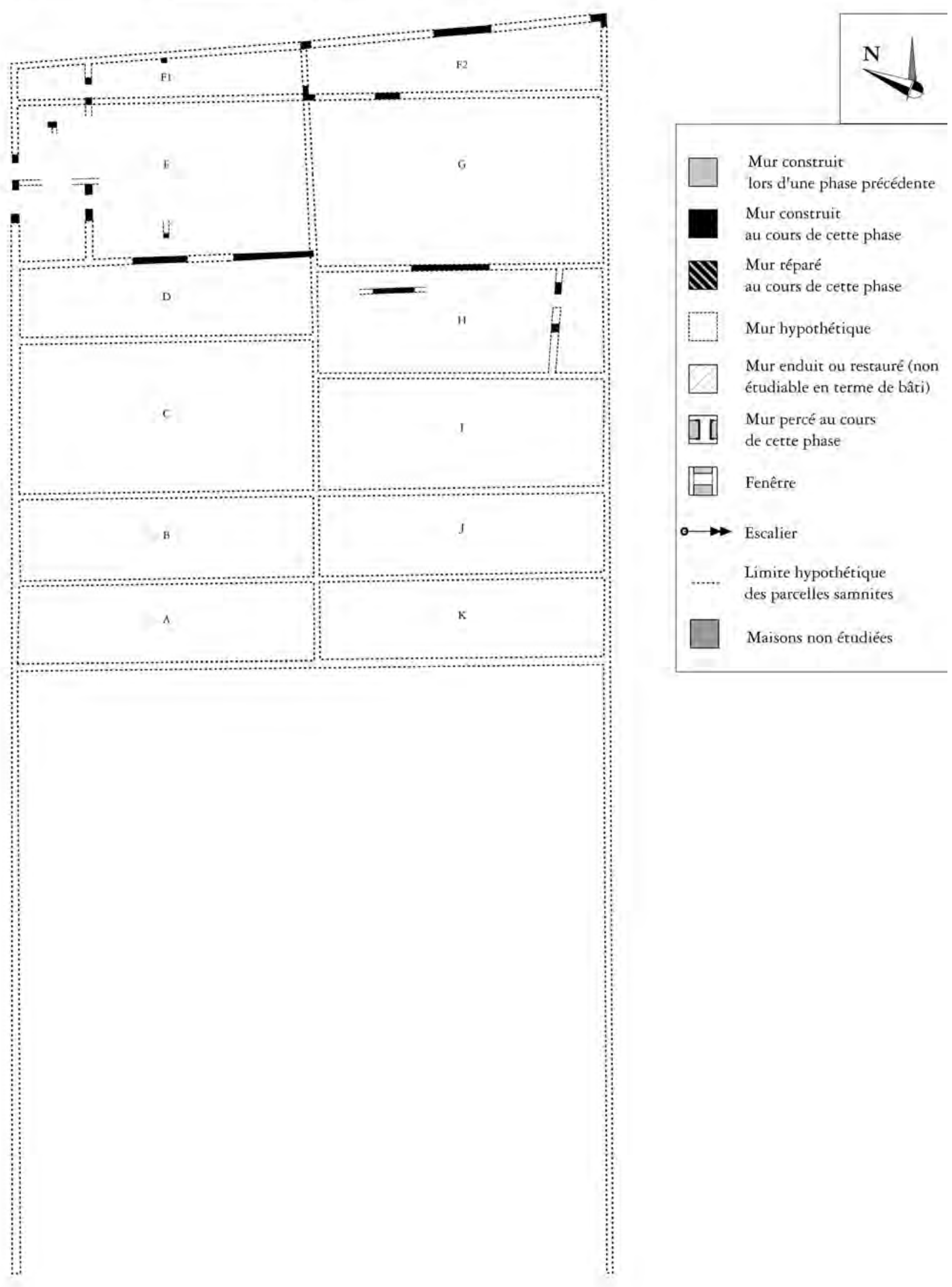

Fig. 143 - Insula III - phase pré-romaine (échelle: 1/400). 
au plus permettent-elles de suggérer certains passages ainsi que les limites de parcelles. Sans pouvoir proposer de chronologie absolue, cette maison s'est progressivement étendue sur trois de ces lots. Le premier à avoir été construit est vraisemblablement le lot $G$, à l'est. Lorsque cette domus s'étend vers l'ouest, sur le lot E, elle se dote très certainement d'un étage ${ }^{7}$. Avant la guerre sociale, la Casa del tramezzo di legno s'étend donc déjà sur toute la largeur de l'îlot, mais pas encore jusqu'au decumanus inférieur. Très fortement remaniée au cours du I ${ }^{\text {er }}$ siècle de notre ère, les premières phases de la Casa a graticcio sont quant à elles impossibles à restituer ${ }^{8}$.

C'est au cours de la période précédant le règne d'Auguste que la Casa del tramezzo di legno pourrait avoir développé un plan faisant se succéder l'atrium et le jardin à péristyle, au-delà duquel se développent quelques pièces (fig. 144). La domus s'étend également vers l'ouest, en annexant la parcelle $\mathrm{F} 1{ }^{9}$. Les travaux alors réalisés, ouvertures de portes, réfection ou construction ex novo de parois, emploient l'opus incertum $\mathrm{C}$ de tuf et l'opus vittatum. La pièce située dans son angle nord-ouest est transformée en boutique, munie d'un seuil à rainure en calcaire (fig. 145). Outre son accès principal sur le cardo IV et cette boutique, la Casa del tramezzo di legno présente alors deux entrées sur le decumanus inférieur ainsi qu'une autre sur le cardo III. Il est également probable que les deux accès menant à des appartements situés à l'étage - en III, 5 et en III, 12

${ }^{7}$ La répartition des murs construits en opus incertum B permet de justifier cette hypothèse. Celui composé majoritairement de lave ( $I n c \mathrm{~B}$ ou Ba selon la typologie de Th. Ganschow [1989: 38]) ne se trouve que dans la partie orientale. En revanche, celui qui comporte presque exclusivement de la cruma rouge (Inc $\mathrm{B}^{1}$ ou $\mathrm{Bb}$ selon la typologie de Th. Ganschow [1989: 39]), est présent au rez-de-chaussée de la partie occidentale et à l'étage de la partie orientale, où il s'appuie sur la maçonnerie antérieure. R. de Kind (1993: 164 ; 1998: 109-112) suggère une hypothèse similaire, bien qu'il considère que le lot $\mathrm{F}$ a été aggloméré dès le départ avec chacun des lots $\mathrm{E}$ et $\mathrm{G}$, en se fondant notamment sur une analyse métrologique. Il estime également que la réunion des deux lots n'a pas eu lieu avant la fin du $\mathrm{I}^{\text {er }} \mathrm{s}$. avant notre ère, sans toutefois spécifier les raisons de cette datation.

${ }^{8}$ On peut cependant signaler, dans le mur de refend entre les pièces 1 et 2 , la présence d'un montant de porte construit en blocs de tuf rossiccio. Ce passage, situé au sud selon la nomenclature correspondant à la situation lors de l'éruption - existent déjà. Au cours de la période augustéenne, la domus acquiert son extension maximale en s'étendant vers la parcelle F2 (fig. 146). Parmi les remaniements alors effectués il faut très probablement considérer la mise en place d'un étage dont l'escalier correspond à la porte III, 7 , après la fermeture des portes situées à l'est de la pièce 9. La porte donnant dans la pièce 14 est murée. Il est possible, malgré l'absence de tout vestige dans la maçonnerie - restaurée dans l'Antiquité puis lors de la fouille - que la boutique III, 8 soit alors créée. Seules l'ouverture de l'accès

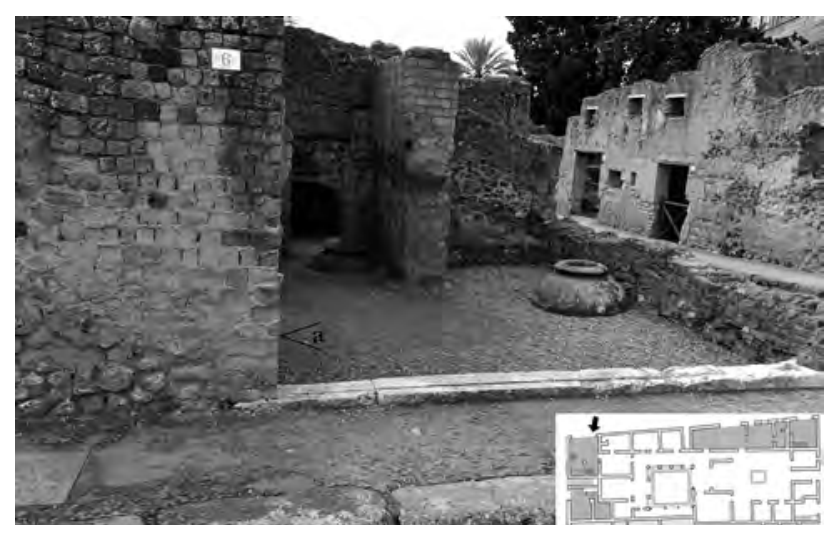

Fig. 145 - Boutique III, 6. Le montant est (à gauche) permet de proposer une datation pré-augustéenne pour l'ouverture de cette boutique: la maçonnerie antique (dont la limite supérieure est indiquée en a) est composée d'opus vittatum et d'opus incertum C.

du montant, a été obturé dans une phase ultérieure, indéterminée.

${ }^{9}$ En dépit de ce que propose R. de Kind (1993: 164), rien ne permet d'affirmer que la parcelle située au nord de l'Insula III n'a pas été divisée comme le reste de l'îlot en deux lots selon un axe médian nord-sud. Ses explications plus détaillées (de Kind 1998: 110-111) ne sont guère plus claires: il refuse notamment la possibilité que ce lot ait été construit avant son rattachement avec les deux parcelles au sud. Pourtant, l'usage différencié des maçonneries laisse supposer non seulement la présence de cette ligne de division, mais également une extension progressive de la Casa del tramezzo di legno vers le nord. Ainsi, l'opus incertum C associé à l'opus vittatum ne se retrouve que dans la moitié occidentale, tandis qu'une partie de la façade orientale, à l'est de l'entrée III, 7 est construite en opus reticulatum B comme nous l'avons vu précédemment (cf. supra, p. 230233). 

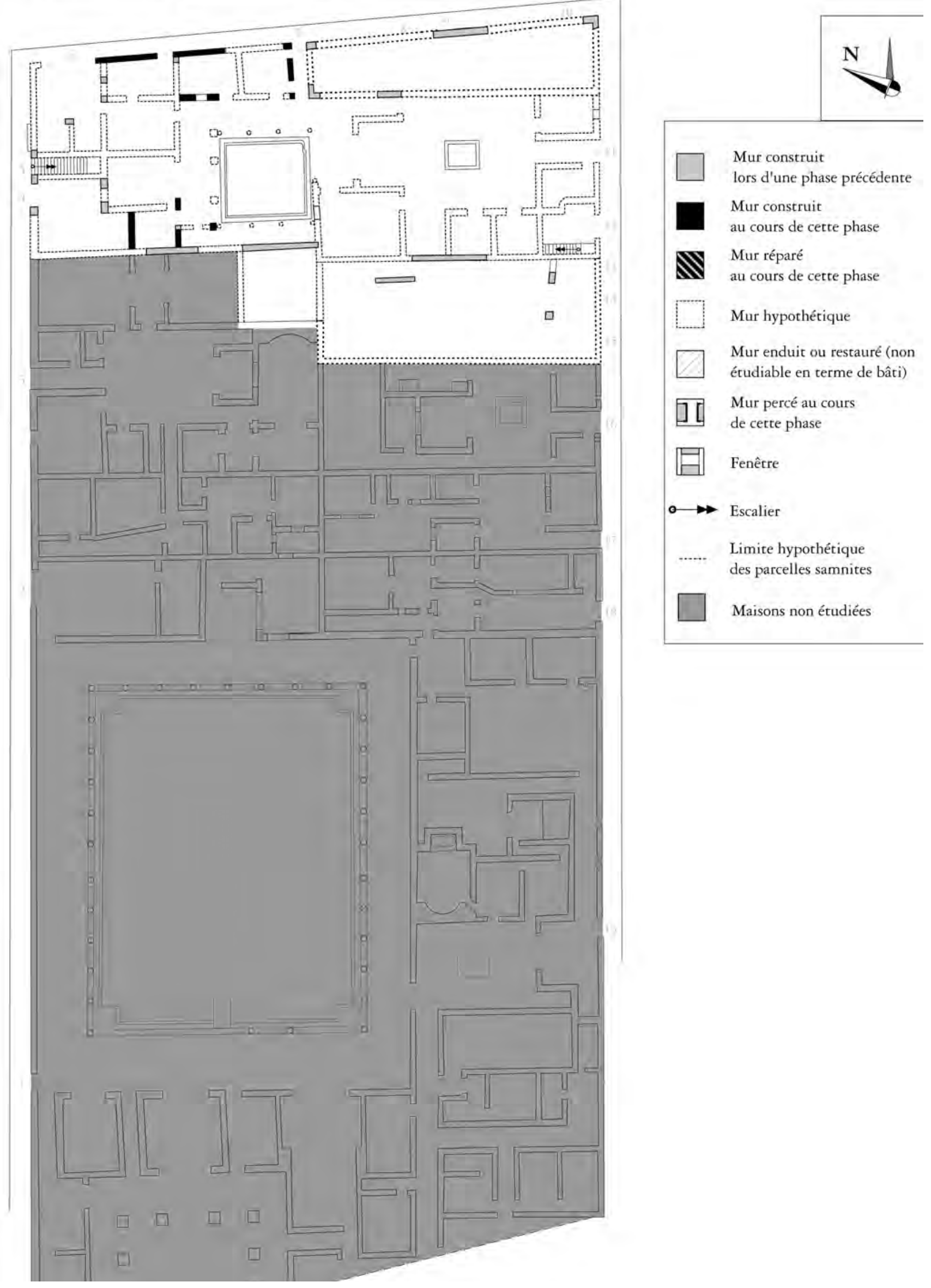

Fig. 144 - Insula III - phase pré-augustéenne (échelle: 1/400). 

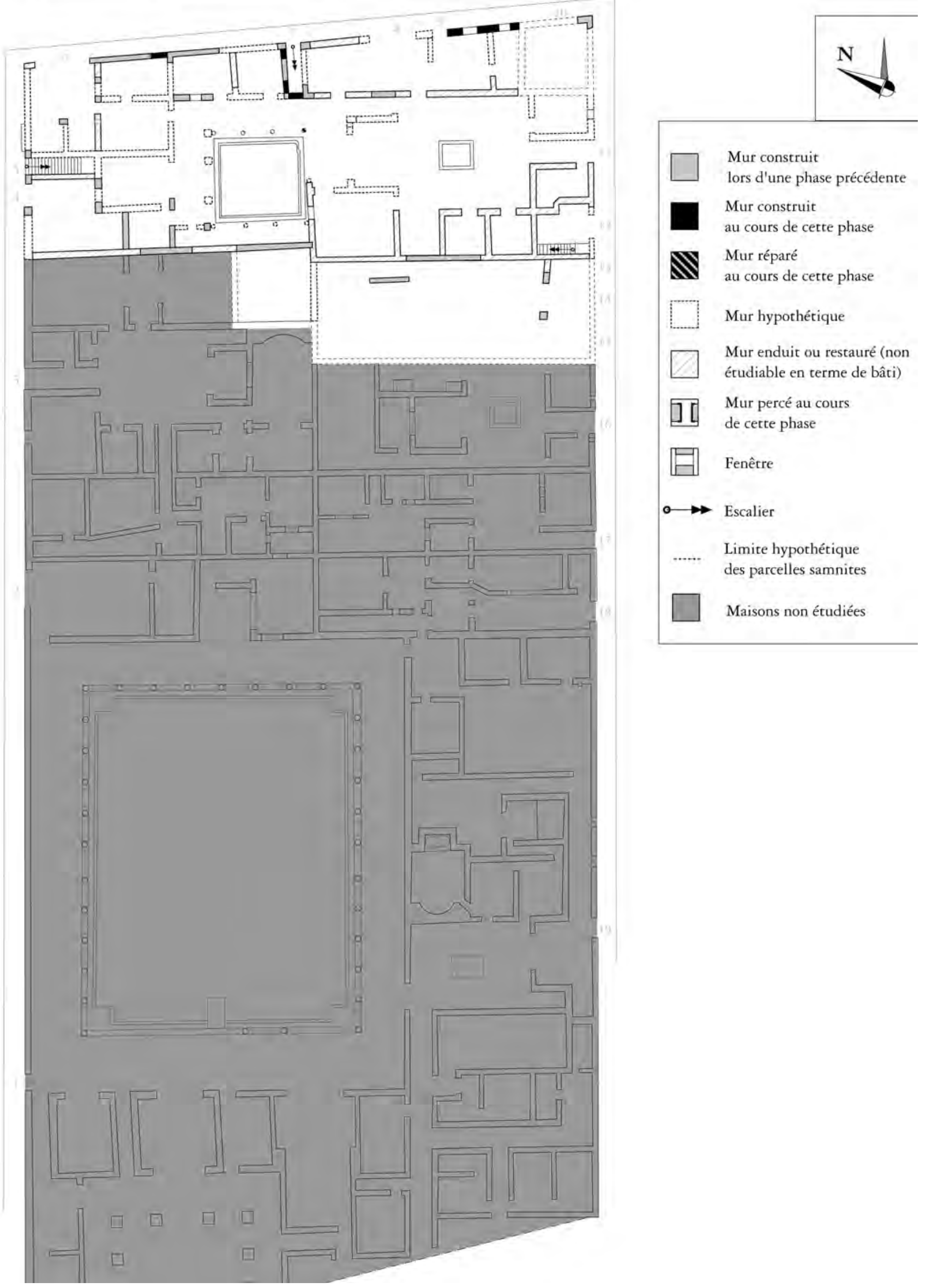

Fig. 146 - Insula III - phase augustéenne (échelle: 1/400). 


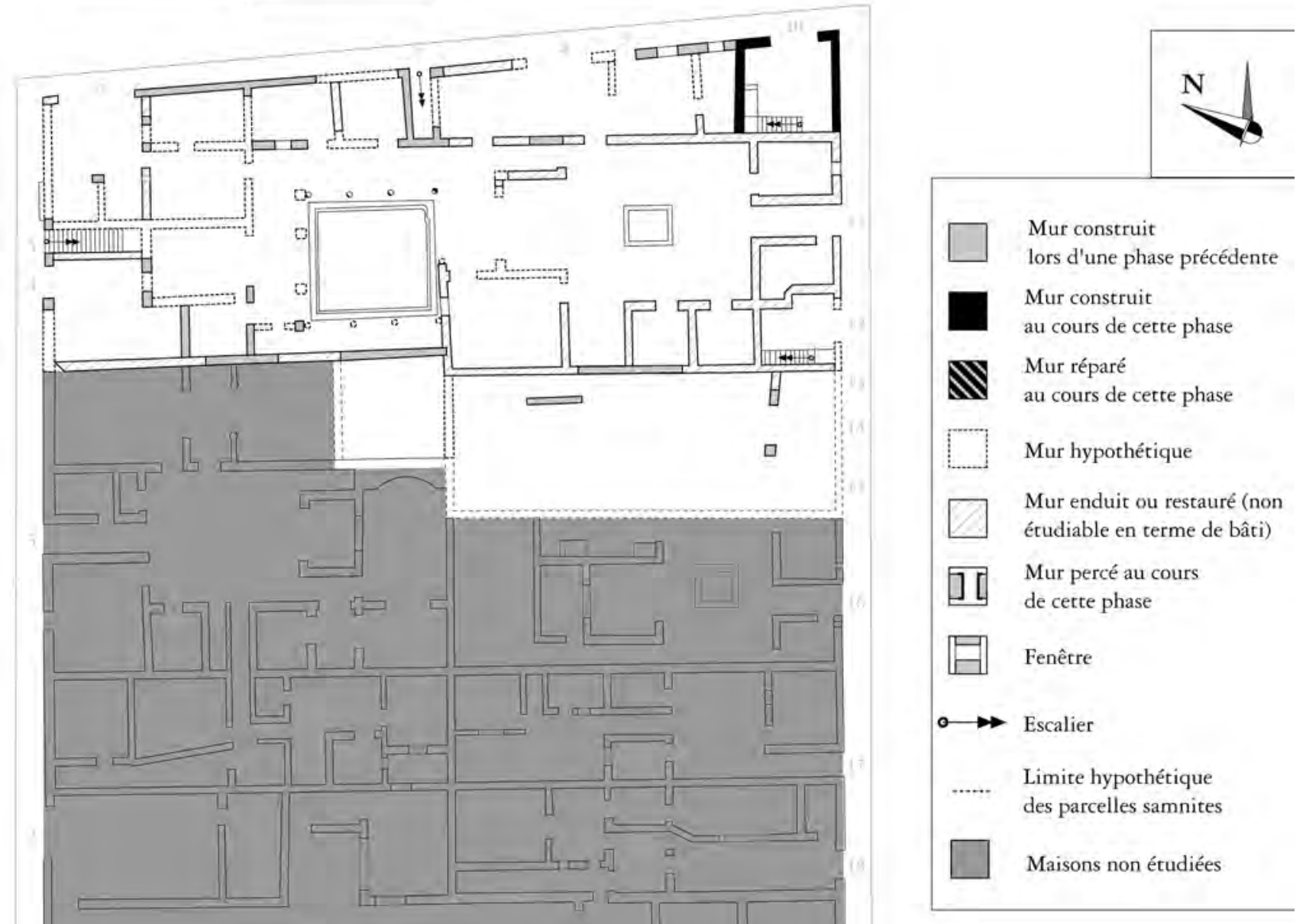


en III, 9 et la réfection de la façade se trouvant à l'est de cette porte peuvent être positivement rattachées à cette période: elles sont réalisées en opus vittatum et en opus reticulatum B de mauvaise facture. L'espace correspondant à la boutique III, 10 est très certainement rattaché, au moins du point de vue de la propriété, à la Casa del tramezzo di legno. Toutefois, son lien physique est délicat à déterminer. À l'étage, l'ouverture de la porte entre la pièce qui surplombe III, 10 et celle qui se trouve au-dessus de la pièce 2 paraît avoir été percée à ce moment, comme en témoignent les montants construits en opus vittatum. Les réfections postérieures de ses murs latéraux au rez-dechaussée empêchent cependant de proposer une restitution des accès entre cet espace et la Casa del tramezzo di legno. Cette situation évolue lors de la phase post-augustéenne, avec l'ouverture de la boutique III, 10 (fig. 147). Les murs qui la ceignent sont intégralement reconstruits et une extension de l'étage sur le decumanus inférieur est ménagée. L'ensemble de ces constructions est réalisé en opus reticulatum A assez irrégulier et en opus vittatum mixtum à une seule rangée de briques (fig. 111) ${ }^{10}$. Durant la même période, l'atrium est décoré à neuf, en particulier le sol qui est refait en employant un tapis de tesselles noires et blanches ${ }^{11}$.

Les dégâts occasionnés par le séisme de 62 paraissent particulièrement importants si l'on en juge par les réparations effectuées dans la moitié occidentale de la Casa del tramezzo di legno (fig. 148). En effet, toute la zone à l'ouest du tablinum paraît avoir été reconstruite en utilisant fréquemment les moellons des murs effondrés. L'exemple le plus frappant est constitué par la pièce 11, certainement complètement rebâtie après un effondrement conséquent de ses parois :

${ }^{10}$ Cf. supra, p. $230-233$ et $252-253$ pour une discussion plus détaillée concernant cette partie de la Casa del tramezzo di legno.

${ }^{11}$ Sur le système décoratif de la Casa del tramezzo di legno, cf. Esposito 2005: 64-66.

12 Th. Ganschow (1989: 171-174, 180) estime que la construction du nymphée et la séparation de la pièce 12-13 de la Casa dello scheletro sont plus précoces et antérieures au séisme de 62. Cette différence d'interprétation tient à nos chronologies respectives concernant les types de mise en œuvre associés aux réparations du tremblement de terre, et en particulier en ce qui concerne l'emploi des briques (cf. supra, p. 251 sq.). les piliers de tuf préalablement employés pour l'opus quadratum sont réutilisés pour raidir la nouvelle maçonnerie; les moellons récupérés de toute nature sont mélangés à des fragments de tuiles. L'importance de ces dommages est telle que l'on peut soupçonner qu'il ait été décidé d'abattre les murs instables ou fragilisés. Un constat similaire peut être dressé pour les murs entourant la parcelle de la Casa a graticcio encore en devenir: le mur sud de la pièce 12-13, qui appartient alors à la Casa dello scheletro (III, 3) est complètement reconstruit. Toutefois, au lieu d'employer des moellons provenant des murs détruits, ce sont essentiellement des amphores concassées qui sont employées pour constituer le parement (fig. 149). Cette technique a également été employée dans le reste de cette maison, en particulier dans les murs nord de la pièce 6 et du «nymphée». Ce dernier espace est restauré: les montants de la fenêtre donnant sur la pièce 12-13 sont reconstruits en utilisant des briques. Peu après, cette baie est bouchée et la pièce 12-13 est intégrée à la parcelle de la Casa a graticcio $^{12}$. Les travaux de transformation qui sont effectués dans cette demeure lui donnent un aspect relativement proche de celui qu'elle présente au moment de l'éruption. Les piliers maçonnés en briques qui forment l'ossature de la structure d'ensemble sont alors construits, probablement déjà reliés entre eux par des cloisons en pan de bois. Un unique appartement occupe la moitié sud du rez-de-chaussée. S'il est possible qu'il s'ouvre sur la rue avec un local commercial, son accès à la cour 4 est en revanche limité à la seule porte à double battant entre les pièces 6 et 5 . De plus, la pièce 7 est divisée en deux par un mur de refend orienté est-ouest, probablement conçu en pan de bois ${ }^{13}$. Il semble que dès cette phase,

${ }^{13}$ Un effet de paroi est très net à $1,16 \mathrm{~m}$ du mur nord de la pièce 7 : il montre que le sol actuellement visible a été construit contre une forme rectiligne qui a maintenant disparu. La dimension et la position du lit découvert dans cette pièce (GSE 1928: «19 novembre. L'ambiente n. 3 [= Maiuri 7] piano terraneo dello scavo $\mathrm{C}$ è stato svuotato. Misura 3.35 di lunghezza per m. 3.35 di larghezza. [...] Al lato nord dell'ambiente trovasi un avanzo di letto di legno carbonizzato [...]) indiquent clairement que cette cloison avait déjà été démantelée au moment de l'éruption, sauf à considérer que seuls $15 \mathrm{~cm}$ permettaient de circuler dans ce couloir. 

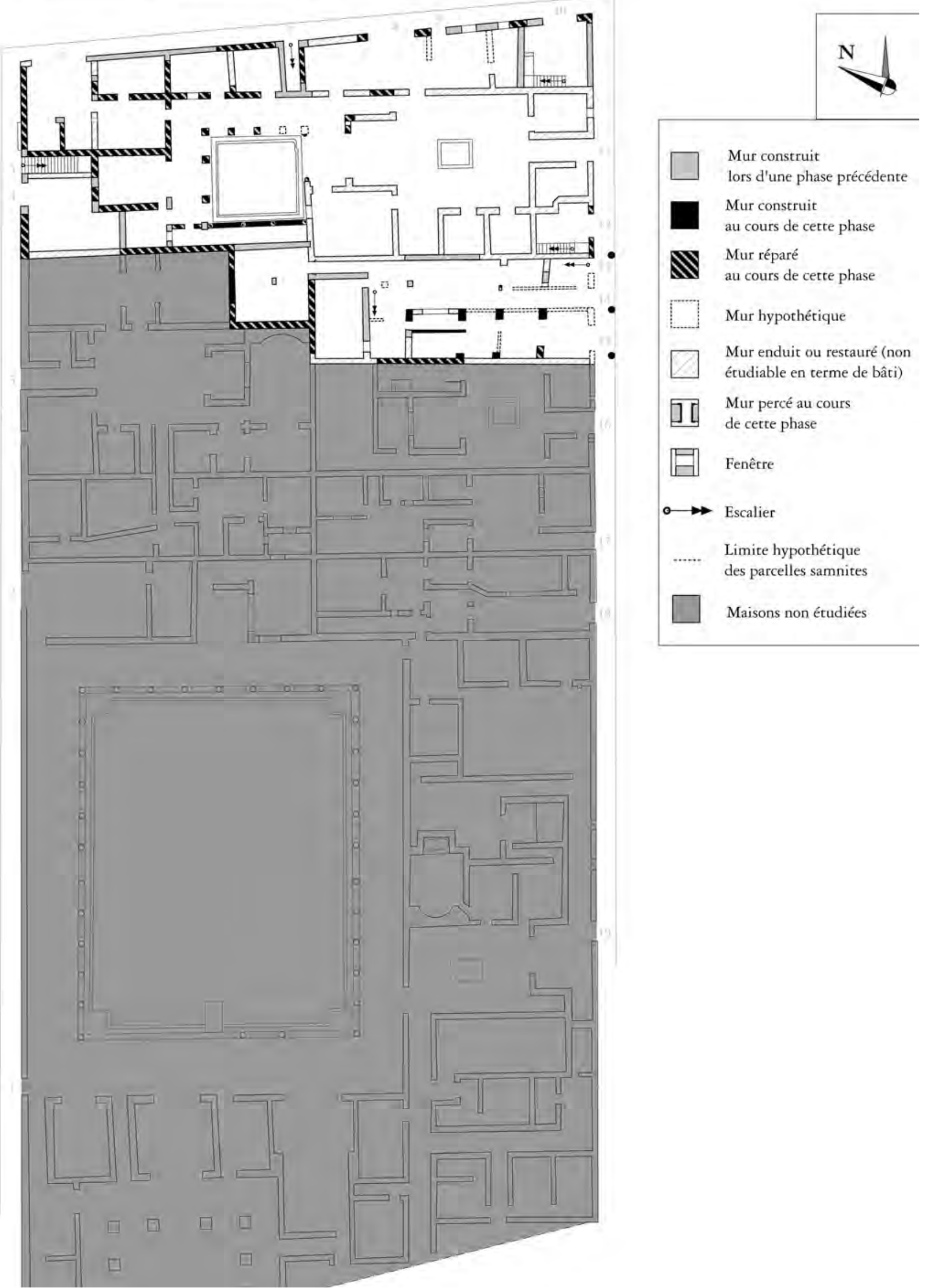

Fig. 148 - Insula III - 62 - ca. 70/75 (échelle: 1/400). 


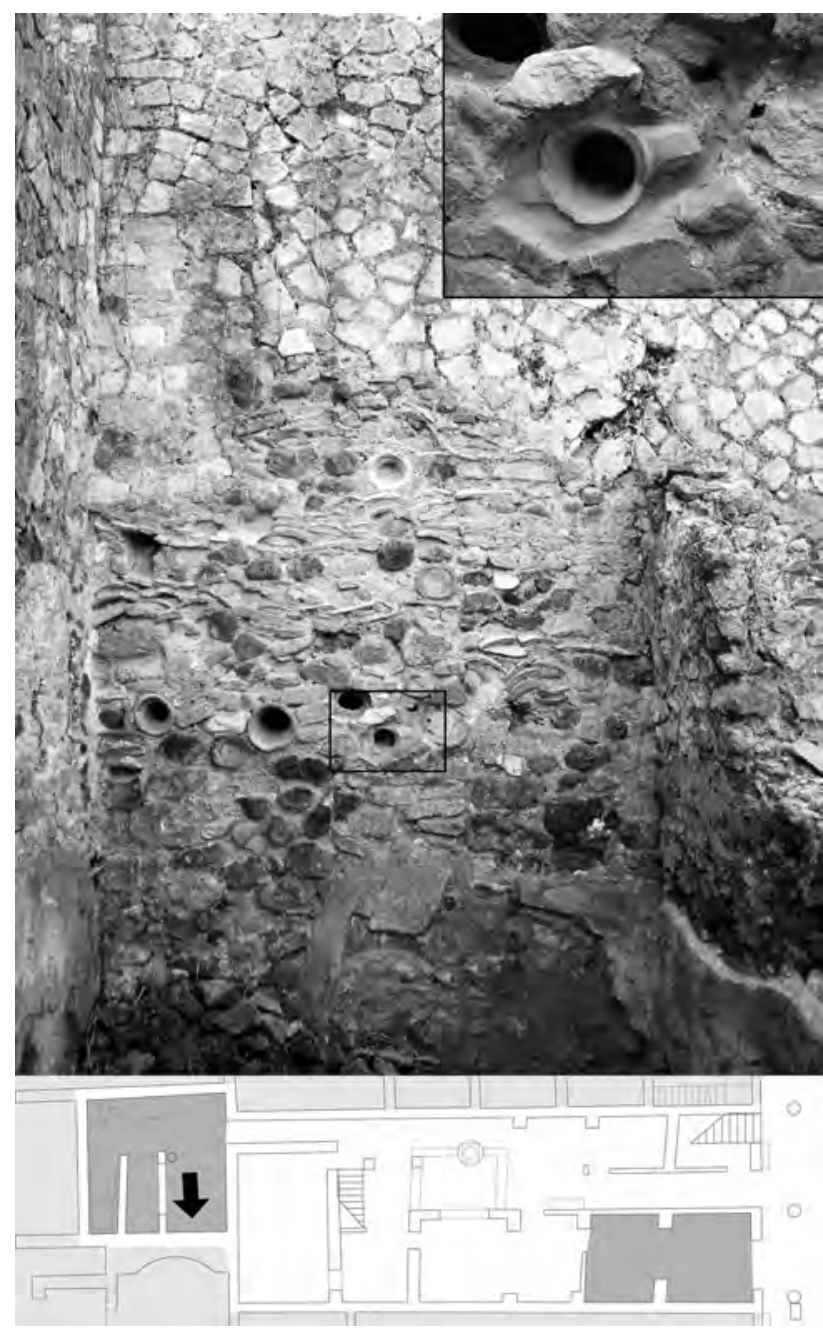

Fig. 149 - Casa a graticcio (III, 13-15), pièce 12, mur sud. Fortement endommagée lors du séisme de 62, cette paroi, qui appartient alors à la Casa dello scheletro (III, 3) a été reconstruite en utilisant des moellons de récupération, mais également des amphores (encadré).

l'étage ait été divisé en deux appartements, l'un accessible de la rue, l'autre depuis un escalier interne. Les transformations consécutives au second séisme sont moindres dans la Casa del tramezzo di legno (fig. 150). Seule la boutique

${ }^{14}$ Cette interprétation des phases du péristyle de la Casa del tramezzo di legno suit celle proposée par A. Maiuri (1958 b: 217-218). En raison de la présence d'une fresque de III ${ }^{\mathrm{e}}$ style, identifiée par M. et A. De Vos (1982: 268-269), cette datation relativement tardive de la fermeture de l'aile sud du péristyle a été contestée par R. de Kind (1998: 110). située en III, 10 voit sa situation transformée par la disparition de l'extension de son étage au-dessus du decumanus inférieur et la mise en place d'une latrine dans ce même étage. C'est certainement à ce moment que le péristyle est fermé sur son côté sud, ce qui permet également la mise en place d'une mezzanine au-dessus du couloir ainsi formé. Une partie des colonnes est très certainement remplacée par des pilastres de section carrée ${ }^{14}$. En comparaison, le second séisme n'a eu que beaucoup moins d'incidence dans ces deux maisons. Les dégâts sont moindres, sans comparaison: seuls une petite partie de la façade nord, deux piliers et le montant ouest de la porte III, 9 ont dû être reconstruits. Les mises en œuvre utilisées pour ces restaurations sont respectivement de l'opus reticulatum $\mathrm{B}$ polychrome et de l'opus vittatum mixtum à deux assises de briques. Dans la Casa a graticcio, les dégâts n'ont nécessité qu'une reconstruction des montants de la façade en opus vittatum mixtum. En revanche, dans cette maison, les transformations sont un peu plus conséquentes. Outre l'abolition de la cloison divisant en deux la pièce 7 , des vasques sont installées dans les pièces 12-13, probablement utilisées dans le cadre d'une activité liée au textile. Quant aux transformations au rez-de-chaussée, elles semblent ne pas avoir été achevées au moment de l'éruption, alors même que les deux appartements de l'étage étaient en fonction ${ }^{15}$. Dans la Casa del tramezzo di legno, le seul changement perceptible est la création d'un mur de refend entre les pièces 16 et 17 de la boutique III, 4, ainsi que l'installation d'une mezzanine au-dessus de ces deux espaces.

VII.1.2 Le lent développement et la diversification des commerces dans l'insula IV

À l'instar de l'insula III, l'îlot IV ne présente que peu de boutiques sur chacune de ces façades (pl. vII, h.t.). Cette situation est due à la présence, dans la moitié sud, des deux domus, assimilables

${ }^{15}$ Sur l'interprétation des vasques, cf. supra, p. 203205 ; sur les travaux incomplets au moment de l'éruption, cf. supra, p. 82-83. 

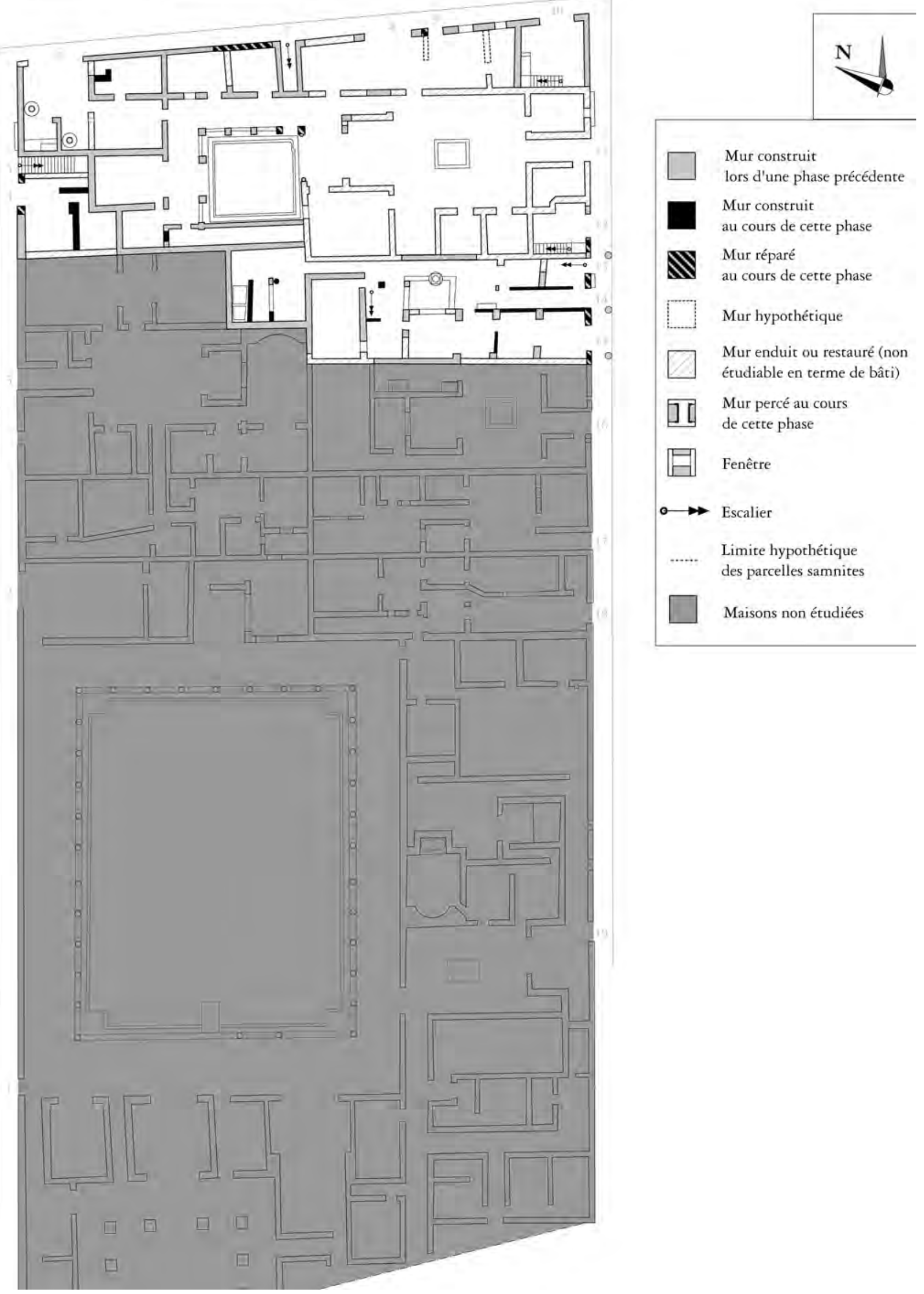

Fig. 150 - Insula III - ca. 70/75 - 79 (échelle: 1/400). 
à des villas urbaines, que sont la Casa dell'atrio a mosaico (IV, 1-2) et la Casa dei cervi (IV, 21). Les deux autres maisons situées au nord de ces dernières, la Casa dell'alcova (IV, 3-4) et la Casa della stoffa (IV, 19-20), ne disposent pas non plus de locaux commerciaux en façade. L'étude de leurs maçonneries n'autorise pas à supposer une telle présence dans une phase antérieure à l'éruption ${ }^{16}$. En dépit de restaurations parfois importantes, les cinq autres maisons de l'insula IV permettent une étude sur la longue durée (fig. 151 ${ }^{17}$. En effet, de nombreux éléments des maçonneries les plus anciennes ont été conservés en élévation. Cette remarquable préservation ne permet toutefois pas de restituer de façon extensive les plans des maisons de la période samnite. En revanche, R. de Kind a proposé un schéma de la division originelle des parcelles. Il a ainsi identifié onze lots pour les deux tiers septentrionaux de l'îlot. Comme dans l'insula III, ces parcelles auraient été obtenues selon une ligne de division médiane, orientée nord-sud. Cinq lots feraient exception, correspondant à l'emplacement final de la Casa dell'alcova (IV, 3-4), de la Casa della fullonica (IV, 5-7), de la Casa

${ }^{16}$ Sur le développement de la Casa dell'atrio a mosaico (IV, 1-2), cf. Maiuri 1958 b: 280-302, part. 281-282; Cerulli Irelli 1971; de Kind 1998: 131-138. Sur la Casa dell'alcova (IV, 3-4), cf. Maiuri 1958 b: 388-393; de Kind 1998: 139145. Je ne m'étendrai pas sur la Casa della stoffa (IV, 19-20), en dépit de ses supposées activités artisanales (sur ce point, cf. supra, p. 81). Sur cette maison, voir Maiuri 1958 b: 425426; Ganschow 1989: 207-208; de Kind 1998: 171-175. La Casa dei cervi (IV, 21) a été l'objet d'une monographie rédigée par V. Tran Tam Tinh (1988). L'analyse de sa construction a toutefois été menée par Th. Ganschow (1989: 184-219). Le premier considère que cette maison n'est pas antérieure au séisme de 62, tandis que le second propose une date de construction au début de l'empire.

${ }^{17}$ Quatre de ces maisons disposent d'un espace commercial à un moment de leur histoire : la Casa della fullonica (IV, 5-7), la Bottega con abitazione (IV, 10-11), la Grande taberna con abitazione (IV, 12-13.15-16) et la Casa del priapo (IV, 17-18). Les liens entre la Bottega con abitazione et la Casa del papiro dipinto (IV, 8-9) sont tels qu'il m'a semblé utile de l'inclure dans cette étude, bien qu'elle ne semble jamais avoir présenté une boutique ou une activité artisanale.

${ }^{18}$ de Kind 1998: 70-74.

${ }^{19}$ Cette éventualité a été discutée par R. de Kind (1998: 72-74). Après avoir décliné les différentes hypothèses, il réfute celle que je suis ici. Son seul argument contre le maintien d'une ligne de séparation médiane originelle séparant la Casa della fullonica de la moitié septentrionale de la Casa del priapo (IV, 17-18) et de la Casa della stoffa (IV, 19-20). Il me semble pourtant que contrairement à ce qu'il propose, la Casa della fullonica ne se présente pas, au moment de l'éruption, avec la même extension que lors de son découpage originel ${ }^{18}$ : l'extension vers l'est de cette maison apparaît tardive, correspondant à la dernière phase précédant l'éruption ${ }^{19}$. Les six parcelles sur lesquelles ces maisons se sont implantées avaient donc une profondeur identique de part et d'autre de la ligne médiane. La plus ancienne maçonnerie conservée, le mur séparant la Casa della fullonica de la Casa del papiro dipinto peut être datée de la première moitié du $\mathrm{II}^{\mathrm{e}}$ siècle avant notre ère par l'étude des tessons contenus dans une partie qui s'est écroulée peu avant $2003^{20}$. Aucune boutique ne saurait être identifiée pour cette période préromaine. Notons toutefois l'existence de deux phases successives, la première employant de l'opus incertum $\mathrm{B}$, la seconde l'opus incertum $\mathrm{B}^{1}$. Au cours de ces deux périodes, des traces d'étage peuvent être observées dans différentes maisons: dans la Casa della fullonica avant la période tardo-républicaine et dans la moitié sud de la Grande taberna con

del priapo est discutable. Il invoque l'absence de lien structurel entre le mur oriental de la pièce 6 de la Casa della fullonica et le mur séparant la Casa del papiro dipinto (IV, 8-9, p. 6) de la Grande taberna con abitazione (IV, 12-13.15-16, p. 2 et 4). L'absence de chaînage est patente mais ne saurait caractériser autre chose qu'une construction un peu plus tardive de la Casa della fullonica. En revanche, le maintien d'une décoration de $I^{\text {er }}$ style dans les deux pièces orientales de cette domus montrent qu'elles n'ont subi que peu d'altérations entre leur création et l'éruption. Chacune d'entre elles montre une ouverture vers l'est, bouchée en 79 de notre ère. Les réparations que les montants de ces passages ont subies permettent de considérer qu'elles étaient en fonction lors de l'un des séismes. Enfin, la présence de deux montants de tuf, un seul par porte de la phase finale, ne permet pas nécessairement de considérer que ces passages entre la pièce 8 et les espaces 6 et 7 existaient dès l'origine. Ils peuvent au contraire correspondre à la limite orientale de la parcelle. D'autres arguments confortant cette hypothèse sont développés infra, p. 304-309.

${ }^{20}$ Ce sont essentiellement des fragments de céramique campanienne et d'amphores gréco-italiques qui permettent une telle datation. R. de Kind (1998: 147) considère également que l'opus incertum $\mathrm{B}$ doit être daté du $\mathrm{II}^{\mathrm{e}}$ siècle av. J.-C., sans toutefois préciser les raisons de cette datation. De façon plus pragmatique, Th. Ganschow (1989: 122) considérait que cette technique de construction remontait à la période précédant la guerre sociale. 


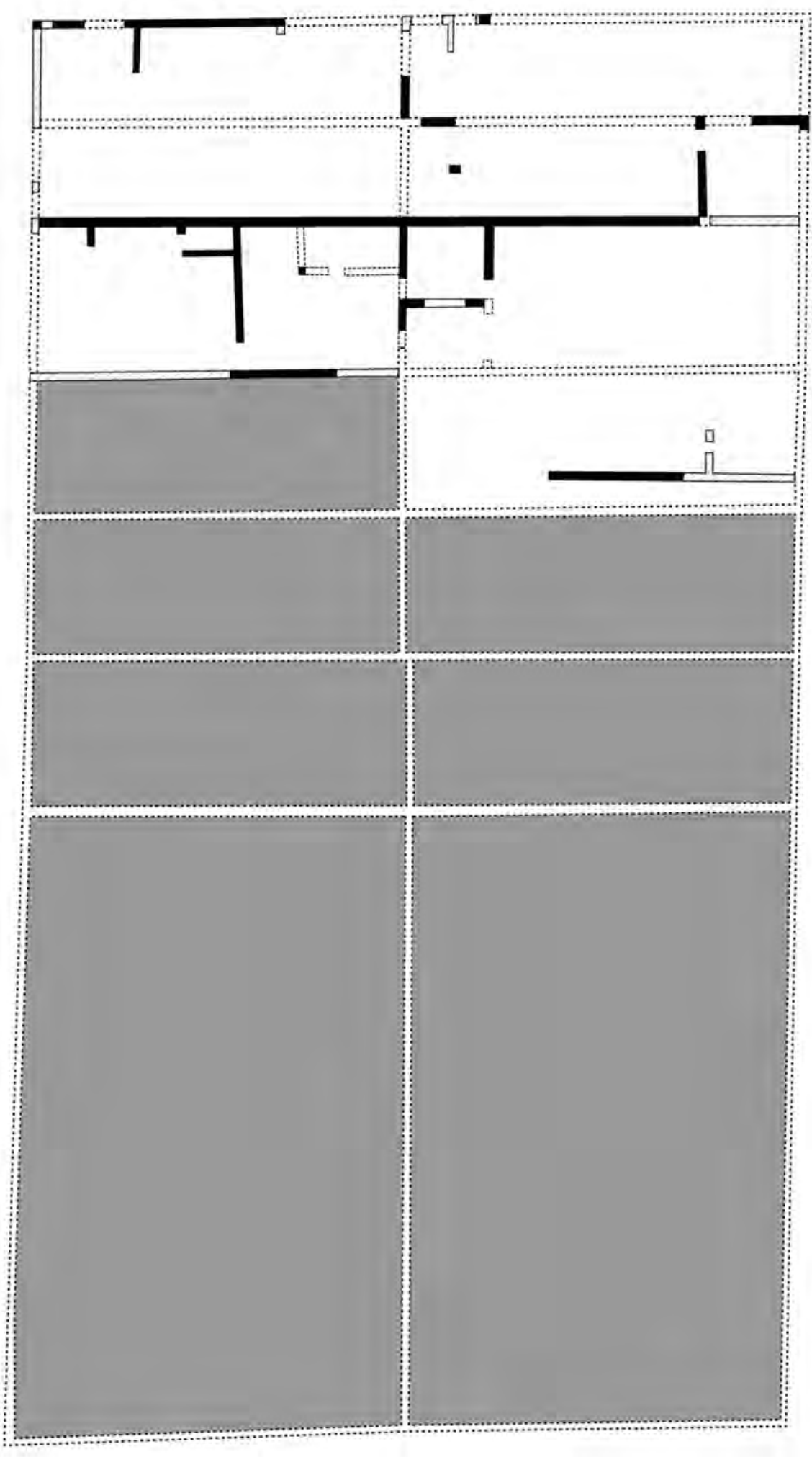

Mur construit
lors d'une phase précédente
Mur construit
au cours de cetté phase
Mur réparé
au cours de cette phase

Fig. 151 - Insula IV - phase pré-romaine (échelle: 1/400). 
abitazione $^{21}$. Au cours du premier quart du $\mathrm{I}^{\mathrm{er}} \mathrm{s}$. av. J.-C., des travaux sont effectués dans la Casa del papiro dipinto (IV, 8-9) et dans la Bottega con abitazione (IV, 10-11), conduits en employant de l'opus incertum $\mathrm{C}$ de tuf rossiccio, mélangé avec des moellons de cruma (fig. 152). Elles se présentent alors avec un plan identique: trois pièces sont reliées par un couloir longitudinal situé au sud. Ces espaces sont couverts par une toiture à double pente asymétrique, dont les pannes reposent sur le mur de refend entre les pièces 1 et 3 de la Bottega con abitazione et entre les pièces 2 et 3 de la Casa del papiro dipinto. Le mur séparant les deux maisons a conservé la trace de cette disposition (fig. 153, a). L'extrémité orientale de la maison est occupée par un espace ouvert, probablement un jardin. Cette phase ne montre que la fermeture de l'étage entre les pièces 2 et 4 de la Casa della fullonica, réalisée en opus incertum C de tuf rossiccio. Au cours de la période suivante (fig. 154), qui précède immédiatement le règne d'Auguste, de nouveaux travaux sont effectués dans la Bottega con abitazione: dans la moitié orientale, la disposition du toit, désormais orienté nord-sud, est transformée. Le jardin est réduit et ceint par un couloir qui permet probablement l'accès au decumanus inférieur. Dans la Casa del papiro dipinto, un étage, qui ne se développe certainement pas au-delà de la pièce 2 , est ajouté dans la moitié occidentale. On y accède par une porte ménagée en façade. Des aménagements similaires sont effectués dans la Casa della fullonica avec l'ouverture de la porte IV, 5 d'où partait l'escalier permettant d'atteindre un appartement d'étage indépendant ${ }^{22}$. Cette domus se dote également d'une pièce dont la situation correspond à celle d'un tablinum. Il est possible

${ }^{21}$ Un passage à l'étage est visible entre les pièces 2 et 4 de la Casa della fullonica. Ce passage a été oblitéré en opus incertum $\mathrm{C}$ de tufrossiccio, probablement durant la première moitié du $\mathrm{I}^{\mathrm{er}} \mathrm{s}$. avant notre ère. Dans la Grande taberna con abitazione, le mur sud de l'atrium présente, dans la partie supérieure de son élévation, des portions conservées d'opus incertum B1 qui indiquent soit une seconde phase samnite au cours de laquelle un étage est créé, soit la mise en place, sur la parcelle ensuite occupée par la Casa del priapo, d'une nouvelle maison disposant d'un étage.

22 Si A. Maiuri (1958 b: 422-423) considère également que l'escalier permettant d'atteindre l'étage partait de cet espace, il ne spécifie pas que l'entrée constituait un accès indépendant de la maison. que ce soit au cours de cette phase que la boutique IV, 7 soit ouverte. Les transformations successives, et notamment les travaux de restauration consécutifs au séisme de 62 , ont complètement modifié la nature de la maçonnerie, empêchant de déterminer son aspect originel.

Les parcelles remontant à la période samnite sont fortement remaniées au cours de la période augustéenne (fig. 155). Les premiers changements surviennent dans la Grande taberna con abitazione qui semble prendre alors son extension définitive, par l'agglomération des deux parcelles IV G et IV $\mathrm{H}^{23}$. La majeure partie des murs est alors construite en opus incertum C / quasi reticulatum de tuf jaune (fig. 156, a-b). La datation augustéenne est soutenue par le pavement de la «taberna vasaria » (IV, 14) en devenir, qui est alors un triclinium (fig. 23) ${ }^{24}$. L'entrée est délicate à mettre en évidence: les restaurations effectuées sur les montants des portes IV, 12 et IV, 13 empêchent une détermination précise. Il est possible que l'arc de décharge de la façade nord, restauré après le séisme de 62 , indique un accès du decumanus inférieur vers la pièce $6 / 7$. Il est également possible que la boutique IV, 15-16 soit déjà ouverte. Si tel est le cas, elle ne dispose pas d'espace annexe: la pièce $8 / 9$ constitue également une pièce de réception. Certainement en raison du maintien de structures antérieures, l'atrium ne se trouve pas en position centrale, d'autant plus que la probable entrée en $6 / 7$ et le triclinium 14 lui offrent une façade aveugle. Quant à l'étage, il ne se développe certainement qu'au-dessus des pièces $5,6 / 7$ et $13^{25}$. Bien que les éléments permettant une telle hypothèse soient particulièrement ténus, en raison des restaurations datant des dernières phases,

${ }^{23} \mathrm{R}$. de Kind (1998: 162) considère toutefois que cette agglomération des deux parcelles a eu lieu au cours de la période républicaine.

${ }^{24}$ Pour la description de ce pavement, cf. supra, p. 6162.

25 Les travaux effectués peu après dans la Casa del papiro dipinto - qui impliquent un rehaussement des murs et le percement d'une fenêtre donnant au-dessus de la pièce 4 de la Grande taberna con abitazione - ainsi que la ligne de toiture plate mise en évidence dans le mur ouest des pièces 1 et 2 empêchent la présence d'un étage au-dessus de la partie occidentale de la Grande taberna con abitazione (cf. fig. 156, a, b et d). 


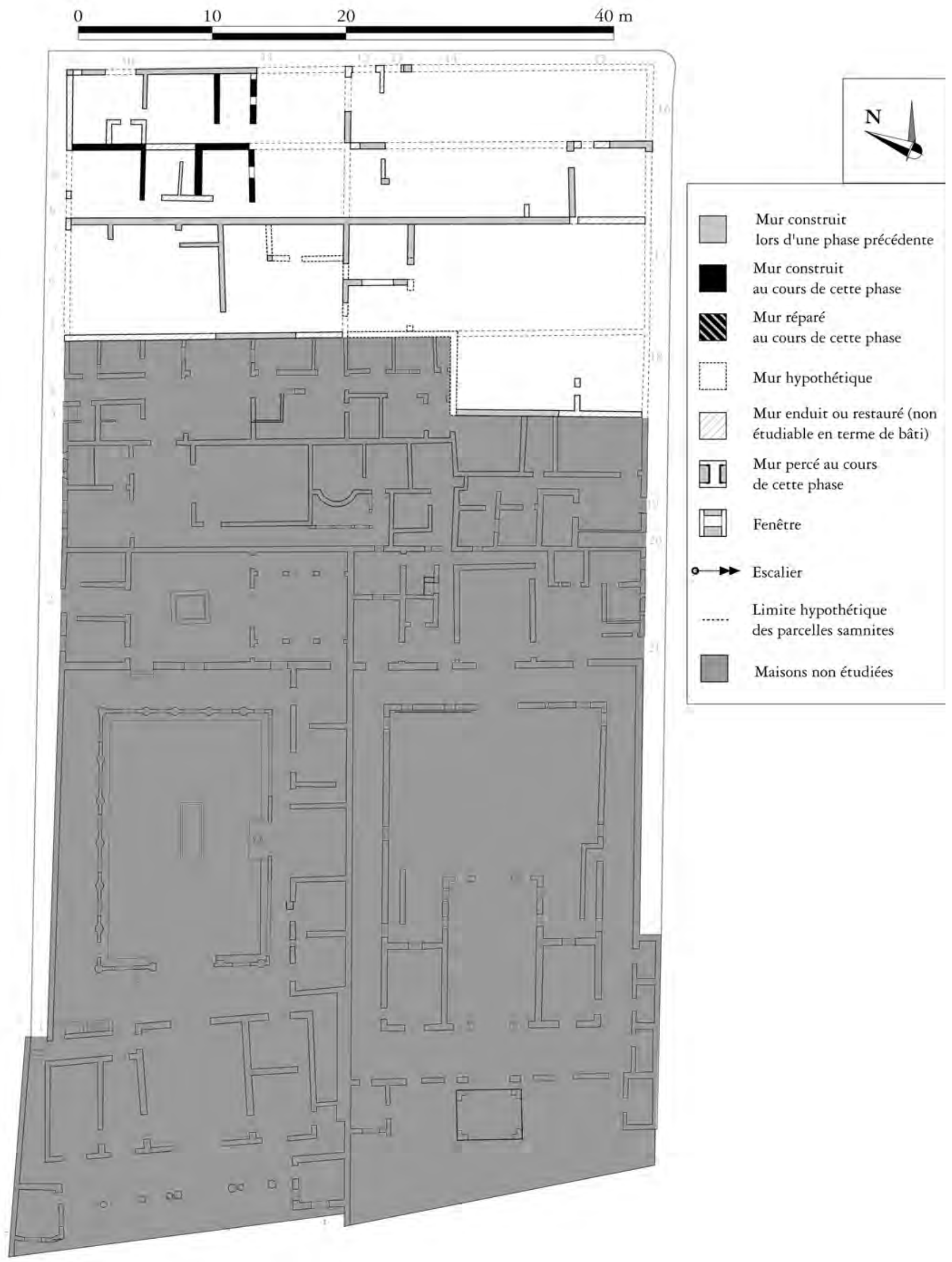

Fig. 152 - Insula IV - première phase pré-augustéenne (échelle: 1/400). 


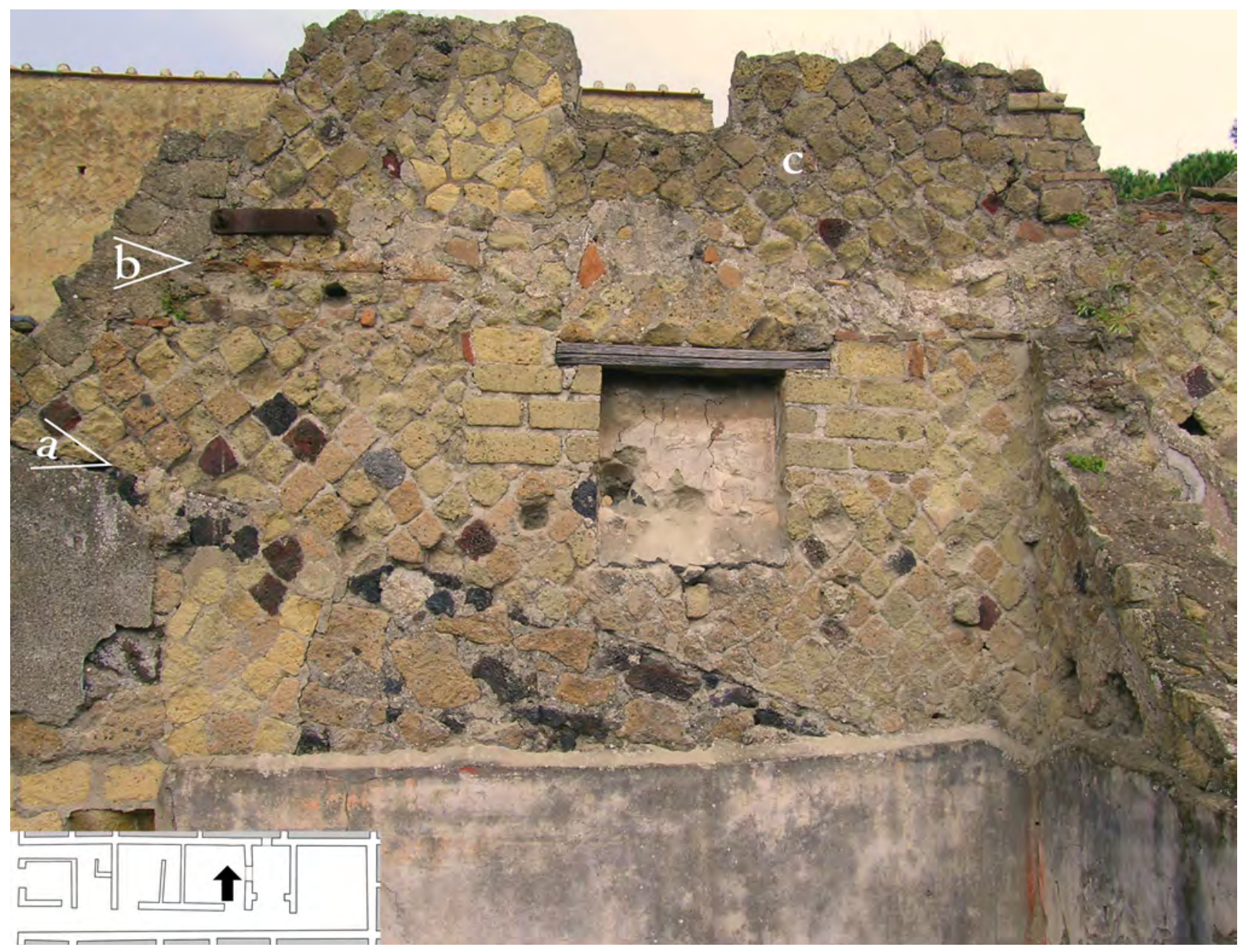

Fig. 153 - Casa del papiro dipinto (IV, 8-9), pièce 4, mur nord. Cette portion de mur permet de suivre les différentes transformations survenues dans cette maison et dans celle située immédiatement au nord, la Bottega con abitazione (IV, 10-11). Une limite oblique (a) correspond à la mise en place d'une toiture asymétrique à double pente dans les deux domus, au début du $\mathrm{I}^{\mathrm{er}}$ siècle avant notre ère. Durant la période augustéenne, la Casa del papiro dipinto accroît le volume de ses pièces avec une toiture plus élevée (b) supportée par de l’opus reticulatum B, sans créer un véritable étage. Ce dernier n'est mis en place que lors d'une extension en hauteur réalisée en opus incertum C / opus reticulatum grossier de tuf jaune (c) par les occupants de la Bottega con abitazione qui dotent alors leur maison d'une sous-pente après le séisme de 62.

il semble que des réaménagements entre les parcelles originelles aient également lieu autour de la Casa del priapo (IV, 17-18), qui gagnerait alors son extension définitive au sud ${ }^{26}$. À l'ouest

${ }^{26}$ Le raisonnement permettant d'arriver à cette hypothèse est essentiellement régressif: les différentes pièces situées au nord, au sud et à l'ouest de la cour tétrastyle de la Casa del priapo ont été construites après le second séisme (cf. supra, p. 243-244). Lors d'une phase de travaux de réparation associée à ce même tremblement de terre, les deux montants de l'entrée IV, 17 ont été reconstruits en opus vittatum mixtum à deux assises de briques, laissant dès lors supposer qu'ils existaient avant cette catas- en revanche, elle serait - comme au cours des phases précédentes - dotée des pièces 6 et 7 qui ne seront rattachées à la Casa della fullonica que peu avant l'éruption. Certainement au cours de

trophe. Les murs des pièces 9 et 10 présentent quant à eux des traces de restauration en lien avec la secousse de 62 . De cette façon, les pièces $9,10,15$ et 16 - ce qui inclut la boutique IV, 17 - présenteraient une disposition antérieure au premier séisme. Seule l'importance généralement constatée à Herculanum des transformations survenues durant le règne d'Auguste paraît justifier à titre d'hypothèse la mise en place de ces pièces durant cette période. 


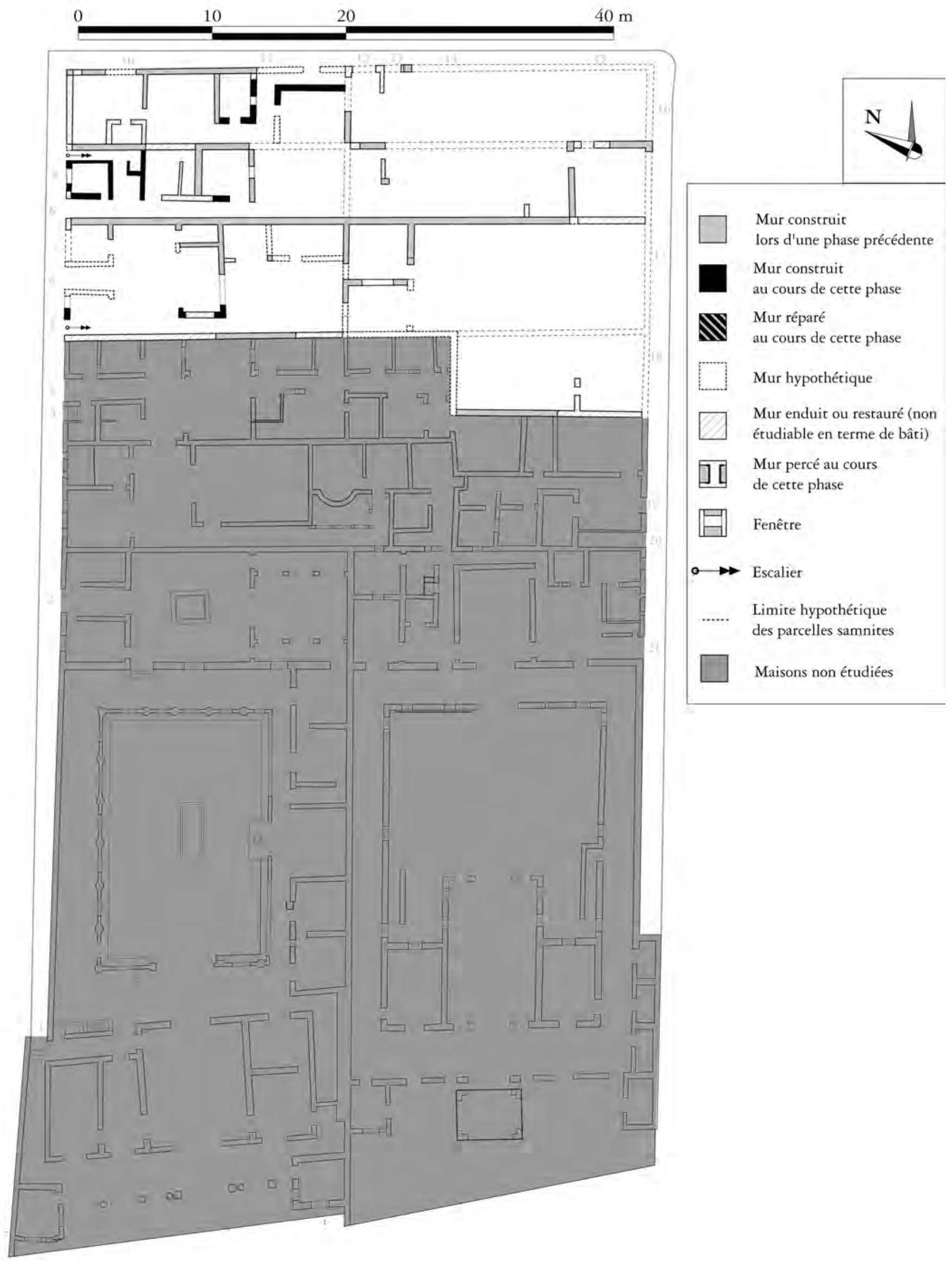

Fig. 154 - Insula IV - seconde phase pré-augustéenne (échelle: 1/400). 


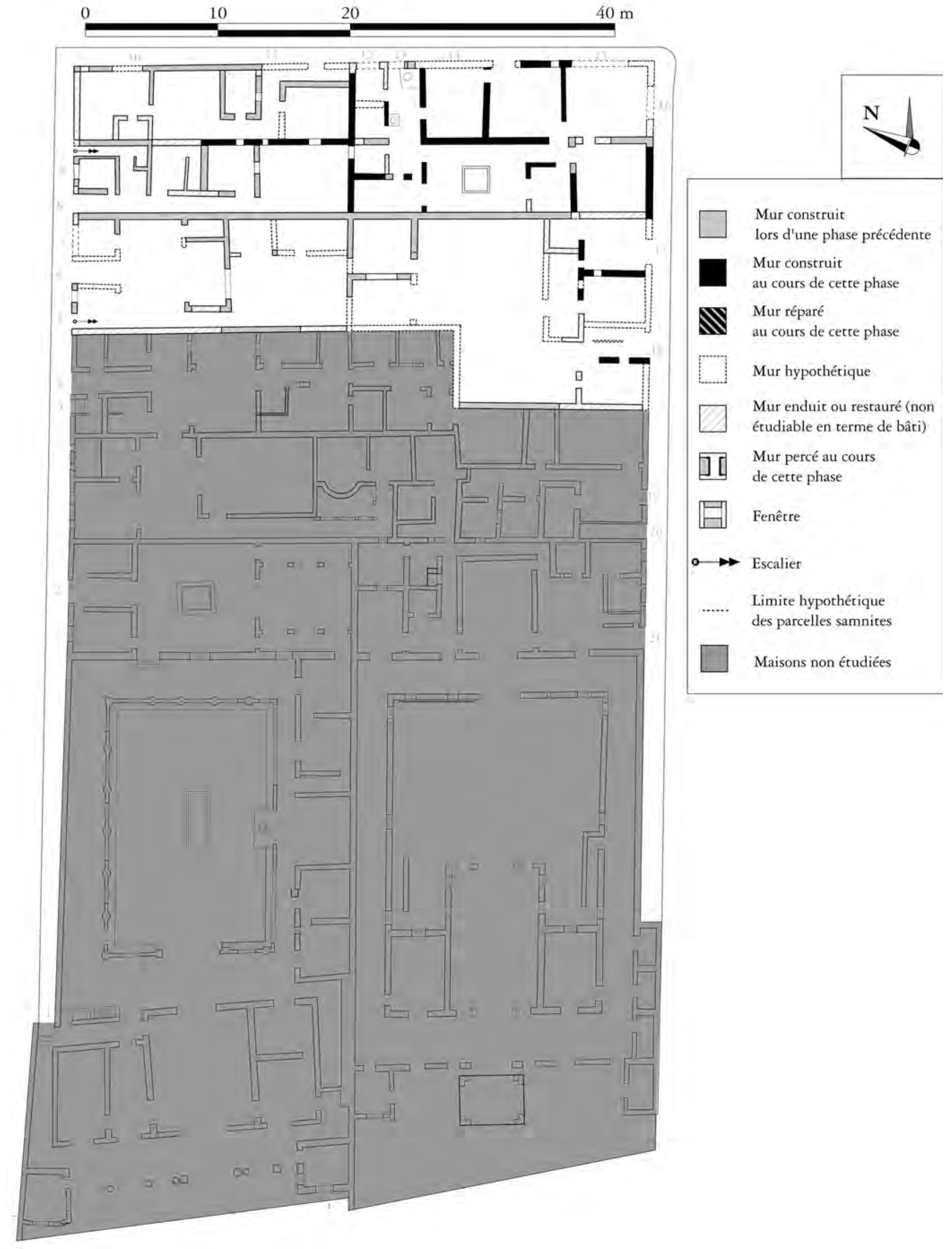

Fig. 155 - Insula IV - phase augustéenne (échelle: 1/400). 
cette même phase, mais après la première série de travaux que je viens de décrire, la Casa del papiro dipinto accroît la hauteur sous plafond des pièces 4 à 7 situées dans sa moitié orientale. Le jardin est alors aboli. Ces travaux de rehaussement sont effectués en opus reticulatum B et en opus vittatum (fig. 153, b et 156, c-e). Durant la période augustéenne, la plupart des maisons de cette moitié nord de l'insula IV s'agrandissent, soit en regroupant plusieurs parcelles, soit en créant de nouveaux volumes. Une première série de boutiques pourrait alors avoir été créée. Au cours de la phase suivante, la seule transformation qui paraît pouvoir être mentionnée est l'ouverture de la boutique IV, 10. Je ne saurais fixer de période plus précise: mon hypothèse d'une telle création se fonde sur l'emploi de l'opus vittatum mixtum à une seule assise de briques pour les montants de ce local commercial $^{27}$. Enfin, au cours de cette même phase, la décoration pariétale est refaite, au moins dans les pièces $8 / 9$ et $14^{28}$.

En fonction des maisons, le séisme de $62 \mathrm{a}$ eu des effets contrastés, mais de toute façon moindres que ceux relevés dans la Casa del tramezzo di legno en particulier (fig. 157). Ainsi, dans la Casa della fullonica, seuls le couloir d'entrée et les murs sud et est de la pièce 5 paraissent avoir nécessité une reconstruction. Les autres murs, en dépit de leur ancienneté, paraissent avoir largement résisté à la secousse. Les réparations ont été effectuées soit en remployant les moellons effondrés comme dans la pièce 5 , soit en enfermant ceux-ci entre deux piliers de briques comme dans le couloir d'entrée. Dans la Casa del papiro dipinto, aucune réparation n'a pu être clairement identifiée, ce qui ferait de cette maison l'une des rares à avoir été complètement épargnée par les différentes secousses sismiques ayant précédé l'éruption. Dans la Bottega con abitazione (IV, 10-11), les dégâts apparaissent tous localisés dans la partie nord-orientale: une partie de la façade s'est effondrée, ainsi que la poutre soutenant le toit incliné du nord au sud au-dessus de la pièce 6 . Ici

\footnotetext{
${ }^{27}$ La prudence est toutefois de mise quant à cet emploi. Les deux montants qui sont actuellement visibles paraissent être des restaurations effectuées au moment des fouilles. Certains montants restaurés avec cette technique peuvent avoir été construits différemment durant l'Antiquité.
}

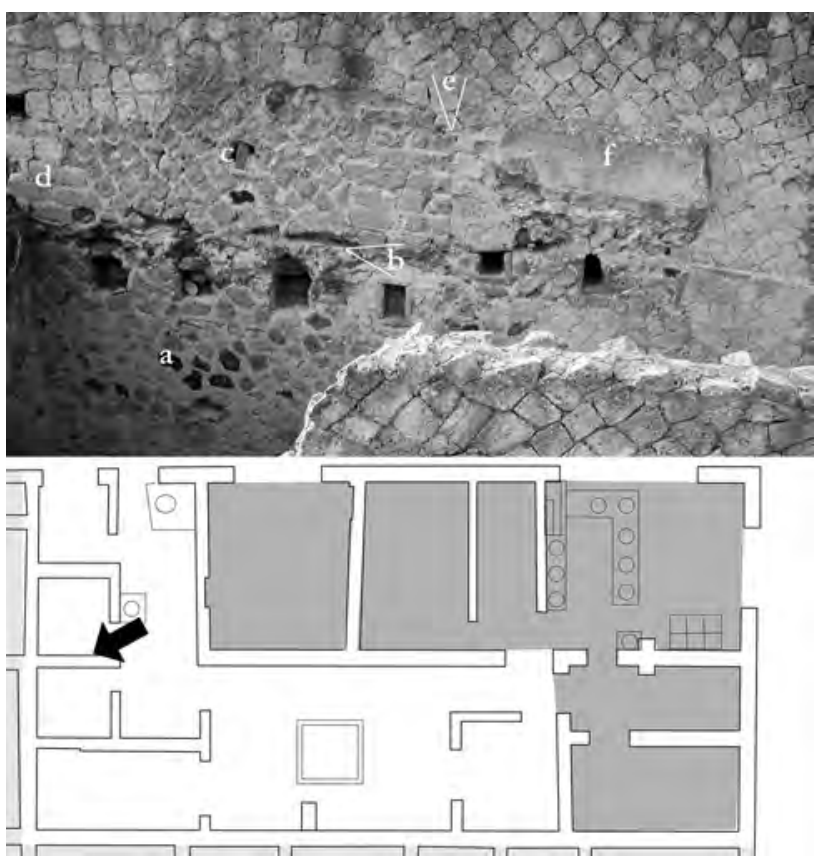

Fig. 156 - Grande taberna con abitazione (IV, 12-13.15-16), pièces 1 et 2 , mur ouest. Un mur en opus incertum $\mathrm{C}$ est construit durant la période augustéenne (a) lors des travaux définissant l'ensemble de la maison. Une toiture plate (b) protège la pièce 2 et probablement les pièces 1 et 13 . Lors de la même phase, mais plus tard, les pièces de la Casa del papiro dipinto sont rehaussées de murs en opus reticulatum $\mathrm{B}$ (c). Une fenêtre (d) est ménagée et ces travaux ne débordent pas sur la Bottega con abitazione (IV, 10-11) comme l'indique l'arrêt de la maçonnerie (e). Successivement, un réservoir d'eau est installé au-dessus de la pièce 1 et de l'entrée IV, 12 (f).

également, les réparations ont été effectuées avec les moellons de déblais. Pour remettre la toiture en place, une saignée a été pratiquée dans le mur séparant la pièce 6 de la pièce 4 , ensuite comblée avec des briques. Dans la Grande taberna con abitazione, les dommages causés par le tremblement de terre paraissent d'une ampleur assez considérable: une fissure à l'étage de la pièce 14 ; le mur de refend entre les pièces 12 et 1 s'est effondré tout comme une partie de la façade septentrionale; l'écroulement du mur ouest de la

\footnotetext{
${ }^{28}$ Sur ces fresques de III ${ }^{\mathrm{e}}$ style final, datées du règne de Claude, voir Esposito 2005: 130-132 et 216-217.
} 


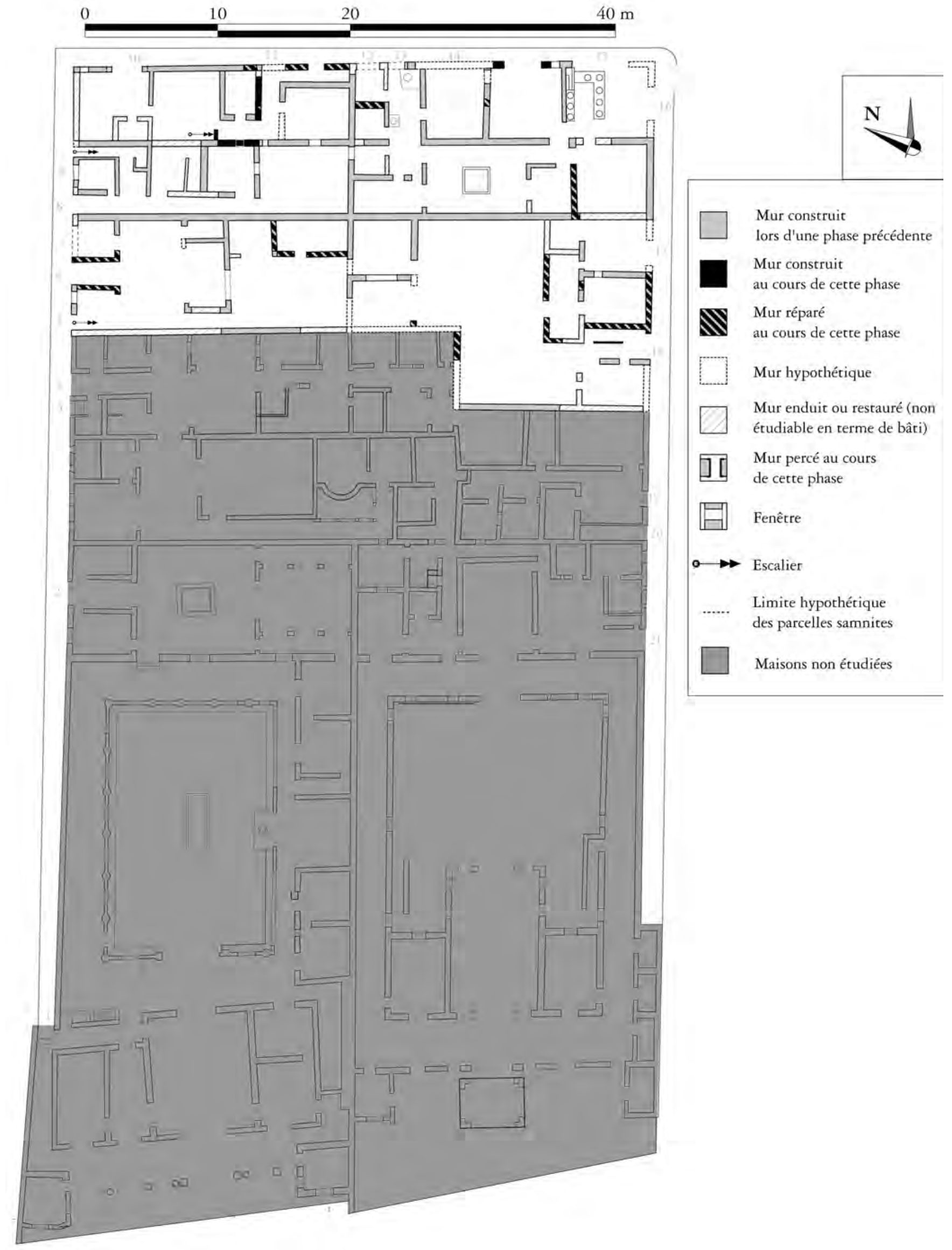

Fig. 157 - Insula IV - 62 - ca. 70/75 (échelle: 1/400). 
pièce $8 / 9$ paraît avoir été complet. Pour le réparer, outre des moellons de remploi, la technique du coffrage a été utilisée ${ }^{29}$. La réfection de la fresque de $\mathrm{III}^{\mathrm{e}}$ style qui ornait les parois a été effectuée avec de subtiles modifications ${ }^{30}$. C'est finalement la maison située à l'emplacement de la Casa del priapo qui paraît avoir ressenti de la façon la plus importante cette première secousse: l'angle sudouest de l'atrium ainsi qu'une importante partie des pièces 9 et 10 ont dû être restaurés. D'une façon générale, les changements consécutifs à ce premier séisme sont très peu nombreux. La Casa della fullonica, la Casa del papiro dipinto et le bâtiment situé sur l'emplacement de la Casa del priapo semblent, pour autant que l'on puisse l'observer, avoir été restaurés à l'identique. Dans la Bottega con abitazione, les murs entourant les pièces 4 et 5 sont rehaussés en opus incertum $\mathrm{C} /$ opus quasi reticulatum. Cet exhaussement permet, après avoir bouché une fenêtre d'où la pièce 4 de la Casa del papiro dipinto tirait de la lumière, la mise en place d'une sous-pente dans la pièce $4^{31}$. Elle est accessible par une échelle de meunier qui s'appuie sur un piédroit d'échiffre construit en toutvenant. Dans la Grande taberna con abitazione, la pièce $7 / 8$ devient probablement une boutique, doublant ainsi la surface commerciale de cette maison.

Bien qu'ayant eu un impact matériel apparemment moindre, le second séisme semble avoir eu des conséquences plus importantes sur la physionomie de la portion septentrionale de cet îlot (fig. 158). Je distinguerai deux ensembles en commençant par le groupe formé par la Casa

\footnotetext{
${ }^{29}$ L'emploi de cette technique est visible depuis la Casa del priapo, dans l'angle supérieur du mur nord de la pièce 16 , à l'est.

${ }^{30}$ La différence de traitement entre la paroi occidentale qui s'est effondrée, et la paroi méridionale, originelle, est particulièrement perceptible dans les frises médianes, ainsi qu'à certains détails des panneaux de la paroi. Sur les réparations des fresques effectuées après le séisme, cf. supra, p. 236 et 249 .

${ }^{31}$ Faute de conservation suffisante de l'élévation, on ne saurait affirmer si ce rehaussement a également lieu audessus des pièces 1 et 3 .

${ }^{32}$ Les deux pièces " 6 et 7 de la Casa della fullonica» appartiennent alors à la Casa del priapo.

${ }^{33} \mathrm{R}$. de Kind (1998: 74) a interprété cette fosse comme le témoignage d'un escalier. L'hypothèse que cette fosse ait été destinée à empêcher un - nouvel? - affaissement du
}

della fullonica et la Casa del priapo. Seule cette dernière, dans son extension d'alors, semble avoir subi quelques dégâts : les deux montants de la boutique IV, 17 ont été réparés en employant de l'opus vittatum mixtum à deux assises de briques. L'angle sud-est de l'atrium, commun avec la Casa dell'alcova (IV, 3-4), a également dû être de nouveau réparé. Deux autres montants paraissent également avoir été endommagés, au nord et au sud des portes permettant de passer des pièces 6 et 7 de Casa della fullonica aux pièces 6 et 5 de la Casa del priapo ${ }^{32}$. Le premier a été réparé en utilisant l'opus vittatum mixtum à deux assises de briques (fig. 159), tandis que pour le second un coffrage a été dressé (fig. 160, a). Ce n'est qu'après ces réparations que les deux pièces situées à l'ouest ont été rattachées à la Casa della fullonica: la porte au sud a été simplement bouchée. En revanche, la porte au nord a nécessité le creusement d'une fosse, de façon à ce que le bouchage dispose de fondations propres (fig. 159, c-d) ${ }^{33}$. Une fois les différentes communications - portes et oculus - entre ces deux maisons obturées, des travaux ont été effectués de chaque côté: fermeture de la fenêtre entre les pièces 6 et 7 de la Casa della fullonica, création d'un accès entre ces deux pièces et l'atrium. De plus, le tablinum est alors transformé en pièce refermée sur elle-même. Cette dernière transformation pourrait être due à la construction des stalles de fouleries dans la pièce $9^{34}$. Du côté de la Casa del priapo, les différentes pièces situées autour de l'atrium sont alors créées ex nihilo selon la technique de la paroi parementée/

mur faute de fondation est issu d'un parallèle avec la situation observée dans l'arrière-boutique de l'atelier VI, 12 (cf. Monteix 2007 b: 169-170). Durant la période augustéenne, lors de la construction d'un mur nord-sud percé d'une porte donnant dans l'atrium, la maçonnerie de fondation ne déborde pas sous le passage proprement dit. Seul le remblai d'exhaussement y a été déposé. Une telle rupture de construction ne peut, en cas de secousse sismique, que créer un point de moindre résistance et donc faciliter l'écroulement des montants. La fosse creusée dans le signinum de la pièce 6 de la Casa della fullonica aurait ainsi permis d'étendre le bouchage de la porte jusqu'aux fondations, recréant de la sorte une unité structurelle du bâti. Seule la fouille de cette fosse permettrait toutefois de vérifier cette hypothèse.

${ }^{34}$ Aucune datation pour la mise en place de ce local consacré au nettoyage du textile ne saurait être proposée. 


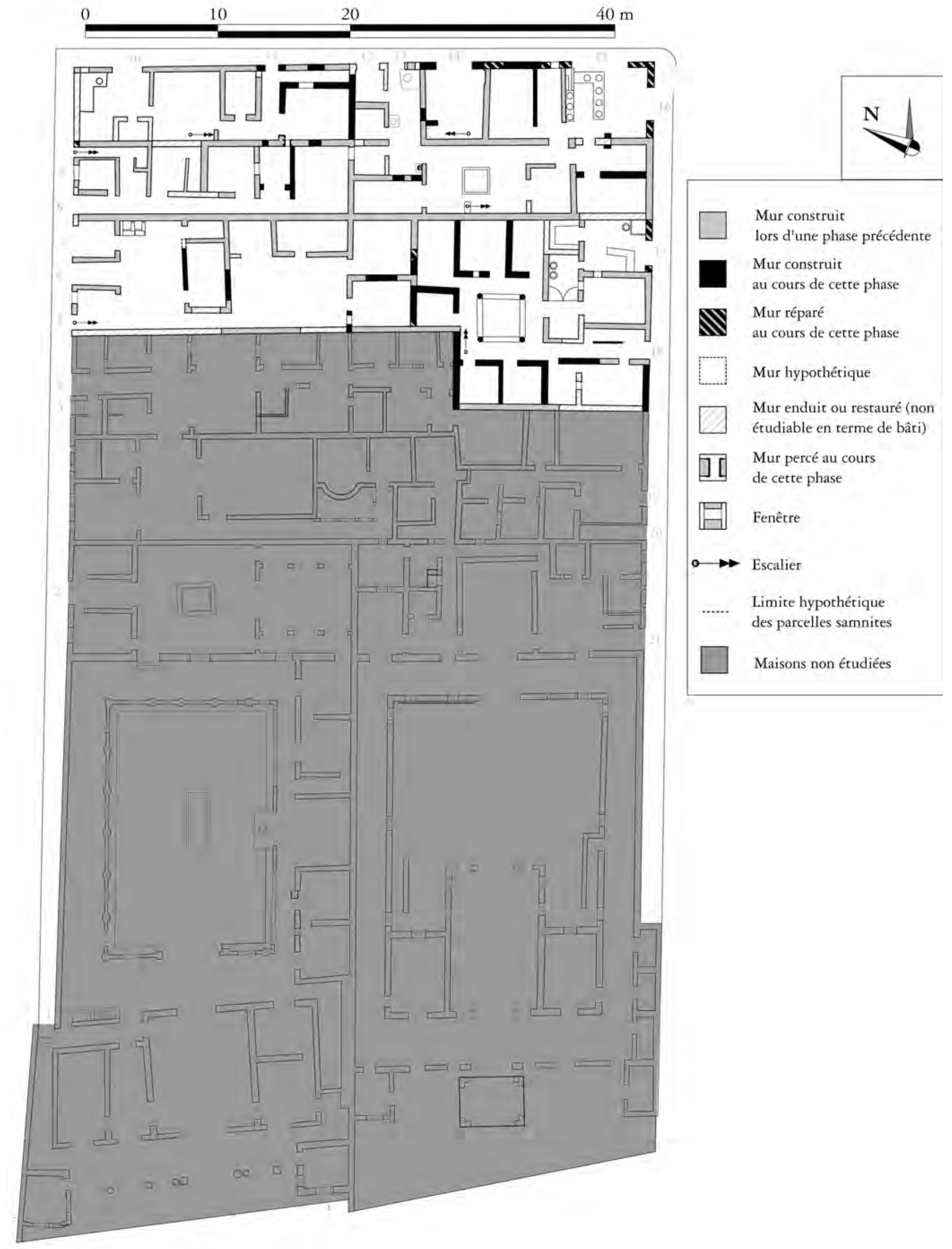

Fig. 158 - Insula IV - ca. 70/75 - 79 (échelle : 1/400). 


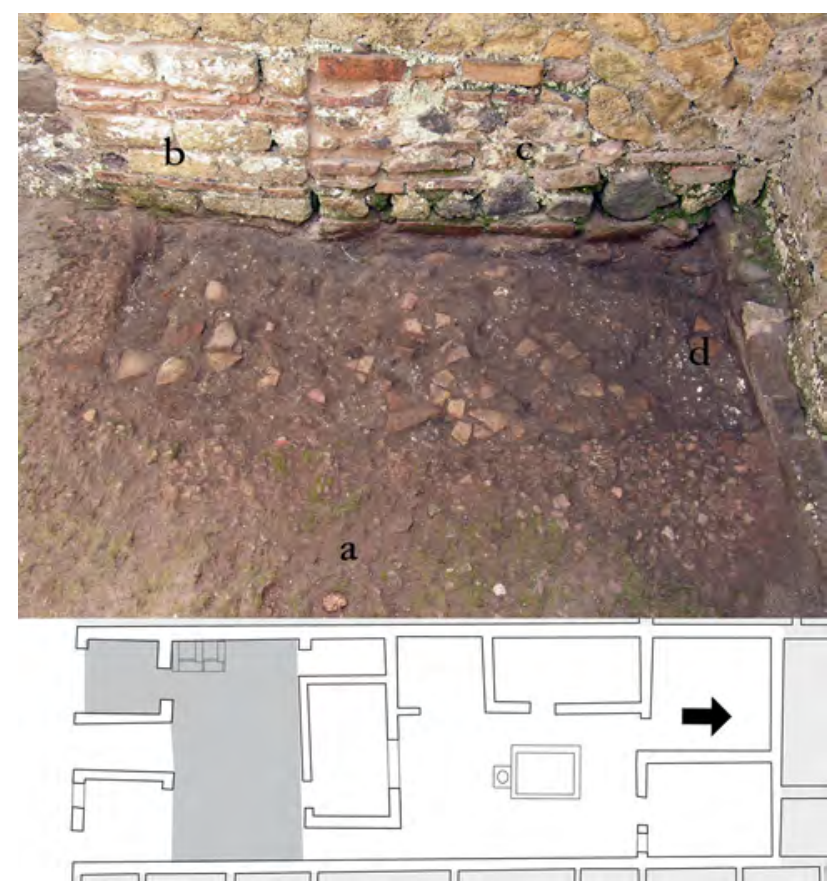

Fig. 159 - Casa della fullonica (IV, 5-7), pièce 6, mur est. Le bouchage (c) de la porte réparée (b) donnant sur la pièce 6 de la Casa del priapo (IV, 17-18) a nécessité de percer le sol en signinum (a) d'une fosse (d) pour recréer une fondation saine. Le remblai de la fosse contient notamment des fragments d'amphores.

coulée exposée plus haut ${ }^{35}$. Les autres maisons de la moitié nord de l'îlot ont également subi des remaniements importants durant cette ultime phase. Seule la Grande taberna con abitazione (IV, 12-13.15-16) paraît avoir subi les dommages du second séisme: les différents montants des deux boutiques ont été restaurés en employant l'opus vittatum mixtum à deux assises de briques, tandis que des piliers érigés avec le même type de mise en œuvre sont installés de part et d'autre du mur de refend entre la boutique s'ouvrant en IV, 15-16 et la pièce 8/9 (fig. 161). Après ces restaurations, divers travaux sont effectués: la boutique occupant les pièces 6/7 est condamnée et une paroi en opus craticium est construite dans l'espace ainsi libéré, qui devient une annexe

${ }^{35}$ Sur la technique employée, cf. supra, p. 229, 243244. Cette unicité de construction - à l'exception des pièces situées dans la partie orientale - justifie partiellement les remarques de R. de Kind (1998: 168) qui considère que les informations disponibles sont trop peu nombreuses pour déterminer les différentes phases d'évolution.

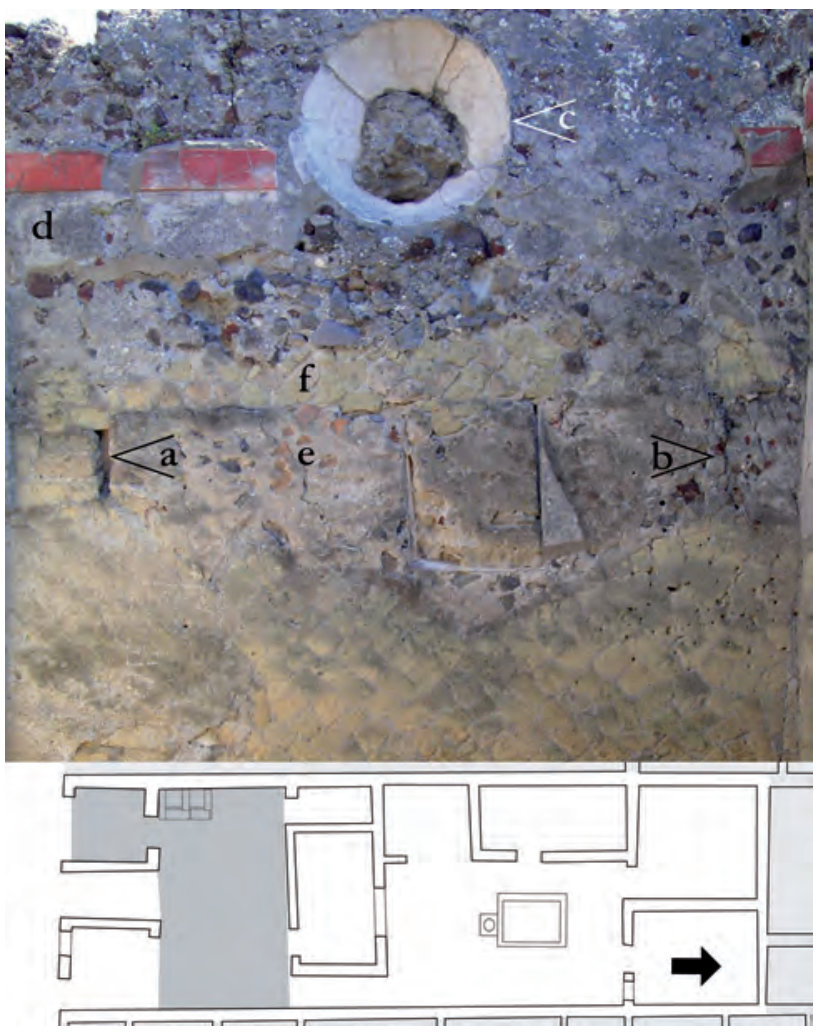

Fig. 160 - Casa della fullonica (IV, 5-7), pièce 7, mur est. Cette paroi, s'ouvre sur la pièce 5 de la Casa del priapo (IV, 17-18), grâce à une porte dont on perçoit les montants (a-b) et l'empreinte du linteau (f), et à un oculus (c). Des fragments de décoration de $\mathrm{I}^{\mathrm{er}}$ style (d) sont conservés. Après le second séisme, le montant sud (b) a été réparé en employant la technique du coffrage, puis dans un second temps, la porte a été murée (e).

du commerce alimentaire situé en IV, 15-16. De la même façon, une paroi divise en deux la pièce $8 / 9$. Les deux pièces créées sont également transformées en espaces dans la dépendance de la boutique. Le triclinium 14 est détaché de la maison: il devient une boutique indépendante disposant d'une latrine et d'un accès à l'appartement qui se développe au-dessus du local et s'étend partiellement sur la rue ${ }^{36}$. Tous les autres travaux effectués dans cette maison et dans les deux domus voisines sont liés entre eux, mais ne

${ }^{36}$ Les importantes restaurations modernes effectuées dans la maçonnerie de ce local empêchent de déterminer l'emplacement de l'escalier permettant d'accéder à l'étage. Les traces de ce dernier, mentionnées par A. Maiuri (1958 b: 436), ne sont pas claires sur le site. 
correspondent pas nécessairement à des conséquences du second séisme. Ainsi, du côté de la Grande taberna con abitazione, le mur ouest de la pièce 1 et de l'entrée IV, 12 est rehaussé pour permettre l'installation d'un réservoir d'eau

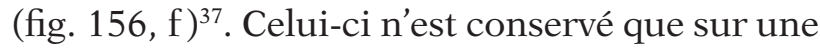
cinquantaine de centimètres de hauteur dont le tiers inférieur est occupé par un glacis incliné à 60 degrés. La construction de ce réservoir a obligé à transformer les modalités d'approvisionnement hydraulique: désormais, une canalisation récupère l'eau tombant sur la toiture des pièces 2,4 et $10^{38}$. Pour permettre l'installation de ce tuyau, les deux passages entre les pièces 4 et 10 sont bouchés avec l'opus reticulatum A. Ce n'est qu'après ces différents travaux que des transformations ont lieu dans la Casa del papiro dipinto (IV, 8-9) et dans la Bottega con abitazione (IV, 10-11). La cour ou le jardin de la pièce 8 devient une pièce à vivre après la construction de hauts murs en opus quasi reticulatum de tuf au nord et à l'ouest de cette pièce. Conjointement, les murs entourant les pièces 4 et 5 à l'est et à l'ouest sont également rehaussés. De ce fait, la sous-pente de la pièce 4 devient un véritable étage, tandis que deux mezzanines sont installées au-dessus de l'entrée IV, 11 et à l'extrémité occidentale de la pièce 7 . Après ces travaux, la cour 5 de la Casa del papiro dipinto est réduite en installant une cloison qui la distingue de la pièce 6. Deux fenêtres sont bouchées dans le mur nord, obligeant le bricolage d'une ouverture qui tienne compte de la nouvelle configuration des lieux.

Ces différentes transformations lors de la dernière phase précédant l'éruption ne sont que le point d'aboutissement d'une évolution sur le temps moyen, qui se caractérise par un accroissement progressif des surfaces domestiques, alors même que le mouvement de concentra-

${ }^{37} \mathrm{La}$ présence du béton hydraulique qui permet de définir un réservoir d'eau empêche de caractériser la maçonnerie sous-jacente. Elle pourrait être considérée comme $\mathrm{du}$ remploi de moellons divers, soit de l'opus incertum D. Toutefois, le soin apporté à la réalisation du mur et du réservoir, ainsi que la présence de tuiles et de briques pour marquer les encastrements de poutres empêchent de considérer que ce mur appartient aux réparations effectuées dans l'urgence, à la suite immédiate d'un séisme.

38 Les quelques vestiges de cet aménagement pourraient laisser croire qu'il s'agit d'un espace permettant d'entreposer des céréales, comme ceux observés dans la Casa

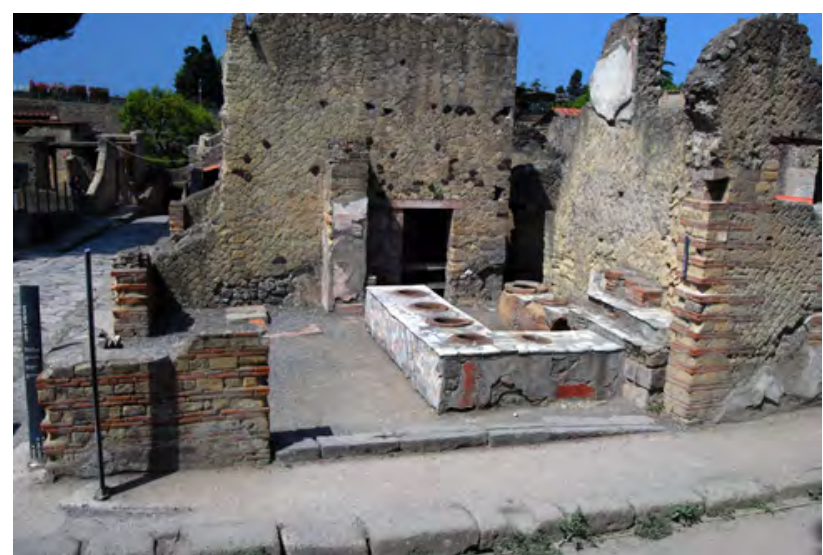

Fig. 161 - Grande taberna con abitazione (IV, 12-13.15-16), boutique IV, 15-16. Après le second séisme, un pilier a été ajouté au sud pour maintenir le mur de refend avec la pièce $8 / 9$, tandis que les montants des entrées ont été restaurés. Ces travaux ont été effectués en opus vittatum mixtum à deux assises de briques (cliché pris du nord).

tion des maisons semble se stabiliser de façon assez précoce. D'une manière plus globale, les rythmes de transformation paraissent proches entre les îlots III et IV.

\section{VII.2 Les transformations heurtées de l'insula V}

Entre la période samnite et l'éruption du Vésuve, les remembrements de propriétés ont été particulièrement importants dans l'insula $\mathrm{V}$ (pl. vIII, h.t.). Plus que la séquence de ces divisions et rassemblements de parcelles fragmentées, c'est la forme originelle du découpage qui a suffisamment marqué l'îlot pour permettre de regrouper l'étude de l'évolution en deux grands ensembles. Selon l'hypothèse de W. Johannowsky, deux types de parcelles ont été implantés à l'origine ${ }^{39}$. Dans

dell'Apollo citaredo (V, 9-12; cf. Monteix 2008: 130-131). La présence d'un appartement indépendant au-dessus de la boutique IV, 14 empêche toute communication entre l'étage de la Grande taberna con abitazione et cet aménagement. Une structure similaire peut être observée au sommet du «nymphée » de la Casa di Nettuno e Anfitrite (V, 6-7). Si dans ce dernier exemple, le rôle de réservoir pour alimenter une fontaine paraît hors de doute, l'intérêt de l'aménagement de la Grande taberna con abitazione reste plus délicat à déterminer: la citerne bénéficie d'un approvisionnement en eau de pluie par l'impluvium et par le tuyau maçonné qui récolte les eaux tombant sur la toiture des pièces 2,4 et 10 . 
la moitié septentrionale, elles sont orientées dans le sens nord-sud: la largeur de l'îlot aurait été divisée en trois lots de largeur et de profondeur variant quelque peu. En revanche, la moitié sud a été partagée, comme les insulae III et IV, selon une ligne médiane: les parcelles sont organisées en bandes orientées est-ouest. Au sein des maisons qui se sont installées sur ces dernières, trois ne paraissent jamais avoir disposé de locaux commerciaux en façade: la Casa del mobilio carbonizzato $(\mathrm{V}, 5)$, la Casa dell'atrio corinzio $(\mathrm{V}, 30)$ et la Casa del sacello di legno (V, 31); elles n'ont pas été prises en compte dans cette étude ${ }^{40}$. La Casa sannitica se trouve dans une situation identique, toutefois, l'évolution de sa forme rend son étude nécessaire pour suivre les changements survenus dans les maisons voisines. Les différentes mutations de propriété auraient dû me conduire à étudier séparément les parcelles de la moitié nord de celles de la moitié sud. Je suivrai ce principe avec toutefois une exception: la Casa di Nettuno e Anfitrite (V, 6-7) qui se situe sur une parcelle orientée est-ouest sera étudiée en même temps que les maisons de la portion septentrionale de l'îlot. En effet, bien qu'aucune communication n'ait jamais été établie entre cette domus et celles qui la jouxtent au nord, elle se trouve, par sa position topographique, plus liée aux transformations qui se sont déroulées dans la Casa del bel cortile $(\mathrm{V}, 8)$ et dans la Casa del bicentenario (V, 13-16) qu'avec les maisons de la portion méridionale.

VII.2.1 Transformation des parcelles de la moitié méridionale (Casa sannitica, Casa del telaio, Casa con giardino et Casa del gran portale)

${ }^{39}$ Johannowsky 1982: 148-149.

${ }^{40}$ Sur la Casa del mobilio carbonizzato (V, 5), cf. Maiuri 1958 b: 251-261; Ganschow 1989: 261-283. Sur la Casa dell'atrio corinzio (V, 30), cf. Maiuri 1958 b: 261-265. Sur la Casa del sacello di legno (V, 31), cf. Maiuri 1958 b: 252255. Ces deux dernières maisons ont été l'objet d'une étude plus approfondie menée par une équipe néerlandaise, cf. Binnebeke 1993, Binnebeke - de Kind 1996.

${ }^{41}$ A. Maiuri (1958 b: 197-199) considère que le péristyle associé à la Casa sannitica se serait développé sur une partie de la Casa del gran portale (V, 34-35) et sur toute l'aire du jardin de la Casa con giardino (V, 32-33a). Pour stimulante qu'elle soit, cette hypothèse est difficile à soutenir avec des faits précis. Le principal manque tient à l'impossibilité de déterminer la date de fermeture de la liaison entre la Casa
La difficulté de l'étude de la portion méridionale de l'insula $\mathrm{V}$ tient à la fréquence des changements de plan des maisons qui s'y sont succédées entre la période samnite et l'éruption du Vésuve. Toutefois, cette très intéressante zone d'Herculanum a bénéficié d'une analyse approfondie menée par Th. Ganschow. Dans l'ensemble, je suis et reprend ses conclusions. Sur certains points, notamment sur la chronologie fine des années qui s'écoulent entre 62 et 79, mes vues sont sensiblement différentes en raison de la mise en évidence du second séisme.

Les vestiges des plus anciens types de construction ont permis, d'abord à W. Johannowsky, puis à R. de Kind de proposer une hypothèse sur le découpage originel de l'îlot (fig. 162). Dans la moitié méridionale, les lots auraient été obtenus après avoir scindé l'insula selon une ligne médiane nord-sud. Les maçonneries les plus anciennes tendraient à confirmer cette hypothèse. Des anomalies sont toutefois remarquables par rapport à ce schéma de restitution. Tout d'abord, l'angle sud-est de la Casa del mobilio carbonizzato $(\mathrm{V}, 5)$ semble indiquer que la parcelle sur laquelle cette maison s'est installée était plus large que celle de la Casa del sacello di legno $(\mathrm{V}, 31)$ et qu'elle aurait été construite avant cette dernière. La seconde anomalie tient à l'hypothèse que la Casa sannitica aurait disposé, dans sa phase proprement samnite, d'un péristyle. Cette idée a tout d'abord été proposée par A. Maiuri, dans une version maximaliste, datée des années 120-100 avant notre ère, puis reprise par Th. Ganschow ${ }^{41}$. Les arguments suggérés contre cette hypothèse par R. de Kind, qui refuse de considérer que la première

sannitica et la Casa del gran portale, en raison des fresques ornant le mur de division entre ces deux maisons. Toutefois, si l'on suit la description des structures effectuées par Th. Ganschow (1989: 290), une portion du mur occidental de la pièce 6 et de la pièce 10 de la Casa del gran portale est constituée d'opus incertum $\mathrm{C}$, pouvant être rattaché à une phase augustéenne. Même avec cette datation pour la réduction de la Casa sannitica, le doute subsiste quant à l'extension du péristyle vers le nord dans la phase précédente. En l'état actuel des connaissances, rien ne permet de fixer une réponse à cette question. Par excès de prudence, je suis Th. Ganschow (1989: 296-299) sur ce point, qui limite l'extension du péristyle à une bande est-ouest dans la partie méridionale de l'îlot. 

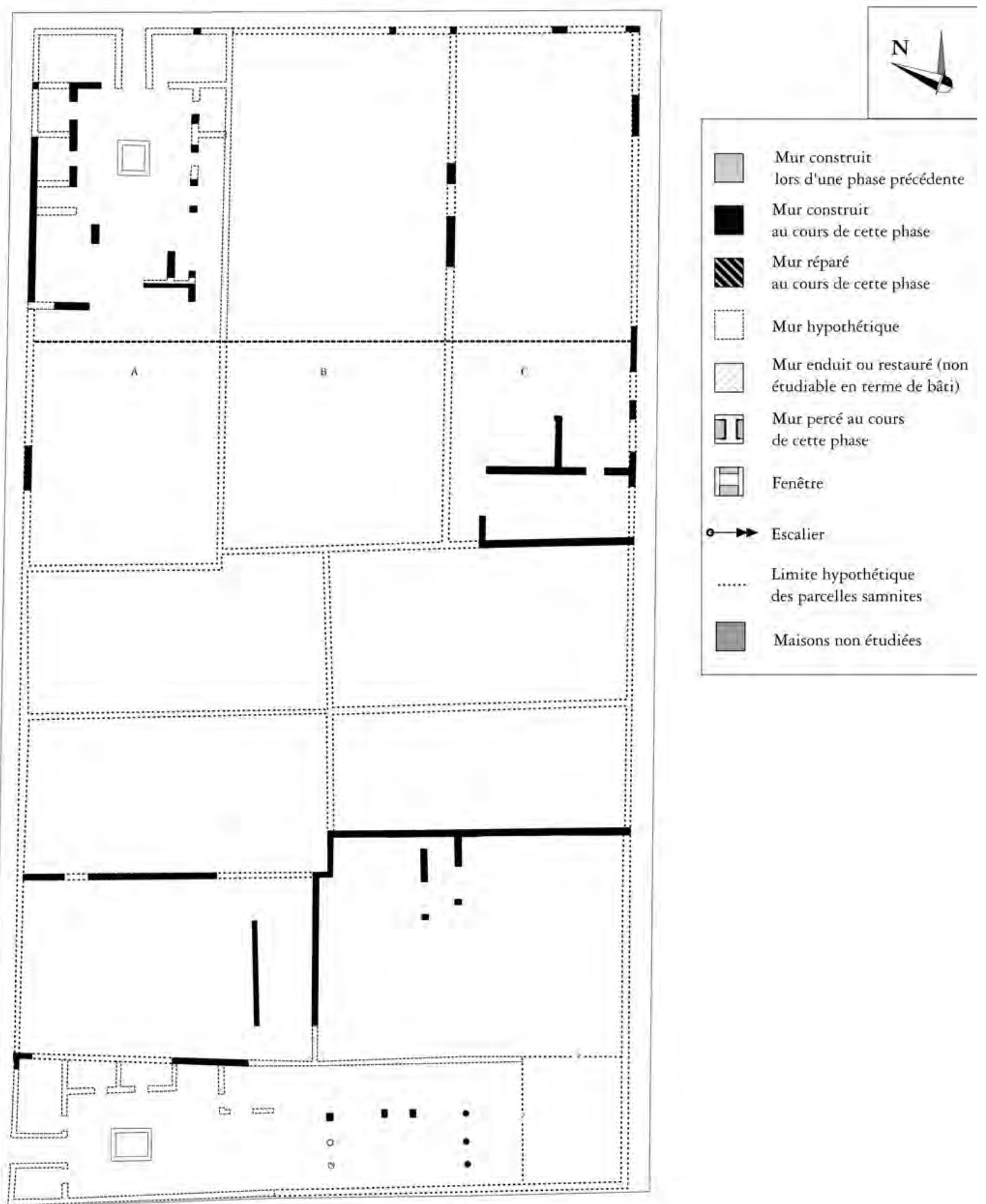

Fig. 162 - Insula V - phase pré-romaine (échelle: 1/400). 
phase de construction de cette maison ait pu comporter un péristyle, semblent fragiles face aux attestations de certaines structures ${ }^{42}$. Ainsi, le mur oriental de la boutique V, 33 dispose d'un socle en opus incertum B dans lequel des bases de colonnes en tuf gris sont prises (fig. 163). Si l'on utilise avec prudence la datation fournie par le mur effondré de la Casa della fullonica construit avec la même technique, ce stylobate pourrait remonter au $\mathrm{II}^{\mathrm{e}}$ siècle avant notre ère. Seule la situation à l'est de ce péristyle nous échappe complètement: s'agit-il d'un espace de jardin se développant vers le nord ou bien une série de pièces était-elle disposée à l'extrémité du péristyle ${ }^{43}$ ? Les éléments subsistant dans les parcelles ensuite occupées par la Casa del telaio $(\mathrm{V}, 3)$ et la Casa con giardino ne permettent pas de proposer une restitution de plan. Le seul indice des mutations à haute époque est fourni lors de la phase suivante, entre la guerre sociale et le règne d'Auguste: le mur séparant la Casa del telaio de la Casa del gran portale est percé d'une porte munie d'un linteau en tuf rossiccio. À cette extension en plan s'ajoute la probable création d'un étage, l'ensemble étant construit en opus incertum $\mathrm{C}$ utilisant cette même roche $\mathrm{e}^{44}$.

La phase suivante, remontant à la période augustéenne, est essentiellement marquée par le démembrement partiel de la Casa sannitica et par la construction de la Casa del telaio (fig. 164).

${ }^{42}$ Cette remarque de R. de Kind $(2005$ : 222, 224) semble sans réel fondement. L'un de ses arguments est que tous les chercheurs en faveur de cette hypothèse auraient suivi les dessins de restitution proposés par V. Catalano (1953 b: fig. 14 p. 83). Une lecture attentive des légendes aux figures proposées dans cet ouvrage de vulgarisation aurait permis d'éviter un contresens. En effet, V. Catalano (1953 b: p. 7583), dans le cadre d'un chapitre consacré à l'évolution de la maison dans l'Antiquité mêle les restitutions idéalisées de maisons osques ou samnites à des dessins de maisons d'Herculanum. La restitution invoquée par R. de Kind n'entend pas être une représentation de la Casa sannitica d'Herculanum, mais bien un schéma axonométrique de la «casa di tipo sannitico » durant la période hellénistique comme l'indique le texte illustré par ce dessin (ibid., p. 78 et n. 3). L'hypothèse de la ligne médiane pour la division de la portion méridionale de l'insula $\mathrm{V}$ ne saurait être abandonnée pour autant: si l'on considère que le découpage en parcelles a pu avoir lieu vers 400 av. J.-C. (de Kind 1998: $62-64,198)$, la Casa sannitica disposant d'un péristyle pourrait n'être qu'une évolution, résultant de l'agglomération des deux parcelles situées à l'extrémité méridionale de l'in-

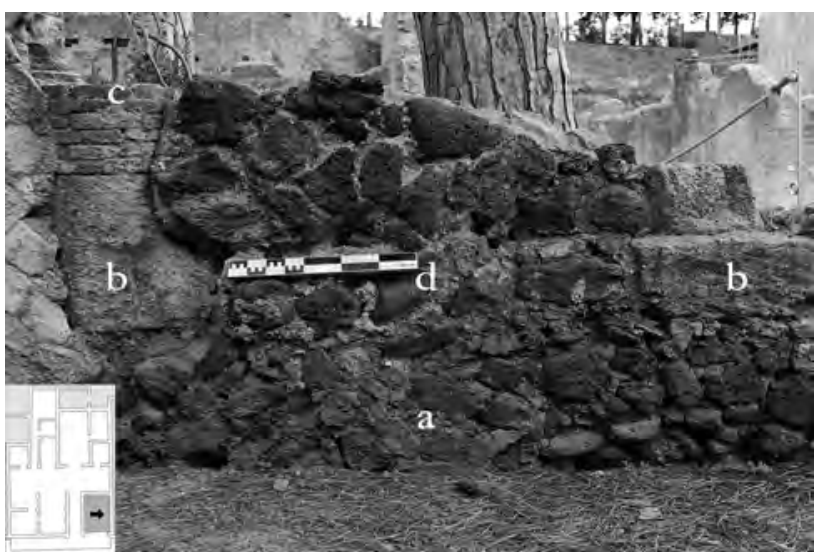

Fig. 163-Casa del gran portale (V, 33-34), boutique V, 33, mur est. Vestiges du stylobate correspondant au péristyle associé à la Casa sannitica $(\mathrm{V}, 1)$ avant la période augustéenne. Sur celui-ci, construit en opus incertum B (a), deux bases de colonnes en tuf rossiccio ont subsisté (b). Celle située au nord présente un fût reconstruit avec des briques (c). Après le démantèlement du péristyle, des moellons sont remployés pour édifier le mur périmétrique de la boutique (d).

L'ensemble des constructions effectuées durant cette période dans cette partie de l'insula $\mathrm{V}$ emploie la technique de l'opus incertum C, associé à l'opus vittatum, tous deux réalisés avec du tuf jaune. En ce qui concerne la Casa del telaio, je me trouve ici en désaccord avec les interprétations proposées par Th. Ganschow. En

sula $\mathrm{V}$. À défaut de constituer la première phase absolue de la Casa sannitica, cette maison dotée d'un péristyle est la première que l'on peut restituer en se fondant sur l'observation des maçonneries encore en élévation au moment de l'éruption du Vésuve.

${ }^{43}$ Sur ces questions, cf. Ganschow 1989: 299 et les deux notes précédentes.

${ }^{44}$ Bien que la présence de ce linteau ait été notée par Th. Ganschow (1989: 243, 244, 249), il ne semble pas avoir considéré qu'il se soit agi des restes d'une porte dont les montants auraient été détruits par un tunnel du XVIII siècle. On retrouve, dans le mur nord de la Casa sannitica, des portions de maçonneries érigées selon la même technique, correspondant également à la création d'un étage. Il serait nécessaire de déterminer si la similitude de parement correspond effectivement à une même phase de construction. Une réponse affirmative permettrait de redonner de la vigueur à l'hypothèse d'A. Maiuri faisant des parcelles de la Casa sannitica, de la Casa del gran portale et de la Casa con giardino une unique propriété avant la période augustéenne. 

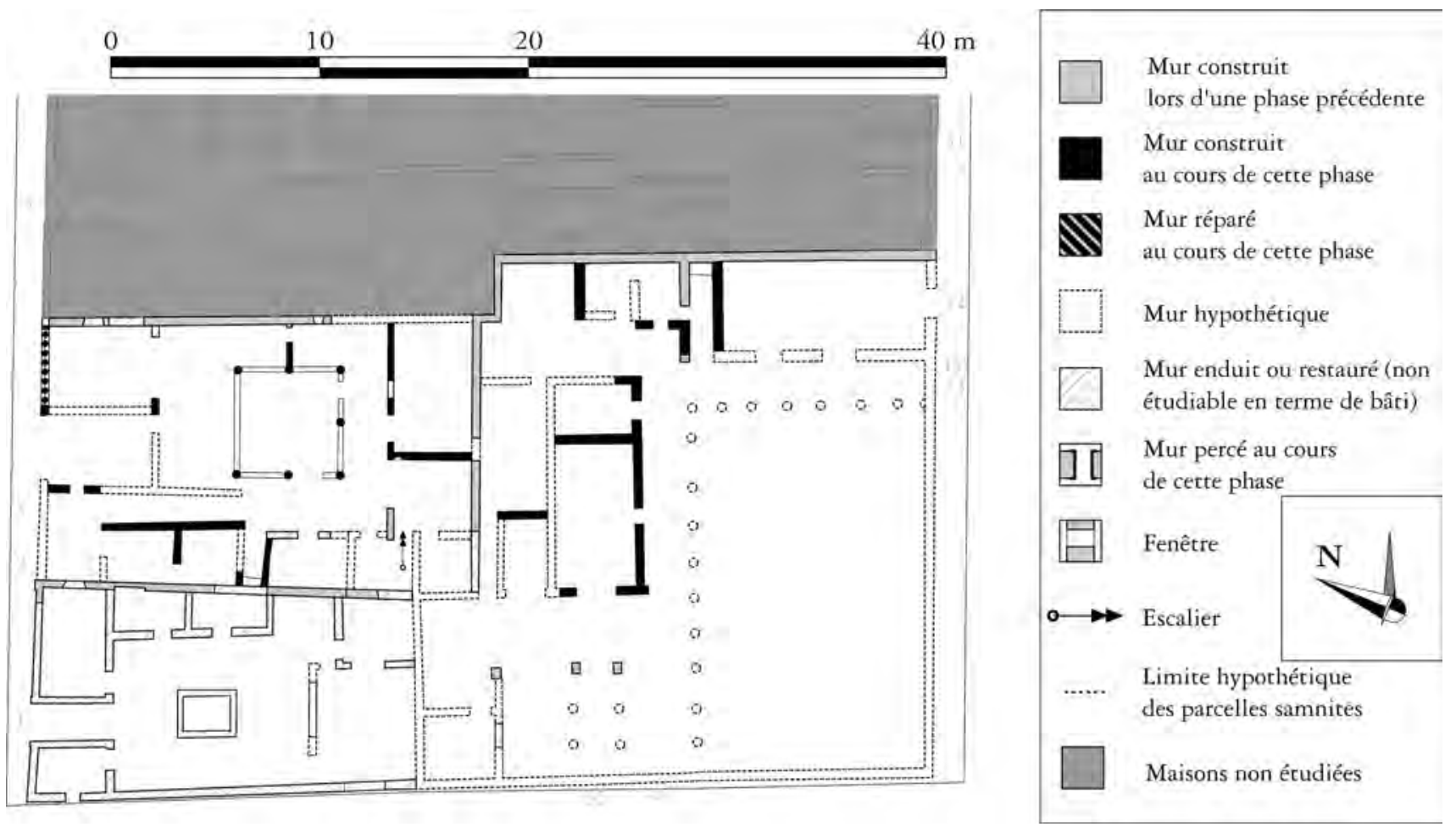

Fig. 164 - Insula V - moitié méridionale - phase augustéenne (échelle: 1/400).
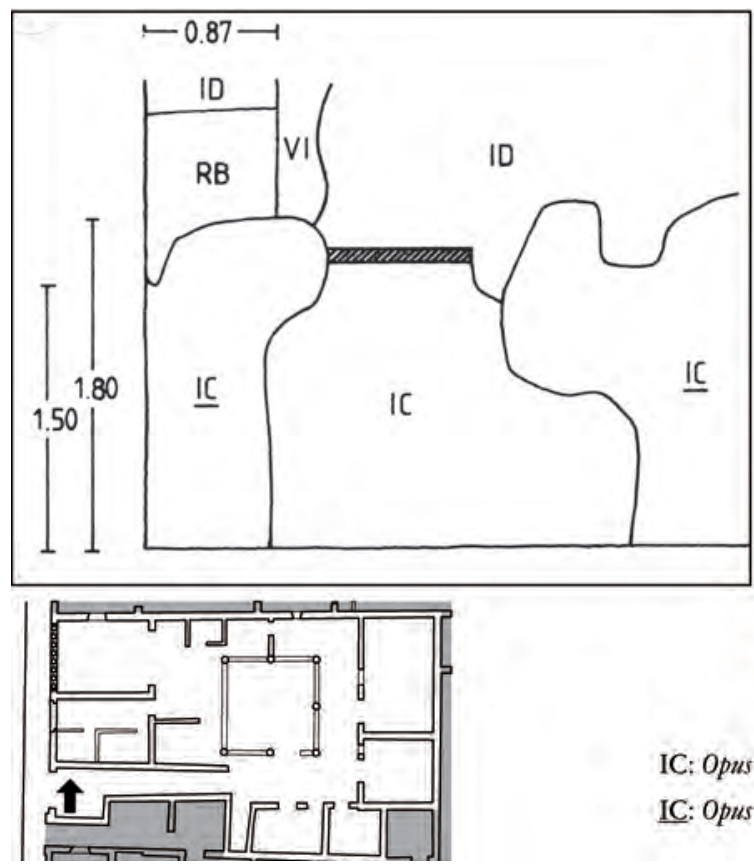
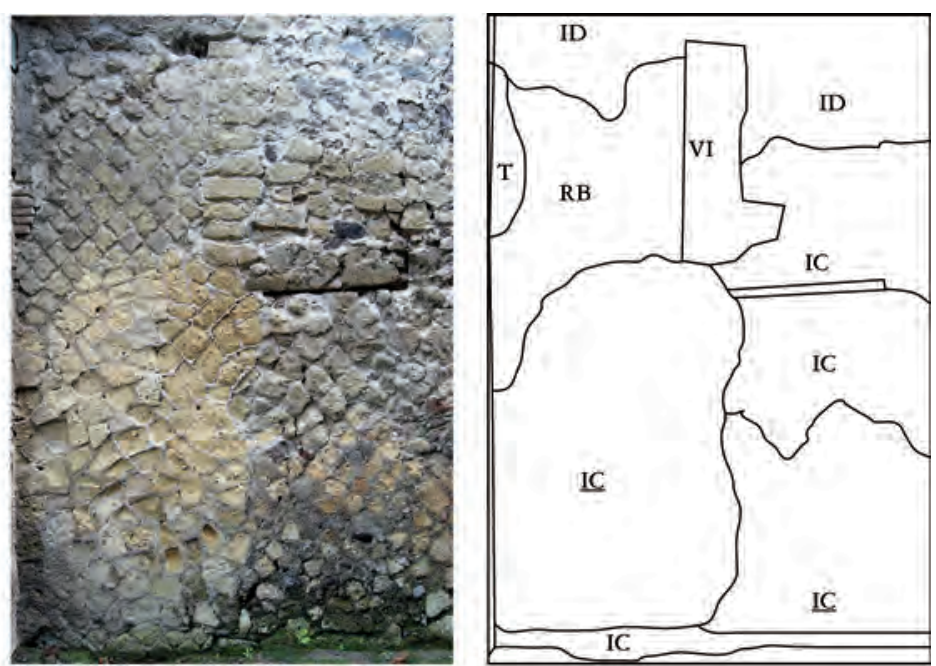

IC: Opus incertum $\mathrm{C}$

IC: Opus incertum $\mathrm{C}$ moderne
VI: Opus vittatum

RB: Opus reticulatum B (fin)
ID: Opus incertum $\mathrm{D}$

T: Opus Testaceum (façade)

Fig. 165 - Casa del telaio (V, 3), pièce B mur nord. Au centre, la photo de la paroi, à gauche le schéma d'interprétation proposé par Th. Ganschow (1989: fig. 22), à droite une nouvelle interprétation. La précédente non-reconnaissance de l'opus incertum $\mathrm{C}$ au-dessus de la porte bouchée a conduit à inverser les phases d'opus reticulatum $\mathrm{B}$ et celle d'opus incertum $\mathrm{C}$. 
effet, selon ce dernier, une phase de construction employant l'opus reticulatum B aurait précédé l'utilisation de l'opus incertum $\mathrm{C}$ en tuf jaune, plus importante en volume dans cette maison. Cette différence d'appréciation s'explique certainement par une interprétation différente de la paroi nord de l'entrée V, 3 (fig. 165). Pour lui, l'opus incertum $\mathrm{C}$ n'aurait été utilisé que pour boucher la porte de communication entre la pièce a et la pièce $\mathrm{B}$, l'ensemble s'appuyant sur de l'opus reticulatum $\mathrm{B}^{45}$. Il me semble plutôt nécessaire de voir dans cette paroi une porte et une fenêtre construites en opus incertum $\mathrm{C}$ et en opus vittatum. La fenêtre est d'abord bouchée avec de l'opus reticulatum $\mathrm{B}$. Une réparation de la paroi est ensuite effectuée en opus incertum $\mathrm{D}$, puis la porte oblitérée avec de l'opus incertum C de nouveau. Il est possible que durant cette première construction, deux boutiques aient été disposées en façade. La première est attestée sans difficulté, grâce au maintien en place du seuil après son oblitération. La seconde en revanche, postulée par Th. Ganschow, pourrait être inférée en raison de la largeur de la porte $\mathrm{V}, 3^{46}$. Au-delà de cette pièce, à l'est, deux pièces sont construites contre le mur nord de la Casa sannitica, correspondant aux pièces 8 et 9 , rattachées à cette domus dans une phase ultérieure. Une mezzanine se déploie sur toute la longueur du couloir B et permet d'atteindre l'étage situé au-dessus des pièces 8 et 9 par le franchissement d'une porte donnant dans la pièce $8^{47}$. Le reste de la maison s'organise autour d'une cour à colonnade. Outre les pièces 8 et 9 , l'étage ne paraît se développer qu'au-dessus de la pièce I et de la pièce 5 - ensuite rattachée à la Casa del gran portale. Durant cette phase, la Casa sannitica se réduit au simple aspect d'une maison de plan italique, centrée sur un atrium sur les trois

${ }^{45}$ Ganschow 1989: 252-253; pour la mise en évidence du seuil, cf. fig. 18 , b, p. 54 .

${ }^{46}$ Th. Ganschow (1989: 254) considère cependant qu'elle appartient à une phase postérieure, mais surtout qu'elle constituerait une unité indépendante avec les pièces 8 et 9 rattachées ensuite à la Casa sannitica. Aucun élément positif ne me semble permettre cette interprétation, d'autant plus qu'avec ma lecture des phases, une fenêtre et une porte permettrait alors de relier la pièce $\mathrm{B}$ avec la boutique $\mathrm{A} / \mathrm{a} / \mathrm{a}$.

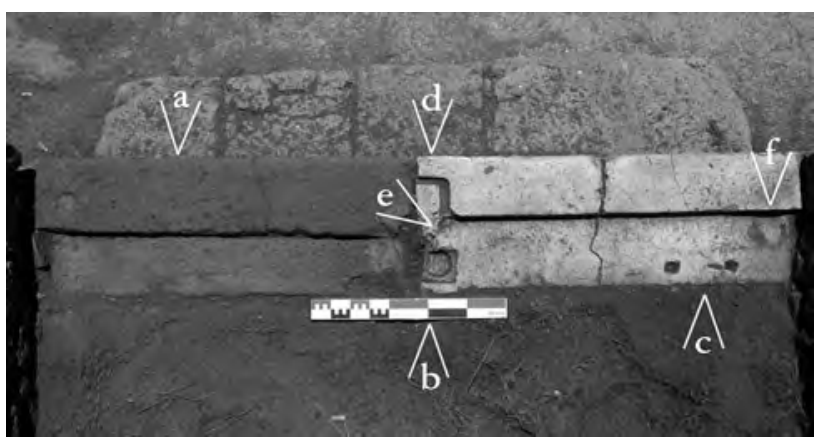

Fig. 166 - Seuils V, 33a et V, 33, Casa con giardino. Le seuil V, 33a en lave (a) donne accès à un appartement indépendant. L'autre seuil, en calcaire, donne accès à la Casa con giardino et présente deux phases: la crapaudine (b), les deux gâches (c) et la mortaise - à l'origine en forme de $\Pi$ - (d) ont originellement fonctionné ensemble; ce seuil aurait alors eu une largeur de 1,42 m. Récupéré, le pas a été réduit et deux nouvelles crapaudines (e et f) ont été taillées (cliché pris de l'ouest).

côtés duquel se développent les pièces d'habitation. Toute la moitié orientale de cette partie de l'insula $\mathrm{V}$ est réunie dans un seul ensemble occupé pour plus de la moitié de sa surface par un jardin entouré d'un péristyle. L'accès unique devait se trouver à l'emplacement de la boutique $\mathrm{V}, 32$. Le seuil de cette maison paraît avoir été coupé et déplacé pour être remployé, lors de la création de la Casa con giardino proprement dite, après le séisme de 62 , comme seuil pour l'accès en V, 33 (fig. 166) ${ }^{48}$. La présence de colonnes restaurées en briques dans les fauces de la Casa del gran portale et dans l'angle nord-ouest du jardin lorsqu'il est réduit pour la Casa con giardino, ainsi que les bases de colonnes en tuf maintenues dans le mur oriental de la boutique V, 34 permettent de restituer deux espaces à découvert: le premier, de forme rectangulaire et

\footnotetext{
${ }^{47}$ Sur le plan de phase, la position de l'escalier permettant d'accéder à cet étage n'est pas indiquée, faut d'avoir pu observer un système de poutraison signalant une cage d'escalier. Il pourrait également s'agir d'une échelle mobile.

${ }^{48}$ Sans mentionner l'hypothèse d'une première porte large puis d'un remploi du seuil, A. Maiuri (1958 b: 431432) signale que l'accès $V, 33$ comporte une bipartition, une porte menant au rez-de-chaussée, l'autre à l'étage. Je considère qu'il s'agit d'un accès à un appartement indépendant après le séisme de 62, appelé V, $33 \mathrm{a}$.
} 
entouré de colonnes sur ses côtés septentrional et occidental, est probablement un jardin; le second est réduit à un espace entouré de quatre colonnes, immédiatement à l'est de la pièce 6 . Les pièces 1 - de la Casa del gran portale - et 7 - de la Casa con giardino - s'ouvrent sur cet espace $^{49}$. Au cours de la phase suivante (fig. 167), des transformations mineures sont apportées à cette vaste demeure de plan inhabituel. Une latrine et la pièce 7 sont créées à l'ouest du salon s'ouvrant sur l'espace tétrastyle. Plus tard, dans la partie septentrionale de la maison, la pièce 6 est modifiée, en employant l'opus reticulatum $\mathrm{B}$ et l'opus vittatum mixtum à une rangée de briques: le large passage est réduit et partiellement remplacé par une fenêtre. La Casa del telaio est amputée de son hypothétique seconde boutique. Un mur en équerre est construit en opus reticulatum B pour abriter un escalier permettant d'accéder à l'appartement V, 2 qui se développe au-dessus de la partie occidentale de la Casa sannitica. La mezzanine située dans le couloir B reste en usage, mais l'étage situé au-dessus des pièces 8 et 9 est condamné par l'obturation des portes permettant d'y accéder. Ces deux pièces font désormais partie de la Casa sannitica grâce à l'hypothétique percement d'une porte $^{50}$. Il est possible que la boutique V, 4 soit également fermée au cours de cette phase, peu de temps avant le séisme de $62^{51}$.

Le tremblement de terre de 62 semble avoir eu des conséquences importantes dans cette portion de l'îlot (fig. 168). Comme pour les autres insulae, j'ai distingué dans la période entre les deux séismes une phase de restauration et une

\footnotetext{
${ }^{49}$ Les peintures observées dans la pièce 7 de la Casa con giardino correspondent, selon D. Esposito (2005: 117-119), au $\mathrm{III}^{\mathrm{e}}$ style, phase Ia, et auraient été réalisées dans le troisième quart du I ${ }^{\mathrm{er}} \mathrm{s}$. avant notre ère.

${ }^{50}$ Les montants de cette porte ont été restaurés après la fouille, empêchant de vérifier qu'ils ont bien été construits en opus vittatum.

51 Ce sont les irrégularités dans la maçonnerie en briques du montant nord de la porte V, 3 (cf. fig. 165) qui permettent de proposer qu'au moment où cette réparation a été effectuée, la boutique était éventuellement déjà condamnée.

${ }^{52}$ Ces deux moments correspondent, dans l'étude de Th. Ganschow, à deux phases distinctes.

${ }_{53}$ Outre les quatre colonnes des fauces de la Casa del gran portale, une de ces colonnes restaurées est visible dans
}

phase de transformations ${ }^{52}$. C'est dans l'ensemble encore formé par la Casa del gran portale et la Casa con giardino que les dommages paraissent avoir été les plus marqués. Ainsi, nous pouvons supposer qu'une grande partie des colonnes du péristyle ont été abattues, puis restaurées en briques $^{53}$. Le mur séparant les pièces donnant sur le jardin des espaces de service paraît avoir été presque complètement abattu, tout comme le mur sud de l'entrée «V, 32 ». Dans chacun de ces cas, les restaurations ont été effectuées avec les moellons provenant des murs effondrés. Certaines pièces ornées de fresques de $\mathrm{III}^{\mathrm{e}}$ style, en particulier la pièce 7 ensuite rattachée à la Casa con giardino, se sont effondrées sur la majeure partie de leur élévation, mais les fresques ont ensuite dû être partiellement refaites ${ }^{54}$. Après ces réparations, dans un laps de temps que je ne saurais définir avec précision, les deux maisons se séparent. L'analyse des maçonneries dans la pièce 9 de la Casa del gran portale permet de mettre en évidence cette succession d'événements. Toute la partie occidentale est très clairement reconstruite avec des moellons récupérés sur des murs effondrés, mélangeant notamment lave, cruma et tuf (fig. 169, a). Chaîné à cette réparation, le montant d'une porte donnant dans la pièce 6 de la Casa con giardino a été restauré en opus vittatum de tuf jaune. Après cette réparation, la porte est bouchée avec des moellons de tuf rossiccio (fig. 169, b). La nouvelle configuration de la Casa del gran portale tente d'utiliser au mieux les structures préexistantes. Une partie du péristyle est remployée pour créer un couloir d'entrée, flanqué d'une boutique qui reste alors

la boutique V, 34, une autre à l'angle nord-ouest du jardin de la Casa con giardino.

${ }^{54}$ Pour la pièce 7 de la Casa del gran portale, les données fournies par Th. Ganschow s'accordent avec cette interprétation. Ainsi, il signale (Ganschow 1989: 306-307) que le mur sud de la pièce 6 est construit, dans sa moitié gauche, en opus incertum D, qu'il a par ailleurs (ibid., p. 42, 132-133) placé parmi les opera utilisés en réparation du séisme de 62 . Il considère pourtant (ibid., p. 109), que les fresques sont de $\mathrm{III}^{\mathrm{e}}$ style augustéen tardif. Si l'exemple récent de l'effondrement d'un mur à moitié, visible dans la Casa della fullonica, permet de supposer que, parfois, le mur s'est ouvert en deux, il serait étonnant que les parois de cette pièce aient toutes réagi de cette façon. Sur la datation originelle de ces fresques, cf. supra, n. 49. 

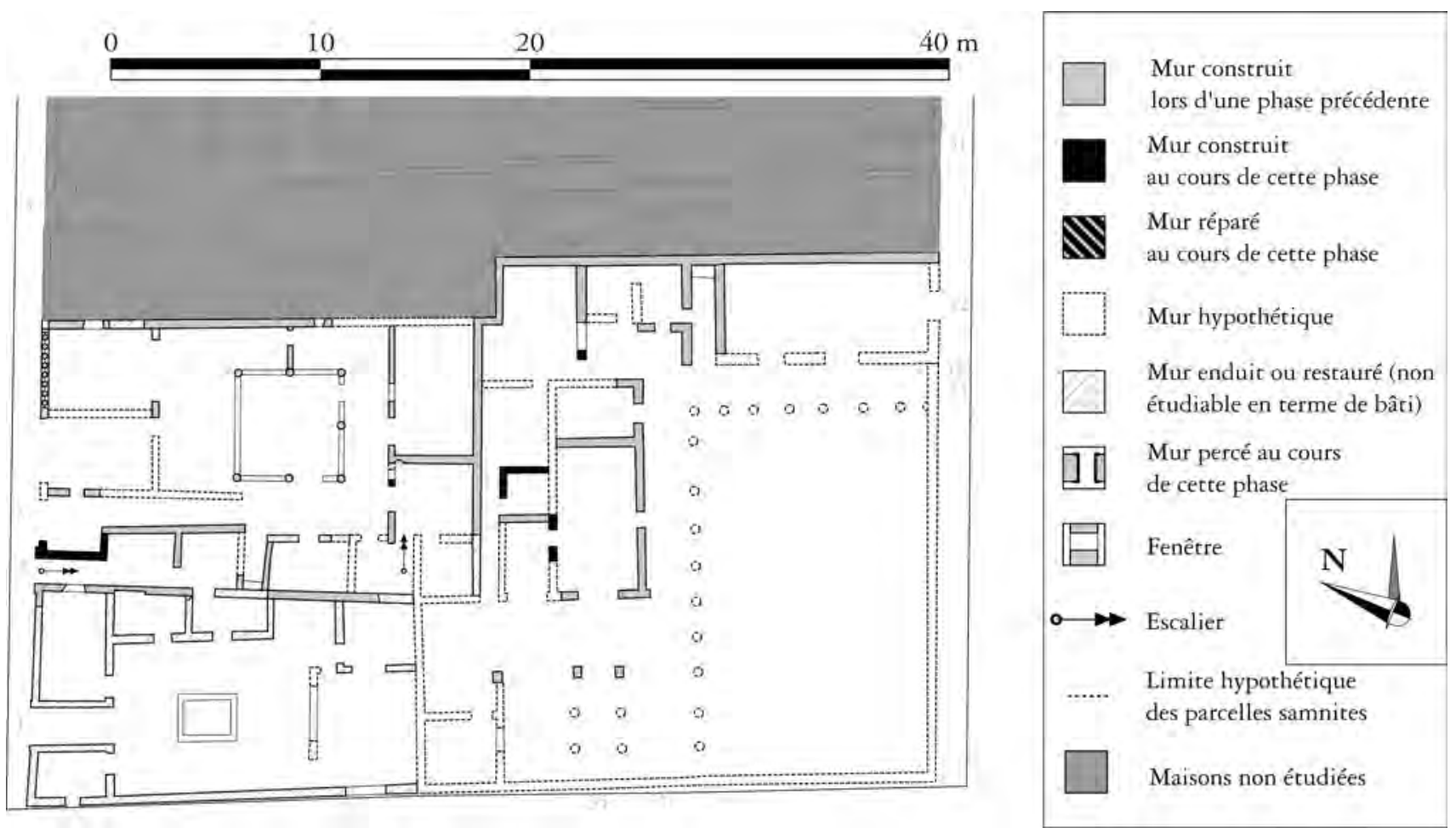

Fig. 167 - Insula V - moitié méridionale - phase post-augustéenne (échelle: 1/400).
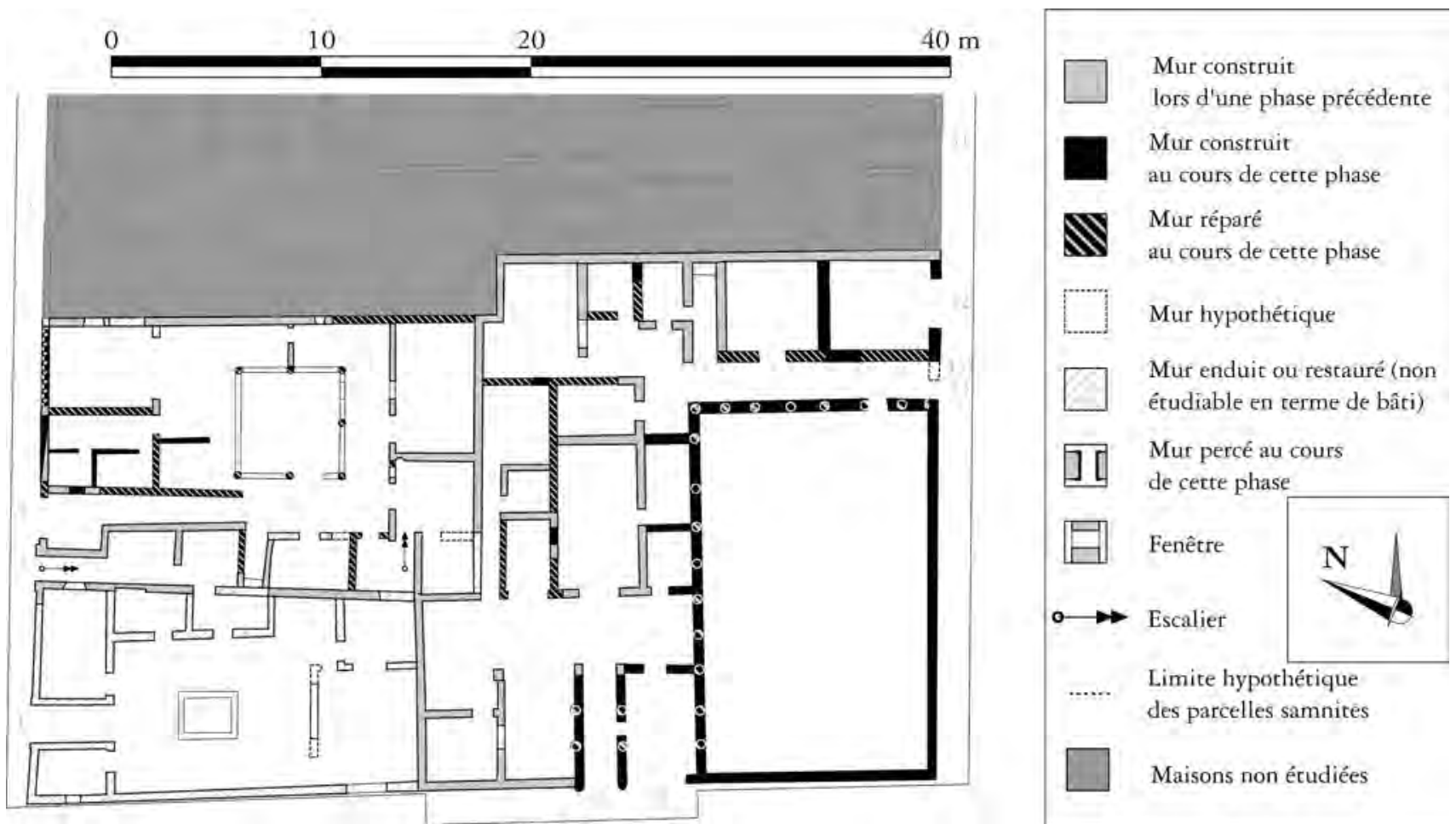

Fig. 168 - Insula V - moitié méridionale - 62 - ca. 70/75 (échelle: 1/400). 


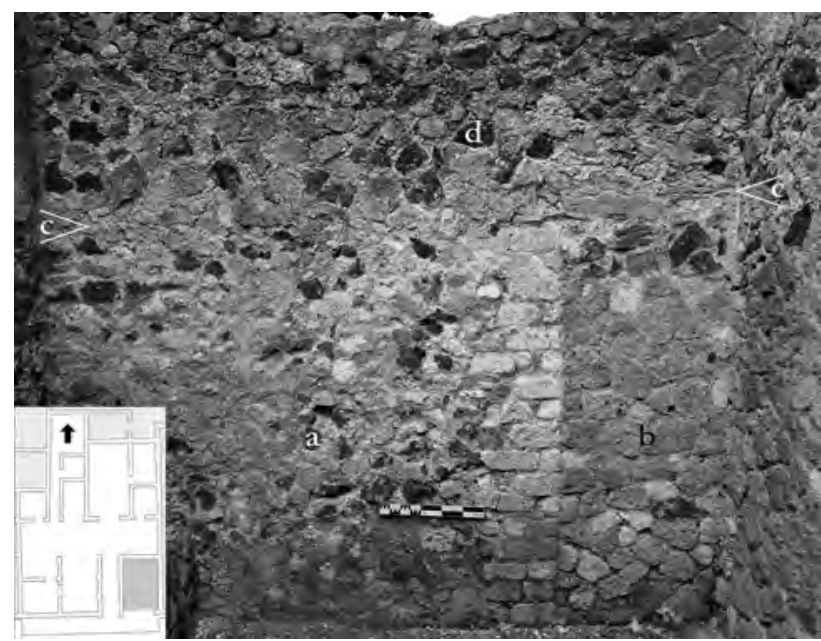

Fig. 169 - Casa del gran portale $(\mathrm{V}, 35)$, pièce 9, mur nord. Ce mur a été restauré en utilisant des moellons de remploi après le séisme de $62(\mathrm{a})$, en préservant la porte de communication vers la pièce 6 de la Casa con giardino $(\mathrm{V}, 33)$. Peu après, les deux maisons sont divisées et la porte bouchée (b). Après le second séisme, le mur subit de nouveaux dommages et est reconstruit au-dessus de la ligne c-c (d). Les deux phases de réparations se distinguent par la quantité de mortier employée.

dans la dépendance de l'occupant de la domus. Un trottoir - le seul du côté nord de ce tronçon du decumanus inférieur - est également construit, en correspondance des limites latérales de la maison. Les travaux d'érection des nouveaux murs de séparation sont essentiellement réalisés en opus reticulatum B. Le jardin échoit à la Casa con giardino, qui conserve également toutes les pièces situées au nord de la parcelle. L'entrée est décalée de quelques mètres vers le sud $(\mathrm{V}, 33)$. Une boutique est créée à l'emplacement de l'entrée de la phase précédente, sans communication avec la domus. Dans la Casa del telaio, une fois les réparations effectuées, essentiellement à l'ouest de la cour à colonnade, la boutique V, 4 est définitivement fermée - si cela n'avait pas déjà été le cas au cours de la phase précédente.

${ }^{55}$ Il est possible qu'une partie de la façade se soit également effondrée et ait alors été reconstruite en opus reticulatum A.
Des cloisons en équerre sont disposées dans cet espace de façon à ménager trois pièces, qui ne communiquent plus avec le couloir d'entrée B. La longue fenêtre barrée de petits piliers quadrangulaires de tuf donnant sur le cardo IV est également murée. Le second séisme provoque des dégâts de moindre importance dans ces différentes maisons (fig. 170). Une partie de l'étage de la Casa sannitica a dû s'effondrer, entraînant la reconstruction du sommet de la façade de l'accès V, 2 en opus vittatum à deux assises de briques. Un arc de décharge, construit avec la même technique est alors ménagé dans cette partie de façon à améliorer la résistance ${ }^{55}$. Le tablinum de cette maison est également endommagé. Dans la Casa del telaio, la pièce 5 a subi des dégâts importants. Après la réparation de ses parois et des portes la mettant en communication avec la pièce I, à l'étage comme au rez-dechaussée, cette pièce est cédée à la Casa del gran portale (fig. 171). Dans cette dernière maison, les dommages sont peu nombreux. Ils paraissent se limiter à la chute du mur restauré dans la phase précédente au nord de la pièce 9 (fig. 169, d $)^{56}$. Outre l'agrandissement de la domus à l'ouest, la boutique V, 34 devient indépendante. Divers aménagements y sont effectués, sans être achevés au moment de l'éruption. Enfin, dans la Casa con giardino, seul le mur méridional de la boutique V, 32 paraît avoir été restauré. Peu après, un escalier menant à un appartement indépendant, accessible depuis l'entrée V, 33a (fig. 166, a), est créé. Il est probable que la boutique reste dépourvue de tout espace d'habitation.

VII.2.2 Évolution des parcelles de la moitié septentrionale

Contrairement à la moitié méridionale, vraisemblablement divisée en bandes orientées estouest de part et d'autre d'une ligne médiane, la moitié septentrionale de l'insula $\mathrm{V}$ a été divisée, selon W. Johannowsky et R. de Kind, en trois parcelles orientées nord-sud. Au-delà des considérations strictement métrologiques, la question de la longueur originelle de ces parcelles

${ }^{56}$ La décoration pariétale des pièces 6 et 10 est refaite en IV style, selon D. Esposito (2005: 188-189, 213), par l'atelier «de la Casa dell'atrio a mosaico». 

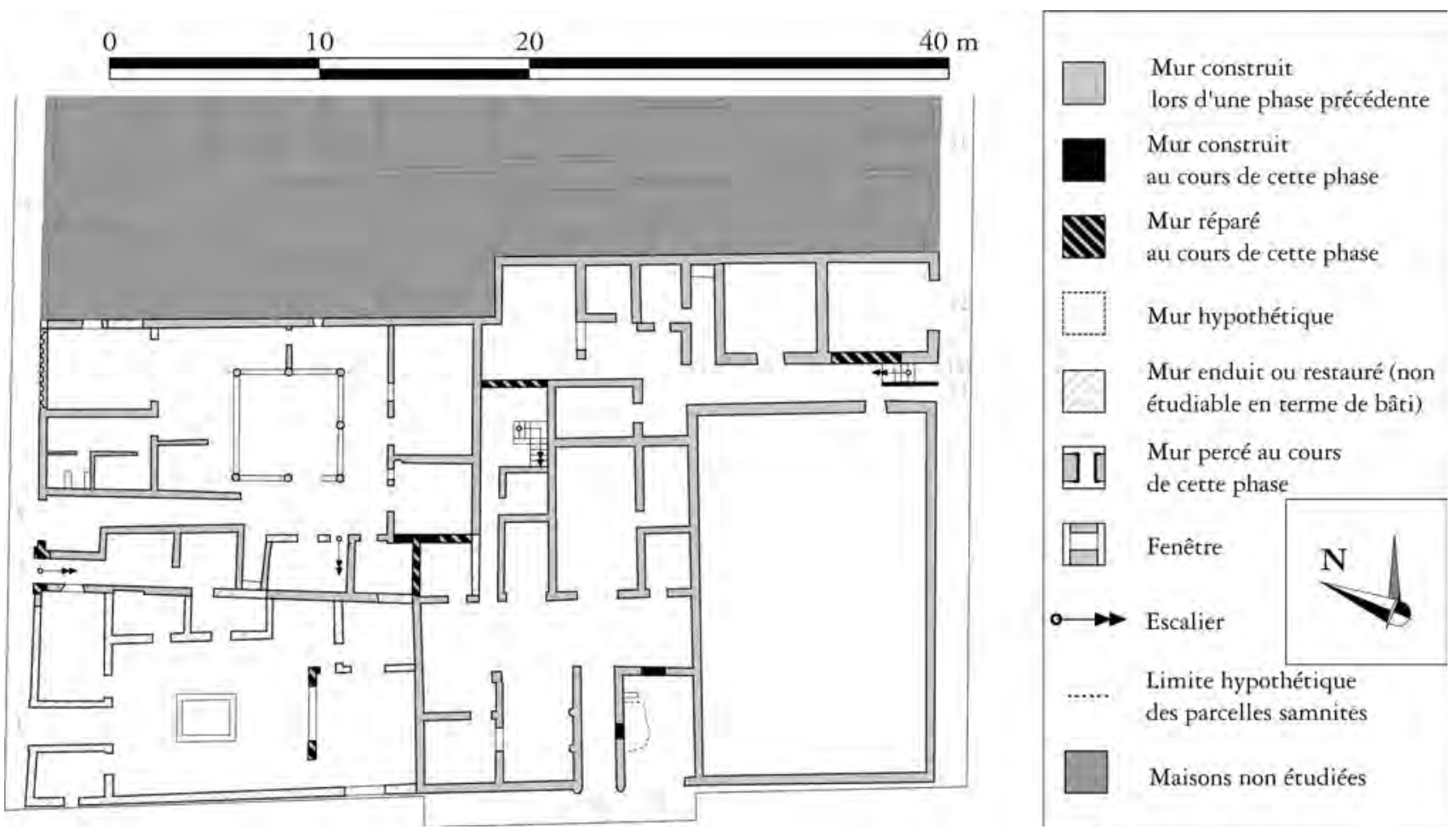

Fig. 170 - Insula V - moitié méridionale - ca. 70/75 - 79 (échelle: 1/400).

reste sujette à débat ${ }^{57}$. R. de Kind suggère une division en trois lots de dimensions identiques, soit 50 pieds de large pour 80 de long. Cela le conduit à placer la limite des parcelles septentrionales au niveau du mur sud du tablinum de la Casa del bicentenario (V, 13-16) (fig. 162) Pourtant, le relevé des maçonneries les plus anciennes ainsi qu'une anomalie dans la division des parcelles - telle qu'elle peut être suivie de la période augustéenne à l'éruption - permet de proposer une longueur plus importante et une largeur moins régulière. En effet, alors que la Casa di Nettuno e Anfitrite (V, 6-7) a été construite intégralement après le règne d'Auguste, elle présente une anomalie dans son plan: l'angle sud-est de la Casa del bel cortile (V, 8), construit sous Auguste, est saillant dans l'atrium. Une telle

57 W. Johannowsky (1982: 148-149) restituait les parcelles originelles avec un pied attique de $29,6 \mathrm{~cm}$, tandis que R. de Kind $(2005: 224,226)$ lui préfère un pied «osque» de $27,5 \mathrm{~cm}$.

${ }^{58}$ de Kind $2005: 226$ et fig. 4 p. 225.

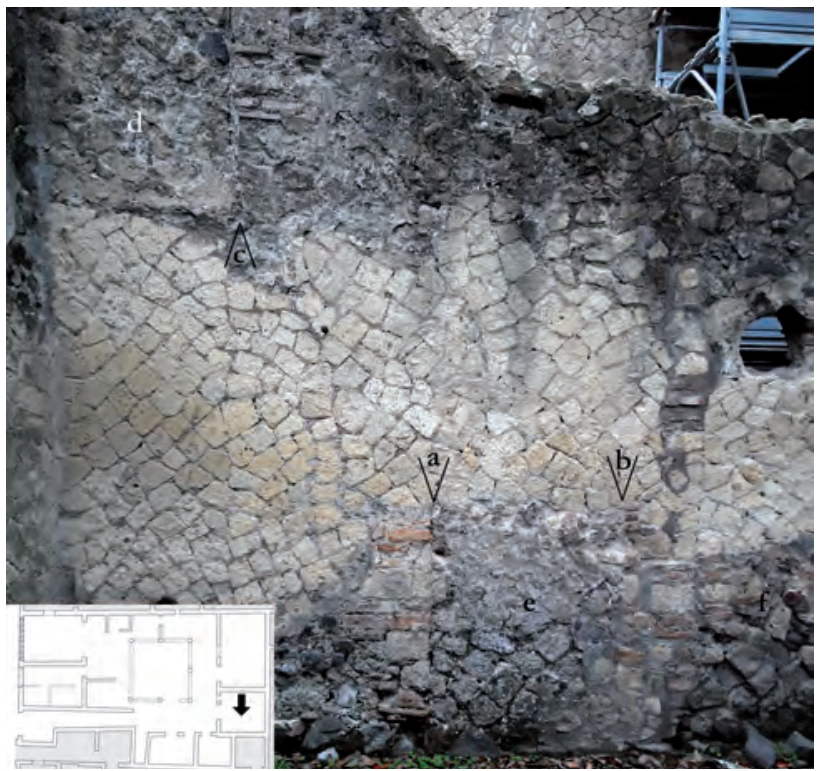

Fig. 171 - Casa del telaio (V, 3), pièce I, mur sud. Après le second séisme, les dégâts ont été réparés en employant de l'opus vittatum mixtum à deux assises de briques, pour les montants est (a) et ouest (b) de la porte donnant au sud, au rez-de-chaussée comme à l'étage (c). Peu après, quand la pièce 5 est cédée à la Casa del gran portale $(\mathrm{V}, 35)$, ces deux portes sont bouchées (d-e). Le bouchage (f) correspond au déplacement de l'escalier. 
forme pourrait constituer un héritage des transformations des parcelles originelles. La Casa dell'Apollo citaredo (V, 9-12) semble remonter au $\mathrm{II}^{\mathrm{e}}$ siècle av. J.-C. si l'on suit les quelques indices chronologiques disponibles pour l'utilisation de l'opus incertum B employé avec des piliers en tuf rossiccio. Sur son côté oriental, elle présente une porte obturée sans remplir l'intégralité de l'épaisseur du mur. Du même côté, mais désormais uniquement visible depuis la pièce 3 de la Casa del bicentenario, un linteau en bois a été restauré lors de la fouille, supporté par un pilier en tuf. Ces deux éléments incitent à proposer que la Casa dell'Apollo citaredo se présentait, dans le courant du $\mathrm{II}^{\mathrm{e}}$ siècle av. J.-C., sous la forme d'une maison à plan italique, centrée sur un atrium de chaque côté duquel des pièces s'ouvraient. J'ai restitué la largeur de cette maison en prolongeant l'axe obtenu par l'angle sud-est de la Casa del bel cortile. Notons toutefois, que, si les parcelles originelles ont eu comme longueur près de la moitié de l'îlot, telle ne saurait être la longueur de la Casa dell'Apollo citaredo durant toute la longue phase osco-samnite. Entre le lotissement initial et le $\mathrm{II}^{\mathrm{e}}$ siècle av. J.-C., voire le début du $\mathrm{I}^{\text {er }}$ s. av. J.-C., des modifications de parcellaire ont parfaitement pu se développer, comme cela semble avoir été le cas dans la moitié méridionale de l'îlot. Les divers travaux effectués durant la période impériale ont complètement fait disparaître tout élément pertinent à la phase samnite dans la moitié nord de l'insula. En revanche, une importante transformation est perceptible à la fin de la République. Ainsi, tout le côté oriental de l'îlot semble alors partagé

\footnotetext{
${ }^{59}$ L'entrée V, 26 est de création tardive dans la parcelle V, 27-29.

${ }^{60}$ Cette singulière importance de la Casa del bicentenario pour la morphologie de l'insula $\mathrm{V}$ a été pressentie par A. Maiuri (1958 b: 223-224). Toutefois, l'explication qu'il propose pour les transformations survenues dans cette maison reste schématique et fortement teintée par sa méfiance à l'égard des boutiques situées en façade des domus à plan «canonique» (sur ce point, cf. supra, p. 5-7).

${ }^{61} \mathrm{Ce}$ lien a également été nettement perçu par A. Maiuri : «[...] altri vani che appaiono occlusi lungo l'ambulacro ovest del peristilio [...] non meno chiaramente indicano che la Casa del bel cortile appartenne anche essa per qualche tempo alla Casa del bicentenario, e di tale appartenenza è chiaro segno una grande sala rettangolare
}

en trois ensembles de dimensions voisines. Les constructions réalisées durant cette phase (fig. 172) en opus incertum $\mathrm{C}$ de tuf rossiccio, qui correspondent aux espaces V, 23-25 et V, 27-29, ne sont pas des domus à plan "canonique ${ }^{59}$. Si l'on se fie à la largeur des ouvertures pour déterminer la fonction des espaces donnant sur la rue, ces deux bâtiments peuvent être interprétés comme de petits ensembles de rapport, comportant de une ou deux boutiques associées à des espaces d'habitation au rez-de-chaussée et à des appartements à l'étage. Quelle que soit la construction qui a très probablement été réalisée à l'emplacement des boutiques V, 19-21, elle n'a laissé aucune trace clairement visible.

Durant la période augustéenne, la morphologie de la moitié nord de l'insula $V$ a été profondément et définitivement modifiée par la construction de la vaste Casa del bicentenario (fig. 173) ${ }^{60}$. Pour commencer, cette construction ampute la Casa dell'Apollo citaredo de son aile orientale: les deux portes donnant encore sur les pièces situées à l'est de l'atrium sont alors fermées et leurs murs périmétriques arasés. Lors de la construction initiale, réalisée en opus reticulatum B et en opus vittatum, outre l'atrium et le péristyle, sensiblement alignés selon un axe nord-sud, la maison s'étend également vers l'ouest, intégrant l'ensemble de la Casa del bel cortile ${ }^{61}$. La façade septentrionale est délicate à restituer avec exactitude, tant les réparations consécutives au second séisme ont pu transformer le système d'ouverture. Les boutiques V, 13, V, 16 et V, 17/18 pourraient avoir été ouvertes sur le decumanus maximus dès la construction originelle. Toutefois, aucun estranea al carattere singolarissimo di quella, per il resto, minuscola abitazione» (Maiuri 1958 b: 223). Que les pièces 3 et 4 de la Casa del bel cortile aient été associées à la Casa del bicentenario ne fait guère de doute en raison des portes et fenêtres les mettant en communication avec le péristyle. En ce qui concerne les autres pièces, un lien existe grâce aux décorations pariétales des pièces 2,5 et 6 qui présentent toutes les trois des restes d'une composition de $\mathrm{II}^{\mathrm{e}}$ style simple: des blocs de grand appareil travaillés en bossage sont figurés par des traits rouges dans le champ supérieur. De cette façon, dans cette première phase, éventuellement tardo-augustéenne, les pièces 1,2 et 5 à 9 de la Casa del bel cortile constituent un posticum à la Casa del bicentenario, accessible depuis le cardo IV par une porte d'abord non alignée sur la pièce 3 . 


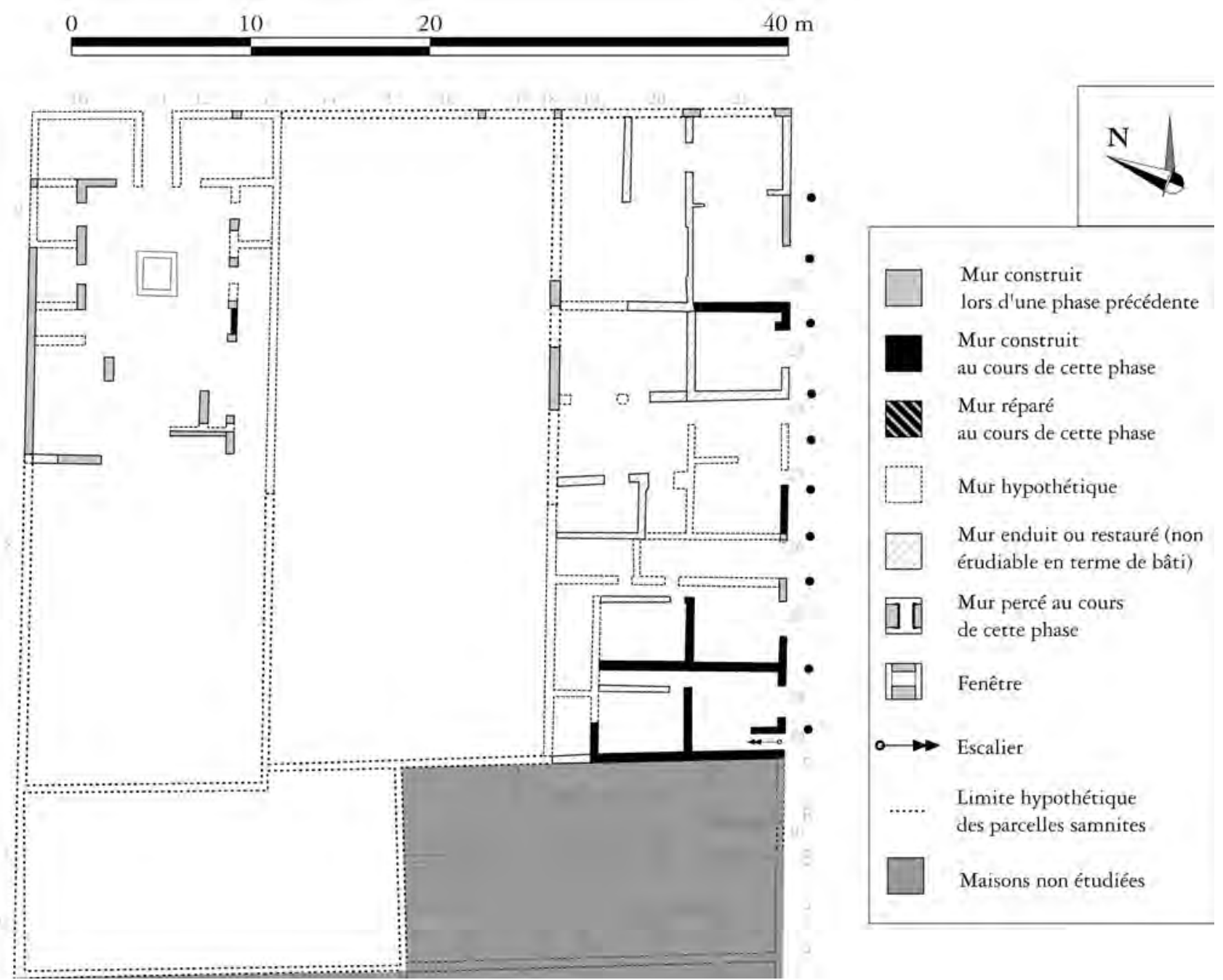

Fig. 172 - Insula V - moitié septentrionale - phase pré-augustéenne (échelle: 1/400).

élément ne permet de le confirmer avec certitude. La configuration de la moitié nord de la Casa del salone nero, de construction certainement antérieure de peu à la Casa del bicentenario, montre ainsi que sur les quatre pièces situées en façade, seules deux étaient ouvertes sur la rue ${ }^{62}$. L'entrée $\mathrm{V}, 14$, qui donne accès à un appartement dans une phase ultérieure, est peut-être déjà ouverte, sans possibilité d'en avoir la certitude. Sur la façade occidentale s'ouvrant sur le cardo IV,

${ }^{62}$ Cf. infra, p. 336-338.

${ }^{63}$ Aucune porte condamnée n'est visible dans le mur de aucun des différents montants encore visibles n'autorise à restituer, à quelque moment que ce soit, une ouverture de boutique. Enfin, en ce qui concerne l'étage, il se développe dès l'origine audessus de la Casa del bicentenario, divisé en deux parties qui ne communiquent pas entre elles ${ }^{63}$; en revanche, il semble qu'il soit absent dans la première phase au-dessus du posticum. La Casa dell'Apollo citaredo est amputée de l'aile orientale de l'atrium lors de cette phase. Cette réduction

refend séparant la pièce $\mathrm{C}$ de l'appartement II de l'appartement I (cf. Maiuri 1958 b: fig. 184 p. 234). 


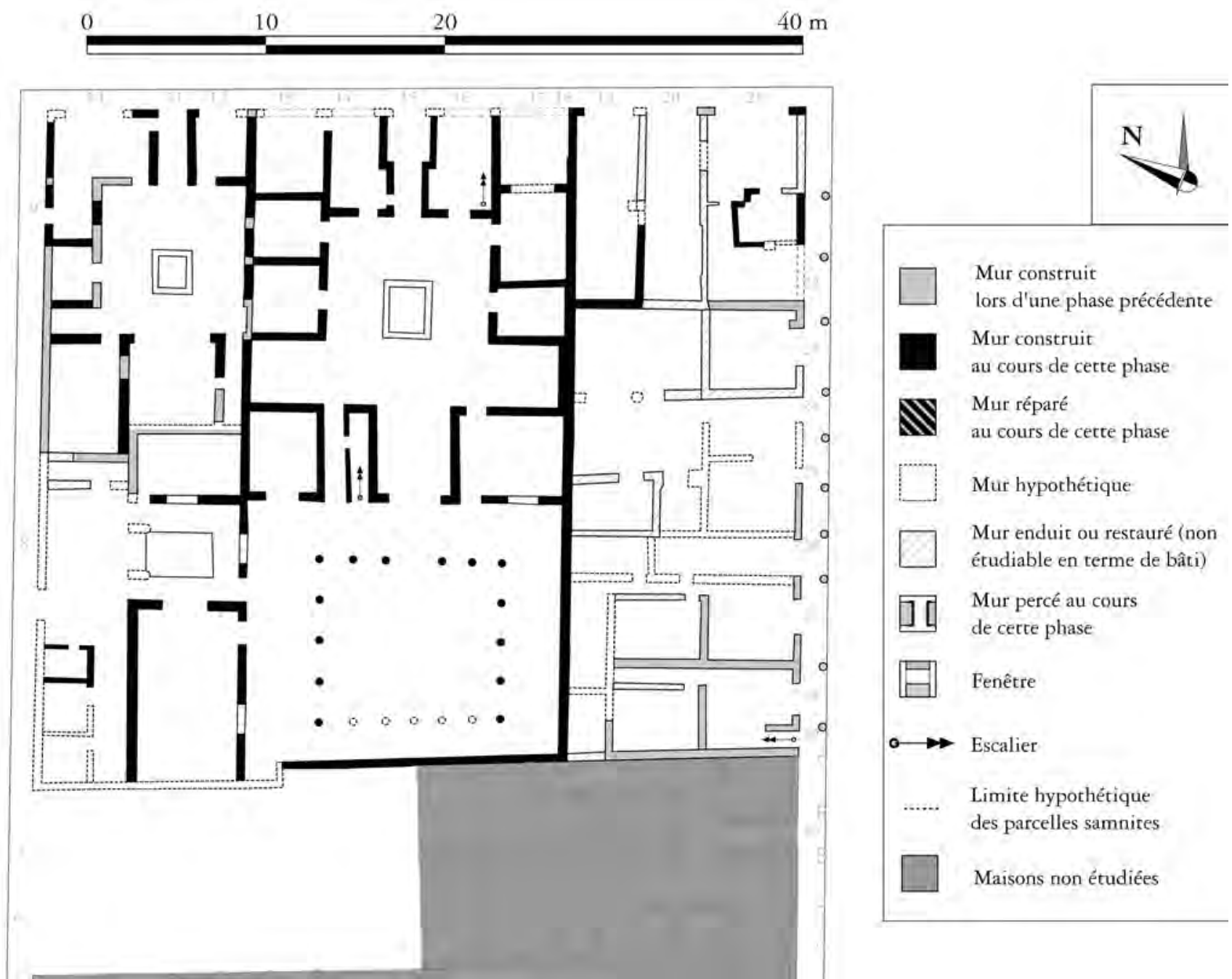

Fig. 173 - Insula V - moitié septentrionale - phase augustéenne (échelle: 1/400).

mise à part, elle acquiert alors sa physionomie définitive, au moins en terme d'emprise au sol. Le bouchage d'une des deux portes entre l'atrium et le local V, 9-10, ainsi que l'ouverture de la porte 9 permettent de supposer que dès cette phase, une boutique se trouve dans l'angle nord-ouest de la maison. Il est également possible, bien que cela soit difficile à confirmer, que la boutique V, 12 ait également été ouverte au cours de cette période. Une fois la construction de la Casa del

${ }^{64}$ Une fenêtre percée dans le mur mitoyen entre la boutique V, 19 et la pièce 3-4 de la Casa della colonna laterizia $(\mathrm{V}, 24)$ illumine l'arrière salle de cette nouvelle boutique. Contrairement à ce que propose F. Pirson (1999: 73), cette ouverture n'est pas une porte permettant la communication bicentenario achevée, la parcelle située dans l'angle nord-est de l'îlot est bâtie. Il semble que, lors de cette première phase, elle ait été divisée au rez-de-chaussée en trois espaces comportant chacun une boutique s'ouvrant sur le decumanus maximus et une probable pièce d'habitation ${ }^{64}$. Ce principe est quelque peu transformé en V, 21 où la largeur plus importante du local permet de créer deux pièces d'habitation s'ouvrant dans la boutique.

entre l'étage V, 22 et l'étage de cette maison. En effet, du côté de la Casa della colonna laterizia, l'étage est un ajout postérieur au second séisme, après que la fenêtre a été bouchée. 


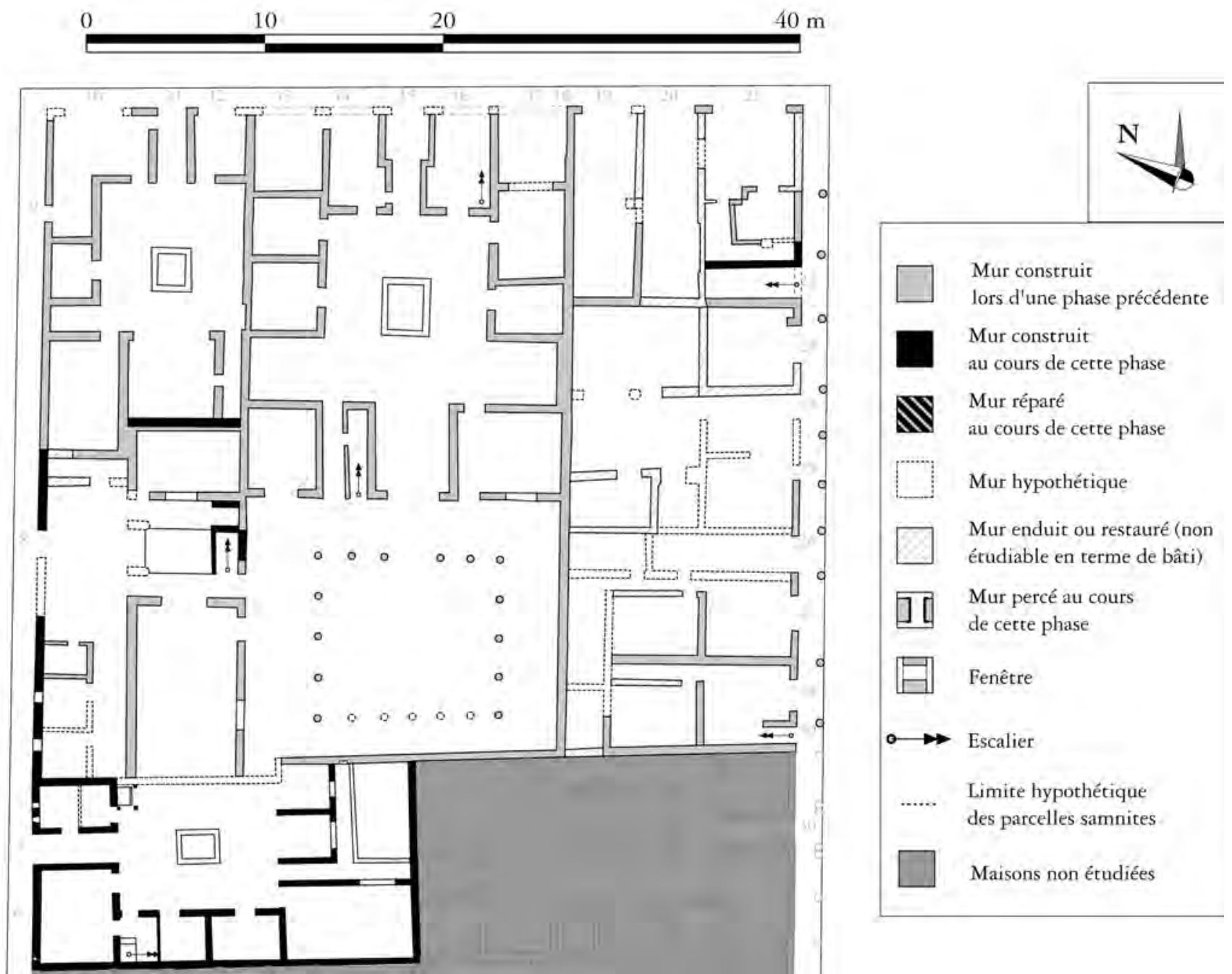

Fig. 174 - Insula V - moitié septentrionale - phase post-augustéenne (échelle: 1/400).

La phase suivante s'étend de la fin du règne d'Auguste au séisme de 62 et peut être partagée en deux moments distincts (fig. 174). Le premier d'entre eux est caractérisé par l'érection de la Casa di Nettuno e Anfitrite (V, 7) après avoir complètement arasé les probables structures préexistantes. Cette domus est intégralement construite en opus reticulatum B et en opus vittatum simple. Dans sa conception originelle, elle est dépourvue de boutique en façade. Elle présente, à ce local commercial près, un plan rigoureusement identique à celui de l'ultime phase, ensevelie par l'éruption. Bien que ni la mosaïque pariétale représentant Neptune et
Amphitrite, ni la fontaine "nymphée» n'existent encore dans la pièce 8 - alors occupée par un jardin autour duquel au moins sur les côtés ouest et sud se trouve une rigole maçonnée -, la structure architecturale tend à faire de cette pièce le point focal des axes de vision. Après cette construction ex nihilo, la façade de la Casa del bicentenario - en fait de la Casa del bel cortile - donnant sur le cardo IV est refaite en opus reticulatum A: l'accès est déplacé vers le nord, de façon à se trouver dans l'axe de la pièce 3. Il est possible que ce soit au même moment, sinon immédiatement ensuite que ce même espace soit transformé par l'adjonction d'un 


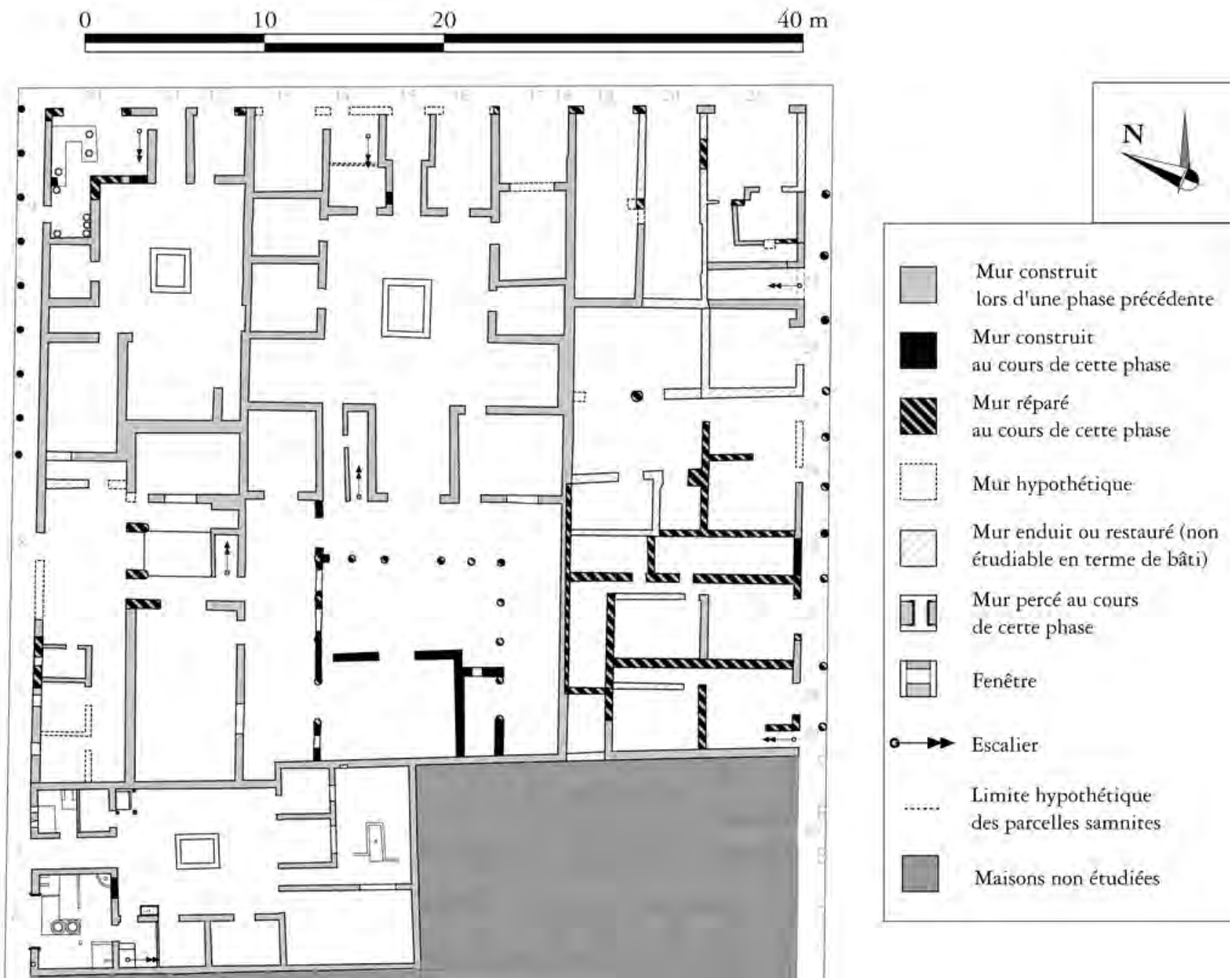

Fig. 175 - Insula V - moitié septentrionale - 62 - ca. 70/75 (échelle: 1/400).

étage $^{65}$. La fenêtre donnant sur le péristyle est obturée et un escalier maçonné est construit. $\mathrm{Au}$ nord-est de l'îlot, un appartement est créé au-dessus des locaux V, 19 à V, 21, accessible depuis un l'escalier V, 22. Comme F. Pirson l'a déjà signalé, cet étage déborde au-dessus de la boutique V, $23^{66}$.

${ }^{65}$ La réfection de la décoration de la pièce $2-$ en $\mathrm{III}^{\mathrm{e}}$ style final datant du règne de Claude (Esposito 2005: 132134) - participe de ces travaux. Les peintures situées à l'étage de la pièce 2 pourraient être postérieures à celles du rez-de-chaussée. Je ne saurais dire si l'étage se développe au-delà de la pièce 2 de la Casa del bel cortile et notamment au-dessus des pièces 1, 5, 6-9; les transformations ulté-
La secousse de 62 a eu des effets particulièrement importants au nord de l'insula $\mathrm{V}$ (fig. 175). L'analyse des maçonneries de la série de boutiques situées sur le cardo V montre, au moins pour les deux édifices situés entre V, 23 et V, 29 une destruction presque complète, suivie par une réparation avec les moellons provenant

rieures tendraient plutôt à proposer que cela n'ait pas été le cas et que l'étage dans cette partie de la maison ait été limité à la seule pièce 2 .

${ }^{66}$ Pirson 1999: 73. L'utilisation conjointe de l'opus reticulatum A et de l'opus vittatum pour le percement de l'entrée $\mathrm{V}, 22$ pourrait permettre de considérer que cet ajout est effectué durant la seconde phase post-augustéenne. 
des murs abattus. Cet endommagement massif pourrait être dû à la vétusté des maçonneries. En effet, il semble que l'opus reticulatum B de la Casa del bicentenario a offert une meilleure résistance au choc sismique: le mur oriental du péristyle ne présente aucune lésion, tandis que de l'autre côté, le mur occidental notamment de l'édifice V, 27-29 a été intégralement reconstruit en opus incertum D, comme la plupart de ses murs de refend ${ }^{67}$. La Casa del bicentenario en revanche ne paraît pas avoir subi beaucoup d'autres dommages qu'au niveau du péristyle,

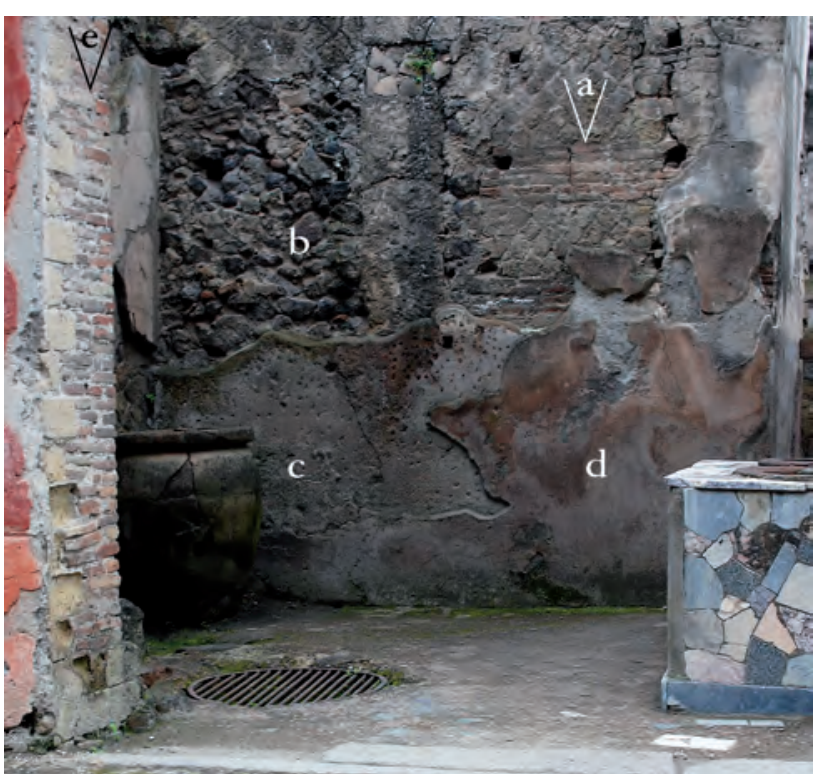

Fig. 176 - Casa dell'Apollo citaredo (V, 9-12), boutique V, 9-10, mur sud. La paroi porte les stigmates du premier séisme: l'entrechoquement du mur sud et du mur est les a fait s'écrouler; ils ont été réparés en opus reticulatum A alterné avec des assises de tuiles (a), les montants d'entrée avec des tuiles (e). Après ces réfections, la porte donnant au sud sur l'atrium a été bouchée (b) et la paroi enduite à deux reprises (c, d), correspondant aux phases du commerce alimentaire V, 9-10.

${ }^{67}$ Ce type d'effondrement partiel d'un mur où un seul des deux parements est détruit a été observé dans la Casa della fullonica au début des années 2000.

${ }^{68}$ A. Maiuri (1958 b: 236) signale l'escalier permettant d'accéder à ce deuxième étage, mais l'interprète comme un moyen d'accès aux terrasses de couverture.

${ }^{69}$ Pour que l'escalier soit fonctionnel, il aurait fallu déployer des solives est-ouest dans la moitié sud du local; la conservation de l'enduit sur le mur ouest rend impos- dont une partie des colonnes auraient alors été reconstruites avec des briques. Il faut également signaler la destruction des colonnes in antis de la pièce 3 de la Casa del bel cortile, ainsi que du montant occidental de la large porte menant dans la salle 4. Ces dégâts ont également été réparés en utilisant des briques. La façade occidentale de la maison paraît avoir subi un écroulement partiel à l'ouest de la pièce 6 , réparé en remployant les moellons d'opus reticulatum préexistants. Dans la Casa dell'Apollo citaredo, seule la boutique a été touchée: les deux murs constituant l'angle saillant au sud-est ont certainement dû avoir un effet de bélier l'un sur l'autre (fig. 176, a). Les deux montants de l'entrée V, 10 se sont également écroulés (fig. 176, e). Face à ces dommages importants, la Casa di Nettuno e Anfitrite, qui semble avoir été complètement épargnée, est tout particulièrement privilégiée. Une fois les premières réparations achevées, des transformations non négligeables apparaissent autour de la Casa del bicentenario. La principale d'entre elle se situe autour du péristyle. Celui-ci est fermé sur deux côtés: à l'ouest, l'entrecolonnement est partiellement fermé par l'aménagement de fenêtres (fig. 177, c); au sud, la surface du jardin est réduite par la création des pièces 10, 12 et 13 (fig. 178, a-b). La fermeture du côté occidental pourrait correspondre à la nécessité de renforcer les maçonneries en lien avec la création d'un second étage de ce côté du péristyle ${ }^{68}$. Cette transformation de l'étage à l'arrière de la maison pourrait être mise en relation avec la probable séparation de l'appartement de façade. Un escalier est créé en V, 14, tandis que celui de $\mathrm{V}, 16$, bien que vraisemblablement laissé en place comme l'indique l'enduit recouvrant la paroi orientale de ce local, n'aboutit plus à l'étage (fig. 179) ${ }^{69}$. Plusieurs transformations se développent au nord de la Casa dell'Apollo citaredo: il semble qu'un étage soit alors ajouté,

sible une telle restitution. La seule autre alternative subsistant amène à considérer que les trois fragments de poutres insérés dans la partie orientale du mur sud sont des restaurations abusives et que la niche (fig. 179, d) ne servait à rien. Par ailleurs, l'examen des parois de cet appartement de façade permet en effet d'exclure qu'un mur de refend ait coupé en deux l'appartement, ce qui aurait justifié le maintien de deux escaliers. 


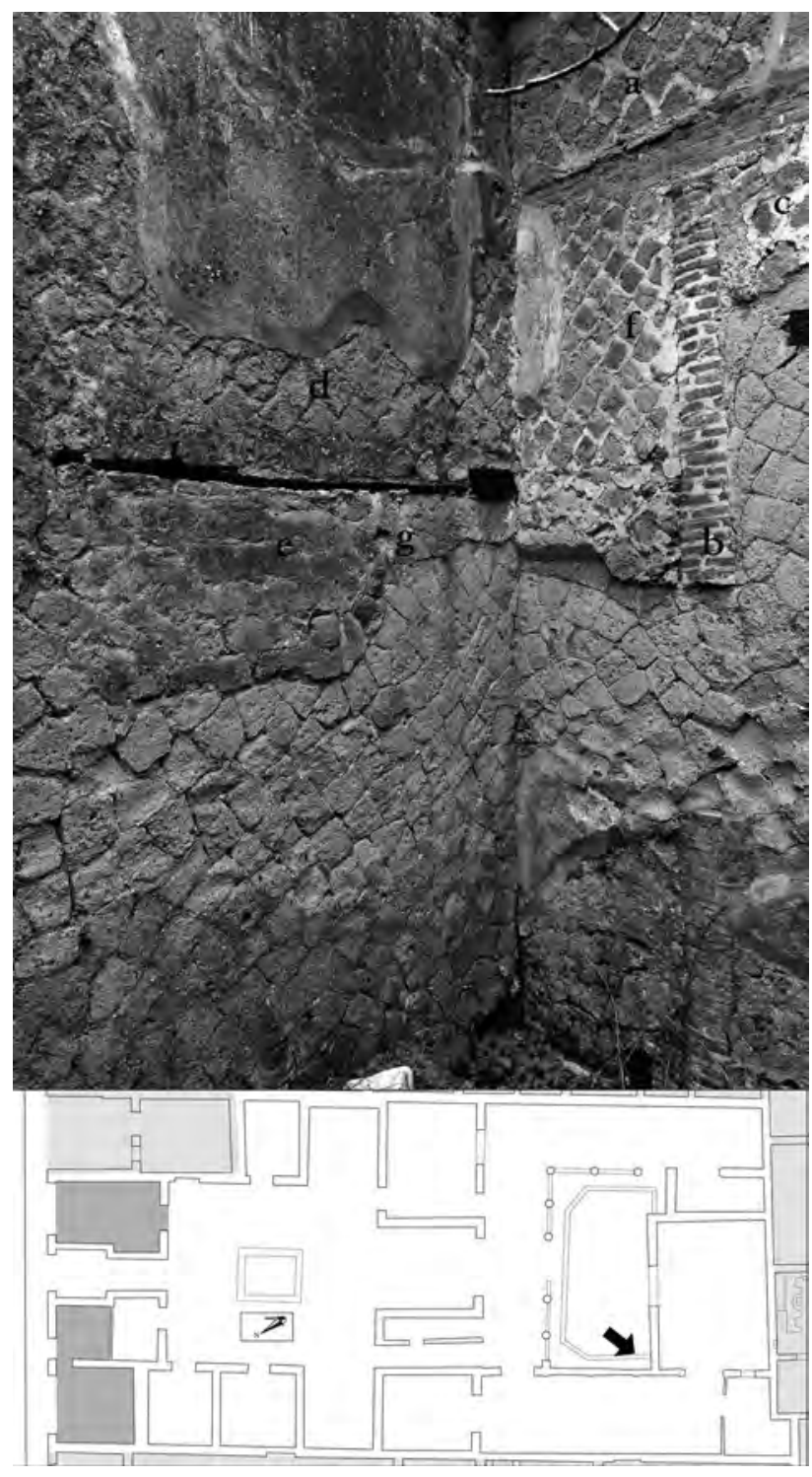

Fig. 177 - Casa del bicentenario (V, 13-16), jardin, angle sud-ouest. Les colonnes (b) supportant un mur en opus reticulatum B (a) correspondent au premier aspect du péristyle. Après le séisme de 62, l'entrecolonnement est bouché sur tout le côté occidental (c) et la pièce 10 créée au sud (d). On y accède par plusieurs portes (e). Les réparations suivant le second séisme sont effectuées en employant l'opus reticulatum A (f). Les portes entre le jardin et la pièce 10 sont alors bouchées $(\mathrm{g})$.

en façade et pour partie sur le côté occidental, accessible depuis un escalier qui est installé dans la boutique V, 9-10, après le bouchage de la porte donnant au sud sur l'atrium (fig. 176, b). Le maintien de la communication entre cet espace commercial et les fauces permet de déduire que cette boutique ne devient pas une unité d'habi-

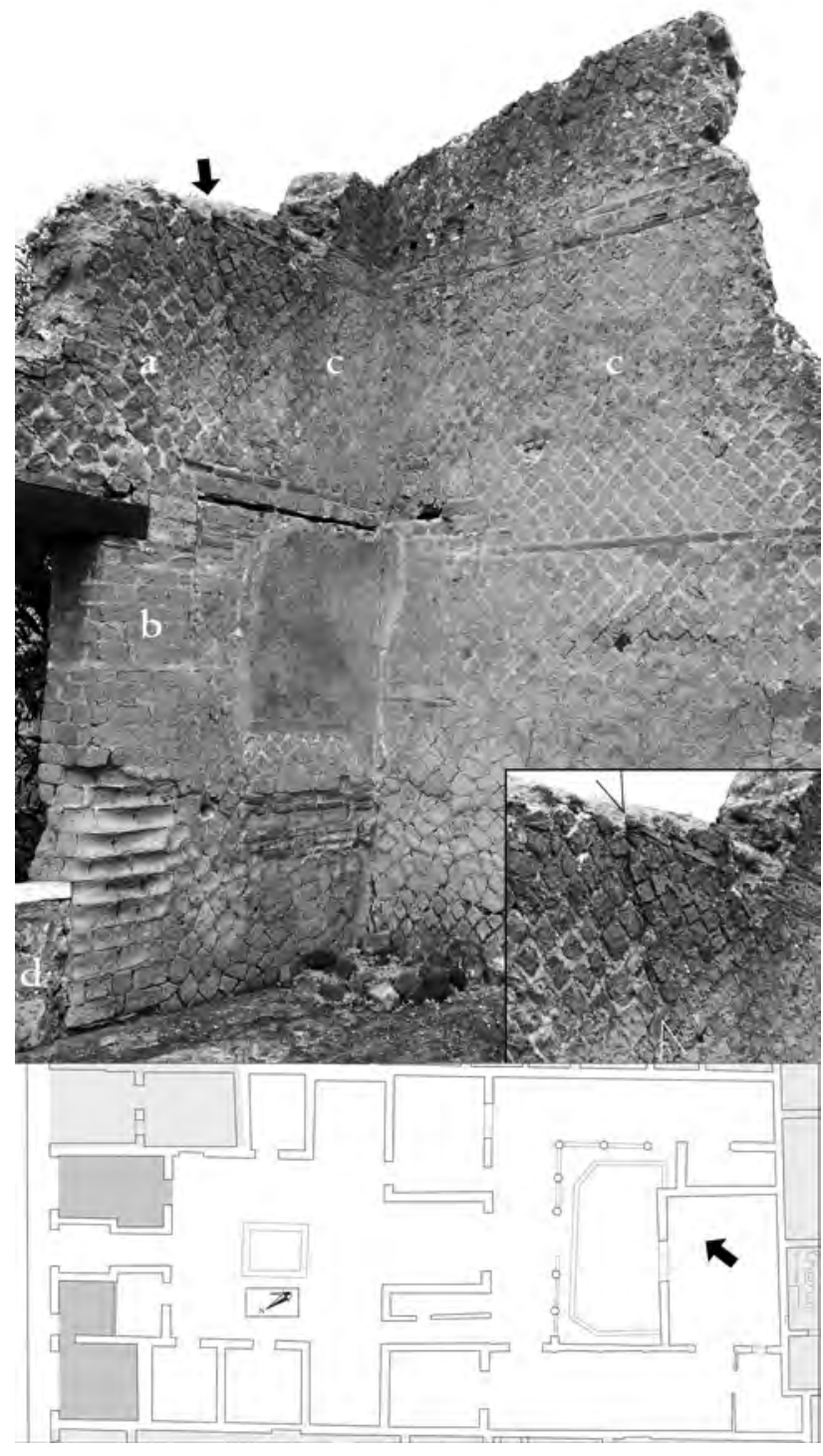

Fig. 178 - Casa del bicentenario (V, 13-16), pièce 10, angle nord-est. La maçonnerie originelle de la pièce 10 utilise l'opus reticulatum B (a) et l'opus vittatum pour les baies (b). Après le second séisme, l'angle nord-est été reconstruit en opus reticulatum A comportant des assises d'opus vittatum mixtum à deux assises de briques (c; la flèche indique la ligne de rupture de la première maçonnerie, agrandie en encadré). Le passage entre la pièce 10 et le jardin est finalement bouché (d).

tation indépendante. Enfin, la Casa di Nettuno $e$ Anfitrite se dote d'un commerce alimentaire en façade. La porte de communication entre cet espace et l'atrium est fermée, la mezzanine, le comptoir et les deux tables de cuisson sont aménagés. Un tuyau en plomb passe sous le mur nord pour alimenter un chauffe-eau disposé 
dans l'angle nord-ouest ${ }^{70}$. Dans la boutique, la décoration pariétale de la phase antérieure est laissée en place. En revanche, dans la pièce 8 , une peinture de jardin est exécutée sur toutes les parois avant l'installation d'un triclinium d'été.

Le second séisme semble avoir causé des dommages beaucoup moins importants que le premier (fig. 180). C'est la moitié méridionale de la Casa del bicentenario qui a été le plus fortement touchée: l'angle nord-est de la pièce 10 s'effondre et est restauré en opus reticulatum A (fig. 178, c); une partie des murs de la pièce 4 de la Casa del bel cortile, encore liée à la Casa del bicentenario, s'écroule: les portes donnant sur le péristyle, les montants de la large porte septentrionale (fig. 181), et toute la façade méridionale doivent être reconstruits. La chute de cette dernière a nécessairement entraîné la destruction du compluvium de la Casa di Nettuno e Anfitrite. Les restaurations des parois sont effectuées en opus reticulatum A, tandis que les montants des portes et fenêtres sont reconstruits en opus vittatum mixtum à deux assises de briques (fig. 182, b). Une nouvelle décoration de l'ensemble de la maison a alors été initiée, aux bons soins de l'atelier «de la Casa dell'atrio a mosaico ${ }^{71}$. Dans l'atrium, cette opération n'était pas achevée au moment de l'éruption, comme en témoigne l'inscription peinte CIL IV, 10480 qui indique les couleurs

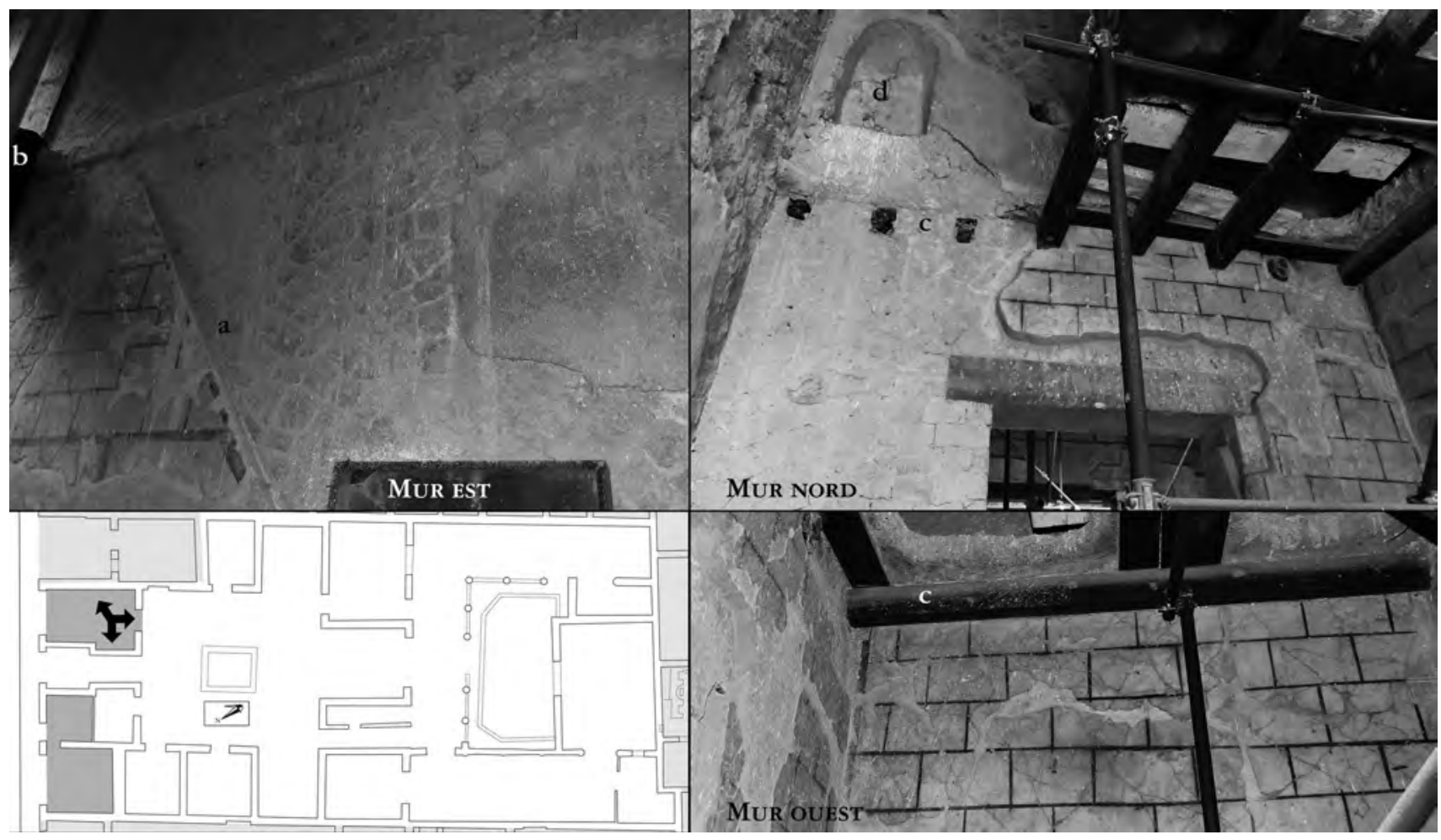

Fig. 179 - Casa del bicentenario (V, 13-16), boutique V, 16, murs est, sud et ouest. L'empreinte de l'escalier dans la paroi orientale (a) est un leurre au moment de l'éruption. Dans la moitié nord, les solives sont orientées est-ouest (b); dans la moitié sud, elles sont orientées nord-sud (c). À l'intersection, une solive est-ouest (b) est doublée, de façon à soutenir les solives nordsud. Tel qu'elles sont visibles actuellement, les solives ne permettent pas de dégager une cage d'escalier: l'escalier est fictif.

${ }^{70}$ Ce tuyau est prolongé jusque dans la pièce 8 , dans laquelle la rigole du jardin, alors recouverte, l'abrite. Une ${ }^{71}$ Esposito 2005: 195-197. dérivation est également réalisée vers le labrum disposé dans la pièce 6. 


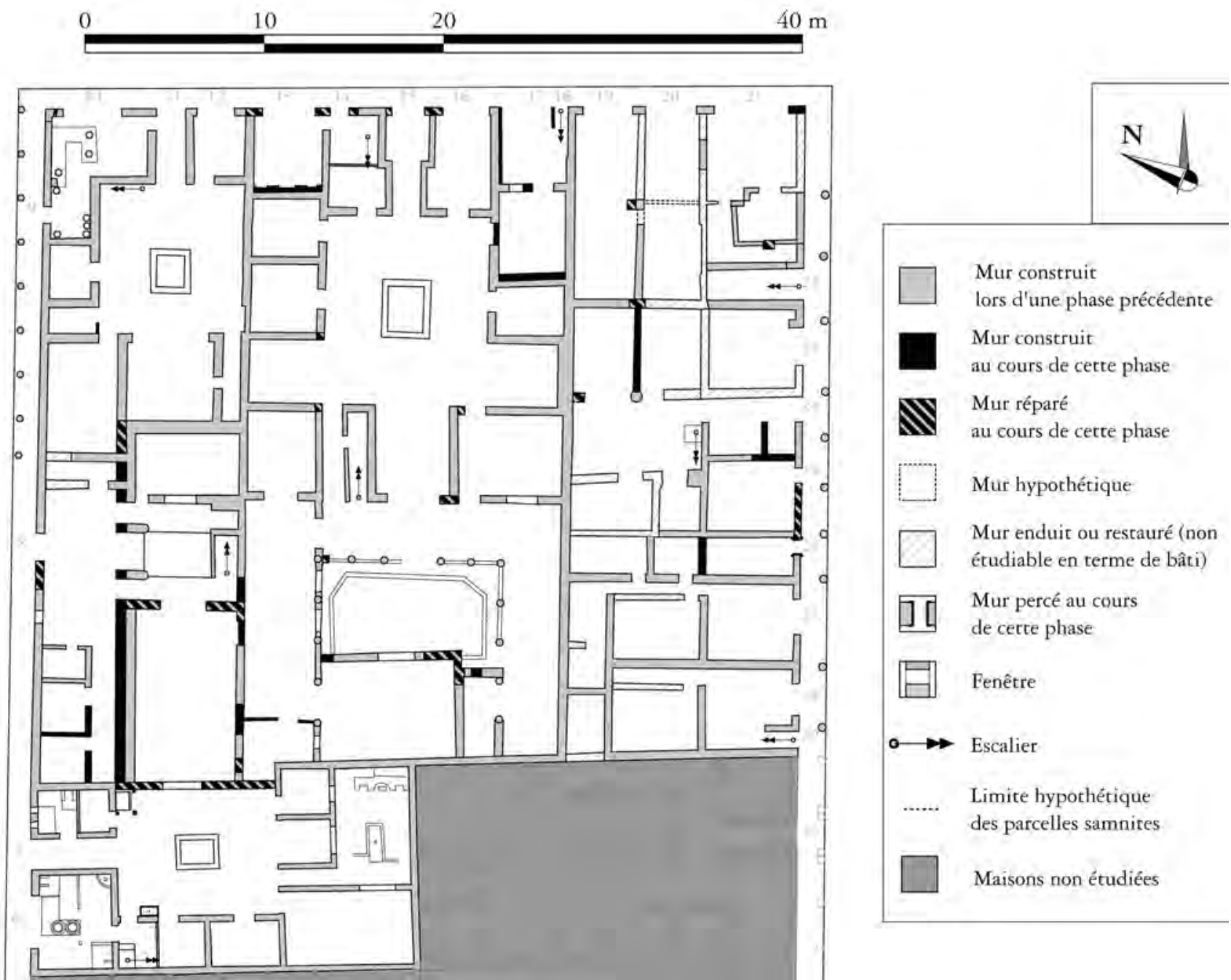

Fig. 180 - Insula V - moitié méridionale - ca. $70 / 75$ - 79 (échelle: 1/400).

devant encore être ajoutées ${ }^{72}$. Une partie de la façade de la maison V, 23-25 s'est également effondrée. Cette faiblesse relative des dégâts occasionnés par cette seconde secousse n'a pas empêché d'importants remaniements. La Casa

${ }^{72}$ CIL IV, 10480: purpura. Elle a été découverte le $1^{\mathrm{er}}$ mars 1933 (GSE 1933: «1 marzo. [...] Nella casa N$^{\circ} 6$ sul IV cardine, lato est, nella parete ovest sopra un riquadro di un soggetto mitologico vi è la seguente iscrizione fatta con pittura: [dessin de l'inscription sans respecter sa forme en équerre, attestée sur le dessin exécuté par F. Ferrajoli (Archivio disegni SANP, Pompei, P658 fo9)] È lunga m. 0.085 e le lettere sono alte m. 0.03 ». Le Corpus donne la pièce 3 de la Casa dell'alcova (IV, 3-4) comme provenance. Cette localisation est erronée: la fouille de cette maison a été achevée en mai 1932. L'atrium de la Casa di Nettuno e Anfitrite a été appelé ambiente 3 durant la fouille. Cette maison étant la del bicentenario est démembrée. La boutique V, 17/18 devient indépendante: la porte permettant de passer de l'atrium à l'arrière-boutique est obturée, une partie des murs est doublée. Elle est immédiatement transformée en deux appar-

quatrième fouillée dans l'insula V, soit M. Della Corte, soit P. Ciprotti, n'ont pas réussi à traduire convenablement les notes prises par M. Della Corte au moment de la découverte. Le cadre à sujet mythologique autour duquel cette inscription a été peinte a désormais disparu. Sa localisation dans l'atrium de la Casa di Nettuno e Anfitrite peut se déduire du résumé final de fouille, inséré à la fin du mois de juin 1934, qui le mentionne de nouveau (GSE 1934: «[...] Ambiente 3. È l'atrio tuscanico con cisterna e ara votiva nell'angolo nord ovest. [...] Sulla parete ovest, che conserva maggiore quantità di stucco, sul campo alto si nota una prospettiva con due centauri e nel centro un quadro con figure mitologiche». 


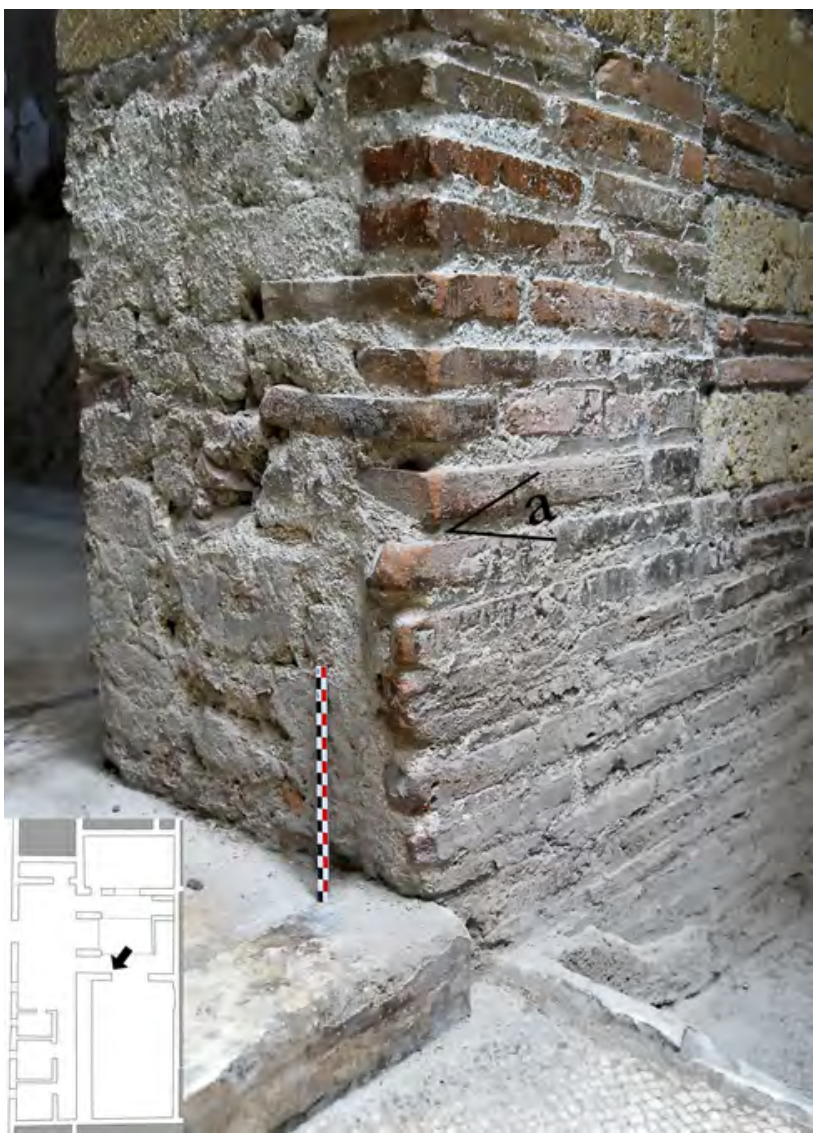

Fig. 181 - Casa del bel cortile (V, 8), pièce 4, montant ouest. Cette portion du montant montre une phase de construction en opus testaceum (limite supérieure en a), remontant au séisme de 62. Dans un second temps, le reste du montant a été reconstruit en opus vittatum mixtum à deux assises de briques.

tements ${ }^{73}$. Toutes les communications entre le péristyle de la Casa del bicentenario et les pièces 3 et 4 de la Casa del bel cortile sont obturées. L'étage de cette nouvelle domus est élargi vers le cardo IV: pour accueillir cette nouvelle structure, le mur occidental des pièces 2 , 3 et 4 est doublé sur toute sa longueur ${ }^{74}$. Enfin, le mur sud de la boutique V, 13 paraît avoir lui aussi été doublé. Cet accroissement du nombre d'unités indépendantes ne se déroule pas qu'autour de la Casa del bicentenario. En effet, une entrée V, 26 est créée au nord-est de la maison V, 26-29, créant ainsi un probable appartement à pièce unique au rez-de-chaussée ou bien un accès à un appartement situé au premier étage ${ }^{75}$. De la même façon, l'espace V, 25 est transformé d'une improbable boutique en un appartement

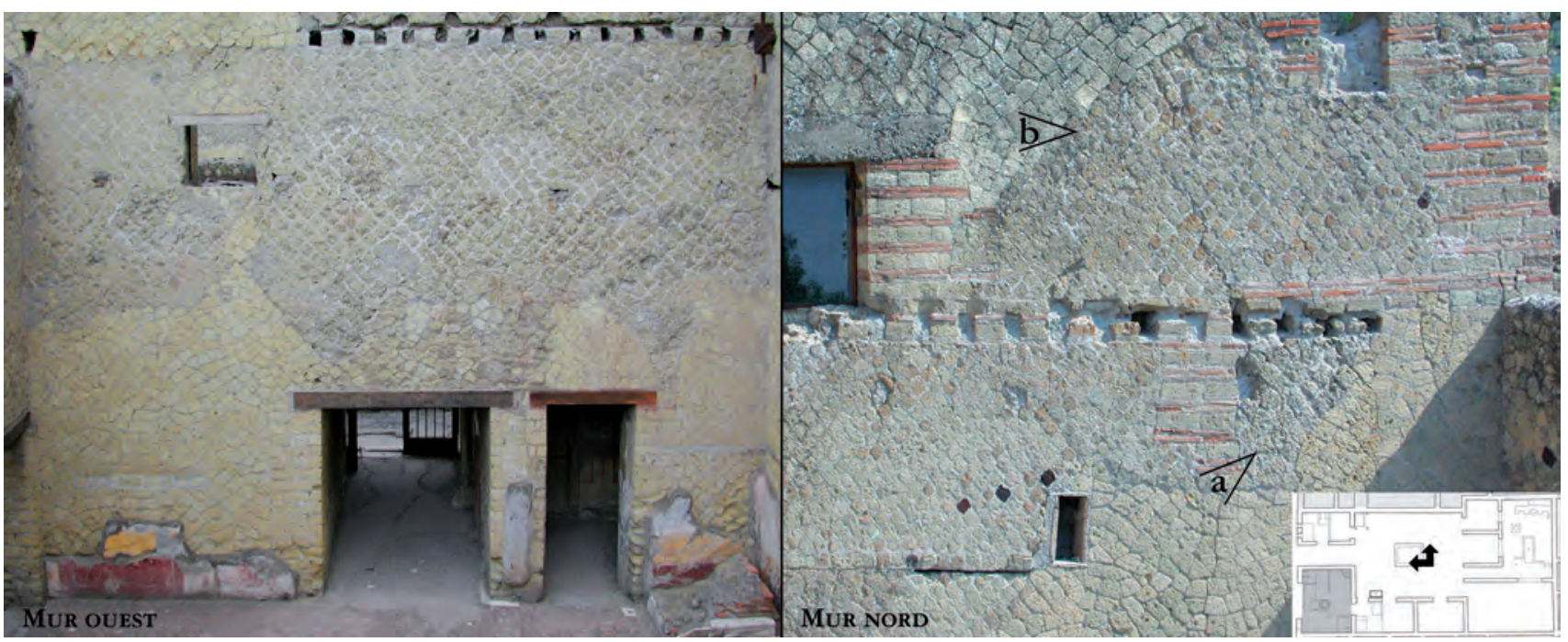

Fig. 182 - Casa di Nettuno e Anfitrite (V, 6-7), atrium, murs ouest et nord. La maçonnerie du mur ouest, remontant à la construction de la maison, est intégralement réalisée en opus reticulatum B. Le mur nord montre, outre les lambeaux de la maçonnerie originelle (a), d'importantes réparations effectuées après le second séisme (b), en employant l'opus reticulatum A et l'opus vittatum mixtum à deux assises.

${ }^{73}$ Sur la transformation de cette boutique en deux appartements une fois devenue indépendante de la Casa del bicentenario, cf. supra, p. 83-87.

${ }^{74}$ Le doublement de ce mur est très nettement repré- senté sur le plan publié par A. Maiuri (1958 b: fig. 316 p. 384).

${ }^{75}$ A. Maiuri (1958 b: 444-445) estime que cette entrée donne accès à l'étage, tout comme à sa suite F. Pirson (1999: 287). 
isolé de la Casa della colonna laterizia (V, 24). Dans cette dernière maison, pour compenser la perte de cette surface, l'étage est développé audessus des pièces 3 et $4^{76}$. En revanche, dans le bloc de boutiques V, 19-21, la seule transformation visible est constituée par la réduction de la surface de la boutique V, 20, au profit du local $\mathrm{V}, 19$. Selon les journaux de fouilles, une cloison en bois aurait séparé l'espace V, 20, transformant la pièce au sud en chambre utilisée par le boutiquier de V, 1977. Dans la Casa dell'Apollo citaredo, les dernières transformations sont de faible importance. Dans la boutique V, 9-10, passe désormais un tuyau d'alimentation en eau sous pression tandis que la décoration pariétale est refaite (fig. 176, d). L'escalier permettant de gagner l'étage est déplacé dans l'atrium. Quant à la Casa di Nettuno e Anfitrite, en plus des travaux déjà signalés dans l'atrium, la seule transformation perceptible tient dans la construction d'un nymphée-fontaine au sommet duquel se trouve un réservoir recueillant l'eau de pluie.

L'évolution de l'insula $\mathrm{V}$ pourrait se résumer par le fractionnement lent mais régulier de deux grandes domus situées de part et d'autre de l'îlot, amenant ainsi à la multiplication d'abord des espaces d'habitation à l'étage, puis des unités indépendantes. Dans ces grandes maisons, les boutiques semblent être présentes dès l'origine, ou peu s'en faut. En dépit des ouvertures et des

${ }^{76}$ La disparition partielle des élévations empêche non seulement d'avoir une idée exacte de l'extension de l'étage, mais surtout de déterminer le point d'où il était accessible. Cette question a déjà été soulevée par F. Pirson (1999: 7374): il suppose que l'accès à l'étage se faisait par l'escalier $\mathrm{V}, 22$. Une telle hypothèse reste possible, toutefois l'absence de communication entre l'étage de la boutique V, 23 et l'étage de la pièce $3 \mathrm{~m}$ 'a fait considérer que la Casa della colonna laterizia a très certainement conservé un accès propre à l'étage. Peut-être faudrait-il chercher la base de l'escalier dans la pièce 7 , le long du mur est. Un podium y a été mis au jour, interprété comme une cuisine tant par les journaux de fouilles (GSE 1938: «[21 febbraio] Descrizione della casa n. 19 posta sul V cardine Insula V. [...] Un basso e quasi distrutto podio dell'altezza attuale di m. 0.45, m. 0.95 di larghezza e m. 1.02 di spessore che è addossato alla parete est fa supporre che doveva servire come cucina [...]») que par A. Maiuri (1958 b: 444). Son état actuel rend difficile toute interprétation précise, mais n'interdit pas de le considérer comme une base d'escalier. En dépit de ce désaccord minime avec les réflexions de F. Pirson, il me semble que fermetures de ces espaces commerciaux, leur nombre semble relativement stable.

\section{VII.3 Évolution des espaces publics et privés dans l'insula VI}

Contrairement aux autres îlots étudiés jusqu'à présent - l'Insula Orientalis $I I^{a}$ exceptée - l'insula VI n'est pas exclusivement occupée par des maisons appartenant à des particuliers: une partie de sa superficie est destinée à un usage public, qu'il soit religieux ou thermal (pl. Ix, h.t.). Comme l'insula III, cet îlot a été dégagé en plusieurs étapes. La portion sud a été mise au jour à la fin du XIX ${ }^{\mathrm{e}}$ siècle, la partie centrale entre 1927 et 1940, tandis que la façade septentrionale n'est exhumée que durant les années 1960. Cet éclatement des travaux de fouilles a entraîné une multiplication des techniques de restauration des murs, rendant parfois difficile la distinction entre les maçonneries modernes et les murs antiques. Ainsi, le supposé hospitium qui se développe en VI, 2-3 n'a pas pu être étudié, avant même de déterminer son éventuelle fonction commerciale, tant il a été reconstruit ${ }^{78}$. En plus de cet édifice, je n'ai pas non plus analysé les rares variations concernant la Casa dei due atri (VI, 28-29), qui semble n'avoir jamais disposé d'espace commercial en façade ${ }^{79}$. Contrairement aux autres îlots, la reconstitution des parcelles originelles se heurte à la disparition presque inté-

sa suggestion que les ensembles V, 19-22 et V, 23-25 constituent une unique propriété est juste.

77 GSE 1938: "Casa 22. 23. 24. Decumano Massimo Insula V. Descrizione. [...] Ad ovest tiene un vano con l'altro numero 3. [...] Si nota sulla parete est un incavo di letto largo m. 2.77 alto m. 1.02. Poiché tra il primo e il secondo ambiente non vi era nessun muro di comunicazione, e dato che sulla parete est all'altezza di m. 2.37 dal pavimento si nota in un'alveola tracce di trave carbonizzato ciò fa supporre che doveva starci una separazione di legno per impedire ai passanti di guardare nell'interno. La forma molto sviluppata del letto ci indica che poteva servire per coloro che sostavano per mangiare o bere seduti [...]». Les case 22, 23 et 24 correspondent respectivement aux boutiques V, 21, V, 20 et V, 19. La Casa n. 24 est décrite comme comportant trois pièces, tandis que la casa $n .23$ n'en possède qu'une. Cette description est insérée à la fin du mois d'avril 1938.

${ }^{78}$ Sur l'édifice VI, 2-3, cf. Maiuri 1958 b: 111-112.

${ }^{79}$ Sur la Casa dei due atri, cf. Maiuri 1958 b: 275-279. 
grale des éléments de maçonnerie préromaine après les importants travaux qui ont pris place durant le règne d'Auguste (fig. 183). De plus, des portions de murs qui, sans autre technique de datation, auraient été interprétées comme préromaines se sont avérées augustéennes grâce aux sondages effectués en façade de la Casa del salone nero (VI, 11-15) ${ }^{80}$. Tout au plus les quelques éléments isolés ou certaines formes rémanentes permettent-ils de suggérer un découpage mixte. Comme dans l'insula V, le tiers septentrional aurait été découpé en trois parcelles inégales orientées nord-sud. En revanche, il conviendrait d'ajouter également le tiers méridional à ce type de découpage: le maintien de la forme de l'«hospitium» (VI, 2-3) et de l'aile orientale des thermes laisse supposer un découpage en trois voire quatre parcelles. Seul le tiers central aurait ainsi été partagé en lots orientés est-ouest, séparés par une ligne médiane, selon le schéma observé dans les insulae III, IV et dans la moitié méridionale de l'insula V. Le plan de la Casa del colonnato tuscanico est difficile à cerner, tant les destructions provoquées par les fouilleurs du XVIII ${ }^{\mathrm{e}}$ siècle et les restaurations successives ont perturbé ses murs. Elle pourrait avoir été scindée en deux parties durant cette phase. Au nord se trouve une maison organisée autour d'un atrium dont certains éléments ont été observés lors de la fouille ${ }^{81}$. Inscrite dans un rectangle de $22,20 \mathrm{~m}$ de longueur pour $14 \mathrm{~m}$ de largeur, cette maison ne possède pas de pièces à l'est de l'atrium. À l'ouest s'ouvrent au moins deux espaces. Le premier correspond à la boutique VI, 19, le second à la pièce 7 . Le tablinum est surmonté d'un étage ${ }^{82}$ auquel on accédait par un escalier probablement situé dans la pièce 6 . Au sud de cette pièce semble se développer une aire découverte occupant la surface des pièces $9,10,11$ et une partie de la pièce 13 . Les remaniements successifs empêchent de connaître les autres éléments de son plan. La limite sud de cette maison paraît avoir été cons-

${ }^{80}$ Cf. supra, p. 247-248.

${ }^{81}$ Cerulli Irelli 1974: 24-25.

${ }^{82}$ Cerulli Irelli 1974: 36, fig. 9.

${ }^{83}$ M. Pagano (1996 a: 236) propose soit la période de domination césarienne, soit le début du règne d'Auguste comme datation pour la création du bâtiment thermal. Cette fourchette chronologique apparaît en adéquation avec le type de maçonnerie utilisée. tituée par le mur sud de la pièce 11 , construit en opus incertum B, dont quelques restes sont encore visibles. Seule une porte percée entre les pièces 16 et 17 subsiste comme témoignage de cette construction. Il est extrêmement difficile de déterminer si des boutiques s'ouvrent sur les rues dans ces deux demeures. L'entrée VI, 25 pourrait avoir correspondu à l'accès d'un bâtiment se développant sur la moitié de la largeur de l'insula. Il me semble, comme nous le verrons plus loin, que la boutique VI, 16 est d'ouverture tardive. Il est impossible de se prononcer pour les boutiques VI, 18 et VI, 19.

La fin de la République voit une transformation majeure se dérouler dans l'îlot: l'édification des thermes (fig. 184) ${ }^{83}$. Malgré les préventions d'A. Maiuri, lors de sa construction, l'édifice thermal ne se présentait pas sous la forme que nous lui connaissons actuellement ${ }^{84}$. Cette première phase de construction a essentiellement employé l'opus incertum C et l'opus vittatum. Les thermes se déploient déjà dans la majeure partie du sud de l'îlot, mais ils prennent la forme d'un " $\mathrm{T}$ ". Ils sont composés de deux sections: l'accès aux thermes féminins, situés à l'est, se fait par l'entrée VI, 9 sur le cardo IV. L'entrée des thermes masculins se trouve sur le cardo III, éventuellement en VI, 1, bien qu'une pièce d'entrée soit vraisemblablement située en VI, 30, probable couloir d'accès aux espaces de service ${ }^{85}$. La palestre se développe jusqu'au decumanus inférieur. L'aile située à l'est de cette dernière est occupée par un bâtiment doté d'un étage qui ne communique pas avec la section féminine. En ce qui concerne les édifices privés, le seul élément visible est un mur supportant un toit à double pente asymétrique, réalisé en opus incertum $\mathrm{C}$ de tuf jaune situé entre la Casa del salone nero et les thermes, au sud des pièces $\mathrm{C}$ et D. Cette disposition rappelle, avec toutefois une conservation moindre, celle observée pour la même période dans l'angle nord-ouest de l'insula $\mathrm{IV}^{86}$.

\footnotetext{
${ }^{84}$ Maiuri 1958 b: 93

${ }^{85}$ L'entrée principale de cette zone est déjà située sur le cardo IV. La présence d'arcs de décharge pour soulager les ouvertures paraît caractéristique de cette première implantation. Deux de ces arcs sont visibles: l'un au-dessus de l'entrée VI, 9 - partiellement détruit vraisemblablement lors du premier séisme - l'autre au-dessus de VI, 10.

${ }^{86}$ Cf. supra, p. 302 et fig. 153, a p. 304.
} 

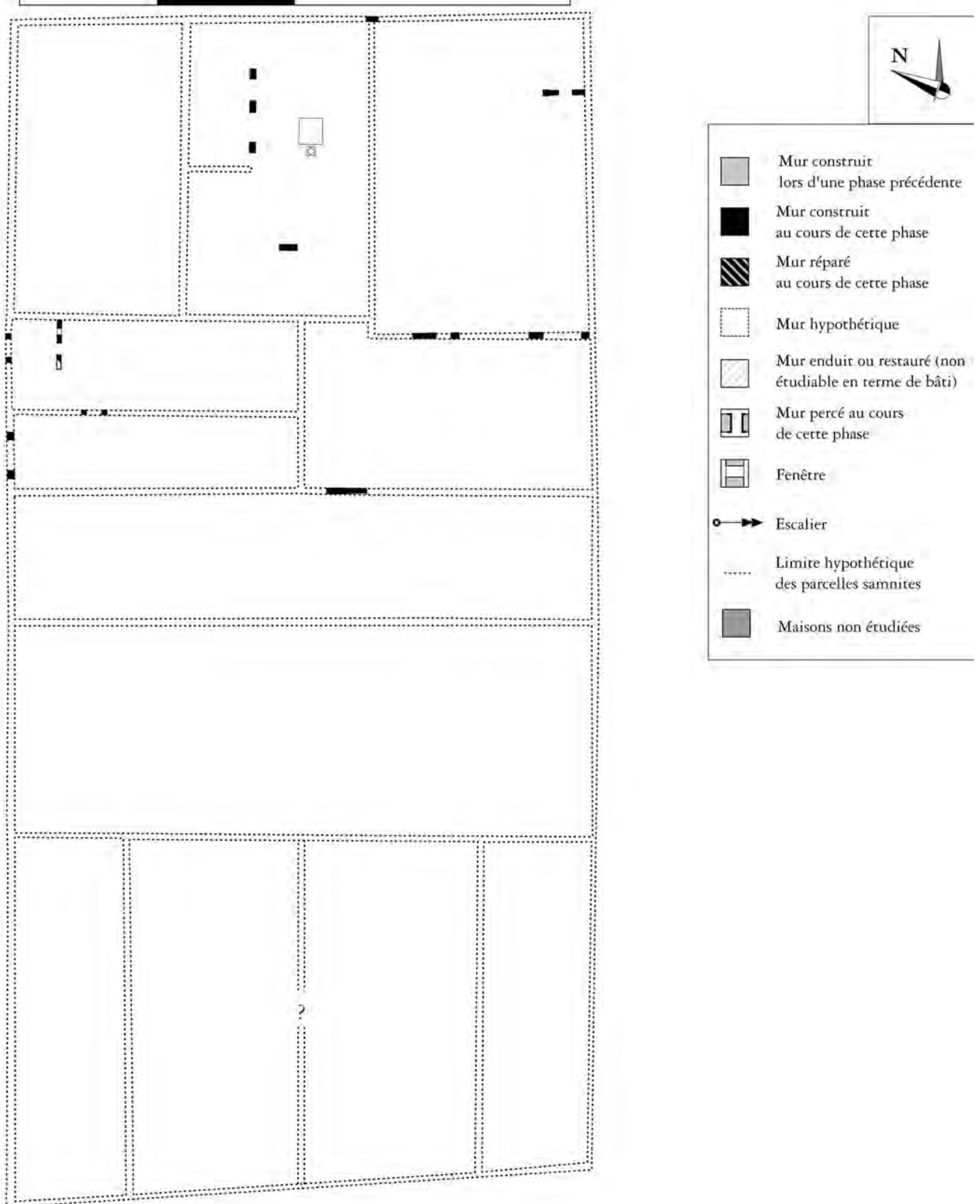

Fig. 183 - Insula VI - phase pré-romaine (échelle: 1/400). 

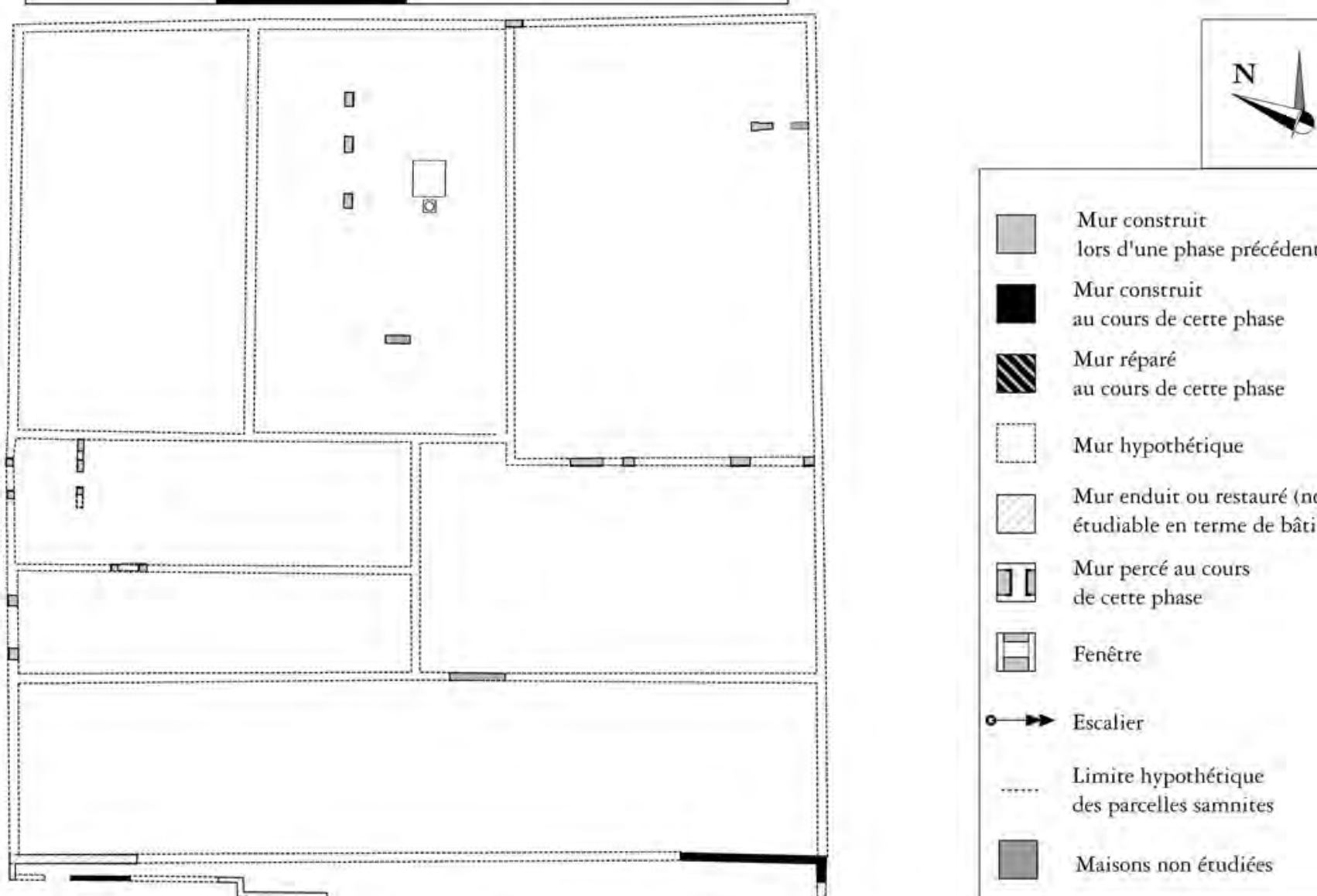

Mur construit

lors d'une phase précédente

Mur construit

au cours de certe phase

W Mur réparé

au cours de certe phase

Mur hypothérique

Mur enduit ou restauré (non étudiable en terme de bâti)

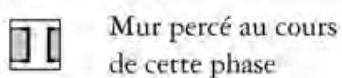

\section{Fenêtre}

$\rightarrow$ Escalier

Limire hypothétique des parcelles samnites

Maisons non érudiées
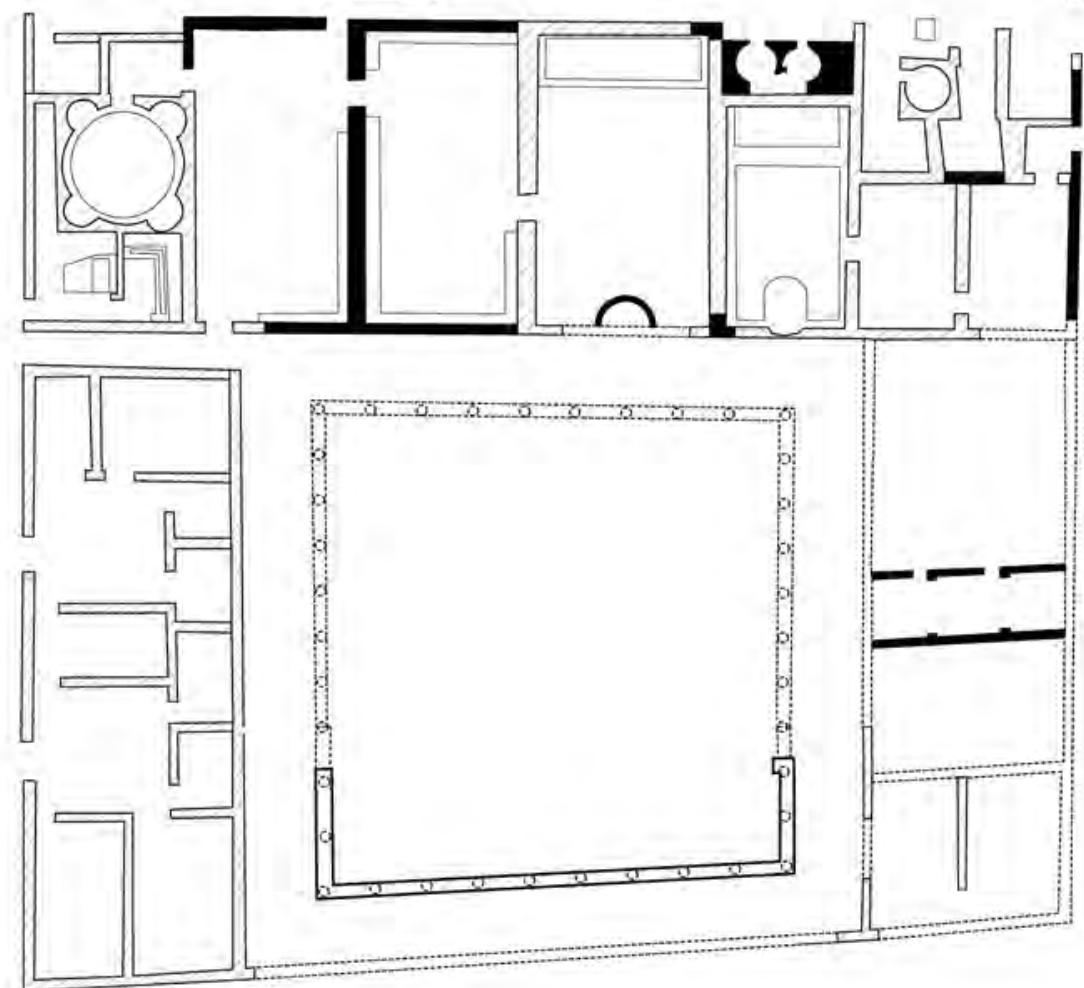

Fig. 184 - Insula VI - phase pré-augustéenne (échelle: 1/400). 
Lors de la période augustéenne, un important terrassement est effectué dans la partie nord de l'insula (fig. 185). Les sondages réalisés en façade de la Casa del salone nero ont montré un exhaussement d'au moins $40 \mathrm{~cm}$ dans les boutiques VI, 12, VI, 14 et VI, $15^{87}$. Ces travaux de remblaiement servent de fondation à la domus qui est alors construite. En dépit de l'utilisation généralisée du tuf jaune, l'érection de cette maison semble avoir été faite en opus incertum B impliquant également l'emploi de piliers de tuf rossiccio pour les montants de portes. De ce fait, il semble que cette première phase restituable de la Casa del salone nero soit d'une dimension plus réduite que lors de la phase finale: aucune trace d'opus incertum n'a pu être observée au sud du tablinum. Durant cette période, la maison se développe dans un rectangle d'environ 23,60 m sur 16,40 m. Ouverte sur le decumanus maximus par un court vestibule correspondant à l'entrée VI, 13, elle est organisée autour d'une cour centrale. La forme des espaces situés au sud de cette cour ne peut être précisée. Quatre pièces sont disposées en façade, partiellement accessibles depuis l'atrium. Deux d'entre elles ont probablement constitué des boutiques, situées de part et d'autre du vestibule d'entrée. Les éléments recueillis lors de la fouille des espaces VI, 14 et VI, 15 - alors réunis - ne permettent pas de déterminer les activités s'y déroulant. La Casa del colonnato tuscanico a été profondément transformée. Elle est ainsi agrandie, en annexant la parcelle située immédiatement au sud, qui est partiellement arasée: toutes les pièces qui pouvaient se trouver à l'est de cette parcelle sont détruites et remplacées par un péristyle ${ }^{88}$. Dans le noyau primitif au nord, un mur de refend est érigé entre la pièce 7 et la pièce 13 en opus reticulatum B. L'escalier permettant

87 En dépit des remarques supposant une incertitude quant à la date de création de cette maison avec son organisation centrée sur un atrium (Pesando - Guidobaldi 2006: 363), les données apportées par la fouille stratigraphique en 2005 donnent un terminus post quem de la fin du $\mathrm{I}^{\mathrm{er}} \mathrm{s}$. av. notre ère pour la mise en place du remblai sur lequel se développe la Casa del salone nero. Pour les détails, cf. Monteix 2007 b: 169-170.

${ }^{88}$ G. Cerulli Irelli (1974: 73) considérait que la construction du péristyle remontait aux débuts du I ${ }^{\mathrm{er}} \mathrm{s}$. av. J.-C. Les sondages effectués dans cet espace montrent qu'il a été construit durant le règne d'Auguste (Pagano 1993 b: 598).

89 Le mur actuellement visible, construit en opus d'accéder au premier étage semble avoir été déplacé de la pièce 6 à la pièce 10 . Du fait de cet aménagement, la fenêtre s'ouvrant dans le mur sud du tablinum est partiellement bouchée par une paroi, vraisemblablement construite en opus reticulatum $\mathrm{B}$, éventuellement associé à de l'opus vittatum $^{89}$. De part et d'autre de celle-ci, des ouvertures hautes sont ménagées. La base de celle située à l'est se trouve au même niveau que les marches. Dans l'atrium, l'impluvium est rehaussé et doté d'une margelle en plaques de marbre simples. La parcelle au sud est tout d'abord surélevée de façon à compenser la pente pour mettre l'ensemble de la maison à niveau ${ }^{90}$. Trois pièces s'ouvrent sur le péristyle. Au nord, la pièce 14-22 est divisée en trois espaces. Son sol est composé d'un revêtement de signinum décoré de lignes de tesselles blanches. Immédiatement au sud, la pièce 15 s'ouvre au milieu du péristyle. Enfin, après le couloir permettant d'accéder à la porte VI, 26, une grande pièce 16-19-21 est ouverte sur trois côtés. Une partie de l'étage de cette aile est accessible par un escalier indépendant appliqué le long du mur de l'édifice voisin au nord. Il est probable que cet appartement n'ait pas eu une surface supérieure au local VI, 25. Ce dernier pourrait être une boutique, bénéficiant de deux espaces annexes, l'un sous l'escalier, l'autre dans un réduit ménagé dans la pièce 14/22 et accessible par un étroit passage. Il est difficile de déterminer si cette boutique communique ou non avec la pièce 14/22. Dans la partie nord de la maison, l'accès entre le local VI, 19 et l'atrium est fermé ${ }^{91}$. Une boutique est probablement installée alors dans cet espace. Elle aurait déjà accès aux pièces de l'étage situées au-dessus des pièces VI, 16 à VI, 19. Quant aux deux autres boutiques de cette maison, rien ne permet de déterminer

vittatum mixtum à deux arases de briques est une restauration postérieure aux séismes frappant la ville après 62 ap. J.-C. Il repose sur des assises d'opus reticulatum B. L'existence de deux phases, l'une d'opus vittatum, l'autre d'opus vittatum mixtum est visible dans l'angle nord, entre la pièce 9 et le couloir 8 .

${ }^{90}$ Cette surélévation est visible non seulement dans la pièce annexe de la boutique VI, 25 , où une fenêtre des phases antérieure se situe au niveau du sol, mais également grâce à l'effondrement qui a eu lieu dans l'angle nord-ouest de la pièce 16.

${ }^{91}$ Cerulli Irelli 1974: 23, fig. 12. 

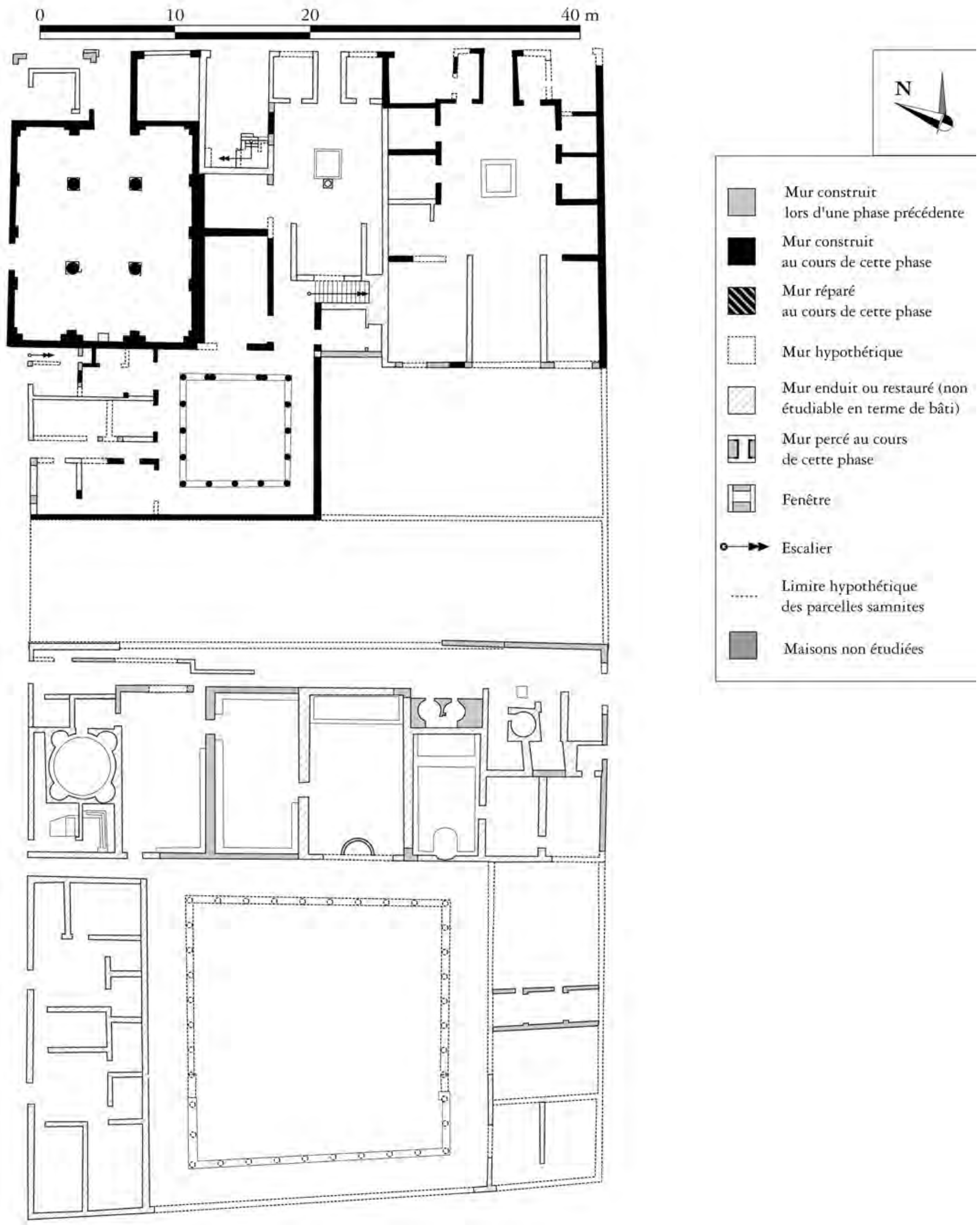

Fig. 185 - Insula VI - phase augustéenne (échelle: 1/400). 
si elles ont été ouvertes durant cette phase. Au moment des travaux d'extension de cette domus, l'angle nord-ouest de l'insula VI est également profondément modifié. Un nouvel édifice public est créé, l'Aedes Augustalium, utilisant pour partie le mur périmétrique de la maison nouvellement étendue ${ }^{92}$.

Au cours d'une première phase post-augustéenne, des travaux sont effectués dans la boutique située à l'ouest du vestibule d'entrée de la Casa del salone nero: le sol est légèrement surélevé, tandis qu'une vaste cuve est installée dans la moitié occidentale du local (fig. 186). Un aménagement hydraulique - de fonction délicate à établir - permet de convoyer de l'eau vers un orifice de citerne, situé au sud de la boutique.

Lors d'une seconde phase post-augustéenne, des travaux d'ampleur variée ont lieu dans l'ensemble de l'insula VI (fig. 187). Ainsi, la Casa del salone nero s'agrandit vers le sud en agrégeant des parcelles complètes ou fragmentaires ${ }^{93}$. Les maisons préexistantes sont presque complètement arasées. Le nouvel ensemble est érigé en opus reticulatum $\mathrm{B}$. Un péristyle est construit, devenant le second pôle de la domus, accessible depuis la nouvelle entrée créée sur le cardo IV. Cette dernière dessert les pièces de service qui sont installées à l'extrémité sud de la maison ${ }^{94}$.
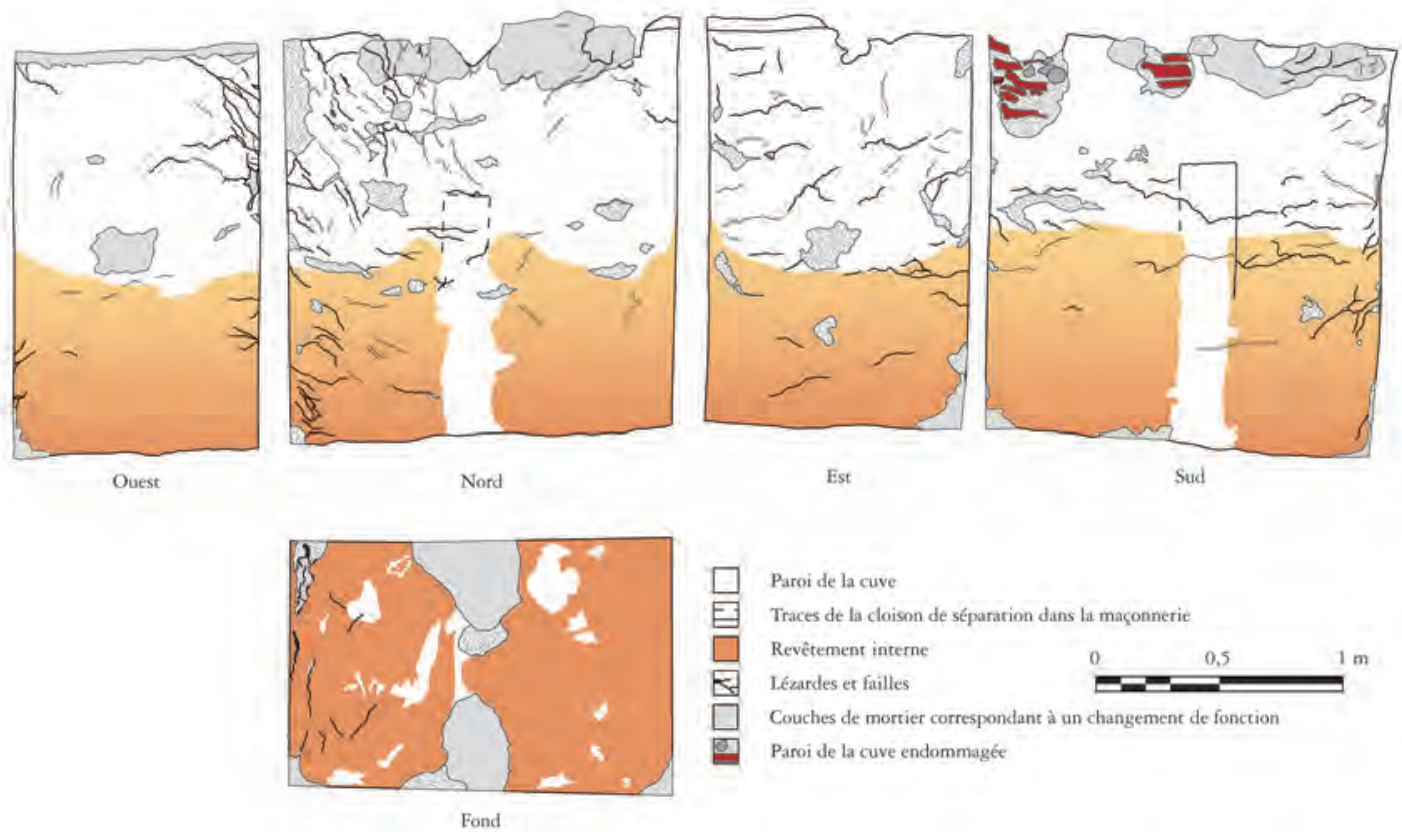

Fig. 186 - Relevé des parois de la cuve mise au jour dans la boutique VI, 15. Les différentes empreintes montrent qu'une cloison divisait cette cuve en deux lors de sa première phase d'utilisation, avant son abolition à un moment ultérieur. La cuve a finalement été condamnée après le séisme de 62 (échelle: 1/25).

${ }^{92}$ Guadagno 1983: 167-168. Cet aedes s'appuie à l'est sur la Casa del colonnato tuscanico, avec un mur doublé. En revanche, au sud, le mur est mitoyen. Sans entrer dans le détail des relations juridiques que cette situation implique, cela confirme l'antériorité de la portion nord de la maison.

$93 \mathrm{Si}$ l'on considère les éléments stylistiques pour proposer une datation plus précise, la construction de l'extension de la Casa del salone nero aurait eu lieu entre 35 et 45 ap. J.-C., les fresques notamment de la pièce I correspondant à la phase IIb du IIIe style (cf. Bastet - De Vos 1979: 62-99, 103). En revanche, pour D. Esposito (2005 : 155-161), l'ensemble correspondrait à un moment de transition entre le $\mathrm{III}^{\mathrm{e}}$ et le $\mathrm{IV}^{\mathrm{e}}$ style, daté entre la fin du règne de Claude et le début de celui de Néron.

${ }^{94}$ Le puits de lumière $\mathrm{F}$ illumine les pièces $\mathrm{C}$ et $\mathrm{E}$. Une troisième fenêtre donne sur la parcelle située immédiatement à l'ouest. Elle a vraisemblablement été bouchée lors de la phase suivante, quand la Casa dei due atri est créée. Un autel maçonné a été installé dans ce puits de lumière, malgré l'impossibilité d'y accéder; cf. GSE 1939: «10 luglio. L'ambiente 7 della casa 11 era un pozzo di luce. (...) Sulla parete sud vi è un'ara votiva descritta il 21 giugno ultimo scorso. Non tiene vano di accesso, e per entrarvi bisogna scavalcare una finestra aperta nella parete nord». 

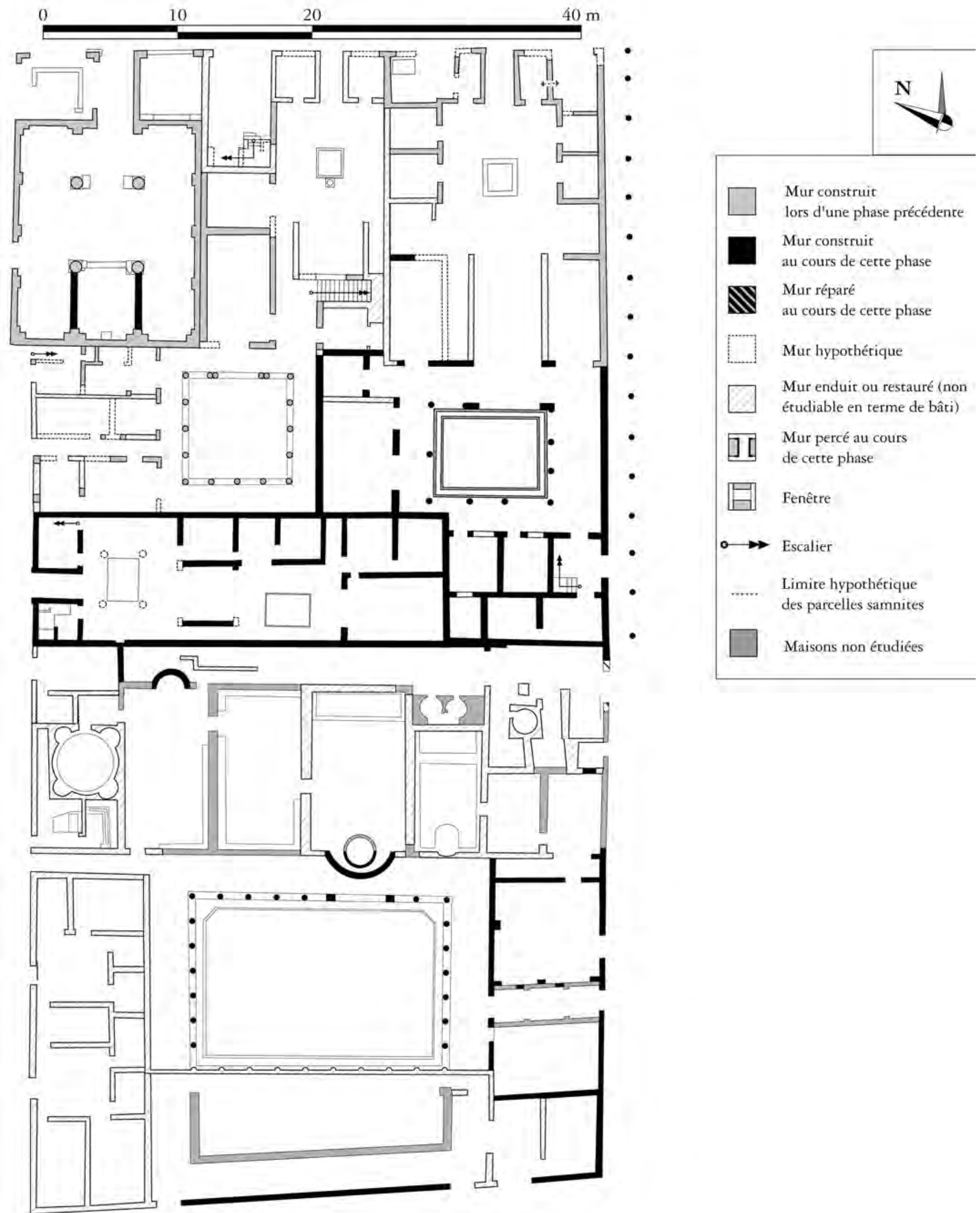

Fig. 187 - Insula VI - seconde phase post-augustéenne (échelle: 1/400). 
De plus, la maison est élargie sur la rue, par le biais d'une colonnade destinée à soutenir l'avancée de l'étage. L'accès à cet étage se fait par un escalier dont seules les premières marches sont maçonnées, situé en recul par rapport à l'entrée secondaire VI, 11, dans la pièce A. Des transformations, d'importance mineure sont également conduites en façade. Ainsi, la cuve de la boutique VI, 15 change probablement de fonction en perdant sa cloison médiane; l'aménagement hydraulique est démonté. Un passage est percé entre la pièce 12' et la pièce U. D'autres travaux ont concerné les thermes: les façades sud et est (au sud du corps de bâtiment principal) sont complètement reconstruites; deux des trois pièces ainsi annexées par les thermes sont adjointes à la section féminine dont l'entrée est déplacée en VI, $8^{95}$. L'extension de la palestre est réduite d'environ 8 mètres, cependant le bâtiment est doté non seulement d'une nouvelle entrée par le cardo IV (VI, 7), mais également d'un accès à la pièce I. La principale transformation reste l'adjonction d'un étage au-dessus du corps principal. L'accès à ce niveau se fait par un escalier maçonné puis en bois, situé à l'extrémité est du couloir de service. Cet étage ne se développe pas encore au-dessus du cardo IV. Autour des thermes, mais sur la parcelle occupée par ceux-ci, prennent place des espaces sans rapport avec l'activité balnéaire. A l'angle sud-est de l'îlot est installée une boutique qui s'ouvre sur le decumanus inférieur (VI, 6). La transformation de l'entrée des thermes sur le cardo III libère de l'espace pour la mise en place d'une éventuelle boutique en VI, 30. Au moment de ces travaux d'agrandissement dans les thermes, la Casa dei due Atri est construite ex novo. Dans la Casa del colonnato tuscanico, peu de travaux sont réalisés. Dans la pièce 7 , les murs sont décorés d'une fresque en $\mathrm{III}^{\mathrm{e}}$ style $^{96}$. Dans la pièce VI, 16, une

${ }^{95}$ La fonction de l'entrée VI, 9, transformée en pièce exiguë reste difficile à déterminer. Selon A. Maiuri (1958 b: 107), il se serait agi d'une salle où stationnait le gardien des thermes.

${ }^{96}$ Manni 1974: 20 ; Cerulli Irelli 1974: 39-40.

${ }^{97}$ Manni 1974: 16. R. Ling (1991: 72-73) considère quant à lui que cette fresque renvoie à la période de transition entre le $\mathrm{III}^{\mathrm{e}}$ et le $\mathrm{IV}^{\mathrm{e}}$ style. Cette différence d'analyse stylistique ne change que peu la datation de cette décoration. fresque du même style, représentant Hercule, est peinte vers 60 ap. J.-C. ${ }^{97}$, tandis que le sol a été refait en opus sectile soit au même moment, soit peu avant. Dans le «Collège des Augustales », un mur de refend est dressé entre les colonnes et le mur du fond. L'espace ainsi délimité est rehaussé et son accès transformé par la construction de deux marches. Un podium est également mis en œuvre dans le local VI, $20^{98}$.

Comme dans les autres îlots, le premier séisme a eu des effets contrastés en fonction des maisons (fig. 188). Dans la Casa del colonnato tuscanico, les traces de la catastrophe sont nombreuses. Au nord, ce sont essentiellement les montants des pièces 7 et 13 qui ont été endommagés et reconstruits en briques. Les dégâts semblent plus importants dans l'aile ouest: les montants de porte des pièces 16/19/21, 18 et 20 ont été abattus, tout comme le mur ouest de la pièce 15 et une partie du mur nord de la pièce 16/19/21. Les réparations de ces parois ont été effectuées en employant la technique du coffrage. Une partie des colonnes a subi le même sort, mais des briques ont été utilisées pour la restauration. Enfin, deux fractures dans le mur séparant la Casa del colonnato tuscanico de la Casa dei due atri ont été comblées avec des fragments de tuiles et de briques. Les remaniements effectués dans le plan de la maison à la suite de cette catastrophe sont peu nombreux mais significatifs: deux - éventuellement trois boutiques sont créées. La première est en VI, 16, où une ouverture sur le decumanus maximus a certainement détruit une partie de la fresque représentant Hercule ${ }^{99}$. Il est possible que son pendant en VI, 18, de l'autre côté du vestibule d'entrée, ait été créé au même moment. La boutique VI, 25 est agrandie vers l'est et obtient très certainement l'usage de l'appartement se développant à son étage. Dans la maison propre-

\footnotetext{
${ }^{98}$ Guadagno 1983: 166.

${ }^{99}$ Il est hautement improbable que cette transformation ait eu lieu avant la mise en place de la décoration de cette pièce, comme le considère M. Manni (1974: 12), sans réels arguments. G. Cerulli Irelli (1974: 21) considère, elle, que l'ouverture a eu lieu après la mise en place de la décoration pariétale.
} 

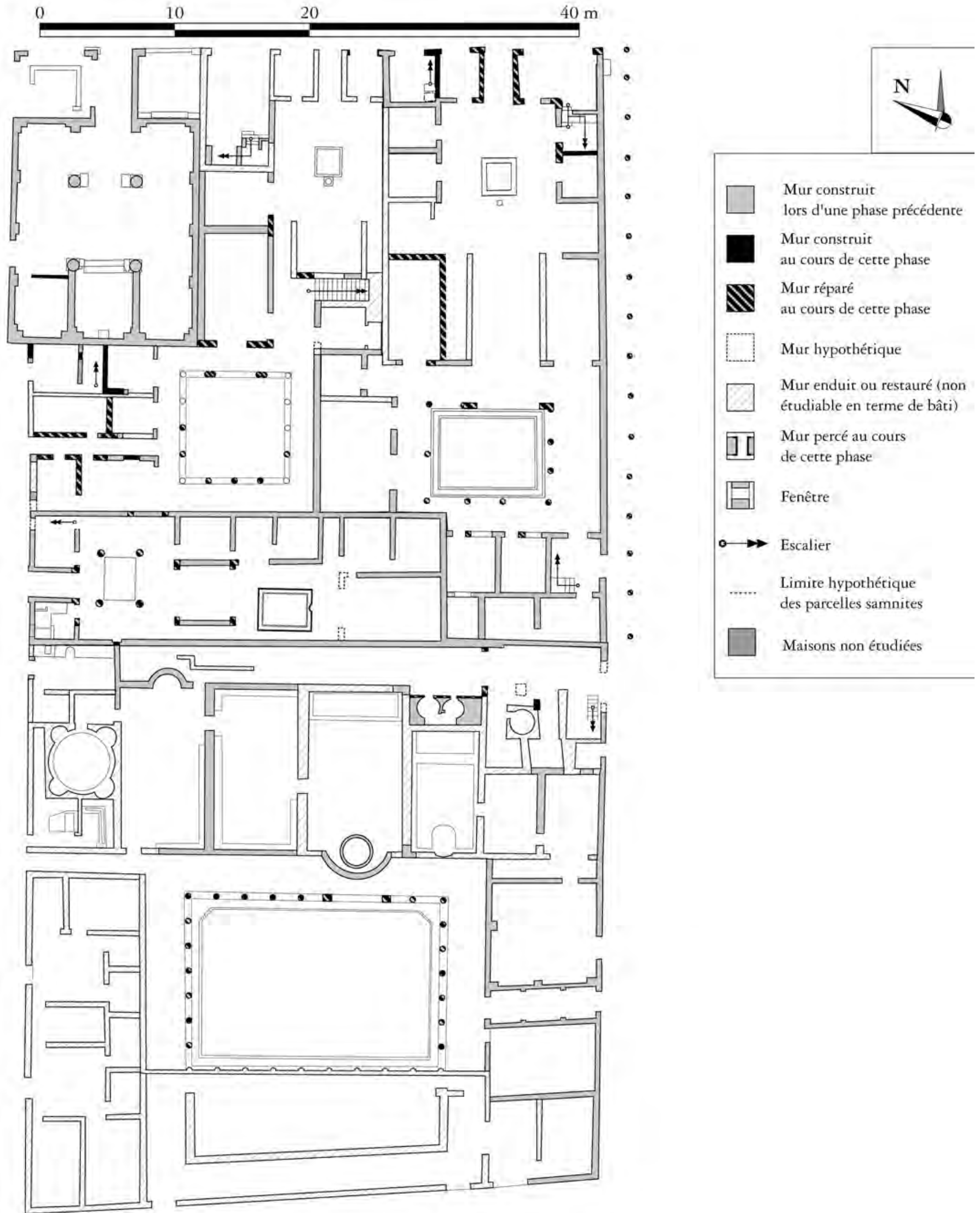

Fig. 188 - Insula VI - 62 - ca. 70/75 (échelle: 1/400). 
ment dite, outre la réduction de la surface de la pièce 14 - dont le sol en mosaïque est alors modifié $^{100}$-, la pièce $16 / 19 / 21$ perd l'un de ses accès au couloir 17.

Dans la Casa del salone nero, les dégâts paraissent s'être concentrés dans la partie la plus ancienne de la maison au nord: les murs septentrional et oriental de la pièce $\mathrm{N}$ sont abattus (fig. 189); les deux côtés du vestibule VI, 11 s'effondrent, ainsi que l'angle saillant de la boutique VI, 12. Ce dernier est restauré en briques, en lui donnant une forme arrondie, certainement pour éviter un second écroulement (fig. 190). Dans la partie méridionale de la maison, certaines colonnes sont tombées, ainsi que les montants orientaux des accès aux pièces $\mathrm{D}$ et $\mathrm{E}$. La façade nord est considérablement transformée. À l'ouest, à la place d'une unique boutique disposant d'une pièce annexe, deux espaces commerciaux sont créés après avoir

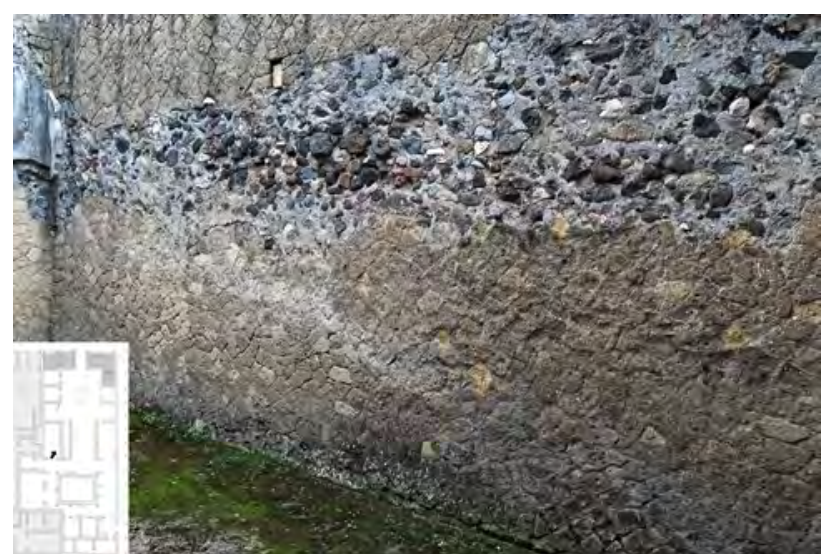

Fig. 189 - Casa del salone nero, pièce $\mathrm{N}$, mur est. Les parties inférieure et supérieure du mur ont été détruites par un tunnel. Seul subsiste une ligne d'opus incertum D, caractéristique des réparations consécutives au séisme.

${ }^{100}$ Dans la moitié orientale, le tapis de mosaïque est composé par une bordure faite d'une tresse à deux brins au trait, insérée entre deux filets triples. Le motif central est un carré présentant des fleurettes aux quatre angles internes et un bouclier à cinq rangs au centre. Si le motif central est datable du $\mathrm{I}^{\mathrm{er}}$ s. de notre ère (Blake 1930: 115-116; Pernice 1938: Pl. 38.5), la bordure est caractéristique du IVe style (Pernice 1938: 96).

101 Cette datation et les transformations planimétriques qu'elle suppose ont été critiquées par M.P. Guidobaldi (2006: 192-194): l'argument avancé contre une datation condamné la cuve et érigé un mur de refend en utilisant des moellons de remploi. La boutique VI, 15 devient ainsi indépendante de la domus et bénéficie de l'usage d'un appartement sur deux niveaux. La boutique VI, 14 alors créée reste quant à elle dépourvue de mezzanine ou d'accès à l'étage et continue d'être accessible depuis l'atrium de la Casa del salone nero ${ }^{101}$. La

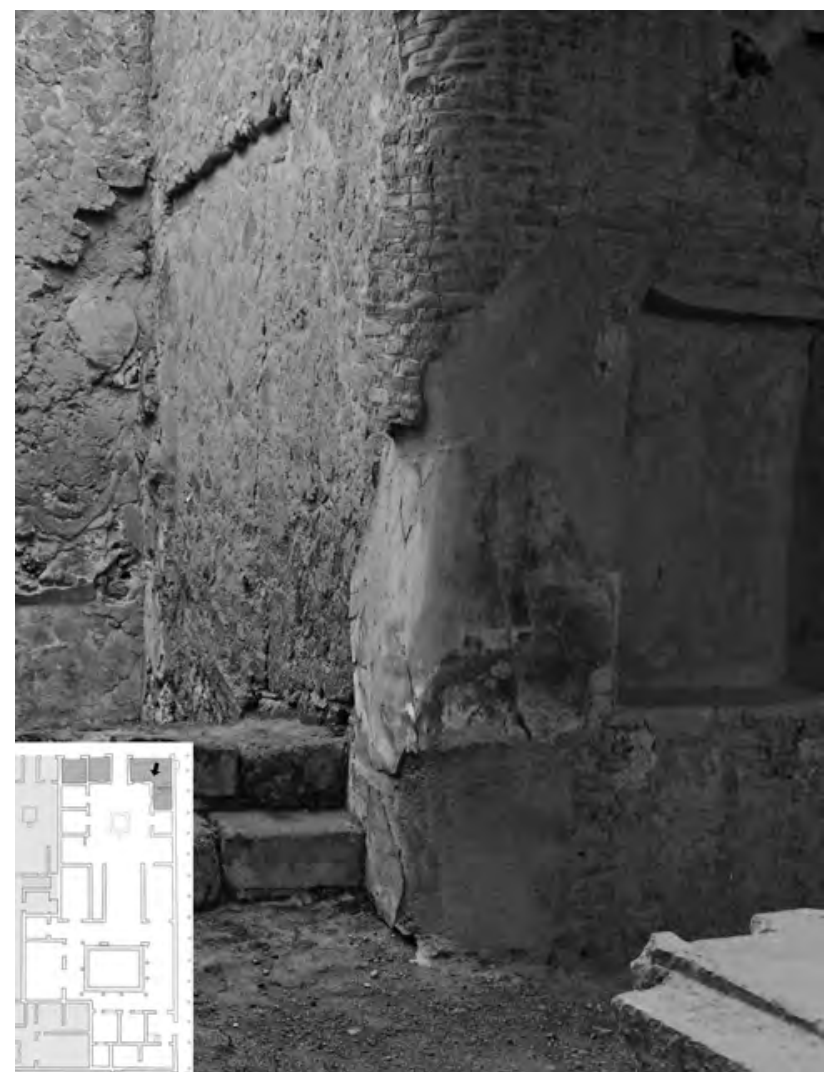

Fig. 190 - Atelier VI, 12, angle rentrant au sud-ouest. La forme arrondie employée pour cette réparation pourrait être un essai pour limiter l'effet des coups de bélier entre les murs en cas de séisme.

fondée sur une étude céramologique et une fouille stratigraphique fine est constitué par la nature géologique des montants de la boutique VI, 15. Pourtant, les blocs de tuf rossiccio ne sont que principalement et non "sistematicamente» associés aux phases les plus anciennes de la ville; la différence est particulièrement sensible dans un contexte sismique où de tels blocs peuvent être remployés. Pour éviter d'apesantir une note qui ne saurait présenter l'intégralité du dossier, je préfère renvoyer le lecteur à la consultation du rapport de fouille (Monteix 2007 b). 


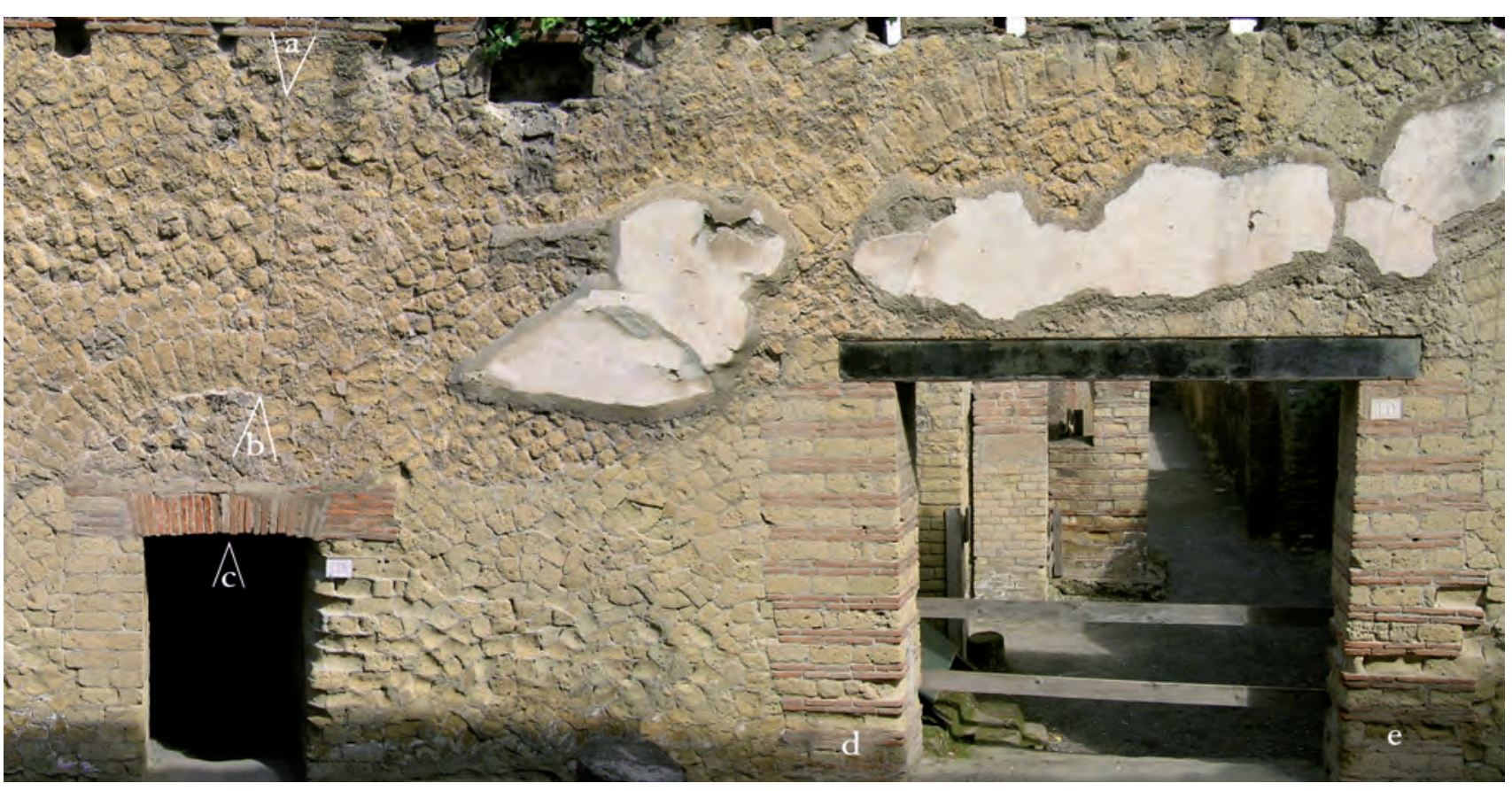

Fig. 191 - Façade orientale des thermes, entrées VI, 9 et VI, 10 (montage numérique de photos). La porte VI, 9 s'est écroulé dans sa portion nord, selon une ligne de fracture claire (a-b), l'arc a été remplacé par un linteau clavé (c). En revanche, sans que cela ne soit lié à un effondrement, les montants de la porte VI, 10 ont été remplacés après le second séisme (d, e).

boutique VI, 12 est élargie par la destruction de sa pièce annexe occidentale. Le maintien d'un porte-amphores au moment de l'éruption sur le mur ouest de ce local laisse supposer que c'est un commerce alimentaire qui s'y installe alors. Au sud de cet espace, un double escalier - accessible depuis la boutique et depuis la pièce 12' - permet de se rendre à l'étage.

Dans les thermes, la façade orientale présente très nettement les signes de plusieurs restaurations successives. Toutefois, seule la portion située entre les entrées VI, 9 et VI, 10 paraît s'être écroulée à la suite du premier séisme (fig. 191, a-c). Quelques dégâts peuvent également être discernés autour des bouches des praefurnia. Un étage est ajouté au corps principal une fois les restaurations effectuées. Cet étage ne dispose d'une avancée sur la rue qu'au-dessus de l'entrée VI, 10, comme en témoignent les encastrements de solives prévus dès la construction. Les matériaux de récupération employés pour confectionner la vasque maçonnée dans le local VI, 30 laissent supposer que ce n'est qu'après le séisme de 62 qu'une officine de nettoyage des toisons s'y installe.
Les dommages infligés par le second tremblement de terre semblent beaucoup moins importants que ceux de la première secousse (fig. 192): dans la Casa del salone nero, seule une partie du mur oriental de la pièce 12' s'écroule; de même, dans la Casa del colonnato tuscanico, outre quelques dommages au tablinum, seuls les montants de l'accès à la pièce 11 sont reconstruits, ainsi que le montant nord de la porte permettant de circuler entre les pièces 20 et 16/19/21. Enfin, dans les thermes, les deux montants de l'entrée VI, 10 sont restaurés (fig. 191, d-e), tandis qu'un pilier de soutènement est construit dans le couloir de service. Une seconde avancée de l'étage est ménagée le long d'une partie de la façade orientale; elle repose sur une colonnade construite sur une extension du trottoir qui déborde sur la chaussée du cardo IV. Le local VI, 30 cesse d'être un atelier de nettoyage de la laine brute: au milieu de cet atelier, un four a été installé. La forte dégradation de cet aménagement empêche de déterminer le type d'activités qui se déroulait dans ce local. La date de cette construction et ses éventuels liens avec le second séisme sont impossibles à préciser. 

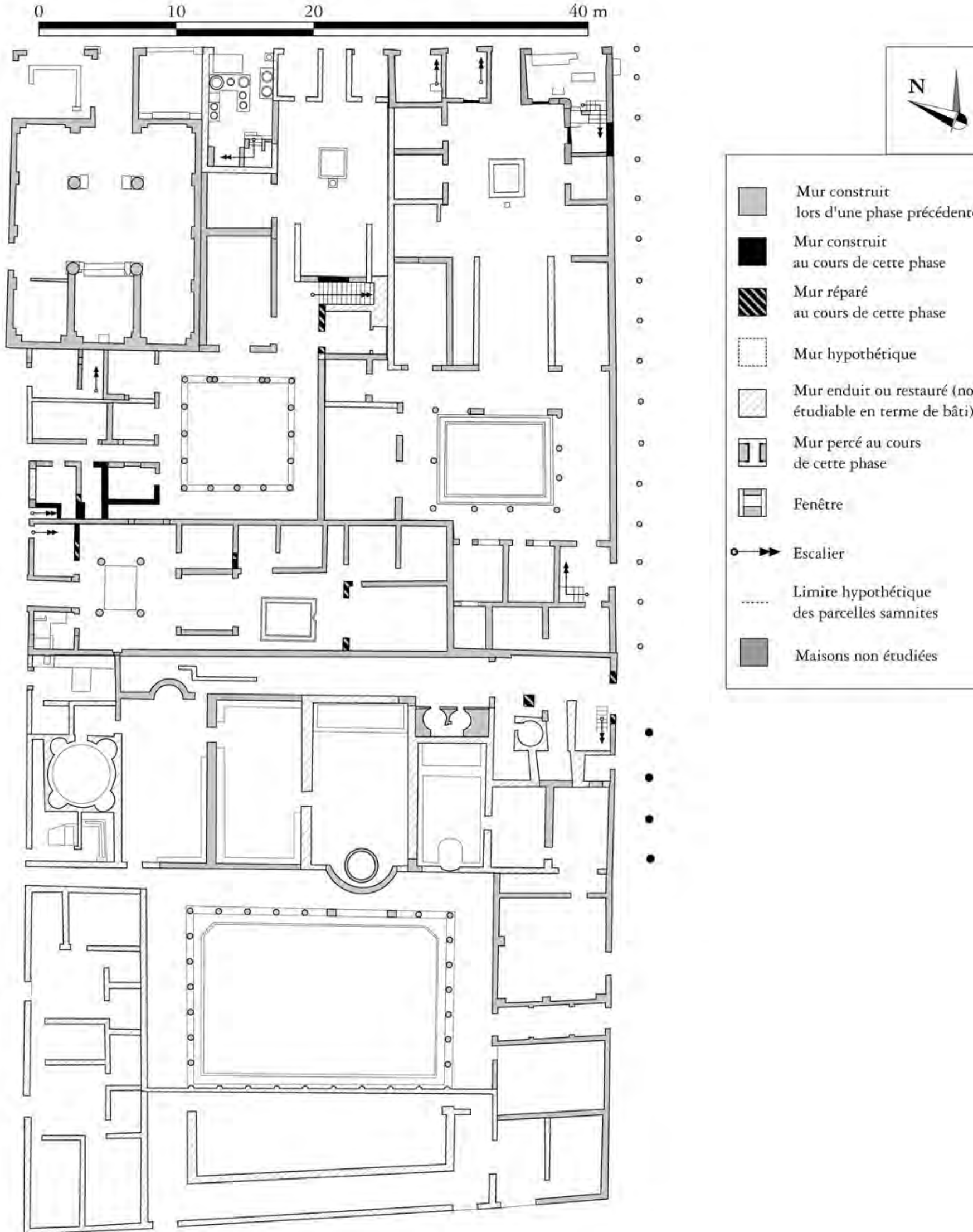

Mur construit

lors d'une phase précédente

Mur construit

au cours de certe phase

W Mur réparé

au cours de cerre phase

Mur hypothérique

Mur enduit ou restauré (non étudiable en terme de bâti)

7] Mur percé au cours de cette phase

Fenêtre

Escalier

Limite hypothétique des parcelles samnites

Maisons non érudiées

Fig. 192 - Insula VI - ca. 70/75 - 79 (échelle: 1/400). 
Une fois les restaurations effectuées, l'articulation de la façade des deux domus est considérablement transformée. Ainsi, dans la Casa del colonnato tuscanico, l'atrium, le tablinum et les pièces 13 et 14 ont été intégralement repeints en IV $^{\mathrm{e}}$ style $^{102}$. Quelques retouches ont été apportées à la décoration de la pièce $7^{103}$. Au sud, la pièce 16-19-21 a été divisée en trois parties, dont deux (19 et 21) pourraient être des espaces de service. La communication entre les pièces 19 et 20 a été obturée en laissant la porte en place: son empreinte est conservée sous la cage d'escalier. Enfin, une partie de l'étage est transformée en appartement indépendant, dont l'accès est déplacé au sud (VI, 27). De la sorte, cette domus se présente au moment de l'éruption avec quatre boutiques en façade - dont deux (VI, 19 et VI, 25) sont indépendantes et bénéficient d'un espace d'habitation à l'étage - et avec un accès à un appartement en VI, 27. Dans la Casa del salone nero, diverses transformations ont lieu dans les boutiques VI, 12 et VI, 14. Dans la première, un atelier de plumbarius remplace le commerce alimentaire. Un établi composé de grands blocs de calcaire blanc est installé à l'avant du local. L'origine même des blocs constituant cette structure montre que ce changement d'activité est lié aux séismes: ce sont notamment des fragments de seuil récupérés dans un complexe monumental, peut-être endommagé par une secousse sismique. Toutefois, le plus important des changements qui se déroulent dans cette façade est le gain d'indépendance des boutiques par rapport à la domus: les trois portes qui donnaient au préalable accès à l'atrium sont bouchées. La contemporanéité de ces travaux est mise en évidence par l'identité du mortier utilisé pour les bouchages ${ }^{104}$. Des appartements sont ménagés en connexion avec ces deux boutiques, accessibles

${ }^{102}$ Cerulli Irelli 1974: 26, 53-54, 56; Manni 1974: 10, 34, 36. L'aspect brouillon des fresques des pièces 14 et 15 pourrait laisser penser qu'elles n'étaient pas terminées au moment de l'éruption. Dans la pièce 15, deux épaisseurs d'enduit sont visibles, notamment sur le mur nord; la seconde, limitée à une fine couche de chaux est incomplète.

${ }^{103}$ Manni 1974: 20. après la mise en place d'une échelle de meunier en VI, 14 et le réaménagement partiel de l'escalier en VI, 12. C'est vraisemblablement alors que s'installe le plumbarius dans ce dernier local. Peu avant l'éruption, des travaux sont entrepris dans la boutique VI, 15 - réfection de l'enduit peint, excavation préalable à l'installation d'une nouvelle structure commerciale - et dans la pièce annexe de l'atelier. Toutes ces transformations sont brutalement arrêtées par l'éruption du Vésuve. Enfin, il semble que les travaux de restauration du reste de la maison n'ont pas été achevés avant la catastrophe finale. En effet, la mise au jour d'un important dépôt de tuiles au premier étage de cette maison laisse présumer que la toiture n'était pas achevée lors de l'ensevelissement de la ville ${ }^{105}$.

L'évolution de l'insula VI montre des rythmes relativement différents de ceux observés dans les autres îlots. La présence de plusieurs bâtiments publics n'a pas eu d'effet de réduction du tissu commercial. Si dans un premier temps aucune boutique n'est perceptible dans la parcelle des thermes, dès le courant du I ${ }^{\mathrm{er}}$ siècle de notre ère, en lien avec l'extension de l'édifice thermal, deux locaux se développent. En ce qui concerne les domus, elles ne se transforment pas à la même vitesse. Il faut ainsi attendre le second tiers du $\mathrm{I}^{\mathrm{er}}$ s. ap. J.-C. pour que la Casa del salone nero s'étende d'une maison à atrium en une maison à péristyle, tandis que cette mutation s'opère dès la période augustéenne pour la Casa del colonnato tuscanico. Bien qu'une certaine parcellisation des maisons se développe après les deux séismes, elles ne sont pas démembrées, comme a pu l'être la Casa del bicentenario, et les réactions de leurs propriétaires pour être similaires - par la création d'appartements et de boutiques indépendantes - ne suivent pas le même rythme.

\footnotetext{
${ }^{104}$ Sur les analyses de mortiers se reporter aux travaux d'A. Coutelas (2009; cf. également Monteix 2007 b: 178).

105 GSE 1939: « 21 marzo. In un ambiente del piano superiore, nell'angolo sud est si è sterrato un deposito di coppi e di tegole di terracotta. Le tegole misurano m. 0.50 di larghezza per m. 0.64 di altezza. I coppi sono lunghi m. $0.50 »$.
} 
QUELQUES REMARQUES CONCLUSIVES SUR

LES DONNÉES CONCERNANT L'ÉVOLUTION DES BOUTIQUes À HERCULANUM

Les données que je viens d'exposer sur l'évolution des boutiques à Herculanum appellent plusieurs remarques. Il faut d'abord souligner l'aspect hypothétique de cette restitution. J'ai tenté d'appliquer un système interprétatif cohérent aux différentes maçonneries utilisées au fil de l'histoire d'Herculanum, d'autres interprétations restent possibles, du moins en ce qui concerne la chronologie absolue. Ma conviction reste que les deux secousses qui ont frappé Herculanum dans la seconde moitié du $\mathrm{I}^{\text {er }}$ siècle de notre ère ont lourdement endommagé ses structures maçonnées, les travaux de restauration ou de consolidation réalisés à la suite de ces catastrophes «effaçant» une grande partie de l'histoire des bâtiments. Le problème de cette question reste la fixation d'une chronologie absolue qui ne saurait être obtenue ni par la seule étude des appareils de construction, ni par les datations stylistiques des fresques décoratives: s'il existe une période marquant le début de l'utilisation des uns et des autres, suivie par une phase d'emploi préférentiel, il est impossible de définir un arrêt définitif d'utilisation, particulièrement pour des durées aussi brèves que celles qui ont été présentées ${ }^{106}$. Quant au recours aux sondages stratigraphiques pour affiner cette chronologie, il reste délicat: non seulement l'étude de la céramique ne permet que difficilement d'obtenir des datations fiables et précises dans un intervalle de temps aussi restreint que les dix-sept dernières années de la vie d'Herculanum, mais la présence de matériel résiduel complexifie encore plus l'interprétation. Pour illustrer ces conclusions quelque peu pessimistes, je soulignerai ici ce qui m'a semblé constituer l'apport principal de sondages pratiqués en façade de la Casa del salone nero. L'analyse stratigraphique a permis de mettre en évidence six phases et d'en étudier cinq. Parmi ces dernières, seules

${ }^{106}$ Le seul rappel de l'exemple du vestibule de la Casa sannitica, dont les parois sont ornées de reliefs en stuc de $\mathrm{I}^{\text {er }}$ style (Laidlaw 1985: 304-306) et dont le plafond est en $\mathrm{II}^{\mathrm{e}}$ style (Barbet 1985: 86), l'un comme l'autre encore intacts au moment de l'éruption, soit entre près de trois siècles et trois étaient perceptibles par la seule étude des élévations conservées; leur chronologie absolue a été resserrée. En revanche, le matériel mis au jour était très fortement résiduel ou non datant. Si la nature commerciale de ces locaux explique partiellement l'absence de tout fragment étudiable de céramique sigillée, la part des éléments résiduels dans le matériel mis au jour tient pour beaucoup aux importants travaux de terrassement effectués à la suite du séisme de 62. Pour en revenir aux seules techniques de construction, celles qui ont été mises en œuvre entre la période augustéenne et les réparations du séisme de 62 - piliers de tuf rossiccio, opus incertum présentant de nombreux moellons de lave peu retaillés - auraient dû, selon l'essai de chronologie que j'ai proposé, être considérées comme antérieures à la période romaine. Finalement, n'aurait été l'étude des mortiers qui a permis de faire le lien entre les différentes boutiques en mettant en évidence des "recettes» de préparation du mortier interprétées comme autant de chantiers et donc de phases - les différents éléments mis en évidence lors de la fouille auraient pu être interprétés différemment et les résultats contestés ${ }^{107}$.

La relative fragilité des interprétations chronologiques que j'ai proposées pour le développement des commerces dans les insulae III à VI ne saurait donc être passée sous silence. Cette fragilité est d'autant plus perceptible que l'ensemble étudié n'est aucunement homogène. Contrairement à la situation de l'Insula Orientalis $I I^{a}$, où l'état initial de l'édifice est tout à la fois restituable et daté, les données sur les différentes maisons dont les maçonneries ont été étudiées fluctuent considérablement d'un exemple à l'autre. S'il est toujours possible de tenir un discours sur l'évolution de chacune de ces maisons de manière générale, l'étude des apparitions et transformations des locaux commerciaux et artisanaux en particulier se révèle plus délicate. En effet, en l'absence de fouille, seules les parois, dans le meilleur des cas, permettent

un siècle et demi après leur période principale d'utilisation est pertinent aux difficultés d'utiliser les systèmes décoratifs comme critère de datation, sauf à les considérer comme des termini post quos.

${ }^{107}$ Pour le détail de ces résultats, cf. Monteix 2007 b. 
de suggérer une date d'implantation. Toutefois, dans la majeure partie des exemples, ce sont les entrées larges - caractéristique importante mais non unique des boutiques - qui servent de fil conducteur à l'établissement d'une date pour la mise en place de tel ou tel local. Lorsque la pierre de seuil n'a pas été englobée dans la maçonnerie en cas de fermeture ultérieure, seuls les montants de l'entrée permettent de suggérer une hypothèse. Or la façade est certainement la partie d'un édifice qui a été le plus remaniée, que ce soit à la suite des séismes ou lors des restau- rations consécutives à la fouille. Il s'ensuit que les hypothèses qui peuvent être formulées pour retracerl'évolution des commerces à Herculanum sont nécessairement fragiles si elles tentent de se vouloir absolues. C'est pourquoi, dans les essais d'interprétation d'ordre plus général que je vais formuler en conclusion de cette partie, je tenterai autant que possible de distinguer deux chronologies, l'une «maximaliste» qui utilise les datations les plus hautes, l'autre "minimaliste» qui s'appuie sur des fourchettes chronologiques de création plus basses. 



\section{ÉCONOMIE ET SOCIÉTÉ À HERCULANUM}

$\mathrm{Au}$ terme de cet essai de restitution des transformations survenues dans les propriétés d'Herculanum, je proposerai une synthèse de ces mutations, qui amènera à définir la place du commerce de proximité dans le tissu urbain, et, de là, à esquisser quelques réflexions sur son rôle dans l'économie de cette petite ville. Cependant, plusieurs points doivent être rappelés. Le premier d'entre eux est le cadre chronologique: les données recueillies sont, par la méthode même qui a permis de les mettre en forme, d'autant plus fragmentaires que l'on s'éloigne de l'éruption. À l'exception de certaines portions de l'insula IV et de quelques autres exemples éparpillés à travers la ville, la restitution de la situation antérieure au règne d'Auguste s'est avérée souvent impossible. De ce fait, je limiterai cette analyse conclusive à une durée à peine supérieure à un siècle, des environs de 30 av. J.-C. à l'éruption du Vésuve en 79. L'intérêt de cette période est d'autant plus élevé qu'il s'agit de la phase institutionnellement romaine de la ville, si l'on suit l'hypothèse faisant de $\mathrm{Cl}$. Appius Pulcher le personnage ayant donné à Herculanum son statut de municipe ${ }^{1}$. L'obtention du droit de cité

\footnotetext{
${ }^{1}$ Sur ce point, cf. supra, n. 72 p. 245.

${ }^{2}$ Un phénomène proche se déroule à Pompéi entre la période syllanienne et le début de l'Empire. Les antagonismes ont toutefois été certainement beaucoup plus aigus dans cette ville, en raison même de la déduction coloniale, punition infligée en réponse à l'attitude de Pompéi lors de la guerre sociale. Le point de départ de ce problème est issu d'un discours de Cicéron dans lequel il montre des dissensions profondes entre les Pompéiens, indigènes, et les colons syllaniens (Cic., pro Sylla, 21, 60-62). Sur cette
}

romain n'a probablement pas induit des changements immédiats dans la vie économique et sociale de la ville. En revanche, cette obtention tardive, probable conséquence des choix d'alliances lors de la guerre sociale, pourrait être le signe de rapports finalement apaisés entre la ville et la puissance romaine ${ }^{2}$. Les nombreux travaux, que ce soit en termes de construction publique - thermes, théâtre, basilica Noniana, Insula Orientalis $I I^{a}-$ ou privée, qui sont commencés ou achevés durant le règne d'Auguste constituent un signe évident de ce renouveau urbain.

Pour conserver cette cohérence chronologique, je ne prendrai pas en considération ici deux maisons qui ont pourtant présenté des boutiques en façade: la Casa a graticcio (III, 13-15) et la Casa del priapo (IV, 17-18). En effet, leur création tardive ne pourrait que donner un trop fort grossissement à la période allant du séisme de 62 à l'éruption et accroître mécaniquement l'image d'un important développement immobilier et commercial à ce moment ${ }^{3}$. L'échantillon ainsi réduit a l'avantage de présenter une emprise au sol des bâtiments sensiblement constante et donc d'autoriser une véritable comparaison

question, son interprétation et son empreinte dans la ville, voir Lo Cascio 1996, Zevi 1996 et Coarelli 2000.

${ }^{3}$ La Casa a graticcio ne se révèle dans l'étude du bâti qu'à partir du séisme de 62. En ce qui concerne la Casa del priapo, la boutique IV, 17 pourrait avoir été créée durant la période augustéenne. Toutefois, les modifications apportées à l'ensemble de la parcelle qu'elle occupe après le second séisme font que les données disponibles à son propos ne peuvent pas être comparées avec celles des autres maisons. 
entre les différentes phases identifiées ${ }^{4}$. D'une façon générale, j’ai également écarté les unités d'habitation pour lesquelles les données sont trop fragmentaires, en tentant toutefois de maintenir une certaine cohérence. Ainsi, dans l'Insula Orientalis $I I^{a}$, je n'ai pas pris en considération les appartements dont les limites et les transformations ne pouvaient pas être établies tout au long de l'existence de ce bâtiment ${ }^{5}$. Quant à l'absence, parmi les maisons qui servent de support à mes réflexions, non seulement de certaines domus "traditionnelles», mais également des vastes demeures situées sur le front de mer, elle ne paraît pas poser de problème. En effet, dépourvues de locaux commerciaux en façade, l'intégration de ces maisons ne changerait pas le tableau général de la ville, qui reste centré sur la place des lieux de métier dans l'économie urbaine. Leur prise en compte conduirait tout au plus à une réduction de la part des boutiques dans l'occupation du sol, alors que leur évolution générale ne semble pas contredire les grandes tendances mises en évidence, bien que mon étude de ces maisons ait été moins détaillée que pour celles disposant d'un local commercial.

Cette proposition de synthèse s'appuie essentiellement sur l'étude des surfaces employées. Devant l'impossibilité d'utiliser des données chiffrées précises sur l'évolution du marché foncier, que ce soit à Herculanum ou ailleurs, la valeur intrinsèque des surfaces utilisées pour différents usages ne peut être prise en compte. En revanche, la décision prise par le propriétaire - ou l'occupant - d'une maison de transformer une fraction de son espace d'habitation en jardin plutôt qu'en atelier et réciproquement répond à des besoins et constitue un choix économique, révélateur de son rapport avec l'entreprise commerciale. De plus, la bonne conservation

\footnotetext{
${ }^{4}$ L'extension de la Casa del salone nero pose un problème similaire aux deux maisons exclues: son extension est relativement tardive ( $2^{\mathrm{e}}$ phase post-augustéenne) et les connaissances sur sa moitié méridionale avant son rattachement à la maison à atrium est quasiment nulle. Il eut toutefois été négligent de ne pas prendre en considération une domus pour laquelle les données disponibles sont tout à la fois variées et d'une certaine fiabilité, par la combinaison de l'étude du bâti et des fouilles stratigraphiques.

${ }^{5}$ J'ai ainsi écarté l'étage du bloc méridional, ainsi que l'ensemble de l'étage continu, accessible depuis les escaliers
}

des élévations à Herculanum permet de restituer les étages et donc d'avoir une vue véritablement globale sur les conditions d'habitation. Sans proposer pour l'instant d'interprétation, il faut immédiatement souligner l'importance des étages dans l'occupation du sol: entre la période augustéenne et l'éruption du Vésuve, dans cet échantillon, l'emprise au sol des bâtiments employés pour l'habitation ou le commerce s'est accrue de $4153 \mathrm{~m}^{2}$ à $5811 \mathrm{~m}^{2}(+40 \%)$. La prise en considération des étages transforme cet accroissement de la surface totale utile de $6010 \mathrm{~m}^{2}$ à $9263 \mathrm{~m}^{2}(+54 \%)$. Ne pas prendre en compte les étages induirait à passer outre l'une des évolutions majeures d'Herculanum lors de la période impériale.

Pour éviter de tomber dans l'écueil d'une définition trop précise des fonctions de chaque espace - précision d'autant plus inutile qu'elle s'avèrerait illusoire pour les premières phases étudiées $^{6}-\mathrm{j}$ 'ai analysé les surfaces selon quatre catégories: 1. commerce, 2. habitat, 3. étage et mezzanine, 4 . jardin, péristyle et puits de lumière. Une telle division n'a pas d'autre but que de distinguer clairement les activités commerciales et artisanales des autres fonctions de la sphère domestique, quelles qu'elles soient. En ce qui concerne les boutiques, j'ai considéré comme espace d'habitation toute pièce annexe dans laquelle aucun signe d'aménagement directement lié à l'exercice du métier - n'a été mis en évidence. Cette distinction est d'autant plus valable pour la dernière phase où la découverte d'objets associés au travail effectué facilite cette reconnaissance fonctionnelle. Ainsi, les pièces 6 à 9 de la Grande taberna con abitazione (IV, 12-13.15-16) ont été considérées comme directement associées au commerce alimentaire IV, 15-16 entre ca.70/75 et 79. En revanche, dans

situés en Or. II, 17 et pour partie en Or. II, 7. Concernant cette dernière entrée, seul l'appartement situé dans le "demi-étage», dont la transformation peut être suivie de la construction originelle à l'éruption du Vésuve, a été pris en compte.

${ }^{6}$ En ce qui concerne la définition des fonctions dans la maison romaine et les difficultés diverses qu'elle peut susciter, voir en particulier Binnebeke 1993, Allison 1993, Binnebeke - de Kind 1996: 210-216, Allison 1997, Schoonhoven 1999. 
la phase précédente, $(62-c a$. 70/75) le maintien et la réparation de la fresque de $\mathrm{III}^{\mathrm{e}}$ style ainsi que l'absence de mezzanine m'ont laissé supposer que la pièce $8 / 9$ relevait alors de l'habitat. Dans cette catégorie sont rassemblés sans distinction de fonction précise tous les espaces qui ne sont pas impliqués dans la production ou la commercialisation, qu'ils soient voués au couchage, à la réception, à la cuisine ou à toute autre activité à but immédiat non commercial ${ }^{7}$. Ont toutefois été exclues de cette catégorie les superficies non bâties, qu'elles aient eu des fonctions d'agrément - jardins et péristyles - ou plus strictement utilitaires comme les puits de lumière et d'aération. Enfin, les étages et mezzanines ont été comptabilisés dans une même catégorie. Ils constituent une extension des espaces d'habitat, mais avec la spécificité de pouvoir accroître la surface habitable avec une emprise au sol constante.

Pour pouvoir suivre l'évolution du patrimoine foncier au cours de cette période, il faut également apporter quelques précisions sur un point qui voit s'entrecroiser les pratiques juridiques transmises par les textes et les vestiges matériels. La difficulté de déterminer les limites d'une propriété par ses éléments physiques a déjà été soulignée, particulièrement au cours

\footnotetext{
${ }^{7}$ Le problème de la localisation de la production textile dans la maison (supra, p. 185-186) prend ici toute son acuité, des portions d'atrium ayant par exemple pu être utilisées pour y installer des métiers à tisser. Déjà difficile à trancher en bénéficiant des vestiges correspondant aux derniers moments de la vie d'Herculanum, cette question est insoluble avec la seule archéologie du bâti.

${ }^{8}$ Les principales études et réflexions concernant l'exploitation des sources juridiques concurremment aux vestiges archéologiques sont les suivantes: Saliou 1994; Wallace-Hadrill 1994: 131-134; Pirson 1999: 53-84; Saliou 1999.

${ }^{9}$ Un exemple très convaincant en ce sens a été mené par R. Ling (1997 b: 238-242, 247-252) dans l'îlot I 10 de Pompéi. En croisant une étude archéologique très précise avec certains textes provenant du Digeste, il suggère ainsi que le propriétaire de la maison du Ménandre (I 10, 4.14-17) possédait également le reste de l'îlot, qui aurait ainsi formé une insula au sens juridique du terme.

${ }^{10} \mathrm{Je}$ reviendrai plus loin sur la définition de la gestion «directe» qui n'implique pas nécessairement que le propriétaire de la boutique soit personnellement derrière le comptoir; cf. infra p. 364 et suivantes.

${ }^{11}$ CIL IV, 138, cit. supra, p. 47. Sur cette inscription et le rapport entre le texte et les vestiges, cf. De Albentiis 1989;
}

des quinze dernières années ${ }^{8}$. Certains éléments épars - aspect du trottoir, doublement des murs, ouverture ou fermeture de fenêtres vers un espace mitoyen - permettent parfois de proposer des hypothèses quant aux fractions d'un îlot qui pourraient appartenir à un unique propriétaire? . Une telle question est particulièrement importante pour cerner la part prise dans le patrimoine des propriétaires par la gestion «directe» des affaires par opposition à l'investissement locatif ${ }^{10}$. Or, outre l'absence très fréquente de moyens pour identifier des unités de propriété, s'ajoute le champ d'application de la location, qui est particulièrement large. L'inscription peinte en façade de l'Insula Arriana Polliana à Pompéi indique que l'ensemble de l'îlot VI 6 était à louer en 79, de la plus petite des tabernae à la domus traditionnellement appelée Casa di Pansa (VI 6, 1.8.12-13) ${ }^{11}$; son propriétaire, Cn. Alleius Nigidius Maius, n'y habitait donc probablement pas ${ }^{12}$. L'incertitude liée à ce seul exemple suffirait à empêcher toute interprétation d'un bâtiment en termes de location. Conscient des limites de ce raisonnement, j'ai considéré que les parcelles identifiées comme relevant d'une unique propriété n'étaient pas louées dans leur intégralité. Trois exceptions à ce principe d'in-

Pirson 1997 et Pirson 1999: 15-21, 23-47. F. Pirson (1997: 172 ; 1999: 41-42) rejette l'idée que la Casa di Pansa ait pu être louée parmi les domus signalées sur l'affiche de location. Ses arguments contre une telle hypothèse sont essentiellement l'adéquation entre d'une part le statut de ce personnage dans Pompéi et d'autre part les objets découverts dans la maison et l'architecture de cette dernière. Faute d'éléments plus décisifs, il me semble difficile de rejeter complètement l'hypothèse que la Casa di Pansa ait pu être louée.

${ }^{12}$ Les remarques d'E. De Albentiis (1989: 82), qui considère que la mention d'un esclave auquel s'adresser pour louer la maison serait caractéristique de l'abandon vraisemblable ( "verosimile ») du propriétaire à la suite du séisme de 62, doivent être amendées. Un personnage de l'importance de $\mathrm{Cn}$. Alleius Nigidius Maius, entre autre duumvir quinquennal en 55 de notre ère et candidat à plusieurs reprises après 62 (Mouritsen 1988: 32, 34, 36 et 126), n'allait que difficilement s'occuper en personne de la gestion de son patrimoine, confiant plutôt ce soin à son esclave Primus. À tout le moins, cette inscription ne permet pas nécessairement de soutenir la thèse d'A. Maiuri (1942 a: 214-218) sur le retrait des élites municipales hors de la ville après le séisme de 62. 
terprétation doivent toutefois être signalées: les appartements V, 17-18 et les édifices V, 19-25 et V, 28-29. Ces trois édifices constituent des blocs de propriété autonomes de leur voisinage immédiat, dans lesquels il semble peu probable que le propriétaire ait pris son logement ${ }^{13}$. Pour les éléments constituant ces trois propriétés, mais également pour d'autres parcelles, les critères permettant de considérer qu'ils ont été loués sont ceux établis par F. Pirson: autonomie et insertion dans une unité de propriété ${ }^{14}$. En revanche, le critère d'habitabilité (Bewohnbarkeit) me semble moins pertinent ici ${ }^{15}$. En effet, en dépit de certaines mentions dans les textes, s'il est effectivement possible d'habiter dans une taberna, cette possibilité n'est pas consubstantielle du $\operatorname{lieu}^{16}$ : l'atelier VI, 30 , qui était certainement loué - comme le suggère sa situation sur une parcelle publique liée aux thermes -, ne dispose d'aucun espace propre à l'habitation. De la même façon, la boutique V, 32 ne semble pas avoir eu accès à l'étage - accessible depuis l'escalier V, 33a - et apparaît dépourvue de tout espace habitable. Ces espaces seraient donc exclusivement destinés à une activité commerciale ou artisanale et loués dans ce but. Quant à la présence de niches associées au culte domestique dans certaines boutiques, elle n'indique pas nécessairement la présence d'une unité d'habitation: les Lares peuvent être évoqués pour la protection d'un territoire précis - en ce cas le lieu de métier - tandis que les Pénates ont pour vocation de protéger des activités et peuvent ainsi s'insérer dans un cadre professionnel strict ${ }^{17}$. Pour résumer, j'ai appelé «parcelle» tout édifice formant un ensemble dans lequel des unités autonomes - boutiques, appartements indé-

${ }_{13}$ Je reviendrai plus loin (infra, p. 361-363) sur le cas de $V, 17-18$. En ce qui concerne l'ensemble V, 19-25, il semble, en plan, formé de deux unités distinctes (V, 19-22 et V, 23-25). Toutefois, le développement de l'appartement accessible par l'entrée V, 22 au-dessus de ces deux unités indiquerait, en fonction du principe de droit superficies solo cedit une unicité de propriété (Saliou 1994: 45-50; Pirson 1999: 73-74). Quant à la boutique V, 28 et à l'appartement $\mathrm{V}, 29$, le traitement différencié du trottoir, recouvert de galets uniquement devant ces deux entrées, autorise, par rapprochement avec une clause de la table d'Héraclée ( $R S$ I: 355-391, 1. 53-55 ; cf. Saliou 1999: 171, 198-200), à supposer qu'ils appartiennent à un unique propriétaire, différent de celui de V, 26-27 ou de celui de V, 30. pendants - ont pu être louées. Faute de pouvoir déterminer si un unique propriétaire détenait plusieurs de ces parcelles, chacune d'entre elles a été traitée individuellement. Dans deux cas la Casa sannitica et la Casa del bicentenario -, la propriété a débordé des limites de ces maisons, ce qui permet de proposer une restitution de deux blocs de propriété. Toutefois, les différentes maisons ayant pu constituer ces blocs ont également été traitées individuellement tout au long de cette étude.

Un dernier rappel des grandes lignes interprétatives proposées jusqu'alors doit être fait. Je ne reviendrai pas sur le détail des idées développées de façon éparse par A. Maiuri. Ce dernier postulait que durant la seconde moitié $\mathrm{du} \mathrm{I}^{\mathrm{er}}$ siècle de notre ère, le "patriciat» samnite avait été progressivement évincé par des affranchis enrichis par le commerce d'outre-mer, qui avaient profondément transformé Herculanum. Signe de ce déclin, l'insertion de boutiques en façade et la création d'appartements indépendants auraient rapidement défiguré les maisons, tandis que, si l'on suit le modèle interprétatif élaboré pour Pompéi mais peu mentionné à Herculanum, le séisme de 62 aurait porté un coup de grâce aux anciennes élites ${ }^{18}$. Aucune interprétation alternative à ce modèle n'a été proposée pour Herculanum. Seul E. Lepore a suggéré quelques hypothèses, écrites avant la publication des nuovi scavi et donc fondées essentiellement sur les sources littéraires et les quelques maisons partiellement publiées par A. Maiuri. Comme il l'avait déjà fait à propos de Pompéi, il signale, avec moins de force toutefois, son hésitation quant à l'invasion des affranchis enrichis et préfère y voir au contraire une

En ce qui concerne l'inadéquation entre ces trois unités et la présence du propriétaire en leur sein, elle n'est guère impossible; elle ne me semble en revanche que peu plausible.

${ }^{14}$ Pirson 1997: 173-178; 1999: 56-84.

15 Pirson 1997 : 173 ; 1999 : 53-55.

${ }^{16}$ Sur les textes indiquant un lien entre les tabernae et l'habitation, cf. supra, p. 46-47.

${ }^{17}$ Une étude des manifestations du culte domestique dans les boutiques en particulier serait à mener à Pompéi et Herculanum. Les travaux de W. van Andringa (2009: 289304) apportent des réponses à cette épineuse question.

${ }^{18}$ Sur les origines et les variations de cette interprétation, cf. supra, p. 5-8. 
adaptation des élites face à la croissance de la population ${ }^{19}$. Quant aux critiques plus récentes d'A. Wallace-Hadrill, elles restent substantiellement fondées sur Pompéi ${ }^{20}$.

Quelques remarques générales permettent d'esquisser une évolution globale de la place des boutiques dans la ville. La situation lors du règne d'Auguste montre un développement déjà relativement important des étages, qui constituent 31\% de la surface bâtie (fig. 193). Des boutiques sont déjà installées en façade des maisons, à raison de 6 à $8 \%$ de cette surface, selon que l'on suive la restitution minimale (18 boutiques) ou maximale (24 locaux). Si l'on ne prend en considération que les édifices privés, la surface exploitable ne cesse d'augmenter, sans heurts, passant de $6010 \mathrm{~m}^{2}$ durant la période augustéenne à $7933 \mathrm{~m}^{2}$ au moment de l'éruption (+32\%) (fig. 194) ${ }^{21}$. Aucun des deux séismes ne semble avoir perturbé l'allure de cette évolution. Cet accroissement est majoritairement dû à la construction d'étages et de mezzanines, l'espace qu'ils occupent se développant de $65 \%$ en un peu plus d'un siècle. Si le pourcentage d'occupation du sol par les boutiques augmente tout au long de la période (fig. 195 et 196), indiquant une légère croissance commerciale, cette augmentation n'est guère heurtée ${ }^{22}$. En ne prenant en compte que les édifices privés, on constate une très probable augmentation régulière de la population $^{23}$. Aucun des deux séismes ne paraît avoir eu d'effet - comme moteur ou comme frein

${ }^{19}$ Les critiques d'E. Lepore par rapport aux interprétations d'A. Maiuri sur Pompéi ont été exposées dans le volume publié à l'occasion du bicentenaire des fouilles (Lepore 1950 = 1989: 123-146). Ses remarques pertinentes sur la condition d'Herculanum durant la période impériale ont été publiées alors que seul le guide des fouilles (Maiuri 1936 a) était paru; cf. Lepore 1955, part. 430-432 (= Lepore 1989: 243-263, part. 252-255).

20 A. Wallace-Hadrill (1994: 124-129) critique de façon détaillée les présupposés d'A. Maiuri en se fondant sur le plan de la publication des fouilles. Toutefois, dans les pages précédant et suivant ces remarques spécifiques à Herculanum (ibid., p.122-123, 129-142), il s'intéresse essentiellement à Pompéi.

${ }^{21}$ Deux légères inflexions sont perceptibles durant les phase post-augustéennes. Elles sont dues à la création de la Casa di Nettuno e Anfitrite et à l'extension de la Casa del salone nero au-delà de son tablinum vers le sud, étendant de la sorte l'échantillon avec des parcelles non prises en compte pour les phases précédentes, faute de données.

${ }^{22}$ Le léger recul en pourcentage des périodes post-

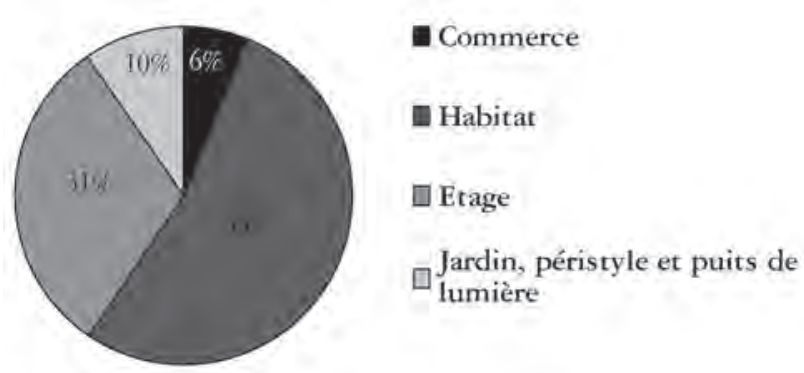

Fig. 193 - Formes de l'occupation du sol à Herculanum durant la période augustéenne.

- sur cette structure macroscopique. À tout le moins, une invasion subite des affranchis dans la seconde moitié du $\mathrm{I}^{\mathrm{er}} \mathrm{s}$. de notre ère est invisible dans les maisons tenues par des particuliers. En revanche, si l'on ajoute à ce tableau les boutiques et surtout les appartements de l'Insula Orientalis $I I^{a}$ qui sont définitivement achevés lors de la seconde phase post-augustéenne, cette évolution sur un siècle devient un peu moins atone $^{24}$. En effet, que ce soit le développement global des surfaces habitables, la part prise dans celui-ci par les commerces, ou le nombre en valeur absolue de ces derniers (fig. 197 et 198), un net infléchissement à la hausse est perceptible durant la dernière phase, entre le second séisme et l'éruption de $79^{25}$. La seule idée d'un

augustéennes est lié au phénomène expliqué à la note précédente.

${ }^{23}$ Il faudrait mettre en parallèle cette augmentation de population perçue par les transformations architecturales avec le renouvellement des habitants, mis en évidence par G. Camodeca (2008: 93) sur fondements épigraphiques, particulièrement sensible après 62 .

${ }^{24}$ Les travaux de l'Insula Orientalis $I I^{a}$ se sont déroulés entre la phase augustéenne et la première phase post-augustéenne. J'ai donc considéré, pour simplifier, que les locaux commerciaux et les appartements situés en façade de cet édifice n'ont été pleinement fonctionnels qu'à partir du début de la seconde phase post-augustéenne.

25 D'une phase à l'autre, alors que la surface totale n'a augmenté que de $10 \%$, la surface habitable de $4 \%$ et la surface des étages - mezzanines inclues - de 14\%, l'espace au sol consacré au commerce s'est développé de 30\%. 9 nouvelles boutiques ont été créées, soit une augmentation de leur nombre de près de $22 \%$. Les implantations commerciales ont alors crû plus vite que les autres formes d'occupation du sol. 


\begin{tabular}{|c|c|c|c|c|c|c|c|c|c|c|}
\hline & $\begin{array}{c}\text { Surface } \\
\text { totale } \\
\left(\mathrm{m}^{2}\right)\end{array}$ & $\begin{array}{l}\text { Com- } \\
\text { merce } \\
\left(\mathrm{m}^{2}\right)\end{array}$ & $\begin{array}{c}\text { Habitat } \\
\left(\mathrm{m}^{2}\right)\end{array}$ & $\begin{array}{c}\text { Etage } \\
\left(\mathrm{m}^{2}\right)\end{array}$ & $\begin{array}{c}\text { Mezzanine } \\
\left(\mathrm{m}^{2}\right) \\
\end{array}$ & \begin{tabular}{|c|} 
Jardin, \\
péristyle et \\
puits de \\
lumière $\left(\mathrm{m}^{2}\right)$
\end{tabular} & \begin{tabular}{|c|} 
Nombre de \\
boutiques
\end{tabular} & $\begin{array}{c}\text { Commerce } \\
\text { / surface } \\
\text { rotale }\end{array}$ & $\begin{array}{c}\text { Jardin, ... } \\
\text { / surface } \\
\text { totale }\end{array}$ & $\begin{array}{c}\text { Etage / } \\
\text { surface } \\
\text { totale }\end{array}$ \\
\hline \multirow{2}{*}{$\begin{array}{c}\text { Phase } \\
\text { augustéenne }\end{array}$} & 6070 & 382 & 3193 & 1852 & 5 & 578 & 18 & 696 & $10 \%$ & 319 \\
\hline & 6010 & 472 & 3103 & 1852 & 5 & 578 & 24 & $8 \%$ & $10 \%$ & $31 \%$ \\
\hline \multirow{2}{*}{$\begin{array}{c}\mathrm{Ph} \text {. post } \\
\text { augustéenne } \mathrm{I}\end{array}$} & 6476 & 377 & 3359 & 2118 & 17 & 605 & 16 & $6 \%$ & $9 \%$ & $33 \%$ \\
\hline & 6476 & 512 & 3224 & 2118 & 17 & 605 & 25 & $8 \%$ & $9 \%$ & $33 \%$ \\
\hline \multirow{2}{*}{$\begin{array}{c}\text { Ph. post } \\
\text { augustéenne } 2\end{array}$} & 7274 & 360 & 3630 & 2600 & 17 & 667 & 16 & $5 \%$ & $9 \%$ & 3680 \\
\hline & 7274 & 505 & 3485 & 2600 & 17 & 667 & 24 & $7 \%$ & $9 \%$ & $36 \%$ \\
\hline \multirow{2}{*}{\begin{tabular}{|c|} 
Ph. post \\
augustéenne 2
\end{tabular}} & 8221 & 689 & 3969 & 2879 & 17 & 667 & 28 & $8 \%$ & $8 \%$ & $35 \%$ \\
\hline & 8221 & 834 & 3824 & 2879 & 17 & 667 & 36 & $10 \%$ & $8 \%$ & $35 \%$ \\
\hline \multirow{2}{*}{$62-70 / 75$} & 7373 & 575 & 3480 & 2706 & 28 & 584 & 27 & $8 \%$ & $8 \%$ & $37 \%$ \\
\hline & 7373 & 583 & 3472 & 2706 & 28 & 584 & 28 & $8 \%$ & $8 \%$ & $37 \%$ \\
\hline \multirow{2}{*}{$62-70 / 75$} & 8440 & 972 & 3862 & 2985 & 37 & 584 & 40 & $12 \%$ & $7 \%$ & $36 \%$ \\
\hline & 8440 & 980 & 3854 & 2985 & 37 & 584 & 41 & $12 \%$ & $7 \%$ & $36 \%$ \\
\hline $70 / 75-79$ & 7933 & 692 & 3588 & 3060 & 82 & 511 & 32 & $9 \%$ & $6 \%$ & $40 \%$ \\
\hline $70 / 75-79$ & 9263 & 1279 & 4021 & 3312 & 140 & 511 & 50 & $14 \%$ & $6 \%$ & $37 \%$ \\
\hline
\end{tabular}

\begin{tabular}{|c|c|c|c|c|c|c|c|}
\hline & Location & $\begin{array}{c}\text { Nombre de } \\
\text { parcelles }\end{array}$ & $\begin{array}{l}\text { Unités } \\
\text { indépen- } \\
\text { dantes }\end{array}$ & $\begin{array}{c}\text { Unités } \\
\text { indépen- } \\
\text { dantes } \\
\text { habitables }\end{array}$ & $\begin{array}{c}\text { Boutique } \\
\text { sans } \\
\text { habitat }\end{array}$ & $\begin{array}{l}\text { Surface louée } \\
\left(\mathrm{m}^{2}\right)\end{array}$ & $\begin{array}{l}\text { Surface de } \\
\text { rapport }\left(\mathrm{m}^{2}\right)\end{array}$ \\
\hline \multirow{2}{*}{$\begin{array}{c}\text { Phase } \\
\text { augustéenne }\end{array}$} & $30 \%$ & 75 & 26 & 23 & 3 & 1196 & 1354 \\
\hline & $30 \%$ & 15 & 26 & 23 & 3 & 1196 & 1480 \\
\hline \multirow{2}{*}{$\begin{array}{c}\text { Ph. post } \\
\text { augustéenne } 1\end{array}$} & $50 \%$ & 16 & 28 & 25 & 3 & 1460 & 1656 \\
\hline & $50 \%$ & 16 & 28 & 25 & 3 & 1460 & 1791 \\
\hline \multirow{2}{*}{$\begin{array}{c}\text { Ph. post } \\
\text { augustéenne } 2\end{array}$} & $52 \%$ & 16 & 35 & 32 & 3 & $1+60$ & 1649 \\
\hline & $52 \%$ & 16 & 35 & 32 & 3 & 1460 & 1784 \\
\hline \multirow{2}{*}{$\begin{array}{c}\text { Ph. post } \\
\text { augustéenne } 2\end{array}$} & $64 \%$ & 18 & 47 & 42 & 5 & 2407 & 2596 \\
\hline & $64 \%$ & 18 & 47 & 42 & 5 & 2407 & 2688 \\
\hline \multirow{2}{*}{$62-70 / 75$} & $51 \%$ & 17 & 36 & 34 & 2 & 1667 & 2039 \\
\hline & $51 \%$ & 17 & 36 & 34 & 2 & 1667 & 2047 \\
\hline \multirow{2}{*}{$62-70 / 75$} & $63 \%$ & 19 & 47 & 43 & 4 & 2734 & 3106 \\
\hline & $63 \%$ & 19 & 47 & 43 & 4 & 2734 & 3114 \\
\hline $70 / 75-79$ & $58 \%$ & 19 & 49 & 45 & 4 & 2200 & 2589 \\
\hline $70 / 75-79$ & $70 \%$ & 21 & 67 & 61 & 6 & 3530 & 3919 \\
\hline
\end{tabular}

Fig. 194 - Tableau récapitulatif de l'évolution des surfaces d'Herculanum. Les valeurs en italique correspondent au nombre minimal de boutiques, le double encadrement inclut les parcelles publiques.

développement économique important à la suite d'un deuxième tremblement de terre laisse sceptique, sauf à considérer cet ultime accroissement des boutiques et des appartements dans son contexte. Le premier point qu'il faut conserver à l'esprit est la nature même des commerces créés: les activités qui se développent alors restent de l'ordre du commerce de proximité ou de l'artisanat d'intérêt infrarégional. Aucun de ces locaux commerciaux ne semble susceptible de fournir des produits au-delà des besoins de la population locale. Un effet de loupe est certain: par son seul volume, l'Insula Orientalis $I I^{a}$ représente une surface très importante, que ce soit en termes de locaux commerciaux ou d'appartements. De plus, les résultats des travaux financés par Vespasien sont doubles: d'une part, ils ont abouti à une division et à une redistri- 

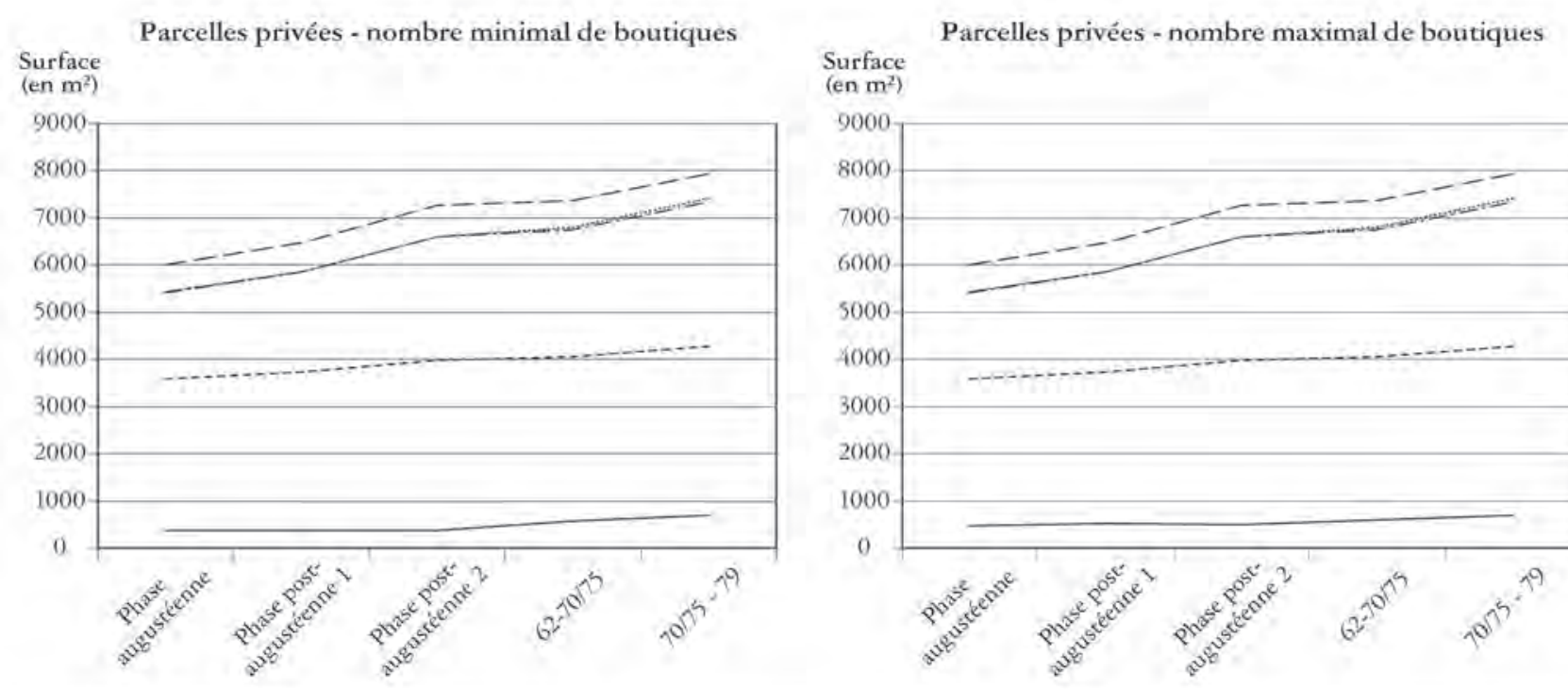

\begin{tabular}{|c|c|c|c|c|}
\hline Commerce & Habitat & _. Etage & Mezzanine & 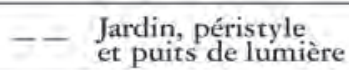 \\
\hline
\end{tabular}
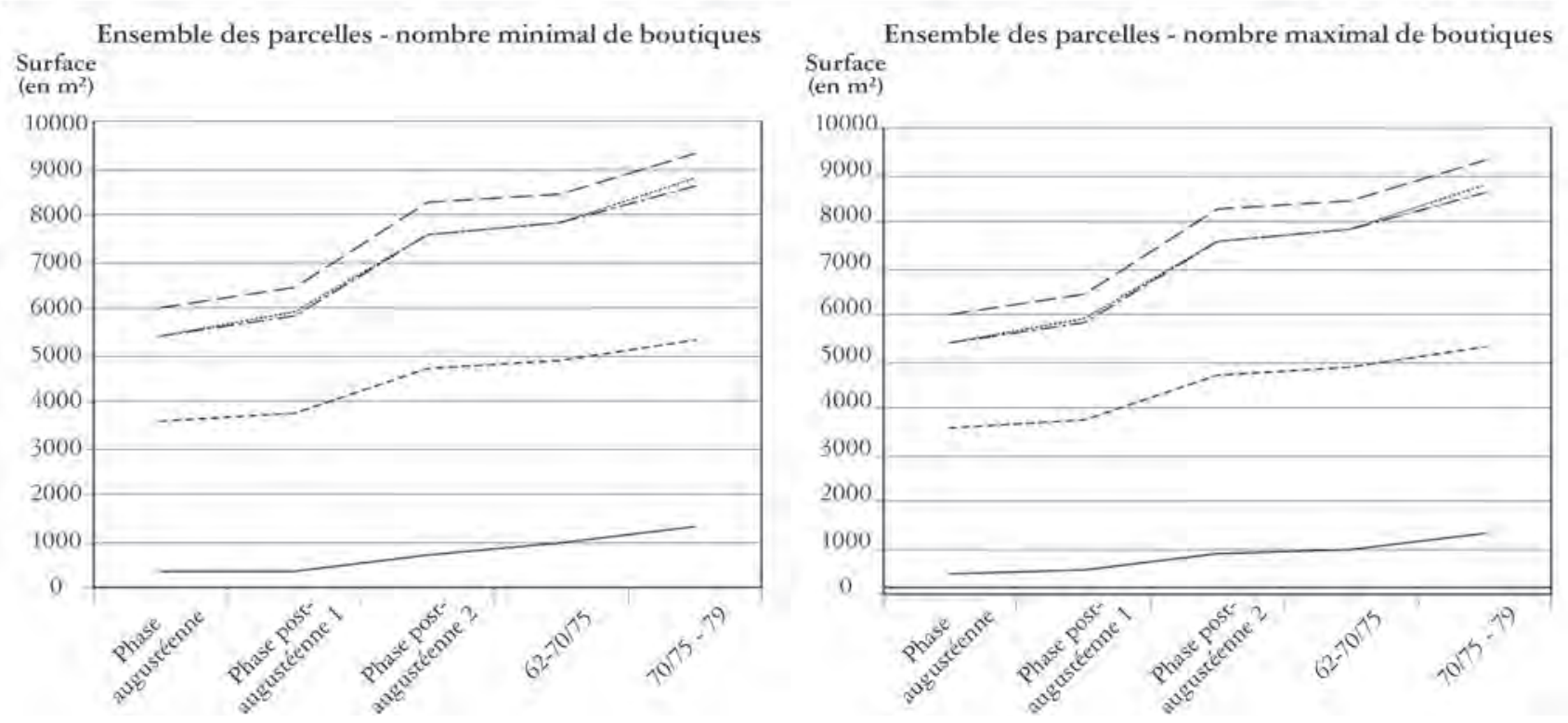

Fig. 195 - Courbes d'évolution de l'occupation du sol dans l'ensemble des édifices étudiés, surfaces cumulées (indiquées en mètres carrés).

bution des espaces concentrés; d'autre part, les boutiques ont été multipliées, gagnant sur les zones publiques. Sans que cette augmentation finale du nombre de commerce ne constitue un essor économique, les travaux impériaux ont eu un indéniable effet d'entraînement. Il est d'autant plus notable que leur financement a été, par définition, détaché des ressources locales et de la capacité économique des élites de la ville. Loin de mettre en évidence une quelconque invasion commerciale qui aurait bouté hors de leurs domus les aristocraties samnites, cette esquisse de l'évolution des implantations commerciales montre que la part la plus forte des créations de boutiques revient au promoteur de l'Insula Orientalis $I I^{a}$, probablement le municipe. Toutefois, ce mouvement n'est pas isolé et les propriétaires de domus y participent 
Parcelles privées - nombre minimal de boutiques

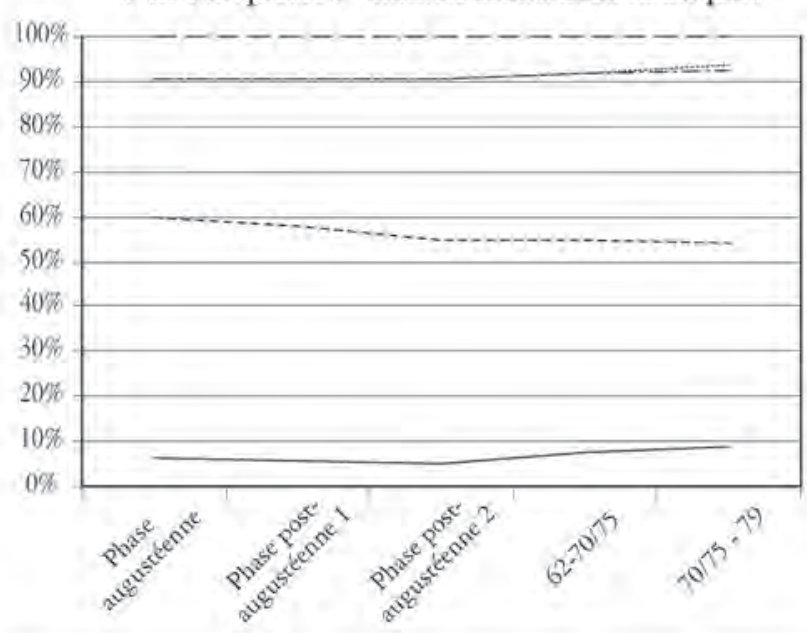

Parcelles privées - nombre maximal de boutiques

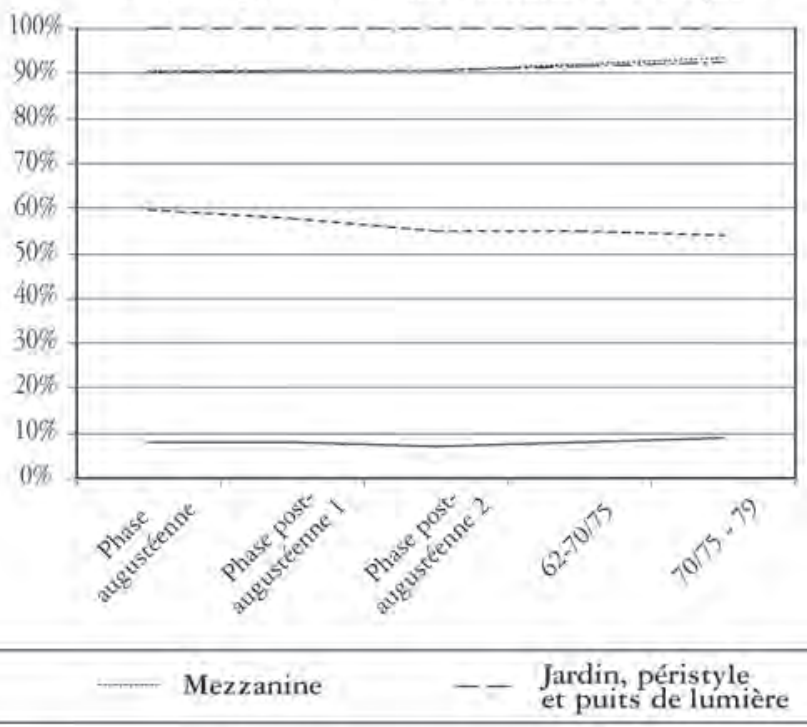

Ensemble des parcelles - nombre minimal de boutiques

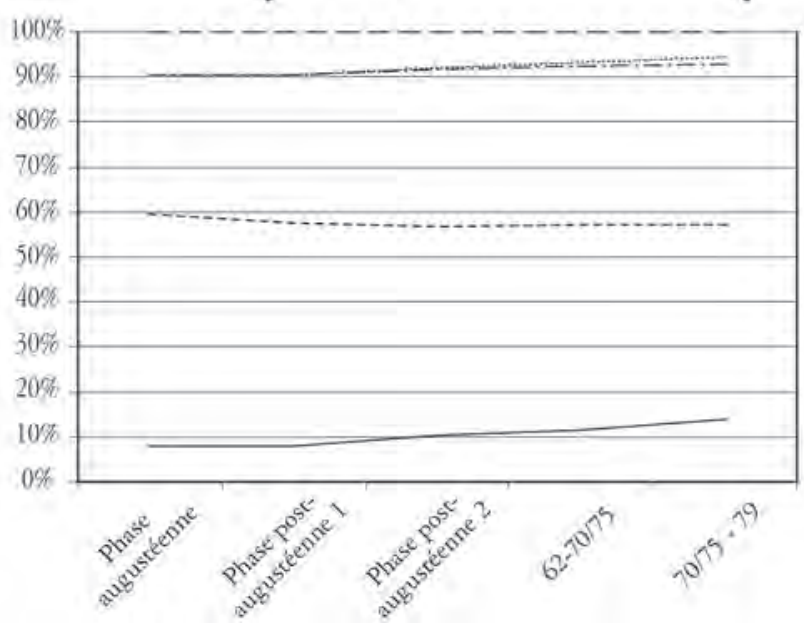

Ensemble des parcelles - nombre maximal de boutiques

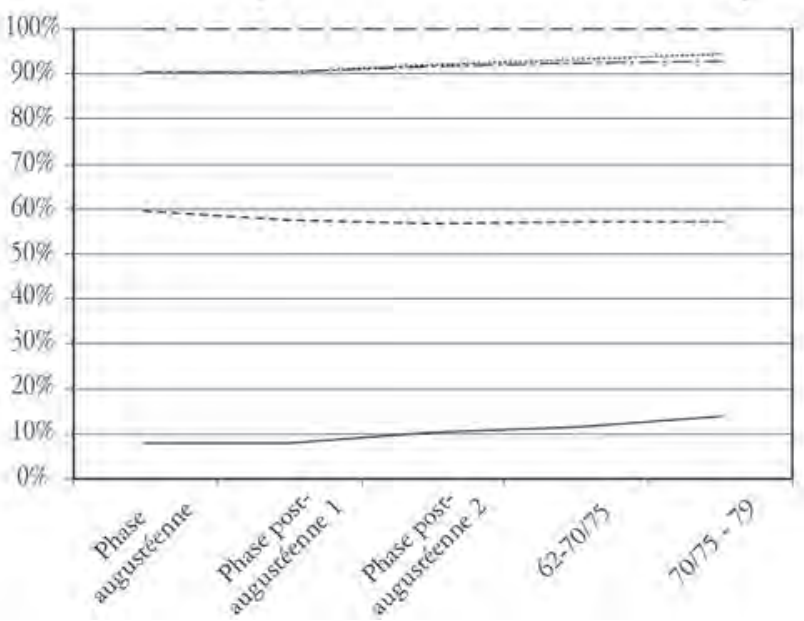

Fig. 196 - Courbes d'évolution de l'occupation du sol dans l'ensemble des édifices étudiés, pourcentages cumulés.

également: une fois effectuées les réparations consécutives au séisme de 62 , les boutiques sont créées en plus grand nombre dans les parcelles privées que dans les espaces publics. Quel que soit le point de vue que l'on adopte, la participation des élites au développement commercial de la ville est patente, par le biais de constructions réalisées soit sur les parcelles qui lui appartiennent, soit dans les espaces publics ${ }^{26}$.

${ }^{26}$ Un même phénomène a été observé par F. Pirson (1999: 146-147) à Pompéi: il y aurait ainsi un parallèle entre le développement des boutiques en façade des édifices
La compréhension des formes d'investissements urbains passe par une analyse plus détaillée. J'ai déjà souligné la part importante de la création des étages dans le processus d'accroissement de l'espace habitable, qu'ils soient ou non liés à des boutiques. Il convient cependant de discerner si ces étages constituent des gains de surface au sein d'une maison ou s'ils constituent la création de nouvelles unités d'habita-

publics et celui qui peut être observé dans les domus; dans les deux cas, les élites pourraient y installer leurs propres conductores. 


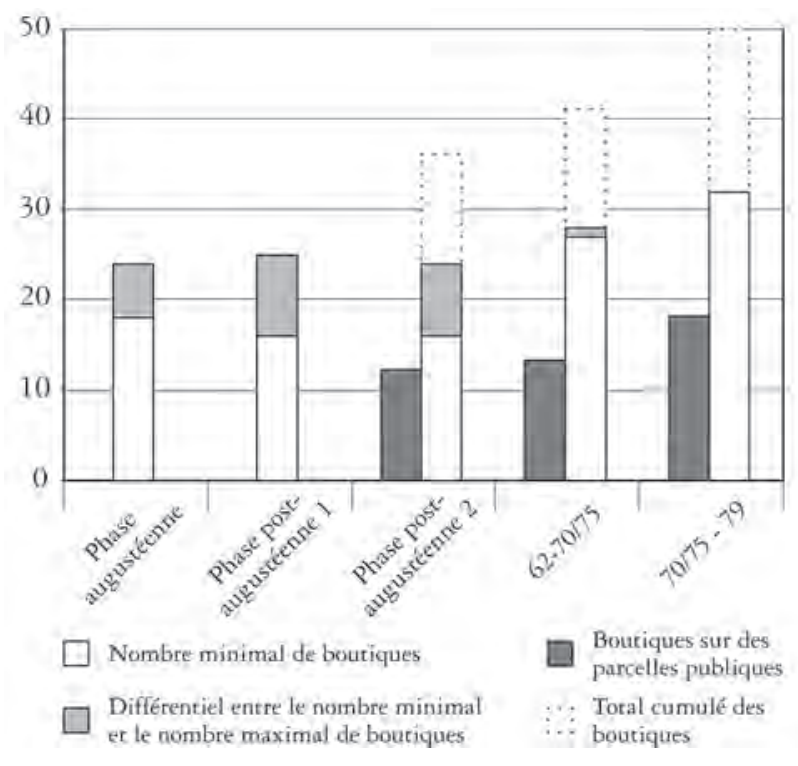

Fig. 197 - Évolution du nombre de boutiques, par phase

tion. L'étude comparée de l'évolution du nombre de parcelles et de celui des unités indépendantes d'habitation permet de mettre en évidence une fragmentation progressive des parcelles telles que définies plus haut (fig. 199, parcelles privées). En effet, tandis que leur nombre reste relative- ment stable durant toute la période étudiée - un léger accroissement est dû à la séparation entre la Casa del gran portale et la Casa con giardino d'une part et au démembrement tardif de la Casa del bicentenario d'autre part - le nombre d'unités habitables ne cesse de croître, passant de 23 durant la période augustéenne à 61 lors de l'éruption. Une telle évolution montre une forte fragmentation de l'habitat et un développement important des appartements. Cette division progressive ne cesse de s'accélérer tout au long de la période impériale. Elle apparaît d'autant plus importante à partir de la deuxième phase post-augustéenne avec l'achèvement de l'Insula Orientalis II ${ }^{a}$ (fig. 199, ensemble des parcelles).Le premier séisme ne semble pas altérer le rythme de ce développement. En revanche, l'accélération de ce processus est impressionnante après le second. Si A. Maiuri avait signalé ce développement rapide des appartements, il le considérait comme un phénomène tardif, n'apparaissant pas avant la seconde moitié du $\mathrm{I}^{\mathrm{er}}$ siècle de notre ère ${ }^{27}$. Cependant, cette évolution est déjà largement en cours dès la période augustéenne, comme l'indique le seul exemple de la Casa del tramezzo di legno (III, 4-12) qui présente alors trois unités indépendantes en plus du cœur de
Parcelles privées

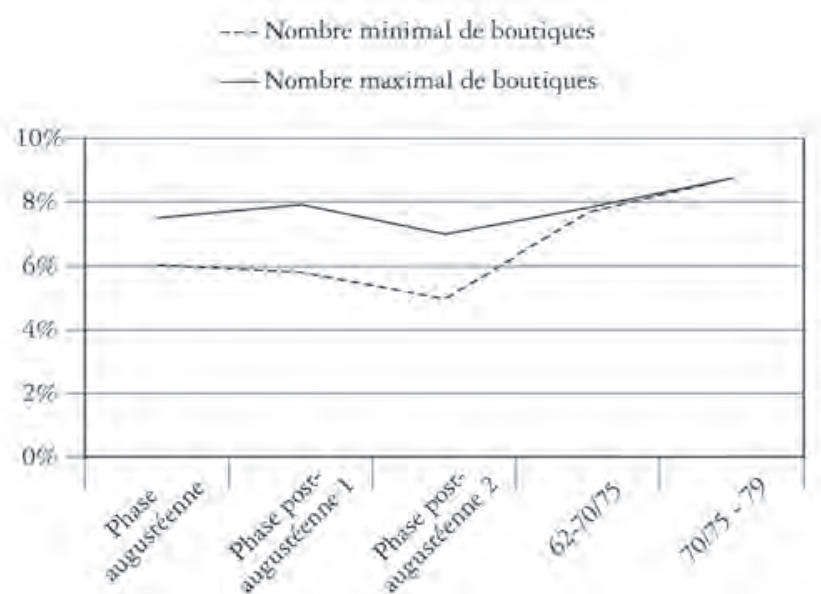

Ensemble des parcelles

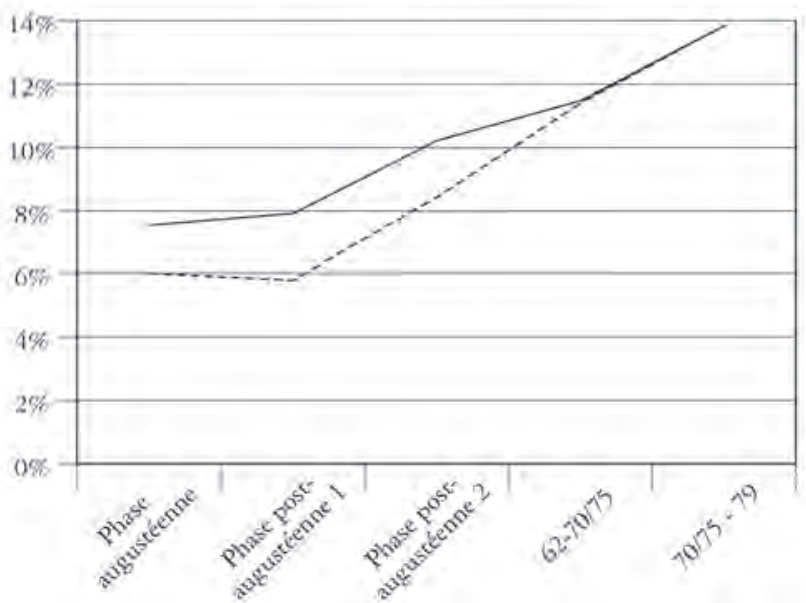

Fig. 198 - Courbes d'évolution de la part des commerces dans l'occupation du sol.

${ }^{27}$ La formulation la plus explicite de cette vision de l'évolution urbaine a été rédigée à propos de la Casa del bicentenario (Maiuri 1950 a: 253, cit. supra, p. 289 en exergue). Pour d'autres références, cf. supra, p. 4-8. 

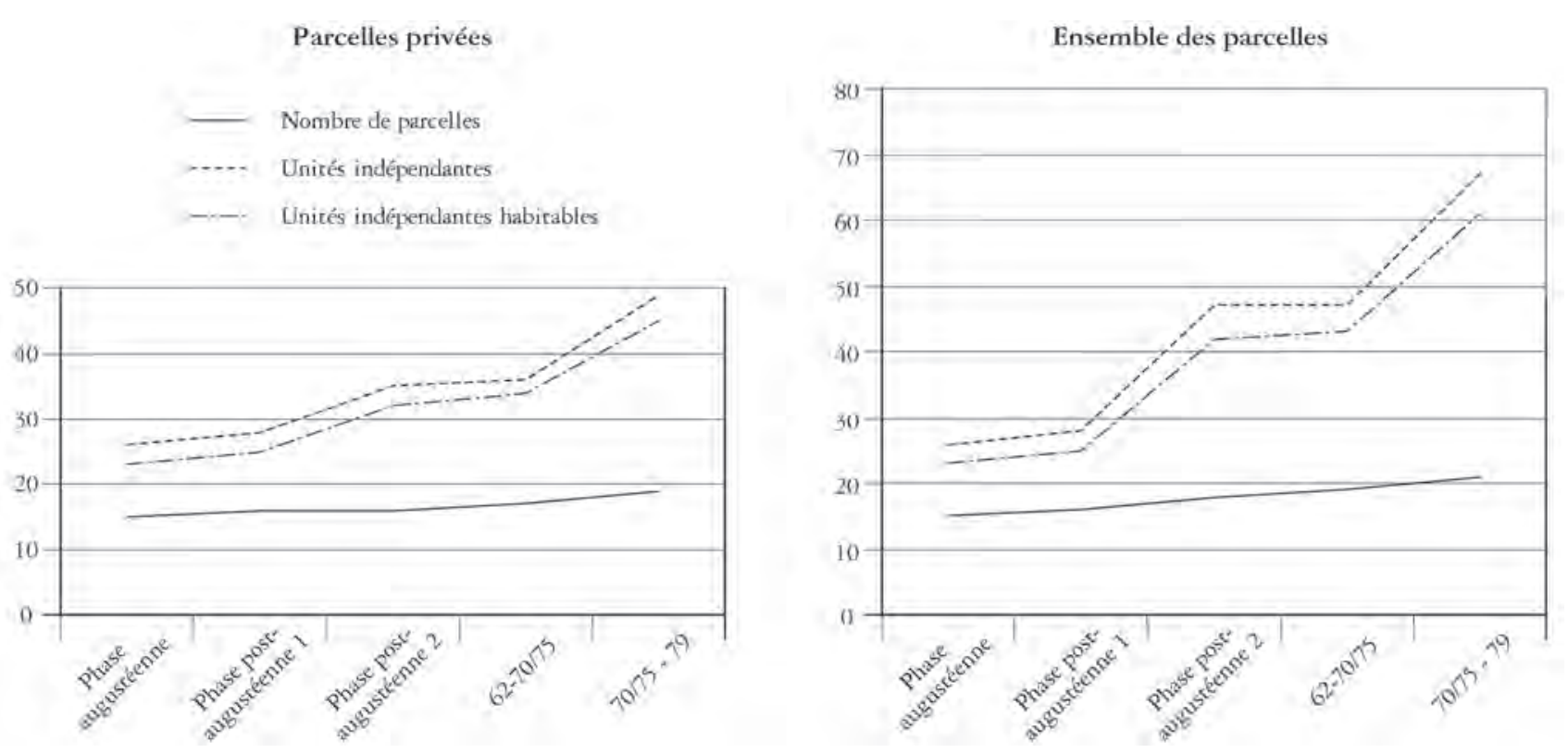

Fig. 199 - Courbes d'évolution du nombre de parcelles et d'unités indépendantes.

la $d o m u s^{28}$. Quant à proposer une interprétation sur cette évolution, l'idée d'un accroissement général de la population paraît fournir une explication plausible. Il serait toutefois nécessaire, en analysant la chronologie de mise en place des vastes demeures sur le front de mer, de voir si la construction de ces dernières n'aurait pas également contribué à ce phénomène en obligeant à une concentration de la population dans les quartiers centraux.

La concomitance entre le processus de fragmentation des formes d'habitat et la multiplication des espaces commerciaux incite à s'interroger sur la nature économique de ces deux phénomènes pour tenter de caractériser les transformations des investissements urbains. Pour ce faire, j'ai comparé l'évolution des surfaces en location avec celle des surfaces de rapport en général. Les surfaces de location comprennent les boutiques et les appartements loués. Les surfaces de rapport regroupent les précédentes, ainsi que les boutiques tenues en gestion directe par l'occupant d'une domus ${ }^{29}$. Ces boutiques, qui communiquent avec la maison en façade

${ }^{28}$ Cf. supra, p. 292-296. A. Maiuri (1958 b: 207) ne présente pas la situation de façon très claire: soit cette fragmentation de la domus est liée au dernier propriétaire, issu de laquelle elles sont implantées, ne sont pas indépendantes et ne peuvent donc être louées. Le rapport entre ces deux surfaces constitue une image de la gestion directe des espaces commerciaux (fig. 200 et 201). Les premières phases, entre la période augustéenne et le séisme de 62, sont d'interprétation délicate. En effet, les variations du nombre de boutiques liées à des domus, dues aux incertitudes concernant leur période de création, renvoient deux images radicalement opposées. Si l'on considère le nombre maximal de boutiques, on observe un lent développement de la mise en location, qui s'accélère après le séisme de 62: les occupants des maisons se dégageraient de plus en plus de la gestion directe des commerces. En revanche, si l'on considère le nombre minimal de boutiques, une lente érosion de la location serait perceptible, brutalement accélérée par le séisme de 62, à partir duquel la location se développe de nouveau. Bien que j'aurais tendance à considérer la première interprétation comme plus plausible, notamment par rapport aux autres évolutions évoquées jusqu'à présent, il est inutile, sans apport de nouvelles

du «ceto mercantile di arricchiti», soit elle survient seulement après la période augustéenne.

${ }^{29}$ Sur la gestion directe, cf. infra, p. 364 et suivantes. 
données, de chercher à trancher entre ces deux visions opposées. Conservons simplement l'idée que d'un séisme à l'autre, la gestion directe des boutiques tend à avoir une fréquence de plus en plus réduite. Je reviendrai plus loin sur cette question, en étudiant en profondeur les comportements perceptibles dans certaines maisons après les deux catastrophes.

Les grandes lignes d'évolution dégagées pour la vie économique d'Herculanum durant la période impériale sont les suivantes. Dès la période augustéenne, les maisons montrent l'amorce d'une transformation. Elles tendent à se structurer pour accroître la diversification des catégories d'habitants, par la création d'appartements indépendants et de boutiques également pourvues de logements. Cette utilisation des façades et des étages des domus comme investissement urbain par la location ne cesse de croître tout au long du ${ }^{\text {er }}$ siècle. Ce mouvement est accompagné et soutenu par les constructions publiques qui développent les mêmes formes d'unités d'habitation en façade d'édifices probablement gérés par le municipe. Ni le

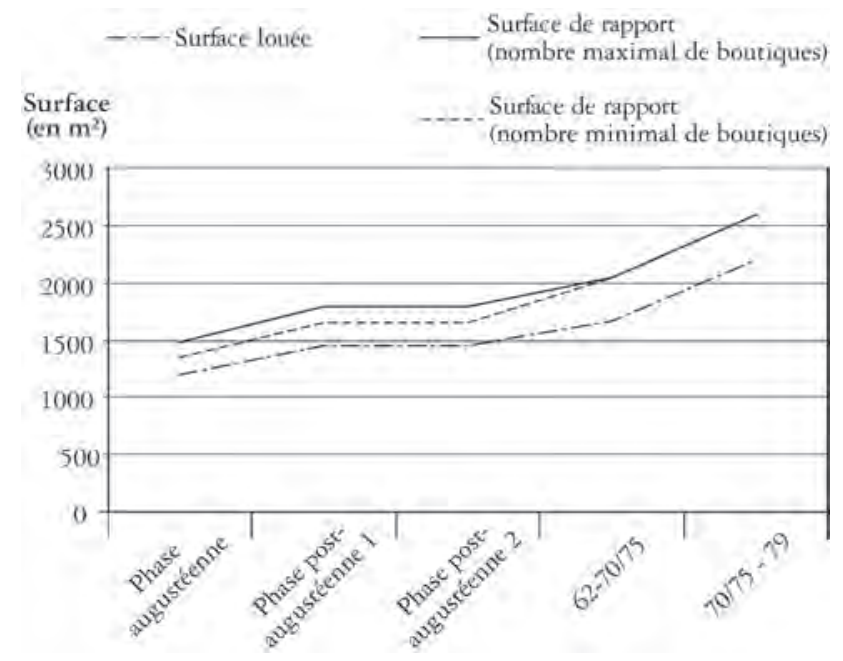

Fig. 200 - Évolution des surfaces de rapport et des surfaces en location.

${ }^{30}$ Dans son article consacré aux effets du séisme de 62 sur les conditions économiques de Pompéi, J. Andreau (1973: 374-376) souligne l'importance de la période de transition qui se déroule entre l'immédiat après-séisme et la reprise "normale» des activités. Nous ne disposons d'aucun moyen pour évaluer la durée ou les conséquences immédiates de cette période de transition à Herculanum. séisme de 62, ni sa réplique du début des années 70 ne semblent avoir freiné cette évolution. Au contraire, ils paraissent même avoir eu un rôle d'accélérateur dans ces transformations. Du point de vue de la vie commerciale, en lien avec une probable augmentation de population, le nombre de boutiques et d'ateliers croît régulièrement durant ce long siècle impérial. Là encore, les effets économiques des séismes paraissent nuls, tout du moins ne semblent-ils pas freiner cette croissance régulière. Ils auraient même eu pour effet d'accélérer la mutation du rapport entre les boutiquiers et le local qui est leur premier instrument de travail: entre 62 et 79, la gestion directe des boutiques s'érode de plus en plus, laissant la place à la location. Je ne saurai trop souligner que l'absence de "récession» visible après les deux séismes est due pour partie à la scansion chronologique de cette période troublée: la précision des données archéologiques ne permet que difficilement de saisir des transformations brutales non pérennisées et donc de percevoir les conséquences précises de ces catastrophes ${ }^{30}$. L'autre explication tient

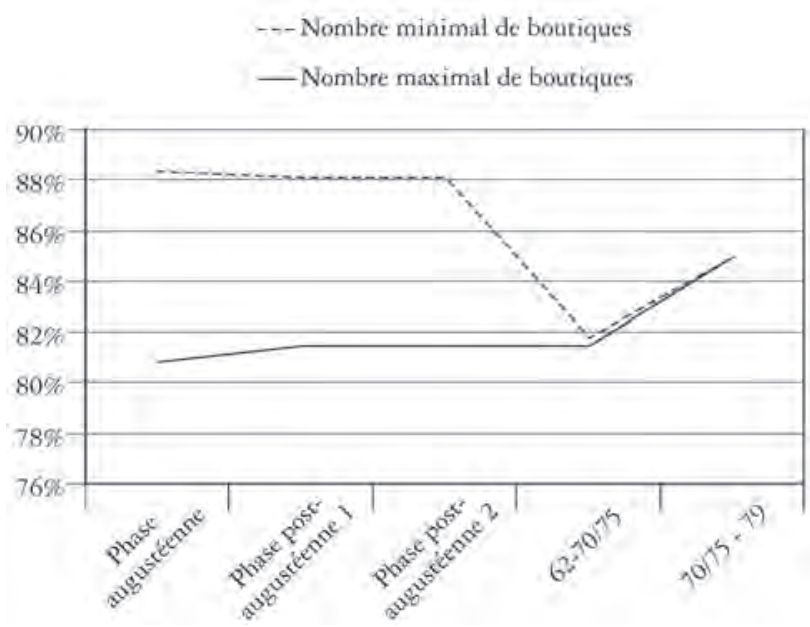

Fig. 201 - Évolution de la gestion directe des activités commerciales (rapport entre les surfaces louées et les surfaces de rapport).

La présence fréquente de deux phases de réparations, chacune éventuellement suivie par une phase de transformation incite à considérer que les dommages du séisme de 62 étaient réparés, peut-être dès le second séisme, de toute façon au moment de l'éruption. Cela reste une hypothèse qui, pour probable qu'elle soit, ne pourra que difficilement être démontrée ou réfutée. 
certainement à la nature même du tissu économique d'Herculanum, essentiellement constitué de boutiques et d'ateliers destinés à la consommation locale et donc d'une nécessité absolue pour la population de la ville.

Ce tableau très synthétique de l'évolution des conditions économiques d'Herculanum, perçues à travers le prisme certainement déformant des seuls espaces commerciaux, cache mal la variété des situations évoquées dans les chapitres précédents. Plusieurs points permettent d'approfondir certains aspects socio-économiques. Pour commencer, l'analyse détaillée des plus grandes domus - la Casa del tramezzo di legno, la Casa del bicentenario, le groupe formé par la Casa sannitica, la Casa con giardino et la Casa del gran portale, la Casa del salone nero et la Casa del colonnato tuscanico - sur toute la période, mais en insistant plus particulièrement sur les conséquences des séismes, offre la possibilité de suivre le comportement économique de membres probables de l'élite herculanéenne ${ }^{31}$. Deux exemples de grandes propriétés montrent un démembrement au cours de leur évolution. Le premier correspondrait au tiers méridional de l'insula V. La limite septentrionale de cette propriété aurait été constituée par le mur méridional de la Casa del mobilio carbonizzato. En effet, lors des fouilles du toit de la Casa del telaio,

${ }^{31}$ Les propriétaires de ces différentes maisons restent inconnus. Des hypothèses variées ont pu être proposées, en fonction des découvertes, notamment de sceaux en bronze ou d'archives. Ainsi, L. Venidius Ennychus a été le propriétaire de la Casa del salone nero pour A. Wallace-Hadrill (1994: 181) et pour G. Camodeca (2002: 265), avec toutefois un raisonnement différent. Ses archives ont été découvertes à l'étage de cette maison, mais rien n'indique, parmi les tablettes qui sont datées, que ce personnage était vivant en 79. Faute de pouvoir déterminer le nom et la place dans la société des occupants - éventuels propriétaires - de ces maisons, j'ai considéré que ces derniers, en raison de la taille de leur domicile, pouvait avoir fait partie de l'élite de la ville. Signalons qu'en employant ce terme, je ne cherche pas à renvoyer en particulier à l'un des groupes constitués de la société romaine. Tout au plus mettrais-je en avant la position probablement importante occupée dans la société d'Herculanum par les habitants de ces domus.

32 GSE 1931: «3 Febbraio. All'estremità nord della tettoia ieri accennata, appoggiato sopra esso, è stato raccolto un pezzo di marmo a forma rettangolare lungo m. 0.33 e largo m. 0.145, con iscrizione sia sulla faccia anteriore e posteriore. La prima iscrizione sopra una delle due è la seguente: [texte de l'inscription, cf. note suivante] une plaque de marbre portant une inscription sur chaque face a été mise au jour ${ }^{32}$. Elle indique un paries perpetuus privatus, soit un mur non mitoyen $^{33}$. En revanche, au sud de cette maison, divers signes traduisent, au moment de l'éruption, des propriétés différentes. Ainsi, le traitement du trottoir entre la Casa del telaio et la Casa sannitica est très nettement différencié selon les limites de ces deux maisons: simple béton de tuileau devant la première, béton rehaussé d'éclats de marbre devant la seconde. Le trottoir au sud de l'îlot est encore plus marqué. Il est réduit à sa plus simple expression - large d'une vingtaine de centimètres, sans aménagement de surface - tout au long de la Casa sannitica; en parfaite correspondance avec les limites de la Casa del gran portale un trottoir large d'un peu plus d'un mètre; sa disparition est complète sur tout le reste de la portion sud de l'îlot, le long de la Casa con giardino ${ }^{34}$. Les liens unissant la Casa del gran portale et la Casa con giardino durant toute la période impériale ont déjà été évoqués ${ }^{35}$. En dépit des incertitudes liées aux phases tardo-républicaines de la Casa sannitica et de son extension vers l'est et vers le nord, ces différents éléments permettent de suggérer l'hypothèse que tout le tiers méridional de l'insula $\mathrm{V}$ a constitué un unique bloc de propriété entre la fin de la République et le séisme de 62, puis a

larga m. 0.31 ed alta m. 0.06. Dalla parte opposta: [idem] Lunga m. 0.30 ed alta m. 0.06 [idem] Lunga m. 0.30 ed alta m. 0.035 ». L'attribution originelle de cette plaque à la paroi de la Casa del mobilio carbonizzato tient au contexte de découverte: à plat, vers l'extrémité méridionale de la toiture de la Casa del telaio, comme transportée par le flux pyroclastique.

${ }^{33} A E$ 1937, 176 = AE 1945, 95: Iuliae pari[es]/privat(us) perpetuus // M(arci) Noni M(arci) l(iberti) Dama[e] / paries perpetuus priv(atus).

Le texte de l'inscription présenté ici a été corrigé après contrôle direct. Le I de la première face pourrait être la haste d'une autre lettre $(\mathrm{M} / \mathrm{N}$ ?), ce qui permettrait de centrer l'ensemble du texte sur une pierre raccourcie dans un deuxième temps. La seconde face est complète, privatus a été abrégé en PRIV.

Sur les conditions de découverte de cette plaque sur le toit de la Casa del telaio, cf. supra n. 154 p. 26. Il est probable qu'elle ait été fixée sur la façade sud de la Casa del mobilio Carbonizzato $(\mathrm{V}, 5)$.

${ }^{34}$ Sur ce trottoir, cf. Maiuri 1958 b: 36; sur les trottoirs comme possibles marqueurs de propriété, cf. supra, n. 13.

${ }^{35}$ Cf. supra, p. 315-320. 
été progressivement morcelé. Cette hypothèse permettrait de restituer le scénario suivant. Au début de la période augustéenne, la propriété est divisée en trois ensembles indépendants mais appartenant à un unique propriétaire, occupant possible de la Casa sannitica: au sud-ouest, la Casa sannitica limitée dans son extension en simple maison à atrium; à l'est, un ensemble formé par une vaste demeure dont la majeure partie est occupée par un jardin bordé d'un péristyle; au nord-ouest, la Casa del telaio, qui présente une ou deux boutiques en façade. Au cours de la phase suivante, pour développer ses revenus locatifs, le propriétaire procède à un léger remaniement dans le plan d'occupation du sol: il agrège une partie du corps de la Casa del telaio à la Casa sannitica pour louer un appartement situé à l'étage de cette dernière ${ }^{36}$. Après le séisme de 62 , les trois maisons sont réparées à l'identique. Cette restauration semble confirmée par la présence de colonnes en briques prises dans la maçonnerie des fauces de la Casa del gran portale, alors même que les bases - laissées en place - et les chapiteaux des colonnes originelles étaient en tuf. Ce n'est que dans un second temps qu'une première mutation de propriété s'opère: la Casa sannitica est vendue ou du moins son propriétaire n'est plus le même que pour les autres maisons. Les chapiteaux du péristyle sont remployés pour constituer l'ébauche de trottoir devant la Casa sannitica. Une réfection du trottoir du cardo IV pourrait survenir, signe de la nouvelle indépendance de la Casa sannitica. Pour les trois autres maisons - Casa del telaio, Casa del gran portale et Casa con giardino-, seules les relations entre les deux premières peuvent encore être suivies. En effet, lors de la phase suivante, après le second séisme, une fois les réparations effectuées, le propriétaire de la Casa del gran portale récupère une pièce sur la Casa del telaio. Une telle substitution d'espace pourrait être interprétée comme un signe que ces deux maisons ont alors eu le même propriétaire. Il est en revanche plus délicat de se prononcer

\footnotetext{
${ }^{36}$ L'alignement du mur sud de la pièce $\mathrm{K}$ de la Casa del telaio, parallèle avec les limites septentrionales de cette maison mais divergent par rapport au mur nord de la Casa sannitica constitue un argument rendant plausible cette restitution.
}

sur les relations de la Casa con giardino avec les deux autres maisons. De nombreux éléments dans cette reconstitution sont très hypothétiques. Toutefois, des arguments épars la rendent plausible. En ce cas, le séisme n'aurait pas eu de conséquences immédiates - au-delà des destructions matérielles - sur la structure de la propriété dans cette partie de l'îlot. Le démembrement, peut-être effectué en deux temps, pourrait ainsi être dégagé du lien de cause à effet par rapport à la catastrophe. Au-delà de cette question qui ne saurait trouver de réponse, cette restitution montre surtout que l'augmentation du nombre de parcelles dans ce tiers de l'insula V serait liée à un changement de propriété.

Une situation proche peut être restituée pour la Casa del bicentenario et certaines maisons environnantes. Les trottoirs y jouent un rôle moins important, mais toutefois non nul. L'élément le plus pertinent est ici constitué par la mise en place de murs doublés à divers moment de l'évolution de cette maison. De tels murs se retrouvent de façon certaine au milieu et au nord de la Casa del bel cortile, telle qu'on la perçoit actuellement. De plus, dans la Casa del bicentenario, on note la présence de ces aménagements atypiques au nord de la pièce 3 , à l'est de la pièce 6 , au sud de la pièce 20 et à l'ouest de la pièce 21 - ces deux dernières localisations correspondant, au moment de l'éruption, à l'intérieur de l'appartement V, 17 (fig. 30). Les explications strictement architecturales ne permettent pas de trouver une réponse univoque à de tels doublements pour l'ensemble de ces cas: la nécessité de renforcer une paroi lors de l'ajout d'un étage expliquerait le doublement médian de la Casa del bel cortile, mais pas ceux de l'appartement V, 17. Dans ce dernier cas, une explication juridique permet une restitution plus compréhensible. Les murs mitoyens constituent la forme la plus simple pour séparer deux bâtiments possédés par deux propriétaires distincts ${ }^{37}$. La plaque opisthographe trouvée sur le toit de la Casa del telaio atteste de l'existence

\footnotetext{
${ }^{37}$ Sur la mitoyenneté facultative dans le droit de la construction romaine, cf. Saliou 1994: 37-71.
} 
d'un mur mitoyen: les propriétaires des édifices sont deux, mais un seul possède le mur - dans ce cas, successivement une éventuelle Julia puis l'affranchi M. Nonius Damas. Lors de l'extension verticale de l'une des deux maisons, l'insertion de poutres dans un tel mur est possible grâce à une servitude d'appui ou de support ${ }^{38}$. Une alternative peut être de construire un mur en copropriété, paries communis ${ }^{39}$. La troisième solution consiste à éviter d'avoir à insérer des solives dans le mur du voisin et donc, soit à doubler celui-ci, soit à positionner les supports de plancher de façon à ne pas avoir à les faire porter par la paroi du voisin ${ }^{40}$. Un mur doublé serait alors parfois le signe tangible d'une absence de mitoyenneté ou de copropriété, et permettrait donc d'individualiser deux biens-fonds distincts. Une telle situation est partiellement perceptible dans les appartements V, 17-18 (fig. 30). En effet, dans la première pièce, le mur occidental est doublé, le long de la boutique V, 16 de la Casa del bicentenario. Cette paroi supporte les poutres de la mezzanine accessible depuis l'entrée V, 18. Les solives du premier étage sont orientées nord-sud et sont donc portées par le mur de refend et par la façade ${ }^{41}$. En revanche, les solives de l'étage surplombant la seconde pièce (20) sont dans le sens est-ouest, donc portées par le mur de la Casa del bicentenario, alors même que le mur sud a été doublée ${ }^{42}$. Une telle situation pourrait constituer un argument contre toute interpré-

38 La servitude d'appui (servitus tigni immittendi) permet à celui qui n'est pas propriétaire du mur d'y insérer des solives (Saliou 1994: 39). La servitude de support (servitus oneris ferendi) est une extension de la précédente, le propriétaire du mur étant obligé de maintenir ce dernier en état pour qu'il puisse supporter les éléments insérés (Saliou 1994: 42-45). Si l'existence de telles servitudes peut être inférée sur des fondements archéologiques, il serait vain de tenter de les distinguer. Je ne mentionnerai donc que la servitude d'appui.

${ }^{39}$ Sur le mur en copropriété, cf. Saliou 1994: 51-71.

${ }^{40}$ Une telle possibilité est envisagée par J. Boersma (1985: 235-236) pour les rapports entre d'une part les bâtiments 1 et 14 de l'îlot V, II d'Ostie, et d'autre part le bâtiment 2. Il signale toutefois seulement l'absence de servitude d'appui, sans évoquer l'idée d'une propriété séparée. Il en est de même pour un mur entre le jardin R de la Casa del Menandro et la Casa degli amanti (I 10, 10-11), d'épaisseur double $(90 \mathrm{~cm})$. Cette situation serait antérieure à la construction du jardin proprement dit, au I ${ }^{\mathrm{er}} \mathrm{s}$. de notre ère (Ling 1997 a: 103, 249-250). tation supposant une vente des appartements V, 17-18 par le propriétaire de la Casa del bicentenario. Pourtant, elle ne témoigne en fait que de l'histoire de ce bâtiment, telle que l'on peut la restituer. Ainsi, lors de la séparation de ces deux biens-fonds, il aurait été jugé inutile de détruire les maçonneries antérieures pour sanctionner la nouvelle situation juridique: les poutres portant l'étage au-dessus de la pièce 20 sont laissées en place. En revanche, les nouveaux aménagements, comme la mezzanine de la pièce 21 et la paroi méridionale portant la toiture et percée d'une fenêtre ont amené au doublement de certains murs $^{43}$. En dépit de la vente, une servitude d'appui aurait été créée entre la Casa del bicentenario, fonds servant, et les appartements V, 17-18. Une seconde servitude entre ces deux fonds a été mise en évidence par F. Pirson: la servitus altius non tollendi, qui empêche le fonds servant (la Casa del bicentenario) de se développer en hauteur de façon à ne pas réduire l'entrée de la lumière dans le fonds dominant $(\mathrm{V}, 17-18)^{44}$. Une telle servitude expliquerait ainsi non seulement la forme du toit à cet endroit de la maison, mais également l'insertion entre la pièce 5 et le compluvium de la domus d'une canalisation permettant de recueillir les eaux provenant de cette toiture ${ }^{45}$. Ces différents éléments autorisent à considérer que la séparation entre la Casa del bicentenario et l'appartement V, 17-18 a été assortie d'une vente de ce dernier.

41 Cette disposition permet notamment de pouvoir étendre l'étage au-dessus du trottoir, en réduisant les risques de porte-à-faux.

${ }^{42}$ L'absence de doublement du mur occidental de la pièce 20 est très nettement perceptible sur le seul plan récent et fiable de cette maison, réalisé en 2003 sous la responsabilité de l'architecte V. Papaccio. Sur les deux plans publiés par A. Maiuri (1958 b: fig. 174 p. 222 et pl. IIIa), aucun des murs n'apparaît doublé.

${ }^{43}$ Cette restitution incite à considérer que l'étage de la Casa del bicentenario, avant la vente de V, 17-18, s'étendait au-dessus de toute l'aile orientale de l'atrium. Un coup de sabre vertical dans la maçonnerie supérieure de la pièce 5 semble autoriser.

${ }^{44}$ Pirson 1999: 71-73. Sur la servitus altius non tollendi et ses évolutions, cf. Saliou 1994: 217-220.

45 Cette canalisation est perceptible grâce au léger tassement du pavement en mosaïque dans l'atrium 19, mais également par sa bouche, visible dans l'angle nord-ouest de la pièce 5 . 
Il est possible que, depuis la création de la Casa del bicentenario durant la phase augustéenne, les deux tiers nord-occidentaux de l'insula V constituent un unique bien-fonds, partagé en plusieurs maisons ${ }^{46}$. L'accaparement de l'aile orientale de la Casa dell'Apollo citaredo lors de cette construction pourrait constituer un argument en ce sens. Le démembrement de la Casa del bicentenario ne serait vraiment visible qu'après le second séisme avec la vente de l'espace $\mathrm{V}, 17-18$, où une partie des murs est doublée, tandis que le trottoir de V, 17 est décoré de façon telle qu'il se distingue nettement de ses voisins ${ }^{47}$.

Dans les trois autres grandes domus, l'évolution a été sensiblement différente, en dépit d'un résultat proche: des maisons fractionnées, comportant plusieurs unités indépendantes au moment de l'éruption. La croissance de ces trois maisons n'a pas suivi le même rythme. Dès la période augustéenne, la Casa del colonnato tuscanico (VI, 16-18.26) a atteint son extension maximale au sol. Il en est de même pour la Casa del tramezzo di legno (III, 4.5.8-9.11): à partir du règne d'Auguste, grâce à l'extension sur la dernière parcelle lui ayant probablement échappé jusqu'alors, cette maison cesse de s'étendre horizontalement. En revanche, d'abord réduite à la forme d'une maison à atrium, la Casa del salone nero ne s'étend en se dotant d'un péris-

\footnotetext{
${ }^{46}$ Les limites de cette propriété correspondraient aux parcelles A et $B$ (fig. 162). La forme de ces parcelles suggère une acquisition durant la période samnite, en deux temps (cf. supra, p. 320-322). L'extension de cette propriété au tiers oriental - à la parcelle $\mathrm{C}$ - peut être envisagée, avec toutefois une restriction qui concerne la boutique et l'appartement V, 28-29, dont le traitement différencié du trottoir suggère fortement un bien-fonds distinct des espaces voisins. Une telle extension a déjà été proposée par A. Wallace-Hadrill (1994: 132) qui est cependant resté prudent: «[...] It is conceivable that the Casa del bicentenario formed part of an insula that extended over (say) the group of shops and flats to its east (H V.17-29) and possibly also over the houses and shops to its west (H V.8-12), with which there are traces of previous interconnecting doors. The problem with housing of the Pompeian type is that it is virtually impossible to demonstrate such legal boundaries. Perhaps the block I have suggested round the Casa del bicentenario was three separate insulae or blocks of ownership. Or perhaps it had once been a single insula but had by A.D. 79 been split into several. Archaeolgy cannot give an answer to questions about legal ownership». Les analyses de F. Pirson (1999:
}

tyle qu'au cours de la seconde phase post-augustéenne. En dépit de ce rythme d'accroissement différent, ces trois domus se présentent sous un aspect similaire au moment du séisme de 62 - une maison à atrium et péristyle - et sont de taille équivalente ${ }^{48}$. Les réactions face au séisme sont différentes: aucune transformation n'est effectuée dans la Casa del tramezzo di legno, à l'exception de la destruction du balcon s'avançant sur le decumanus inférieur, au-dessus de la boutique III, 10; dans la Casa del colonnato tuscanico, les espaces en location sur le cardo III sont remaniés, mais ce sont surtout deux boutiques qui sont créées, pour de la gestion directe en VI, 16 et en VI, 18. Dans la Casa del salone nero, l'origine des revenus devient mixte: l'une des boutiques (VI, 14/15) est divisée en deux locaux distincts, dont l'un (VI, 15) est doté d'un appartement qui se développe au-dessus de la boutique. À la suite du second séisme, seule la Casa del tramezzo di legno maintient sans changement la double nature directe et indirecte de ses revenus. Dans la Casa del colonnato tuscanico, l'appartement de l'aile occidentale, un temps rattaché à la boutique VI, 25, est subdivisé et donné en location, accentuant d'autant la fragmentation de la maison. Quant à la Casa del salone nero, les deux dernières boutiques en gestion directe sont retranchées de la maison, rattachées à des appartements et données en location.

70-74) aboutissent à une conclusion similaire aux miennes, bien qu'effectuées pour la seule phase finale.

${ }^{47}$ Les rapports juridiques, au moment de l'éruption, entre la Casa del bicentenario et ses voisines à l'ouest - Casa dell'Apollo citaredo et Casa del bel cortile - ne se laissent pas entrevoir de façon aussi consistante que pour l'appartement V, 17-18. Dans ces deux cas, l'interprétation du doublement du mur paraît devoir être liée à des problèmes de statique plus qu'à des questions juridiques, incitant de ce fait à la prudence.

${ }^{48}$ Lors de la seconde phase post-augustéenne, la Casa del tramezzo di legno s'étend sur $1076 \mathrm{~m}^{2}$, dont 51\% (544m²) sont loués, auxquels il convient d'ajouter les $95 \mathrm{~m}^{2}$ de boutiques en gestion directe. La Casa del colonnato tuscanico dispose d'une surface de $887 \mathrm{~m}^{2}$, dont $18 \%\left(158 \mathrm{~m}^{2}\right)$ sont loués, entre appartement et boutiques. La Casa del salone nero est sensiblement plus grande, avec $1108 \mathrm{~m}^{2}$ en tout. Une partie de cette différence s'explique certainement par le balcon débordant sur le cardo IV. Dans une vision maximaliste, seuls $3 \%$ de cette surface $\left(29 \mathrm{~m}^{2}\right)$ sont alors dévolus au commerce en gestion directe. 
Abordons la gestion directe: par ce terme, je n'entends pas que l'occupant de la maison se soit trouvé impliqué en personne dans la tenue quotidienne du commerce situé en façade de sa domus, situation d'autant plus improbable quand plusieurs espaces commerciaux existent dans une même maison. Ce terme tend à caractériser une forme d'investissement urbain différente de la mise en location, et qui pourrait correspondre - sans prendre en compte la probable, mais certainement surestimée ${ }^{49}$, différence de perception entre la possession de terres agricoles et celle d'immeubles en ville - à la "stratégie de repli » ou "de sécurité» mise en évidence par P. Veyne ${ }^{50}$. De cette façon, la gestion directe, où l'occupant tient la boutique ou la fait tenir par un membre de sa familia, correspondrait à une stratégie de profit, à la fois plus risquée car dépendant de la bonne tenue de la boutique en propre, mais également susceptible de dégager un rendement plus élevé. Dans certains cas, en particulier pour les commerces alimentaires, la gestion directe peut même être perçue comme le moyen d'écouler la production d'un éventuel domaine agricole ${ }^{51}$. En revanche, la nature des relations entre l'occupant et le tenancier de la boutique est un point sur lequel la documentation archéologique n'offre aucune possibilité d'interprétation. Sauf à proposer des conjectures sans fondement solide, il ne saurait être question de parler d'institor ou de procurator

49 À l'exception d'un article de P. Garnsey (1976), les réflexions sur la propriété urbaine des élites ne semblent pas avoir été particulièrement développées dans l'historiographie récente. Si, comme il a été rappelé lors d'une journée d'études de la Société française d'Epigraphie romaine que l'opposition classiquement revendiquée entre des chevaliers impliqués dans le commerce et des sénateurs propriétaires fonciers ne pouvait guère être tenue (voir les articles réunis dans les Cahiers du Centre G. Glotz, 16, 2005), la variété des investissements effectués par ces deux groupes reste encore à étudier. Quant aux élites municipales, la difficulté de rassembler des sources permettant une évaluation de leur patrimoine semble avoir rendu vaine toute tentative en ce sens. Sur ces différents aspects, voir les remarques de J. Andreau (2004 a).

${ }^{50}$ Cf. Veyne 1991. Dans cet article, publié une première fois en 1979, P. Veyne étudie les différentes stratégies d'investissement déployées durant la période romaine. Il distingue ainsi l'exploitation agricole destinée à produire des moyens de subsistance et conduisant son propriétaire vers un comportement "autarcique»; des entreprises de en ce qui concerne la gestion quotidienne de ces locaux: l'absence de toute attestation épigraphique empêche le recours à des termes aussi précis $^{52}$, même si quelques hypothèses peuvent être avancées dans certains cas. À partir de cette interprétation sur les stratégies des possédants, revenons sur les réactions perceptibles dans les trois domus qui n'ont pas été suffisamment touchées pour entraîner leur démembrement. En dépit de dégâts importants au cœur de la maison, l'occupant de la Casa del tramezzo di legno a maintenu un comportement alliant la sécurité de la location avec le profit plus risqué, mais à toute petite échelle, du commerce de proximité en gestion directe. Possible signe d'un changement de propriétaire, celui de la Casa del colonnato tuscanico profite du séisme de 62 pour se lancer dans de telles opérations supposées plus rentables. En revanche, tout en cherchant à augmenter la rentabilité de sa propriété urbaine, en accroissant le nombre d'unités indépendantes, le propriétaire de la Casa del salone nero a opté pour le repli, se dégageant complètement de toute gestion directe. La mise en place de cette option en deux temps, scandés par des secousses sismiques, pourrait finalement s'avérer être la marque la plus directe des deux catastrophes, si l'on excepte la nécessité du démembrement par la vente.

Ces groupes de domus participent au même mouvement de fond qui tend à la multiplication

profit effectuées sur ses propres terres, plus risquées; enfin des entreprises de profit effectuées sans avoir la propriété des moyens de production. J. Andreau (2004 a: 73-76) a contesté cette position, considérant que le principe d'affrontement entre deux stratégies globales ne saurait être soutenu. Il a ainsi dégagé au moins cinq catégories des sources de revenus. Mon recours à la grille d'interprétation proposée par P. Veyne tendrait justement à montrer le glissement progressif dans certains exemples vers une attitude plus souple ou plus sécurisante dans les investissements urbains.

51 À Herculanum, l'analyse des différentes collections d'archives laisse supposer un patrimoine agricole peu développé, ou du moins non orienté vers la production extensive, en raison notamment des conditions topographiques du site. Sur les attestations de propriétés agricoles à Herculanum, perçues à travers les tabulae ceratae, cf. Lepore 1989: 255-262 et Camodeca 2000:69-70.

${ }^{52}$ Sur les institores en général, et comme tenanciers de boutiques en particulier, cf. Aubert 1994 et Andreau 2004 b. 
des unités indépendantes par la fragmentation des grandes maisons. Toutefois, leur évolution est très contrastée, particulièrement dans les réponses trouvées à la suite des séismes. Les deux grandes propriétés constituées autour de la Casa del bicentenario et de la Casa sannitica - probables vestiges d'une concentration des parcelles remontant à la période samnite - ne résistent pas à la catastrophe: elles sont probablement matériellement démembrées par la vente de leurs éléments constitutifs au gré des séismes. D'un autre côté, la Casa del colonnato tuscanico et la Casa del tramezzo di legno ont une évolution similaire, au-delà de leurs légères variations quant aux dates de création et d'agrandissement ${ }^{53}$ : elles montrent une fragmentation progressive, mais sans démembrement. Elles développent et conservent ainsi, des espaces de rapport en location - appartements et boutiques indépendantes dans leur façade. Seule la part de la gestion directe varie sensiblement entre les deux: dans la Casa del tramezzo di legno, les revenus mixtes sont permanents tout au long de la période impériale par le maintien des boutiques III, 4, III, 6 et III, 8-9 en communication directe avec la domus. En revanche, la gestion directe est une alternative supplémentaire qui ne se développe qu'après le séisme de 62 dans la Casa del colonnato tuscanico. Entre ces deux formes d'évolution se trouve la Casa del salone nero, qui abandonne progressivement la gestion directe d'un séisme à l'autre, son propriétaire ou son occupant préférant la stratégie de la sécurité offerte par le développement des espaces locatifs.

Cette réduction de la gestion directe, voire son abandon pur et simple dans une partie des grandes domus, n'est pas uniforme à l'échelle de la ville. $\mathrm{Si}$, tendanciellement, cette pratique diminue, certaines domus en conservent le principe. Deux cas sont particulièrement intéressants à observer de ce point de vue. Le premier est constitué par la Casa dell'Apollo citaredo, en dépit du léger problème qu'elle pose, en raison

${ }^{53}$ La Casa del tramezzo di legno est de création plus ancienne et d'extension plus progressive que la Casa del colonnato tuscanico, qui s'accroît fortement au moment de la période augustéenne.

${ }^{54}$ Aucune explication ne saurait être fournie pour la construction de ce local après le séisme de 62 . Il peut tout de l'incertitude sur la période d'ouverture de la boutique V, 12. Elle constitue un cas rare à Herculanum de domus à atrium qui, en dépit des vicissitudes des séismes, a toujours conservé au moins une boutique en gestion directe dans sa façade, et ce depuis la période augustéenne. Elle n'a jamais été fragmentée ou démembrée, si ce n'est l'amputation de son aile orientale lors de la construction de la Casa del bicentenario. La surface consacrée dans cette maison aux activités commerciales est sensiblement constante, seulement modifiée après la seconde phase post-augustéenne par une plus grande certitude quant à l'existence de la boutique $\mathrm{V}, 12$. La part de cette surface de rapport oscille entre 13 et $22 \%$, en raison des augmentations de l'espace habitable, qui passe de 175 à $264 \mathrm{~m}^{2}$, par la création d'un étage à la suite du séisme de 62. Un second exemple est constitué par la Casa di Nettuno e Anfitrite. Dépourvue de boutiques jusqu'à la catastrophe, elle ouvre un espace commercial $(\mathrm{V}, 6)$ dans sa façade à la suite de la première secousse. Ce dernier reste ensuite ouvert et en gestion directe jusqu'à l'éruption de $79^{54}$. De ce fait, la part de sa surface consacrée au rapport reste stable à $7 \%\left(21 \mathrm{~m}^{2}\right.$ en incluant la mezzanine située dans la boutique). Ces deux exemples présentent des similitudes par le maintien de leur implication dans le commerce en gestion directe et surtout par l'absence de fragmentation des deux maisons.

La situation de la Grande taberna con abitazione (IV, 12-13.15-16) est sensiblement différente, puisque cette maison montre un rapport au commerce beaucoup plus heurté. Il est difficile de déterminer avec certitude si la boutique située dans la pièce 13 de cette maison a été ouverte dès la période augustéenne ou s'il faut prudemment attendre le séisme de 62 pour voir ce local en place. Faute d'assurances, concentrons-nous sur la période allant du premier tremblement de terre à l'éruption de 79. Une fois effectuées les réparations liées à la secousse, des

autant s'agir d'un changement de propriétaire ou d'occupant, comme d'une volonté de la part de ce dernier de profiter de sa situation en face de la sortie des thermes. 
transformations importantes sont réalisées dans cette maison: une porte s'ouvrant sur le decumanus inférieur est fermée, remplacée par une boutique qui s'installe dans la pièce $6 / 7$, tandis que de façon évidente à ce moment, une seconde boutique existe dans la pièce 13 , s'ouvrant sur les deux rues à l'angle desquelles elle se trouve. Ces deux commerces sont en gestion directe. Après le second séisme, la première boutique est fermée, remplacée par la «taberna vasaria " (IV, 14), unité indépendante dotée d'un appartement à l'étage qui s'étend partiellement sur la rue. De son côté, la boutique IV, 15-16 est agrandie et pourvue de quatre pièces annexes (6 à 9) après la partition de deux espaces plus grands. En valeur absolue, le nombre de boutiques dans cette parcelle reste stable, mais un choix alternatif a été effectué, semblable à celui observé dans la Casa del salone nero entre 62 et 70/75: des deux locaux en gestion directe, l'occupant ou le propriétaire de cette maison en conserve un seul, le second étant probablement donné en location ${ }^{55}$. Entre l'extension de l'étage et la multiplication des pièces annexes de la boutique IV, 15-16, 40\% (167 $\left.\mathrm{m}^{2}\right)$ de cette maison est consacrée au rapport, contre seulement $21 \%\left(62 \mathrm{~m}^{2}\right)$ lors de la phase précédente avec les deux boutiques en gestion directe. La Casa della fullonica ne peut pas être insérée dans un discours dont les bornes chronologiques s'étendraient en-deçà du premier séisme: la période de mise en place des vasques de foulerie ne peut pas être définie avec précision. Tout au plus la transformation de la pièce 1 , survenue après le second séisme, laisse-t-elle supposer que cet artisanat est d'installation tardive. De ce fait, il est probable que la boutique IV, 7 ait eu une autre fonction avant cette seconde catastrophe. Avec ces deux hypothèses, l'évolution de cette maison se rapprocherait de celle dressée pour la Grande taberna con abitazione: alors

\footnotetext{
${ }^{55}$ Telle que cette maison est conservée, aucun élément permettant de déterminer son statut juridique - en propriété plein ou louée - ne peut être mis en évidence. Tout au plus est-il possible de signaler une probable servitude de lumière avec la Casa del papiro dipinto, dont la pièce 6 est illuminée par une fenêtre percée au-dessus de la pièce 4 (fig. 156, d). En ce qui concerne la boutique située en IV, 14, la parfaite verticalité de son implantation ne permet pas de définir avec
}

qu'un appartement (IV, 5) est en location au moins depuis la période augustéenne, si ce n'est depuis la phase précédente, une boutique en gestion directe existerait en 62. Après le second séisme, la surface employée pour dégager des revenus augmente de 43 à $82 \mathrm{~m}^{2}$, de telle façon qu'au moment de l'éruption, $37 \%$ de la surface de cette maison sont consacrés au rapport.

Quelle interprétation proposer pour ces domus plus petites? Le rapprochement de leurs situations et de leurs évolutions est délicat entre d'un côté celles - la Casa dell'Apollo citaredo et la Casa di Nettuno e Anfitrite - qui ne disposent que de boutique(s) en gestion directe, et de l'autre côté, la Grande taberna con abitazione et la Casa della fullonica, qui, par le mélange des formes d'investissement que l'on y rencontre, peuvent être comparées aux plus grandes domus, alors même que la part de ces édifices consacrée aux surfaces commerciales leur donne un aspect particulier. Si l'on ajoute à ce tableau la Casa del gran portale (dotée d'une boutique, d'abord en gestion directe puis en location) et la Casa con giardino (où la location s'étend à une boutique à laquelle s'ajoute dans un second temps un appartement), la variété des situations devient inextricable. Le principal point commun entre ces différentes maisons est une taille somme toute modeste - de 113 à $412 \mathrm{~m}^{2}$ - en comparaison des domus dotées d'un péristyle dont la surface totale s'échelonne entre 882 et $1108 \mathrm{~m}^{2}$. Un second point pourrait être constitué par la proportion de cette surface relativement réduite utilisée pour dégager des revenus, mais cette part varie de 10 à $40 \%$ de la surface totale ${ }^{56}$. Faute de pouvoir connaître le statut juridique de ces maisons, et encore plus d'avoir une idée du patrimoine de leur occupant, toute interprétation reste très conjecturelle. Néanmoins, les occupants de ces domus pouvaient correspondre à une partie de la plèbe moyenne telle que définie par P. Veyne ${ }^{57}$. Dans certitude qu'elle était louée. Elle aurait pu être vendue, mais aucun argument ne permet de trancher en faveur d'une telle évolution.

${ }^{56}$ Signalons toutefois que dans les "grandes » domus, seule la Casa del tramezzo di legno emploie 58\% de sa surface pour dégager des revenus. Les autres oscillent entre 13 et $23 \%$ de leur surface consacrée au rapport.

${ }^{57}$ Veyne 2005. 
cet échantillon de situations si différentes, peuton considérer l'occupant - le propriétaire? - de la Grande taberna con abitazione comme le plus emblématique de cette plèbe dont la caractéristique principale est «de posséder un patrimoine, [...] gage de revenus assurés " ${ }^{58}$ ? Certainement, à titre d'hypothèse. La possession ou la location d'une maison en ville, avec laquelle on cherche à dégager des revenus selon un spectre de stratégies variées - de la location prudente à la gestion directe plus spéculative - avec des degrés d'implication plus ou moins importants, pourrait ainsi être le signe de ce mélange si délicat à établir entre patrimoine foncier et investissements urbains. Peut-être l'exemple d'Herculanum est-il toutefois trop restreint pour permettre une véritable compréhension de cette couche de la société, dont seule l'étude sur une plus vaste échelle - ne serait-ce qu'à Pompéi - permettrait certainement de distinguer les caractéristiques générales au-delà des destins individuels de maisons éparpillées.

Achevons cette réflexion sur les boutiques et leurs tenanciers en examinant la majorité d'entre eux: le principal effet de la fragmentation de la propriété est la multiplication des unités indépendantes et parmi celles-ci des boutiques certainement dotées d'un appartement ou d'une pièce à vivre. Il est inutile de revenir sur la difficulté de définir les critères d'habitabilité des boutiques sauf pour souligner l'importance du travail restant à effectuer de ce point de vue, si tant est que l'état de conservation de ces espaces permette de fournir des données autres qu'éparses et très lacunaires. Sur les différentes boutiques étudiées dans cette seconde partie, 26 - sur un total de 50 - sont, au moment de l'éruption, très certainement dotées d'un appartement qui permet au boutiquier et à sa famille de vivre. La croissance de ces formes de commerce a été particulièrement importante entre la période augustéenne, où l'on en recense seulement 5, et l'éruption du Vésuve. C'est une fois de plus

\footnotetext{
${ }^{58}$ Veyne 2005: 127.

${ }^{59}$ Quelques exceptions sont à signaler: lors de l'éruption, l'appartement V, 14 est passablement étendu (119 m²), tout comme la boulangerie Or. II, 1a $\left(206 \mathrm{~m}^{2}\right)$.

${ }^{60}$ Andreau 1973: 374-376. Sur la difficulté de cerner la durée et les conséquences de cette phase de transition, cf. supra, n. 30. Rappelons que le rythmes des secousses
}

avec la création de l'Insula Orientalis $I I^{a}$ que la multiplication de ces unités commerciales avec habitation devient très sensible (fig. 202). En revanche, l'un des invariants qui les caractérisent le mieux est la dimension réduite des espaces dédiés à l'habitation, qui ne dépassent presque jamais les $100 \mathrm{~m}^{2}$, et qui constituent entre 35 et $75 \%$ de la surface prise en location ${ }^{59}$. Aucune tendance n'est perceptible dans les variations de ce rapport, si ce n'est l'extrême variété des situations. Pour partie, ce sont les tenanciers/ habitants de ces boutiques qu'A. Maiuri a cru voir envahir la ville. Pourtant, ils ne constituent guère plus que la frange la plus modeste de la plèbe moyenne: certes, ils disposent d'un métier et probablement du savoir-faire un tant soit peu élaboré qui correspond à ce métier; toutefois, ils restent à la merci des propriétaires fonciers à qui ils louent leur boutique et l'espace d'habitation qui lui est lié. Leur situation n'est certainement pas indépendante. Ils ne constituent pas non plus une «classe» consciente d'elle-même qui aurait pu amener une quelconque éviction des «aristocraties traditionnelles».

À ce stade, la comparaison avec Pompéi s'imposerait presque d'elle-même. Toutefois, elle est rendue délicate pour une raison majeure. La mise en évidence du second séisme est intervenue trop récemment dans l'historiographie pompéienne pour que ses conséquences aient déjà été pleinement mesurées. De la sorte, en dépit des études ponctuelles qui proposent des attestations ou des réflexions sur cette seconde catastrophe, aucune synthèse n'a été proposée; les données sur la période entre 62 et 79 restent pour l'essentiel celles publiées par A. Maiuri dans l'ultima fase edilizia di Pompei. L'analyse des conséquences du séisme de 62 sur la vie économique de Pompéi, effectuée par J. Andreau, était déjà tributaire des données publiées par A. Maiuri. Bien qu'elle soit sous-tendue par l'idée que toute la période entre 62 et 79 a été une phase transitoire de reconstruction $^{60}$, certaines de ses remarques générales

sismiques paraît avoir été différent entre les deux villes: durant la première moitié des années 70 à Herculanum, probablement au cours de l'année précédant l'éruption à Pompéi (cf. supra, p. 236-238). La - seconde - phase de transition n'était donc certainement pas achevée en 79 à Pompéi, qui restait une ville certainement très perturbée. 
se rapprochent des constatations que j'ai effectuées pour Herculanum. En effet, J. Andreau a particulièrement insisté sur la spéculation survenant à la suite de telles catastrophes, distinguant quatre modes dont seuls deux peuvent éventuellement être appréhendés par les sources archéologiques: la location à prix élevés par les propriétaires d'immeubles, particulièrement une fois les restaurations effectuées; le rachat à bas prix d'édifices vendus par leur propriétaire pour faire face à d'autres frais, liés au séisme ${ }^{61}$. Ces deux situations ont pu se produire à Herculanum. Laccélération de la fragmentation des maisons et de l'augmentation du nombre d'unités indépendantes pourrait être liée à de tels phénomènes spéculatifs, particulièrement si l'on place les données recueillies sur un axe temporel gradué en fonction du temps qui s'est effectivement écoulé au cours des différentes phases (fig. 203). L'accélération apparaît d'autant plus forte que les deux dernières phases se déroulent en un nombre d'années particulièrement réduit ${ }^{62}$.

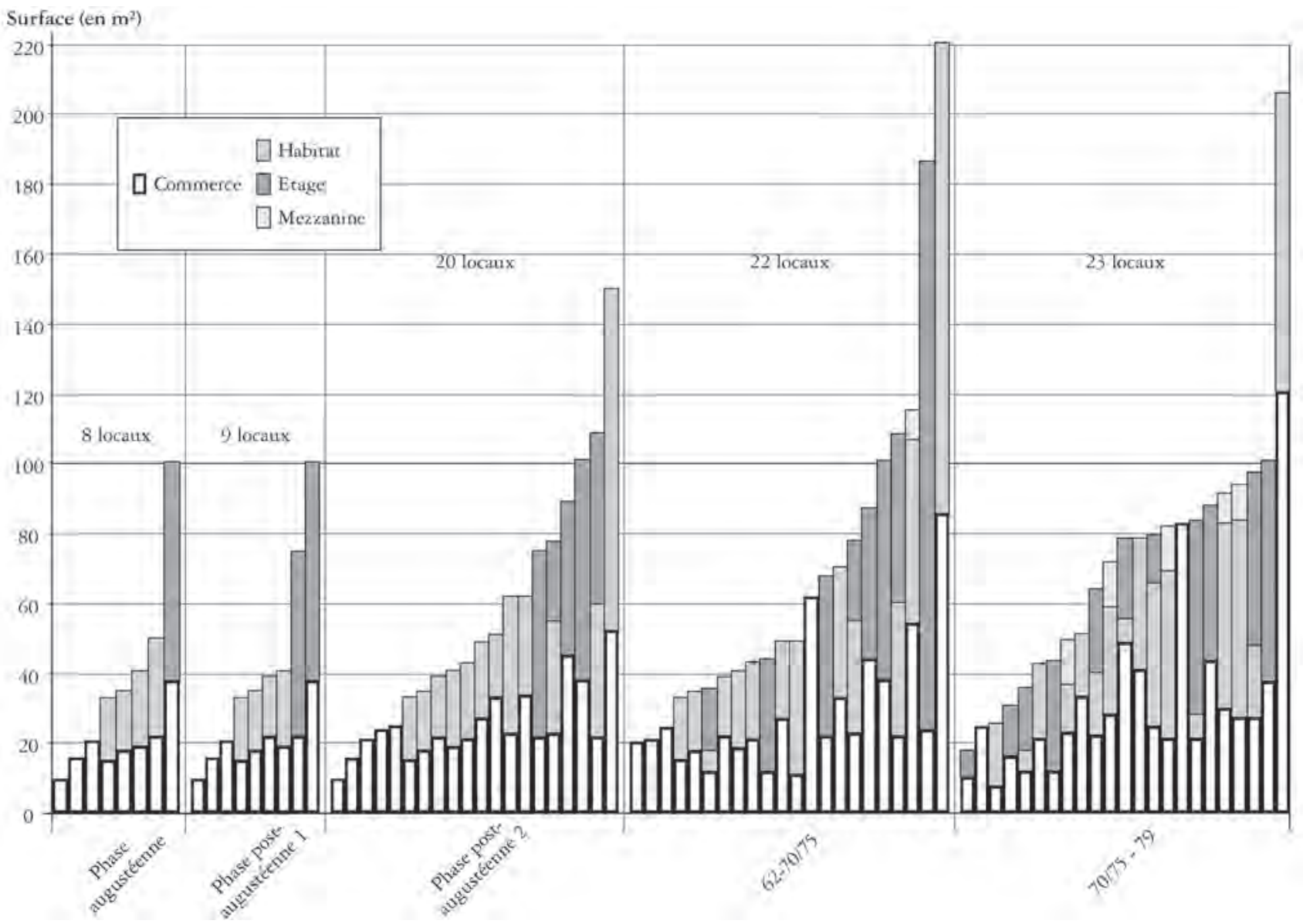

Fig. 202 - Évolution du nombre et de la surface des boutiques indépendantes.

${ }^{61}$ Les autres formes de spéculation sont: la pratique du prêt à intérêt, à taux élevés; l'adjudication de la restauration des édifices publics (aucune source sur ce sujet à Herculanum: le seul édifice dont la restauration est connue est l'Insula Orientalis $I I^{a}$, dont le financement a été pris en charge par Vespasien). Les autres réflexions sur la spécu- lation concernent l'identité des spéculateurs. Sur ces différents points, cf. Andreau 1973: 380-383.

${ }_{62}$ Signalons immédiatement qu'une telle courbe est d'autant plus trompeuse qu'elle est fausse d'un point de vue statistique. Les phases sont des intervalles alors que les bornes chronologiques utilisées pour placer les courbes 
Parcelles privées

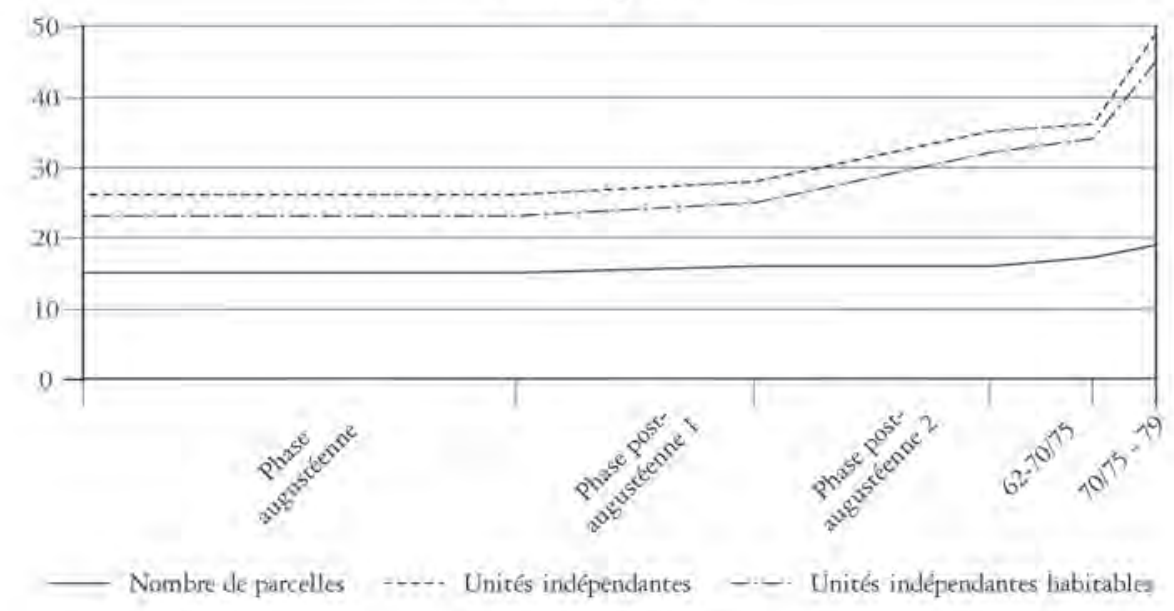

Ensemble des parcelles

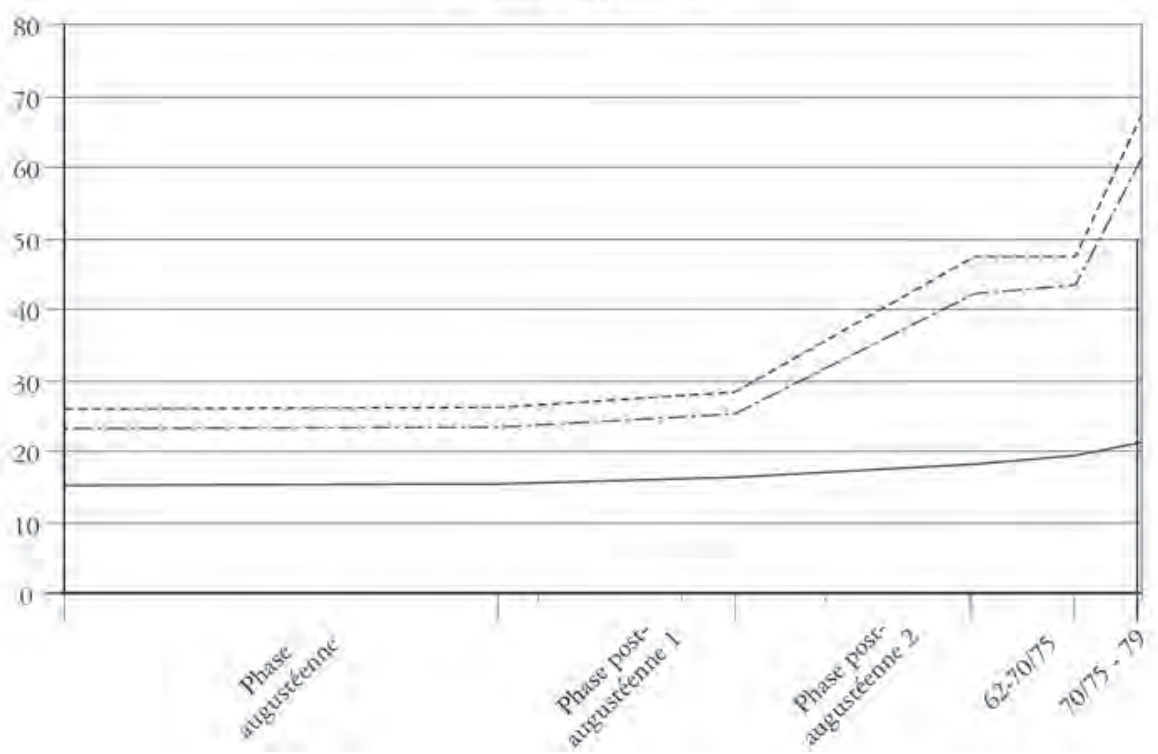

Fig. 203 - Courbes d'évolution du nombre de parcelles et d'unités indépendantes; contrairement à la figure 199, l'axe des abscisses est proportionnel au temps $(1 \mathrm{~mm}=1 \mathrm{an})$. Bien que plus suggestive, cette courbe est statistiquement fausse.

Au-delà de ce jeu de présentation statistique, disons qu'une accélération de la fragmentation s'est effectivement déroulée entre le séisme de 62 et l'éruption de 79, d'autant plus forte à la suite du second séisme. Quant à la revente de certains

sont des points - obtenus mathématiquement, à l'exception des dates du règne d'Auguste, du séisme de 62 et de l'éruption de 79. Cette courbe donne l'impression d'une évolution continue alors que les rythmes de reconstruction ne peuvent pas être appréhendés avec une telle précision. De plus, l'effet de loupe ainsi obtenu favorise les deux dernières édifices, un tel phénomène peut s'être déroulé, pour la Casa sannitica et éventuellement pour la Casa del bicentenario. Rien ne permet de dire que de telles ventes se sont déroulées à vil prix. Enfin, je rappellerai qu'à Herculanum ces phénomènes

phases, déjà largement mises en avant par le mode d'obtention des données, qui laisse la part belle aux dernières transformations. Un axe des abscisses proportionnel à la durée effective des phases ne pourrait être utilisé qu'avec des données parfaitement calées chronologiquement, éventuellement obtenues grâce à des fouilles stratigraphiques. 
ne naissent pas avec les deux catastrophes. Les études de F. Pirson sur Pompéi ont abouti à la même conclusion ${ }^{63}$. La comparaison entre les deux villes ne saurait être plus développée tant que l'ultima fase edilizia di Pompei ne sera pas repensée avec cette nouvelle donnée majeure qu'est l'existence d'au moins un second séisme.

En dépit d'une augmentation sensible de la population, avec les conséquences qu'elle a eues sur la façon de vivre, en dépit du nombre croissant des petits boutiquiers qui s'installent dans des locaux loués, c'est le rôle des élites locales dans l'économie urbaine qui a été mis en évidence. Et pour cause: ces locaux - appartements et boutiques - constituent avant tout des investissements réputés sûrs pour leur propriétaires. Les caractéristiques d'une plèbe moyenne aux contours multiformes, dont la population ne fait que s'accroître durant la période étudiée, continuent de nous échapper. Cette lente évolution a certainement été accélérée par les deux catastrophes. Toutefois, pour traumatiques qu'ils aient pu être, les deux séismes n'ont renversé - ou même contribué à renverser - ni l'ordre social avec sa structure pyramidale, ni le fonctionnement économique d'une petite ville du golfe de Naples. 


\section{CONCLUSION GÉNÉRALE}

\author{
« Ma Ercolano è una ripetizione di Pompei? \\ Vana domanda!» \\ A. Maiuri, "Il primo volto di Ercolano », Pompei ed \\ Ercolano, Fra case e abitanti, Padoue, Le tre venezie, 1950 \\ (Itinerari del Sud, 2), p. 226.
}

Au fil de cette étude, j’ai tenté de cerner les caractéristiques d'une fraction de la population urbaine, les gens de métier - «artisans» et boutiquiers -, en cherchant autant que possible à me soustraire au filtre dépréciateur du discours des élites à leur propos. Le choix de privilégier l'exploitation des sources archéologiques par rapport aux sources littéraires ou épigraphiques m'a conduit à analyser le lieu d'exercice du métier plutôt que le discours sur celui-ci. Si la possible esquisse de cette population y a perdu en subjectivité, elle n'en reste pas moins partielle. Une importante fraction de cette partialité tient au "cas» d'Herculanum qui a retenu mon attention et à la nature même des sources disponibles sur celui-ci.

En effet, par la relative exiguïté de la surface dégagée, alors même qu'une zone non négligeable de celle-ci est occupée par de grandes domus proches des villas urbaines par leur forme, toute interprétation trop tranchée sur les aspects sociaux et économiques d'Herculanum serait imprudente. Un second point, loin d'être négligeable, tient à l'histoire des fouilles de cette petite ville et à l'omniprésente ombre tutélaire d'A. Maiuri. Le recours systématique aux journaux de fouilles m'a permis de me dégager en partie de cette influence tout en l'éclairant sous un jour nouveau. Le résultat reste ambigu. Les manipulations des données de la fouille effectuées lors de la rédaction de la synthèse consacrée au site, conscientes ou non, ont amené A. Maiuri à forger une vision certainement trop personnelle d'Herculanum, que ce soit pour l'insérer de force dans une histoire plus large ou pour se dégager de l'influence de ses rares prédécesseurs, dans un processus qu'il n'a pas pu accomplir à Pompéi. Toutefois, en dépit des corrections de détails - d'importance variable - que l'on doit apporter aux interprétations qu'il a proposées, la profonde connaissance du site dont A. Maiuri a fait preuve dans ses écrits reste une référence indispensable. D'un autre côté, il me semble également nécessaire de s'affranchir de cette tutelle protectrice en ouvrant, comme cela a été fait pour Pompéi à l'aube des années 1980, les «temps de la documentation». Seul le récolement aussi exhaustif que possible des archives de fouilles - toutes périodes confondues et sous toutes leurs formes - peut favoriser de nouvelles interprétations et laisser émerger une image différente du site.

L'utilisation de ces archives me paraît avoir porté ses premiers fruits à propos des lieux de métier. Les quelques exemples d'espaces commerciaux et de procédés techniques que j'ai étudiés ont largement bénéficié des annotations effectuées au cours de leur dégagement. L'impressionnante invisibilité du commerce de proximité se consacrant à la distribution de biens 
manufacturés est remarquable dans ces archives; la cause en est toutefois plus à rechercher dans les choix opérés au moment de la fouille que dans une absence dès l'Antiquité. Les autres lieux d'exercice de métiers montrent quant à eux une variété de solutions d'aménagement qui défie toute synthèse. Quelques regroupements peuvent parfois être effectués au sein d'une même catégorie de négoces, comme les commerces alimentaires. Pourtant, la boutique et l'atelier me semblent devoir être considérés comme des espaces très génériques, dont la spécificité ne devrait pas être réduite aux aménagements dont ils sont dotés, mais à l'ensemble des techniques développées par leurs occupants. Si cette réflexion ne paraît pouvoir être appliquée que difficilement en dehors des sites exceptionnels par leur conservation que sont Herculanum et Pompéi, elle exige de toute évidence d'approfondir les recherches sur les savoir-faire. Cet approfondissement devrait à la fois être effectué en diachronie - pour cerner des évolutions - et dans le détail des techniques employées, afin de distinguer les particularités propres à chaque équipe constituée par des praticiens des différents métiers.

C'est toutefois à l'échelle supérieure, celle de la place des espaces commerciaux dans les propriétés urbaines, que les changements d'optique auxquels j'ai abouti paraissent les plus marqués. Pour longue et âpre qu'elle puisse être, la synthèse des données issues de l'archéologie du bâti a permis de réfuter l'une des principales théories d'A. Maiuri sur les conditions socioéconomiques d'Herculanum. En effet, le principe même d'une "invasion" commerciale menée par des affranchis évinçant les élites traditionnelles ne saurait être soutenu. Les hypothèses de restitution de l'évolution du tissu commercial que j'ai esquissées tendent au contraire à montrer une croissance régulière des implantations de boutiques, à peine accélérée par les deux catastrophes qui ont frappé la ville peu avant son ensevelissement. Si les boutiques disposant d'un espace d'habitation - physiquement indépendantes des domus - se développent tout au long du premier siècle de notre ère, leur accroissement numérique ne correspond certainement pas à un affranchissement de la tutelle économique des élites, bien au contraire. Le développement des nouvelles formes d'habitation ne saurait correspondre à un changement de mains ou à un éparpillement du capital foncier: pour autant que les sources disponibles permettent une telle affirmation, les élites restent propriétaires du sol occupé par ces commerces indépendants. L'extension de la location ne nous semble pas devoir être interprétée en termes sociaux, mais bien selon une optique économique d'adaptation des formes d'investissement urbain. Cette conclusion n'en constitue pas moins un paradoxe: en cherchant à comprendre les espaces commerciaux, et à travers eux les gens de métier, le regard se tourne de nouveau vers les élites. Peutêtre serait-il alors nécessaire d'abandonner l'étude distincte de ces deux "groupes » inextricablement mêlés pour privilégier l'analyse de leurs rapports et des différences qu'ils présentent pour mieux les identifier. Un approfondissement détaillé des questions relatives au mode d'habitation - de la forme architecturale aux décorations sans oublier les objets de la vie quotidienne et ce qu'ils sont susceptibles de révéler sur les habitudes culturelles - ou à la pratique de la religion domestique permettrait certainement d'aboutir progressivement à une définition plus fine du groupe multiforme constitué par les gens de métier.

Que ce soit l'interprétation des activités pratiquées dans les boutiques ou leur manque de variété, tous les éléments rassemblés contribuent à faire percevoir Herculanum comme une ville différente de Pompéi, comme l'indiquait déjà, dans un contexte différent, A. Maiuri. Bien qu'ayant connu une croissance tout au long du premier siècle de notre ère, le tissu commercial et artisanal d'Herculanum ne présente aucun signe de concentration des activités ou d'extension de leur production. Les commerces identifiés peuvent tous être considérés comme relevant des activités banales, indispensables à la vie quotidienne, sans prétention ni grande envergure. Pour conclure cet ouvrage, je m'autoriserai à citer les remarques d'Ettore Lepore, rédigées alors que le résultat des fouilles n'était pas encore publié sous sa forme définitive:

La vita della 'piccola città' si orientò, dunque, dalla tarda età repubblicana e fino alla sua scomparsa in età flavia, su questa società agiata romano-campana che ne garantì (e insieme ne limitò) il respiro economico, su un regime di puri consumi e di spese scarsamente 
produttive, alimentate dalle piccole e medie fortune, di origine fondiaria, da un commercio e artigianato di carattere locale, e dagli investimenti dei grandi proprietari romani e della casa imperiale, sopratutto a soddisfazione di convenzionali necessità personali e sociali, d'ordine voluttuario ed estetico. [...] Uno sguardo alle varie forme di vita e di attività sembra confermarci il quadro sommario ora tracciato e, malgrado gli scarsi dati e rischi di argomentazioni ex silentio, rivelarci ch'esso è assai più di una prudente ipotesi (E. Lepore, «Sul carattere economico-sociale di Ercolano», La parola del passato, 10, 1955, p. 430).

J'espère avoir, par cette étude, contribué à apporter quelques arguments permettant de soutenir cette prudente et néanmoins remarquable intuition. 



\section{ANNEXE \\ CATALOGUE DES LIEUX DE MÉTIER D'HERCULANUM}

\section{Notice}

Dans ce catalogue sont inventoriés les cinquante lieux de métiers intégralement fouillés à Herculanum, regroupés par maison ou par bâtiment public, selon des hypothèses minimales de " parcelles » unitaires.

Ce dénombrement tend à donner une image du paysage commercial et de production au moment de l'éruption du Vésuve. Cet aperçu est nécessairement partiel: dans le corps du livre, d'autres espaces de vente ou de production ont été abordés; leur situation aux limites de la zone fouillée à ciel ouvert empêche cependant de les intégrer dans cette annexe faute de pouvoir dresser une planimétrie complète du lieu de métier proprement dit - pour ne même pas évoquer l'unité architecturale dans laquelle il s'insère. À ces cinquante locaux ont été ajoutés les renseignements minimaux concernant deux unités d'habitation, dépourvues de boutique en 79 mais en ayant compté au cours de leur évolution (Casa del telaio, appartements V, 17.18). En revanche, certains espaces, réputés avoir présenté des activités commerciales, ont été écartés faute de trace concluante ${ }^{1}$.

Pour les édifices privés - et pour les thermes -, le choix d'une présentation par ensemble unitaire va de soi: il contribue à souligner la diversité des rapports aux activités commerciales au sein d'une même maison. Pour l'Insula Orientalis $I I^{a}$, j'ai repris la division en trois blocs opérée par A. Maiuri. Peu satisfaisant sur le plan architectural ou de la propriété foncière, ce choix reste exclusivement dicté par des considérations éditoriales: il permet de présenter les boutiques et ateliers de cette insula à la même échelle que ceux du reste de la ville thermes exceptés. Les plans publiés dans les pages qui suivent correspondent au relevé effectué par F. Ferrajoli, avec d'éventuels ajouts ou de rares corrections, nécessairement minimes tant il conviendrait de refaire un relevé général des vestiges de la ville. Les limites indiquées pour les étages débordant sur la rue restent indicatives et minimales: si la verticale du trottoir paraît convenir pour les étages non soutenus par des colonnes, l'exemple de la Casa a graticcio (cf. supra p. 28-29) laisse penser que les colonnes permettent d'aller au-delà de cette verticale et de déborder au-dessus de la voirie.

Dans chaque description synthétique des parcelles, le lecteur trouvera les champs suivants:

- Nom courant de l'édifice, généralement donné par A. Maiuri ou par ses successeurs, suivi, entre parenthèses, de la localisation du bâtiment. Harmonisée selon des principes proches de ceux décrits, pour Pompéi, par H. et L. Eschebach (1993), cette nomenclature regroupe l'îlot (indiqué en chiffres romains) et, séparé d'une virgule, les différentes entrées donnant accès au bâtiment. Le tiret signale des entrées dont la succession est continue, le point indique une rupture dans cette continuité.

${ }^{1}$ Il s'agit de l'espace II, 4 (cf. supra p. 87) et de la Casa della stoffa (cf. supra p. 179).
- Période de fouille: arc temporel (par années) durant lequel le bâtiment a été mis au jour, selon les journaux de fouille (GSE). Cette chronologie peut différer de celle présentée par A. Maiuri (1958 b: 59).

- Bibliographie: mention des principales études à vocation généraliste traitant de l'édifice et incluant les lieux de métier.

- Nombre d'unité(s) architecturale(s) en 79: nombre d'unités indépendantes les unes des autres, regroupées dans la parcelle étudiée. Le nombre de lieux de métier présents en 79 est rapporté aux différentes unités. 
- Seuils: rapide description des seuils observés lors d'un examen réalisé en 2005. Outre la présence ou l'absence des pierres constituant le seuil, sont indiquées la nature géologique de celles-ci ainsi que le type d'ouverture qu'elles renseignent, synthétisé par un renvoi à la typologie dressée par A. Bouet (1995).

Dans les descriptions synthétiques des lieux de métier, sont développés les renseignements suivants:

- Numérodulieu de métier, suivi de son interprétation selon une vocation strictement commerciale (boutique) ou présentant les signes d'une activité de production (atelier) et de sa localisation dans la nomenclature générale du site selon les principes rappelés ci-dessus.

- Période de fouille: arc temporel (par années) durant lequel le lieu de métier a été mis au jour, à partir du dépouillement des journaux de fouille (GSE). La date de début correspond systématiquement à la première mention, tandis que la date de fin peut manquer si aucun élément ne permet de déterminer l'achèvement du dégagement. Les éventuels sondages stratigraphiques ne sont pas inclus dans ces dates de fouille.

- Bibliographie: principales mentions du lieu de métier et études lui ayant été consacrées. Parmi les études thématiques ou transversales, seules les monographies ont été indiquées; ont été écartés tous les articles ne renvoyant que de manière ponctuelle à la boutique ou à l'atelier.

- Données métriques (longueur; largeur; surface): les données métriques linéaires (en mètres, mesuré sur le site) donnent les dimensions de la boutique ou de l'atelier. La surface reste approchée au demi-mètre carré près et a été calculée à partir des plans fournis ci-après.

- Pièce annexe: mention du nombre et de la surface des pièces directement liées aux activités exercées dans le local.

- Période hypothétique de création: proposée à partir des données de l'étude du bâti, à l'exception des boutiques en façade de la Casa del salone nero et de l'Insula Orientalis $I I^{a}$ qui ont bénéficié de fouilles stratigraphiques, cette hypothèse renvoie à la période de création ou de transformation du local concerné en espace commercial ou de production. Seuls des sondages permettraient éventuellement de déterminer la phase d'installation des activités présentes au moment de l'éruption. Pour les locaux exclus de l'étude du bâti qui appartiennent aux îlots II et VII, aucune période de création n'est proposée.

- Situation par rapport à la parcelle: évocation des liens - au moment de l'éruption - entre le lieu de métier et l'édifice occupant le reste de la parcelle sur laquelle il est érigé. Deux situations principales existent. L'indépendance indique que la boutique ou l'atelier sont détachés de tout lien (hors de la mitoyenneté physique) avec cet édifice. La liaison avec la domus signale au contraire l'existence d'une porte entre l'édi- fice et le lieu de métier, signe d'une relation de rattachement de l'un à l'autre. Le lien aboli se situe entre ces deux principales situations: il décrit une indépendance de fait au moment de l'éruption, obtenue par le bouchage d'une porte et donc de l'annulation des possibilités de communication directe entre les deux.

- Situation par rapport à l'habitat: description de l'hypothèse la plus probable quant au lieu dans lequel le tenancier du local pouvait habiter; cette situation est en général une conséquence directe du rapport à la parcelle. Les locaux en liaison avec la domus disposent ainsi toujours d'un accès à la domus pour les fonctions d'habitat. En revanche, les cas sont plus variés pour les locaux indépendants - qu'ils aient eu ou non un lien avec l'édifice mitoyen. Certains de ces lieux de métier sont considérés comme sans espace d'habitation soit quand ils ne présentent aucune pièce annexe ou aucune mezzanine permettant de vivre, soit quand la pièce annexe est manifestement occupée par des aménagements liés à la fonction commerciale ou de production. En revanche, quand la pièce annexe ne présente aucun de ces signes ou dispose au contraire de traces permettant de déduire un espace de vie, j'ai considéré que le local entrait dans la catégorie d'habitat en pièce annexe. Enfin, la dernière possibilité est matérialisée par la présence d'un départ d'escalier prenant la forme de vestiges ligneux, d'un dé maçonné ou d'empreinte dans l'enduit: le local dispose alors d'un accès à l'étage, susceptible de permettre l'habitation.

- Description des aménagements: aperçu synthétique des différents aménagements maçonnés ou en bois encore visibles dans le local considéré ou attestés dans les GSE.

- Interprétations de la situation en 79: rappel de la première interprétation proposée pour le local considéré et, en cas de révision de celle-ci, mention de la nouvelle interprétation développée dans ce volume.

- Inventaire des objets mis au jour dans le local: Citation - pour les locaux fouillés dans le cadre des Nuovi scavi (1927-1961) - des livres d'inventaire reportant les objets découverts, répartis selon les différentes pièces - principale et éventuelles annexes. Les objets trop fragmentés pour bénéficier d'un numéro d'inventaire - mais indiqués dans les GSE en raison d'inscriptions peintes ou en relief - sont regroupés par pièce et par catégorie. Les objets découverts à l'étage ne sont mentionnés que si le lien entre celui-ci et le local est immédiat. À titre d'exemple, les 16 ou plus amphores et les 9 amphorisques découverts à l'étage de la boutique IV, 15-16 ne sont pas répertoriés ci-dessous en raison des liens entre le local et la domus: bien qu'il soit extrêmement probable que ce dépôt d'amphores mentionné lors de la fouille soit directement lié à l'activité commerciale, ces récipients pourraient constituer les réserves de la maison. En revanche, les 5 amphores stockées dans la pièce annexe (a) de la boutique IV, 17 sont dûment répertoriées ci-après. 
INSULA II

AbitaZione e botteghe (II, 4-8) (fig. 204)
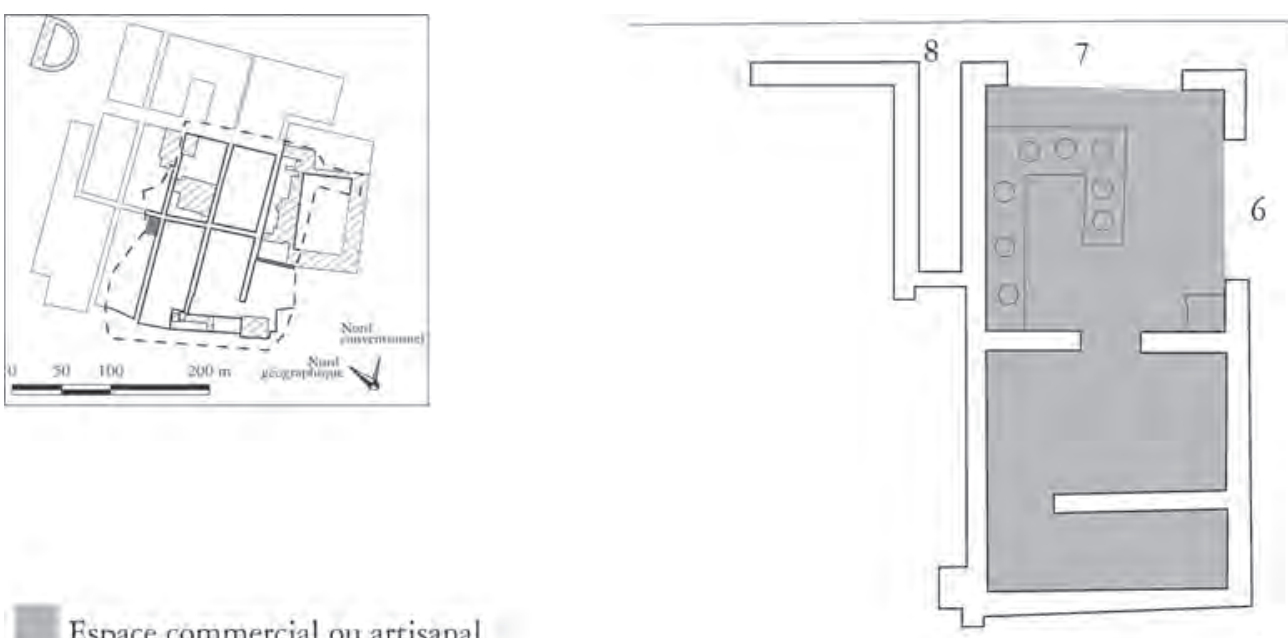

Espace commercial ou artisanal

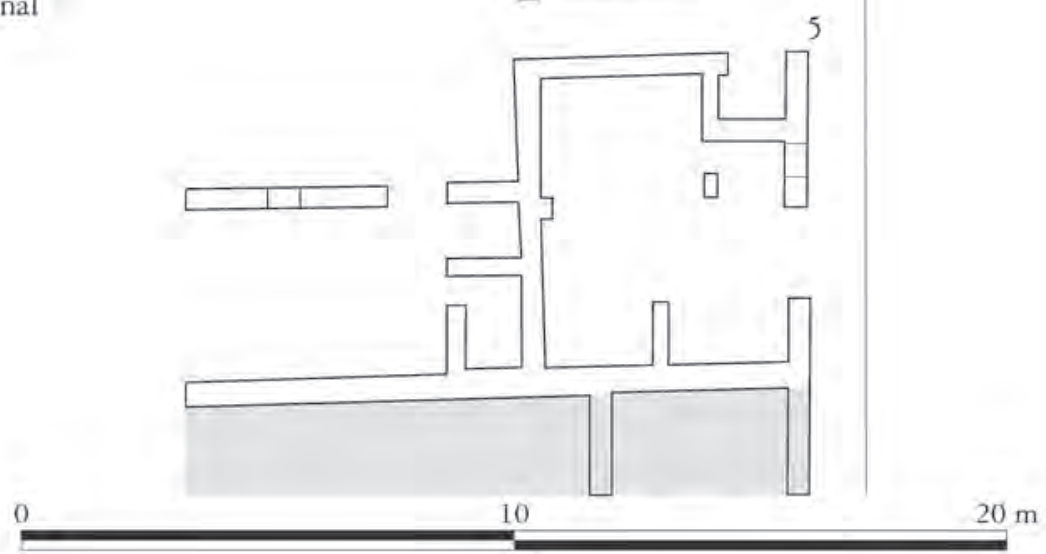

Extension du $1^{\mathrm{er}}$ étage

Extension du $2^{\epsilon}$ étage

Extension des mezzanines

Fig. 204 - Plan de l'Abitazione e botteghe (II, 4-8) et de sa boutique (échelle: 1/200).

Période de fouille: 1872-1875.

Bibliographie: Maiuri 1958 b (445-447).

Nombre d'unité(s) architecturale(s) en 79: non déterminé (n.d.), comportant au moins 1 local commercial.

Seuils: II, 6 (seuil emporté); II, 7 (seuil emporté).

\section{Boutique II, 6-7}

Période de fouille: 1872-1873.

Bibliographie: Maiuri 1958 b (446-447); Pagano 1997 (40); Pesando - Guidobaldi 2006 (316).

Longueur: 4,9 m; largeur: 4,9 m; surface: $24 \mathrm{~m}^{2}$.

Pièce annexe: deux pièces, d'une surface respective de 14 et $7,5 \mathrm{~m}^{2}$.

Période hypothétique de création: n.d.

Situation par rapport à la parcelle: indépendance probable.

Situation par rapport à l'habitat: n.d.
Description des aménagements: comptoir maçonné en double équerre comportant sept dolia; fourneau disposé contre le mur oriental du local principal.

Interprétations de la situation en 79: hospitium (?) (A. Maiuri) / commerce alimentaire (type 1).

Inventaire des objets mis au jour dans le local:

Boutique principale. Monnaie d'argent; pendentif rectangulaire en pâte de verre (GSE 1872: 5 settembre); huit monnaies de bronze; une clochette; deux casseroles en bronze; une lampe céramique; des fragments de corde (GSE 1873: 7-14 gennaio); deux petites têtes féminines en marbre; du grain (GSE 1873: 28-29 gennaio).

Pièce annexe. Divers éléments en bronze, dont une base de candélabre et des fragments de serrure (GSE 1873: 1-7 febbraio) [objets probablement conservés au MANN]. 


\section{INSULA III}

CASA del tramezzo di legno (III, 4-12) (fig. 205)

Période de fouille: 1869-1875; 1927-1929.

Bibliographie: Maiuri 1958 b (207-222); de Vos de Vos 1982 (268-269); Wallace-Hadrill 1994 (83, 127, 199); Pagano 1997 (50-51); de Kind 1998 (105-113); Guidobaldi 2006 (199-205); Pesando - Guidobaldi 2006 (321-325).

Nombre d'unité(s) architecturale(s) en 79: 9; 1 comporte 3 locaux commerciaux; 1 local commercial indépendant.

Seuils: III, 4 (seuil emporté); III, 5 (seuil emporté); III, 6 (seuil de type D1a en travertin); III, 7 (seuil emporté); III, 8 (seuil emporté); III, 9 (seuil emporté); III, 10 (seuil de type D1a en lave et tuf); III, 11(seuil de type B1 en calcaire blanc); III, 12 (seuil emporté).

\section{Boutique III, 4}

Période de fouille: 1869.

Bibliographie: Maiuri 1958 b (221-222); de Vos - de Vos 1982 (269).

Longueur: 5,4 m; largeur: 3,6 m; surface: $17 \mathrm{~m}^{2}$.

Pièce annexe : une pièce annexe ( $\mathrm{Lxl}: 2,8$ x 2,8 m), dont la surface est doublée par une mezzanine.

Période hypothétique de création: phase préaugustéenne.

Situation par rapport à la parcelle: liaison vers la domus.

Situation par rapport à l'habitat: accès à la domus.

Description des aménagements : l'ensemble constitué par la boutique et sa pièce annexe est doublé par une mezzanine. Communication vers la boutique III, 6 par un passage ménagé sous l'escalier III, 5. Pas d'autre aménagement visible.

Interprétation de la situation en 79: boutique, commerce ou production indéterminés.

Inventaire des objets mis au jour dans le local: dans la pièce (17), annexe de la boutique, ont été découverts des éléments de serrure, du grain dans une quantité non spécifiée, des oignons et une anse en corde (GSE 1869: 9 luglio) [objets probablement conservés au MANN].

\section{Boutique III, 6}

Période de fouille: 1869.

Bibliographie: Maiuri 1958 b (220-221); de Vos - de Vos 1982 (268-269); Pagano 1997 (40).

Longueur: $6,3 \mathrm{~m}$; largeur: $4,8 \mathrm{~m}$; surface: $30 \mathrm{~m}^{2}$.

Pièce annexe: aucune, sauf à considérer la boutique III, 4 comme un espace annexe.

Période hypothétique de création: phase préaugustéenne.
Situation par rapport à la parcelle: liaison avec la domus.

Situation par rapport à l'habitat: accès à la domus.

Description des aménagements: deux dolia encastrés dans le sol. Présentent des lésions réparées avec des agrafes en plomb. Pas de trace de comptoir. Vasque contre la paroi méridionale.

Interprétation de la situation en 79: taberna per servizio di cucina (A. Maiuri) / commerce alimentaire (type 3).

Inventaire des objets mis au jour dans le local: divers outils (marteau, haches) découverts, avec une colonne vertébrale humaine dans l'un des deux dolia (GSE 1869: 10 luglio); balance avec deux coupelles; lampe céramique; récipient céramique contenant des écailles et arêtes de poissons; oignon; petite monnaie de bronze [objets probablement conservés au $M A N N]$.

\section{Boutique III, 8-9}

Période de fouille: 1874-1875 (?). 1927

Bibliographie: Maiuri 1958 b (218-219).

Longueur: 13,6 m; largeur: 4,2 m; surface: $50 \mathrm{~m}^{2}$.

Pièce annexe: à l'est de la boutique, un réduit contient une latrine.

Période hypothétique de création: phase augustéenne.

Situation par rapport à la parcelle: liaison avec la domus.

Situation par rapport à l'habitat: accès à la domus.

Interprétation de la situation en 79: boutique, commerce ou production indéterminés.

Description des aménagements : aucun aménagement visible. Située à la limite entre les fouilles du $\mathrm{XIX}^{\mathrm{e}}$ siècle et la reprise de 1927, cet espace n'a pas fait l'objet de la moindre description.

Inventaire des objets mis au jour dans le local: aucun objet signalé.

\section{Atelier III, 10}

Période de fouille: 1928

Bibliographie: Maiuri 1958 b (219-220); Moeller 1976 (113); de Vos - de Vos 1982 (269); Pagano 1997 (49); Pesando - Guidobaldi 2006 (321-325).

Longueur: 4,9 m; largeur: 4,7 m; surface: $22 \mathrm{~m}^{2}$

Pièce annexe: aucune.

Période hypothétique de création: phases postaugustéennes. dance.

Situation par rapport à la parcelle: indépen- 


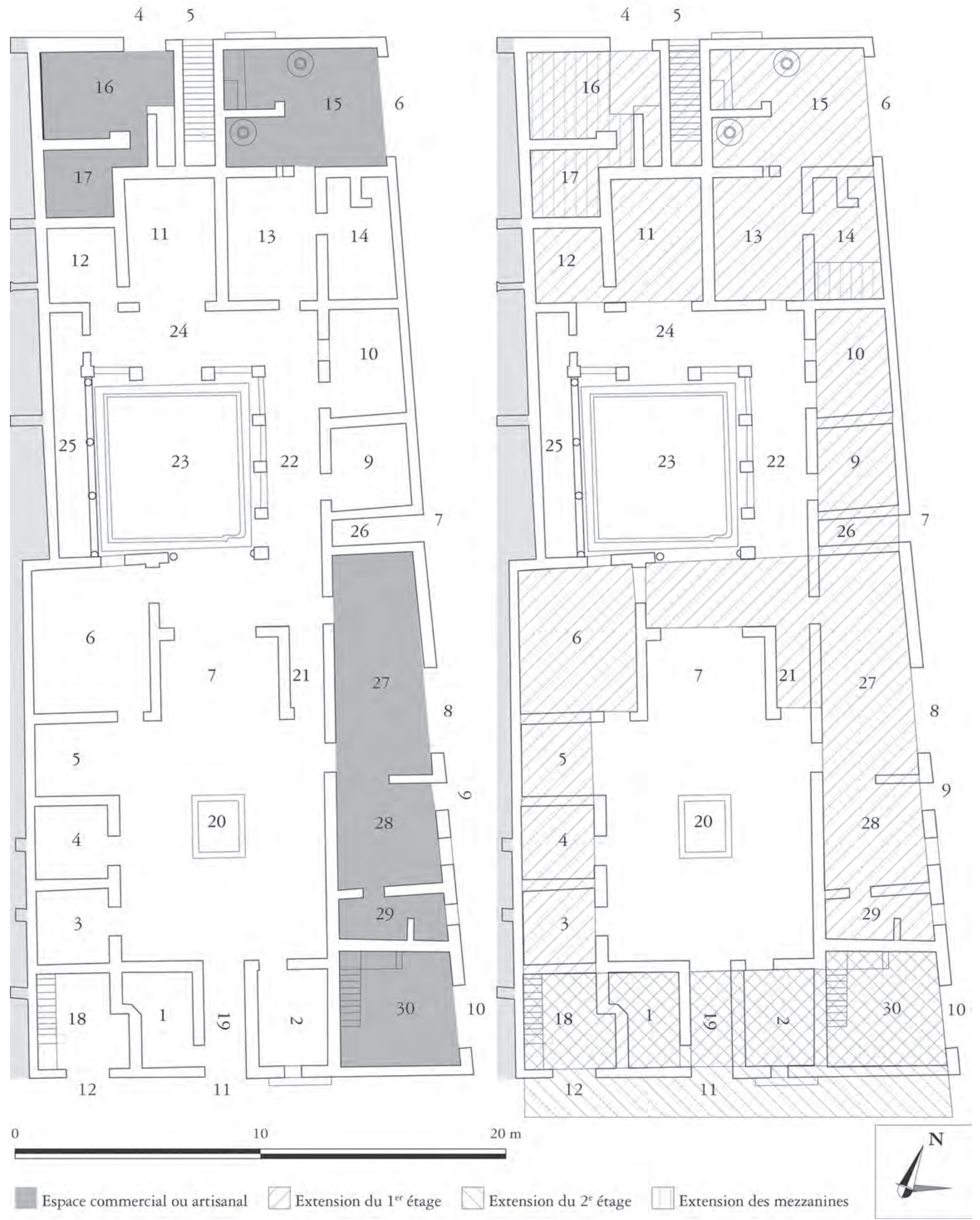

Fig. 205 - Plan de la Casa del tramezzo di legno (III, 4-12), de son atelier et de ses trois boutiques (échelle: 1/200). 
Situation par rapport à l'habitat: accès à l'étage.

Description des aménagements: le seul aménagement ayant subsisté est une presse à vis en bois.

Interprétations de la situation en 79: atelier de nettoyage des vêtements (A. Maiuri) / atelier de parfumerie.
Inventaire des objets mis au jour dans le local:

Boutique principale. $75554=$ E278: [Bronze] Piastra di forma rettangolare, lunga $m$. in 0.225, larga m. $0.14 ; 75560=\mathrm{E} 284$ : [Minéraux] Una piccola quantità di colore verde.
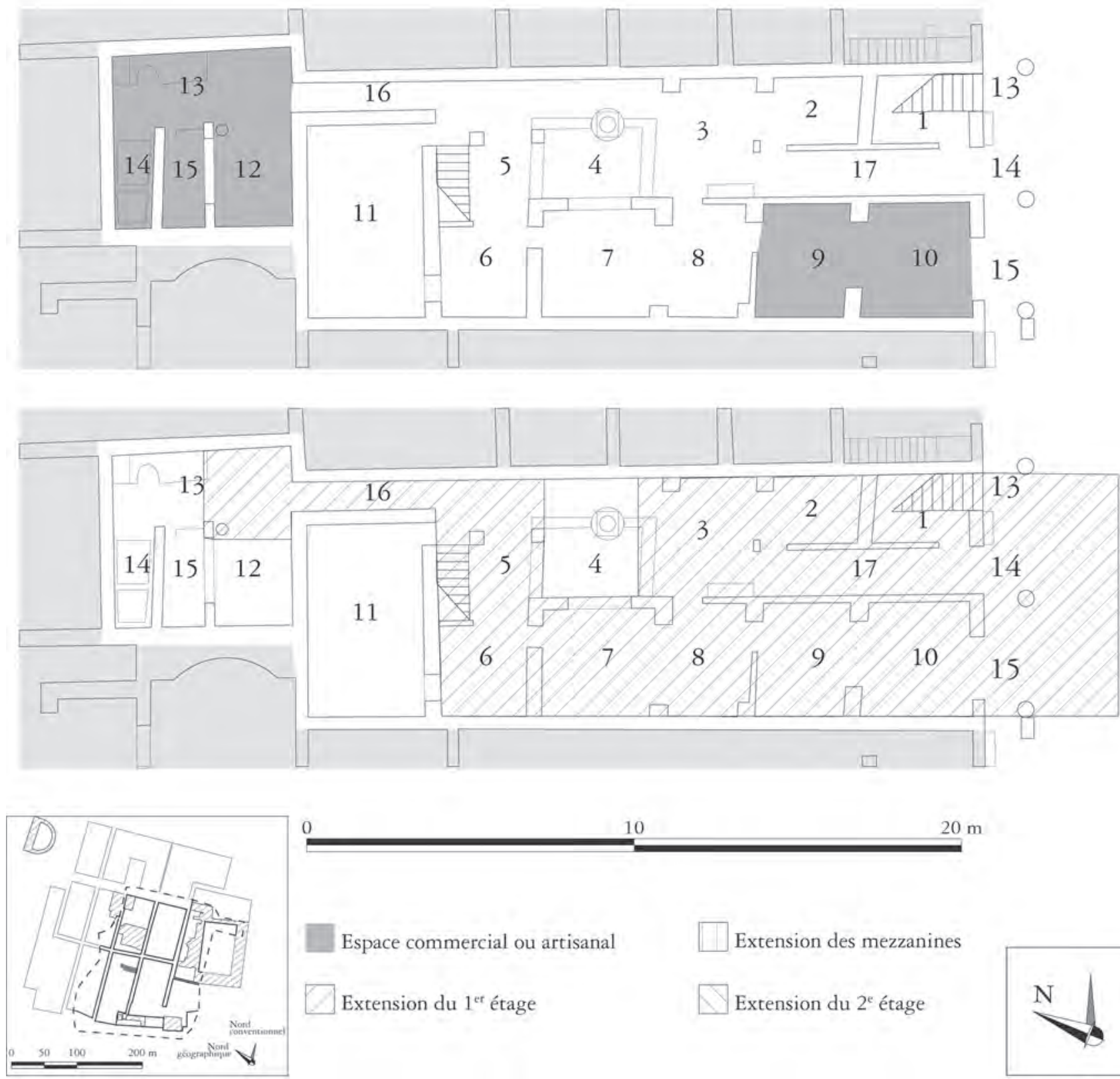

$20 \mathrm{~m}$

Fig. 206 - Plan de la Casa a graticcio (III, 13-15) et de sa boutique (échelle: 1/200). 
Période de fouille: 1927-1928.

Bibliographie: Maiuri 1958 b (407-420); de Vos - de Vos 1982 (269-270); Papaccio 1993; Pagano 1997 (51-53); de Kind 1998 (113-122); Pesando Guidobaldi 2006 (325-327).

Nombre d'unité(s) architecturale(s) en 79: 4 dont 1 comportant 1 local commercial.

Seuils: III, 13 (seuil de type C1a en calcaire blanc); III, 14 (seuil de type C1a en calcaire blanc); III, 15 (seuil de type D1a en lave et tuf).

\section{Boutique III, 15}

Période de fouille: 1927-1928

Bibliographie: Maiuri 1958 b (414); de Vos - de Vos 1982 (270); Pesando - Guidobaldi 2006 (325).

Longueur: 3,5 m; largeur: 3,1 m; surface: $11,5 \mathrm{~m}^{2}$. Pièce annexe: une pièce annexe située à l'ouest $(\mathrm{L} \times 1: 3,5 \times 2,7 \mathrm{~m})$ sans porte de séparation. de 62.
Situation par rapport à la parcelle: lien avec le reste de l'édifice.

Situation par rapport à l'habitat: habitat en pièce annexe au rez-de-chaussée.

Description des aménagements: aucun aménagement visible. La découverte d'un treuil et la réfection inachevée de l'enduit laissent supposer des travaux en cours au moment de l'éruption. Les vasques situées dans les pièces 12 à 13 pourraient indiquer une activité artisanale liée au textile.

Interprétations de la situation en 79: bottega di un artigiano (A. Maiuri) / espace commercial en travaux, éventuel atelier lié au textile dans la partie arrière de la maison.

Inventaire des objets mis au jour dans le local:

Boutique principale. 75669 = E393: [Bois et corde] Corda carbonizzata m. 4.00, spessore m. 0.017. All'estremità di un capo di un nodo notasi un pezzo di legno carbonizzato a guisa di pinoli. 


\section{INSULA IV}

Casa della fullonica (IV, 5-7) (fig. 207)

Période de fouille: 1931-1932 (dernière mention alors que certaines pièces n'ont pas encore été décrites).

Bibliographie: Maiuri 1958 b (422-423); de Vos - de Vos 1982 (273); Pagano 1997 (56); de Kind 1998 (146-150); Pesando - Guidobaldi 2006 (335).

Nombre d'unité(s) architecturale(s) en 79:2, dont 1 comportant 1 local commercial.

Seuils: IV, 5 (seuil emporté); IV, 6 (seuil de type C1a en travertin); IV, 7 (seuil de type D1a en lave).

\section{Atelier IV, 7}

Période de fouille: 1931.

Bibliographie: Maiuri 1958 b (422-423); Moeller 1976 (113); de Vos - de Vos 1982 (273); Pagano 1997 (56); Pesando - Guidobaldi 2006 (335).

Longueur: 2,9m; largeur: 2,8 m; surface totale: $46 \mathrm{~m}^{2}$.

Pièce annexe: Outre le local principal, l'atriolo coperto $(4,9 \times 8,2 \mathrm{~m})$ est occupé par les deux vasques de lavage.
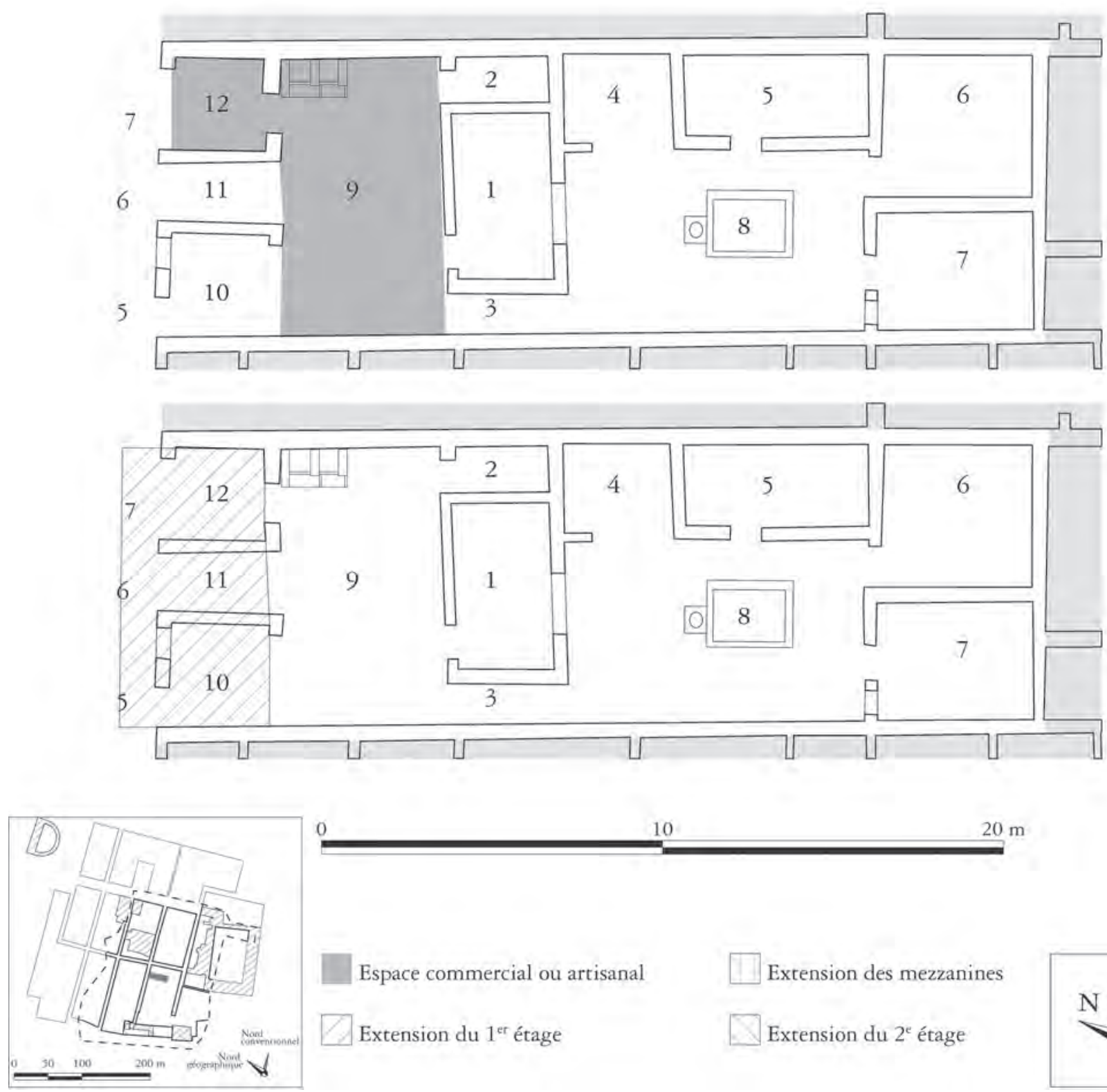

$20 \mathrm{~m}$

Espace commercial ou artisanal

Extension du $1^{\text {er }}$ étage
Extension des mezzanines

Extension du $2^{e}$ étage

Fig. 207 - Plan de la Casa della fullonica (IV, 5-7) et de son atelier (échelle: 1/200). 
Période hypothétique de création: après le second séisme?

Situation par rapport à la parcelle: lien avec la domus.

Situation par rapport à l'habitat: accès à la domus.

Description des aménagements: deux vasques de foulage contre le mur septentrional. Chacune dispose d'un vase pris dans la maçonnerie pour contenir les agents détergents.

Interprétation de la situation en 79: foulerie.

Inventaire des objets mis au jour dans le local: aucun objet signalé.

\section{Bottega Con ABITAZione (IV, 10-11) (fig. 208)}

Période de fouille: 1929-1932.

Bibliographie: Maiuri 1958 b (432-433); de Vos de Vos 1982 (273); de Kind 1998 (155-158); Pesando - Guidobaldi 2006 (336).

Nombre d'unité(s) architecturale(s) en 79: 1, comportant 1 local commercial.

Seuils: IV, 10 (seuil emporté); IV, 11 (seuil de type C1a en tuf).

\section{Boutique IV, 10}

Période de fouille: 1929-1932.

Bibliographie: Maiuri 1958 b (432-433); de Vos de Vos 1982 (273); Pesando - Guidobaldi 2006 (336).
Période hypothétique de création: phases postaugustéennes.

Situation par rapport à la parcelle: lien avec la domus.

Situation par rapport à l'habitat: accès à la domus.

Description des aménagements: comptoir en équerre (endommagé par les fouilles en galerie) comportant un unique dolium.

Interprétations de la situation en 79: bottega di cereali / commerce alimentaire (type 3 ).

Inventaire des objets mis au jour dans le local:

75741 = E464: [Céramique] Anfora vinaria biansata dell'altezza di metri 0.75 e del diametro della bocca di metri 0.14 sul collo tiene alcune lettere rosse.
10

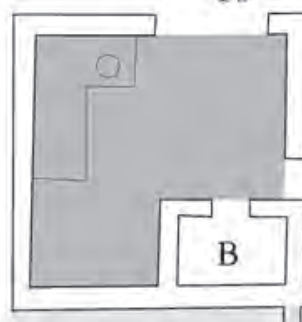

10

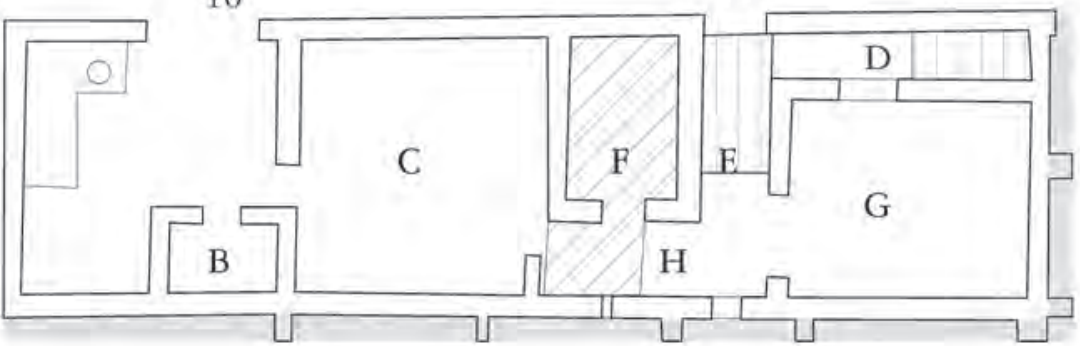

11

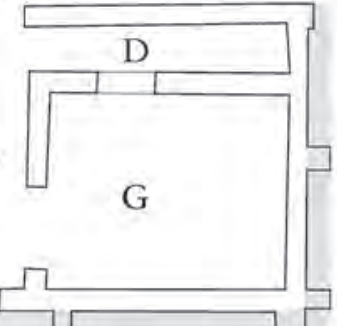

11

\section{C}

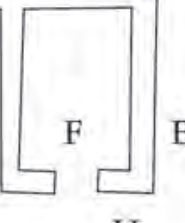

$\mathrm{H}$

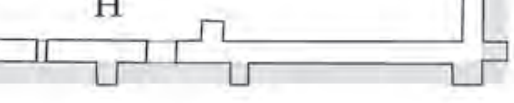
. 
Période de fouille: 1931-1932.

Bibliographie: Maiuri 1958 b (433-436); de Vos - de Vos 1982 (273-274); de Kind 1998 (159-164); Pesando - Guidobaldi 2006 (336-337).

Nombre d'unité(s) architecturale(s) en 79: 2; 1 comportant 1 local commercial; 1 local commercial indépendant.

Seuils: IV, 12 (seuil emporté); IV, 13 (seuil de type C1a en tuf); IV, 14 (seuil emporté); IV, 15 (seuil de type D1b en lave); IV, 16 (seuil de type D1b en tuf).

\section{Boutique IV, 14}

Période de fouille: 1932.

Bibliographie: Maiuri 1958 b (436); de Vos - de Vos 1982 (273); Pesando - Guidobaldi 2006 (337).

Longueur: 5,2 m; largeur: 4,4 m; surface: 23,2 m². Pièce annexe: aucune.

Période hypothétique de création: après le second séisme.

Situation par rapport à la parcelle: lien aboli.

Situation par rapport à l'habitat: accès à l'étage.

Description des aménagements: aucun aménagement directement perceptible, à l'exception de la latrine située dans l'angle sud-est de la boutique.

Interprétations de la situation en 79: taberna vasaria (A. Maiuri) / commerce de vin (crétois).

Inventaire des objets mis au jour dans le local: aucun objet inventorié au moment de la fouille. 36 amphores de type AC2 ou AC4 découvertes et répertoriées grâce aux inscriptions peintes qu'elles portaient non inventoriées lors de la fouille.

\section{Boutique IV, 15-16}

Période de fouille: 1931-1932.

Bibliographie: Maiuri 1958 b: (434-435); de Vos - de Vos 1982 (273-274); Jansen 1990 (n. 21); Pagano 1997 (84); Pesando - Guidobaldi 2006 (336-337).

Longueur: 6,5 m; largeur: $5,3 \mathrm{~m}$; surface: $32,3 \mathrm{~m}^{2}$.

Pièces annexes: quatre pièces annexes (surface cumulée: $54 \mathrm{~m}^{2}$.) utilisées pour la réception des clients et la préparation des mets.

Période hypothétique de création: phase postaugustéenne.

Situation par rapport à la parcelle: lien avec la domus.

Situation par rapport à l'habitat: accès à la domus.

Description des aménagements: comptoir maçonné en double équerre le long du mur occidental, contenant huit dolia. Un bras annexe se situe contre la paroi méridionale, avec un seul dolium. Dans la partie nord du comptoir, présentoir de trois gradins. Dans l'angle sud-est du local principal, une latrine. Les plats sont préparés dans la pièce 8 . Les pièces 6,7 et 9 servent tout autant au stockage qu'à la réception des clients.

Interprétations de la situation en 79: taberna et popina (A. Maiuri) / commerce alimentaire (type 1).

Inventaire des objets mis au jour dans le local:

Boutique principale. $75961=$ E684: [Bronze] Casserola con ansa rotta. Alta m. 0.09 e del diametro superioredim. 0.15;75962=E685:[Verre]Unguentario. Alto m. 0.08 e del diametro superiore di m. 0.015; 75963 = E686: [Bronze] Vaso a forma circolare con orlo svasato. Inventario 686. È alto m. 0.10 e del diametro superiore di $m$. 0.20; $76057=\mathrm{E} 780$ : [Bronze] Moneta di modulo medio. Del diametro di m. 0.024 e dello spessore di m. 0.002 è dell'epoca della Repubblica; 76058 = E781: [Bronze] Moneta di modulo medio del diametro di m. 0.024 e dello spessore di m. 0.002. Data la forte incrostazione non si conosce l'epoca; $76059=$ E782: [Bronze] Moneta di modulo medio. Del diametro di m. 0.025 e dello spessore di $m$. 0.002; 76062 = E785: [Bronze] Moneta di modulo medio. Del diametro di m. 0.024 e dello spessore di m.0.002.

Pièce annexe 6. $76026=$ E749: [Céramique arétine] Piatti numero 7 frammentati ma di facile composizione. Misurano m. 0.17 di diametro e m. 0.03 di profondità; $76027=$ E750: [Céramique] Piatto frammentato. Del diametro di m. 0.34 e profondo m. $0.04 ; 76028$ = E751: [Céramique] Urceo con orlo svasato. Alto m. 0.24 e del diametro bocca di m. 0.03 ; 76029 = E752: [Céramique] Urceo monoansato $e$ del diametro di m. 0.04 ed alto m. 0.19; 76030 = E753: [Bronze] Brocchetta monoansata. Mancante di una parte dell'orlo alta m. 0.13 e del diametro di $m$. 0.06.

Pièce annexe 7. 76001 = E724: [Bronze] Pentola col fondo distaccato contenente una piccola quantità di orzo. É alta m. 0.20 e del diametro base m. 0.10; 76002 = E725: [Bronze] Brocchetta con ansa distaccata e frammentata alla base. Alta m. 0.19 e del diametro della base di m. 0.15; 76011 = E734: [Bronze] Piccolo campanello. Alto m. 0.055 con la base a forma rettangolare di $m .0 .03$ per $0.025 ; 76012$ = E735: [Bronze] Piccolo campanello. Alto m. 0.055 con la base di m. 0.03 per $0.025 ; 76013=$ E736: [Argent] Anello con due teste di serpente con gli occhi di oro. Il diametro è di m. 0.017; $76014=$ E737: [Argent] Moneta? Del diametro di 0.015; 76015 = E738: [Céramique] Vasettino a forma circolare con ansa. E' alto m. 0.055 e del diametro della bocca di m. 0.035; 76016 = E739: [Pain] Un pezzo mancante di una piccola parte. Il diametro superiore è di 0.18; $76017=\mathrm{E} 740$ : [Bronze] Campanello. Alto m. 0.055 e con la base di m. 0.03 per $0.025 ; 76064=$ E787: [Corde] Zoccoli per cavalli n. 11 . Essi sono di corda di varie dimensioni; $76065=$ E788: 
[Verre] Unguentario. Lungo m.0.10 e del diametro di m.0.16; 76066 = E789: [Verre] Unguentario. Lungo m.0.055 di m.0.017 di diametro. Fragments provenant d'un nombre d'amphores indéterminé, dont un nombre non spécifié est pourvu d'une unique inscription peinte, non inventoriés au moment de la fouille; 1 fragment de vase en céramique arétine, non inventorié.
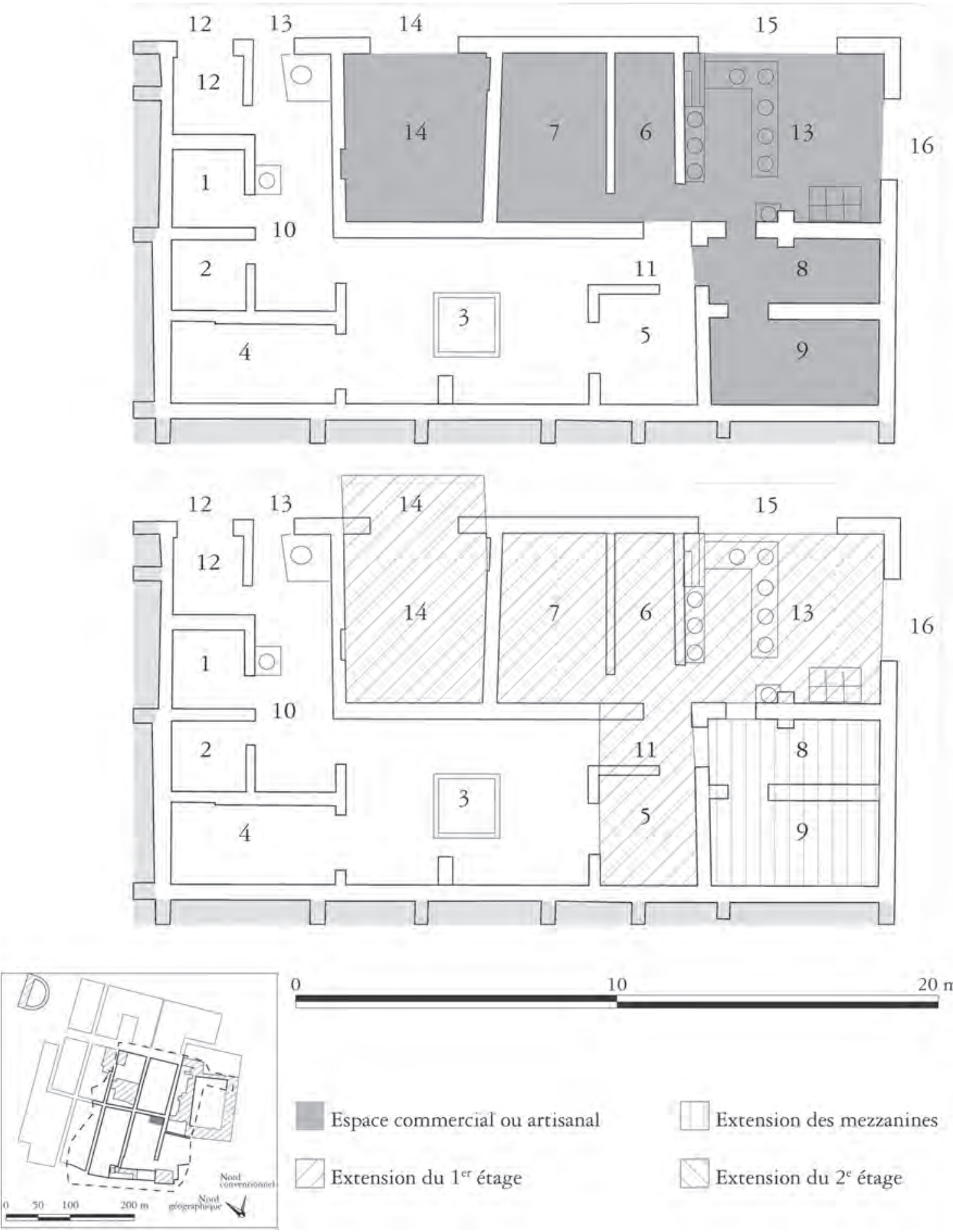

Fig. 209 - Plan de la Grande taberna con abitazione (IV, 12-16) et de ses boutiques (échelle: 1/200). 

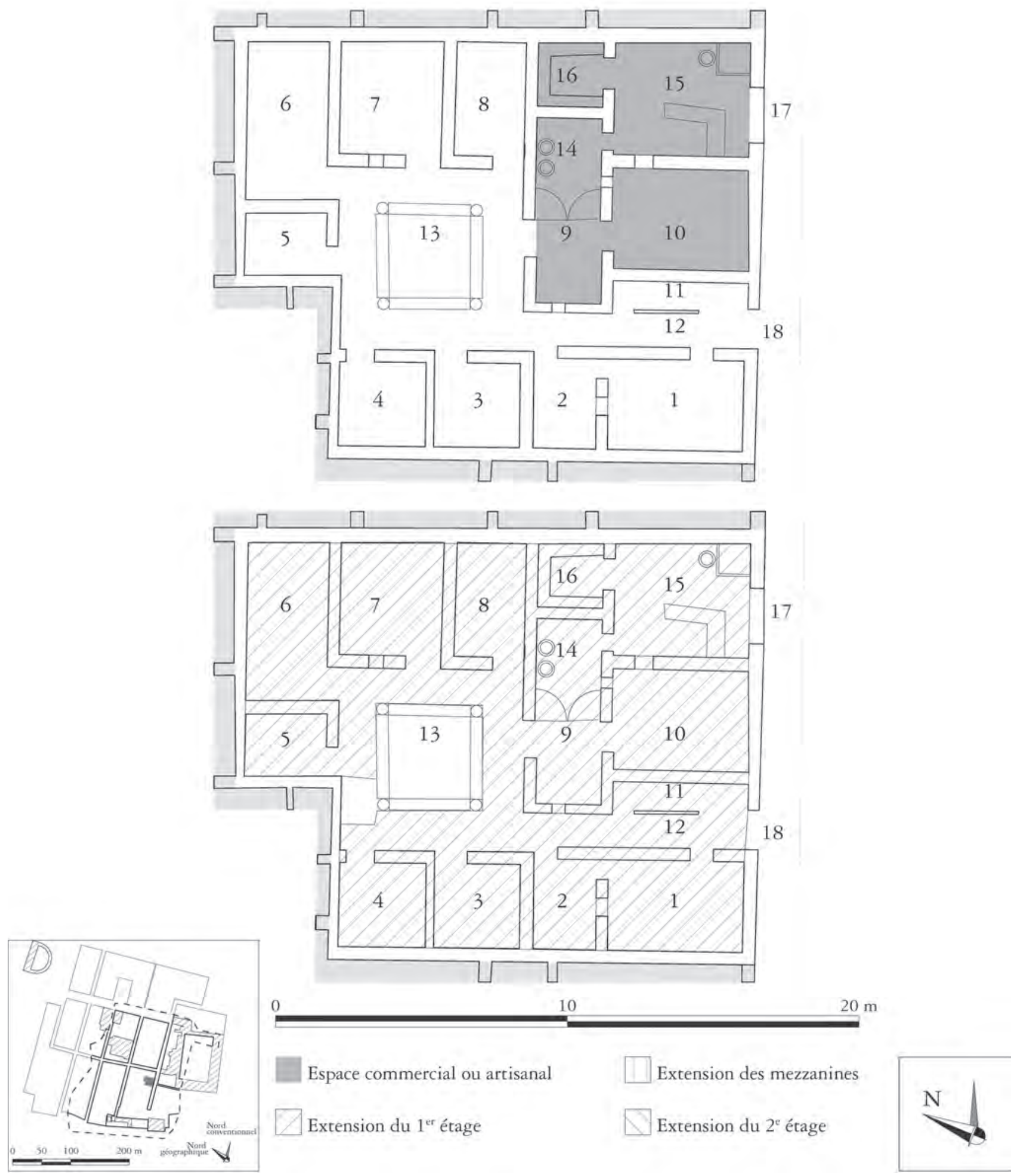

Fig. 210 - Plan de la Casa del priapo (IV, 17-18) et de sa boutique (échelle: 1/200). 
Période de fouille: 1931-1932.

Bibliographie: Maiuri 1958 b (436-440); de Vos de Vos 1982 (274); de Kind 1998 (165-170); Pesando - Guidobaldi 2006 (337-338).

Nombre d'unité(s) architecturale(s) en 79: 1, comportant 1 local commercial.

Seuils: IV, 17 (seuil emporté); IV, 18 (seuil emporté).

\section{Boutique IV, 17}

Période de fouille: 1931-1932.

Bibliographie: Maiuri 1958 b (437); de Vos - de Vos 1982 (274); Pagano 1997 (84-85); Pesando Guidobaldi 2006 (338).

Longueur: 4,7 m; largeur: 3,9 m; surface totale: $54,3 \mathrm{~m}^{2}$ (en incluant les pièces $9,10,14$ et 16).

Pièces annexes: les pièces 9 et14 servent au service et au stockage, les pièces 10 et 16 à la réception des clients.

Période hypothétique de création: dès la période augustéenne? domus

Situation par rapport à la parcelle: lien avec la

Situation par rapport à l'habitat: accès à la domus.

Description des aménagements: comptoir maçonné en équerre sans inclusion de dolium. Une telle jarre est disposée contre la paroi septentrionale du local, à proximité de la table de cuisson. Un passe-plat est ménagé dans la paroi méridionale, vers la pièce 10 . Un banc maçonné court sur trois côtés dans la pièce 16. Au-dessus de celui-ci se trouvaient des porte-amphores. Dans la pièce 14, deux dolia ont été observés lors de la fouille, dont l'un contenait des noix laissées sur le site après la fouille.

Interprétations de la situation en 79: taberna et popina (A. Maiuri) / commerce alimentaire (type 1).

Inventaire des objets mis au jour dans le local:

Boutique principale. $75996=$ E719: [Bronze] Moneta di modulo medio. Del diametro di m. 0.024 e dello spessore di m. 0.003 è dell'epoca di Cesare; 75997 = E720: [Bronze] Urceo ben conservato. Alto m. 0.13 e del diametro della base di m. 0.05. 1 amphore indéterminée pourvue d'inscription peinte, non inventoriée au moment de la fouille.

Pièce annexe a. 75985 = E708: [Végétaux] Kg 15 di fave. 5 amphores indéterminées pourvues d'inscriptions peintes, non inventoriées au moment de la fouille.

Pièce annexe 9. 75970 = E693: [Bronze] Vaso imitazione dolio con orlo alto. Misura m. 0.29 di altezza per m. 0.14 di diametro della bocca. L'orlo è alto m. 0.04. Nell'interno vi sono delle noci; $75971=\mathrm{E} 694$ : [Bronze] Guantiera con orlo svasato lunga m. $0.41 \mathrm{e}$ largo m. 0.30. L'orlo è largo m. 0.03 e la profondità è di m. $0.015 ; 75972$ = E695: [Bronze] Casserola. Lunga m. 0.27 ansa compresa, alta m. 0.07 e del diametro superiore di m. 0.14; $75980=$ E703: [Bronze] Urceo con bocca a forma di becco. Alto m. 0.15 del diametro della bocca di m. 0.045. Il becco è lungo m. 0.01; 75981 = E704: [Bronze] Vaso a forma circolare con orlo svasato e schiacciato al centro. È alto m. 0.20 e il diametro della bocca è di m. 0.24. L'orlo è largo m. 0.15. Il vaso in parola è rotto in varie parti. 3 amphores indéterminées pourvues d'inscriptions peintes, non inventoriées au moment de la fouille. 


\section{INSULA V}

Casa del telaio (V, 3) (fig. 211)

Période de fouille: 1928-1932.

Bibliographie: Maiuri 1958 b (425-429); de Vos - de Vos 1982 (294); Ganschow 1989 (239-257); Pagano 1997 (58); Pesando - Guidobaldi 2006 (347).

Nombre d'unité(s) architecturale(s) en 79: 1, sans local commercial.

Seuils: V, 3 (seuil de type C1a en tuf gris); le supposé seuil V, 4 est la fraction d'un seuil de boutique (type D1a) dont seule la glissière aurait été fonctionnelle. Cette porte a été créée lors de la restauration.
Interprétations de la situation en 79: A. Maiuri a interprété cette comme le lieu de résidence et de travail d'un tisserand, comme le montre la partie «industrielle» de la maison, tout en soulignant l'absence d'espace de vente. En l'état actuel des recherches sur la production textile, il est impossible de déterminer si le métier à tisser découvert dans la branche orientale du portique avait une vocation marchande ou s'il s'agissait d'un métier utilisé dans le seul cadre des activités domestiques.
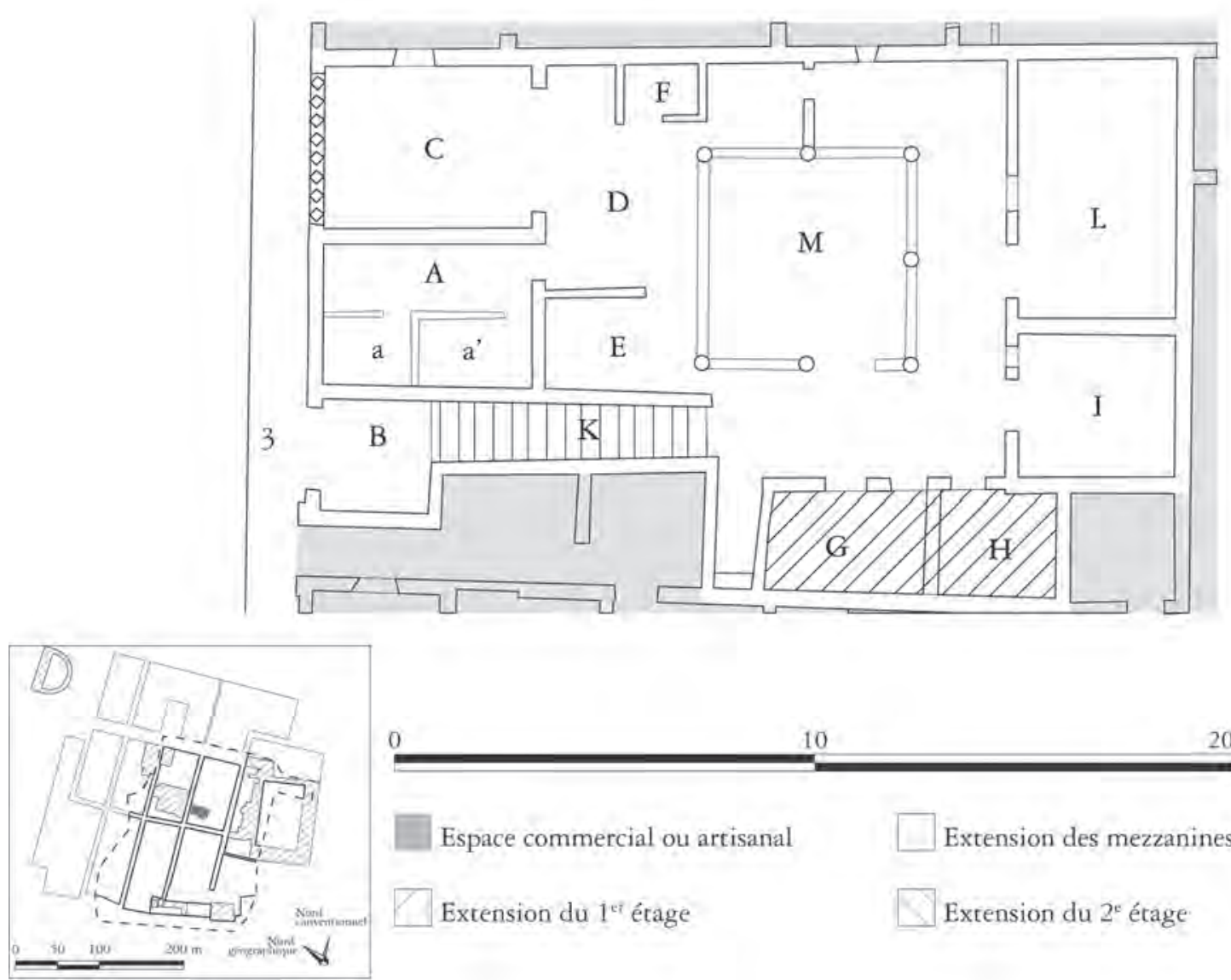

0

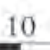

$20 \mathrm{~m}$

Espace commercial ou artisanal

Extension des mezzanines

Extension du $1^{\text {et }}$ étage

Extension du $2^{\mathrm{c}}$ étage

Fig. 211 - Plan de la Casa del telaio (IV, 3 ; échelle: 1/200).

Casa di Nettuno e Anfitrite (V, 6-7) (fig. 212)

Période de fouille: 1932-1934.

Bibliographie: Maiuri 1958 b (393-403); de Vos - de Vos 1982 (293); Pagano 1997 (60-63); Pesando - Guidobaldi 2006 (348-350).
Nombre d'unité(s) architecturale(s) en 79: 1, comportant 1 local commercial.

Seuils: V, 6 (seuil emporté); V, 7 (seuil de type C1a en calcaire blanc). 


\section{Boutique V, 6}

Période de fouille: 1933.

Bibliographie: Maiuri 1958 b (402-403); de Vos - de Vos 1982 (293); Pagano 1997 (60-61); Mols 1999 (200-202); Pesando - Guidobaldi 2006 (350).

Longueur: 5,2 m; largeur: 4,1 m; surface: $21 \mathrm{~m}^{2}$. Pièce annexe: aucune.
Période hypothétique de création: après le séisme de 62.

Situation par rapport à la parcelle: lien avec la domus.

Situation par rapport à l'habitat: accès à la domus.

Description des aménagements: comptoir maçonné en équerre dans lequel sont inclus deux
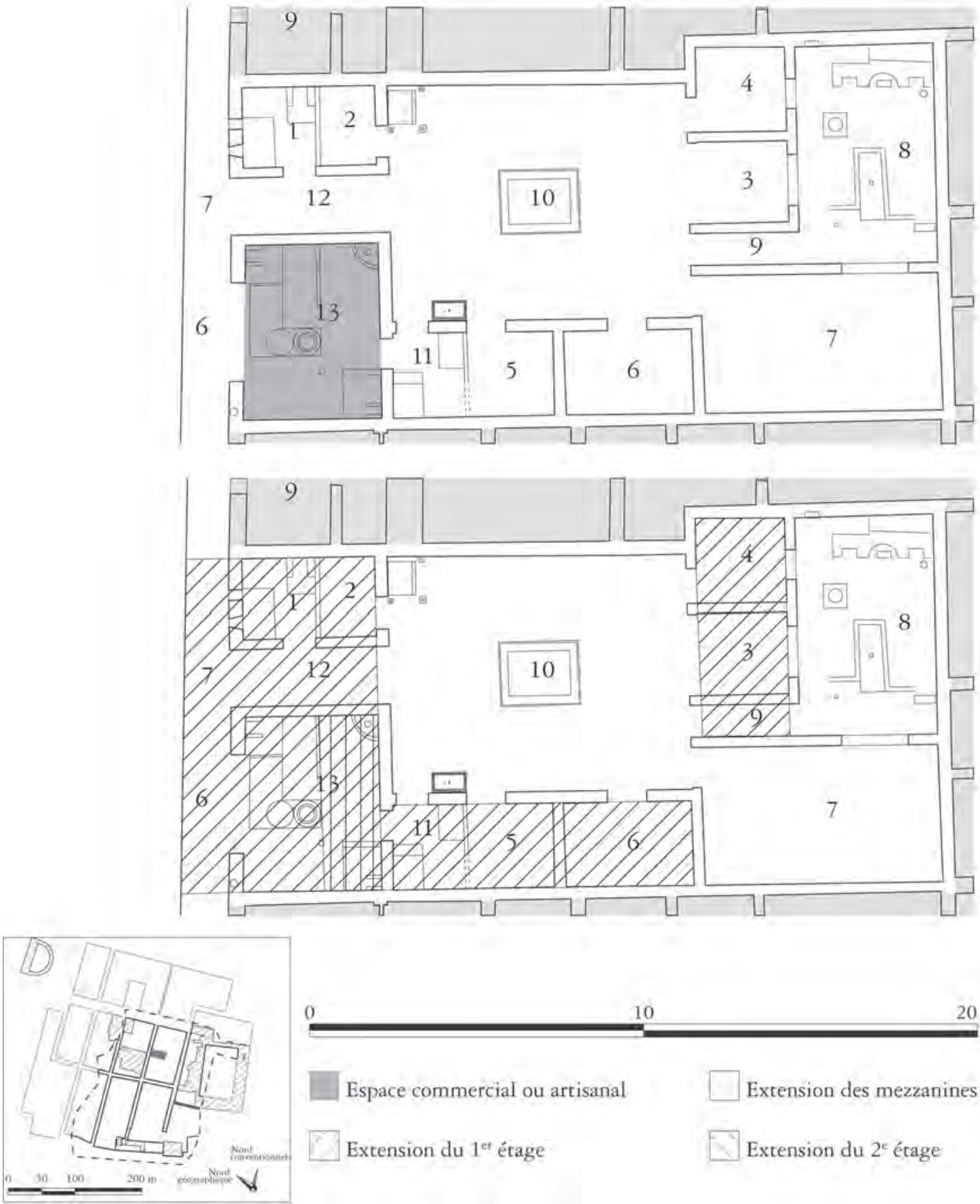

$20 \mathrm{~m}$

Espace commercial ou artisanal

Extension du $1^{\text {et étage }}$
Extension des mezzanines

Extension du $2^{e}$ étage

Fig. 212 - Plan de la Casa di Nettuno e Anfitrite (V, 6-7) et de sa boutique (échelle: 1/200). 
dolia. Àl'extrémité septentrionale, une table de cuisson présentait un chauffe-eau alimenté en eau sous pression. Une seconde table de cuisson est disposée dans l'angle sud-est. La paroi méridionale présente un porte-amphores trouvé vide. Une cloison en bois délimite un espace en retrait du comptoir. Derrière celleci, au sol, une évacuation d'eau a pu servir «d'évier». Au-dessus de cet espace se trouve une mezzanine.

Interprétations de la situation en 79: caupona (A. Maiuri) / commerce alimentaire (type 1).

Inventaire des objets mis au jour dans le local:

Boutique principale. $76281=\mathrm{E} 1004$ : [Bronze] Forma per pasticceria lunga m. 0.18 e del diametro al centro di $m$. 006. È divisa in due parti $; 76282=\mathrm{E} 1005$ : [Bronze] Utensile da cucina a forma circolare e con orlo svasato. É alto m. 0.18 e del diametro di m. 0.30; 76288 = E1011: [Bronze] Moneta di modulo medio del diametro di m. 0.026 e dello spessore di m. 0.002;
$76289=$ E1012: [Bronze] Moneta di modulo medio del diametro di m. 0.026 e dello spessore di m. 0.002; $76290=$ E1013: [Céramique] Lucerna bilichne con rostri prolungati e col fondo superiore rotto. La lunghezza totale è di $m .0 .135$ e del diametro di m. 0.05 ; 76291 = E1014: [Céramique] Fritillo alto m. $0.09 e$ del diametro della bocca di m. 0.03; 76292 = E1015: [Céramique] Fritillo con piede. Misura m. 0.09 di altezza per m. 0.03 di diametro; $76293=\mathrm{E} 1016$ : [Bronze] Tripode mancante di due piedi e parta della decorazione. Ė alto m. 0.125 ed il diametro superiore è di m. 0.112. Tra un piede e l'altro vi è una palmetta, ora una solamente è in sito lunga m. 0.08 e larga al centro m. 0.07; 76306 = E1029: [Bronze] Patera con ansa distaccata. Misura m. 0.33 di diametro e m. 0.135 di altezza; $76307=$ E1030: [Céramique] Terracotta aretina. Lucerna monolichne col rostro rotto. È lunga m. 0.10 e m. 0.035 di diametro superiore.

\section{Casa dell'Apollo citaredo (V, 9-12) (fig. 213)}

Période de fouille: 1938-1939.

Bibliographie: Maiuri 1958 b (247-252); de Vos - de Vos 1982 (290-292); Pagano 1997 (71); Pesando - Guidobaldi 2006 (351-352).

Nombre d'unité(s) architecturale(s) en 79: 1, comportant 2 locaux commerciaux.

Seuils: V, 9 (seuil emporté); V, 10 (seuil de type D1b en lave); V, 11 (seuil de type C1a en travertin); V, 12 (seuil de type D1a en tuf).

\section{Boutique V, 9-10}

Période de fouille: 1938.

Bibliographie: Maiuri 1958 b (251); de Vos - de Vos 1982 (292); Pagano 1997 (71); Pesando Guidobaldi 2006 (351).

Longueur: 6,8 m; largeur: 5,5 m; surface: $26 \mathrm{~m}^{2}$.

Pièce annexe: aucune. L'espace situé au sud du comptoir a pu servir de pièce annexe.

Période hypothétique de création: phase augustéenne.

Situation par rapport à la parcelle: lien avec la domus.

Situation par rapport à l'habitat: accès à la domus.

Description des aménagements: comptoir maçonné en double équerre disposé contre la paroi orientale. Trois dolia y sont insérés. Quatre autres dolia sont fixés dans le sol au sud du comptoir. Des empreintes d'étagères sont visibles sur le mur méridional du local. Une base maçonnée a pu servir, dans une phase antérieure à l'éruption, de base d'escalier. Il n'est plus en usage en 79. Après la création du commerce alimentaire (consécutive au séisme de 62), une conduit d'alimentation en eau sous pression traverse le local.

Interprétations de la situation en 79: taberna (A. Maiuri) / commerce alimentaire (type 3).

Inventaire des objets mis au jour dans le local:

Boutique principale. $77228=$ E1948: [Céramique] Lucerna bilichne con ansa rotta e rostri prolungati. Misura m. 0.11 per 0.07 di diametro. Sul fondo superiore tiene il seguente bollo [Lvc].

\section{Boutique V, 12}

Période de fouille: 1938-1939.

Bibliographie: Maiuri 1958 b (252); de Vos - de Vos 1982 (290); Pagano 1997 (71); Mols 1999 (205207); Pesando - Guidobaldi 2006 (351).

Longueur: $3,4 \mathrm{~m}$; largeur: $2,9 \mathrm{~m}$; surface: $10 \mathrm{~m}^{2}$.

Pièce annexe: aucune.

Période hypothétique de création: phase augustéenne.

Situation par rapport à la parcelle: lien avec la domus.

Situation par rapport à l'habitat: accès à la domus.

Description des aménagements: le seul aménagement visible est une étagère fixée au mur occidental, retrouvée vide.

Interprétation de la situation en 79: boutique, commerce ou production indéterminés.

Inventaire des objets mis au jour dans le local: quatre balayettes de paille non inventoriées lors de leur découverte, a priori conservées sur place. 

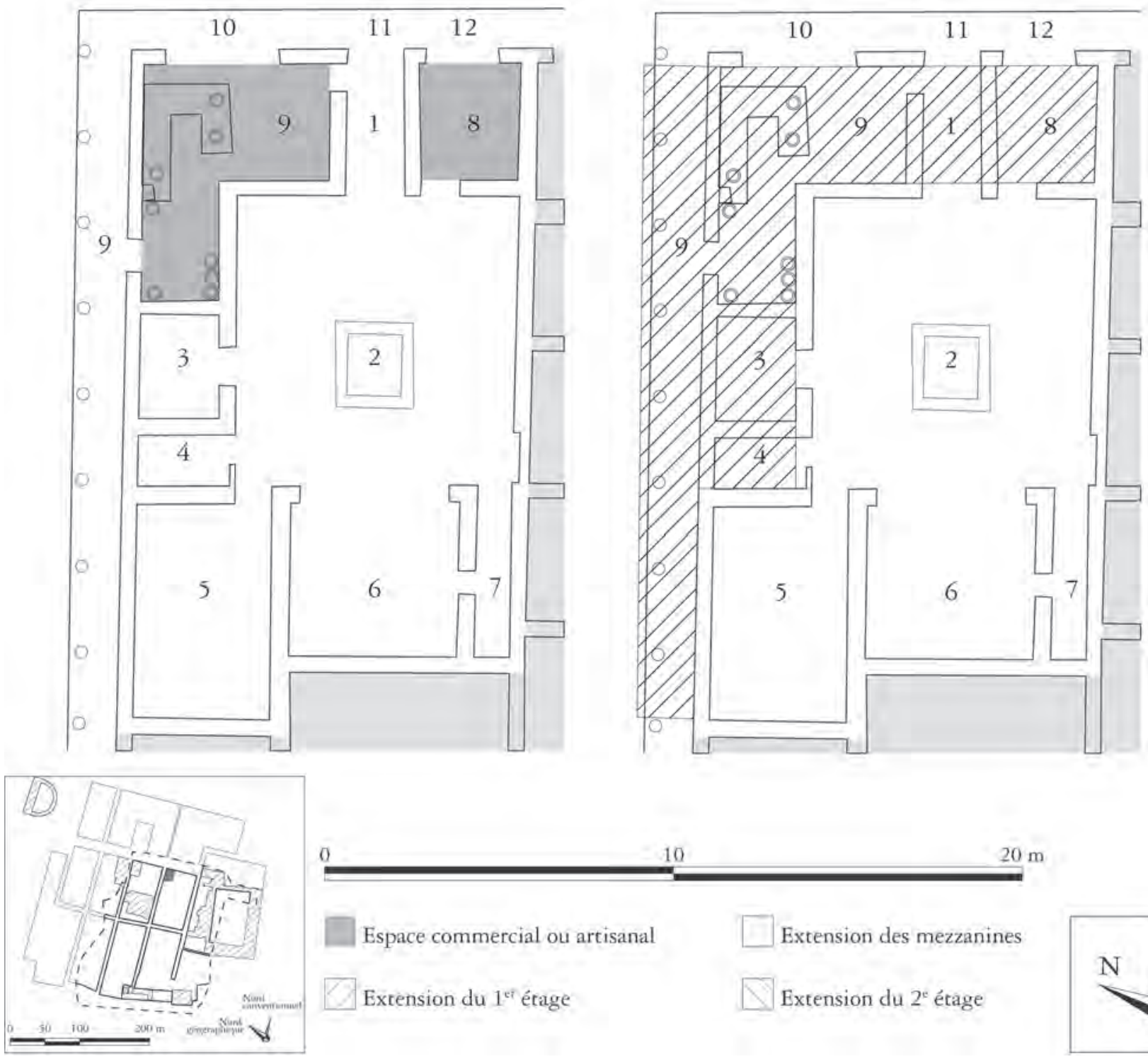

$20 \mathrm{~m}$

Espace commercial ou artisanal

Exrension du $1^{\text {eq }}$ érage

Extension des mezzanines

Extension du $2^{\mathrm{c}}$ étage

Fig. 213 - Plan de la Casa dell'Apollo citaredo (V, 9-12) et de ses boutiques (échelle: 1/200).

Casa del bicentenario (V, 13-16) (fig. 214)

Période de fouille: 1937-1939.

Bibliographie: Maiuri 1958 b (222-239); de Vos - de Vos 1982 (288-290); Wallace-Hadrill 1994 (131133); Pagano 1997 (72-73); Pirson 1999 (72-74); Guidobaldi 2006 (185-190); Pesando - Guidobaldi 2006 (352-355).

Nombre d'unité(s) architecturale(s) en 79: 2, chacune comportant 1 local commercial.

Seuils: V, 13 (seuil de type D1a+b en tuf); V, 14 (seuil de type C1a en calcaire blanc); V, 15 (seuil de type C1a en marbre); V, 16 (seuil de type D1a en calcaire blanc).

\section{Boutique V, 13}

Période de fouille: 1938.

Bibliographie: Maiuri 1958 b (228).

Longueur: 3,9 m; largeur: 3,8 m; surface: $15 \mathrm{~m}^{2}$.

Pièce annexe: aucune.

Période hypothétique de création: phase augustéenne.

Situation par rapport à la parcelle: lien aboli.

Situation par rapport à l'habitat: accès à l'étage.

Description des aménagements: seules trois niches rectangulaires sont ménagées dans la paroi méridionale. 

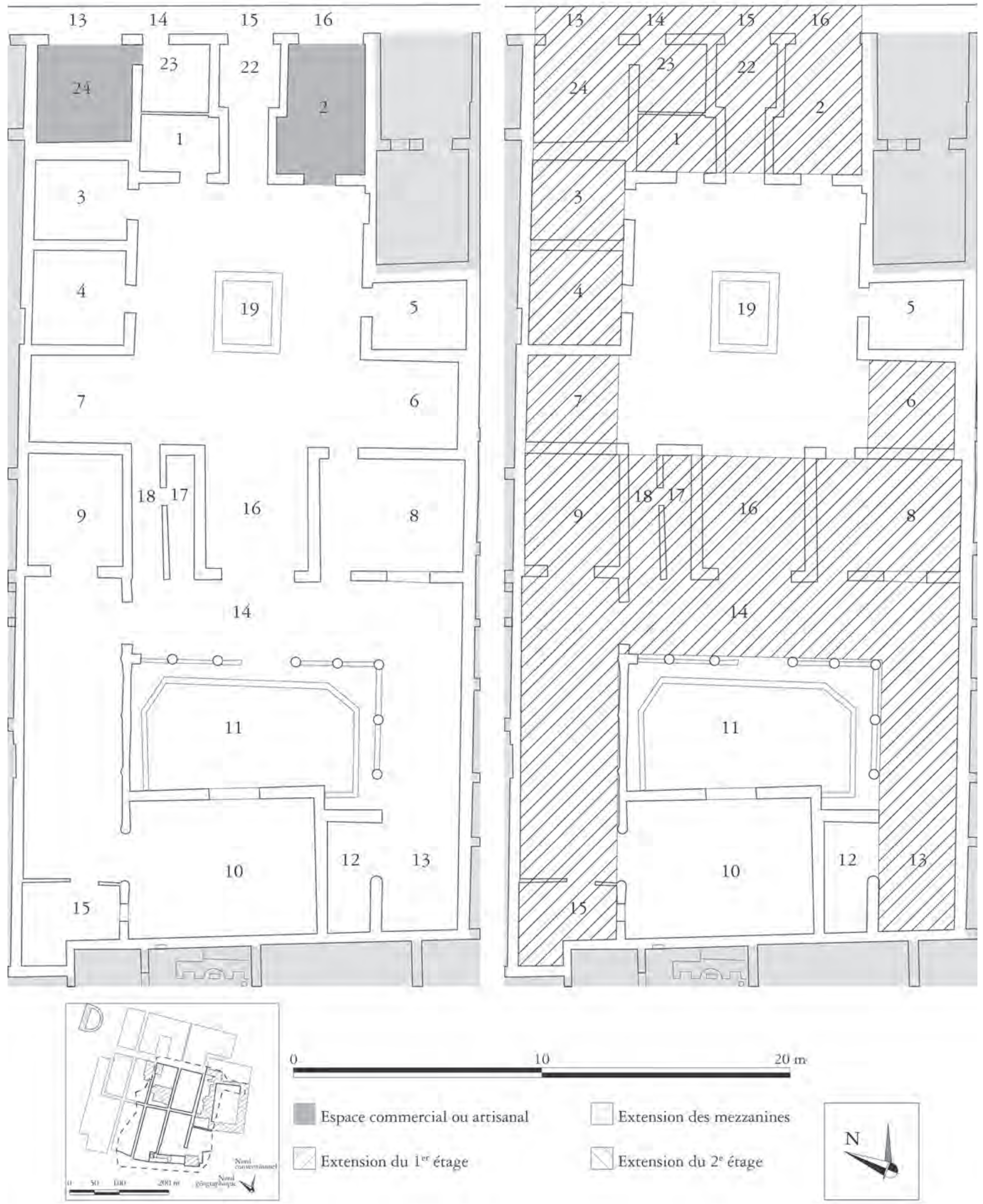

10

$20 \mathrm{~m}$

Fig. 214 - Plan de la Casa del bicentenario (V, 13-16) et de ses boutiques (échelle: 1/200). 
Interprétations de la situation en 79: boutique, commerce ou production indéterminés.

Inventaire des objets mis au jour dans le local: aucun.

\section{Boutique V, 16}

Période de fouille: 1937-1938.

Bibliographie: Maiuri 1958 b (228).

Longueur: $6 \mathrm{~m}$; largeur: 3,6 m; surface: $18 \mathrm{~m}^{2}$.

Pièce annexe: aucune.

Période hypothétique de création: phase augustéenne.
Situation par rapport à la parcelle: lien avec la domus.

Situation par rapport à l'habitat: accès à la domus.

Description des aménagements: aucun aménagement n'est visible. L'empreinte d'un escalier dans le décor de la paroi orientale semble renvoyer à une phase antérieure à l'éruption.

Interprétation de la situation en 79: boutique, commerce ou production indéterminés.

Inventaire des objets mis au jour dans le local: aucun.
Période de fouille: 1937-1938.

Bibliographie: Maiuri 1958 b (238-239); Pagano 1997 (73-74); Pesando - Guidobaldi 2006 (355).

Nombre d'unité(s) architecturale(s) en 79: 2, dépourvues de local commercial.
Seuils: V, 17 (seuil de type C1a en marbre); V, 18 (seuil de type non déterminable en tuf).

Interprétations de la situation en 79: Bottega di merce non troppo commune (A. Maiuri) / boutique transformée en appartement.
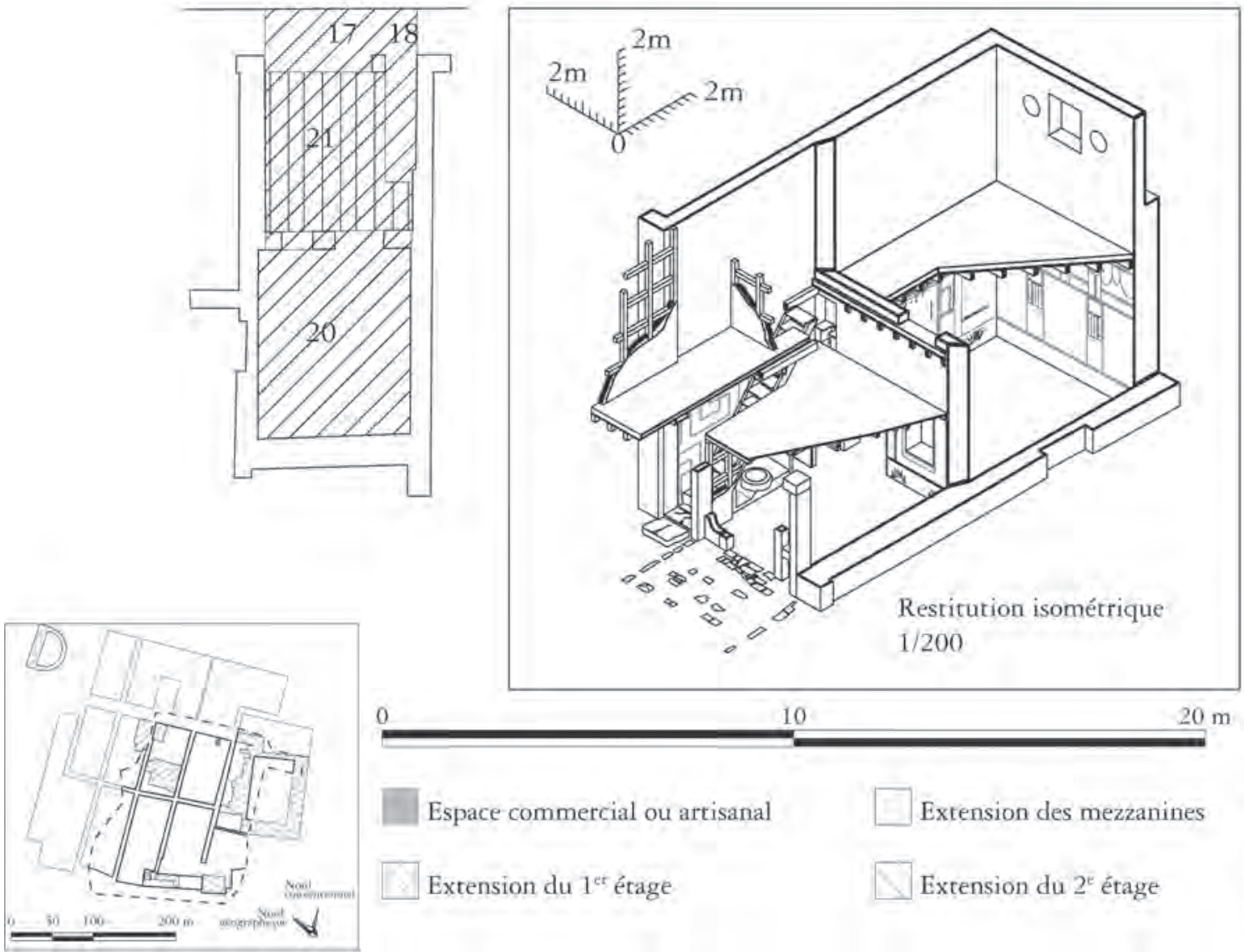

Espace commercial ou artisanal

Extension des mezzanines

Extension du $1^{\text {er }}$ étage

Extension du $2^{e}$ étage

Fig. 215 - Plan et écorché isométrique des appartements V, 17 et V, 18 (échelle: 1/200). 
Botteghe sul decumano massimo, Casa della colonna laterizia (V, 19-25) (fig. 216)

Période de fouille: 1933-1938.

Bibliographie: Maiuri 1958 b (440-444); de Vos - de Vos 1982 (288); Pirson 1999 (72-74); Pesando - Guidobaldi 2006 (355-356).

Nombre d'unité(s) architecturale(s) en 79: 7 dont 4 locaux commerciaux indépendants.
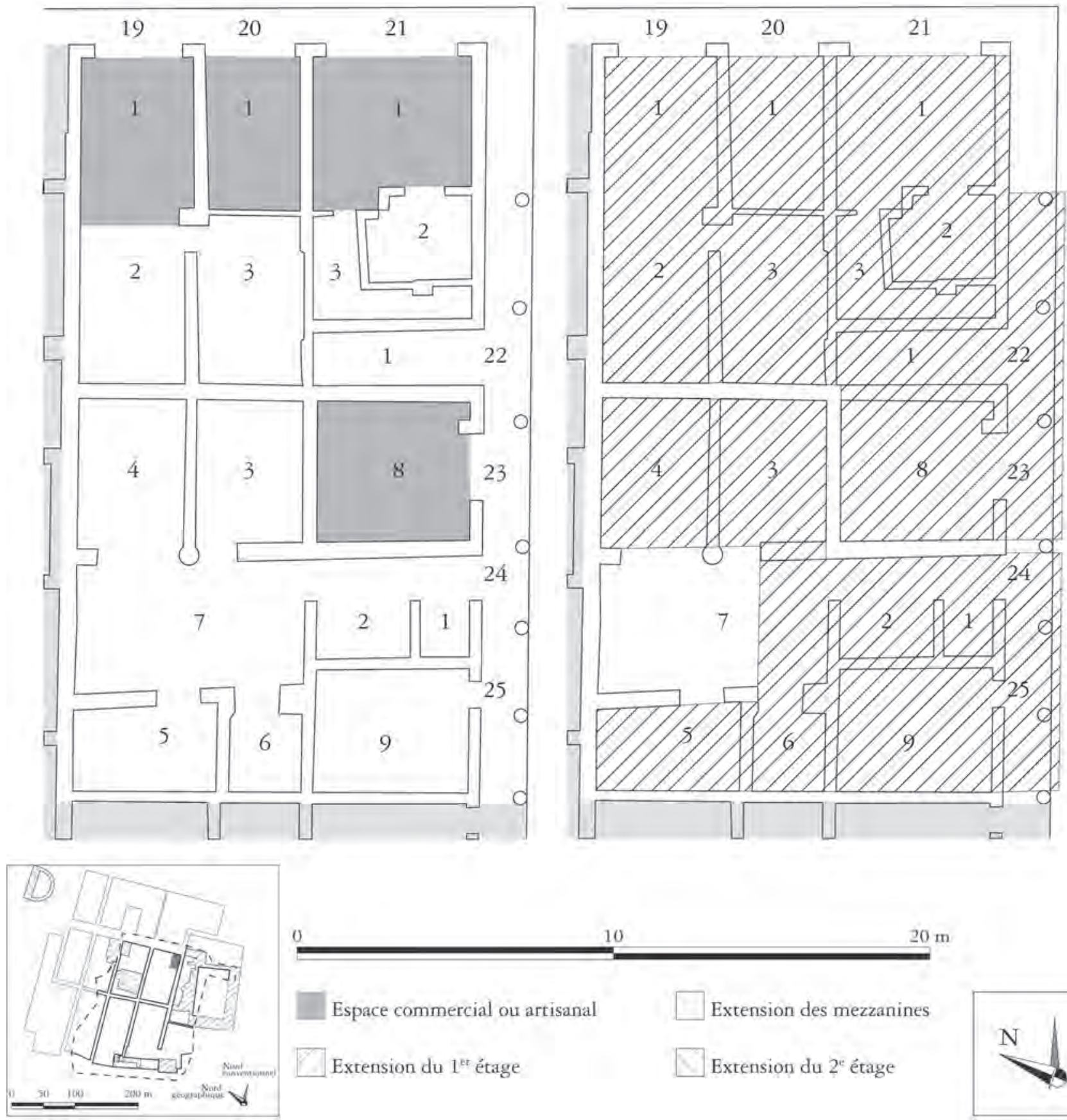

0

10 $20 \mathrm{~m}$

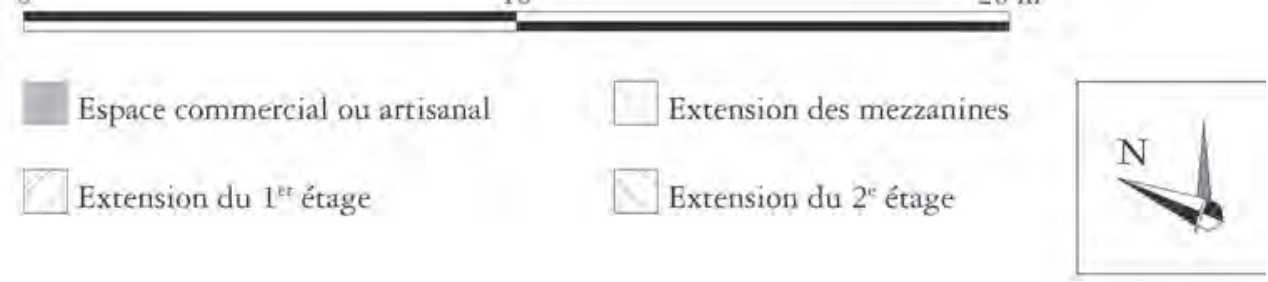

Seuils: V, 19 (seuil de type D1b en tuf); V, 20 (seuil de type D1b en tuf); V, 21 (seuil de type D1b en tuf); V, 22 (seuil emporté); V, 23 (seuil de type C1a en marbre); V, 24 (seuil emporté); V, 25 (seuil emporté).

Fig. 216 - Plan des Botteghe sul decumano massimo (V, 19-22), de la Casa della colonna laterizia (V, 23-25) et de leurs boutiques (échelle: 1/200). 


\section{Boutique V, 19}

Période de fouille: 1937-1938.

Bibliographie: Maiuri 1958 b (441); Pesando - Guidobaldi 2006 (355).

Longueur: 5,3 m; largeur: 3,6 m; surface: $19 \mathrm{~m}^{2}$.

Pièce annexe: deux pièces annexes dont l'une se situe au sud de la boutique V, 20 (surface totale: $34 \mathrm{~m}^{2}$.), utilisées pour y habiter.

Période hypothétique de création: phase préaugustéenne.

Situation par rapport à la parcelle: indépendance.

Situation par rapport à l'habitat: habitat en pièce annexe.

Description des aménagements: le seul élément signalé est une table de cuisson située contre la paroi occidentale du local principal. La pièce 3 présente un encastrement pour l'insertion d'un lit.

Interprétations de la situation en 79: Taberna (A. Maiuri) / commerce alimentaire (type 5).

Inventaire des objets mis au jour dans le local:

Boutique principale. $77053=$ E1774: [Bronze] Anforetta mancante delle anse. È alta metri 0.20 e metri 0.05 di diametro alla bocca; $77056=\mathrm{E} 1777$ : [Bronze] Moneta di modulo piccolo del diametro di metri $0.011 \mathrm{e}$ dello spessore di metri 0.02. E corrosa; $77141=$ E1861: [Bronze] Piede di un tripode alto m. 0.21. La basetta è alta m. 0.02; $77145=$ E1865: [Céramique] Pentola ben conservata. È alta m. 0.10 per m. 0.11 di diametro; 77146 = E1866: [Céramique] Pentola mancante di una piccola parte dell'orlo. Misura m. 0.22 di diametro e m. 0.16 di altezza $; 77147=$ E1867: [Céramique] Piatto alto $m .0 .05$ e m. 0.24 di diametro. Un fond de vase en céramique arétine ; un nombre non spécifié d'amphores [non inventoriées au moment de leur découverte].

Pièce annexe 2. $77114=$ E1834: [Bronze] Patera con ansa spezzata piede sollevato e fondo rotto. $\dot{E}$ alta metri 0.04, metri 0.145 di diametro e metri 0.26 di lunghezza; 77115 = E1835: [Bronze] Utensile per cucina a forma ovale e ansa allungata. Ė in buono stato di conservazione. La sua lunghezza è di metri 0.425 e il diametro metri 0.13; $77126=$ E1846: [Céramique] Oggetto di cucina. É alto m. 0.095 e m. 0.08 di diametro; 77127 = E1847: [Bronze] Candelabro mancante di un piede. È alto m. 1.27; $77136=\mathrm{E} 1856$ : [Bronze] Pentola discretamente conservata. È alta m. 0.21 e m. 0.23 di diametro alla bocca; $77137=\mathrm{E} 1857$ : [Céramique] Piatto molto lesionato. È alto m. 0.05 e il diametro è di m. 0.16; 77138 = E1858: [Verre] Bottiglia panciuta a collo lungo. È in buono stato di conservazione. La sua altezza è di m. 0.18; 77139 = E1859: [Céramique] Piatto fondo mancante di qualche pezzo. Tiene il piede alto. Misura m. 0.075 di altezza e m. 0.245 di diametro. Nel fondo interno tiene il seguente bollo: E lungo m. $0.02 \mathrm{~m} .0 .005$ di altezza.

Pièce annexe 3. 77117 = E1837: [Céramique] Lucerna monolichne col rostro prolungato. Si osserva nel fondo superiore una testa di satiro. La lunghezza è di metri 0.085 e il diametro metri 0.045; $77149=$ E1869: [Céramique] Urceo discretamente conservato alto $m$. 0.43. Nella parte anteriore tiene [un']iscrizione fatta con pittura nera; $77151=$ E1871: [Bronze] Utensile da cucina con anse staccate e fondo rotto. Il diametro è di m. 0.30 e l'altezza m. 0.12.

Provenance non spécifiée. $77084=$ E1804: [Céramique] Lucerna monolichne col rostro prolungato. É alta metri 0.02, metri 0.04 di diametro e metri 0.095 di lunghezza; $77085=$ E1805: [Céramique] Lucerna con ansa rotta e fondo incavato. La sua lunghezza è di metri 0.085 e il diametro metri 0.07; 77086 = E1806: [Céramique] Lucerna con ansa costolata e rostro accorciato. Sui fianchi tiene fisse due false anse. Il diametro è di metri 0.095 la lunghezza metri $0.115 ; 77087$ = E1807: [Céramique] Lucerna monolichne e monoansata lunga metri 0.09, metri 0.035 di altezza e metri 0.07 di diametro; 77088 = E1808: [Céramique] Lucerna lunga metri 0.083 e del diametro di metri 0.078; $77089=$ E1809: [Céramique] Vasettino per pomate con bocca rimboccata e ansa a guscio e a ponte. L'altezza è di metri 0.06 e il diametro alla bocca metri 0.04; 77091 = E1811: [Céramique] Vasettino per pomate alto metri 0.055 del diametro di metri 0038 ; 77092 = E1812: [Verre] Unguentari 2 ben conservati; $77093=\mathrm{E} 1813$ : [Céramique] Coppetta mancante dell'orlo e buona parte della pancia. Nell'interno conserva pece greca; $77094=\mathrm{E} 1814$ : [Céramique] Coppetta del diametro di metri 0.07 e alta metri 0.016; 77095 = E1815: [Verre] Unguentario sostenuto da tre piccoli piedini. Ė mancante di una parte dell'orlo. La sua altezza è di metri 0.06; $77096=\mathrm{E} 1816$ : [Bronze] Pinze lunghe metri 0.081; $77097=\mathrm{E} 1817$ : [Verre] Unguentario di forma allungata alto metri 0.112 e metri 0.015 di diametro alla bocca; 77119 = E1839: [Céramique] Lucerna monolichne col rostro accorciato. E lunga metri 0.09 e metri 0.055 di diametro.

\section{Boutique V, 20}

Période de fouille: 1937.

Bibliographie: Maiuri 1958 b (441); Pesando - Guidobaldi 2006 (355).

Longueur: 4,9 m; largeur: 2,9 m; surface: $14 \mathrm{~m}^{2}$. Pièce annexe: aucune.

Période hypothétique de création: phase préaugustéenne.

Situation par rapport à la parcelle: indépendance.

Situation par rapport à l'habitat: sans espace d'habitation.

Description des aménagements: une vasque haute et dépourvue de système d'évacuation se trouve contre la paroi orientale.

Interprétation de la situation en 79: boutique, commerce ou production indéterminés.

Inventaire des objets mis au jour dans le local: 
Boutique principale. $77080=\mathrm{E} 1800:$ [Bronze] Cassarola con ansa rotta. È alta metri 0.053 e del diametro di metri 0.11; $77101=\mathrm{E} 1821$ : [Céramique] Urceo in buono stato di conservazione alto metri 0.134 e del diametro alla bocca di metri 0.03;77102 = E1822: [Céramique] Lucerna bilichne di formato piccolo. Tiene l'ansa rotta. È lunga metri 0.05 e metri 0.04 di diametro; $77103=$ E1823: [Céramique] Lucerna col rostro prolungato ben conservata. La sua lunghezza è di metri 0.09 di diametro di metri 0.04; $77104=$ E1824: [Céramique] Lucerna con una parte del rostro mancante. Il diametro è di metri 0.04 e la lunghezza metri 0.07; $77116=$ E1836: [Bronze] Gutturnium con ansa distaccata. Ė alto metri 0.12. Un col d'amphore portant une inscription peinte [non inventorié au moment de sa découverte].

\section{Boutique V, 21}

Période de fouille: 1937.

Bibliographie: Maiuri 1958 b (442); Pagano 1997 (74); Pesando - Guidobaldi 2006 (355).

Longueur: $5 \mathrm{~m}$; largeur: 4,85 m; surface: $22 \mathrm{~m}^{2}$.

Pièce annexe: deux pièces annexes se développent au sud du local principal. La seconde contient une latrine.

Période hypothétique de création: phase préaugustéenne.

Situation par rapport à la parcelle: indépendance.

Situation par rapport à l'habitat: habitat en pièce annexe?

Description des aménagements: un comptoir se développait contre la paroi occidentale et présentait deux dolia. Trop endommagé pour déterminer sa forme. Dans la pièce 2 se trouve l'encastrement pour un lit.

Interprétations de la situation en 79: Caupona/ taberna (A. Maiuri)/commerce alimentaire (type 1-3). Inventaire des objets mis au jour dans le local:

Boutique principale. $77050=$ E1772: [Bronze] Moneta di modulo medio del diametro di metri $0.025 e$ dello spessore di metri 0.003. È molto corrosa; $77099=$ E1819: [Céramique] Lucerna monolichne lunga metri 0.095 e del diametro di metri 0.07. Nel fondo superiore tiene per decorazione un grifo; $77100=\mathrm{E} 1820$ : [Céramique] Lucerna lunga metri 0.085 e del diametro di metri 0.07. Un fond de vase en céramique arétine, non inventorié au moment de sa découverte.

\section{Boutique V, 23}

Période de fouille: 1933.

Bibliographie: Maiuri 1958 b (443-444).

Longueur: 4,8 m; largeur: 4,4 m; surface: $21 \mathrm{~m}^{2}$.

Pièce annexe: sans.

Période hypothétique de création: phase préaugustéenne.

Situation par rapport à la parcelle: indépendance. Situation par rapport à l'habitat: accès à l'étage.

Description des aménagements: les GSE indiquent une table de cuisson, disparue.

Interprétation de la situation en 79: boutique, commerce ou production indéterminés.

Inventaire des objets mis au jour dans le local: 1 amphore non inventoriée au moment de sa découverte.

Taberna con abitazione (V, 26-27) (fig. 217)

Période de fouille: 1933-?

Bibliographie: Maiuri 1958 b (444-445); Pagano 1997 (77).

Nombre d'unité(s) architecturale(s) en 79:2 dont 1 comporte 1 local commercial.

Seuils: V, 26 (seuil emporté); V, 27 (seuil de type C1a en tuf).

\section{Boutique V, 27}

Période de fouille: 1933-?

Bibliographie: Maiuri 1958 b (444-445).

Longueur: 4,8 m; largeur: 4,3 m; surface: $20 \mathrm{~m}^{2}$.
Pièce annexe: Sans.

Période hypothétique de création: phase préaugustéenne.

Situation par rapport à la parcelle: lien avec la domus.

Situation par rapport à l'habitat: accès à la domus.

Description des aménagements: aucun aménagement visible.

Interprétation de la situation en 79: boutique, commerce ou production indéterminés.

Inventaire des objets mis au jour dans le local: aucun.

TABerna Con ABitaZione (V, 28-29) (fig. 218)

Période de fouille: 1933-?

Bibliographie: Maiuri 1958 b (445).

Nombre d'unité(s) architecturale(s) en 79: 2 dont 1 local commercial.

Seuils: V, 28 (seuil emporté); V, 29 (seuil emporté).

\section{Boutique V, 28}

Période de fouille: 1933-?

Bibliographie: Maiuri 1958 b (445).

Longueur: 4,8 m; largeur: 4,5 m; surface: $20 \mathrm{~m}^{2}$.

Pièce annexe: la pièce se développant à l'ouest de la boutique a pu servir d'annexe au commerce. 

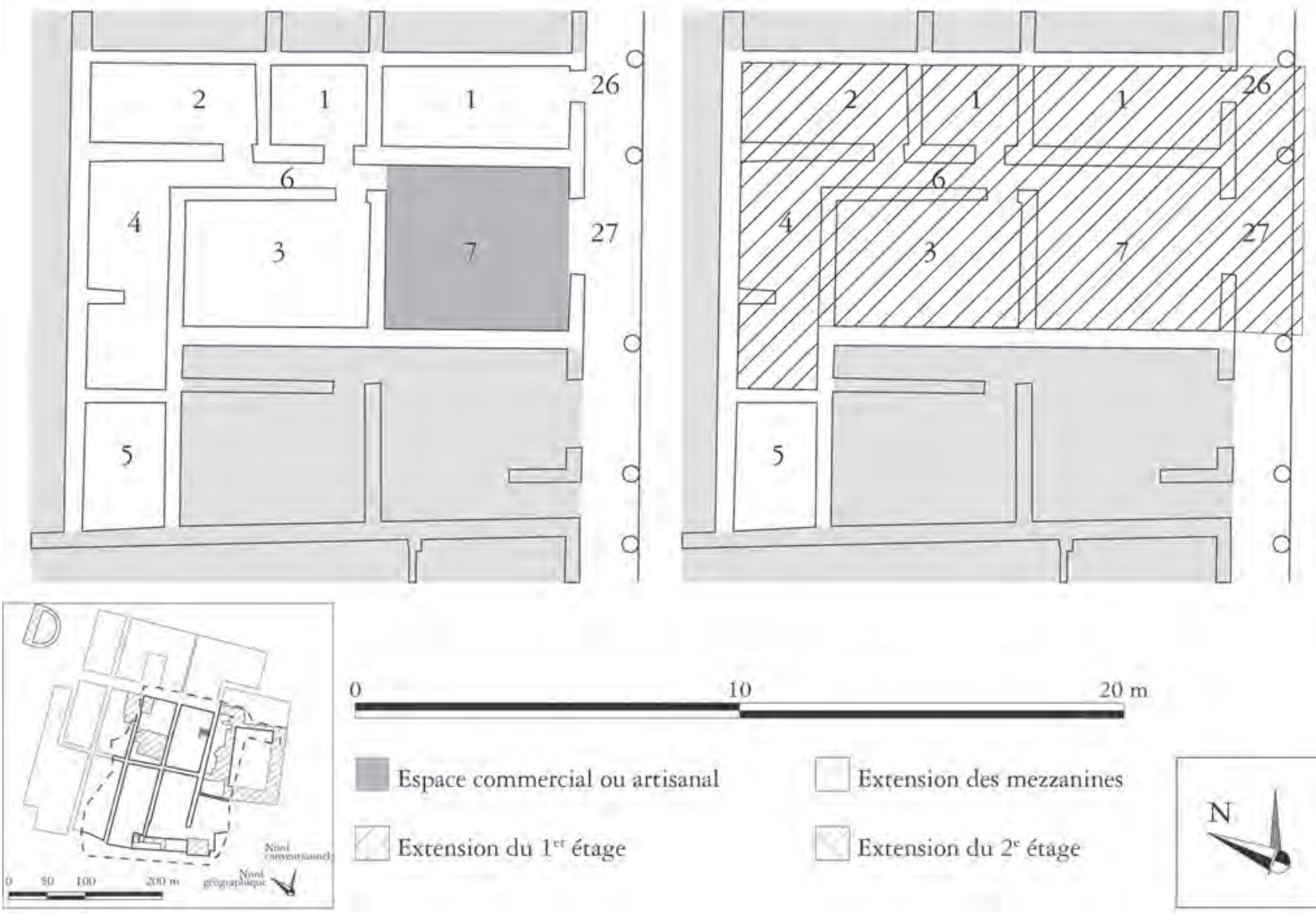

Fig. 217 - Plan de la Taberna con abitazione (V, 26-27) et de sa boutique (échelle: 1/200).
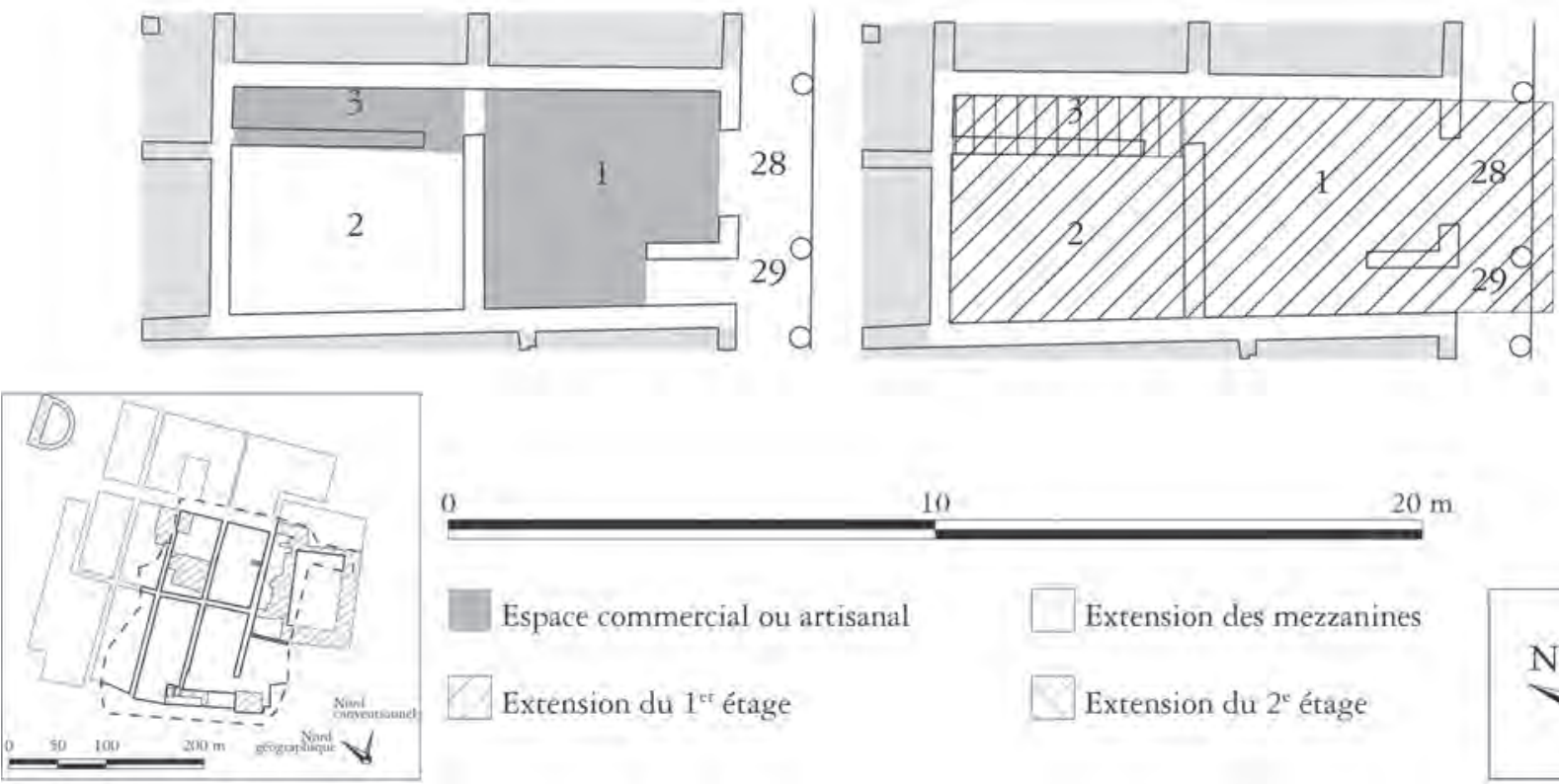

Espace commercial ou artisanal

Extension des mezzanines

Extension du $1^{\mathrm{et}}$ étage

Extension du $2^{\mathrm{e}}$ étage

Fig. 218 - Plan de la Taberna con abitazione (V, 28-29) et de sa boutique (échelle: 1/200). 
Période hypothétique de création: phase préaugustéenne.

Situation par rapport à la parcelle: indépendance.

Situation par rapport à l'habitat: habitat en pièce annexe (?) ou sans lien avec l'habitat.

Description des aménagements: aucun aménagement visible. Une mezzanine est ménagée dans la pièce annexe.
Interprétation de la situation en 79: boutique, commerce ou production indéterminés.

Inventaire des objets mis au jour dans le local:

Boutique principale. $76407=$ E1130: [Verre] Unguentario alto m. 0.11 e del diametro della bocca di m. 0.01 .

CASA con giardino (V, 32-33a) (fig. 219)

Période de fouille: 1931-1933.

Bibliographie: Maiuri 1958 b (431-432); Ganschow 1989 (305-318); Pesando - Guidobaldi 2006 (358).

Nombre d'unité(s) architecturale(s) en 79: 3 dont 1 local commercial indépendant.

Seuils: V, 32 (seuil de type B3 en tuf); V, 33a (seuil de type C1a en calcaire blanc); V, 33 (seuil de type B1 en lave).

\section{Boutique V, 32}

Période de fouille: 1933.

Bibliographie: Maiuri 1958 b (432); Pesando - Guidobaldi 2006 (358).

Longueur: 4,8 m; largeur: 4,3 m; surface: $20 \mathrm{~m}^{2}$.
Pièce annexe: Sans. de 62 .

Période hypothétique de création: après le séisme

Situation par rapport à la parcelle: indépendance.

Situation par rapport à l'habitat: sans lien avec l'habitat.

Description des aménagements: aucun aménagement visible.

Interprétations de la situation en 79: bottega di lavoro di un artigiano (A. Maiuri) / boutique, commerce ou production indéterminés.

Inventaire des objets mis au jour dans le local: aucun.

Casa del gran portale (V, 34-35) (fig. 220)

Période de fouille: 1931-1933.

Bibliographie: Maiuri 1958 b (377-384); Ganschow 1989 (285-302); Papaccio 1990; Pagano 1997 (79); Pesando - Guidobaldi 2006 (358-360).

Nombre d'unité(s) architecturale(s) en 79: 2 dont 1 local commercial indépendant.

Seuils: V, 34 (seuil de type D1a en tuf); V, 35 (seuil de type $\mathrm{C} 1 \mathrm{a}$ en calcaire blanc).

\section{Boutique V, 34}

Période de fouille: 1931.

Bibliographie: Maiuri 1958 b (378).

Période hypothétique de création: après le séisme de 62.
Situation par rapport à la parcelle: lien aboli.

Situation par rapport à l'habitat: habitat à l'étage?

Description des aménagements: une vaste fosse était ouverte au moment de l'éruption dans la partie occidentale du local. Dans l'angle nord-est est visible un muret maçonné dans lequel est inclus un vase céramique.

Interprétation de la situation en 79: Bottega con abitazione a sè (A. Maiuri) / local en travaux lors de l'éruption.

Inventaire des objets mis au jour dans le local: aucun 

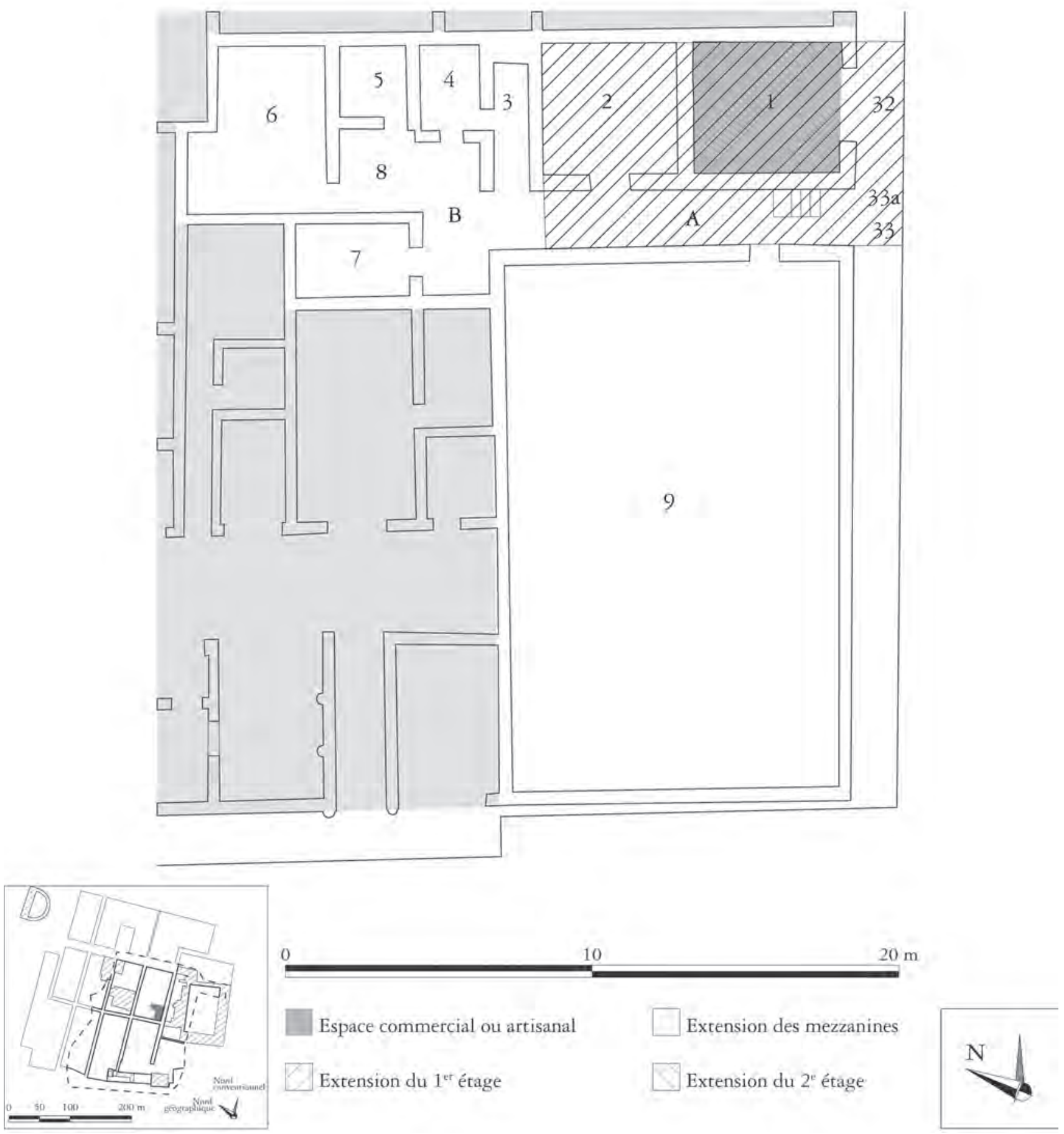

Fig. 219 - Plan de la Casa con giardino (V, 32-33) et de sa boutique (échelle: 1/200). 

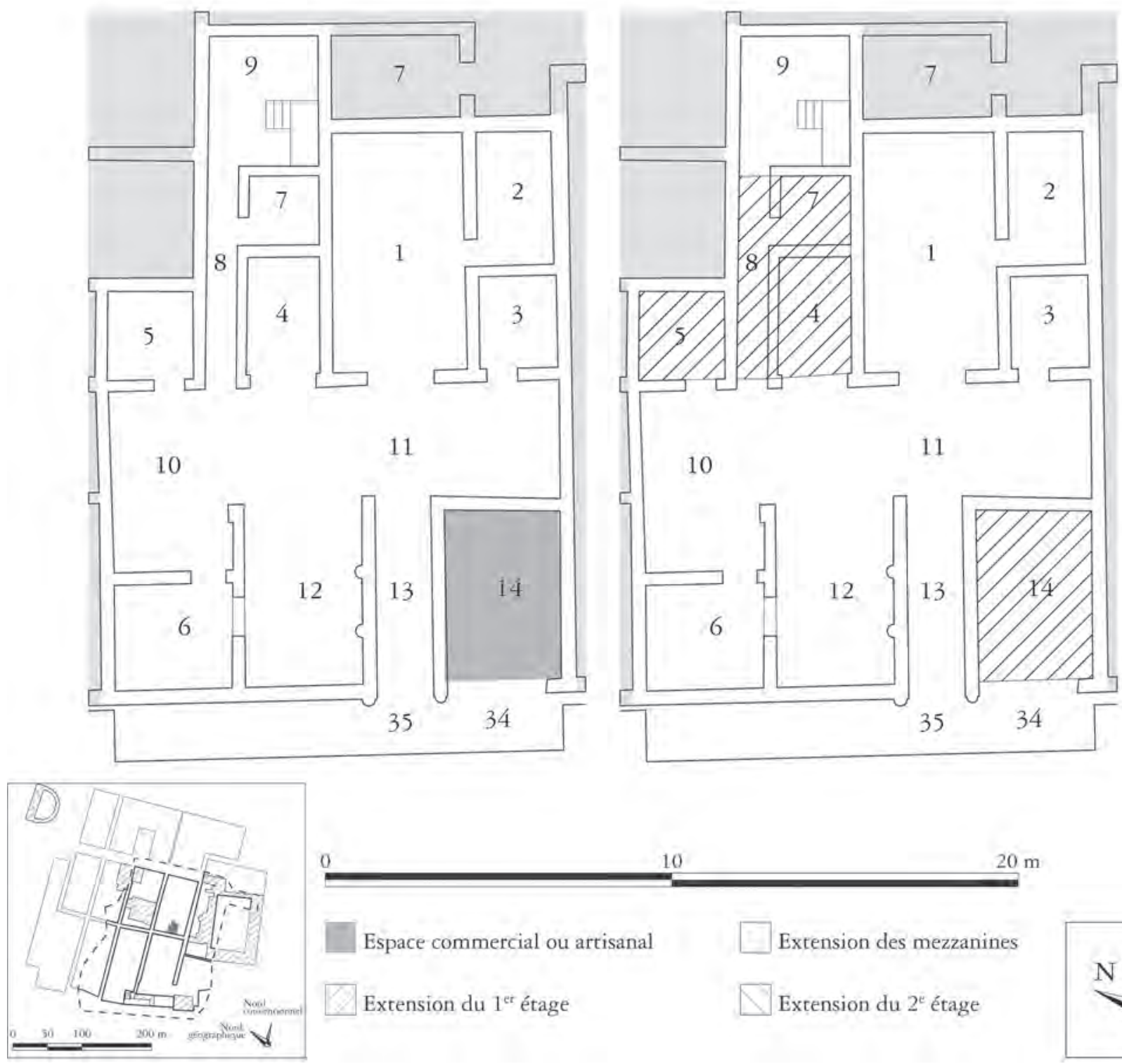

10

$20 \mathrm{~m}$

Espace commercial ou artisanal

Extension des mezzanines

Extension du $1^{\text {et }}$ étage

Extension du $2^{e}$ étage

Fig. 220 - Plan de la Casa del gran portale (V, 34-35) et de sa boutique (échelle: 1/200). 


\section{INSULA VI}

Thermes (VI, 1.4-6.7-10.30) (fig. 221)

Période de fouille: 1870-1875, 1927-1932.

Bibliographie: Maiuri 1958 b (91-112); de Vos de Vos 1982 (296-297); Pagano 1997 (41-44); Pesando - Guidobaldi 2006 (360-362); Monteix 2006.

Nombre d'unité(s) architecturale(s) en 79:0 (édifice public); 2 locaux commerciaux indépendants sont inclus dans le bâtiment.

Seuils: VI, 1 (seuil de type C1a en lave); VI, 4 (seuil emporté); VI, 5 (seuil emporté); VI, 6 (seuil de type D1 de nature non spécifiée); VI, 7 (seuil de type B1 en marbre); VI, 8 (seuil de type C1a en lave); VI, 9 (seuil de type C1a en lave); VI, 10 (seuil emporté); VI, 30 (seuil de type C1a en tuf).

\section{Boutique VI, 6}

Période de fouille: 1927-1928.

Bibliographie: Maiuri 1958 b (109); Monteix 2006 (38-39).

Longueur: $5,9 \mathrm{~m}$; largeur: $3,5 \mathrm{~m}$; surface: $21 \mathrm{~m}^{2}$.

Pièce annexe: une pièce annexe ( $\mathrm{L} \mathrm{x} 1: 5,8$ x 3,8; $22 \mathrm{~m}^{2}$.) à l'est du local principal.

Période hypothétique de création: $2^{\mathrm{e}}$ phase postaugustéenne.

Situation par rapport à la parcelle: éventuel lien avec VI, 4-5. lable.

Situation par rapport à l'habitat: sans lien déce-

Description des aménagements: aucun aménagement perceptible.

Interprétation de la situation en 79: local ni artisanal ni commercial («ambienti rustici dei locali di servizio per spogliatoio e deposito di attrezzi ») / boutique, commerce ou production indéterminés.

Inventaire des objets mis au jour dans le local: aucun.

\section{Atelier VI, 30}

Période de fouille: 1932 ?

Bibliographie: Maiuri 1932 (pl. h.t.); Pagano 1997 (43); Monteix 2006 : 23-27.

Longueur: 6,1 m; largeur: 3,4 m; surface: $20 \mathrm{~m}^{2}$.

Pièce annexe: au sud-est, se développe une petite pièce annexe ( $\mathrm{L}$ x l: 2,7 x 2,1 $\mathrm{m} ; 5 \mathrm{~m}^{2}$.).

Période hypothétique de création: $2^{\mathrm{e}}$ phase postaugustéenne.

Situation par rapport à la parcelle: indépendance.

Situation par rapport à l'habitat: sans espace d'habitation.

Description des aménagements: le sol est constitué de tuiles posées à plat. Au nord se développe une table maçonnée dont l'extrémité occidentale est occupée par une vasque. Au centre, un massif quadrangulaire pourrait avoir servi de four. Dans la pièce annexe, quatre empreintes de solives décrivent un hypothétique séchoir correspondant à la laverie de toisons qui se trouvait dans ce local au cours d'une phase antérieure.

Interprétations de la situation en 79: tintoria (M. Pagano) / boulangerie sans meule (?).

Inventaire des objets mis au jour dans le local: aucun.

Casa del salone nero (VI, 11-15) (fig. 222)

Période de fouille: 1933.1938-1941; 1961.

Bibliographie: Maiuri 1958 b (239-243); de Vos - de Vos 1982 (302-303); Pagano 1997 (66-67); Guidobaldi 2006 (190-199); Monteix 2006; Pesando - Guidobaldi 2006 (362-366).

Nombre d'unité(s) architecturale(s) en 79: 4 dont 3 locaux commerciaux indépendants.

Seuils: VI, 11 (seuil de type C1a en tuf et lave); VI, 12 (seuil de type D1b en tuf); VI, 13 (seuil de type C1a en marbre); VI, 14 (seuil emporté); VI, 15 (seuil de type D1b en tuf).

\section{Atelier VI, 12}

Période de fouille: 1961.

Bibliographie: de Franciscis 1973 (311); Maiuri 1978 (340); de Vos - de Vos 1982 (303); Pagano 1997 (65-66) ; Mols 1999 (202-203) ; Pagano 2004; Monteix 2004 ; Monteix 2005 ; Monteix 2006 : 19-23 ; Pesando -
Guidobaldi 2006 (362-363) ; Monteix 2007 b; Monteix - Pernot - Coutelas 2008.

Longueur: 5,8 m; largeur: 4,1 m; surface: $21 \mathrm{~m}^{2}$. Pièce annexe: au sud du local, après un muretpalier, une pièce annexe comprend une latrine.

Période hypothétique de création: phase augustéenne.

Situation par rapport à la parcelle: liens abolis.

Situation par rapport à l'habitat: accès à l'étage.

Description des aménagements: comptoir constitué de blocs de calcaire blanc en remploi, restauré en équerre. À l'origine, un établi construit en deux parties parallèles. Le long du mur occidental, casier à amphore partiellement détruit. Creuset de fusion du plomb disposé en arrière de l'établi.

Interprétations de la situation en 79: termopolio puis atelier de plombier (GSE 1961) / atelier de métallurgie du plomb. 

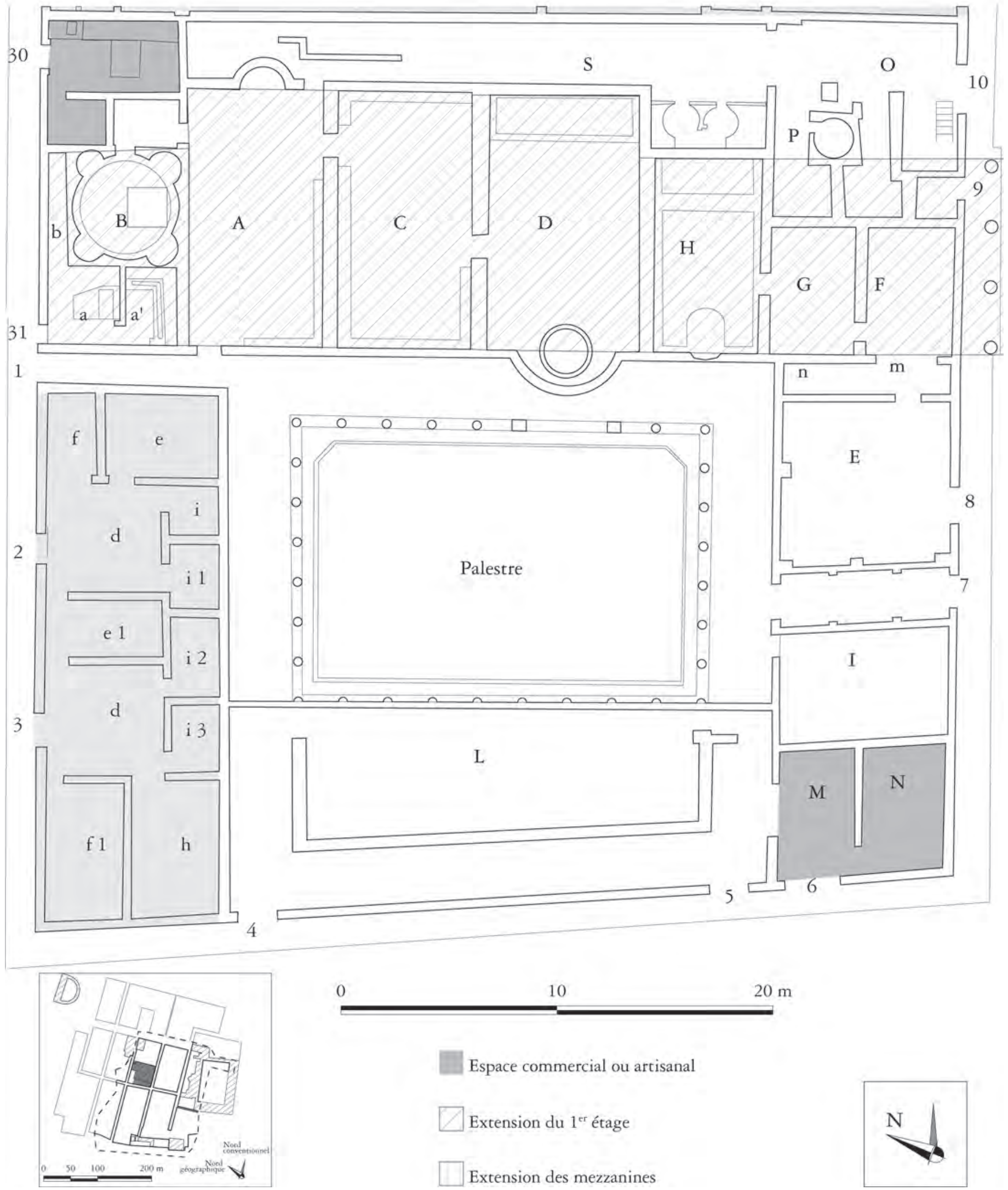

Fig. 221 - Plan des thermes (VI, 1.4-6.7-10.30), de sa boutique et de son atelier (échelle: 1/250). 
Inventaire des objets mis au jour dans le local:

Boutique principale. 77588 = E2292: [Bronze] Statuetta di Bacco nudo, alta $\mathrm{cm}$ 62, in ottimo stato di conservazione. La statua poggia su di una base circolare di bronzo di diametro $\mathrm{cm} 26$ ed alta $\mathrm{cm}$ 6. Su detta base trovasi una tigre lunga $\mathrm{cm} 17$ rappresentata con la testa rivolta verso l'alto; $77589=$ E2293: [Bronze] Candelabro massiccio a 4 bracci. La base è composta di numero 8 foglie rovesce fasciate da un anello. Al di sopra si sviluppa il fusto scannellato di diametro $\mathrm{cm} 9$ ed alto $\mathrm{cm} \mathrm{50.} \mathrm{Al}$ di sopra numero 8 foglie a punta curvata e disposte in cerchio $; 77590=$ E2294: [Bronze $]$ Candelabro con fusto scannellato mancante della base e del piattello; alto metri 1.23; 77591 = E2295: [Bronze] Candelabro: parte di fusto con tre zampe di leone intervallate da tre foglie; il tutto alto metri 0.68; $77592=$ E2296: [Bronze] Caldaia a forma di crogiuolo in discreto stato di conservazione, con diametro di bocca metri 0.55 ed alto metri 0.50; $77593=$ E2297: [Plomb] Numero 2 caldaie a forma tronco conica con collo di $\mathrm{cm}$ 6, dette caldaie misurano alla base metri 0.70 , alla parte alta metri 0.45 , sono alte metri 0.50 ; 77594 = E2298: [Bronze] Pinza a molletta lunga cm 8; 77595 = E2299: [Plomb] Framm. n.3 di conduttura frammentata. Lunga circa metri 1; spiombata; 77596 = E2300: [Céramique] Lucerna monoansata in buono stato e senza figurazioni; $77597=\mathrm{E} 2301$ : $[\mathrm{Plomb}]$ Caldaia a forma tronco conica con collo; diametro di

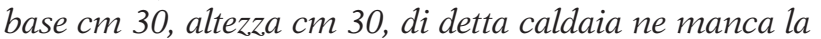
metà; 77598 = E2302: [Plomb] Numero due lingotti di piombo vergine di forma piramide rettangolare tronca; lunghi metri 0.47 , alti metri 0.085. Su di essi è stata rilevata una serie di scritte incavate e riportate nel disegno in appendice [cf. Monteix 2006: fig. 11 p. 25]; $77599=$ E2303: [Plomb] Numero 3 pesi lunghi $\mathrm{cm}$ 9, 5 per $\mathrm{cm} 10$ per cm 9, 5. Alti $\mathrm{cm}$ 3.5; $77600=$ E2304: [Marbre] Serie di pesi di numero 14 pezzi. Portano l'accenno di manico ossidato e piombato. Il minore della serie è a forma conica di altezza $\mathrm{cm}$ 6. I restanti sono a forma conica ovale tronca; $77601=\mathrm{E} 2305$ : [Céramique] Recipiente a forma cilindrica con bordo scorniciato mancante del fondo, alto cm 65 con diametro cm 35 .

\section{Boutique VI, 14}

Période de fouille: 1961.

Bibliographie: de Franciscis 1973 (311); de Vos - de Vos 1982 (302); Pagano 1988; Pagano 1997 (68); Monteix 2006: 27-29; Monteix 2007 b; Pesando - Guidobaldi $2006(363,366)$.

Longueur: $3,3 \mathrm{~m}$; largeur: $3 \mathrm{~m}$; surface: $10 \mathrm{~m}^{2}$.

Pièce annexe: aucune.

Période hypothétique de création: après le séisme de 62.

Situation par rapport à la parcelle: lien aboli.

Situation par rapport à l'habitat: accès à l'étage.

Description des aménagements: escalier en bois (à marches et contremarches; détruit après la fouille). Traces de foyer sur le sol (quart nord-occidental du local). Niche ménagée dans le mur sud.
Interprétation de la situation en 79: commerce de vin.

Inventaire des objets mis au jour dans le local:

Boutique principale. 77682 = E2386: [Bronze] Lucerna a due becchi opposti con foro centrale, diametro $\mathrm{cm}$ 6, lunghezza cm 15, altezza cm 3.5; 77683 = E2387: [Marbre] Testa con collo e parte di petto rappresentante Bacco, in ottimo stato e finemente lavorata., altezza cm 19, 5.

\section{Boutique VI, 15}

Période de fouille: $1961 ; 2002$.

Bibliographie: Maiuri 1978 (340, 347); Pagano 1997 (68); Monteix 2003; Monteix 2005; Guidobaldi 2006 (192-194); Pesando - Guidobaldi 2006 (363); Monteix 2006: 34-37; Monteix 2007 b.

Longueur: 3,4m; largeur: 3,4m; surface: $12 \mathrm{~m}^{2}$. Pièce annexe: aucune.

Période hypothétique de création: phase augustéenne.

Situation par rapport à la parcelle: indépendance (location probable: citerne partagée).

Situation par rapport à l'habitat: accès à l'étage.

Description des aménagements: Sol de la boutique percé d'une fosse quadrangulaire.

Interprétation de la situation en 79: local en travaux lors de l'éruption.

Inventaire des objets mis au jour dans le local:

Boutique principale. 77696 = E2400: [Marbre] Testa rappresentante volto di donna con il naso e le labbra parzialmente corrose, porta capelli a riccioli); tenuti da un cordone, il collo funziona da base; è alta $\mathrm{cm} 14 ; 77697=\mathrm{E} 2401$ : [Céramique] Urceo intero alto

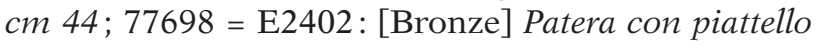
attaccato a fondo, bordo rivolto all'esterno, diametro cm 23.5, altezza $\mathrm{cm} 7$.

Étage. 77685 = E2389: [Corde] Corda di grosso spessore disposta a cerchi sovrapposti; 77686 = E2390: [Bronze] Patera con bordo svasato con due rotture ai fianchi diametro $\mathrm{cm} 23.5$, altezza $\mathrm{cm}$ 6.5; $77687=\mathrm{E} 2391$ : [Céramique] Pentola svasata con orlo rotto per un terzo, alta $\mathrm{cm} 25$ con diametro di $\mathrm{cm}$ 27.5; $77688=\mathrm{E} 2392$ : [Céramique] Anforetta monoansata con rottura nella pancia e svasatura del collo, alta $\mathrm{cm} 41$, diametro $\mathrm{cm} \mathrm{17;}$ 77689 = E2393: [Céramique] Anforetta con collo rotto priva di anse, rottura alla pancia, frammentata ma restaurabile, altezza $\mathrm{cm}$ 22, diametro $\mathrm{cm}$ 15; $77690=\mathrm{E} 2394$ : [Céramique] Anforetta oblunga priva di collo ed ansa con rottura alla pancia, alta $\mathrm{cm} 38$, diametro $\mathrm{cm} \mathrm{14;77691=}$ E2395: [Céramique] Urceo intero con ansa, alto cm 35, diametro cm 11; 77692 = E2396: [Céramique] Numero 3 coperchi di cui uno rotto, diametro cm 12; 77693 = E2397: [Céramique] Numero 2 coperchi diametro cm 17; 77694 = E2398: [Bronze et pâte de verre] Tazzina emisferica contenente numero 78 bottoni vitrei, diametro $\mathrm{cm} 7$, altezza $\mathrm{cm}$ 6; 77695 = E2399: [Céramique] Numero 4 lucerne spezzettate e senza figurazioni; 77699 = E2403: [Céramique] Scodella dal diametro $\mathrm{cm} 16$ ed altezza $\mathrm{cm} 5$. 


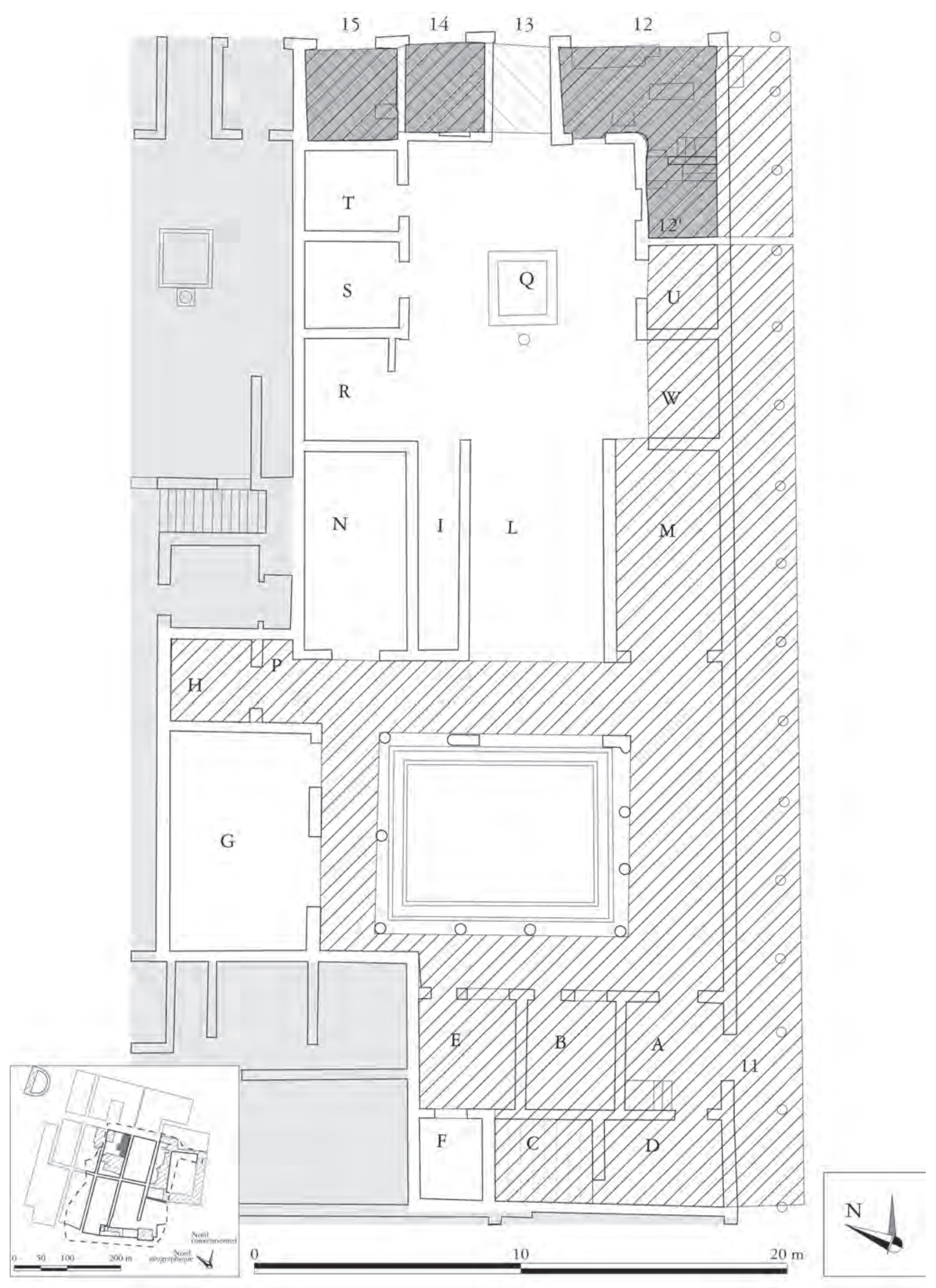

Espace commercial ou artisanal $\square$ Extension du $1^{\text {to }}$ étage $\square$ Extension du $2^{c}$ étage $\square$ Extension des mezzanines

Fig. 222 - Plan de la Casa del salone nero (VI, 11-15), de son atelier et de ses boutiques (échelle: 1/200). 
Période de fouille: 1960-1961.

Bibliographie: de Franciscis 1973 (fig. 325 p. 311); Cerulli Irelli 1974; Manni 1974; de Vos - de Vos 1982 (300-302); Pagano 1997 (69-70); Monteix 2006; Pesando - Guidobaldi 2006 (366-368).

Nombre d'unité(s) architecturale(s) en 79: 4, dont 1 comporte 2 locaux commerciaux; 2 locaux commerciaux indépendants.

Seuils: VI, 16 (seuil emporté); VI, 17 (seuil emporté); VI, 18 (seuil emporté); VI, 19 (seuil de type D1b en tuf et calcaire blanc); VI, 25 (seuil emporté); VI, 26 (seuil emporté); VI, 27 (seuil emporté).

\section{Boutique VI, 16}

Bibliographie: Cerulli Irelli 1974 (21-22); Manni 1974 (12-16); de Vos - de Vos 1982 (301); Pagano 1997 (68-69); Coralini 2001 (237-238); Monteix 2006 (37); Pesando - Guidobaldi 2006 (367).

Longueur: 3,1 m; largeur: 2,7 m; surface: $8 \mathrm{~m}^{2}$.

Pièce annexe: sans.

Période hypothétique de création: après le séisme de 62.

Situation par rapport à la parcelle: lien avec la domus.

Situation par rapport à l'habitat: accès à la domus.

Description des aménagements: aucun aménagement préservé. Fresque représentant l'un des cycles du mythe d'Hercule. Sol en opus sectile.

Interprétation de la situation en 79: boutique, commerce ou production indéterminés.

Inventaire des objets mis au jour dans le local: aucun.

\section{Boutique VI, 18}

Période de fouille: 1961.

Bibliographie: Cerulli Irelli 1974 (20-21); Monteix 2006 (37).

Longueur: 3,1 m; largeur: $3 \mathrm{~m}$; surface: $9 \mathrm{~m}^{2}$.

Pièce annexe: sans.

Période hypothétique de création: après le séisme de 62.

Situation par rapport à la parcelle: lien avec la domus.

Situation par rapport à l'habitat: accès à la domus.

Description des aménagements: les empreintes d'une étagère sont visibles sur la paroi occidentale. Toutefois, ce mur ayant été restauré, il est probable que ces empreintes ne soient pas antiques.

Interprétation de la situation en 79: boutique, commerce ou production indéterminés.

Inventaire des objets mis au jour dans le local:

Boutique principale. $77752=$ E2456: [Céramique]

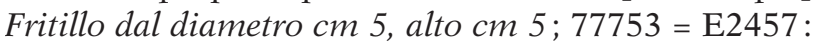
[Bronze] Numero 2 cardini circolari dal diametro $\mathrm{cm}$ 6.5, alto cm 5.5; 77754 = E2458: [Bronze] Ornamento centrale posto alla parte alta di un cancello, lavorato a foglie contorte, lungo cm 25, piede di tripode con busto rappresentante donna nuda, capelli lunghi a trecce; 77755 = E2458 bis: [Bronze] Piede di tripode con busto rappresentante donna nuda, capelli lunghi a trecce; 77756 = E2459: [Céramique] Vasettino con orlo svasato di colore arancione carico, frammentata ma restaurabile, diametro all'orlo $\mathrm{cm}$ 9, altezza cm $10.5 ; 77757$ = E2460: [Bronze et argent] Groviglio di monete non distinguibili, di cui una piccola quantità di monete d'argento.

\section{Boutique VI, 19}

Période de fouille: 1961.

Bibliographie: Monteix 2006 (29-34).

Longueur: 8,2 m; largeur: 4,7 m; surface: $38 \mathrm{~m}^{2}$.

Pièce annexe: Sans, sauf à considérer l'espace situé sous l'arc soutenant l'escalier comme une pièce annexe.

Période hypothétique de création: phase augustéenne.

Situation par rapport à la parcelle: lien aboli.

Situation par rapport à l'habitat: accès à l'étage.

Description des aménagements: comptoir maçonné en double équerre comportant 7 dolia. Un bras annexe muni de deux dolia se trouve contre le mur oriental. En avant du comptoir principal, une fosse enduite de béton de tuileau a été identifiée lors de la fouille. Au nord-est du local se trouve une bouche de citerne ou de puits.

Interprétations de la situation en 79: termopolio (GSE 1961) / commerce alimentaire (type 3).

Inventaire des objets mis au jour dans le local:

Boutique principale. $77758=\mathrm{E} 2461$ : [Bronze] Numero 17 monete di varia coniatura e non distinguibili perché molto corrose; $77759=\mathrm{E} 2462$ : [Bronze] Numero 2 basette di cardini di lato $\mathrm{cm} 7$ e cm 7.5; 77760 = E2463: [Céramique] Urceo con ansa rotta dal diametro $\mathrm{cm} \mathrm{13,} \mathrm{altezza} \mathrm{cm} \mathrm{16,} \mathrm{rinvenuto} \mathrm{frammentato}$ ma restaurabile.

\section{Boutique VI, 25}

Période de fouille: 1960.

Bibliographie: Cerulli-Irelli 1974 (66); Monteix 2006 (38).

Longueur: $3,6 \mathrm{~m}$; largeur: 3,4 m; surface: $12 \mathrm{~m}^{2}$.

Pièce annexe: cage d'escalier conduisant à l'étage.

Période hypothétique de création: phase augustéenne.

Situation par rapport à la parcelle: lien aboli.

Situation par rapport à l'habitat: accès à l'étage.

Description des aménagements: aucun aménagement visible. Sol incomplètement dégagé.

Interprétation de la situation en 79: boutique, commerce ou production indéterminés.

Inventaire des objets mis au jour dans le local: aucun. 


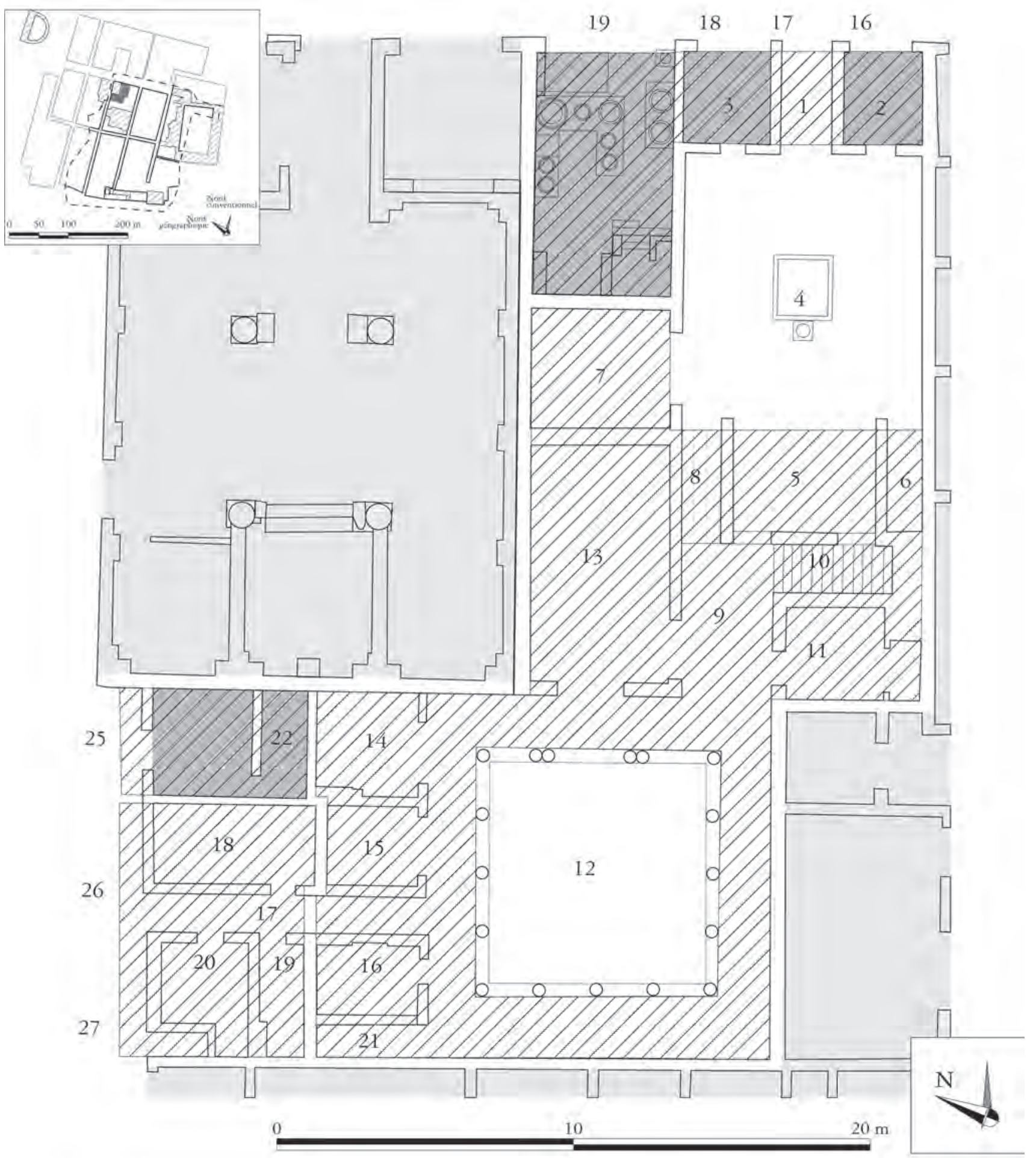

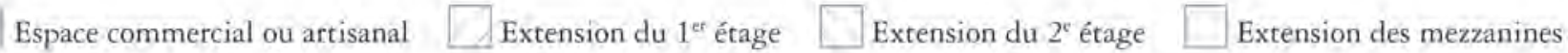

Fig. 223 - Plan de la Casa del colonnato tuscanico (VI, 16-19.25-27) et de ses boutiques (échelle: 1/200). 


\section{INSULA VII}

Casa di C. Messenius Eunomus (VII, 1-1b) (fig. 224)
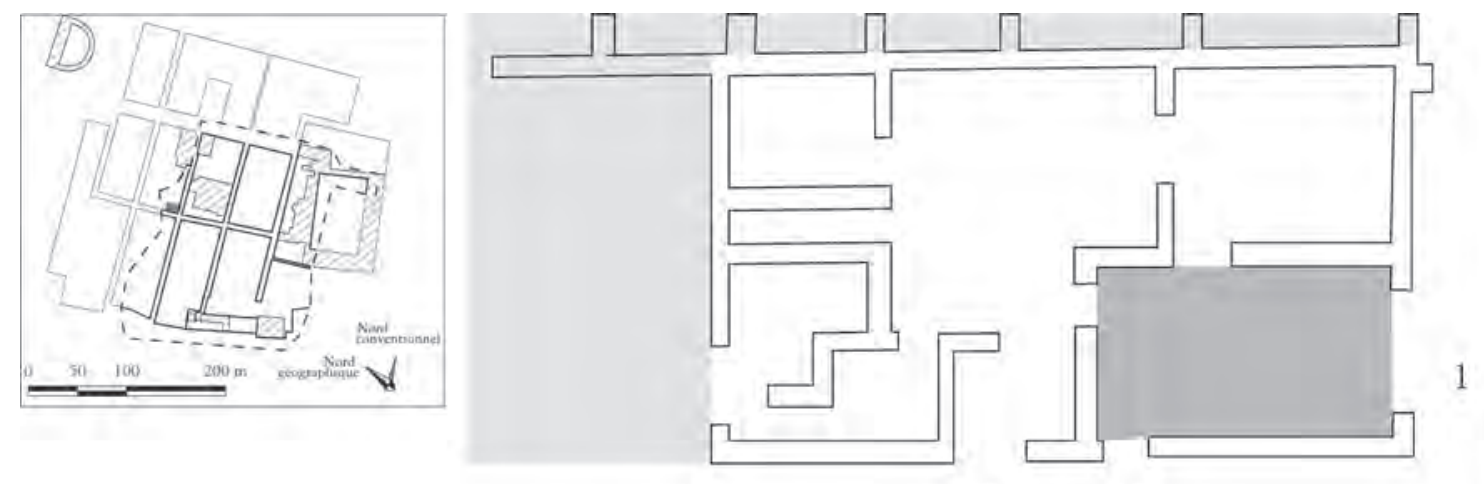

18 17

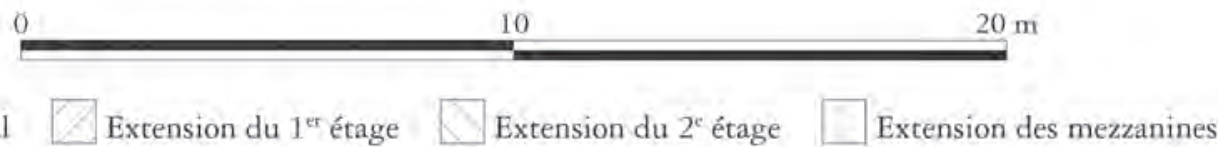

Espace commercial ou artisanal

Fig. 224 - Plan de la Casa di C. Messenius Eunomus (VII, 1-1b) et de sa boutique (échelle: 1/200).

Période de fouille: 1872-1873.

Bibliographie: Maiuri 1958 b (447-449); Pesando - Guidobaldi 2006 (371).

Nombre d'unité(s) architecturale(s) en 79: 1, comportant 1 local commercial.

Seuils: VII, $1 \mathrm{~b}$ (seuil de type B1 en calcaire blanc); VII, 1a (seuil emporté); VII, 1 (seuil emporté).

\section{Boutique VII, 1a-1}

Période de fouille: 1872-1873.

Bibliographie: Maiuri 1958 b (448-449).

Longueur: $6 \mathrm{~m}$; largeur: 3,5 m; surface: $21 \mathrm{~m}^{2}$.

Pièce annexe: aucune.
Période hypothétique de création: n.d. domus.

Situation par rapport à la parcelle: lien avec la

Situation par rapport à l'habitat: accès à la domus.

Description des aménagements: aucun aménagement préservé ou décrit.

Interprétation de la situation en 79: boutique, commerce ou production indéterminés.

Inventaire des objets mis au jour dans le local: Voir liste reportée par M. Ruggiero (1885: 631-632), correspondant aux entrées du 2 au 14 décembre 1872 des GSE.

Casa di Galba (VII, 2-6) (fig. 225)

Période de fouille: 1873-1875.

Bibliographie: Maiuri 1958 b (403-407); Pesando - Guidobaldi 2006 (371-373).

Nombre d'unité(s) d'habitation en 79: au moins 3 , dont 1 comportant 1 local commercial.

Seuils: VII, 2 (seuil emporté); VII, 3 (seuil emporté); VII, 4 (seuil emporté); VII, 5 (seuil emporté); VII, 6 (seuil emporté).

\section{Atelier VII, 4-5}

Période de fouille: 1873-1874.

Bibliographie: Maiuri 1958 b (407).

Longueur: 5,7 m; largeur: 3,8 m; surface: $21 \mathrm{~m}^{2}$.
Pièce annexe: aucune.

Période hypothétique de création: n.d.

Situation par rapport à la parcelle: indépendance.

Situation par rapport à l'habitat: accès à l'étage.

Description des aménagements: un podium maçonné se dresse au milieu du local, intégralement restauré. Les GSE (1874: 7-17 marzo; cit. in Ruggiero 1885: 650-651) signalent l'existence d'un «ammezzato"sur lequel des objets ont été découverts. A. Maiuri mentionne due grossi focolari cilidrici per grosse caldaie qui ont disparu. Cette description ainsi que la mention d'une fullonica dei vecchi scavi dans les GSE pourrait laisser supposer l'existence 
d'une laverie de toisons dans cet espace.

Interprétations de la situation en 79: bottega

(A. Maiuri) / atelier textile (?).

Inventaire des objets mis au jour dans le local: outre les objets déjà indiqués dans la description des aménagements, des «caldaie» en bronze ont pu être découvertes dans cette boutique (GSE 1874: 1 aprile, cit. in Ruggiero 1885: 651) ${ }^{2}$.
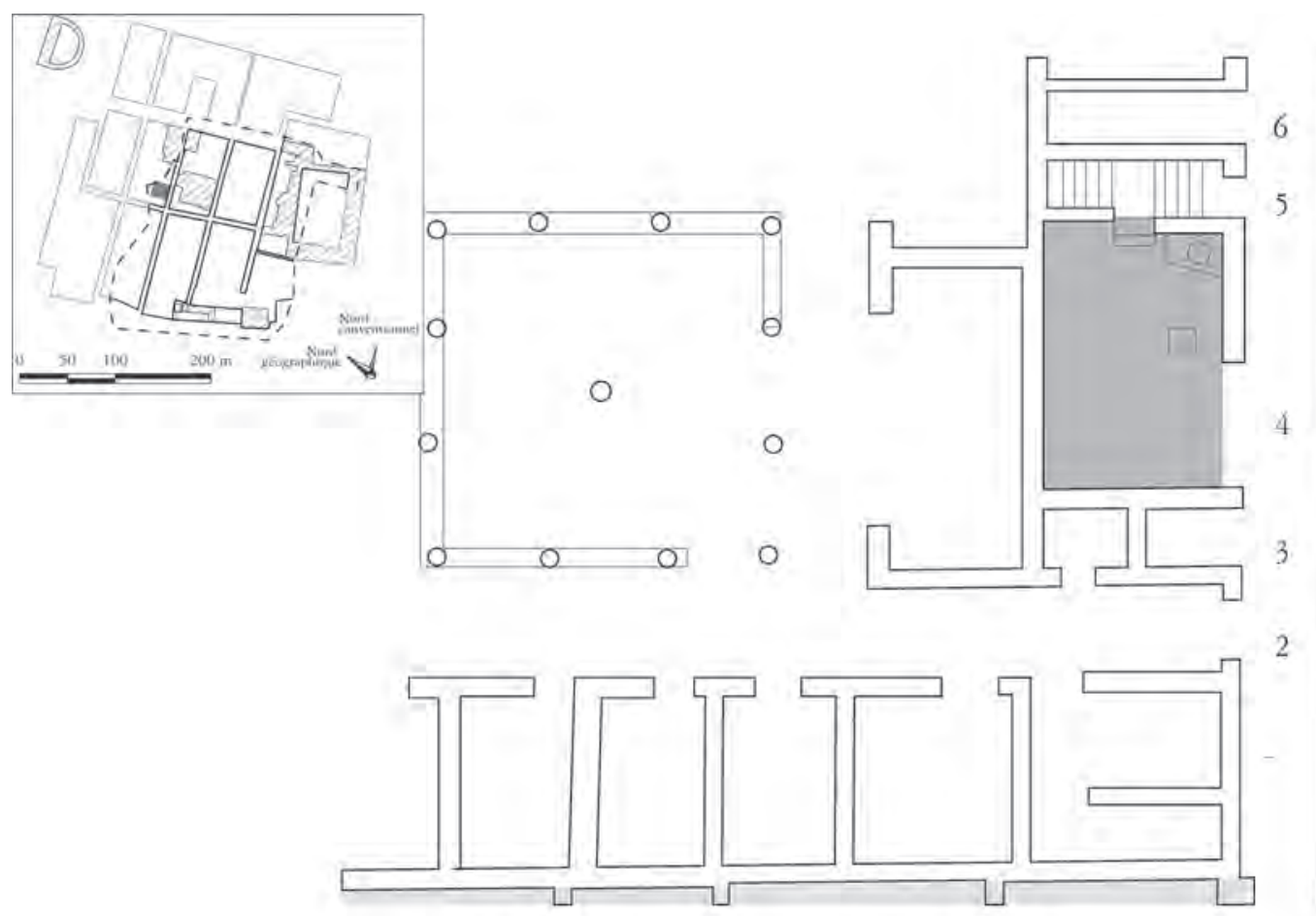

0

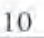
$20 \mathrm{~m}$

Espace commercial ou artisanal Extension du $1^{\text {er }}$ étage Extension du $2^{\mathrm{r}}$ étage Extension des mezzanines

Fig. 225 - Plan de la Casa di Galba (VII, 2-6) et de sa boutique (échelle: 1/200).

${ }^{2}$ La mention comme provenance d'une « una stanzetta interna appartenente alla prima bottega " laisse un doute quant à cette interprétation: le plan ne présente aucune division interne à cette boutique ou aucune pièce annexe; peut-être faut-il y restituer des cloisons en pan de bois? 


\section{INSULA ORIENTALIS II ${ }^{\mathrm{a}}$}

BLOC MÉRIDIONAL (Or. II, 1a à 3) (fig. 226)

Période de fouille: 1932; 1935-1937.

Bibliographie: Maiuri 1958 b (451-455); de Vos - de Vos 1982 (282-286); Pirson 1999 (152-153); Pesando-Guidobaldi 2006 (380-385); Wallace-Hadrill - Guidobaldi - Camardo - Moesch 2008: 415-421.

Nombre d'unité(s) architecturale(s) en 79: 5 dont 3 locaux commerciaux indépendants.

Seuils: Or. II, 1a (seuil de type C1a en tuf); Or. II, 1 (seuil de type D1a en tuf); Or. II, 1b (seuil de type C1a en calcaire blanc); Or. II, 2 (seuil de type C1a en tuf); Or. II, 3 (seuil de type D1a en tuf).

\section{Atelier Or. II, 1a}

Période de fouille: 1935.

Bibliographie: Maiuri 1958 b (451-455); de Vos - de Vos 1982 (283-286).

Longueur: 7,7 m; largeur: 5,9 m; surface totale: $121 \mathrm{~m}^{2}$.

Pièce annexe: local divisé en 5 pièces, dont une seule s'ouvre sur la rue sans être une pièce de vente.

Période hypothétique de création: après le second séisme.

Situation par rapport à la parcelle: lien aboli.

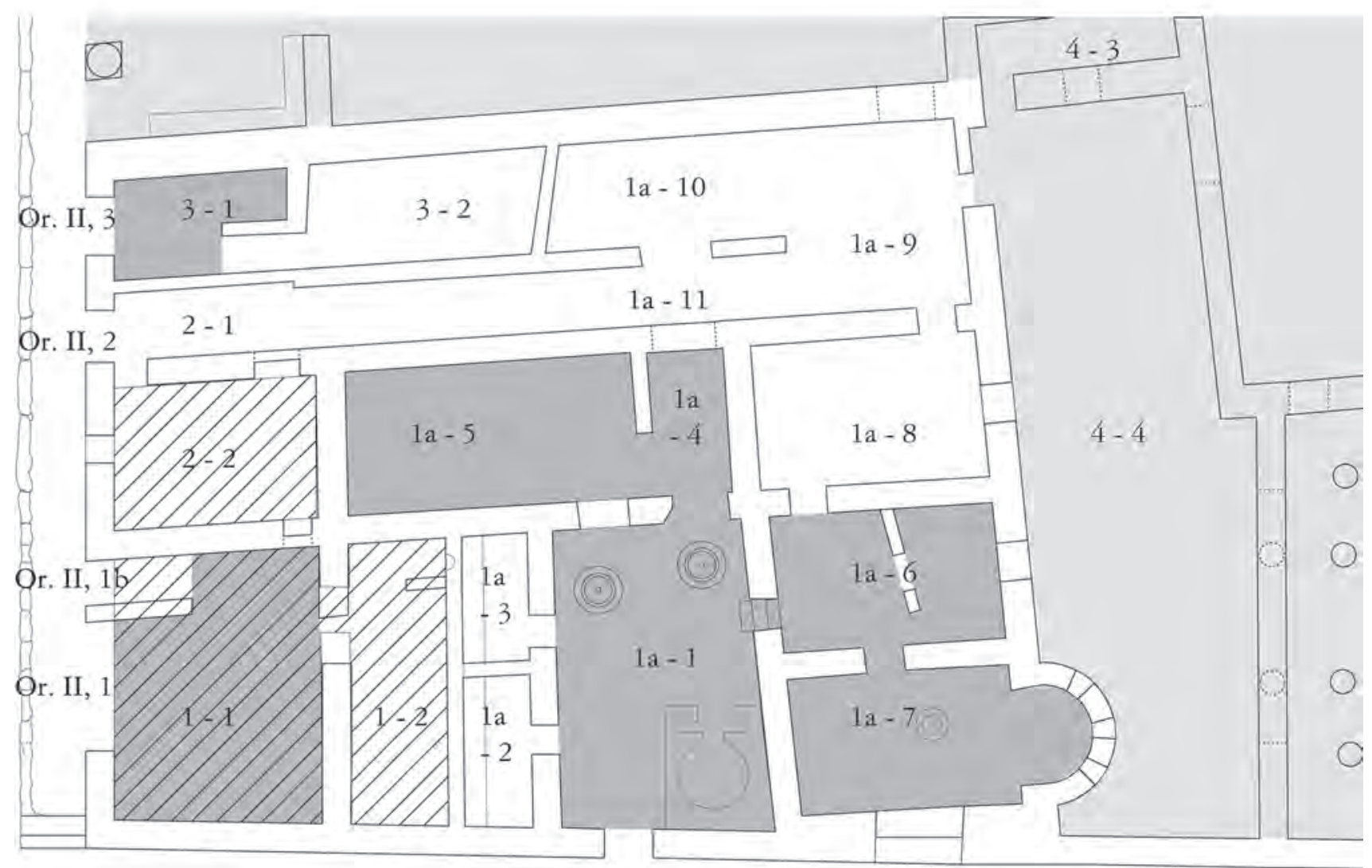

Or. II, 1a
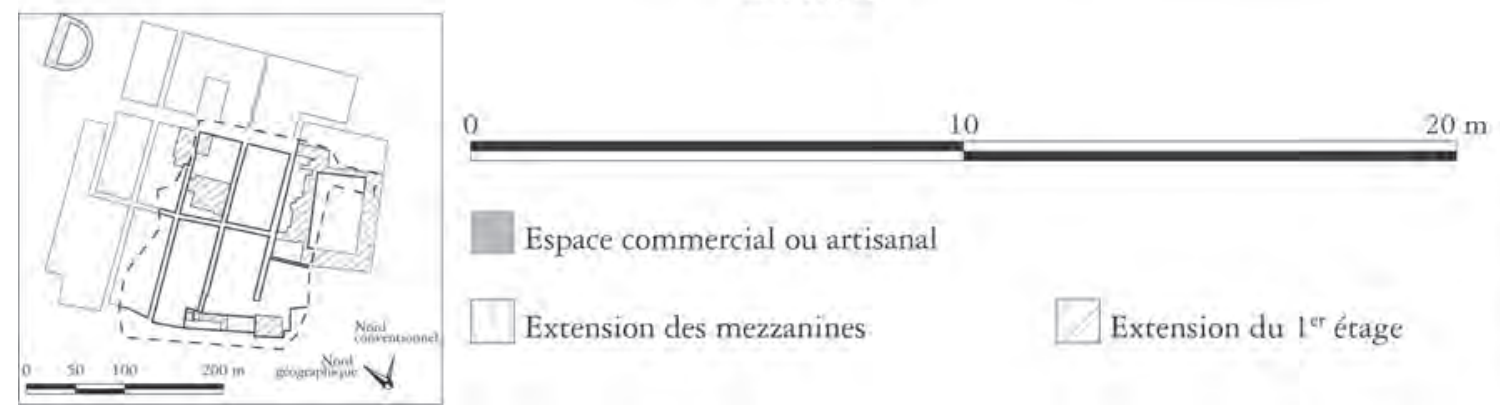

Espace commercial ou artisanal

Extension des mezzanines

Extension du $L^{\mathrm{er}}$ étage

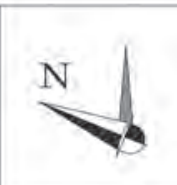

Fig. 226 - Plan de l'Insula Orientalis II ${ }^{a}$ - bloc méridional (Or. II, 1a à 3), de son atelier et de ses boutiques (échelle: 1/200). 
Situation par rapport à l'habitat: habitat en pièce annexe (pièces $1 \mathrm{a}-8$ à $1 \mathrm{a}-11$ ?).

Description des aménagements : Dans la pièce 1a-1 se trouvent deux meules pouvant avoir été actionnées par des animaux ainsi qu'un four pourvu d'un mur diaphragme dans lequel est inclus un chauffe-eau. Un pétrin a été découvert dans la pièce 1a-7. La pièce 1a-5 pourrait avoir servi d'écurie pour les éventuels animaux faisant tourner les meules.

Interprétation de la situation en 79: boulangerie. Inventaire des objets mis au jour dans le local:

Boutique principale. $76660=\mathrm{E} 1382$ : [Bronze] Anforetta con anse staccate ben conservata. Tiene la bocca svasata e collo accorciato. Misura m. 0.11 di altezza e m. 0.05 di diametro; $76662=\mathrm{E} 1384$ : [Fer] Piccozzino molto corroso. È lungo metri 0.145 e largo metri $0.11 ; 76665=$ E1387: [Bronze] Campanella alta m. 0.18 e del diametro della bocca di metri 0.07. E discretamente conservata; $76666=\mathrm{E} 1388$ : [Bronze] Anforetta con ansa mancante. È in buono stato di conservazione. Misura m. 0.26 di altezza per metri 0.06 di diametro della bocca; 76667 = E1389: [Céramique] Utensile per cucina mancante di un'ansa. Il piede è basso circolare. La bocca è svasata. È ben conservato. Misura m. 0.085 di altezza per metri 0.06 di diametro; 76668 = E1390: [Coquillage] Tofa in ottimo stato di conservazione. É lunga m. 0.22 e l'apertura anteriore è di metri 0.07; $76671=\mathrm{E} 1393$ : [Céramique] Lucerna col rostro prolungato. È in buono stato di conservazione. Misura m. 0.95 di lunghezza, rostro compreso e m. 0.04 di diametro; $76672=\mathrm{E} 1394$ : [Bronze] Moneta di modulo medio del diametro di metri $0.025 e$ dello spessore di metri 0.001. Ė dell'epoca di Cesare. Un fond de vase en céramique arétine et un amphorisque présentant une inscription peinte, non inventoriés lors de leur découverte.

Provenance non spécifiée. 76655 = E1377: [Verre] Ariballo sferico ben conservato alto metri $0.08 \mathrm{e}$ del diametro della bocca di metri 0.012; $76656=\mathrm{E} 1378$ : [Bronze] Anforetta con le anse distaccate discretamente conservata, alta m. 0.145 e del diametro di metri 0.055; $76657=$ E1379: [Bronze] Anforetta con anse distaccate e con qualche lesione. La bocca è svasata. Misura m. 0.30 di altezza per metri 0.09 di diametro della bocca; 76669 = E1391: [Bronze] Forma per pasticceria discretamente conservata. Misura m. 0.25 di lunghezza per metri 0.12 di apertura.

Pièce annexe. $76670=$ E1392: [Bronze] Campanella in buone condizioni. È alta m. $0.16 e$ m. 0.07 di diametro; $76676=\mathrm{E} 1398$ : [Céramique] Porta lucerna così formata; La base è a forma rettangolare di metri 0.18 di lunghezza, metri 0.05 altezza e m. 0.055 di spessore. Sulla faccia anteriore vi sono tre maschere a rilievo; $76683=\mathrm{E} 1405:$ [Marbre] Tavolino così composto: la basetta è a forma rettangolare $e$ misura m. 0.28 per 0.24 , e m. 0.07 di altezza. tavolo è alto metri 0.87 , largo metri 0.485 e dello spessore di metri 0.025; 76684 = E1406: [Céramique] Lucerna monolichne col rostro accorciato e ben conservata. Sul fondo superiore vi è a rilievo un'aquila. Misura m. 0.95 di lunghezza per metri 0.078 di diametro; $76685=$ E1407: [Céramique] Lucerna monolichne con ansa rotta e rostro prolungato. Nell'incavo superiore); vi è a rilievo Giove con l'aquila. È ben conservata. Misura m. 0.075 di diametro e m. 0.10 di lunghezza $; 76686=$ E1408: [Céramique] Lucerna monolichne e monoansata ben conservata. Tiene il rostro sviluppato. Misura m. 0.11 di lunghezza per metri 0.085 di diametro; 76687 = E1409: [Céramique] Pithos mancante di una parte dell'orlo. Ė alto metri 0.18 e del diametro di metri 0.095 .

\section{Boutique Or. II, 1}

Période de fouille: 1932.

Bibliographie: Maiuri 1958 b (455).

Longueur: 6,9 m; largeur: 5,3 m; surface: $33 \mathrm{~m}^{2}$.

Pièce annexe: à l'est, une pièce annexe comporte une latrine.

Période hypothétique de création: $2^{\mathrm{e}}$ phase postaugustéenne.

Situation par rapport à la parcelle: lien aboli.

Situation par rapport à l'habitat: habitat en pièce annexe? Létage qui se développe au-dessus de la boutique est indépendant (entrée Or. II, 1b).

Description des aménagements: aucun aménagement visible.

Interprétation de la situation en 79: boutique, commerce ou production indéterminés.

Inventaire des objets mis au jour dans le local: aucun objet inventorié.

\section{Boutique Or. II, 3}

Période de fouille: 1932.

Bibliographie: Maiuri 1958 b (455).

Longueur: 4,4 m; largeur: 2,6 m; surface: $9 \mathrm{~m}^{2}$.

Pièce annexe: une pièce annexe se développe à l'est du local, sans aménagement particulier.

Période hypothétique de création : après le second séisme.

Situation par rapport à la parcelle: lien aboli.

Situation par rapport à l'habitat: habitat en pièce annexe?

Description des aménagements: aucun aménagement visible. Les GSE signalent que le sol est constitué de tuiles et qu'un fond de dolium a été découvert.

Interprétation de la situation en 79: boutique, commerce ou production indéterminés.

Inventaire des objets mis au jour dans le local: aucun objet inventorié. 
Bloc central (Or. II, 5 à 9) (fig. 227)

Période de fouille: 1932-1936.

Bibliographie: Maiuri 1958 b (455-462); de Vos - de Vos 1982 (282-286); Pagano 1997 (75-77); Pirson 1999 (152-153); Pesando - Guidobaldi 2006 (380-385); Wallace-Hadrill - Guidobaldi - Camardo - Moesch 2008: 415-421.

Nombre d'unité(s) architecturale(s) en 79: 7 dont 4 locaux commerciaux indépendants.

Seuils: Or. II, 5 (seuil de type D1a en tuf); Or. II, 6 (seuil de type D1a en lave et tuf); Or. II, 7 (seuil de type C1a en tuf); Or. II, 8 (seuil de type D1a en tuf); Or. II, 9 (seuil de type D1a+b en tuf).

\section{Atelier Or. II, 5}

Période de fouille: 1932-1933.

Bibliographie: Maiuri 1958 b (455); de Vos - de Vos 1982 (286); Pagano 1997 (76).

Longueur: 5,9 m; largeur: 4,7 m; surface: $44 \mathrm{~m}^{2}$.

Pièce annexe: Deux pièces se développent à l'est du local principal.

Période hypothétique de création: $2^{\mathrm{e}}$ phase postaugustéenne.

Situation par rapport à la parcelle: lien aboli.

Situation par rapport à l'habitat: accès à l'étage.

Description des aménagements: un dolium sans fond, utilisé comme fourneau, s'appuie sur les vestiges d'une table maçonnée pourvue d'un bassin, ayant servi, dans un phase précédente, à une laverie de toisons. Cinq fosses, remblayées au moment de l'éruption ont été identifiées dans l'angle nord-ouest du local.

Interprétation de la situation en 79: Officina tinctoria (A. Maiuri) / atelier de feutrier, en travaux lors de l'éruption.

Inventaire des objets mis au jour dans le local:

Boutique principale. $76099=\mathrm{E} 822$ : [Marbre] Mortaio con tre anse e con becco forato. Inventario $n$. 822. Diametro di m. 0.17 e profondo m. 0.02. Il becco è lungo m. 0.025 e largo m. 0.01. Le anse sono lunghe m. 0.018 e larga m. 0.02; $76100=\mathrm{E} 823$ : [Céramique] Bicchiere alto m. 0.09 e del diametro della bocca di m. 0.025. Inventario n. 823. L'orlo è svasato e misura m. 0.005 di larghezza; $76101=\mathrm{E} 824$ : [Bronze] Cassarola col fondo rotto e ansa allungata. Inventario n. 824. Misura m. 0.10 di diametro profondo m. 0.05 e lungo m. 0.20 ansa compresa .

Étage. 76266 = E989: [Céramique] Lagena alta m. 0.24 e del diametro di m. 0.06; $76267=\mathrm{E} 990$ : [Céramique] Pelvi del diametro di m. 0.43; 76270 = E993: [Céramique] Coppetta con piede alto, del diametro superiore di m. 0.075 e profonda m. 0.025. Il piede è alto $m .0 .01 ; 76271=\mathrm{E} 994$ : [Céramique] Lucerna monolychne e monoansata, col rostro prolungato. È lunga m. 0.08 e del diametro di m. 0.05.
Tiene due alette laterali; 76272 = E995: [Céramique] Lucerna monolychne e monoansata col rostro sviluppato. È lunga m. 0.08 e del diametro di m. 0.05. Tiene la stessa decorazione dell'altra precedente $; 76273=\mathrm{E} 996$ : [Céramique] Anforetta con piede piatto e bocca svasata. Misura m. 0.31 di altezza e m. 0.11 di diametro $; 76274$ = E997: [Céramique] Urceo con bocca svasata e ansa costolata. É alto m. 0.25 e del diametro di m. 0.10. Un fond de vase en céramique arétine non inventorié lors de sa découverte.

\section{Boutique Or. II, 6}

Période de fouille: 1932-1933.

Bibliographie: Maiuri 1958 b (455-456); de Vos - de Vos 1982 (286); Pagano 1997 (76).

Longueur: 5,8 m; largeur: 4,7 m; surface: $27 \mathrm{~m}^{2}$.

Pièce annexe: deux pièces annexes se développent à l'est du local.

Période hypothétique de création: $2^{\mathrm{e}}$ phase postaugustéenne. dance.

Situation par rapport à la parcelle: indépen-

Situation par rapport à l'habitat: accès à l'étage.

Description des aménagements: un comptoir maçonné en équerre se dresse contre la paroi septentrionale. Il contient 5 dolia en dépit des destructions par les fouilles en galerie. En revanche, un probable chauffe-eau n'a pas été restauré à son extrémité orientale.

Interprétation de la situation en 79: taberna (A. Maiuri) / commerce alimentaire (type 2).

Inventaire des objets mis au jour dans le local:

Boutique principale. 76412 = E1135: [Bronze] Moneta di modulo medio del diametro di m. 0.025 e dello spessore di m. 0.002. E' dell'epoca di Cesare. Trois fonds de vases en céramique arétine non inventoriés lors de leur découverte.

Étage. 76297 = E1020: [Verre] Ariballo sferico? mancante dell'ansa e termina la parte inferiore a punta. La bocca è svasata e la pancia è metà costolata. Misura m. 0.11 di altezza per m. 0.075 di diametro. L'oggetto è lesionato; $76298=\mathrm{E} 1021$ : [Céramique] Fritillo alto m. 0.076 e del diametro di m. 0.065; $76299=\mathrm{E} 1022$ : [Céramique] Anforetta mancante di una parte dell'orlo. È alta m. 0.25 e del diametro di $m .0 .11 ; 76300=$ E1023: [Céramique] Urceo con ansa rotta e collo mancante. Misura m. 0.30 di altezza; $76413=\mathrm{E} 1136$ : [Bronze] Secchio con ansa curva di ferro schiacciato al centro e rotto in varie parti. L'altezza è di m. 0.11 ed il diametro superiore di $m .0 .15 ; 76414=\mathrm{E} 1137$ : [Bronze] Imitazione di olpe, rotta ad un lato. E' alto m. 0.14 ed il diametro superiore è di m. 0.07; $76415=$ E1138: [Bronze] Vaso imitazione di olpe mancante di una buona parte del fondo e piccola parte della pancia. 

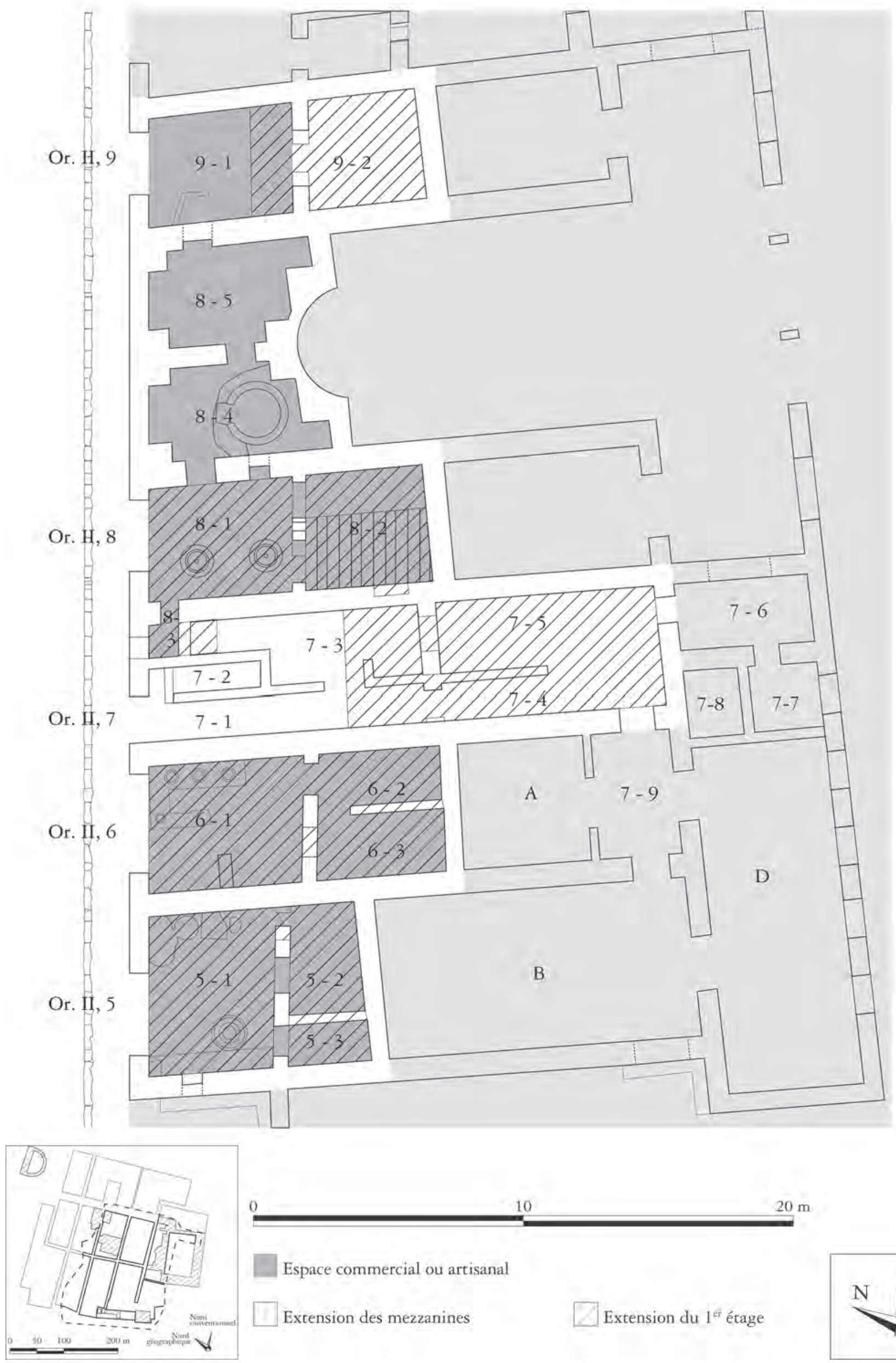

Fig. 227 - Plan de l'Insula Orientalis $I I^{a}$ - bloc central (Or. II, 5 à 9), de ses ateliers et de ses boutiques (échelle: 1/200). 
L'orlo è svasato. Misura m. 0.13 di altezza e la bocca è dim. 0.08 .

\section{Atelier Or. II, 8}

Période de fouille: 1933-1936.

Bibliographie: Maiuri 1958 b (456-458); de Vos - de Vos 1982 (283-286); Pagano 1997 (76). $83 \mathrm{~m}^{2}$.

Longueur: 5,3m; largeur: 4,2 $\mathrm{m}$; surface totale:

Pièce annexe: l'ensemble du local est divisé en 5 pièces (8-1 à 8-5), dont une seule (8-3) n'est pas directement liée à la production de pain.

Période hypothétique de création: $2^{\mathrm{e}}$ phase postaugustéenne.

Situation par rapport à la parcelle: lien aboli.

Situation par rapport à l'habitat: lien indécelable. Pas d'accès à l'étage surplombant la boulangerie.

Description des aménagements: deux meules se trouvent dans la pièce $8-1$, laissant un peu d'espace pour l'éventuel accueil de la clientèle. Le four, situé dans la pièce 8-4, est simple, dépourvu d'aménagements annexes. Aucun pétrin n'a été découvert.

Interprétation de la situation en 79: boulangerie. Inventaire des objets mis au jour dans le local:

Boutique principale (8-1). $76334=$ E1057: [Bronze] Campanello alto m. 0.11 e del diametro della bocca di m. 0.05; 76844 = E1566: [Bronze] Moneta di modulo medio del diametro di m.0.025, e dello spessore di m. 0.002. È dell'epoca di Cesare; $76845=$ E1567: [Céramique] Olla lesionata in vari punti. Tiene l'orlo rimboccato. Il diametro è di $\mathrm{m}$. 0.095 e l'altezza di m. 0.14; 76846 = E1568: [Bronze] Patera larga $m$. 0.15, lunga $m$. 0.29 e alta $m$. 0.05. Deux fragments d'amphores présentant des inscriptions peintes, non inventoriés lors de leur découverte.

Pièce annexe (8-2). 76717 = E1439: [Céramique] Lucerna monolichne col rostro accorciato. È ben conservata. Misura m. 0.010 di lunghezza per m. 0.085 di diametro; 76718 = E1440: [Céramique] Lucerna col rostro allungato. Misura m. 0.075 di diametro per m. 0.11 di lunghezza; 76719 = E1441: [Céramique] Lucerna ben conservata col rostro allungato. È lunga m. 0.11 e m. 0.08 di diametro $; 76720=\mathrm{E} 1442$ : [Verre] Unguentario col collo basso e panciuto.); $\dot{E}$ ben conservato. Misura m. 0.05 di altezza per m. 0.018 di diametro della bocca; 76723 = E1445: [Bronze] Moneta di modulo medio del diametro di m. 0.023 e dello spessore di $\mathrm{m}$. 0.002 .

\section{Boutique Or. II, 9}

Période de fouille: 1933-1936.

Bibliographie: Maiuri 1958 b (462-463); Pagano 1997 (76); Mols 1999 (204-205; 165-167).

Longueur: 5,4 m; largeur: 4,1 m; surface: $22 \mathrm{~m}^{2}$.

Pièce annexe: une pièce annexe, présentant notamment une voute suspendue, se développe à l'est du local principal.
Période hypothétique de création: $2^{\mathrm{e}}$ phase postaugustéenne.

Situation par rapport à la parcelle: lien aboli.

Situation par rapport à l'habitat: habitat en pièce annexe / accès à l'étage (?).

Description des aménagements: à droite de l'entrée, une table de cuisson jouxte la latrine. Un comptoir en bois est signalé par les GSE. Au dessus du mur oriental se développe un porte-amphores. Le mur septentrional est percé d'une niche vouée au culte domestique. L'accès à l'étage se fait par une échelle de meunier. Il semble que l'étage a été destiné à entreposer des marchandises plus qu'à l'habitat.

Interprétations de la situation en 79: taberna vinaria (A. Maiuri) / commerce alimentaire (type 5).

Inventaire des objets mis au jour dans le local:

Boutique principale. $76389=\mathrm{E} 1112$ : [Céramique] Bruciaprofumi con piede basso a forma circolare. Misura m. 0.085 di altezza, m. 0.125 di diametro e m. 0.05 di profondità; $76390=\mathrm{E} 1113$ : [Céramique] Bruciaprofumi con piede alto e orlo svasato. E' alto m. 0.10, m. 0.147 di diametro e m. 0.05 di profondità; 76802 = E1524: [Bronze] Fusto di candelabro a canna liscia completamente contorto. É alto m. 0.98; 76803 = E1525: [Bronze] Piatto fondo in cattivo stato di conservazione. E alto m. 0.10 e m. 0.26 di diametro. Deux fonds de vases en céramique arétine; un amphorisque et cinq fragments d'amphores présentant une inscription peinte [non inventoriés lors de leur découverte].

Pièce annexe. 76753 = E1475: [Bronze] Lucerna monolichne con due piccole alette che servivano per mantenere le catiniglie. Manca del turacciolo. Misura m. 0.19 di lunghezza, m. 0.045 di diametro e m. 0.05 di altezza; 76754 = E1476: [Marbre] Peso a forma circolare del diametro di m. 0.03 ed alto m. 0.04; $76760=$ E1482: [Céramique] Lucerna bilichne col piede rotto. È avvolta da una massa di ferro. È alta m. 0.025, lunga m. 0.05 e del diametro di m. 0.045; 76994 = E1716: [Céramique] Bicchiere con parte dell'orlo mancante. È alto m. 0.09 e m. 0.03 di diametro alla bocca; 76995 = E1717: [Céramique] Bicchiere ben conservato alto m. 0.12 e del diametro alla bocca di m. 0.05; 76996 = E1718: [Verre] Unguentario con orlo rimboccato $e$ collo lungo. Misura m. 0.11 di altezza per m. 0.02 di diametro alla bocca; 76997 = E1719: [Céramique] Coppetta in buono stato di conservazione con piede basso. Il suo diametro è di m. 0.12, l'altezza di m. 05 e profonda m. 0.04. Nella parte interna tiene il bollo impresso; 76998 = E1720: [Bronze] Presenta qualche lesione presso il collo. É alto m. 0.10 e del diametro di m. 0.12 alla bocca; 76999 = E1721: [Céramique] Urceo mancante di una piccola parte presso il fondo. La sua altezza è di $m$. 0.165; $77000=\mathrm{E} 1722$ : [Bronze] Lucerna monolichne col piede alto e rostro prolungato. Manca di turacciolo. È in buono stato di conservazione. Come decorazioni tiene attaccata all'ansa 
una foglia. Misura m. 0.12 di lunghezza, m. 0.05 di altezza e m. 0.03 di diametro; $77001=\mathrm{E} 1723$ : [Bois] Rocchetto per avvolgere filo. È alto m. $0.04 \mathrm{e} \mathrm{m.} 0.03 \mathrm{di}$ diametro. Si conserva discretamente; $77002=\mathrm{E} 1724$ : [Céramique] Urceo col bollo rimboccato ben conservato. Alto m. 0.16 e m. 0.095 di diametro alla bocca; 77003 = E1725: [Verre] Unguentario con orlo svasato e lungo collo. Ė alto m. 0.115 e m. 0.015 di diametro alla bocca; $77004=$ E1726: [Céramique] Piattino del diametro di m. 0.08 e alto $m .0 .015 ; 77005=\mathrm{E} 1727$ : [Céramique] Vasettino per conservare unguenti. È ben conservato. Tiene l'ansa costolata e l'orlo rimboccato. La sua altezza è di $\mathrm{m}$. 0.065 e il diametro alla bocca è di m. 0.045; $77006=$ E1728: [Céramique] Vasettino per conservare i profumi. Ė alto m. 0.055 e del diametro alla bocca di m. 0.028; 77007 = E1729: [Bronze] Moneta di modulo medio del diametro di m. 0.022 e dello spessore di m. 0.002. E discretamente conservata. Cinq fonds de vases en céramique arétine; trois amphores présentant des inscriptions peintes [non inventoriés lors de leur découverte].
Étage. 76387 = E1110: [Marbre] Erma di Bacco, alta m. 0.19 e larga al centro m. 0.12. Come copricapo tiene pampini $; 76388=$ E1111: [Céramique] Lucerna monolychne lunga m. 0.12 e del diametro di m. 0.075; 76786 = E1508: [Bronze] Oinochoe con ansa distaccata, collo basso e panciuto. Ė alto m. 0.13 e m. 0.07 di larghezza della bocca; 76787 = E1509: [Bronze] Cassarola con ansa mancante e parte dell'orlo rotto. E' molto schiacciata per la pressione del materiale. Ė alta m. 0.09; 76788 = E1510: [Bronze] Guttus mancante di ansa con orlo svasato. É discretamente conservato. Misura m. 0.07 di diametro per m. 0.20 di altezza; $76789=$ E1511: [Bronze] Urceo mancante di ansa. L'altezza è di m. 0.21 e m. 0.058 di diametro; $76964=$ E1686: [Bronze] Patina con anse distaccate e fondo rotto. Il diametro è di m. 0.35 e l'altezza m. 0.12; 76965 = E1687: [Céramique] Lucerna monolichne col rostro accorciato discretamente conservata. Il diametro è di m. 0.07, la lunghezza m. 0.09 e l'altezza di m. 0.045. Un fragment d'amphore présentant une inscription peinte, non inventorié lors de sa découverte.

Bloc SePtentrional (Or. II, 10 À 18) (fig. 228)

Période de fouille: 1933-1937.

Bibliographie: Maiuri 1958 b (462-467); de Vos - de Vos 1982 (282-286); Pagano 1997 (75-77); Pirson 1999 (152-153); Pesando - Guidobaldi 2006 (380-385); Wallace-Hadrill - Guidobaldi - Camardo - Moesch 2008: 415-421.

Nombre d'unité(s) architecturale(s) en 79: 9 dont 7 locaux commerciaux indépendants.

Seuils: Or. II, 10 (seuil de type D1a en tuf); Or. II, 11 (seuil de type D1a en tuf); Or. II, 12 (seuil de type C1a en tuf); Or. II, 13 (seuil de type D1a en tuf); Or. II, 14 (seuil de type D1a en tuf); Or. II, 15 (seuil de type C1a en tuf); Or. II, 16 (seuil de type D1a en tuf); Or. II, 17 (seuil de type C1a en tuf); Or. II, 18 (seuil de type D1a en tuf).

\section{Atelier Or. II, 10}

Période de fouille: 1933, 1936.

Bibliographie: Maiuri 1958 b (463-464); de Vos de Vos 1982 (286); Pagano 1997 (75-76); Guidobaldi 2003; Pesando - Guidobaldi 2006 (385).

Longueur: 5,3 m; largeur: 3,8 m; surface totale: $49 \mathrm{~m}^{2}$.

Pièce annexe: le local de travail est divisé en deux pièces séparées par un couloir. Une chambre se trouve entre les deux.

Période hypothétique de création: $2^{\mathrm{e}}$ phase postaugustéenne.

Situation par rapport à la parcelle: indépendance.
Situation par rapport à l'habitat: habitat en pièce annexe (et à l'étage?).

Description des aménagements: aucun aménagement artisanal n'est visible. La nature des objets découverts permet de postuler que l'artisan travaillant dans ce local maniait le tour, pour inciser des pierres semi-précieuses et pour sculpter des objets de révolution.

Interprétations de la situation en 79: gemmarius (A. Maiuri) / atelier d'incision et de tournage.

Inventaire des objets mis au jour dans le local:

Boutique principale (10-1). $76391=$ E1114: [Bronze] Oenochoe mancante della bocca. E' alto m. 0.16 e del diametro della bocca di m. 0.06; $76392=$ E1115: [Bronze] Campanello alto m. 0.08 e di m. 0.05 per lato; $76393=$ E1116: [Bronze] Moneta di modulo medio del diametro di 0.025 e dello spessore di $m$. 0.002; $76791=$ E1513: [Bronze] Piccolo candelabro mancante della parte superiore. Il fusto è fatto a canna e tra un piede e l'altro tiene come decorazione una palmetta. $\grave{E}$ alto m. 0.30; $76792=\mathrm{E} 1514$ : [Verre] Bottiglia col collo allungato, bocca svasata e panciuta. Si conserva bene e non presenta tracce di lesioni. Ė alta m. 0.165 e del diametro di m. 0.025; 76793 = E1515: [Céramique] Lucerna monolichne col rostro accorciato. Il fondo superiore è molto incavato. È lungo m. $0.088 \mathrm{e}$ il diametro è di $m$. 0.048; $76794=\mathrm{E} 1516$ : [Céramique] Lucerna monolichne e monoansata. È lunga m. 0.085 e m. 0.05 il diametro; $76795=\mathrm{E} 1517$ : [Céramique] Lucerna monolichne lunga m.0.07 e m.0.04 di 


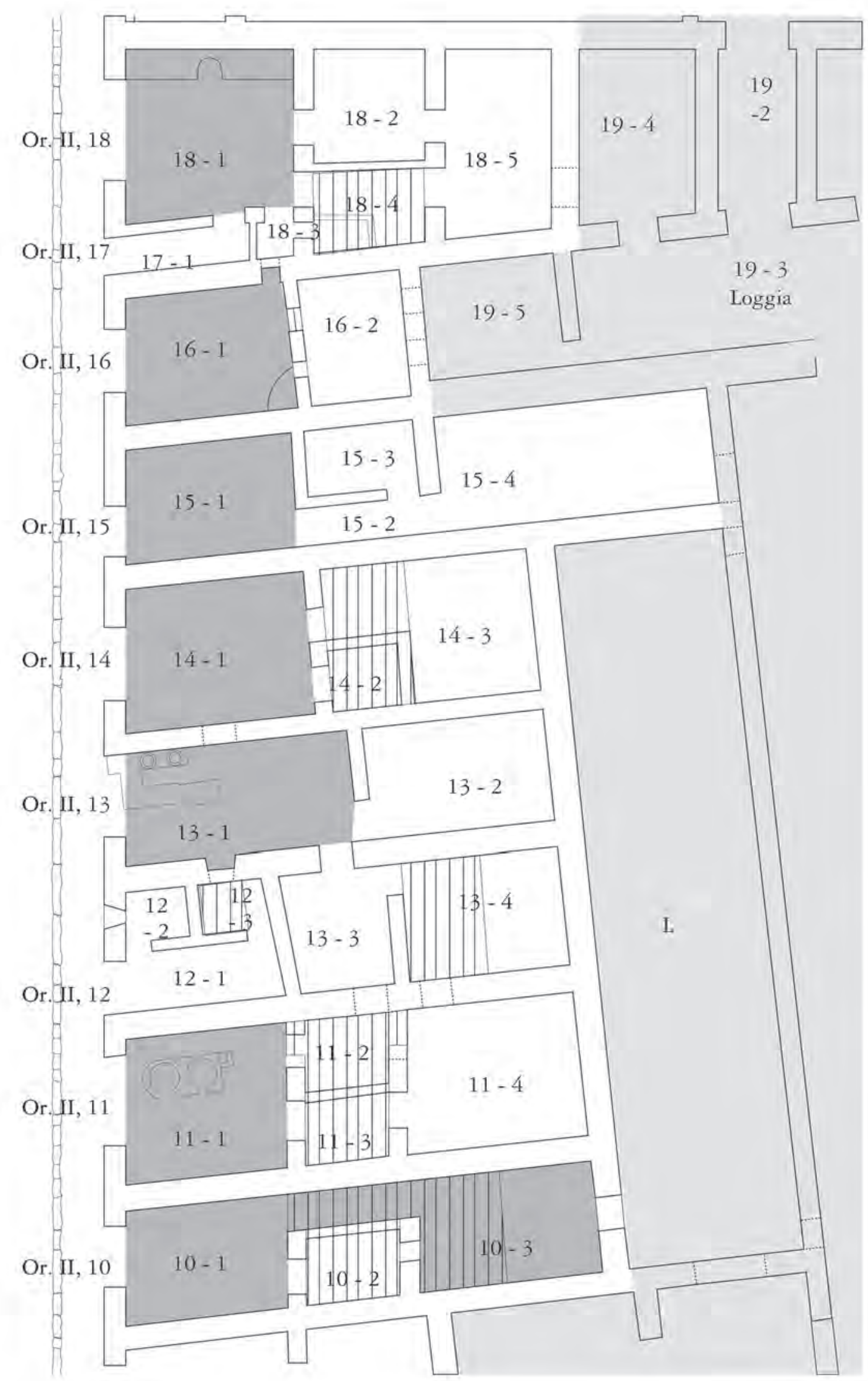

Fig. 228 - Plan de l'Insula Orientalis $I I^{a}-$ bloc septentrional (Or. II, 10 à 18), de ses ateliers et de ses boutiques (échelle: $1 / 200)$.

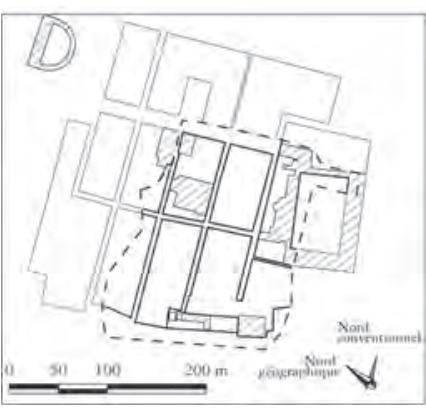

0

10

$20 \mathrm{~m}$

Espace commercial ou artisanal

Extension des mezzanines

Extension du Ler étage 
diametro; $76796=$ E1518: [Céramique] Lucerna discretamente conservata col fondo superiore rotto. Misura m. 0.07 di lunghezza e m. 0.038 di diametro; 76797 = E1519: [Verre] Bottiglia col collo allungato alta m. 0.16 e m. 0.025 di diametro della bocca; 76798 = E1520: [Verre] Bottiglia ben conservata alta m. 0.12 e del diametro di m. 0.02; $76799=\mathrm{E} 1521$ : [Bronze] Lucerna monolichne col rostro molto sviluppato, ansa mancante e piede sollevato. È discretamente conservata. Misura m. 0.095 di lunghezza, m. 0.04 di altezza e m. 0.035 di diametro $; 76800=\mathrm{E} 1522$ : [Céramique] Bicchiere con orlo svasato alto m. 0.10 e m. 0.035 di diametro; $76801=$ E1523: [Bronze] Patera con ansa distaccata in ottimo stato di conservazione. È alta m. 0.055, il diametro è di m. 0.20 e la lunghezza m. 0.34; $76807=$ E1529: [Bronze] Lucerna monolichne col rostro accorciato. Ė a forma circolare mancante di ansa. Il piede è sollevato. È discretamente conservata. La sua lunghezza è di m. 0.13 e il diametro di m. $0.105 ; 76808=\mathrm{E} 1530$ : [Bronze] 2 strigili, uno mancante della punta. Sono mediocremente conservati. Misurano m. 0.19 di lunghezza $; 76809=\mathrm{E} 1531$ : [Céramique] Oinochoe mancante di una piccola parte dell'orlo. L'ansa è costolata. È ben conservato. Misura m. 0.25 di altezza per $m .0 .10$ di diametro $; 76810=$ E1532:[Céramique] Urceo ben conservato. Nell'interno contiene materia farinosa nera. L'altezza è di m. 0.13 e il diametro di m. 0.04; 76812 = E1534: [Céramique] Bicchiere con orlo svasato. La sua altezza è di m. 0.095 e m.. 0.045 di diametro $; 76825$ = E1547: [Céramique] Lucerna monolichne col rostro accorciato. Ė in buono stato di conservazione. Misura m. 0.05 di diametro per m. 0.09 di lunghezza $; 76858=$ E1580: [Marbre] Tavolo alto m. 1.05. Manca la base. Il piede è di marmo bianco ridotto in più pezzi, ma nessuno ne manca. Il tavolo è d'alabastro largo m. 0.63, lungo m. 0.95 e dello spessore di m. 0.04; $76859=\mathrm{E} 1581:[\mathrm{Fer}]$ Roncola per tagliare piccoli tronchi. È lunga m. 0.33; $76860=$ E1582: [Pierre semi précieuse, cornaline] Figura di guerriero bendato seduto a terra con una gamba distesa ed appoggiantesi ad un grande scudo rotondo. Misura m. 0.016 per 0.014; 76861 = E1583: [Pierre semi précieuse, cornaline] Figura di giovane guerriero nudo con la testa coperta dall'elmo, seduto sulla roccia e sorreggente un grande scudo sul ginocchio. Misura m. 0.014 per 0.017; 76862 = E1584: [Pierre semi précieuse, cornaline] Figura femminile forse di Fortuna con cornucopia. Misura m. 0.01 per 0.011; $76863=$ E1585: [Pierre semi précieuse, cornaline] Parallelepipedo con figure di animali incise su ciascuna delle quattro facce. Forato al centro per uso di collana. Misura m. 0.013 per $0.007 ; 76864=\mathrm{E} 1586:$ [Os] Disco forato per sospensione con incisione di testa silenica dalla lunga barba fluente di profilo destro. Misura m. 0.033; $76865=$ E1587: [Pâte de verre] Cammeo a rilievo bianco sul fondo turchino di m. 0.026 per 0.019 . Busto virile di profilo a destra ritratto ellenistico di persona macedone $; 76866=\mathrm{E} 1588:$ [Argent $]$ Utensile terminante ad una estremità a punta e dall'altra a forma concava. È lungo m. 0.15; $76867=\mathrm{E} 1589$ : [Argent] Utensile lungo m. 0.15; $76868=\mathrm{E} 1590$ : [Argent] Anello perornamento di mobile. E' del diametro di m. 0.02; $76869=$ E1591: [Bronze] Stiletto per scrivere lungo $m .0 .118 ; 76870=\mathrm{E} 1592$ : [Bronze] Patera con ansa distaccata del diametro di m. 0.25, alta m. 0.07 e lunga m. 0.32; 76871 = E1593: [Pâte de verre] Pezzi numero 140. Gli oggetti servivano per collana $; 76872$ = E1594: [Pierre semi précieuse, jaspe $]$ Diaspro variegato giallo e rosso con intaglio. Vi è incisa la figura di un felino, forse una tigre. Misura m. 0.01 per 0.009; $76873=$ E1595: [Pâte de verre] Pasta vitrea verde con fascia turchina filettata di bianco, intrecciata di m. 0.014 per 0.017. Vi è intagliato il gruppo di due figure di un fanciullo che si abbandona riverso tra le braccia di una donna (Bacco e Semele?); $76874=$ E1596: [Pâte de verre] Pasta vitrea piccolissima recante incise sinistro grado le parole: SPES; $76875=$ E1597: [Pierre semi précieuse, cornaline] Corniola con intaglio di figura virile che stringe nella sinistra un fascio di fulmini; 76876 = E1598: [Pierre semi précieuse, améthyste] Ametista ovale di m. 0.015 per 0.012 recante incisa nella superficie più larga un piccolo oinochoe; $76877=$ E1599: [Verre] Bottiglia con orlo piatto e panciuta. È alta m. 0.135 e del diametro di m. 0.025; 76878 = E1600: [Céramique] Vasettino con orlo rimboccato. Serviva per conservare unguenti. È ben conservato. La sua altezza è di m. 0.0 6 ed il diametro di $m .0 .04 ; 76880=\mathrm{E} 1602$ : [Bronze] Anforetta con le anse staccate. E in ottimo stato di conservazione. Misura m. 0.16 di altezza e m. 0.045 di diametro della bocca; $76881=\mathrm{E} 1603$ : [Bronze] Uncinetto per lavorare reti. Ė alto m. 0.19; $76882=$ E1604: [Bronze] Bacinella a forma ovale discretamente conservata. È alta m. 0.055, e lunga m. 0.165 e m. 0.09 di diametro al centro $; 76883=\mathrm{E} 1605:[$ Bronze $]$ Due pinze lunghe m. 0.10; $76884=\mathrm{E} 1606$ : [Bronze] Cassarola in ottimo stato di conservazione. È larga m. 0.285, alta m. 0.095 e del diametro di m. 0.145; 76885 = E1607: [Bronze] Piatto a forma ovale lungo m. 0.29, alto m. 0.08 e del diametro di m. 0.175. Tiene l'orlo svasato e piede sollevato (Boutique principale) 76886 = E1608: [Bronze] Candelabro con fusto scanalato. Tiene due piedi distaccati. Misura m. 1.30 di altezza; $76887=\mathrm{E} 1609$ : [Verre] Tre unguentari alti m. $0.11 ; 76888=\mathrm{E} 1610$ : [Céramique] Urceo con ansa costolata e panciuto. È ben conservato. La sua altezza è di m. 0.20 e il diametro di m. 0.05; $76889=\mathrm{E} 1611$ : [Céramique] Lucerna bilichne con ansa e rostri rotti. È lunga m. 0.115 e il diametro di m. 0.055; $76890=$ E1612: [Pierre semi précieuse, agathe] Bombylios a corpo leggermente schiacciato corto collo cilindrico e piccole anse rettangolari forate. Vasetto unguentario della misura di m. 0.054 di altezza per m. 0.044 di larghezza, diametro della bocca m. 0.016; $76891=$ 
E1613: [Céramique] Lucerna ben conservata con il rostro accorciato. Il diametro è di m. 0.07, l'altezza m. 0.025 e la lunghezza m. 0.015; 76892 = E1614: [Bronze] Oinochoe mancante di anse. È discretamente conservato. Ĺaltezza è di m. 0.135 e il diametro di m. 0.07; $76893=$ E1615: [Céramique] Anforetta con anse costolate e orlo rimboccato. É alta m. 0.31 e del diametro di m. 0.115; 76894 = E1616: [Bronze] Lampada monolichne con rostri prolungati e piede sollevato. Mancano le catiniglie per tenerla sospesa. È lunga m. 0.18, alta m. 0.05 e del diametro di m. 0.08; 76895 = E1617: [Marbre] Erma di Bacco di buona fattura $e$ in ottimo stato di conservazione. E alta m. 0.195; $76896=$ E1618: [Bronze] Candelabro mancante del piattello. In buono stato di conservazione. Misura m. 1.23 di altezza; 76902 = E1624: [Verre] Bottiglia panciuta con collo corto. È alta m. 0.18 per 0.02 di diametro $; 76910=\mathrm{E} 1632$ : [Pierre semi précieuse, agathe] Bombylios discretamente conservato. Presenta qualche screpolatura. L'orlo è svasato. È alto m. 0.119 e il diametro alla bocca è di m. 0.03; 76911 = E1633: [Albâtre] Piccolo vasettino a forma circolare, esso serviva per unguenti. Il diametro alla bocca è di m. 0.03 e l'altezza di m. 0.02; $76912=$ E1634: [Bronze] Moneta di modulo medio del diametro di m. 0.025 e dello spessore di m. 0.002. Non si conosce l'epoca; 76913 = E1635: [Pâte de verre] Holmos col piede e parte dell'orlo mancante. È alto m. 0.025 e del diametro di m. 0.038; 76914 = E1636: [Céramique] Bruciaprofumo a forma rettangolare con piede basso. E lungo m. 0.17, largo m. 0.15 e profondo m. 0.06; 76915 = E1637 : [Céramique] Lucerna ben conservata. Sul fondo superiore tiene a rilievo una pianta carica di frutti con un cervo. Ė lungo m. 0.09 ed il diametro m. 0.045; 76916 = E1638: [Céramique] Lucerna monolichne col rostro prolungato. È lunga m. 0.10 e il diametro è di m. 0.045. Tiene a rilievo la dea Fortuna; 76917 = E1639: [Céramique] Piatto discretamente conservato. Il diametro è di m. 0.285 e l'altezza di m. 0.06; 76933 = E1655: [Bronze] Cassarola ben conservata con ansa allungata. Misura m. 0.29 di lunghezza e m. 0.15 di diametro e m. 0.10 di altezza; 76934 = E1656: [Bronze] Utensile per cucina con orlo svasato. É alto m. 0.10 e m. 0.21 di diametro $; 76935=$ E1657: [Céramique] Urceo alto m. 0.14 e m. 0.03 di diametro alla bocca; 76936 = E1658: [Céramique] Bicchiere alto m. 0.11 e del diametro di m. 0.04 la bocca; 76937 = E1659: [Céramique] Bombylios mancante di una parte del collo e della bocca. È alto m. 0.13 e il diametro alla bocca è di m. 0.04; $76938=$ E1660: [Bronze] Strigile mancante dell'impugnatura. Èlungo m. 0.20; $76939=\mathrm{E} 1661$ : [Bronze] Campanello alto m. 0.04 e m. 0.03 di diametro; 76947 = E1669: [Marbre] Tavolo mancante della base. La lunghezza è di m. 0.94, lo spessore m. 0.3 e la larghezza m. 0.55 ; 76948 = E1670: [Bronze] Utensile per cucina a forma ovale con piede basso. Tiene l'orlo svasato. La lunghezza è di m. 0.33 e la larghezza al centro di m. 0.26. Manca di un ansa. È discretamente conservato; $76949=$ E1671: [Bronze] Bilancia a mano di piccole dimensioni. Conserva per intero l'asta, il romano e due ganci. Manca del piatto e parte della catiniglia. L'asta è lunga $m$. 0.158, il romano $m$. 0.06 e i ganci $m$. 0.04; $76950=$ E1672: [Verre] Bombylios con collo basso. È in ottimo stato di conservazione. E alto m. 0.09 e m. 0.02 di diametro alla bocca; 76951 = E1673: [Bronze] Askos con becco prolungato e piede sollevato. Misura m. 0.10 di diametro e m. 0.06 di altezza. Il beccuccio è lungo m. 0.04; 76952 = E1674: [Céramique] Bicchiere discretamente conservato alto m.0.08 e m. $0.015 \mathrm{di}$ diametro alla bocca; 76958 = E1680: [Céramique] Brocchetta in buono stato di conservazione. Tiene il piede basso ed ansa costolata. È alta m. 0.15 e m. 0.11 di diametro della bocca; $76826=$ E1548: [Bronze] Cassarola in buono stato di conservazione. Misura m. 0.22 di lunghezza, m. 0.10 diametro e m. 0.054 di profondità. Deux fonds de vases en céramique arétine non inventoriés lors de leur découverte.

Pièce annexe (10-3). 76827 = E1549: [Bronze] 2 strigilidiscretamente conservati. Sonolunghim. 0.32; 76828 = E1550: [Céramique] Urceo mancante dell'orlo. É alto m. 0.38 e m. 0.04 di diametro della bocca; 76842 = E1564: [Bronze] Cassarola in buono stato di conservazione. É lunga m. 0.21, alta m. 0.065 e del diametro di m. 0.10; 76843 = E1565: [Bronze] Coppa col fondo rotto. È alta $m .0 .08$ per $m .0 .115$ di diametro; 76847 = E1569: [Bronze] Moneta di modulo medio del diametro di $m .0 .025$ e dello spessore di $m$. 0.003. $\dot{E}$ molto corrosa $; 76848$ = E1570: [Bronze] Moneta di modulo medio del diametro di m. 0.025 e dello spessore di m. 0.003. È anche corrosa; $76849=\mathrm{E} 1571$ : [Argent] Gruppo di trenta monete di piccolo modulo di età repubblicana (triumviri monetali) ed imperiali costituenti un piccolo ripostiglio; 76850 = E1572: [Pâte de verre] Vetro bianco. Disco ovale con intaglio matrice per pasta vitrea. Testa femminile di profilo a destra con acconciatura di età Giulio Claudia. Ritratto di Agrippina minore. Misura m. 0.032 per 0.025; 76851 = E1573: [Pierre semi précieuse, cornaline] Con intaglio. Vi è incisa una figura di Nike volante che regge tra le mani un serto. Misura m. 0.025 per 0.014; 76852 = E1574: [Pierre semi précieuse, cornaline] Piccolissima di m. 0.009 per 0.007 con intaglio a figura virile in abito talare [?] recante un tirso. La rappresentazione è poco riconoscibile per lo sfaldamento della superficie; 76853 = E1575: [Os] Tre dadi a forma rettangolare. Ciascuno è alto $m .0 .013$ per 0.008 . Su ogni faccia vi sono dei piccoli circoletti che indicano un numero. Essi variano da 1 a 6; 76854 = E1576: [Verre] 4 unguentari di varie grandezze discretamente conservati; 76855 = E1577: [Céramique] Lucerna monolichne con ansa costolata e rostro prolungato. È lunga m. 0.08, alta m. 0.025 e del diametro di m. 0.035; 76856 = E1578: [Céramique] Lucerna monolichne col 
rostro accorciato. È ben conservata. Il diametro è di m. 0.05, la lunghezza m. 0.075 e l'altezza m. 0.025; 76857 = E1579: [Céramique] Lucerna monolichne con ansa rotta. Misura m. 0.03 di altezza, m. 0.04 di diametro e m. 0.07 di lunghezza $; 76897$ = E1619: [Tuf] Ara votiva di ottima fattura e ben conservata. L'altezza è m. 0.13. Nella faccia anteriore vi è intagliato un tempietto il cui frontone è sostenuto da colonnine con capitelli dorici; 76898 = E1620: [Céramique] Lucerna monolichne ben conservata del diametro di m. $0.04 e$ lunga $\mathrm{m}$. 0.075. Sul fondo superiore vi è a rilievo un delfino; $76899=$ E1621: [Céramique] Lucerna lunga m. 0.075, alta m. 0.025 e del diametro di $m .0 .04 ; 76900$ = E1622: [Bronze] Campanello alto m. 0.09; $76918=$ E1640: [Céramique] Lucerna monolichne col rostro alquanto sviluppato. È lungo m. 0.09 ed il diametro è di m. 0.06; 76919 = E1641: [Céramique] Lucerna ben conservata. Sul fondo superiore vi è a rilievo Diana. Misura m. 0.08 di lunghezza per m. 0.055 di diametro; 76920 = E1642: [Céramique] Lucerna discretamente conservata alta m. 0.03, lunga m. 0.09 e del diametro di m. 0.055; 76921 = E1643: [Nacre] Piattino per unguenti. È di m. 0.04 di diametro e m. 0.01 di altezza. Huits fragments d'amphores présentant des inscriptions peintes, non inventoriés lors de leur découverte.

Pièce annexe (10-2). $76923=$ E1645: [Marbre] Ritratto di uomo di ottima fattura. Manca della punta del naso e la calotta cranica è divisa in due parti. I capelli sono policromati rossi. L'altezza è di m. 0.37; 76972 = E1694: [Céramique] Lucerna monolichne con ansa rotta. È lunga m. 0.089 e il diametro è di m. 0.053 .

\section{Atelier Or. II, 11}

Période de fouille: 1936.

Bibliographie: Maiuri 1958 b (464); de Vos - de Vos 1982 (286); Pagano 1997 (75).

Longueur: 5,3 m; largeur: $4,8 \mathrm{~m}$; surface: $25 \mathrm{~m}^{2}$.

Pièce annexe: au-delà de l'espace de travail se trouvent trois pièces, dont au moins une chambre.

Période hypothétique de création: $2^{\mathrm{e}}$ phase postaugustéenne.

Situation par rapport à la parcelle: lien aboli.

Situation par rapport à l'habitat: habitat en pièce annexe.

Description des aménagements: deux foyers circulaires se trouvent dans le local principal, fortement dégradés; ils pourraient être associés à l'artisanat textile. L'hypothèse d'une teinturerie reste discutable.

Interprétations de la situation en 79: tintoria (A. Maiuri) / atelier lié à la production textile (?).

Inventaire des objets mis au jour dans le local:

Boutique principale (11-1). $76940=\mathrm{E} 1662$ : [Céramique] Anforetta alta m. 0.295 e del diametro alla bocca di m. 0.12. Nell'interno vi sono delle lentic- chie $; 76941=$ E1663: [Céramique] Anforetta discretamente conservata. Alta m. 0.31 e m. 0.13 di diametro alla bocca. Contiene vecce; $76942=\mathrm{E} 1664:$ [Bronze $]$ Moneta di modulo medio del diametro di m. 0.027 e dello spessore di m. 0.003. È molto corrosa; 76943 = E1665: [Bronze] Cassarola con ansa rotta e corpo lesionato. L'altezza è di m. 0.06, il diametro m. 0.10 e la lunghezza m. 0.22; $76944=\mathrm{E} 1666$ : [Bronze] Lucerna monolichne col rostro prolungato e ansa mancante. È discretamente conservata. Misura m. 0.09 di lunghezza per m. 0.02 di diametro alla bocca; $76945=\mathrm{E} 1667$ : [Verre] Bombylios con ansa a ponte e corto collo. E alto m. 0.09 e m. 0.02 di diametro $; 76946=\mathrm{E} 1668$ : [Céramique] Urceo con ansa rotta. Manca di una piccola parte dell'orlo. Ė alto m. 0.06 e il diametro alla bocca è di m. 0.04; $76953=$ E1675: [Bronze $]$ Cassarola avvolta da materiale tufaceo. È lunga m. 0.26, alta m. 0.07 e il diametro è di m. 0.12; $76954=\mathrm{E} 1676$ : [Bronze] Piattello col piede basso in buono stato di conservazione. É alto m. 0.02 e m. 0.095 di diametro; 76955 = E1677: [Fer] Martello lungo m. 0.098, alto m. 0.06 e dello spessore di m. 0.05; $76956=\mathrm{E} 1678$ : [Fer] Utensile da muratore formato a mo' di forchetta. L'asta è spezzata. La lunghezza è di m. 0.40; $76960=$ E1682: [Bronze] Patera ben conservata lunga m. 0.30e del diametro di m. 0.15; $76961=\mathrm{E} 1683$ : [Céramique] Lucerna a forma di corno col rostro molto prolungato. Sul fondo superiore vi sono a rilievo due corni dell'abbondanza e sopra ciascuno di essi vi è sempre a rilievo una testina. E lunga $m .0 .16 ; 76962=\mathrm{E} 1684$ : [Coquillage] Tofa molto corrosa. L'apertura è di m. 0.0 8 e la lunghezza m. 0.29; 76963 = E1685: [Bronze] Moneta di modulo medio del diametro di m. 0.02 e dello spessore di m. 0.002. È molto corrosa. Un fond de vase en céramique arétine et un amphorisque présentant une inscription peinte [non inventoriés lors de leur découverte].

Pièce annexe (11-4). 76973 = E1695: [Céramique] Lucerna monolichne col rostro accorciato. È ben conservata. Il suo diametro è di m. 0.05 e la lunghezza m. 0.09; $76974=$ E1696: [Bronze] Moneta di modulo medio del diametro di m. 0.015 e dello spessore di m. 0.002 .

\section{Boutique Or. II, 13}

Période de fouille: 1936.

Bibliographie: Maiuri 1958 b (464-465); Pagano 1997 (75).

Longueur: 7,3 m; largeur: $3,7 \mathrm{~m}$; surface: $27 \mathrm{~m}^{2}$.

Pièce annexe: 3 pièces annexes se développent à l'est du local principal, sans que leurs liens avec l'activité soient clairs.

Période hypothétique de création: $2^{\mathrm{e}}$ phase postaugustéenne.

Situation par rapport à la parcelle: lien aboli.

Situation par rapport à l'habitat: habitat en pièce annexe? 
Description des aménagements: un comptoir en double équerre se déploie contre la paroi septentrionale, avec deux dolia incorporés. L'extrémité du comptoir est constituée par un chauffe-eau. Un fourneau est mentionné par les GSE. Aucun élément ne permet d'associer ou non les autres pièces à ce restaurant.

Interprétations de la situation en 79: taberna et popina (A. Maiuri) / commerce alimentaire (type 2).

Inventaire des objets mis au jour dans le local:

Boutique principale (13-1). $76924=$ E1646: [Céramique] Lucerna monolichne e ben conservata della lunghezza di m. 0.085 e del diametro di m. 0.057. Nel fondo superiore vi sono delle figure a rilievo, ma esse sono poco chiare; 76925 = E1647: [Argent] Anello del diametro dim. 0.02. Le due estremità terminano con una testa di serpentello. Esse sono separate tra loro a mezzo di una piccola placchetta sulla quale doveva starci qualche corniola; 76926 = E1648: [Argent] Anello di formato piccolo del diametro di m. 0.016. Anche esso termina con testa di serpe; 76927 = E1649: [Argent] Anellino del diametro di m. 0.015. È simile al precedente; 76928 = E1650: [Bronze] Timbro a forma rettangolare lungo m. 0.06 e alto m. 0.014. Tiene il seguente nome fatto con lettere a rilievo A.FVFER [lettres inversées]. L'ansa è a forma circolare e sopra essa vi sono le seguenti lettere $\mathrm{R}<$ vasa $>\mathrm{E}$ [lettres inversées]; $76929=\mathrm{E} 1651$ : [Bronze] Parecchi anelli fusi dall'azione di un fulmine. Si osserva ancora qualche corniola. È difficile poterli riparare; 76959 = E1681: [Bronze] Moneta di modulo medio del diametro di m. 0.023 e dello spessore di m. 0.02; 76978 = E1700: [Bronze] Casserola con ansa allungata ben conservata. Misura m. 0.29 di lunghezza, m. 0.14 di diametro e m. 0.10 di altezza $; 76979=\mathrm{E} 1701:$ [Bronze] Secchio alto m. 0.27 e del diametro di m. 0.23. L'ansa manca $; 76990=$ E1712: [Bronze] Otto monete, di cui quattro di modulo piccolo del diametro di m. 0.015 e dello spessore di m. 0.0015 e quattro di modulo medio del diametro di m. 0.025 e dello spessore di m. 0.003.

\section{Boutique Or. II, 14}

Période de fouille: 1933, 1936.

Bibliographie: Maiuri 1958 b (465).

Longueur: 6,3 m; largeur: 4,7 m; surface: $28 \mathrm{~m}^{2}$.

Pièce annexe: deux pièces annexes, dont une probable chambre se situent à l'est du local principal.

Période hypothétique de création: $2^{\mathrm{e}}$ phase postaugustéenne.

Situation par rapport à la parcelle: lien aboli.

Situation par rapport à l'habitat: habitat en pièce annexe.

${ }^{3}$ Il est probable que les objets découverts dans cette pièce correspondent au remblai de l'accès au portique de
Description des aménagements: aucun aménagement ne permet de déterminer la nature des activités se déroulant dans ce local.

Interprétations de la situation en 79: bottega d'artigiano (A. Maiuri) / boutique, commerce ou production indéterminés.

Inventaire des objets mis au jour dans le local:

Boutique principale (14-1). 76982 = E1704: [Céramique] Lucerna monolichne col rostro accorciato. $\dot{E}$ in buono stato di conservazione. Misura m. 0.08 di lunghezza, m. 0.055 di diametro e m. 0.04 di altezza $; 76983=\mathrm{E} 1705$ : [Céramique] Lucerna lunga m. 0.08, m. 0.045 di diametro e m. 0.09 di altezza; 76984 = E1706: [Bronze] Forma per pasticceria col fondo rotto. Ė alta m. 0.075 la lunghezza m. 0.22 e del diametro di m. 0.15.

\section{Atelier Or. II, 15}

Période de fouille: 1936-1937.

Bibliographie: Maiuri 1958 b (466).

Longueur: 5,6 m; largeur: 3,8 m; surface: $21 \mathrm{~m}^{2}$.

Pièce annexe: deux pièces annexes (15-3, 15-4) reliées par un couloir (15-2) sont incluses dans ce local. La pièce (15-4) est issue du comblement d'un accès au portique.

Période hypothétique de création: après le second séisme.

Situation par rapport à la parcelle: lien aboli.

Situation par rapport à l'habitat: habitat en pièce annexe?

Description des aménagements: aucun aménagement n'est visible ou n'a été décrit par les GSE. Un nettoyage effectué vers 2005 pourrait permettre d'identifier une table maçonnée comportant un fourneau contre le mur nord.

Interprétations de la situation en 79: bottega d'artigiano (A. Maiuri) / atelier lié à la production textile (?).

Inventaire des objets mis au jour dans le local:

Boutique principale (15-1). 76987 = E1709: [Bronze] Bronzo. Moneta di modulo medio ben conservata. È di m. 0.025 di diametro e m. 0.002 di spessore; 76991 = E1713: [Céramique] Piatto con una piccola parte dell'orlo mancante. Ė alto m. 0.06 e del diametro dim. 0.20 .

Pièce annexe (15-4) $)^{3} .77022=$ E1744: [Bronze] Moneta di modulo medio del diametro di metri 0.025 e dello spessore di metri 0.002. È molto corrosa; 77023 = E1745: [Céramique] Bicchiere con orlo svasato ben conservato. È alto metri 0.086 e del diametro di metri 0.025 alla coppa. 9 fonds de récipients de céramique

la "Palestre » plus qu'aux niveaux d'occupation de la pièce remblayée au moment de l'éruption. 
arétine présentant des timbres différents, 2 fragments d'amphores munis d'inscriptions peintes, non inventoriés lors de la découverte.

\section{Boutique Or. II, 16}

Période de fouille: 1936-1937.

Bibliographie: Maiuri 1958 b (466).

Longueur: 5,4 m; largeur: 4,2 m; surface: $23 \mathrm{~m}^{2}$.

Pièce annexe: Un espace d'habitation se trouve à l'est du local principal, au-delà d'une volée de deux marches.

Période hypothétique de création: $2^{\mathrm{e}}$ phase postaugustéenne.

Situation par rapport à la parcelle: lien aboli.

Situation par rapport à l'habitat: habitat en pièce annexe.

Description des aménagements: une fosse en quart de cercle se trouve dans l'angle sud-est du local. Comblée avant l'éruption, et située sous le mur de refend nord-sud, elle pourrait être une indication des activités se déroulant dans ce local avant le second séisme.

Interprétation de la situation en 79: boutique, commerce ou production indéterminés, éventuellement en travaux lors de l'éruption.

Inventaire des objets mis au jour dans le local:

Pièce annexe (16-2). 77013 = E1735: [Verre] Unguentario lungo metri 0.14 e del diametro alla bocca di metri 0.018; $77015=$ E1737: [Céramique] Bicchiere con bocca svasata e ben conservato. La sua altezza è di metri 0.07 e il diametro alla bocca di metri 0.04.

\section{Atelier Or. II, 18}

Période de fouille: 1936-1937.
Bibliographie: Maiuri 1958 b (466-467); de Vos - de Vos 1982 (286); Pagano 1997 (75).

Longueur: 5,5 m; largeur: 5,4 m; surface: $30 \mathrm{~m}^{2}$.

Pièce annexe: trois pièces annexes se développent à l'est du local principal.

Période hypothétique de création: après le séisme de 62.

Situation par rapport à la parcelle: lien aboli.

Situation par rapport à l'habitat: habitat en pièce annexe.

Description des aménagements: le sol est constitué de tuiles posées à plat. Contre le mur septentrional, une table maçonnée avec un fourneau circulaire en son centre. En dépit de l'absence de vasque associée à cette table, ce local a été une laverie de toisons avant l'éruption.

Interprétations de la situation en 79: officina tinctoria (A. Maiuri) / laverie de toisons.

Inventaire des objets mis au jour dans le local:

Boutique principale (18-1). $76992=$ E1714: [Corde] Vari pezzi a fili intrecciati grossi da formare una stuoia. Essi sono discretamente conservati; 76993 = E1715: [Céramique] Vasettino con orlo svasato. Serviva per conservare i profumi. La sua altezza è di m. 0.04, e m. 0.02 di diametro alla bocca; $77017=$ E1739: [Bronze] 6 monete di modulo medio discretamente conservate. Il diametro è di metri 0.025 e lo spessore metri 0.002 .

Pièce annexe (18-2). $77020=$ E1742: [Bronze] Moneta di modulo medio del diametro di metri $0.025 \mathrm{e}$ dello spessore di metri 0.002. È ben conservata; 77021 = E1743: [Bronze] Moneta di modulo grande del diametro di metri 0.04 e dello spessore di metri 0.004. Non si vede l'epoca. 


\section{BIBLIOGRAPHIE}

Ouvrages de référence et recueils de sources

AtLANTE = Pugliese Caratelli (G.) (dir.), Atlante delle forme ceramiche, 2 vol., Roma, Istituto della Enciclopedi italiana, 1981-1985.

$B D I=$ Bulletino dell'Istituto di Corrispondenza archeologica, Rome, 1829-1885.

BIASA = Bolletino del (Reale) Istituto di Archeologia e Storia dell'Arte, 1922-.

BULLARCHNAP = Bullettino archeologico napoletano, $1842-1848 ; 1853-1860$.

$C I L=$ Corpus inscriptionum Latinarum, Berlin, 1863-

Conspectus = ETTLINGER (E.) (et al.), Conspectus formarum terrae sigillatae Italico modo confectae, Bonn, R. Habelt, 1990 (Materialen zur römisch-germanischen Keramik, 10).

CVARRII = Oxé (A.), Comfort (H.), Kenrick (P.), Corpus vasorum arretinorum, $2^{\text {nd }}$ ed., Bonn, Habelt, 2000 (Antiquitas, 41).

$D P=$ Mommsen (Th.), Le droit public romain, "Manuel des antiquités romaines », 6 vol., Paris, Thorin et fils, 1889-1896.

EsPÉRANDIEU = Espérandieu (E.), Recueil général des bas-reliefs, statues et bustes de la Gaule Romaine, 10 vol., Paris, Imprimerie Nationale, 19071928 (Documents inédits sur l'Histoire de France publiés par les soins du ministre de l'Instruction publique).

GSE = Giornale degli scavi di Ercolano, manuscrits conservés à l'Ufficio scavi di Ercolano et partiellement à l'Archivio storico de la Soprintendenza speciale per $i$ beni archeologici di Napoli e Pompei - sede di Napoli.

GSP = Giornale degli scavi di Pompei, manuscrits conservés à l'Ufficio scavi di Pompei et partiellement à l'Archivio storico de la Soprintendenza speciale per $i$ beni archeologici di Napoli e Pompei - sede di Napoli.

GSPOMP = Giornale degli Scavi di Pompei, Napoli, Stamperia della R. Università, 1850-1851, 18611865, 1868-1879.
ILLRP = Degrassi (A.), Inscriptiones Latinae liberae rei publicae, 2 vol., Firenze, 1965.

ILS = Dessau (H.), Inscriptiones Latinae Selectae, 3 vol., Berolino, apud Weidmannos, 1892-1916.

LTUR = Steinby (M.) (ed.), Lexicon Topographicum Urbis Romae, 5 vol., Roma, Quasar, 1993-2000.

$M B=$ Reale Museo Borbonico, 1824-1867.

$N S C=$ Atti della (reale) Accademia (nazionale) dei Lincei. Notizie degli Scavi di Antichità, 1876 -.

PAH = Fiorelli (G.) (ed.), Pompeianarum antiquitatum historia quam ex cod. mss. et a schedis diurnisque R. Alcubierre, C. Weber, M. Cixia, I. Corcoles, I. Perez-Conde, F. et P. La Vega, R. Amicone, A. Ribau, M. Arditi, N. d'Apuzzo ceteror. quae in publicis aut provatis bibliothecis servantur, 3 vol., Neapoli, 1860-1864.

PPM = Pompei: pavimenti e mosaici, 11 vol., Roma, Istituto della enciclopedia italiana, 1990-2003.

$R E=$ Pauly (A. F.) (hrsg.), Paulys RealEncyclopädie der classischen Altertumswissenschaft / Neue Bearbeitung unter Mitwirkung zahlreicher fachgenossen, hrsg. begonnen von Georg Wissowa, Stuttgart, J.B. Metzlerscher Verlag - A. Druckenmueller Verlag, 1894-1972.

$R S$ = Crawford (M.) (ed.), Roman Statutes, 2 vol., London, Institute of Classical Studies, 1996 (Bulletin of the Institute of Classical Studies Supplement, 64).

$S E H R E^{2}=$ Rostovtzeff (M.), The Social and Economic history of the Roman Empire, $2^{\text {nd }}$ ed. revised by P.M. Fraser, 2 vol., Oxford, Clarendon Press, 1957.

$T L L=$ Thesaurus Linguae Latinae, Leipzig, Teubner, 1900-.

\section{Travaux cités}

ADAm 1986 = Adam (J.-P.), « Observations sur les suites du tremblement de terre de 62 à Pompéi », dans Albore Livadie (Cl.) (dir.), Tremblements de terre, 
éruptions volcaniques et vie des hommes dans la Campanie antique, Naples, 1986 (Publications de l'Institut français de Naples, $2^{\mathrm{e}}$ s., 7), p.67-87.

AdAm 1995 = Adam (J.-P.), La construction romaine, $3^{e}$ éd., Paris, Picard, 1995 (Les grands manuels Picard).

Allison 1992 = Allison (P.), «Artefact assemblage: not the Pompeii premise», dans Herring (R.) et al., Papers of the fourth conference of Italian archaeology: new developments in Italian archaeology, vol. 1, London, 1992, p. 49-56.

Allison 1993 = Allison (P.), « How do we identify the use of space in roman housing? ", dans Moormann (E.) (ed.), Functionnal and spatial analysis of wall painting: proceedings of the fifth international congress on the wall painting, Leiden, 1993, p. 1-8.

AlLISON 1995 = Allison (P.), «On-going seismic activity and its effects on the living conditions in Pompeii in the last decades", dans Fröhlich - Jacobelli 1995, p. 183-190.

Allison 1997 = Allison (P.), «Artefact distribution and spatial function in the Pompeian houses", dans Rawson (B.), Weaver (P.), The roman family in Italy, Oxford, Clarendon Press - Australian National University, 1997, p. 321-354.

Allison $2001=$ Allison (P.M.), " Using the material and written sources: turn of the millennium approaches to Roman domestic space », AJA, 105, 2001, p. 181-208.

Allison $2004=$ Allison (P.M.), Pompeian households. An analysis of the material culture, Los Angeles, Cotsen Institute of Archaeology, 2004 (Monograph, 42).

Allison $2006=$ Allison (P.M.), The insula of the Menander at Pompeii, III: the finds, a contextual study, Oxford, Clarendon Press, 2006.

Allroggen-Bedel 1974 = Allroggen-Bedel (A.), «Das sogenannte Forum von Herculanum und die borbonischen Grabungen von 1739», CronErcol, 4, 1974, p. 97-109.

Allroggen-Bedel 1975 = Allroggen-Bedel (A.), «Der Hausherr der Casa dei cervi in Herculaneum», CronErcol, 5, 1975, p. 99-103.

Allroggen-Bedel 1983 = Allroggen-Bedel (A.), «Dokumente des 18. Jahrhunderts zur Topographie von Herculaneum ", CronErcol, 13, 1983, p. 139-158.

Allroggen-Bedel $1991=$ Allroggen-Bedel (A.), "Lokalstile in der campanischen Wandmalerei ", Kölner Jahrbuch für Fruh- und Vorgeschichte, 24, 1991, p. 35-41.

Allroggen-Bedel 1993 = Allroggen-Bedel (A.), «Gli scavi di Ercolano nella politica culturale dei Borboni ", dans Franchi dell'Orto 1993, p. 35-40.

Ammann 1925 = Ammann (L.), Meunerie et boulangerie, «Encyclopédie agricole», $2^{\mathrm{e}}$ éd., Paris, Baillière et Fils, 1925.
Amodio 1873 = Amodio (M.), Pompei. Détruite à 23 novembre 79. Empire Néron. Découverte en 1748, s.l., 1873 [album de photographies dont un exemplaire est conservé à la bibliothèque de l'INHA, Paris].

Amouretti - Brun 1993 = Amouretti (M.-C.), Brun (J.-P.) (éd.), La production du vin et de l'huile en Méditerranée, Athènes, École française d'Athènes, 1993 (Bulletin de Correspondance Hellénique - Supplément, 26).

Amouretti - Comet - Ney - Paillet $1984=$ Amouretti (M.-C.), Comet (G.), Ney (C.), Paillet (J.-L.), «À propos du pressoir à huile: de l'archéologie industrielle à l'histoire », MEFRA, 96, 1, 1984, p. 379-421.

ANDRÉ 1981 = André (J.), L'alimentation et la cuisine à Rome, $2^{\mathrm{e}}$ éd., Paris, Les Belles-Lettres, 1981 (Collection d'études anciennes, 143).

Andreau - France - Pittia $2004=$ Andreau (J.), France (J.), Pittia (S.) (dir.), Mentalités et choix économiques des Romains, Bordeaux, Ausonius éditions, 2004 (Scripta Antiqua, 7).

ANDREAu 1973 = Andreau (J.), «Histoire des séismes et histoire économique. Le tremblement de terre de Pompéi (62 ap. J.-C.) ", AnnEconSocCiv, 28, 2, 1973, p. 369-395.

ANDREAu 1995 = Andreau (J.), «Présentation. Vingt ans après L'Économie antique de Moses I. Finley ", Annales (HSS), 50, 5, 1995, p. 947-960.

ANDREAu 2004 A = Andreau (J.), "Sur les choix économiques des notables romains ", dans Andreau - France - Pittia 2004, p. 71-85.

ANDREAu 2004 в = Andreau (J.), «Les esclaves 'hommes d'affaires' et la gestion des ateliers et commerces», dans Andreau - France - Pittia 2004, p. 111-126.

Angelone 1986 = Angelone (R.), L'officina coactiliaria di M. Vecilio Verecundo a Pompei, Napoli, Arte tipografica, 1986 (Accademia di archeologia, lettere e belle arti di Napoli-Monumenti, 6).

ANDREAu 2008 = Andreau (J.), «The use and survival of coins and of gold and silver in the Vesuvian cities ", dans Harris (W.V.), The monetary system of the Greeks and Romans, Oxford, Oxford University Press, 2008, p. 208-225.

AnNecchino 1977 = Annecchino (M.), «Frittillus, un piccolo vaso di terracotta ", CronPomp, 3, 1977, p. 198-213.

Anniboletti - Befani - Boila $2009=$ Anniboletti (L.), Befani (V.), Boila (P.), «Progetto 'Rileggere Pompei'. Per una nuova forma urbis della città. Le indagini geofisiche nell'area non scavata e l'urbanizzazione del settore orientale ", FOLD\&R 148, 2009, p. 1-11.

Ansaloni $E T$ AL. 2007 = Ansaloni (I.), Pederzoli (A.), Iotti (M.), Del Villano (L.), «Identificazione zoologica della fenice rappresentata sulla facciata della caupona di Exinus a Pompei», Ocnus, 15, 2007, p. 23-26. 
AsAKA 1993 = Asaka (T.), «Note on the Plan of the Villae Rusticae in the vicinity of Pompeii", Opuscula Pompeiana, 3, 1993, p. 25-53.

AtKInson 1914 = Atkinson (D.), "A hoard of Samian Ware from Pompeii », JRS, 4, 1914, p. 27-64.

AUBERT 1994 = Aubert (J.-J.), Business managers in Ancient Rome. A social and economic study of institores, 200 B.C. - A.D. 250, Leiden - New York - Köln, Brill, 1994 (Columbia studies in classical tradition, 21).

Avellino 1837 = Avellino (M.F.), Descrizione di una casa pompeiana con capitelli figurati all'ingresso disotterrata negli anni 1831, 1832 e 1833, la terza alle spalle del tempio della Fortuna Augusta con ingresso sulla strada che volgesi verso la porta detta di Nola, Napoli, Tipografia Tramater, 1837.

BAKKER 1999 = Bakker (J.Th.) (ed.), The mills-bakeries of Ostia, Amsterdam, Gieben, 1999 (Dutch monographs on ancient history and archaeology, 21).

Balasco 2000 A = Balasco (A.), "L'architettura del teatro di Ercolano ", dans Pagano 2000, p. 79-85.

Balasco 2000 B = Balasco (A.), "The architectural structure of the theatre», dans Pagano (M.), Balasco (A.), The ancient theatre of Herculaneum, Napoli, Electa Napoli, 2000, p. 74-99.

BALDi 1964 = Baldi (A.), «Elementi di epigrafia pompeiana ", Latomus, 23, 1964, p. 793-801.

BARBERAN - PiQUÈS - RAUX - SANCHEZ 2006 = Barberan (S.), Piquès (G.), Raux (S.), Sanchez (C.), «Un dispositif de cuisson original en Languedoc dans l'Antiquité: les fours à pain à cloche mobile en céramique", dans Rivet (L.) (éd.), S.F.É.C.A.G. Actes du congrès de Pézenas. 25-28 mai 2006, Marseille, S.F.É.C.A.G., 2006, p. 257-271.

BARBET 1985 = Barbet (A.), La peinture romaine. Les styles décoratifs pompéiens, Paris, Picard, 1985.

BASTET - DE Vos 1979 = Bastet (F.L.), de Vos (M.), Il terzo stile pompeiano, Rome, Nederlands Instituut te Rome, 1979 (Archeologische Studiën van het Nederlands Instituut te Rome, 4).

Bats 1996 = Bats (M.) (dir.), Les céramiques communes de Campanie et de Narbonnaise ( ${ }^{e r}$ s. av. J.-C. - II ${ }^{e}$ s. ap. J.-C.). La vaiselle de cuisine et de table, Naples, Centre Jean-Bérard, 1996 (Collection du Centre Jean-Bérard, 14).

BÉAL 1996 = Béal (J.-C.), «Instrumentum et production textile en Gaule romaine: l'exemple des pesons de terre cuite", dans Aspects de l'artisanat du textile dansle monde méditerranéen (Egypte, Grèce, monde romain), Lyon, Université Lumière - Lyon 2, 1996 (Collection de l'Institut d'Archéologie et d'Histoire de l'Antiquité de Lyon, 2), p. 121-131.

BELli 1963 = Belli (C.), «Amedeo Maiuri, poeta dell'archeologia», NuovAnt, 98, giugno 1963, vol. 488, fasc. 1950 , p. 147-162 (reproduit dans Maiuri 1978, p. 11-22).

Beloch 1890 = Beloch (J.), Campanien, Geschichte und Topographie des antiken Neapel und seiner
Umgebung, 2 auflage, Breslau, E. Morgenstern, 1890.

Beloch 1989 = Beloch (J.), Campania: storia e topografia della Napoli antica e dei suoi dintorni, tr. it. de Beloch 1890, Ferone (C.), Pugliese Carratelli (F.) (cur.), Napoli, Bibliopolis, 1989

Beretta - Di Pasouale 2006 = Beretta (M.), Di Pasquale (G.) (dir.), Arts et sciences. Le verre dans l'empire romain, Florence-Milan, Giunti, 2006.

BERRY 1997 A = Berry (J.), « The conditions of domestic life in Pompeii in AD 79: a case-study of houses 11 and 12, insula 9 region $\mathrm{I} », P B S R, 65,1997$, p. 103-125.

BERRY 1997 B = Berry (J.), "Household artefacts: towards a re-interpretation of Roman domestic space», dans Laurence - Wallace-Hadrill 1997, p. 183-195.

Beulé 1872 = Beulé (Ch.-E.), Le drame du Vésuve, $2^{\mathrm{e}}$ éd., Paris, Lévy frères, 1872.

BiLliard 1913 = Billiard (R.), La vigne dans l'Antiquité, Lyon, H. Lardanchet, 1913, (rééd. anastatique, Marseille, Laffitte reprints, 1997).

BinneBEKE - DE KIND 1996 = Binnebeke (M.C. van), de Kind (R.), "The casa dell'Atrio Corinzio and the casa del sacello di Legno at Herculaneum ", CronErcol 26, 1996, p. 173-228.

BinNEBEKE 1993 = Binnebeke (M.C. van), "The houses «dell'Atrio Corinzio» $(\mathrm{V}, 30)$ and «del sacello di Legno" $(\mathrm{V}, 31)$ at Herculaneum: the use of space », dans Franchi dell'Orto 1993, p. 229-236.

Bisi Ingrassia 1977 = Bisi Ingrassia (A.M.), «Le lucerne fittili dei nuovi scavi di Ercolano », dans Carandini 1977, p. 73-104.

BLAKE 1930 = Blake(M.E.), The pavements of the Roman buildings of the Republic and early Empire, Rome, American Academy in Rome, 1930 (Memoirs of the American Academy in Rome, 8).

BLoch 1959 = Bloch (H.), «The Serapeum of Ostia and the brick-stamps of 123 A.D. A new landmark in the history of Roman Architecture ", $A J A, 63,3$, 1959 , p. 225-240.

BLÜMnER 1912 = Blümner (H.), Technologie und Terminologie der Gewerbe und Künste bei Greichen und Römern, Leipzig - Berlin, B.G. Teubner, 1912.

Boersma 1985 = Boersma (J.S.), Amoenissima civitas. Block V.ii at Ostia: description and analysis of its visible remains, Assel, van Gorcum, 1985.

Bonucci 1827 = Bonucci (C.), Pompei descritta, 3a ed., Napoli, R. Miranda, 1827.

Bonucci 1835 = Bonucci (C.), Ercolano e Pompei, Napoli, 1835 [n.v.].

Boon 1987 = Boon (G.C.), "Legionnary bread and other stamps", The Antiquaries Journal, 67, 2, p. 368-371.

Borgard - Brun - Leguilloux - Tuffreau-Libre 2002 = Borgard (Ph.), Brun (J.-P.), Leguilloux (M.), Tuffreau-Libre (M.), «Pompéi: recherches sur les 
productions artisanales », MEFRA, 114, 1, 2002, p. 470-481.

Borgard - Puybaret $2003=$ Borgard $($ Ph. $)$, Puybaret (M.-P.), « Approche archéologique du travail de la laine au Ir siècle ap. J.-C. », dans Cresci Marrone (G.), Tirelli (M.), Produzioni, merci e commerci in Altino preromana e romana, Roma, Quasar, 2003 (Altinum. Studi di archeologia, epigrafia e storia, 3), p. 299-318.

Borgard - Puybaret 2004 = Borgard $($ Ph. $)$, Puybaret (M.-P.), « Le travail de la laine au début de l’Empire: l'apport du modèle pompéien. Quels artisans? Quels équipements? Quelles techniques? ", dans Alfaro (C.), Wild (J.P.), Costa (B.) (eds.), Purpureae vestes. Actes del I symposium Internacional sobre Textiles y Tintes del Mediterráneo en época romana, València, P.U.V., 2004, p. 47-59.

BorgONGINO - STEFANI 2002 = Borgongino (M.), Stefani (G.), «Intorno alla data dell'eruzione del 79 d.C.», RStPomp, 12-13, 2001-2002, p. 177-215.

Borgongino - STEFANI $2007=$ Borgongino (M.), Stefani (G.), « Ancora sulla data dell'eruzione", RStPomp, 18, 2007, p. 204-206.

Borgongino 2006 = Borgongino (M.), Archeobotanica . Repertivegetali da Pompei e dal territorio vesuviano, Roma, "L'Erma» di Bretschneider, 2006 (Studi della Soprintendenza archeologica di Pompei, 16).

BorlenghI 2006 = Borlenghi (A.) Le campus dans l'Italie romaine et les provinces occidentales: typologie et fonction d'un complexe public, thèse de doctorat soutenue sous la direction de P. Gros et d'E. Lippolis, Aix-en-Provence, Université de Provence, 2006.

Bотте 2009 = Botte (E.), Salaisons et sauces de poissons en Italie du Sud et en Sicile durant l'Antiquité, Naples, Centre Jean-Bérard, 2009 (Collection du Centre Jean-Bérard, 31; Archéologie de l'artisanat antique, 1).

Bouet 1995 = Bouet (A.), «Seuils de pierre en Gaule méridionale: l'exemple d'Olbia (Hyères, Var)», RAN, 27-28, 1994-1995, p. 9-39.

BRADLEY 2002 = Bradley (M.), «'It all comes out in the wash': Looking harder at the Roman fullonica ", JRA, 15, 1, 2002, p. 20-44.

Breton 1855 = Breton (E.), Pompeia décrite et dessinée. Suivie d'une notice sur Herculanum, $2^{\mathrm{e}}$ éd., Paris, Gide et Baudry, 1855.

Brun - Monteix $2010=$ Brun (J.-P.), Monteix (N.), «Les parfumeries en Campanie antique», dans Brun (J.-P.) (éd.), Artisanats antiques d'Italie et de Gaule. Mélanges offerts à Maria Francesca Buonaiuto, Naples, Centre Jean-Bérard, 2010 (Collection du Centre Jean-Bérard, 13; Archéologie de l'artisanat antique, 2), p. 115-133.

BRUN 1986 = Brun (J.-P.), L'oléiculture antique en Provence. Les huileries du département du Var, Paris, Éd. du CNRS, 1986 (Revue archéologique de Narbonnaise - Supplément, 15).
BRUN 1993 A = Brun (J.-P.) (éd.), «La discrimination entre les installations oléicoles et vinicoles », dans Amouretti - Brun 1993, p. 511-537

BRUN 1993 в = Brun (J.-P.) (éd.), «Les innovations techniques et leur diffusion dans les pressoirs", dans Amouretti - Brun 1993, p. 539-562.

BRUN 1998 = Brun (J.-P.), «Une parfumerie romaine sur le forum de Paestum», MEFRA, 110, 1, p. 419-472.

BRUN $2000=$ Brun (J.-P.), « The production of Perfumes in Antiquity: The cases of Delos and Paestum ", AJA, 104, 2, 2000, p. 277-308.

BRUN 2001 = Brun (J.-P.), «La viticulture antique en Provence ", Gallia, 58, 2001, p. 69-89.

BRUN 2003 = Brun (J.-P.), "L'artigianato dei profumi », dans Borgard (Ph.), Brun (J.-P.), Leguilloux (M.), Tuffreau-Libre (M.), «Le produzioni artigianali a Pompei. Ricerche condotte dal Centre Jean Bérard ", RStPomp, 14, 2003, p. 8-29.

BRUN 2004 A = Brun (J.-P.), Archéologie du vin et de l'huile de la préhistoire à l'époque hellénistique, Paris, Errance, 2004 (Collection des Hespérides).

BRUN 2004 в = Brun (J.-P.), Archéologie de l'huile et du vin dans l'Empire romain, Paris, Errance, 2004 (Collection des Hespérides).

Buffone - Lorenzoni - Pallara - Zanttin $1999=$ Buffone (L.), Lorenzoni (S.), Pallara (M.), Zanttin (E.), «Le macine rotatorie in rocce vulcaniche di Pompei », RStPomp, 10, 1999, p. 117-130.

BuKowIECKI - Dessales - Dubouloz 2008 = Bukowiecki (E.), Dessales (H.), Dubouloz (J.), Ostie, l'eau dans la ville: châteaux d'eau et réseaux d'adduction, Rome, École française de Rome, 2008 (Collection de l'École française de Rome, 402).

Buonocore 1999 = Buonocore (M.), "Rostovzev e l'epigrafia», dans Marcone (A.) (cur.), Rostovtzeff e l'Italia, Napoli, Edizioni Scientifiche Italiane, 1999 (Incontri perugini di storia della storiografia antica e sul mondo antico, IX), p. 419-437.

Cagiano de Azevedo 1951 = Cagiano de Azevedo (M.), Le antichità di Villa Medici, Roma, Libreria dello Stato, 1951.

CAGnat 1927 = Cagnat (R.), "Les fouilles d'Herculanum », dans Cagnat (R.), En pays romain, Paris, De Boccard, 1927 (Collection d'études d'histoire et d'archéologie), p. 88-105.

CAMARDo 2006 = Camardo (D.), « Gli scavi ed i restauri di Amedeo Maiuri. Ercolano e l'esperimento di una città museo », Ocnus, 14, 2006, p. 69-81.

CAmodeca 2000 = Camodeca (G.), « La società ercolanese », dans Pagano 2000, p. 67-70.

CAmodeca 2002 = Camodeca (G.), «Per una riedizione dell'archivio ercolanese di L. Venidius Ennychus ", CronErcol, 32, 2002, p. 257-280.

CAmodeca $2008=$ Camodeca (G.), $«$ La popolazione degli ultimi decenni di Ercolano», dans Guidobaldi 2008, p. 86-103. 
Capogrossi Colognesi 1981 = Capogrossi Colognesi (L.), « Proprietà agraria e lavoro subordinato nei giuristi e negli agronomi latini tra Repubblica e Principato », dans Giardina (A.), Schiavone (A.) (cur.), Società romana e produzione schiavistica. Volume primo. L'Italia: insediamenti e forme economiche, Bari, Laterza, 1981, p. 445-454.

CARANDINI 1977 = Carandini (A.) (dir.), L'instrumentum domesticum di Ercolano e Pompei nella prima età imperiale, Roma, «L'Erma » di Bretschneider, 1977 (Quaderni di cultura materiale, 1).

CARra de VAux 1988 = Carra de Vaux (B.) (éd.), Héron d'Alexandrie. Les mécaniques ou l'élévateur des corps lourds. Texte arabe de Qusta Ibn Luqa établi et traduit par B. Carra de Vaux, réimpression anastatique de l'édition de 1894, introduite par D.R. Hill, commentée par A.G. Drachmann, Paris, Les Belles-Lettres, 1988 (Collection sciences et philosophie arabe).

CARrIÉ 2004 = Carrié (J.-M.), «Vitalité de l'industrie textile à la fin de l'Antiquité: considérations économiques et technologiques", AnTard, 12, 2004, p. 13-43.

Castello - Oliviero 1997 = Castello (D.), Oliviero (S.), "Il ripostiglio del termopolio I,8,8 di Pompei ", AnnIstItNum, 44, 1997, p. 93-205.

Castiglione Morelli - Vitale 1989 = Castiglione Morelli (V.), Vitale (R.), "L'insula 8 della Regio I: un campione d'indagine socio-economica», RStPomp, 3, 1989, p. 185-211.

Catalano 1953 A = Catalano (V.), «Archeologia e filologia nella vexata quaestio delle origini di Resina », Samnium, 26, 1-2, 1953, p. 68-96.

Catalano 1953 в = Catalano (V.), Storia di Ercolano, Napoli, Arte tipografica, 1953.

CéBeIllac-Gervasoni 1996 = Cébeillac-Gervasoni (M.) (dir.), Les élites municipales de l'Italie péninsulaire des Gracques à Néron. Actes de la table ronde internationale de Clermont-Ferrand, Naples - Rome, Centre Jean Bérard - École française de Rome, 1996 (Collection du Centre Jean-Bérard, 13; Collection de l'École française de Rome, 215).

Cerulli Irelli 1971 = Cerulli Irelli (G.), Le pitture della Casa dell'Atrio a mosaico, Roma, Istituto poligrafico dello Stato, 1971 (Monumenti della pittura antica scoperti in Italia. Sezione Terza, la pittura ellenistico-romana. Ercolano, 1).

Cerulli Irelli 1974 = Cerulli Irelli (G.), La casa "del colonnato Tuscanico» ad Ercolano, Napoli, G. Macchiaroli, 1974 (Memorie dell'Accademia di archeologia, lettere e belle arti di Napoli, 7).

Cerulli Irelli 1977 = Cerulli Irelli (G.), « Una officina di lucerne fittili a Pompei », dans Carandini 1977, p. 53-72.

Chaumartin 1988 = Chaumartin (F.-R.), "Sénèque, lecteur de Posidonius (à propos des Lettres 88 et 90)», REL, 66, 1988, p. 21-28.
Ciancio Rossetto 1973 = Ciancio Rossetto (P.), Il sepolcro del fornaio Marco Vergilio Eurisace a Porta Maggiore, Roma, Istituto di Studi Romani Editore, 1973 (I monumenti romani, 5).

Cinque - Irollo 2008 = Cinque (A.), Irollo (G.), « La paleografia dell'antica Herculaneum e le fluttuazioni, di origine bradisismisca, della sua linea di costa » in Guzzo - Guidobaldi 2008, p. 425-438.

Ciszuk - Hammarlund 2008 = Ciszuk (M.), Hammarlund (L.), « Roman looms - A study of craftsmanship and technology in the Mons Claudianus textile project», dans Alfaro (C.), Karali (L.) (eds.), Purpureae vestes: Textiles and dyes in Antiquity. II. Vestidos, textiles y tintes: Estudios sobre la producción de bienes de consumo en la Antiguedäd: actas des II Symposium internacional sobre textiles y tintes del Mediterraneo en el mundo antiguo, València, Universitat de València , 2008, p. 119133.

Ciurletti 1996 = Ciurletti (G.), «La chiave in età romana», in Raffaelli (U.) (cur.), Oltre la porta. Serrature, chiavi e forzieri dalla preistoria all'età moderna nelle Alpi orientali. Cataogo della mostra tenuta a Trento, Castelo del Buonconsiglio (13 luglio - 31 ottobre 1996), Trento, Provincia autonoma di Trento, 1996, p. 67-83.

CLARKe 2003 = Clarke (J.R.), Art in the lives of ordinary Romans. Visual representation and non elite viewer in Italy, 100 B.C. - A.D. 315, Berkeley - Los Angeles - London, University of California Press, 2003.

Coarelli - Pesando 2006 = Coarelli (F.), Pesando (F.) (cur.), Rileggere Pompei. I. L'insula 10 della Regio VI, Roma, «L'Erma » di Bretschneider, 2006 (Studi della Soprintendenza archeologica di Pompei, 12).

CoArelli 1977= Coarelli (F.), «Public building in Rome between the second Punic war and Sulla», $P B S R, 45,1977$, p. 1-23.

CoARelli 2000 = Coarelli (F.), «Pompei : il foro, le ele-

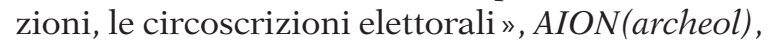
n.s., 7, 2000, p. 87-111.

Combet-Farnoux $1980=$ Combet-Farnoux (B.), Mercure romain. Le culte public de Mercure et la fonction mercantile à Rome de la République archaïque à l'époque augustéenne, Rome, École française de Rome, 1980 (Bibliothèque des Écoles françaises d'Athènes et de Rome, 232)

Conticello De Spagnolis-De Carolis 1988 = Conticello De Spagnolis (M.), De Carolis (E.), Le lucerne di bronzo di Ercolano e Pompei, Roma, «L'Erma» di Bretschneider, 1988 (Cataloghi Soprintendenza archeologica di Pompei, 2).

Coralini 2001 = Coralini (A.), Hercules domesticus. Immagini di Ercole nelle case della regione vesuviana (I secolo a.C. - 79 d.C.), Napoli, Electa Napoli, 2001 (Studi della Soprintendenza archeologica di Pompei, 4). 
Coutelas 2009 = Coutelas (A.) (dir.), Le mortier de chaux, Paris, Errance, 2009 (Archéologiques).

Curtis 2001 = Curtis (R.I.), Ancient food technology, Leiden - Boston, Brill, 2001.

D'Amвra 1993 = D’Ambra (E.), Private Lives, Imperial virtues. The Frieze of the Forum Transitorium in Rome, Princeton, Princeton University Press, 1993.

D'Ambrosio - Guzzo - Mastroroberto 2003 = d'Ambrosio (A.), Guzzo (P.G.), Mastroroberto (M.), Storie da un'eruzione. Pompei, Ercolano, Oplontis, Milano, Electa, 2003.

D’Ambrosio 1996 = d'Ambrosio (A.), «Termopolio e Casa di L. Vetuzio Placido», dans Borriello (M.), d'Ambrosio (A.), De Caro (S.), Guzzo (P.G.) (cur.), Pompei. Abitare sotto il Vesuvio (Ferrara, Palazzo dei Diamanti, 29 settembre 1996 - 19 gennaio 1997, Ferrara, Ferrara Arte, 1996, p. 109-113.

De Albentiss 1989 = De Albentiis (E.), "Indagini sull'insula Arriana Polliana di Pompei», DialArc, $3^{\text {e }}$ s., 7, 1, 1989, p. 43-84

DE CARo 1994 = De Caro (S.), La villa rustica in località Villa Regina a Boscoreale, Roma, Giorgio Bretschneider, 1994 (Pubblicazioni scientifiche del centro di studi della Magna Grecia, s. 3, 1).

DE CARolis 2006 = De Carolis (E.), «Le verre dans la vie quotidienne», dans Beretta - Di Pasquale 2006, p. 73-81.

DE FRANCISCIS 1963 = de Franciscis (A.), «Vetri antichi scoperti ad Ercolano », JGS, 5, 1963, p. 137-139.

DE Franciscis $1973=$ de Franciscis (A.), s.v. "Ercolano», dans Becatti (G.) (dir.), Enciclopedia dell'arte antica classica ed orientale. Supplemento 1970, Roma, Istituto della Enciclopedi italiana, 1973, p. 310-311.

DE KIND 1993 = de Kind (R.), « Houses at Herculaneum. An analysis of town planning and of measurements in insulae III and IV », CronErcol, 23, 1993, p. 161-167.

DE KIND 1998 = de Kind (R.), Houses in Herculaneum. A new view on the town planning and the building of insulae III and IV, Amsterdam, Gieben, 1998 (Circumvesuviana, 1).

DE KIND 2005 = de Kind (R.), "Observations on the building history of insula $\mathrm{V}$ in Herculaneum. A general overview of the allotment», dans Mols - Moormann 2005, p. 221-227.

DE Luca 1863 = De Luca (S.), «Ricerche chimiche sul pane e sul grano rinvenuto a Pompei», Rendiconto della R. Accademia delle scienze Fisiche e Matematiche di Napoli, 2, 1863, p. 172-179.

DE LuCA 1866 = De Luca (S.), "Osservazioni sopra i pesi e le misure provvenienti dagli scavi di Pompei e che si trovano nel Museo Nazionale di Napoli », Rendiconto della R. Accademia delle scienze Fisiche e Matematiche di Napoli, 5, 3, Napoli, 1866, p. 67-70.
DE Luca 1878 = De Luca (S.), «Ricerche chimiche sopra una particolare argilla trovata negli scavi di Pompei ", Rendiconto dell'Accademia delle Scienze fisiche e matematiche di Napoli, 1878, p. 46-47.

De Luca 1880 = De Luca (S.), "Osservazioni sopra taluni pesi rinvenuti degli scavi di Pompei presso Napoli », Atti dell'Accademia Pontaniana, 13, 2, Napoli, 1880, p. 405-417.

De Ruyt 1996 = De Ruyt (C.), «Un exemple de discontinuité des fonctions monumentales dans un quartier de la ville romaine d'Ostie (Reg. III, Ins. II) ", Revue belge d'archéologie et d'histoire de l'art, 65, 1996, p. 5-16.

De Ruyt 2001 = De Ruyt (C.), «Les foulons, artisans des textiles et blanchisseurs", dans Descoeudres (J.-P.) (dir.), Ostia. Port et porte de la Rome antique, Genève, Georg éditeur, 2001 (Catalogue de l'exposition du Musée Rath, 23 février-22 juillet 2001), p. 186-191.

De Spagnolis Conticello $1995=$ De Spagnolis Conticello (M.), "Osservazioni sulle fasi edilizie di alcune ville rustiche di Scafati, suburbio orientale di Pompei, seppellite dalla eruzione del 79 d.C. ", dans Fröhlich - Jacobelli 1995, p. 93-102.

De Vos - De Vos 1982 = de Vos (A.), de Vos (M.), Pompei Ercolano Stabia, Bari, Laterza, 1982 (Guide archeologiche Laterza, 11).

Degrassi 1960 = Degrassi (A.), «Sul duovirato nei municipi italiani », dans Omagiu lui Constantin Daicoviciu cul prilejul implinirii a 60 de ani, s.l., 1960, p. 141-145 [=Degrassi (A.), Scritti vari di Antichità. Raccolti da amici e allievi nel $75^{\circ} \mathrm{com}$ pleanno dell'autore, 4 vol., Roma, Comitato d'Onore, 1962-1971, vol. 1 p. 185-192].

Della Corte 1935 = Della Corte (M.), Pompéi. Les nouvelles fouilles et l'amphithéâtre (maisons et habitants), Pompei, F. Sicignano, 1935.

Della CoRTe 1958 = Della Corte (M.), «Le iscrizioni di Ercolano », RAAN, n.s. 33, 1958 (1959), p. 239-309.

Della Corte 1965 = Della Corte (M.), Case ed abitanti di Pompei, 3a. edizione curata da Pietro Soprano, Napoli, F. Fiorentino, 1965.

Delor AHÜ 2004 = Delor Ahü (A.), «Consommation et production: remarques sur les stratégies du commerce de la céramique sigillée du Centre de la Gaule durant le Haut-Empire», Pallas, 66, 2004, p. 79-96.

Delpino 2001= Delpino (F.), «Vittorio Spinazzola. Tra Napoli e Pompei, fra scandali e scavi », dans Guzzo 2001, p. 51-61.

Desbat 2004 = Desbat (A.), «Les tours de potiers antiques", dans Feugère (M.), Gérold (J.-C.) (dir.), Le tournage des origines à l'an Mil. Actes du colloque de Niederbonn, octobre 2003, Montagnac, Éd. M. Mergoil, 2004 (Monographies instrumentum, 27), p. 137-154.

Dickmann - Pirson 2000 = Dickmann (J.-A.), Pirson (F.), « Die Casa dei Postumii VIII 4, 4.49 in Pompeji 
und ihre insula. Bericht über die 3. Kampagne 1999 », MDAIR, 107, 2000, p. 451-467.

Dobbins 1994 = Dobbins (J. J.), «Problems of Chronology, Decoration, and Urban Design in the Forum at Pompeii », AJA, 98, 1994, p. 629-694.

Domergue 1994 = Domergue (C.), «Production et commerce des métaux dans le monde romain: l'exemple des métaux hispaniques d'après l'épigraphie des lingots", dans Epigrafia della produzione e della distribuzione. Rencontre franco-italienne sur l'épigraphie du monde romain, Rome, École française de Rome, 1994 (Collection de l'École française de Rome, 193), p. 61-91.

Drachmann 1936 = Drachmann (A.G.), «Heron's Screwcutter », JHS, 56, 1936, p. 72-77.

DrachMANN 1963 = Drachmann (A.G.), The mechanical technology of greek and roman Antiquity, Copenhagen, Munksgaard, 1963 (Acta Historica Scientiarum Naturalium et Medicinalium, 17).

Drummond 1810 = Drummond (W.), Herculanensia; or archeologica land philological dissertations, containing a manuscript found among the ruins of Herculaneum, London, W. Bulmer and co. Cleveland-Row, 1810.

Dubouloz 2011 = Dubouloz (J.), La propriété immobilière à Rome et en Italie ( $I^{e r}$-V $V^{e}$ siècle). Organisation et transmission des praedia urbana, Rome, École française de Rome, 2011 (Bibliothèque des Écoles françaises d'Athènes et de Rome, 343).

EHRHARDT 1995 = Ehrhardt (W.), « Seismische Shäden und Reparaturen in der Casa di Paquius Proculus (I 7, 1) in Pompeji », dans Fröhlich - Jacobelli 1995, p. 57-65.

Ellis - Devore 2008 = Ellis (S.J.), Devore (G.), «Uncovering Plebeian Pompeii: Broader implications from excavating a forgotten working-class neighbourhood», dans Guzzo - Guidobaldi 2008, p. 309-320.

Ellis 2004 A = Ellis (S. J. R.), "The Pompeian bar: archaeology and the role of food and drink outelts in an ancient community ", Food \& History, 2, 1, 2004, p. 41-58.

ELLIS 2004 B = Ellis (S. J. R.), « The distribution of bars at Pompeii : archaeological, spatial and viewshed analyses », JRA, 17, 1, 2004, p. 371-384.

ERISTOV 1994 = Eristov (H.), Les éléments architecturaux dans la peinture campanienne du quatrième style, Rome, École française de Rome, 1994 (Collection de l'École française de Rome, 107).

Escheвасн 1970 = Eschebach (H.), Die Städtebauliche Entwicklung des antiken Pompeji mit einem Plan 1:1000 und einem Exkurs: die Baugeschichte der Stabianer Thermen, Heidelberg, F. H. Kerle Verlag, 1970 (MDAIR Ergäzungsheft, 17).

EscheвACH 1993 = Eschebach (L.) (hrsg.), Gebäudeverzeichnis und Stadtplan der antken Stadt Pompeji, Köln - Weimar - Wien, Bölhau, 1993.
EsPosito 2005 = Esposito (D.), La pittura di Ercolano, Dottorato di ricerca in scienze archeologiche e storico-artistiche, XVII ciclo, Napoli, Università degli studi di Napoli Federico II, 2005.

FALKENER 1852 = Falkener (E.), « Report on a house at Pompeii, excavated under personal superintendence in 1847 ", The museum of classical antiquities. Essays on ancient art, V, march 1852, p. 3589.

FERDIÈRE 1984 = Ferdière (A.), «Le travail du textile en Région Centre de l'Âge du Fer au Haut Moyen Âge », RACF, 23, 2, 1984, p; 209-275.

FERDIÈRE 2001 = Ferdière (A.), «La 'distance critique' : artisans et artisanat dans l'Antiquité romaine et en particulier en Gaule », Les petits cahiers d'Anatole, $\mathrm{n}^{\circ} 1,2001,31$ p. (www.univ-tours.fr/lat/ Pages/F2_1.html).

FINLEY 1975 = Finley (M.I.), L'économie antique, Paris, Éditions de Minuit, 1975 (Le sens commun).

Fiorelli 1873 = Fiorelli (G.), Gli scavi di Pompei dal 1861 al 1872. Relazione al ministro della Istruzione Pubblica, Napoli, 1873.

FIorelli 1875 = Fiorelli (G.), Descrizione di Pompei, Napoli, Tipografia italiana, 1875.

FLoHR 2003 = Flohr (M.), "Fullones and Roman society: a reconsideration ", JRA, 16, 2, 2003, p. 447450.

FloHR 2005 A = Flohr (M.), «Ars Fullonia. Interpreting and contextualising Roman fulling», dans Briault (C.) et al. (eds.), SOMA 2003. Symposium on Mediterranean Archaeology, Oxford, Archaeopress, 2005 (British Archaeological Reports - International Series, 1391), p. 59-63.

FLoHR 2005 в = Flohr (M.), "Keeping up appearances. Design, history and use of domus VI 14, 21-22», RStPomp, 16, 2005, p. 37-63.

Flohr 2007 A = Flohr (M.), "Cleaning the laundries. Report of the 2006 season », RStPomp, 18, 2007, p. 131-136.

FLOHR 2007 в = Flohr (M.), «Nec quicquam ingenuum habere potest officina? Spatial contexts of urban production at Pompeii, AD $79 »$, BABesch, 82, 1, p. 129-148.

FLoHR 2008 = Flohr (M.), "Cleaning the laundries II. Report of the 2007 campaign », FOLD\&R, 111, 2008 (www.fastionline.it).

FLORIANI SoUARCIAPINO 1958 = Floriani Squarciapino (M.), «Piccolo corpus dei mattoni scolpiti ostiensi », BullCom, 76, 1956-1958, p. 183-215.

Forbes $1955=$ Forbes (R.J.), Studies in Ancient Technology. Volume III, Leiden, Brill, 1955.

Forbes $1956=$ Forbes (R.J.), Studies in Ancient Technology. Volume IV, Leiden, Brill, 1956.

Foss $1997=$ Foss (P.), «Watchful Lares: Roman household organization and the rituals of cooking and eating ", dans Laurence - Wallace Hadrill 1997, p. 196-218. 
Foy - Nenna 2003 A = Foy (D.), Nenna (M.-D.), Échanges et commerce du verre dans le monde antique, Montagnac, Éd. Monique Mergoil, 2003 (Monographies instrumentum, 24).

Foy - Nenna 2003 в = Foy (D.), Nenna (M.-D.), «Productions et importations de verre antique dans la vallée du Rhône et le Midi méditerranéen de la France (I ${ }^{\text {er-III }}{ }^{\text {e }}$ siècles) », dans Foy - Nenna 2003 a, p. 227-296.

FRANCHI DELL'ORTO $1993=$ Franchi dell'Orto (L.) (cur.), Ercolano 1738-1988. 250 anni di ricerca archeologica, Roma, L'Erma di Bretschneider, 1993 (Monografie Soprintendenza archeologica di Pompei, 6).

FRANK 1920 = Frank (T.), An Economic History of Rome to the end of the Republic, Baltimore, J. Hopkins press, 1920.

FRÖHLICH - JACOBELLI 1995 = Fröhlich (Th.), Jacobelli (L.), Archäologie und Seismologie, la regione vesuviana dal 62 al $79 d C$, problemi archeologicie sismologici, Convegno di Boscoreale, 26-27 novembre 1993, München, Biering und Brinkmann, 1995.

FRÖHLICH 1991 = Fröhlich (Th.), Lararien- und fassadenbilder in den Vesusvstädten. Untersuchungen zur volkstümlichen' pompejanischen Malerei, Mainz, von Zabern, 1991 (MDAIR Ergäzungsheft, 32).

FRÖHLICH 1995 = Fröhlich (Th.), «La porta di Ercolano a Pompei e la cronologia dell'opus vittatum mixtum », dans Fröhlich - Jacobelli 1995, p. 153-159.

Fulford - Wallace-Hadrill 1998 = Fulford (M.), Wallace-Hadrill (A.), "Unpeeling Pompeii», Antiquity, 72, 1998, p. 128-145.

Fulvio 1879 = Fulvio (L.), «Delle fornaci e dei forni pompeiani », dans Pompei 1879, I, p. 273-291.

Fulvio Giuliani 2002 = Fulvio Giuliani (C.), L'edilizia nell'Antichità, 9a ed., Roma, Carocci, 2002.

Ganschow 1989 = Ganschow (T.), Untersuchungen zur baugeschichte in Herculaneum, Bonn, R. Habelt, 1989 (Antiquitas, 30).

GaRCía y García 1998 = García y García (L.), Nova bibliotheca pompeiana. 250 anni di bibliografia archeologica: catalogo dei libri e degli scritti riguardanti la storia, l'arte e gli scavi di Pompei, Ercolano, Stabia ed Oplonti, Roma, Bardi, 1998 (Monografie Soprintendenza archeologica di Pompei, 6).

García y García 2006 = García y García (L.), Danni di guerra a Pompei. Una dolorosa vicenda quasi dimenticata, Roma, "L’Erma» di Bretschneider, 2006 (Studi della Soprintendenza archeologica di Pompei, 15).

GARNSEY 1976 = Garnsey (P.), « Urban Property investment », dans Finley (M.I.) (ed.), Studies in Roman property, Cambridge, Cambridge University Press, 1976, p. 123-136.

GaRRUCCI 1861 = Garrucci (R.), Monumenti del Museo Lateranense, Roma, 1861.
GASPEREtTI 1996 = Gasperetti (G.), «Produzione e consumo della ceramica comune da mensa e da dispensa nella Campania romana», dans Bats 1996, p. 19-63.

GASSNER 1984 = Gassner (V.), «Zur Terminologie der Kaufläden im Lateinischen», $M B A H$, 3, 1984, p. 108-115.

GaSSNER 1986 = Gassner (V.), Die Kaufläden in Pompeji, Wien, VWGÖ, 1986 (Dissertationen der Universität Wien, 178).

Gell - Gandy $1821=$ Gell (W.), Gandy (J.P.), Pompeiana. The topography, edifices and ornaments of Pompeii, $2^{\text {nd }}$ ed., Rodwell and Martin, London, 1821.

Gell 1828 = Gell (W.), Vues des ruines de Pompéi, d'après l'ouvrage publié à Londres en 1819 par sir William Gell et J.-P. Gandy, architecte, sous le titre de Pompeiana, Firmin Didot, Paris, 1828.

Gell 1832 = Gell (W.), Pompeiana. The topography, edifices and ornaments of Pompeii. The results of excavations since 1819, Jennings and Chaplin, London, 1832.

George 1997 = George (M.), «Servus and domus: the slave in the Roman house", dans Laurence - Wallace-Hadrill 1997, p. 15-24.

GIRRI 1956 = Girri (G.), La taberna nel quadro urbanistico e sociale di Ostia, Roma, 1956.

Gordon 1927 = Gordon (M.), «The ordo of Pompeii », JRS, 17, 1927, p. 165-183.

Goudineau 1970 = Goudineau (C.), «Note sur la céramique à engobe interne rouge-pompéien ("pompejanisch-roten platten»)», MEFRA, 82, 1970, p. 157-186.

Grell 1982 = Grell (Ch.), Herculanum et Pompéi dans les récits des voyageurs français du XVIII ${ }^{e}$ siècle, Naples, Centre Jean-Bérard, 1982 (Mémoires et documents sur Rome et l'Italie méridionale, $3^{\mathrm{e}}$ s., 2).

GUADAGNO 1978 = Guadagno(G.), « Supplemento epigrafico ercolanese », CronErcol, 8, 1978, p. 132-155.

GuAdaGNo 1981 = Guadagno (G.), «Supplemento epigrafico ercolanese II», CronErcol, 11, 1981, p. $129-164$.

GUADAGNO 1982 = Guadagno (G.), «Contributi epigrafici per la storia amministrativa e la topografia ercolanese ", dans La regione sotterrata dal Vesuvio. Studi e prospettive. Atti del convegno internazionale 11-15 novembre 1979, Napoli, Università degli Studi di Napoli, 1982, p. 193-210.

GuAdaGNo 1983 = Guadagno (G.), «Herculanensium Augustalium Aedes», CronErcol, 13, 1983, p. $159-177$.

GuADAGNO 1993 = Guadagno (G.), «Ercolano. Eredità di cultura e nuovi dati,», dans Franchi dell'Orto 1993, p. 73-98.

GuADAGNO 1995 = Guadagno (G.), «Documenti epigrafici ercolanesi relativi ad un terremoto ", dans Fröhlich-Jacobelli 1995, p. 119-128. 
Guidobaldi - Olevano 1995 = Guidobaldi (F.), Olevano (F.), «Sectilia pavimenta dell'area vesuviana ", dans Pensabene (P.), Marmi antichi II. Cave e technica di lavorazione. Provenienze e distribuzione, Roma, "L'Erma » di Bretschneider, 1995 (Studi miscellanei, 31), p. 223-258.

Guidobaldi - Pesando 1998 = Guidobaldi (M.P.), Pesando (F.), «Variazioni di proprietà nell'insula VI, 9: indagine nella Casa del Centauro (VI, 9, 3-5 e 10-12)», RStPomp, 9, 1998, p. 217-229.

Guidobaldi 2003 = Guidobaldi (M.P.), «La bottega di un gemmarius (ins. Or. II, 10) e l'ingannevole "stanza della ricamatrice" ", dans d'Ambrosio(A.), Guzzo (P.G.), Mastroroberto (M.), Storie da un'eruzione. Pompei, Ercolano, Oplontis, Milano, Electa, 2003 (Museo archeologico nazionale di Napoli, 20 marzo-31 agosto 2003), p. 102-111.

Guidobaldi 2006 = Guidobaldi (M.P.), «Abitare a Ercolano », dans Pesando (F.), Guidobaldi (M.P.), Gli 'ozi' di Ercole. Residenze di lusso a Pompei ed Ercolano, Roma, "L’Erma» di Bretschneider, 2006 (Studia archaeologica, 143), p. 179-270.

Guidobaldi 2008 = Guidobaldi (M.P.) (cur.), Ercolano. Tre secoli di scoperte, Milano, Electa, 2008 (Napoli, Museo Archeologico Nazionale, 16 ottobre 2008 13 aprile 2009).

Guzzo - Guidobaldi 2008 = Guzzo (P.G.), Guidobaldi (M.P.) (cur.), Nuove ricerche archeologiche nell'area vesuviana (scavi 2003-2006), Roma, L'Erma di Bretschneider, 2008 (Studi della Soprintendenza archeologica di Pompei, 25).

Guzzo 2001 = Guzzo (P.G.) (cur.), Pompei. Scienza e Società. Atti del Convegno internazionale di Napoli (25-27 novembre 1998) per il 250 Anniversario degli Scavi di Pompei, Napoli, Electa, 2001.

Guzzo 2005 = Guzzo (P.G.), "Sul fregio figurato dai praedia di Giulia Felice di Pompei (II, 4, 3)», dans Sapielli Ragni (M.) (ed.), Studi di archeologia in memoria di Liliana Mercando, Torino, Soprintendenza per i beni archeologici dell'Emilia Romagna, 2005, p. 102-113.

Hald 1980 = Hald (M.), Ancient Danish textiles from bogs and burials. A comprative study of costume and Iron Age textiles, $2^{\text {nd }}$ ed., Copenhagen, National Museum of Denmark, 1980 (Publications of the National Museum - Archaeological-Historical series, 21).

Hedinger - SchneIder - Soricelli 1994 = Hedinger (B.), Schneider (G.), Soricelli (G.), « L'origine della "Tripolitania Sigillata" / "Produzione A della Baia di Napoli” », dans Olcese (G.), (cur.), Ceramica romana e archeometria: lo stato degli studi, Firenze, All'Insegna del Giglio, 1994, p. 67-86.

Heres 1982 = Heres (T.L.), Paries: a proposal for a dating system of late-antique masonry structures in Rome and Ostia, Amsterdam, Academisch proefschrift Vrije Universiteit te Amsterdam, 1982.
Herter 1938 = Herter (H.), «Phallos », dans RE, 19, 2, col. 1681-1748.

Herzog Hauser 1937 = Herzog Hauser (G.), «Tintinnabulum », dans RE, VI A, 2, col. 1406-1410

HOFFMAN 1979 = Hoffman (A.), "L'architettura », dans Zevi 1979, p. 97-118.

HoFFMANN 1983 = Hoffmann (M.), The warp-weighted loom. Studies in the history and technology of an ancient implement, $2^{\text {nd }}$ ed. ( $1^{\text {st }}$ ed. 1964), Oslo,Uni versitetsforlaget, 1983 (Studia Norvegica, 14).

HopPENBROUWERS-VERMEULEN 1996 = Hoppenbrouwers (R.), Vermeulen (E.), "The wall structures », dans Binnebeke - de Kind 1996, p. 180-188.

Hori 1992 = Hori (Y.), "Thresholds in Pompeii», Opuscula Pompeiana, 2, 1992, p. 73-91.

IEZZI - ScAFATI 1984 = Iezzi (B.), Scafati (N.), «Amedeo Maiuri. Vita e contatti di archeologo », dans Pompei Ercolano Stabiae Oplontis. LXXIX - MCMLXXIX, Mostra bibliografica, Napoli, Biblioteca universitaria di Napoli, 1984, p. 255-288.

JACOBELLI 1995 = Jacobelli (L.), «I terremoti fra il 62 e il 79 nell'area vesuviana: le ragioni di un convegno », dans Fröhlich - Jacobelli 1995, p. 15-21.

JACOBI 1930 = Jacobi (H.), «Die Ausgrabungen der Jahre 1925-1928. Kastell Saalburg», Saalburg Jahrbuch, 7, 1930, p. 8-34.

JAсовI 1937 = Jacobi (H.), «Das Kastell Saalburg», dans Fabricius (E.), Hettner (F.), von Sarwey (O.) (hrsg.), Der Obergermanisch-Raetische Limes des Römerreiches, B, II, 1, Berlin - Leipzig, O. Petters, $1937, \mathrm{n}^{\circ} 11,75 \mathrm{p}$.

JAHN 1861 = Jahn (O.), «Ueber Darstellung antiker Reliefs, welche sich auf Handwerk und Handelsverkehr beziehen", Berichte über die Verhandlungen der Sächsischen Akademie der Wissenschaft zu Leipzig, 13, 1861, p. 291-374.

JAHN 1868 = Jahn (O.), Ueber Darstellung des Handwerks und Handelsverkehrs auf antiken Wandgemälden, Leipzig, 1868.

JANSEN 1991 = Jansen (G.), "Water systems and sanitation in the houses of Herculaneum », MNIR 50, 1991, p. 145-166.

JASHEMSKI 1973 = Jashemski (W.F.), «The Discovery of a Large Vineyard at Pompeii: University of Maryland Excavations, $1970 », A J A, 77,1973$, p. 27-41.

JASHEMSKI 1979 = Jashemski (W.), The gardens of Pompeii, Herculaneum and the villas destroyed by Vesuvius, New Rochelle, Caratzas Brothers, 1979.

JASHEMSKI 1993 = Jashemski (W.), The gardens of Pompeii, Herculaneum and the villas destroyed by Vesuvius. 2. Appendices, New Rochelle, Caratzas Brothers, 1993.

JoHANNOWSKY 1982 = Johannowsky (W.), "Problemi urbanistici di Ercolano», CronErcol, 12, 1982, p. 145-149.

Johnson 1936 = Johnson (A.C.), An economic survey of ancient Rome. Volume 2. Roman Egypt to 
the reign of Diocletian, Baltimore, John Hopkins Press, 1936.

JoNGMAN 1988 = Jongman (W.), The economy and society of Pompeii, Amsterdam, Gieben, 1988.

JunKELMANN 1997 = Junkelmann (M.), Panis militaris. Die Ernähung des röimischen Soldaten oder der Grundstoff der Macht, Mainz, Philipp von Zabern, 1997 (Kulturgeschichte der antiken Welt, 75).

Kastenmeier 2001 = Kastenmeier (P.), «Priap zum Grusse. Der Hauseingang der Casa dei Vettii in Pompeji », MDAIR, 108, 2001, p. 301-311.

KASTENMEIER $2007=$ Kastenmeier (P.), I luoghi del lavoro domestico nella casa pompeiana, Roma, "L'Erma» di Bretschneider, 2007 (Studi della Soprintendenza archeologica di Pompei, 23).

KING 2002 = King (A.), « Mammals: evidence from wall paintings, sculpture, mosaics, faunal remains and ancient literary sources », dans Jashemski (W.F.), Meyer (F.G.) (eds.), The natural history of Pompeii, Cambridge, Cambridge U.P., 2002, p. 401-450.

KLERBERg 1957 = Kleberg (T.), Hôtels, restaurants et cabarets dans l'antiquité romaine. Études historiques et philologiques, Uppsala, Almqvist \& Wiksells Boktryckeri, 1957 (Bibliotheca Ekmaniana, 61).

KNIERRIEM - LÖHNIG 1997 = Knierriem (P.), Löhnig (E.), «Panificium im experiment. Ein Erfahrungsbericht aus dem Saalburgkastell», dans Junkelmann 1997, p. 134-136.

Koloski Ostrow $1990=$ Koloski Ostrow (A.), The Sarno Bath complex, Roma, «L'Erma » di Bretschneider, 1990 (Monografie Soprintendenza archeologica di Pompei, 4).

La Rocca - De Vos - De Vos 2002 = La Rocca (E.), De Vos (A.), De Vos (M.), Pompei, $3^{\mathrm{a}}$ ed., Milan Mondadori, 2002 (Guide archeologiche Mondadori).

LA Torre 1988 = La Torre (G.F.), "Gli impianti commerciali ed artigianali nel tessuto urbano di Pompei», dans Pompei, l'informatica al servizio di una città antica, 1, Roma, "L'Erma» di Bretschneider, 1988, p. 73-102.

LA Vega 1797 = La Vega (P.), Dissertationis isagogicae ad Herculanensium voluminium explicationem pars prima, Napoli, 1797.

LaIDLAw 1985 = Laidlaw (A.), The first Style in Pompeii: painting and architecture, Roma, G. Bretschneider, 1985 (Archeologica, 57).

LAKEN 2003 = Laken (L.), "Zebrapatterns in Campanian wall painting: a matter of function", BABesch, 78, 2003, p. 167-189.

Laurence - Wallace-Hadrill 1997 = Laurence (R.), Wallace-Hadrill (A.) (eds.), Domestic space in the Roman world: Pompeii and beyond, Portsmouth, Journal of Roman Archaeology, 1997 (Journal of Roman Archaeology supplement series, 22).

Leduc 2008 = Leduc (M.), "Les pistrina volubilitains, témoins majeurs du dynamisme économique municipal», dans González (J.), Ruggeri
(P.), Vismara (C.), Zucca (R.), L'africa romana. Le richezze dell'Africa. Risorse, poduzioni, scambi. Atti del XVII Convegno di studio, vol. I, Roma, Carocci, 2008, p. 475-505.

LEHOËRFF 2004 = Lehoërff (A.) (dir.), «L'artisanat métallurgique dans les sociétés anciennes en Méditerranée occidentale. Techniques, lieux et formes de production", Rome, École française de Rome, 2004 (Collection de l'École française de Rome, 332).

Lenel 1889 = Lenel (O.), Palingenesia iuris civilis, 2 vol., Leipzig, B. Tauchnitz, 1889.

LEPORE 1950 = Lepore (E.), «Orientamenti per la storia sociale di Pompei », dans Pompeiana. Raccolta di studi per il secondo centenario degli scavi di Pompei, Napoli, G. Macchiaroli, 1950, p. 144-166.

LEPORE 1955 = Lepore (E.), « Sul carattere economicosociale di Ercolano », PP, 10, 1955, p. 423-439.

LEPORE 1989 = Lepore (E.), Origini e strutture della Campania antica. Saggi di storia etno-sociale, Bologna, Il mulino, 1989.

Levi 1941 = Levi (D.), "The evil eye and the lucky hunchback», dans Stillwell (R.) (ed.), Antiochon-the-Orontes III. The excavations 1937-1939, Princeton, Princeton University Press, 1941, p. 220-232.

Ligios 2001 = Ligios (M.A.), "taberna, negotiatio, taberna cum instrumento e taberna instructa nella riflessione giurisprudenziale classica», dans Antecesori oblata. Cinque studi dedicati ad Aldo Dell'Oro, Padova, CEDAM, 2001 (Memorie della facoltà di Giurisprudenza di Alessandria, 5), p. 23-143.

LING - LING 2005 = Ling (R.), Ling (L.), The insula of the Menander at Pompeii. Volume II: the decorations, Oxford, Clarendon Press, 2005.

LiNg 1991 = Ling (R.), Roman painting, Cambridge, Cambridge University Press, 1991.

LING 1992 = Ling (R.), "The study of houses at Herculaneum », JRA, 5, 1992, p. 331-337.

LiNG 1995 = Ling (R.), «Earthquake damage in Pompeii I 10: one earthquake or two?», dans Fröhlich-Jacobelli 1995, p. 201-209.

Ling $1997 \mathrm{~A}=$ Ling (R.), The insula of the Menander at Pompeii. Volume I: the structures, Oxford, Clarendon Press, 1997.

LiNG 1997 в = Ling (L.A.), «Appendix E. Thresholds and doorways », dans Ling 1997 a, p. 336-341.

Lo CAscio 1996 = Lo Cascio (E.), « Pompei dalla città sannitica alla colonia sillana: le vicende istituzionali », dans Cébeillac-Gervasoni 1996, p. 111-123.

Łos 1992 = Łos (A.), «Quibus patet curia municipalis. Remarques sur la structure de la classe dirigeante de Pompei », CahGlotz, 3, 1992, p. 259-297.

Łos $1995=$ Łos (A.), « La condition sociale des affranchis au I ${ }^{\text {er }}$ siècle après J.-C. », Annales HSS, 1995, n. 5, p. 1011-1043. 
Łos 1997 = Łos (A.), «Qui exportait le vin crétois en Campanie à l'époque julio-claudienne?", Acta universitatis wratislaviensis, 1874, 1997 (Antiquitas Wroctaw, 22), p. 63-75.

Łos 2000 = Łos (A.), «Les affaires «industrielles» des élites des villes campaniennes sous les Julio-Claudiens et les Flaviens », MEFRA, 112, 1, 2000, p. 243-277.

LovéN 2001 = Lovén (L.L.), «Images of textile manufacture in funerary iconography", dans Polfer (M.) (dir.), L'artisanat romain: évolutions, continuités et ruptures (Italie et provinces occidentales), Montagnac, Editions M. Mergoil, 2001 (Monographies instrumentum, 20), p. 43-53.

Lugli 1942 = Lugli (G.), "Criteri di massima per la datazione dei più antichi monumenti di Roma», RendLinc, s. 7, 3, 1942, p. 383-390.

LugLI 1957 = Lugli (G.), La tecnica edilizia romana con particolare riguardo a Roma e Lazio, 2 vol., Roma, Bardi, 1957.

Mac Mahon - Price 2005 = Mac Mahon (A.), Price (J.) (ed.), Roman working lives and urban living, Oxford, Oxbow books, 2005.

Mac Mahon 2003 = Mac Mahon (A.), The taberna structures of Roman Britain, Oxford, Hadrian Books, 2003 (BAR - British Series, 356).

Mac Mahon 2005 a = Mac Mahon (A.), "The shops and workshops of Roman Britain", dans Mac Mahon-Price 2005, p. 48-69.

Mac Mahon 2005 в = Mac Mahon (A.), «The taberna counters of Pompeii and Herculaneum», dans Mac Mahon - Price 2005, p. 70-87.

MAgaldi 1930 = Magaldi (E.), «Il commercio ambulante a Pompei », Atti dell'Accademia Pontaniana, 60, 1930, p. 1-32.

MAgGi 1974 = Maggi (G.), Archeologia magica di Amedeo Maiuri, Napoli, Marotta, 1974.

MAIURi 1927 A = Maiuri (A.), «La ripresa degli scavi di Ercolano », RFilIstrCl, 55, 1927, p. 240-243.

MAIURi 1927 в = Maiuri (A.), « La ripresa degli scavi di Ercolano ", RendNap, n.s. 41 (1927), 1928, p. 4552 (reproduit dans Maiuri 1954 a, p. 355-362).

Maiuri 1928 = Maiuri (A.), Pompei, Novara, Istituto Geografico De Agostini, 1928.

MAIURI 1931 A = Maiuri (A.), "Herculaneum. Four years of discovery. Social life in Roman Italy", The Times, 6 novembre 1931, p. 15.

MAIURI 1931 в = Maiuri (A.), "Il progresso degli scavi ad Ercolano», L'illustrazione italiana, $\mathrm{n}^{\circ}$ 51, année LVIII, 20/12/1931, p. 898-899.

MAIURI 1931 c = Maiuri (A.), «Ercolano», BIASA, 4, fasc. I-III, 1931, p. 12-13.

MAIURI 1932 = Maiuri (A.), Herculanum, Paris, Alpina, 1932 [trad. fr. de Maiuri (A.), Ercolano, Roma - Novara, Istituto Geografico De Agostini, 1932 (Visioni italiche)].

MAIURi 1933 = Maiuri (A.), "La technique des fouilles d'Herculanum », dans La conservation des monu- ments d'artetd'histoire, Paris, Institut International de Coopération Intellectuelle - Office international des Musées, 1933, p. 251-255.

Maiuri 1936 A = Maiuri (A.), Ercolano, Roma, Libreria dello Stato, 1936 [Anno XIV E.F.] (Itinerari dei musei e monumenti d'Italia, 53).

MAIURI 1936 в = Maiuri (A.), Herculaneum, Roma, Libreria dello Stato, [1936, Anno XV E.F.; trad. fr. de Maiuri 1936 a] (Itinéraires des musées et monuments de l'Italie, 53).

MAIURI 1938 = Maiuri (A.), "Note su di un nuovo dipinto ercolanese », $B d$ 'A , s. 3, 31 (1937), fasc. 11, maggio 1938, p. 481-489.

MAIURI 1939 = Maiuri (A.), "La croce di Ercolano", RendPontAcc, 15, (1939), 1940, p. 193-218.

MAIURI 1941 = Maiuri (A.), «Roma nell'Oriente europeo", Nuova antologia, 76, fasc. 1673, 1941, p. 213-225.

MAIURI 1942 a = Maiuri (A.), L'ultima fase edilizia di Pompei, Spoleto, Istituto di Studi Romani, 1942 (Campania romana, 2).

MAIURI 1942 в = Maiuri (A.), «Un decreto onorario di M. Nonio Balbo, scoperto recentemente ad Ercolano ", RendAccIt, s. 7, 3, 1942, p. 253-278.

MaIURi 1943 = Maiuri (A.), Pompéi, Paris, Alpina, 1943.

MAIUri 1945 = Maiuri (A.), La cena di Trimalchione di Petronio Arbitro. Saggio, Testo e commento, Napoli, R. Pironti, 1945.

MAIURI 1948 = Maiuri (A.), Gli studi pompeiani nel $I I^{\circ}$ Centenario degli scavi, Roma, Bardi, 1948 (Accademia nazionale dei Lincei. Problemi attuali di scienza e di cultura, 9).

Maiuri 1950 a = Maiuri (A.), Pompei ed Ercolano fra case e abitanti, Padova, Le Tre Venezie, 1950 (Itinerari del Sud, 2).

MaIuri 1950 в = Maiuri (A.), "Gli scavi di Pompei dal 1879 al $1948 »$, in Pompeiana 1950, p. 9-40.

Maturi 1950 c = Maiuri (A.), «Pompei - Scoperta di un edificio termale nella Regio VIII, Insula 5, nr. 36 », NSc, 1950, p. 116-136.

MAIUri 1954 A = Maiuri (A.), Saggi di varia antichità, Venezia, Neri Pozza, 1954 (Varia Critica, 12).

MaIuri 1954 в = Maiuri (A.), «Due singolari dipinti pompeiani », MDAIR, 60-61, 1953-1954, p. 88-99.

MAIURI 1958 A = Maiuri (A.), Vita d'archeologo. Cronache dell'archeologia napoletana, Napoli, Montanino, s.d. [1958].

MAIURI 1958 B = Maiuri(A.), Ercolano. Inuovi scavi. (19271958), vol. 1, Roma, Libreria della Stato, 1958.

MaIuri 1960 = Maiuri (A.), La villa dei misteri, $3^{\text {a }}$ ed., Roma, Libreria dello Stato, 1960.

MAIURI 1978 = Maiuri (A.), Mestiere d'archeologo. Antologia di scritti a cura di Carlo Belli, Milano, Scheiwiller, 1978 (Antica Madre, 1).

MAIURI 1991 = Maiuri (A.), Dallo scavo di Ercolano allo svolgimento dei papiri. Scritti e documenti inediti, éd. M. Capasso, Napoli, Ferraro, 1991. 
MaIURI 2008 = Maiuri (A.), Cronache degli scavi di Ercolano (1927-1961), Sorrento, Franco di Mauro, 2008.

MANACORDA 1982 = Manacorda (D.), « Per un'indagine sull'archeologia italiana durante il ventennio fascista ", AMediev, 9, 1982, p. 443-470.

ManNi 1974 = Manni (M.), Le pitture della Casa del colonnato tuscanico, Roma, Istituto poligrafico dello Stato, 1974 (Monumenti della pittura antica scoperti in Italia. Sezione Terza, la pittura ellenistico-romana. Ercolano, 2).

MANNI 1990 = Manni (M.), « Per la storia della pittura ercolanese », CronErcol, 20, 1990, p. 129-143.

MAR 1995 = Mar (R.), "El Serapeum ostiense y la urbanística de la ciudad. Una aproximación a su estudio », BA, 13-15, 1992-1995, p. 31-51.

MAR 1996 = Mar (R.), «Santuarios e inversion inmobiliaria en la urbanística ostiense del siglo II», dans Gallina Zevi (A.), Claridge (A.) (eds.), 'Roman Ostia' revisited. Archaeological and historical papers in memory of Russell Meigs, London, British School at Rome, 1996, p. 115-164.

Marangou-Lerat 1995 = Marangou-Lerat (A.), Le vin et les amphores de Crète de l'époque classique à l'époque impériale, Athènes, École française d'Athènes, 1995 (Études crétoises, 30).

MARLIÈRE 2002 = Marlière (E.), L'outre et le tonneau dans l'Occident romain, Montagnac, éd. M. Mergoil, 2002 (Monographies instrumentum, 22).

MARQUARDT 1892 = Marquardt (J.), La vie privée des Romains, t. II, $2^{\mathrm{e}}$ éd., Paris, Thorin et Fils, 1892 (Manuel des Antiquités romaines, 15).

Marrou - Meyerovitch 1942 = Marrou (H.-I.), Meyerovitch (J.), «Une inscription d'Herculanum relative au droit de 'superficie' ", REA, 44, 1942, p. 135-138.

MARROU 1937 = Marrou (H.-I.), "Herculanum à la lumière des dernières fouilles », Annales de l'École des Hautes Études de Gand, 1, 1937, p. 102-103

MARTURANO - RiNALDIS 1995 = Marturano (A.), Rinaldis (V.), «Il terremoto vesuviano del 62 d.C.: un evento carico di responsabilità », dans Fröhlich - Jacobelli 1995, p. 131-135.

Mattingly 1990 = Mattingly (D.J.), « Paintings, presses and perfume production at Pompeii », OJA, 9, 1, 1990, p. 71-90.

MAU 1886 = Mau (A.), « Su certi apparecchi nei pistrini di Pompei », MDAIR, 1, 1886, p. 45-48.

Mau 1899 = Mau (A.), Pompeii. Its life and art, trad. angl. par Kelsey (F.W.), London, MacMillan, 1899.

Mau 1900 = Mau (A.), Pompeji in Leben und Kunst, Leipzig, W. Engelmann, 1900.

MAYESKE 1972 = Mayeske (B.J.), Bakeries, bakers and bread at Pompeii: a study in social and economic history, Unpublished PhD Thesis, University of Maryland, 1972.
MAYESKE 1988 = Mayeske (B.J.), «A pompeian bakery on the Via dell'Abbondanza», dans Curtis (R.I.) (ed.), Studia Pompeiana and Classica in honor of Wilhelmina F. Jashemski. Volume I: Pompeiana, New Rochelle, Orpheus Publishing, 1988, p. 149-165.

Mazois 1824 A = Mazois (F.), Les ruines de Pompéi dessinées et mesurées par F. Mazois... 1 1ere partie, Firmin Didot, Paris, 1812-1824.

Mazors 1824 в = Mazois (F.), Les ruines de Pompéi dessinées et mesurées par $F$. Mazois... $2^{e}$ partie, Firmin Didot, Paris, 1822-1824.

Mazois [Gau] 1829 = Mazois (F.), Gau (F.), Les ruines de Pompéi dessinées et mesurées par F. Mazois..., ouvrage continué par M. Gau... $3^{e}$ partie, Firmin Didot, Paris, 1829.

McGinn 2004 = McGinn (T.A.J.), The economy of prostitution in the Roman world. A study of social history and the brothel, Ann Arbor, University of Michigan Press, 2004.

McIlwaIne 1988 = McIlwaine (I.C.), Herculaneum: $a$ guide to printed sources, 2 vol. Napoli, Bibliopolis, 1988.

Mercando - Paci 1998 = Mercando (L.), Paci (G.), Stele romane in Piemonte, Roma, G. Bretschneider, 1998 (Monumenti antichi, 57; Serie miscellanea, $5)$.

Miele 1989 = Miele (F.), "La casa a schiera I, 11, 16, un esempio di edilizia privata a Pompei», RStPomp, 3, 1989, p. 165-184.

Moeller 1969 = Moeller (W.O.), «The Male Weavers at Pompeii », Technology \& Culture, 10, 4, 1969, p. 561-566.

Moeller $1976=$ Moeller (W.O.), The wool trade in ancient Pompeii, Leiden, Brill, 1976.

Mols - Moormann 1994 = Mols (S.T.A.M.), Moormann (E.M.), «Ex parvo crevit. Proposta per una lettura iconografica della Tomba di Vestorius Priscus fuori Porta Vesuvio a Pompei», RStPomp, 6, 1993-1994, p. 15-52.

Mols - Moormann 2005 = Mols (S.T.A.M.), Moormann (E.M.), Omni pede stare. Saggi architettonici e circumvesuviani in memoriam Jos de Waele, Napoli, Electa Napoli, 2005 (Studi della Soprintendenza archeologica di Pompei, 9).

Mols $1999=$ Mols (S.), Wooden furniture in Herculaneum. Form, technique and function, Amsterdam, Gieben, 1999 (Circumvesuviana, 2).

Mommsen $1881=$ Mommsen (Th.), «Attische Gewichte aus Pompeii », Hermes, XVI, p. 317-320.

MommSEn-KrÜGer-KunKel $1954=$ Mommsen (Th.), Krüger (P.) (ed.), Kunkel (W.) (rec.), Corpus Juris Civilis, 1. Digesta, Berolini, apud Weidmannos, 1954.

Monteix - Pernot - Coutelas $2008=$ Monteix (N.), Pernot (M.), Coutelas (A.), «La metallurgia del piombo tra archeometria e approcci classici», dans Guzzo - Guidobaldi 2008, p. 439-447. 
Monteix - Rosso 2008 = Monteix (N.), Rosso (E.), "Pompéi: étude sur la métallurgie du plomb», MEFRA, 120, 1, 2008, p. 241-247.

Monteix 2003 = Monteix (N.), "Reprise de la fouille de la boutique VI, 15 à Herculanum », RStPomp, 14, 2003, p. 333-341.

Monteix 2004 A = Monteix (N.), «Les lingots de plomb de l'atelier VI, 12 à Herculanum et leur usage. Aspects épigraphiques et techniques", dans Lehoërff 2004, p. 365-378.

Monteix 2004 B = Monteix (N.), «La plomberie», MEFRA, 116, 1, 2004, p. 624-626.

MonteIX 2005 = Monteix (N.), «Fouilles de l'atelier de métallurgie du plomb (VI, 12) et de la boutique VI, 15 en façade de la Casa del salone nero à Herculanum », RStP, 16, 2005, p. 262-274.

MonteIX 2006 = Monteix (N.), «Les boutiques et les ateliers de l'insula VI à Herculanum», dans Contributi di Archeologia Vesuviana, I, Roma, "L'Erma» di Bretschneider, 2006 (Studi della Soprintendenza archeologica di Pompei, 17), p. 7-76.

MonteIX 2007 A = Monteix (N.), "Cauponae, popinae et 'thermopolia', de la norme littéraire à la réalité pompéienne», dans Contributi di Archeologia Vesuviana, III, Roma, «L'Erma » di Bretschneider, 2007 (Studi della Soprintendenza archeologica di Pompei, 20), p. 115-126.

MonteIx 2007 B = Monteix (N.), «Fouilles des boutiques en façade de la Casa del salone nero à Herculanum (VI, 12, VI, 14 et VI, 15) », RStPomp, 18,2007, p. 168-184

Monteix 2007 c = Monteix (N.), « Du couteau au boucher: remarques préliminaires sur la préparation et le commerce de la viande à Pompéi », Food \& History, 5.1, 2007, p. 167-193.

MonteIx 2008 = Monteix (N.), «La conservation des denrées dans l'espace domestique à Pompéi et Herculanum », MEFRA, 120, 1, 2008, p. 123-138.

Monteix 2009 = Monteix (N.), "Inventio Herculaneis : perlariletturadeiGiornalidegliScavidiErcolano ", dans Coralini (A.), Vesuviana. Archeologie a confronto (Atti del Convegno Internazionale, Bologna, 14-16 gennaio 2008), Ante Quem, Bologna, 2009 (Studi e Scavi del Dipartimento di Archeologia. Vesuviana, 4), p. 181-198.

MonteIx 2010 = Monteix (N.), «La localisation des métiers dans l'espace urbain: quelques exemples pompéiens", dans Chardron-Picault (P.) (dir.), L'artisanat antique en milieu urbain de Gaule romaine et des régions voisines, Actes du colloque d'Autun, 21-23 sept. 2007, Dijon, Société archéologique de l'Est (Revue archéologique de l'Est - suppléments, 28), à paraître [2010].

Moormann 1986 = Moormann (E.M.), «Un fior di giardino ed altri frammenti di pittura ercolanese », CronErcol, 16, 1986, p. 123-133.
Moormann 1987 = Moormann (E.M.), «Die Wandmalereien in der Casa del mobilio Carbonizzato in Herculaneum ", dans Pictores per provincias, Avenches, Association Pro Aventico, 1987 (Cahiers d'archéologie romande, 43; Aventicum, 5), p. 127-134.

Morel 1979 = Morel (J.-P.), «La ceramica e il vetro », dans Zevi 1979, p. 241-264.

Morel 1981 = Morel (J.-P.), Céramique campanienne: les formes, Rome, École française de Rome, 1981 (Bibliothèque des Écoles françaises d'Athènes et de Rome, 244).

Morel 1987 = Morel (J.-P.), «La topographie de l'artisanat et du commerce dans la Rome antique», dans L'Vrbs. Espace urbain et histoire. I ${ }^{\text {er }}$ siècle av. J.C. - III siècle ap. J.C., Rome, École française de Rome, 1987 (Collection de l'École française de Rome, 98), p. 127-155.

Morel 1992 = Morel (J.-P.), « L'artisan », dans Giardina (A.) (éd.), L'homme romain, Paris, Le Seuil, 1992 (L'univers historique), p. 267-302.

MorITz 1958 = Moritz (L.A.), Grain-mills and flour in classical Antiquity, Oxford, Clarendon Press 1958.

Motte - Martin $2003=$ Motte (S.), Martin (S.), «L'atelier de verrier antique de la Montée de la Butte à Lyon et ses productions ", dans Foy Nenna 2003 a, p. 303-319.

Mouritsen 1988 = Mouritsen (H.), Elections, magistrates and municipal élite. Studies in Pompeian Epigraphy, Roma, L'Erma di Bretschneider, 1988 (Analecta romana instituti danici - supplementum, 15).

MüHLEnbrock - Richter 2005 = Mühlenbrock (J.), Richter (D.), (hrsg.), Verschüttet vom Vesuv. Die letzten Stunden von Herculaneum, Mainz, von Zabern, 2005.

Mussolini 1927 = Mussolini (B.), «Adunanza del 9 aprile 1927 [Discorso del socio Benito Mussolini]», Atti della Reale Società Romana di Storia Patria, 50, 1927, p. 135-142.

NAJBJERG 2002 = Najbjerg (T.), «A reconstruction and reconsideration of the so-called basilica in Herculaneum », dans Pompeian brothels, Pompeii's ancient history, mirrors and mysteries, art and nature at Oplontis, and the Herculaneum basilica, Portsmouth, Journal of Roman Archaeology (Journal of Roman Archaeology supplement series, 47), p. 122-165.

Nappo 1989 = Nappo (S. C.), «Fregio dipinto dal «praedium » di Giulia Felice con rappresentazione del foro di Pompei », RStPomp, 3, 1989, p. 79-96.

Nappo 1993 = Nappo (S.C.), «Pompei: la casa Regio I, ins. 20, n. 4 nelle sue fasi. Considerazioni e problemi ", dans Franchi dell'Orto 1993, p. 667-676.

Nappo 1994 = Nappo (S.), «Alcuni esempi di tipologie di case popolari della fine III, inizio II secolo a.C. a Pompei », RStPomp, 6, 1993-1994, p. 77-104. 
NAPPo 1995 = Nappo (S. C.), « Evidenze di danni strutturali, restauri e rifacimenti nelle insulae gravitanti su via Nocera a Pompei», dans Fröhlich - Jacobelli 1995, p. 45-55.

NAPPO 1997 = Nappo (S.C.), «Urban transformation at Pompeii in the late $3^{\text {rd }}$ and early $2^{\text {nd }}$ c. B.C.», dans Laurence - Wallace Hadrill 1997, p. 93-120.

Nenna-Vichy -Picon 1997 = Nenna (M.-D.), Vichy (M.), Picon (M.), «L'atelier de verrier de Lyon, du Ir siècle ap. J.-C. et l'origine des verres "romains" », Revue d'Archéométrie, 21, 1997, p. 81-87.

NeUfERT 1966 = Neufert (E.), Enciclopedia pratica per progettare e costruire, $2^{\mathrm{a}}$ ed. (15 ${ }^{\mathrm{a}}$ tedesca), Milano, U. Hoepli, 1966.

PACKER 1975 = Packer (J.), « Middle and lower class housing in Pompeii and Herculaneum: a preliminary survey», dans Andreae (B.), Kyrieleis (H.) (hrsg.), Neue Forschungen in Pompeji un den anderen vom Vesuvausbruch 79 n. Chr. verschütteten Städten, Recklinghausen, A. Bongers, 1975, p. 133-142.

PACKeR 1978 = Packer (J.), «Inns at Pompeii : a short survey », CronPomp , 4, 1978, p. 5-53.

Pagano 1987 = Pagano (M.), « Una iscrizione elettorale da Ercolano », CronErcol, 17, 1987, p. 151-152.

Pagano 1988 = Pagano (M.), "Semo Sancus in una insegna di bottega a Ercolano», CronErcol, 18, 1988, p. 209-214.

Pagano 1989 = Pagano (M.), « Altra insegna di bottega da Ercolano », RStPomp, 3, 1989, p. 268.

Pagano 1990 = Pagano (M.), "Tegulae campanae ad Ercolano », CronErcol, 20, 1990, p. 157-176.

Pagano 1993 A = Pagano (M.), «Ricerche sull'impianto urbano di Ercolano », dans Franchi dell'Orto 1993, p. 595-608.

Pagano 1993 в = Pagano (M.), «Il teatro di Ercolano », CronErcol, 23, 1993, p. 121-156.

Pagano 1996 A = Pagano (M.), «La nuova pianta della città e di alcuni edifici pubblici di Ercolano», CronErcol 26, 1996, p. 229-262.

Pagano 1996 B = Pagano (M.), «Ercolano. Attività dell'Ufficio Scavi: 1995-1996», RStPomp, 7, 1996, p. 189-192.

PaGano $1997=$ Pagano (M.), Ercolano. Itinerario archeologico ragionato, Napoli, T\&M, 1997.

Pagano 2000 = Pagano (M.) (cur.), Gli Antichi Ercolanesi. Antropologia, Società, Economia, Ercolano, Villa Campolieto, 30 marzo - 26 luglio 2000, Napoli, Electa Napoli, 2000.

Pagano 2004 = Pagano (M.), «Un officina di plumbarius a Ercolano », dans Lehoërff 2004, p. 353-363.

Panella - Fano 1977 = Panella (C.), Fano (M.), «Le anfore con anse bifide conservate a Pompei: contributo ad una loro classificazione», dans Méthodes classiques et méthodes formelles dans l'étude des amphores, Rome, École française de Rome, 1977, p. 133-177 (Collection de l'École française de Rome, 32).
Panella 1986 = Panella (C.), «Oriente ed Occidente: considerazioni su alcune anfore "orientali" di età imperiale ad Ostia», dans Empereur (J.-Y.), Garlan (Y.), Recherches sur les amphores grecques, Athènes, École française d'Athènes, 1986 (Bulletin de correspondance hellénique - Supplément, 13), p. 609-636.

Papaccio 1990 = Papaccio (V.), «La casa del Gran Portale in Ercolano: note in margine al restauro ", RStPomp, 4, 1990, p. 221-226.

Papaccio 1993 = Papaccio (V.), «Il telaio ligneo (opus craticium) ercolanese: considerazioni e ricerche sui requisiti antisismici», dans Franchi dell'Orto 1993, p. 607-616.

PAPI 2002 = Papi (E.), «La turbia inpia: artigiani e commercianti del Foro Romano e dintorni (I sec. a.C. -64 d.C.) ", JRA, 15, 1, p. 45-62.

PAsour 1897 = Pasqui (A.), « La villa pompeiana della Pisanella presso Boscoreale», MonAccLinc, 7, 1897, col. 397-554.

Pavolin 1980 = Pavolini (C.), «Appunti sui «vasetti ovoidi e piriformi" di Ostia», MEFRA, 92, 2, 1980, p. 993-1020.

Pavolin 1986 = Pavolini (C.), « L'edilizia commerciale e l'edilizia abitativa nel contesto di Ostia tardoantica», dans Giardina (A.) (a cura di), Società romana e impero tardoantico. 2. Roma: politica, economia, paesaggio urbano, Bari, Laterza, 1986, p. 239-297.

Реасоск 1980 = Peacock (D.S.), « The Roman millstone trade: a petrological sketch », World Archaeology, 12, p. 43-53.

PeAcock $1989=$ Peacock (D.S.), «The mills of Pompeii », Antiquity, 239, vol. 63, 1989, p. 205214.

PeÑa - McCallum 2009 = Peña (J. Th.), McCallum (M.), «The Production and Distribution of Pottery at Pompeii: A Review of the Evidence; Part 1, Production », AJA, 113, 1, 2009, p. 57-79.

Pernice $1890=$ Pernice (E.), "Creduti pesi di Pompei e Napoli », MDAIR, 5, 1890, p. 40-45.

Pernice 1938 = Pernice (E.), Pavimente und figürliche Mosaiken, Berlin, 1938 (Die hellenistischen Kunst in Pompeji, 6).

Pesando - Guidobaldi 2006 = Pesando (F.), Guidobaldi (M.P.), Pompei, Oplontis, Ercolano, Stabiae, Roma-Bari, Laterza, 2006 (Guide archeologiche Laterza, 14).

PICON - VichY 2003 = Picon (M.), Vichy (M.), « D’Orient en Occident: l'origine du verre à l'époque romaine et durant le haut Moyen Âge ", dans Foy - Nenna 2003 a, p. 17-31.

Pietrogrande $1976=$ Pietrogrande (A.L.) (cur.), Le fulloniche, Roma, Istituto poligrafico dello Stato, 1976 (Scavi di Ostia, 8).

PIRSON 1997 = Pirson (F.), «Rented accomodation at Pompeii, the evidence of the Insula Arriana 
Polliana VI, 6 », dans Laurence - Wallace-Hadrill 1997, p. 161-185.

PIRSON $1999=$ Pirson (F.), Mietwohnungen in Pompeji und Herculaneum. Untersuchungen zur Architektur zum Wohnen und zur Sozial- und Wirschaftgeschichte der Vesuvstädte, München, Pfeil, 1999 (Studien zur antiken Stadt, 5).

Pompei 1879 = Pompei e la regione sotterrata dal Vesuvio nell'anno LXXIX, parte I-II, Napoli, F. Giannini, 1879 (Memorie e notizie pubblicate dall'ufficio tecnico degli scavi della province meridionali).

Potтs 2009 = Potts (C.R.), « The art of piety and profit at Pompeii. A new interpretation of the painted shop façade at IX.7.1-2 », GaR, 56, 2009, p. 55-70.

QuARANTA 1833 = Quaranta (B.), "Origini, vicende e scavazioni di Ercolano e Pompei », Annali Civili del regno delle Due Sicile, 1, 1833, fasc. 1, p. 52-64.

RAST-EICHER 2005 = Rast-Eicher (A.), «Römische Gewebe in der Schweiz », Helvetia Archaeologica, 143, vol. 36, 2005, p. 70-95.

RoBERTSON 1949= Robertson (R.H.S.), "The fuller's earths of the Elder Pliny», Classical Review, 63, 2, 1949, p. 51-52.

Rosini 1797 = Rosini (C.), Dissertationis isasogicae ad Herculanensium Voluminium explanationem, pars prima, Neapoli, Regiis typis, 1797.

Rossiter - HALDENBY 1989 = Rossiter (J.J.), Haldenby (E.), «A wine-making plant in Pompeii insula II.5 ", Echos du Monde Classique / Classical views, 33, n.s. 8, 1989, p. 229-239.

Rostovtsev 1932 = Rostovtzev (M.), "Compte rendu de Maiuri 1932 », AJA, 36, 1932, p. 585-587.

Rostovtsev 1988 = Rostovtsev (M.), Histoire économique et sociale de l'empire romain, trad. fr. de SEHRE', Robert Laffont, Paris, 1988 (Bouquins).

Ruggiero 1885 = Ruggiero (M.), Storia degli Scavi di Ercolano, Napoli, Tipografia dell'Accademia Reale delle Scienze, 1885.

SALIOU 1994 = Saliou (C.), Les lois du bâtiment: voisinage et habitat urbain dans l'Empire romain, recherches sur les rapports entre le droit et la construction privée du siècle d'Auguste au siècle de Justinien, Beyrouth, 1994 (Bibliothèque archéologique et historique, 116).

Saliou 1999 = Saliou (C.), "Les trottoirs de Pompéi: une première approche», BABesch, 74, 1999, p. 161-218.

Salza Prina Ricotti 1980 = Salza Prina Ricotti (E.), "Cucine e quartieri servili in epoca romana", RendPontAc, s. 3, 51-52, 1978-1980, p. 237-294.

SANTORO 2004 = Santoro (S.), "Artigianato e produzione nella Cisalpina romana. Proposte di metodo e prime applicazioni », dans Santoro (S.) (ed.), Artigianato e produzione nella Cisalpina, 1. Proposte di metodo e prime applicazioni, Firenze, Edizioni all'Insegna del Giglio, 2004, p. 19-69 (Flos Italiae, 3).
SANTORo 2007 = Santoro (S.) (cur.), Pompei. Insula del Centenario (IX, 8). Indagini diagnostiche geofisiche e analisi archeometriche, Bologna, AnteQuem, 2007 (Studi e scavi, n.s., 16).

ScATOzza HöRICHT 1986 = Scatozza Höricht (L.A.), I vetri romani di Ercolano, Roma, «L'Erma» di Bretschneider, 1986 (Cataloghi della Soprintendenza Archeologica di Pompei, 1).

Scatozza Höricht 1988 = Scatozza-Höricht (L. A.), «Pompejanisch-rote Platten», Rivista di Studi Pompeiani, 2, 1988, p. 81-86.

ScATOzza HöRIcht 1991 = Scatozza Höricht (L.A.), «Syrian elements among the glass from Pompéii and Herculaneum », dans Newby (M.), Painter (K.) (eds.), Roman glass: two centuries of art and invention, London, The society of Antiquaries of London, 1991 (Occasional papers, 13), p. 76-85.

ScATOzZa HöRicht 2000 = Scatozza Höricht (L.A.), «Il commercio del vetro ad Ercolano ", dans Pagano 2000, p. 152-153.

SCHALlmAYER 1997 = Schallmayer (E.), «Kastelle am Limes. Die entwicklung der römischen Militäranlagen auf dem Saalburg-Paß», in Schallmayer (E.) (Hrsg.), Hundert Jahre Saalburg. Von römischen Grenzposten zum europäischen Museum, Mainz, von Zabern, 1997 (Sonderhefte der antiken Welt, 40), p. 106-118.

Schefold 1957 = Schefold (K.), "Zur Chronologie der Dekorationen im Haus der Vettier », MDAIR, 64, 1957, p. 149-153.

SchIERER 1987 = Schierer (I.), «Ein Webstuhlbefund aus Gars-Thunau. Rekonstruktionsversuch und Funktionsanalyse», Archaeologia Austriaca, 71, 1987, p. 29-87.

Schoonhoven 1999 = Schoonhoven(A.V.), « Residences for the rich? Some observations on the alleged residential and elitist character of Regio VI of Pompeii », BABesch, 74, 1999, p. 219-246.

Schoonhoven 2006 = Schoonhoven (A.V.), Metrology and meaning in Pompeii: the urban arrangement of Regio VI, Roma, "L'Erma » di Bretschneider, 2006 (Studi della Soprintendenza archeologica di Pompei, 26).

ScHÖRNER 1995 = Schörner (G.), Römische Rankenfriese. Untersuchungen zur Baudekoration der späten Republik und der frühen und mittleren Kaiserzeit im Westen des Imperium Romanum, Mainz, von Zabern, 1995 (Beiträge zur Erschliessung hellenistischer und kaiserzeitlicher Skulptur und Architektur, 15).

Schumacher $1976=$ Schumacher (L.), «Das Ehrendekret für M. Nonius Balbus aus Herculaneum (AE 1947, 53)», Chiron, 6, 1976, p. 165-184.

SEgEnNi 1985 = Segenni (S.), Amiternum e il suo territorio in età romana, Pisa, Giardini editori, 1985 (Biblioteca di studi antichi, 49). 
SeIler 1992 = Seiler (F.), Häuser in Pompeji, 5. Casa degli Amorini dorati (VI 16, 7.38), München, Hirmer, 1992.

Sogliano 1904 = Sogliano (A.), "Gli scavi di Pompei dal 1873 al $1900 "$, dans Atti del congresso internazionale di scienze storiche (Roma 1 - 9 aprile 1903), vol. V, Roma, Tipografia della R. Accademia dei Lincei, 1904, p. 295-349.

Sogliano 1914 = Sogliano (A.), «Rectina Tasci: per la critica del testo delle lettere Pliniane ", RendLinc, s. 5, 23, 1914, p. 187-190.

Solin $1973=$ Solin (H.), «Die herkulanensischen Wandinschriften. Ein soziologischer Versuch», CronErcol, 3, 1973, p. 97-103.

Sorgente-Fiorelli[1860] = Sorgente(C.), Fiorelli (G.), Tabula Coloniae Veneriae Corneliae Pompeis quam denuo recognitam edidit Ioseph Fiorelli, Napoli, [1858-1860].

Spinazzola 1953 = Spinazzola (V.), Pompei alla luce dei nuovi scavi di via dell'Abbondanza, Roma, Libreria della Stato, 1953.

SteFAnI 2005 A = Stefani (G.) (cur.), Cibi e sapori a Pompei e dintorni. Antiquarium di Boscoreale, 3 febbraio - 26 giugno 2005, Pompei, Flavius, 2005.

Stefani 2005 в = Stefani (G.), «Il termopolio di Asellina », dans Stefani 2005 a, p. 115-128.

SteFani 2005 c = Stefani (G.), «Labor. Il cibo come lavoro », dans Stefani 2005 a, p. 96-103.

StEFAnI 2006 = Stefani (G.), «I contenitori di alimenti di origine vegetale», dans Borgongino 2006, p.157-169.

STERN 1999 = Stern (E.M.), « Roman glassblowing in a cultural context», AJA, 103, 3, 1999, p. 441-485.

STERN 2006 = Stern (E.M.), «Les verriers dans la Rome antique», in Beretta - Di Pasquale 2006, p. 39-61.

STERNINI 1993 = Sternini (M.), «I vetri », dans Harris (W.V.), The inscribed economy. Production and distribution in the Roman empire in the light of instrumentum domesticum, Ann Arbor, University of Michigan, 1993 (Journal of Roman Archaeology - supplement series, 6), p. 81-94.

Strocka 1991 = Strocka (V.M.), Häuser in Pompeji, 4. Casa del Labirinto (VI 11, 8-10), München, Hirmer, 1991.

Susini 1958 = Susini (G.), «L'insegna della fullonica di Forum Popili », AttMemBol, n.s. 9, 1957-1958, p. 199-205.

Tамміsто 1986 = Tammisto (A.), « The representation of the Phoenix in Roman Art », Arctos, 20, 1986, p. 171-225.

TASSINARI 1979 = Tassinari (S.), «Il vasellame bronzeo », dans Zevi 1979, p. 229-240.

TAssinari 1993 = Tassinari (S.), Il vasellame bronzeo di Pompei, 2 vol., Roma, «L'Erma » di Bretschneider, 1993 (Cataloghi Soprintendenza archeologica di Pompei, 5).
TASSINARI 1996 = Tassinari (S.), «Bouillir, mijoter et cuire, porter et mesurer: le rôle de la vaisselle métallique dans les cuisines de Pompéi », dans Bats 1996, p. 113-119.

TChernIA - BRUN 1999 = Tchernia (A.), Brun (J.-P.), Le vin romain antique, Glénat, Grenoble, 1999.

TCHERNIA 1986 = Tchernia (A.), Le vin de l'Italie romaine: essai d'histoire économique d'après les amphores, Rome, École française de Rome, 1986 (Bibliothèque des Écoles françaises d'Athènes et de Rome, 261).

TCHERnIA $2000=$ Tchernia (A.), «La vente du vin», dans Lo Cascio (E.) (a cura di), Mercati permanenti e mercati periodici nel mondo romano: atti degli Incontri capresi di storia dell'economia antica (Capri 13-15 ottobre 1997), Bari, Edipuglia, 2000 (Pragmateiai, 2), p. 199-209.

ThuRMOND 2006 = Thurmond (D. L.), A handbook of food processing in classical Rome: for her bounty no winter, Leiden, Brill, 2006.

Tosti - Zanella 2008 = Tosti (F.), Zanella (S.), « Domus VIII 6, 5 (cd. Villa publica)», RStPomp, 19, 2008, p. 97-98.

TrAN 2007 = Tran (N.), «Le 'procès des foulons'. L'occupation litigieuse d'un espace vicinal par des artisans romains », MEFRA, 119, 2, 2007, p. 597 611.

Tran TAm TInH 1971 = Tran Tam Tinh (V.), Le culte des divinités orientales à Herculanum, Leiden, E.J. Brill, 1971 (Études préliminaires aux religions orientales dans l'Empire romain, 17).

TRAn TAM TINH 1977 = Tran Tam Tinh (V.), « À la recherche d'Herculanum préromaine», CronPomp, 3, 1977, p. 40-56.

Tran Tam Tinh 1988 = Tran Tam Tinh (V.), La Casa dei cervi à Herculanum, Roma, G. Bretschneider, 1988 (Archeologica, 74).

TREgGiari 1980 = Treggiari (S.M.), «Urban labour in Rome: mercennarii and tabernarii », dans Garnsey (P.), Non-slave labour in the graeco-roman world, Cambridge, Cambridge philological Society, 1980 (Cambridge philological Society - Supplementary volumes, 6), p. 48-64.

VÄÄNÄNEN 1958 = Väänänen (V.), Le latin vulgaire des inscriptions de Pompéi, $2^{\mathrm{e}}$ éd. augmentée, Berlin, Akademie-Verlag, 1959 (Abhandlungen der deutschen Akademie der Wissenschaften zu Berlin. Klasse für Sprachen, Literatur und Kunst. Jahrg, 1958, 3).

VALLOTTO - Verità 2002 = Vallotto (M.), Verità (M.), «Glasses from Pompeii and Herculaneum and the sands of the rivers Belus and Volturno», dans Renn (J.), Castagnetti (G.) (eds.), Homo Faber: studies on nature, technology and science at the time of Pompeii, Roma, "L'Erma» di Bretschneider, 2002 (Studi della Soprintendenza Archeologica di Pompei, 6), p. 63-73. 
VAN ANDRINGA 2009 = van Andringa (W.), Le quotidien des dieux et des hommes. La vie religieuse dans les cités du Vésuve à l'époque romaine, Rome, École française de Rome, 2009 (Bibliothèque des Écoles françaises d'Athènes et de Rome, 337).

VAN BuREN 1966 = Van Buren (A.W.), «Where authors and monuments converge", dans Mélanges d'archéologie, d'épigraphie et d'histoire offerts à J. Carcopino, Paris, Hachette, 1966, p. 955-963.

VARONE 1989 = Varone (A.), « Pompei. Attività dell'Ufficio Scavi: $1989 »$, RStPomp, III, 1989, p. 225238.

VARONE 1995 = Varone (A.), « Più terremoti a Pompei? I nuovi dati degli scavi di via dell'Abbondanza», dans Fröhlich-Jacobelli 1995, p. 29-35.

VARONE 2000 = Varone (A.), «Spigolature epigrafiche ercolanesi », RStPomp, 11, 2000, p. 276-281.

VARONE 2005 = Varone (A.), "Convivere con i terremoti. La travagliata ricostruzione di Pompei dopo il terremoto del 62 d.C. alla luce delle nuove scoperte », dans Mols - Moormann 2005, p. 315-323.

VARONE 2008 = Varone (A.), "Per la storia recente, antica e antichissima del sito di Pompei », dans Guzzo - Guidobaldi 2008, p. 349-362.

VAST 1895 = Vast (H.), "Herculanum », dans La grande encyclopédie. Inventaire raisonné des sciences, des lettres et des arts par une société de savants et de gens de lettres, Paris, Lamirault et $\mathrm{C}^{\mathrm{ie}}$, vol. 19, 1895, col. 1162.

VERITÀ 2006 = Verità (M.), «Nature et technique des verres pompéiens à travers les analyses chimiques des pièces archéologiques", dans Beretta - Di Pasquale 2006, p. 171-173.

Veyne 1990 = Veyne (P.), "Images de divinités tenant une phiale ou patère. La libation comme « rite de passage» et non pas offrande», Métis, 5, 1990, p. 17-30.

VEYnE 1991 = Veyne (P.), « Mythe et réalité de l'autarcie à Rome», dans Veyne (P.), La société romaine, Paris, Le Seuil, 1991 (Des travaux), p. 131-162.

Veyne 2005 = Veyne (P.), «Existait-il une classe moyenne en ces temps lointains?", dans Veyne (P.), L'empire gréco-romain, Paris, Le Seuil, 2005 (Des travaux), p. 117-162.

VILledieu 2007 = Villedieu (F.), La vigna Barberini, 2. Domus, palais impérial et temples. Stratigraphie du secteur nord-est du Palatin, Rome, École française de Rome, 2007 (Roma Antiqua, 6).

VILLENEUVE 1988 = Villeneuve (F.), «Fouilles à Khirbet Edh-Dharih (Jordanie), 1984-1987: un village, son sanctuaire et sa nécropole aux époques nabatéennes et romaines ( $\mathrm{I}^{\mathrm{er}}-\mathrm{IV}^{\mathrm{e}}$ siècles ap. J.-C.)", CRAI, 1988, 2, p. 458-479.

Viola 1879 = Viola (L.), « Gli scavi di Pompei dal 1873 al $1878 »$, dans Pompei 1879, II, p. 7-85.

VIRLOuvet 1995 = Virlouvet (C.), Tessera frumentaria. Les procédures de la distribution de blé public à Rome, Rome, École française de Rome, 1995 (Bibliothèque des Écoles françaises d'Athènes et de Rome, 286).

Waldstein - Shoobridge 1908 = Waldstein (Ch.), Shoobridge (M.A.), Herculaneum. Past present \& future. With appendixes, London, MacMillan, 1908.

Wallace-Hadrill - Guidobaldi - CAMardo - Moesch 2008 = Wallace-Hadrill (A.), Guidobaldi (M.P.), Camardo (D.), Moesch (V.), «Le ricerche archeologiche nell'ambito dell'Herculaneum Conservation Project" in Guzzo - Guidobaldi 2008, p. 409-24.

WALlace-HADRILL 1994 = Wallace-Hadrill (A.), Houses and society in Herculaneum and Pompei, Princeton, Princeton University Press, 1994.

Wallace-Hadrill 1995 = Wallace-Hadrill (A.), «Public honour and private shame: the urban texture of Pompeii », dans Cornell (T.J.), Lomas (K.), Urban society in Roman Italy, London, UCL Press, 1995, p. 39-62.

WARSCHER 1930= Warscher (T.), «Bread-making in old Pompeii », Art and Archaeology, 30, 4, 1930, p. 103-112.

White 1970 = White (K.D.), Roman farming, London, Thames and Hudson, 1970.

WILD 1968 = Wild (J.P.), "The Roman flax-hackle (AENA)», Museum Helveticum, 25, 1968, p. 139142.

WILD $1970=$ Wild (J.P.), Textile manufacture in the northern Roman provinces, Cambridge, Cambridge U.P., 1970 (Cambridge Classical Studies).

WILD 2002 = Wild (J.P.), "The textile industries of Roman Britain », Britannia, 33, 2002, p. 1-42.

WILD 2008 = Wild (J.P.), "Textile production», dans Oleson (J.P.) (ed.), The Oxford Handbook of engineering and technology in the Roman world, New York, Oxford UP, 2008, p. 465-482

Williams-Thorpe $1988=$ Williams-Thorpe (O.), «Provenancing and archaeology of Roman millstones from the Mediterranean area », Journal of Archaeological Science, 15, 1988, p. 253-305.

Wilson - Schörle 2009 = Wilson (A.), Schörle (K.), "A baker's funerary relief from Rome ", $P B S R$, 77, 2009, p. 101-123.

WiLson 2001 = Wilson (A.), «Timgad and textile production », dans Mattingly (D.J.), Salmon (J.) (eds.), Economies beyond agriculture in the classical world, London, Routledge, 2001 (Leicester-Nottingham studies in ancient society, 9), p. 271-296.

WILson 2003 = Wilson (A.), " The archaeology of the Roman fullonica », JRA, 16, 2, 2003, p. 442-446.

Wilson-Flohr À PARAître = Wilson (A.), Flohr (M.), "The Economy of Ordure», dans Koloski-Ostrow (A.O.), Jansen (G.C.M.), Moormann (E.M.) (eds), Roman Toilets: Their Archaeology and 
Cultural History, Leiden, à paraître (BABesch Supplement).

WitTMANn - Jouguand 2003 = Wittmann (A.), Jouquand (A.-M.), «La boutique d'un marchand de vases dans la seconde moitié du $\mathrm{III}^{\mathrm{e}}$ siècle après J. - C. à Poitiers (Vienne)», dans Rivet (L.) (éd.), S.F.É.C.A.G. Actes du congrès de Saint-Romain-enGal. 29 mai - $1^{e r}$ juin 2003, Marseille, S.F.É.C.A.G., 2003, p. 621-639.

WORDSWORTH 1837 = Wordsworth (C.), Inscriptiones Pompeianae, or specimens and facsimilies of ancient inscriptions discovered on the walls of buildings at Pompeii, London, J. Murray, 1837.

YegÜL 1993 = Yegül (F. K.), «The Palaestra at Herculaneum as a new architectural type », dans Scott (R.T), Scott (A.R.) (eds.), Eius virtutis studiosi. Classical and postclassical studies in memory of Frank Edward Brown, 1908-1988, Washington,
National Gallery of Art, 1993 (Studies in the history of art, 43) p. 369-393.

Zevi 1979 = Zevi (F.) (cur.), Pompei 79. Raccolta di studi per il decimonono centenario dell'eruzione vesuviana, Napoli, G. Macchiaroli Editore, 1979.

Zevi 1996 = Zevi (F.), « Pompei dalla città sannitica alla colonia sillana: per un'interpretazione dei dati archeologici», dans Cébeillac-Gervasoni 1996, p. 125-138.

ZEVI 2001 = Zevi (F.), «Aspetti dell'archeologia pompeiana nel Novecento: gli scavi del Maiuri a Pompei », dans Guzzo 2001, p. 73-79.

ZIMMER 1982 = Zimmer (G.), Römische Berufsdarstellungen, Berlin, Gebr. Mann, 1982 (DAI - Archäologische Forschungen, 12).

ZotToLI 1928 = Zottoli (G. P.), "Bibliografia Ercolanese (a cura di A. Maiuri)», BIASA, 2, 1928, p. 51-88. 


\section{LISTE DES ILLUSTRATIONS}

Sauf mention contraire, les dessins, tableaux et photographies sont de l'auteur.

Les photographies d'Herculanum, de Pompéi et d'Ostie ont été réalisées sur concession du Ministero per i Beni e le Attività Culturali - Soprintendenza Speciale per i Beni Archeologici di Napoli e Pompei (SANP); Soprintendenza Speciale per i Beni Archeologici di Roma - sede di Ostia (SAR-O).

Les figures 61 et 62 sont de l'auteur, sur concession des Musei Vaticani, tandis que la figure 63 a été réalisée avec l'accord de l'Académie de France à Rome. Les figures 66, 70 et 77 ont été réalisées sur concession du Museo Civico Archeologico di Bologna.

Sauf mention contraire, les plans sont issus du relevé d'Herculanum dressé par F. Ferrajoli, numérisé et modifié par l'auteur. Le plan de la Casa del salone Nero a été levé par O. Cerasuolo en 2004. Les relevés en plan de l'Insula Orientalis II ${ }^{a}$ ont été dressés par M.R. Acetoso et L. Trinca, puis modifiés par l'auteur.

Toute reproduction, par quelque moyen que ce soit, reste interdite sans autorisation écrite des ayant-droits.

Fig. 1. Casa del bicentenario, tablinum, mur ouest, vue générale et détail.

Fig. 2. Casa del bicentenario, premier étage; cliché Archivio fotografico SANP, C2757 (ex E421), 1938.

Fig. 3. "Chambre de la brodeuse», pièce annexe de la boutique Or. II, 10; cliché Archivio fotografico SANP, EB56 (ex 3301, ex 28), 1957.

Fig. 4. $\quad$ Avancée de la fouille de la Casa a graticcio à Herculanum (août - octobre 1927).

Fig. 5. $\quad$ Avancée de la fouille de la Casa a graticcio à Herculanum (février 1928).

Fig. 6. $\quad$ Avancée de la fouille de la Casa a graticcio à Herculanum (mars 1928).

Fig. 7. Restitutions isométriques de la façade de la Casa a graticcio à Herculanum (échelle: 1/150).

Fig. 8. $\quad$ Avancée de la fouille de la Casa a graticcio à Herculanum (avril 1928).

Fig. 9. Avancée de la fouille de la Casa a graticcio à Herculanum (septembre - octobre 1928).

Fig. 10. Avancée de la fouille de la Casa a graticcio à Herculanum (novembre 1928).

Fig. 11. Avancée de la fouille de la Casa a graticcio à Herculanum (décembre 1928).

Fig. 12. Étapes de la reconstruction de la Casa a graticcio (Herculanum); clichés Archivio fotografico SANP, A2803, D7987 et C2414, datés de 1929.

Fig. 13. Variations dans les positions des lits de la Casa a graticcio (Herculanum) entre la fouille et la restauration.

Fig. 14. Casa della calce (VIII 5, 28-29.34-35) sur la maquette en liège de Pompéi conservée au Museo Archeologico Nazionale di Napoli (MANN; Inv. s.n. 3).

Fig. 15. «Enseigne » de la boutique VI, 14 à Herculanum après sa restauration; cliché archivio fotografico SANP D50897, [s.d., probablement 1960/1061].

Fig. 16. "Enseigne» sur la façade sud de l'îlot II 3 à Pompéi; Archivio storico SANP, 142 fo 17, cliché $\mathrm{n}^{\circ} 478$ du11 octobre 1938.

Fig. 17. Diagramme de répartition des divinités représentées sur les «enseignes» des boutiques de Pompéi.

Fig. 18. «Entrée» V, 4 de la Casa del telaio à Herculanum.

Fig. 19. Représentation de Priape et d'un dolium à l'arrière du comptoir de la boutique IV, 17; cliché Archivio fotografico SANP EC 201, daté de 1931.

Fig. 20. Lampe en bronze suspendue aux bourses d'un pygmée ithyphallique; Pompéi, Inv. n P1198.

Fig. 21. Seuils en façade de l'Insula Orientalis II ${ }^{a}$ (Or. II, 1 et Or. II, 1 b). 
Fig. 22. Restitution isométrique du système d'encastrement des planches fermant la boutique DM 4E à Herculanum (échelle: 1/40; détail encadré, échelle: 1/10).

Fig. 23. Pavement de la boutique IV, 14.

Fig. 24. Détail de la fresque représentant une distribution de pains; MANN, Inv. nº 9071.

Fig. 25. Boutique I 6, 7 à Pompéi. Empreinte du creusement pour un comptoir maçonné.

Fig. 26. Étagère murale dans la boutique $\mathrm{V}, 12$.

Fig. 27. Porte-amphores de la boutique V, 6.

Fig. 28. Distribution des objets découverts dans les locaux commerciaux et artisanaux d'Herculanum en fonction de leur espace de provenance.

Fig. 29. Plan de la boutique VI, 15 dans son état au moment de l'éruption (échelle $1 / 60$; relevé O. Cerasuolo - B. Faticoni).

Fig. 30. Restitution isométrique des appartements V, 17 et V, 18 (échelle 1/100).

Fig. 31. Cinq des dix-neuf lampes provenant d'une caisse trouvée en V, 17; Herculanum, Inv. $n^{\circ} 1883$ $\mathrm{a}-\mathrm{c}=77163 \mathrm{a}-\mathrm{c}, 1884 \mathrm{a}-\mathrm{b}=77164 \mathrm{a}-\mathrm{b}$. Dans l'encadré, détail de la lampe Inv. n 1884b.

Fig. 32. Décoration du comptoir du local I 19, 1-2 à Pompéi; cliché Archivio fotografico SANP A2119 du 19 juin 1933.

Fig. 33. Comptoir de la boutique «de Pherusa » (III 6, 1); d'après NSc 1936.

Fig. 34. Restitutions isométrique (échelle: 1/100) et axonométrique (échelle: 1/50) de la boutique «d'Asellina (Pompéi, IX 11, 2).

Fig. 35. Chauffe-eau en plomb provenant de la Villa des Mystères; Pompéi, Inv. nº 4496.

Fig. 36. Comptoir du commerce alimentaire « de Sotericus» (Pompéi, I 12, 3).

Fig. 37. Aménagement pour la cuisson construit avec des tuiles dans le local DM 8E à Herculanum.

Fig. 38. Table de cuisson dans l'arrière-boutique du local VII 9, 30-31 (Pompéi).

Fig. 39. Arrière du comptoir de la boutique V, 6 à Herculanum; détail du cliché Archivio fotografico SANP EC 259, daté de 1933.

Fig. 40. Commerce alimentaire VI, 19 (Herculanum).

Fig. 41. Dolia dans le probable commerce alimentaire VII 4, 17 (Pompéi).

Fig. 42. Dolia provenant de la villa Musigno a Scafati; cliché M. Amodio [1873], INHA, $4^{\circ}$ Ae 109.

Fig. 43. Dessin d'une fresque disparue, découverte dans la pièce annexe du local VI 10, 19; G. Marsigli, Archivio disegni SANP, $\mathrm{n}^{\circ} 360$; d'après PPM V.

Fig. 44. Entonnoir en bronze provenant de la boutique dite "d'Asellina» (IX 11, 2); Pompéi, Inv. $\mathrm{n}^{\circ} 1151$.

Fig. 45. Comparaison entre les commerces alimentaires d'Herculanum et de Pompéi; échelle 1/200.

Fig. 46. Chronologie des découvertes de céréales et de légumineuses à Herculanum et Pompéi.

Fig. 47.

Fig. 48.

Restitution isométrique du commerce alimentaire V, 6 (échelle: 1/100).

Fig. 49. Boutique «d'Asellina» (Pompéi, IX 11, 2) en cours de fouille; cliché Archivio storico SANP P/C 438 ex P694, daté de 1912.

Fig. 50. Cruche en forme de chien provenant de la boutique "d'Asellina» (IX 11, 2; Pompéi, Inv. $\left.\mathrm{n}^{\circ} \mathrm{P} 1100\right)$.

Fig. 51. Échantillon de la vaisselle provenant de la boutique "d'Asellina» (IX 11, 2); Pompéi, Inv. $\mathrm{n}^{\circ} \mathrm{P} 1194, \mathrm{P} 1142, \mathrm{P} 1149 ; \mathrm{P} 1148, \mathrm{P} 1147, \mathrm{P} 1131$; P1145, P1123 (de gauche à droite et de haut en bas).

Fig. 52. Instruments de préparation culinaire provenant de la boutique «d'Asellina » (IX 11, 2; Pompéi, Inv. $n^{\circ}$ P1191, P1150).

Fig. 53. Restitution axonométrique de la boutique VI, 19 à Herculanum; échelle: 1/75.

Fig. 54. Commerce alimentaire (V, 9-10) en façade de la Casa dell'Apollo citaredo à Herculanum.

Fig. 55. Amphores stockées tête-bêche à l'étage de la boutique I 7, 13-14; Archivio storico SANP, 142 fo 14 , cliché $n^{\circ} 219$, daté du 25 novembre 1935.

Fig. 56. Fonction des pièces dans la boutique IV, 15-16 à Herculanum; échelle: 1/200.

Fig. 57. Assiettes en céramique sigillée provenant de la pièce 6 du commerce alimentaire IV, 15-16 (Herculanum, Inv. ${ }^{\circ} 749=76026$ ) et dessins des timbres moulés sur le fond des assiettes (échelle 1/1).

Fig. 58. Scènes de vie peintes dans la pièce annexe du commerce alimentaire VI 10, 1.19 (Pompéi).

Fig. 59. Répartition des commerces alimentaires à Herculanum et Pompéi en fonction de leur type.

Fig. 60. Frise du mausolée de M. Vergilius Eurysaces; d'après Cianco Rossetto 1973.

Fig. 61. Relief du caisson de P. Nonius Zethus; Museo Chiaramonti, Inv. n 1343. 
Fig. 62. Relief de la Porta San Giovanni; Museo Chiaramonti, Inv. n 1370.

Fig. 63. Sarcophage de la Villa Médicis (détail).

Fig. 64. Sarcophage d'Annius Octavius Valerianus (Museo Gregorio Profano, Inv. n 10536); d'après Blümner 1912.

Fig. 65. Plaque funéraire de la tombe de Ti. Claudius Eutychus (Ostie, Isola Sacra); d'après Zimmer 1982.

Fig. 66. Détail du relief conservé au Museo Civico Archeologico di Bologna (cliché N.Monteix/Archivio Fotografico del Museo Civico Archeologico di Bologna; Inv. Rom 1872).

Fig. 67. Meule de la boulangerie VII 2, 22 à Pompéi.

Fig. 68. Relief conservé au Museo Civico Archeologico di Bologna (Inv. Rom 1872); d'après Zimmer 1982.

Fig. 69. Relief fragmentaire conservé à Ostie (Museo Ostiense, Inv. n 137 ; cliché SAR-O).

Fig. 70. Détail du relief conservé au Museo Civico Archeologico di Bologna (cliché N.Monteix/ Archivio Fotografico del Museo Civico Archeologico di Bologna; Inv. Rom 1872).

Fig. 71. Plats en bronze provenant de l'appartement situé au-dessus de la boulangerie Or. II, 8 ; cliché Archivio fotografico SANP, $\mathrm{n}^{\circ}$ B44, daté de 1957; Herculanum, Inv. n 1625, c-h, l =76903, c-h, 1.

Fig. 72. $\quad$ Pain provenant de la Casa dell'ara laterizia (III, 17); Herculanum, Inv. ${ }^{\circ}$ E411=75688.

Fig. 73. Four de la boulangerie Or. II, 8 à Herculanum.

Fig. 74. Intérieur du four de la boulangerie Or. II, 8 à Herculanum.

Fig. 75. Four de la boulangerie Or. II, 1a à Herculanum.

Fig. 76. Four de la boulangerie I 12, 1-2 à Pompéi.

Fig. 77. Détail du relief conservé au Museo Civico Archeologico di Bologna (cliché N.Monteix/Archivio Fotografico del Museo Civico Archeologico di Bologna; Inv. Rom 1872).

Fig. 78. Boulangerie VI 5, 15 à Pompéi, salle des meules.

Fig. 79. Carte de répartition des espaces voués à la boulangerie à Pompéi (échelle: 1/5000).

Fig. 80. Table maçonnée dans l'atelier Or. II, 18 à Herculanum.

Fig. 81. Restitution axonométrique de l'atelier VI, 30 à Herculanum; échelle: 1/50).

Fig. 82. Vestiges de la chaudière «basse » dans l'atelier Or. II, 5 à Herculanum.

Fig. 83. Table maçonnée arasée dans l'atelier Or. II, 5 à Herculanum.

Fig. 84. Nomenclature d'un métier vertical à pesons; dessin d'après Ciszuk - Hammarlund 2008.

Fig. 85. Deux types de métiers verticaux sans peson; dessin d'après Ciszuk - Hammarlund 2008).

Fig. 86. Restes d'un métier à tisser vertical découvert à Herculanum dans la Casa del telaio (V, 3); dessin F. Ferrajoli, Archivio disegni SANP P658 fo 3, 18 janvier 1933.

Fig. 87. Peson en plomb provenant de la maison I 9, 10; Pompéi, Inv. n P9919-1.

Fig. 88. Proposition de restitution isométrique de la disposition des pesons en plomb employés dans un métier à tisser; échelle: $1 / 5$.

Fig. 89. Carte de répartition des groupements de pesons pouvant indiquer des métiers à tisser à Pompéi (échelle: 1/5000).

Fig. 90. Teinturerie à Pompéi (I 8, 19); Archivio storico SANP, 142 fo 17, cliché du 12 février 1938, [s.n.].

Fig. 91. Atelier de teinturerie à Pompéi (VII 2,11) représenté sur la maquette en liège du MANN (Inv. s.n. 3).

Fig. 92. Fresque située en façade de l'atelier de feutre «de Verecundus» (Pompéi, IX 7, 5-7); d'après Spinazzola 1953.

Fig. 93. Dolium emmuré pour être utilisé comme fourneau dans l'atelier Or. II, 5 à Herculanum.

Fig. 94. Fosses remblayées au nord de l'atelier Or. II, 5 à Herculanum.

Fig. 95. Fresque de l'oecus q de la Casa dei Vettii (Pompéi, VI 15, 1.27).

Fig. 96. Fresque découverte dans la fullonica de L. Veranius Hypsaeus (Pompéi, VI 8, 2.20-21); MANN, Inv. $n^{\circ} 9774$.

Fig. 97. Bassine en calcaire dans l'une des stalles de foulage de la fullonica «de Stephanus » à Pompéi (I 6, 7).

Fig. 98. Stalles de foulage de la fullonica VI 14, 21-22 à Pompéi.

Fig. 99. Fullonica «de Stephanus» (Pompéi, I 6, 7), angle sud-ouest de la zone de foulerie.

Fig. 100. Fullonica «de Stephanus " (Pompéi, I 6, 7), paroi sud et fond du second bassin de rinçage.

Fig. 101. Casa della fullonica (Herculanum, IV, 7), pièce 9.

Fig. 102. Casa della fullonica (IV, 7), pièce 9; cliché Archivio fotografico SANP, n A2615, daté de 1941.

Fig. 103. Casa a graticcio (III, 13-15), pièce 13, vestiges de deux aménagements dans l'angle nord-ouest de la pièce. 
Fig. 104. Boutique III, 10 à Herculanum, vue du plateau et de la maie de la presse.

Fig. 105. Boutique III, 10, vue de la presse restaurée.

Fig. 106. Représentation de la presse à vêtements sur la fresque de la fullonica de L. Veranius Hypsaeus (Pompéi, VI 8, 2.20-21); MANN, Inv. nº 9774.

Fig. 107. Fullonica "de Stephanus» (Pompéi, I 6, 7), entrée, mur oriental, traces de la presse à vêtements.

Fig. 108. Restitution de la presse de la fullonica «de Stephanus» (Pompéi, I 6, 7); d'après Spinazzola 1953.

Fig. 109. Restitutions isométriques des presses à vis de la fullonica de «Stephanus» (Pompéi, I 6, 7) et de la boutique III, 10 à Herculanum; échelle: 1/40.

Fig. 110. Façade de l'Insula Orientalis II ${ }^{a}$ en cours de fouille; cliché Archivio fotografico SANP E/C 217, 1932.

Fig. 111. Façade nord-orientale de la Casa del tramezzo di legno (Herculanum, III, 9.10); mosaïque d'orthophotographies et schéma d'interprétation; échelle: 1/100.

Fig. 112. Répartition des différents types de maçonnerie dans l'Insula Orientalis $I I^{a}$ (Herculanum); échelle: $1 / 1000$.

Fig. 113. Aula absidata dans la «Palestre» (Herculanum, Or. II, 4).

Fig. 114. Montant nord est de la pièce II dans la «Palestre» (Herculanum, Or. II, 4).

Fig. 115. Mur de séparation entre le pronaos et la salle L dans l'Insula Orientalis II ${ }^{a}$ (Herculanum, Or. II, 4).

Fig. 116. Évolution des relations entre la salle $\mathrm{L}$ et le pronaos de l'Aula absidata (Herculanum, Or. II, 4).

Fig. 117. Façade de l'Insula orientalis $I I^{a}$ entre les locaux Or. II, 8 et Or. II, 9 à Herculanum.

Fig. 118. Étapes de la construction d'un mur dans la Casa del priapo (Herculanum, IV, 17-18).

Fig. 119. Tableau récapitulatif des chronologies d'utilisation des types de construction à Herculanum.

Fig. 120. Cardo V vu depuis le sud-est à Herculanum.

Fig. 121. Partie ouest du cryptoportique donnant sur de la terrasse inférieure de l'Insula orientalis $I^{a}$ à Herculanum.

Fig. 122. Mur sud de la pièce 19-3, loggia de l'Insula orientalis $I^{a}{ }^{a}$ à Herculanum.

Fig. 123. Insula orientalis $I I^{a}$, pièce B, mur sud (Herculanum).

Fig. 124. Insula orientalis $I I^{a}$, pièce 1a-8, mur ouest (Herculanum). Fresque de III ${ }^{\mathrm{e}}$ style.

Fig. 125. Insula orientalis $I I^{a}$, pièce 7-4, mur sud (Herculanum).

Fig. 126. Insula orientalis $I I^{a}$, pièce A, mur nord (Herculanum).

Fig. 127. Insula orientalis $I I^{a}$, pièce 1a-10, mur nord (Herculanum).

Fig. 128. Façade de l'entrée Or. II, 2 à Herculanum.

Fig. 129. Porte bouchée dans la paroi nord de la pièce 1a-4 de l'Insula orientalis II ${ }^{a}$ (Herculanum).

Fig. 130. Insula orientalis $I I^{a}$, péristyle méridional, mur ouest (Herculanum).

Fig. 131. Façade du local Or. II, 13 à Herculanum.

Fig. 132. Tableau de répartition des boutiques de l'Insula Orientalis $I I^{a}$ en fonction des espaces dont elles disposent.

Fig. 133. Évolution des fonctions des différents espaces de l'aile occidentale de l'Insula Orientalis $I^{a}$ (échelle: 1/1000).

Fig. 134. Insula Orientalis $I I^{a}$ - transformations consécutives au séisme de 62 (échelle: 1/500).

Fig. 135. Insula orientalis $I I^{a}$, pièce 18-5, mur est (Herculanum); porte bouchée vers la pièce 19-4.

Fig. 136. Insula orientalis $I I^{a}$, pièce 8-2, mur sud (Herculanum).

Fig. 137. Insula Orientalis $I I^{a}$ - transformations consécutives au second séisme (ca. 70/75; échelle: $1 / 500)$.

Fig. 138. Insula orientalis $I I^{a}$, pièce 7-3, côté ouest. Vestiges de maçonneries non restaurées lors de la fouille (Herculanum).

Fig. 139. Insula orientalis $I I^{a}$, pièce 7-3, mur est (Herculanum).

Fig. 140. Insula orientalis $I I^{a}$, pièce 8-2, étage, angle sud-est (Herculanum).

Fig. 141. Boutique Or. II, 16, local principal (Herculanum).

Fig. 142. Atelier Or. II, 18, pièce 18-4, mur sud (Herculanum).

Fig. 143. Insula III - phase pré-romaine (échelle: 1/400).

Fig. 144. Insula III - phase pré-augustéenne (échelle: 1/400).

Fig. 145. Boutique III, 6 à Herculanum.

Fig. 146. Insula III - phase augustéenne (échelle: 1/400).

Fig. 147. Insula III - phase post-augustéenne (échelle: 1/400).

Fig. 148. Insula III - 62 - ca. 70/75 (échelle: 1/400). 
Fig. 149. Casa a graticcio (III, 13-15), pièce 12, mur sud (Herculanum).

Fig. 150. Insula III - ca. 70/75 - 79 (échelle: 1/400).

Fig. 151. Insula IV - phase pré-romaine (échelle: 1/400).

Fig. 152. Insula IV - première phase pré-augustéenne (échelle: 1/400).

Fig. 153. Casa del papiro dipinto (IV, 8-9), pièce 4, mur nord (Herculanum).

Fig. 154. Insula IV - seconde phase pré-augustéenne (échelle: 1/400).

Fig. 155. Insula IV - phase augustéenne (échelle: 1/400).

Fig. 156. Grande taberna con abitazione (IV, 12-16), pièces 1 et 2, mur ouest (Herculanum).

Fig. 157. Insula IV - 62 - ca. 70/75 (échelle: 1/400).

Fig. 158. Insula IV - ca. 70/75 - 79 (échelle: 1/400).

Fig. 159. Casa della fullonica (IV, 5-7), pièce 6, mur est (Herculanum).

Fig. 160. Casa della fullonica (IV, 5-7), pièce 7, mur est (Herculanum).

Fig. 161. Grande taberna con abitazione (IV, 12-16), boutique IV, 15-16 (Herculanum).

Fig. 162. Insula $\mathrm{V}$ - phase pré-romaine (échelle: 1/400).

Fig. 163. Casa del gran portale (V, 34-35), boutique V, 34, mur est (Herculanum).

Fig. 164. Insula V - moitié méridionale - phase augustéenne (échelle: 1/400).

Fig. 165. Casa del telaio (V, 3), pièce B mur nord (Herculanum); schéma d'interprétation proposé par Th. Ganschow (1989: fig. 22) et nouveau schéma d'interprétation.

Fig. 166. Seuils V, 33a et V, 33, Casa con giardino à Herculanum.

Fig. 167. Insula V - moitié méridionale - phase post-augustéenne (échelle: 1/400).

Fig. 168. Insula V - moitié méridionale - 62 - ca. $70 / 75$ (échelle: 1/400).

Fig. 169. Casa del gran portale (V, 34-35), pièce 9, mur nord (Herculanum).

Fig. 170. Insula V - moitié méridionale - ca. 70/75 - 79 (échelle: 1/400).

Fig. 171. Casa del telaio (V, 3), pièce I, mur sud (Herculanum).

Fig. 172. Insula V - moitié septentrionale - phase pré-augustéenne (échelle: 1/400).

Fig. 173. Insula V - moitié septentrionale - phase augustéenne (échelle: 1/400).

Fig. 174. Insula V - moitié septentrionale - phase post-augustéenne (échelle: 1/400).

Fig. 175. Insula V - moitié septentrionale - 62 - ca. 70/75 (échelle: 1/400).

Fig. 176. Casa dell'Apollo citaredo (V, 9-12), boutique V, 9-10, mur sud (Herculanum).

Fig. 177. Casa del bicentenario (V, 13-16), jardin, angle sud-ouest (Herculanum).

Fig. 178. Casa del bicentenario (V, 13-16), pièce 10, angle nord-est (Herculanum).

Fig. 179. Casa del bicentenario (V, 13-16), boutique V, 16, murs est, sud et ouest (Herculanum).

Fig. 180. Insula V - moitié méridionale - ca. $70 / 75$ - 79 (échelle: 1/400).

Fig. 181. Casa del bel cortile (V, 8), pièce 4, montant ouest (Herculanum).

Fig. 182. Casa di Nettuno e Anfitrite (V, 6-7), atrium, murs ouest et nord (Herculanum).

Fig. 183. Insula VI - phase pré-romaine (échelle: 1/400).

Fig. 184. Insula VI - phase pré-augustéenne (échelle: 1/400).

Fig. 185. Insula VI - phase augustéenne (échelle: 1/400).

Fig. 186. Relevé des parois de la cuve mise au jour dans la boutique VI, 15 à Herculanum; échelle: 1/25.

Fig. 187. Insula VI - seconde phase post-augustéenne (échelle: 1/400).

Fig. 188. Insula VI - 62 - ca. 70/75 (échelle: 1/400).

Fig. 189. Casa del salone nero, pièce N, mur est (Herculanum).

Fig. 190. Atelier VI, 12, angle rentrant au sud-ouest (Herculanum).

Fig. 191. Façade orientale des thermes, entrées VI, 9 et VI, 10 (Herculanum).

Fig. 192. Insula VI - ca. 70/75 - 79 (échelle: 1/400).

Fig. 193. Formes de l'occupation du sol à Herculanum durant la période augustéenne.

Fig. 194. Tableau récapitulatif de l'évolution des surfaces d'Herculanum. Les valeurs en italique correspondent au nombre minimal de boutiques, le double encadrement inclut les parcelles publiques.

Fig. 195. Courbes d'évolution de l'occupation du sol dans l'ensemble des édifices étudiés, surfaces cumulées (indiquées en mètres carrés).

Fig. 196. Courbes d'évolution de l'occupation du sol dans l'ensemble des édifices étudiés, pourcentages cumulés.

Fig. 197. Évolution du nombre de boutiques à Herculanum, par phase.

Fig. 198. Courbes d'évolution de la part des commerces dans l'occupation du sol à Herculanum.

Fig. 199. Courbes d'évolution du nombre de parcelles et d'unités indépendantes à Herculanum.

Fig. 200. Évolution des surfaces de rapport et des surfaces en location à Herculanum. 
Fig. 201. Évolution de la gestion directe des activités commerciales (rapport entre les surfaces louées et les surfaces de rapport) à Herculanum.

Fig. 202. Évolution du nombre et de la surface des boutiques indépendantes à Herculanum.

Fig. 203. Courbes d'évolution du nombre de parcelles et d'unités indépendantes à Herculanum.

Fig. 204. Plan de l'Abitazione e botteghe (II, 6-7) et de sa boutique (échelle: 1/200).

Fig. 205. Plan de la Casa del tramezzo di legno (III, 4-12), de son atelier et de ses trois boutiques (échelle: $1 / 200)$.

Fig. 206. Plan de la Casa a graticcio (III, 13-15) et de sa boutique (échelle: 1/200).

Fig. 207. Plan de la Casa della fullonica (IV, 5-7) et de son atelier (échelle: 1/200).

Fig. 208. Plan de la Bottega con abitazione (IV, 10-11) et de sa boutique (échelle: 1/200).

Fig. 209. Plan de la Grande taberna con abitazione (IV, 12-16) et de ses boutiques (échelle: 1/200).

Fig. 210. Plan de la Casa del priapo (IV, 17-18) et de sa boutique (échelle: 1/200).

Fig. 211. Plan de la Casa del telaio (IV, 3 ; échelle: 1/200).

Fig. 212. Plan de la Casa di Nettuno e Anfitrite (V, 6-7) et de sa boutique (échelle: 1/200).

Fig. 213. Plan de la Casa dell'Apollo citaredo (V, 9-12) et de ses boutiques (échelle: 1/200).

Fig. 214. Plan de la Casa del bicentenario (V, 13-16) et de ses boutiques (échelle: 1/200).

Fig. 215. Plan et écorché isométrique des appartements V, 17 et V, 18 (échelle: 1/200).

Fig. 216. Plan des Botteghe sul decumano massimo (V, 19-22) et de la Casa della colonna laterizia (V, 23-25) et de leurs boutiques (échelle: 1/200).

Fig. 217. Plan de la Taberna con abitazione (V, 26-27) et de sa boutique (échelle: 1/200).

Fig. 218. Plan de la Taberna con abitazione (V, 28-29) et de sa boutique (échelle: 1/200).

Fig. 219. Plan de la Casa con giardino (V, 32-33) et de sa boutique (échelle: 1/200).

Fig. 220. Plan de la Casa del gran portale (V, 34-35) et de sa boutique (échelle: 1/200).

Fig. 221. Plan des thermes (VI, 1.4-6.7-10.30), de sa boutique et de son atelier (échelle: 1/250).

Fig. 222. Plan de la Casa del salone nero (VI, 11-15), de son atelier et de ses boutiques (échelle: 1/200).

Fig. 223. Plan de la Casa del colonnato tuscanico (VI, 16-19.25-27) et de ses boutiques (échelle: 1/200).

Fig. 224. Plan de la Casa di C. Messenius Eunomus (VII, 1-1b) et de sa boutique (échelle: 1/200).

Fig. 225. Plan de la Casa di Galba (VII, 2-6) et de sa boutique (échelle: 1/200).

Fig. 226. Plan de l'Insula Orientalis $I^{a}$ - bloc méridional (Or. II, 1a à 3), de son atelier et de ses boutiques (échelle: 1/200).

Fig. 227. Plan de l'Insula Orientalis II ${ }^{a}$ - bloc central (Or. II, 5 à 9), de ses ateliers et de ses boutiques (échelle: 1/200).

Fig. 228 Plan de l'Insula Orientalis $I I^{a}$ - bloc septentrional (Or. II, 10 à 18), de ses ateliers et de ses boutiques (échelle: 1/200).

Dépliants hors-texte

I. Proposition de restitution de l'Insula Orientalis $I^{a}$ lors de sa construction originelle, avec indication des étages; échelle: 1/500.

II. Transformations de l'Insula Orientalis $I I^{a}$ transformations consécutives au second séisme (ca. 70/75) avec indication des étages; échelle: 1/500.

III. Planimétrie générale d'Herculanum; échelle: 1/1000 (ajouts au relevé de F. Ferrajoli et numérisation réalisés par U. Pastore, SANP).

IV. Comparaison des commerces et espaces de production dans les tissus urbains d'Herculanum (d'après plan F. Ferrajoli, complété avec les relevés du XVIII' s.) et de Pompéi (d'après plan $\mathrm{H}$. Eschebach, complété avec les résultats de prospection électrique publiés dans Anniboletti - Befani - Boila 2009); échelle: 1/5000.

V. Nomenclature de l'Insula Orientalis $I I^{a}$; échelle: 1/500.

VI. Nomenclature de l'Insula III; échelle: 1/400.

VII. Nomenclature de l'Insula IV; échelle: 1/400.

VIII. Nomenclature de l'Insula V; échelle: 1/400.

IX. Nomenclature de l'Insula VI; échelle: 1/400. 
INDEX 



\section{INDEX DES SOURCES ANTIQUES}

Les indications de pagination en italique renvoient à des mentions sans citation.

SOURCES ÉPIGRAPHIQUES

$A E$

$1902,40: 235$

1937, 176: 26, 360

$1945,95: 26,360$

1947, 53:24, 245, 265

1960, 277: 245

1967, 86 d: 56, 91

1976, 144: 24, 245, 265

1978, 119: 266

1979, 170: 235

1996, 409: 235

CIL

$\mathrm{I}^{2}, 1154: 48$

IV, $64: 48$

IV, 138: 47, 351

IV, $494: 220$

IV, $537: 220$

IV, $677: 154$

IV, 806: 56

IV, $807: 56$

IV, 1048: 220

IV, 1190: 170

IV, $1291: 98$

IV, 1493-1506: 176

IV, 1507: 175

IV, 1508-1509: 176

IV, 1569: 183

IV, 1570: 183

IV, $1571: 183$

IV, 3948: 98

IV, 4888: 132

IV, 5380: 132

IV, 5942: 79

IV, 6356: 79
IV, 6408: 79

IV, 7574: 51, 52

IV, 7809: 189

IV, 7838: 187

IV, 7839: 188

IV, 8380: 185

IV, $8381: 185$

IV, 8384: 185

IV, 8489: 127

IV, 8490: 127

IV, 8491: 127

IV, $8561: 132$

IV, 9108: 185

IV, 9109: 185

IV, 9764: 79

IV, 9765: 79

IV, 9850: 56, 91

IV, 10150: 220

IV, 10443: 79

IV, 10480: 331

IV, 10527: 78

IV, 10528-10545: 129

IV, 10664: 185

IV, 10722: 125, 126, 111

IV, 10761: 126

IV, 10766: 129

IV, 10767: 129

IV, 10770 a : 70

IV, $10770 \mathrm{c}: 110$

IV, 10784: 126

IV, 10785: 126

IV, 10786: 126

IV, 10787: 126

IV, 10788: 126

IV, 10794: 126 
IV, 10795: 79

IV, 10802: 79

IV, $10802 \mathrm{a}: 22$

IV, 10806: 79

IV, 10831: 129

IV, 10832: 129

IV, 10857: 126

IV, 10858 a: 126

IV, 10858 b: 126

IV, 10859: 126

IV, 10877: 126

IV, 10878: 107

IV, 10881: 126

IV, 10882 a: 126

IV, $10882 \mathrm{~b}: 126$

IV, 10889 a: 79

IV, 10889 b: 79

IV, 10890: 79, 126

IV, 10896: 129

IV, 10897: 242

IV, 10899: 126

IV, 10904: 242

IV, 10910: 242

IV, 10911: 242

IV, 10913: 126

$\mathrm{X}, 929: 267$

$\mathrm{X}, 932: 263$

$\mathrm{X}, 1136: 9,47$

$\mathrm{X}, 1403: 224,266$

$\mathrm{X}, 1406: 23,235,263,278$

$\mathrm{X}, 1412: 245$

$\mathrm{X}, 1413: 246$

$\mathrm{X}, 1416: 246$

$\mathrm{X}, 1417: 246$

$\mathrm{X}, 1418: 246$

$\mathrm{X}, 1419: 246$

Apulée

Met.

$10,13,3: 162$

$10,13,4: 162$

$2,15: 72$

7, 15, 3-5: 139

$9,10,5$ à $9,14,5: 139$

$9,12,1: 138$

9, 23, 2:134

9, 24, 2:193, 197

Cassiodore

Psalm. 14, 1: 46

Caton

Agr.

$74: 147$

$76,3: 143$
$\mathrm{X}, 1420: 246,266$

$\mathrm{X}, 1424: 245$

$\mathrm{X}, 1425: 266$

$\mathrm{X}, 1453: 245$

$\mathrm{X}, 1481: 235$

$\mathrm{X}, 8042,41: 259$

$\mathrm{X}, 8047: 103$

$\mathrm{X}, 8058,18: 152$

$\mathrm{X}, 8062,5 \mathrm{a}: 75,76$

$\mathrm{X}, 8062,5 \mathrm{~b}: 75$

$\mathrm{X}, 8067,5: 181$

$\mathrm{X}, 8067,6: 181$

$\mathrm{X}, 8339: 88$

\section{CVArrII}

$19,1: 81$

$279,2: 120$

$298,1: 124$

$298,2 / 8: 126$

$848: 130$

$848,1: 126$

1212: 130

$1342,14-16: 117$

1586 [?]: 130

1690, $42: 117$

$1690,48: 120$

$1839,9: 242$

ILLRP

1122: 48

ILS

74 a: 245

$250: 23,235,263,278$

$890: 245$

$5722: 9,47$

SouRCES LITTÉRAIRES ET JURIDIQUES

Cicéron

Att.

$14,9,1: I X, 46$

$14,10,3: 46$

Cat. 4, (VIII), 17: 43

Flac. 18: 43

Off. 1, 150:IX, 43, 219

Pis. 67: 105

pro Sylla 21, 60-62: 349

Digeste

4, 9, 5 pr.: 207

9, 1, 2 pr: : 207

$9,1,2,1: 45$

$12,7,2: 207$

$14,3,5,6: 207$

$14,3,5,10: 44,46,207$ 
$14,4,1,1: 207$

$19,2,13,6: 207$

$19,2,25,8: 207$

$19,2,31: 207$

$19,2,60,2: 207$

33, 7, 13 pr.: 105

47, 2, 12 pr. : 207

47, 2, 83 pr.: 207

47, 2, 91 pr.: 207

$50,16,183: 42$

$50,16,183.185: 46$

$50,16,184: 46$

$50,16,185: 43$

Festus

L. $490: 45$

Frontin

Aq. 94, 3-4: 195

Héron d'Alexandrie

Mec.

2, $4: 215$

$3,15: 213$

3, 16-17:215

3, 19: 212

3, $20: 216$

Horace

Ep. 14, 21 : IX

O. 1, 4, 13-14: 46

Isidore de Séville

Etym. 15, 2, $43: 46$

Martial

1, 56: 98

2, 43, 6:194, 213

2, $51: 98$

6, 93, 1-2: 194

7, 61: IX, 48

$11,8,5: 194,213$

14, $222: 162$

Ovide

Met. 6, 55-60: 179

Pline l'ancien

NH

8, 192: 187

$15,5: 215$

16, 244: 195

18, $104: 148$

$18,105: 145,148$
$18,108: 143$

$18,67: 148$

18, $68: 148$

$18,87: 136$

$18,89-90: 143$

18, 97-98: 134

24, 111: 195

$27,91: 195$

28, 174: 194

$28,66: 194$

$28,91: 194$

35, 175: 207

35, 196-198: 193

Pline le jeune

Ep.

$6,16,9: 11$

$6,20,3: 234$

Sénèque

$$
\begin{aligned}
& \text { Ben. 7, 21, 2: } 45 \\
& \text { Ep. } \\
& {[2,] 15,4: 194} \\
& {[6,] 56,2: I X} \\
& {[14,] 90,20: 179} \\
& {[14,] 90,23: 154} \\
& \text { Nat. } \\
& \text { 1, 3, 2: 195, } 213 \\
& \text { 6, 1, 1-2:234 } \\
& \text { Tranq. 1, 5: 194 }
\end{aligned}
$$

Suétone

Claud. 38, 4: IX

Nero

20, $3: 234$

26, 1: IX

Tacite

Ann.

$15,22: 234$

$15,34,1: 234$

Titinius

Fullones 5 (21-22): 194

Varron

L. 8, 30, 55: 43

R. 1, 2, 23: 44

Vitruve

$6,5,2: 44$

7, 10, 2:162 



\title{
INDEX DES SOURCES MODERNES
}

Les indications de pagination en italique renvoient à des mentions sans citation.

\author{
Ordre ChronologiQue
}

GSE

1869

13 maggio: 69 (Casa del tramezzo di legno)

1927

26 aprile: 81 (VI, 6)

6 giugno: 69 (Casa dello scheletro)

10 ottobre: 26 (Casa dello scheletro; Casa a graticcio)

14 ottobre: 204 (III, 15; Casa a graticcio)

20 ottobre: 204 (III, 15; Casa a graticcio)

26 ottobre: 27 (Casa a graticcio)

14 dicembre: 175 (Casa del tramezzo di legno)

20 dicembre: 28 (cardo IV)

1928

1 febbraio: 27 (généralités)

13 febbraio: 27 (Casa a graticcio)

17 febbraio: 175 (Casa a graticcio)

12 marzo: 28 (Casa a graticcio)

28 marzo: 34 (Casa dell'erma di bronzo)

30 marzo: 34 (Casa dell'ara laterizia)

14 aprile: 34 (Casa dell'ara laterizia)

17 aprile: 29, 32 (Casa a graticcio)

19 aprile: 30 (Casa a graticcio)

20 luglio: 206, 207 (III, 10; Casa del tramezzo di legno)

24 luglio: 206, 207 (III, 10; Casa del tramezzo di legno)

31 agosto: 151 (cardo IV)

4 ottobre: 30 (Casa a graticcio)

9 novembre: 30 (Casa a graticcio)

17 novembre: 30,30 (Casa a graticcio)

19 novembre: 31, 296 (Casa a graticcio)

27 novembre: 58 (IV, 7; Casa della fullonica)

1 dicembre: 28 (Casa a graticcio)

3 dicembre: 28 (Casa a graticcio)
11 dicembre: 31 (Casa a graticcio)

12 dicembre: 28, 31 (Casa a graticcio)

18 dicembre: 31 (Casa a graticcio)

27 dicembre: 60 (III, 15; Casa a graticcio)

28 dicembre: 28 (Casa a graticcio)

1929

5 gennaio: 31,83 (III, 15; Casa a graticcio)

9 gennaio: 31 (Casa a graticcio)

15 febbraio: 34 (Casa dell'erma di bronzo)

23 febbraio: 28, 34, 83, 204 (Casa a graticcio)

4 marzo: 139 (Casa dell'atrio a mosaico)

4 aprile: 152 (Casa dell'ara laterizia)

27 maggio: 93 (III, 6; Casa del tramezzo di legno),

57, 207 (III, 10; Casa del tramezzo di legno)

31 luglio: 139 (Casa dell'atrio a mosaico)

27 novembre: 90 (IV, 10)

1930

22 ottobre: 175 (Casa dei cervi)

24 novembre: 69 (Casa dei cervi) 1931

3 febbraio: 360 (Casa del telaio)

22 agosto: 58, 60 (V, 3 ; Casa del telaio)

5 settembre: 60 (V, 3 ; Casa del telaio)

11 novembre: 179 (Casa della stoffa)

24 novembre: 90, 129 (IV, 15-16; Grande taberna con abitazione)

3 dicembre: 24, 264 (Temple de Cybèle [Or. II, 4])

10 dicembre: 110 (IV, 17; Casa del Priapo)

11 dicembre: 110, 111 (IV, 17; Casa del Priapo)

15 dicembre: 70 (IV, 17 ; Casa del Priapo)

18 dicembre: 203 (Casa della fullonica)

21 dicembre: 110 (IV, 17; Casa del Priapo) 1932

13 gennaio: 70 (IV, 17 ; Casa del Priapo)

14 gennaio: 70, 110 (IV, 17 ; Casa del Priapo) 
20 gennaio: 22 (Casa del Priapo)

25 gennaio: 78, 79, 106, 129 (IV, 15-16; Grande taberna con abitazione)

30 gennaio: 79 (IV, 14; Grande taberna con abitazione)

2 febbraio: 78 (IV, 14; Grande taberna con abitazione)

4 febbraio: 150 (V, 6; Casa di Nettuno e Anfitrite)

11 febbraio: 69 (IV, 15-16; Grande taberna con abitazione)

26 febbraio: 110, 108 (Casa del Priapo)

29 febbraio: 107 (IV, 15-16; Grande taberna con abitazione)

2 marzo: 82 (IV, 13; Grande taberna con abitazione)

12 marzo: 70, 108, 110, 111 (IV, 17; Casa del Priapo)

29 marzo: 203 (Casa della fullonica)

7 aprile: 57 (Or. II, 1b; Or. II, 1), 282 (Or. II, 3)

30 aprile: 190 (Or. II, 5)

5 luglio : 172 (cardo III)

7 novembre: 23 (Casa di Nettuno e Anfitrite) 1933

21 gennaio: 21 (Casa del telaio)

[description insérée après le compte rendu du mois de janvier]: 82 (Casa del gran portale), 20 (Casa del telaio)

1 febbraio: 71 (V, 6; Casa di Nettuno e Anfitrite)

1 marzo: 330 (Casa di Nettuno e Anfitrite)

17 marzo: 117 (Or. II, 6)

[description insérée après le compte rendu du mois d'avril]: 69 (Casa del mobilio carbonizzato)

6 maggio: 57, 90, 94, 99 (V, 6; Casa di Nettuno e Anfitrite)

5 giugno: 50 (Cardo V; Decumano massimo)

4 agosto: $83(\mathrm{~V}, 25)$

13 settembre: 94, 107 (Or. II, 6)

6 settembre: 90, 94, 117 (Or. II, 6) 1934

22 aprile: 69 (Casa della gemma)

[description insérée après le compte rendu du mois de juin]: 70, 330 (V, 6 ; Casa di Nettuno e Anfitrite)

1935

4 luglio: 269 (Temple de Cybèle [Or. II, 4])

11 luglio: 155 (Or. II, 1a)

13 luglio: 157 (Or. II, 1a)

22 luglio: 159 (Or. II, 1a)

9 agosto: 139 (Or. II, 1a)

1936

8 gennaio: 126 (Temple de Cybèle [Or. II, 4])

13 febbraio: 125 (Or. II, 9)

24 marzo: 125 (Or. II, 9)

14 giugno: 126 (vicolo au sud de l'Ins. Or. II)

[description insérée après le compte rendu du mois de juin]: 125 (Or. II, 6; Or. II, 7; Or. II, 8)

8 luglio: 282 (Or. II, 7)
14 luglio: 126 (Or. II, 9)

5 agosto: 21 (Or. II, 10)

7 agosto: 21 (Sud de la ville)

21 agosto: 22 (Or. II, 10)

24 settembre: 103 (Or. II, 13)

30 settembre: 139 (Or. II, 11)

8 ottobre: 21 (Or. II, 10)

16 ottobre: 192 (Or. II, 11)

22 ottobre: 100, 103 (Or. II, 13)

26 novembre: 24 (Temple de Cybèle [Or. II, 4])

2 dicembre: 242 (Temple de Cybèle [Or. II, 4])

31 dicembre: 63, 70, 125 (Or. II, 9)

1937

29 aprile: 285 (Or. II, 15)

30 giugno: 280 (Or. II, 15; Temple de Cybèle [Or. II, 4])

1 luglio: 280 (Or. II, 15; Temple de Cybèle [Or. II, 4])

7 luglio: 280 (Or. II, 15; Temple de Cybèle [Or. II, 4])

18 settembre: 51 (Decumano massimo)

9 novembre: $86(\mathrm{~V}, 18)$

$1937 *$

22 novembre: 16 (Casa del bel cortile)

1938

3 gennaio: $85(\mathrm{~V}, 17)$

21 febbraio: 332 (V, 24; Casa della colonna laterizia)

1 marzo: $74,86(\mathrm{~V}, 17)$

8 aprile: $86(\mathrm{~V}, 17)$

14 aprile: $86(\mathrm{~V}, 17)$

[description insérée après le compte rendu du mois d'avril]: 69, $332(\mathrm{~V}, 19 ; \mathrm{V}, 20)$

5 settembre: 90, 123 (V, 9-10; Casa dell'Apollo citaredo) $1938 *$

3 febbraio: 20 (Casa del bicentenario) 1939

21 marzo: 345 (Casa del salone nero)

22 marzo: 68 (V, 12; Casa dell'Apollo citaredo)

31 marzo: 16 (Casa del bel cortile; Casa del bicentenario)

11 aprile: 68 (V, 12; Casa dell'Apollo citaredo)

2 giugno: 71 (Casa del salone nero)

3 giugno: 69 (Casa del salone nero)

10 luglio: 338 (Casa del salone nero)

29 settembre: 69 (Casa del salone nero) 1940

3 marzo: 69 (Casa di M. Pilus Primigenius Granianus)

29 aprile: 150 (Casa di M. Pilus Primigenius Granianus)

1956

12 agosto: 281 (Temple de Cybèle [Or. II, 4])

1960

25 ottobre: 172 (VII, 12)

26 ottobre: 172 (VII, 12) 
13 dicembre: 81 (VI, 25; Casa del colonnato tuscanico)

22 dicembre: 81 (VI, 25; Casa del colonnato tuscanico)

23 dicembre: 81 (VI, 25; Casa del colonnato tuscanico)

1961

12 luglio: 70 (VI, 12; Casa del salone nero)

18 agosto: 49,50 (VI, 14)

8 agosto: 58, 75, 75 (DM 2O)

19 settembre: 69 (VI, 18; Casa del colonnato tuscanico)

25 settembre: 80, 90, 93, 107, 121, 123 (VI, 19;

Casa del colonnato tuscanico)

GSP

1771

19 gennaio (PAH I, $1: 248$ ): 183 (VI 1, 7 [?])

1789

12 marzo (PAH I, 2: 44-45): 99 (VI 1, 18-20)

1818

11 giugno (PAH III: 15): 77 (tronçon occidental du vicolo degli Augustali)

13 giugno (PAH I, 3: 205): 77 (tronçon occidental du vicolo degli Augustali)

14 luglio (PAH I, 3: 208): 77 (VII 9 [flanc du macellum])

28 luglio (PAH I, 3: 209): 77 (VII 9 [flanc du macellum])

1 agosto (PAH III: 16): 77 (VII 9 [flanc du macellum])

23 settembre (PAH III : 17): 78 (VII 4, 15-16)

1820

16 novembre (PAH II : 28) : 183 (VII 9, 47)

18 novembre (PAH III : 26): 183 (VII 9, 47)

1821

6 ottobre (PAH II : 40-41): 128 (VII 13)

novembre (PAH II : 43-44): 128 (VII 13, 24)

1824

7 agosto (PAH II: 111): 74 (VII 5, 2.7-8.10.12.24)

23 agosto (PAH II: 112-113): 74 (VII 5, 2.7-

$8.10 .12 .24)$

12 settembre (PAH II: 114): 74 (VII 5, 2.7-

8.10.12.24)

4 dicembre (PAH II: 121): 74 (VII 5, 2.7$8.10 .12 .24)$

1826

[s.d., antérieur au 5 mars] (PAH II: 145): 196 (VI $8,2.20-21)$

3 giugno (PAH II : 162): 210 (VI 8, 2.20-21)

15 giugno (PAH II: 164): 210 (VI 8, 2.20-21)

30 giugno (PAH II: 165): 209 (VI 8, 2.20-21)

1827

10 gennaio (PAH III: 74): 196 (VI 8, 2.20-21)

1829

27 febbraio (PAH II: 219): 77 (VII 5, 29)
1830

31 marzo (PAH II : 236) : 183 (VI 9, 7)

1841

21 giugno (PAH II : 398-399): 128 (VIII 5, probable commerce alimentaire)

3 luglio (PAH II : 387-399): 74 (VIII 5, 8 / 10 / 11)

1862

9 agosto: 158 (VII 1, 36-37)

14 agosto: 78 (VII 2, 52)

23 settembre: 128 (IX 2, 9)

24 settembre: 128 (IX 2, 9)

1868

30 maggio (GSPomp 1868: 48): 139 (VII 2, 3.6)

1869

6 febbraio (GSPomp 1868: 245): 170 (I 3, 15)

1870

10 marzo (GSPomp 1873: 170): 183 (IX 2, 5)

1872

7 marzo (GSPomp 1873: 416): 183 (VII 15, 8)

1873

30 dicembre (GSPomp 1874: 93): 183 (I 2, 27-29)

1875

1 aprile (GSPomp 1874: 171): 198 (VI 14, 21-22)

1 aprile (GSPomp 1874: 171): 202 (VI 14, 21-22)

1911

dicembre: 90 (IX 11, 2)

1912

[annotations lacunaires]: 118, 119 (IX 11, 2)

13 maggio: 183 (I 6, 10)

1924

12 aprile: 128 (I 7, 4)

1927

18 aprile: 66 (I 6,11$)$

2 giugno: 66 (I 6,11$)$

16 agosto: 66 (I 6, 8-9)

24 agosto: 65 (I 6, 8-9)

15 settembre: 182 (I 6, 10), 183 (I 9, 10)

1932

7 luglio: 98, 106 (I 10, 13)

28 novembre: 185 (I 10, 8)

1933

19 giugno: 96, 106 (I 19, 1-2)

1935

25 novembre: 125 (I 7, 13-14)

1936

[annotations lacunaires]: 124 (I 7, 13-14)

27 febbraio: 124 (I 7, 13-14)

28 febbraio: 96 (I 7, 13-14)

2 marzo: 124 (I 7, 13-14)

5 marzo: 124 (I 7, 13-14)

1939

7 marzo: 116 (I 8, 8-9)

15 giugno: 115 (I 8, 8-9)

23 maggio: 116 (I 8, 8-9)

25 maggio: 115 (I 8, 8-9)

27 maggio: 107 (I 8, 8-9)

29 maggio: 108, 116 (I 8, 8-9) 
30 maggio: 107 (I 8, 8-9)

31 maggio: 107 (I 8, 8-9)

1 giugno: 116 (I 8, 8-9)

1961

13 marzo: 139 (I 12, 1-2)

14 marzo: 139 (I 12, 1-2)

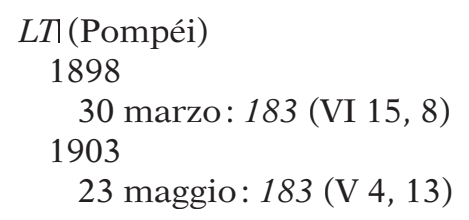

1904

21 dicembre: 183 (VI 16, 26)

1918

12 giugno: 183 (III 4, a/b)

1953

13 gennaio: 183 (II 3, 3)

16 gennaio: 183 (II 3,3 )

1955

14 dicembre: 183 (I 13, 2)

1962

16 gennaio: 183 (VII 16, 19)

ORDRE TOPOGRAPHIQUE

Herculanum

Insula III

Casa dello scheletro (III, 3 )

GSE 1927, 6 giugno: 69 ; 10 ottobre: 26

Casa del tramezzo di legno (III, 4-6.8-9.11)

GSE 1869, 13 maggio: 69

GSE 1927, 14 dicembre: 175

III, 6 [Casa del tramezzo di legno]

GSE 1929, 27 maggio: 93

III, 10 [Casa del tramezzo di legno]

GSE 1928, 20 luglio: 206, 207; 24 luglio: 206, 207

GSE 1929, 27 maggio: 57, 207

Casa a graticcio (III, 13.14.15)

GSE 1927, 10 ottobre: 26; 26 ottobre: 27

GSE 1928, 13 febbraio: 27; 17 febbraio: 175; 12 marzo: 28; 17 aprile: 29, 32; 19 aprile: 30; 4 ottobre: 30 ; 9 novembre: 30 ; 17 novembre: 30; 19 novembre: 31,$296 ; 1$ dicembre: $28 ; 3$ dicembre: 28 ; 11 dicembre: $31 ; 12$ dicembre: 28, $31 ; 18$ dicembre: $31 ; 28$ dicembre: 28

GSE 1929, 5 gennaio: 31; 9 gennaio: $31 ; 23$ febbraio: $28,34,83,204$

III, 15 [Casa a graticcio]

GSE 1927, 14 ottobre: 204; 20 ottobre: 204

GSE 1928, 27 dicembre: 60

GSE 1929, 5 gennaio: 83

Casa dell'erma di bronzo (III, 16)

GSE 1928, 28 marzo : 34

GSE 1929, 15 febbraio: 34

Casa dell'ara laterizia (III, 17)

GSE 1928, 30 marzo: 34 ; 14 aprile: 34

GSE 1929, 4 aprile: 152

Insula IV

Casa dell'atrio a mosaico (IV, 4)

GSE 1929, 4 marzo: 139; 31 luglio: 139

Casa della fullonica (IV, 6-7)

GSE 1931, 18 dicembre: 203

GSE 1932, 29 marzo: 203

IV, 7 [Casa della fullonica]

GSE 1928, 27 novembre: 58
IV, 10

GSE 1929, 27 novembre: 90

Grande taberna con abitazione (IV, 12-13.15-16)

GSE 1932, 2 marzo: 82

IV, 14

GSE 1932, 25 gennaio: 78, 79; 30 gennaio: 79; 2 febbraio: 78

IV, 15-16 [Grande taberna con abitazione]

GSE 1931, 24 novembre: 90, 129

GSE 1932, 25 gennaio: 106, 129; 11 febbraio: 69; 29 febbraio: 107

Casa del Priapo (IV, 17-18)

GSE 1932, 14 gennaio: 110; 20 gennaio: 22; 26 gennaio: 108; 12 marzo: 108, 110

IV, 17 [Casa del Priapo]

GSE 1931, 10 dicembre: 110; 11 dicembre: 110, $111 ; 15$ dicembre: $70 ; 21$ dicembre: 110

GSE 1932, 13 gennaio: 70; 14 gennaio: 70; 26 febbraio: 110; 12 marzo: 70, 110, 111

Casa della stoffa (IV, 20)

GSE 1931, 11 novembre: 179

Casa dei cervi (IV, 21)

GSE 1930, 22 ottobre: $175 ; 24$ novembre: 69

Insula $\mathrm{V}$

Casa del telaio $(\mathrm{V}, 3)$

GSE 1931, 3 febbraio: 360; 22 agosto: 58, 60

GSE 1931, 5 settembre: 60

GSE 1933, 21 gennaio: 21

GSE 1933, 31 gennaio: 20

Casa del mobilio carbonizzato (V, 5)

GSE 1933, 30 aprile: 69

Casa di Nettuno e Anfitrite (V, 6-7)

GSE 1932, 7 novembre: 23

GSE 1933, 1 marzo : 330

GSE 1934, 30 giugno: 330

V, 6 [Casa di Nettuno e Anfitrite]

GSE 1932, 4 febbraio: 150

GSE 1933, 1 febbraio: 71; 6 maggio: 57, 90, 94, 99

GSE 1934 [description insérée après le compte rendu du mois de janvier]: 70 
Casa del bel cortile (V, 8) GSE 1937*, 22 novembre: 16

GSE 1939, 31 marzo: 16

V, 9-10 [Casa dell'Apollo citaredo]

GSE 1938, 5 settembre: 90, 123

V, 12 [Casa dell'Apollo citaredo]

GSE 1939, 22 marzo: 68; 11 aprile: 68

Casa del bicentenario (V, 15-16)

GSE 1938*, 3 febbraio: 20

GSE 1939, 31 marzo: 16

$\mathrm{V}, 17$

GSE 1938, 3 gennaio: 85; 1 marzo: 74, 86; 8 aprile: $86 ; 14$ aprile: 86

$\mathrm{V}, 18$

GSE 1937, 9 novembre: 86

$\mathrm{V}, 19$

GSE 1938, 30 aprile: 332, 69

$\mathrm{V}, 20$

GSE 1938, 30 aprile: 332

Casa della colonna laterizia $(\mathrm{V}, 24)$

GSE 1938, 21 febbraio: 332

$\mathrm{V}, 25$

GSE 1933, 4 agosto: 83

Casa del gran portale (V, 35)

GSE 1933, 31 gennaio: 82

Insula VI

VI, 6

GSE 1927, 26 aprile: 81

Casa del salone nero (VI, 11.13)

GSE 1939, 21 marzo: 345 ; 2 giugno: 71 ; 3 giugno: $69 ; 10$ luglio: $338 ; 29$ settembre: 69

VI, 12 [Casa del salone nero] GSE 1961, 12 luglio: 70

VI, 14 [Casa del salone nero] GSE 1961, 18 agosto: 49, 50

VI, 18 [Casa del colonnato tuscanico] GSE 1961, 19 settembre: 69

VI, 19 [Casa del colonnato tuscanico] GSE 1961, 25 settembre: 80, 90, 93, 107, 121, 123

VI, 25 [Casa del colonnato tuscanico]

GSE 1960, 13 dicembre: 81; 22 dicembre: 81; 23 dicembre: 81

\section{Insula VII}

VII, 12

GSE 1960, 25 ottobre: 172; 26 ottobre: 172

Insula Orientalis $I^{a}$

Casa della gemma (Or. I, 1)

GSE 1934, 22 aprile: 69

Casa di M. Pilus Primigenius Granianus (Or. I, 1a) GSE 1940, 3 marzo: 69; 29 aprile: 150

Insula Orientalis $I I^{a}$

Or. II, 1

GSE 1932, 7 aprile: 57
Or. II, $1 \mathrm{a}$

GSE 1935, 11 luglio: 155 ; 13 luglio: 157 ; 22 luglio: $159 ; 9$ agosto: 139

Or. II, $1 \mathrm{~b}$

GSE 1932, 7 aprile: 57

Or. II, 3

GSE 1932, 7 aprile: 282

Templum matris deum (temple de Cybèle, accès en Or. II, 4)

GSE 1931, 3 dicembre: 24, 264

GSE 1935, 4 luglio: 269

GSE 1936, 8 gennaio: 126; 26 novembre: 24; 2 dicembre: 242

GSE 1956, 12 agosto: 281

Templum matris deum (temple de Cybèle, accès condamné par Or. II, 15)

GSE 1937, 30 giugno: 280; 1 luglio: 280; 7 luglio: 280

Or. II, 5

GSE 1932, 30 aprile: 190

Or. II, 6

GSE 1933, 17 marzo: 117; 13 settembre: 94, 107 ; 6 settembre: $90,94,117$

GSE 1936, 30 giugno: 125

Or. II, 7

GSE 1936, 30 giugno: 125; 8 luglio: 282

Or. II, 8

GSE 1936, 30 giugno: 125

Or. II, 9

GSE 1936, 13 febbraio: 125; 24 marzo: 125;

14 luglio: 126 ; 31 dicembre: 63, 70, 125

Or. II, 10

GSE 1936, 21 agosto: 22 ; 5 agosto: 21 ; 8 ottobre: 21

Or. II, 11

GSE 1936, 30 settembre: 139; 16 ottobre: 192

Or. II, 13

GSE 1936, 24 settembre: 103; 22 ottobre: 100, 103

Or. II, 15

GSE 1937, 29 aprile: 285; 30 giugno: 280; 1 luglio: 280 ; 7 luglio: 280

Côté septentrional du decumanus maximus

DM, $2 \mathrm{O}$

GSE 1961, 8 agosto: 58, 75

cardo III

GSE 1932, 5 luglio: 172

cardo IV

GSE 1927, 20 dicembre: 28

cardo IV

GSE 1928, 31 agosto: 151

cardo $\mathrm{V}$

GSE 1933, 5 giugno: 50 
decumano massimo

GSE 1933, 5 giugno: 50

GSE 1937, 18 settembre: 51

vicolo au sud de l'Ins. Or. II

GSE 1936, 14 giugno: 126

Pompéi

Regio I

I 2, 27-29

GSP 1873, 30 dicembre (GSPomp 1874: 93): 183

I 3,15

GSP 1869, 6 febbraio (GSPomp 1868: 245): 170

I $6,8-9$

GSP 1927, 16 agosto: $66 ; 24$ agosto: 65

I 6,10

GSP 1912, 13 maggio: 183

GSP 1927, 15 settembre: 182

I 6,11

GSP 1927, 18 aprile: $66 ; 2$ giugno: 66

I 7, 4

GSP 1924, 12 aprile: 128

I 7, 13-14

GSP 1935, 25 novembre: 125

GSP 1936, [annotations lacunaires]: 124;

27 febbraio: 124 ; 28 febbraio: 96 ; 2 marzo:

124; 5 marzo : 124

I $8,8-9$

GSP 1939, 7 marzo: 116; 23 maggio: 116;

25 maggio: 115; 27 maggio: 107; 29 maggio:

108, 116; 30 maggio: 107; 31 maggio: 107;

1 giugno: 116 ; 15 giugno: 115

I 9,10

GSP 1927, 15 settembre: 183

I 10,8

GSP 1932, 28 novembre: 185

I 10,13

GSP 1932, 7 luglio: 98, 106

I $12,1-2$

GSP 1961, 13 marzo: 139; 14 marzo: 139

I 13,2

LT 1955, 14 dicembre: 183

I $19,1-2$

GSP 1933, 19 giugno: 96, 106

Regio II

II 3, 3

LT 1953, 13 gennaio : 183; 16 gennaio: 183

Regio III

III 4, a/b

LT 1918, 12 giugno: 183

Regio V

$\mathrm{V} 4,13$

LT 1903, 23 maggio: 183

Regio VI

VI 1, 7(?)
GSP 1771, 19 gennaio (PAH I, 1:248): 183

VI $1,18-20$

GSP 1789, 12 marzo (PAH I, 2: 44-45): 99

VI $8,2.20-21$

GSP 1826, [s.d., antérieur au 5 mars] (PAH II:

145): 196; 3 giugno (PAH II: 162): 210;

15 giugno (PAH II: 164): 210; 30 giugno

(PAH II: 165): 209

GSP 1827, 10 gennaio (PAH III: 74): 196

VI 9,7

GSP 1830, 31 marzo (PAH II: 236): 183

VI $14,21-22$

GSP 1875, 1 aprile (GSPomp 1874: 171): 198, 202

VI 15,8

LT 1898, 30 marzo : 183

VI 16, 26

LT 1904, 21 dicembre: 183

Regio VII

VII 1, 36-37

GSP 1862, 9 agosto : 158

VII 2, 3.6

GSP 1868, 30 maggio (GSPomp 1868: 48): 139

VII 2, 52

GSP 1862, 14 agosto: 78

VII $4,15-16$

GSP 1818, 23 settembre (PAH III: 17): 78

VII 5, 2.7-8.10.12.24 (thermes du forum)

GSP 1824, 7 agosto (PAH II: 111): 74; 23 agosto (PAH II: 112-113): 74; 12 settembre (PAH II: 114): $74 ; 4$ dicembre (PAH II : 121): 74

VII 5, 29

GSP 1829, 27 febbraio (PAH II : 219): 77

VII 9 (flanc du macellum) GSP 1818, 14 luglio (PAH I, 3: 208): 77; 28 luglio (PAH I, $3: 209): 77 ; 1$ agosto (PAH III: 16): 77

VII 9, 47

GSP 1820, 16 novembre (PAH II: 28): 183; 18 novembre (PAH III : 26) : 183

VII 13

GSP 1821, 6 ottobre (PAH II: 40-41): 128

VII 13, 24

GSP 1821, novembre (PAH II: 43-44): 128

VII 15,8

GSP 1872, 7 marzo (GSPomp 1873: 416): 183

VII 16,19

LT 1962, 16 gennaio: 183

Regio VIII

VIII 5

GSP 1841, 21 giugno (PAH II: 398-399): 128

VIII $5,8 / 10 / 11$

GSP 1841, 3 luglio (PAH II: 387-399): 74

Regio IX

IX 2, 5 
GSP 1870, 10 marzo (GSPomp 1873: 170): 183

IX 2, 9

GSP 1862, 23 settembre: $128 ; 128$

IX 11, 2

GSP 1911, dicembre: 90
GSP 1912, [annotations lacunaires]: 118, 119

Vicolo degli Augustali

GSP 1818, 11 giugno (PAH III : 15) : 77 ; 13 giugno (PAH I, $3: 205): 77$ 



\section{INDEX GÉOGRAPHIQUE}

Note: les astérisques renvoient vers les lieux de provenance ou de conservation des reliefs mentionnés dans le texte.

Autriche

Gars Thunau: 181

Oberleisrberg: 181

Bretagne: $\mathrm{x}$

Danemark

Marbøgger: 181

Égypte

[outils utilisés dans la boulangerie]: 143

[provenance des composants du verre]: 76

Fayoum: 205

Karanis : 215

Espagne

[outils utilisés dans la boulangerie]: 143

Gaule

[développement du stockage en tonneau]: 105

[diffusion de la céramique sigillée]: 80

[fours à pains]: 154

[outils utilisés dans la boulangerie]: 143

[pesons de métiers à tisser]: 176

Gaule Aquitaine

Poitiers [commerce d'objets céramiques]: 80

Saintes [production d'objets en verre]: 76

Gaule Belgique

Arlon* [relief de métier]: 67

Metz* [relief de métier]: 67

Gaule lyonnaise

Dijon* [relief de métier]: 118

Lyon [production d'objets en verre]: 76

Sens* [relief de foulerie]: 180, 198

Gaule Narbonnaise

Olbia: 57

Germanie supérieure

Mayence* [relief fragmentaire]: 136

Saalburg : 158, 160

Trèves* [relief de métier]: 67

Zugmantel : 158

Grèce

Crète [production de vin]: 78
Israël, Jalame [production d'objets en verre]: 76

Italie

Bologne* [relief de boulangerie]: 138, 140, 143, $144,149,159,234$

Campanie

[développement économique]: 12

[formes d'habitat]: 23

[origine géographique de la population d'Herculanum]: 10

[production céramique]: 300

[production de vin]: 78

[production d'objets en verre]: 76

Herculanum: cf. infra, index topographique.

Misène: 234

Naples

[activité sismique]: 234, 239

[influence sur Herculanum]: 3, 5, 10, 11, 49

[origine géographique de la population d'Herculanum]: 5

[relations commerciales avec Herculanum]: 3

Nocera

[réparation des dégâts sismiques]: 235

Pompéi: cf. infra, index topographique.

Pouzzoles

[production céramique]: 242

[production d'objets en verre]: 76

[relations commerciales avec Herculanum]: 3

Champs Phlégréens

[activité sismique]: 234, 235

[extraction de matériaux de construction]: 226

Latium

Orvieto [extraction de matériaux de construction]: 137

Ostie

[archéologie de la construction]: 225

[boulangeries]: 138, 146, 164

[formes d'habitat]: 255, 275

[fouleries]: 199, 205 
[relief fragmentaire]*: 144

[sarcophage de P. Nonius Zethus]": 134, 135, 138,144

Cassegiato dei molini (I, III, 1-2): 147

Cassegiato delle fornaci (II, vI, 7): 147

Cassegiato di Annio (III, xiv, 4): 105

Molino (I, XIII, 4): 147

Îlot du sanctuaire d'Hercule (I, xiv) : 288

Place des corporations: 136

Porta Romana: 225

V, II, $1: 362$

V, II, $14: 362$

V, II, $2: 362$

Portus

Isola sacra*: 67, 96, 105, 138

Rome

[archéologie de la construction]: 225

[boulangeries]: 140

[développement de la boulangerie]: 133

[formes d'habitat]: 255

[fouleries et distribution d'eau]: 195

[métiers urbains]: 39, 48

[origine géographique de la population d'Herculanum]: 5

[production d'objets en verre]: 76

[topographie des lieux de métier]: 42, 48

Forum transitorium: 180

Thermes de Caracalla: 255

Via Appia: 139
Rome*

[relief de boulangerie]: 148

[sarcophage d'A. Octavius Valerianus]: 139

Porta Latina, sepolcro dei Scipioni : 138

Porta Maggiore[reliefde M. Vergilius Eurysaces]: $134,138,143,145,146,149,158,160$

Porta San Giovanni: 137, 140, 143

Villa Médicis [sarcophage avec une scène de boulangerie]: 138,160

Lucanie

Paestum: 215

Sicile

Etna [extraction de matériaux de construction]: 137

Jordanie

Khirbet Edh-Dharih: 215

Maurétanie tingitane

Volubilis : 167

Norvège

[exemple ethnographique]: 176

Oseberg: 179

Palestine

[origine du métier à tisser vertical à deux traverses]: 176

[provenance des composants du verre]: 76 


\title{
INDEX TOPOGRAPHIQUE (HERCULANUM - POMPÉI)
}

\author{
Herculanum
}

Note: les lieux de métier - boutiques ou ateliers - d'Herculanum sont indiqués en gras.

decumanus maximus: 4, 6, 11, 18, 50-51, 58, 63, 75, $80,87,92,100,151,152,247,251,256,289,292$, $322,324,336,340$.

decumanus inférieur: 152, 256, 292, 296, 298, 302, $320,333,340,363,366$

cardo III: $171,172,289,333,340,363$

cardo IV: 16, 28, 28, 29, 34, 57, 58, 108, 151, 203, 292,

$320,322,323,325,331,333,338,340,361,363$

cardo V: 6, 50, 239, 256, 266, 268, 269, 280, 284, 286, 326

vicolo au sud de l'Ins. Or. II : 86, 126, 281

Abitazione e botteghe, cf. II, 4-8

Aedes augustalium, cf. VI, 20-24

Bottega con abitazione, cf. IV, 10-11

Casa a graticcio, cf. III, 13-15

Casa con giardino, cf. V, 32-33a

Casa d'Argo, cf. II, 2

Casa dei cervi, cf. IV, 21

Casa dei due atri, cf. VI, 28-29

Casa del bel cortile, cf. V, 8

Casa del bicentenario, cf. V, 15-16

Casa del colonnato tuscanico, cf. VI, 16-18.26

Casa del genio, cf. II, 3

Casa del gran portale, cf. V, 34-35

Casa del mobilio carbonizzato, cf. V, 5

Casa del papiro dipinto, cf. IV, 8-9

Casa del priapo, cf. IV, 17-18

Casa del rilievo di Telefo, cf. Or. I, 2-3

Casa del sacello di legno, cf. V, 31

Casa del salone nero, cf. VI, 11.13

Casa del telaio, cf. V, 3

Casa del tramezzo di legno, cf. III, 4-6.8-9.11

Casa dell'Apollo citaredo, cf. V, 9-12

Casa della colonna laterizia, cf. V, 24

Casa della fullonica, cf. IV, 5-7
Casa della gemma, cf. Or. I, 1

Casa della stoffa, cf. IV, 19-20

Casa dell'albergo, cf. III, 1-2.18-19

Casa dell'alcova, cf. IV, 3-4

Casa dell'ara laterizia, cf. III, 17

Casa dell'atrio a mosaico, cf. IV, 1-2

Casa dell'atrio corinzio, cf. V, 30

Casa dell'erma di bronzo, cf. III, 16

Casa dello scheletro, cf. III, 3

Casa di Aristide, cf. II, 1

Casa di C. Messenius Eunomus, cf. VII, 1-1a

Casa di M. Pilus Primigenius Granianus, cf. Or. I, 1 a

Casa di Nettuno e Anfitrite, cf. V, 6-7

Casa sannitica, cf. V, 1-2

Grande taberna con abitazione, cf. IV, 12-13.15-16

"Palestre », cf. Temple de Cybèle

Temple de Cybèle, cf. Or. II, 4

Thermes, cf. VI, 1.4-6.7-10.30

Insula II

II, 1 (Casa di Aristide): 228, 229

II, 2 (Casa d'Argo): 59-60, 69, 228, 229, 289

II, 3 (Casa del genio): 60

II, 4-8 (Abitazione e botteghe) : 7

II, $4: 80,87,375$

II, 6-7 : 111,377

Insula III : 27, 290-298, 300, 332

III, 1-2.18-19 (Casa dell'albergo): 7, 26, 59, 60, 82, 290

III, 3 (Casa dello scheletro): 26, 59, 69, 152, 204, 290, 296, 298

III, 4-6.8-9.11 (Casa del tramezzo di legno): 6, 7, 17, $22,23,26,69,71,175,228,230-232,243,252-$ 253, 290-298, 307, 357, 360, 363-365, 366 
III, $4: 71,72,81,298,365$

III, $6: 93,102,121,292,365$

III, $7: 292$

III, 8-9: 230-233, 253, 292-293, 365

III, 10: 22, 57, 81, 205-216, 207, 220, 230, 232-233, 252-253, 296, 298, 363

III, $12: 292$

III, 13-15 (Casa a graticcio) : 22, 26-35, 82, 172, 175, 203-205, 290-292, 296-298, 349, 375

III, $15: 31,34,60,80,82-83$

III, 16 (Casa dell'erma di bronzo): 27, 34, 290

III, 17 (Casa dell'ara laterizia) : 27, 34, 152

Insula IV : 290, 298-312, 333, 349

IV, 1-2 (Casa dell'atrio a mosaico): 139, 248, 300, 320,329

IV, 3-4 (Casa dell'alcova) : 300, 309, 330

IV, 5-7 (Casa della fullonica): 6, 7, 17, 202-203, 228, 300-302, 304-309, 315, 318, 327, 366

IV, $7: 58$

IV, 8-9 (Casa del papiro dipinto): 5, 227, 300-309, 312,366

IV, 10-11 (Bottega con abitazione) : 300-309, 312

IV, $10: 90$

IV, 12-13.15-16 (Grande taberna con abitazione): 7, $55,62,229,300-312,350,365-367$

IV, $12: 302,307,312,82-83$

IV, $13: 302$

IV, 14: 61-62, 78-79, 128, 132, 229, 302, 312, 366

IV, 15-16: 55, 60, 69, 90, 93, 106, 107, 111, 129-130, 152, 302, 311-312, 350-351, 366, 376

IV, 17-18 (Casa del priapo) : 7, 22, 108, 111, 243-244, 300, 302-304, 309-311, 349

IV, 17: 54, 70, 85, 93, 104, 108-112, 113, 121, 130131, 304, 309, 349, 376

IV, 19-20 (Casa della stoffa): 81, 129, 152, 179, 247, 300

IV, 21 (Casa dei cervi): XI, 69, 152, 175, 175, 213, 229, 246-247, 266, 300

Insula V: 312-332, 360, 361, 363

V, 1-2 (Casa sannitica): 6, 17, 60, 229, 313-320, 346, 352, 360-361, 365, 369

V, 3 (Casa del telaio): 7, 20-21, 22, 26, 53-54, 60, 83, $177-179,185,227,313-320,360-361,375$

$[\mathrm{V}, 4]: 58,60$

V, 5 (Casa del mobilio carbonizzato): 26, 69, 126, $249,313,360$

V, 6-7 (Casa di Nettuno e Anfitrite) : 22-23, 69, 123, 150, 228, 312, 313, 321-322, 325-332, 353, 365, 366

V, 6: 23, 57, 62, 69, 70-71, 72, 90, 94, 99, 101-102, $108,111,114-115,116,150,365$

V, 8 (Casa del bel cortile): 16, 18, 229, 313, 321-322, 325-331, 361, 363

V, 9-12 (Casa dell'Apollo citaredo) : 6, 7, 15, 18, 124, 228, 312, 322-327, 332, 365

V, 9-10: 7, 62, 90, 94, 121, 123, 124, 324, 328, 332
V, 12: 7, 68-69, 324, 365

V, 13-14: 4, 81, 322-323, 331

V, 15-16 (Casa del bicentenario): 4, 6, 7, 15, 16, 18$20,23,26,81,84-85,313,321-325,327-331,345$, $352,357,360,361-363,365,369$

V, 17: 4, 8, 18, 34, 69, 74, 83-87, 102, 228, 322-323, $330-331,352,361-362,363$

$\mathrm{V}, 18: 83-87,362$

V, 19-21: 322, 332, 352

V, 19: 69, 81, 93, 324, 326, 332

V, $20: 81,332$

V, $21: 93,102,324,326,332$

V, $22: 324,326,332,352$

V, 23-25 ([parcelle de la Casa della colonna laterizia]): $6,322,330,332,352$

V, 23: 81, 332

V, 24 (Casa della colonna laterizia) : 324, 332, 332

$\mathrm{V}, 25: 83,331-332$

$\mathrm{V}, 26: 322,331$

V, 27:81

V, 28.29: 352, 363

V, 28: 71, 72, 81, 352

$\mathrm{V}, 29: 81,326,352$

V, 30 (Casa dell'atrio corinzio): 7, 313, 352

V, 31 (Casa del sacello di legno): 7, 34, 313

V, 32.33-33a (Casa con giardino): 6, 7, 8, 17, 313, 313-320, 357, 360-361, 366

V, 32: 59, 80, 81, 317, 318, 320, 325

V, 33a: 317, 320, 352

V, 34-35 (Casa del gran portale): 6, 17, 82, 313-321, $357,360-361,366$

V, 34: 61, 81, 82, 203, 205, 317-320

Insula VI: 35, 63, 172, 332-345

VI, 1.4-6.7-10.30 (thermes): 59, 172, 229, 252, 333, $340,343,345,349,352,362,375$

VI, 2-3: 332, 333

VI, $6: 81,340$

VI, $7: 340$

VI, $8: 229$

VI, 9: 229, 333, 340, 343

VI, $10: 333,343$

VI, 11.13 (Casa del salone nero): XIII, 34, 50, 57, 69, 71, 82, 229, 247-248, 252, 323, 333, 336-340, 338, 342-, 345, 346, 350, 353, 360, 363-365, 366, 376

VI, 12: XIII, 20, 70, 74, 127, 229, 247, 252, 309, 336, $342-343,345$

VI, 14: XIII, 49-50, 51, 61, 80, 132, 248, 336, 342, 345,363

VI, 15 : XIII, 61, 81-82, 121, 336-340, 342, 345, 363

VI, 16-18.26 (Casa del colonnato tuscanico): XI, 62, $80,81,121,243,246,247,248,333-345,360,363$, $363,364-365$

VI, 16: 62, 80, 81, 333, 336, 340, 363

VI, 18: 69, 80, 81, 333, 340, 363

VI, 19: 80, 90, 93, 103, 107, 121-123, 124, 333, 336, 345 
VI, 20-24 (Aedes augustalium): 77, 235, 245-246, $251,338-340$

VI, 25: 61, 80-81, 228, 333, 336, 340, 345, 363

VI, $27: 345$

VI, 28-29 (Casa dei due atri): 228, 229, 251, 252, $332,338-340$

VI, 30: 59, 62-63, 80, 81, 172-175, 333, 340, 343, 352

\section{Insula VII: 92}

VII, 1-1a (Casa di C. Messenius Eunomus) : 20, 81

VII, 12: 59, 171-172, 175

Insula Orientalis $I^{a}: 233,256,289$

Or. I, 1 (Casa della gemma): 22, 69, 126, 150

Or. I, 1 a (Casa di M. Pilus Primigenius Granianus): 69

Or. I, 2-3 (Casa del rilievo di Telefo) : 55, 245, 289

Insula Orientalis $I I^{a}: 23-24,70,126,171,239-243$, $244,245,251,255-288,332,346,349,350,353-356$, $357,367,368$

Or. II, $1: 57,81,155,256,268,272,277,281$

Or. II, 1 a: 7, 22, 137, 139-140, 141, 143, 147, 154$155,156-157,159,161-162,164-166,260,268$, $281,288,367$

Or. II, 1 b: 57, 268

Or. II, $2: 260,268,281,286$

Or. II, $3: 81,268,282$

Or. II, 4 (temple de Cybèle): 5, 6, 23-24, 125, 126, $152,174,234-235,239,242,247,251,256,259-$
261, 263-267, 268, 269, 272, 275-277, 281, 419

(accès condamné par Or. II, 15) : 280-281

Or. II, 5: 63, 81, 125, 172-175, 190-191, 192, 270, $272,277,286$

Or. II, 6: 90, 94, 97, 107, 117, 272, 286, 287

Or. II, $7: 270-271,272,280,282,284,288,350$

Or. II, 8: 22, 54, 137, 139, 141, 143, 150-152, 153, 154-157, 159, 161-162, 164-166, 242, 262, 270, $271,272,278,280,283,284$

Or. II, 9: $22,63,70,79,93,125-126,130,242,262$, $271,284,286$

Or. II, 10: $15,18,20-21,22,55,74,80,185,192$, 268, 270, 285

Or. II, 11: 126, 139, 191-192, 216, 268, 270-271, $272,277,285,287$

Or. II, $12: 271,286$

Or. II, 13: 94, 97, 100, 102-103, 271, 272, 277, 280, $285,286,287$

Or. II, 14: $80,81,272,277,285,287$

Or. II, $15: 80,172,268,272,285,287$

Or. II, 16: $80,81,272,277,284,287$

Or. II, $17: 271,277,350$

Or. II, 18: 59, 63, 71, 72, 171-172, 175, 230, 270, $271,277,284,287$

Or. II, 19: 229, 247, 256, 259, 263, 267, 275

(accès à la loggia depuis Or. II, 18): 272

DM, 20: 58, 75

DM, 1E: 152

DM, 4E: 58

DM, 8E: 63,100

PoMPÉI

Note: quand les lieux de métier sont soulignés, c'est qu'ils appartiennent à une parcelle de plus grande ampleur. Pour éviter d'alourdir le texte, les espaces commerciaux et de production de Pompéi ne sont pas rehaussés en gras.

Boutique d'Asellina, cf. IX 11, 2

Boutique de Fortunata, cf. VI 3, 18-20

Boutique de Modestus, cf. VI 5, 12-13

Boutique de Pherusa, cf. III 6, 1

Boutique de Phoebus, cf. VI 1, 18.20

Boutique de Stabilio Oenoclion, cf. I 19, 1-2

Casa degli amanti, cf. I 10, 10.11

Casa degli amorini dorati, cf. VI 16, 7.38

Casa dei capitelli figurati, cf. VII 4, 29

Casa dei casti amanti, cf. IX 12, 6.8

Casa dei Postumii, cf. VIII 4, 2-6.49-50

Casa dei quadretti teatrali, cf. I 6, 8-9.11

Casa dei Terentii, cf. VII 2, 3.6-7

Casa dei Vettii, cf. VI 15, 1.27

Casa del Camillo, cf. VII 12, 22

Casa del centenario, cf. IX 8, 6.3.a

Casa del centenario, cf. IX 8, 6.3.a
Casa del Duca d'Aumale, cf. VI 9, 1.14

Casa del forno, cf. VI 3, 3.27-28

Casa del labirinto, cf. VI 11, 8-10

Casa del magistrato anonimo, cf. VII 3, 30

Casa del marinaio, cf. VII 15, 1-2.15

Casa del Menandro, cf. I 10, 4.14-17

Casa del panettiere, cf. VII 1, 36-37

Casa del Parnasso, cf. IX 1, 22.29

Casa del poeta tragico, cf. VI 8, 8

Casa del Principe di Napoli, cf. VI 15, 8

Casa del Trittolemo, cf. VII 7, 2.5.14-15

Casa della calce, cf. VIII 5, 28-29.34-35

Casa della fontana grande, cf. VI 8, 22

Casa della Regina d'Inghliterra, cf. VII 14, 5.17-19

Casa di Amaranto, cf. I 9, 11-12

Casa di Giulio Polybio, cf. IX 13, 1-3

Casa di Laocoonte, cf. VI 14, 32 
Casa di M. Lucrezio Stabia, cf. IX 3, 5.24

Casa di Mercurio, cf. VII 2, 27

Casa di Narcisso, cf. VII 12, 17

Casa di pansa, cf. VI 6, 1.8.12-13

Casa di Paquio Proculo, cf. I 7, 1.20

Casa di Pinario Ceriale, cf. III 4, b

Casa di Sallustio, cf. VI 2, 3-5.30-31

Caupona d'Euxinus, cf. I 11, 10-11

Domus Sirici, cf. VII 1, 25.46-47

Fullonica di L. Veranius Hypsaeus, cf. VI 8, 2.20-21

Fullonica di M. Vesonius Primus, cf. VI 14, 21-22

Fullonica di Stephanus, cf. I 6, 7

Hospitium Sittii, cf. VII 1, 44-45

Insula Arriana Polliana, cf. VI 6

Macellum, cf. VII 9, 7-8.19.42

Palestre, cf. II 7, 1.10

Praedia Iuliae Felicis, cf. II 4

Terme del Sarno, cf. VIII 2, 17

Thermes du forum, cf. VII 5, 2.7-8.12.24

Regio I: XI, 8, 75, 236

I 1, 1.1a.10: 127

I 1, 3-5: 127

I 1, 6.8-9: 91, 99

I 2, 24: 91

I 2, 27-29: 183

I $3,1: 154,156,163,164$

I $3,15: 170,217$

I 3, 16: 170, 217

I $3,27: 166$

I 3, 30: 170

$\underline{\text { I 4, 3 }: 90}$

I 4, 7: 198, 199

I 4, 12-17: 142, 163, 164

I 4, 12: 142

I 4, 13: 162

I 4, 17: 114

I $4,26: 170,198$

I 6, 5: 100, 120, 129

I 6, 7 (Fullonica di Stephanus): 198, 199, 200, 201, 202, 210-213, 214

I 6, 8-9.11 (Casa dei quadretti teatrali): 66

I 6, 8-9: $65-66,93,100$

I $6,10: 182-183,186$

I 7, 1.20 (Casa di Paquio Proculo): 103

I $7,4: 128$

I $7,5: 105$

I $7,13-14: 96,124-125$

Insula I 8: XI

I $8,1: 96$

I 8, 8: 94, 95, 107, 108, 111, 115-116, 124

I $8,10: 51,53$
I 8, 15-16: 94, 139, 142, 156, 163, 164

I 8, 19: 170, 171, 187, 202, 217

I $9,10: 181,183$

I 9, 11-12 (Casa di Amaranto): 129, 236, 252

I 9, 11: 129, 237

Insula I $10: 57,225,237,249,351$

I 10, 4.14-17 (Casa del Menandro): 74, 160, 238, 351,362

I $10,6: 198,199,201$

I $10,8: 180,183-185$

I 10, 10.11 (Casa degli amanti): 362

I 10, 13: 91, 98, 106

I $11,1: 95$

I 11, 10-12: 91

I 11, 10-11 (Caupona d'Euxinus): 83

I 11, 16:91, 94

I 12, 1-2: 139, 140, 143, 147, 150, 153, 156, 157, $159,161,163,166$

I 12, 3: 95-96, 99, 102, 111

I $12,4: 190$

I 13, 2: 183

I 14, 15: 93

I 19, 1-2 (Boutique de Stabilio Oenoclion): 95, 96, 106,126

$\underline{\text { I 20, 3: }} 78$

I $21,4-5: 127$

Regio II

II 1, 1: 95

II $2,3: 65,127$

II $3,3: 183$

II 3, 7-9: 51-52, 53

Insula II 4 (Praedia Iuliae Felicis): 47-48, 50, 219

II $4,1: 48$

II $4,5: 48,100$

II $4,7: 48,131$

II $5,1: 116$

II $5,4: 116$

II 7, 1.10 (Palestre) : 23, 24, 255, 264-265

Regio III

III 4, a: 183

III 4, b (Casa di Pinario Ceriale): 175, 183, 185

III 6, 1 (Boutique de Pherusa): 95, 117, 121 


\section{Regio V}

V 1, 2: 198, 199

V 1, 4: 187

V 1, 5: 187

V 1, 13:91, 98

V 1, 14-16: 162-163, 164

V 2, 13: 91

V 2, 19: 95,98

V 3, 1-2: 198, 199

V 3, 8: 153, 154, 156, 163, 166

V 4, 1-2: 139, 150, 159, 163, 164

V 4, 6-8: 55, 156

V 4,6:55

V 4, 7: 95, 111

V 4, 13:183

Regio VI: XI

VI 1, 2-4: 90

VI 1, 2: 90

VI 1, 7 [?]: 183

VI 1, 18.20 (Boutique de Phoebus): 99

VI 2, 3-5.30-31 (Casa di Sallustio): 160 VI 2, 5: 90

VI 2, 6: 142, 160, 180

VI 3, 3.27-28 (Casa del forno): 134, 137, 139, 153, $160,166,167$

VI 3, 18-20 (Boutique de Fortunata): 90

VI 4, 1: 90

VI 5, 12-13 (Boutique de Modestus) : 223

VI 5, 15: 154, 156, 161, 163, 164

Insula VI 6 (Insula Arriana Polliana): 47-48, 351

VI 6, 1.8.12-13 (Casa di pansa): 8, 47, 90, 351

VI 6, 2: 47

VI 6, 3:47

VI $6,4-5: 47,163,164$

VI $6,14: 47$

VI 6, 15: 47

VI $6,16: 47$

VI 6, 17-21: 54, 142, 161, 164

VI $6,23: 47$

VI 7, 8-12: 52

VI $7,8: 53$

VI 8, 2.20-21 (Fullonica di L. Veranius Hypsaeus): 196-198, 198-199, 200, 205-206, 208-210, 210213

VI 8,8 ([Casa del poeta tragico ]): 124,142

VI 8, 22 (Casa della fontana grande): 210

VI 9, 1.14 (Casa del Duca d'Aumale): 91

VI 9, 7: 183
VI 10, 1.19: 67, 90, 98, 101, 102, 105, 111, 131

VI 11, 8-10 (Casa del labirinto): 146, 153, 159, 160, 166

VI $13,6.8-9: 52,175,185$

VI 14, 21-22 (Fullonica di M. Vesonius Primus): 171, 198, 199, 200, 201-202, 210, 211, 217

VI 14, 32 ([Casa di Laocoonte]): 54, 142, 156, 166,171

VI 14, 33: 137, 145, 146,147, 159, 166

VI 14, 35-36: 91, 118, 131

VI 15, 1.27 (Casa dei Vettii): 55, 106, 195-196, 197, 209,213

VI 15, 3: 198, 199, 201, 217

VI 15, 8 (Casa del Principe di Napoli): 180, 183

VI 15, 15: 98

VI 16, 3-4: 170, 171, 198, 199, 200, 202

VI 16, 6: 198, 199, 201

VI 16, 7.38 (Casa degli amorini dorati): 201, 236, 249

VI 16, 12: 100

VI 16, 19.26-27: 180, 182, 183

VI $16,19: 186$

VI 16, 32-33: 106

VI 17, 1-2: 90

VI 17, 3-4: 90

Regio VII

VII 1, 25.46-47 (Domus Sirici): 166

VII 1, 36-37 (Casa del panettiere): 15, 152, 156, 158, 159, 160, 166

VII 1, 44-45 (Hospitium Sittii): 56

VII 2, 3.6-7 (Casa dei Terentii): 139, 142, 143, 160, 166

VII 2, $22: 142,146-147,164$

VII 2, 27 ([Casa di Mercurio $]): 170$

VII 2, 41: 198, 201

VII 2, $51: 166$

VII 2, 52: 78

VII 3, 13: 127

VII 3, 23: 127

VII 3, 24: 170

VII 3, 30 (Casa del magistrato anonimo): 64-65, 133

VII 4, 4: 90, 107, 142

VII 4, 13: 103

VII 4, 15-16 (VII 4, 15-16): 78

VII 4, 17: 93, 103, 114

VII 4, 29.57 (Casa dei capitelli figurati): 183 
VII 4, 29 ([Casa dei capitelli figurati]): 150, 162163

VII 4, 39-40: 170

VII 5, 2.7-8.12.24 (Thermes du forum): 74

VII $5,14: 220$

VII 5, 17:220

VII 5, 28: 127

VII 5, 29: 77

VII 6, 2: 111

VII 6, 22: 220

VII 7, 2.5.14-15 (Casa del Trittolemo): 213

VII $7,11: 127$

VII 9 [flanc du macellum]: 77

VII 9, 7-8.19.42 (macellum): 77

VII 9, 30-31: 101, 102

VII $9,41: 170$

VII 9, 43: 170, 217

VII 9, 44:170, 217

VII $9,47: 183$

VII 10, 13: 170

VII 11, 3: 170

VII 11, 5: 170

VII 11, 7: 190

VII 11, 11.14: 8

VII 11, 16-17: 83

VII 12, 1-2.36: 163, 164

VII $12,7: 156,162,163,164$

VII 12, 11: 157, 163, 164

VII 12, 13: 156, 163, 164

VII 12, 15-16: 170, 192

VII 12, 17 ([Casa di Narcisso]): 170

VII 12, 22 ([Casa del Camillo]): 170

VII 12, 25: 170

VII 12, 30: 170

VII 12, 34-35: 91

Insula VII 13: 128

VII 13, 21: 170

VII 13, 24: 128

VII 14, 5.17-19 (Casa della Regina d'Inghliterra): $170,171,187,217$

VII 15, 1-2.15 (Casa del marinaio): 147, 153, 166 VII $15,8: 183$

VII 16, 19: 183

Regio VIII

VIII 2, 17 (Terme del Sarno): 236

VIII 4, 1.53: 170

VIII 4, 2-6.49-50 (Casa dei Postumii): 170, 171, 174
VIII 4, 25: 127

VIII 4, 26-29: 54, 157, 160, 164

VIII 4, 35: 170

VIII 4, $37: 170$

VIII 5, [commerce alimentaire ?]: 128

VIII 5, 8/ 10/11: 74

VIII 5, 28-29.34-35 (Casa della calce): 48

VIII $5,34: 48$

VIII 5, 33: 48

VIII 6, 1.9-11: 74, 142, 180

VIII $6,3: 83$

VIII 6, 6:8

Regio IX

IX 1, 3.33:54, 153, 164

IX $1,6: 90$

IX 1, 16:220

IX 1, 22.29 (Casa del Parnasso): 166

IX 2, 5: 183

IX 2, 25: 65

IX 2, 9: 128

IX 3, 5.24 (Casa di M. Lucrezio Stabia): 78

IX 3, 10-12: 164

IX 3, 13: 170

IX 3, 14: 53,170

IX 3, 16: 189

IX 3, 19-20: 147, 153, 164

IX 5, 4:153, 156, 166

IX 6, a.1: 198, 199

IX $7,1: 56,189$

IX $7,2: 53,56,187$

IX $7,7: 52,58,66$

IX 7, 10: 58

IX 7, 19: 181

IX 7, 24-25: 132

IX 8, 6.3.a (Casa del centenario): 166, 208

IX 11, 2 (Boutique d'Asellina): 36, 54, 55, 56, 57, 90-91, 97-98, 99-100, 102, 106, 107, 117-120

IX 11, 4: 56

IX 11, 5: 56

IX 12, 1-2: 53, 185

IX $12,3-5: 185$

IX 12, 6.8 (Casa dei casti amanti): 236, 249

IX 12, 6 (boulangerie): 139, 140, 143, 146-147, $153,154,159,160,163,164$

IX 13, 1-3 (Casa di Giulio Polybio): 74

IX 13, 5: 198 


\section{INDEX THÉMATIQUE}

Pour éviter la perte de certaines notions, l'index est divisé en seize rubriques thématiques. Le catalogue des lieux de métier d’Herculanum (supra, p. 375-420) n’a pas été indexé.

\section{Acteurs}

artisans

cf. Métiers, noms de

boutiquiers

abus: 48

croyances et pratiques religieuses: 50, 54-56, 96

dépréciation: $4,7,43,53,182$

représentation: 56, 61, 105

statut: 12,63

clients

accès aux locaux commerciaux et artisanaux: 59,

94, 108, 110-111, 116-118, 129-130, 166, 220

perception des locaux par les : 56, 94-95, 182, 219

représentation des $\sim: 50,51,67,98,131$

ségrégation spatiale des $~: 62-63,66-68,92,93-$ 94, 114-115

élite: 1-7, 12, 14-15, 131, 237, 351-356, 360, 364, 370-372

esclaves

délégation aux : 351

gestion de la production par les $\sim: 7,72,152$

institores: 44, 46, 48, 364

spécialisation des $\sim: 162$

intermédiaires: 39, 52, 75, 79-80, 164, 166, 202

producteurs

empreintes: 75-77, 81, 117, 120, 124, 126, 130, $151,152,252,259$

Actions et activités économiques

achat: 45,185

incitation à l': 181

activités banales: $39,217,372$

choix économique: 164, 350, 367

circuit de distribution: 72-75, 87

du pain: 166

développement économique: 286

d'Herculanum: 1, 4 de Pompéi: 13

en Campanie: 12

suite au second séisme: 353-356

emptio venditio: 44

gestion directe: $358-359$

définition: 364

évolution: 364-367

investissement

locatif: $351,359,370,372$

urbain: 44-45, 356-360, 364, 366, 372

lucrum: $53-54$

negotiatio: $43,44,47$

production domestique:166, 169, 185-186

profit: 44, 53, 364

vente: $39,44,72-80$

contrat: 180

directe: 52

espace de $\sim$ dans les boulangeries: 164-166

représentation: 50, 61, 66-67

Construction et architecture

aménagements hydrauliques

avaloir: 115, 159, 172, 174

bassin

alimentation: 200

de rinçage: 200-201, 205

débordement: 195

en bois: 201

en plomb: 170, 202

maçonné: 171, 174, 200-202, 204, 216-217

ornemental: 256-257, 265, 267, 281, 286

vestiges de $\sim: 191$

canalisation

en plomb: $62,98,101,102,123,157,200,328$ 329,332

en terre cuite: $171,200,284,312$

maçonnée: 362 
chauffe-eau, cf. outils, chauffe-eau

chauffe-eau / fourneau, cf. Outils, chauffe-eau/ fourneau

citerne: $82,83,86,116,121,123,124,204,312$, 338

cuve: 340,342

à huile: 207

à salaisons (?): 338

à vin: 105

de mordançage: 186-187

égout: 171, 174, 272

fontaine

domestique: $196,325,332$

ornementale: 267

publique: 50

réservoir: 312

latrines

à l'étage: 253, 272, 298

emplacement dans les espaces de production:

$161,190,284$

installation: $62,86,269,285,318$

proximité avec les cuisines: 86,125

transformation: 277,284

puits: $121,124,158$

système de levage: 82

vasque

associée à la foulerie: 201

associée au lavage des toisons: 170, 172, 192

associée aux procédés de teinturerie: 53, 186

dans les commerces alimentaires: 127

de stockage: 113

liée à une activité de production: 26,83

charpente et techniques apparentées

balcon / avancée sur la rue: 23, 28-29, 31-32, 34, $185,233,270,296,298,331,340,343,362$

cloison: 26, 45, 62, 69, 71, 82, 85, 110, 115, 117, $172,228,285,296,298,312,320,332,340$

escalier: $31-32,47,74,81,82,83,85,87,118$, $120,121,190,244,268,269,270-271,272$, 277, 280, 282, 283, 286, 292, 298, 302, 309, $311,317,318,320,321,326,327,328,329$, $332,333,336,340,343,345,350,376$

escalier (base d'): 164, 190, 376

escalier (échelle de meunier): 85, 309, 345

escalier fictif: 329

mortaise: 206, 208, 317

panne: 302

plafond: $27,32,39,70,264,270,286,307,346$

planche: $42,43,45,47,48,58-59,60,64,70,87$, $94,134,146,149,153,156,189,200,206,208$, 216, 229

plancher: $64-65,70-72,121,125,261,283,362$

poteau: $64,71,85,153,180,228$

poutre: $46,70,71,146-147,212,216,282,307$, 327,362

poutre (encastrement): 71, 147, 172, 232, 233, 312 poutrelle: 110, 206-207, 211-212, 233, 278

sablière: 228

solive: $70,71,121,171,174,211,228,244,261$, $270,277,278,283,327,329,362$

solive (insertion des): 268, 270, 271, 283, 343, 362

solive passante: 71,278

tenon: 58, 138, 147, 208

toiture / toit: 26, 32, 171, 259, 302, 304, 307, 312,

$333,345,360,361-262$

toiture plate: 302,307

formes de mise en œuvre

opus caementicium: 226

opus craticium: $16,17,32,71,228,244,311$

opus incertum: 17, 154, 227, 228, 229, 247, 336, 346

opus incertum A: 227, 247

opus incertum B: 227, 230, 232, 233, 252, 292,

300, 315-317, 322, 333, 336

opus incertum $\mathrm{B}^{1}$ : 227, 300, 302

opus incertum $\mathrm{B}^{2}: 227,243$

opus incertum C: $227,229,230,243,252,292$,

302, 307, 309, 313, 315-317, 317, 322, 333

opus incertum D: 227, 229, 243, 312, 317, 318,

327,342

opus quadratum: 228, 247, 252, 296

opus quasi reticulatum: 228

opus reticulatum: 17, 154, 192, 226, 228, 228, 229 ,

$244,245,246,271,327$

opus reticulatum A: 229, 232, 233, 252, 253, 271,

296, 312, 320, 325, 326, 329, 331

opus reticulatum B: 229, 230, 232, 233, 239, 241,

$242,246,247,251,252,255,257,262,268,271$,

292, 296, 298, 304, 307, 307, 315-317, 318, 320,

$322,325,327,336,338$

opus testaceum: 154, 229, 232, 239, 240, 242, 243, $244,245,246,249,251,275,331$

opus vittatum: 156, 229, 230, 233, 239, 241, 243, $245,247,255,257,268,270,271,278,280,292$, 296, 307, 315-317, 318, 322, 325, 326, 333, 336

opus vittatum mixtum, 1 rangée de briques: 229 , $232,233,237,239,240,243,245,246,251,253$, 255, 261, 262, 268, 280, 296, 298, 307, 318, 336 opus vittatum mixtum, 2 rangées de briques: 229 , $232,233,239,240,241,242,244,246,251,261$, $271,278,298,304,309,311,312,320,321,329$, 331,336

huisserie

crapaudine: $57,59,60,85,107,317$

porte: $29,31,41,45,48,51,57,58,59,65,70$, $78,81,84,85,116,141,172,203,223,228,229$, $230,240,243,249,252,261,264,269,270,271$, $272,280,296,315,317,318,322,327,329,336$, 340,343

porte bouchée: $60,85,125,174,229,240,242$, 261-262, 277, 278, 280, 284, 292, 309, 317, 318, $322,328,330,345,366$ 
porte percée: 202, 230, 233, 247-248, 268, 270, $277,281,283,284,302,315,324,333$

seuil: 54, 59-61, 80, 81, 84-85, 268, 271, 317, 345, 347

à rainure: 57-59, 81, 87, 94, 121, 166, 172, 282, 292,317

matériaux

[briques] terres cuites architecturales: 17, 42, 62, $84,85,154-157,172,174,186,227,229,232-$ $233,236,240,242-243,245-246,249,251,271$, $275,283,296,307,312,317,318,320,327,340$, 342,361

calcaire blanc: 57, 59, 99, 127, 171, 199, 268, 292, 345

calcaire «du Sarno» : 226

imbrices: 101

lave / basalte: 57, 121, 146, 155, 171, 226, 227, 230, 232, 243, 292, 317, 318, 346

tegulae: 42, 83, 93, 98, 100, 155, 156, 227, 229, 232, 236, 259, 268, 270, 271, 278, 283, 296, 312, 340,345

tuf: 57, 62, 110, 155, 157, 226-229, 230, 232, 244, 251, 292, 302, 312, 315, 317, 318, 320, 333, 336 tuf gris «de Nocera »: 57, 59, 60, 85, 155, 226, 228, 252, 268, 296, 300, 315

tuf rossicio: 226, 227, 228, 292, 302, 315, 318, 322, 336, 342, 346

revêtements pariétaux

béton de tuileau (enduit hydraulique): 121, 123, 172, 198, 203

enduit peint: $18-19,21,29,61,62,86,94,123$, $191,202,247,248,261-262,284,290,327,345$

enduit simple: 147, 203, 236, 257, 271

$\mathrm{I}^{\mathrm{er}}$ style: 6, 249, 300, 346

II ${ }^{\mathrm{e}}$ style: $17,322,346$

III $^{\mathrm{e}}$ style: 116, 236, 247, 249, 251, 258, 260, 261, $298,307,309,318,320,326,338,340,351$

style de transition: $62,95,338,340$

IV style: 85, 116, 236, 245, 249, 251, 286, 345

techniques

béton: 61, 63, 98, 101, 140, 156, 215, 226, 229, 237, 243, 247, 251, 260

béton de tuileau: 57, 85, 110, 159, 198, 204, 227, 312,360

bricolage: 242, 271, 280, 288, 312

coffrage: 156, 229, 243-244, 251, 309, 311, 340

coulée: 156, 244, 247, 309

mortier: 54, 226, 227, 233, 236, 237, 243, 277, $282,345,346$

traitement des surfaces horizontales:

blocs de lave: 140, 163

mosaïque: 10, 94, 136, 202, 260, 282, 342, 362

opus signinum: 61, 282, 309, 311, 336

terre battue: $61,63,140$

tuiles: 63, 101, 155, 156, 174, 190, 192

opus sectile: $3,62,95,266,340$
Datation

chronologie relative: 225, 230-233, 239, 243-244, 253

typo-chronologie: 17, 154, 161, 251-253

Énergie

chaleur: $99,153,155,156,158,161,186,187,189$, 190

braise: 98, 101, 151, 156, 157, 158

équidés: 138, 139-141, 145

Gestes techniques et processus

assemblage: $67-68,87,138,147,156,206,208,212$, 220

criblage: $136,144-145$

façonnage

des pains: $149-154$

des vases : 51

fermentation

en teinture: 186

panaire: $148-150,152-153,154$

vinaire: 104,108

filage: $175-176,185-186,193,202,216-217$

lustrage: 194, 195-197, 198, 205, 213, 217

meunerie: 137, 141, 161, 164, 166

mouture: 134-136, 144, 145, 164, 166

nettoyage

grain: 134-136, 145

toisons: 59, 61, 62, 63, 170-175, 191, 202, 217, $277,284,343$

savoir-faire: $145,158,220,367,372$

soufflage : 76

au moule: 76

teinture: 186-190, 192, 202, 217

vannerie: 134, 136, 144, 145

Habitation

appartement de plain-pied: 74, 83-87, 271

domus (pour le détail de chaque maison, voir l'index topographique): $3,5-7,22,41,47,55,71-72,81$, $84-85,219,224,251,253,256,349-370$

étage

abolition: 280, 286, 318

accès à l' : 57, 81, 118, 190, 244, 253, 267, 269, 270, 272, 277, 282, 283, 286, 292, 302, 311, 317, $331,332,333,336,340,343,352$

activités à l' : 175, 179, 185

stockage à l' : 23, 69, 70, 82, 117, 124-126, 129 , 345

appartement: 4, 18-19, 26-35, 47-48, 62, 83-87, $124,151-152,252-253,287,296-298,322,324$, $332,340,345,361,366$

architecture de l' : 108, 228, 244, 261, 267, 270, $283,284,296,302-304,320,326,333,361-362$

création: 292, 315, 327, 340, 343, 353, 356-357, 365

extension: $312,324,332,366$ 
surface: $74,272,288,350,353$

jardin: 7, 8, 52, 91, 116, 205, 229, 246, 247, 292, $302,307,312,313,315,317-318,320,325,327$, $329,350-351,361,362$

généralités: 12, 23, 42-43, 46-47, 58, 60, 83, 83, 287 $288,317,324,332,345,350,352,359,367,372$

mezzanine: 72

pergula: 47

unité d’, cf. Propriétés urbaines, unités d'habitation

Historiographie

artisanat, définition traditionnelle: 220

commerces alimentaires: 89-91

sur Herculanum : 1-26

Matières premières

argile (terre à foulons): 193-194, 203

basalte / lave: 57, 121, 140, 146, 155, 163, 171, 226, $227,230,232,243,292,318,346$

bois

architecture: 4, 26, 57, 58, 60, 71, 82, 84, 85, 110 , 114-115, 117, 153, 156, 228, 236, 244, 277, 296, $322,332,340$

de combustion: $70,98,101,157$

instruments / outils: 21, 31, 118, 119, 120, 134, $136,137-138,143,145,146-147,154,158-159$, $177,189,195,198,201,205-215$

mobilier: 19, 33-34, 63-70, 74, 80, 86, 93, 114, $116,118,125,127,150$

chanvre: 128

combustible: 157-158, 162 (cf. aussi Matières premières, bois, de combustion)

grain: 137-145, 161-162, 164-167

laine: 169-171, 175-176, 187-189, 190, 193, 202, 217

marbre: $7,9,18$

en architecture: $57,62,84-85,117,266,336,360$

comptoir: 94-95, 96, 121

inscrit: 34,360

instruments / outils: $74,91,108$

mobilier: 21, 27, 33, 66, 171, 266-267

relief: $138-140$

statue: 50

natron: 76

orge : 130

pigments: $66,82,162,163$

plomb

coulé: 119,146

lingots: 74

mis en forme à partir d'une feuille: 98-99, 101, $116,123,142,143,157,170,186,200,202,328$ 329

moulé: 181-185

roches volcaniques (cf. aussi Construction et architecture, matériaux): 137, 142, 156, 159, 174, 226-227

soufre: 193-194, 197-198, 201 stockage des

en amphores: 22-23, 34, 56, 69-70, 72, 78-79, 82, $89,91,92,98,104-108,110,114-116,117-120$, $124-125,125,126,128,129,167,194,195,199$, 203, 242, 248

en dolia : 23, 55, 65-66, 86, 89, 92-93, 94, 95, 100 , $102-113,114-117,117-121,123-124,127,128$ $129,159,282$

stockage

du bois : 70

du grain: 112, 162, 167

de la laine: 217

du liquide: 103-105

fonction de $\sim: 45,72$

formes de $\sim: 112$

Métiers

lieux

atelier de bronzier: 50

atelier de céramique: $51,53,78$

atelier de feutre: 58, 66, 187-191, 286

atelier de gravure au tour: 74

atelier de plombier: 20, 70, 74, 127, 345

atelier de verrier: 76

boulangerie: $15,22,54,68,74,98,102,113,128$, $133-167,219,236,260,268,270,278,281,283-$ $284,287,367$

commerce alimentaire: 54-55, 62, 62, 65-66, 69, $80,89-132,150,152,170,175,190,192,282$, $311,328,343,345$

«thermopolium »: 89-91, 128

caupona: 4, 51, 56, 89-131

thermipolium: 90,91

concentration horizontale: 217

concentration verticale : 217

foulerie: 44, 170, 171, 180, 192-205, 208-209, 213, 216-217, 309, 366

officina: 42

officine de nettoyage des toisons: 59, 62-63, 71, $72,170-175,186,189,190-192,202,204,216-$ $217,277,284,287,343$

pièces annexes

arrière boutique: $55,69,70,71,101,142,151$, $152,186,228,247,309,330$

cave: 115

écurie: 44, 145, 161, 162, 167

fournil: 140, 153-154, 157-158, 161-162, 164, 166,167

mezzanine: $23,34,62,70-72,81,85,87,110$, $114-115,123,151,166,270,277,278,284$, $285,286,288,298,312,317,328,342,350$ $351,353,362,365,376$

pergula: 70

taberna: 3, 42-48, 87, 127, 351-352

teinturerie : 53, 171, 186-192, 202, 216-217, 286 noms

copo / caupo: 189,220 
fullo: 44, 46, 193, 213

gemmarius : 18,185

pistor: 153

pistor dulciarius : 158

\section{Meubles}

armoire: 27-28, 30, 32-33, 34, 66, 86, 106, 150, 175

caisse ou coffre: 86,148

casier à amphores, porte-amphores: 22, 23, 62, 69$70,110,114,123,343$

comptoir: 7, 39, 54, 62, 87, 97

en bois: $63-68$

gradins: 96,127

insertion des chauffe-eau: 99-100, 102

insertion des dolia : 102-113

maçonné: 80-81, 142, 150, 237, 285, 328, 351

dans les comptoirs alimentaires: $92-97$

mentions historiographiques: 89-92

variation des équipements intégrés au : 114-131

étagères: 19, 68-70, 72, 87, 98, 107, 116, 119, 120, 124, 134, 144, 152, 153-154, 167

empreintes d' : 66, 98, 110, 123, 153-154

lit: 21-22, 28-34, 116, 131, 296

encastrement de $\sim: 87$

table: $21,27,33,51,66-67,143,145,149,171,188-$ $189,266-267$

pieds maçonnés de: 65

table de cuisson: 66, 86, 99, 101-102, 108, 114-117, $125,129,131$

table maçonnée: 170-174, 190, 192, 204, 216, 277

Outils

baquet en bois: 136, 145, 201

blutoir: 143-144, 145

chaudière, pour la confection du feutre: 188-191

chaudière basse: 170-171, 172, 174, 190, 202, 204, 216-217, 277

hypothétique: 172

chaudière haute, (teinturerie) : 186, 190-192

chauffe-eau

dans les boulangeries: 156-157, 160

dans les commerces alimentaires: 95, 98-99, 100, 101-102, 114-115, 124-125, 129, 328

en bronze: 22

traces: 66

chauffe-eau / fourneau: 66, 94, 97-98, 100-101, 102, $111,118,127$

crible: $136,144-145$

entonnoir: $56,106,112-113,118,128$

feuille de boucher: 119

four: 289,343

four à pain: 54, 55, 138, 142, 144, 150, 153, 163$166,219,236,268,278$

autel: $154,156-157,158,159,160$

en cloche: 154

fonctionnement: 151, 154-161

système d'aération: 153, 158 four à réverberation: 162

four de verrier: 76

fourneau: 66, 67, 94, 97-98, 101-102, 113, 114-115, 117,118

d'enfleurage : 216

fusaïole: 175,216

fuseau: 175

métier à tisser: 20-22, 176-185

meule

à rotation animale: 136-142, 143, 144, 145, 148, $161,162,163-167,219,236,268,278$

catillus : 136-139, 140, 142, 163, 164, 166, 236

meta: 136-138, 140, 142-143, 159, 163, 164, 236

mola: 136

à rotation humaine: 142

manuelle: $119,127,162$

moule

à pâtisserie (?): 150-152, 163, 283

en boulangerie (?): 144

de pesons en plomb): 181

pour le verre: 76

peson: 20-21, 176, 177, 179-185, 186, 216

pétrin: 135, 139, 145-148, 153-154, 161, 164, 167, 219

en remploi : 159

fraseur (lame de pétrissage) : 147

presse: 194, 195-196, 198, 201, 202, 205-216

à coins : 208, 213, 215

à vis : 22, 205-216, 220

maie: 206-209, 211-215

quenouille: 175

séchoir: 171, 180, 195, 278

stalle de foulage: 196, 198-199, 201, 202, 203, 205, 217,309

tamis : $136,143-145,149$

tour: $51,74,148,185$

trépied de cuisson: 98, 101, 119, 129

treuil : $31,34,82-83$

vaisselle

assiette: 117, 120, 124, 126, 130, 131

céramique sigillée ou arétine: $74,80,116,117$, $120,121,124,126,130,242,247,248,346$

chaudron: $106,111,117,119,187$

de table ou de service: $66,75,80,111,113,115$, 119-120, 126

gobelet: $115,116,117,120,131$

marmite: 22, 78, 96, 98, 115, 119, 120, 130

œnochœ: 56, 104, 111, 118, 208

de préparation culinaire: $80,100,102,111,120$, 129,132

stampi: 119,150

tasse: $69,77,120$

teglie : 151-152

Perturbations

flux pyroclastique: $19,68,82,107,185,264,360$

fouilles en tunnel : 23, 69, 72, 93, 108, 117, 140, 151, 
$153,171,172,190,216,230,268,282,289,315$, 342

restauration moderne: $34,57,69,84,85,86,206$, $210-211,215,227,230,241,246,268,282,290$, 311,332

séisme: $17,54,155$

conséquences économiques: 355-356, 358-360, $361,364-365,367-370$

conséquences économiques et sociales: $352-353$

de $62: 81,82,121,154,160-161,202,233,234$,

$236,242-245,247-248,249,251,253,266,275-$

278, 280, 287-288, 296-298, 302, 307-309, 317,

$318-320,326-329,340-343,346,349,351,352$,

$353,361,363,365,367-370$

de $64: 234$

postérieur à celui de $62: 62,66,108,137,140,234$ -

235, 235-236, 236-238, 240, 242-245, 247, 251,

253, 261, 278-282, 298, 309-312, 320, 329-332,

$343,349,353,359,361,363,365-366,367-370$

travaux en cours au moment de l'éruption: 61, 74, $82-83,108,145,191,192,203,236$

Produits finis et semi-finis

bouillie (puls): 101, 120, 133

céramique: 49, 66, 69, 74, 77-78, 100, 112, 113, 115, $116,117,119-120,124,126,130,152,181,183$, $199,203,242,243,247,248,253,300$

farine: 104, 113, 120, 134-136, 143-145, 148-149, $152,154,163-167,66,187-191,286$

fromage: 142,143

lampe

céramique: $74,77,78,86,115,123$

en bronze: $50,54,74$

pain: $54-55,64-65,69,131-132,133-134,154,158-$

$160,166-167,219,283$

parfum: 77, 213-216, 220

pâtisserie: $67,162-164$

pigments: $66,82,162,163$

productions rurales: 45, 169

sous-produits de fabrication

boulange: $142-143$

déchets: 134,175

fumée: 97, 153, 159-160, 194, 236

levain: 134, 148-149, 152

son: 143,145

textile: $177-186,216-218$

verre: $22,49-50,75-77,80,96,104,115,117,120,128$

viande: $43-44,120,217$

vin: $43-44,50,53,55-56,67-70,78-80,98,101,103-$

$108,111-113,115-116,117-118,120,126,128$, $132-133$

Propriétés urbaines

démembrement: 315-318, 330-332, 357, 360-363, 364-365

espace public

trottoir: 84-85, 94, 320, 343, 351, 352, 360-361, 363 location: 4, 9, 12, 19, 46, 47-48, 351-352, 358-359, $361,363,364-367,368,370,372$

mitoyenneté: $324,338,351,360,361-362,376$

parcelle

concentration: 365

délimitation: 228-229

fragmentation: 357

primitive: $247,290-292,300-304,312-315,320-$

$322,332-333$

publique : 352 , 355-356

rapport entre et propriété: 351-352, 361

remaniement: 6, 296, 307, 320, 336, 338, 349, 363

patrimoine foncier: 44, 223, 351-352, 364, 366-367 revenus

locatifs : 288,361

mixtes (locatifs et issus de la gestion directe):

$363,365,366$

sources de: $364,366-367$

surface

de location: 358-359, 366, 367

de rapport: 358-359, 365, 366

unité architecturale: 287

unité d'habitation: 34, 352, 357, 359

usage commercial: $6,7,350-351,352,353,358$, $364-365,366,372$

Religion

culte domestique

autel: 51, 117, 126, 196, 338

divinités

Atoun: 267

Bacchus: 50, 53, 55, 78, 117, 126, 196, 208, 212

Cybèle: 24, 264, 267, 288

Diane: 30,96

Hephaïstos: 51

Hercule: $62,126,340$

Lares: 30, 352

Libera: 53

Magna Mater: 235, 239, 245, 251, 286

Mercure: 51-53, 55, 56, 66, 126, 185

Minerve: 30, 51-53, 180

Pan: 96

Pénates: 30, 55, 56, 117, 126, 212, 352

Priape: $53-55,96,110$

Semo Sancus: 49-50, 52

serpent: 110, 126, 196, 212

Vénus: 196, 202

Vénus Pompéienne: 55, 187

Vulcain: 51-53

imagines maiorum: 18

niche: 117, 126, 352

protection contre les mauvais sorts

clochette: 54-55, 69, 203

phallus: $53-54,60,155$

statuette: $30,32-33,34,50$ 


\section{TABLE DES MATIÈRES}

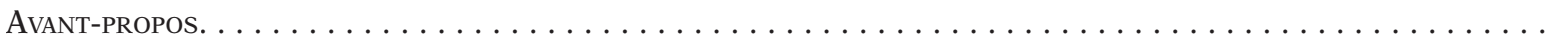

IX-XIV

Introduction. Inventio Herculanei : Amedeo Maiuri et les fouilles d’Herculanum . . . . . . . . . . . . . .

1932: Prem ier ouvrage sur Herculanum (2). Le guide des fouiles de 1936 (3). L'invasion des afrranchis À Herculanum , conséou ence de la fouime de la via del Foro (4). Ercolano: I nuovi scavi (1958) (5). Lévolution socio-économique d'Herculanum (6) présente des situations hors du cadre théorique (7).

Aux sources de l'œuvre d'A. Maiuri: la tradition des écrits sur Herculanum (8); le contexte historiographique des années 1920-1930 (12). L’influence du fascisme: réelle ou feinte (14)? L'utilisation des données de la fouille par A. Maiuri (16), entre innovation et théorisation (17). L'exemple de la Casa del bicentenario (18). Des carnets de fouille personnels, utilisés de préférence aux journaux officiels (19)? L'exemple du métier à tisser de la Casa del telaio (IV, 3) (20). Des divergences dues à la présentation vivante du site (22)? L’influence de Pompéi (23).

De la nécessité de consulter les journaux de fouille: l'exemple de la Casa a graticcio (III, 13-15) (26): restitution de son état lors de sa découverte (27); bilan des transformations entre la fouille et la restauration (32); la Casa a graticcio telle que présentée par A. Maiuri (32).

Première partie

DES MOTS AUX ESPACES:

AMÉNAGEMENTS ET FONCTIONNEMENT DES LIEUX DE MÉTIER

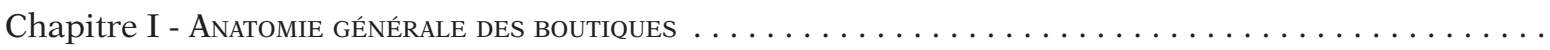

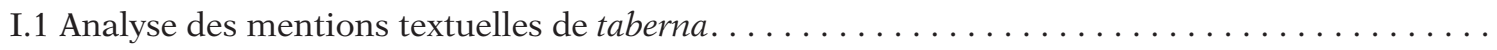

I.1.1 Analyse des textes littéraires . . . . . . . . . . . . . . . . . . . . . La taberna, lieu de commerce (43) situé en façade d'un bâtiment (44), fermé par des planches (45) et ayant pu bénéficier d'espaces d'habitation (46)

I.1.2 Les inscriptions pompéiennes mentionnant des tabernae. . . . . . . . . . . . . . . . . Les affiches de location en façade de l'Insula Arriana Polliana et des Praedia Juliae Felicis (47); un larcin dans l'insula 5 de la regio VIII (47).

I.2 La façade des lieux de métier . . . . . . . . . . . . . . . . . . . . . . .

I.2.1 Les «enseignes», entre manifestation religieuse et représentation des métiers . . . . . . . . La fresque ad cucumas (VI, 14) (49). Une seconde «enseigne» à Herculanum (50). L'exemple pompéien: représentations religieuses (51) et figurations apotropaïques en façade et en lien avec les instruments de travail (53).

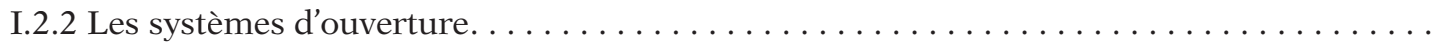
Fonctionnement des seuils à rainure longitudinale (57). Seuils de boutiques sans coulisse - seuils larges non associés à des boutiques (59). Évolution des seuils et remplois (59). 
I.3 Les aménagements internes . . . . . . . . . . . . . . . . . . . .

I.3.1 Le traitement du sol et des murs $\ldots \ldots \ldots \ldots \ldots \ldots \ldots \ldots \ldots \ldots \ldots \ldots \ldots$

Sobriété de la décoration des boutiques (61). Un programme décoratif unitaire en V, 9-10 (62).

I.3.2 Comptoirs, étagères et mezzanines $\ldots \ldots \ldots \ldots \ldots \ldots \ldots \ldots \ldots \ldots \ldots \ldots \ldots \ldots \ldots \ldots \ldots \ldots \ldots$ Les comptoirs en bois à Herculanum (63) et deux exemples supposés à Pompéi: la fresque de la distribution de pains (VII 3, 30) (64) et le commerce alimentaire I 6, 8-9 (65). Iconographie des comptoirs en bois (66). Étagères murales d'Herculanum (68). Mezzanines et demi-étages (70).

I.4 De l'étude des artefacts à la caractérisation des locaux . . . . . . . . . . . . . . . . . .

I.4.1 Les artefacts, vecteurs d'identification $d u$ commerce . . . . . . . . . . . . . . . . . . Fondements interprétatifs (72). Quelques produits du commerce de proximité: le verre (75), la céramique (77), le vin crétois (78).

I.4.2 L'interprétation des « boutiques » d'Herculanum. . . . . . . . . . . . . . . . . . Nouvelles interprétations à la suite de celles proposées par A. Maiuri (81). Locaux en travaux lors de l'éruption (82). Un appartement de plain-pied en V, 17 (83).

Comment reconnaître les lieux de métier, un bilan $\ldots \ldots \ldots \ldots \ldots \ldots \ldots \ldots \ldots \ldots \ldots \ldots \ldots \ldots \ldots$

Chapitre II - Les commerces alimentaires: RESTAURATion ET VEnTE AU détAil. . . . . . . . . . . . . .

Bilan des recherches, de l'invention du «thermopolium » (89) à la réinterprétation des commerces alimentaires (91).

II.1 Les différents aménagements des commerces alimentaires (comptoir, dispositifs de cuisson et de stockage)

II.1.1 Particularités des comptoirs maçonnés $\ldots \ldots \ldots \ldots \ldots \ldots \ldots \ldots \ldots \ldots \ldots \ldots \ldots \ldots \ldots \ldots \ldots$ Les fonctions des comptoirs: diviser l'espace (dimensions et formes) (92), attirer la clientèle et exposer les marchandises (décoration et gradins) (94).

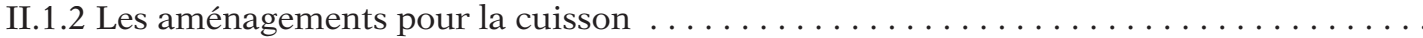
Les chauffe-eau/fourneaux: l'exemple de la boutique IX 11, 2 à Pompéi (97); les chaudières en plomb (98); restitution des chauffe-eau détruits et variations formelles (99). Les tables de cuisson (101).

II.1.3 Le stockage des denrées et la fonction des dolia . . . . . . . . . . . . . . . . . . État de la documentation concernant les jarres (102). Le stockage du vin dans les dolia: problèmes de porosité (103); attestations induites pour l'aire vésuvienne (104); apport contrasté des sources textuelles et iconographiques (104); l'alternative des amphores (105); incompatibilités diverses (107). Le stockage des denrées en vrac dans les dolia: l'exemple de la boutique IV, 17 (108). Les autres formes de stockage des denrées: vasques maçonnées et conteneurs céramiques (112).

II.2 Propositions pour une typologie des commerces alimentaires à Herculanum et Pompéi . . . . .

II.2.1 Type 1 : les restaurants utilisant une table de cuisson . . . . . . . . . . . . . . La boutique en façade de la Casa di Nettuno e Anfitrite (V, 6) (114). Le restaurant «de L. Vetutius Placidus » $(\mathrm{I} 8,8)(115)$.

II.2.2 Type 2 : des locaux entre le restaurant et le débit de boissons . . . . . . . . . . . . Le local Or. II, 6 (117). L’idéal-type de la boutique dite «d'Asellina » (117).

II.2.3 Type 3 : la vente de produits alimentaires non préparés . . . . . . . . . . . . Deux exemples d'Herculanum: les boutiques VI, 19 (121) et V, 9-10 (123).

II.2.4 Type 4 : les débits de boissons sans service de restauration . . . . . . . . . . . . Le commerce de vin I 7, 13-14 (124).

II.2.5 Type 5 : des restaurants aux capacités de stockage incertaines . . . . . . . . . . . . La boutique Or. II, 9, tenue par M. Livius Alcimus (124)?

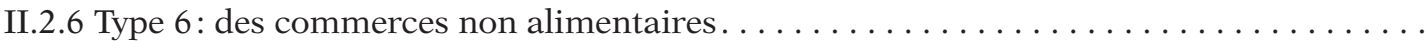

Perspectives pour l'étude des commerces alimentaires $\ldots \ldots \ldots \ldots \ldots \ldots \ldots \ldots$

Détermination, dénombrement (127) et variété des commerces alimentaires (127). Limites de la typologie (128). Aperçu global du commerce alimentaire à Herculanum et Pompéi (129). 
Chapitre III - BoulANGERIES ET CONFECTION DU PAIN $\ldots \ldots \ldots \ldots \ldots \ldots \ldots \ldots \ldots \ldots \ldots \ldots$

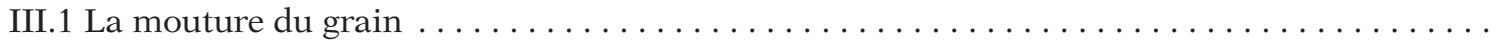
Nettoyage du grain (134). Le broyage du grain: forme des meules (136) et force de rotation (animale ou humaine?) (139). Récupération de la boulange (142). Blutage de la farine (143).

III.2 Pétrissage et façonnage du pain . . . . . . . . . . . . . . . . . . . . . . . Les pétrins mécaniques: iconographie et description (145). Le pétrissage manuel (147). Ingrédients du pain et fonctionnement des pétrins (148). Iconographie du façonnage et aménagements associés (149). La question des moules à pâtisserie (150). Le façonnage des pains (152).

III.3 Utilisation des fours pour la cuisson du pain. . . . . . . . . . . . . . . . . . Les différents modes de cuisson du pain (154). Les éléments constitutifs du four: le socle maçonné (154), la chambre de cuisson (155) et l'autel (156). La cuisson du pain (158). Typologie des fours (160).

Les boulangeries d'Herculanum et de Pompéi: essai de synthèse. . . . . . . . . . . . . . Les différents espaces des boulangeries (161).Une spécialisation de la production (163) ? Typologie des boulangeries et circuit de distribution du pain (164).

Chapitre IV - Tisser, NetToyer, teindRe: LEs LIEUX De L'ARTISANAT TEXTILE. $\ldots \ldots \ldots \ldots \ldots \ldots \ldots \ldots$

IV.1 De la laine à l'étoffe, des officines de lavage des toisons au métier à tisser. . . . . . . . . . . .

IV.1.1 Les officines de lavage des toisons . . . . . . . . . . . . . . . . . . . . Définition des aménagements pompéiens (170). Les officines d'Herculanum en fonction au moment de l'éruption (Or. II, 18 et VII, 12) (171); des ateliers condamnés avant 79 ap. J.-C. (VI, 30 et Or. II, 5) (172).

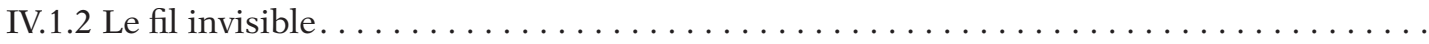
Fuseaux, quenouilles et fusaïoles (175). Linscription CIL IV, 1507 (175).

IV.1.3 Les attestations de métiers à tisser à Herculanum et Pompéi ................ Un métier à tisser vertical dans la Casa del telaio (177). Retour sur l'apparition du métier vertical à deux traverses (179). Autres attestations du tissage: les pesons de tisserand en terre cuite (180) et en plomb (181); les graffites (183).

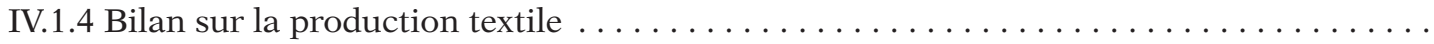

IV.2 Teinturerie et confection du feutre à travers deux exemples d'Herculanum. . . . . . . . .

IV.2.1 Teinture et feutre: les ateliers de Pompéi. . . . . . . . . . . . . . . . . . Brèves remarques sur le fonctionnement des teintureries pompéiennes (186). Les ateliers de feutre: des procédés techniques rarement mentionnés (187). Description (187) et interprétation de la fresque dite «de Verecundus» (188); quelques exemples possibles (189).

IV.2.2 Les ateliers Or. II, 5 et Or. II, 11 à Herculanum. . . . . . . . . . . . . . . . . . . Les fonctions de l'atelier Or. II, 5 : confection du feutre (190) et teinturerie (191) ? Le local Or. II, 11: teinturerie, laverie de toisons ou commerce alimentaire (191).

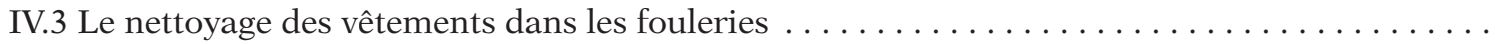

IV.3.1 La reconstitution du processus de lavage . . . . . . . . . . . . . . . . . . Les mentions littéraires: terre à foulons et saltus fullonius (193); autres opérations de foulerie (195). Les sources iconographiques: la fresque de la Casa dei Vettii (VI 15, 1.27) (195) et celle de la fullonica «de L. Veranius Hypsaeus» (VI 8, 2.20-21) (196).

IV.3.2 Du foulage au lustrage: architecture des fouleries . . . . . . . . . . . . . . . . Stalles de foulage (198), bassins (200) et autres aménagements des fouleries pompéiennes (201). Les fouleries d'Herculanum: la Casa della fullonica (IV, 5-7) (202) et deux hypothèses (203).

IV.4 Une réinterprétation de la presse «à vêtements » de l'atelier III, 10 à Herculanum......... . Description de la presse à vis découverte à Herculanum (205). La presse représentée sur le pilier de la fullonica «de L. Veranius Hypsaeus» (208) et ses vestiges (209). La fullonica «de Stephanus» (I 6, 7): éléments d'une presse (210) et propositions de restitution (211). III, 10: des vêtements aux olives (213).

Essai de comparaison des activités textiles à Herculanum et Pompéi $\ldots \ldots \ldots \ldots \ldots \ldots \ldots$ 


\section{DEUXIÈME PARTIE}

\section{LA PLACE DES BOUTIQUES AU SEIN DES PROPRIÉTÉS URBAINES: ESSAI D'ARCHÉOLOGIE DU BÂTI}

Chapitre V - Fondements d'une archéologie du BÂti À Herculanum $\ldots \ldots \ldots \ldots \ldots \ldots \ldots$

V.1 Les techniques de mise en œuvre dans la construction à Herculanum . . . . . . . . . . . .

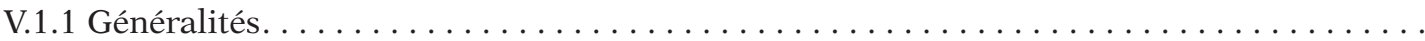

Murs et opera (226). Les matériaux de construction employés (226).

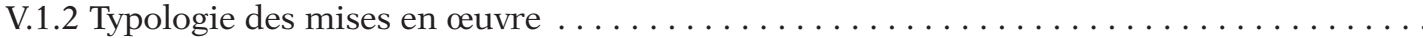
Techniques de construction des murs: opera incerta A, B, C et D (227), opera reticulata A et B (228), opus craticium (228). Montants des portes et des fenêtres, éléments porteurs: opus quadratum (228), opus vittatum, opus vittatum mixtum (229), opus testaceum (229). Les coffrages, maçonnerie hors typologie (229).

V.1.3 Principes de chronologie relative: l'exemple de la façade nord-est de la Casa del tramezzo

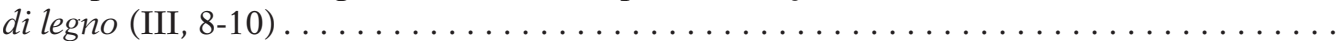
Principes de chronologie relative (230). Inventaire des types de mise en œuvre (230). Rapports stratigraphiques (232). Chronologie relative de la façade (233).

V.2 Herculanensis oppidi pars ruit (Sen., Nat., 6, 1, 2): questions sismiques . . . . . . . . . . . .

V.2.1 Les attestations littéraires et épigraphiques des phénomènes sismiques . . . . . . . . . . Sénèque, Suétone et Pline rapporteurs de séismes (234). Attestations épigraphiques à Herculanum (234). Explications sismologiques (235).

V.2.2 Retour sur L'ultima fase edilizia di Pompei . . . . . . . . . . . . . . . . . . . . . . Les attestations de plusieurs séismes dans la Casa dei casti amanti (236) et dans d'autres maisons pompéiennes (236). Des techniques de construction propres aux réparations (237). Quelques conséquences liées à l'individualisation d'autre(s) séisme(s) postérieur(s) à 62 (237).

V.2.3 Transformations des techniques de construction à Herculanum entre 62 et $79 \ldots . . .$. Bilan sur le second séisme d'Herculanum (238). Les réparations effectuées dans l'Insula Orientalis $I I^{a}$ (239). Les autres mises en œuvre liées aux réparations (243).

V.3 Éléments pour une chronologie « absolue $» \ldots \ldots \ldots \ldots \ldots \ldots \ldots \ldots \ldots \ldots$

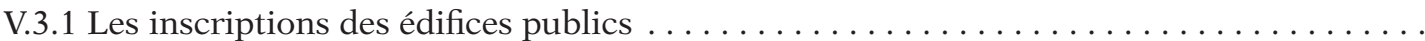
Le théâtre (245); l'Aedes Augustalium (245); le portique au nord du decumanus maximus (246).

V.3.2 Le résultat des fouilles . . . . . . . . . . . . . . . . . . . . . . . Les différents sondages effectués à Herculanum: dans la Casa dei cervi (246); dans l'Insula Orientalis $I I^{a}$ et dans la Casa del colonnato tuscanico (247); en façade de la Casa del salone nero (247).

V.3.3 Les styles décoratifs . . . . . . . . . . . . . . . . . . . . . . Problèmes de détermination des styles à Herculanum (248). Styles, chronologie et réparations (249). Conséquences chronologiques (249).

De la chronologie des types de construction à l'évolution du bâti à Herculanum . . . . . . . . . . . . Corrections à la chronologie proposée par Th. Ganschow (252). Définition générale des phases de construction à Herculanum (252), appliquées à un exemple (252).

Chapitre VI - L'Insula ORIENTALIS II ${ }^{a}$ : ARCHITECTURE, FONCTION ET ÉVOLUTION D'Un BÂTIMENT PUBLIC ......

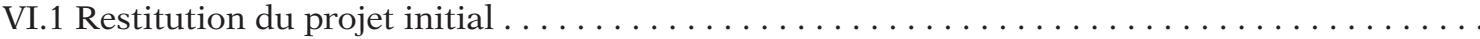

VI.1.1 Date et techniques de construction $\ldots \ldots \ldots \ldots \ldots \ldots \ldots \ldots \ldots \ldots \ldots \ldots \ldots \ldots$ L'unité architecturale du complexe (258). Un long chantier de construction (259) montrant les signes d'une évolution du projet initial (260). Esquisse du déroulement du chantier (262).

VI.1.2 Réflexions sur la fonction du bâtiment public . . . . . . . . . . . . . . . La position de l'inscription CIL X, 1406 (263). Une palestre (264) où se dérouleraient des ludi gymnici (265)? Un édifice cultuel plurifonctionnel (266).

VI.1.3 L'aile occidentale . . . . . . . . . . . . . . . . . . . . . . . . . . . . . . . Principes généraux de restitution (268). Le bloc méridional (268). La partie centrale: caractères communs et étages (269); variations par rapport au modèle général (271); locaux commerciaux et espaces publics ouverts sur le cardo V (272). 
VI.2 Les transformations successives $\ldots \ldots \ldots \ldots \ldots \ldots \ldots \ldots \ldots \ldots \ldots \ldots \ldots$

VI.2.1 Le séisme de 62 et les premières transformations de l'Insula Orientalis $I I^{a} \ldots \ldots \ldots \ldots$ Des dégâts relativement limités. Premières transformations de l'aile occidentale (275).

VI.2.2 Du second séisme (ca. 70-75 ap. J.-C.) à l'éruption du Vésuve. . . . . . . . . . . . . . . . Des réparations et consolidation effectuées par Vespasien (278). Une importante transformation du plan de l'édifice dans le bloc méridional (281), au sud de l'Aula absidata (282) et autour des boutiques Or. II, 16 et 18 (284). Derniers changements dans les locaux commerciaux (284).

L'Insula Orientalis $I I^{a}$ entre fonctions publiques et vie commerciale $\ldots \ldots \ldots \ldots$

Chapitre VII - EsSAi dE RESTITUTION DES IMPLANTATIONS COMMERCIALES EN FAÇADE DES DOMUS D'HERCULANUM . .

VII.1 Évolution des insulae III et IV . . . . . . . . . . . . . . . . . . . .

VII.1.1 Les transformations des implantations commerciales dans l'insula III: la Casa del tramezzo di legno (III, 4-12) et la Casa a graticcio (III, 13-15) . . . . . . . . . . . . . . . Les phases préromaines (290). L'extension progressive de la Casa del tramezzo di legno durant la période romaine (292). Les changements consécutifs aux deux séismes dans la Casa del tramezzo di legno et la Casa a graticcio (296).

VII.1.2 Le lent développement et la diversification des commerces dans l'insula IV. . . . . . . . Restitution de la moitié nord de l'îlot jusqu'à la fin de la République (300). Les remaniements effectués durant le règne d'Auguste (302). Activité sismique et transformations des maisons (307).

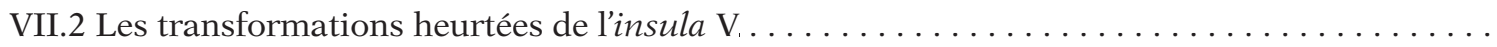

VII.2.1 Transformation des parcelles de la moitié méridionale (Casa sannitica, Casa del telaio, Casa con giardino et Casa del gran portale $\ldots \ldots \ldots \ldots \ldots \ldots \ldots \ldots \ldots \ldots \ldots . \ldots \ldots \ldots$ Une imparfaite division préromaine selon un axe médian (313). Démembrement de la Casa sannitica et construction de la Casa del telaio durant la période augustéenne (315). Derniers remaniements à la faveur des séismes (318).

VII.2.2 Évolution des parcelles de la moitié septentrionale . . . . . . . . . . . . . . Des lots originels orientés nord-sud, remaniés durant la période samnite (320). D'importantes transformations dues à la construction de la Casa del bicentenario (322). Extension verticale et réduction des surfaces au sol (62-79 ap. J.-C.) (326).

VII.3 Évolution des espaces publics et privés dans l'insula VI . . . . . . . . . . . . . . . . Difficile appréhension des phases préromaines (332). La construction des thermes (333). Transformation de l'îlot durant la période augustéenne (336). Extension de la Casa del salone nero et des thermes au cours des phases post-augustéennes (338). Fractionnement des façades du séisme de 62 à l'éruption de 79 (340).

Quelques remarques conclusives sur les données concernant l'évolution des boutiques à

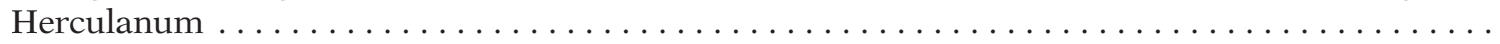

Conclusion À la deuxième Partie: Économie et société À Herculanum $\ldots \ldots \ldots \ldots \ldots$

ReM aRques PRÉUM INAIRES: CHRONOLOGIE (349) ET EXTENSION DE L'ÉCHANTILON (349); iA SURFACE COM M E VECTEUR DE COM PARAISON (350); DÉfinition DES CATÉGORIES EM P LOYÉES (350); LM ITES DE PROP RiÉlÉ ET LOCATION (351); RAP P EL DES INTERP RÉTATIONS ANTÉRIEURES (352).

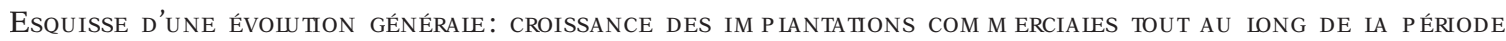
IM P ÉRIALE (353); FRAGM ENTATION DES UNITÉS D'HABITATION (356); TRANSFORM ATION DES FORM ES D'INVESTISSEM ENTS uRbains (358). BiLAN à l'Écheme de la ViUe (359).

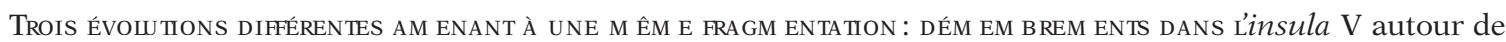
la Casa sannitica (360) et de la Casa del bicentenario (361); le fractionnement de la Casa del tramezzo di legno, de la Casa del colonnato tuscanico et de la Casa del salone nero (363), entre gestion directe et mise en location (364). Bilan de l'évolution contrastée des grandes domus (364).

Le cas des autres domus: la Casa dell'Apollo citaredo, la Casa di Nettuno e Anfitrite (365), la Grande taberna con abitazione et la Casa della fullonica (365).

Une classe moyenne pratiquant l'investissement urbain (366)? Des hommes de métier sans autre bien que celui-ci (367). Quelques éléments de comparaison avec Pompéi (367). 


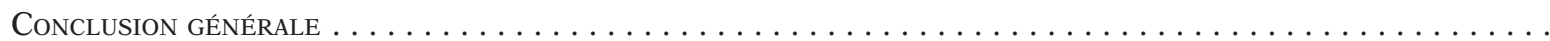

Annexe - Catalogue des lieux de métier d'Herculanum $\ldots \ldots \ldots \ldots \ldots \ldots \ldots$

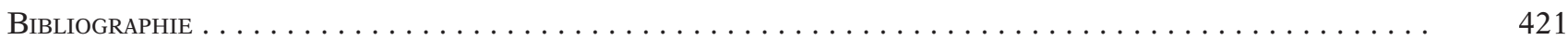

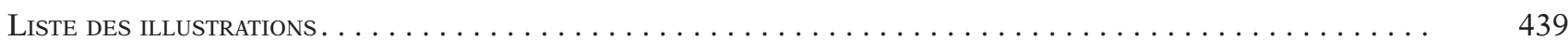

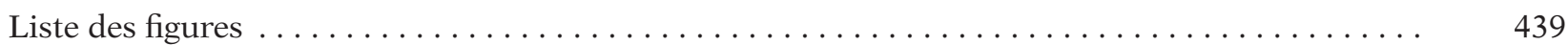

Liste des planches. . . . . . . . . . . . . . . . . . . . . . . 444

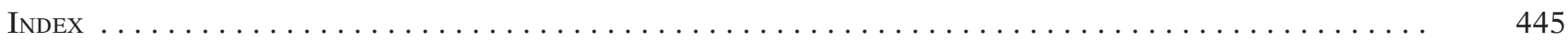

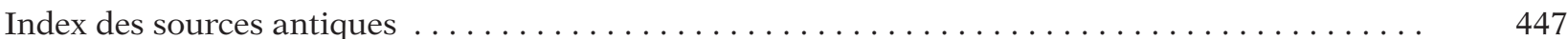

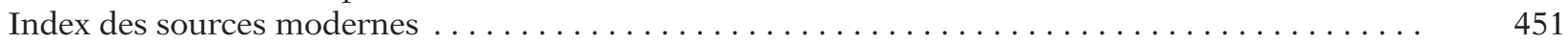

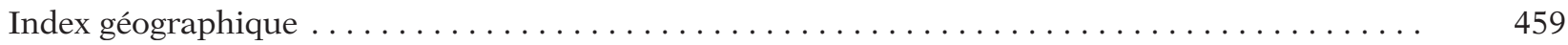

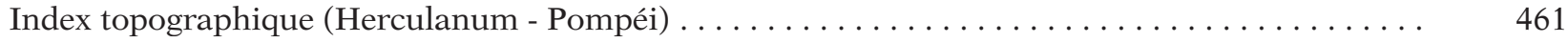

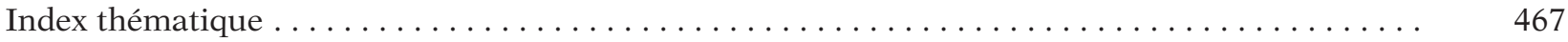

TABLE DES MATIÈRES $\ldots \ldots \ldots \ldots \ldots \ldots \ldots \ldots \ldots \ldots \ldots \ldots \ldots \ldots \ldots \ldots \ldots \ldots$ 

Composition: Hélène Franchi

Achevé d'imprimer

en janvier 2011

sur les presses de la

Scuola Tipografica S. Pio X

Via degli Etruschi, 7

00185 Roma 


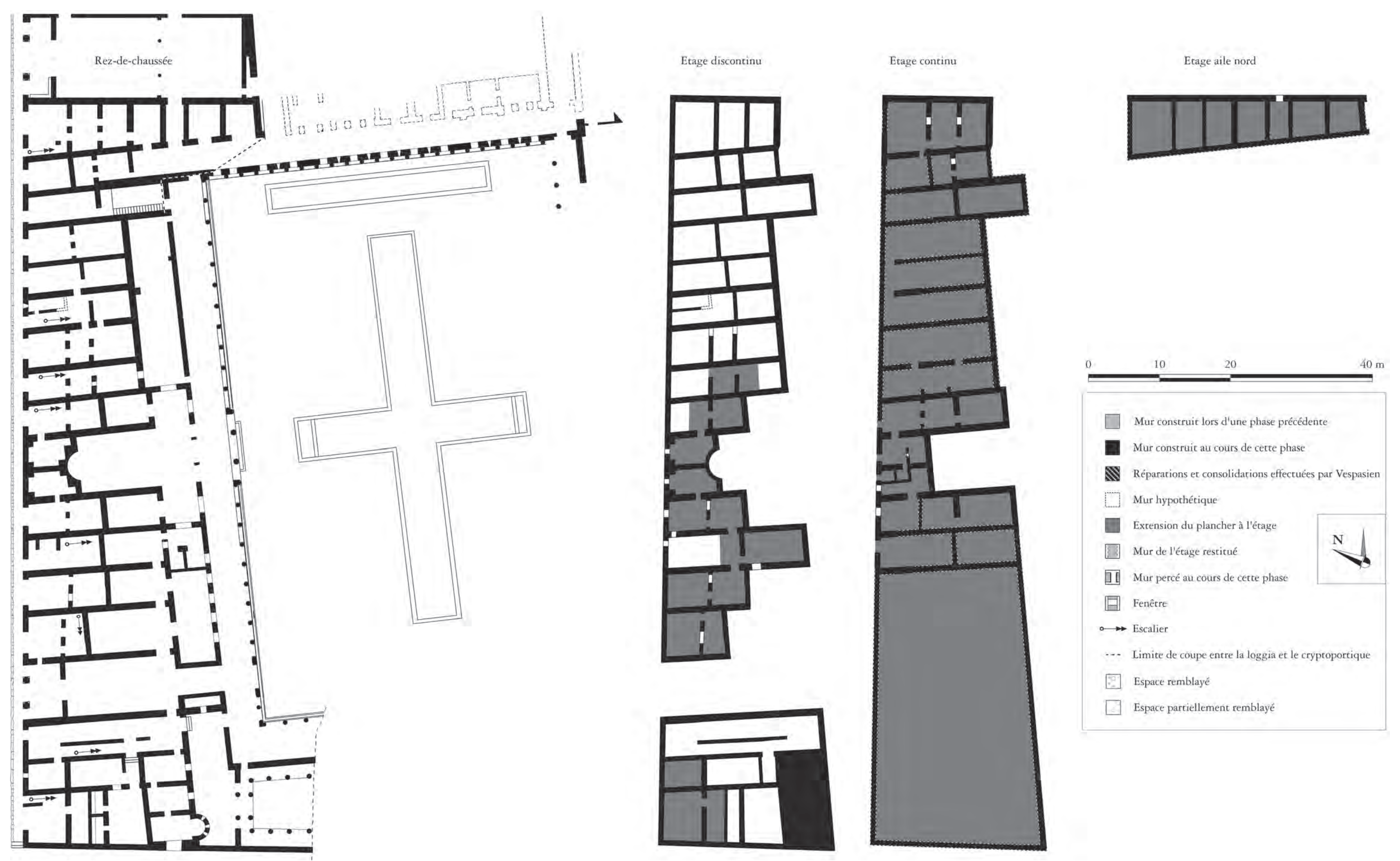



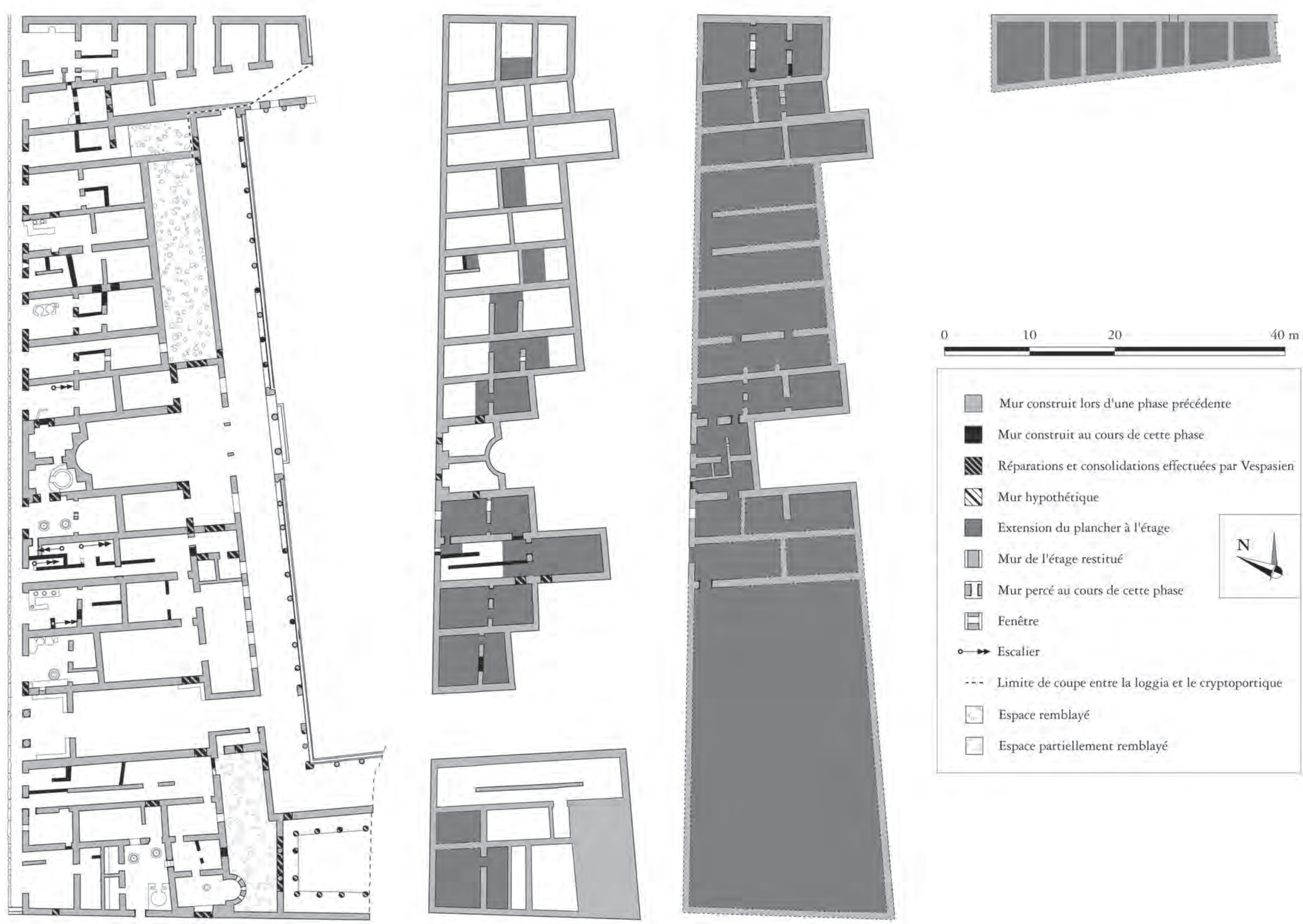


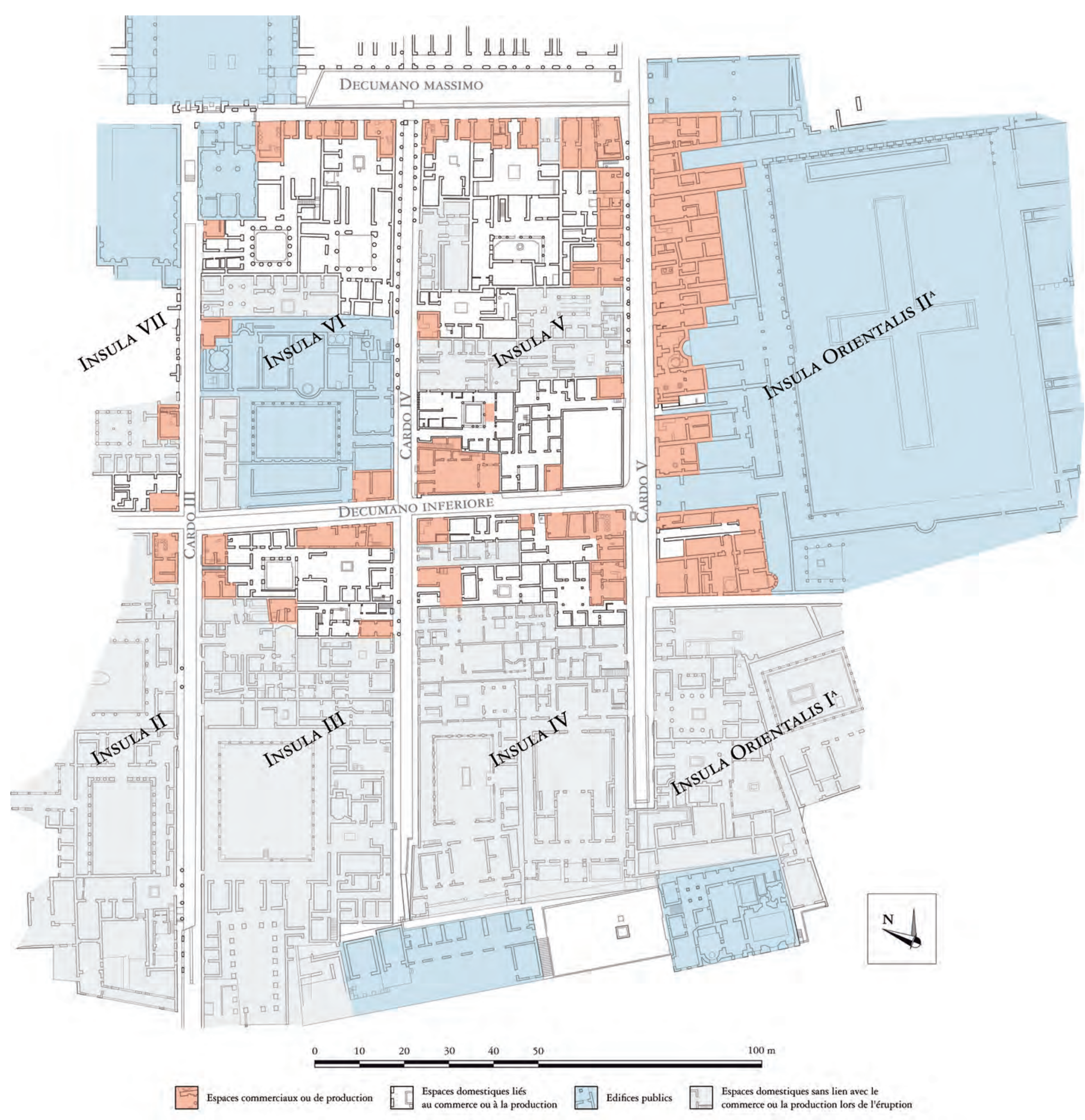

Pl. III - Planimétrie générale d'Herculanum; échelle: 1/1000 (ajouts au relevé de F. Ferrajoli et numérisation réalisés par U. Pastore, SANP). 


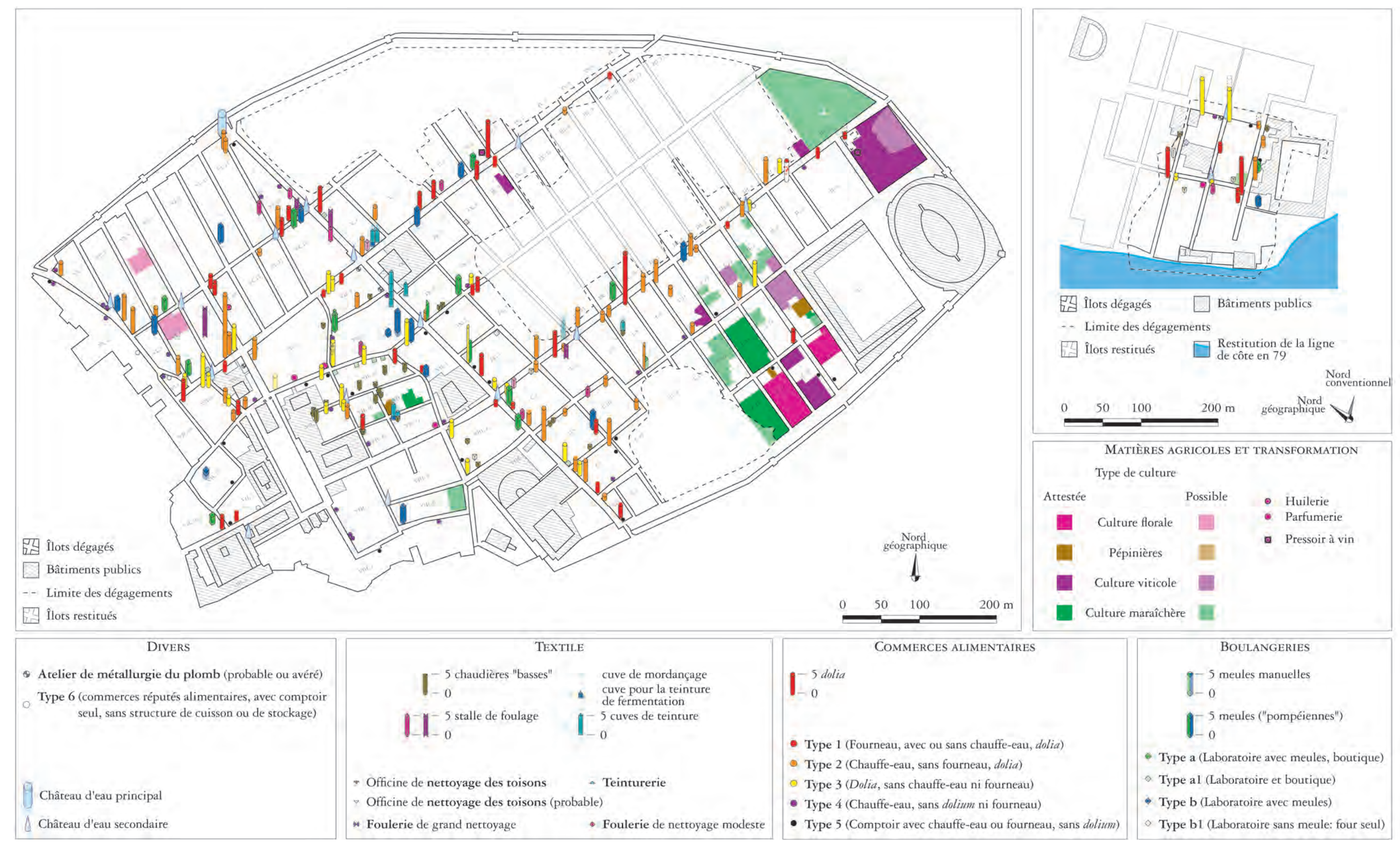




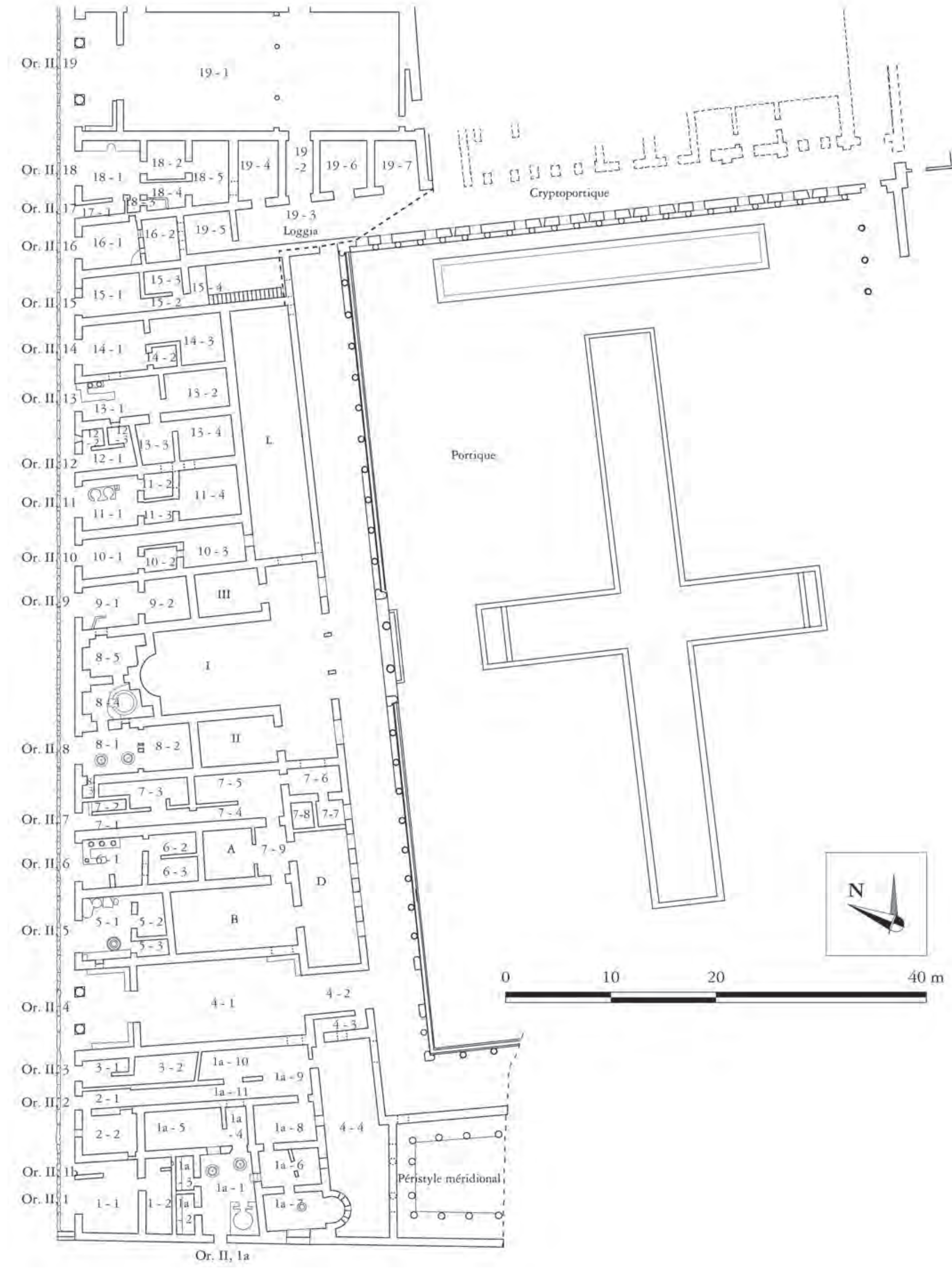

Pl. V - Nomenclature de l'Insula Orientalis II ${ }^{a}$; échelle: 1/500.

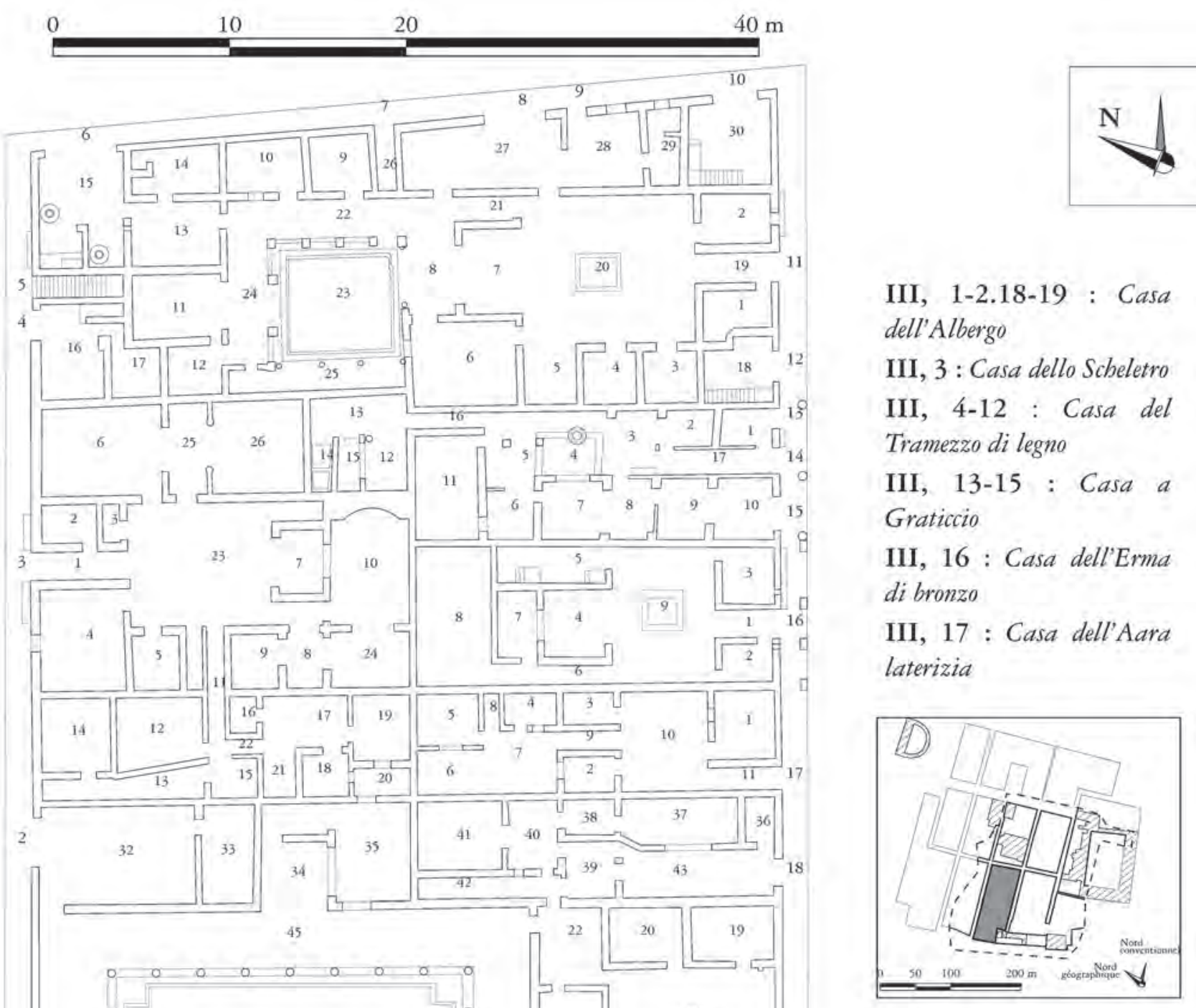

III, 1-2.18-19 : Casa

III, 4-12 : Casa del

dibronzo 


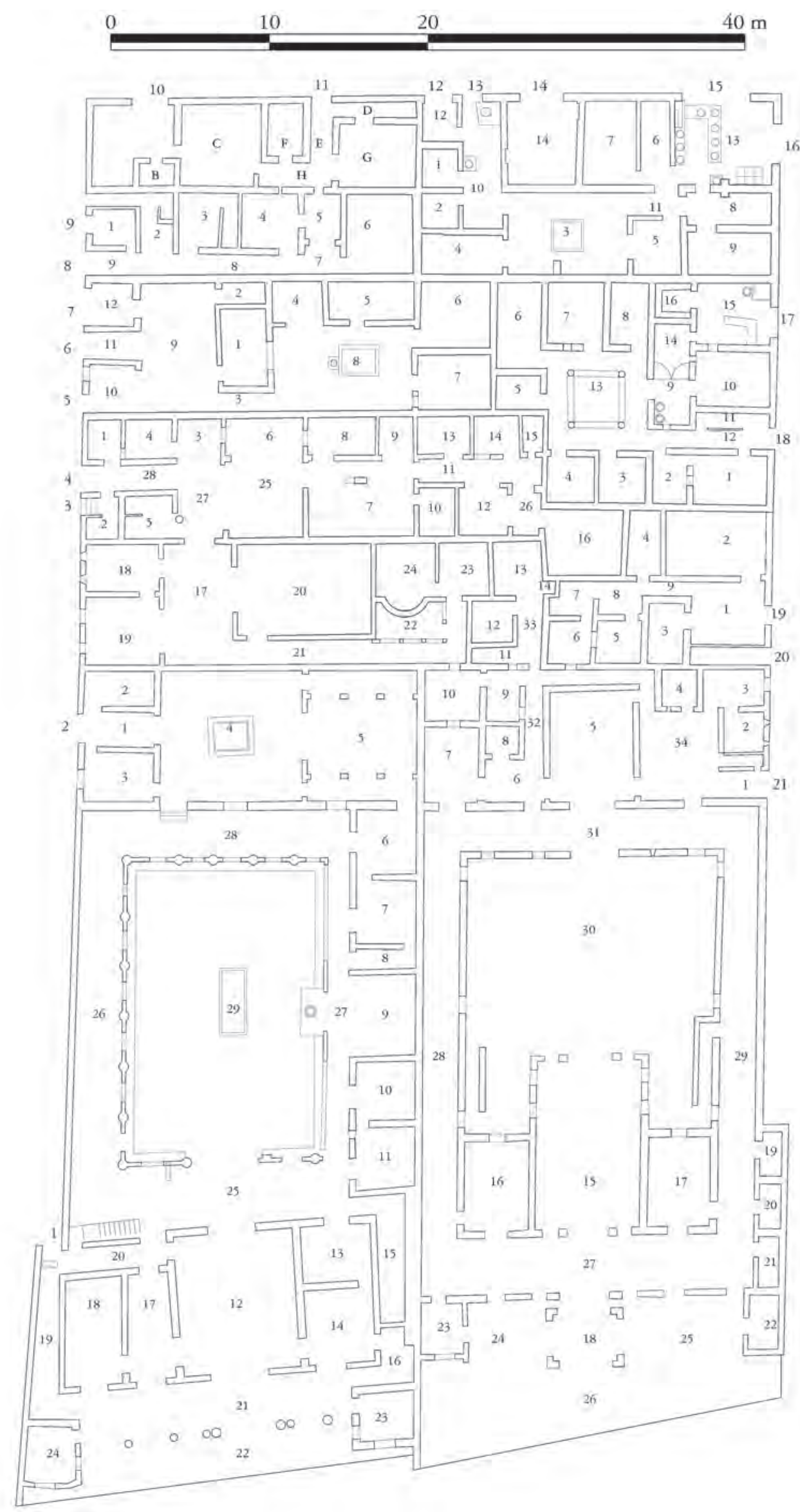

IV, 1-2 : Casa dell'Atrio a mosaico

IV, 3-4 : Casa dell'Alcova IV, 5-7 : Casa della Fullonica

IV, 8-9 : Casa del papiro dipinto

IV, 10-11 : Bottega con abitazione

IV, 12-13.15-16: Grande taberna con abitazione

IV, 14 : Taberna vasaria

IV, 17-18 : Casa del

Priapo

IV, 19-20: Casa della stoffa

IV, 21 : Casa dei Cervi

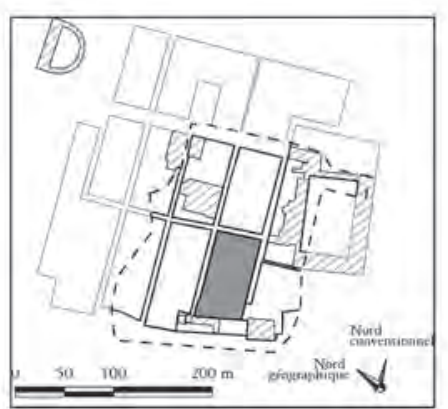

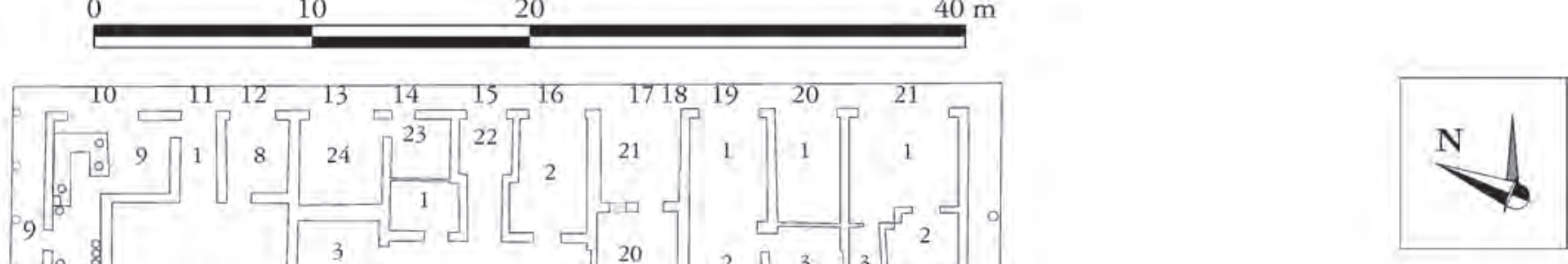

V, 1-2: Casa Sannitica V, 3 : Casa del Telaio

V, 5: Casa del Mobilio carbonizzato

V, 6-7: Casa di Nettuno Anfitrite

V, 8: Casa del Bel cortile

V, 9-12: Casa dell'Apollo citaredo

V, 13-16 : Casa del Bicentenario

V, 17-18: Appartements

V, 19-22 : Botteghe sul

decumano massimo con abitazione

V, 23.24.25 : Casa con taberna

V, 26-27 : Taberna con abitazione

V, 28-29: Tabern

V, 30 : Casa dell'Atrio corinzio

V, 31 : Casa del Sacello di legno

V, 32-33a : Casa con giardino

V, 34-15: Casa del Gran portale

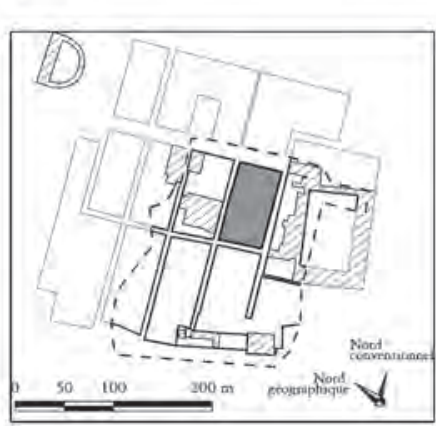




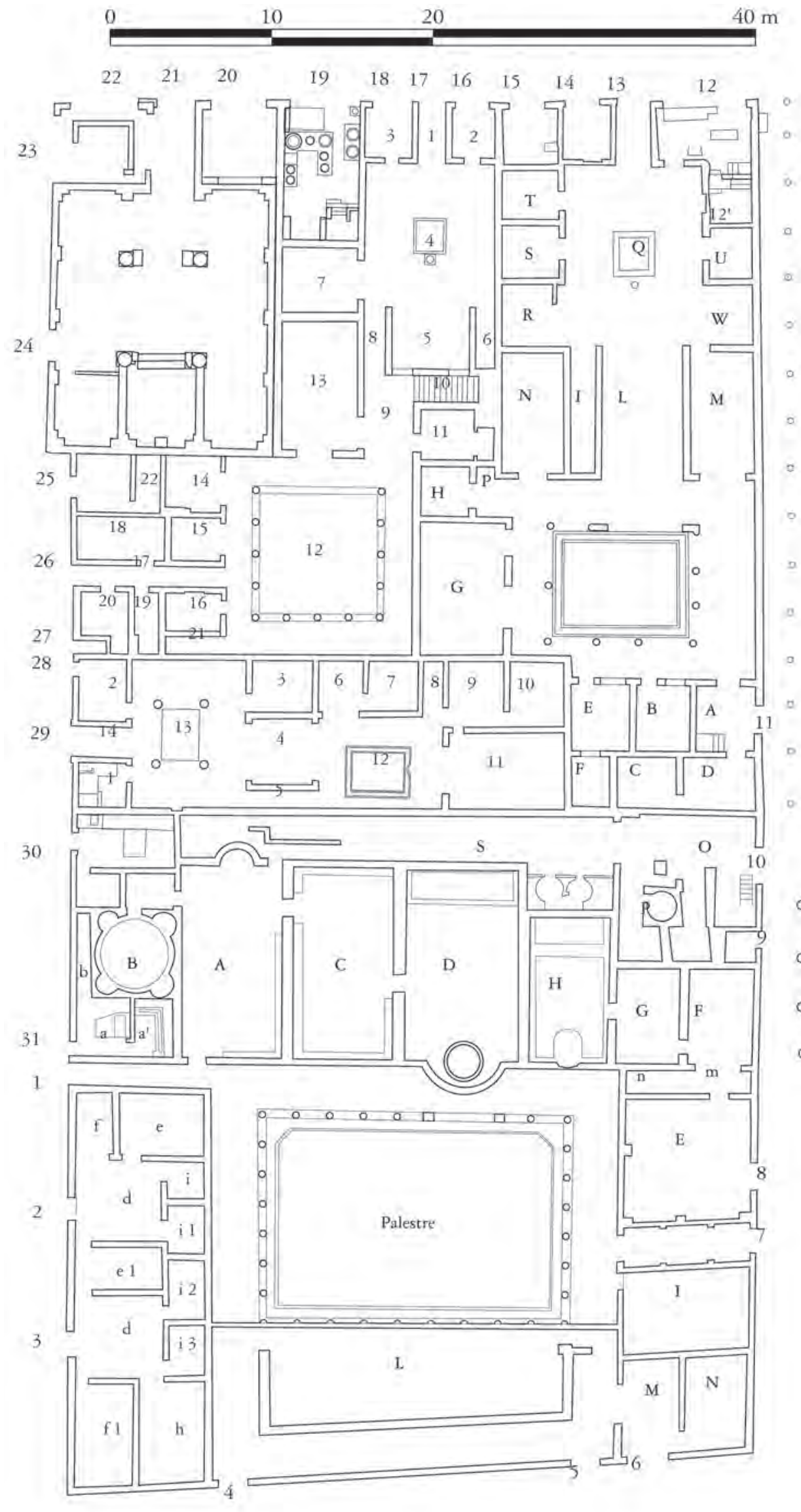

VI, $1.7-10.31:$ Thermes VI, 2-3: "Hospitium"

VI, 4-6 : Boutique des thermes

VI, 11-15 : Casa del Salone Nero

VI, 16-19.25-27 : Casa del Colonnato Tuscanico

VI, 20-24 : Aedes

VI, 28-29: Casa dei due Atri

VI, 30 : Atelier des thermes

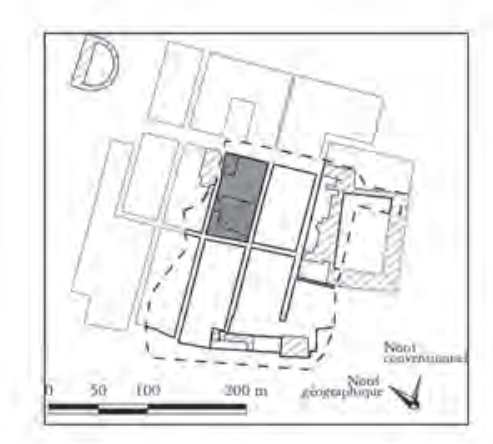

